\title{
SÍNTESIS Y APLICACIONES DE \\ TETRAHIDROPIRANOS Y PIRROLIDINAS \\ QUIRALES
}

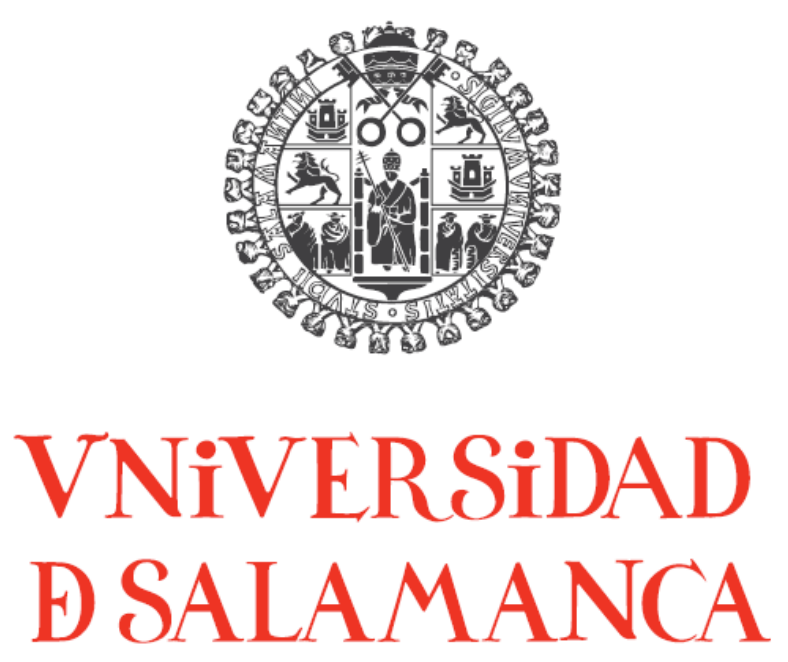

FACULTAD DE CIENCIAS QUÍMICAS

Departamento de Química Orgánica

Marta García Núñez

NOVIEMBRE 2008 



\section{SÍNTESIS Y APLICACIONES DE TETRAHIDROPIRANOS Y PIRROLIDINAS QUIRALES}

Trabajo presentado para optar al título de Doctor en Química por:

Marta García Núñez

Salamanca, Noviembre 2008

Visado en Salamanca

Octubre 2008

Fdo. David Díez Martín

Catedrático de Química Orgánica
Fdo. Rosalina Fernández. Moro

Prof. Titular de Química Orgánica
Fdo. Julio González Urones

Catedrático de Química Orgánica 

Este trabajo ha sido realizado en el Departamento de Química Orgánica de la Facultad de Ciencias Químicas de la Universidad de Salamanca, bajo la dirección de los Dres. D. David Díez Martín, Dña. Rosalina Fernández Moro y D. Julio González Urones, a los que quiero expresar mi más sincero agradecimiento por la confianza que han depositado en mí y por el apoyo que me han brindado hasta la conclusión de este trabajo. Gracias David por tu optimismo cuando más lo he necesitado.

Asimismo quisiera hacer extensible mi agradecimiento a las siguientes personas:

A los Dres. D. Narciso Martín Garrido, Dña. Pilar Basabe Barcala, Dña. Maria José Sexmero Cuadrado y D. Isidro Sánchez Marcos por la ayuda prestada durante estos años.

A los Dres. Dña. Anna Lithgow, del servicio de Resonancia Magnética Nuclear, Dña. Francisca Sanz, del Servicio de Difracción de Rayos-X y D. César Raposo, del Servicio de Espectrometría de Masas por la ayuda y el interés mostrados en todo momento. A Marisol y $\mathrm{M}^{\mathrm{a}}$ José por estar siempre dispuestas a echar una mano.Y no quisiera olvidarme del Dr. D. Howard B. Broughton por su inestimable ayuda en las modelizaciones moleculares incluidas en este trabajo.

Al Dr. Alan C. Spivey del Imperial Collage London y al Proffesor Steven V. Ley de la University of Cambridge por haberme dado la oportunidad de formar parte de sus grupos de investigación durante mis “estancias breves”.

También agradezco al Ministerio de Educación y Ciencia la concesión de una beca FPU para la realización de este trabajo de investigación. 

Igualmente, quisiera tener un recuerdo muy especial para mis compañeros de laboratorio durante estos años. Sin ellos esta aventura no habría sido la misma. Desde los primeros que me recibieron y me enseñaron a "hacer manos" en el laboratorio (Pilar G., Mariajo, Merce, Noelia, Alber, Víctor, Miguel, Sergio), mis compañeros de promoción (Pilar F., Mónica, Álvaro, Belén, Wences), la marabunta del segundo año, algunos de los cuales se han convertido en grandes amigos (Olga, Bari, Marta, Piedad, $\mathrm{M}^{\mathrm{a}}$ Rosa, Lourdes, Almudena, Alfonso, Imanol, Enrique, David), hasta las incorporaciones de los últimos años (Patri, Cheli, Magda, Isabel y Ana), sin olvidarme de mis compañeros de tierras “villarribenses” (Andrés, María, Roberto, Muñiz, Simón, Lidia, María, Pablo). A todos vosotros, gracias por vuestra paciencia y ayuda. Y entre todos ellos, quisiera agradecer enormemente a Álvaro, mi compañero de batallas por tierras inglesas, el gran interés mostrado y las muchas horas de trabajo invertidas en los estudios de modelización molecular de este trabajo.

Finalmente, quisiera darles las gracias de todo corazón a mis padres por haber estado siempre a mi lado y porque sin ellos no estaría escribiendo esta memoria. Y por supuesto a Juan, por su apoyo incondicional y por su cariño, comprensión y paciencia. 

La frase más excitante que se puede oír en ciencia, la que anuncia nuevos descubrimientos, no es "iEureka!" sino 'Es extraño ...'.

Isaac Asimov 

Índice general

ABREVIATURAS Y ACRÓNIMOS. .15

INTRODUCCIÓN .19

Parte I. Síntesis de anillos tetrahidropiránicos: Estrategias y aplicación a la síntesis de productos naturales

1. Metodologías de tipo A: Formación del enlace O1-C2 .......................29

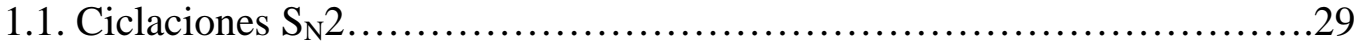

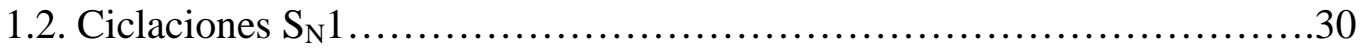

1.3. Ciclaciones de hidroxiepóxidos....................................32

1.4. Ciclaciones sobre alquenos.........................................36

1.5. Ciclaciones sobre alenos.............................................44

1.6. Ciclaciones sobre alquinos........................................44

1.7. Otras ciclaciones catalizadas por metales.............................46

1.8. Adiciones conjugadas de Michael intramoleculares......................50

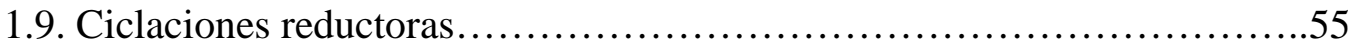

1.10. Ciclaciones oxidativas de 1,6-dienos..................................57

2. Metodologías de tipo B y C: Formación de los enlaces C2-C3 y C3-C4...........59

2.1. Reacción de oxo-hetero-Diels-Alder..................................59

2.2. Metátesis........................................................64

2.3. Ciclaciones sobre iones oxocarbenio...............................70

Parte II. Organocatálisis: aplicación a la síntesis de heterociclos oxigenados de seis $\underline{\text { miembros }}$

1. Adiciones conjugadas organocatalíticas................................... 81

1.1. Adición conjugada de nucleófilos carbonados..........................81

1.2. Adición conjugada de nucleófilos oxigenados..........................84 
2. Reacciones de oxo-hetero-Diels-Alder organocatalíticas......................85

2.1. oxo-HDA con activación por enlace de hidrógeno.......................86

2.2. oxo-HDA con activación por formación de enamina.....................87

OBJETIVOS.....................................................................

DISCUSIÓN Y RESULTADOS ............................................ 95

\section{Capítulo 1: Síntesis y aplicaciones de tetrahidropiranos y tetrahidrofuranos}

1.1. Síntesis de tetrahidropiranos 3-hidroxi-2,2,6,6-tetrasustituidos de 10 átomos de carbono....................................................

1.2. Síntesis y aplicaciones de tetrahidrofuranos..........................128

1.3. Síntesis y aplicaciones de tetrahidropiranos 3-hidroxi-2,2,6,6tetrasustituidos de 9 átomos de carbono...........................141

\section{Capítulo 2: Organocatálisis aplicada a la síntesis de tetrahidropiranos}

2.1. Síntesis de pirrolidinas quirales como catalizadores orgánicos............152

2.2. Síntesis organocatalítica de tetrahidropiranos........................160

TABLAS DE CARBONO ...................................................... 185

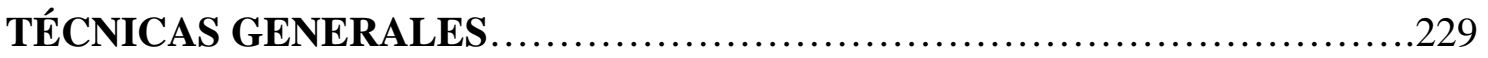

1. Instrumentación...................................................231

2. Técnicas generales cromatográficas.................................235

3. Purificación de reactivos y disolventes...............................236 
Capítulo I: Síntesis y aplicaciones de tetrahidropiranos y tetrahidrofuranos......239

- Síntesis de tetrahidropiranos 3-hidroxi-2,2,6,6-tetrasustituidos de 10 átomos de carbono..................................................241

- Uso de los nitrilos en síntesis: Síntesis de ent- Sachalinol A.................289

- Síntesis y aplicaciones de tetrahidrofuranos..................................297

- Síntesis y aplicaciones de tetrahidropiranos 3-hidroxi-2,2,6,6-tetrasustituidos

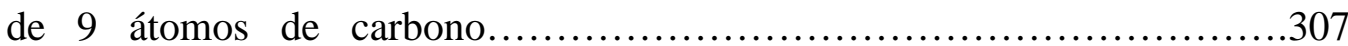

Capítulo II: Organocatálisis aplicada a la síntesis de tetrahidropiranos

- Síntesis de pirrolidinas quirales como catalizadores orgánicos.

- Síntesis organocatalítica de tetrahidropiranos

ESPECTROSCOPÍA

CROMATOGRAMAS.

CONCLUSIONES

ANEXO: Relación de moléculas sintetizadas. .643 



\section{Abreviaturas y acrónimos}

- Ac: acetato

- AcOEt: acetato de etilo

- AcOH: ácido acético

- $\quad \mathbf{A c}_{2} \mathbf{O}$ : anhídrido acético

- AEDT: ácido etilendiaminotetracético

- AIBN: azaisobutironitrilo

- Ar: aromático

- $[\alpha]_{D}^{25}$ : rotación específica o poder rotatorio medido a $589 \mathrm{~nm}$ (línea D de emisión del sodio) y a $25^{\circ} \mathrm{C}$.

- BINOL: 1,1'-bi-2-naftol

- Bn: bencilo

- Boc: terc-butoxicarbonil

- BTHF: complejo boranotetrahidrofurano

- Bu: butilo

- n-BuLi: $n$-butillitio

- Bz: benzoilo

- c: cuartete

- CCF: cromatografía de capa fina

- CI: Chemical Ionization

- $\mathbf{C M}$ : cross metathesis

- C-PCM: Conductor Polarizable Continuum Model

- CSA: ácido canforsulfónico

- c/u: cada uno
- d: doblete

- DBU: 1,8-diazabiciclo[5.4.0]undec7-eno

- DCC: $N, N^{\prime}-$ diciclohexilcarbodiimida

- DCE: dicloroetano

- DCM: diclorometano

- dd: doble doblete

- DDQ: 2,3-dicloro-5,6dicianobenzoquinona

- DET: tartrato de dietilo

- DFT: Density Functional Theory

- DHP: 3,4-dihidro-2H-pirano

- DIBAL-H: hidruro de diisobutilaluminio

- dig: digonal

- DMAP: 4-dimetilaminopiridina

- DMF: $N, N$-dimetilformamida

- DMPS: dimetilfenilsililo

- DMSO: dimetilsulfóxido

- d.r.: relación diastereoisomérica

- dt: doble triplete

- $\delta$ : desplazamiento químico

- $\quad \mathbf{E}$ : electrófilo

- ee: exceso enantiomérico

- ed: exceso diastereoisomérico

- EI: Electronic Impact 
- ESI: Electrospray Ionization

- Et: etilo

- $\mathbf{E t}_{3} \mathbf{N}$ :trietilamina

- $\mathbf{E t}_{2} \mathbf{O}$ : éter dietílico, dietiléter

- EtOH: alcohol etílico, etanol

- $\mathbf{e V}$ : electrón-Voltio

- FAB: Fast Atom Bombardement

- fig.: figura

- g: gramo

- GHz: Gigahertzio

- HMBC: Heteronuclear Multiple Bond Conectivity

- HMPA: hexametilfosforamida

- HMQC: Heteronuclear Multiple Quantum Coherence

- HRMS: High Resolution Mass Spectrum

- Hz: Hertzio

- IR: Infrarrojo

- IRC: Intrinsic Reaction Coordinate

- $\mathbf{J}$ : constante de acoplamiento

- KHMDS: hexametildisilazida de potasio

- LDA: diisopropilamiduro de litio

- LRMS: Low Resolution Mass Spectrum

- $\mathbf{M}$ : molar

- $\mathbf{m}$ : multiplete

- m-CPBA: ácido $m$ cloroperbenzoico
- Me: metilo

- MeOH: alcohol metílico, metanol

- mg: miligramo

- MHz: Megahertzio

- $\mathbf{m L}$ : mililitro

- mmol: milimol

- MOM: metoximetilo

- Ms: metanosulfonilo (mesilo)

- MTPA: ácido metoxi(trifluorometil)fenilacético

- $\mathbf{m} / \mathbf{z}$ : relación masa/carga

- NBS: $N$-bromosuccinimida

- NPSP: $N$-fenilselenoftalimida

- NMO: $N$-óxido de 4-metilmorfolina

- nOe: nuclear Overhauser effect

- Nu: nucleófilo

- OPLS: Optimized Potential for Liquid Simulations

- PBB: $p$-bromobencilo

- PDC: dicromato de piridinio

- P.F.: punto de fusión

- Ph: fenilo

- Pi: piridina

- Piv o Pv: pivaloilo

- PMB: $p$-metoxibencilo

- ppm: partes por millón

- PPTS: $p$-toluensulfonato de piridinio

- Pr: propilo 
- RCM: ring closing metathesis

- RMN: Resonancia Magnética Nuclear

- ROESY: Rotating frame Overhauser Effect SpectroscopY

- ROM: ring opening metathesis

- RRM: ring rearrangement metathesis

- RX: rayos X

- $\mathbf{s}$ : singlete

- sa: singlete ancho

- $\mathbf{t}$ : triplete

- TADDOL: trans- $\alpha, \alpha$ '-(dimetil-1,3dioxolano-4,5diil)bis(difenilmetanol)

- TBAI: yoduro de tetra-nbutilamonio

- TBAF: fluoruro de tetra- $n$ butilamonio

- TBDPS: terc-butildifenilsililo

- TBHP: terc-butilhidroperóxido

- TBS o TBDMS: tercbutildimetilsililo

- TEA: trietilamina

- TES: trietilsililo

- tet: tetragonal

- Tf: trifluorometanosulfonilo

- TFA: ácido trifluoroacético

- THF: tetrahidrofurano
- THP: tetrahidropirano

- $\quad \operatorname{Ti}\left({ }^{i} \operatorname{PrO}\right)_{4}$ : tetraisopropóxido de titanio

- TMEDA: tetrametiletilendiamina

- TMS: trimetilsililo

- tol: tolueno

- TPAP: perrutenato de tetrapropilamonio

- trig: trigonal

- TS: transition state

- TsCl: cloruro de $p$-toluensulfonilo (tosilo)

- $p$-TsOH: ácido $p$-toluensulfónico

- $\boldsymbol{V}_{\max }$ : frecuencia máxima 

INTRODUCCIÓN 

Introducción

Parte I. Síntesis de anillos tetrahidropiránicos: Estrategias y aplicación a la síntesis de productos naturales

\section{Metodologías de tipo A: Formación del enlace O1-C2}

1.1. Ciclaciones $\mathrm{S}_{\mathrm{N}} 2$

1.2. Ciclaciones $\mathrm{S}_{\mathrm{N}} 1$

1.3. Ciclaciones de hidroxiepóxidos

1.4. Ciclaciones sobre alquenos

1.4.1. Ciclaciones estequiométricas

1.4.2. Ciclaciones catalíticas

1.4.2.1. Ciclaciones catalizadas por $\operatorname{Pd}(0)$

1.4.2.2. Ciclaciones catalizadas por $\mathrm{Pd}(\mathrm{II})$

1.4.2.2. Ciclaciones catalizadas por otros metales

1.4.3. Ciclaciones en medio ácido

1.5. Ciclaciones sobre alenos

1.6. Ciclaciones sobre alquinos

1.7. Otras ciclaciones catalizadas por metales

1.7.1. Ciclaciones de diazocompuestos

1.7.2. Reacciones de eterificación intramolecular de haluros de arilo y vinilo

1.8. Adiciones conjugadas de Michael intramoleculares

1.8.1. Ciclaciones 6-exo

1.8.2. Ciclaciones 6-endo

1.9. Ciclaciones reductoras

1.10. Ciclaciones oxidativas de 1,6-dienos

1.10.1. Ciclaciones de 1,6-dienos catalizadas por tetróxido de rutenio

1.10.2. Ciclaciones de 1,6-dienos catalizadas por permanganato 

2. Metodologías de tipo B y C: Formación de los enlaces C2-C3 y C3-C4

2.1. Reacción de oxo-hetero-Diels-Alder

2.2. Metátesis

2.2.1. RCM de éteres de enol

2.2.2. RCM de éteres de alilo

2.2.3. RCM de éteres de alquinilo

2.2.4. Procesos de metátesis con apertura de anillo (ROM)

2.3. Ciclaciones sobre iones oxocarbenio

2.3.1. Ciclación de Sakurai

2.3.2. Reordenamiento de Petasis-Ferrier

2.3.3. Ciclación de Prins

Parte II. Organocatálisis: aplicación a la síntesis de heterociclos oxigenados de seis miembros

\section{Adiciones conjugadas organocatalíticas}

1.1. Adición conjugada de nucleófilos carbonados

1.1.1. Adición conjugada de silil enol éteres

1.1.2. Reacción de Stetter

1.1.3. Reacciones tándem

1.2. Adición conjugada de nucleófilos oxigenados

\section{Reacciones de oxo-Hetero-Diels-Alder organocatalíticas}

2.1. oxo-HDA con activación por enlace de hidrógeno

2.2. oxo-HDA con activación por formación de enamina 

INTRODUCCIÓN. PARTE I:

SÍNTESIS DE ANILLOS TETRAHIDROPIRÁNICOS.

ESTRATEGIAS Y APLICACIÓN A LA SÍNTESIS DE PRODUCTOS

NATURALES 

Los tetrahidropiranos son probablemente una de las unidades estructurales más frecuentes en los productos naturales bioactivos. Estos heterociclos oxigenados saturados de seis miembros forman parte del esqueleto de importantes carbohidratos, así como de sus oligómeros y polímeros, los cuales son las biomoléculas más abundantes en la Tierra y están involucrados en procesos cruciales para los seres vivos.

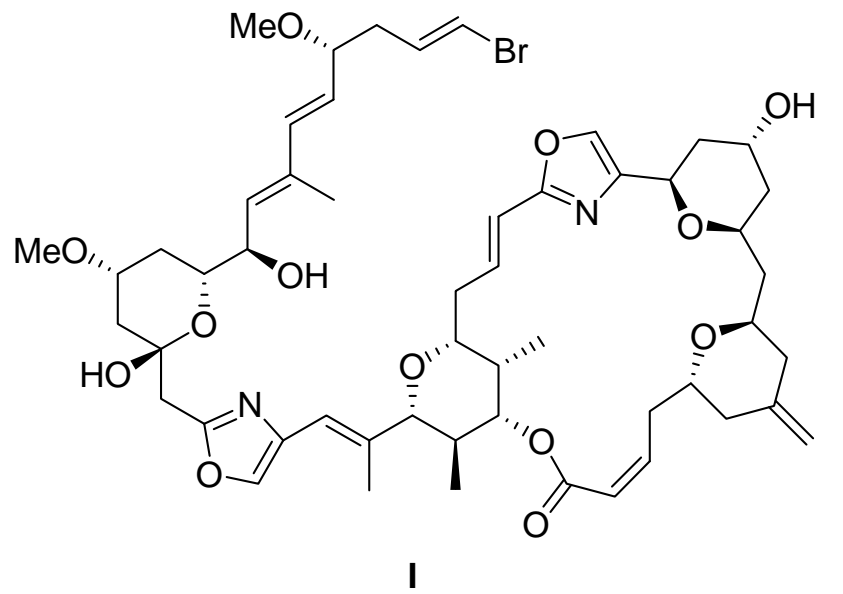

Figura 1. Phorboxazol A

También encontramos anillos de tetrahidropirano en metabolitos como el phorboxazol A, un potente agente antitumoral (Figura 1, I), ${ }^{1,2}$ o la decarestrictina L, ${ }^{3}$ inhibidor de la síntesis del colesterol. Asimismo, forman parte de estructuras mucho más complejas presentes en poliéteres de origen marino como la palitoxina, las brevetoxinas A y B (Figura 4, pág. 35, XVI) o la maitotoxina (Figura 2, II). ${ }^{4}$

\footnotetext{
${ }^{1}$ Síntesis totales de phorboxazol A: (a) Williams, D. R.; Kiryanov, A. A.; Emde, U.; Clark, M. P.; Berliner, M. A.; Reeves, J. T. Proc. Natl. Acad. Sci. U.S.A. 2004, 101, 12058; (b) Smith III, A. B.; Razler, T. M.; Ciavarri, J. P.; Hirose, T.; Ishikawa, T. Org. Lett. 2005, 7, 4399; (c) Smith III, A. B.; Razler, T. M.; Ciavarri, J. P.; Hirose, T.; Ishikawa, T.; Meis, R. M. J. Org. Chem. 2008, 73, 1192 (d) Wang, B.; Forsyth, C. J. Org. Lett. 2006, 8, 5223; (e) White, J. D.; Kuntiyong, P.; Lee, T. H. Org. Lett. 2006, 8, 6029; (f) White, J. D.; Lee, T. H.; Kuntiyong, P. Org. Lett. 2006, 8, 6043.

${ }^{2}$ Revisión bibliográfica sobre la síntesis de phorboxazoles: Haustedt, L. O.; Hartung, I. V.; Hoffmann, H. M. R. Angew. Chem., Int. Ed. 2003, 42, 2711.

${ }^{3}$ Revisión bibliográfica sobre la síntesis de decarestrictinas: Riatto, V. B.; Pilli, R. A.; Victor, M. M. Tetrahedron 2008, 64, 2279.

${ }^{4}$ (a) Kishi, Y. Pure Appl. Chem. 1998, 70, 339; (b) Faulkner, D. J. Nat. Prod. Rep. 2002, 19, 1 y referencias allí citadas.
} 


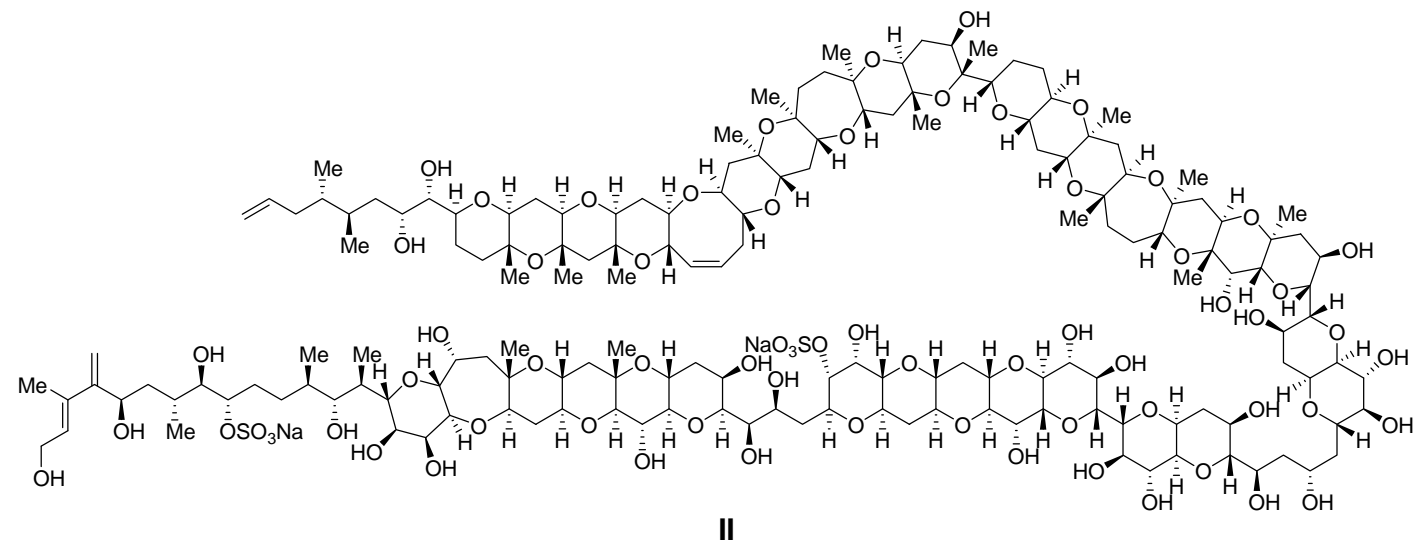

Figura 2. Maitotoxina

Por todo ello, la síntesis estereoselectiva de tetrahidropiranos se ha convertido en un campo de especial interés para el químico orgánico sintético. ${ }^{5}$ Desde el año 2000 , se ha utilizado un número creciente de reacciones para la obtención de este tipo de anillos, y numerosos grupos de investigación las han aplicado a la síntesis de productos naturales. Aquellas que han tenido un mayor impacto han sido la reacción de Prins y relacionadas, la hetero-Diels-Alder, y las ciclaciones de grupos hidroxilo catalizadas por metales de transición. Asimismo, métodos más clásicos como la ciclación sobre epóxidos, las reacciones oxo-Michael intramoleculares o las transformaciones de carbohidratos como precursores, siguen teniendo gran importancia dentro de este campo.

Las metodologías sintéticas mencionadas anteriormente se pueden clasificar en tres clases atendiendo al enlace formado en la reacción de ciclación (Figura 3).

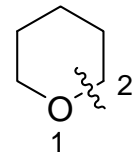

Tipo A<smiles>C1CCOCC1</smiles>

Tipo B<smiles>C[As]1CCOCC1</smiles>

Tipo C

Figura 3.

\footnotetext{
${ }^{5}$ Revisiones bibliográficas sobre la síntesis de tetrahidropiranos: (a) Boivin, T. L. B. Tetrahedron 1987, 43, 3309; (b) Elliott, M. C. J. Chem. Soc., Perkin Trans. 1 2002, 2301; (c) Clarke, P. A.; Santos, S. Eur. J. Org. Chem. 2006, 2045; (d) Tang, Y.; Oppenheimer, J.; Song, Z.; You, L.; Zhang, X.; Hsung, R. P. Tetrahedron 2006, 62, 10785; (e) Larrosa, I.; Romea, P.; Urpí, F. Tetrahedron 2008, 64, 2683.
} 
A continuación se comentarán las diferentes reacciones que forman parte de cada tipo de metodología (A, B y C), haciendo especial hincapié en los avances que se han realizado más recientemente y las aplicaciones que han tenido en la síntesis de productos naturales.

\section{METODOLOGÍAS DE TIPO A: FORMACIÓN DEL ENLACE O-C2}

\section{1. $\underline{\text { Ciclaciones } S_{\underline{N}}} \underline{2}$}

Las transformaciones basadas en la ciclación tipo $\mathrm{S}_{\mathrm{N}} 2$ intramolecular de un grupo hidroxilo son la estrategia más sencilla para la obtención de tetrahidropiranos. La combinación de la base $\mathrm{B}^{-} \mathrm{y}$ el grupo saliente $\mathrm{X}^{-}$(Esquema 1) adecuados promueve la ciclación 6-exo-tet, la cual se produce con inversión de la configuración en C-X. De esta forma, la estereoquímica del tetrahidropirano formado solo dependerá de la configuración del precursor acíclico. Además, se pueden obtener tanto 2,6-cistetrahidropiranos como 2,6-trans-tetrahidropiranos aplicando las mismas condiciones experimentales.

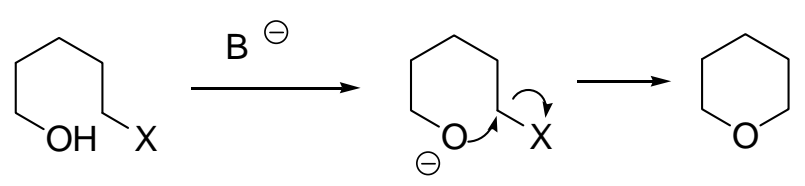

Esquema 1

Esta metodología se ha utilizado en numerosas síntesis de productos naturales ${ }^{6}$ como el gambierol, ${ }^{6 \mathrm{~g}}$ la leucascandrolida $\mathrm{A}^{6 \mathrm{f}}$ o los phorboxazoles $\mathrm{A}^{6 \mathrm{~h}, \mathrm{j}}$ y B. ${ }^{6 \mathrm{i}}$

\footnotetext{
${ }^{6}$ (a) Smith III, A. B.,; Zhu, W.; Shirakami, S.; Sfouggatakis, C.; Doughty, V. A.; Bennett, C. S.; Sakamoto, Y. Org. Lett. 2003, 5, 761; (b) Brenner, E.; Baldwin, R. M.; Tamagnan, G. Org. Lett. 2005, 7, 937; (c) Chakraborty, T. K.; Reddy, V. R.; Reddy, T. J. Tetrahedron 2003, 59, 8613; (d) Hicks, J. D.; Flamme, E. M.; Roush, W. R. Org. Lett. 2005, 7, 5509; (e) Chakraborty, T. K.; Reddy, V. R. Tetrahedron Lett. 2006, 47, 2099; (f) Williams, D. R.; Plummer, S. V.; Patnaik, S. Angew. Chem., Int. Ed. 2003, 42, 3934; (g) Furuta, H.; Hase, M.; Noyori, R.; Mori, Y. Org. Lett. 2005, 7, 4061; (h) Williams, D. R.; Kiryanov, A. A.; Emde, U.; Clark, M. P.; Berliner, M. A.; Reeves, J. T. Proc. Natl. Acad. Sci. U.S.A. 2004, 101, 12058; (i) Li, D.-R.; Zhang, D.-H.; Sun, C.-Y.; Zhang, J.-W.; Yang, L.; Chen, J.; Liu, B.; Su, C.; Zhou, W.-S.; Lin, G.-Q. Chem. Eur. J. 2006, 12, 1185; (j) White, J. D.; Lee, T. H.; Kuntiyong, P. Org. Lett. 2006, 8, 6043.
} 
Como ejemplo podemos observar en el Esquema 2 la formación del tetrahidropirano C11-C15 de la estructura del phorboxazol A (Figura 1, I).<smiles>C=C(C[C@@H](O)CCO[R17](=O)c1ccccc1)C[C@@H](OC1CCCCO1)c1coc(COC(C)(C)C)n1</smiles>

1) $\mathrm{MsCl}, \mathrm{NEt}_{3}$

2) $p-\mathrm{TsOH}, \mathrm{MeOH}$

3) $\mathrm{NaH}$, Tol., $\Delta$

$72 \%$<smiles>C=C1C[C@H](CCO[Na])O[C@@H](c2coc(COC(C)(C)C)n2)C1</smiles>

IV

Esquema 2

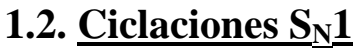

En las reacciones $\mathrm{S}_{\mathrm{N}} 1$ la ciclación ocurre por ataque nucleofílico de un grupo hidroxilo sobre un carbocatión alílico o bencílico (Esquema 3$).^{7}$ En este caso el intermedio carbocatiónico planar no ejerce control alguno sobre la configuración del nuevo estereocentro, y ésta vendrá determinada por elementos estereogénicos del sustrato y por las condiciones experimentales.

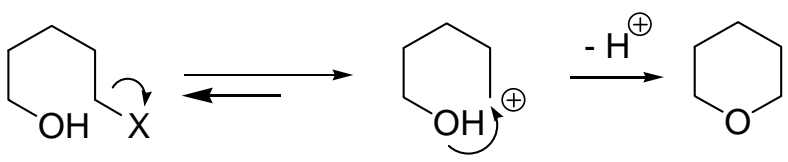

\section{Esquema 3}

\footnotetext{
${ }^{7}$ (a) Miura, K.; Hondo, T.; Okajima, S.; Nakagawa, T.; Takahashi, T.; Hosomi, A. J. Org. Chem. 2002, 67, 6082; (b) Smith III, A. B.; Kanoh, N.; Ishiyama, H.; Minakawa, N.; Rainier, J. D.; Hartz, R. A.; Cho, Y. S.; Cui, H.; Moser, W. H. J. Am. Chem. Soc. 2003, 125, 8228; (c) Pichlmair, S.; Marques, M. M. B.; Green, M. P.; Martin, H. J.; Mulzer, J. Org. Lett. 2003, 5, 4657; (d) Hua, D. H.; Huang, X.; Chen, Y.; Battina, S. K.; Tamura, M.; Noh, S. K.; Koo, S. I.; Namatame, I.; Tomoda, H.; Perchellet, E. M.; Perchellet, J.-M. J. Org. Chem. 2004, 69, 6065; (e) Prasad, K.; Anbarasan, P. Tetrahedron 2007, 63, 1089; (f) Zhou, J.; Snider, B. B. Org. Lett. 2007, 9, 2071;
} 
Los mejores resultados se obtienen para los 2,6-cis-tetrahidropiranos, ya que normalmente se trata de los diastereoisómeros más estables. Por ejemplo, la síntesis del 2,6-cis-tetrahidropirano C22-C26 del phorboxazol A llevada a cabo por Williams et al. se consigue mediante una reacción $\mathrm{S}_{\mathrm{N}} 1$ intramolecular del alcohol $\mathbf{V}$ (Esquema 4). ${ }^{8}$

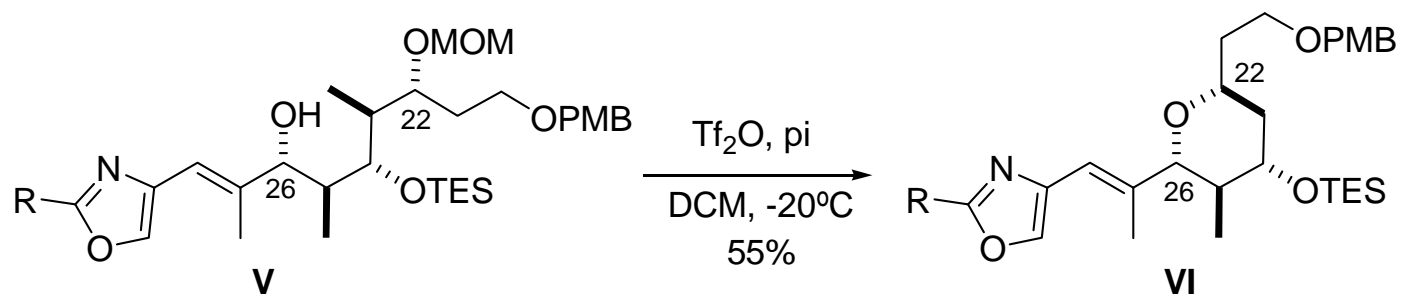

Esquema 4

El tratamiento de complejos $\mathrm{Co}_{2}(\mathrm{CO})_{6}$-alquinol tanto con ácidos de Lewis como de Brønsted genera carbocationes propargílicos lo suficientemente estables como para ser atrapados por nucleófilos oxigenados en ciclaciones tipo Nicholas intramoleculares. ${ }^{9,10}$ Dichos nucleófilos oxigenados pueden ser tanto grupos hidroxilos ${ }^{10}$ como epóxidos. De hecho, los precursores que contienen un epoxialcohol protegido participan en ciclaciones altamente regio- y estereoselectivas.

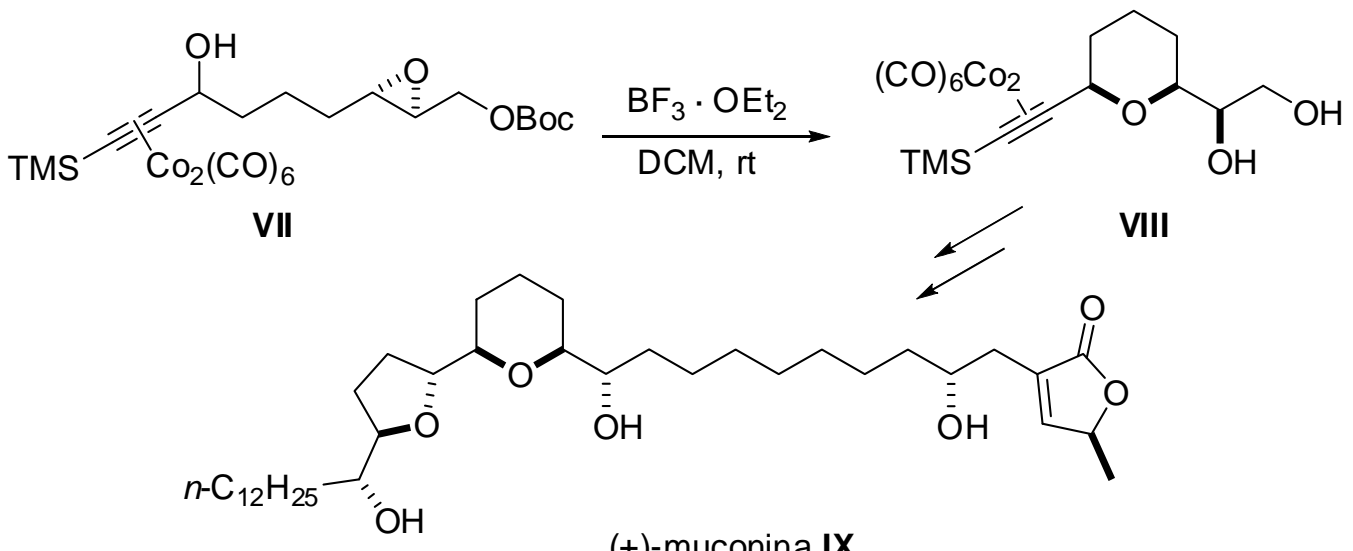

(+)-muconina IX

\section{Esquema 5}

\footnotetext{
${ }^{8}$ (a) Williams, D. R.; Kiryanov, A. A.; Emde, U.; Clark, M. P.; Berliner, M. A.; Reeves, J. T. Angew. Chem., Int. Ed. 2003, 42, 1258; (b) Williams, D. R.; Kiryanov, A. A.; Emde, U.; Clark, M. P.; Berliner, M. A.; Reeves, J. T. Proc. Natl. Acad. Sci. U.S.A. 2004, 101, 12058.

${ }^{9}$ Díaz, D. D.; Betancort, J. M.; Martín, V. S. Synlett 2007, 343.

${ }^{10}$ Betancort, J. M.; Martín, T.; Palazón, J. M.; Martín, V. S. J. Org. Chem. 2003, 68, 3216.
} 
Como se observa en el Esquema 5, el tratamiento del carbonato VII con $\mathrm{BF}_{3} \cdot \mathrm{OEt}_{2}$ proporciona el 2,6-cis-tetrahidopirano VIII como único diastereoisómero. Este hecho ha dado lugar a una síntesis formal del producto natural (+)-muconina IX, una acetogenina que exhibe una citotoxicidad in vitro potente y selectiva frente a líneas tumorales de páncreas y pulmón. ${ }^{11}$

\subsection{Ciclaciones de hidroxiepóxidos}

Desde los estudios de Nicolau sobre la apertura intramolecular de epóxidos en los que establecía los criterios estructurales necesarios para la síntesis regio y estereocontrolada de heterociclos oxigenados de seis miembros, ${ }^{12}$ las ciclaciones de hidroxiepóxidos catalizadas por ácido se han convertido en una estrategia muy común para la síntesis estereoselectiva de tetrahidropiranos.<smiles>[R]C(O)C1CCCO1</smiles>

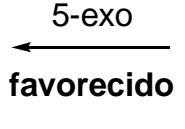<smiles>[R]C(O)C1CCCO1</smiles>

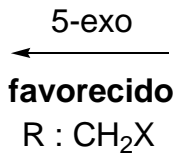<smiles>[R]C1OCCCCC1O</smiles><smiles>[R]C1(O)OCCCCC1O</smiles><smiles>CC1CCCCC1C</smiles>

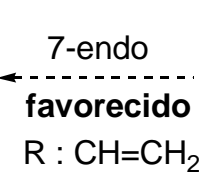<smiles>[R]C1OC1CCO</smiles>
epóxido cis

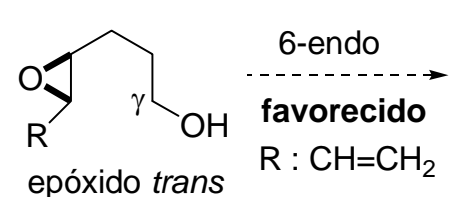
epóxido trans<smiles>[R]C1OCCCC1O</smiles><smiles>[R]C1([2H])OCCC[C@@H]1O</smiles><smiles>[R]C1OC1CCCO</smiles><smiles>[R]C(O)[C@H]1CCCCO1</smiles>
epóxido cis<smiles>[R]C1OC1CCCCO</smiles>

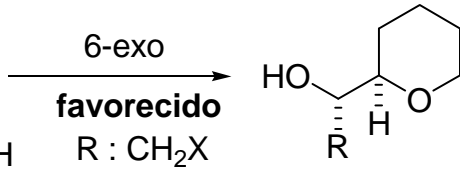

\section{Esquema 6}

${ }^{11}$ Crisóstomo, F. R. P.; Carrillo, R.; León, L. G.; Martín, T.; Padrón, J. M.; Martín, V. S. J. Org. Chem. 2006, 71, 2339.

${ }^{12}$ (a) Nicolaou, K. C.; Prasad, C. V. C.; Somers, P. K.; Hwang, C.-K. J. Am. Chem. Soc. 1989, 111, 5330; (b) Nicolaou, K. C.; Prasad, C. V. C.; Somers, P. K.; Hwang, C.-K. J. Am. Chem. Soc. 1989, 111, 5335. 
La efectividad de este método está muy relacionada con la capacidad que posea el sustrato para adoptar una conformación en la cual el oxígeno nucleofílico y el enlace oxiránico, C-O, sean colineales. Este proceso es estereoespecífico, teniendo lugar una inversión de la configuración en el carbono oxiránico y pudiendo ser además altamente regioselectivo.

El Esquema 6 resume las distintas regioselectividades de la ciclación de $\gamma$ y $\delta$ hidroxiepóxidos. Estos modelos explican la mayoría de los procedimientos sintéticos aparecidos recientemente en bibliografía, ${ }^{13,14}$ excepto en los casos en que haya restricciones conformacionales en el sustrato. ${ }^{15}$ Como ejemplo podemos citar la reacción del fragmento $\mathbf{X}$ con CSA para dar $\mathbf{X I}$, intermedio en la síntesis de la ciguatoxina CTX3C (Esquema 7, XII), una potentes toxina de origen marino producida por el dinoflagelado Gambierdiscus toxicus. ${ }^{13 \mathrm{e}}$

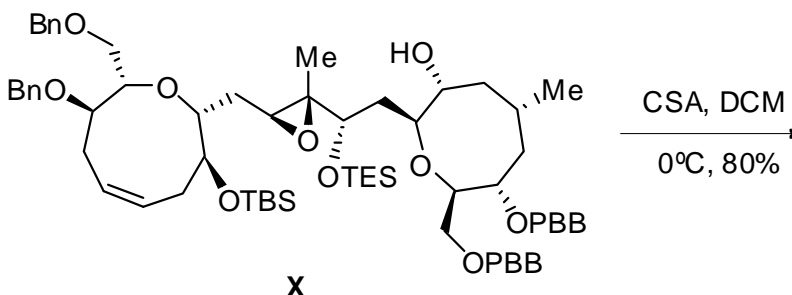

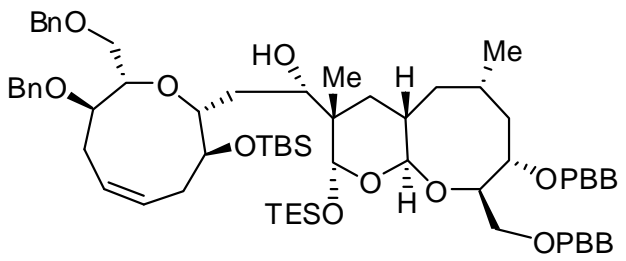

XI

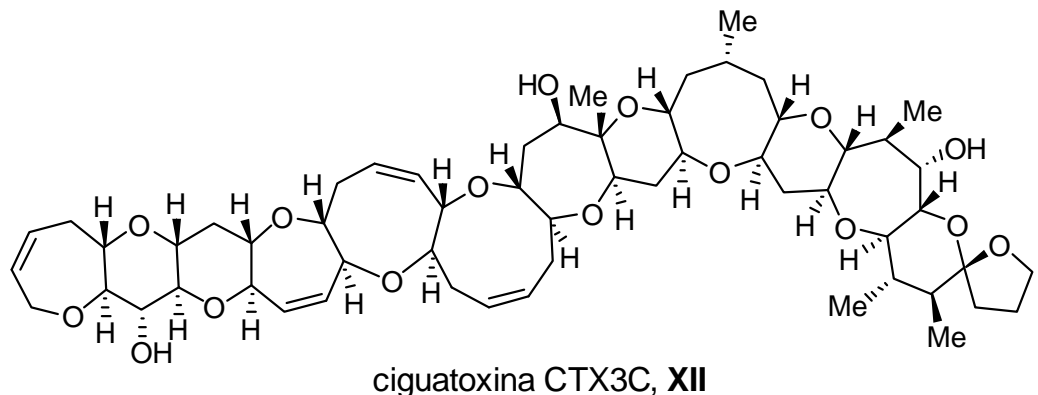

Esquema 7

\footnotetext{
${ }^{13}$ Ejemplos de ciclaciones 6-exo: (a) Yoshimitsu, T.; Makino, T.; Nagaoka, H. J. Org. Chem. 2004, 69, 1993; (b) Chang, S.-K.; Paquette, L. A. Synlett 2005, 2915; (c) Kadota, I.; Abe, T.; Sato, Y.; Kabuto, C.; Yamamoto, Y. Tetrahedron Lett. 2006, 47, 6545; (d) Takahashi, S.; Hongo, Y.; Ogawa, N.; Koshino, H.; Nakata, T. J. Org. Chem. 2006, 71, 6305; (e) Takizawa, A.; Fujiwara, K.; Doi, E.; Murai, A.; Kawai, H.; Suzuki, T. Tetrahedron 2006, 62, 7408; (f) Crimmins, M. T.; Haley, M. W. Org. Lett. 2006, 8, 4223; (g) Bedore, M. W.; Chang, S.-K.; Paquette, L. A. Org. Lett. 2007, 9, 513.

${ }^{14}$ Ejemplos de ciclaciones 6-endo (a) Uehara, H.; Oishi, T.; Inoue, M.; Shoji, M.; Nagumo, Y.; Kosaka, M.; Le Brazidec, J.-Y.; Hirama, M. Tetrahedron 2002, 58, 6493; (b) Ha, J. D.; Shin, E. Y.; Kang, S. K.; Ahn, J. H.; Choi, J.-K. Tetrahedron Lett. 2004, 45, 4193; (c) Fuwa, H.; Ebine, M.; Bourdelais, A. J.; Baden, D. G.; Sasaki, M. J. Am. Chem. Soc. 2006, 128, 16989; (d) Sato, K.; Sasaki, M. Angew. Chem., Int. Ed. 2007, 46, 2518; (e) Shangguan, N.; Kiren, S.; Williams, L. J. Org. Lett. 2007, 9, 1093.

${ }^{15}$ Nicolaou, K. C.; Harrison, S. T. J. Am. Chem. Soc. 2007, 129, 429 y referencias allí citadas.
} 
Como se señalaba en el Esquema 6, los dobles enlaces adyacentes a $\gamma$ hidroxiepóxidos favorecen la ciclación 6-endo frente a la habitual 5-exo (Esquema 6, 2). Este es el comportamiento observado en la ciclación del epóxido $\alpha, \beta$-insaturado XIII hasta el tetrahidropirano altamente sustituído XIV intermedio en la síntesis de brevenal (Esquema $8, \mathbf{X V}){ }^{14 \mathrm{c}}$

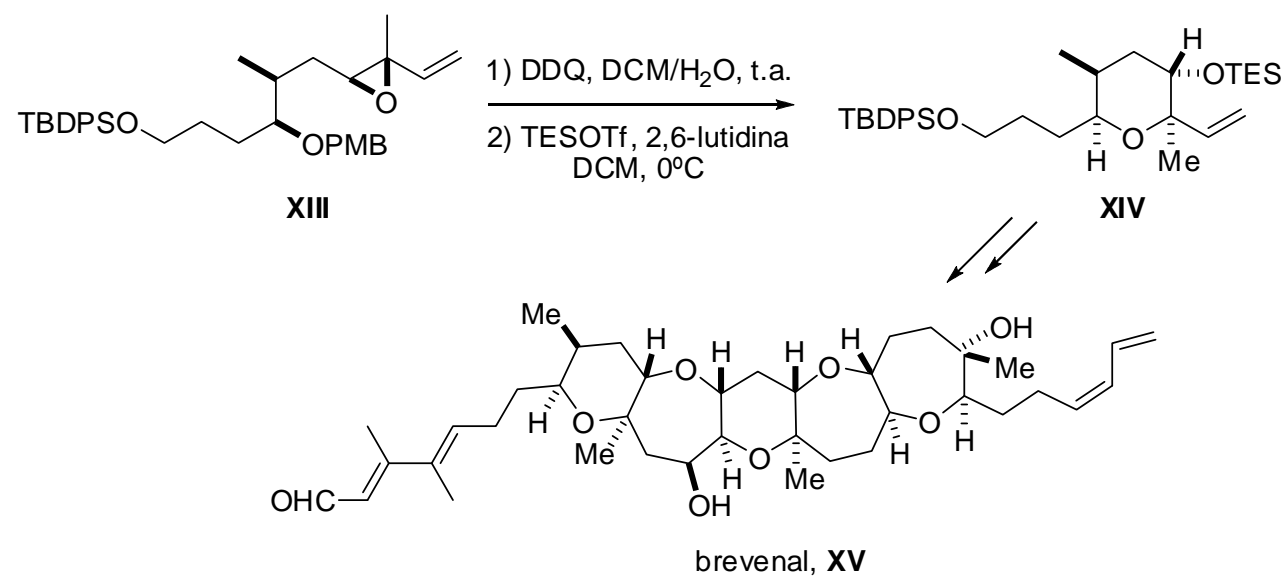

Esquema 8

Sin embargo, resultan más interesantes las nuevas metodologías capaces de cambiar los procesos 5-exo a 6-endo independientemente del sustituyente en posición $\alpha$ al epóxido. En este sentido, recientemente Morimoto et al. han utilizado la apertura de epóxidos activada por grupos sililtriflato voluminosos en nitrometano para la obtención regioselectiva del tetrahidropirano deseado. ${ }^{16}$ Los procesos de ciclación sobre $\gamma$ hidroxiepóxidos catalizados por vanadio tampoco están de acuerdo con las reglas de regioselección resumidas en el Esquema 6, obteniéndose tetrahidropiranos mediante un proceso 6-endo. ${ }^{17}$

La importancia de encontrar nuevos métodos de ciclación regioselectiva 6-endo tiene su origen en la síntesis de poliéteres cíclicos fusionados, una familia de metabolitos marinos con gran actividad biológica. ${ }^{18}$ Una característica común a este tipo de compuestos, como se puede observar en la brevetoxina B (Figura 4, XVI), es la presencia en su estructura de poliéteres cíclicos fusionados de seis a nueve miembros en una disposicón estereoquímica muy definida.

16 (a) Morimoto, Y.; Nishikawa, Y.; Ueba, C.; Tanaka, T. Angew. Chem., Int. Ed. 2006, 45, 810; (b) Morimoto, Y.; Yata, H.; Nishikawa, Y. Angew. Chem., Int. Ed. 2007, 46, 6481.

${ }^{17}$ Blanc, A.; Toste, F. D. Angew. Chem., Int. Ed. 2006, 45, 2096.

${ }^{18}$ (a) Nakata, T. Chem. Rev. 2005, 105, 4314; (b) Inoue, M. Chem. Rev. 2005, 105, 4379. 


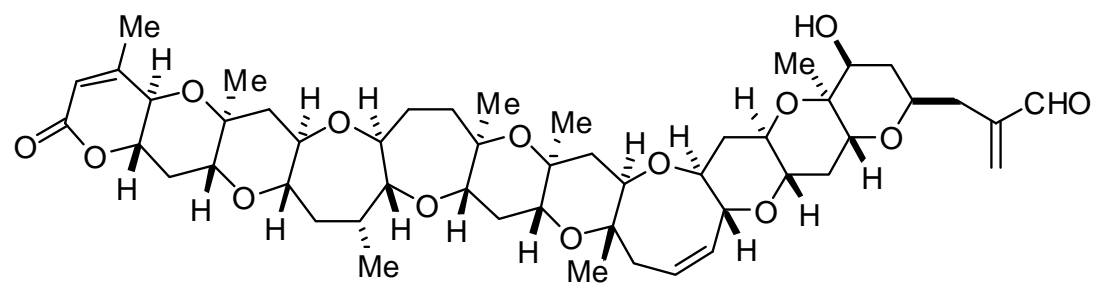

XVI

Figura 4. Brevetoxina B

Numerosas estrategias sintéticas para la obtención de este tipo de compuestos se basan en las hipótesis existentes sobre su biosíntesis, la mayoría de ellas basadas en el modelo de Cane-Celmer-Westley. ${ }^{19}$ Dicho modelo propone que las estructuras de estos poliéteres cíclicos fusionados surgirían de la ciclación de un precursor poliepoxídico a través de una cascada de aperturas de anillo $\mathrm{S}_{\mathrm{N}} 2{ }^{20}$

Así pues, las síntesis biomiméticas de este tipo de compuestos deberían tener como precursor un poliepóxido con elementos estructurales que permitan cierres de anillo 6-endo y den como resultado anillos tetrahidropiránicos.

En el siguiente ejemplo, McDonald et al. llevan a cabo la oxaciclación de XVII catalizada por $\mathrm{BF}_{3} \cdot \mathrm{OEt}_{2}$, obteniendo el poliéter XVIII (Esquema 9). Estos autores demuestran que este tipo de ciclaciones dan como resultado poliéteres cis- o transfusionados dependiendo de la naturaleza del nucleófilo terminal. ${ }^{21,22}$<smiles>CNC(=O)OCC1OC1(C)C[C@@H]1O[C@@]2(C)CC3CC3(C)CC12</smiles>

XVII

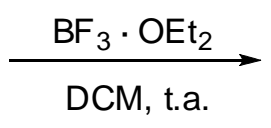

DCM, t.a.<smiles>CC1(C)O[C@H]2C[C@]3(C)OC(=O)OC[C@H]3O[C@]2(C)C[C@@H]1O</smiles>

XVIII

Esquema 9

\footnotetext{
${ }^{19}$ Cane, D. E.; Celmer, W. D.; Westley, J. W. J. Am. Chem. Soc. 1983, 105, 3594.

${ }^{20}$ (a) Marmsäter, F. P.; West, F. G. Chem. Eur. J. 2002, 8, 4346; (b) Valentine, J. C.; McDonald, F. E. Synlett 2006, 1816; (c) Gallimore, A. R.; Spencer, J. B. Angew. Chem., Int. Ed. 2006, 45, 4406.

${ }^{21}$ Bravo, F.; McDonald, F. E.; Neiwert, W. A.; Do, B.; Hardcastle, K. I. Org. Lett. 2003, 5, 2123.

${ }^{22}$ Para otras publicaciones sobre la obtención de poliéteres, ver: (a) Tokiwano, T.; Fujiwara, K.; Murai, A. Synlett 2000, 335; (b) Simpson, G. L.; Heffron, T. P.; Merino, E.; Jamison, T. F. J. Am. Chem. Soc. 2006, 128, 1056.
} 


\subsection{Ciclaciones sobre alquenos}

Un número importante de metodologías para la síntesis de tetrahidropiranos se basa en el ataque intramolecular de un nucleófilo oxigenado sobre una olefina activada por electrófilos. Los precursores más comunes son los $\delta$-hidroxialquenos, los cuales ciclan hasta los correspondientes tetrahidropiranos de forma totalmente regioselectiva mediante un proceso 6-exo. En primer lugar se forma un complejo $\pi$ entre el electrófilo y el alqueno y posteriormente se produce el ataque del nucleófilo oxigenado, siempre por la cara opuesta del electrófilo (Esquema 10).

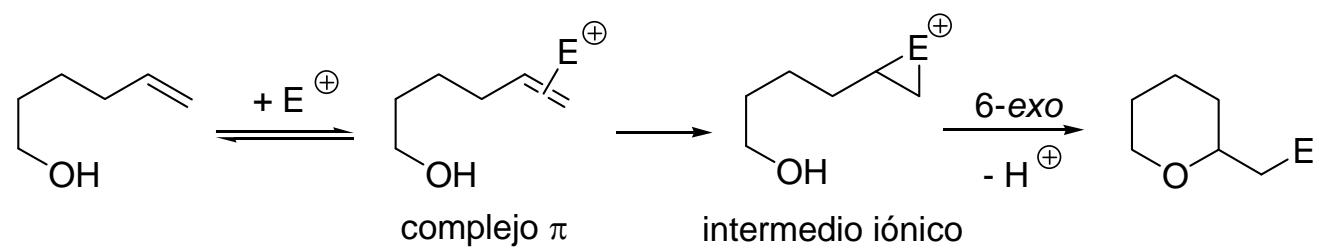

Esquema 10

Estas ciclaciones se pueden dividir en estequiométricas o catalíticas dependiendo de la cantidad de electrófilo usada en el proceso. Las primeras suelen utilizar sales de mercurio (II), reactivos de selenio o de halógenos para la activación del doble enlace, mientras que las segundas utilizan mayoritariamente complejos de paladio.

\subsubsection{Ciclaciones estequiométricas}

Las reacciones de oximercuriación intramolecular utilizan sales de mercurio (II) como electrófilos y normalmente el enlace carbono-mercurio formado se reduce con $\mathrm{NaBH}_{4}$ o $n-\mathrm{Bu}_{3} \mathrm{SnH}^{23}{ }^{23}$ Estas ciclaciones dependen de la estabilidad de los intermedios catiónicos y en la mayoría de los casos se obtiene el tetrahidropirano termodinámicamente más estable. Además, si el hidroxialqueno dispone de los elementos estructurales necesarios para que se logre la discriminación $\pi$-facial del doble enlace C-C deseada, el proceso tendrá un control total de la estereoquímica.

${ }^{23}$ (a) Liu, B.; Zhou, W.-S. Tetrahedron Lett. 2003, 44, 4933; (b) Takao, H.; Wakabayashi, A.; Takahashi, K.; Imagawa, H.; Sugihara, T.; Nishizawa, M. Tetrahedron Lett. 2004, 45, 1079; (c) Petri, A. F.; Bayer, A.; Maier, M. E. Angew. Chem., Int. Ed. 2004, 43, 5821; (d) Nicolaou, K. C.; Pihko, P. M.; Bernal, F.; Frederick, M. O.; Qian, W.; Uesaka, N.; Diedrichs, N.; Hinrichs, J.; Koftis, T. V.; Loizidou, E.; Petrovic, G.; Rodriquez, M.; Sarlah, D.; Zou, N. J. Am. Chem. Soc. 2006, 128, 2244. 


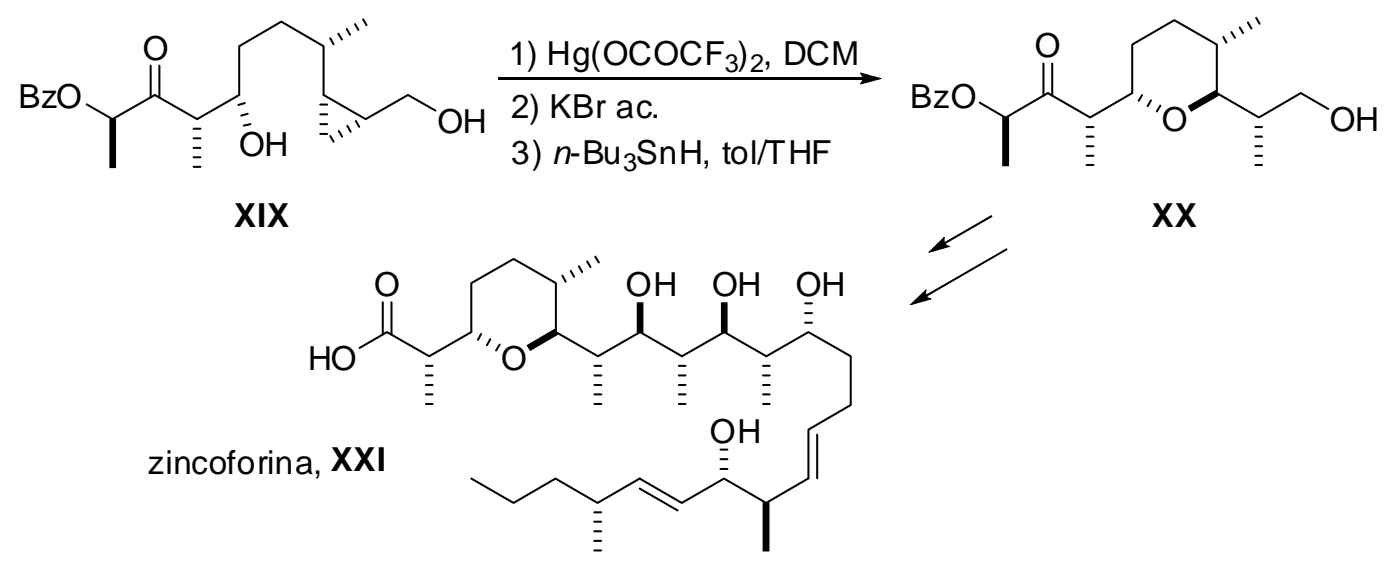

\section{Esquema 11}

Un ejemplo interesante de este tipo de reacciones son las aperturas electrofílicas de anillo con $\mathrm{Hg}(\mathrm{II})$ de derivados $\delta$-hidroxi-ciclopropilcarbinol, en las que el anillo de ciclopropano se comporta como una olefina activada. La estereoquímica de estas ciclaciones depende de la configuración del anillo ciclopropánico. Esta estrategia ha sido utilizada por Meyer, Cossy et al. en la síntesis del ionóforo zincoforina (Esquema $11, \mathbf{X X I})^{24}$

Las haloeterificaciones ${ }^{25}$ son similares a los procesos anteriormente descritos. En este caso se suele utilizar mayoritariamente yodo o $N$-yodosuccinimida para formar el complejo $\pi$, aunque también se pueden utilizar otros reactivos como bis(colidina) $\mathrm{I} \cdot \mathrm{PF}_{6}($ Esquema 12$){ }^{25 \mathrm{e}}$<smiles>COC(=O)CC=CCCCCC(O)CC(=O)OCc1ccccc1</smiles>

XXII<smiles>COC(=O)C[C@@H]1CCC[C@@H](/C=C/C(=O)OCc2ccccc2)O1</smiles>

XXIII

\section{Esquema 12}

${ }^{24}$ Defosseux, M.; Blanchard, N.; Meyer, C.; Cossy, J. J. Org. Chem. 2004, 69, 4626.

${ }^{25}$ (a) Kang, S. H.; Kang, S. Y.; Kim, C. M.; Choi, H.-w.; Jun, H.-S.; Lee, B. M.; Park, C. M.; Jeong, J. W. Angew. Chem., Int. Ed. 2003, 42, 4779; (b) Gao, X.; Snider, B. B. J. Org. Chem. 2004, 69, 5517; (c) White, J. D.; Smits, H. Org. Lett. 2005, 7, 235; (d) Nicolaou, K. C.; Koftis, T. V.; Vyskocil, S.; Petrovic, G.; Tang, W.; Frederick, M. O.; Chen, D. Y.-K.; Li, Y.; Ling, T.; Yamada, Y. M. A. J. Am. Chem. Soc. 2006, 128, 2859; (e) Hiebel, M.- A.; Pelotier, B.; Goekjian, P.; Piva, O. Eur. J. Org. Chem. 2008, 713; (f) Albert, B. J.; Koide, K. Org. Lett. 2004, 6, 3655. 
Esta metodología ha sido utilizada recientemente por Nicolau et al. en uno de los últimos pasos de la síntesis de la neurotoxina marina azaspiracida-1, cuya estructura correcta no fue descrita hasta 2004 por este mismo grupo. ${ }^{25 \mathrm{~d}}$

Aunque en la inmensa mayoría de los casos el nucleófilo oxigenado implicado en este tipo de reacciones se trata de un grupo hidroxilo, en alguna ocasión se ha utilizado como nucleófilo el oxígeno carbonílico de una cetona. Esta estrategia, que transcurre a través de un ión oxocarbenio, ha sido utilizada por Koide et al. en la síntesis del agente antitumoral FR-901464 (Esquema 13, XXVI). ${ }^{25 f}$ Sin embargo, la estereoquímica del fragmento XXV no coincidía con la de FR-901464.

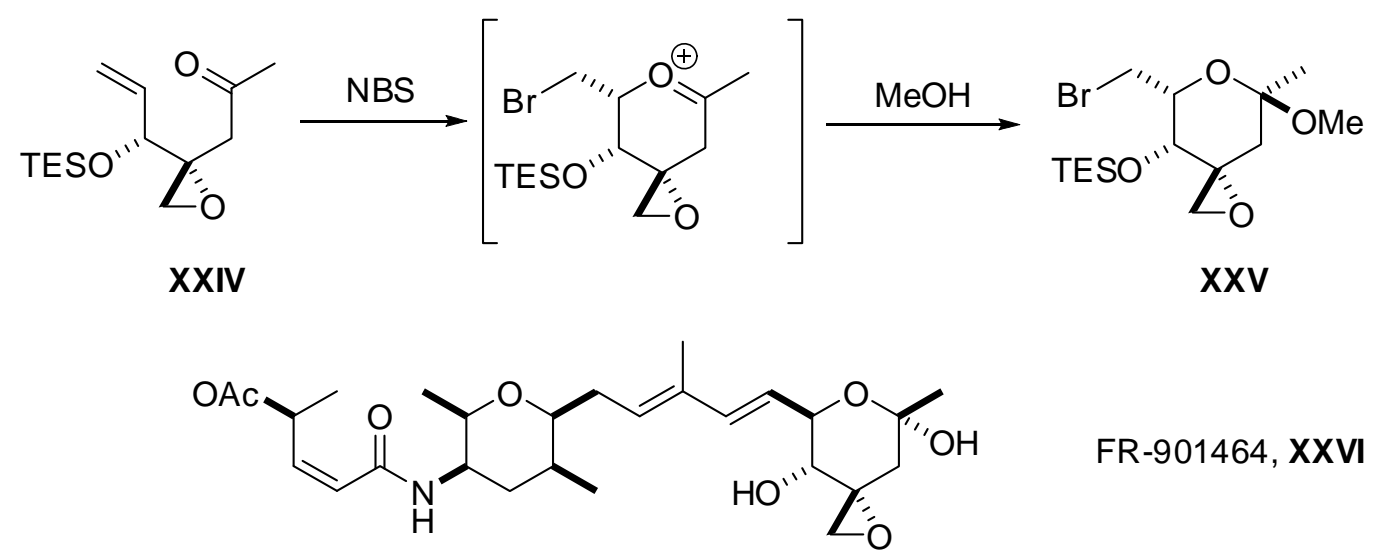

Esquema 13

Las ciclaciones sobre alquenos basadas en reactivos de selenio, como $\mathrm{PhSeCl}$ o $\mathrm{N}$-fenilselenoftalimida (NPSP), son mucho menos frecuentes que las que utilizan $\mathrm{Hg}(\mathrm{II})$ o halógenos. En este caso, la estereoselectividad de la reacción de ciclación depende de la coordinación del electrófilo con la olefina y se obtienen preferentemente transtetrahidropiranos. ${ }^{26}$ Esta es la tendencia observada en la síntesis del tetrahidropirano XXVIII (Esquema 14).

\footnotetext{
${ }^{26}$ (a) Ver ref. 7d; (b) Fettes, A.; Carreira, E. M. J. Org. Chem. 2003, 68, 9274; (c) Iwasaki, K.; Nakatani, M.; Inoue, M.; Katoh, T. Tetrahedron 2003, 59, 8763; (d) Hart, D. J.; Patterson, S.; Unch, J.P. Synlett 2003, 1334.
} 


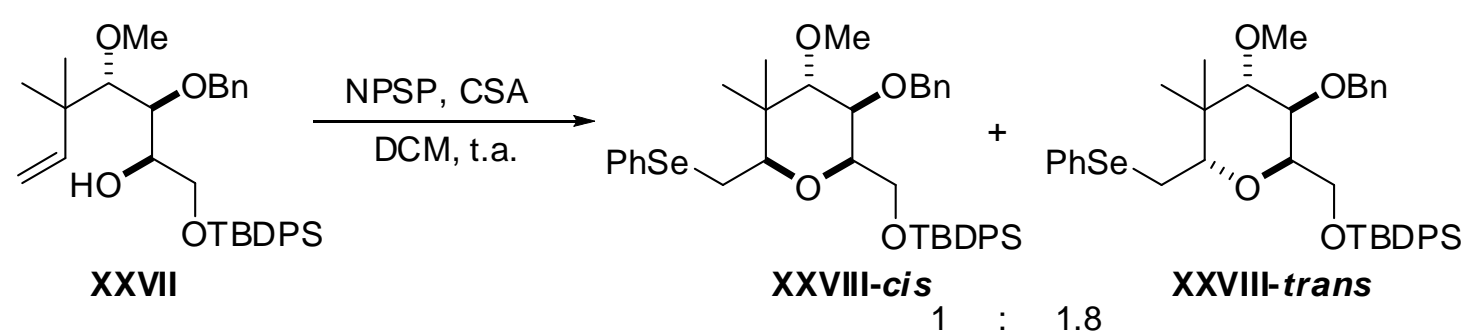

\section{Esquema 14}

\subsubsection{Ciclaciones catalíticas}

\subsubsection{Ciclaciones catalizadas por $\operatorname{Pd}(0)$}

Los complejos de $\operatorname{Pd}(0)$ son nucleofílicos, por lo que las ciclaciones de $\delta$ hidroxialquenos transcurren a través de cationes $\pi$-alilpaladio (reacción de Tsuji-Trost) que posteriormente son atacados por el grupo hidroxilo para dar el tetrahidropirano correspondiente (Esquema 15). Estas reacciones son regioselectivas, ya que las ciclaciones 6-exo están mucho más favorecidas que las 8-endo. La coordinación del paladio al doble enlace C-C tiene lugar por la cara menos impedida y el ataque del nucleófilo al complejo catiónico $\pi$-alilpaladio se produce por la cara opuesta al metal, con lo que la reacción transcurre con total retención de la estereoquímica.

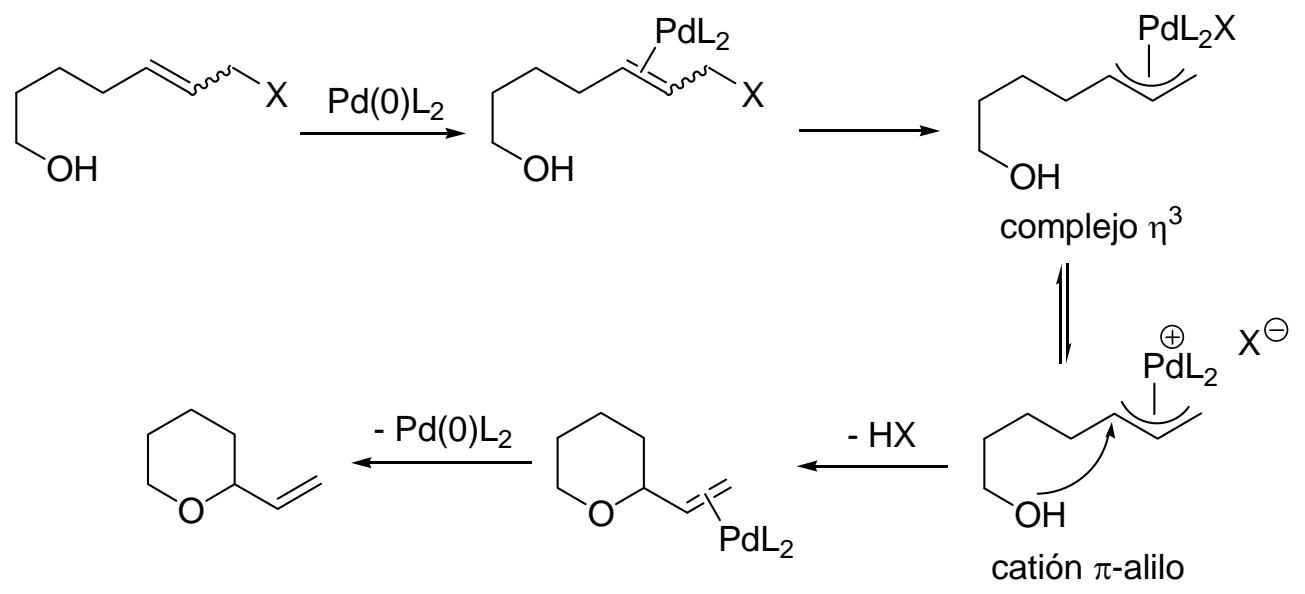

\section{Esquema 15}


Lee et al., en sus estudios sobre la síntesis de 2-alquenil-4metilentetrahidropiranos han demostrado que este proceso puede ser altamente diastereoselectivo (Esquema 16). ${ }^{27}$<smiles>C=C(C/C=C/C(COc1ccccc1)OC(=O)OCC)CC(O)COCc1ccccc1</smiles>

XXIX-a

$\mathrm{XXX}-$ cis

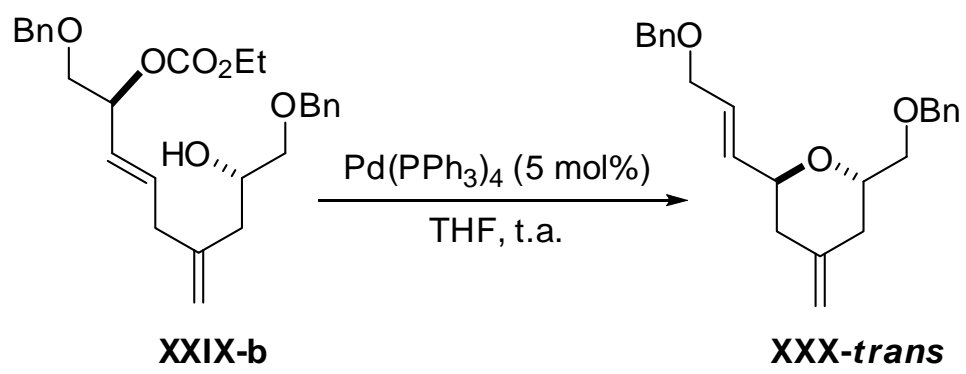

Esquema 16

Si se utilizan ligandos quirales (p. ej. difosfinas quirales), también se pueden llevar a cabo ciclaciones enantioselectivas con catalizadores de $\operatorname{Pd}(0){ }^{28}$

\subsubsection{Ciclaciones catalizadas por Pd(II)}

El carácter electrofílico que presenta el $\mathrm{Pd}(\mathrm{II})$ hace que se coordine con los dobles enlaces $\mathrm{C}$-C formando complejos $\pi$, los cuales son atacados fácilmente por nucleófilos en posición anti al metal dando un intermedio $\delta$-alquilpaladio que finalmente sufre una $\beta$-eliminación de hidruro (Esquema 17). Así, la ciclación intramolecular de $\delta$-hidroxialquenos catalizada por $\operatorname{Pd}(\mathrm{II})$ representa una estrategia sencilla para la síntesis de tetrahidropiranos mediante un proceso 6-exo.

\footnotetext{
${ }^{27}$ Hansen, E. C.; Lee, D. Tetrahedron Lett. 2004, 45, 7151.

${ }^{28}$ (a) Campbell, J. E.; Englund, E. E.; Burke, S. D. Org. Lett. 2002, 4, 2273; (b) Trost, B. M.; Crawley, M. L. Chem. Rev. 2003, 103, 2921; (c) Lucas, B. S.; Burke, S. D. Org. Lett. 2003, 5, 3915; (d) Zacuto, M. J.; Leighton, J. L. Org. Lett. 2005, 7, 5525. (e) Trost, B. M.; Machacek, M. R.; Faulk, B. D. J. Am. Chem. Soc. 2006, 128, 6745.
} 


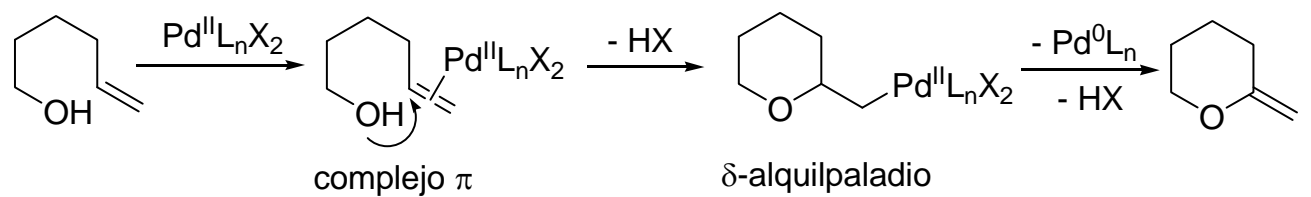

Esquema 17

Como se observa en el Esquema 17, en el paso final se libera $\operatorname{Pd}(0)$, por lo que se necesita un oxidante suave (p. ej. $\mathrm{CuCl}_{2}, \mathrm{Cu}(\mathrm{OAc})_{2}, \mathrm{HNO}_{3}$ ) que lo transforme de nuevo en $\operatorname{Pd}(\mathrm{II})$ sin afectar a los sustratos ni a los productos para que el proceso sea realmente catalítico. ${ }^{29}$

El hecho de que esta metodología no se haya utilizado demasiado en la síntesis de productos naturales radica en que el paso de $\beta$-eliminación no es muy regioselectivo y depende en gran medida del disolvente. ${ }^{30}$ Esta limitación se ha resuelto introduciendo un grupo hidroxilo en posición alílica, el cual se coordina con el metal y determina el ataque sin del alcohol en posición $\delta \mathrm{y}$, por tanto, la estereoselección de la reacción. ${ }^{31}$ Uenishi ha utilizado esta metodología en la síntesis de laulimalida (Esquema 18, XXXIII), un potente agente antitumoral. ${ }^{31 \mathrm{a}}$

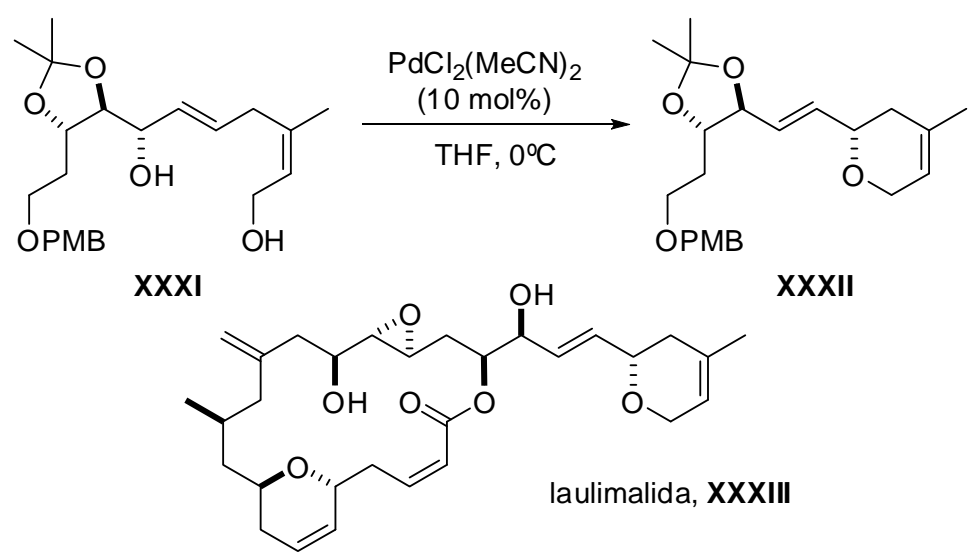

\section{Esquema 18}

\footnotetext{
${ }^{29}$ Hegedus, S. L. Organometallics in Synthesis: A Manual; Schlosser, M., Ed.; John Wiley \& Sons: Chichester, UK, 2002; Capítulo 10, pp 1123-1217.

${ }^{30}$ (a) Trend, R. M.; Ramtohul, Y. K.; Ferreira, E. M.; Stoltz, B. M. Angew. Chem., Int. Ed. 2003, 42, 2892; (b) Koh, J. H.; Mascarenhas, C.; Gagné, M. R. Tetrahedron 2004, 60, 7405.

31 (a) Uenishi, J.; Ohmi, M. Angew. Chem., Int. Ed. 2005, 44, 2756; (b) Uenishi, J.; Ohmi, M.; Ueda, A. Tetrahedron: Asymmetry 2005, 16, 1299; (c) Kawai, N.; Lagrange, J.-M.; Ohmi, M.; Uenishi, J. J. Org. Chem. 2006, 71, 4530; (d) Kawai, N.; Lagrange, J.-M.; Uenishi, J. Eur. J. Org. Chem. 2007, 2808; (e) Miyazawa, M.; Hirose, Y.; Narantsetseg, M.; Yokoyama, H.; Yamaguchi, S.; Hirai, Y. Tetrahedron Lett. 2004, 45, 2883.
} 
Como se mostraba en el Esquema 17, la adición intramolecular de un grupo hidroxilo a un alqueno catalizada por $\operatorname{Pd}(\mathrm{II})$ producía un intermedio $\delta$-alquilpaladio. Este intermedio puede evolucionar de otros modos además del indicado en dicho esquema. Una de ellas es la inserción de $\mathrm{CO}$ en el enlace C-Pd, formándose una especie acilpaladio que se puede transformar fácilmente en el correspondiente metil éster (Esquema 19). ${ }^{32}$ Esta metodología ha sido utilizada recientemente por White et al. en la síntesis de phorboxazol A. ${ }^{32 \mathrm{~b}}$

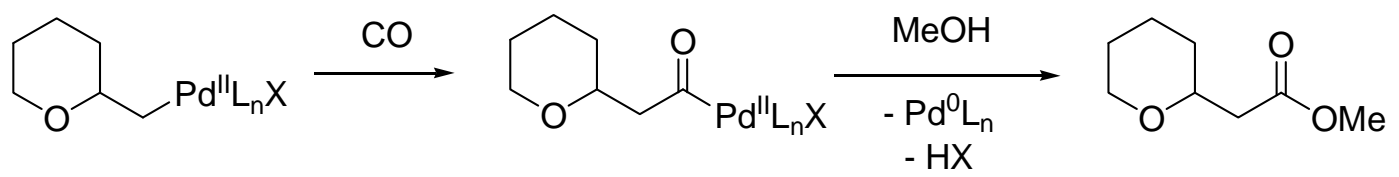

Esquema 19

Otra manera de atrapar el complejo $\delta$-alquilpaladio es a través de una reacción de Heck. En el Esquema 20 se puede ver una aplicación de esta estrategia en la síntesis de $\alpha$-tocoferol (XXXVI). ${ }^{33}$

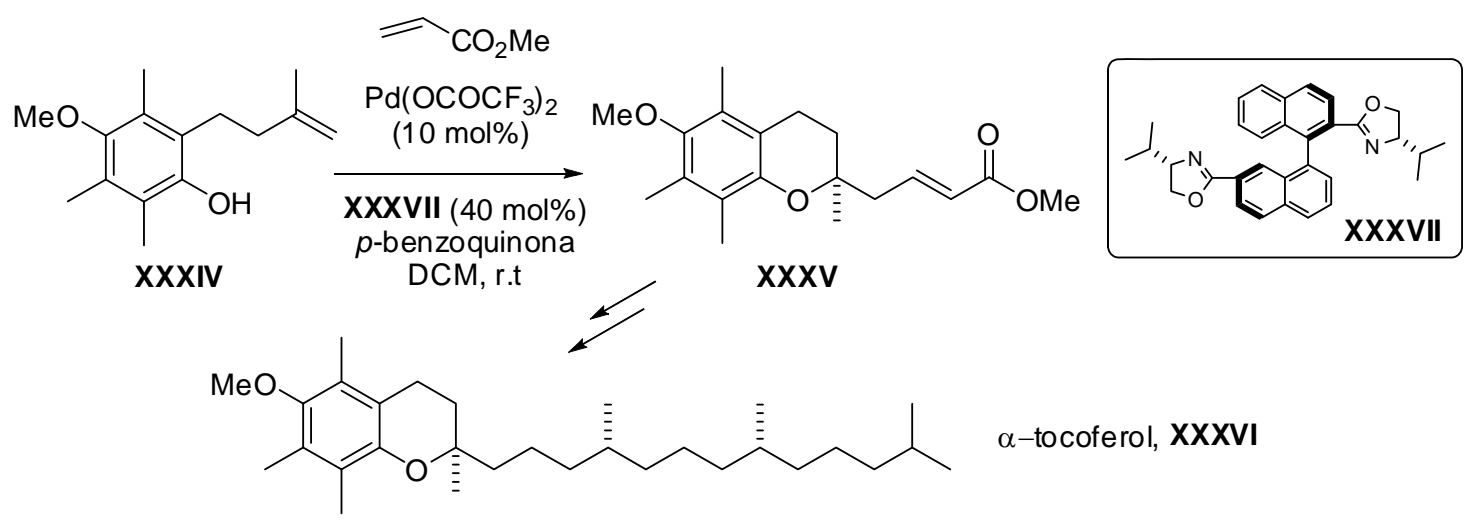

Esquema 20

32 (a) Blakemore, P. R.; Browder, C. C.; Hong, J.; Lincoln, C. M.; Nagornyy, P. A.; Robarge, L. A.; Wardrop, D. J.; White, J. D. J. Org. Chem. 2005, 70, 5449; (b) White, J. D.; Kuntiyong, P.; Lee, T. H. Org. Lett. 2006, 8, 6039.

${ }^{33}$ Tietze, L. F.; Sommer, K. M.; Zinngrebe, J.; Stecker, F. Angew. Chem., Int. Ed. 2005, 44, 257. 


\subsubsection{Ciclaciones catalizadas por otros metales}

Además de la química del paladio, existen otras metodologías para la ciclación catalítica de $\delta$ - y $\gamma$-hidroxialquenos basadas en la activación de la olefina por otros metales como platino, estaño, plata, cerio y oro, ${ }^{34}$ aunque desde el punto de vista sintético no pueden competir de momento con la catálisis por paladio.

\subsubsection{Ciclaciones en medio ácido}

Las ciclaciones en medio ácido de hidroxialquenos están promovidas por cantidades catalíticas o estequiométricas de ácidos de Brønsted. Aunque los aspectos mecanísticos son bastante especulativos, la regioselectividad de estas reacciones suele estar controlada por la regla de Markovnikov y la mayoría de ellas utiliza ácidos fuertes en gran cantidad. ${ }^{35}$ No obstante, también se pueden llevar a cabo en condiciones catalíticas, como en el ejemplo del Esquema 21. ${ }^{36}$

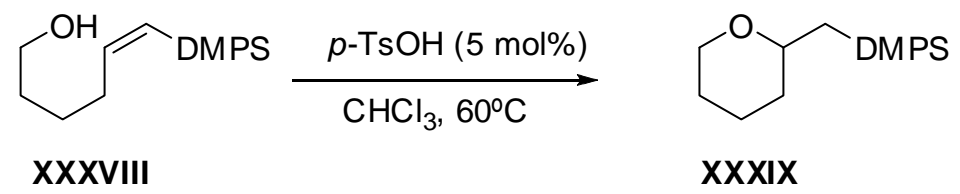

\section{Esquema 21}

En algunos casos también se utilizan ácidos de Lewis, los cuales se coordinan con el grupo hidroxilo y aumentan la acidez del protón. ${ }^{37}$ Esta estrategia ha sido utilizada por Woggon et al. en la síntesis biomimética de $\alpha$-tocoferol (Esquema 22). ${ }^{37 \mathrm{c}}$

\footnotetext{
34 (a) Qian, H.; Han, X.; Widenhoefer, R. A. J. Am. Chem. Soc. 2004, 126, 9536; (b) Coulombel, L.; Favier, I.; Duñach, E. Chem. Commun. 2005, 2286; (c) Yang, C.-G.; Reich, N. W.; Shi, Z.; He, C. Org. Lett. 2005, 7, 4553; (d) Marotta, E.; Foresti, E.; Marcelli, T.; Peri, F.; Righi, P.; Scardovi, N.; Rosini, G. Org. Lett. 2002, 4, 4451; (e) Jung, H. H.; Floreancig, P. E. Org. Lett. 2006, 8, 1949.

${ }^{35}$ (a) Nicolaou, K. C.; Li, A.; Edmonds, D. J. Angew. Chem., Int. Ed. 2006, 45, 7086; (b) Zou, Y.; Chen, C.-H.; Taylor, C. D.; Foxman, B. M.; Snider, B. B. Org. Lett. 2007, 9, 1825; (c) Kaliappan, K. P.; Ravikumar, V. Org. Lett. 2007, 9, 2417; (d) Nicolaou, K. C.; Tang, Y.; Wang, J. Chem. Commun. 2007, 1922.

${ }^{36}$ Rosenfeld, D. C.; Shekhar, S.; Takemiya, A.; Utsunomiya, M.; Hartwig, J. F. Org. Lett. 2006, 8, 4179.

${ }^{37}$ (a) Coulombel, L.; Rajzmann, M.; Pons, J.-M.; Olivero, S.; Duñach, E. Chem. Eur. J. 2006, 12, 6356; (b) Uyanik, M.; Ishihara, K.; Yamamoto, H. Bioorg. Med. Chem. 2005, 13, 5055. (c) Grütter, C.; Alonso, E.; Chougnet, A.; Woggon, W.-D. Angew. Chem., Int. Ed. 2006, 45, 1126.
} 
<smiles>[R]Oc1c(C)c(C)c(O)c(CN2CCC[C@H]2C(=O)[O-])c1CC(C)CCC(C)CC(C)CCC(C)(C)C(C)C</smiles>

$\mathbf{X L}$

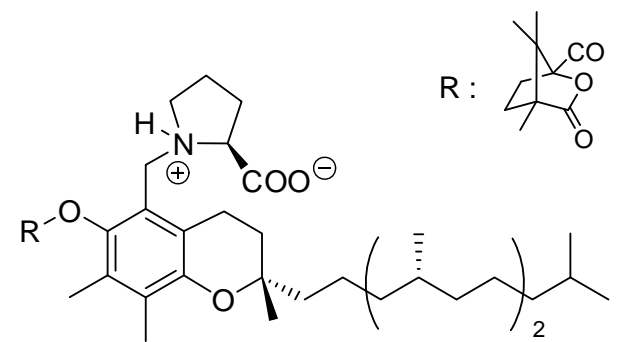

XLI

Esquema 22

\subsection{Ciclaciones sobre alenos}

Las cicloisomerizaciones de $\beta$ - o $\delta$-hidroxialenos catalizadas por complejos de oro dan lugar a heterociclos oxigenados de seis miembros de una manera sencilla. Inicialmente el catalizador se coordina con uno de los dobles enlaces terminales del $\beta$ hidroxialeno, obteniéndose un intermedio que posteriormente sufre el ataque nucleofílico del grupo hidroxilo de forma 6-endo-trig (Esquema 23). ${ }^{38}$ En un proceso totalmente similar, los $\delta$-hidroxialenos experimentan una hidroalcoxilación 6-exo-trig para formar el correspondiente 2-alquenil-tetrahidropirano. ${ }^{39}$

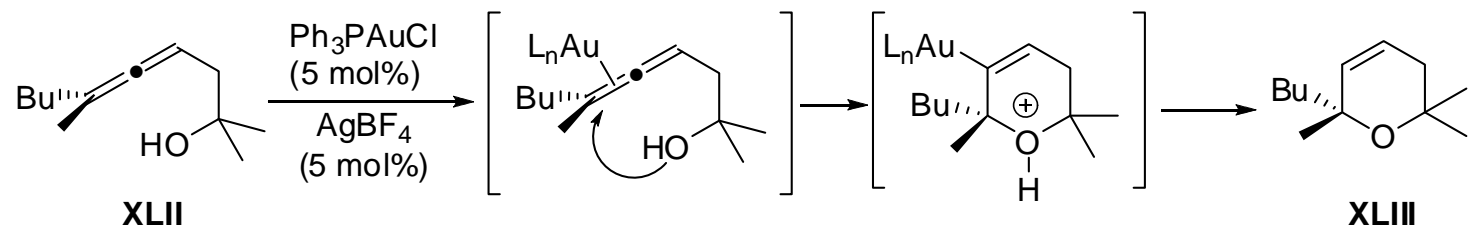

Esquema 23

\subsection{Ciclaciones sobre alquinos}

Las ciclaciones intramoleculares de hidroxialquinos catalizadas por metales apenas han sido utilizadas para la síntesis de heterociclos oxigenados. Sin embargo,

${ }^{38}$ Gockel, B.; Krause, N. Org. Lett. 2006, 8, 4485.

39 (a) Zhang, Z.; Liu, C.; Kinder, R. E.; Han, X.; Qian, H.; Widenhoefer, R. A. J. Am. Chem. Soc. 2006, 128, 9066; (b) Zhang, Z.; Widenhoefer, R. A. Angew. Chem., Int. Ed. 2007, 46, 283. 
recientemente han aparecido en bibliografía ciclaciones 6-endo-dig de alcoholes 2alquinilbencílicos con triples enlaces internos catalizadas por paladio e iridio para dar los correspondientes isocromenos (Esquema 24). ${ }^{40}$ La regioselectividad 6-endo-dig estará favorecida frente a la 5-exo-dig cuando $\mathrm{R}=$ alquilo y por control de algunas variables experimentales (polaridad, temperatura, dilución).

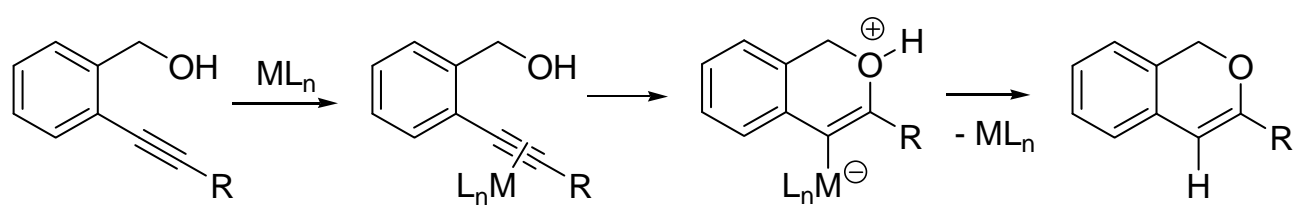

Esquema 24

Los 5-alquinoles con triple enlace terminal dan lugar a enol éteres exocíclicos a través de ciclaciones 6-exo-dig catalizadas por paladio, iridio, platino u oro de forma totalmente regioselectiva (Esquema 25$){ }^{41}$

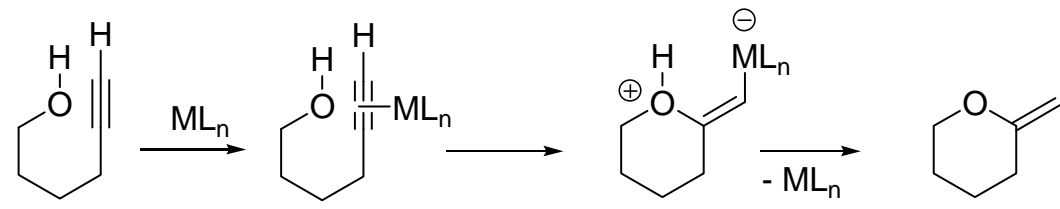

\section{Esquema 25}

Los alquinoles internos también participan en este tipo de cicloisomerizaciones regioselectivas y el enol éter resultante es atrapado por otros nucleófilos. ${ }^{42}$ Esta estrategia ha sido utilizada por Forsyth en la bi-espirocetalización catalizada por oro para formar los anillos A y B de las azaspiracidas (Esquema 26). ${ }^{42 \mathrm{~b}}$

\footnotetext{
${ }^{40}$ (a) Gabriele, B.; Salerno, G.; Fazio, A.; Pitelli, R. Tetrahedron 2003, 59, 6251; (b) Li, X.; Chianese, A. R.; Vogel, T.; Crabtree, R. H. Org. Lett. 2005, 7, 5437.

${ }^{41}$ (a) Marshall, J. A.; Yanik, M. M. Tetrahedron Lett. 2000, 41, 4717; (b) Genin, E.; Antoniotti, S.; Michelet, V.; Genêt, J.-P. Angew. Chem., Int. Ed. 2005, 44, 4949; (c) Barluenga, J.; Diéguez, A.; Fernández, A.; Rodríguez, F.; Fañanás, F. J. Angew. Chem., Int. Ed. 2006, 45, 2091; (d) Antoniotti, S.; Genin, E.; Michelet, V.; Genêt, J.-P. J. Am. Chem. Soc. 2005, 127, 9976.

${ }^{42}$ (a) Liu, B.; DeBrabander, J. K. Org. Lett. 2006, 8, 4907; (b) Li, Y.; Zhou, F.; Forsyth, C. J. Angew. Chem., Int. Ed. 2007, 46, 279.
} 

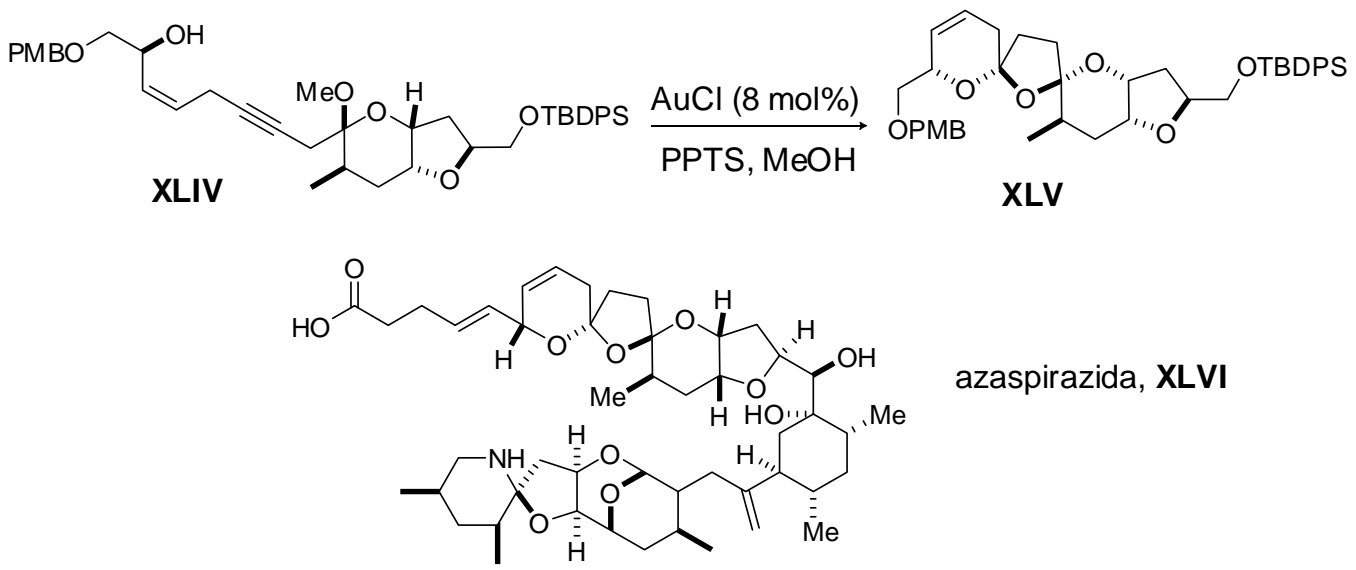

\section{Esquema 26}

Yamamoto et al. han utilizado el carácter hidroxílico de los hemiacetales y han llevado a cabo la activación simultánea de un grupo carbonilo y de un triple enlace C-C mediante catalizadores de paladio para la síntesis de alquenil éteres cíclicos XLVIII a partir de aldehídos acetilénicos XLVII (Esquema 27). ${ }^{43}$
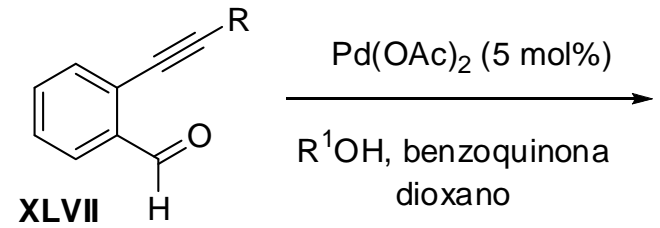<smiles>[R17]OC1OC([R])=Cc2ccccc21</smiles>

\section{Esquema 27}

\subsection{Otras ciclaciones catalizadas por metales}

\subsubsection{Ciclaciones de diazocompuestos}

Los diazocompuestos estabilizados, como $\alpha$-diazocetonas o ésteres, son precursores de carbenos metálicos, los cuales tienen carácter electrofílico en el carbono carbénico y pueden ser atacados por distintos nucleófilos. Así, el ataque intramolecular de alcoholes, éteres o carbonilos en posición $\delta$ dará lugar a tetrahidropiranos (Esquema 28).

\footnotetext{
43 (a) Asao, N.; Nogami, T.; Takahashi, K.; Yamamoto, Y. J. Am. Chem. Soc. 2002, 124, 764; (b)
} Mondal, S.; Nogami, T.; Asao, N.; Yamamoto, Y. J. Org. Chem. 2003, 68, 9496. 


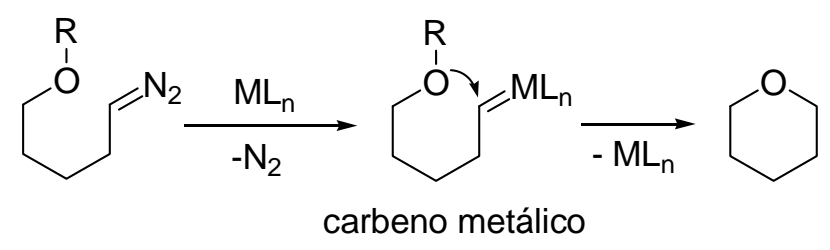

Esquema 28

Las reacciones que utilizan alcoholes como nucleófilos no han sido muy utilizadas para la síntesis de tetrahidropiranos, probablemente debido a que el mecanismo de reacción no ha sido muy estudiado. ${ }^{44,45}$

Los éteres también pueden reaccionar con carbenos metálicos a través de un iluro de oxonio intermedio que evoluciona a través un reordenamiento [1,2] ([2,3] para los éteres alílicos) hasta el correspondiente tetrahidropirano (Esquema 29).

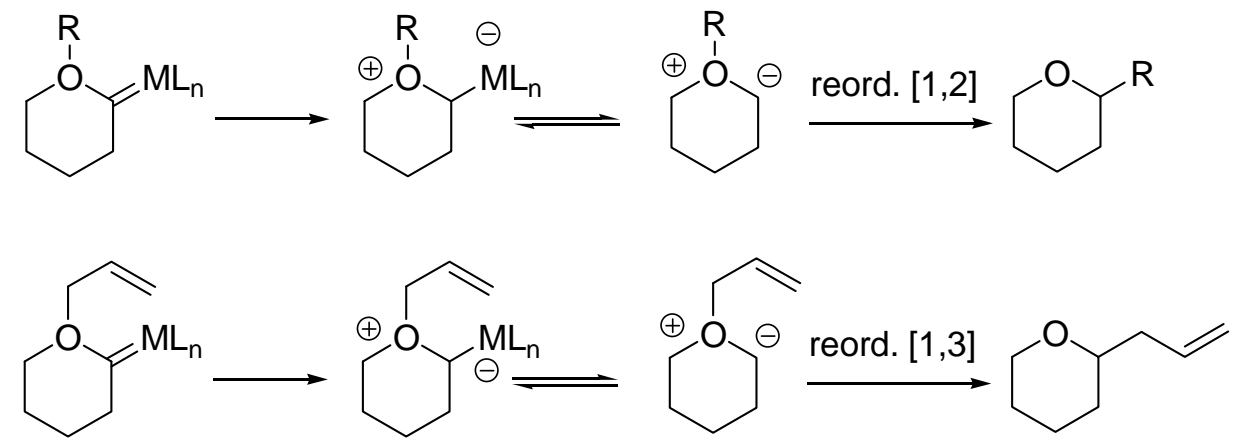

\section{Esquema 29}

En este caso, los catalizadores de cobre son los que dan mejores resultados, probablemente porque favorecen la formación del iluro frente a la inserción en el enlace C-H. De hecho, las ciclaciones de $\alpha$-diazocetonas con un éter alílico catalizadas por cobre se han utilizado en la síntesis de productos naturales. ${ }^{46}$ En el Esquema 30 se muestra el paso de formación del tetrahidropirano presente en la estructura de la decarestrictina L (LI) llevada a cabo por Clark et al. ${ }^{46 \mathrm{~d}}$

\footnotetext{
44 (a) Qu, Z.; Shi, W.; Wang, J. J. Org. Chem. 2004, 69, 217; (b) Lu, C.-D.; Liu, H.; Chen, Z.-Y.; Hu, W.H.; Mi, A.-Q. Org. Lett. 2005, 7, 83.

${ }^{45}$ Sarabia, F.; Chammaa, S.; López Herrera, F. J. Tetrahedron 2001, 57, 10271.

${ }^{46}$ (a) Marmsäter, F. P.; West, F. G. J. Am. Chem. Soc. 2001, 123, 5144; (b) Marmsäter, F. P.; Vanecko, J. A.; West, F. G. Tetrahedron 2002, 58, 2027; (c) Clark, J. S.; Whitlock, G.; Jiang, S.; Onyia, N. Chem. Commun. 2003, 2578; (d) Clark, J. S.; Fessard, T. G.; Whitlock, G. A. Tetrahedron 2006, 62, 73.
} 


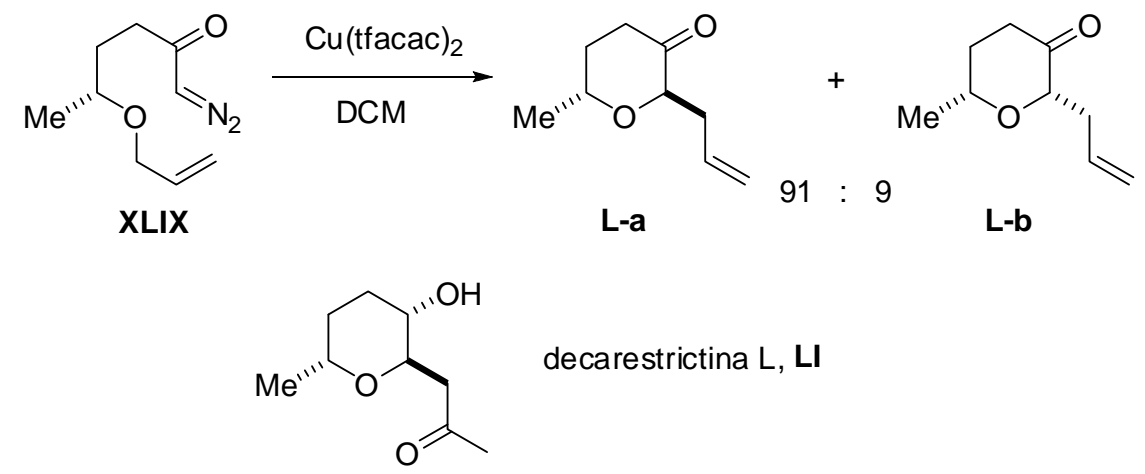

Esquema 30

La adición intramolecular de carbonilos a carbenos metálicos es una metodología muy interesante, ya que se produce un iluro intermedio que puede participar en cicloadiciones 1,3-dipolares, dando lugar a sistemas bicíclicos estructuralmente complejos (Esquema 31). Para estas ciclaciones se suelen emplear catalizadores de Rh(II). ${ }^{47,48}$

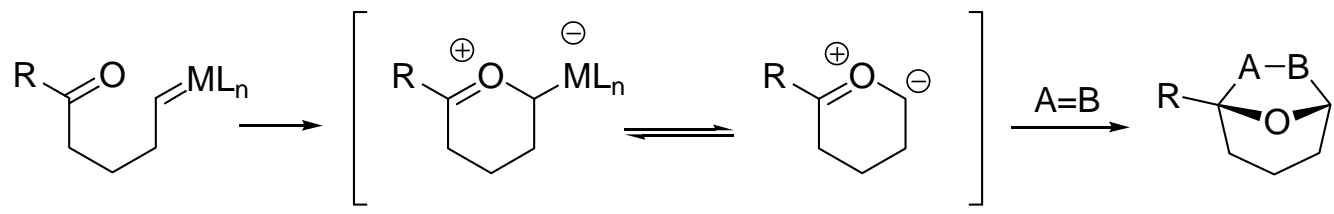

\section{Esquema 31}

Esta estrategia ha sido empleada en la síntesis estereoselectiva de los sistemas bicíclicos presentes en productos naturales estructuralmente complejos como el ácido pseudoalárico $\mathrm{A},{ }^{49 \mathrm{c}}$ la poligalolida $\mathrm{A}^{49 \mathrm{~b}}$ o el ácido zaragózico C. ${ }^{49 a}$ En el Esquema 32 se muestra como ejemplo un paso de la síntesis de este último (LIV) llevada a cabo por Hashimoto et al.

\footnotetext{
47 (a) Mehta, G.; Muthusamy, S. Tetrahedron 2002, 58, 9477; (b) Padwa, A. Helv. Chim. Acta 2005, 88, 1357.

${ }^{48}$ Hodgson, D. M.; Angrish, D. Adv. Synth. Catal. 2006, 348, 2509.

49 (a) Nakamura, S.; Hirata, Y.; Kurosaki, T.; Anada, M.; Kataoka, O.; Kitagaki, S.; Hashimoto, S. Angew. Chem., Int. Ed. 2003, 42, 5351; (b) Nakamura, S.; Sugano, Y.; Kikuchi, F.; Hashimoto, S. Angew. Chem., Int. Ed. 2006, 45, 6532; (c) Geng, Z.; Chen, B.; Chiu, P. Angew. Chem., Int. Ed. 2006, 45, 6197.
} 


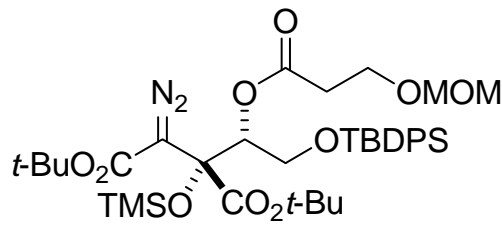

LII $\frac{\mathrm{Rh}_{2}(\mathrm{OAc})_{4}(5 \mathrm{~mol} \%)}{\mathrm{HC} \equiv \mathrm{CCOMe}(3 \mathrm{eq})} \begin{gathered}\text { benceno } \\ \text { bencon }\end{gathered}$

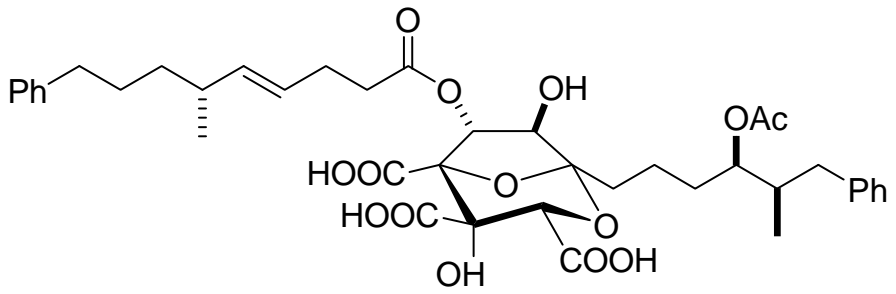

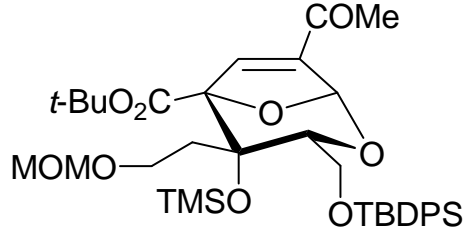

LIII ácido zaragócico LIV

Esquema 32

\subsubsection{Reacciones de eterificación intramolecular de haluros de arilo y vinilo}

Las reacciones de eterificación intramolecular de haluros de arilo catalizada por paladio utilizan $o$-biarilfosfinas voluminosas y ricas en electrones en presencia de bases débiles. La elección de la fosfina adecuada resulta ser de suma importancia, ya que su tamaño acelera el paso de eliminación reductora y minimiza la $\beta$-eliminación de hidruro competitiva (Esquema 33).

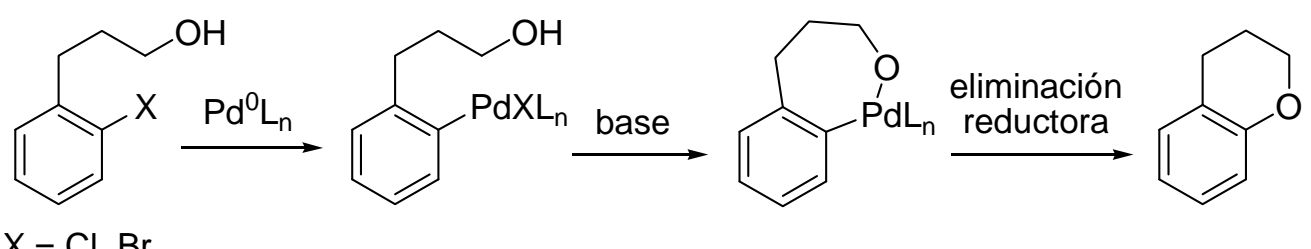

\section{Esquema 33}

Esta metodología se ha aplicado a la síntesis de varios compuestos

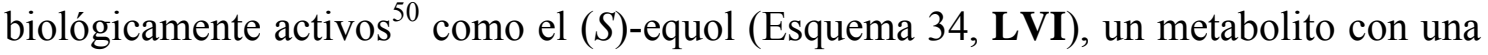
gran actividad estrogénica. ${ }^{50 \mathrm{c}}$

\footnotetext{
${ }^{50}$ (a) Kuwabe, S.-i.; Torraca, K. E.; Buchwald, S. L. J. Am. Chem. Soc. 2001, 123, 12202; (b) Palucki, M.; Yasuda, N. Tetrahedron Lett. 2005, 46, 987; (c) Heemstra, J. M.; Kerrigan, S. A.; Doerge, D. R.; Helferich, W. G.; Boulanger, W. A. Org. Lett. 2006, 8, 5441.
} 


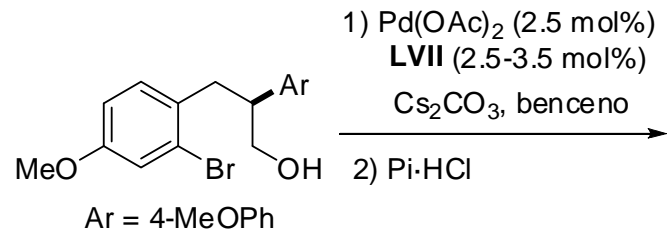

LV
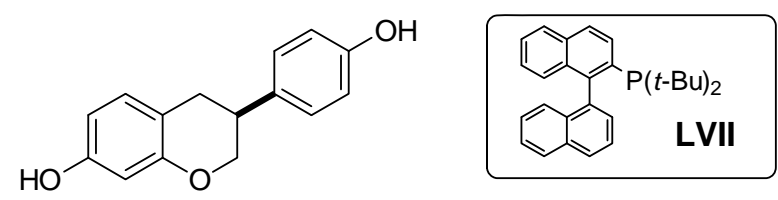

(S)-equol, LVI

Esquema 34

Además de las ciclaciones catalizadas por paladio, recientemente se ha publicado una reacción de eterificación intramolecular de haluros de vinilo catalizada por cobre. $^{51}$

\subsection{Adiciones conjugadas de Michael intramoleculares}

La reacción de $o x o-M i c h a e{ }^{52}$ ha sido utilizada con éxito en numerosas ocasiones para la síntesis de tetrahidropiranos. Como se indica en el Esquema 35, el ataque nucleofílico de un grupo hidroxilo sobre el carbono deficiente en electrones de un sistema $\alpha, \beta$-insaturado, transcurre a través de cierres de anillo exo o endo para dar los correspondientes tetrahidropiranos.
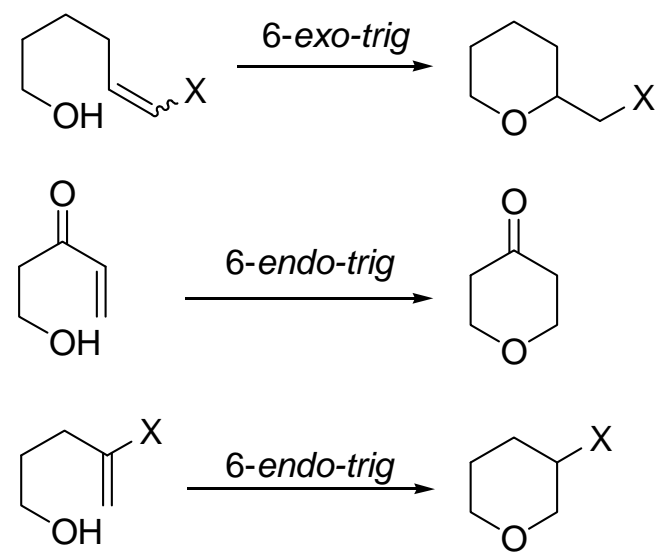

(X: grupo atractor de $\mathrm{e}^{-}$)

\section{Esquema 35}

\footnotetext{
${ }^{51}$ Fang, Y.; Li, C. J. Am. Chem. Soc. 2007, 129, 8092.

${ }^{52}$ Para una revision bibliográfica reciente sobre la reacción de oxo-Michael, ver: Nising, C. F.; Bräse S. Chem. Soc. Rev. 2008, 37, 1218.
} 


\subsubsection{Ciclaciones 6-exo}

Es el procedimiento más común para la síntesis de tetrahidropiranos basada en la reacción de Michael (Esquema 35, 1). La reversibilidad de la reacción conduce a los productos termodinámicamente más estables, esto es, con los sustituyentes más voluminosos situados preferentemente en posiciones ecuatoriales, obteniéndose mayoritariamente 2,6-cis-tetrahidropiranos.

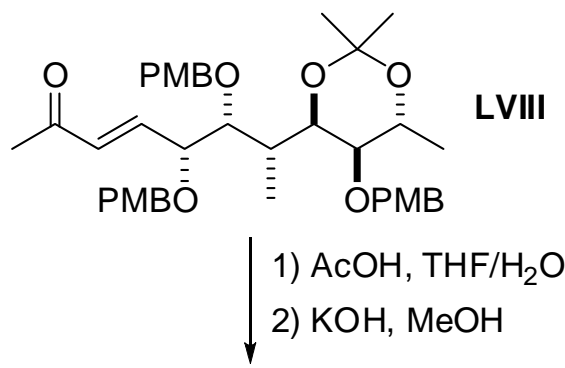

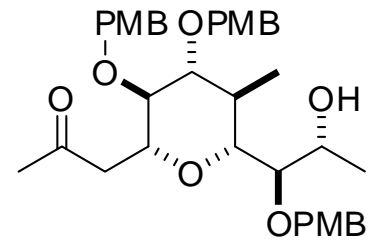

LIX

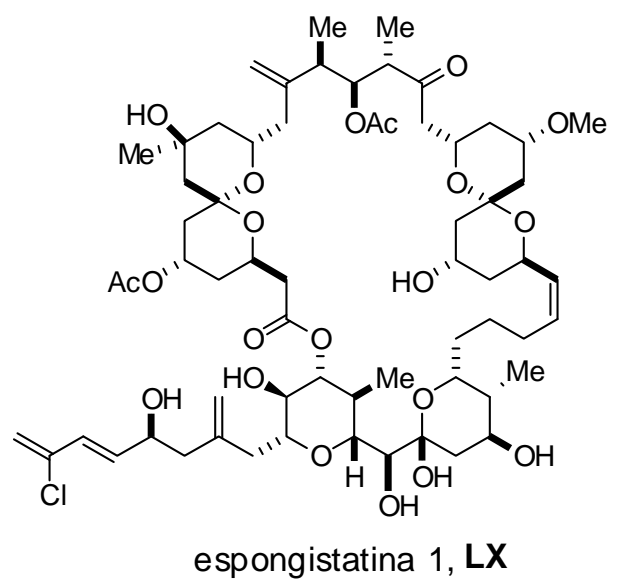

Esquema 36

Esta metodología se ha utilizado ampliamente en la síntesis de productos naturales. ${ }^{53}$ En el Esquema 36 se muestra como ejemplo la síntesis del anillo $\mathrm{F}$ de la espongistatina $1(\mathbf{L X})$ llevada a cabo por Paterson et al. con un e.d. $>90 \%{ }^{53 \mathrm{~b}}$

La optimización de las condiciones de reacción (bajas temperaturas y menores tiempos de reacción) puede dar lugar a la obtención de los diastereoisómeros cinéticos 2,6 -trans. ${ }^{54}$

\footnotetext{
${ }^{53}$ (a) Ver ref. 26b; (b) Paterson, I.; Chen, D. Y.-K.; Coster, M. J.; Aceña, J. L.; Bach, J.; Gibson, K. R.; Keown, L. E.; Oballa, R. M.; Trieselmann, T.; Wallace, D. J.; Hodgson, A. P.; Norcross, R. D. Angew. Chem., Int. Ed. 2001, 40, 4055; (c) Crimmins, M. T.; Siliphaivanh, P. Org. Lett. 2003, 5, 4641; (d) Pattenden, G.; González, M. A.; Little, P. B.; Millan, D. S.; Plowright, A. T.; Tornos, J. A.; Ye, T. Org. Biomol. Chem. 2003, 1, 4173; (e) Wang, Y.; Janjic, J.; Kozmin, S. A. Pure Appl. Chem. 2005, 77, 1161; (f) Alonso, D.; Pérez, M.; Gómez, G.; Covelo, B.; Fall, Y. Tetrahedron 2005, 61, 2021; (g) Lambert, W. T.; Hanson, G. H.; Benayoud, F.; Burke, S. D. J. Org. Chem. 2005, 70, 9382; (h) Avery, T. D.; Caiazza, D.; Culbert, J. A.; Taylor, D. K.; Tiekink, E. R. T. J. Org. Chem. 2005, 70, 8344; (i) Son, J. B.; Kim, S. N.; Kim, N. Y.; Lee, D. H. Org. Lett. 2006, 8, 661; (j) Nonoyama, A.; Hamajima, A.; Isobe, M. Tetrahedron 2007, 63, 5886; (k) Bates, R. W.; Song, P. Tetrahedron 2007, 63, 4497.
} 
Los estudios de V. S. Martín ${ }^{55}$ pusieron de manifiesto que la estereoselectividad de las reacciones de ciclación oxo-Michael sobre ésteres $\alpha, \beta$-insaturados con un grupo hidroxilo adicional en posición alílica depende tanto del grupo protector como de la estereoquímica del doble enlace (Esquema 37). ${ }^{56}$<smiles>CCCCCC(C=CC(=O)OC)OCCO</smiles>

$E$-LXI<smiles>COC(=O)C=CC(CCCO)OC(=O)OC</smiles>

Z-LXI

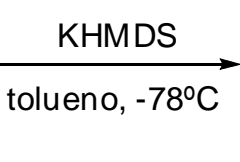

tolueno, $0^{\circ} \mathrm{C}$

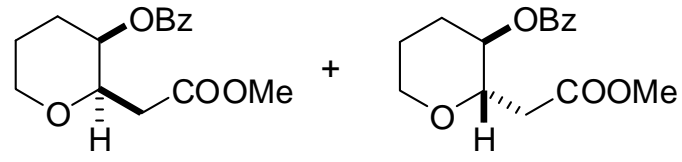

LXII-cis

$9: 1$

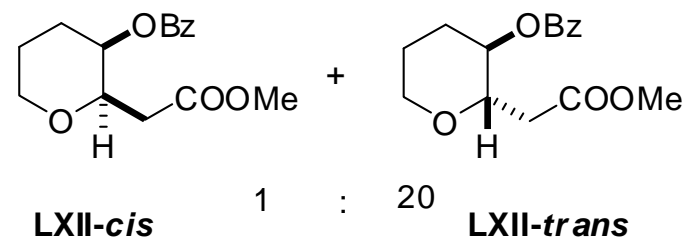

\section{Esquema 37}

La reacción de adición de Michael se ha utilizado en reacciones en cascada ${ }^{57} \mathrm{y}$, más recientemente, también en una reacción tándem de acoplamiento alquino-enona y adición de Michael para la síntesis de 2,6-cis-tetrahidropiranos (Esquema 38, LXV). ${ }^{58}$ El paso de ciclación del intermedio representado en este esquema parece estar catalizado por el ácido de Lewis de rutenio. Aunque existe algún ejemplo de adición de Michael para la síntesis de tetrahidropiranos catalizada por ácidos de Lewis, ${ }^{59}$ se han publicado más ejemplos de ciclaciones de cetonas $\alpha, \beta$-insaturadas catalizadas por ácidos de Brønsted para la síntesis de productos naturales. ${ }^{60}$

54 (a) Oishi, T.; Suzuki, M.; Watanabe, K.; Murata, M. Tetrahedron Lett. 2006, 47, 3975; (b) Li, M.; O’Doherty, G. A. Org. Lett. 2006, 8, 6087; (c) Pan, Y.; De Brabander, J. K. Synlett 2006, 853.

55 (a) Martín, V. S.; Núñez, M. T.; Ramírez, M. A.; Soler, M. A. Tetrahedron Lett. 1990, 31, 763; (b) Martín, V. S.; Palazón, J. M. Tetrahedron Lett. 1992, 33, 2399; (c) Betancort, J. M.; Martín, V. S.; Padrón, J. M.; Palazón, J. M.; Ramírez, M. A.; Soler, M. A. J. Org. Chem. 1997, 62, 4570; (d) Ramírez, M. A.; Padrón, J. M.; Palazón, J. M.; Martín, V. S. J. Org. Chem. 1997, 62, 4584.

${ }^{56}$ Strand, D.; Norrby, P.-O.; Rein, T. J. Org. Chem. 2006, 71, 1879.

${ }^{57}$ Nicolaou, K. C.; Lim, Y. H.; Papageorgiou, C. D.; Piper, J. L. Angew. Chem., Int. Ed. 2005, 44, 7917.

${ }^{58}$ (a) Trost, B. M.; Yang, H.; Wuitschik, G. Org. Lett. 2005, 7, 4761; (b) Trost, B. M.; Yang, H.; Thiel, O. R.; Frontier, A. J.; Brindle, C. S. J. Am. Chem. Soc. 2007, 129, 2206.

${ }^{59}$ Evans, P. A.; Andrews, W. J. Tetrahedron Lett. 2005, 46, 5625.

60 (a) O'Brien, M.; Taylor, N. H.; Thomas, E. J. Tetrahedron Lett. 2002, 43, 5491; (b) Paterson, I.; Luckhurst, C. A. Tetrahedron Lett. 2003, 44, 3749; (c) Chandrasekhar, S.; Shyamsunder, T.; Prakash, S. 


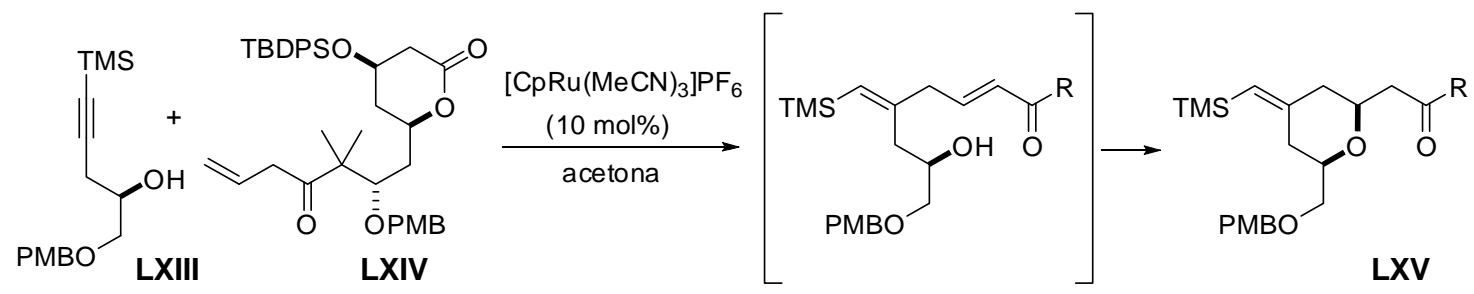

Esquema 38

Forsyth et al. han descrito una doble adición de Michael intramolecular catalizada por ácidos de Brønsted basada en una primera ciclación 6-exo-dig seguida de otra 6-exo-trig estereoselectiva (Esquema 39). ${ }^{61}$

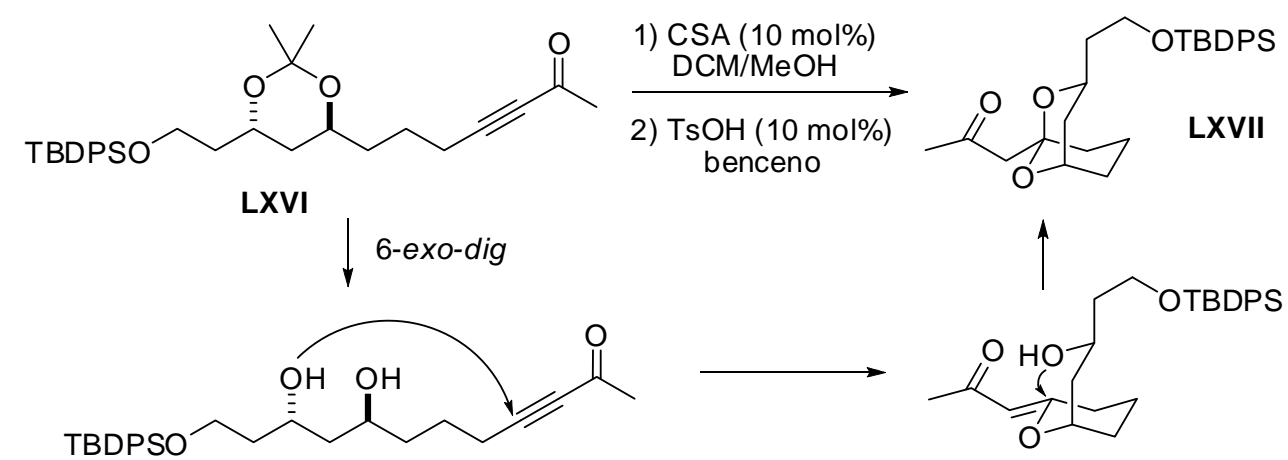

Esquema 39

\subsubsection{Ciclaciones 6-endo}

Las ciclaciones 6-endo-trig (Esquema 35, 2) suponen una alternativa a la reacción de hetero-Diels-Alder para la formación de di- $\mathrm{y}$ tetrahidropiranonas. ${ }^{62}$ Gouverneur y col. han demostrado la capacidad de algunos ácidos de Brønsted y de Lewis, así como de complejos de Pd (II), para catalizar ciclaciones 6-endo-trig de $\beta$ hidroxienonas como LXVIII (Esquema 40). ${ }^{63}$

J.; Prabhakar, A.; Jagadeesh, B. Tetrahedron Lett. 2006, 47, 47; (d) Liu, J.; Yang, J. H.; Ko, C.; Hsung, R. P. Tetrahedron Lett. 2006, 47, 6121.

${ }^{61}$ Nguyen, S.; Xu, J.; Forsyth, C. J. Tetrahedron 2006, 62, 5338.

62 (a) Nicolaou, K. C.; Xu, H.; Wartmann, M. Angew. Chem., Int. Ed. 2005, 44, 756; (b) Gao, B.; Yu, Z.; Fu, Z.; Feng, X. Tetrahedron Lett. 2006, 47, 1537; (c) Hjelmgaard, T.; Søtofte, I.; Tanner, D. J. Org. Chem. 2005, 70, 5688.

${ }^{63}$ Reiter, M.; Turner, H.; Gouverneur V. Chem. Eur. J. 2006, 12, 7190. 


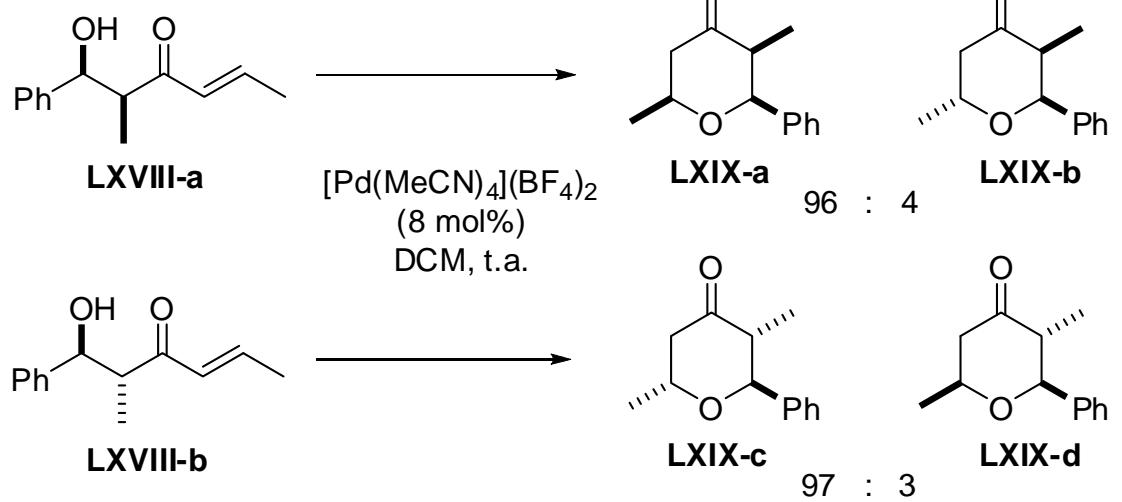

\section{Esquema 40}

Precisamente, el último paso de la recientemente rescatada reacción de Maitland-Japp se trata de una adición de Michael 6-endo-trig. ${ }^{64}$ Esta reacción multicomponente en un solo paso se ha utilizado para la síntesis del antibiótico natural $\left( \pm\right.$ )-centrolobina (Esquema 41, LXXIII). ${ }^{65}$ Una adición aldólica de Mukaiyama entre el dieno LXX y el aldehído LXXI, seguida de una condensación de Knoevenagel con anisaldehído, genera el cetoéster $\alpha, \beta$-insaturado intermedio. Éste experimenta una ciclación 6-endo-trig basada en una adición de Michael catalizada por ácido, obteniéndose la tetrahidropiranona LXXII.
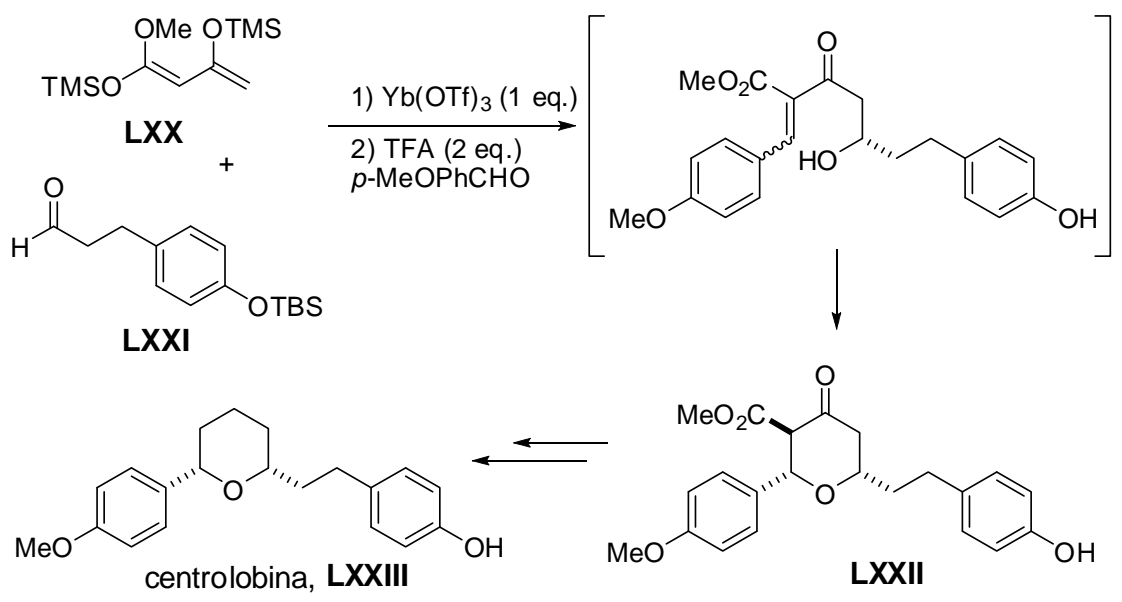

\section{Esquema 41}

${ }^{64}$ (a) Clarke, P. A.; Martin, W. H. C.; Hargreaves, J. M.; Wilson, C.; Blake, A. J. Chem. Commun. 2005, 1061; (b) Clarke, P. A.; Martin, W. H. C.; Hargreaves, J. M.; Wilson, C.; Blake, A. J. Org. Biomol. Chem. 2005, 3, 3551.

${ }^{65}$ (a) Clarke, P. A.; Martin, W. H. C. Tetrahedron Lett. 2004, 45, 9061; (b) Clarke, P. A.; Martin, W. H. C. Tetrahedron 2005, 61, 5433. 


\subsection{Ciclaciones reductoras}

Otro de los métodos utilizados recientemente para la síntesis de tetrahidropiranos 2,6-disustituídos es la ciclación reductora de $\delta$-hidroxicetonas.

La síntesis de éteres mediante condensación reductora de compuestos carbonílicos y alcoxisilanos catalizada por TMSOTf fue utilizada por Olah para la obtención de éteres lineales ${ }^{66}$ y posteriormente modificada por Nicolau para la síntesis de oxepanos. ${ }^{67}$ Sin embargo, esta estrategia apenas ha sido utilizada en la síntesis asimétrica de tetrahidropiranos. ${ }^{68}$

M. C. Carreño ha desarrollado un método para la síntesis enantioselectiva de cistetrahidropiranos 2,6-disustituídos basado en la ciclación reductora de $\delta$-hidroxi- $\varepsilon$ sulfinilcetonas enantioméricamente puras promovida por $\mathrm{Et}_{3} \mathrm{SiH} / \mathrm{TMSOTf}$ (Esquema 42). ${ }^{69}$ El mecanismo de reacción propuesto por estos autores pasa por un intermedio oxocarbénico (A) que es atacado en posición axial por el $\mathrm{Et}_{3} \mathrm{SiH}$, formándose mayoritariamente el diastereoisómero cis (Esquema 42, LXXV). ${ }^{69 a}$ Esta metodología ha sido utilizada para la síntesis enantioselectiva de (-)-centrolobina. ${ }^{69}$

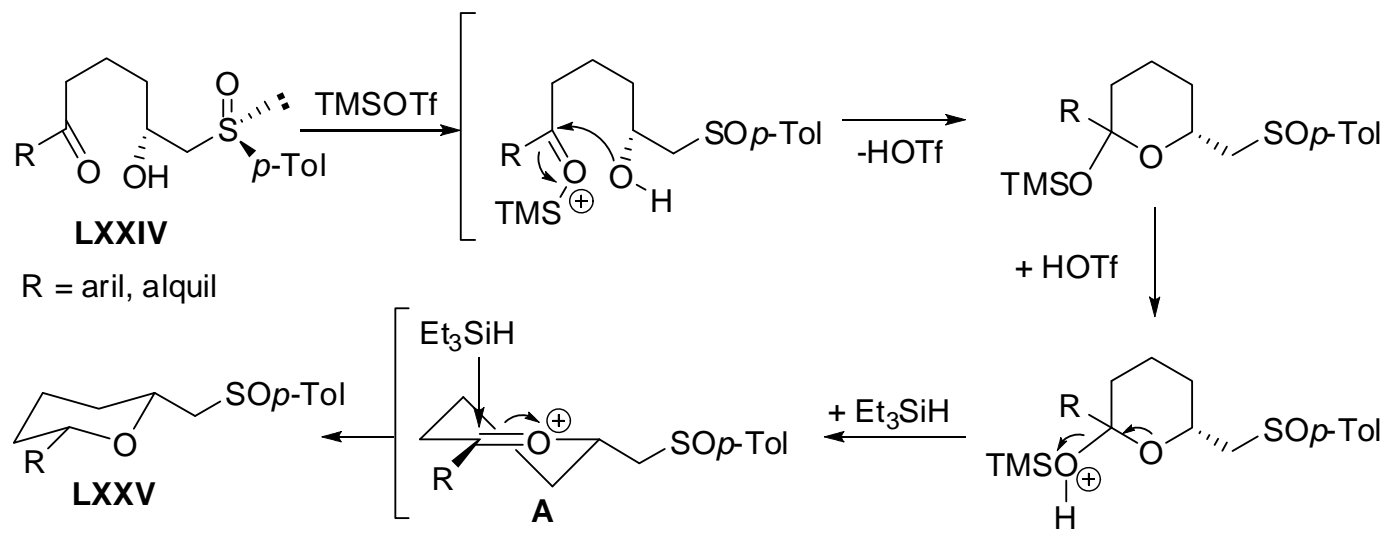

\section{Esquema 42}

\footnotetext{
${ }^{66}$ (a) Sassaman, M. B.; Prakash, G. K. S.; Olah, G. A. Tetrahedron 1988, 44, 3771. (b) Sassaman, M. B.; Kotian, K. D.; Prakash, G. K. S.; Olah, G. A. J. Org. Chem. 1987, 52, 4314.

${ }^{67}$ Nicolau, K. C.; Hwang, C.-K.; Duggan, M. E.; Nugiel, D. A.; Abe, Y.; Reddy, K. Bal.; DeFrees, S. A.; Reddy, D. R.; Awartani, R. A.; Conley, S. R.; Rutjes, F. P. J. T.; Theodorakis, E. A. J. Am. Chem. Soc. 1995, 117, 10227.

${ }^{68}$ González, I.; Forsyth, C. J. J. Am. Chem. Soc. 2000, 122, 9099.

${ }^{69}$ (a) Colobert, F.; Des Mazery, R.; Solladié, G.; Carreño, M. C. Org. Lett. 2002, 4, 1723; (b) Carreño, M. C.; Des Mazery, R.; Urbano, A.; Colobert, F.; Solladié, G. J. Org. Chem. 2003, 68, 7779; (c) Colobert, F.; Choppin; Ferreiro-Mederos, L.; Obringer, M.; Arratta, S. L.; Urbano, A.; Carreño, M. C. Org. Lett. 2007, 22, 4451.
} 
Evans et al. también han llevado a cabo reacciones de ciclación reductora de $\delta$ trialquilsililoxi-cetonas utilizando $\mathrm{Et}_{3} \mathrm{SiH} / \mathrm{BiBr}_{3}$. En este caso, los autores plantean que la hidrólisis in situ de esta especie genera bromuro de hidrógeno y oxibromuro de bismuto, responsables de la catálisis. ${ }^{70}$ Este método se ha empleado para la síntesis de (-)-centrolobina ${ }^{70 b}$ y del agente antitumoral (-)-mucocina (Esquema 43, LXXVIII). ${ }^{70 c}$
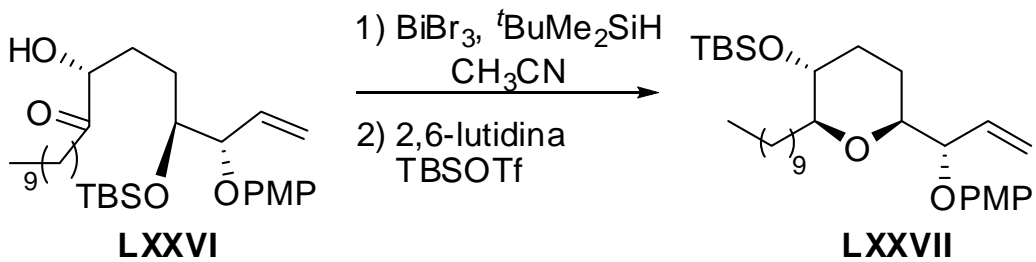

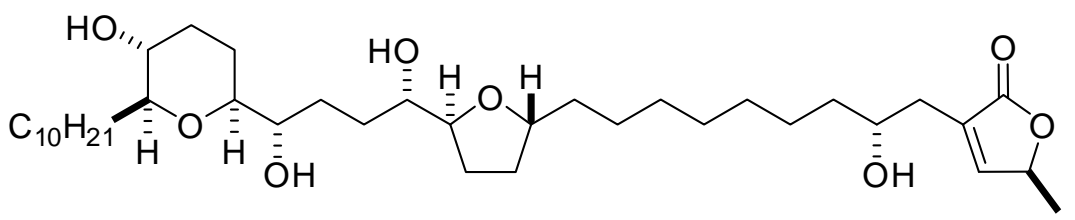

mucocina, LXXVIII

\section{Esquema 43}

Mientras que en las ciclaciones reductoras se obtienen los diastereoisómeros cis (Esquema 43), en las reacciones tándem ciclación-adición se obtienen mayoritariamente los diastereoisómeros trans (Esquema 44). Este hecho es consistente con la aproximación axial del nucleófilo al ión oxocarbenio intermedio. ${ }^{70 a, 71}$

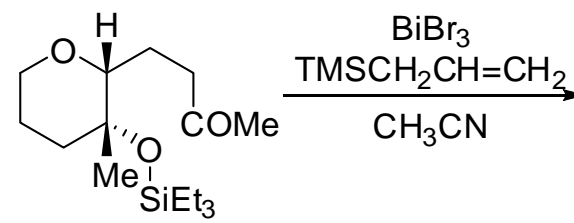

LXXIX<smiles>C=CC[C@H]1CC[C@H]2OCCC[C@]2(C)O1</smiles>

trans-LXXX

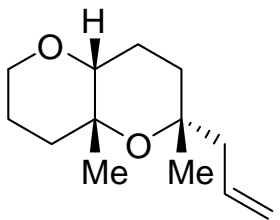

$19: 1^{\text {cis-LXXX }}$

\section{Esquema 44}

\footnotetext{
${ }^{70}$ (a) Evans, P. A.; Cui, J.; Gharpure, S. J.; Hinkle, R. J. J. Am. Chem. Soc. 2003, 125, 11456; (b) Evans, P. A.; Cui, J.; Gharpure, S. J. Org. Lett. 2003, 5, 3883; (c) Evans, P. A.; Cui, J.; Gharpure, S. J.; Polosukhin, A.; Zhang, H.-R. J. Am. Chem. Soc. 2003, 125, 14702.

${ }^{71}$ Hinkle, R. J.; Lian, Y.; Litvinas, N. D.; Jenkins, A. T.; Burnette, D. C. Tetrahedron 2005, 61, 11679.
} 


\subsection{Ciclaciones oxidativas de 1,6-dienos}

La ciclación oxidativa de 1,5-dienos con cantidades estequiométricas de permanganato o con cantidades catalíticas de tetróxido de osmio o rutenio es un proceso muy establecido para la síntesis de tetrahidrofuranos 2,5-disustituídos. Sin embargo, la correspondiente ciclación oxidativa de 1,6-dienos homólogos apenas ha sido estudiada. 72 Los métodos existentes para dicha transformación utilizan tetróxido de rutenio catalítico o permanganato en cantidades estequiométricas.

\subsubsection{Ciclaciones de 1,6-dienos catalizadas por tetróxido de rutenio}

La ciclación oxidativa de 1,6-dienos hasta dioles tetrahidropiránicos con $\mathrm{RuO}_{4}$ catalítico (generado por oxidación de $\mathrm{RuCl}_{3}$ con $\mathrm{NaIO}_{4}$ ) fue llevada a cabo por primera vez por Piccialli ${ }^{73 a}$ y más recientemente estudiada por Stark et al. ${ }^{73 \mathrm{~b}}$

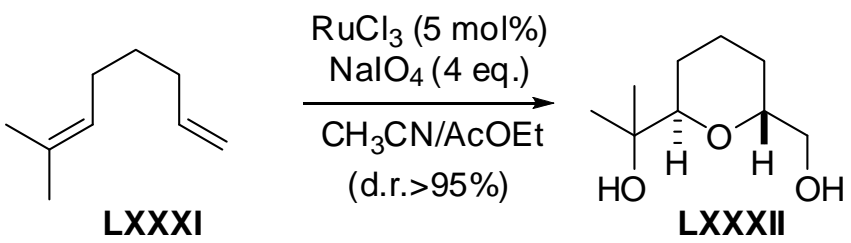

Esquema 45

Esta reacción es altamente diastereoselectiva, obteniéndose mayoritariamente trans-tetrahidropiranos (Esquema 45, LXXXII). Este hecho se puede explicar a través del mecanismo de reacción propuesto, el cual comienza con una cicloadición [3+2] del $\mathrm{RuO}_{4}$ con uno de los dobles enlaces del dieno. Posteriormente, una segunda cicloadición [3+2] intramolecular con la olefina adyacente fija la estereoquímica trans del tetrahidropirano formado (Esquema 46).

72 (a) Elliot, M. C.; Williams, E. J. Chem. Soc. Perkin Trans. 1 2001, 2303 y referencias allí citadas; (b) Piccialli, V. Synthesis 2007, 2585, y referencias allí citadas.

${ }^{73}$ (a) Piccialli, V. Tetrahedron Lett. 2000, 41, 3731; (b) Roth, S.; Stark, C. B. S. Angew. Chem. Int. Ed. 2006, 45, 6218. 


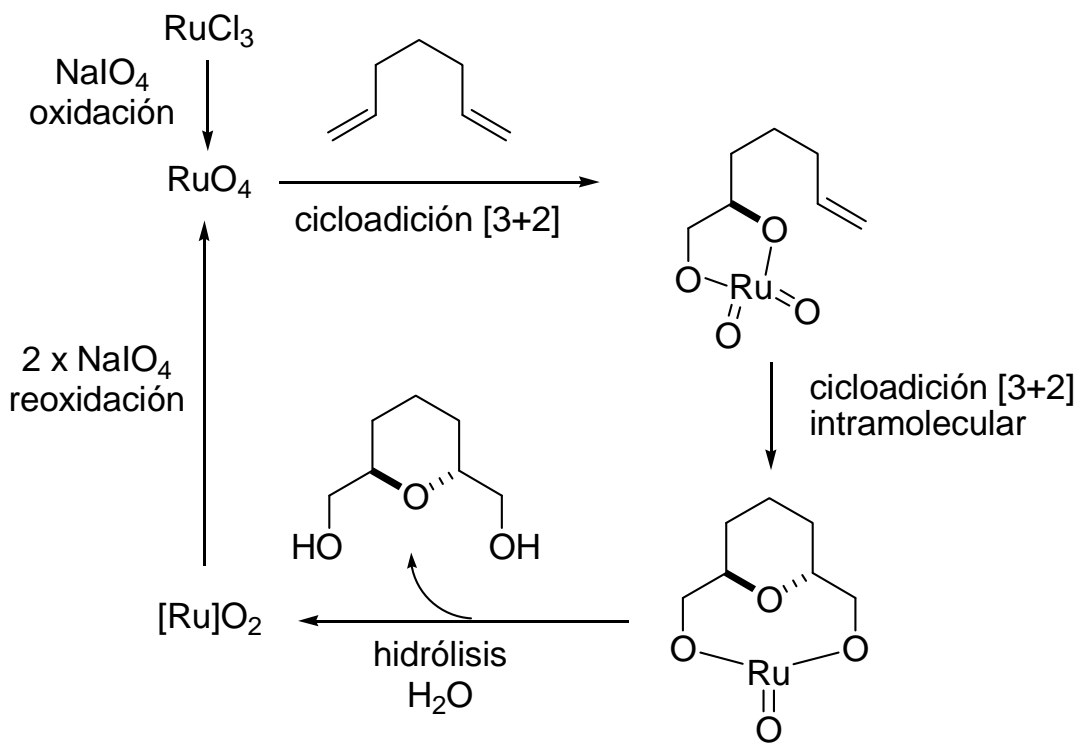

Esquema 46

\subsubsection{Ciclaciones de 1,6-dienos catalizadas por permanganato}

Brown y col. han demostrado que los 1,6-dienos se pueden someter a ciclación oxidativa en presencia de permanganato para obtener dioles cis-tetrahidropiránicos (Esquema 47, LXXXIV). Sin embargo, los rendimientos obtenidos en todos los casos son bajos. $^{74}$

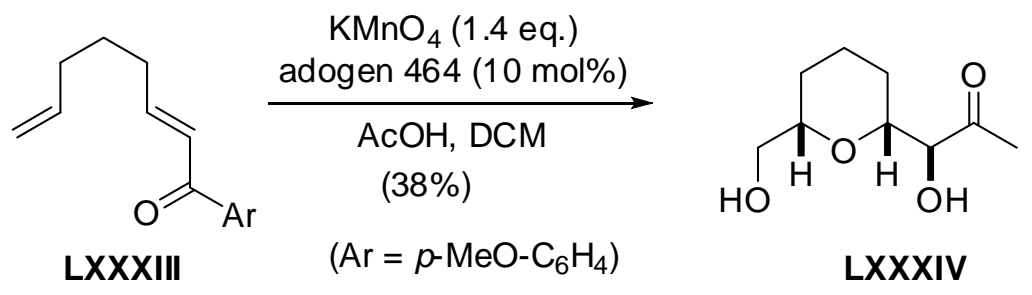

Esquema 47

${ }^{74}$ Cecil, A. R. L.; Brown, R. C. D. Tetrahedron Lett. 2004, 45, 7269. 


\section{METODOLOGÍAS DE TIPO B Y C: FORMACIÓN DE LOS ENLACES C2-}

\section{C3 Y C3-C4}

\subsection{Reacción de oxo-hetero-Diels-Alder}

La reacción de oxo-hetero-Diels-Alder (oxo-HDA) está entre las metodologías más importantes para la construcción de heterociclos oxigenados de seis miembros (dihidropiranos, dihidropironas) y se ha utilizado ampliamente en la síntesis de productos naturales. $^{75}$<smiles>[R]C([R])=O</smiles><smiles>[R][C]=C</smiles><smiles>[R]C1=CCOC([R2])(CC)C1</smiles><smiles>[R]C([R])=C([R])C=C</smiles><smiles>[R][I-]</smiles><smiles>[R]C1=C([R])OCC([R])CCC1</smiles>

\section{Esquema 48}

Este tipo de cicloadición $\left[\pi 4_{s}+\pi 2_{s}\right]$ concertada se puede clasificar en dos tipos, la reacción de oxo-HDA de demanda electrónica normal (Esquema 48, 1) y la oxo-HDA de demanda electrónica inversa (Esquema 48, 2). La primera es una reacción controlada por el orbital HOMO del dieno y el LUMO del dienófilo que ocurre entre dienos ricos en electrones y dienófilos deficientes en electrones (aldehídos o cetonas). La oxo-HDA de demanda electrónica inversa es una reacción controlada principalmente por el LUMO del dieno y el HOMO del dienófilo y tiene lugar por ejemplo entre enonas o compuestos análogos y alquenos con grupos donadores de electrones.

\footnotetext{
75 (a) Thomson, C. F.; Jamison, T. F.; Jacobsen, E. N. J. Am. Chem. Soc. 2001, 123, 9974; (b) Liu, P.; Jacobsen, E. N. J. Am. Chem. Soc. 2001, 123, 10772; (c) Smith III, A. B.; Minbiole, K. P.; Verhoest, P. R.; Schelhaas, M. J. Am. Chem. Soc. 2001, 123, 10942; (d) Ghosh, A. K.; Shirai, M. Tetrahedron Lett. 2001, 42, 6231; (e) Paterson, I.; Luckhurst, C. A. Tetrahedron Lett. 2003, 44, 3749; (f) Paterson, I.; Steven, A.; Luckhurst, C. A. Org. Biomol. Chem. 2004, 2, 3026; (g) Voight, E. A.; Seradj, H.; Roethle, P. A.; Burke, S. D. Org. Lett. 2004, 6, 4045; (h) Lucas, B. S.; Luther, L. M.; Burke, S. D. J. Org. Chem. 2005, 70, 3757; (i) Referencia 1c;
} 
La introducción de un auxiliar quiral en el dieno o en el dienófilo o el uso de un catalizador quiral, principalmente ácidos de Lewis quirales, permite llevar a cabo reacciones enantioselectivas. ${ }^{76}$ Últimamente se han desarrollado notablemente los métodos que hacen uso de ácidos de Brønsted quirales (p. ej. TADDOL) como catalizadores de activación por enlace de hidrógeno, sin embargo, dado que estos pertenecen al campo de la organocatálisis, serán tratados más adelante en el segundo apartado de esta introducción dedicado a la catálisis orgánica.

Un auxiliar quiral empleado con dienófilos tipo benzaldehído es el $\mathrm{Cr}(\mathrm{CO})_{3}$. Las cicloadiciones promovidas por $\mathrm{ZnCl}_{2}$ de una serie de complejos enantioméricamente puros benzaldehído-Cr(CO) ${ }_{3}$ orto-sustituídos y el dieno de Danishefsky (LXXXVI) dan lugar, tras la descomplejación, a las correspondientes (S)-2-arilpiranonas (Esquema 49, LXXXVII). ${ }^{77}$<smiles>Cc1cc(C(C)(C)C)ccc1C=O</smiles>

LXXXV<smiles>C=C(C=COC)OC(C)C</smiles>

LXXXVI<smiles>CO[Mg]</smiles>
$(\mathrm{CO})_{3} \mathrm{Cr}$<smiles>Cc1ccccc1C1CC(=O)C=CO1</smiles>

LXXXVII

\section{Esquema 49}

Jacobsen ha dado un paso importante en el desarrollo de una reacción de HDA catalítica y enantioselectiva más general gracias a la introducción de los complejos tridentados de $\mathrm{Cr}(\mathrm{III})$ como catalizadores (Figura 5). ${ }^{75 \mathrm{a}}$

\footnotetext{
${ }^{76}$ Revisiones bibliográficas sobre la reacción de Diels-Alder y hetero-Diels-Alder: (a) Jørgensen, K. A. Angew. Chem. Int. Ed. 2000, 39, 3558; (b) Nicolaou, K. C.; Snyder, S. A.; Montagnon, T.; Vassilikogiannakis G. Angew. Chem. Int. Ed. 2002, 41, 1668; (c) Osborn H. M. I.; Coisson D. MiniReviews in Organic Chemistry 2004, 1, 41.

${ }_{77}$ Baldoli, C.; Maiorana, S.; Lisandro, G.; Zinzalla, M.; Lanfranchi, M.; Tiripicchio, A. Tetrahedron: Asymmetry 2001, 12, 2159.
} 

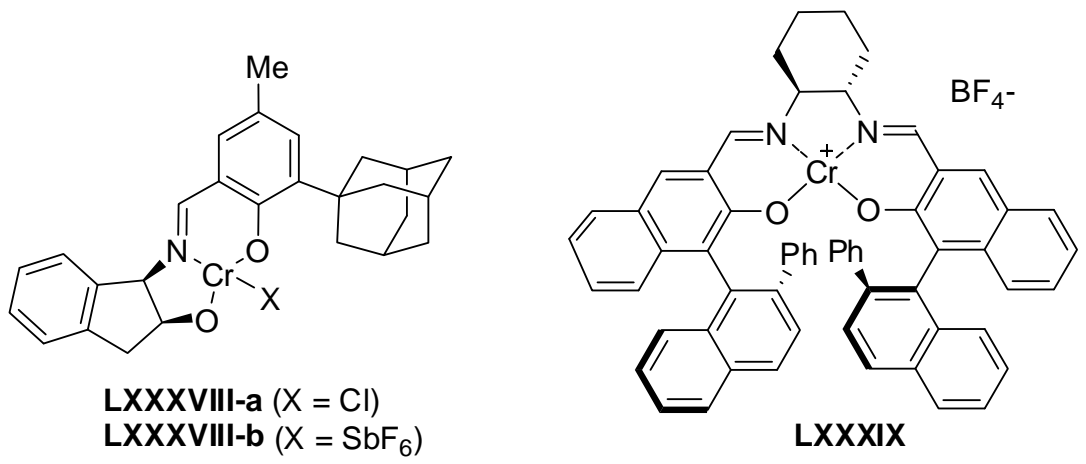

Figura 5: Catalizadores de Jacobsen (LXXXVIII) y Katsuki (LXXXIX).

Este catalizador base de Schiff quiral-Cr(III), que se ha dado en denominar catalizador de Jacobsen (Figura 5, LXXXVIII), ha sido utilizado en numerosas síntesis asimétricas de productos naturales, como el citotóxico natural FR901464, ${ }^{75 a}$ el agente antifúngico (+)-ambruticina, ${ }^{75 b}$ o el phorboxazol A. ${ }^{75 c-h}$

En el Esquema 50 se muestran dos ejemplos de la aplicación de esta metodología a la síntesis de phorboxazoles. El primero se trata de la construcción del anillo tetrahidropiránico pentasustituído presente en el fragmento C20-C32 (XCI) llevado a cabo por Burke et al. ${ }^{7 \mathrm{~h}} \mathrm{El}$ segundo ejemplo es el primer paso de la síntesis total de (+)-phorboxazol A llevada a cabo recientemente por Smith III et al., en el que se observa que se obtienen mejores resultados utilizando el catalizador de Jacobsen LXXXVIII-a que con las condiciones de Keck $\left(\mathrm{Ti}\left({ }^{i} \mathrm{OPr}\right)_{4},(R)\right.$-BINOL) para la síntesis del fragmento XCIII (Esquema 50). ${ }^{75 c}$
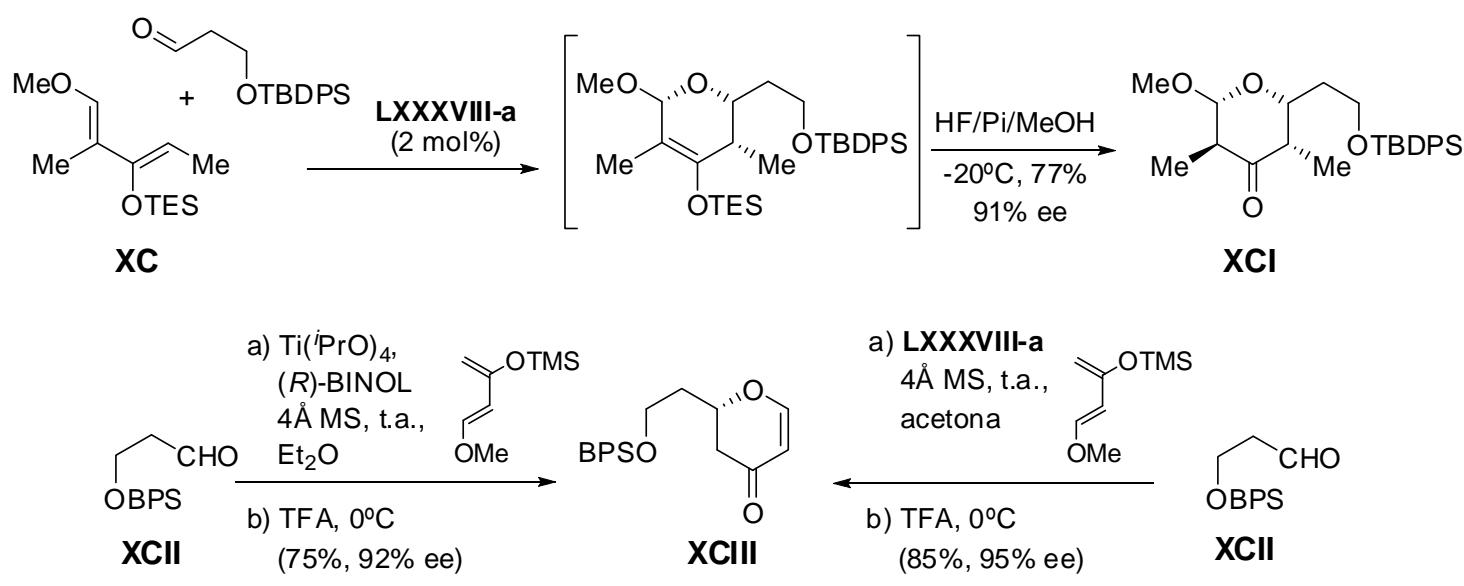

\section{Esquema 50}


Jacobsen también ha demostrado que este complejo es un catalizador altamente diastéreo y enantioselectivo para reacciones de oxo-HDA de demanda electrónica inversa, como la mostrada en el Esquema 51 entre diferentes aldehídos $\alpha, \beta$-insaturados diferentemente sustituídos y etil vinil éter. ${ }^{78}$<smiles>[R]C=C([R])C=O</smiles><smiles>[R]C1=COC(OCC)CC1[R]</smiles>

\section{Esquema 51}

El catalizador de Katsuki, ${ }^{79 a} \mathrm{Cr}(\mathrm{III})$-salen (Figura 5, LXXXIX), ha sido utilizado recientemente en una reacción de oxo-HDA en fase sólida entre diferentes aldehídos y el dieno de Danishefsky. ${ }^{79 b}$ El ligando salen, al igual que otros ligandos con simetría $C_{2}$, se ha usado en numerosas ocasiones en reacciones de oxo-HDA enantioselectivas como complejante de metales que actúan como ácidos de Lewis. Los ligandos tipo bisoxazolina (BOX, Figura 6) han sido de los más empleados. ${ }^{80}$

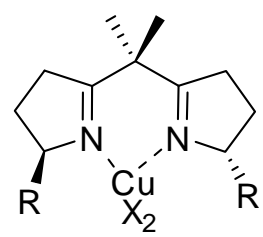

Figura 6: Catalizador bis-oxazolina (BOX)-Cu(II)

\footnotetext{
${ }^{78}$ Gademann, K.; Chavez, D. E.; Jacobsen, E. N. Angew. Chem. Int. Ed. 2002, 41, 3059.

${ }^{79}$ (a) Aikawa, K.; Irie, R.; Katsuki, T. Tetrahedron 2001, 57, 845; (b) Sanz, M. A.; Voigt, T.; Waldmann, H. Adv. Synth. Catal. 2006, 348, 1511.

${ }^{80}$ (a) Audrain, H.; Thorhauge, J.; Hazell, R. G.; Jørgensen, K. A. J. Org. Chem. 2000, 65, 4487; (c) Evans, D. A.; Johnson, J. S.; Olhava, E. J. J. Am. Chem. Soc. 2000, 122, 1635; (d) Para un estudio tanto experimental como teórico de los intermedios implicados en las reacciones enantioselectivas catalizadas por BOX-Cu(II), ver: Thorhauge, J.; Roberson, M.; Hazell, R. G.; Jørgensen, K. A. Chem. Eur. J. 2002, 8, 1888; (e) Wada, E.; Koga, H.; Kumaran, G. Tetrahedron Lett. 2002, 43, 9397; (f) Wada, E.; Koga, H.; Tetrahedron Lett. 2003, 44, 715; (f) van Lingen, H. L.; van Delft, F. L.; Storcken, R. P. M.; Hekking, K. F. W.; Klaassen, A.; Smits, J. J. M.; Ruskowska, P.; Frelek, J.; Rutjes, F. P. J. T. Eur. J. Org. Chem. 2005, 4975; (g) Landa, A.; Richter, B.; Johansen, R. L.; Minkkilä, A.; Jørgensen, K. A. J. Org. Chem. 2007, 72, 240.
} 
Recientemente se han desarrollado sistemas catalíticos heterogéneos con catalizadores BOX-Cu(II) y derivados, ${ }^{81}$ así como sistemas en los que el catalizador está inmovilizado en líquidos iónicos, ${ }^{82}$ lo cual permite su reutilización.

En ninguno de los ejemplos aquí comentados se utilizan cetonas como dienófilos, ya que son mucho menos reactivas que los aldehídos en reacciones de oxoHDA debido tanto a factores estéricos como electrónicos. ${ }^{83}$ De hecho, el número de reacciones oxo-HDA de cetonas desactivadas con dienos es muy limitado. ${ }^{84}$

Sin embargo, el número de reacciones oxo-HDA de cetonas activadas, como $\alpha$ cetoésteres es mucho mayor. Este tipo de sustratos están en una disposición muy adecuada para la coordinación bidentada con ácidos de Lewis tipo BOX-Cu(II) y derivados. ${ }^{85}$ Dicha metodología, que permite obtener cicloaductos con carbonos cuaternarios quirales, ha sido utilizada por Ghosh y col. en la síntesis de malingolida (Esquema 52, XCVI). ${ }^{75 d}$<smiles>C=C(C=COC(C)=O)C(=O)OC</smiles>

1) XCIV-b (10 mol\%),

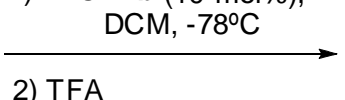

$(>99 \%$ ee)

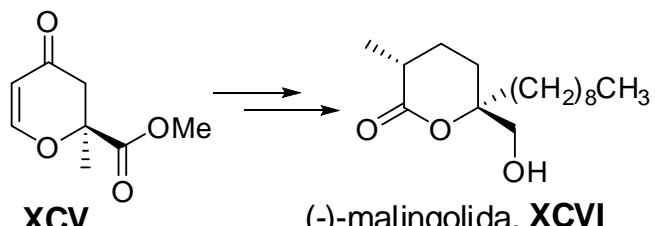

(-)-malingolida, XCVI

Esquema 52

Las reacciones oxo-HDA en las que la cetona está formando parte de un heterodieno ha sido muy estudiada. ${ }^{86}$ Wada et al. han desarrollado una reacción tándem asimétrica de transeterificación-oxo-HDA intramolecular para obtener hidropiranpiranos (XCIX) utilizando XCIV-b como catalizador (Esquema 53). ${ }^{80 \mathrm{e}}$

\footnotetext{
${ }^{81}$ (a) Brase, S.; Lauterwasser, F.; Ziegert, R. E. Adv. Synth. Catal. 2003, 345, 869; (b) Kurosu, M.; Porter, J. R.; Foley, M. A. Tetrahedron Lett. 2004, 45, 145; (c) O’Leary, P.; Krosveld, N. P.; De Jong, K. P.; van Koten, G.; Klein Gebbink, R. J. M. Tetrahedron Lett. 2004, 45, 3177.

${ }^{82}$ Shin, Y. J.; Yeom, C.-E.; Kim, M. J.; Kim, B. M. Synlett 2008, 89.

${ }^{83}$ Jørgensen, K. A. Eur. J. Org. Chem. 2004, 2093.

${ }^{84}$ Pierres, C.; George, P.; Van Hijfte, L.; Ducep, J.-B.; Hilbert, M.; Mann, A. Tetrahedron Lett. 2003, 44, 3645.

85 (a) Yao, S.; Roberson, M.; Reichel, F.; Hazell, R. G.; Jørgensen, K. A. J. Org. Chem. 1999, 64, 6677; (b) Bolm, C.; Simic, O. J. Am. Chem. Soc. 2001, 123, 3830. (c) Dalko, P. I.; Moisan, L.; Cossy, J. Angew. Chem. Int. Ed. 2002, 41, 625; (d) van Lingen, H. L.; van de Mortel, J. K. W.; Hekking, K. F. W.; van Delft, F. L.; Sonke, T.; Rutjes, F. P. J. T. Eur. J. Org. Chem. 2003, 19, 317.

${ }^{75 d}$ Ghosh, A. K.; Shirai, M. Tetrahedron Lett. 2001, 42, 6231.

${ }^{86}$ Ver referencias: 80e-f, 81b-c, 82, 83.
} 


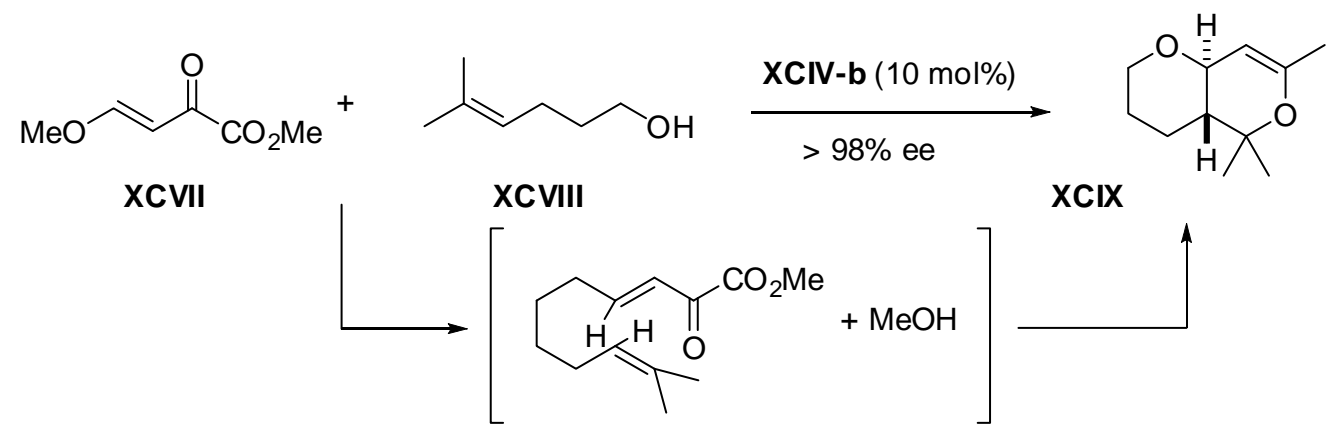

Esquema 53

\subsection{Metátesis}

La metátesis de olefinas catalizada por metales ha tenido un enorme impacto en síntesis orgánica. Gracias al descubrimiento de catalizadores basados en molibdeno ${ }^{87}$ y rutenio (Figura 7), ${ }^{88}$ la metátesis de cierre de anillo $(\mathrm{RCM})^{89}$ se ha convertido en uno de los métodos más importantes para la síntesis de carbo y heterociclos de pequeño, mediano y gran tamaño. ${ }^{90}$

$$
\begin{gathered}
\mathrm{Cl} \backslash \stackrel{\mathrm{I}}{\mathrm{PC}} \mathrm{y}_{3} \\
\mathrm{Cl}-\underset{1}{\mathrm{R} u}=\mathrm{Ph} \\
\mathrm{PCy}_{3}
\end{gathered}
$$

Catalizador Grubbs $1^{a}$ generación, C

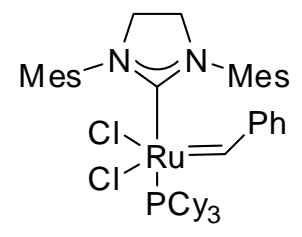

Catalizador Grubbs $2^{\mathrm{a}}$ generación, $\mathbf{C l}$<smiles>CCCc1cccc(C(C)C)c1N=C(OC(C)(C)C(F)(F)F)OC(C)(C(F)(F)F)C(F)(F)F</smiles>

Catalizador de Schrock, CII

Figura 7. Catalizadores para RCM

\footnotetext{
${ }^{87}$ Schrock, R. R.; Murdzek, J. S.; Bazan, G. C.; Robbins, J.; DiMare, M.; O’Regan, M. J. Am. Chem. Soc. 1990, 112, 3875.

${ }^{88}$ Fu, G. C.; Nguyen, S. T.; Grubbs, R. H.; Ziller, J. W. J. Am. Chem. Soc. 1993, 115, 9856.

${ }^{89}$ En adelante utilizaremos las siglas del proceso en inglés (ring closing metathesis: RCM; ring opening metathesis: ROM; cross metathesis: CM; ring rearrangement metathesis: RRM)

${ }^{90}$ Para revisions bibliográficas sobre metátesis de olefinas, ver: (a) Fürstner, A. Angew. Chem. Int. Ed. 2000, 39, 3012; (b) Grubbs, R. H.; Chang, S. Tetrahedron 1998, 54, 4413; (c) Fürstner, A. en Topics in Organometallic Chemistry; Alkene Metathesis in Organic Synthesis, Vol. 1 (Ed.: A. Fürstner), Springer, Berlin, 1998, pp. 37; (d) Phillips, A. J.; Abell, A. D.; Aldrichimica Acta 1999, 32, 75; (e) Wright, D. L. Curr. Org. Chem. 1999, 3, 211; (e) Hoveyda, A. H.; Schrock, R. R. Chem. Eur. J. 2001, 7, 945; (f) Schrock, R. R.; Hoveyda, A. H. Angew. Chem. Int. Ed. 2003, 42, 4592.
} 
Los enol y alil éteres acíclicos pueden participar en reacciones de RCM para dar los correspondientes éteres cíclicos (Esquema 54). Así, cuando n=1, se podrán sintetizar dihidropiranos.

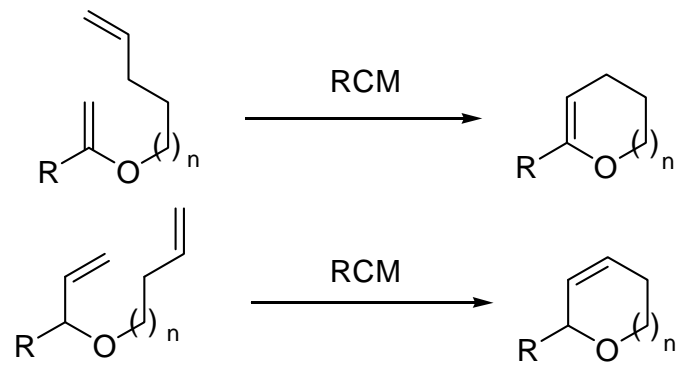

\section{Esquema 54}

\subsubsection{RCM de éteres de enol}

Desde que en 1994 Grubbs y col. demostraron que era posible preparar dihidropiranos simples a partir de enol éteres acíclicos (Esquema 54, 1), ${ }^{91}$ esta metodología ha sido aplicada en numerosas ocasiones. ${ }^{92}$

Recientemente se ha utilizado esta estrategia en la preparación de varios $C$ glicósidos (Esquema 55, CV) con actividad in vitro frente a algunas líneas celulares tumorales. $^{93}$

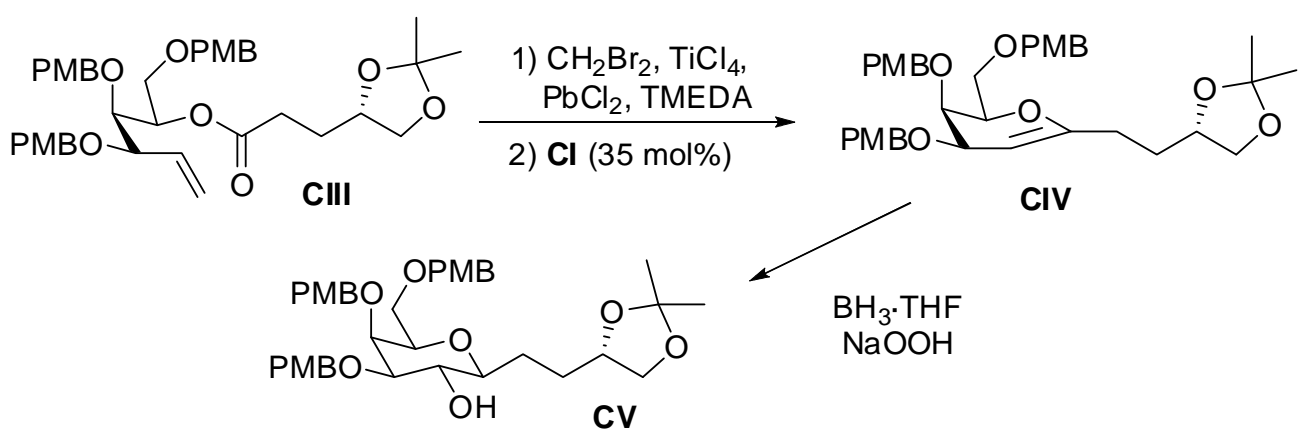

\section{Esquema 55}

\footnotetext{
${ }^{91}$ Fujimura, O.; Fu, G. C.; Grubbs, R. H. J. Org. Chem. 1994, 59, 4029.

92 (a) Postema, M. H. D.; Calimente, D.; Liu, L.; Behrmann, T. L. J. Org. Chem. 2000, 65, 6061 у referencias allí citadas; (b) Clark, J. S.; Kettle, J. G. Tetrahedron 1999, 55, 8231 y referencias allí citadas. ${ }^{93}$ Postema, M. H. D.; Piper, J. L.; Betts, R. L. J. Org. Chem. 2005, 70, 829.
} 
Los enol éteres precursores se suelen obtener a partir de los correspondientes ésteres por metilenación de Takai, ${ }^{94}$ aunque también se ha demostrado que dicho reactivo de Takai $\left(\mathrm{CH}_{2} \mathrm{Br}_{2}, \mathrm{TiCl}_{4}, \mathrm{PbCl}_{2}, \mathrm{TMEDA}\right)$ puede inducir directamente la ciclación de los ésteres olefínicos hasta los correspondientes enol éteres cíclicos sin utilizar catalizadores de rutenio o molibdeno. ${ }^{95,96}$

Esta estrategia ha sido utilizada por Clark y col. en la síntesis de poliéteres cíclicos fusionados (Esquema 56, CVII) ${ }^{97}$<smiles>C=CCC1(C=C)OCCCC1OC=C</smiles>

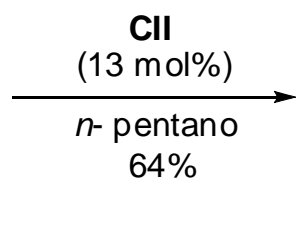<smiles>C1=COC2CCCOC2C1</smiles>

Esquema 56

El desarrollo de nuevos catalizadores quirales de Mo y Ru ha permitido llevar a cabo las primeras reacciones de RCM enantioselectivas. La transformación del enol éter aquiral CVIII en el enol éter quiral CIX se ha logrado utilizando el catalizador de Mo CX, desarrollado por el grupo de Hoveyda y Schrock (Esquema 57)..$^{98}$
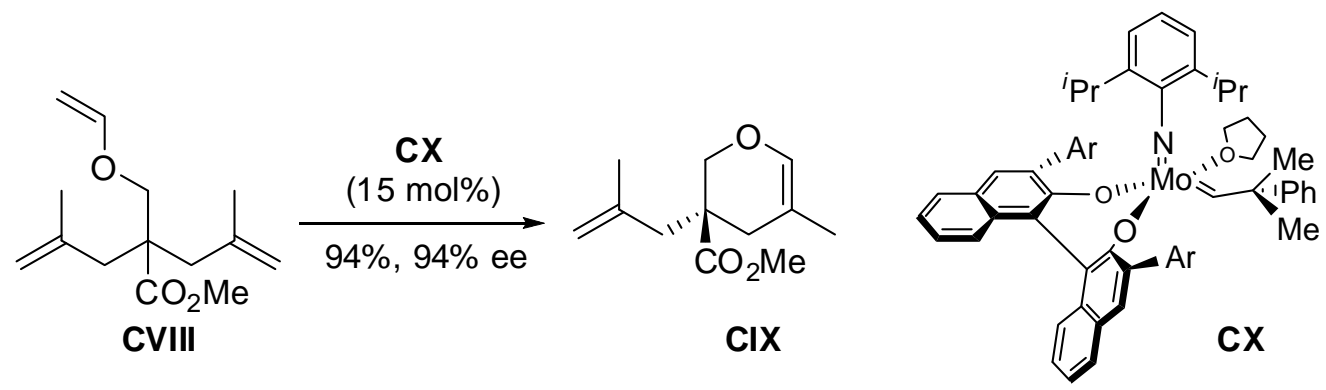

Esquema 57

\footnotetext{
${ }^{94}$ Okazoe, T.; Takai, K.; Oshima, K.; Utimoto, K. J. Org. Chem. 1987, 52, 4410.

${ }_{95}$ Majumder, U.; Rainier, J. D. Tetrahedron Lett. 2005, 46, 7209.

${ }^{96}$ Para la utilización de una metodología alternativa a la metilenación de Tebbe/RCM, ver: Inoue, M.; Hirama, M. Synlett 2004, 577.

${ }^{97}$ Clark, J. S. Chem. Commun. 2006, 3571 y referencias allí citadas.

${ }^{98}$ Lee, A.-L.; Malcolmson, S. L.; Puglisi, A.; Schrock, R. R.; Hoveyda, A. H. J. Am. Chem. Soc. 2006, 128,5153
} 


\subsubsection{RCM de éteres de alilo}

Las reacciones de RCM con éteres de alilo como sustratos más reactivos (Esquema 54, 2) utilizan los catalizadores de Grubbs de $1^{\text {a }}$ (Figura 7, C) y $2^{\text {a }}$ (Figura 7, CI) generación. ${ }^{99}$

Recientemente, Hsung ha utilizado esta metodología en la síntesis del fragmento C11-C23 (Esquema 58, CXII) de la macrolida de origen marino espirastrellolida A (CXIII), el cual contiene una unidad espirocetálica. ${ }^{100}$

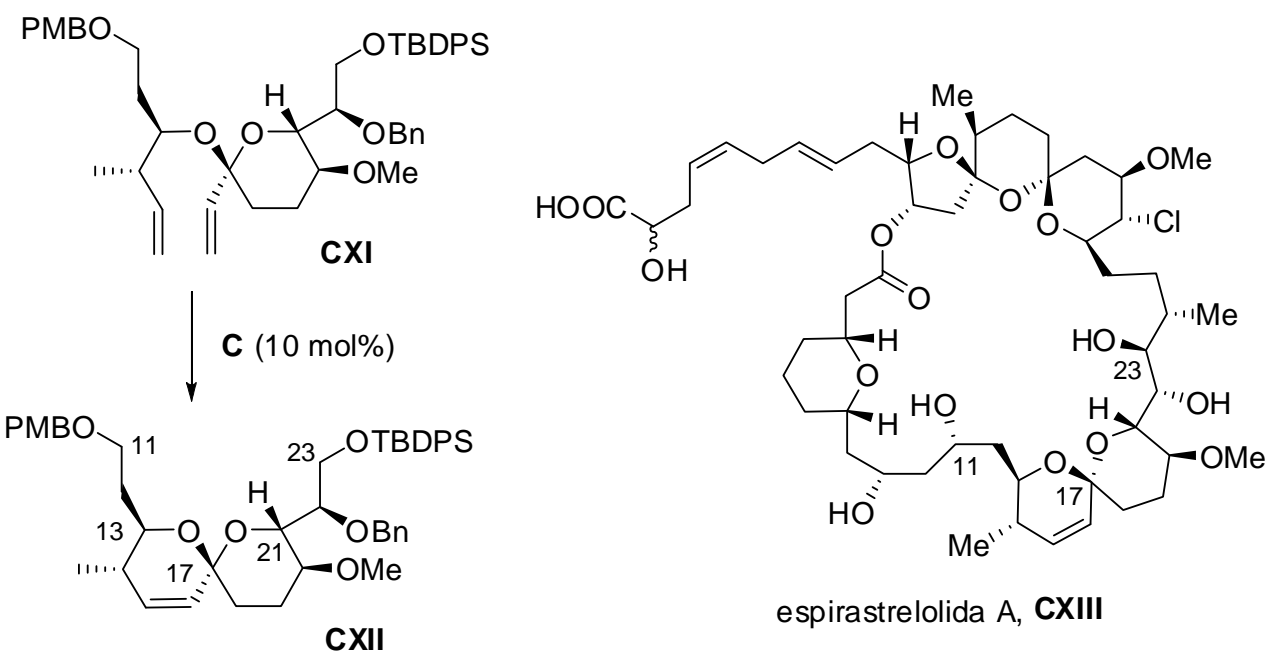

\section{Esquema 58}

Las reacciones de RCM en sustratos que poseen más de dos dobles enlaces son potencialmente muy útiles desde el punto de vista sintético. ${ }^{101}$ Sin embargo, la regioselectividad deviene un aspecto importante para estos tri- o tetraenos si varios modos de ciclación que conducen a diferentes tamaños de anillo, son posibles. Schmidt et al. han demostrado que la síntesis de oxaciclos de cinco y seis miembros

\footnotetext{
${ }^{99}$ Para ejemplos recientes de síntesis de enol éteres cíclicos de seis miembros por RCM a partir de enol éteres lineales, ver: (a) Ahmed, A.; Öhler, E.; Mulzer, J. Synthesis 2001, 2007; (b) Heck, M.-P.; Baylon, C.; Nolan, S. P.; Mioskowski, C. Org. Lett. 2001, 3, 1989; (c) Schimdt, B.; Pohler, M.; Costisella, B. Tetrahedron 2002, 58, 7951; (d) Sutton, A. E.; Seigal, B. A.; Finnegan, M D. F.; Snapper, L. J. Am. Chem. Soc. 2002, 124, 13390. (e) Schmidt, B. Eur. J. Org. Chem. 2003, 816; (f) Evans, P. A.; Leahy, D. K.; Andrews, W. J.; Uraguchi, D. Angew. Chem. Int. Ed. 2004, 43, 4788.

${ }^{100}$ (a) Ghosh, S. K.; Hsung, R. P.; Wang, J. Tetrahedron Lett. 2004, 45, 5505; (b) Liu, J.; Hsung, R. P. Org. Lett. 2005, 7, 2273.

${ }^{101}$ Schmidt, B.; Hermanns, J. Curr. Org. Chem. 2006, 10, 1363.
} 
mediante un proceso de RCM se puede llevar a cabo a partir del mismo sustrato, estando favorecida la formación de dihidropiranos frente a dihidrofuranos cuando en dicho sustrato existe un alcohol alílico no protegido (Esquema 59). Los autores explican este hecho sugiriendo que el grupo hidroxilo libre es capaz de dirigir el catalizador de Grubbs $\mathbf{C}$ selectivamente hacia el doble enlace $b .^{102}$

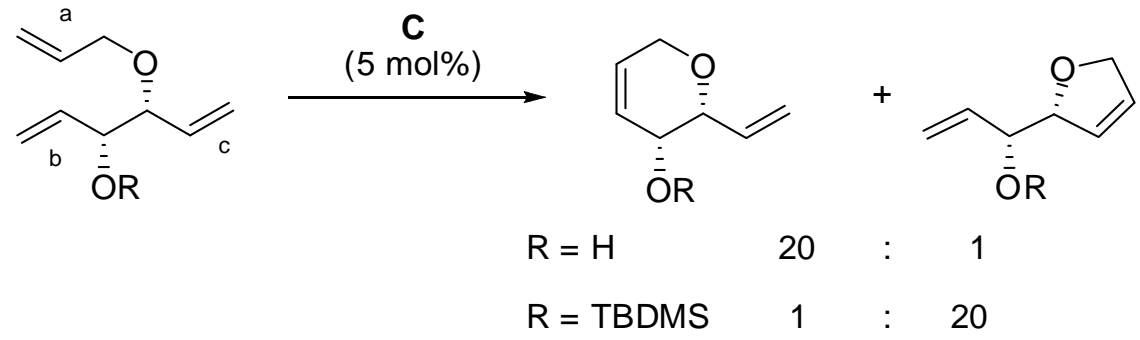

Esquema 59

\subsubsection{RCM de éteres de alquinilo}

Clark y col. también han empleado las reacciones de RCM de alquinil éteres en la síntesis de poliéteres cíclicos fusionados. ${ }^{103}$ En el ejemplo del Esquema 60, la reacción de RCM del alquinil éter CXIV, seguido de metátesis cruzada (CM) del dieno resultante con diacetato de but-E-2-en-1,4-diol, proporciona el dieno $\mathbf{C X V}$ con buen rendimiento. $^{103 \mathrm{~b}}$<smiles>C#COC1[C@H](CC=C)O[C@H](CO)[C@@H](OCc2ccccc2)[C@H]1Cc1ccccc1</smiles>

CXIV

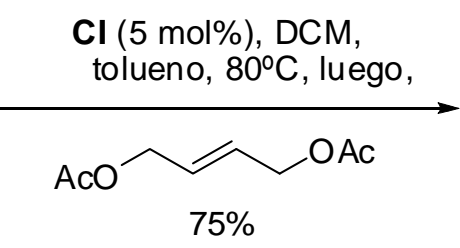

$75 \%$<smiles>CC(=O)OC/C=C/C1=CC[C@H]2O[C@H](COc3ccccc3)[C@H](OCc3ccccc3)[C@H](O)[C@H]2O1</smiles>

\section{Esquema 60}

\footnotetext{
${ }^{102}$ Schmidt, B.; Nave, S. Chem. Commun. 2006, 2489.

103 (a) Clark, J. S.; Elustondo, F.; Trevitt, G. P.; Boyall, D.; Robertson, J.; Blake, A. J.; Wilson, C.; Stammen, B. Tetrahedron 2002, 58, 1973; (b) Clark, J. S.; Elustondo, F.; Kimber, M. C. Chem. Commun. 2004, 2470 .
} 


\subsubsection{Procesos de metátesis con apertura de anillo (ROM)}

Las transformaciones por ROM, aunque menos explotadas que las RCM, también ofrecen métodos interesantes para la síntesis de tetrahidropiranos. Como veíamos en el ejemplo del Esquema 60, las transformaciones basadas en procesos de metátesis se pueden combinar en un solo paso (reacciones dominó), ya que están promovidas por los mismos catalizadores carbénicos. Así, podemos encontrar procesos de formación de tetrahidropiranos por ROM/CM tanto no asimétricos como asimétricos. ${ }^{104}$ Pero sin duda, los más interesantes y los que han demostrado su gran utilidad en la síntesis de carbo y heterociclos, son los procesos ROM/RCM (Esquema 61), también llamados metátesis por reordenamiento de anillo (RRM). ${ }^{105}$

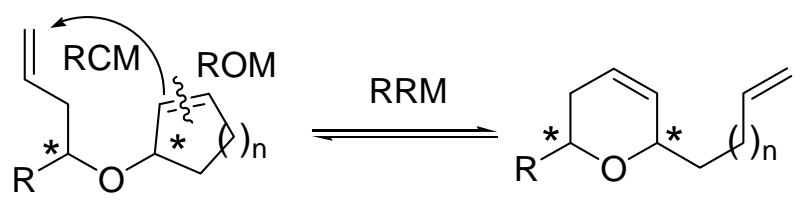

Esquema 61

Nicolau et al. describieron la síntesis del compuesto CXVII, en el cual hay dos sistemas de poliéteres cíclicos fusionados, a partir del ciclobuteno simétrico CXVI a través de un proceso de RRM (Esquema 63). ${ }^{106}$<smiles>C1=CC(OC2CCCO[C@@H]2/C=C/C2C=CC2OC2CCCO2)CC1</smiles>

CXVI

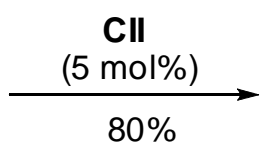<smiles>[CH]1OCCC[C@H]1O[C@H]1C=C[C@@H]2OCCC[C@H]2O1</smiles>

CXVII

\section{Esquema 62}

\footnotetext{
104 (a) Wright, D. L.; Usher, L. C.; Estrella-Jiménez, M. Org. Lett. 2001, 3, 4275; (b) Gillingham, D. G.; Kataoka, O.; Garber, S. B.; Hoveyda, A. H. J. Am. Chem. Soc. 2004, 126, 12288.

${ }_{105}$ Para un revisión bibliográfica de RRM, ver: Holub, N.; Blechert, S. Chem. Asian J. 2007, $2,1064$.

${ }^{106}$ Nicolau, K. C.; Vega, J. A.; Vassilikogiannakis, G. Angew. Chem. Int. Ed. 2001, 40, 4441.
} 
Una característica importante de las reacciones de RRM es que existe una transferencia total de información estereoquímica del sustrato al producto, algo que han aprovechado Blechert y col. en la síntesis de (-)-centrolobina mediante una secuencia RRM de isomerización diastereoselectiva. ${ }^{107}$

El grupo de Hoveyda y Schrock ha desarrollado procesos de RRM enantioselectivos en los que se obtienen dihidropiranos quirales a partir de sustratos no quirales (Esquema 63) gracias a la utilización de catalizadores asimétricos de Mo como CX (Esquema 57). ${ }^{108}$

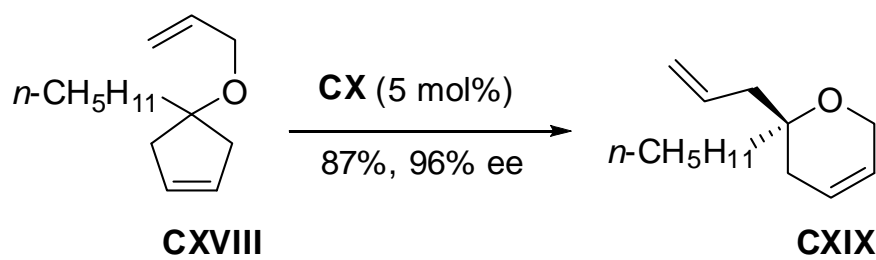

Esquema 63

\subsection{Ciclaciones sobre iones oxocarbenio}

Las reacciones de ciclación promovidas por ácido de hidroxialquenos con aldehídos y acetales a través de intermedios oxocarbénicos son muy útiles para la obtención de sistemas tetrahidropiránicos. Dentro de este apartado se pueden agrupar todas las reacciones tipo Prins, como la reacción de Sakurai, el reordenamiento de Petasis-Ferrier o la propia reacción de Prins. En todas ellas, el paso último de ciclación es el ataque nucleofílico de un doble enlace a un ión oxocarbenio, que de forma general se puede representar como en la figura 8.

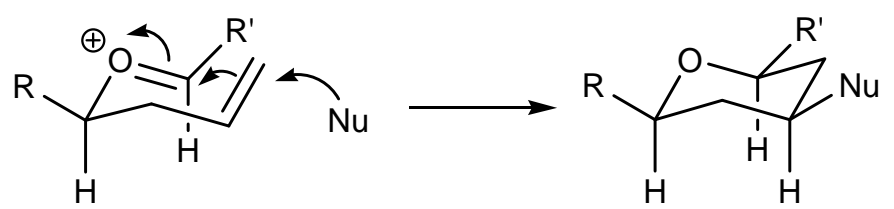

\section{Figura 8}

\footnotetext{
${ }^{107}$ (a) Böhrsch, V.; Neidhöfer, J.; Blechert, S. Angew. Chem. Int. Ed. 2006, 45, 1302; (b) Böhrsch, V.; Blechert, S. Chem. Commun. 2006, 1968.

${ }^{108}$ Cefalo, D. R.; Kiely, A, F.; Wuchrer, M.; Jamieson, J. Y.; Schrock, R. R.; Hoveyda, A. H. J. Am. Chem. Soc. 2001, 123, 3139.
} 


\subsubsection{Ciclación de Sakurai}

En la reacción de Sakurai tiene lugar la alilación de un electrófilo con alilsilanos catalizada por ácidos de Lewis, ${ }^{109}$ aunque también se han utilizado ácidos de Brønsted como catalizadores. Este es el caso de Hoye et al., que utilizaron una ciclación de Sakurai catalizada por CSA en su síntesis de dactilolida (Esquema 64). ${ }^{110}$<smiles>CC(C)=CCC=CCOc1ccccc1</smiles><smiles>C=C(COC)CC(CCOC)OCCOC</smiles>

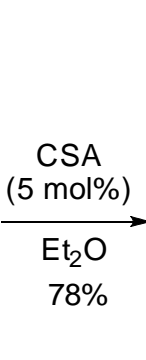

CXXI

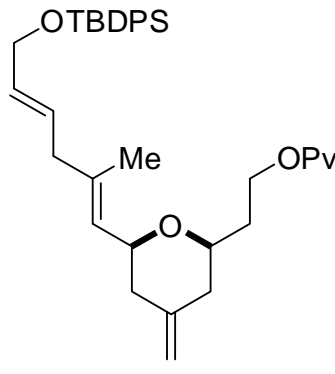

CXXII<smiles>C=CC#CCC(OC(=O)/C=C/C=C(/C)CC(=O)/C=C/CC1CC(=C)CC(C=O)O1)C(=O)CC</smiles>

dactilolida, CXXIII

\section{Esquema 64}

El grupo de Markó ha investigado considerablemente esta metodología, desarrollando reacciones tándem énica-ciclación de Sakurai, ${ }^{111}$ o aplicándola a la síntesis de los fragmentos tetrahidropiránicos de productos naturales como la policarvenosida $\mathrm{A}^{112 \mathrm{a}}$ o el amphidinol 3. ${ }^{112 b}$ También ha aplicado esta metodología a la síntesis del tetrahidropirano presente en la estructura del metil monato C, el éster metílico derivado del ácido pseudomónico C (Esquema 65). ${ }^{112 c}$

\footnotetext{
109 (a) Kjellgren, J.; Szabó, K. J. Tetrahedron Lett. 2002, 43, 1123; (b) Keck, G. E.; Covel, J. A.; Schiff, T.; Yu, T. Org. Lett. 2002, 4, 1189; (c) Miura, K.; Itaya, R.; Horiike, M.; Izumi, H.; Hosomi, A. Synlett 2005, 3148.

${ }^{110}$ (a) Hoye, T. R.; Hu, M. J. Am. Chem. Soc. 2003, 125, 9576; (b) Para otra síntesis de dactilolida en la que se hace uso de una ciclación de Sakurai catalizada por $\mathrm{CeCl}_{3}$, ver: Aubele, D. L.; Wan, S.; Floreancig, P. E. Angew. Chem. Int. Ed. 2005, 44, 3485.

${ }^{111}$ (a) Markó, I. E.; Dumeunier, R.; Leclercq, C.; Leroy, B.; Plancher, J.-M.; Mekhalfia, A.; Bayston, D. J. Synthesis 2002, 958; (b) Leroy, B.; Markó, I. E. J. Org. Chem. 2002, 67, 8744.

112 (a) Pérez-Balado, C.; Markó, I. E. Tetrahedron Lett. 2005, 46, 4887; (b) Dubost, C.; Markó, I. E.; Bryans, J. Tetrahedron Lett. 2005, 46, 4005; (c) van Innis, L.; Plancher, J.-M.; Markó, I. E. Org. Lett. 2006, 8, 6111.
} 


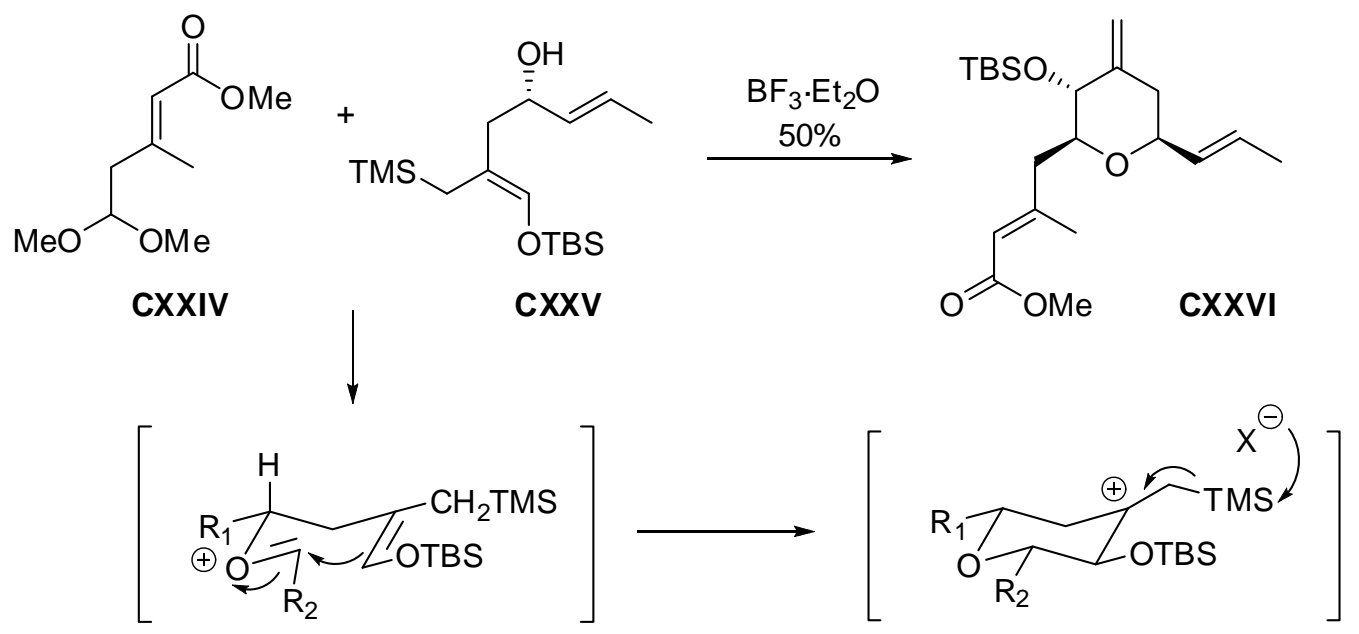

\section{Esquema 65}

\subsubsection{Reordenamiento de Petasis-Ferrier $^{113}$}

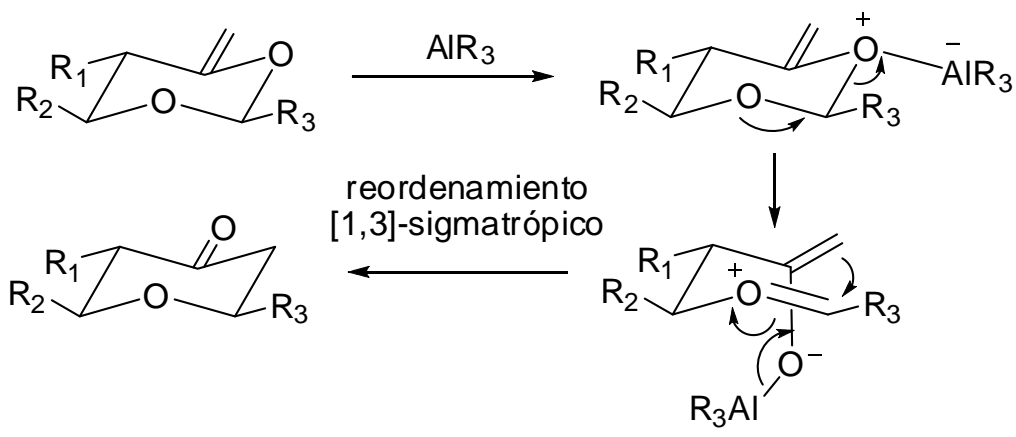

\section{Esquema 66}

Este reordenamiento [1,3]-sigmatrópico catalizado por compuestos de aluminio (Esquema 66) ha sido muy utilizado por el grupo de Smith en la síntesis de varios productos naturales, como la (+)-zampanolida, ${ }^{114 \mathrm{a}}$ la (+)-dactilolida ${ }^{114 \mathrm{~b}}$ o el phorboxazol A. ${ }^{115}$ En el Esquema 67 vemos como ejemplo el uso de dicho reordenamiento en la síntesis del fragmento bis-tetrahidropiránico del phorboxazol A. ${ }^{115 b}$

\footnotetext{
${ }^{113}$ Para una revisión reciente del reordenamiento de Petasis-Ferrier y su aplicación a la síntesis de productos naturales, ver: Smith III, A. B.; Fox, R. J.; Razler, T. M. Acc. Chem. Res. 2008, 41, 675.

114 (a) Smith III, A. B.; Safonov, I.; Corbett, R. M. J. Am. Chem. Soc. 2001, 123, 12426; (b) Smith III, A. B.; Safonov, I.; Corbett, R. M. J. Am. Chem. Soc. 2002, 124, 11102.

115 (a) Smith III, A. B.; Verhoest, P. R.; Minbiole, K. P.; Schelhaas, M. J. Am. Chem. Soc. 2001, 123, 4834; (b) Referencia 75c; (c) Referencia 1c.
} 
<smiles>C=C1C[C@H](CCO[Se]S(=O)(=O)c2ccccc2)OC(c2coc(COC(C)(C)C)n2)O1</smiles>

CXXVII
$\mathrm{Me}_{2} \mathrm{AlCl}, \mathrm{DCM}$ $89 \%$<smiles>C=C1C[C@H](CCO[Se])O[C@@H](CC2CC(=O)C[C@H](c3coc(CO[R5](=O)(=O)c4ccccc4)n3)O2)C1</smiles>

CXXVIII

Esquema 67

\subsubsection{Ciclación de Prins}

Durante los últimos años, la reacción de Prins se ha aplicado en numerosas ocasiones a la síntesis de productos naturales, debido a su convergencia y eficacia para la formación de anillos tetrahidropiránicos. Sin embargo, hasta hace poco tiempo, tenía la desventaja de que los productos de reacción podían sufrir racemización parcial debido a un reordenamiento 2-Oxonio-Cope simétrico (Esquema 68).<smiles>[R]C1OC([R])C2C(N)C12</smiles>

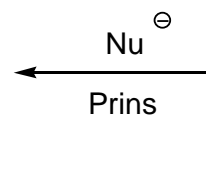<smiles>[R]C(=O)C([R])[CH]CCO</smiles><smiles>[R]C1CCCC1[R]</smiles>

\section{Esquema 68}

Algunos autores han superado este problema utilizando ácidos de Lewis como $\mathrm{SnBr}_{4}{ }^{116} \mathrm{o} \mathrm{In}(\mathrm{OTf})_{3},{ }^{117}$ los cuales promueven la ciclación de Prins más rápidamente que otros ácidos, como $\mathrm{BF}_{3} \cdot \mathrm{OEt}_{2}$, con lo que se suprime el proceso competitivo de reordenamiento.

\footnotetext{
${ }^{116}$ Marumoto, S.; Jaber, J. J.; Vitale, J. P.; Rychnovsky, S. D. Org. Lett. 2002, 4, 3919.

${ }^{117}$ Chan, P. K.; Loh, P. T. Org. Lett. 2005, 7, 4491.
} 
Debido a la gran cantidad de bibliografía sobre el estudio o las aplicaciones de la reacción de ciclación de Prins para la formación de tetrahidropiranos aparecida en los últimos años, ${ }^{118}$ en los siguientes párrafos nos centraremos en algunas de las aplicaciones más interesantes y recientes que ha tenido dicha reacción en la síntesis de productos naturales.

Rychnovsky et al. han utilizado la reacción de Prins en la síntesis de varios productos naturales, como el anillo de tetrahidropirano pentasustituído ${ }^{119 a}$ y la unidad bis-tetrahidropiránica $^{119 \mathrm{~b}}$ presentes en la estructura de los phorboxazoles A y B. Asimismo, han llevado a cabo la síntesis del fragmento C18-C25 del agente antitumoral lasonolida A mediante la aplicación de una ciclación en cascada 2-Oxonia-Copeciclación de Prins (Esquema 69). ${ }^{120}$

\footnotetext{
${ }^{118}$ Revisión bibliográfica sobre la reacción de Prins: (1) Pastor, I. M.; Yus, M. Curr. Org. Chem. 2007, 11, 925; Bibliografía seleccionada: (2) Alder, R. W.; Harvey, J. N.; Oakley, M. T. J. Am. Chem. Soc. 2002, 124, 4960; (3) Crosby, S. R.; Harding, J. R.; King, C. D.; Parker, G. D.; Willis, C. L. Org. Lett. 2002, 4, 577; (4) Crosby, S. R.; Harding, J. R.; King, C. D.; Parker, G. D.; Willis, C. L. Org. Lett. 2002, 4, 3407; (5) Barry, C. S.; Crosby, S. R.; Harding, J. R.; Hughes, R. A.; King, C. D.; Parker, G. D.; Willis, C. L. Org. Lett. 2003, 5, 2429; (6) Cho, Y. S.; Karupaiyan, K.; Kang, H. J.; Pae, A. N.; Cha, J. H.; K, H. Y.; Chang, M. H. Chem. Commun. 2003, 2346; (7) Miranda, P. O.; Díaz, D. D.; Padrón, J. I.; Bermejo, J.; Martín, V. S. Org. Lett. 2003, 5, 1979; (8) Yadav, J. S.; Reddy, B. V. S.; Reddy, M. S.; Niranjan, N.; Prasad, A. R. Eur. J. Org. Chem. 2003, 1779; (9) Hart, D. H.; Bennet, C. E.; Org. Lett. 2003, 5, 1499; (10) Aubele, D. L.; Lee, C. A.; Floreancig, P. E. Org. Lett. 2003, 5, 4521; (11) Yu, C.- M.; Yoon, S.- K.; Hong, Y.- T.; Kim, J. Chem. Commun. 2004, 1840; (12) Yadav, J. S.; Reddy, B. V. S.; Gupta, M. K.; Biswas, S. K. Synthesis 2004, 2711; (13) Patterson, B.; Rychnovsky, S. D. Synlett, 2004, 543; (14) Jasti, R.; Vitale, J.; Rychnovsky, S. D. J. Am. Chem. Soc. 2004, 126, 9904; (15) Yadav, V. K.; Kumar, N. V. J. Am. Chem. Soc. 2004, 126, 8652; (16) Chan, K.- P.; Loh, T.- P. Tetrahedron Lett. 2004, 45, 8387; (17) Miranda, L. S. M.; Meireles, B. A.; Costa, J. S.; Pereira, V. L. P.; Vasconcellos, M. L. A. A. Synlett 2005, 869; (18) Yang, X.- F.; Wang, M.; Zhang, Y.; Li, C.-J. Synlett 2005, 1912; (19) Dziedzic, M.; Lipner, G.; Furman, B. Tetrahedron Lett. 2005, 46, 6861; (20) Kumar, H. M. S.; Qazi, N. A.; Shafi, S.; Kumar, V. N.; Krishna, A. D.; Yadav, J. S. Tetrahedron Lett. 2005, 46, 7205; (21) Jasti, R.; Anderson, C. D.; Rychnovsky, S. D. J. Am. Chem. Soc. 2005, 127, 9939; (22) Barry, C. S.; Bushby, N.; Harding, J. R.; Hughes, R. A.; Parker, G. D.; Roe, R.; Willis, C. L. Chem. Commun. 2005, 3727; (23) Sabitha, G.; Reddy, K. B.; Reddy, G. S. K. K.; Fatima, N.; Yadav, J. S. Synlett 2005, 2347; (24) Miranda, P. O.; Díaz, D. D.; Padrón, J. I.; Ramírez, M. A.; Martín, V. S. J. Org. Chem. 2005, 70, 57; (25) Miranda, P. O.; Ramírez, M. A.; Padrón, J. I.; Martín, V. S. Tetrahedron Lett. 2006, 47, 283; (26) Miranda, P. O.; Ramírez, M. A.; Martín, V. S.; Padrón, J. I. Org. Lett. 2006, 8, 1633; (27) Miranda, P. O.; Ramírez, M. A.; Martín, V. S.; Padrón, J. I. Org. Lett. 2006, 8, 1633; (28) Mullen, C. A.; Gagné, M. R. Org. Lett. 2006, 8, 665; (29) Miles, R. B.; Davis, C. E.; Coates, R. M. J. Org. Chem. 2006, 71, 1493; (30) Epstein, O. L.; Rovis, T. J. Am. Chem. Soc. 2006, 128, 16480; (31) Nannei, R.; Dallavalle, S.; Merlini, L.; Bava, A.; Nasini, G. J. Org. Chem. 2006, 71, 6277; (32) Liu, F.; Loh, T.- P. Org. Lett. 2007, 9, 2063; (33) Yadav, J. S.; Reddy, B. V. S.; Krishna, V. H.; Swamy, T.; Kumar, G. G. K. S. N. Can. J. Chem. 2007, 85, 412; (34) Tian, G.- Q.; Shi, M. Org. Lett. 2007, 9, 2405.

119 (a) Rychnovsky, S. D.; Thomas, C. R. Org. Lett. 2000, 2, 1217; (b) Vitale, J. P.; Wolckenhauer, S. A.; Do, N. M.; Rychnovsky, S. D. Org. Lett. 2005, 7, 3255.

${ }^{120}$ Dalgard, J. E.; Rychnovsky, S. D. Org. Lett. 2005, 7, 1589.
} 
Más recientemente este mismo grupo ha utilizado esta metodología en la obtención del $C$-arilglicósido que se encuentra en la estructura de la macrolida kendomicina. $^{121}$

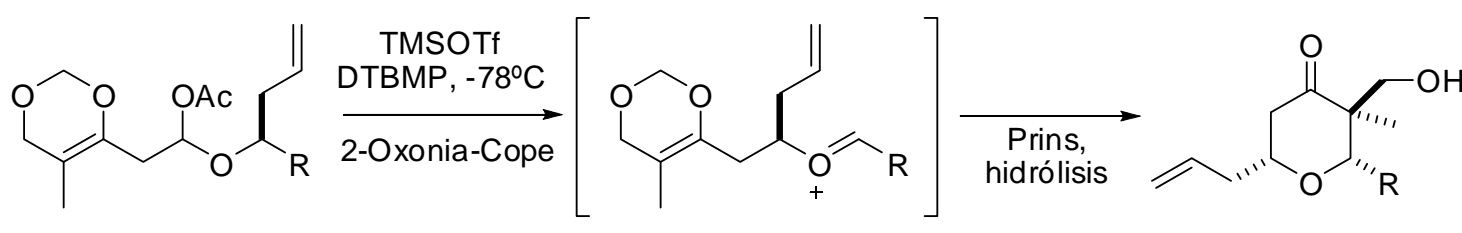
CXXIX

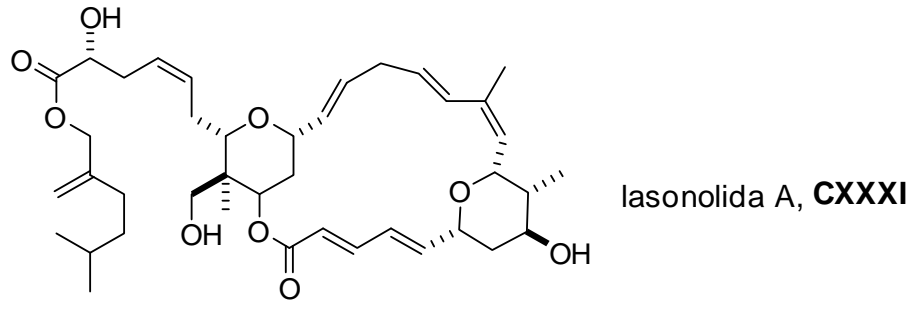

\section{Esquema 69}

La síntesis formal de (+)-SCH 351448, un nuevo activador del promotor de LDL-R (receptor de la lipoproteína de baja densidad), se ha llevado a cabo recientemente en el grupo de Loh haciendo uso de la reacción de Prins. ${ }^{122}$

Un paso clave en la primera síntesis total de blepharocalixina D (Esquema 70, CXXXIV), un agente con actividad antiproliferativa frente a algunas líneas celulares tumorales, es el reordenamiento Prins-pinacolínico de CXXXII a CXXXIII. El aldehído axial es el producto cinético mayoritario obtenido tras la ciclación, el cual se puede equilibrar hacia el aldehído ecuatorial deseado (Esquema 70). ${ }^{123}$

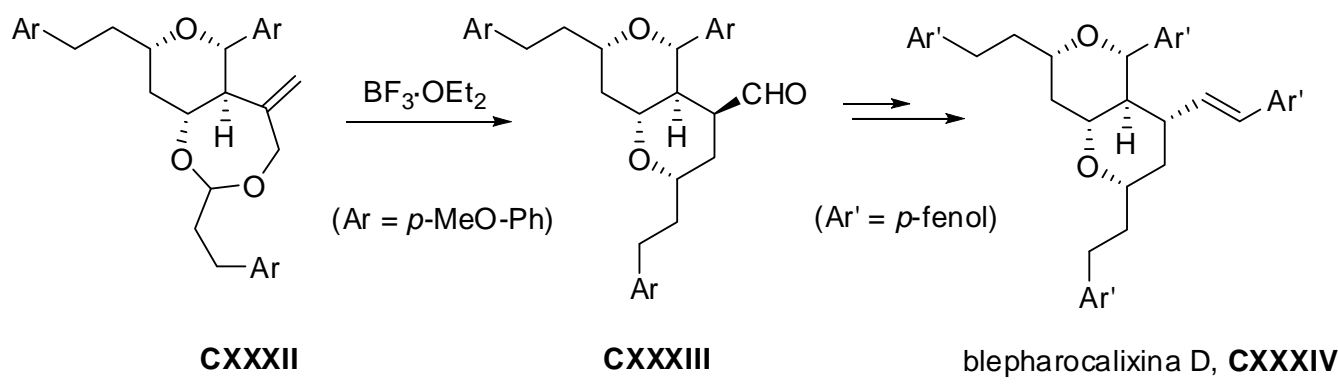

\section{Esquema 70}

\footnotetext{
${ }^{121}$ Bahnck, K. B.; Rychnovsky, S. D. Chem. Commun. 2006, 2388.

${ }^{122}$ Chan, K.-P.; Ling, Y. H.; Loh, T.-P. Chem. Commun. 2007, 939.

${ }^{123}$ Ko, H. M.; Lee, D. G.; Kim, M. A.; Kim, H. J.; Park, J.; Lah, M. S.; Lee, E. Org. Lett. 2007, 9, 141.
} 

INTRODUCCIÓN. PARTE II:

ORGANOCATÁLISIS: APLICACIÓN A LA SÍNTESIS DE HETEROCICLOS OXIGENADOS DE SEIS MIEMBROS 

El término organocatálisis, acuñado por MacMillan, describe la aceleración de una reacción química mediante la adición de cantidades subestequiométricas de moléculas orgánicas de pequeño tamaño, en las que ningún elemento inorgánico forma parte del principio activo.

El interés en este campo de la química ha aumentado drásticamente en los últimos años, habiendo aparecido gran cantidad de bibliografía sobre el tema, tanto artículos o capítulos de libros como números monográficos. ${ }^{124}$ Resulta sorprendente que un campo como la organocatálisis que hace no muchos años ni siquiera existía como tal, ${ }^{125}$ hoy día se haya convertido, junto con la biocatálisis y la catálisis con complejos metálicos en uno de los tres grandes pilares de la catálisis asimétrica.

La mayoría de los catalizadores orgánicos pueden clasificarse en cuatro grandes grupos: bases de Lewis, ácidos de Lewis, bases de Brønsted y ácidos de Brønsted. Estos catalizadores inician el ciclo catalítico proporcionando o sustrayendo electrones o protones de un determinado sustrato o estado de transición. Así, el catalizador que actúa como base de Lewis (B:), inicia el ciclo catalítico mediante una adición nucleofílica al sustrato (S). El complejo resultante propicia la formación del producto (P) al mismo tiempo que el catalizador es liberado. De igual manera, el catalizador que

${ }^{124}$ Para una bibliografía seleccionada, ver: Revisiones bibliográficas: (a) Dalko, P. I.; Moisan, L. Angew. Chem., Int. Ed. 2001, 40, 3726; (b) List, B. Tetrahedron 2002, 58, 5573; (c) Jarvo, E. R.; Miller, S. J. Tetrahedron 2002, 58, 2481; (d) Dalko, P. I.; Moisan, L. Angew. Chem., Int. Ed. 2004, 43, 5138; (e) Seayad, J.; List, B. Org. Biomol. Chem. 2005, 3, 719; (f) List, B. Chem. Commun. 2006, 819; (g) Marigo, M.; Jørgensen, K. A. Chem. Commun. 2006, 2001; (g) Marcelli, T.; van Maarseveen, J. H.; Hiemstra, H. Angew. Chem., Int. Ed. 2006, 45, 7496; (h) Palomo, C.; Mielgo, A. Angew. Chem., Int. Ed. 2006, 45, 7876; (i) Cozzi F. Adv. Synth. Catal. 2006, 348, 1367; (i) Gaunt, M. J.; Johansson, C. C. C.; McNally, A.; Vo, N. T. Drug Discovery Today 2007, 12, 8; (j) de Figueiredo, R. M.; Christmann, M.; Eur. J. Org. Chem. 2007, 2575; (k) Enders, D.; Grondal, C.; Hüttl, M. R. M. Angew. Chem. Int. Ed. 2007, 46, 1570; (1) Ting, A.; Schaus, S. E. Eur. J. Org. Chem. 2007, 5797; (m) Tsogoeva, S. B.; Eur. J. Org. Chem. 2007, 1701; (n) Doyle, A. G.; Jacobsen, E. N. Chem. Rev. 2007, 107, 5713; (ñ) Almași, D.; Alonso, D. A.; Nájera, C. Tetrahedron: Asymmetry 2007, 18, 299; (o) Vicario, J. L.; Badia, D.; Carrillo, L. Synthesis 2007, 2065; (p) Pellisier, H. Tetrahedron 2007, 63, 9267; (q) Barbas III, C. F. Angew. Chem. Int. Ed. 2008, 47, 42; (r) Dondori, A.; Massi, A. Angew. Chem., Int. Ed. 2008, 47, 4638; Números especiales sobre organocatálisis asimétrica: (s) Acc. Chem. Res. 2004, 37, 487 (Eds.: Houk, K. N.; List, B.); (t) Tetrahedron 2006, 62, 255 (Eds.: Kočovský, P.; Malkov, A.V.); (u) Chem. Rev. 2007, 107, 5413 (Ed.: List, B.); Libros: (v) Berkessel, A.; Gröger, H. Asymmetric Organocatalysis: From Biomimetic Concepts to Applications in Asymmetric Synthesis; Wiley-VCH: Weinheim, 2004; (w) Enantioselective Organocatalysis (Ed.: Dalko, P. I.) Wiley-VCH, Weinheim, 2007.

${ }^{125}$ Por ejemplo, en los últimos años de la década de los 90, Sorensen y Nicolau definieron en su libro "Classics in Total Synthesis" la catálisis asimétrica afirmando que: "En una reacción catalítica asimétrica se usa una pequeña cantidad de un catalizador enantioméricamente puro, ya sea una enzima o un complejo soluble con un metal de transición sintético, para obtener grandes cantidades de un compuesto ópticamente activo a partir de un precursor que puede ser quiral o aquiral" (Nicolaou, K. C.; Sorensen, E. J. Classics in Total Synthesis, Wiley-VCH: Weinheim, 1996). 
funciona como ácido de Lewis (A) activa el sustrato (S) de forma nucleofílica, mientras que los catalizadores que funcionan como bases o ácidos de Brønsted inician el ciclo catalítico mediante la desprotonación o protonación del sustrato (Figura 9). ${ }^{124 \mathrm{e}}$
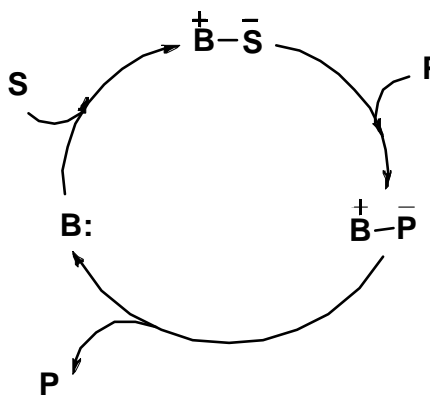

Catálisis por Base de Lewis
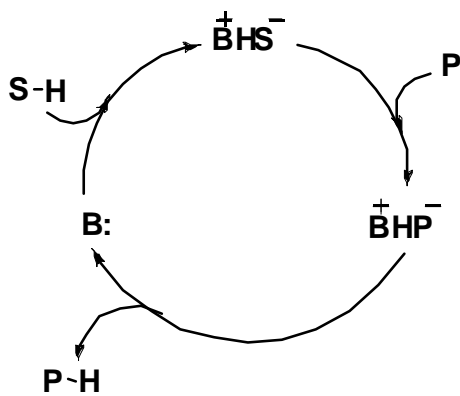

Catálisis por Base de Brönsted

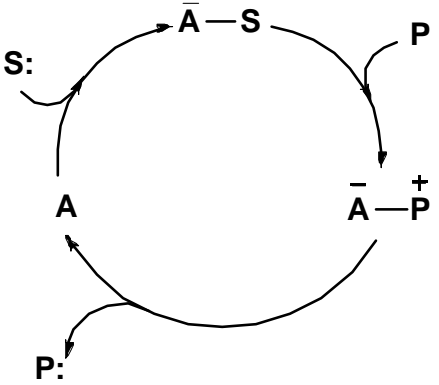

Catálisis por Ácido de Lewis
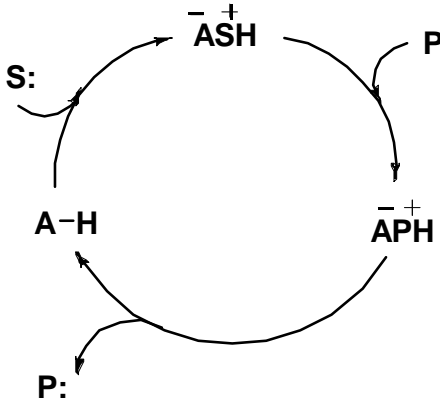

Catálisis por Ácido de Brönsted

Figura 9. Ciclos catalíticos

A continuación se comentarán diversas metodologías desarrolladas recientemente para la formación de heterociclos oxigenados de seis miembros que utilizan catalizadores orgánicos, las cuales se pueden englobar en dos grandes grupos: adiciones conjugadas y oxo-Hetero-Diels-Alder (oxo-HDA). Dentro del primer grupo domina la organocatálisis por bases de Lewis, en la que se utilizan catalizadores como aminas o carbenos. En las reacciones de oxo-HDA organocatalíticas, aparte de algunos casos de catálisis por aminas, predomina el uso de ácidos orgánicos de Brønsted quirales, lo que supone un concepto relativamente novedoso en el campo de la catálisis asimétrica. 


\section{ADICIONES CONJUGADAS ORGANOCATALÍTICAS}

\subsection{Adición conjugada de nucleófilos carbonados}

\subsubsection{Adición conjugada de silil enol éteres}

Mukaiyama y col. han utilizado fenóxidos de amonio cuaternarios derivados de alcaloides de Cinchona en un método nuevo y eficiente para la preparación de derivados 3,4-dihidropiran-2-ona quirales a través de una reacción tándem adición de MichaelMukaiyama/lactonización entre cetonas $\alpha, \beta$-insaturadas y el silil enolato derivado del fenil isobutirato. De todos los fenóxidos de amonio cuaternario probados, CXXXVI mostró la mejor actividad catalítica (Esquema 71). ${ }^{126}$

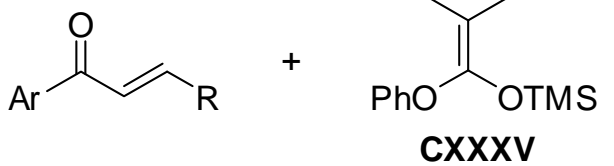<smiles>[R]C1C=C([Al])OC(=O)C1(C)C</smiles>

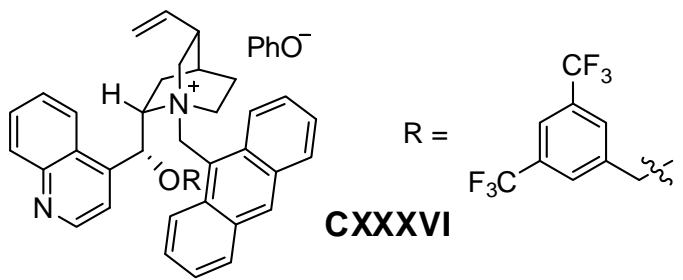

Esquema 71

\subsubsection{Reacción de Stetter}

La reacción de Stetter consiste en la adición conjugada de un aldehído a una olefina deficiente en electrones. Para ello, un carbeno de heteroazolio quiral lleva a cabo el "umpolung" o cambio de la polaridad normal del aldehído, con lo que el carbono carbonílico de éste se transforma en nucleofílico. ${ }^{127}$

\footnotetext{
${ }^{126}$ Tozawa, T.; Yamane, Y.; Mukaiyama, T. Chem. Lett. 2006, 35, 56.

${ }^{127}$ La reacción de Stetter es un tipo de reacción benzoínica en la que el anión de acilo formado se adiciona sobre un aceptor de Michael. Suzuki y col. también han utilizado una condensación benzoínica cruzada intramolecular organocatalítica para la síntesis de croman-4-onas: Takikawa, H.; Hachisu, Y.; Bode, J. W.; Suzuki, K. Angew. Chem. Int. Ed. 2006, 45, 3492.
} 
<smiles>CC1(C)CC[C@@H](n2cn[n+](-c3ccccc3)c2)[C@H](c2ccccc2)O1</smiles>

CXXXVII<smiles>[R16]C(N)C(=O)N[C@@H](Cc1csc[n+]1CC)C(=O)NC([R1])c1cccc2ccccc12</smiles>

CXXXVIII<smiles>[X][X]O[Na]</smiles><smiles></smiles>

CXL

Figura 10

La primera reacción de Stetter intramolecular organocatalítica asimétrica ${ }^{128}$ fue llevada a cabo por Enders en 1996 utilizando la sal de triazolio CXXXVII quiral como catalizador (Figura 10). ${ }^{129}$ Esta metodología abrió una nueva vía para la síntesis enantioselectiva de derivados croman-4-ona. Posteriormente, Rovis et al. mejoraron la enantioselectividad y el rango de sustratos de la reacción utilizando catalizadores tipo CXXXIX y CXL. ${ }^{130}$ Estos mismos autores llevaron a cabo la síntesis de croman-4onas (CXLII) con formación de estereocentros cuaternarios, como se muestra en el ejemplo del Esquema $72 .{ }^{131}$<smiles>CC(=O)/C=C(/COc1ccccc1C=O)c1ccccc1</smiles>

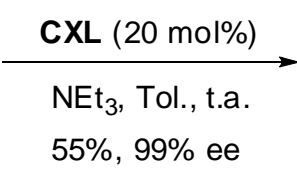

$55 \%, 99 \%$ ee CXLI<smiles>CC(=O)C[C@]1(P)COc2ccccc2C1=O</smiles>

CXLII

\section{Esquema 72}

Miller y col. han utilizado una serie de catalizadores que incorporan una unidad de tiazolilalanina en una secuencia peptídica (Figura 10, CXXXVIII) para este mismo tipo de reacciones. Sin embargo, en ningún caso han mejorado los resultados obtenidos por Rovis et al. ${ }^{132}$

\footnotetext{
${ }^{128}$ Para una version no asimétrica anterior, ver: Ciganek, E. Synthesis 1995, 1311.

${ }^{129}$ Enders, D.; Breuer, K.; Runsik, J. Helv. Chim. Acta 1996, 79, 1899.

${ }^{130}$ (a) Kerr, M. S.; Read de Alaniz, J.; Rovis, T. J. Am. Chem. Soc. 2002, 124, 10298; (b) Kerr, M. S.; Rovis, T. Synlett 2003, 1934; (c) Read de Alaniz, J.; Rovis, T. J. Am. Chem. Soc. 2005, 127, 6284.

131 (a) Kerr, M. S.; Rovis, T. J. Am. Chem. Soc. 2004, 126, 8876. (b) Moore, J. L.; Kerr, M. S.; Rovis, T. Tetrahedron 2006, 62, 11477; (c) Para una versión no asimétrica, ver: Nakamura, T.; Hara, O.; Tamura, T.; Makino, K.; Hamada, Y. Synlett 2005, 155.

${ }^{132}$ Mennen, S. M.; Blank, J. T.; Tran-Dubé, M. B.; Imbriglio, J. E.; Miller, S. J. Chem. Commun. 2005, 195.
} 


\subsubsection{Reacciones tándem}

Tang y col. han descrito una reacción de ciclación tándem adición de Michael/ eliminación/sustitución catalizada por tetrahidrotiofeno para la síntesis de cromenos a partir del correspondiente bromuro de bencilo sustituído (Esquema 73). Se pueden obtener selectivamente tanto $2 \mathrm{H}$ - como $4 \mathrm{H}$-cromenos dependiendo de la base empleada en cada caso. ${ }^{133}$<smiles>[R]OC(=O)C1=CCc2c([R])cccc2O1</smiles>

Esquema 73

Recientemente, se ha publicado la síntesis organocatalítica enantioselectiva de 1,4-piranonaftoquinonas catalizada por diarilprolinoles quirales (Esquema 74, CXLIV). ${ }^{134}$ En este caso, el mecanismo propuesto implica la formación de un ión iminio por reacción del catalizador con el correspondiente aldehído, seguido de la adición conjugada de la 2-hidroxi-1,4-naftoquinona. Un último paso de hidrólisis y acetalización da lugar a las correspondientes 1,4-piranonaftoquinonas.<smiles>O=C1C=C(O)C(=O)c2ccccc21</smiles>

CXLIII

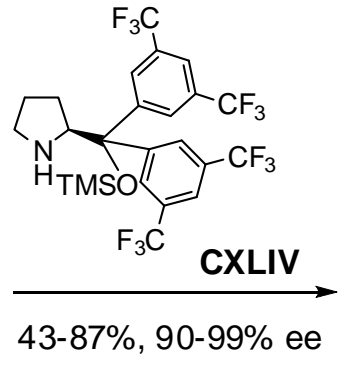<smiles>[R]C1CC(O)OC2=C1C(=O)c1ccccc1C2=O</smiles>

\section{Esquema 74}

\footnotetext{
${ }^{133}$ Ye, L.-W.; Sun, X.-L.; Zhu, C.-Y.; Tang, Y. Org. Lett. 2006, 8, 3853.

${ }^{134}$ Rueping, M.; Sugiono, E.; Merino, E. Angew. Chem. Int. Ed. 2008, 47, 3046.
} 


\subsection{Adición conjugada de nucleófilos oxigenados}

Los primeros estudios de adición conjugada organocatalítica de nucleófilos oxigenados fueron llevados a cabo por Ishikawa et al., quienes describieron la adición conjugada de fenoles catalizada por quinina en el curso de la síntesis del producto natural con actividad anti-VIH (+)-calanolida A (Esquema 75, CXLVII). ${ }^{135,136}$

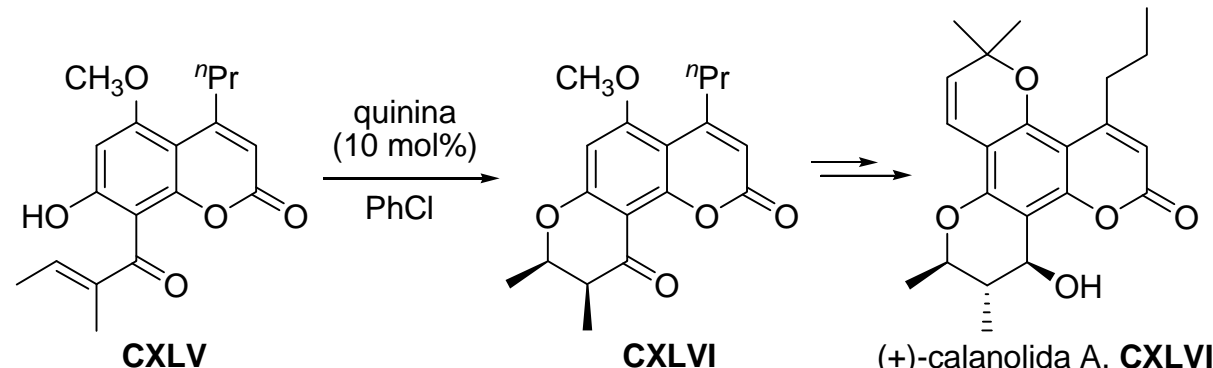

Esquema 75

La adición oxo-Michael asimétrica organocatalítica ha sido recientemente empleada por Arvidsson y col. en la síntesis de benzopiranos. ${ }^{137}$ La formación de estos heterociclos implica una reacción dominó que comienza con la adición oxo-Michael de los derivados del aldehído salicílico sobre el ión iminio formado por el catalizador difenilprolinol CXLVIII y el aldehído correspondiente, seguido de una reacción aldólica intramolecular y eliminación de agua (Esquema 76).

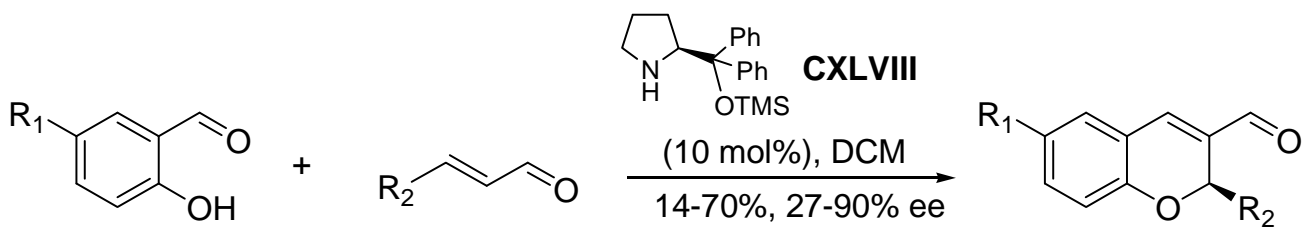

\section{Esquema 76}

\footnotetext{
135 (a) Ishikawa, T.; Oku, Y.; Tanaka, T.; Kumamoto, T. Tetrahedron Lett. 1999, 40, 3777; (b) Tanaka, T.; Kumamoto, T.; Ishikawa, T. Tetrahedron: Asymmetry 2000, 11, 4633; (c) Sekino, E.; Kumamoto, T.; Tanaka, T.; Ikeda T.; Ishikawa, T. J. Org. Chem. 2004, 69, 2760; (d) Para una síntesis asimétrica de esqueletos de cromano 2,2-disustituídos mediante una reacción oxo-Michael intramolecular catalizada por guanidina, ver: Saito, N.; Ryoda, A.; Nakanishi, W.; Kumamoto, T.; Ishikawa, T. Eur. J. Org. Chem. 2008, 2759.

${ }^{136}$ Para otros ejemplos recientes del uso de derivados de Cinchona como catalizadores orgánicos en adiciones conjugadas de nucleófilos fenólicos para la síntesis de estructuras benzopiránicas, ver: (a) Merschaert, A.; Delbeke, P.; Daloze, D.; Dive, G. Tetrahedron Lett. 2004, 45, 4697; (b) Biddle, M. M., Lin, M., Scheidt, K. A. J. Am. Chem. Soc. 2007, 129, 3830; (c) Dittmer, C., Raabe, G., Hintermann, L. Eur. J. Org. Chem. 2007, 5886.

${ }^{137}$ Govender, T.; Hojabri, L.; Moghaddam, F. M.; Arvidsson, P. I. Tetrahedron: Asymmetry 2006, 17, 1763.
} 
Más tarde, Córdova ${ }^{138}$ y Wang $^{139}$ emplearon esta misma reacción con catalizadores tipo pirrolidina, mejorando los resultados tanto en rendimientos como en enantioselectividades.

\section{REACCIONES DE oxo-HETERO-DIELS-ALDER ORGANOCATALÍTICAS}

La mayoría de las reacciones de oxo-hetero-Diels-Alder (oxo-HDA) organocatalíticas asimétricas descritas en los últimos años para la síntesis de heterociclos oxigenados de seis miembros se basan en procesos de catálisis orgánica por ácidos de Brønsted. En éstos, moléculas sintéticas quirales de bajo peso molecular, las cuales poseen uno o varios sitios activos para la formación de puentes de hidrógeno, actúan como catalizadores orgánicos activando el sustrato. ${ }^{140}$ Aunque la mayor parte del desarrollo en el campo de los enlaces de hidrógeno en catálisis asimétrica se ha materializado en los últimos seis años, este subcampo de la organocatálisis encuentra sus fundamentos en investigaciones realizadas en varias disciplinas durante las pasadas décadas. Por ejemplo, el estudio del mecanismo de acción de los enzimas puso de manifiesto la vital importancia de los enlaces de hidrógeno en la activación de electrófilos, ${ }^{141}$ a la vez que, simultáneamente, se descubrió que diversas moléculas aquirales que podían formar puentes de hidrógeno eran capaces de catalizar transformaciones orgánicas. ${ }^{142}$

Otro grupo menos extenso de reacciones oxo-HDA organocatalíticas para la síntesis de este tipo de heterociclos se basa en la catálisis orgánica por aminas quirales, las cuales actúan como bases de Lewis activando en algunos casos al dienófilo y en otros (los menos) al dieno.

\footnotetext{
138 (a) Rios, R.; Sundén, H.; Ibrahem, I.; Córdova, A. Tetrahedron Lett. 2007, 48, 2181; (b) Sundén, H.; Ibrahem, I.; Zhao, G- L.; Eriksson, L.; Córdova, A. Chem. Eur. J. 2007, 13, 574; (c) Ibrahem, I.; Sundén, H.; Rios, R.; Zhao, G- L.; Córdova, A. Chimia 2007, 61, 219.

${ }^{139}$ Li, H.; Wang, J.; E-Nunu, T.; Zu, L.; Jiang, W.; Wei, S.; Wang, W. Chem. Commun. 2007, 507.

${ }^{140}$ De la ref. 124u, ver el artículo: Doyle, A. G.; Jacobsen, E. N. Chem. Rev. 2007, 107, 5713.

141 (a) Fersht, A. Stucture and Mechanism in Protein Science; Freeman: New York, 1999; (b) Silverman, R. B. The Organic Chemistry of Enzyme-Catalyzed Reactions; Academic Press: San Diego, CA, 2002.

${ }_{142}$ (a) Hine, J.; Linden, S.-M.; Kanagasabapathy, V. M. J. Org. Chem. 1985, 50, 5096. (b) Hine, J.; Hahn, S.; Miles, D. E. J. Org. Chem. 1986, 51, 577.
} 


\section{1. oxo-HDA con activación por enlace de hidrógeno}

Rawal y col. observaron que los disolventes próticos como el 2-butanol aceleraban la reacción de oxo-HDA entre aldehídos desactivados y cetonas. ${ }^{143}$ A la vista de estos resultados, se comenzaron a introducir alcoholes quirales como catalizadores para así poder llevar a cabo la reacción de oxo-HDA de forma enantioselectiva.<smiles>CC1(C)O[C@@H](C(O)(Br)C(Br)(Br)Br)C(Br)(Br)O1</smiles>

$\operatorname{Ar}=$ 1-Naftilo :

TADDOL (CXLIX)

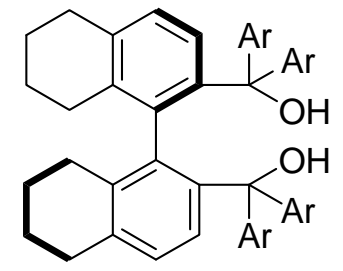

$\mathrm{Ar}=4-\mathrm{F}-3,5-\mathrm{Et}_{2} \mathrm{C}_{6} \mathrm{H}_{2}$ :

BAMOL (CL)

Figura 11

Los derivados de TADDOL ${ }^{144}$ (Figura 11, CXLIX) y dioles relacionados como el BAMOL $^{145}$ (Figura 11, CL) fueron los primeros catalizadores por enlace de hidrógeno que se introdujeron para la síntesis enantioselectiva de dihidropironas mediante reacción de oxo-HDA. El grupo de Rawal fue de nuevo el primero en describir una reacción de oxo-HDA enantioselectiva entre aminosililoxidienos y aldehídos catalizada por TADDOL. ${ }^{144 a}$ También se han utilizado otros tipos de dienos en estas transformaciones, como el 1,3-dimetoxi-1-(trimetilsililoxi)-butadieno (dieno de Brassard). Este sustrato ha sido utilizado por Ding et al. en la síntesis del producto natural (+)-dihidrokawaina (Esquema 77, CLI). ${ }^{144 \mathrm{~b}}$ Estos autores han propuesto un mecanismo para esta transformación en el que el grupo carbonilo del benzaldehído se activa mediante la formación de un enlace de hidrógeno intermolecular con uno de los grupos hidroxilo del TADDOL (Esquema 77$).{ }^{144 b, d}$

\footnotetext{
${ }^{143}$ (a) Huang, Y.; Rawal, V. H. Org. Lett. 2000, 2, 3321; (b) Huang, Y.; Rawal, V. H. J. Am. Chem. Soc. 2002, 124, 9662.

144 (a) Huang, Y.; Unni, A. K.; Thadani, A. N.; Rawal, V. H. Nature 2003, 424, 146; (b) Du, H.; Zhao, D.; Ding, K. Chem. Eur. J. 2004, 10, 5964. (c) Harriman, D. J.; Deslongchamps, G. J. Mol. Model. 2006, 12, 793; (d) Zhang, X.; Du, H.; Wang, Z.; Wu, Y.-D.; Ding, K. J. Org. Chem. 2006, 71, 2862.

${ }^{145}$ Unni, A. K.; Takenaka, N.; Yamamoto, H.; Rawal, V. H. J. Am. Chem. Soc. 2005, 127, 1336.
} 


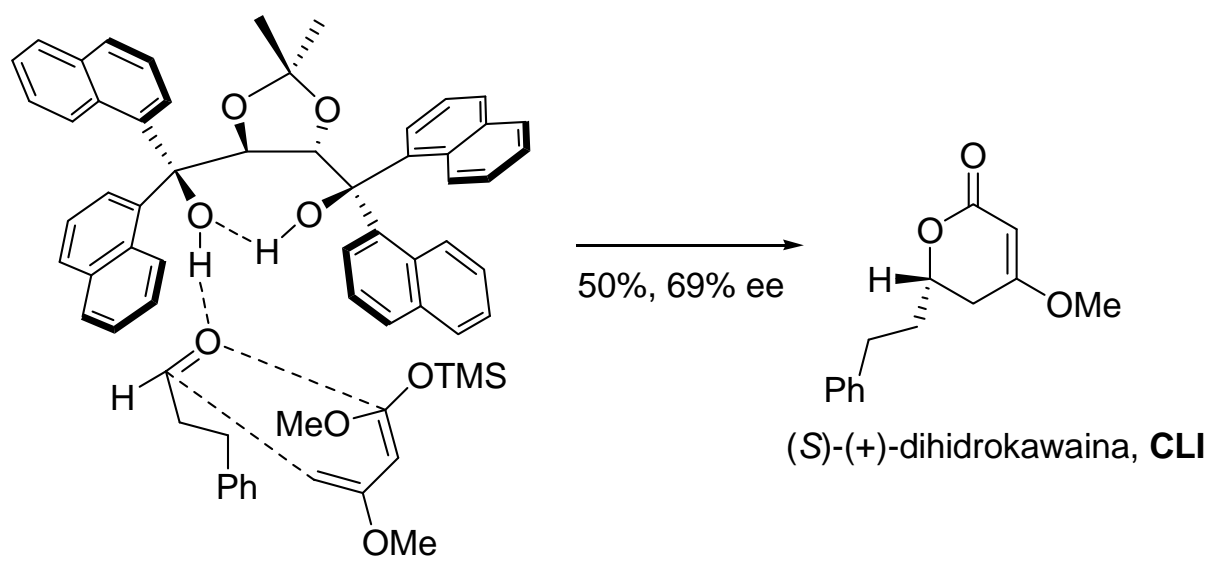

Esquema 77

A diferencia de este tipo de catalizadores, que activan al sustrato mediante un solo enlace de hidrógeno, también se han utilizado otro tipo de moléculas quirales bastante diferentes como catalizadores en reacciones de oxo-HDA enantioselectivas. Dichas moléculas, como la bis-triflilamida CLII y la sulfonamida CLIII (Figura 12), activan el sustrato mediante doble enlace de hidrógeno. ${ }^{146}$
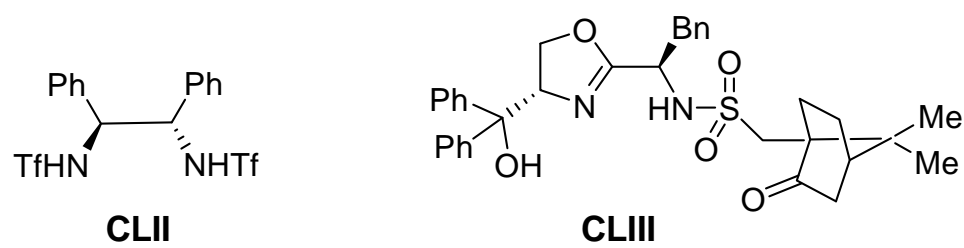

Figura 12

\section{2. oxo-HDA con activación por formación de enamina}

En 2003, Jørgensen describió la primera reacción de oxo-HDA enantioselectiva entre enaminas quirales, generadas a partir de aldehídos y pirrolidinas quirales, y enonas según el ciclo catalítico descrito en el Esquema $78 .{ }^{147}$ Esta reacción fue probada con varios aldehídos y enonas, consiguiéndose sintetizar hemiacetales con rendimientos en el rango 62-93\% y excesos enantioméricos en el rango 84-92\% utilizando (S)-2(Bis(3,5-dimetilfenil)metil)pirrolidina $\left(\mathrm{R}^{4}=\mathrm{CH}\left(3,5-\mathrm{Me}_{2}-\mathrm{C}_{6} \mathrm{H}_{3}\right)_{2}\right)$ como catalizador.

\footnotetext{
146 (a) Tonoi, T.; Mikami, K. Tetrahedron Lett. 2005, 46, 6355; (b) Rajaram, S.; Sigman, M. S. Org. Lett. 2005, 7, 5473.

${ }^{147}$ Juhl, K.; Jørgensen, K. A. Angew. Chem. Int. Ed. 2003, 42, 1498.
} 


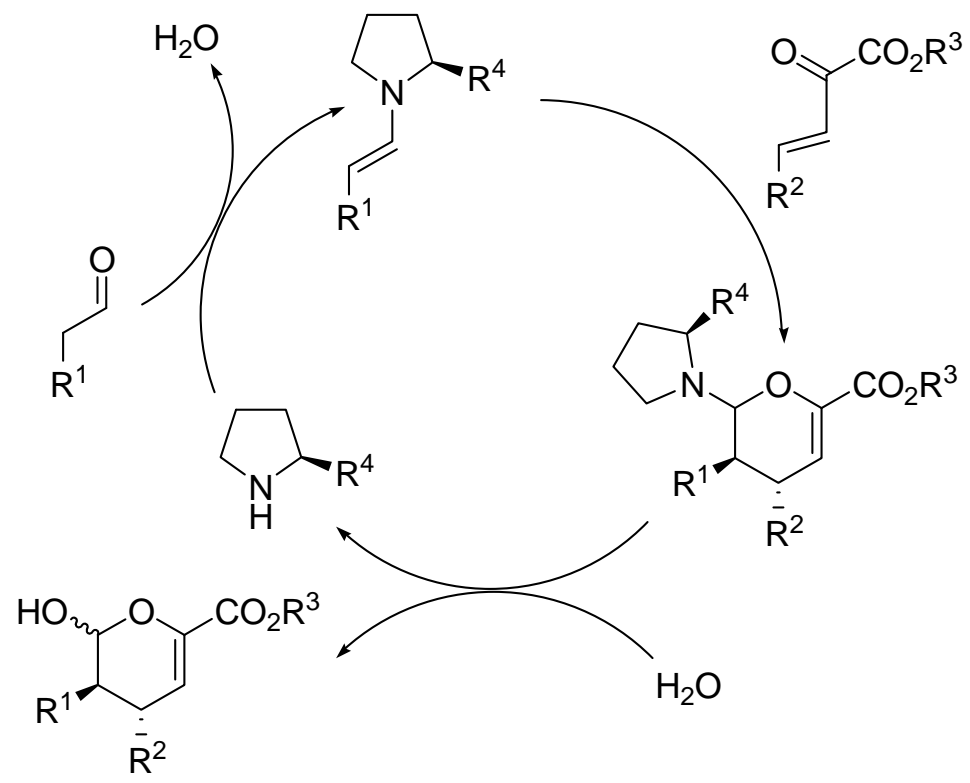

\section{Esquema 78}

Aparte de $\alpha$-cetoésteres $\beta, \gamma$-insaturados, también se han utilizado otro tipo de sustratos como dienos en reacciones de oxo-HDA organocatalíticas de demanda electrónica inversa. Zhao y col. describieron la reacción de oxo-HDA entre aldehídos enolizables y $\alpha$-cetofosfonatos $\beta, \gamma$-insaturados catalizada por derivados ditioacetálicos de L-prolinal. ${ }^{148}$

Otro ejemplo de reacción de oxo-HDA organocatalítica no asimétrica relacionado con los comentados anteriormente pero mecanísticamente diferente ha sido descrito muy recientemente por el grupo de Xiao. ${ }^{149}$ En este caso, el catalizador activa la enona (dieno) en lugar del aldehído (dienófilo), obteniéndose tetrahidropiran-4-onas (Esquema 79) con unos rendimientos moderados y excesos diastereoisoméricos de hasta $>95: 5$.

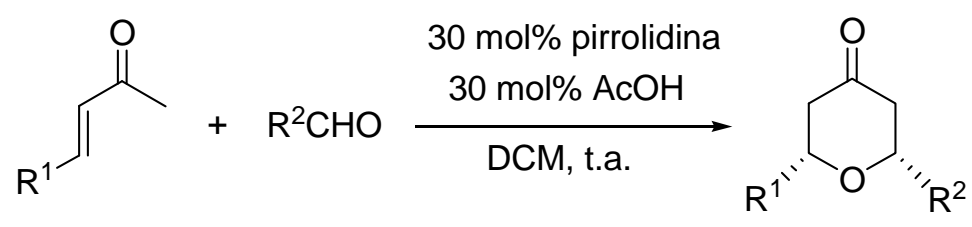

\section{Esquema 79}

\footnotetext{
${ }^{148}$ Samanta, S.; Krause, J.; Mandal, T.; Zhao, C.-G. Org. Lett. 2007, 9, 2745.

${ }^{149}$ Lu, L.-Q.; Xing, X.-N.; Wang, X.-F.; Ming, Z.-H.; Wang, H.-M.; Xiao, W.-J. Tetrahedron Lett. 2008, 49, 1631.
} 
Esta revisión bibliográfica da una idea de la importancia que tiene en química orgánica la obtención de anillos di- y tetrahidropiránicos, dada su presencia en infinidad de productos naturales. En los siguientes apartados de esta memoria, mostraremos nuestro trabajo en este campo de la síntesis. 

OBJETIVOS 

El presente trabajo está encuadrado dentro de los estudios realizados en nuestro grupo de investigación en los últimos años, centrados estos en la búsqueda de nuevas formas de síntesis estereoselectiva de tetrahidropiranos. Derivados de esta línea de investigación, en el presente estudio se han planteado dos objetivos principales que a su vez se subdividen en varios objetivos secundarios:

1. Síntesis de tetrahidropiranos cis-3-oxi-2,2,6,6-tetrasustituidos. Estudio de reacciones de ciclación.

Este apartado se subdivide en los siguientes objetivos secundarios:

Síntesis de los materiales de partida para el estudio de reacciones de yodociclación. Dichos sustratos comprenden tanto alcoholes alílicos como olefinas deficientes en electrones (nitrilos, aldehídos y ésteres $\alpha, \beta$ insaturados).

$\checkmark$ Preparación estereoselectiva de sistemas tetrahidropiránicos de 10 átomos de carbono mediante reacciones de yodociclación.

$\checkmark$ Preparación estereoselectiva de sistemas tetrahidropiránicos de 9 átomos de carbono mediante ciclación de $\delta$-hidroxiepóxidos y aplicación de éstos como catalizadores orgánicos en reacciones de epoxidación asimétrica.

\section{Síntesis organocatalítica de tetrahidropiranos.}

Este objetivo comprende la síntesis de nuevas pirrolidinas quirales para su utilización como catalizadores orgánicos en la síntesis organocatalítica enantioselectiva de tetrahidropiranos mediante reacciones oxo-Michael intramoleculares. 
Derivados de la metodología desarrollada en nuestro grupo de investigación para la síntesis de heterociclos oxigenados de cinco y seis miembros, se han planteado otros dos objetos de estudio en este trabajo:

Síntesis de ent-Sachalinol A, aprovechando la metodología llevada a cabo en nuestro grupo para la síntesis de nitrilos $\alpha, \beta$-insaturados.

$\checkmark$ Síntesis y aplicaciones de tetrahidrofuranos. 
DISCUSIÓN Y RESULTADOS 



\section{Capítulo 1: Síntesis y aplicaciones de tetrahidropiranos y tetrahidrofuranos}

\subsection{Síntesis de tetrahidropiranos 3-hidroxi-2,2,6,6-tetrasustituidos de 10 átomos de carbono}

\subsubsection{Antecedentes}

\subsubsection{Análisis retrosintético}

1.1.3. Procedimiento sintético: síntesis del tosilato intermedio $\mathbf{1 5}$

1.1.4. Síntesis de los sustratos para la reacción de yodociclación: alcoholes alílicos y olefinas deficientes en electrones (nitrilos, aldehídos y ésteres)

1.1.4.a. Síntesis de olefinas deficientes en electrones: obtención de los nitrilos $\alpha, \beta$-insaturados 19 y 20

1.1.4.b. Síntesis de olefinas deficientes en electrones : obtención de los aldehídos $\alpha, \beta$-insaturados 21 y 22

1.1.4.c. Síntesis de olefinas deficientes en electrones: obtención de los ésteres $\alpha, \beta$-insaturados 26, 27, 30 у 31

1.1.4.d. Síntesis de los alcoholes alílicos 32 y 33

1.1.5. Estudio de la reacción de yodociclación de los alcoholes alílicos 32 y 33

1.1.6. Estudio de las reacciones de yodociclación de olefinas deficientes en electrones

1.1.6.a. Yodociclación de los nitrilos $\alpha, \beta$-insaturados 19 y 20

1.1.6.b. Yodociclación de aldehídos $\alpha, \beta$-insaturados 21 y 22

1.1.7. Uso de los nitrilos en síntesis: Síntesis de ent- Sachalinol A

\subsection{Síntesis y aplicaciones de tetrahidrofuranos}

1.2.1. Síntesis de los tetrahidrofuranil-dioxolanos $\mathbf{5 4}$ y $\mathbf{5 8}$

1.2.2. Extracción de picratos

1.2.3. Estudios de modelización molecular 

1.3. Síntesis y aplicaciones de tetrahidropiranos 3-hidroxi-2,2,6,6-tetrasustituidos de 9 átomos de carbono

\subsubsection{Antecedentes}

1.3.2. Síntesis de los aldehídos 68 y 69 como catalizadores orgánicos para epoxidaciones asimétricas

\section{Capítulo 2: Organocatálisis aplicada a la síntesis de tetrahidropiranos}

\subsection{Síntesis de pirrolidinas quirales como catalizadores orgánicos}

2.1.1. Importancia de los catalizadores tipo pirrolidina

2.1.2. Síntesis de los análogos de prolina 84 y 88

\subsection{Síntesis organocatalítica de tetrahidropiranos}

2.2.1. Síntesis del sustrato $\mathbf{1 0 3}$ para la reacción de ciclación organocatalítica

2.2.2. Optimización de las condiciones de ciclación organocatalítica con el sustrato 103

2.2.3. Estudios de modelización molecular

2.2.4. Síntesis de los sustratos 129 y 141 y posterior utilización en la reacción de ciclación organocatalítica bajo condiciones de reacción optimizadas 

Capítulo 1: Síntesis y aplicaciones de tetrahidropiranos

y tetrahidrofuranos 



\subsection{SÍNTESIS DE TETRAHIDROPIRANOS 3-HIDROXI-2,2,6,6- TETRASUSTITUIDOS DE 10 ÁTOMOS DE CARBONO}

\subsubsection{Antecedentes}

En estudios precedentes de nuestro grupo de investigación, se consiguió sintetizar el compuesto (2S,3S)-2-Yodometil-2,6,6-trimetiltetrahidropiran-3-ol 2 de forma totalmente estereoselectiva a partir del diol $1,{ }^{150}$ sin embargo, todos los intentos de extender la cadena lateral fueron infructuosos. Así pues, como nuestro interés se centraba en la síntesis enantioselectiva de tetrahidropiranos cis-3-hidroxi-2,2,6,6tetrasustituídos que pudieran ser usados como sintones de importantes productos naturales, se decidió llevar a cabo la reacción de yodociclación en sustratos más complicados y estudiar la estereoselección de la reacción.

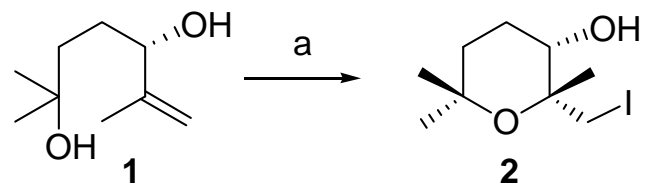

Esquema 80. a) $\mathrm{I}_{2}, \mathrm{NaHCO}_{3}, \mathrm{MeCN}, 0{ }^{\circ} \mathrm{C}, 99 \%$.

\subsubsection{Análisis retrosintético}

Para la obtención de tetrahidropiranos tipo CLIV de diez átomos de carbono, planteamos el esquema retrosintético mostrado a continuación (Esquema 81). Los compuestos CLV se podrán obtener fácilmente mediante una reacción de yodociclación de las correspondientes $\delta$-hidroxiolefinas CLVI, obtenidas a partir del epoxinitrilo CLVII por desprotonación en posición $\alpha$ al nitrilo y apertura del epóxido. Dicho epoxinitrilo CLVII procede a su vez del tosilato 15, para cuya obtención hay desarrollada una ruta sintética en nuestro grupo de trabajo. ${ }^{150}$

\footnotetext{
${ }^{150}$ Diez, D.; Marcos, I. S.; Basabe, P.; Romero, R. E.; Moro, R. F.; Lumeras, W.; Rodriguez, L.; Urones, J. G. Synthesis 2001, 1013.
} 


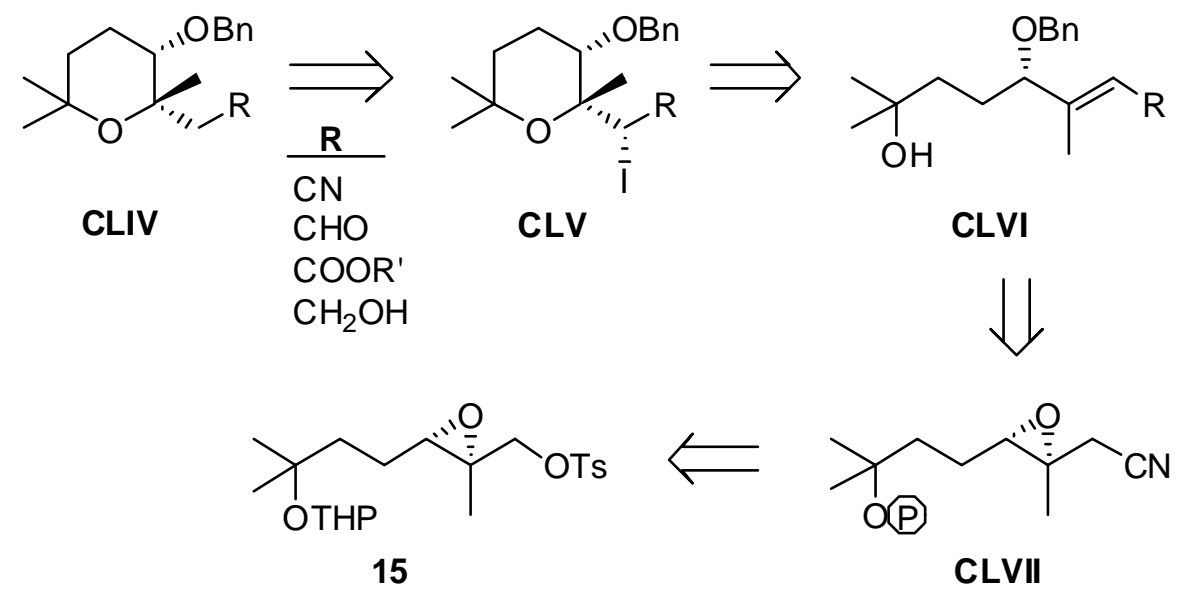

Esquema 81

\subsubsection{Procedimiento sintético: síntesis del tosilato intermedio 15}

La síntesis del tosilato 15, intermedio común en la síntesis de los materiales de partida para el estudio de reacciones de yodociclación en sustratos tipo CLVI (Esquema 81), se lleva a cabo a partir de productos comerciales como acetona y alcohol propargílico protegido en forma de su tetrahidropiranilderivado $\mathbf{3}$, tal como se muestra en el siguiente esquema de reacciones (Esquema 82).

La adición del acetiluro de litio de $\mathbf{3}$ a acetona ${ }^{151}$ conduce al alcohol $\mathbf{4}$, el cual se somete a una hidrogenación a presión atmosférica utilizando Pd sobre carbono como catalizador, ${ }^{152}$ obteniéndose el producto saturado 5. Posteriormente se desprotege éste con $p$-TsOH en $\mathrm{MeOH},{ }^{153}$ lo que conduce al diol hidrosoluble $\mathbf{6}$, cuya oxidación con PDC en $\mathrm{DMF}^{154}$ da la lactona volátil 7 con buen rendimiento. La reducción de dicha lactona con DIBAL-H ${ }^{155}$ lleva al lactol 8 , el cual se somete a una reacción de olefinación de Wittig con (carbetoxietiliden)trifenilfosforano. ${ }^{156}$

${ }^{151}$ Díez, D.; Kotecha, N.; Ley, S.V.; Montegani, S.; Menéndez, J. C.; Organ, E.; White, A. Tetrahedron 1992, 48, 7899.

152 (a) Rylander, P. N. Hydrogenation Methods; Academic Press, New York, 1985; (b) Marvell, E. N.; Li, T. Synthesis 1973, 457; (c) McEwen, A. B.; Guttieri, M. J.; Maier, W. F. J. Org. Chem. 1986, 601.

153 Greene, T.W.; Wuts, P. G. M. Protective Groups in Organic Chemistry, $3^{\text {a }}$ Edición, John Wiley \& Sons: New York, 1999.

${ }^{154}$ (a) Corey, E. J.; Schmidt, G. Tetrahedron 1979, 399; (b) Czernecki, S.; Georgoulis, C.; Stevens, C. L.; Vijayakumaran, K. Tetrahedron Lett. 1985, 26, 1699.

155 (a) Daniewsky, A. R.; Wojceichowska, W. J. Org. Chem. 1982, 47, 2993; (b) Vidari, G.; Ferrino, S.; Grieco, P. A. J. Am. Chem. Soc. 1984, 106, 3539.

${ }^{156}$ Guanti, G.; Banfi, L.; Ghiron, C.; Narisano, E. Tetrahedron Lett. 1991, 32, 267. 
De esta última reacción se obtiene mayoritariamente el éster $\alpha, \beta$-insaturado 9 , con estereoquímica $E$ del doble enlace. Se detecta también una pequeña proporción (4\%) del isómero $Z$ mediante ${ }^{1} \mathrm{H}$ RMN $\mathrm{y}$, aunque en este paso ambos isómeros son inseparables por cromatografía en columna sobre sílicagel, más adelante se consigue aislar el isómero $Z$ de un derivado (14 en Esquema 82). Con el fin de evitar ciclaciones indeseadas, se protege el hidroxilo terciario de 9 por reacción de éste con DHP y PPTS como catalizador para obtener el éster 10, el cual se reduce con DIBAL-H consiguiéndose el alcohol alílico 11 con buen rendimiento (Esquema 82).

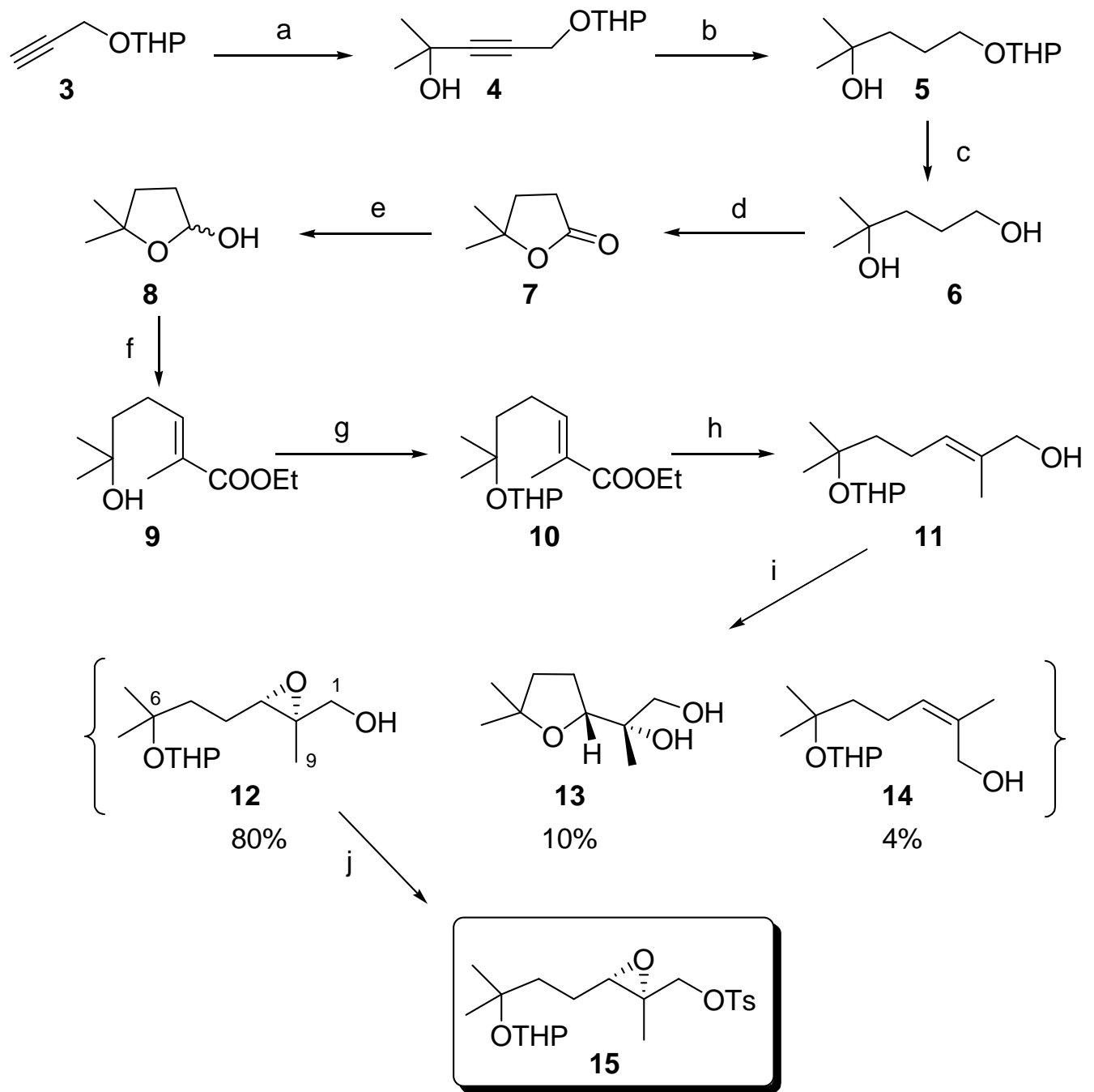

Esquema 82. a) $n$-BuLi, THF, $-20^{\circ} \mathrm{C}$; luego acetona, $-78^{\circ} \mathrm{C}, 98 \%$; b) $\mathrm{H}_{2}, \mathrm{Pd} / \mathrm{C}, \mathrm{AcOEt}, 88 \%$; c) $p$ - $\mathrm{TsOH}$, $\mathrm{MeOH}, 70 \%$; d) PDC, DMF, 94\%; e) DIBAL-H, DCM, $-78^{\circ} \mathrm{C}, 99 \%$; f) $\mathrm{Ph}_{3} \mathrm{P}(\mathrm{C})\left(\mathrm{CH}_{3}\right) \mathrm{COOEt}, \mathrm{C}_{6} \mathrm{H}_{6}, 75 \%$; g) DHP, PPTS, DCM, 93\%; h) DIBAL-H, DCM, $-78^{\circ} \mathrm{C}, 91 \%$; i) L-(+)-DET, Ti( $\left.{ }^{i} \mathrm{OPr}\right)_{4}, \mathrm{TBHP}, \mathrm{DCM}$, $-23^{\circ} \mathrm{C}, 94 \%$; j) $\mathrm{TsCl}, \mathrm{Pi}, 0^{\circ} \mathrm{C}, 82 \%$. 
Una vez obtenido el alcohol alílico 11, se lleva a cabo la reacción de epoxidación enantioselectiva de Sharpless empleando L-(+)-DET. ${ }^{157}$ El exceso enantiomérico (ee) del producto de esta reacción ya había sido determinado previamente en nuestro grupo de investigación ${ }^{158}$ por formación de los ésteres de Mosher ${ }^{159}$ del epoxialcohol 12 y de la mezcla racémica, obtenida al epoxidar el alcohol alílico 11 con $m$-CPBA. En el espectro de RMN ${ }^{1} \mathrm{H}$ del éster de Mosher de 12 no se aprecian las señales desdobladas del metileno sobre C-1 de los ésteres diastereoisoméricos. Sin embargo, en el éster de Mosher de la mezcla racémica sí se observan las señales de los dos diastereoisómeros, con lo que se comprueba que el compuesto $\mathbf{1 2}$ se ha obtenido con un ee $>98 \%$.

Al eliminar las sales de titanio formadas en esta reacción por tratamiento con una disolución acuosa de ácido tartárico (10\%), se produce la desprotección parcial del hidroxilo terciario de $\mathbf{1 2}$, con la consiguiente ciclación hasta el tetrahidrofurano $\mathbf{1 3}{ }^{160}$ En esta reacción se recupera el alcohol alílico 14, con estereoquímica $Z$, debido a su epoxidación más lenta. El tratamiento del epoxialcohol 12 con $\mathrm{TsCl}$ en piridina ${ }^{161}$ conduce al tosilderivado $\mathbf{1 5 .}$

El bloqueo del hidroxilo terciario de 9 es absolutamente necesario, ya que si se lleva a cabo la reacción de epoxidación de Sharpless sobre el diol resultante de la reducción del éster 9 con DIBAL-H, se produce la apertura del epóxido formado, dando exclusivamente el tetrahidrofurano $\mathbf{1 3} .{ }^{160}$

\footnotetext{
157 (a) Katsuki, T.; Sharpless, K. B. J. Am. Chem. Soc. 1980, 102, 5974; (b) Gao, Y.; Hanson, R. M.; Klunder, J. M.; Ko, S. Y.; Masamune, H.; Sharpless, K. B. J. Am. Chem. Soc. 1987, 109, 5765.

${ }^{158}$ Lumeras Amador, W. Tesis Doctoral: Estudio de reacciones de ciclación para la obtención de tetrahidropiranos 2,2,6,6-tetrasustituidos. Síntesis de octahidropirano[3,2-b]piranos. Universidad de Salamanca, 2000.

${ }^{159}$ Dale, J. A.; Mosher, H. S. J. Am. Chem. Soc. 1973, 95, 512.

${ }^{160}$ García, C.; Soler, M. A.; Martín, V. S. Tetrahedron Lett. 2000, 41, 4127.

${ }^{161}$ Mori, K.; Ueda, H. Tetrahedron 1983, 37, 2581.
} 


\subsubsection{Síntesis de los sustratos para la reacción de yodociclación: alcoholes alílicos y olefinas deficientes en electrones (nitrilos, aldehídos y ésteres)}

\subsection{4.a. Síntesis de olefinas deficientes en electrones: obtención de los nitrilos $\alpha, \beta$-insaturados 19 y 20}

Una vez obtenido el tosilato $\mathbf{1 5}$ se procede a la síntesis de los diferentes nitrilos $\alpha, \beta$-insaturados según se indica a continuación (Esquema 83).

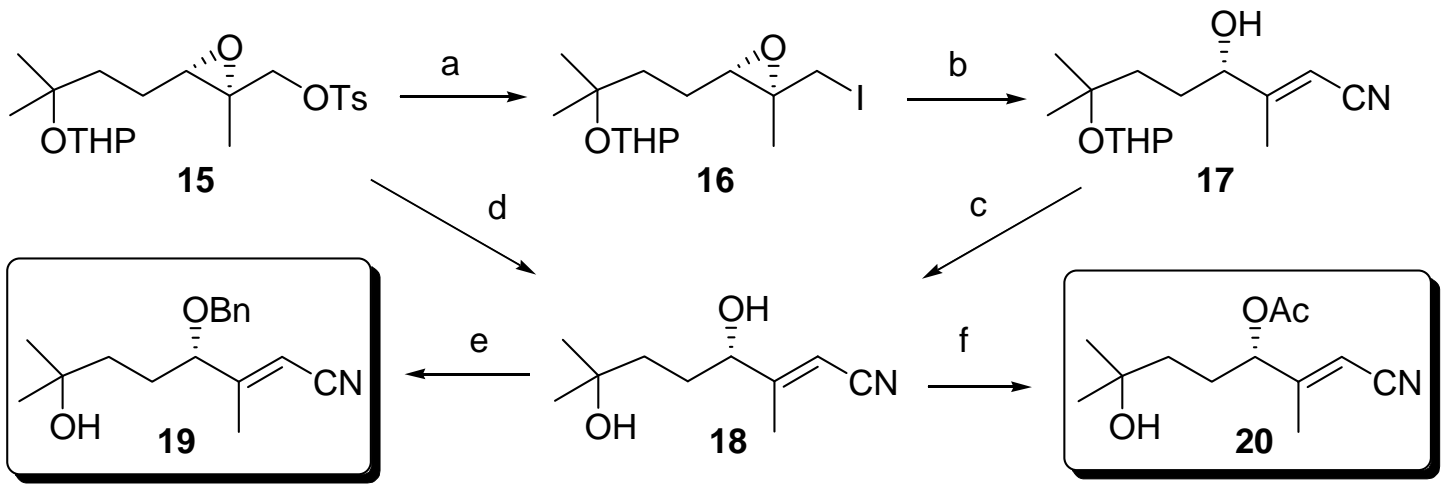

Esquema 83. a) $\mathrm{NaI}$, acetona, reflujo, $85 \%$; b) $\mathrm{KCN}$, 18-corona-6, $\mathrm{CH}_{3} \mathrm{CN}$, reflujo, 33\%; c) $p$ - $\mathrm{TsOH}$, $\mathrm{MeOH}, 81 \%$; d) 1. NaCN, HMPA; 2. p-TsOH, MeOH, 81\%; e) NaH, BnBr, TBAI, THF, 77\%; f) $\mathrm{Ac}_{2} \mathrm{O}$, $\mathrm{Pi}, 78 \%$.

El tratamiento de 15 con $\mathrm{NaI}$ en acetona conduce al yododerivado $16,{ }^{161}$ el cual se trata con $\mathrm{KCN}$ en presencia del éter 18-corona-6, obteniéndose el nitrilo $\alpha, \beta$ insaturado 17 con rendimiento moderado. La desprotección de éste con ácido $p$-TsOH conduce al diol 18. ${ }^{153}$

Como se observa, en la conversión de $\mathbf{1 6}$ en $\mathbf{1 7}$ no sólo se produce la sustitución nucleofílica del átomo de yodo por cianuro, sino que también tiene lugar la desprotonación en la posición $\alpha$ con respecto al nitrilo, con la consiguiente apertura del epóxido. Esta reacción de eliminación transcurre con una alta diastereoselectividad, pues sólo se detecta el diastereoisómero $E$ como puede deducirse de la existencia en el espectro de ${ }^{13} \mathrm{C}$ RMN de una señal correspondiente a un metilo sobre doble enlace a $\delta=17.71$ ppm. $^{162}$

\footnotetext{
${ }^{162}$ Breitmaier, E.; Voelter, W. ${ }^{13}$ C NMR Spectroscopy. Methods and Applications in Organic Chemistry,
} $3^{\text {a }}$ Edición, Verlag Chemie, Weinheim-New York 1987. 
Dado que el rendimiento en la obtención del nitrilo $\alpha, \beta$-insaturado $\mathbf{1 8}$ por el método descrito anteriormente no era demasiado satisfactorio, se decidió tratar el tosilato 15 con $\mathrm{NaCN}$ en HMPA, produciéndose como en el caso anterior la sustitución por cianuro y la eliminación en posición $\alpha$, dando de nuevo el compuesto 17 , que no es necesario aislar. El tratamiento de la mezcla de reacción con ácido p-TsOH en $\mathrm{MeOH}$ conduce al diol 18 con un $81 \%$ de rendimiento desde 15, mejorando así los resultados anteriores. Para evitar interferencias del hidroxilo secundario de $\mathbf{1 8}$ en posteriores reacciones de ciclación, se protege éste selectivamente. Así, por tratamiento de $\mathbf{1 8}$ con $\mathrm{NaH}$ en THF seguido de $\mathrm{BnBr}$ se obtiene el bencilderivado 19 con buen rendimiento. ${ }^{153}$ También se protege en forma de monoacetato por tratamiento con anhídrido acético en piridina, obteniéndose el hidroxiacetato 20 (Esquema 83).

\subsection{4.b. Síntesis de olefinas deficientes en electrones : obtención de los aldehídos $\alpha, \beta$-insaturados 21 y 22}

El nitrilo 19 se reduce con DIBAL-H a baja temperatura, obteniéndose la mezcla de aldehídos diastereoisómeros $\mathbf{2 1}$ y 22 en relación 15:85, separables por cromatografía en columna sobre sílicagel (Esquema 84).
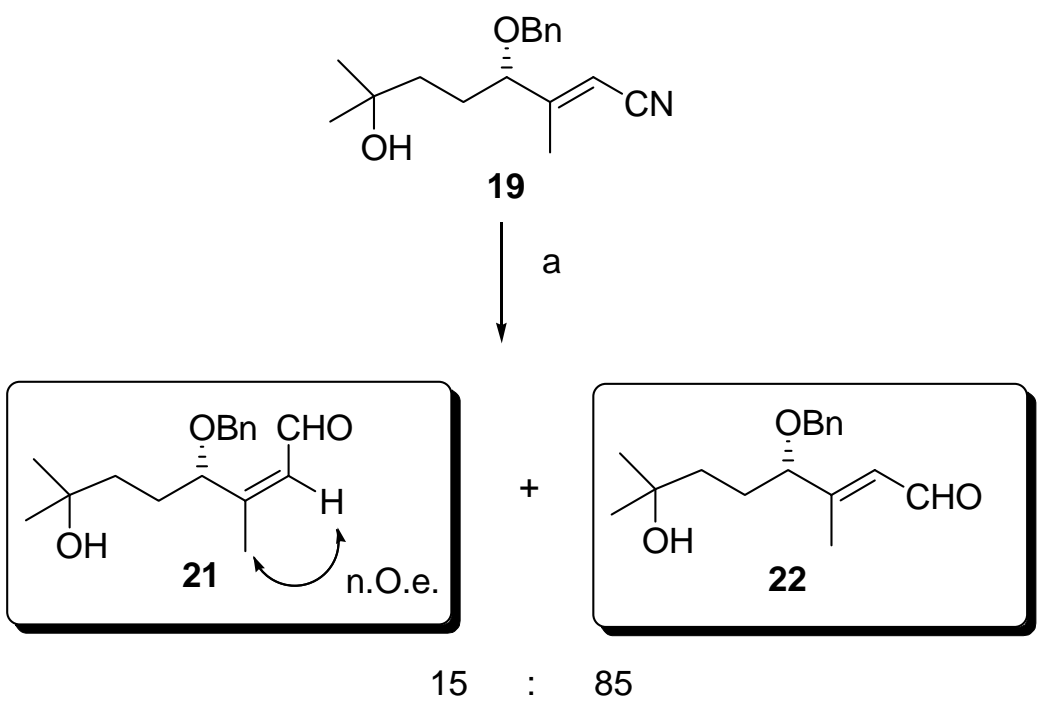

Esquema 84. a) DIBAL-H, DCM, $-78^{\circ} \mathrm{C}, 67 \%$. 
La estereoquímica de $\mathbf{2 1}$ y $\mathbf{2 2}$ se determina por comparación del desplazamiento químico de los metilos sobre doble enlace en sus espectros de ${ }^{13} \mathrm{C}$ RMN, a 19.19 y 12.90 ppm respectivamente, con los de otros compuestos de estereoquímica conocida. ${ }^{163}$ Asimismo, se corrobora por la presencia de nOe en $\mathbf{2 1}$ entre el metilo sobre doble enlace y el hidrógeno olefínico.

\subsection{4.c. Síntesis de olefinas deficientes en electrones: obtención de los ésteres $\alpha, \beta$-insaturados 26, 27, 30 y 31}

A partir del tosilato $\mathbf{1 5}$, por tratamiento de éste con $\mathrm{KI}, \mathrm{I}_{2} \mathrm{y} \mathrm{PPh}_{3}{ }^{164}$ se obtiene una mezcla de los alcoholes alílicos 23 y 1 separables por cromatografía en columna sobre sílicagel. El compuesto $\mathbf{2 3}$ se puede transformar en el diol $\mathbf{1}$ mediante desprotección en las condiciones habituales. ${ }^{153}$ Asimismo, se puede obtener el diol 1 por tratamiento del yododerivado 16, obtenido previamente, con $\mathrm{Zn}$ y AcOH${ }^{161} \mathrm{La}$ mezcla de reacción se trata directamente con $p-\mathrm{TsOH}$ en $\mathrm{MeOH}$ para dar el diol $\mathbf{1}$ con buen rendimiento (Esquema 85).

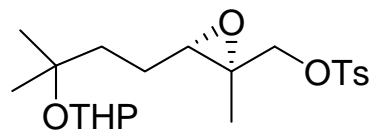

15
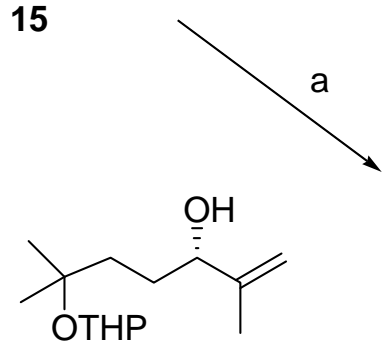

23

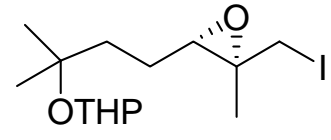

16
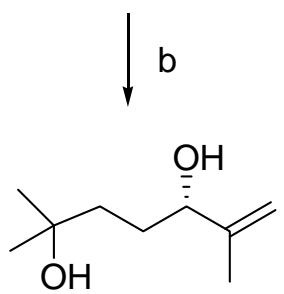

1

Esquema 85. a) KI, $\mathrm{I}_{2}, \mathrm{PPh}_{3}$, acetona/DMF, 55\%; b) 1. $\mathrm{Zn}, \mathrm{AcOH}$; 2. p-TsOH, MeOH, 63\%; c) p-TsOH, $\mathrm{MeOH}, 94 \%$.

163 Urones, J. G.; De Pascual Teresa, J.; Sánchez Marcos, I.; Díez Martín, D.; Martín Garrido, N.; Alfayate Guerra, R. Phytochemistry 1987, 26, 1077

${ }^{164}$ Fujii, N.; Habashita, H.; Akaji, M.; Nakai, K.; Ibuka, T.; Fijiwara, M.; Tamamura, H.; Yamamoto, Y.

J. Chem. Soc., Perkin Trans. 1, 1996, 865. 
La ozonolisis del alcohol $\mathbf{2 3}$ conduce a la correspondiente cetona $\mathbf{2 4}$ con un rendimiento del 40\% (Esquema 86). Cuando ésta se hace reaccionar con (carbetoximetilen)trifenilfosforano, no se obtienen los ésteres $\alpha, \beta$-insaturados deseados, por lo que se decide realizar la ozonolisis con el diol 1 (Esquema 87).

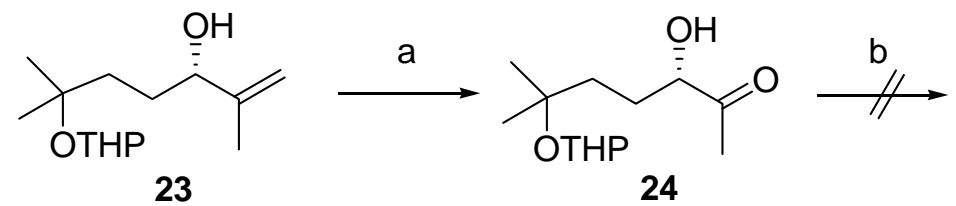

Esquema 86. a) $\mathrm{O}_{3}$, DCM, $-78^{\circ} \mathrm{C}, 40 \%$; b) $\mathrm{PH}_{3} \mathrm{P}(\mathrm{CH}) \mathrm{COOEt}$, DCM/MeOH, LiI.

Al someter a ozonolisis el diol $\mathbf{1}$, se obtiene la cetona $\mathbf{2 5}$, la cual se trata con el fosfonato $(\mathrm{EtO})_{2} \mathrm{P}(\mathrm{O}) \mathrm{CH}_{2} \mathrm{COOMe}$ (Horner-Emmons), ${ }^{165}$ aislándose una pequeña cantidad de los ésteres $\alpha, \beta$-insaturados 26 y 27, pero con muy bajo rendimiento (Esquema 87). Debido a este resultado, se decide proteger selectivamente el hidroxilo secundario de 1 antes de la reacción de ozonolisis. Así, por tratamiento con $\mathrm{NaH}$ y $\mathrm{BnBr}$ se obtiene el bencilderivado $\mathbf{2 8}$ con un $67 \%$ de rendimiento. Posteriormente este compuesto se ozonoliza, produciéndose la correspondiente cetona 29 con un $50 \%$ de rendimiento. También se obtiene este compuesto sometiendo 28 a ruptura oxidativa con $\mathrm{OsO}_{4} \mathrm{y} \mathrm{NaIO}_{4},{ }^{166}$ con lo que aumenta el rendimiento hasta el 70\%. Al tratar la cetona 29 con el reactivo de Wittig (carbetoximetiliden)trifenilfosforano, como sucedía anteriormente con la cetona $\mathbf{2 4}$, no se obtienen los ésteres deseados, por lo que se decide someterla a las condiciones de Horner-Emmons. En este caso se obtiene la mezcla de ésteres $\alpha, \beta$-insaturados 30 y 31 , inseparables por cromatografía en columna sobre sílicagel, en una relación 3:1. Su estereoquímica se determina por el distinto desplazamiento del grupo metilo sobre el doble enlace en el espectro de ${ }^{1} \mathrm{H}$ RMN, siendo de 2.14 ppm para el isómero $E$ y 1.91 ppm para el isómero $Z$ (Esquema 87).

\footnotetext{
${ }^{165}$ Boons G.- J.; Brown D. S.; Clase J. A.; Lennon I. C.; Ley S.V. Tetrahedron Letters 1994, 35, 319.

${ }^{166}$ Hubbs, J. L.; Heathcock, C. H. J. Am. Chem. Soc. 2003, 125, 12836.
} 


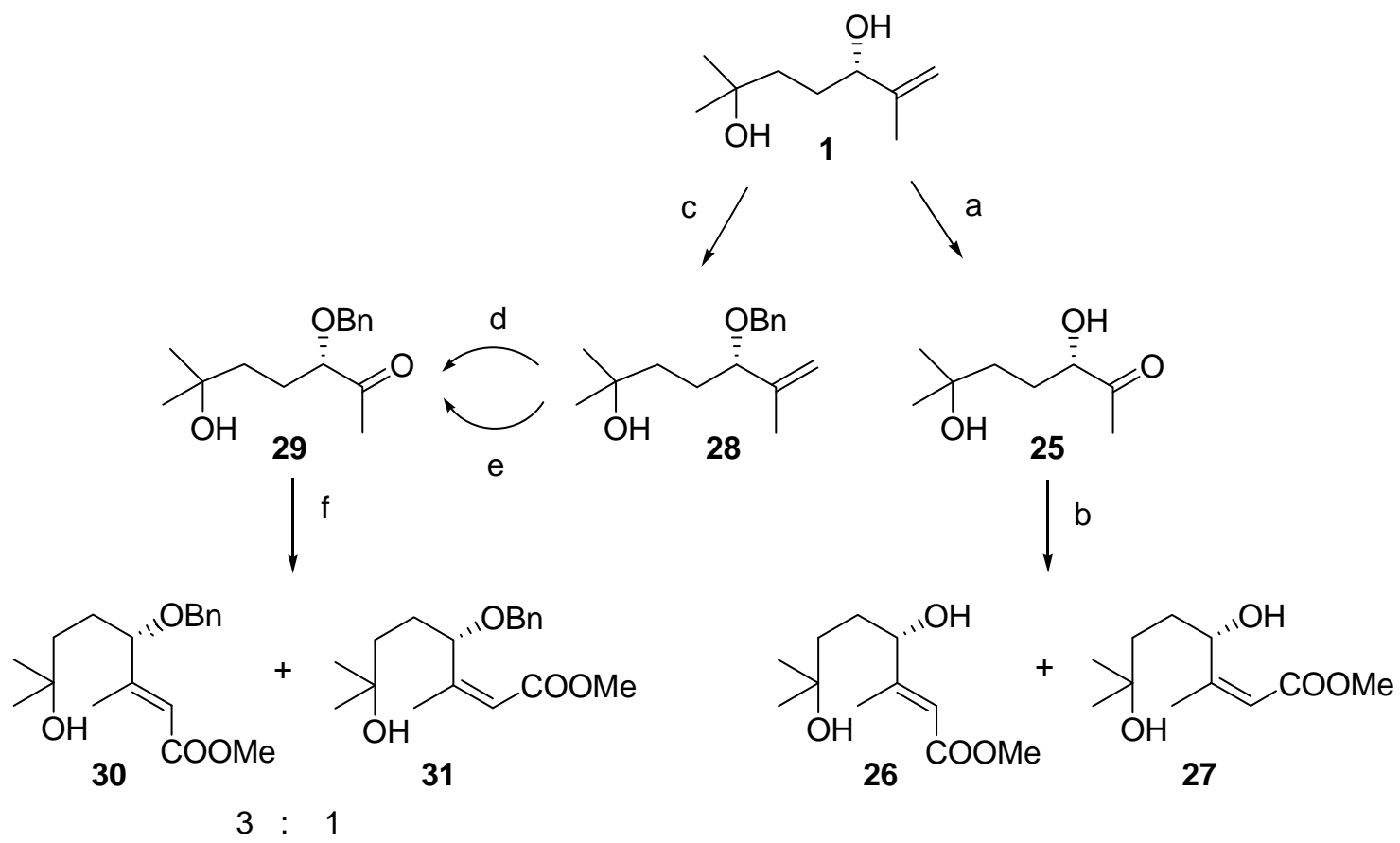

Esquema 87. a) $\mathrm{O}_{3}, \mathrm{DCM},-78^{\circ} \mathrm{C}$; b) $(\mathrm{EtO})_{2} \mathrm{P}(\mathrm{O}) \mathrm{CH}_{2} \mathrm{COOMe}, \mathrm{NaH}$, THF, $10 \%$ en 2 pasos; c) $\mathrm{NaH}$, $\mathrm{BnBr}$, THF, 67\%; d) $\mathrm{O}_{3}, \mathrm{DCM},-78^{\circ} \mathrm{C}, 50 \%$; e) $\mathrm{OsO}_{4} / \mathrm{NaIO}_{4}, \mathrm{THF} / \mathrm{H}_{2} \mathrm{O}, 70 \%$; f) $\mathrm{PH}_{3} \mathrm{P}(\mathrm{CH}) \mathrm{COOEt}$, $\mathrm{DCM} / \mathrm{MeOH}$, LiI, $54 \%$.

Como nuestro objetivo es llevar a cabo la reacción de yodociclación en olefinas deficientes en electrones viendo la influencia de la estereoquímica del sustrato en la estereoselección del proceso, y al no haber conseguido ninguno de los ésteres $\alpha, \beta$ insaturados como diastereoisómeros puros con buenos rendimientos, se decide abandonar este tipo de sustratos. 


\subsection{4.d. Síntesis de los alcoholes alílicos 32 y 33}

Al tratar separadamente los aldehídos $\alpha, \beta$-insaturados 21 y 22 con DIBAL-H, se obtienen respectivamente los alcoholes alílicos $\mathbf{3 2}$ y $\mathbf{3 3}$ con buen rendimiento (Esquema $88)$.<smiles>C/C(=C/C=O)[C@H](Br)CCC(C)(C)O</smiles>

21

a $\downarrow 78 \%$

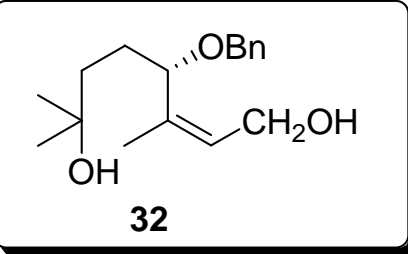<smiles>CC1(C)CC[C@@H](Br)/C(=C\C=O)C1(C)O</smiles>

22

$\mathrm{a} \downarrow 80 \%$

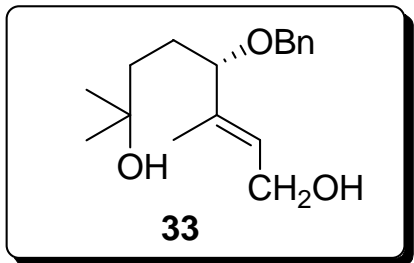

Esquema 88. a) DIBAL-H, DCM, $-78^{\circ} \mathrm{C}$.

Una vez obtenidos los diferentes materiales de partida, en los apartados siguientes pasaremos a estudiar las reacciones de yodociclación de dichos sustratos, en primer lugar los alcoholes alílicos $\mathbf{3 2}$ y $\mathbf{3 3}$ y en segundo lugar las olefinas deficientes en electrones, es decir, los nitrilos 19 y 20 y aldehídos 21 y 22. 


\subsubsection{Estudio de la reacción de yodociclación de los alcoholes alílicos 32 y $\mathbf{3 3}^{167}$}

Al someter el alcohol 33 a condiciones de yodociclación cinética, ${ }^{168}$ se obtuvieron los tetrahidropiranos $\mathbf{3 4}$ y $\mathbf{3 5}$ en una relación 93:7 con buen rendimiento (Esquema 89). Cuando el alcohol 32 se sometió a las mismas condiciones de yodociclación, se obtuvieron los tetrahidropiranos 36 y 37 sin apenas estereoselección (relación 9:10, Esquema 89). En ninguno de los dos casos se detectó la presencia de oxepanos procedentes del proceso de ciclación 7-endo.<smiles>C/C(=C\CO)[C@H](CCC(C)(C)O)OCc1ccccc1</smiles><smiles>C/C(=C/CO)[C@H](CCC(C)(C)O)OCBr</smiles>

32<smiles>CC1(C)CC[C@@H](OCc2ccccc2)[C@](C)(C(I)CO)O1</smiles>

93<smiles>CC1(C)CC[C@@H](Br)[C@H](C(I)CO)O1</smiles>

7<smiles>CC1(C)CC[C@@H](Br)[C@@](C(I)CO)([C@H](I)CO)O1</smiles>
37

$$
9: 10
$$

Esquema 89. a) $\mathrm{I}_{2}, \mathrm{NaHCO}_{3}, \mathrm{CH}_{3} \mathrm{CN}, 0{ }^{\circ} \mathrm{C}$.

La determinación de la estereoquímica de los compuestos obtenidos se llevó a cabo según se detalla a continuación (Esquema 90). El tetrahidropirano 34 se redujo con $\mathrm{Bu}_{3} \mathrm{SnH}$ y $\mathrm{AIBN}^{169}$ hasta el alcohol 38, en cuyo espectro de ${ }^{1} \mathrm{H}-\mathrm{RMN}$ sus tres metilos aparecen como singletes, descartando así la estructura oxepánica para este compuesto. Al oxidar el alcohol 38 en las condiciones de $\operatorname{Swern}^{170}$ se obtiene el aldehído 39 con un $95 \%$ de rendimiento, el cual se oxida espontáneamente, en 24 horas, con el oxígeno atmosférico hasta el ácido 40. Cuando se somete dicho ácido a una hidrogenolisis con

\footnotetext{
${ }^{167}$ Díez, D.; Nuñez, M. G.; Moro, R. F.; Lumeras, W.; Marcos, I. S.; Basabe, P.; Urones, J. G. Synlett, 2006, 939 .

${ }^{168}$ Barks, J. M.; Knight, D.W.; Seaman, C. J.; Weingarten, G. G. Tetrahedron Lett. 1994, 35, 7259.

169 White, J. D.; Mitchell, A. A.; Choudhry, S. C.; Dhingra, O. P.; Gray, B. D.; Kang, M.; Kuo, S.; Whittle, A. J. J. Am. Chem. Soc. 1989, 111, 790.

${ }^{170}$ (a) Mancuso, A. J.; Huang, S.; Swern, D. J. Org. Chem. 1978, 43, 2480; (b) Mancuso, A. J.; Huang, S.; Swern, D. Synthesis 1981, 165.
} 
$\mathrm{H}_{2} / \mathrm{Pd}$ para desproteger el hidroxilo sobre C-3, se produce la $\gamma$-lactona $41,{ }^{171}$ que presenta nOe entre el metilo en posición 2 y el hidrógeno en posición 3. Así pues, 34 tiene una configuración absoluta $R$ en $\mathrm{C}-2$.

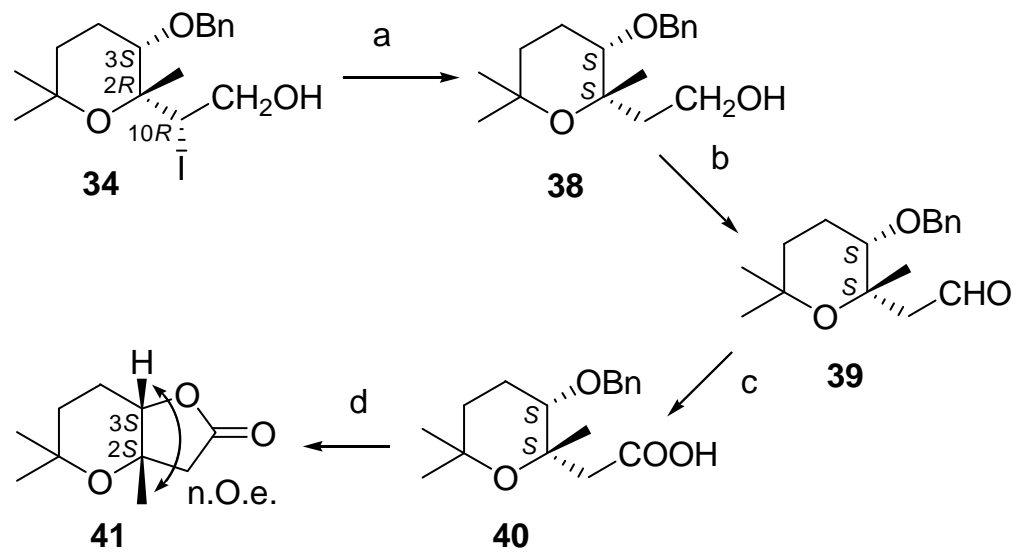

Esquema 90. a) $\mathrm{Bu}_{3} \mathrm{SnH}, \mathrm{AIBN}, \mathrm{C}_{6} \mathrm{H}_{6}$, reflujo, 94\%; b) $(\mathrm{COCl})_{2}, \mathrm{DMSO}, \mathrm{Et}_{3} \mathrm{~N}, \mathrm{DCM},-60{ }^{\circ} \mathrm{C}, 95 \%$; c) $\mathrm{O}_{2}$ (aire, 24 h), $41 \%$; d) $\mathrm{H}_{2}, \mathrm{Pd} / \mathrm{C}, \mathrm{EtOH}$, t.a., $66 \%$.

Habiendo establecido la estereoquímica de $\mathbf{3 4}$ en C-2, procedemos a hacer lo mismo para los otros tres tetrahidropiranos restantes (35-37). La reducción con $\mathrm{Bu}_{3} \mathrm{SnH}$ y AIBN de los cuatro tetrahidropiranos obtenidos en la reacción de yodociclación (3437) produjeron dos alcoholes, 38 y 42, como cabía esperar (Esquema 91). La estereoquímica del tetrahidropirano $\mathbf{3 8}$ ya ha sido determinada previamente $\mathrm{y}$, como la única diferencia entre 38 y $\mathbf{4 2}$ es la configuración en C-2, la estructura del alcohol $\mathbf{4 2}$ será la mostrada en el Esquema 91 (2S). Con esto queda determinada la estereoquímica de los tetrahidropiranos 34-37 en C-2 y también en C-10, la cual se deduce del mecanismo de ciclación, donde se produce una apertura anti del ión yodonio formado.

${ }^{171}$ Díez, D.; Kotecha, N. R.; Ley, S. V.; Mantegani, S.; Menéndez, J. C.; Organ, H. M.; White, A. D.; Banks, B. J. Tetrahedron 1992, 48, 7899. 


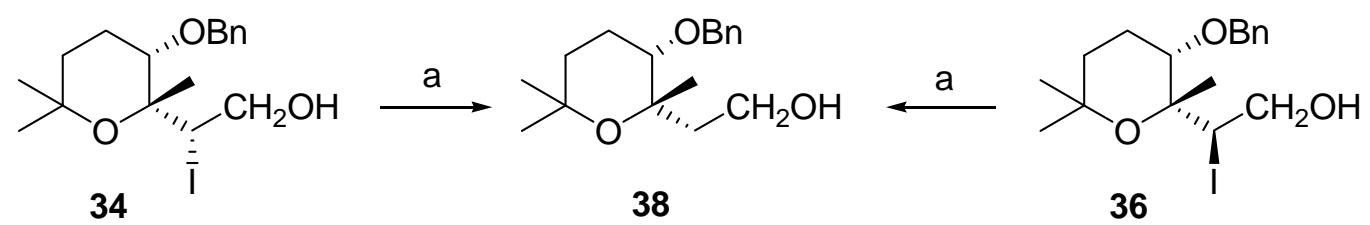<smiles>CC1(C)CC[C@@H](Br)[C@H](C(I)CO)O1</smiles>

35<smiles>CC1(C)CC[C@@H](Br)[C@H](CCO)O1</smiles>

42<smiles>CC1(C)CC[C@@H](Br)[C@H](C(I)CO)O1</smiles>

37

Esquema 91. a) $\mathrm{Bu}_{3} \mathrm{SnH}, \mathrm{AIBN}, \mathrm{C}_{6} \mathrm{H}_{6}$, reflujo.

La estereoquímica de los productos de ciclación, así como la relación en la que se obtienen, se puede explicar teniendo en cuenta los estados de transición propuestos para la reacción de yodociclación (Figura 14). Considerando la preferencia que los alquenos acíclicos oxigenados en C-1 presentan por la conformación en la que el grupo alil-metilo eclipsa el doble enlace C-C descrita por Gung et al. (Figura 13), ${ }^{172}$ y suponiendo una disposición ecuatorial del grupo benciloxi, el estado de transición A para la ciclación de 33 está más favorecido que el B (Figura 14). Este hecho explica que los tetrahidropiranos $\mathbf{3 4}$ y $\mathbf{3 5}$ se obtengan en una proporción 93:7.<smiles>[R]/C=C(/C)[C@@]([R])([2H])[Po]</smiles>

\section{Figura 13}

Sin embargo, los estados de transición $\mathbf{C}$ y $\mathbf{D}$ para la ciclación de $\mathbf{3 3}$ serán muy parecidos en energía debido a la interacción del grupo hidroximetilo con el grupo bencilo en el estado de transición C (Figura 14), lo que explica que los tetrahidropiranos 36 y 37 se obtengan casi en la misma proporción (9:10).

172 (a) Gung, B. W.; Wolf, M. A.; Zhu, Z. J. Org. Chem. 1993, 58, 3350; (b) Gung, B. W.; Wolf, M. A. J. Org. Chem. 1993, 58, 7038; (c) Ver también: Labelle, M.; Guindon, Y. J. Am. Chem. Soc. 1989, 111, 2204. 


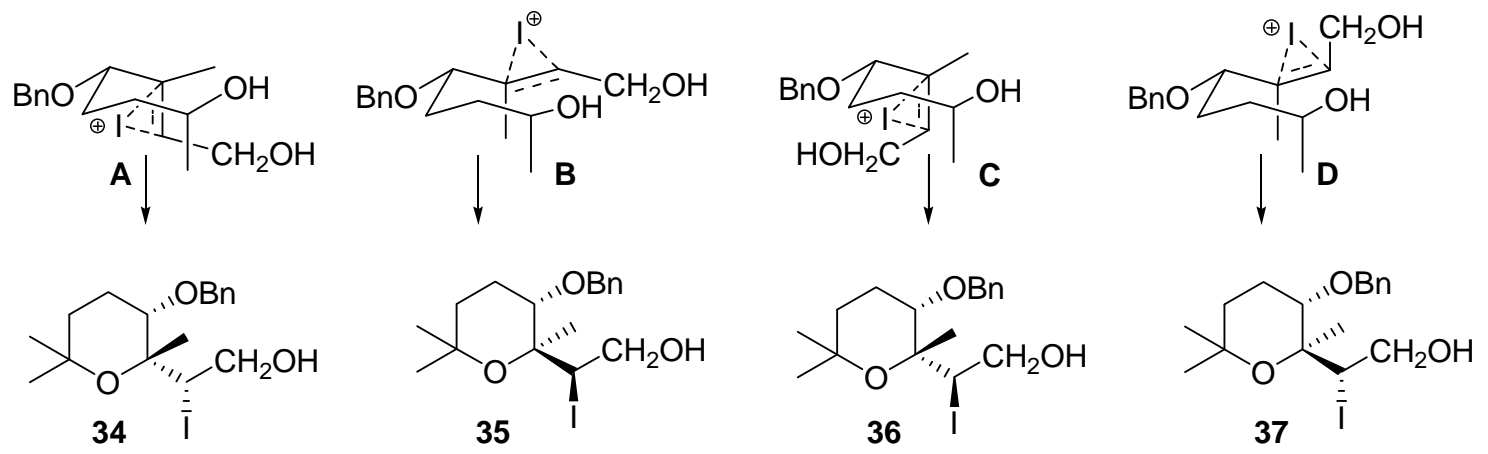

Figura 14 


\subsubsection{Estudio de las reacciones de yodociclación de olefinas deficientes en electrones}

\subsection{6.a. Yodociclación de los nitrilos $\alpha, \beta$-insaturados 19 y 20}

En estudios previos de nuestro grupo de trabajo, se intentó llevar a cabo la yodociclación del nitrilo 18 (Esquema 83). Sin embargo, no se obtuvo el tetrahidropirano deseado, llegando solo a aislarse una pequeña proporción de la cetona producto de oxidación del hidroxilo secundario de 18. ${ }^{158}$ Así, para evitar procesos de interferencia de este tipo, se decidió someter a las condiciones de yodociclación cinéticas habituales los nitrilos 19 y 20 , los cuales tienen su hidroxilo secundario protegido en forma de éter bencílico y de acetilderivado, respectivamente.
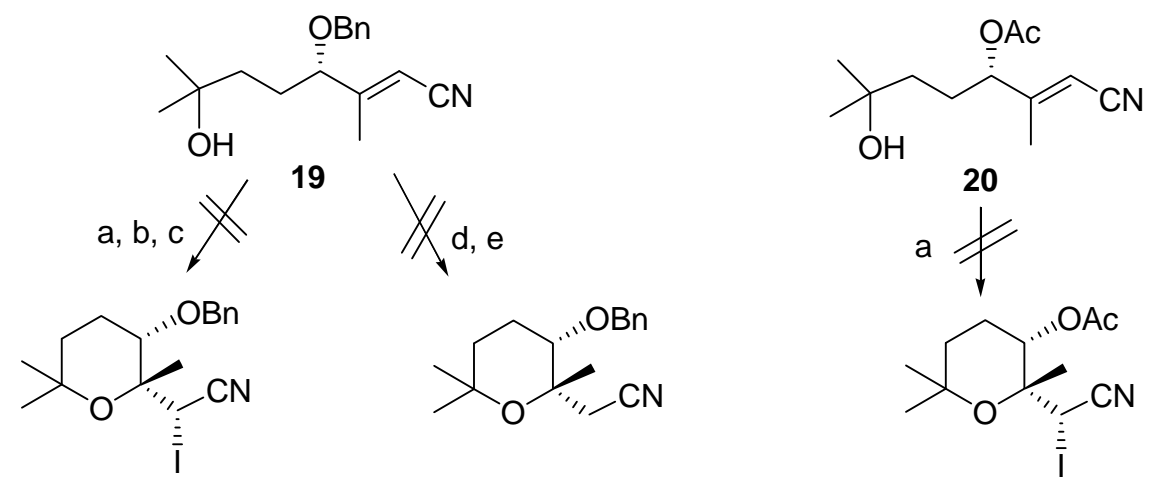

Esquema 92. a) $\mathrm{I}_{2}, \mathrm{NaHCO}_{3}, \mathrm{CH}_{3} \mathrm{CN}, 0{ }^{\circ} \mathrm{C}$; b) $\mathrm{I}_{2}, \mathrm{CH}_{3} \mathrm{CN}, 0{ }^{\circ} \mathrm{C}$; c) $\mathrm{IPi}_{2} \mathrm{BF}_{4}, \mathrm{DCM}$, t.a.; d) $\mathrm{NaH}$, THF; e) $\mathrm{K}_{2} \mathrm{CO}_{3}, \mathrm{MeOH}$.

Cuando se trata tanto el nitrilo 19 como el 20 con $\mathrm{I}_{2}$ y $\mathrm{NaHCO}_{3}$ en $\mathrm{CH}_{3} \mathrm{CN}$ a $0^{\circ} \mathrm{C}$, en ninguno de los dos casos se observa evolución del producto de partida (Esquema 92), debido tal vez a la desactivación del doble enlace por la presencia del nitrilo adyacente, lo que dificulta que el halógeno se coordine con el alqueno y, por tanto, que se produzca la ciclación. Tampoco se observa evolución alguna del sustrato al hacer reaccionar el bencilderivado 19 con $\mathrm{I}_{2}$ en $\mathrm{CH}_{3} \mathrm{CN}$ a $0^{\circ} \mathrm{C}$ o con el reactivo de Barluenga $\mathrm{IPi}_{2} \mathrm{BF}_{4}{ }^{173}$ (Esquema 92, rutas b y c respectivamente) ni en condiciones de adición tipo Michael (Esquema 92, rutas d y e respectivamente).

173 Barluenga, J. Pure Appl. Chem. 1999, 71, 431. 


\subsection{6.b. Yodociclación de los aldehídos $\alpha, \beta$-insaturados 21 y 22}

La reacción de yodociclación con $\mathrm{I}_{2}$ y $\mathrm{NaHCO}_{3}$ en $\mathrm{CH}_{3} \mathrm{CN}$ a $0^{\circ} \mathrm{C}$ (condiciones cinéticas) del aldehido $\alpha, \beta$-insaturado 22 conduce a una mezcla de cuatro aldehídos, 4346, de polaridad semejante (Esquema 93).

Se aíslan por cromatografía en columna sobre sílicagel los tetrahidropiranos $\mathbf{4 3}$, sólido cristalino, y 44. Los compuestos 45 y 46, cuya estructura y estereoquímica se determinan más adelante, permanecen como una mezcla inseparable en proporción 2:1. También se aísla una pequeña proporción del aldehído de partida 22 y de su diastereoisómero 21 en relación 10:1.

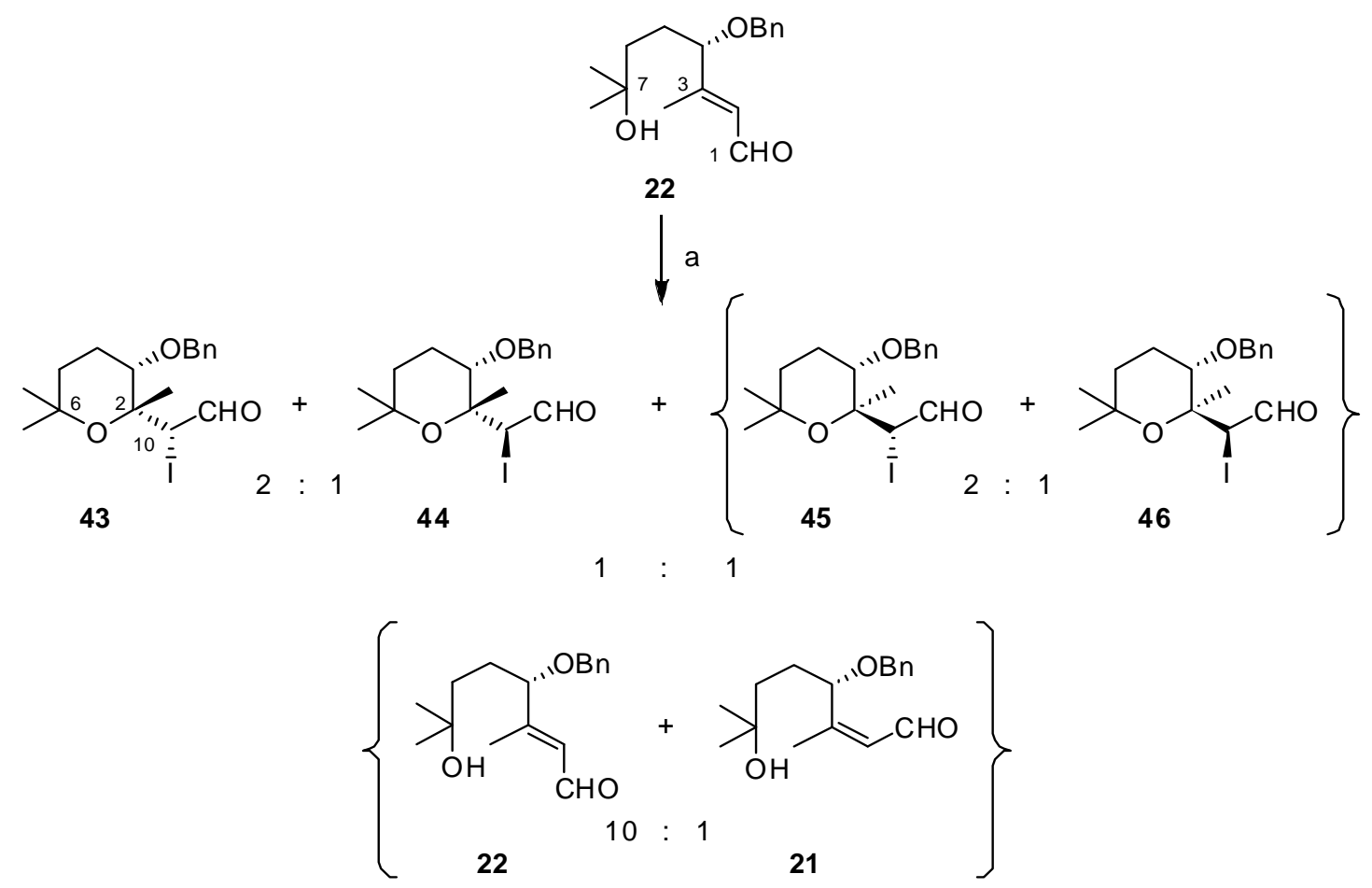

Esquema 93. a) $\mathrm{I}_{2}, \mathrm{NaHCO}_{3}, \mathrm{CH}_{3} \mathrm{CN}, 0{ }^{\circ} \mathrm{C}, 66 \%$.

Al someter tanto al aldehído 21 por separado como a una mezcla de 21/22 a idénticas condiciones cinéticas de yodociclación, se obtiene absolutamente la misma mezcla de tetrahidropiranos y en la misma proporción que en la ciclación de $\mathbf{2 2}$ (Esquema 93), recuperándose igualmente los aldehídos lineales 21 y 22 en una proporción similar. 
Este hecho parece indicar que se produce una interconversión entre los aldehídos 21 y 22 en las condiciones de reacción previa a la ciclación. Para comprobar que dicha interconversión no tiene lugar por apertura de los productos de ciclación, se hizo reaccionar el aldehído 43 con $\mathrm{I}_{2}$ y $\mathrm{NaHCO}_{3}$ en $\mathrm{CH}_{3} \mathrm{CN}$ a $0{ }^{\circ} \mathrm{C}$, recuperándose inalterado.

Esta es la primera vez que se lleva a cabo una reacción de yodoeterificación para la síntesis de tetrahidropiranos utilizando como sustratos aldehídos $\alpha, \beta$-insaturados. Sin embargo, el mecanismo de reacción habitual a través de un intermedio yodonio no puede explicar los resultados obtenidos. Estos se podrán justificar suponiendo la formación de un carbocatión intermedio en C-3 previa a la reacción de ciclación (Esquema 94).

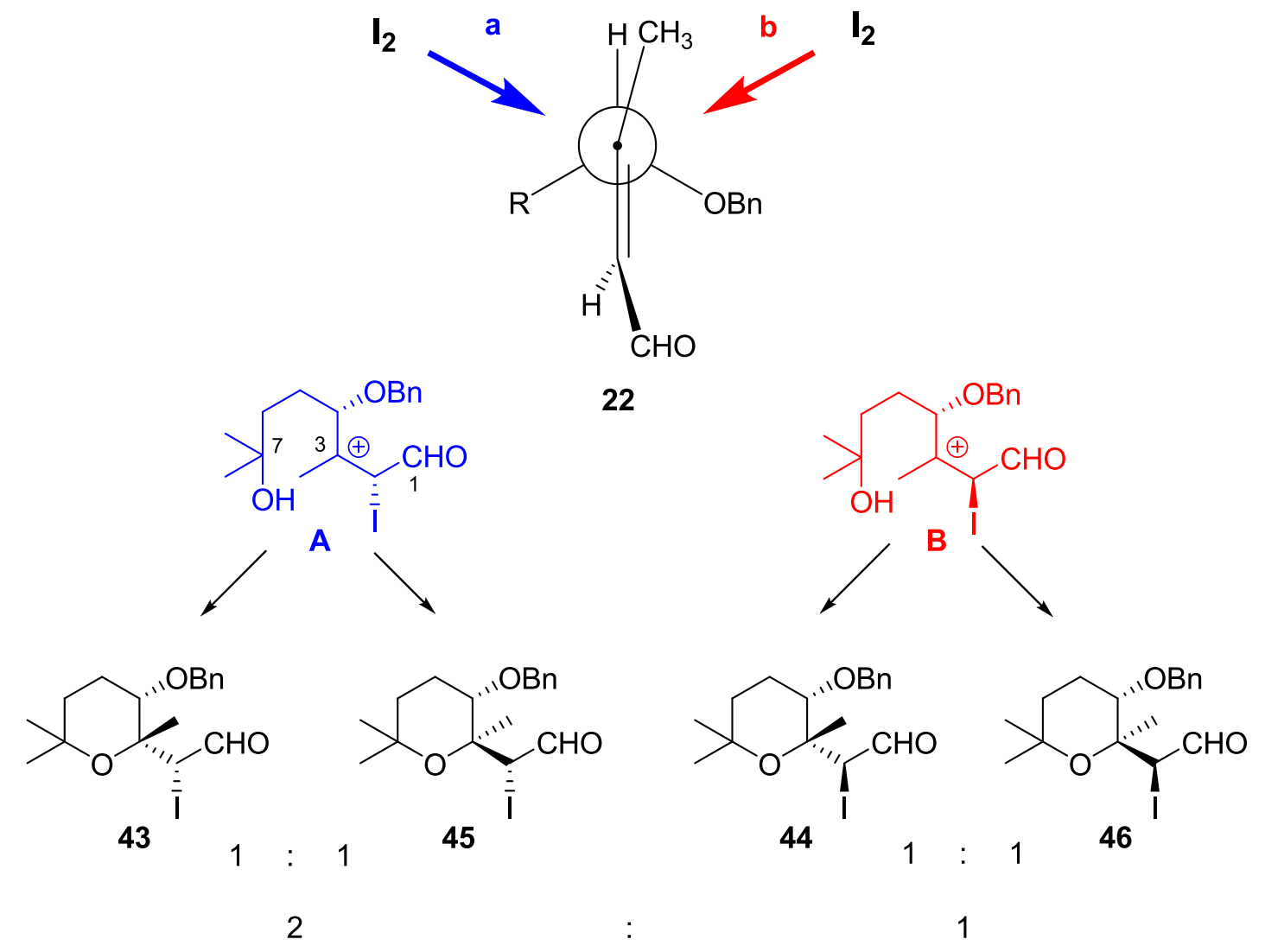

Esquema 94 
Según se observa en la proyección de Newman a lo largo del enlace C3-C4 del aldehído lineal 22 (Esquema 94), la entrada del yodo por la cara del doble enlace menos impedida, es decir, la opuesta al grupo benciloxi, dará lugar al intermedio $\mathbf{A}$, el cual ciclará para dar los tetrahidropiranos 43 y $\mathbf{4 5}$, que son los que se obtienen en una mayor proporción. De igual manera, la entrada del yodo por la cara del doble enlace más impedida, esto es, la más próxima al grupo bencilo, conducirá al intermedio $\mathbf{B}$, que ciclará hasta los tetrahidropiranos 44 y 46. En este caso, el mayor impedimento estérico hace que estos productos se obtengan en menor proporción. La proporción de 1:1 en la que se obtienen tanto 43/45 como 44/46 también se justifica mediante este mecanismo, puesto que la planaridad de los intermedios carbocatiónicos A y B hace que la ciclación ocurra con la misma probabilidad por una cara que por otra.

Con el objetivo de determinar la estereoquímica de los aldehídos 43-46 se procedió según se indica a continuación. Al tratar el aldehído 44 con $\mathrm{NaBH}_{4}$, se obtuvieron los compuestos 36, 39 y 38, cuya estereoquímica ha sido determinada previamente (apartado 1.1.5.), en una proporción 1:2:2 (Esquema 95).

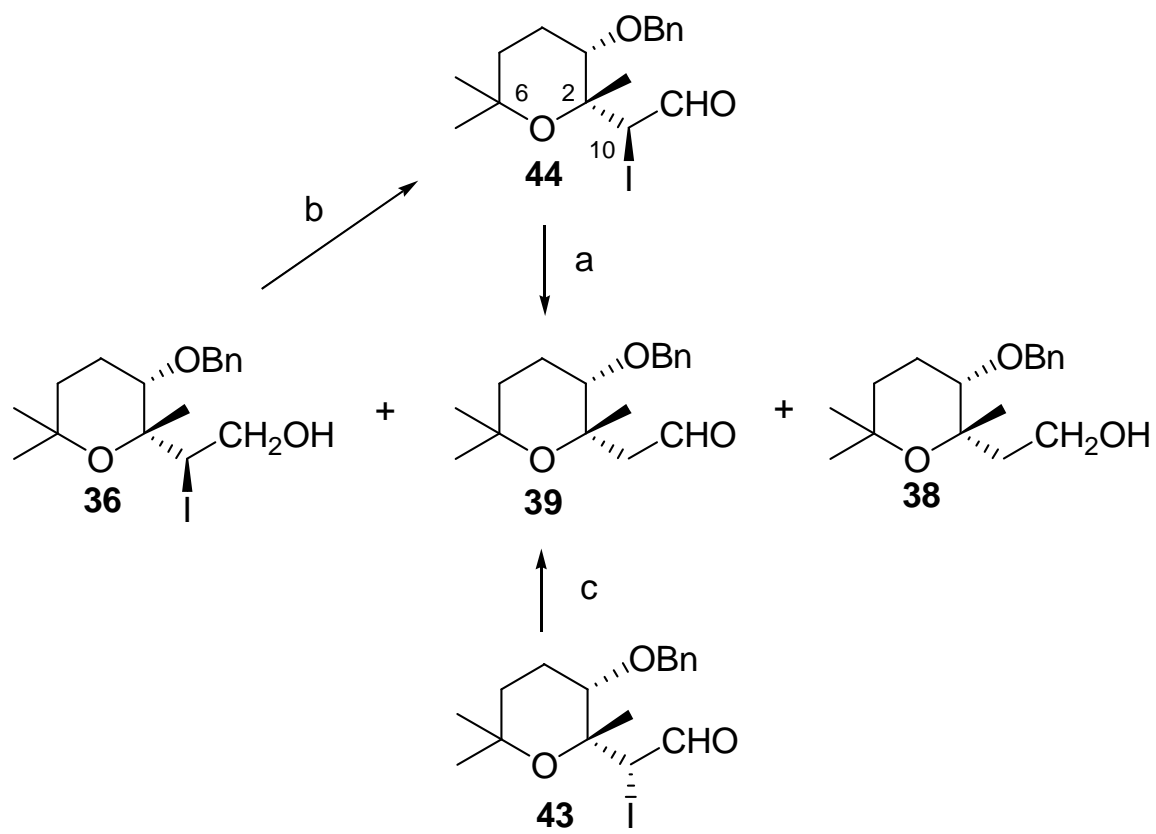

Esquema 95. a) $\mathrm{NaBH}_{4}, \mathrm{MeOH}$, t.a., $82 \%$; b) TPAP, NMO, tamiz molecular ( $3 \AA$ activado), DCM, t.a., $80 \%$; c) $\mathrm{Bu}_{3} \mathrm{SnH}, \mathrm{AIBN}, \mathrm{C}_{6} \mathrm{H}_{6}$, reflujo, $87 \%$. 
Dicho aldehído 44 se había obtenido con anterioridad al someter al alcohol 36, previamente obtenido por yodociclación del alcohol lineal 33 (Esquema 89), a oxidación con TPAP (Esquema 95). ${ }^{174}$ Así pues, la estereoquímica de 44 será la mostrada en el Esquema 95.

Cuando se sometió el otro aldehído aislado 43 a condiciones de deshalogenación con $\mathrm{Bu}_{3} \mathrm{SnH}$ y $\mathrm{AIBN}$, se obtuvo el aldehído 39 con un $87 \%$ de rendimiento (Esquema 95).

Así pues, se puede concluir que la estereoquímica de 43 y 44 es coincidente en C-2, ya que todos los compuestos obtenidos por reducción de éstos en posiciones C-10 y/o C-11 son conocidos y su estereoquímica había sido determinada con anterioridad (apartado 1.1.5.). Dado que la única diferencia entre los aldehídos 43 y 44 es la estereoquímica en la posición C-10 y la de $\mathbf{4 4}$ ya había sido determinada anteriormente, la estereoquímica del aldehído $\mathbf{4 3}$ será la que se muestra en el Esquema 95.

Ya que los aldehídos 43 y 44 tienen la misma estereoquímica en C-2, los aldehídos 45 y 46, que se obtuvieron como una mezcla inseparable por cromatografía en columna sobre sílicagel, deberían tener la misma estereoquímica en C-2 y contraria a la de 43 y 44 (Esquema 93). Por tanto, la única diferencia entre estos dos aldehídos será la estereoquímica en C-10.

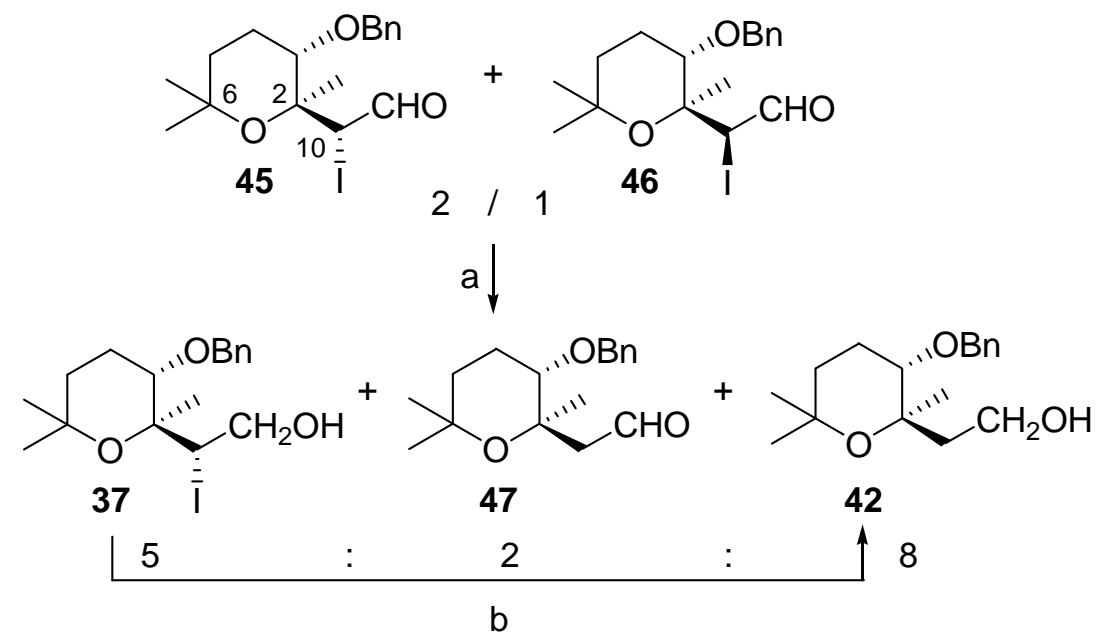

Esquema 96. a) $\mathrm{NaBH}_{4}$, $\mathrm{MeOH}$, t.a., $70 \%$; b) $\mathrm{Bu}_{3} \mathrm{SnH}$, $\mathrm{AIBN}, \mathrm{C}_{6} \mathrm{H}_{6}$, reflujo, $85 \%$.

\footnotetext{
${ }^{174}$ Ley, S. V.; Norman, J.; Griffith, W. P.; Marsden, S. P. Synthesis, 1994, 639.
} 
Para determinar la estereoquímica de los aldehídos 45 y 46 se decidió tratar la mezcla obtenida en proporción 2:1 con $\mathrm{NaBH}_{4}$ en $\mathrm{MeOH}$, obteniéndose la mezcla de compuestos 37, 47 y 42 en una relación 5:2:8 (Esquema 96). La deshalogenación de 37 con $\mathrm{Bu}_{3} \mathrm{SnH}$ y $\mathrm{AIBN}$ produjo el alcohol 42 con un $85 \%$ de rendimiento. Tanto el alcohol 37 como el $\mathbf{4 2}$ habían sido sintetizados previamente y su estereoquímica determinada (apartado 1.1.5.).

Los resultados mostrados en el Esquema 96 se producirán debido a una mayor resistencia frente a la reducción del yodo en el compuesto 45, en el que en primer lugar tiene lugar la reducción de la función aldehído obteniéndose así el alcohol 37. Por tanto, la estereoquímica del tetrahidropirano 45 será la mostrada en el Esquema 96. La estereoquímica del aldehído 46 también coincidirá con la indicada en dicho esquema, lo que está de acuerdo con el mecanismo carbocatiónico propuesto en el Esquema 94.

Con el fin de encontrar una explicación al hecho de que en la reducción de la mezcla de tetrahidropiranos 45/46 (2:1) con $\mathrm{NaBH}_{4}$ se produzcan los compuestos 37, 47 y 42, se llevaron a cabo estudios de modelización molecular. ${ }^{175}$ Para ello se propusieron diferentes modelos en busca de un estado de transición que pudiera dar explicación al mecanismo de reacción, sin embargo no fue posible hallar un estado de transición real. Así pues, se pensó en la posibilidad de que la retención del átomo de yodo en el compuesto 37 pudiera deberse a efectos conformacionales.

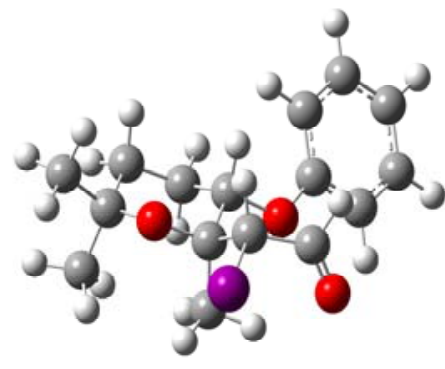

45

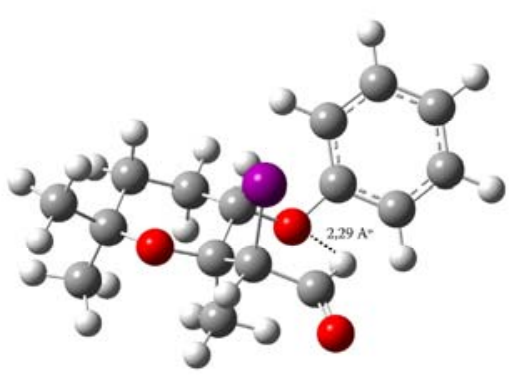

46

Figura 15

\footnotetext{
175 Los cálculos se realizaron en un PC, Pentium IV $1.86 \mathrm{GHz}$ con 2 Gb de RAM utilizando el programa Gaussian 03 (Revision B.03, M. J. Frisch et al.). La optimización de las geometrías se llevó a cabo empleando cálculos semi-empíricos según el modelo de Austin con un nivel teórico Restricted-HartreeFock (AM1/RHF).
} 
Tras llevar a cabo la minimización de energía, se encontró que en 46 el hidrógeno del aldehído está formando un enlace por puente de hidrógeno con el oxígeno bencílico (Figura 15), adquiriendo el sistema una conformación de pseudo-silla y confiriéndole cierta rigidez. En dicha conformación, el átomo de yodo se encuentra en una disposición pseudo-axial, facilitando la entrada del reductor en esta posición. Así, en el compuesto 46 se producirá primero la reducción del yodo seguido de la reducción del aldehído.

Por el contrario, en $\mathbf{4 5}$ no existe enlace por puente de hidrógeno (Figura 15) ya que el hidrógeno del aldehído se encuentra a más de $100^{\circ}$ respecto del oxígeno bencílico. Este hecho hace que, en este caso, el átomo de yodo se encuentre ocupando una posición pseudo-ecuatorial, lo que le hace peor grupo saliente y por tanto, dificulta la entrada del reductor. De este modo, en el compuesto 45 se producirá en primer lugar la reducción del aldehído, obteniéndose el alcohol 37, seguida de la reducción del yodo.

La presencia en los productos de reacción (Esquema 96) del compuesto de reducción parcial 47 se podrá explicar teniendo en cuenta que el hidrógeno de la función aldehído de dicho aldehído se encuentra formando un enlace de hidrógeno con el oxígeno bencílico (Figura 16). Este hecho estabilizará su estructura y lo hará más inerte frente al ataque de un reductor.

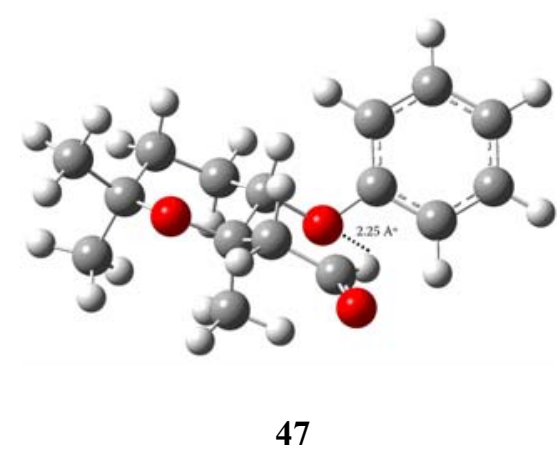

Figura 16

Como conclusión de estos estudios, podemos decir que el mecanismo de la reacción descrita en el Esquema 96 se puede ajustar a una reacción de sustitución nucleofílica $\mathrm{S}_{\mathrm{N}} 2$ del átomo de yodo por un ión hidruro. En el compuesto 46, este desplazamiento nucleofílico se producirá en primer lugar, obteniéndose el aldehído 47. Debido a la estabilidad de dicho aldehído frente a la reducción, sólo se reducirá parcialmente para dar el alcohol $\mathbf{4 2}$. 
Por el contrario, en el compuesto 45 primero tiene lugar la reducción de la función aldehído, obteniéndose el alcohol 37, el cual se reducirá en parte hasta el compuesto 42. Por tanto, los productos de reducción 37 y 47 provendrán únicamente de 45 y 46 respectivamente, mientras que el producto de reducción total 42 procederá tanto de $\mathbf{4 5}$ como de $\mathbf{4 6}$ por reducción parcial de los productos iniciales de reducción 37 y 47.

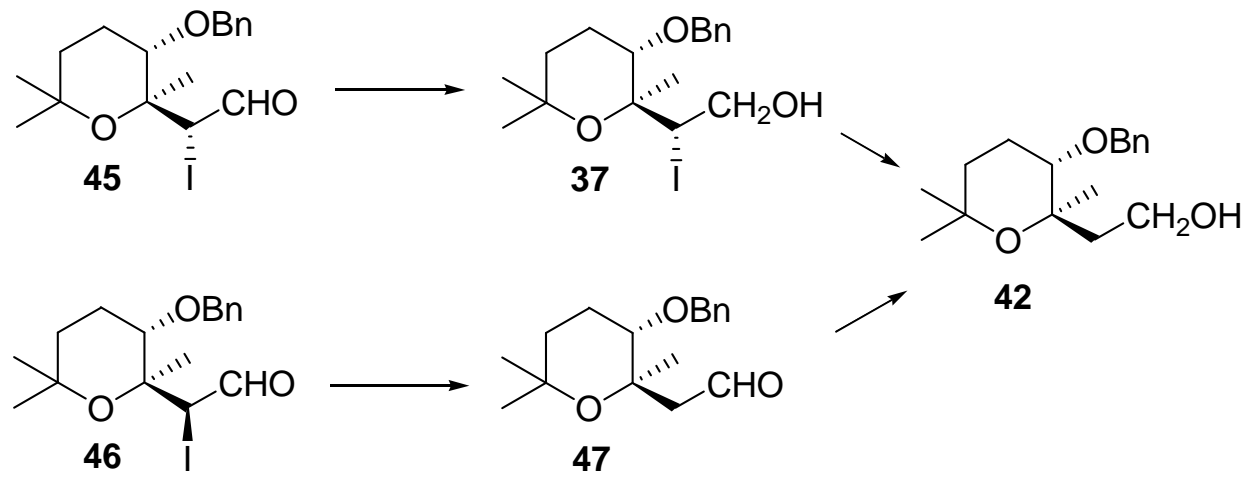

Esquema 97 


\subsubsection{Uso de los nitrilos en síntesis: Síntesis de ent- Sachalinol $\mathbf{A}^{176}$}

Recientemente, Kadota et al. han descrito el aislamiento de los Sachalinoles AC, de Rhodiola Sachalinensis, ${ }^{177}$ como nuevos monoterpenoides. La Rosiridina, glucósido del Sachalinol A, había sido previamente aislada de Rhodiola Rosea ${ }^{178}$ y presenta inhibición no competitiva de la actividad endopeptidasa de Flavobacterium PEP con un $\mathrm{IC}_{50}$ de $84 \mu \mathrm{M}$ (Figura 17).

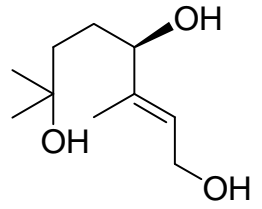

Sachalinol A

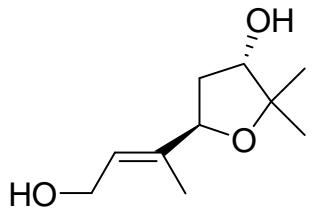

Sachalinol B

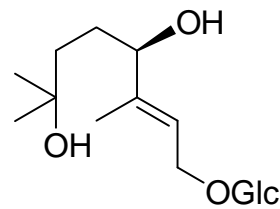

Rosiridina

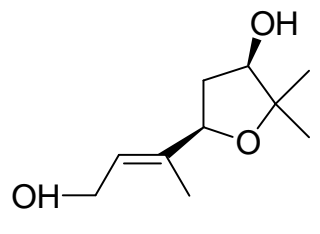

Sachalinol C

Figura 17

Dado que disponíamos del nitrilo 18 (Esquema 83), intermedio en la síntesis de los nitrilos 19 y 20 y los aldehídos 21 y 22 que han sido utilizados como sustratos en reacciones de yodociclación (apartado 1.1.6.), decidimos sintetizar a partir de él el enantiómero del producto natural Sachalinol A. Así, al someterlo a reducción con DIBAL-H, se obtuvo el aldehído 48, el cual se redujo de nuevo con DIBAL-H, dando el triol 49 (Esquema 98). Sin embargo, debido a los problemas que supone la manipulación de moléculas polihidroxiladas de bajo peso molecular como estas, por la dificultad de separación de las sales de aluminio producidas en las reducciones con DIBAL-H, el compuesto 49 se obtuvo en muy pequeña cantidad.

\footnotetext{
${ }^{176}$ Díez, D.; Nuñez, M. G.; Moro, R. F.; Antón, A. B.; Garrido, N. M.; Marcos, I. S.; Basabe, P. Synlett, 2006, 1715.

177 Fan, W. ; Tezuka, Y. ; Ni, K. ; Kadota, S. Chem. Pharm. Bull. 2001, 49, 396.

178 (a) Kurkin, V. A.; Zapesochnaya, G. G.; Shchavinskii, A. N. Khim. Prir. Soedin. 1985, 21, 632; (b) Chem. Abstr. 1986, 104, 102314.
} 
Para obtener el compuesto 49 con un mayor rendimiento se decidió proteger el compuesto 18 en forma de su di-terc-butildimetilsilil derivado en las condiciones habituales. ${ }^{179}$ Una doble reducción con DIBAL-H como en el caso anterior seguido de un paso final de desprotección con $\mathrm{TBAF}^{180}$ produjo el ent-Sachalinol A con un rendimiento global del 35\% a partir del nitrilo 18 (Esquema 98).

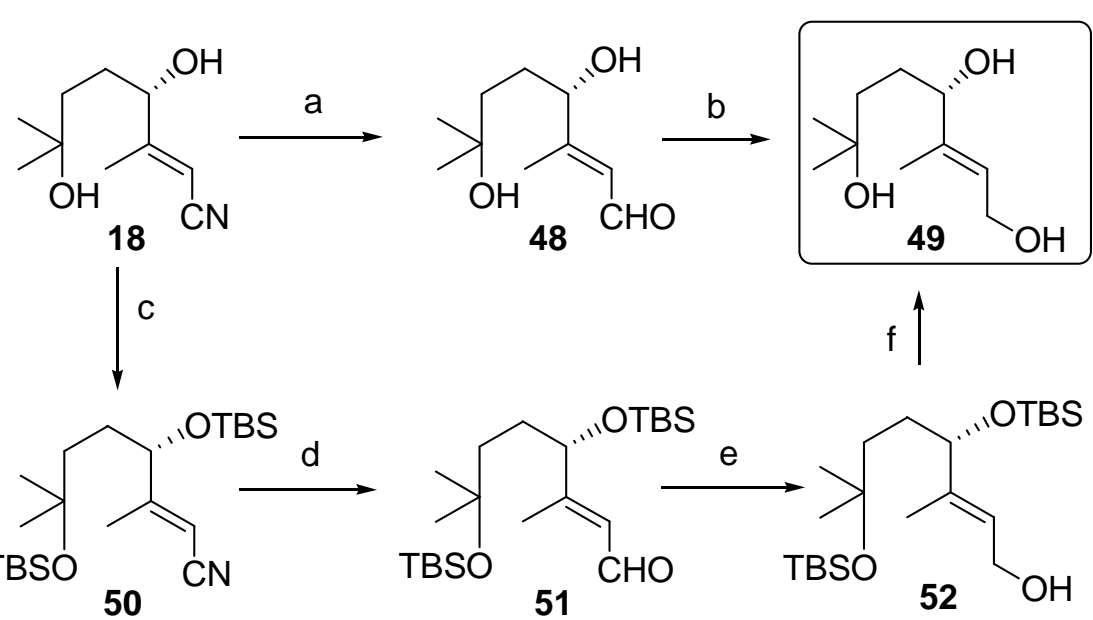

Esquema 98. a) DIBAL-H, DCM, $-78^{\circ} \mathrm{C}, 35 \%$; b) DIBAL-H, DCM, $-78^{\circ} \mathrm{C}, 40 \%$; c) TBDMSOTf, 2,6lutidina, THF, t.a., $85 \%$; d) DIBAL-H, DCM, $-78^{\circ} \mathrm{C}, 85 \%$; e) DIBAL-H, DCM, $-78^{\circ} \mathrm{C}, 65 \%$; f) TBAF, THF, t.a., $75 \%$.

Las propiedades espectroscópicas del triol 49 coinciden con las descritas para el producto natural Sachalinol $\mathrm{A}^{177}$ excepto en el poder rotatorio, siendo $[\alpha]_{\mathrm{D}}^{20}=-17.1(\mathrm{c}=$ $0.17, \mathrm{MeOH})$ para el producto natural y $[\alpha]_{\mathrm{D}}^{20}=-2.0(\mathrm{c}=1.0, \mathrm{MeOH}),[\alpha]_{\mathrm{D}}^{20}=-7.4(\mathrm{c}=$ $0.19, \mathrm{MeOH})$ para 49.

Con el fin de evaluar el exceso enantiomérico de 49, se obtuvo su diéster de Mosher 53 por tratamiento con cloruro de $(S)-(+)-\alpha$-metoxi- $\alpha$-trifluorometilfenilacetilo (10 equivalentes), observándose un solo compuesto en su espectro de ${ }^{1} \mathrm{H}-\mathrm{RMN}$ con un poder rotatorio de $[\alpha]_{\mathrm{D}}^{20}=-48.0\left(\mathrm{c}=1.1, \mathrm{CHCl}_{3}\right)$.

\footnotetext{
${ }^{179}$ Corey, E. J.; Cho, H.; Rücker, C.; Hua, D. H. Tetrahedron Lett. 1981, 22, 3455.

${ }^{180}$ Corey, E. J.; Venkateswarlu, A. J. Am. Chem. Soc. 1972, 94, 6190.
} 
Así pues, podemos concluir que el triol 49 se trata del ent-Sachalinol A, habiendo corroborado de esta manera la estructura y la estereoquímica del producto natural Sachalinol A. El hecho de que tanto el Sachalinol A como el ent-Sachalinol A 49 tengan el mismo signo en el valor del poder rotatorio se explica por la baja concentración utilizada en la medida del producto natural.

El uso del enantiómero del nitrilo 18, el cual se puede obtener de la misma forma que éste, utilizando D-(-)-DET en lugar de L-(+)-DET en el paso de epoxidación asimétrica de Sharpless (Esquemas 82 y 83; apartados 1.1.3. y 1.1.4.), conducirá a la estereoquímica correcta para el Sachalinol A. 


\subsection{SÍNTESIS Y APLICACIONES DE TETRAHIDROFURANOS}

Los tetrahidrofuranos sustituídos son estructuras que se encuentran en numerosos productos naturales y otras moléculas biológicamente activas, por lo que se han desarrollado un gran número de métodos para su síntesis estereoselectiva. Muchas de estas estrategias son las mismas que las comentadas en la introducción de esta memoria para la síntesis de tetrahidropiranos. ${ }^{181}$ Así, aunque este trabajo se centre en la síntesis y aplicaciones de tetrahidropiranos, debido la experiencia de nuestro grupo de trabajo en la obtención de heterociclos oxigenados de cinco y seis miembros, en este apartado se describe la síntesis y posibles aplicaciones de dos análogos del bistetrahidrofurano.

\subsubsection{Síntesis de los tetrahidrofuranil-dioxolanos 54 y 58}

Recientemente se ha descrito la síntesis a partir de D-manitol de bistetrahidrofurano (Figura 18) y sus aplicaciones como ligando quiral para reactivos organolíticos en diferentes tipos de reacciones de adición. ${ }^{182}$

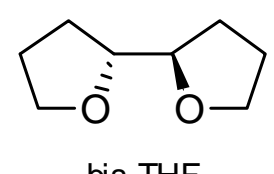

Figura 18

En nuestro grupo de investigación se ha diseñado la síntesis de dos posibles análogos del bis-tetrahidrofurano, 54 y 58, a partir del lactol 8 (Esquema 99), cuya obtención ya ha sido descrita con anterioridad en esta memoria (apartado 1.1.3., Esquema 82).

\footnotetext{
${ }^{181}$ Para una revisión bibliográfica reciente sobre síntesis estereoselectiva de tetrahidrofuranos, ver: Wolfe, J. P.; Hay, M. B. Tetrahedron 2007, 63, 261.

${ }^{182}$ Alexakis, A.; Tomassini, A.; Leconte, S. Tetrahedron 2004, 60, 9479.
} 


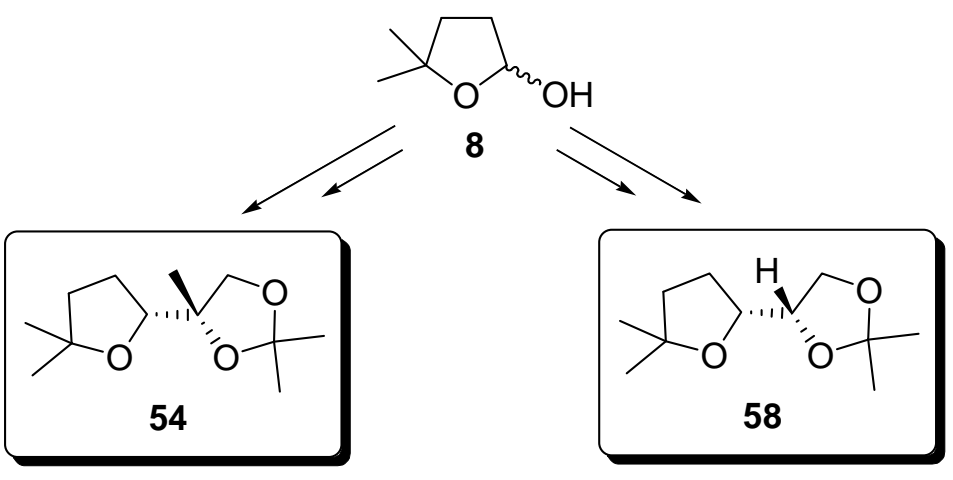

\section{Esquema 99}

La obtención del tetrahidrofurano 13 (Esquema 100), que se obtiene en el paso de la epoxidación de Sharpless, a partir del lactol 8, ya ha sido descrita en el apartado 1.1.3 de este trabajo. Así pues, como ya se disponía de este producto, se le hace reaccionar con acetona, dimetoxipropano y $\mathrm{CuSO}_{4}$ anhidro, obteniéndose el compuesto 54 con buen rendimiento (Esquema 100).
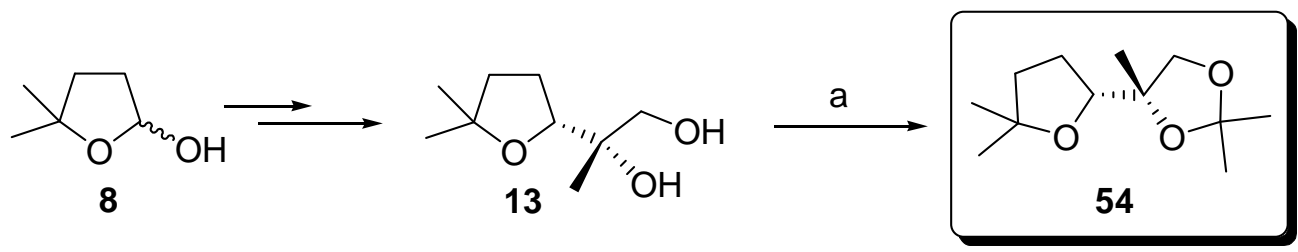

Esquema 100. a) Acetona, dimetoxipropano, $\mathrm{CuSO}_{4}$ anhidro, $68 \%$.

Para obtener el compuesto 58, se trata el lactol $\mathbf{8}$ con (1etoxicarbonilmetilen)trifenilfosforano, obteniéndose el éster $\alpha, \beta$-insaturado $\mathbf{5 5}$ (Esquema 101). Dicho éster se reduce con DIBAL-H hasta el diol 56, el cual se somete a epoxidación de Sharpless con L-(+)-DET, pudiéndose aislar apenas una pequeña cantidad del tetrahidrofurano 57, producto de apertura intramolecular del epóxido formado en la reacción. Tratando 57 con acetona, dimetoxipropano y $\mathrm{CuSO}_{4}$ anhidro se obtiene el acetal deseado 58 (Esquema 101). 


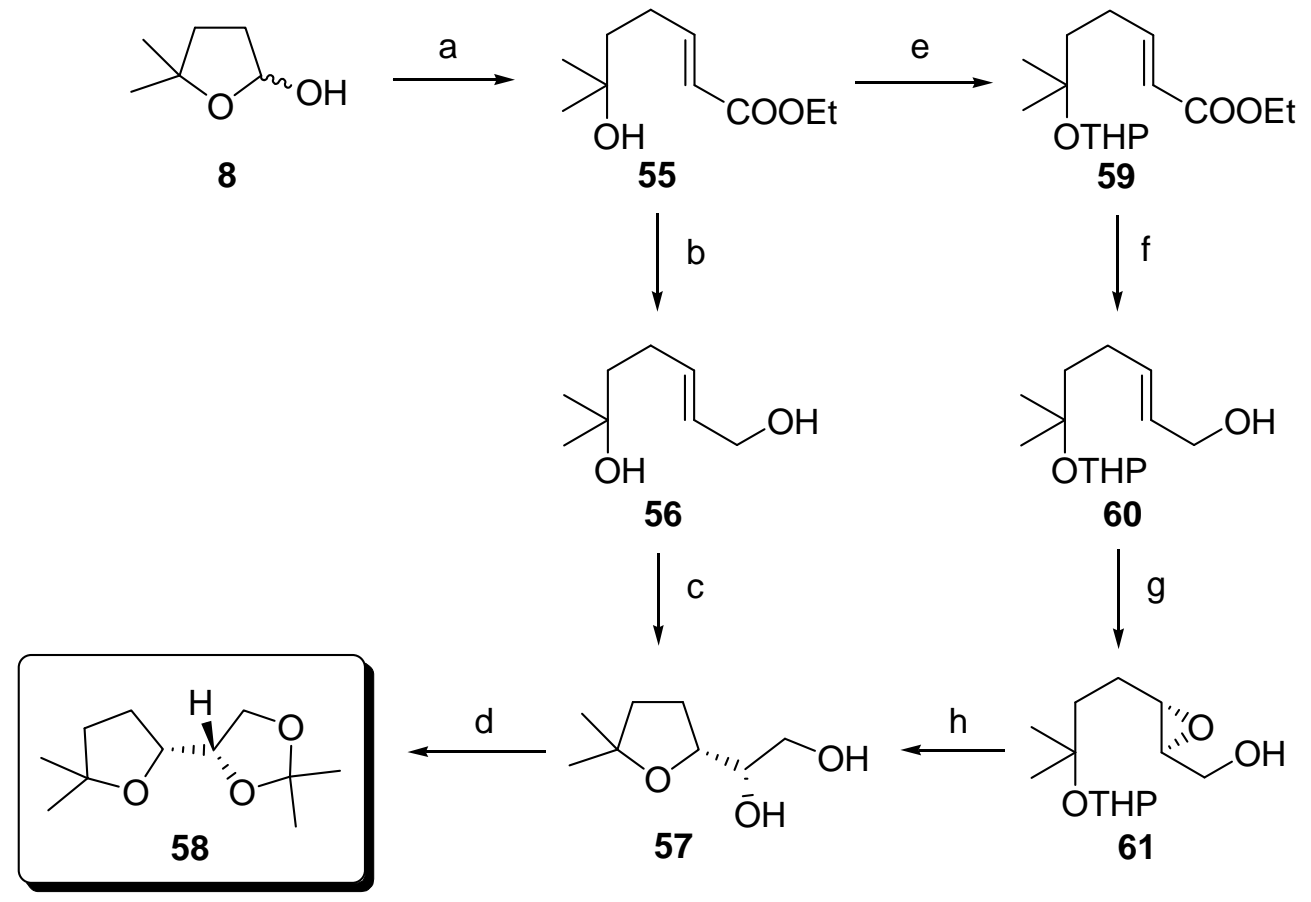

Esquema 101. a) $\mathrm{Ph}_{3} \mathrm{P}(\mathrm{CH}) \mathrm{COOEt}, \mathrm{C}_{6} \mathrm{H}_{6}, 60 \%$; b) DIBAL-H, DCM, $-78^{\circ} \mathrm{C}, 87 \%$; c) L-(+)-DET, $\mathrm{Ti}\left({ }^{i} \mathrm{PrO}\right)_{4}$, TBHP, DCM, $-23^{\circ} \mathrm{C}$; d) Acetona, dimetoxipropano, $\mathrm{CuSO}_{4}$ anhidro, $10 \%$ en 2 pasos; e) DHP, PPTS, DCM, 88\%; f) DIBAL-H, DCM, $-78^{\circ} \mathrm{C}, 82 \%$; g) L(+)-DET, Ti $\left({ }^{i} \mathrm{OPr}\right)_{4}$, TBHP, DCM, $-23^{\circ} \mathrm{C}, 20 \%$; h) $p$ - $\mathrm{TsOH}, \mathrm{MeOH}, 70 \%$.

Debido al bajo rendimiento obtenido en la epoxidación de Sharpless, se decide proteger el éster 55 para dar su tetrahidropiranilderivado 59, el cual se reduce con DIBAL-H hasta el alcohol alílico 60. Al someter éste a epoxidación de Sharpless con L(+)-DET, se obtiene el epóxido 61 con un 20\% de rendimiento. Posteriormente se desprotege en las condiciones habituales produciéndose el tetrahidrofurano 57, el cual se trata nuevamente con acetona, dimetoxipropano y $\mathrm{CuSO}_{4}$ anhidro para dar $\mathbf{5 8}$ (Esquema 101). 


\subsubsection{Extracción de picratos}

Con el fin de evaluar la habilidad de los compuestos 54 y 58 para complejar cationes alcalinos $\left(\mathrm{Li}^{+}, \mathrm{Na}^{+}, \mathrm{K}^{+}\right)$, se formaron los correspondientes picratos de estos metales (Esquema 102). ${ }^{183}$ Lo que posteriormente se mide es la capacidad que tienen $\mathbf{5 4}$ y 58 para extraer los picratos, disueltos en $\mathrm{D}_{2} \mathrm{O}$, mediante $\mathrm{CDCl}_{3}$. El estudio de los desplazamientos químicos en ${ }^{1} \mathrm{H}$ RMN de nuestros compuestos permite conocer el grado de complejación con los cationes.<smiles>Cc1cc([N+](=O)[O-])cc([N+](=O)[O-])c1O</smiles>

ácido pícrico<smiles>O=[N+]([O-])c1cc([N+](=O)[O-])c(O[14N+]([O-])([O-])[O-])c([N+](=O)[O-])c1</smiles>

$\mathrm{M}^{+}=\mathrm{Li}^{+}, \mathrm{Na}^{+}, \mathrm{K}^{+}$

Esquema 102. a) $\mathrm{M}_{2} \mathrm{CO}_{3}, \mathrm{H}_{2} \mathrm{O}, 100^{\circ} \mathrm{C}$.

Como de todas las pruebas que se realizaron los resultados fueron negativos, se llevaron a cabo estudios de modelización molecular que pudiesen explicar dichos resultados.

\subsubsection{Estudios de modelización molecular}

Se realizaron estudios de modelización molecular de los tetrahidrofuranildioxolanos 54 y 58, comparando estas moléculas con el bis-tetrahidrofurano (bis-THF) descrito en bibliografía y así predecir su capacidad como complejantes de cationes alcalinos $\left(\mathrm{Li}^{+}, \mathrm{Na}^{+}, \mathrm{K}^{+}\right)$(Figura 19).

${ }^{183}$ Babb, D. A.; Czech, B. P.; Bartsch, R. A. Arkivoc 2003, 164. 

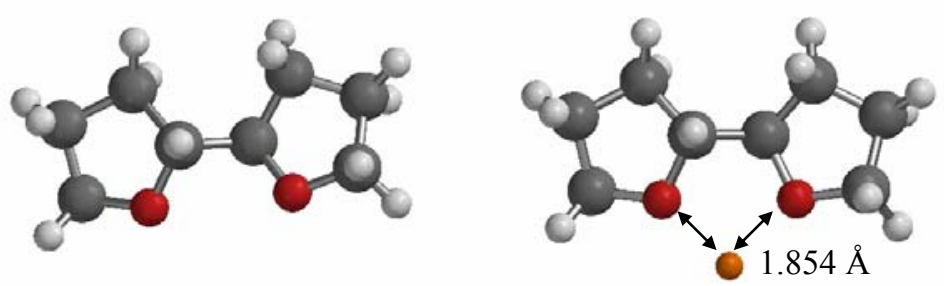

Figura 19. Bis-tetrahidrofurano. La energía de afinidad absoluta por el $\mathrm{Li}^{+}$en el nivel $\mathrm{HF} / 6-31+\mathrm{G}^{*}$ es de $4615.116 \mathrm{kcal} / \mathrm{mol}$.

Como se conoce el comportamiento del bis-THF en la formación de complejos con metales, es interesante comparar las energías de asociación y las propiedades geométricas de los complejos formados por las dos clases de ligandos. ${ }^{184}$ Para ello, se dibujó el complejo bis-THF- $\mathrm{Li}^{+}$y en primer lugar se sometió a minimización de energía por MMFF94s. El resultado de esta operación tenía simetría $\mathrm{C}_{2}$, tal y como se esperaba. Comparando con varios complejos de diéteres con $\mathrm{Li}^{+}$de la base de datos de Cambridge se demostró una superposición satisfactoria.

Posteriormente, el complejo bis-THF-Li ${ }^{+}$se sometió a minimización de energía usando el "Basis Set" 6-31+G*, que con las funciones difusas (indicadas por el +) suele dar buenos resultados para afinidad absoluta con $\mathrm{Li}^{+}{ }^{185} \mathrm{La}$ estructura que se obtuvo con estos cálculos es la indicada en la Figura 19 y, aunque es satisfactoria, la distancia O-Li en este complejo es más corta (normalmente en las estructuras por RX la distancia Li-O es alrededor de $2.0 \AA$ ), probablemente debido a la ausencia de otros ligandos para el $\mathrm{Li}^{+}$. Por tanto, se eliminó el $\mathrm{Li}^{+}$y la minimización se llevó a cabo en las mismas condiciones, dando una energía de asociación con el litio al nivel $\mathrm{HF} / 6-31+\mathrm{G}^{*}$ de $4615.116 \mathrm{kcal} / \mathrm{mol}$. Hay que tener en cuenta que esto puede alterar los resultados, dado que la conformación del ligando $\sin \mathrm{Li}^{+}$no es necesariamente la más baja en energía, sino la más cercana a la que hay en el complejo.

\footnotetext{
${ }^{184}$ El cálculo se hizo con Spartan 'O4 bajo Windows 2000 en un PC Pentium II.

${ }^{185}$ Hehre, W. J. A Guide to Molecular Mechanics and Quantum Chemical Calculations, Wavefunction, inc., Irvine, CA, 2003.
} 
El proceso anterior se repitió añadiendo metilos en los tetrahidrofuranos para ver el efecto de este cambio en la afinidad por el litio (Figura 20).

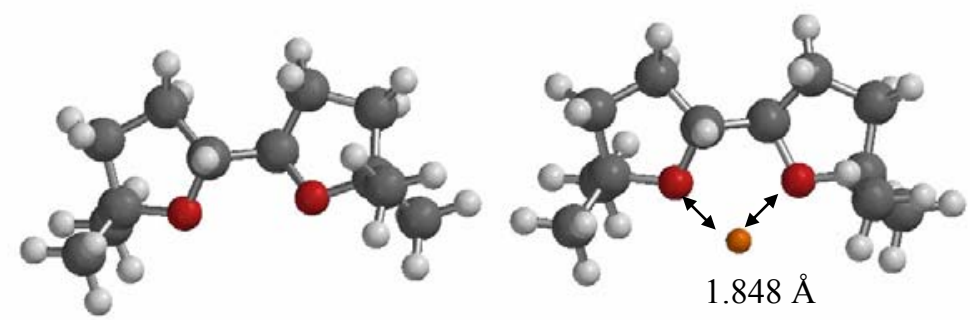

Figura 20. La energía de afinidad absoluta por el $\mathrm{Li}^{+}$en el nivel $\mathrm{HF} / 6-31+\mathrm{G}^{*}$ es de $4616.596 \mathrm{kcal} / \mathrm{mol}$, $1.48 \mathrm{kcal} / \mathrm{mol}$ mayor que en el caso de no tener metilos.

El resultado de los cálculos parece indicar que aumenta la afinidad por el litio, siempre con la aproximación de que la conformación del ligando sin litio, o es el mínimo energético o tiene la misma separación energética en ambos casos. La distancia más corta O-Li está de acuerdo con un aumento de la afinidad.

Se repitió el mismo proceso para el ligando tetrahidrofuranil-dioxolano $\mathbf{5 8}$ (Figura 21). En este caso, la afinidad por el $\mathrm{Li}^{+}$baja bastante y una de las distancias $\mathrm{O}-$ Li es más larga que en el complejo inicial con el bis-THF. Este complejo sigue siendo pseudo-trans alrededor del enlace entre los dos anillos y se observa que el ambiente del litio en este caso es más asimétrico que en el caso de los bis-THF.
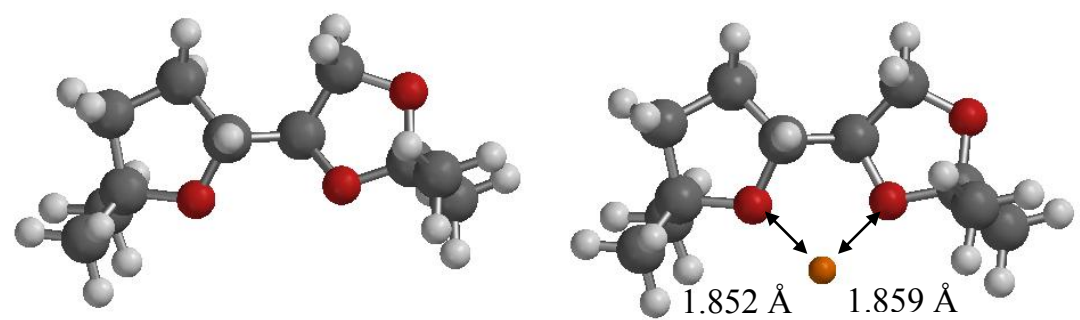

Figura 21. Tetrahidrofuranil-dioxolano 58. La energía de afinidad absoluta por el $\mathrm{Li}^{+}$en el nivel $\mathrm{HF} / 6$ $31+\mathrm{G}^{*}$ es de $4610.182 \mathrm{kcal} / \mathrm{mol}, 6.41 \mathrm{kcal} / \mathrm{mol}$ menor que en el caso del bis-dimetil-tetrahidrofurano. 
Las estructuras de los derivados tetrahidrofuranil-dioxolanos se basaron en la estructura por RX del complejo Nigericina- $\mathrm{Na}^{+}{ }^{186}$ De ella se obtuvo la parte del bisTHF, se cambió el $\mathrm{Na}^{+}$por el $\mathrm{Li}^{+}$y se hizo una optimización de la geometría utilizando el campo de fuerzas MMFF94s. Seguidamente se modificó la estructura para introducir el oxígeno del dioxolano y se volvió a hacer la optimización.

Como había varias posibilidades respecto a la elección del oxígeno del dioxolano destinado a complejarse con el litio, se plantearon tres casos mediante la aplicación de restricciones de distancia (a $1.9 \AA$ ) durante la minimización: que el $\mathrm{Li}^{+} \mathrm{se}$ complejase sólo con el oxígeno del dioxolano con el que forma un ciclo de 5 miembros (caso a), sólo con el que forma un ciclo de 6 miembros (caso b), o con ambos oxígenos a la vez (caso c) (Figura 22).

Las estructuras resultantes se optimizaron en Spartan usando el conjunto de funciones (Basis Set) 6-31+G*, obteniéndose lo indicado en la Figura 22. La optimización de cualquiera de estas estructuras tras eliminar el litio da como resultado la estructutura no complejada representada en la parte superior (Figura 21). Como se puede observar, el sistema más estable es el correspondiente al caso $a$, es decir, cuando el $\mathrm{Li}^{+}$se coordina con el oxígeno del dioxolano con el que forma un ciclo de cinco miembros.

La afinidad de los ligandos tetrahidrofuranil-dioxolanos por el $\mathrm{Li}^{+}$es bastante menor que la de los bis-THF y, aunque en los primeros la distancia entre el oxígeno del tetrahidrofurano y el $\mathrm{Li}^{+}$es similar a la que hay en el bis-THF, la distancia entre el oxígeno del dioxolano y el $\mathrm{Li}^{+}$es mucho más larga. Esto indica una mayor asimetría en el complejo, aunque también puede suponer una menor cantidad de $\mathrm{Li}^{+}$complejado.

\footnotetext{
186 Barrans, Y.; Alleaume, M.; David, L. Acta Cryst., Sect. B. Struct. Crystallogr: Cryst. Chem. 1980, 36, 936.
} 


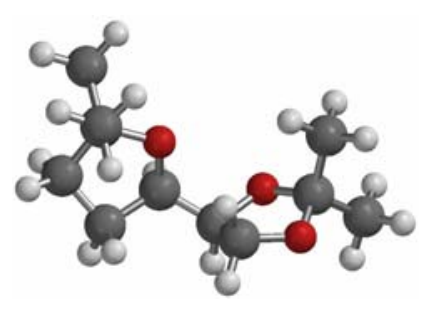

Tetrahidrofuranil-dioxolano $\mathbf{5 8}$

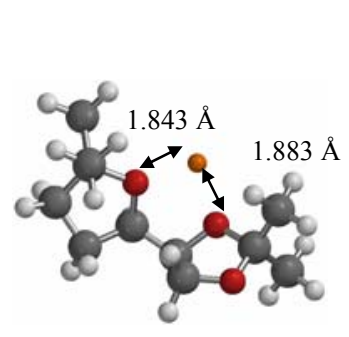

Caso a:

(dicoordinado)

$\mathrm{Ea}=-4607.07408$

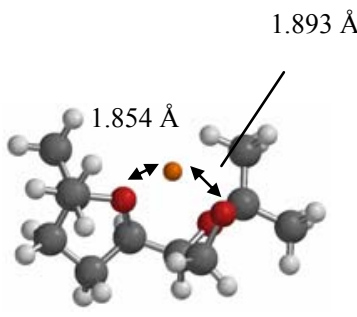

Caso b:

(dicoordinado)

$\mathrm{Ea}=-4606.56318$

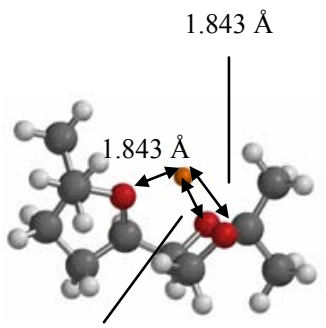

$1.843 \AA$

Caso c:

(tricoordinado) $\mathrm{Ea}=-4605.70309$

Figura 22. Energías de afinidad absolutas por el $\mathrm{Li}+$ en el nivel $\mathrm{HF} / 6-31+\mathrm{G}^{*}(\mathrm{kcal} / \mathrm{mol})$ para los tres casos planteados.

Las estructuras representadas en la siguiente figura (Figura 23) se hicieron cambiando el $\mathrm{Li}^{+}$del caso anterior por $\mathrm{Na}^{+}$y realizando de nuevo la optimización de la geometría con $\mathrm{HF} / 6-31+\mathrm{G}^{*}$. En este caso, las únicas estructuras encontradas tras la optimización son las de la figura, es decir, o el metalociclo de 5 miembros (caso a), o el complejo con tres oxígenos implicados (caso b), que sólo está ligeramente desfavorecido en comparación con el complejo dicoordinado. 


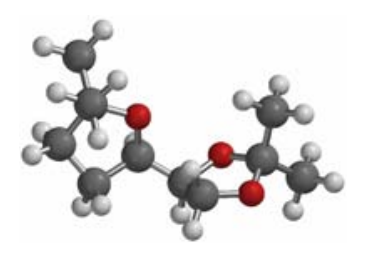

Tetrahidrofuranil-dioxolano $\mathbf{5 8}$

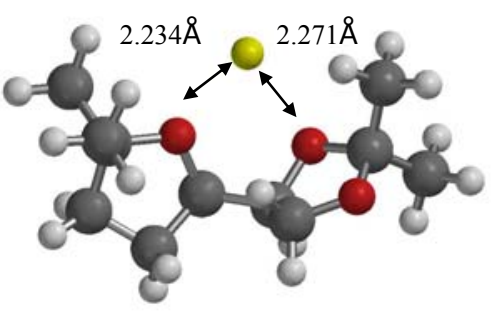

Caso a:

(dicoordinado)

$\mathrm{Ea}=-101488.360$

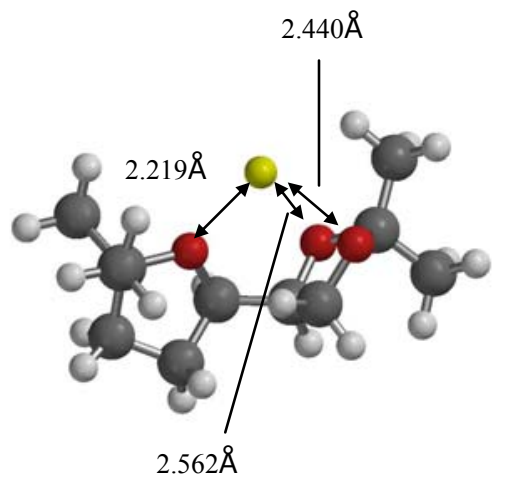

Caso b:

(tricoordinado)

$\mathrm{Ea}=-101487.771$

Figura 23. Energías de afinidad absoluta por el $\mathrm{Na}^{+}$en el nivel $\mathrm{HF} / 6-31+\mathrm{G}^{*}$

De forma similar al método usado para los complejos con $\mathrm{Na}^{+}$, se hicieron los cálculos para los complejos con $\mathrm{K}^{+}$. Se cambió el $\mathrm{Li}^{+}$por $\mathrm{K}^{+}$y se hizo la optimización de la geometría con $\mathrm{HF} / 6-31+\mathrm{G}^{*}$. Los mínimos energéticos encontrados corresponden a la estructura tipo bis-THF (caso a) y a aquella en la que el metal se coordina solo con dos oxígenos pero forma un metalociclo de seis miembros (caso b). El sistema con tres oxígenos ligados al catión no se encontró como mínimo de energía en este caso (Figura 24). 


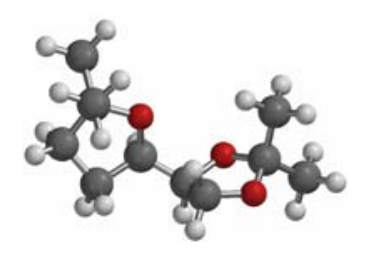

Tetrahidrofuranil-dioxolano $\mathbf{5 8}$

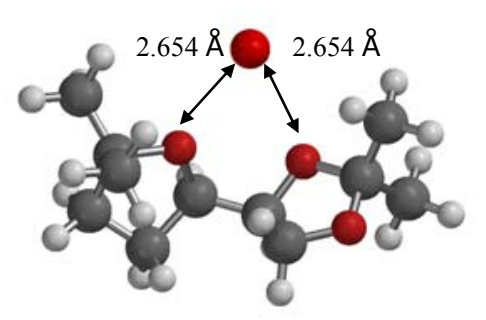

Caso a:

(dicoordinado)

$\mathrm{Ea}=-375892.195$

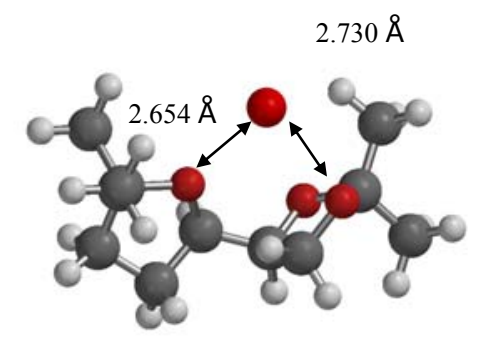

Caso b:

(dicoordinado)

$\mathrm{Ea}=-375890.848$

Figura 24. Energías de afinidad absoluta por el $\mathrm{K}^{+}$en el nivel $\mathrm{HF} / 6-31+\mathrm{G}^{*}$

Hay que tener en cuenta que, aunque esta técnica es capaz de calcular afinidades con una fiabilidad de alrededor de $2 \mathrm{kcal} / \mathrm{mol}$, las diferencias energéticas serían más fiables para series de moléculas estrechamente relacionadas.

Tras estos estudios se puede concluir lo siguiente:

Los ligandos tetrahidrofuranil-dioxolano $\mathbf{5 4}$ y $\mathbf{5 8}$ tendrán menos afinidad por el $\mathrm{Li}^{+}$ que el bis-THF descrito en bibliografía, pero podrían ser más asimétricos y por lo tanto ser útiles como catalizadores asimétricos en reacciones con organometálicos de litio.

La colocación de los dos metilos en alfa al oxígeno del tetrahidrofurano parece aumentar la afinidad de estos ligandos por el litio. 
La estructura del complejo dependerá mucho del catión, aunque la más favorecida siempre es la que tiene el metal coordinado por los oxígenos para formar un anillo de 5 miembros.

Probablemente el disolvente influirá bastante, ya que puede afectar a la coordinación preferida del metal, y podría afectar también la cantidad de complejo formado.

También se llevaron a cabo estudios de modelización molecular para conocer el mecanismo de complejación de los compuestos 54 y 58 con cationes alcalinos $\left(\mathrm{Li}^{+}, \mathrm{Na}^{+}\right.$ $\left.\mathrm{y} \mathrm{K}^{+}\right)$y alcalinotérreos $\left(\mathrm{Na}^{+} \mathrm{y} \mathrm{Mg}^{+}\right) .{ }^{187}$

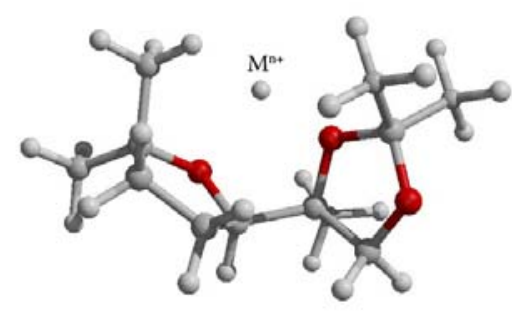

54

Figura 25. Modelo A

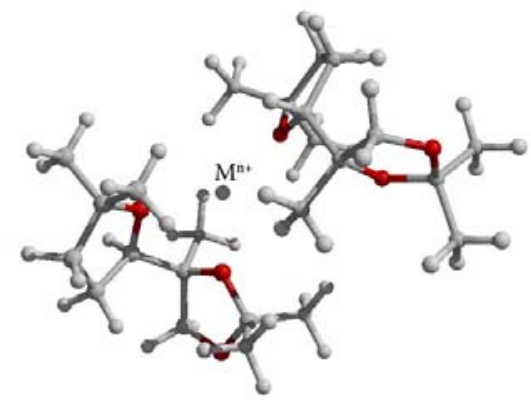

$54 \times 2$

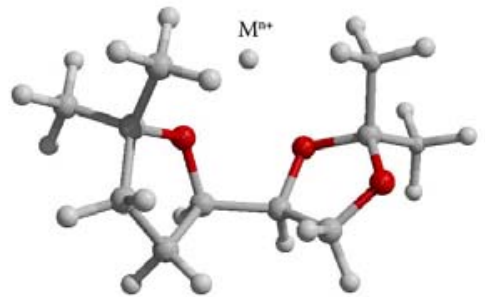

58

Figura 26. Modelo B

\footnotetext{
${ }^{187}$ Los cálculos se realizaron en un PC, Pentium IV $1.86 \mathrm{GHz}$ con 2 Gb de RAM utilizando el programa Gaussian 03 (Revision B.03, M. J. Frisch et al.). Para la optimización de las geometrías de 54 y 58, se empleó el modelo de cálculo PM3/RHF. Los cálculos de las energías se obtuvieron a partir de las geometrías optimizadas mediante un cálculo de single-point con un nivel de teoría $6-31 \mathrm{G}(\mathrm{d}) / \mathrm{RHF}$.
} 
Para ello se propusieron dos modelos: un primer modelo $\mathbf{A}$ en el que una molécula de tetrahidrofuranil-dioxolano está complejando un catión (Figura 25) y un segundo modelo $\mathbf{B}$ en el que dos moléculas de tetrahidrofuranil-dioxolano se encuentran complejando un solo catión (Figura 26).

Lo que se busca es calcular las constantes de afinidad de cada uno de los tetrahidrofuranil-dioxolanos $\mathbf{5 4}$ y $\mathbf{5 8}$ por los cationes correspondientes para cada modelo A o B y ver cuál de ellos presenta una mayor estabilidad. El valor de la constante de afinidad $\mathrm{K}_{\mathrm{a}}$ para cada caso se obtiene a partir del cálculo de las energías libres de Gibbs a través de la ecuación siguiente: $\Delta \mathrm{G}=-\mathrm{RT} \operatorname{lnK}_{\mathrm{a}}$. Así, mediante el cálculo de la energía necesaria para formar el complejo correspondiente, se podrá obtener el valor de $\mathrm{K}_{\mathrm{a}}$ para cada caso.

En las siguientes tablas (Tablas 1-4) se resumen los valores de $K_{a}$ encontrados para el modelo A (unimolecular) y el modelo B (bimolecular) con cada uno de los tetrahidrofuranil-dioxolanos $\mathbf{5 4}$ y 58.

Tabla 1. Constantes de afinidad $\left(\mathrm{K}_{\mathrm{a}}\right)$ calculadas para el compuesto 54 en el modelo $\mathbf{A}$.

\begin{tabular}{|c|c|c|c|}
\hline 54/Complejo & Energía (Hartree) & $\Delta \mathrm{G}(\mathrm{Kcal} / \mathrm{mol})$ & $\mathrm{K}_{\mathrm{a}}\left(\mathrm{M}^{-1}\right)$ \\
\hline 54 & $-652,7521$ & 0,0 & - \\
\hline 54- $\mathrm{Li}^{+}$ & $-660,0607$ & $-45,87$ & $6,0 \cdot 10^{3}$ \\
\hline 54- $\mathrm{Na}^{+}$ & $-814,4668$ & $-34,76$ & $3,4 \cdot 10^{3}$ \\
\hline $54-\mathrm{K}^{+}$ & $-1251,6953$ & $18,07^{*}$ & $9,3 \cdot 10^{2}$ \\
\hline $54-\mathrm{Ca}^{2+}$ & $-1328,8725$ & $-10,22$ & $3,0 \cdot 10^{2}$ \\
\hline $54-\mathrm{Mg}^{2+}$ & $-851,8316$ & $-167,80$ & ${\underline{8,0 \cdot 10^{4}}}^{4}$ \\
\hline
\end{tabular}

Tabla 2. Constantes de afinidad $\left(\mathrm{K}_{\mathrm{a}}\right)$ calculadas para el compuesto $\mathbf{5 8}$ en el modelo $\mathbf{A}$.

* Proceso desfavorecido termodinámicamente 
Tabla 3. Constantes de afinidad $\left(\mathrm{K}_{\mathrm{a}}\right)$ calculadas para el compuesto $\mathbf{5 4}$ en el modelo $\mathbf{B}$.

\begin{tabular}{|c|c|c|c|}
\hline 54×2/Complejo & Energía (Hartree) & $\Delta G($ Kcal $/ \mathrm{mol})$ & $K_{a}\left(M^{-1}\right)$ \\
\hline 54 & $-1305,5042$ & 0,0 & 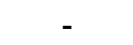 \\
\hline $54 \times 2-\mathrm{Li}^{+}$ & $-1312,8858$ & $-91,68$ & $2,4 \cdot 10^{4}$ \\
\hline $54 \times 2-\mathrm{Na}^{+}$ & $-1467,2939$ & $-81,83$ & $1,9 \cdot 10^{4}$ \\
\hline $54 \times 2-K^{+}$ & $-1904,4710$ & $3,26^{*}$ & $3,0 \cdot 10$ \\
\hline $54 \times 2-\mathrm{Ca}^{2+}$ & $-1981,7604$ & $-95,44$ & $2,6 \cdot 10^{4}$ \\
\hline $54 \times 2-\mathrm{Mg}^{2+}$ & $-1504,6911$ & $-235,19$ & $1,6 \cdot 10^{5}$ \\
\hline
\end{tabular}

* Proceso desfavorecido termodinámicamente

Tabla 4. Constantes de afinidad $\left(\mathrm{K}_{\mathrm{a}}\right)$ calculadas para el compuesto $\mathbf{5 8}$ en el modelo $\mathbf{B}$.

\begin{tabular}{|c|c|c|c|}
\hline 58x2/Complejo & Energía (Hartree) & $\Delta \mathbf{G}(\mathrm{Kcal} / \mathrm{mol})$ & $\mathrm{K}_{\mathrm{a}}\left(\mathrm{M}^{-1}\right)$ \\
\hline $58 \times 2$ & $-1383,5822$ & 0,0 & \\
\hline $58 \times 2-\mathrm{Li}^{+}$ & $-1390,9429$ & $-78,56$ & $1,8 \cdot 10^{4}$ \\
\hline $58 \times 2-\mathrm{Na}^{+}$ & $-1545,3110$ & $-43,61$ & $5,4 \cdot 10^{3}$ \\
\hline $58 \times 2-K^{+}$ & $-1982,6029$ & $-30,56$ & $2,7 \cdot 10^{3}$ \\
\hline $58 \times 2-\mathrm{Ca}^{2+}$ & $-2059,8521$ & $-104,04$ & $\underline{3,1}^{1} 10^{4}$ \\
\hline $58 \times 2-\mathrm{Mg}^{2+}$ & $-1582,7835$ & $-244,23$ & $1,7 \cdot 10^{5}$ \\
\hline
\end{tabular}

A la vista de los resultados, parece muy probable que el mecanismo de complejación de cualquiera de los tetrahidrofuranil-dioxolanos sea bimolecular. Asimismo, tanto 54 como 58 presentan una gran afinidad de complejación por los cationes divalentes, en especial $\mathrm{Mg}^{2+}$, mientras que para los monovalentes es mucho menor, llegando incluso a ser desfavorable termodinámicamente para el $\mathrm{K}^{+}$. 


\subsection{SÍNTESIS Y APLICACIONES DE TETRAHIDROPIRANOS 3-HIDROXI- 2,2,6,6-TETRASUSTITUIDOS DE 9 ÁTOMOS DE CARBONO}

\subsubsection{Antecedentes}

En trabajos precedentes de nuestro grupo de investigación, se llevó a cabo un estudio minucioso de reacciones de ciclación de $\delta$-hidroxiepóxidos, estudiando en particular la influencia de los diferentes grupos protectores. ${ }^{188}$ En este estudio se lograron sintetizar tetrahidropiranos cis y trans con alto rendimiento y regioselección por ciclación con CSA de los $\delta$-hidroxiepóxidos diastereoisoméricos 62 y 63 (Esquema 103). Dichos epóxidos se obtienen en una relación 1:1 por epoxidación, en las condiciones habituales, con $m$-CPBA del compuesto $\mathbf{2 8}$, cuya obtención ya ha sido comentada anteriormente en esta memoria (apartado 1.1.4., Esquema 87).

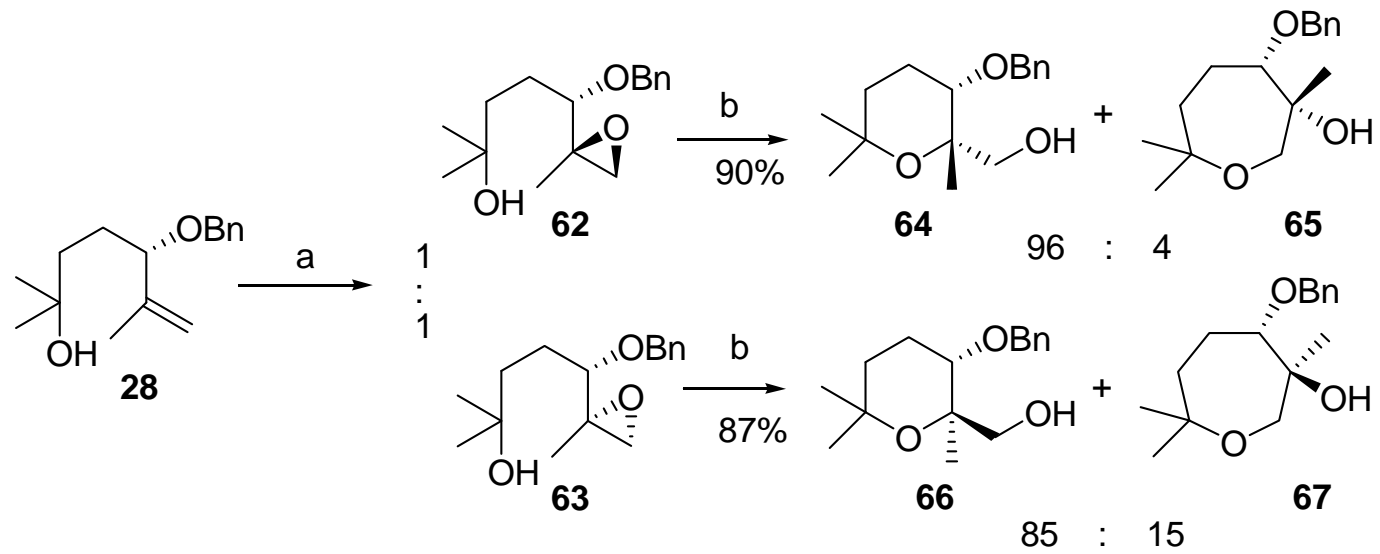

Esquema 103. a) $m$-CPBA, DCM, $0^{\circ} \mathrm{C}, 82 \%$; b) $\mathrm{CSA}, \mathrm{DCM},-40^{\circ} \mathrm{C}$.

188 (a) Díez, D.; Moro, R. F.; Lumeras, W.; Rodríguez, L.; Marcos, I. S.; Basabe, P.; Escarcena, R.; Urones, J.G. Synlett 2001, 8, 1335; (b) Díez, D.; Moro, R. F.; Lumeras, W.; Rodríguez, L.; Marcos, I. S.; Basabe, P.; Escarcena, R.; Urones, J. G. Synthesis 2002, 2, 175. 


\subsubsection{Síntesis de los aldehídos 68 y 69 como catalizadores orgánicos para epoxidaciones asimétricas $^{189}$}

Los dioxiranos son agentes oxidantes muy versátiles que presentan un gran potencial para la síntesis asimétrica, particularmente en las epoxidaciones asimétricas de olefinas no funcionalizadas. ${ }^{190}$ Los dioxiranos se pueden obtener in situ a partir de Oxone ${ }^{\circledR}$ y cetonas (Esquema 104) por lo que, si éstas son quirales, se podrán llevar a cabo epoxidaciones asimétricas.
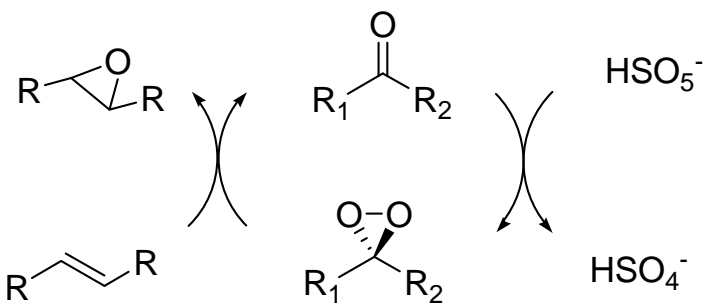

Esquema 104

La primera cetona quiral que se utilizó para este tipo de reacciones fue la isopinocanfona, introducida por $\mathrm{Curci}^{191}$ y con la que se lograron ee del $12.5 \%$, demostrándose que se podían obtener epóxidos quirales si se utilizaban cetonas quirales.

189 Díez, D.; Nuñez, M. G.; Moro, R. F.; Garrido, N. M.; Marcos, I. S.; Basabe, P.; Urones, J. G. Molecules 2006, 11, 959.

${ }^{190}$ Para revisiones bibliográficas sobre epoxidaciones asimétricas organocatalíticas con cetonas quirales, ver: (a) Frohn, M.; Shi, Y. Synthesis 2000, 1979; (b) Shi, Y. Acc. Chem. Res. 2004, 37, 488; (c) Yang, D. Acc. Chem. Res. 2004, 37, 497. Para revisiones bibliográficas sobre epoxidaciones asimétricas organocatalíticas de olefinas deficientes en electrones, ver: (a) Lattanzi, A. Curr. Org. Synth. 2008, 5, 117; (b) Díez, D.; Núñez, M. G.; Antón, A. B.; García, P.; Moro, R. F.; Garrido, N. M.; Marcos, I. S.; Basabe P.; Urones, J. G. Curr. Org. Synth. 2008, en prensa. Para ejemplos recientes, ver: (d) Armstrong, A.; Ahmed, G.; Dominguez-Fernandez, B.; Hayter, B. R.; Wailes, J. S. J. Org. Chem. 2002, 67, 8610; (e) Shing, T. K. M.; Leung, G. Y. C. Tetrahedron 2002, 58, 7545; (f) Stearman, C. J.; Behar, V. Tetrahedron Lett. 2002, 43, 1943; (g) Matsumoto, K.; Tomioka, K. Tetrahedron Lett. 2002, 43, 631; (h) Klein, S.; Roberts, S. M. J. Chem. Soc., Perkin Trans. 1 2002, 2686; (i) Denmark, S. E.; Matsuhashi, H. J. Org. Chem. 2002, 67, 3479; (j) Bortolini, O.; Fantin, G.; Fogagnolo, M.; Forlani, R.; Maietti, S.; Pedrini, P. J. Org. Chem. 2002, 67, 5802; (k) Tian, H. Q.; She, X. G.; Yu, H. W.; Shu, L. H.; Shi, Y. J. Org. Chem. 2002, 67, 2435; (1) Shing, T. K. M.; Leung, G. Y. C.; Yeung, K. W. Tetrahedron Lett. 2003, 44, 9225; (m) Shing, T. K. M.; Leung, Y. C.; Yeung, K. W. Tetrahedron 2003, 59, 2159; (n) Shu, L. H.; Wang, P. Z.; Gan, Y. H.; Shi, Y. Org. Lett. 2003, 5, 293; (ñ) Shu, L. H.; Shi, Y. Tetrahedron Lett. 2004, 45, 8115; (o) Hickey, M.; Goeddel, D.; Crane, Z.; Shi, Y. Proc. Natl. Acad. Sci. U.S.A. 2004, 101, 5794; (p) Armstrong, A.; Dominguez-Fernandez, B.; Tsuchiya, T. Tetrahedron 2006, 62, 6614.

191 (a) Curci, R.; Fiorentino, M.; Serio, M. R. J. Chem. Soc., Chem. Commun. 1984, 155. 
Otros tipos de cetonas quirales utilizadas son las derivadas de binaftilos, utilizadas por primera vez por Yang et al., ${ }^{192}$ las tipo tetrahidropiranonas desarrolladas por Armstrong ${ }^{190 \mathrm{~d}, \mathrm{p}}$ y las derivadas de la D-fructosa, introducidas por Shi (Figura 27). ${ }^{190 k, n, n ̃, o}$

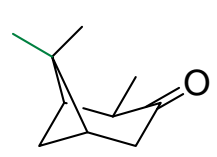

Curci<smiles>O=C(CO)COc1ccc2ccccc2c1-c1c(OCC(=O)CO)ccc2ccccc12</smiles>

Yang

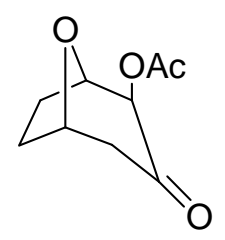

Armstrong<smiles>CC1(C)O[C@H]2CO[C@]3(COC(C)(C)O3)C(=O)[C@@H]2O1</smiles>

Shi

Figura 27

Sin embargo, aunque los dioxiranos de aldehídos estén implicados en algunos procesos biológicos, dichos compuestos no se suelen utilizar para este tipo de reacciones. Esto se debe a que siempre se ha descrito que la reacción de aldehídos con Oxone ${ }^{\circledR}$ produce el correspondiente ácido. Pero como se observa en el Esquema 105, este es sólo uno de los caminos de reacción que pueden seguir por evolución del intermedio de Criegee.

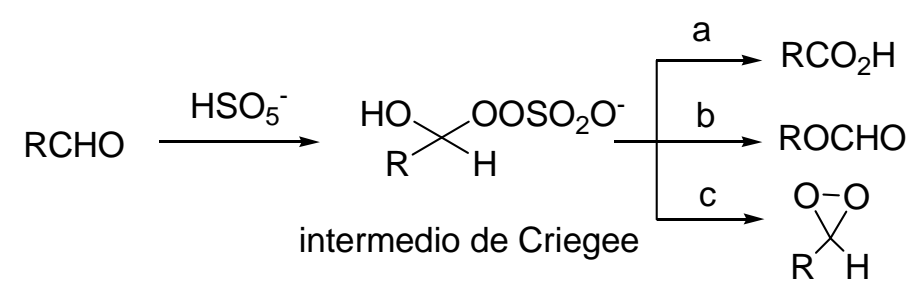

Esquema 105

Recientemente, Zhao et al. probaron que se pueden llevar a cabo reacciones de epoxidación enantioselectiva de olefinas utilizando Oxone ${ }^{\circledR}$ y los aldehidos derivados de fructosa quirales representados en la Figura 28, obteniéndose en algunos casos excesos enantioméricos superiores al $90 \% .{ }^{193}$

\footnotetext{
${ }^{192}$ Yang, D.; Yip Y.- C.; Tang, M.- W.; M.- K. Wong; Zheng, J.- H.; Cheung, K.- K. J. Am. Chem. Soc. 1996, 118, 491.

${ }^{193}$ Bez, G.; Zhao, C.- G. Tetrahedron Lett. 2003, 44, 7403.
} 


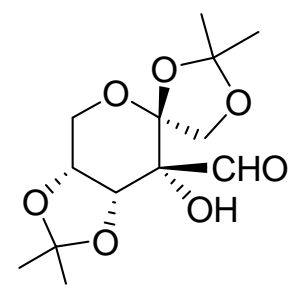<smiles>CC1(C)O[C@H]2CO[C@]3(COC(C)(C)O3)[C@](CO)(OBr)[C@H]2O1</smiles>

Figura 28

Como disponíamos de un procedimiento sencillo para la síntesis de los tetrahidropiranos 64 y 66 (Esquema 103), decidimos utilizarlos como precursores de los aldehídos 68 y 69, los cuales se podrían utilizar como catalizadores orgánicos en reacciones de epoxidación asimétrica de olefinas no funcionalizadas siguiendo la metodología de Zhao. Así, al someter por separado los tetrahidropiranos 64 y 66 a oxidación con el reactivo de Ley, ${ }^{174}$ se obtuvieron los aldehídos 68 y 69 con buen rendimiento (Esquema 106).<smiles>CC1(C)CC[C@@H](OBr)[C@](C)(CO)O1</smiles>

64<smiles>CC1(C)CC[C@@H](OBr)[C@@](C)(CO)O1</smiles>

66

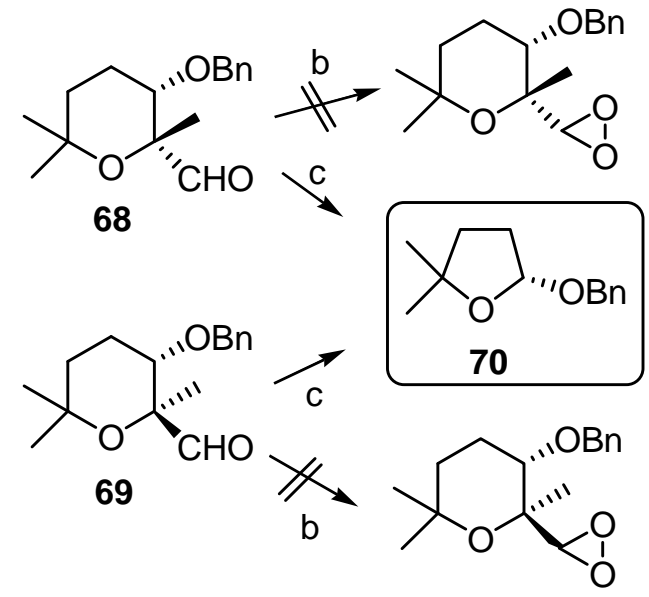

Esquema 106. a) TPAP, NMO, DCM, tamiz molecular ( $3 \AA$ activado); b) Condiciones de epoxidación de Shi (Ref. 194): Oxone ${ }^{\circledR}$ (5 eq.), aq. $\mathrm{K}_{2} \mathrm{CO}_{3}, \mathrm{Na}_{2} \mathrm{AEDT}\left(0.4 \mathrm{mM}\right.$, aq. sol.), Buffer pH=10.5, $\left(\mathrm{Bu}_{4} \mathrm{~N}\right)_{2}^{+} \mathrm{SO}_{4}$, $\mathrm{CH}_{3} \mathrm{CN}, 0 \%$; c) Condiciones de epoxidación de Yang (Ref. 195) (pH=7.5): Oxone ${ }^{\circledR}\left(10\right.$ eq.), $\mathrm{NaHCO}_{3}$ (15 eq.), $\mathrm{Na}_{2} \mathrm{AEDT}$ (0.4mM, aq. sol.), $\mathrm{CH}_{3} \mathrm{CN} / \mathrm{H}_{2} \mathrm{O}, 60 \%$.

Al utilizar los compuestos 68 y 69 como catalizadores orgánicos para la epoxidación de E-estilbeno bajo las condiciones de epoxidación de Shi, ${ }^{194}$ no se observó transformación alguna, recuperándose el material de partida en su totalidad.

${ }^{194}$ Wang, Z. X.; Tu, Y.; Fhron, M.; Zhang, J. R.; Shi, Y. J. Am. Chem. Soc. 1997, 119, 11224. 
Por otra parte, al aplicar las condiciones de epoxidación de Yang $^{195}$ tanto con 68 como con 69 para esta misma reacción, solo se obtuvo un 6\% del óxido de E-estilbeno racémico. Sin embargo, en ambos casos se aisló el tetrahidrofurano $\mathbf{7 0}$ con un $60 \%$ de rendimiento. Dado que este compuesto presentaba rotación óptica, se decidió medir su pureza enantiomérica mediante HPLC quiral (ChiralPak AD-H, $25 \mathrm{~cm}$ x 10 mm, 99:1 hexano/ $\left.{ }^{i} \mathrm{PrOH}\right)$, para lo cual se sintetizó el racémico de $\mathbf{7 0}$ (rac-70) por tratamiento del lactol 8, previamente sintetizado (apartado 1.1.3., Esquema 82), con alcohol bencílico en medio ácido (Esquema 107). ${ }^{196}$ Tras el análisis de HPLC, se vió que el lactol 70 se obtenía con un $78 \%$ ee.

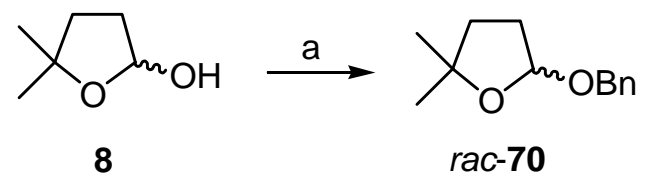

Esquema 107. a) $\mathrm{BnOH}, p$-TsOH, $\mathrm{DCM}, 70 \%$.

Recientemente Armstrong et al. han descrito la contracción de anillo de 2alcoxi-3,4-dihidro-2H-piranos hasta 4,5-cis- tetrahidropiranonas disustituídas mediante un reordenamiento oxidativo (Esquema 108). ${ }^{197}$<smiles>[R9]O[C@@H]1CC([R])([R])C=C(C)O1</smiles>
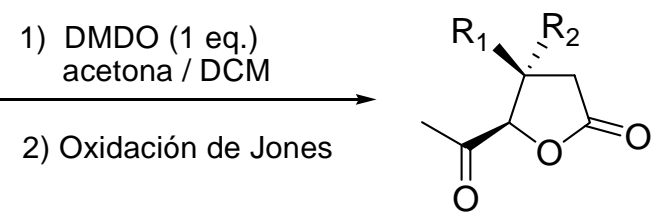

$\mathrm{R}_{3}: \mathrm{H}, \mathrm{Et}, n-\mathrm{Bu}$

\section{Esquema 108}

Así pues, los resultados obtenidos en nuestro caso se podrán explicar de manera análoga mediante un nuevo reordenamiento oxidativo según el mecanismo representado en el Esquema 109 para el caso del aldehído 68.

\footnotetext{
195 Yang, D.; Wong, M. K.; Yip, Y. C. J. Org. Chem. 1995, 60, 3887.

${ }^{196}$ Clive, D. J.; Ardelean, E-S. J. Org. Chem. 2001, 66, 4841.

${ }^{197}$ Armstrong, A.; Chung, H. Tetrahedron Lett. 2006, 47, 1617.
} 
El monopersulfato ataca al aldehido $\mathbf{6 8} \mathrm{y}$ el intermedio de Criegee formado evoluciona mediante una reacción de Baeyer-Villiger ${ }^{198}$ hacia el formiato correspondiente A, el cual se hidroliza hasta el lactol B. Dicho lactol en el medio de reacción está en equilibrio con la hidroxicetona $\mathbf{C}$, la cual sufre una nueva oxidación de Baeyer-Villiger formándose el acetato D. Esta segunda oxidación está favorecida por la existencia de una función oxigenada en posición $\alpha .{ }^{199} \mathrm{El}$ ataque del hidroxilo terciario de $\mathbf{D}$ al carbono carboxílico da como resultado el hemiortoéster $\mathbf{E}$, que es el que reordena finalmente para dar el lactol bencilado 70. Este mismo mecanismo de reacción también explicaría los idénticos resultados obtenidos con el aldehído 69.

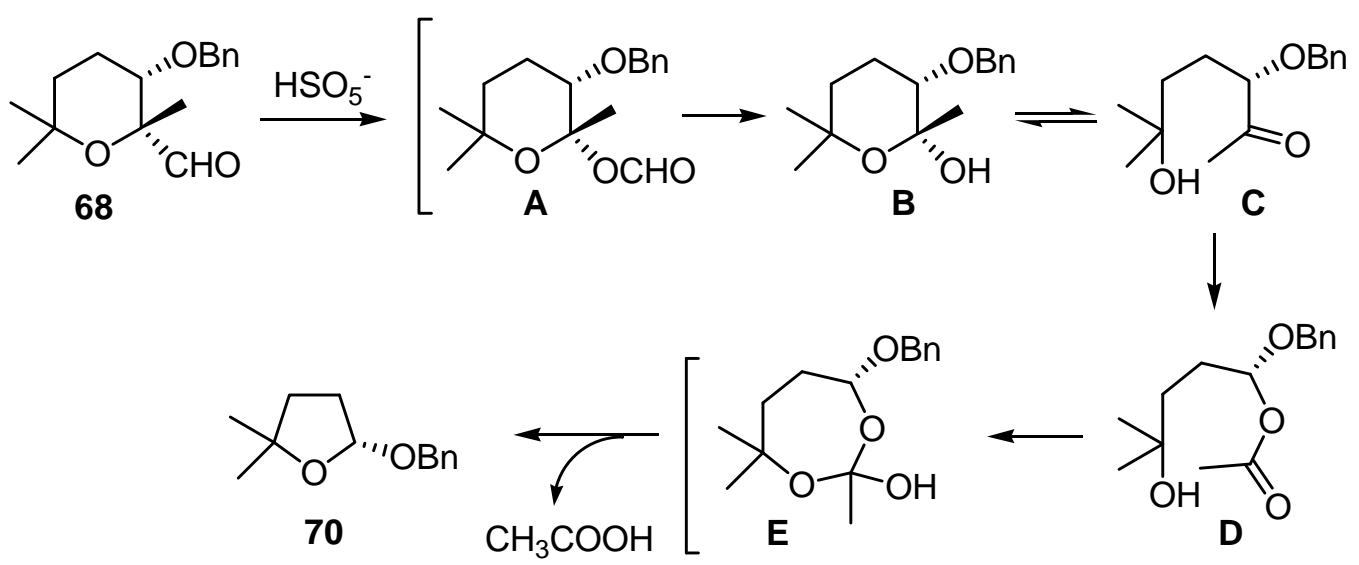

Esquema 109

Con el fin de comprobar el mecanismo propuesto y ver la influencia que tiene el sustituyente benciloxi en posición C-3 en el reordenamiento, se sintetizó un aldehído análogo a 68 y 69 con el grupo benciloxi en posición C-5 (74) y se sometió a las condiciones de epoxidación de Yang (Esquema 110).

\footnotetext{
${ }^{198}$ Para revisiones bibliográficas, ver: (a) Krow, G. R. Org. React. 1993, 43, 251; (b) Renz, M.; Meunier, B. Eur. J. Org. Chem. 1999, 737; (c) ten Brink, G. J.; Arends, I. W. C. E.; Sheldon, R. A. Chem. Rev. 2004, 104, 4105; Ver también: (d) Crudden, C. M.; Chen, A. C.; Calhoun, L. A. Angew. Chem., Int. Ed. 2000, 39, 2851; (e) Krasutsky, P. A.; Kolomytsin, I. V. Arkivoc 2005, 151; (f) Alvarez-Idaboy, J. R.; Reyes, L.; Cruz, J. Org. Lett. 2006, 8, 1763; (g) Frison, J.- C.; Palazzi, C.; Bolm, C. Tetrahedron 2006, 62, 6700; (h) Chang, M.- Y.; Kung, Y.- H.; Chen, S.- T. Tetrahedron Lett. 2006, 47, 4865.

${ }^{199}$ Dave, V.; Warnhoff, E. W. J. Org. Chem. 1983, 48, 2590.
} 


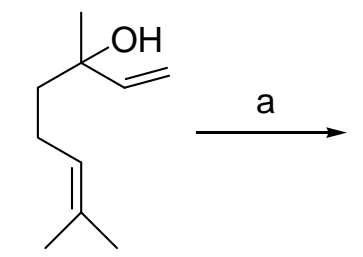

$( \pm)$-Linalool

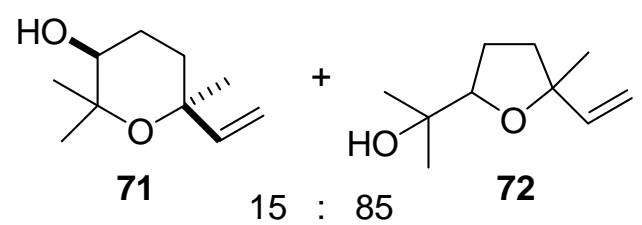

$\mathrm{b}$

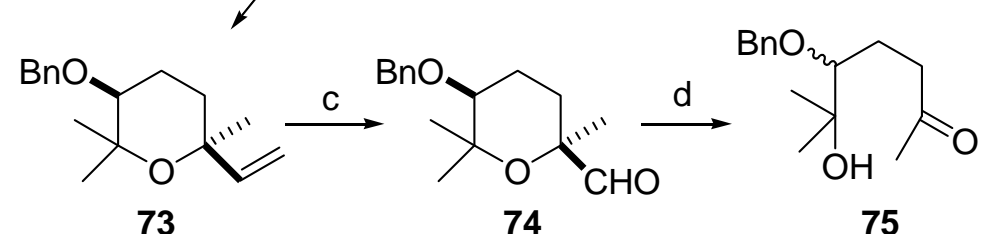

Esquema 110. a) 1. m-CPBA, DCM, $0^{\circ} \mathrm{C}$; 2. $\mathrm{CCl}_{3} \mathrm{COOH}, \mathrm{Et}_{2} \mathrm{O}$, t.a. $80 \%$; b) $\mathrm{NaH}, \mathrm{BnBr}, \mathrm{THF}, 90 \%$; c) 1 . $\mathrm{OsO}_{4}, \mathrm{NMO}, \mathrm{THF} / \mathrm{H}_{2} \mathrm{O} ; 2 . \mathrm{NaIO}_{4}, \mathrm{THF} / \mathrm{H}_{2} \mathrm{O}, 84 \%$; d) Condiciones de epoxidación de Yang $(\mathrm{pH}=7.5)$ : Oxone ${ }^{\circledR}$ (10 eq.), $\mathrm{NaHCO}_{3}$ (15 eq.), $\mathrm{Na}_{2} \mathrm{AEDT}$ (0.4mM, aq. sol.), $\mathrm{CH}_{3} \mathrm{CN} / \mathrm{H}_{2} \mathrm{O}$.

La epoxidación de linalool racémico con m-CPBA y posterior tratamiento en medio ácido produjo una mezcla del tetrahidropirano 71 y el tetrahidrofurano 72 en una proporción 15:85 (Esquema 110). ${ }^{200}$ Tras separar el primero de la mezcla, se trató con $\mathrm{NaH}$ y $\mathrm{BnBr}$ obteniéndose el bencilderivado 73 con buen rendimiento. La ruptura oxidativa del doble enlace de 73 con $\mathrm{OsO}_{4}$ y posterior tratamiento con $\mathrm{NaIO}_{4}$ dio el aldehído deseado 74, el cual se somete a las condiciones de epoxidación de Yang, obteniéndose la metilcetona 75. Por tanto, en este caso ha tenido lugar solamente una oxidación de Baeyer-Villiger, con lo que se puede concluir que es necesaria una función hidroxílica próxima al aldehído para que tenga lugar la segunda oxidación de BaeyerVilliger y se produzca así el reordenamiento hasta el tetrahidrofuranolactol correspondiente.

${ }^{200}$ (a) Urones, J. G.; Díez, D.; Marcos, I. S.; Basabe, P.; Lithgow, A. M.; Moro, R. F.; Garrido, N. M.; Escarcena, R. Tetrahedron 1995, 51, 3691; (b) Khomenko, T. M.; Tatarova, L. E.; Korchagina, D. V.; Barkhash, V. A. Russ. J. Org. Chem. 2002, 38, 498. 

Capítulo 2: Organocatálisis aplicada a la síntesis de tetrahidropiranos 

Como ya se mencionaba en la Introducción de esta memoria, en los últimos años la organocatálisis está ganando importancia dentro del campo de la síntesis orgánica, ya que se ha comprobado que las moléculas orgánicas pequeñas, aparte de los complejos metálicos y los biocatalizadores, pueden ser catalizadores altamente eficientes y selectivos. Dentro de la organocatálisis, se ha prestado especial atención a la catálisis nucleofílica con catalizadores tipo bases de Lewis, como las aminas, mostrándose un creciente interés por las reacciones que se producen a través de intermedios enamina o de una especie iminio.

La adición conjugada de nucleófilos a olefinas deficientes en electrones es una de las metodologías más empleadas en síntesis orgánica para la formación de enlaces CC y C-heteroátomo. ${ }^{201}$ Recientemente, la versión asimétrica catalítica de esta reacción empleando catalizadores orgánicos quirales ha sido ampliamente desarrollada. ${ }^{124 n ̃ ~}$ Más concretamente, en el capítulo de Introducción de esta memoria, vimos que la adición conjugada organocatalítica de nucleófilos oxigenados era uno de los métodos utilizados para la síntesis enantioselectiva de heterociclos oxigenados de seis miembros (Introducción. Parte II, apartado 1.2).

En este capítulo se estudiará la obtención organocatalítica de tetrahidropiranos mediante adiciones conjugadas intramoleculares. Para llevar a cabo dicho estudio, se han sintetizado diversos sustratos y se han probado como catalizadores orgánicos nuevas pirrolidinas quirales sintetizadas en nuestro grupo de investigación, así como otras comerciales o fácilmente obtenibles.

\footnotetext{
${ }^{201}$ Perlmutter, A. Conjugative Additions in Organic Synthesis; Pergamon Press: Oxford, 1992.

${ }^{124 n ̃ ~}$ Almaşi, D.; Alonso, D. A.; Nájera, C. Tetrahedron: Asymmetry 2007, 18, 299.
} 


\subsection{SÍNTESIS DE PIRROLIDINAS QUIRALES COMO CATALIZADORES}

\section{ORGÁNICOS}

\subsubsection{Importancia de los catalizadores tipo pirrolidina}

Hasta el momento, la prolina es la molécula orgánica que ha proporcionado los mejores resultados en organocatálisis. El primer ejemplo de catálisis asimétrica tipo enamina se remonta al año 1971 y se trata de la reacción de Hajos-Parrish-Eder-SauerWiechert, una reacción aldólica intramolecular catalizada por prolina. ${ }^{202}$ Tuvieron que pasar 30 años hasta que List et al., seguido de otros grupos descubrieran la gran variedad de transformaciones asimétricas catalizadas por este aminoácido aparte de la reacción aldólica, como son la reacción de Mannich o la adición de Michael entre muchas otras. ${ }^{203}$ Existen diversas razones por las cuales la prolina se ha convertido en una molécula tan significativa dentro del campo de la catálisis orgánica. Aparte de ser una molécula quiral, abundante, no muy cara y existir en sus dos formas enantioméricamente puras, desde el punto de vista químico es una molécula bifuncional (Figura 29), lo que hace que pueda actuar como un ácido y como una base, catalizando reacciones de forma similar a las enzimas. Además de estas características, que comparte con el resto de aminoácidos, la prolina se diferencia de éstos en que es una amina secundaria cíclica de estructura pirrolidínica (Figura 29), lo que hace que pueda catalizar procesos basados en intermedios iminio-enamina. Por su parte, el ácido carboxílico contribuye al proceso catalítico actuando como un cocatalizador tipo Brönsted. $^{124 \mathrm{~b}}$

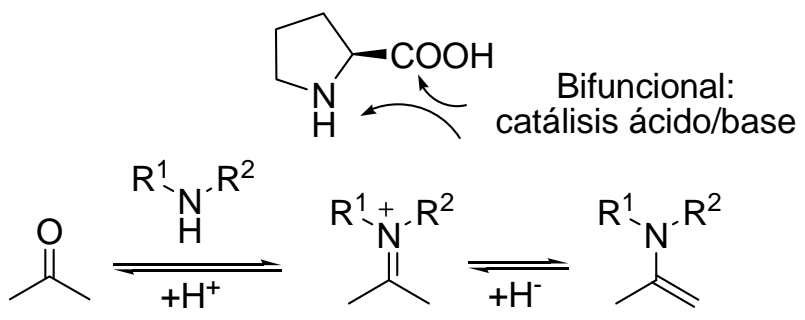

Figura 29

\footnotetext{
202 (a) Hajos, Z. G.; Parrish, D. R.; Patente alemana DE 2102623, 1971; (b) Eder, U.; Sauer, G.; Wiechert, R. Angew. Chem. Int. Ed. Engl. 1971, 10, 496; c) Hajos, Z. G.; Parrish, D. R. J. Org. Chem. 1974, 39, 1615.

${ }^{203}$ Ver referencia 124.

${ }^{124 b}$ List, B. Tetrahedron 2002, 58, 5573.
} 
Sin embargo, algunos inconvenientes de tipo experimental como son la escasa solubilidad de este compuesto en muchos disolventes así como las "elevadas" cantidades de catalizador necesarias (en muchos casos superiores al 30\%), han llevado a buscar nuevos análogos sintéticos que superen estos problemas. Algunos de estos catalizadores son los mostrados en la Figura 30.<smiles>COC(=O)[C@@H]1CCCN1</smiles><smiles>C[C@]1(C(=O)O)CCCN1</smiles><smiles>O=C(O)[C@@H]1NCC[C@H]1O</smiles>

$\mathrm{RO}$.

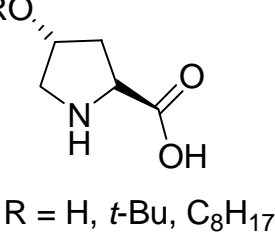<smiles>O=C(O)C1CCN1</smiles>
$\mathrm{R}=\mathrm{H}, \mathrm{Me}$, TIPS<smiles>O=C(O)C1CCCCN1</smiles><smiles>[R]C1([R])SCN[C@@H]1C(=O)O</smiles>

$\mathrm{R}=\mathrm{H}, \mathrm{Me}$<smiles>CN1C[C@H](Br)N[C@H]1C(=O)O</smiles><smiles>C1CNC(c2nnn[nH]2)C1</smiles><smiles>c1ccc(C2CCCN2)nc1</smiles><smiles>[R]=CCCOC</smiles><smiles>CN1C(=O)C(Cc2ccccc2)N[C@H]1C(C)(C)C</smiles><smiles>[R]C1([R2])NC(Br)C(=O)N1C</smiles>

$\mathrm{R}_{1}=\mathrm{H}, \mathrm{R}_{2}=t-\mathrm{Bu}$ $\mathrm{R}_{1}=\mathrm{R}_{2}=\mathrm{Me}$<smiles>CN1C(=O)[C@H](Cc2ccccc2)N[C@H]1C(C)(C)Cl</smiles><smiles>O=C(O)C1NC([PH+]c2ccccc2)[C@H](P)N1</smiles><smiles>C1CN[C@H](CN2CCCC2)C1</smiles><smiles>c1ccc([C](c2ccccc2)C2CCCN2)cc1</smiles><smiles>[R]C(O)(c1ccccc1)C1CCCN1</smiles><smiles>[R]OS(=O)(=O)NC(=O)[C@@H]1CCCN1</smiles><smiles>C=C(C)[R]=C1CCCCCCCCC1=O</smiles><smiles>C1CN[C@H](CN2CCOCC2)C1</smiles><smiles>[R]N1CCC[C@H]1[C@H]1CCCN1</smiles>

$\mathrm{R}=\mathrm{Me}, \mathrm{Et}, \mathrm{Bn}, i-\mathrm{Pr}$ ciclohexano<smiles>[R]OS(=O)(=O)NC[C@H]1CCCN1</smiles><smiles>Cc1c(C)c(C)c(C(=O)c2c(F)c(F)c(F)c(F)c2F)c(C)c1C</smiles>

Figura 30 


\subsubsection{Síntesis de los análogos de prolina 84 y 88}

Los catalizadores tipo pirrolidina han ganado notable importancia en los últimos años dentro del campo de la organocatálisis debido a los excelentes resultados conseguidos en la enantioselección de numerosas reacciones. Por ello, decidimos sintetizar los catalizadores análogos de prolina 84 y 88 (Figura 31) como catalizadores nucleofílicos para reacciones que transcurren mediante intermedios tipo ión iminio.

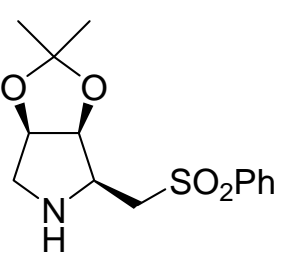

84

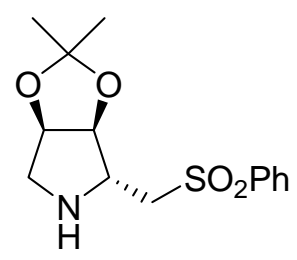

88

Figura 31

El compuesto 84 ya había sido previamente sintetizado en nuestro grupo de investigación aprovechando la metodología desarrollada para la obtención de pirrolidinas quirales a partir de vinilsulfonas y epoxisulfonas. ${ }^{204}$ Recientemente se ha utilizado en nuestro grupo como catalizador orgánico en la reacción de adición conjugada de ciclohexanona a nitroestireno $\mathrm{y}$, aunque los redimientos obtenidos fueron bajos, el exceso enantiomérico superó al descrito con L-prolina (Esquema 111). ${ }^{205}$

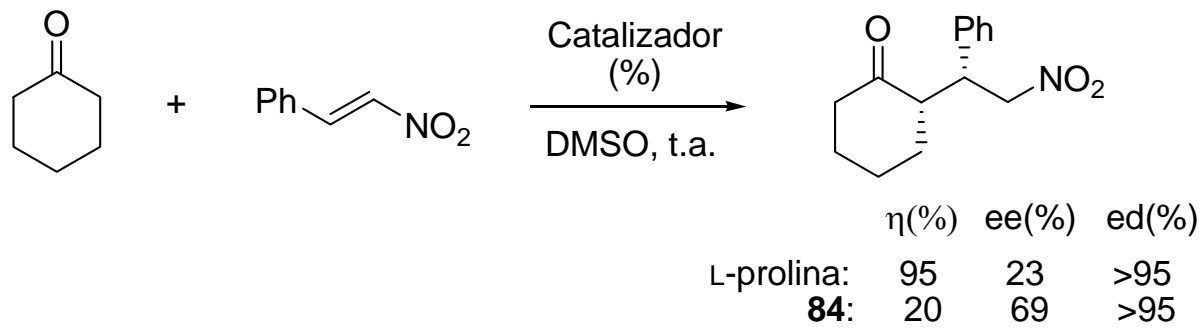

\section{Esquema 111}

204 (a) Díez, D.; Benéitez, M. T.; Marcos, I. S.; Garrido, N. M.; Basabe, P.; Urones, J. G. Tetrahedron: Asymmetry 2002, 13, 639; (b) Díez, D.; Benéitez, M. T.; Marcos, I. S.; Garrido, N. M.; Basabe, P.; Urones, J. G. Synlett 2003, 729; (c) Díez, D.; Gil, M. J.; Moro, R. F.; Garrido, N. M.; Marcos, I. S.; Basabe, P.; Sainz, F.; Broughton, H. B.; Urones, J. G. Tetrahedron: Asymmetry 2005, 16, 2980.

${ }^{205}$ Gil Ingelmo, M. J. Tesis Doctoral: Nuevos catalizadores en síntesis asimétrica. Universidad de Salamanca, 2006. 
El esquema retrosintético para la obtención del catalizador 84 es el que se muestra a continuación (Esquema 112).

La pirrolidina objetivo 84 se obtendrá a partir de la vinilsulfona 79 por reacción de ésta con bencilamina y posterior desbencilación. Dicha vinilsulfona se puede obtener fácilmente por reacción de eliminación del intermedio 79a, el cual procede de la adición de $\mathrm{LiCH}_{2} \mathrm{SO}_{2} \mathrm{Ph}$ al lactol 76 seguida de tosilación. Este último intermedio es fácilmente asequible por redución del producto comercial (-)-2,3-O-isopropiliden-Deritronolactona (Esquema 112).

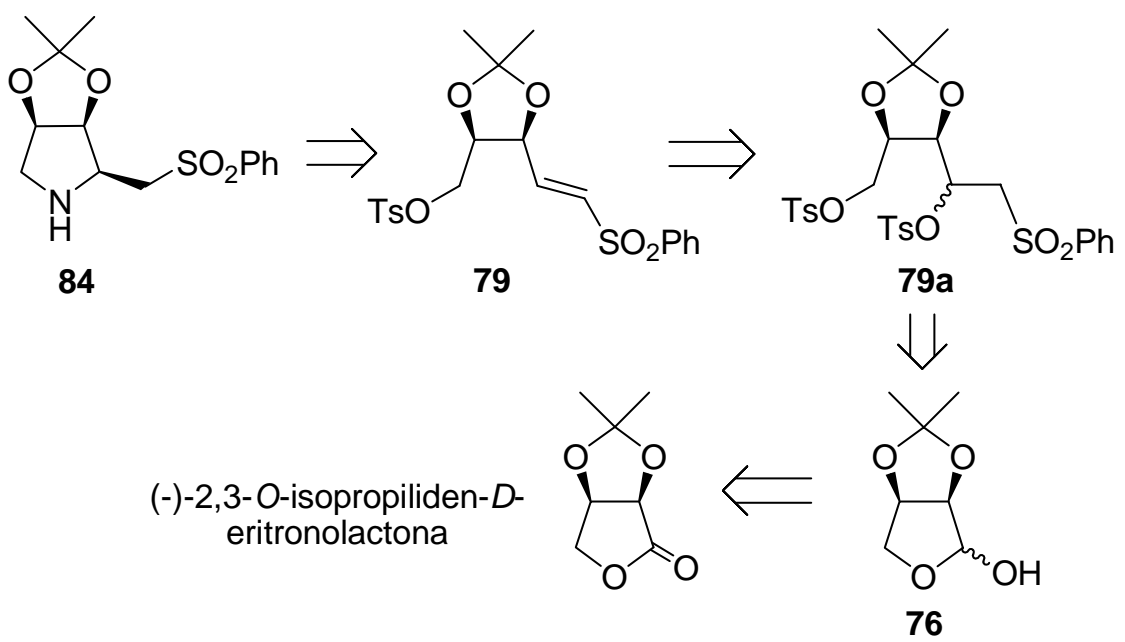

Esquema 112

Así pues, el procedimiento sintético para la obtención de la vinilsulfona intermedia 79 es el que se detalla a continuación (Esquema 113). El material de partida es la (-)-2,3-O-isopropiliden-D-eritronolactona, cuya reducción con DIBAL-H conduce al eritronolactol 76 con un rendimiento del 92\%. La posterior apertura de 76 con $\mathrm{PhSO}_{2} \mathrm{CH}_{2} \mathrm{Li}$ da los alcoholes 77 y 78 en relación $7 / 3$, esto es, con una pequeña estereoselectividad anti. ${ }^{206}$ Tras un estudio detallado de la posterior reacción de eliminación, ${ }^{204}$ se encontró que las mejores condiciones para esta reacción, es decir, las que minimizan los productos de ciclación 81 y 82 y la vinilsulfona con estereoquímica $Z$ 80, son el tratamiento de la mezcla de dioles 77 y 78 con 4 equivalentes de $\mathrm{NaH}$ a $0^{\circ} \mathrm{C}$ $\mathrm{y}$ la adición de 6 equivalentes de $\mathrm{TsCl}$ en THF a $-78^{\circ} \mathrm{C}$. De esta forma se obtiene una mezcla de las vinilsulfonas $\mathbf{7 9}$ y $\mathbf{8 0}$ en una proporción 3:1.

\footnotetext{
${ }^{206}$ La denominación anti está de acuerdo con la nomenclatura de Masamune: Masamune, S.; Kaiho, T.; Garvey, D. S. J. Am. Chem. Soc. 1982, 104, 5521.
} 


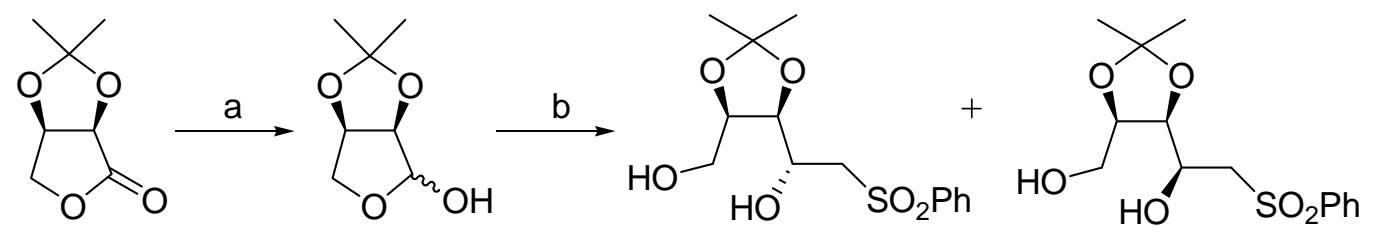

(-)-2,3-O-isopropiliden-Deritronolactona.

76

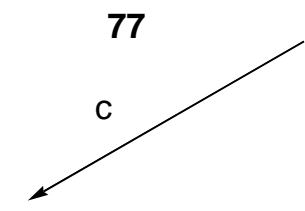

78
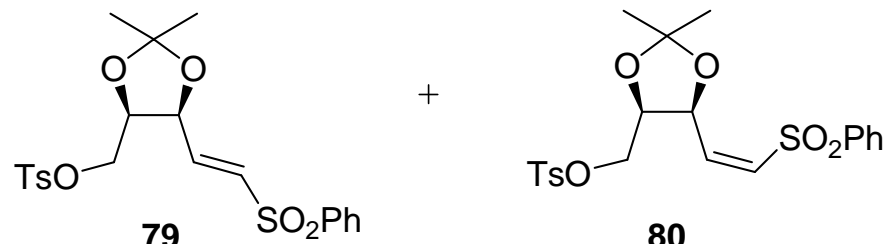

79

80

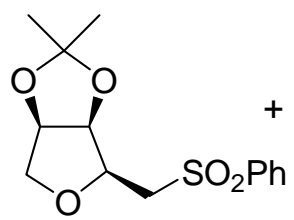

81

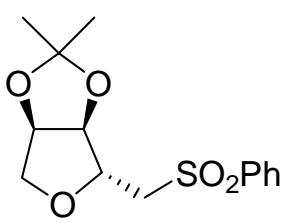

82

Esquema 113. a) DIBAL-H, DCM, $-78^{\circ} \mathrm{C}, 92 \%$; b) $\mathrm{PhSO}_{2} \mathrm{CH}_{2} \mathrm{Li}$, THF, $-78^{\circ} \mathrm{C}, 95 \%$; c) $\mathrm{NaH}(4$ eq. $), 0^{\circ} \mathrm{C}$, $\mathrm{TsCl}$ (6 eq.), $-78^{\circ} \mathrm{C}$, THF, $95 \%$.

En el paso de obtención de las vinilsulfonas 79 y 80, también se aíslan los tetrahidrofuranos 81 y 82 en muy pequeña proporción (5\%). Los resultados obtenidos en la reacción de eliminación pueden entenderse si se consideran los estados de transición de los ditosilatos intermedios formados a partir de los compuestos $\mathbf{7 7}$ y $\mathbf{7 8}$ (Figura 32). Como se observa, no existe una diferencia energética notable entre estos estados de transición, aunque se entiende que se forme mayoritariamente $\mathbf{7 9}$ por impedimento estérico. 

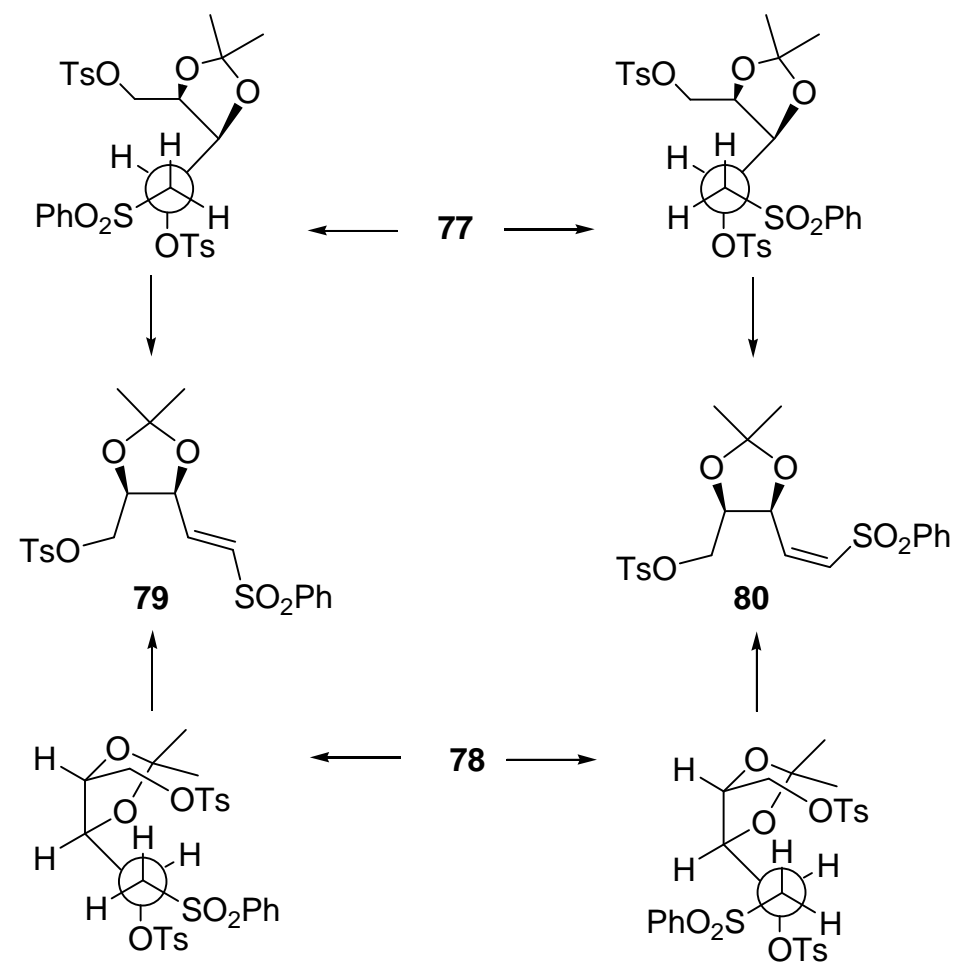

Figura 32

Tras la separación de la vinilsulfona $\mathbf{7 9}$ de la mezcla de reacción, su tratamiento con bencilamina en metanol ${ }^{207}$ conduce a la formación de la pirrolidina $\mathbf{8 3}$ de forma estereoselectiva mediante una reacción $\mathrm{S}_{\mathrm{N}} 2$ seguida de una adición de Michael (Esquema 114). La obtención de un único diastereoisómero implica que, en primer lugar, se produce la reacción de sustitución nucleofílica seguida de la reacción de adición tipo Michael. La posterior desbencilación ${ }^{208}$ de $\mathbf{8 3}$ por hidrogenolisis utilizando $\mathrm{Pd} / \mathrm{C}$ como catalizador conduce al compuesto 84 (Esquema 114).

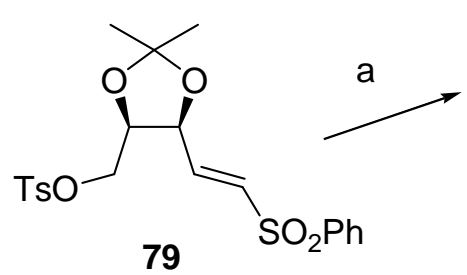

79
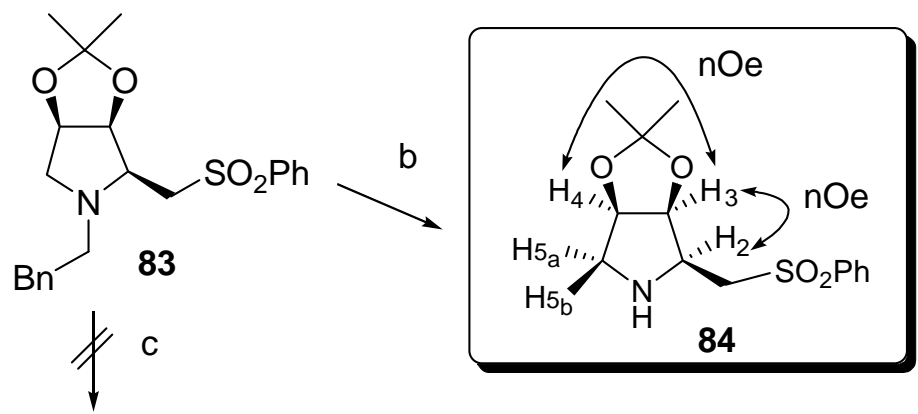

Esquema 114. a) $\mathrm{BnNH}_{2}, \mathrm{MeOH}$, reflujo, $78 \%$; b) $\mathrm{H}_{2}, \mathrm{Pd} / \mathrm{C}, \mathrm{MeOH}, 95 \%$; c) $n$-BuLi, THF, $-78^{\circ} \mathrm{C}$-t.a.

\footnotetext{
${ }^{207}$ Bunce, R. A.; Peeples, C. J.; Jones, P. B. J. Org. Chem. 1992, 57, 1727.

${ }^{208}$ Wang, Q.; Sasaki, A.; Potier, P.; Tetrahedron 1998, 54, 15759.
} 
La estereoquímica del compuesto $\mathbf{8 4}$ se establece mediante experimentos nOe. La existencia de nOe entre $\mathrm{H}-2$ y H-3, así como entre $\mathrm{H}-3$ y H-4 pone de manifiesto una disposición cis del grupo metilsulfona y del grupo acetónido (Esquema 114).

Posteriormente se decidió sintetizar el compuesto 88 (Esquema 115), epímero de 84 en posición C-2, ya que una disposición trans de los sustituyentes metilsulfona y acetónido podría incrementar la estereoselección en posteriores reacciones en las que se utilice como catalizador orgánico. En primer lugar se pensó en llevar a cabo la epimerización en posición C-2 con el compuesto bencilado 83. Sin embargo, al tratar dicho compuesto con $n$-BuLi en THF a $-78^{\circ} \mathrm{C}$, se recuperó inalterado (Esquema 114), por lo que se decidió introducir un grupo sustractor de electrones en el nitrógeno pirrolidínico. De esta manera se conseguiría transformarlo en mejor grupo saliente y tendría lugar la reacción retro-Michael buscada por desprotonación en posición C-1’.

El procedimiento sintético que se siguió es el descrito en el Esquema 115.

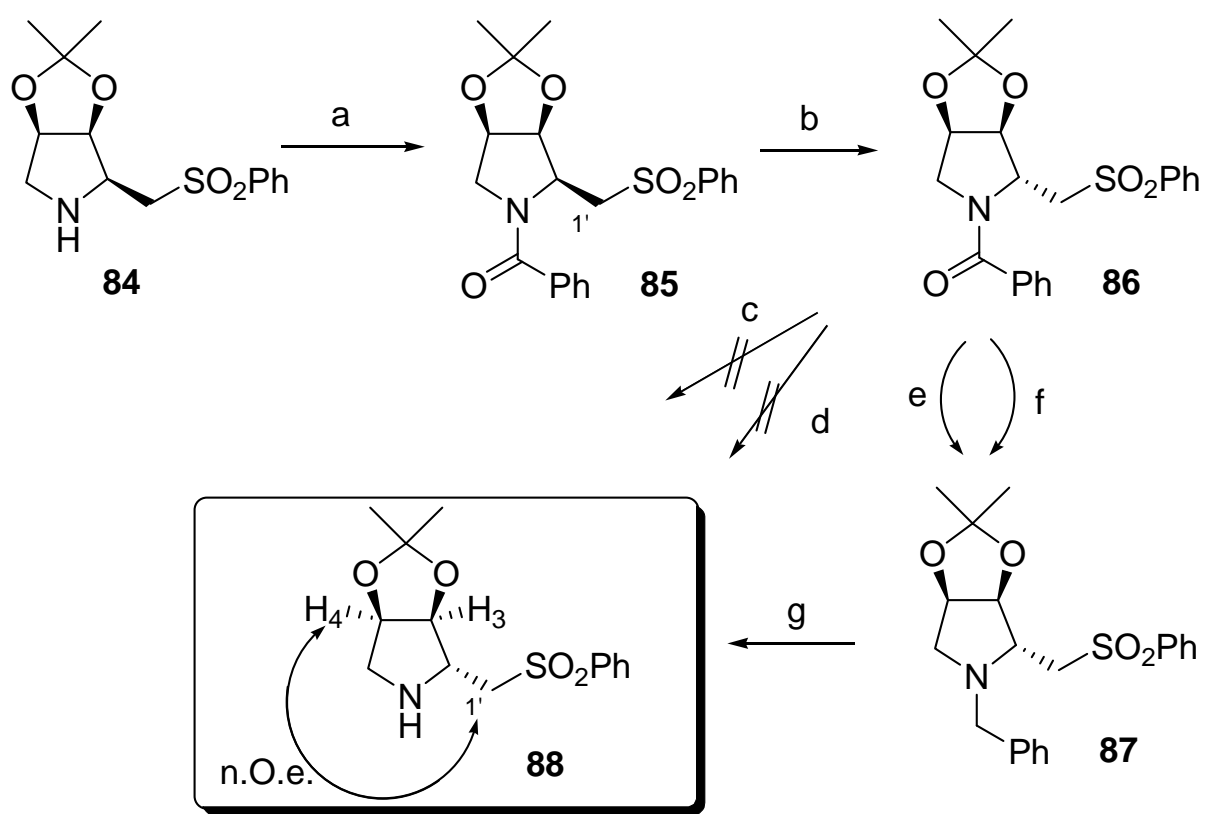

Esquema 115. a) $\mathrm{PhCOCl}, \mathrm{Pi}, 0^{\circ} \mathrm{C}$-t.a., 97\%: b) $n$-BuLi, THF, $-78^{\circ} \mathrm{C}$-t.a., $50 \%$; c) $\mathrm{NH}_{2}-\mathrm{NH}_{2}, \mathrm{EtOH}$, reflujo, 0\%; d) $\mathrm{HCl} \mathrm{6M}$, reflujo, 0\%; e) $\mathrm{LiAlH}_{4}$, THF, $0^{\circ} \mathrm{C}$-t.a., $30 \%$; f) $\mathrm{BH}_{3} \cdot \mathrm{THF}, \mathrm{THF}, 0^{\circ} \mathrm{C}-40^{\circ} \mathrm{C}, 26 \%$; g) $\mathrm{H}_{2}, \mathrm{Pd} / \mathrm{C}, \mathrm{MeOH}$, t.a., $80 \%$.

El tratamiento de la pirrolidina $\mathbf{8 4}$ con PhCOCl en Pi conduce al benzoilderivado 85 con buen rendimiento. Al hacer reaccionar éste con $n$-BuLi a baja temperatura se consigue aislar un 50\% de su diastereoisómero 86, no recuperándose nada del material 
de partida 85. Este proceso retro-Michael ${ }^{209}$ tendrá lugar mediante una $\beta$-eliminación inicial en $\mathbf{8 5}$ favorecida por el carácter ácido de $\mathrm{H}_{2} \mathrm{C}_{1}$, y el buen grupo saliente $\mathrm{N}$ benzoilo seguida de una adición de Michael intramolecular para obtener el compuesto 86. $^{210}$

Los intentos de desbenzoilación directa de $\mathbf{8 6}$ para dar la pirrolidina deseada $\mathbf{8 8}$ tanto con $\mathrm{NH}_{2}-\mathrm{NH}_{2}$ en EtOH a reflujo ${ }^{211}$ como con $\mathrm{HCl} 6 \mathrm{M}$ a reflujo ${ }^{212}$ (Esquema 115, rutas $\mathbf{c}$ y $\mathbf{d}$ respectivamente), no dieron resultado, por lo que se decidió llevar a cabo una reducción del grupo benzoilo hasta bencilo para finalmente obtener la pirrolidina $\mathbf{8 8}$ mediante una reacción de desbencilación. La reducción de 86 a 87 se llevó a cabo tanto con $\mathrm{LiAlH}_{4}$ como con el complejo borano-tetrahidrofurano $\left(\mathrm{BH}_{3} \cdot \mathrm{THF}\right),{ }^{213}$ obteniéndose resultados ligeramente mejores con el primer método. Un último paso de desbencilación con $\mathrm{H}_{2}$ utilizando $\mathrm{Pd} / \mathrm{C}$ como catalizador condujo a la pirrolidina 88 , cuya estereoquímica se corrobora inequívocamente por la existencia de nOe entre $\mathrm{H}-1$ ' y $\mathrm{H}$ 4, lo que pone de manifiesto una disposición trans del grupo metilsulfona y del grupo acetónido. Sin embargo, el compuesto $\mathbf{8 8}$ se obtuvo en muy pequeña cantidad, por lo que no se pudo probar su utilidad como catalizador orgánico.

No obstante, el compuesto $\mathbf{8 4}$, obtenido fácilmente mediante una ruta optimizada en nuestro grupo de trabajo, se probará posteriormente como catalizador orgánico en reacciones de adición $о x o-M i c h a e l$ intramoleculares.

\footnotetext{
209 Vázquez, E.; Galindo, A.; Gnecco, D.; Bernés, S.; Terán, J. L.; Enríquez, R. G. Tetrahedron: Asymmetry 2001, 12, 3209.

${ }^{210}$ Hussaini, S. R.; Moloney, M. G. Org. Biomol. Chem. 2006, 4, 2600.

${ }^{211}$ Boger, D. L.; McKie, J. A.; Nishi, T.; Ogiku, T. J. Am. Chem. Soc. 1997, 119, 311.

212 Gil, A. M.; Buñuel, E.; Díaz-de-Villegas, M. D.; Cativiela, C. Tetrahedron: Asymmetry 2003, 14, 1479.

${ }^{213}$ Larock, R. C. Comprehensive Organic Transformations; Wiley-VCH: NY, 1999.
} 


\subsection{SÍNTESIS ORGANOCATALÍTICA DE TETRAHIDROPIRANOS}

En el campo de la organocatálisis, se han llevado a cabo reacciones de adición conjugada de nucleófilos heteroatómicos como tioles, ${ }^{214}$ amidas, $^{215}$ carbamatos $^{216}$ y triazoles $^{217}$ a aldehídos $\alpha, \beta$-insaturados mediante catálisis tipo iminio. Sin embargo, no existen muchos ejemplos de adiciones conjugadas organocatalíticas de nucleófilos oxigenados a cetonas $^{218}$ o aldehídos ${ }^{219} \alpha, \beta$-insaturados. Algunos de estos ejemplos son las ya descritas síntesis organocatalíticas de sistemas benzopiránicos mediante reacciones dominó en las que el paso clave es una adición de oxo-Michael intramolecular promovida por catalizadores pirrolidínicos (Esquema 116). ${ }^{137-139}$<smiles>[R3]C=CC([R])=O</smiles>

Esquema 116

Sin embargo, no existen ejemplos de este tipo de reacciones en su versión intramolecular, por lo que decidimos abordar la síntesis organocatalítica enantioselectiva de oxaciclos mediante reacciones de adición oxo-Michael intramoleculares en aldehídos $\alpha, \beta$-insaturados promovida por catalizadores pirrolidínicos (Esquema 117).

${ }^{214}$ Marigo, M.; Schulte, T.; Franzén, J.; Jørgensen, K. A. J. Am. Chem. Soc. 2005, 127, 15710.

${ }^{215}$ Takasu, K.; Maiti, S.; Ihara, M. Heterocycles 2003, 59, 51.

${ }^{216}$ (a) Chen,Y. K.;Yoshida, M.; MacMillan, D.W. C. J. Am. Chem. Soc. 2006, 128, 9328; (b) Vesely, J.; Ibrahem, I.; Rios, R.; Zhao, G.-L.; Xu, Y.; Córdova, A. Tetrahedron Lett. 2007, 48, 2193.

${ }^{217}$ Dinér, P.; Nielsen, M.; Marigo, M.; Jørgensen, K. A. Angew. Chem., Int. Ed. 2007, 46, 1983.

218 (a) Ramachary, D. B.; Mondal, R. Tetrahedron Lett. 2006, 47, 7689; (b) Carlone, A.; Bartoli, G.; Bosco, M.; Pesciaioli, F.; Ricci, P.; Sambri, L.; Melchiorre, P. Eur. J. Org. Chem. 2007, 5492; (c) Bartoli, G.; Melchiorre, P. Synlett 2008, 1759.

${ }^{219}$ (a) Kano, T.; Tanaka, Y.; Maruoka, K. Tetrahedron Lett. 2006, 47, 3039; (b) Bertelsen, S.; Dinér, P.; Johansen, R. L.; Jørgensen, K. A. J. Am. Chem. Soc. 2007, 129, 1536; (c) Kano, T.; Tanaka, Y.; Maruoka, K. Tetrahedron 2007, 63, 8658.

137 Govender, T.; Hojabri, L.; Moghaddam, F. M.; Arvidsson, P. I. Tetrahedron: Asymmetry 2006, 17, 1763.

138 (a) Rios, R.; Sundén, H.; Ibrahem, I.; Córdova, A. Tetrahedron Lett. 2007, 48, 2181; (b) Sundén, H.; Ibrahem, I.; Zhao, G- L.; Eriksson, L.; Córdova, A. Chem. Eur. J. 2007, 13, 574; (c) Ibrahem, I.; Sundén, H.; Rios, R.; Zhao, G- L.; Córdova, A. Chimia 2007, 61, 219.

${ }^{139}$ Li, H.; Wang, J.; E-Nunu, T.; Zu, L.; Jiang, W.; Wei, S.; Wang, W. Chem. Commun. 2007, 507. 

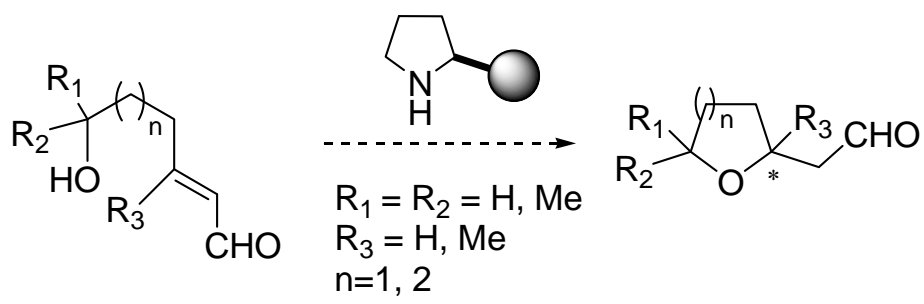

Esquema 117

Así pues, el primer paso para llevar a cabo este estudio será la síntesis de los sustratos para las adiciones de oxo-Michael intramoleculares como los mostrados en el esquema anterior (Esquema 117).

\subsubsection{Síntesis del sustrato 103 para la reacción de ciclación oxo-Michael}

\section{organocatalítica}

En un principio se decidió utilizar como sustrato para la síntesis de tetrahidrofuranos el aldehído 89 (Esquema 118), ya que se podría obtener fácilmente por oxidación del diol 56, producto intermedio en la síntesis del tetrahidrofuranildioxolano 58 (Capítulo 1 de Discusión y resultados, apartado 1.2.1., Esquema 101).

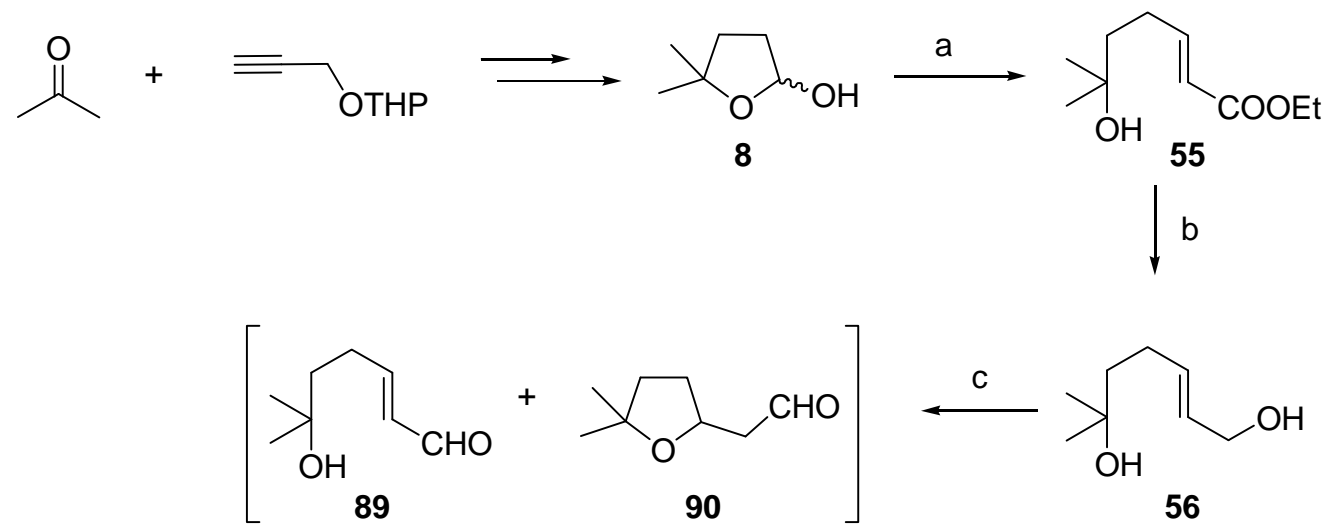

Esquema 118. a) $\mathrm{Ph}_{3} \mathrm{P}(\mathrm{CH}) \mathrm{COOEt}, \mathrm{C}_{6} \mathrm{H}_{6}, 60 \%$; b) DIBAL-H, DCM, $-78^{\circ} \mathrm{C}, 87 \%$; c) TPAP, NMO, DCM, mol. sieves, $98 \%$. 
Sin embargo, este aldehído $\mathbf{8 9}$ no resultó ser útil para su utilización como sustrato en reacciones de ciclación, ya que cicla de forma parcial o total hasta el aldehído 90 durante el trabajo de la reacción de oxidación con TPAP (Esquema 118). Esta mezcla es inseparable por cromatografía en columna sobre sílicagel, ya que en el medio ácido de la sílice el aldehído 89 cicla para dar $\mathbf{9 0}$.

Así pues, decidimos sintetizar un nuevo material de partida 95 para la síntesis de tetrahidropiranos, que se obtendría en pocos pasos a partir de $\delta$-valerolactona tal y como se indica en el Esquema 119. La reducción con DIBAL-H de $\delta$-valerolactona conduce al lactol 91, el cual se somete a condiciones de olefinación de Wittig con (1etoxicarbonilmetilen)trifenilfosforano, obteniéndose la mezcla de ésteres 92 y 93 en una proporción 1:10. ${ }^{221}$ Tras su separación en columna sobre sílicagel, se redujo el éster 93 con DIBAL-H hasta el diol 94, el cual se somete a oxidación alílica con $\mathrm{MnO}_{2}{ }^{222}$ No obstante, durante el trabajo de esta reacción, se encuentra el mismo problema que con el diol 56, ya que se produce la ciclación parcial del aldehído 95 hasta el 96 (Esquema 119). Por tanto, este sustrato tampoco resulta ser de utililidad para el estudio de reacciones de ciclación.
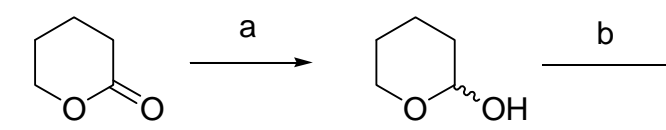

$\delta$-valerolactona

91

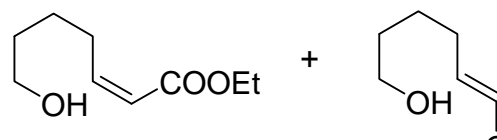

92

$1: 10$ COOEt

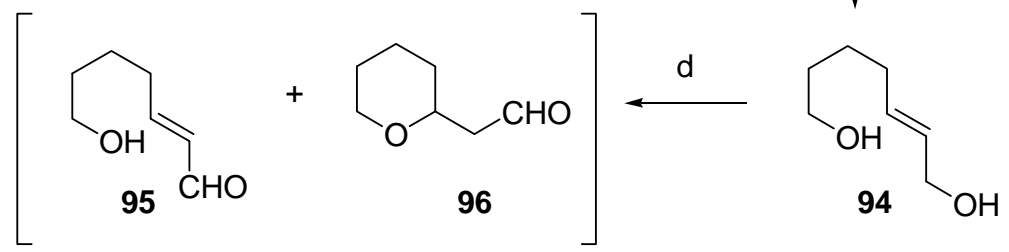

Esquema 119. a) DIBAL-H, DCM, $-78^{\circ} \mathrm{C}$; b) $\mathrm{Ph}_{3} \mathrm{P}(\mathrm{CH}) \mathrm{COOEt}, \mathrm{C}_{6} \mathrm{H}_{6}$, t.a. $65 \%$ en 2 pasos; c) DIBAL-H, DCM, $-78^{\circ} \mathrm{C}, 87 \%$; d) $\mathrm{MnO}_{2}$, DCM, t.a.

${ }^{221}$ Baldwin, J. E.; Chesworth, R.; Parker, J. S.; Russell, A. T. Tetrahedron Lett. 1995, 36, 9551.
${ }^{222}$ Corey, E. J.; Gilman, N. W.; Ganem, B. E. J. Am Chem. Soc. 1968, 90, 5616. 
De nuevo, planteamos otra ruta de obtención de sustratos a partir de $\delta$ valerolactona (Esquema 120), esta vez introduciendo un metilo en posición C-3 para comprobar si un mayor impedimento estérico en este punto evitaba la ciclación previa a la reacción organocatalítica.

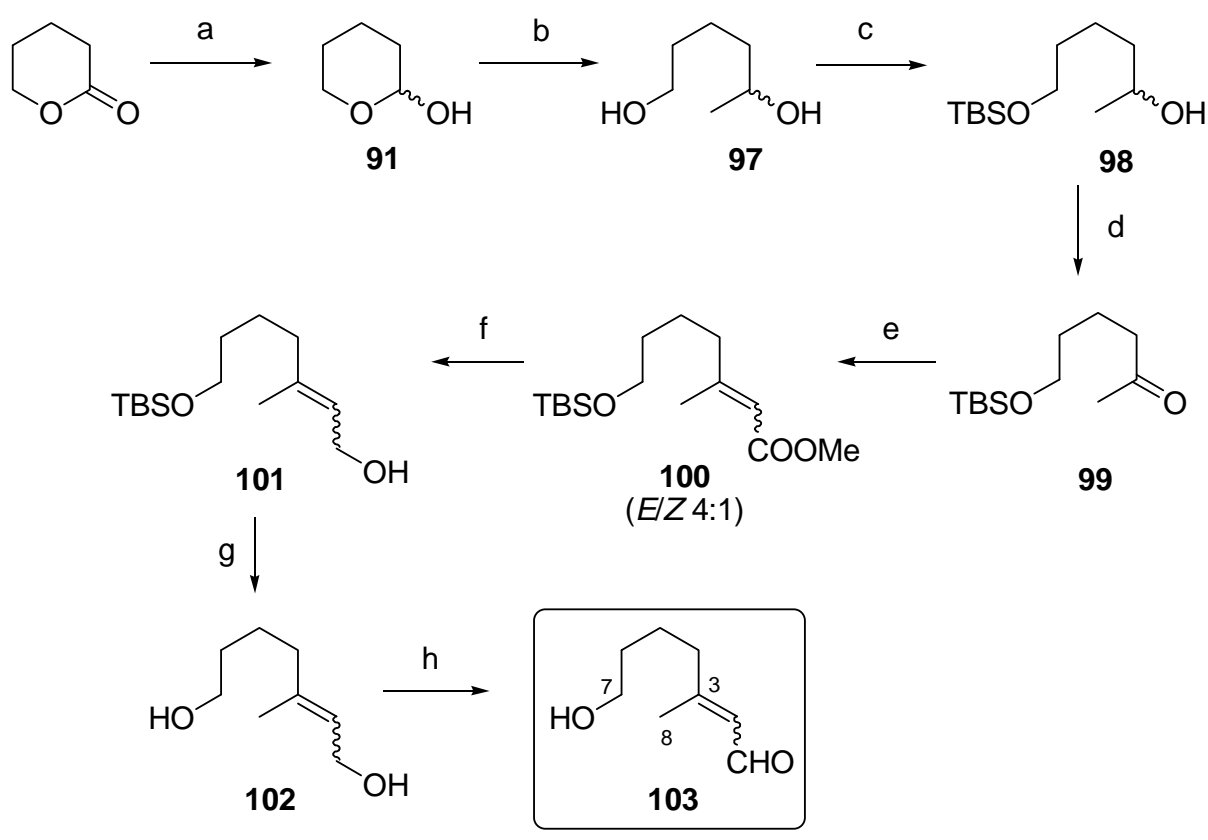

Esquema 120. a) DIBAL-H, DCM, $-78^{\circ} \mathrm{C}$; b) MeMgBr, THF, $0^{\circ} \mathrm{C}, 70 \%$; c) TBDMSCl, imidazol, DMF,

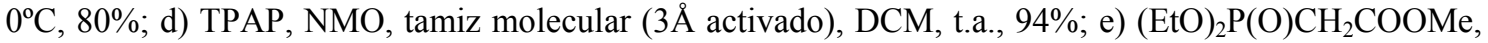
$\mathrm{NaH}$, monoglime, $60^{\circ} \mathrm{C}, 96 \%$; f) DIBAL-H, DCM, $-78^{\circ} \mathrm{C}, 93 \%$; g) TBAF, THF, t.a.; h) $\mathrm{MnO}_{2}$, DCM, t.a. $70 \%$ en 2 pasos.

Para ello, tras la reducción de la $\delta$-valerolactona con DIBAL-H, se hizo reaccionar el lactol obtenido 91 con $\mathrm{MeMgBr}^{223}$ obteniéndose el diol 97. Posteriormente se trató dicho diol con 1 equivalente de TBDMSCl e imidazol para proteger selectivamente el alcohol primario frente al secundario, ${ }^{224}$ obteniéndose el compuesto 98. Éste se oxidó con TPAP hasta la cetona 99, la cual se hizo reaccionar con dietilfosfonoacetato de metilo (Horner-Emmons) ${ }^{225}$ dando una mezcla de ésteres 100 en proporción $E / Z$ 4:1 inseparables por cromatografía en columna sobre sílicagel. Tras la reducción de la mezcla de ésteres con DIBAL-H hasta los correspondientes

\footnotetext{
${ }^{223}$ Marco-Contelles, J.; de Opazo, E.; Arroyo, N. Tetrahedron 2001, 57, 4729.

${ }^{224}$ Black, G. P.; Murphy, P. J.; Thornhill, A. J.; Walshe, N. D. A.; Zanetti, C. Tetrahedron 1999, 55, 6547.

${ }^{225}$ a) van Wyk, A. W. W.; Davies-Coleman, M. T. Tetrahedron 2007, 63, 12179. b) Kelly, S. E. Alkene Synthesis. Phosphorus-Stabilized Alkenation; In Comprehensive Organic Synthesis; Trost, B. M.; Fleming, I., Eds. Pergamon Press: Oxford, 1991; Vol. 1, pp. 755-782.
} 
alcoholes 101 y posterior desprotección del alcohol primario con TBAF, se obtuvieron los dioles 102, los cuales se oxidaron con $\mathrm{MnO}_{2}$ hasta la mezcla de aldehídos 103, no observándose en este caso ciclación parcial del producto de reacción (Esquema 120). Tanto los productos intermedios 101 y 102 como el producto final $\mathbf{1 0 3}$ se obtuvieron como mezclas de diastereoisómeros $E / Z$ en proporción $4: 1$, no siendo ninguno de ellos separable por cromatografía en columna sobre sílicagel. No obstante, decidimos utilizar el sustrato 103 como una mezcla $E / Z$ ya que existen precedentes en bibliografía de adiciones de Michael organocatalíticas tipo ión iminio en las que los sustratos olefínicos con estereoquímica fija $E$ o $Z$, e incluso mezclas $E / Z$ en distinta proporción, convergen hacia el mismo enantiómero. ${ }^{226}$ El origen de esta estereoconvergencia parece provenir de la isomerización $E-Z$ acelerada por el catalizador pirrolidínico previa a la reacción de adición conjugada.

\subsubsection{Optimización de las condiciones de ciclación organocatalítica con el sustrato}

$\underline{103}$

La reacción organocatalítica llevada a cabo implica una adición oxo-Michael intramolecular de $\mathbf{1 0 3}$ para dar el correspondiente tetrahidropirano, cuya función aldehído se reduce in situ en la mayoría de los casos hasta el alcohol 104 con el fin de evitar la epimerización del nuevo centro estereogénico creado (Esquema 121).
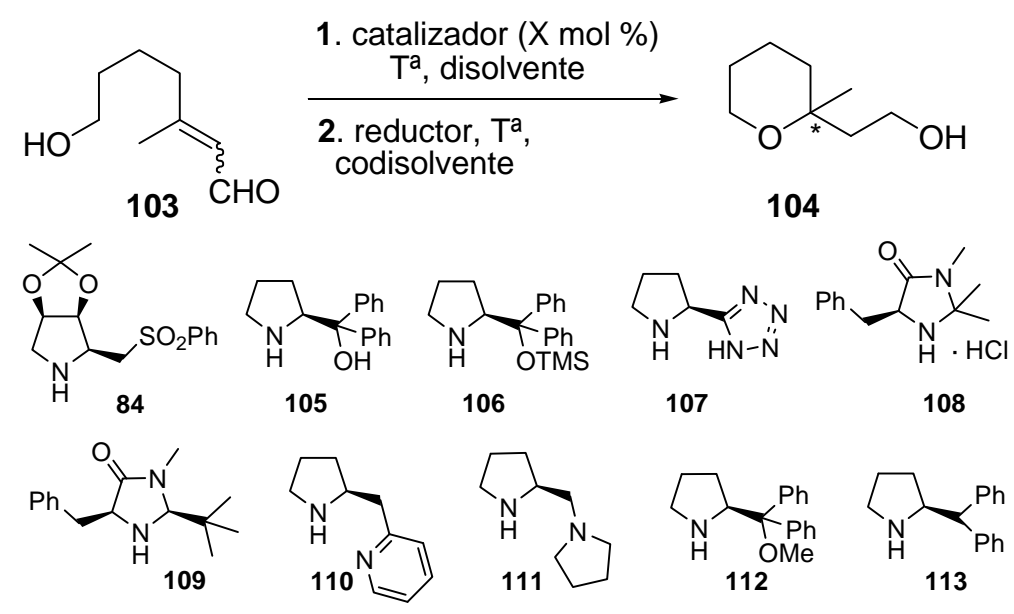

Esquema 121

\footnotetext{
${ }^{226}$ a) Ouellet, S. G.; Tuttle, J. B.; MacMillan, D. W. C. J. Am. Chem. Soc. 2005, 127, 32; b) Marigo, M.; Franzén, J.; Poulsen, T. B.; Zhuang, W.; Jørgensen, K. A. J. Am. Chem. Soc. 2005, 127, 6964.
} 
Los catalizadores tipo pirrolidina empleados son los representados en el Esquema 121. Estos compuestos, excepto el 84, cuya obtención ya ha sido previamente comentada, son comerciales o fácilmente obtenibles ${ }^{227}$ y han sido utilizados previamente en reacciones de adición de Michael organocatalíticas. ${ }^{124 \tilde{n}}$

En primer lugar, se comenzó realizando experimentos a temperatura ambiente (Tabla 5) con catalizadores tipo diarilprolinol (105 y 106, entradas 2-7, tabla 5), con análogos de prolina (107, entrada 8 , tabla 5), tipo imidazolidinona (108 y $\mathbf{1 0 9}$, entradas 9 y 10, tabla 5) y con los catalizadores dibásicos 110 y 111 (entradas 11-19, tabla 5).

Tabla 5. Adiciones oxo-Michael intramoleculares organocatalíticas de $\mathbf{1 0 3}$ para dar los correspondientes tetrahidropiranos con los catalizadores 105-111. ${ }^{\text {a }}$

\begin{tabular}{|c|c|c|c|c|c|c|c|c|}
\hline Entrada & Catalizador & Disolvente & $\mathbf{t}(\mathbf{h})$ & $\mathbf{T}^{\mathrm{a}}\left({ }^{\circ} \mathbf{C}\right)$ & Reductor & Codisolvente & $\begin{array}{c}\eta \\
(\%)\end{array}$ & $\begin{array}{l}\text { e.e. }^{\mathrm{c}} \\
(\%)\end{array}$ \\
\hline 1 & -- & tolueno & 96 & t.a. & --- & ---- & 0 & --- \\
\hline 2 & 105 & DCM & 112 & t.a. & ---- & ---- & 10 & n.d. \\
\hline 3 & 106 & tolueno & 2 & t.a. & ---- & ---- & 75 & n.d. \\
\hline 4 & 106 & $\mathrm{MeOH}$ & 7 & t.a. & $\mathrm{NaBH}_{4}$ & ---- & 60 & 7 \\
\hline 5 & 106 & tolueno & 1 & t.a. & DIBAL-H & ---- & $74^{\mathrm{b}}$ & 0 \\
\hline 6 & 106 & DCM & 3 & t.a. & DIBAL-H & ---- & $60^{\mathrm{b}}$ & 0 \\
\hline 7 & $106^{\mathrm{d}}$ & tolueno & 1 & t.a. & DIBAL-H & --- & 68 & 0 \\
\hline 8 & 107 & $\mathrm{MeOH}$ & 2 & t.a. & $\mathrm{NaBH}_{4}$ & ---- & $30^{\mathrm{b}}$ & 0 \\
\hline 9 & 108 & $\mathrm{MeOH}$ & 7 & t.a. & ----- & ---- & 0 & --- \\
\hline 10 & $109^{\mathrm{e}}$ & $\mathrm{MeOH}$ & 24 & t.a. & ----- & --- & $53^{\mathrm{b}, \mathrm{f}}$ & 0 \\
\hline 11 & 110 & tolueno & 3 & t.a. & $\mathrm{NaBH}_{4}$ & $\mathrm{MeOH}$ & $25^{\mathrm{b}}$ & 0 \\
\hline 12 & 111 & $\mathrm{MeOH}$ & $1 / 2$ & t.a. & $\mathrm{NaBH}_{4}$ & ---- & $30^{\mathrm{b}}$ & 5 \\
\hline 13 & 111 & tolueno & $1 / 2$ & t.a. & $\mathrm{NaBH}_{4}$ & $\mathrm{MeOH}$ & $43^{b}$ & 0 \\
\hline 14 & 111 & clorobenceno & $1 / 2$ & t.a. & $\mathrm{NaBH}_{4}$ & $\mathrm{MeOH}$ & $43^{b}$ & 5 \\
\hline 15 & 111 & tolueno & 3 & -78 & DIBAL-H & ---- & 0 & 0 \\
\hline 16 & 111 & tolueno & 3 & -40 & DIBAL-H & ---- & 0 & 0 \\
\hline 17 & 111 & tolueno & $1 / 2$ & -20 & $\mathrm{NaBH}_{4}$ & $\mathrm{MeOH}$ & $66^{\mathrm{b}}$ & 4 \\
\hline 18 & $111^{\mathrm{d}}$ & tolueno & 1 & -20 & $\mathrm{NaBH}_{4}$ & $\mathrm{MeOH}$ & $64^{b}$ & 5 \\
\hline 19 & 111 & DCM & 1 & -20 & $\mathrm{NaBH}_{4}$ & $\mathrm{MeOH}$ & $40^{\mathrm{b}}$ & 4 \\
\hline
\end{tabular}

\footnotetext{
${ }^{a}$ En todas las reacciones se utilizó un $20 \mathrm{~mol} \%$ del catalizador correspondiente.

${ }^{\mathrm{b}}$ Rendimiento del compuesto puro $\mathbf{1 0 4}$ aislado por cromatografía en 2 pasos.

c Determinado por experimentos de GC-MS quiral (CHIRASIL DEX-CB). Ver cromatogramas en apartado correspondiente de esta memoria.

${ }^{\mathrm{d}}$ Se añadió un $20 \mathrm{~mol} \%$ de ácido benzoico.

e Se añadió un $20 \mathrm{~mol} \%$ de $\mathrm{HCl}$.

${ }^{\mathrm{f}}$ Se obtuvo 2-(2',2'-dimetoxietil)-2-metiltetrahidropirano 114 (Esquema 120) como producto de reacción.
}

${ }^{227}$ Para la obtención de 106, ver: (a) Marigo, M.; Wabnitz, T. C.; Fielenbach, D.; Jørgensen, K. A.; Angew. Chem. Int. Ed. 2005, 44, 794; (b) Sundén, H.; Ibrahem, I.; Córdova, A. Tetrahedron Lett 2006, 47, 99; Para la obtención de 107, ver: Almquist, R. G.; Chao, W.-R.; White, C. J. J. Med. Chem. 1985, 28, 1067. Para la obtención de 110, ver: Ishii, T.; Fujioka, S.; Sekiguchi, Y.; Kotsuki, H. J. Am. Chem. Soc. 2004, 126, 9558 y referencias allí citadas.

${ }^{124 n ̃ n}$ Almaşi, D.; Alonso, D. A.; Nájera, C. Tetrahedron: Asymmetry 2007, 18, 299. 
Al realizar una prueba en blanco (entrada 1), no se obtuvo nada de producto de ciclación tras 96 horas de reacción, con lo que estos compuestos tipo pirrolidina, excepto 105 y la imidazolidinona 108, catalizan la reacción de adición conjugada intramolecular de 103. Sin embargo, aunque algunos catalizadores como el $(S)-(-)-\alpha, \alpha-$ difenil-2-pirrolidinmetanol trimetilsilil éter $\mathbf{1 0 6}$ producen buenos rendimientos, a la vista de los excesos enantioméricos, esta reacción no es enantioselectiva a esta temperatura. En todos los casos, excepto en las entradas 2, 3 y 10, se llevó a cabo la reducción in situ del aldehído producido con DIBAL-H (entradas 5-7) o con $\mathrm{NaBH}_{4}$ (entradas $4,8,11-13$ ), en cuyo caso se añadía $\mathrm{MeOH}$ como codisolvente, ya que se observó la oxidación del aldehído hasta ácido al estar en contacto con el aire. Esta es la razón por la cual en los experimentos de las entradas 2 y 3 no se pudiese determinar el exceso enantiomérico.

La adición de ácido benzoico como co-catalizador de 106 no mejoró el rendimiento de la reacción (entrada 7). Sin embargo, con el catalizador imidazolidinona 109 (entrada 10), no hay evolución alguna del producto de partida antes de añadir como co-catalizador $\mathrm{HCl}$. Tras la adición y pasadas 24 horas de reacción, se aísla el producto de ciclación 114 (Esquema 122), en el cual el medio ácido de reacción en $\mathrm{MeOH}$ ha dado lugar a la formación del acetal. No obstante, al realizar experimentos de GC-MS quiral, se vio que este producto tampoco presentaba enantioselectividad.

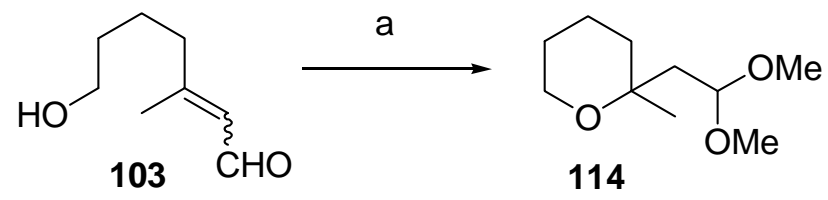

Esquema 122. a) 109 (20 mol\%), $\mathrm{HCl}$ (20 mol\%, disolución 4M en 1,4-dioxano), t.a., 24h, 53\%.

El catalizador (S)-2-(pirrolidin-2-il-metil)piridina 110 no dio buenos resultados (entrada 11), por lo que se continuó con el otro catalizador dibásico $(S)-(+)-1-(2-$ pirrolidinilmetil)pirrolidina 111 (entradas 12-19). Las pruebas realizadas con este catalizador, aunque se dejaron reaccionar durante $1 / 2$ hora previa a la reducción, eran instantáneas. Este hecho se observa por el repentino cambio en la coloración de la mezcla de reacción, que pasa de incolora a naranja intensa inmediatamente después de la adición del catalizador. 
Así pues, se decidió llevar a cabo más pruebas con este catalizador 111 a menor temperatura, para ver si este cambio en las condiciones de reacción conducía a un aumento de la enantioselección.

Como se observa en la tabla 5 , la reacción de ciclación no se produce ni a $-78^{\circ} \mathrm{C}$ ni a $-40^{\circ} \mathrm{C}$ (entradas 15 y 16 respectivamente), por lo que se decide subir la temperatura a $-20^{\circ} \mathrm{C}$. En este caso se observa que en disolventes poco polares (tolueno, DCM) tiene lugar un aumento del rendimiento (entradas 17 y 19), que no se ve incrementado al añadir ácido benzoico como co-catalizador (entrada 18). Sin embargo, en ningún caso se consigue llevar a cabo la reacción con enantioselección.

A la vista de los resultados, decidimos realizar más pruebas de ciclación con los catalizadores 84, 112 y 113 (tabla 6).

Tabla 6. Adiciones oxo-Michael intramoleculares organocatalíticas de $\mathbf{1 0 3}$ para dar los correspondientes tetrahidropiranos con los catalizadores 84 y 112-113. ${ }^{\mathrm{a}}$

\begin{tabular}{|c|c|c|c|c|c|c|c|c|c|}
\hline Entrada & Catalizador & Disolvente & $\mathbf{t}(\mathbf{h})$ & $\mathbf{T}^{\mathrm{a}}\left({ }^{\circ} \mathrm{C}\right)$ & Reductor & Codisolvente & $\begin{array}{c}\eta^{\mathrm{b}} \\
(\%)\end{array}$ & $\begin{array}{l}\text { e.e. }^{\mathrm{c}} \\
(\%)\end{array}$ & Config. \\
\hline 1 & 84 & tolueno & 2 & -20 & $\mathrm{NaBH}_{4}$ & $\mathrm{MeOH}$ & 80 & 13 & $S$ \\
\hline 2 & $84^{\mathrm{d}}$ & tolueno & 2 & -20 & $\mathrm{NaBH}_{4}$ & $\mathrm{MeOH}$ & 70 & 0 & --- \\
\hline 3 & 112 & tolueno & 2 & -20 & $\mathrm{NaBH}_{4}$ & $\mathrm{MeOH}$ & 60 & 41 & $R$ \\
\hline 4 & $112^{\mathrm{d}}$ & tolueno & 2 & -20 & $\mathrm{NaBH}_{4}$ & $\mathrm{MeOH}$ & 63 & 37 & $R$ \\
\hline 5 & 112 & DCM & 2 & -20 & $\mathrm{NaBH}_{4}$ & $\mathrm{MeOH}$ & 70 & 44 & $R$ \\
\hline 6 & 112 & $\mathrm{MeOH}$ & 6 & -20 & $\mathrm{NaBH}_{4}$ & ---- & 61 & 26 & $R$ \\
\hline 7 & 112 & THF & 6 & -20 & $\mathrm{NaBH}_{4}$ & $\mathrm{MeOH}$ & 20 & 33 & $R$ \\
\hline 8 & 112 & DCM & 2 & t.a. & $\mathrm{NaBH}_{4}$ & $\mathrm{MeOH}$ & 62 & 0 & --- \\
\hline 9 & 112 & $\mathrm{DCM}$ & 2 & 0 & $\mathrm{NaBH}_{4}$ & $\mathrm{MeOH}$ & 74 & 14 & $R$ \\
\hline 10 & 112 & $\mathrm{DCM}$ & 2 & -40 & $\mathrm{NaBH}_{4}$ & $\mathrm{MeOH}$ & 30 & 48 & $R$ \\
\hline 11 & 112 & DCM & 12 & -78 & DIBAL-H & ---- & 50 & 57 & $R$ \\
\hline 12 & 113 & tolueno & 1 & -20 & $\mathrm{NaBH}_{4}$ & $\mathrm{MeOH}$ & 60 & 48 & $R$ \\
\hline
\end{tabular}

\footnotetext{
${ }^{\text {a }}$ En todas las reacciones se utilizó un $20 \mathrm{~mol} \%$ del catalizador correspondiente.

${ }^{\mathrm{b}}$ Rendimiento del compuesto puro $\mathbf{1 0 4}$ aislado por cromatografía en 2 pasos.

c Determinado por experimentos de GC-MS quiral (CHIRASIL DEX-CB). Ver cromatogramas en apartado correspondiente de esta memoria.

${ }^{\mathrm{d}}$ Se añadió un $20 \mathrm{~mol} \%$ de ácido benzoico.

e Determinada por comparación de los espectros GC-MS quiral con el compuesto $\mathbf{1 0 4}$ obtenido tal y como se muestra en el esquema 123 (Ver cromatogramas en apartado )
} 
Se comenzó con la sulfona análoga de prolina anteriormente sintetizada 84. Al llevar a cabo la reacción de ciclación de 103 en tolueno y a $-20^{\circ} \mathrm{C}$, se obtuvo el producto de ciclación 104 con buen rendimiento (77\%), sin embargo, el exceso enantiomérico solo fue del 13\% (tabla 6, entrada 1). La adición de ácido benzoico como co-catalizador no mejoró los resultados anteriores (entrada 2).

Los resultados con el catalizador (S)-2-(metoxidifenilmetil)pirrolidina 112 (tabla 6, entradas 3-11) fueron más alentadores. Al realizar la ciclación a $-20^{\circ} \mathrm{C}$ en tolueno, se obtuvo un $60 \%$ de rendimiento y un $41 \%$ de ee (entrada 3 ). Como sucedía anteriormente en otros casos, la adición de ácido benzoico como co-catalizador no mejora la enantioselección (entrada 4).

En las entradas de 5 a 7 se muestran los resultados de las pruebas realizadas en distintos disolventes a $-20^{\circ} \mathrm{C}$, encontrándose que los mejores se obtienen utilizando DCM (entrada 5). Así pues, se realizó un estudio de temperaturas utilizando DCM como disolvente (entradas 8-11). Se encontró que a temperatura ambiente la reacción no es enantioselectiva (entrada 8), y que la enantioselección aumenta progresivamente al disminuir la temperatura, alcanzándose un $57 \%$ ee a $-78^{\circ} \mathrm{C}$. También se observa que el efecto de la temperatura sobre el rendimiento no es significativo.

Por último se probó el catalizador (S)-2-difenilmetilpirrolidina 113 (entradas 12 y 13) para ver si el grupo metoxilo del catalizador 112 tenía un efecto significativo en la catálisis del proceso de ciclación. Al llevar a cabo la reacción en tolueno a $-20^{\circ} \mathrm{C}$ (entrada 12) se obtuvieron resultados casi idénticos a los obtenidos con 112. No sucedió esto sin embargo al realizar la ciclación en DCM y a $-78^{\circ} \mathrm{C}$, donde el exceso enantiomérico se vió reducido (48\%, entrada 13) con respecto al obtenido con el catalizador 112 en las mismas condiciones (57\%, entrada 11$)$. 
Para sintetizar el compuesto 104 racémico (rac-104), el cual es necesario para encontrar las condiciones óptimas de separación en los experimentos de GC-MS quiral, ${ }^{228}$ seguimos el siguiente esquema de reacciones (Esquema 123).
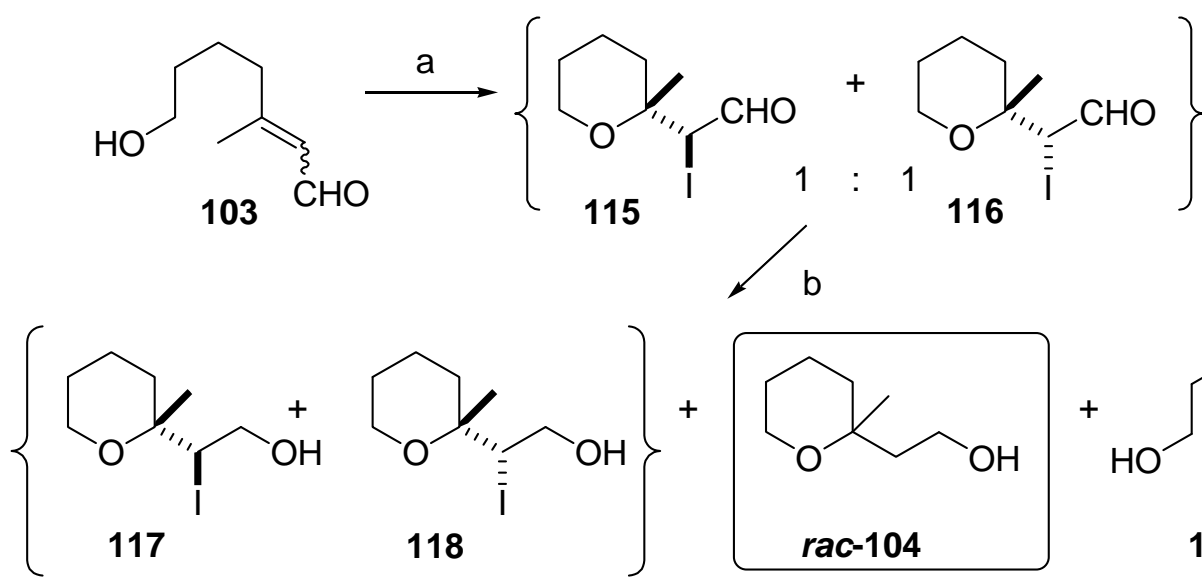

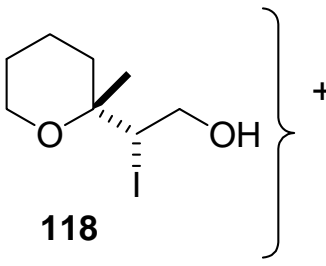

2

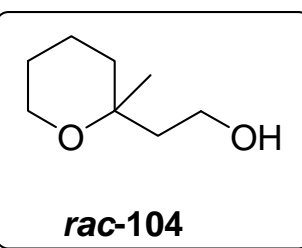

1<smiles>CC(=CC=O)CCCCO</smiles>

3

Esquema 123. a) $\mathrm{I}_{2}, \mathrm{NaHCO}_{3}, \mathrm{CH}_{3} \mathrm{CN}, 0^{\circ} \mathrm{C}$-t.a., $86 \%$; b) $\mathrm{NaBH}_{4}$, EtOH, $0^{\circ} \mathrm{C}$-t.a., $74 \%$.

Al someter la mezcla de aldehídos 103 (E/Z 4:1) a condiciones de yodociclación, se obtuvo una mezcla de los diastereoisómeros 115 y 116, inseparables por cromatografía en columna sobre sílicagel, en proporción 1:1. La posterior reducción de 115/116 con $\mathrm{NaBH}_{4}$ en EtOH, condujo una mezcla de los compuestos de monorreducción 117 y 118, inseparables por cromatografía en columna sobre sílicagel, el producto de doble reducción rac-104 y el de apertura de anillo 103 en una proporción 2:1:3. No fue necesario reducir la mezcla de diastereoisómeros 117/118 con $\mathrm{Bu}_{3} \mathrm{SnH}$ para obtener rac-104, pues ya disponíamos de suficiente cantidad de compuesto para realizar los experimentos de GC-MS quiral.

\footnotetext{
${ }^{228}$ Los experimentos GC-MS se llevaron a cabo utilizando una columna quiral CHIRASIL DEX-CB $(10 \mathrm{~m} \times 0.25 \mathrm{~mm} \times 0.25 \mu \mathrm{m}$ coating) utilizando el siguiente programa de temperaturas a una presión de 93.7 KPa: $100^{\circ} \mathrm{C}, 3 \mathrm{~min}-4^{\circ} \mathrm{C} / \mathrm{min}$ hasta $140^{\circ} \mathrm{C}-140^{\circ} \mathrm{C}, 2 \mathrm{~min}$.
} 
Con el fin de determinar la configuración del nuevo centro estereogénico creado (C-2) al formarse 104 en la reacción de ciclación organocatalítica, se obtuvieron los ésteres de Mosher ${ }^{159}$ del producto quiral 104 (obtenido con el catalizador 112 en DCM a $-78^{\circ} \mathrm{C}$, entrada 11 , tabla 6 ) tanto con $R(+)$-MTPA como con $S(-)$-MTPA (Esquema 124). Sin embargo, en los espectro de ${ }^{1} \mathrm{H}$ RMN (400 MHz) de los productos 119a y 119b no se apreciaban las señales desdobladas de los ésteres diastereoisoméricos en ninguno de los dos casos. Así pues, se preparó el éster de Mosher de la mezcla rac-104 con S(-)MTPA (Esquema 124), pero se obtuvo el mismo espectro de ${ }^{1} \mathrm{H}$ RMN (400 MHz) que en los dos casos anteriores, no observándose tampoco las señales de los dos diastereoisómeros. Probablemente este hecho se deberá a la lejanía de los dos centros quirales en 119, lo que hará que las interacciones conformacionales en ambos diastereoisómeros no se manifiesten en el espectro de ${ }^{1} \mathrm{H}$ RMN.

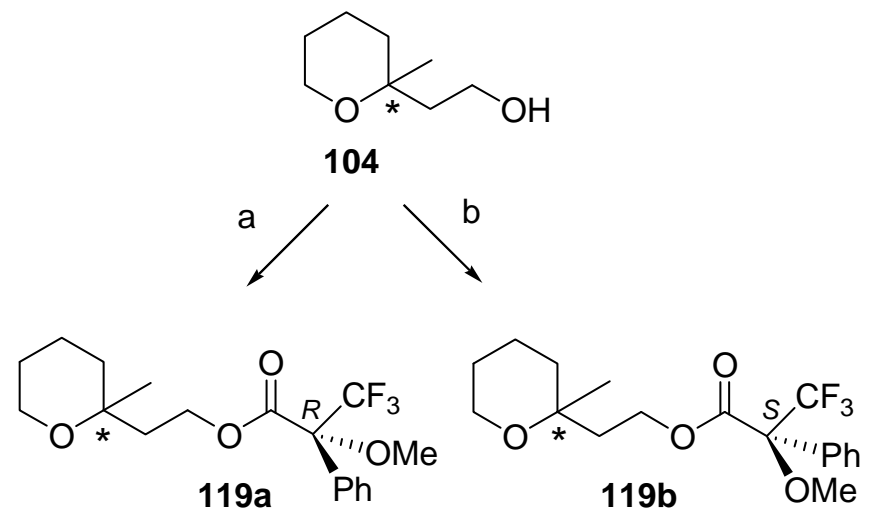

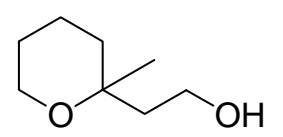

rac-104

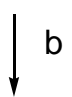

b

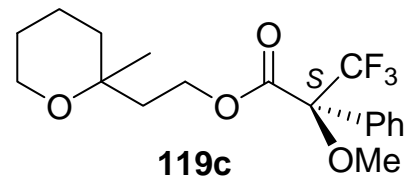

Esquema 124. a) $R(+)-M T P A$, DCC, DMAP, DCM, 70\%; b) $S(-)-M T P A$, DCC, DMAP, DCM, 70\%.

Por tanto, se eligió otra vía para la determinación de la configuración de C-2 en 104, la cual consistió en la síntesis del tetrahidropirano 104 de forma enantioselectiva y configuración absoluta conocida, a partir del alcohol alílico 101, producto intermedio en la síntesis del sustrato 103 (Esquema 125). La epoxidación asimétrica de Sharpless ${ }^{157}$ de la mezcla 101 (E/Z 4:1) con L-(+)-DET condujo al compuesto 120 como enantiómero y diastereoisómero mayoritario con buen rendimiento. Como los diastereoisómeros obtenidos no son separables por cromatografía en columna sobre sílicagel en ninguno

\footnotetext{
${ }^{159}$ Dale, J. A.; Mosher, H. S. J. Am. Chem. Soc. 1973, 95, 512.

157 (a) Katsuki, T.; Sharpless, K. B. J. Am. Chem. Soc. 1980, 102, 5974. (b) Gao, Y.; Hanson, R. M.; Klunder, J. M.; Ko, S. Y.; Masamune, H.; Sharpless, K. B. J. Am. Chem. Soc. 1987, 109, 5765.
} 
de los pasos descritos en el Esquema 125, se trabajó con las mezclas, ya que en el paso final de reducción para la obtención de 104 se elimina el centro quiral en C-8.

La acetilación de $\mathbf{1 2 0}$ produjo el compuesto 121, el cual se trató con TBAF obteniéndose 122. La ciclación de este en medio ácido dio el tetrahidropirano 123, el cual se tosiló obteniéndose el compuesto 124 con un 80\% de rendimiento. Finalmente, la reducción de 124 con $\mathrm{LAH}^{231}$ condujo a una mezcla de los tetrahidropiranos $104 \mathrm{y}$ 125 en proporción 2:1. El compuesto 104 se sometió a experimentos de GC-MS quiral para determinar la configuración en C-2 de los tetrahidropiranos obtenidos en las pruebas de ciclación organocatalíticas por comparación con él, ya que sabemos la configuración del enantiómero mayoritario por epoxidación enantioselectiva de Sharpless, que será la mostrada en el Esquema 125.

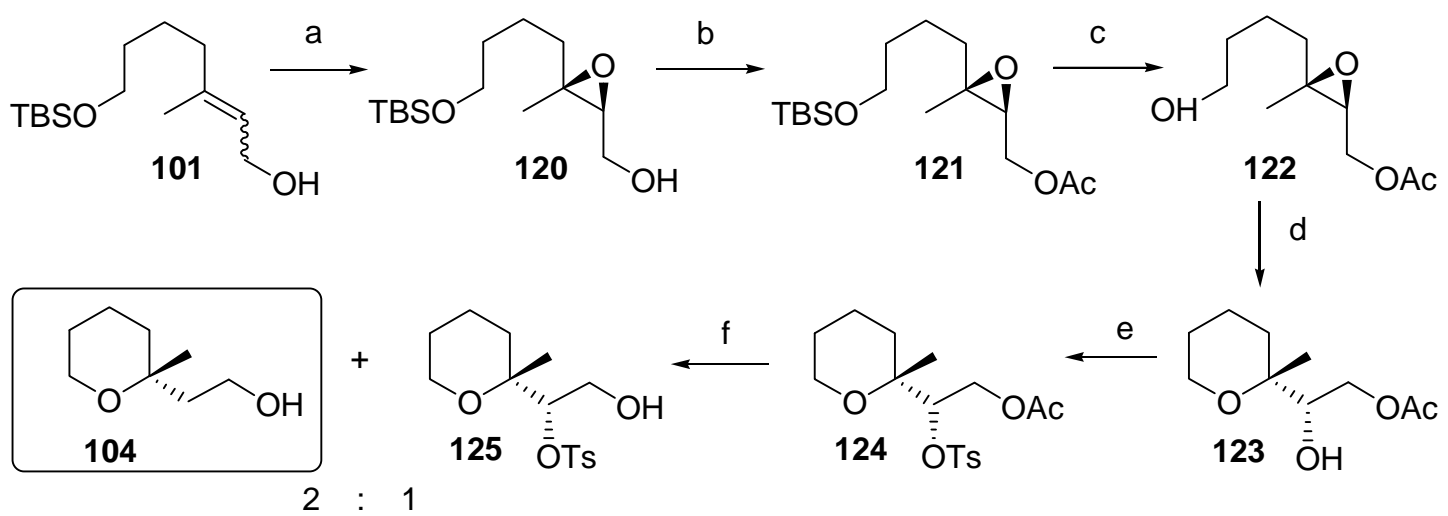

Esquema 125. a) L-(+)-DET, $\mathrm{Ti}\left({ }^{i} \mathrm{OPr}\right)_{4}$, TBHP, DCM, $-20^{\circ} \mathrm{C}, 90 \%$; b) $\mathrm{Ac}_{2} \mathrm{O}$, Pi, t.a., 92\%; c) TBAF, THF, t.a., $80 \%$; d) CSA, DCM, $-40^{\circ} \mathrm{C}$-t.a., $60 \%$; e) TsCl, Pi, $0^{\circ} \mathrm{C}$-t.a., $90 \%$; f) LAH, THF, $0^{\circ} \mathrm{C}, 50 \%$.

El mecanismo catalítico propuesto para esta reacción oxo-Michael organocatalítica intramolecular es el mostrado en el Esquema 126 para el catalizador 112. El primer paso es la formación del ión iminio intermedio A por reacción del aldehído $\alpha, \beta$-insaturado con el catalizador tipo pirrolidina. Seguidamente, tiene lugar el ataque nucleofílico intramolecular del grupo hidroxilo al átomo de carbono $\beta$, formándose el enlace $\mathrm{C}-\mathrm{O}$ del tetrahidropirano que da lugar al intermedio enamina $\mathbf{B}$. Éste a su vez está en equilibrio con el ión iminio $\mathbf{C}$, que por hidrólisis conduce al producto de reacción y al catalizador 112, que vuelve a introducirse en el ciclo catalítico.

${ }^{231}$ Julia, M.; Roy, P. Tetrahedron 1986, 42, 5003. 

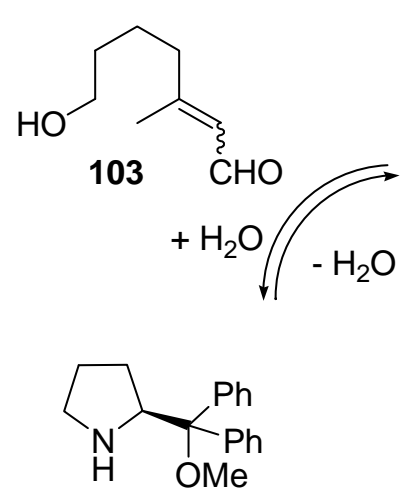

112

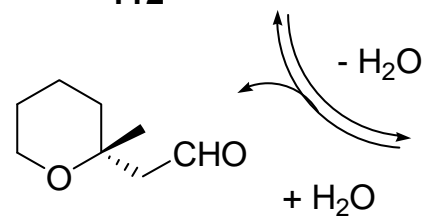<smiles>COC(c1ccccc1)(c1ccccc1)[C@H]1CCCN1CC=C(C)CCCCO</smiles><smiles>C=C=[PH+]</smiles>

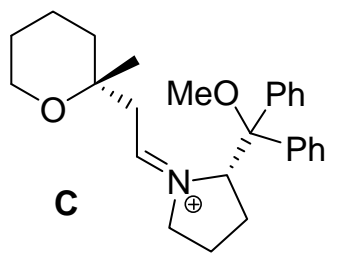

B

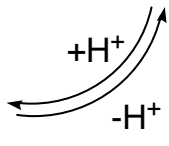<smiles>CCNC</smiles><smiles>OC(c1ccccc1)(c1ccccc1)C1CCCC1</smiles>

\section{Esquema 126}

\subsubsection{Estudios de modelización molecular}

Con el fin de dar explicación tanto a la inducción asimétrica como a los moderados excesos enantioméricos observados en la reacción oxo-Michael intramolecular en el sustrato $\mathbf{1 0 3}$, se ha realizado un estudio de modelización molecular en el que se ha llevado a cabo una amplia búsqueda de todos los estados de transición posibles para este proceso de ciclación. ${ }^{232}$

Inicialmente se realizó un análisis conformacional de todos los posibles iones iminio tipo A resultantes de la adición del catalizador $\mathbf{1 1 2}$ al grupo carbonilo de $\mathbf{1 0 3}$ (Esquema 126), ya que este intermedio de reacción es el más próximo al estado de transición de interés. Para ello se empleó mecánica molecular con OPLS (Optimized Potential for Liquid Simulations) como "force-field", simulando un entorno de solvatación en DCM mediante la utilización de la constante dieléctrica de dicho medio $(\varepsilon=8.93)$. Una vez halladas las conformaciones de mínima energía de los iones iminio tipo A, éstas fueron optimizadas empleando un cálculo semi-empírico RHF/AM1. A partir de las geometrías optimizadas, se llevó a cabo la búsqueda de cada estado de

\footnotetext{
${ }^{232}$ Se han realizado los cálculos únicamente para el caso del catalizador $\mathbf{1 1 2}$.
} 
transición mediante un cálculo de IRC (Intrinsic Reaction Coordinate) para la localización de los mínimos $\mathrm{y}$, una vez encontrados, se procedió al análisis de frecuencias para cada uno de ellos. En todos los casos se halló una única frecuencia imaginaria (negativa), lo que confirma la existencia de un estado de transición. Los valores de las energías de los estados de transición se calcularon mediante single-point en DFT (Density Functional Theory) con un nivel de teoría B3LYP/6-31G* realizando el cálculo en dos modalidades: gas-phase y modelo de solvatación C-PCM (Conductor Polarizable Continuum Model). En este último caso, se empleó un additional input para la descripción de la cavidad del disolvente denominado radii=uahf (United Atom Topology Model). Todos los cálculos se han hecho con Gaussian $03^{233}$ a $298.15 \mathrm{~K}$ y a 1 atm.

Como se observa en el diagrama mostrado en la Figura 33, las conformaciones de mínima energía encontradas para el ión iminio-1 y para el ión iminio-2 adoptan una disposición espacial en la que el grupo hidroxilo de la cadena se aproxima al sistema conjugado por la cara menos impedida, esto es, por la cara opuesta a los grupos fenilos del catalizador 112. Ambas conformaciones se encuentran próximas a la de silla, lo que explica que sean las conformaciones más estables halladas. Como se ha comentado anteriormente, estos iones iminio presentan una conformación muy cercana a la de los estados de transición de más baja energía encontrados, siendo el ión iminio-1 el más favorecido energéticamente. De igual modo, el estado de transición al que este ión iminio da lugar, TS-1, resulta ser más bajo en energía que TS-2, lo que sugiere un mecanismo cinético. Por tanto, el enantiómero $R$ parece ser el producto cinético de reacción, lo cual está de acuerdo con los resultados experimentales obtenidos.

233 Frisch, M. J.; Trucks, G. W.; Schlegel, H. B.; Scuseria, G. E.; Robb, M. A.; Cheeseman, J. R.; Montgomery, J. A.; Jr. Vreven, T.; Kudin, K. N.; Burant, J. C.; Millam, J. M.; Iyengar, S. S.; Tomasi, J.; Barone, V.; Mennucci, B.; Cossi, M.; Scalmani, G.; Rega, N.; Petersson, G. A.; Nakatsuji, H.; Hada, M.; Ehara, M.; Toyota, K.; Fukuda, R.; Hasegawa, J.; Ishida, M.; Nakajima, T.; Honda, Y.; Kitao, O.; Nakai, H.; Klene, M.; Li, X.; Knox, J. E.; Hratchian, H. P.; Cross, J. B.; Adamo, C.; Jaramillo, J.; Gomperts, R.; Stratmann, R. E.; Yazyev, O.; Austin, A. J.; Cammi, R.; Pomelli, C.; Ochterski, J. W.; Ayala, P. Y.; Morokuma, K.; Voth, G. A.; Salvador, P.; Dannenberg, J. J.; Zakrzewski, V. G.; Dapprich, S.; Daniels, A. D.; Strain, M. C.; Farkas, O.; Malick, D. K.; Rabuck, A. D.; Raghavachari, K.; Foresman, J. B.; Ortiz, J. V.; Cui, Q.; Baboul, A. G.; Clifford, S.; Cioslowski, J.; Stefanov, B. B.; Liu, G.; Liashenko, A.; Piskorz, P.; Komaromi, I.; Martin, R. L.; Fox, D. J.; Keith, T.; Al-Laham, M. A.; Peng, C. Y.; Nanayakkara, A.; Challacombe, M. P.; Gill, M. W.; Johnson, B.; Chen, W.; Wong, M. W.; Gonzalez, C.; Pople J. A.; GAUSSIAN 03, Revision B.03; Gaussian, Inc.; Pittsburgh PA, 2003. 


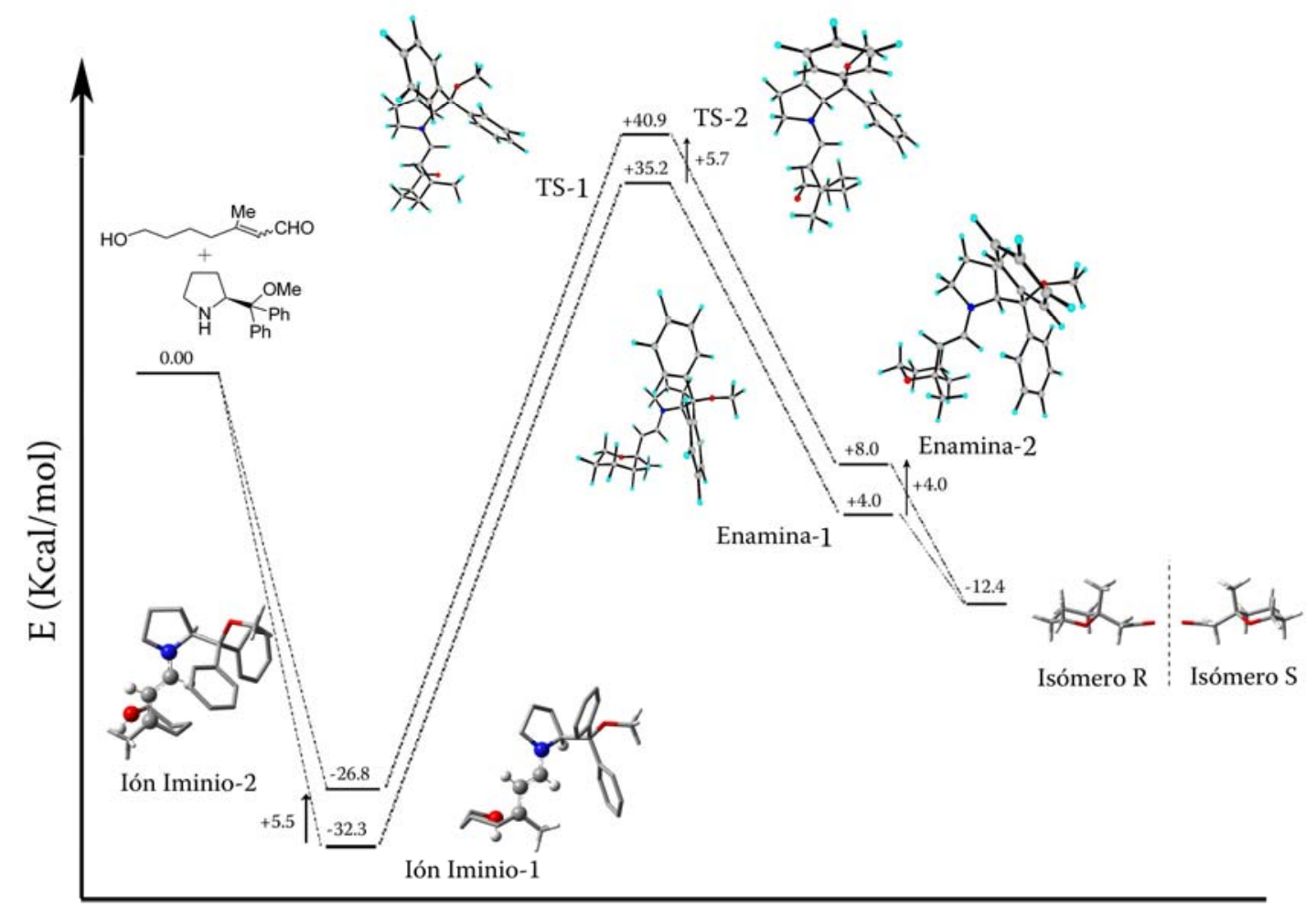

Figura 33. Las diferencias energéticas mostradas en la figura corresponden al cálculo de single-point en DFT con un nivel de teoría B3LYP/6-31G* en modelo de solvatación C-PCM. Estas energías incluyen la corrección correspondiente a la adición o eliminación de agua/protón, para lo que se ha tenido en cuenta la energía del sistema $\mathrm{H}_{2} \mathrm{O} / \mathrm{H}_{3} \mathrm{O}^{+}$calculada al mismo nivel de teoría.

A partir del cálculo de single-point en C-PCM (Figura 33), la diferencia de energía encontrada para los estados de transición TS-1 y TS-2 es de $5.7 \mathrm{kcal} / \mathrm{mol}$ lo que predeciría un ee del $99.8 \%$, valor muy alejado del obtenido experimentalmente. Teniendo en cuenta que la diferencia de energía teórica necesaria para predecir un ee del 34-58 \% sería aproximadamente de $0.4-0.8 \mathrm{kcal} / \mathrm{mol}$, el error cometido tendría su origen en el nivel de teoría empleado. No obstante, si nos fijamos en la diferencia de energía obtenida entre estos mismos estados de transición en el cálculo de single-point en gasphase (6.4 kcal/mol, Tabla 7) se puede observar que es $0.7 \mathrm{kcal} / \mathrm{mol}$ mayor que para el modelo de solvatación, lo que demuestra que el modelo de solvatación elegido para este caso parece ser el adecuado. En cualquier caso, los estados de transición encontrados a nivel semi-empírico (AM1) son consistentes con los resultados experimentales obtenidos y han sido capaces de predecir el producto mayoritario obtenido en esta reacción, esto es, el isómero $R$. 
De igual forma, el análisis termodinámico elaborado a partir de los cálculos semi-empíricos (Tabla 7), sugiere que el control más probable para la reacción aquí descrita sea cinético, lo que se encuentra apoyado por los resultados experimentales, donde se observa que la disminución de la temperatura supone un cambio drástico en los ee a favor del isómero $R$.

\begin{tabular}{|c|c|c|c|c|c|c|}
\hline & $\begin{array}{c}\mathrm{H} \\
(\mathrm{kcal} / \mathrm{mol})^{\mathrm{a}}\end{array}$ & $\begin{array}{c}\mathrm{G} \\
(\mathrm{kcal} / \mathrm{mol})^{\mathrm{a}}\end{array}$ & $\begin{array}{c}\mathrm{S} \\
(\mathrm{cal} / \mathrm{mol} \cdot \mathrm{K})^{\mathrm{a}} \\
\end{array}$ & Dipolo $^{a}$ & $\begin{array}{l}\text { Gas-phase } \\
\text { (Hartrees) }^{b}\end{array}$ & $\begin{array}{c}\text { C-PCM } \\
\text { (Hartrees) }^{\mathrm{b}}\end{array}$ \\
\hline TS_1 & 0.6251 & 0.5388 & 181.622 & 5.403 & -1215.7147 & -1215.7157 \\
\hline TS_2 & 0.6343 & 0.5490 & 179.427 & 6.406 & -1215.7045 & -1215.7066 \\
\hline TS_3 & 0.6306 & 0.5462 & 177.713 & 3.491 & -1215.7090 & -1215.7065 \\
\hline TS_4 & 0.6109 & 0.5260 & 178.656 & 3.079 & -1215.7275 & -1215.7260 \\
\hline TS_5 & 0.6286 & 0.5444 & 177.176 & 4.232 & -1215.7067 & -1215.7075 \\
\hline TS_6 & 0.6202 & 0.5364 & 176.554 & 3.638 & -1215.7155 & -1215.7151 \\
\hline TS_7 & 0.6339 & 0.5490 & 178.751 & 5.464 & -1215.7052 & -1215.7059 \\
\hline TS_8 & 0.6165 & 0.5306 & 180.884 & 4.956 & -1215.7222 & -1215.7216 \\
\hline
\end{tabular}

${ }^{\text {a }}$ Valores obtenidos a partir del cálculo de frecuencias a nivel semi-empírico RHF/AM1.

${ }^{\mathrm{b}}$ Valores obtenidos en DFT con un nivel de teoría B3LYP/6-31G*.

La elección de los estados de transición TS-1 y TS-2 como estados de transición más probables para esta reacción de ciclación oxo-Michael, se realizó teniendo en cuenta los datos tanto termodinámicos como de single-point recogidos en la Tabla 7. Considerando los datos correspondientes al dipolo y el valor de la entropía como principales factores, se descartaron los TS del 3 al 6 por presentar entropías y dipolos mucho menores que TS-1, TS-2, TS-7 y TS-8. Este primer criterio de discriminación se siguió basándonos en lo que sucede experimentalmente, ya que la polaridad del disolvente afecta significativamente al ee obtenido. Este hecho se pone aún más de manifiesto en las variaciones de energía observadas al pasar del modelo gas-phase al modelo de solvatación. TS-7 se descartó frente TS-2 debido a que TS-7 presenta una disminución de $0.4 \mathrm{kcal} / \mathrm{mol}$ al pasar de gas-phase al estado solvatado, mientras que para TS-2 el descenso es de $1.3 \mathrm{kcal} / \mathrm{mol}$, lo cual sugiere que en disolución TS-2 será el estado de transición más probable (ver Tabla 7). La elección entre TS-8 y TS-1 (basándonos en el mismo criterio seguido anteriormente), se puede explicar de forma análoga a los casos anteriores, con la única diferencia de que en TS-8 se produce un 
aumento de $0.3 \mathrm{kcal} / \mathrm{mol}$ al pasar de gas-phase al modelo de solvatación, mientras que TS-1 reduce su energía en $0.6 \mathrm{kcal} / \mathrm{mol}$ al pasar al estado solvatado.

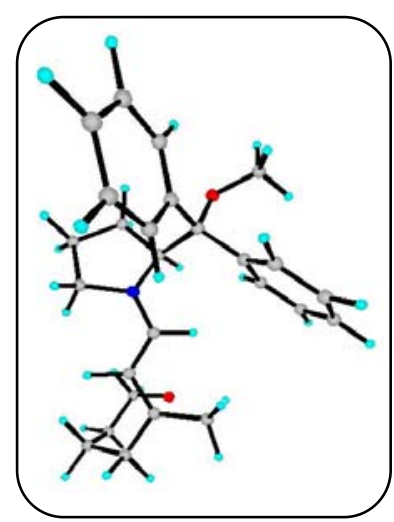

TS-1

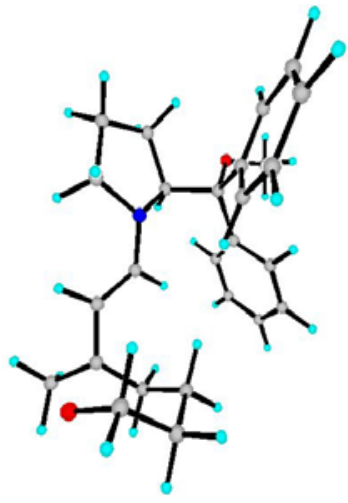

TS-8

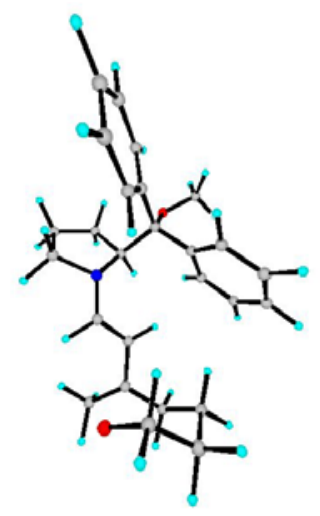

TS-6

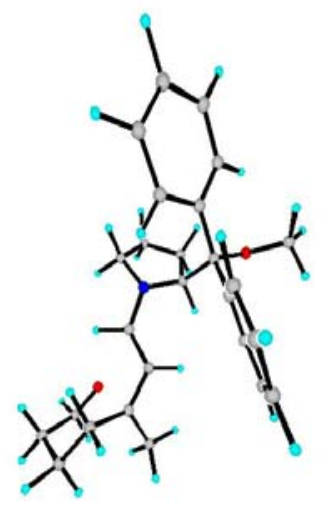

TS-5

Figura 34. Geometrías de los estados de transición para el isómero $R$.

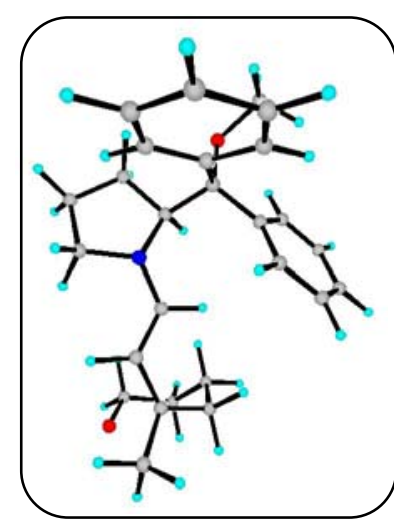

TS-2

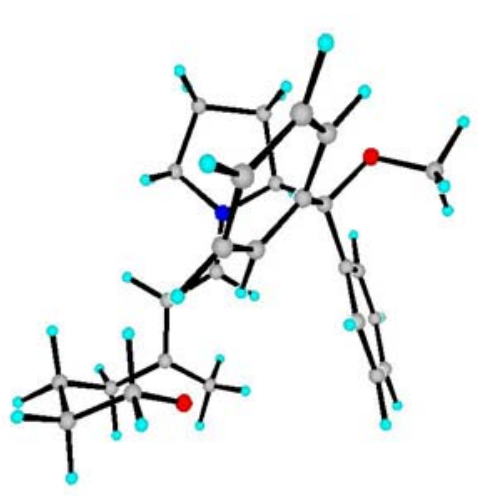

TS-3

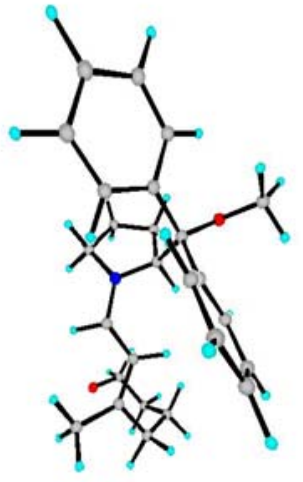

TS-7

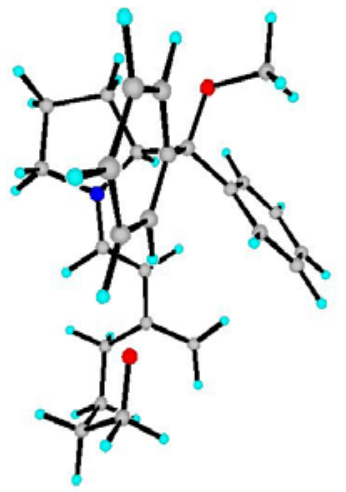

TS-4

Figura 35. Geometrías de los estados de transición para el isómero $S$.

Dado que los resultados teóricos obtenidos son bastante satisfactorios, actualmente se están llevando a cabo cálculos a un mayor nivel de teoría en los dos estados de transición hallados a nivel semi-empírico con objeto de poder predecir ee más aproximados a los experimentales. Además, estos cálculos podrán ser empleados por nuestro grupo de investigación en el diseño y la síntesis de sustratos que puedan dar lugar a mayores ee en este tipo de reacciones. 
Una vez optimizadas las condiciones de reacción con el sustrato 103, el siguiente paso de este estudio será probar dichas condiciones con otros sustratos y ver de este modo el alcance de la reacción de ciclación oxo-Michael organocatalítica.

\subsubsection{Síntesis de los sustratos 129 y 141 para su posterior utilización en la reacción} de ciclación oxo-Michael organocatalítica

Para determinar la influencia que tiene la introducción de grupos más voluminosos en posición $\alpha$ al grupo hidroxilo, se decidió sintetizar el sustrato 129, donde $\mathrm{R}_{1}=\mathrm{R}_{2}=\mathrm{Me}$ (Esquema 117), a partir de geraniol (Esquema 127). La oxidación alílica de este compuesto con $\mathrm{MnO}_{2}$ conduce al aldehído $\alpha, \beta$-insaturado 126, el cual se epoxida con $m$-CPBA hasta 127 con buen rendimiento. La posterior reducción con LAH produce el diol 128, el cual se oxida con $\mathrm{MnO}_{2}$ para dar 129 con buen rendimiento. En este caso, el sustrato $\mathbf{1 2 9}$ se obtiene como un único diastereoisómero con estereoquímica $E$.
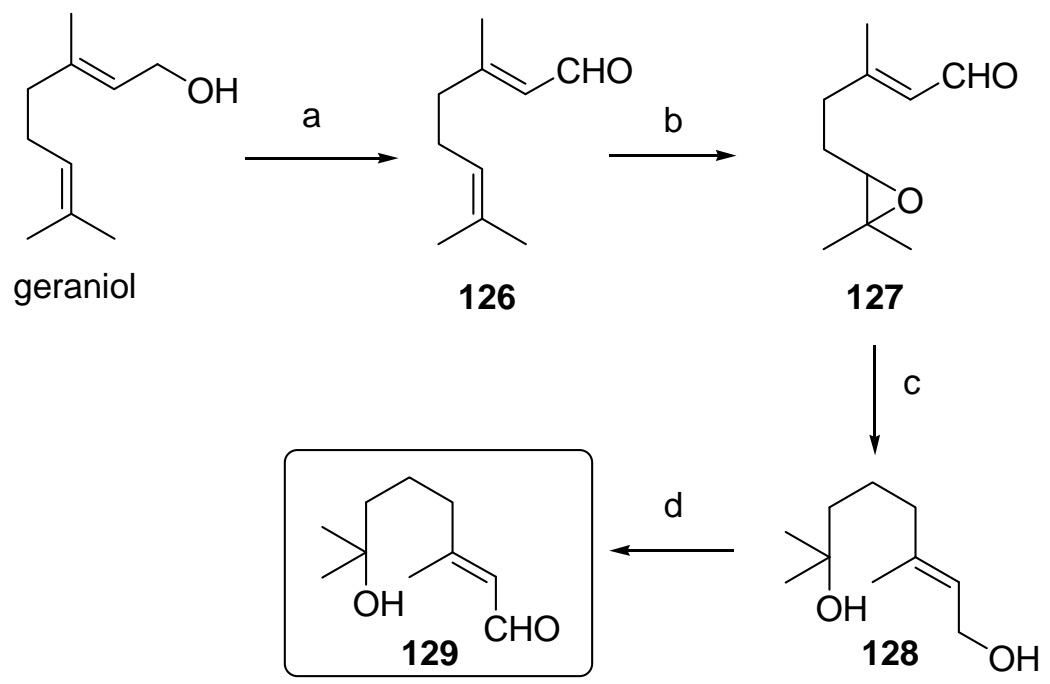

Esquema 127. a) $\mathrm{MnO}_{2}$, DCM. t.a., 97\%; b) m-CPBA, DCM, $0^{\circ} \mathrm{C}$-t.a., 84\%; c) $\mathrm{LAH}^{\mathrm{E}} \mathrm{Et}_{2} \mathrm{O}, 0^{\circ} \mathrm{C}$-t.a.; d) $\mathrm{MnO}_{2}$, DCM, t.a., $91 \%$ en 2 pasos. 
Se llevaron a cabo pruebas de ciclación organocatalíticas con el sustrato 129 y posteriores reducciones in situ con los catalizadores 112 y 113 (20 mol\%), ya que eran los que habían dado mejores resultados con el sustrato 103. Todas las pruebas se realizaron utilizando DCM como disolvente y $\mathrm{MeOH}$ como codisolvente en los casos en los que la reducción se hizo con $\mathrm{NaBH}_{4}$. Los resultados obtenidos están recogidos en la tabla 8 .

Tabla 8. Adiciones oxo-Michael intramoleculares organocatalíticas de $\mathbf{1 2 9}$ para dar los correspondientes tetrahidropiranos con los catalizadores 112 y 113 . $^{\mathrm{a}}$
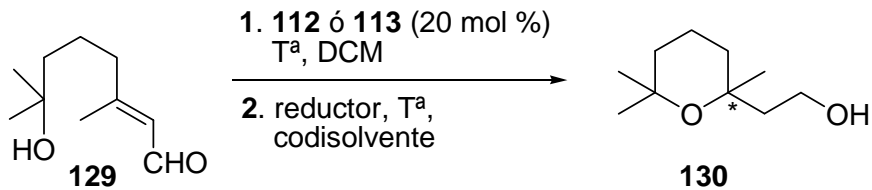

\begin{tabular}{c|cccccc} 
Entrada & Catalizador & $\mathrm{t}(\mathrm{h})$ & $\mathrm{T}^{\mathrm{a}\left({ }^{\circ} \mathrm{C}\right)}$ & Reductor & $\begin{array}{c}\eta^{\mathbf{b}} \\
(\%)\end{array}$ & $\begin{array}{c}\text { e.e. } \\
(\%)\end{array}$ \\
\hline 1 & $\mathbf{1 1 2}$ & 6 & 0 & $\mathrm{NaBH}_{4}$ & 50 & 0 \\
2 & $\mathbf{1 1 2}$ & 7 & -20 & $\mathrm{NaBH}_{4}$ & 67 & 0 \\
3 & $\mathbf{1 1 2}$ & 7 & -40 & $\mathrm{NaBH}_{4}$ & 60 & 54 \\
4 & $\mathbf{1 1 2}$ & 65 & -78 & $\mathrm{DIBAL}^{\mathrm{c}}$ & 50 & 66 \\
5 & $\mathbf{1 1 3}$ & 6 & 0 & $\mathrm{NaBH}_{4}$ & 53 & 0 \\
6 & $\mathbf{1 1 3}$ & 7 & -20 & $\mathrm{NaBH}_{4}$ & 70 & 0 \\
7 & $\mathbf{1 1 3}$ & 7 & -40 & $\mathrm{NaBH}_{4}$ & 65 & 40 \\
8 & $\mathbf{1 1 3}$ & 65 & -78 & $\mathrm{DIBAL}_{-}$ & 54 & 72
\end{tabular}

${ }^{\text {a }}$ En todas las reacciones se utilizó un $20 \mathrm{~mol} \%$ del catalizador correspondiente.

${ }^{\mathrm{b}}$ Rendimiento del compuesto puro 130 aislado por cromatografía en 2 pasos.

${ }^{\mathrm{c}}$ Determinado por experimentos de GC-MS quiral (CHIRASIL DEX-CB). Ver cromatogramas en apartado correspondiente de esta memoria.

Como puede observarse en la tabla 8, la estereoselección de la reacción de ciclación aumenta con la disminución de la temperatura, tanto con el catalizador 112 como con el 113, no observándose exceso enantiomérico en ningún caso ni a $0^{\circ} \mathrm{C}$ ni a $20^{\circ} \mathrm{C}$. En cuanto al rendimiento, no se observa la misma tendencia, ya que primero aumenta al disminuir la temperatura, pero luego se observa un descenso moderado al seguir disminuyendo esta. Este hecho puede ser debido a que, para este sustrato, a bajas temperaturas la reacción sea demasiado lenta.

Los mejores resultados en términos de enantioselección se alcanzaron a $-78^{\circ} \mathrm{C}$ con el catalizador 113, lográndose un ee del $72 \%$. 
Con el fin de sintetizar el compuesto racémico de 130 (rac-130), necesario para los experimentos de GC-MS quiral, se procedió de manera totalmente similar a la empleada para la obtención del compuesto rac-104 (Esquema 128).
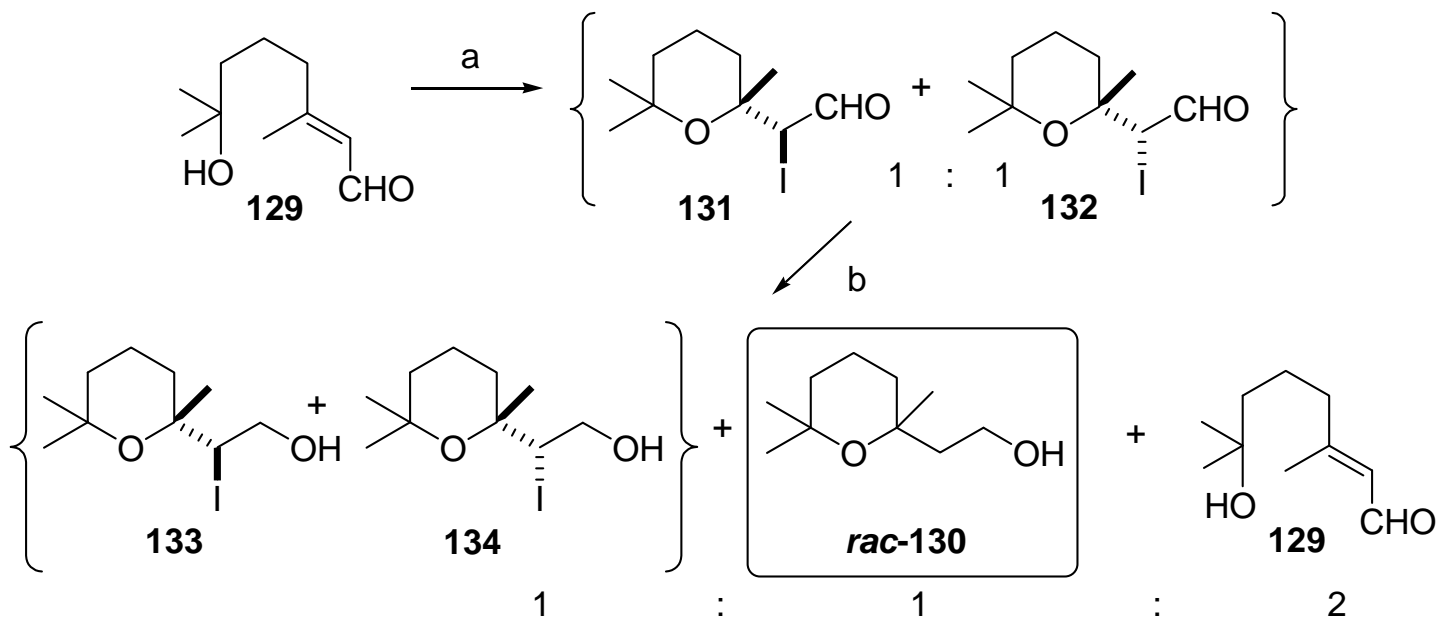

Esquema 128. a) $\mathrm{I}_{2}, \mathrm{NaHCO}_{3}, \mathrm{CH}_{3} \mathrm{CN}, 0^{\circ} \mathrm{C}$-t.a., $80 \%$; b) $\mathrm{NaBH}_{4}$, EtOH, $0^{\circ} \mathrm{C}$-t.a., $60 \%$.

La yodociclación del sustrato $\mathbf{1 2 9}$ dio lugar a la mezcla de diastereoisómeros 131 y 132, inseparables por cromatografía en columna sobre sílicagel, en proporción 1:1 (Esquema 128). La posterior reducción de esta mezcla con $\mathrm{NaBH}_{4}$ en EtOH, condujo una mezcla de los compuestos de monorreducción 133 y 134, inseparables por cromatografía en columna sobre sílicagel, el producto de doble reducción rac-130 y el de apertura de anillo 129 en una proporción 1:1:2. No fue necesario reducir la mezcla de diastereoisómeros $\mathbf{1 3 3} / \mathbf{1 3 4}$ con $\mathrm{Bu}_{3} \mathrm{SnH}$ para obtener rac-130, pues ya disponíamos de suficiente cantidad de compuesto para realizar los experimentos de GC-MS quiral.

Otra forma de obtener aldehídos $\alpha, \beta$-insaturados con un grupo hidroxilo en posición C-7 como sustratos para este tipo de ciclaciones oxo-Michael intramoleculares es la mostrada en el siguiente esquema de reacciones (Esquema 129), en el que el material de partida es de nuevo el geraniol. La epoxidación enantioselectiva de Sharpless con $\mathrm{L}(+)$-DET del geraniol ${ }^{157}$ conduce al epoxigeraniol $\mathbf{1 3 5}$ con buen

157 (a) Katsuki, T.; Sharpless, K. B. J. Am. Chem. Soc. 1980, 102, 5974. (b) Gao, Y.; Hanson, R. M.; Klunder, J. M.; Ko, S. Y.; Masamune, H.; Sharpless, K. B. J. Am. Chem. Soc. 1987, 109, 5765. 
rendimiento y un ee del $95 \%{ }^{235}$ La posterior reducción de 135 con $\mathrm{NaBH}_{3} \mathrm{CN}$ y $\mathrm{BF}_{3} \cdot \mathrm{OEt}_{2}$ produce el 1,2-diol $\mathbf{1 3 6}^{236}$ con rendimiento moderado. Seguidamente, para evitar posibles interferencias en la posterior reacción de oxidación, se protege este diol como acetónido obteniéndose $\mathbf{1 3 7}$, el cual se somete a oxidación alílica con $\mathrm{SeO}_{2}{ }^{237}$ para dar el aldehído 138 con un 41\% de rendimiento. Sin embargo, la desprotección de 138 para dar el compuesto 139, posible sustrato para la reacción de ciclación organocatalítica, resultó problemática. Se probaron condiciones de desprotección tanto con ácidos orgánicos ( $p$ - TsOH en $\mathrm{MeOH})$ como inorgánicos $(\mathrm{HCl} 2 \mathrm{M}$ y $6 \mathrm{M})$, resultando negativas en ambos casos. Al utilizar $\mathrm{HCl} 6 \mathrm{M}$ en $\mathrm{MeOH}$ a $40^{\circ} \mathrm{C}$, el compuesto 138 descompuso, por lo que decidimos utilizar otra vía para la síntesis de un sustrato análogo de 139.
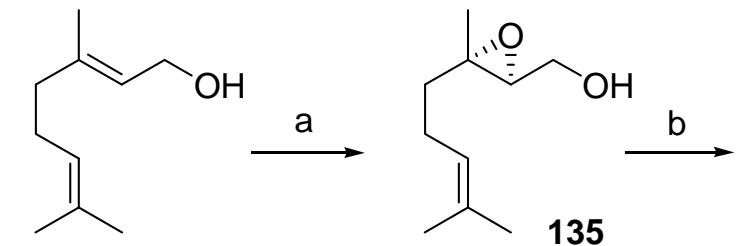<smiles>CC(C)=CCC[C@H](C)[C@H](O)CO</smiles><smiles>CC(C)=CCC[C@@H](C)[C@H](O)CO[SbH2]</smiles>

geraniol<smiles>CC(C)=CCC[C@@H](C)[C@H](O)CO</smiles>
$e, f, g$<smiles>CC(C)=CCC[C@@H](C)[C@H]1COC(C)(C)O1</smiles><smiles>CC(C)=CCC[C@@H](C)C1COC(C)(C)O1</smiles><smiles>CC(C)=CCC[C@@H](CO[SbH3])C[C@H](O)C=O</smiles>

Esquema 129. a) L- (+)-DET, Ti( $\left.{ }^{i} \mathrm{OPr}\right)_{4}, \mathrm{TBHP}, \mathrm{DCM},-23^{\circ} \mathrm{C}, 85 \%$; b) $\mathrm{NaCH}_{3} \mathrm{CN}, \mathrm{BF}_{3} \cdot \mathrm{OEt}_{2}, \mathrm{THF}$, verde de bromocresol, t.a., 50\%; c) dimetoxipropano, acetona, $\mathrm{CuSO}_{4}$ anhidro, t.a., $85 \%$; d) $\mathrm{SeO}_{2}, \mathrm{EtOH}$, reflujo, $41 \%$; e) $p$-TsOH, $\mathrm{MeOH}$, t.a.; f) $\mathrm{HCl} 2 \mathrm{M}, \mathrm{MeOH}$, t.a.; g) $\mathrm{HCl} 6 \mathrm{M}, \mathrm{MeOH}$, t.a.- $40^{\circ} \mathrm{C}$; h) $\mathrm{TBSCl}$, imidazol, DMF, $0^{\circ} \mathrm{C}$-t.a., $77 \%$; i) $\mathrm{SeO}_{2}$, EtOH, reflujo, $27 \%$.

En lugar de llevar a cabo la reacción de oxidación alílica con $\mathrm{SeO}_{2}$ directamente sobre el diol 136, decidimos proteger previamente el hidroxilo primario de este para evitar posibles interferencias. Así, al hacer reaccionar 136 con TBSCl e imidazol en

${ }^{235}$ Determinado mediante GC-MS quiral utilizando una columna CHIRASIL DEX-CB.

${ }^{236}$ (a) Taber, D. F.; Houze, J. B. J. Org. Chem. 1994, 59, 4004; (b) Taber, D. F.; Rahimizadeh, M.; You, K. K. J. Org. Chem. 1995, 60, 529.

${ }^{237}$ Labadie, G. R.; Viswanathan, R.; Poulter, C. D. J. Org. Chem. 2007, 72, 9291. 
DMF, se obtiene el compuesto 140 con un $77 \%$ de rendimiento. Finalmente, se oxida 140 en posición alílica para dar 141 con bajo rendimiento. La estereoquímica del doble enlace se determina por comparación del desplazamiento químico del metilo sobre doble enlace en su espectros de ${ }^{13} \mathrm{C}$ RMN, a $9.47 \mathrm{ppm}$, con el de otros compuestos similares de estereoquímica conocida. ${ }^{237}$

El compuesto 141 se probó como sustrato para la reacción de ciclación oxoMichael organocatalítica con el catalizador 113, pues es el que mejores resultados dio con el sustrato 129. Sin embargo, como puede observarse en el siguiente esquema (Esquema 130), no se obtuvieron resultados positivos a ninguna de las temperaturas ensayadas. Este hecho quizás sea debido a que el gran volumen del grupo $t$ butildimetilsilaniloxi impide el acercamiento del grupo hidroxilo secundario al sistema conjugado.

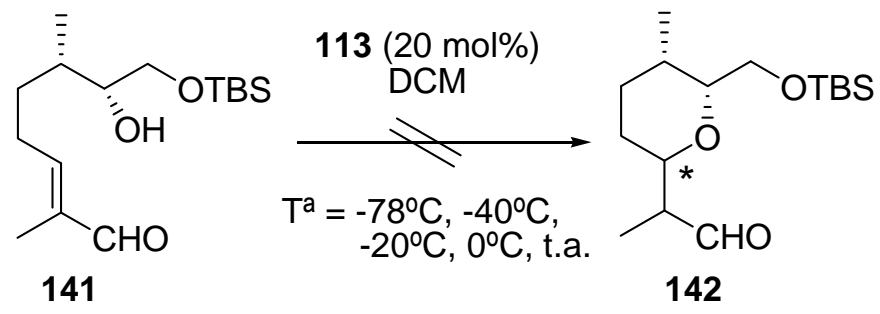

Esquema 130

Los resultados comentados en este último capítulo abren una nueva ruta para la obtención organocatalítica de tetrahidropiranos. Sin embargo, tanto los rendimientos como la enantioselección del proceso han de ser mejorados. 

METODOLOGÍA EXPERIMENTAL 

TABLAS DE ${ }^{13} \mathrm{C}$ 

TABLA I: $R M N{ }^{13} \mathrm{C}$ para los compuestos 4,5 y 6.

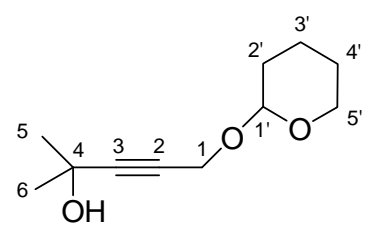

4<smiles>CC(C)(O)CCCOC1CCCCO1</smiles>

5<smiles>CC(C)(O)CCCO</smiles>

6

\begin{tabular}{|c|c|c|c|}
\hline $\mathbf{C}$ & $\delta /$ ppm & $\delta /$ ppm & $\delta / p p m$ \\
\hline 1 & 61.98 & 62.33 & 63.11 \\
\hline 2 & 90.69 & 25.52 & 27.52 \\
\hline 3 & 89.36 & 40.80 & 40.50 \\
\hline 4 & 65.00 & 70.44 & 70.50 \\
\hline 5 & 31.40 & 29.39 & 29.39 \\
\hline 6 & 31.40 & 29.39 & 29.39 \\
\hline $1^{\prime}$ & 96.69 & 98.91 & --- \\
\hline $2^{\prime}$ & 30.26 & 30.75 & --- \\
\hline $3^{\prime}$ & 18.97 & 19.64 & --- \\
\hline $4^{\prime}$ & 25.38 & 24.84 & --- \\
\hline $5^{\prime}$ & 54.30 & 68.07 & --- \\
\hline
\end{tabular}

Nota: La numeración de estos sistemas se realiza como se muestra en las figuras, teniendo únicamente fines comparativos. 
TABLA II: $\mathrm{RMN}{ }^{13} \mathrm{C}$ para los compuestos 7, 8, 13 y 57 .<smiles>[2H][C@@]1([3H])CCC(=O)O1</smiles>

7<smiles>CC1(C)CC[C@H](O)O1</smiles>

8

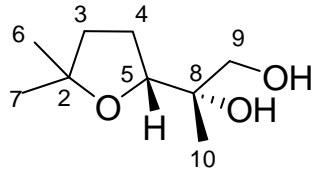

13

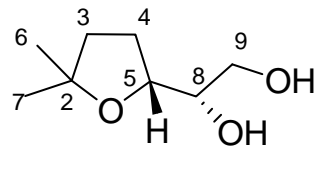

57

\begin{tabular}{|c|c|c|c|c|}
\hline $\mathbf{C}$ & $\delta / p p m$ & $\delta / p p m$ & $\delta /$ ppm & $\delta / p p m$ \\
\hline 2 & 176.36 & 98.73 & 81.22 & 81.57 \\
\hline 3 & 34.78 & 36.29 & 38.60 & 38.39 \\
\hline 4 & 29.33 & 33.80 & 27.02 & 27.53 \\
\hline 5 & 84.37 & 82.52 & 84.08 & 80.11 \\
\hline 6 & 27.35 & 30.18 & 28.72 & 28.97 \\
\hline 7 & 27.35 & 28.56 & 27.66 & 27.98 \\
\hline 8 & --- & --- & 72.97 & 73.33 \\
\hline 9 & --- & --- & 67.64 & 64.18 \\
\hline 10 & --- & --- & 20.82 & --- \\
\hline
\end{tabular}


TABLA III: $\mathbf{R M N}{ }^{13} \mathrm{C}$ para el compuesto 54 .

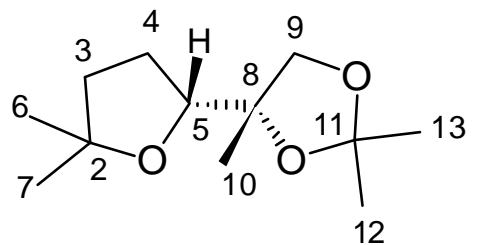

54

\begin{tabular}{|c|c|c|c|c|}
\hline $\mathbf{C}$ & $\delta(\mathbf{p p m})$ & DEPT & $\delta(\mathbf{H}) / \mathbf{p p m}$ & НМВС \\
\hline 2 & 81.17 & $\mathrm{C}$ & --- & H-6, H-7 \\
\hline 3 & 38.45 & $\mathrm{CH}_{2}$ & $1.70-1.63(1 \mathrm{H}, \mathrm{m})$ & H-6, H-7 \\
\hline 4 & 26.87 & $\mathrm{CH}_{2}$ & $\begin{array}{l}1.98-1.93(1 \mathrm{H}, \mathrm{m}) \\
1.84-1.79(1 \mathrm{H}, \mathrm{m})\end{array}$ & --- \\
\hline 5 & 81.73 & $\mathrm{CH}$ & $3.91(1 \mathrm{H}, \mathrm{t}, J=7 \mathrm{~Hz})$ & $\mathrm{H}-10$ \\
\hline 6 & 28.45 & $\mathrm{CH}_{3}$ & $1.20(6 \mathrm{H}, \mathrm{s})$ & $\mathrm{H}-3, \mathrm{H}-7$ \\
\hline 7 & 27.51 & $\mathrm{CH}_{3}$ & $1.17(3 \mathrm{H}, \mathrm{s})$ & H-3, H-6 \\
\hline 8 & 82.03 & $\mathrm{C}$ & --- & $\mathrm{H}-10$ \\
\hline 9 & 73.17 & $\mathrm{CH}_{2}$ & $\begin{array}{c}3.97(1 \mathrm{H}, \mathrm{d}, J=8.5 \mathrm{~Hz}) \\
3.69(1 \mathrm{H}, \mathrm{dd}, J=8.5 \text { y } 0.8 \mathrm{~Hz})\end{array}$ & $\mathrm{H}-5$ \\
\hline 10 & 19.76 & $\mathrm{CH}_{3}$ & $1.20(6 \mathrm{H}, \mathrm{s})$ & $\mathrm{H}-9, \mathrm{H}-5$ \\
\hline 11 & 109.19 & $\mathrm{C}$ & --- & $\begin{array}{c}\mathrm{H}-9, \mathrm{H}-12, \mathrm{H}- \\
13\end{array}$ \\
\hline 12 & 26.91 & $\mathrm{CH}_{3}$ & $1.36(3 \mathrm{H}, \mathrm{s})$ & $\mathrm{H}-13$ \\
\hline 13 & 26.91 & $\mathrm{CH}_{3}$ & $1.35(3 \mathrm{H}, \mathrm{s})$ & $\mathrm{H}-12$ \\
\hline
\end{tabular}


TABLA IV: $\mathbf{R M N}{ }^{13} \mathrm{C}$ para el compuesto 58.

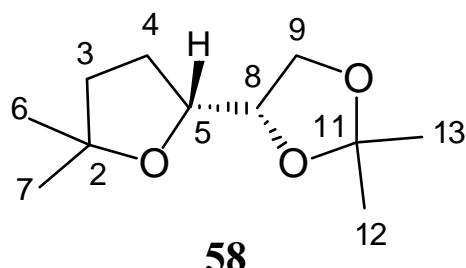

\begin{tabular}{|c|c|c|c|c|}
\hline $\mathbf{C}$ & $\delta(p p m)$ & DEPT & $\delta(\mathbf{H}) / \mathbf{p p m}$ & НМВС \\
\hline 2 & 81.37 & $\mathrm{C}$ & --- & H-6, H-7, H-3 \\
\hline 3 & 37.89 & $\mathrm{CH}_{2}$ & $1.73-1.69(2 \mathrm{H}, \mathrm{m})$ & H-6, H-7 \\
\hline 4 & 28.94 & $\mathrm{CH}_{2}$ & $\begin{array}{l}2.13-2.07(1 \mathrm{H}, \mathrm{m}) \\
1.90-1.86(1 \mathrm{H}, \mathrm{m})\end{array}$ & $\mathrm{H}-3$ \\
\hline 5 & 79.58 & $\mathrm{CH}$ & $3.91-3.87(2 \mathrm{H}, \mathrm{m})$ & H-9, H-3 \\
\hline 6 & 28.82 & $\mathrm{CH}_{3}$ & $1.22(3 \mathrm{H}, \mathrm{s})$ & H-3 \\
\hline 7 & 27.78 & $\mathrm{CH}_{3}$ & $1.19(3 \mathrm{H}, \mathrm{s})$ & H-3 \\
\hline 8 & 78.46 & $\mathrm{CH}$ & $3.91-3.87(2 \mathrm{H}, \mathrm{m})$ & $\mathrm{H}-4$ \\
\hline 9 & 67.68 & $\mathrm{CH}_{2}$ & $\begin{array}{l}4.06(1 \mathrm{H}, \mathrm{dd}, J=8.2 \mathrm{~Hz} \text { y } 5.8 \mathrm{~Hz}) \\
3.81(1 \mathrm{H}, \mathrm{dd}, J=8.2 \mathrm{~Hz} \text { y } 5.8 \mathrm{~Hz})\end{array}$ & H-5 \\
\hline 11 & 109.04 & $\mathrm{C}$ & --- & H-12, H-13 \\
\hline 12 & 26.60 & $\mathrm{CH}_{3}$ & $1.38(3 \mathrm{H}, \mathrm{s})$ & --- \\
\hline 13 & 25.34 & $\mathrm{CH}_{3}$ & $1.33(3 \mathrm{H}, \mathrm{s})$ & --- \\
\hline
\end{tabular}


TABLA V: RMN ${ }^{13} \mathrm{C}$ para los compuestos 9 y 55.

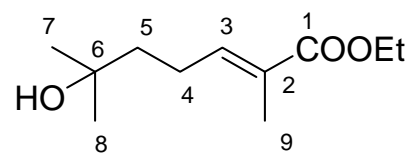

9

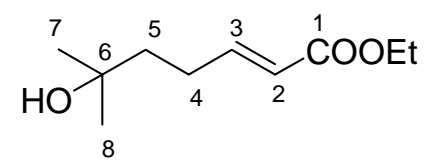

55

\begin{tabular}{ccc}
\hline $\mathbf{C}$ & $\boldsymbol{\delta}(\mathbf{p p m})$ & $\boldsymbol{\delta}(\mathbf{p p m})$ \\
\hline $\mathbf{1}$ & 168.15 & 166.97 \\
$\mathbf{3}$ & 127.83 & 121.32 \\
$\mathbf{4}$ & 142.16 & 149.63 \\
$\mathbf{5}$ & 23.73 & 27.40 \\
$\mathbf{6}$ & 42.34 & 41.92 \\
$\mathbf{7}$ & 70.47 & 70.64 \\
$\mathbf{8}$ & 29.21 & 29.44 \\
$\mathbf{9}$ & 29.21 & 29.44 \\
$\mathbf{0 - \mathbf { C H }}$ & 12.13 & --- \\
\hline $\mathbf{O}-\mathbf{C H}$ & 60.30 & 60.40 \\
\hline
\end{tabular}


TABLA VI: RMN ${ }^{13} \mathrm{C}$ para los compuestos 10 y 59.

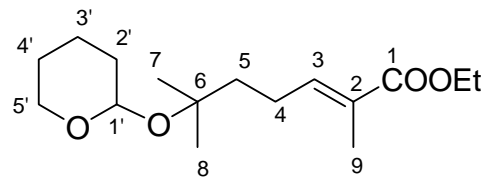

10

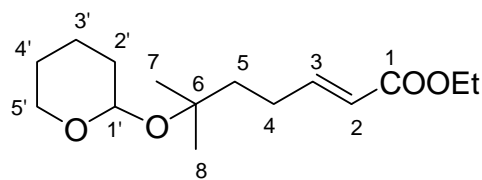

59

\begin{tabular}{|c|c|c|}
\hline $\mathbf{C}$ & $\delta(p p m)$ & $\delta(\mathrm{ppm})$ \\
\hline 1 & 168.30 & 166.98 \\
\hline 2 & 127.64 & 121.09 \\
\hline 3 & 142.52 & 149.99 \\
\hline 4 & 23.59 & 25.60 \\
\hline 5 & 40.84 & 40.38 \\
\hline 6 & 75.86 & 75.73 \\
\hline 7 & 26.02 & 26.25 \\
\hline 8 & 26.80 & 26.97 \\
\hline 9 & 12.17 & --- \\
\hline $\mathrm{O}-\underline{\mathrm{CH}}_{2}-\mathrm{CH}_{3}$ & 60.24 & 60.29 \\
\hline $\mathrm{O}-\mathrm{CH}_{2}-\underline{\mathrm{CH}}_{3}$ & 14.28 & 14.48 \\
\hline 1 ' & 93.81 & 94.14 \\
\hline 2 & 32.51 & 32.64 \\
\hline 3 & 20.57 & 20.98 \\
\hline 4 ' & 25.56 & 27.21 \\
\hline 5 & 63.06 & 63.63 \\
\hline
\end{tabular}


TABLA VII: $\mathrm{RMN}{ }^{13} \mathrm{C}$ para los compuestos 11 y 14 .

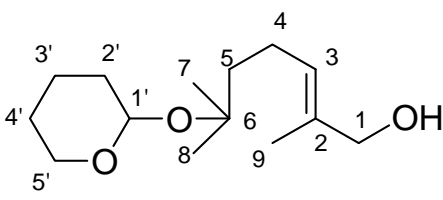

11

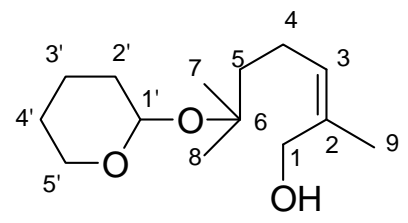

14

\begin{tabular}{lll}
\hline $\mathbf{C}$ & $\boldsymbol{\delta}(\mathbf{p p m})$ & $\boldsymbol{\delta}(\mathbf{p p m})$ \\
\hline $\mathbf{1}$ & 68.93 & 61.33 \\
$\mathbf{2}$ & 134.61 & 134.18 \\
$\mathbf{3}$ & 126.59 & 128.49 \\
$\mathbf{4}$ & 22.47 & 22.34 \\
$\mathbf{5}$ & 41.82 & 42.23 \\
$\mathbf{6}$ & 75.89 & 75.90 \\
$\mathbf{7}$ & 26.10 & 26.19 \\
$\mathbf{8}$ & 26.76 & 26.66 \\
$\mathbf{9}$ & 13.49 & 21.24 \\
$\mathbf{1}$ & 93.74 & 93.86 \\
$\mathbf{2}$ & 32.56 & 32.47 \\
$\mathbf{3}$ & 20.58 & 20.64 \\
$\mathbf{5}$ & 25.56 & 25.40 \\
\hline
\end{tabular}


TABLA VIII: RMN ${ }^{13}$ C para los compuestos 56 y 60 .

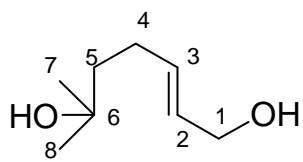

56

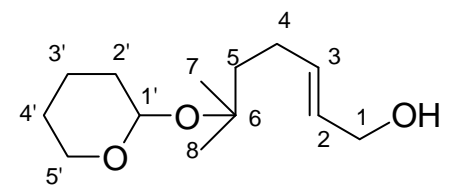

60

\begin{tabular}{lcc}
\hline $\mathbf{C}$ & $\boldsymbol{\delta}(\mathbf{p p m})$ & $\boldsymbol{\delta}(\mathbf{p p m})$ \\
\hline $\mathbf{1}$ & 63.77 & 63.80 \\
$\mathbf{2}$ & 133.32 & 133.60 \\
$\mathbf{3}$ & 129.24 & 128.87 \\
$\mathbf{4}$ & 27.42 & 25.60 \\
$\mathbf{5}$ & 43.16 & 41.45 \\
$\mathbf{6}$ & 71.15 & 76.09 \\
$\mathbf{7}$ & 29.45 & 26.35 \\
$\mathbf{8}$ & 29.45 & 26.92 \\
$\mathbf{1}$ & --- & 94.09 \\
$\mathbf{2}$ & --- & 32.68 \\
$\mathbf{3}$ & --- & 20.99 \\
$\mathbf{4}$ & -- & 27.11 \\
$\mathbf{5}$ & & 63.60 \\
\hline
\end{tabular}


TABLA IX: RMN ${ }^{13} \mathrm{C}$ para los compuestos 12 y 61 .

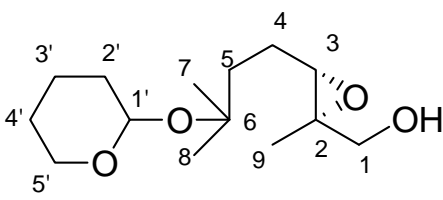

12

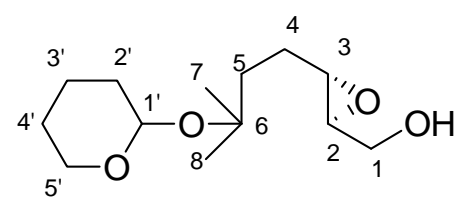

61

\begin{tabular}{lll}
\hline $\mathbf{C}$ & $\boldsymbol{\delta}(\mathbf{p p m})$ & $\boldsymbol{\delta}(\mathbf{p p m})$ \\
\hline $\mathbf{1}$ & 65.89 & 63.81 \\
$\mathbf{2}$ & 61.07 & 58.82 \\
$\mathbf{3}$ & 60.70 & 56.60 \\
$\mathbf{4}$ & 23.15 & 25.60 \\
$\mathbf{5}$ & 38.63 & 38.20 \\
$\mathbf{6}$ & 75.55 & 75.77 \\
$\mathbf{7}$ & 26.12 & 26.33 \\
$\mathbf{8}$ & 26.83 & 27.04 \\
$\mathbf{9}$ & 14.07 & --- \\
$\mathbf{1}$ & 93.82 & 94.32 \\
$\mathbf{2}$ & 32.48 & 32.73 \\
$\mathbf{3}$ & 20.53 & 21.12 \\
$\mathbf{4}$ & 25.47 & 26.67 \\
$\mathbf{5}$ & 63.04 & 62.01 \\
\hline
\end{tabular}


TABLA X: RMN ${ }^{13} \mathrm{C}$ para los compuestos 15 y 16.
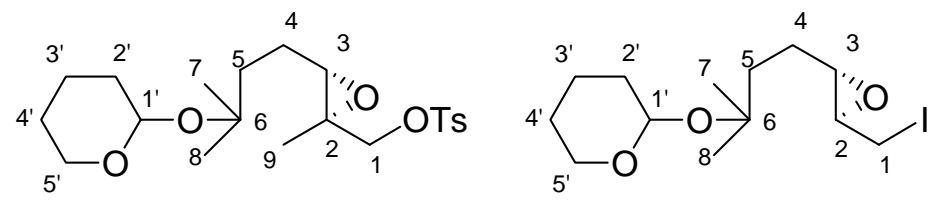

15

16

\begin{tabular}{ccc}
\hline $\mathbf{C}$ & $\boldsymbol{\delta}(\mathbf{p p m})$ & $\boldsymbol{\delta}(\mathbf{p p m})$ \\
\hline $\mathbf{1}$ & 74.51 & 13.89 \\
$\mathbf{2}$ & 57.88 & 60.01 \\
$\mathbf{4}$ & 61.84 & 66.75 \\
$\mathbf{5}$ & 22.99 & 23.99 \\
$\mathbf{6}$ & 38.45 & 38.53 \\
$\mathbf{7}$ & 75.39 & 75.46 \\
$\mathbf{8}$ & 26.87 & 26.93 \\
$\mathbf{9}$ & 26.10 & 26.15 \\
$\mathbf{1}$ & 13.93 & 15.93 \\
$\mathbf{2}$, & 93.87 & 93.88 \\
$\mathbf{3}$, & 32.48 & 32.50 \\
$\mathbf{4}$, & 20.62 & 20.66 \\
$\mathbf{5}$, & 25.47 & 25.52 \\
Tos $_{\text {ipso }}$ & 63.10 & 63.15 \\
Tos $_{\text {orto }}$ & 133.21 & --- \\
Tos $_{\text {meta }}$ & 127.93 & --- \\
Tos $_{\text {para }}$ & 129.88 & --- \\
Me-Ar & 144.90 & -- \\
\hline & 21.54 & \\
\hline & & \\
\hline
\end{tabular}


TABLA XI: RMN ${ }^{13} \mathrm{C}$ para los compuestos 17 y 18.<smiles>CC(=CC#N)C(O)CCC(C)(C)OC1CCCCO1</smiles>

17

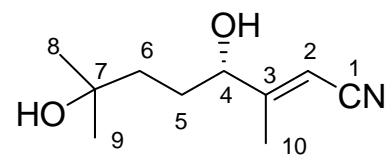

18

\begin{tabular}{|c|c|c|}
\hline $\mathbf{C}$ & $\delta /$ ppm & $\delta(p p m)$ \\
\hline 1 & 117.48 & 117.27 \\
\hline 2 & 94.21 & 94.95 \\
\hline 3 & $166.40-165.84$ & 166.07 \\
\hline 4 & 74.29-73.37 & 74.43 \\
\hline 5 & $29.23-29.84$ & 29.35 \\
\hline 6 & $37.06-35.56$ & 38.36 \\
\hline 7 & 76.32-76.18 & 70.76 \\
\hline 8 & 26.78-26.68 & 29.57 \\
\hline 9 & 29.19-26.05 & 29.53 \\
\hline 10 & $17.70-17.55$ & 17.71 \\
\hline 1 ' & $94.63-94.59$ & --- \\
\hline 2 ' & $32.38-32.28$ & --- \\
\hline 3, & $20.89-20.54$ & --- \\
\hline 4 & $25.09-25.06$ & --- \\
\hline 5 & 64.05-63.64 & --- \\
\hline
\end{tabular}


TABLA XII: RMN ${ }^{13}$ C para los compuestos 19, 21 y 22.

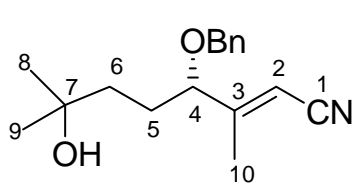

19

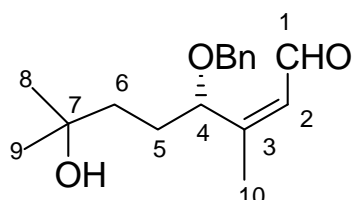

21

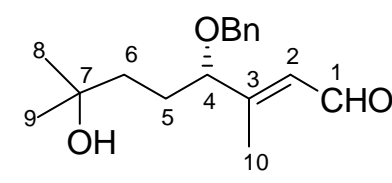

22

\begin{tabular}{|c|c|c|c|}
\hline $\mathrm{C}$ & $\delta(p p m)$ & $\delta(\mathbf{p p m})$ & $\delta(\mathrm{ppm})$ \\
\hline 1 & 116.58 & 189.71 & 191.04 \\
\hline 2 & 96.66 & 130.92 & 127.78 \\
\hline 3 & 163.95 & 162.09 & 161.47 \\
\hline 4 & 82.15 & 76.41 & 83.90 \\
\hline 5 & 28.38 & 29.09 & 28.52 \\
\hline 6 & 38.90 & 39.49 & 39.36 \\
\hline 7 & 70.33 & 70.45 & 70.40 \\
\hline 8 & 29.49 & 29.37 & 29.42 \\
\hline 9 & 29.23 & 29.26 & 29.26 \\
\hline 10 & 16.67 & 19.19 & 12.90 \\
\hline $\mathrm{PhCH}_{2} \mathrm{O}$ & 71.25 & 70.94 & 71.13 \\
\hline $\mathbf{P h}_{\text {ipso }}$ & 137.45 & 137.41 & 137.71 \\
\hline $\mathbf{P h}_{\text {orto }}$ & 127.74 & 127.83 & 127.78 \\
\hline $\mathbf{P h}_{\text {meta }}$ & 128.50 & 128.54 & 128.42 \\
\hline $\mathbf{P h}_{\text {para }}$ & 127.94 & 127.97 & 127.78 \\
\hline
\end{tabular}


TABLA XIII: $\mathrm{RMN}{ }^{13} \mathrm{C}$ para los compuestos 1 y 23 .

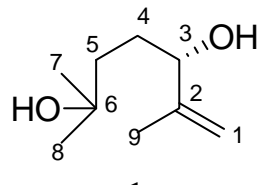

1

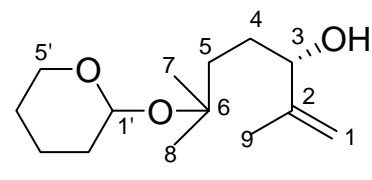

23

\begin{tabular}{|c|c|c|}
\hline C & $\delta /$ ppm & $\delta / p p m$ \\
\hline 1 & 110.80 & 113.77 \\
\hline 2 & 147.66 & 144.19 \\
\hline 3 & 76.07 & 79.61 \\
\hline 4 & 29.83 & 28.54 \\
\hline 5 & 39.68 & 39.83 \\
\hline 6 & 70.55 & 70.53 \\
\hline 7 & 29.55 & 29.39 \\
\hline 8 & 29.30 & 29.39 \\
\hline 9 & 17.76 & 16.77 \\
\hline $1^{\prime}$ & --- & 95.39 \\
\hline $2^{\prime}$ & --- & 30.95 \\
\hline $3^{\prime}$ & --- & 19.84 \\
\hline $4^{\prime}$ & --- & 25.53 \\
\hline $5^{\prime}$ & --- & 62.60 \\
\hline
\end{tabular}


TABLA XIV: $\mathrm{RMN}^{13} \mathrm{C}$ para los compuestos 32 y 33.

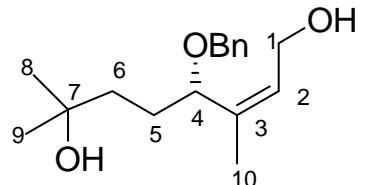

32

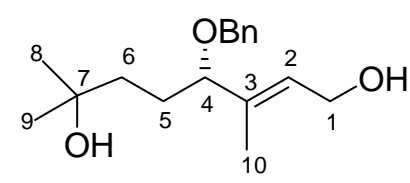

33

\begin{tabular}{|c|c|c|}
\hline $\mathrm{C}$ & $\delta /$ ppm & $\delta /$ ppm \\
\hline 1 & 58.11 & 59.01 \\
\hline 2 & 128.51 & 127.46 \\
\hline 3 & 138.65 & 138.58 \\
\hline 4 & 76.80 & 84.99 \\
\hline 5 & 28.56 & 28.59 \\
\hline 6 & 39.67 & 39.93 \\
\hline 7 & 70.63 & 70.54 \\
\hline 8 & 29.51 & 29.35 \\
\hline 9 & 29.26 & 29.23 \\
\hline 10 & 17.80 & 11.08 \\
\hline $\mathrm{PhCH}_{2} \mathrm{O}$ & 70.17 & 70.13 \\
\hline $\mathbf{P h}_{\text {ipso }}$ & 138.65 & 137.84 \\
\hline $\mathbf{P h}_{\text {orto }}$ & 127.75 & 127.77 \\
\hline $\mathbf{P h}_{\text {meta }}$ & 128.38 & 128.31 \\
\hline $\mathbf{P h}_{\text {para }}$ & 127.60 & 127.57 \\
\hline
\end{tabular}


TABLA XV: $\mathrm{RMN}{ }^{13} \mathrm{C}$ para los compuestos 35, 36, 38 y 42.
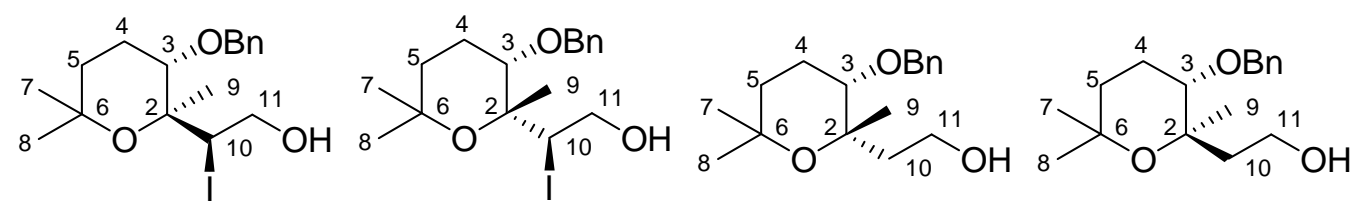

35

36

38

42

\begin{tabular}{|c|c|c|c|c|}
\hline $\mathbf{C}$ & $\delta / p p m$ & $\delta / p p m$ & $\delta / p p m$ & $\delta / p p m$ \\
\hline 2 & 79.11 & 78.21 & 77.67 & 79.02 \\
\hline 3 & 75.79 & 76.34 & 78.99 & 79.35 \\
\hline 4 & 21.45 & 19.27 & 19.82 & 20.88 \\
\hline 5 & 35.79 & 30.34 & 32.43 & 36.37 \\
\hline 6 & 73.20 & 73.34 & 71.97 & 72.20 \\
\hline 7 & 27.03 & 28.20 & 29.80 & 26.89 \\
\hline 8 & 32.36 & 32.26 & 30.91 & 32.85 \\
\hline 9 & 24.49 & 26.64 & 25.98 & 21.37 \\
\hline 10 & 50.86 & 48.50 & 39.34 & 42.50 \\
\hline 11 & 65.84 & 66.60 & 59.68 & 59.52 \\
\hline $\mathrm{PhC \underline {H } _ { 2 }} \mathbf{O}$ & 70.07 & 70.91 & 71.00 & 70.74 \\
\hline $\mathbf{P h}_{\text {ipso }}$ & 137.86 & 137.69 & 138.30 & 138.54 \\
\hline $\mathbf{P h}_{\text {orto }}$ & 127.62 & 127.74 & 127.58 & 127.43 \\
\hline $\mathbf{P h} \mathbf{h}_{\text {meta }}$ & 128.44 & 128.39 & 128.32 & 128.27 \\
\hline $\mathbf{P h}_{\text {para }}$ & 127.82 & 127.94 & 127.58 & 127.52 \\
\hline
\end{tabular}


TABLA XVI: $R M N{ }^{13} \mathrm{C}$ para el compuesto 34 .

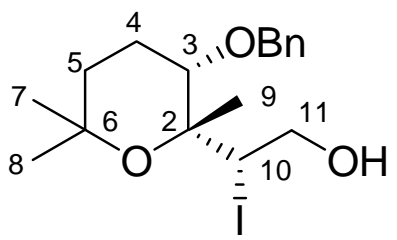

34

\begin{tabular}{|c|c|c|c|c|}
\hline $\mathbf{C}$ & $\delta / \mathbf{p p m}$ & DEPT & $\delta(\mathbf{H}) / \mathbf{p p m}$ & НMBC \\
\hline 2 & 80.40 & $\mathrm{C}$ & --- & H-9, H-10, H-11 \\
\hline 3 & 75.98 & $\mathrm{CH}$ & $3.43(1 \mathrm{H}, \mathrm{m})$ & $\mathrm{PhCH}_{2}, \mathrm{H}-4, \mathrm{H}-9$ \\
\hline 4 & 18.33 & $\mathrm{CH}_{2}$ & $2.05-1.85(2 \mathrm{H}, \mathrm{m})$ & H-5, H-7, H-8 \\
\hline 5 & 29.34 & $\mathrm{CH}_{2}$ & 2.05-1.85 (2H, m) & H-3, H-4, H-7 \\
\hline 6 & 74.04 & $\mathrm{C}$ & --- & $\mathrm{H}-4, \mathrm{H}-5, \mathrm{H}-7$ \\
\hline 7 & 27.44 & $\mathrm{CH}_{3}$ & $1.26(3 \mathrm{H}, \mathrm{s})$ & H-5, H-8 \\
\hline 8 & 32.81 & $\mathrm{CH}_{3}$ & $1.22(3 \mathrm{H}, \mathrm{s})$ & H-5, H-7 \\
\hline 9 & 20.13 & $\mathrm{CH}_{3}$ & $1.51(3 \mathrm{H}, \mathrm{s})$ & $\mathrm{H}-10$ \\
\hline 10 & 39.12 & $\mathrm{CH}$ & $4.85(1 \mathrm{H}, \mathrm{dd} J=3.4 \mathrm{~Hz}$ y $10.1 \mathrm{~Hz})$ & H-9, H-11 \\
\hline 11 & 66.70 & $\mathrm{CH}_{2}$ & $\begin{array}{l}4.09(1 \mathrm{H}, \mathrm{m}) \\
3.94(1 \mathrm{H}, \mathrm{m})\end{array}$ & $\mathrm{H}-10, \mathrm{OH}$ \\
\hline $\mathbf{P h C \underline { H } _ { 2 }}$ & 71.15 & $\mathrm{CH}_{2}$ & $\begin{array}{l}4.58(1 \mathrm{H}, \mathrm{d} J=10.8 \mathrm{~Hz}) \\
4.48(1 \mathrm{H}, \mathrm{d} J=10.8 \mathrm{~Hz})\end{array}$ & $\mathrm{H}-3, \mathrm{H}_{\text {orto }}$ \\
\hline $\mathbf{P h}_{\text {ipso }}$ & 138.45 & $\mathrm{C}$ & --- & $\mathrm{PhCH}_{2}, \mathrm{H}_{\text {meta }}$ \\
\hline $\mathbf{P h}_{\text {orto }}$ & 127.69 & $\mathrm{CH}$ & & $\mathrm{H}_{\text {para }}$ \\
\hline $\mathbf{P h} \mathbf{h}_{\text {meta }}$ & 128.25 & $\mathrm{CH}$ & $7.46-7.30(5 \mathrm{H}, \mathrm{m})$ & $\mathrm{H}_{\text {para }}$ \\
\hline $\mathbf{P h}_{\text {para }}$ & 127.47 & $\mathrm{CH}$ & & $\mathrm{H}_{\text {orto }}$ \\
\hline
\end{tabular}


TABLA XVII: $\mathrm{RMN}{ }^{13} \mathrm{C}$ para el compuesto 37.

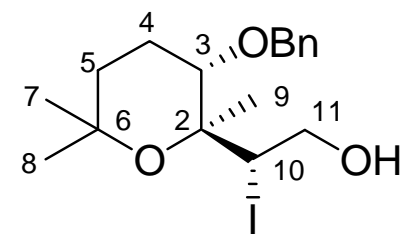

37

\begin{tabular}{|c|c|c|c|c|}
\hline $\mathbf{C}$ & $\delta /$ ppm & DEPT & $\delta(\mathbf{H}) / \mathrm{ppm}$ & HМBC \\
\hline 2 & 79.66 & $\mathrm{C}$ & --- & H-9 \\
\hline 3 & 82.15 & $\mathrm{CH}$ & 3.83-3.76 (1H, m) & H-9 \\
\hline 4 & 29.62 & $\mathrm{CH}_{2}$ & $1.35-1.20(2 \mathrm{H}, \mathrm{m})$ & --- \\
\hline 5 & 35.55 & $\mathrm{CH}_{2}$ & $1.68-1.57(2 \mathrm{H}, \mathrm{m})$ & H-7, H-8 \\
\hline 6 & 72.86 & $\mathrm{C}$ & --- & H-5, H-7, H-8 \\
\hline 7 & 26.65 & $\mathrm{CH}_{3}$ & $1.20(3 \mathrm{H}, \mathrm{s})$ & $\mathrm{H}-8$ \\
\hline 8 & 31.85 & $\mathrm{CH}_{3}$ & $1.24(3 \mathrm{H}, \mathrm{s})$ & $\mathrm{H}-7$ \\
\hline 9 & 18.46 & $\mathrm{CH}_{3}$ & $1.46(3 \mathrm{H}, \mathrm{s})$ & --- \\
\hline 10 & 50.98 & $\mathrm{CH}$ & $4.58(1 \mathrm{H}, \mathrm{t}, \mathrm{J}=3.2 \mathrm{~Hz})$ & $\mathrm{H}-9$ \\
\hline 11 & 66.42 & $\mathrm{CH}_{2}$ & $\begin{array}{l}4.18(1 \mathrm{H}, \mathrm{dd}, \mathrm{J}=12.8 \text { y } 3.2 \mathrm{~Hz}) \\
3.80(1 \mathrm{H}, \mathrm{dd}, \mathrm{J}=12.8 \text { y } 3.2 \mathrm{~Hz})\end{array}$ & --- \\
\hline $\mathrm{PhCH} \underline{\mathrm{CH}}_{2} \mathrm{O}$ & 70.94 & $\mathrm{CH}_{2}$ & $\begin{array}{l}4.64(1 \mathrm{H}, \mathrm{d}, \mathrm{J}=11.5 \mathrm{~Hz}) \\
4.50(1 \mathrm{H}, \mathrm{d}, \mathrm{J}=11.5 \mathrm{~Hz})\end{array}$ & --- \\
\hline $\mathbf{P h}_{\text {ipso }}$ & 138.47 & $\mathrm{C}$ & --- & $\mathrm{PhCH}_{2}$ \\
\hline $\mathbf{P h}_{\text {orto }}$ & 127.58 & $\mathrm{CH}$ & 7 & $\mathrm{PhCH}_{2}, \mathrm{Ph}_{\text {para }}$ \\
\hline $\mathbf{P h} \mathbf{h}_{\text {meta }}$ & 128.43 & $\mathrm{CH}$ & 7.33-7.27 (5H, m) & $\mathrm{Ph}_{\text {para }}$ \\
\hline $\mathbf{P h}_{\text {para }}$ & 127.43 & $\mathrm{CH}$ & & $\mathrm{Ph}_{\text {orto }}$ \\
\hline
\end{tabular}


TABLA XVIII: $R M{ }^{13} \mathrm{C}$ para los compuestos 39, 43 y 44 .

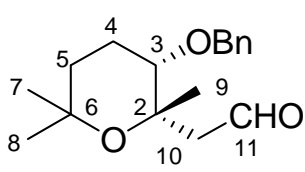

39

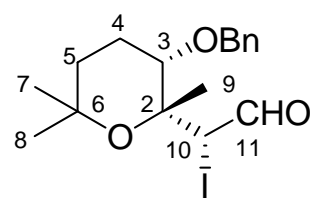

43

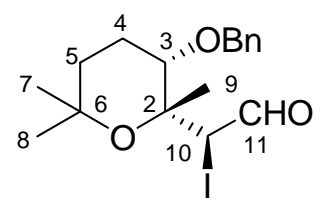

44

\begin{tabular}{|c|c|c|c|}
\hline $\mathbf{C}$ & $\delta / p p m$ & $\delta / \mathbf{p p m}$ & $\delta /$ ppm \\
\hline 2 & 75.43 & 76.48 & 76.19 \\
\hline 3 & 78.55 & 73.64 & 75.97 \\
\hline 4 & 20.04 & 19.61 & 19.68 \\
\hline 5 & 32.36 & 29.31 & 31.53 \\
\hline 6 & 71.90 & 72.92 & 73.25 \\
\hline 7 & 29.93 & 27.41 & 29.10 \\
\hline 8 & 30.42 & 32.61 & 30.86 \\
\hline 9 & 27.70 & 27.02 & 26.73 \\
\hline 10 & 51.73 & 47.28 & 47.79 \\
\hline 11 & 202.91 & 191.72 & 192.19 \\
\hline $\mathrm{PhCH}_{2} \mathrm{O}$ & 70.94 & 70.87 & 71.18 \\
\hline $\mathbf{P h}_{\text {ipso }}$ & 138.13 & 137.71 & 137.40 \\
\hline $\mathbf{P h}_{\text {orto }}$ & 127.57 & 128.20 & 127.91 \\
\hline $\mathbf{P h}_{\text {meta }}$ & 128.30 & 128.33 & 128.32 \\
\hline $\mathbf{P h}$ para & 127.70 & 127.76 & 127.70 \\
\hline
\end{tabular}


TABLA XIX: RMN ${ }^{13} \mathrm{C}$ para el compuesto 41.

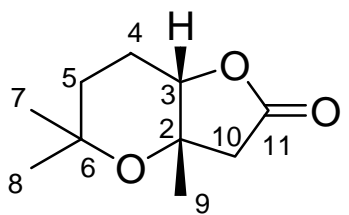

41

\begin{tabular}{|c|c|c|c|c|}
\hline $\mathbf{C}$ & $\delta / \mathbf{p p m}$ & DEPT & $\delta(\mathbf{H}) / \mathbf{p p m}$ & HMBC \\
\hline 2 & 75.66 & $\mathrm{C}$ & --- & $\mathrm{H}-9, \mathrm{H}-10$ \\
\hline 3 & 79.31 & $\mathrm{CH}$ & $4.27(1 \mathrm{H}, \mathrm{t} J=3.0 \mathrm{~Hz})$ & $\mathrm{H}-9, \mathrm{H}-10$ \\
\hline 4 & 19.52 & $\mathrm{CH}_{2}$ & 2.15-1.95 (2H, m) & --- \\
\hline 5 & 28.11 & $\mathrm{CH}_{2}$ & $\begin{array}{l}1.80-1.70(1 \mathrm{H}, \mathrm{m}) \\
1.40-1.30(1 \mathrm{H}, \mathrm{m})\end{array}$ & $\mathrm{H}-7, \mathrm{H}-8$ \\
\hline 6 & 71.55 & $\mathrm{C}$ & --- & $\mathrm{H}-7, \mathrm{H}-8$ \\
\hline 7 & 26.13 & $\mathrm{CH}_{3}$ & $1.24(3 \mathrm{H}, \mathrm{s})$ & $\mathrm{H}-8$ \\
\hline 8 & 32.41 & $\mathrm{CH}_{3}$ & $1.18(3 \mathrm{H}, \mathrm{s})$ & H-5, H-7 \\
\hline 9 & 23.52 & $\mathrm{CH}_{3}$ & $1.45(3 \mathrm{H}, \mathrm{s})$ & $\mathrm{H}-10$ \\
\hline 10 & 47.47 & $\mathrm{CH}_{2}$ & $\begin{array}{l}2.61(1 \mathrm{H}, \mathrm{d}, J=17.0 \mathrm{~Hz}) \\
2.46(1 \mathrm{H}, \mathrm{d}, J=17.0 \mathrm{~Hz})\end{array}$ & H-9 \\
\hline 11 & 175.84 & $\mathrm{C}$ & --- & $\mathrm{H}-10$ \\
\hline
\end{tabular}


TABLA XX: RMN ${ }^{13} \mathrm{C}$ para los compuestos 48,49 y 53.

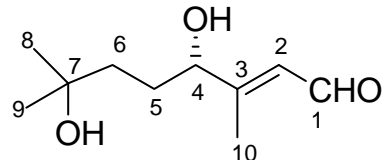

48

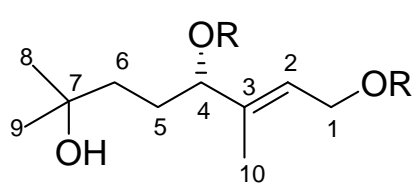

$49(\mathrm{R}=\mathrm{H})$
$53(\mathrm{R}=(R)-\mathrm{MTPA})$

\begin{tabular}{llll}
\hline $\mathbf{C}$ & $\delta / \mathbf{p p m}$ & $\delta / \mathbf{p p m}$ & $\delta / \mathbf{p p m}$ \\
\hline $\mathbf{1}$ & 191.88 & 59.18 & 61.95 \\
$\mathbf{2}$ & 125.83 & 126.23 & 121.70 \\
$\mathbf{3}$ & 162.20 & 140.82 & 139.71 \\
$\mathbf{4}$ & 76.25 & 78.60 & 80.65 \\
$\mathbf{5}$ & 29.89 & 30.57 & 26.98 \\
$\mathbf{6}$ & 39.12 & 40.76 & 38.49 \\
$\mathbf{7}$ & 70.99 & 71.12 & 70.27 \\
$\mathbf{8}$ & 29.80 & 29.14 & 29.26 \\
$\mathbf{9}$ & 29.80 & 29.30 & 29.00 \\
$\mathbf{1 0}$ & 14.10 & 11.54 & 12.42
\end{tabular}


TABLA XXI: RMN ${ }^{13} \mathrm{C}$ para los compuestos 50 y 52 .

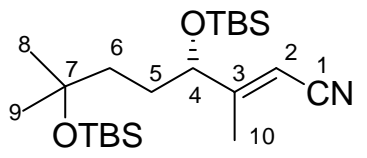

50

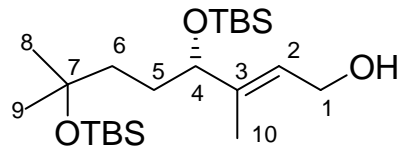

52

\begin{tabular}{|c|c|c|}
\hline $\mathbf{C}$ & $\delta(p p m)$ & $\delta(p p m)$ \\
\hline 1 & 117.58 & 59.45 \\
\hline 2 & 95.06 & 124.04 \\
\hline 3 & 166.74 & 141.72 \\
\hline 4 & 75.47 & 78.46 \\
\hline 5 & 30.42 & 31.08 \\
\hline 6 & 39.58 & 41.10 \\
\hline 7 & 73.07 & 73.40 \\
\hline 8 & 30.18 & 30.19 \\
\hline 9 & 29.95 & 29.92 \\
\hline 10 & 17.69 & 11.71 \\
\hline$\left(\underline{\mathrm{CH}}_{3}\right)_{3}(\mathrm{C}) \mathrm{Si}$ & 26.05 & 26.09 \\
\hline$\left(\mathrm{CH}_{3}\right)_{3}(\underline{\mathrm{C}}) \mathrm{Si}$ & 18.34 & 18.45 \\
\hline$\underline{\mathrm{Me}}_{2}(\mathrm{C}) \mathrm{Si}$ & $-4.64,-4.78$ & $-4.34,-4.71$ \\
\hline
\end{tabular}


TABLA XXII: $\mathrm{RMN}^{13} \mathrm{C}$ para los compuestos 28, 29, 62 y 63 .

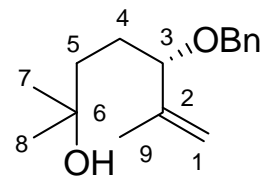

28

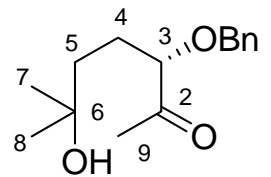

29

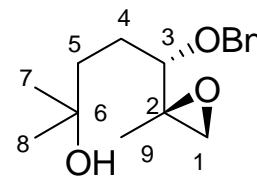

62

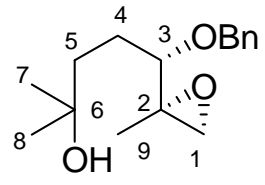

63

\begin{tabular}{|c|c|c|c|c|}
\hline $\mathrm{C}$ & $\delta / p p m$ & $\delta / p p m$ & $\delta / \mathbf{p p m}$ & $\delta / p p m$ \\
\hline 1 & 113.77 & --- & 53.85 & 49.77 \\
\hline 2 & 144.62 & 210.29 & 56.92 & 58.74 \\
\hline 3 & 83.87 & 84.12 & 82.22 & 83.81 \\
\hline 4 & 28.62 & 25.63 & 26.66 & 27.70 \\
\hline 5 & 39.99 & 37.74 & 39.87 & 40.24 \\
\hline 6 & 70.53 & 69.36 & 70.56 & 70.46 \\
\hline 7 & 29.29 & 28.18 & 29.18 & 29.28 \\
\hline 8 & 29.44 & 28.27 & 29.49 & 29.49 \\
\hline 9 & 16.70 & 24.50 & 16.28 & 15.57 \\
\hline $\mathrm{PhCH}_{2} \mathrm{O}$ & 70.07 & 71.35 & 72.15 & 71.78 \\
\hline $\mathbf{P h}_{\text {ipso }}$ & 138.80 & 136.29 & 138.56 & 138.73 \\
\hline $\mathbf{P h}_{\text {orto }}$ & 127.81 & 126.95 & 127.71 & 127.88 \\
\hline $\mathbf{P h} \mathbf{h}_{\text {meta }}$ & 128.32 & 127.54 & 128.39 & 128.28 \\
\hline $\mathbf{P h}_{\text {para }}$ & 127.44 & 126.87 & 127.71 & 127.48 \\
\hline
\end{tabular}


TABLA XXIII: RMN ${ }^{13} \mathrm{C}$ para los compuestos 64, 65, 66 y 67.

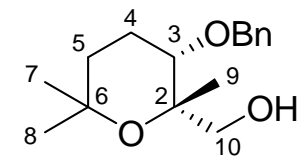

64

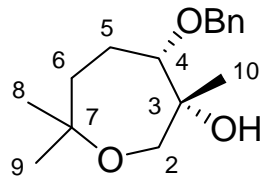

65

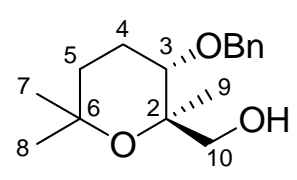

66

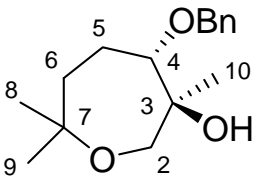

67

\begin{tabular}{|c|c|c|c|c|}
\hline $\mathrm{C}$ & $\delta / p p m$ & $\delta / p p m$ & $\delta /$ ppm & $\delta /$ ppm \\
\hline 2 & 75.36 & 52.60 & 76.60 & 50.70 \\
\hline 3 & 80.09 & 74.64 & 75.60 & 75.35 \\
\hline 4 & 20.46 & 83.09 & 21.25 & 81.31 \\
\hline 5 & 33.55 & 24.95 & 36.50 & 24.43 \\
\hline 6 & 71.60 & 40.84 & 71.94 & 39.96 \\
\hline 7 & 29.26 & 70.85 & 27.08 & 70.72 \\
\hline 8 & 30.75 & 29.50 & 32.57 & 29.59 \\
\hline 9 & 25.05 & 29.11 & 18.98 & 28.98 \\
\hline 10 & 66.99 & 20.74 & 67.93 & 21.35 \\
\hline $\mathrm{PhCH} \underline{\mathrm{H}}_{2} \mathrm{O}$ & 70.94 & 74.29 & 71.20 & 74.21 \\
\hline $\mathbf{P h}_{\text {ipso }}$ & 138.09 & 138.34 & 138.98 & 138.01 \\
\hline $\mathbf{P h}_{\text {orto }}$ & 127.58 & 127.60 & 127.34 & 127.86 \\
\hline $\mathbf{P h} \mathbf{h}_{\text {meta }}$ & 128.45 & 128.49 & 128.25 & 128.45 \\
\hline $\mathbf{P h}_{\text {para }}$ & 127.75 & 127.69 & 127.34 & 127.86 \\
\hline
\end{tabular}


TABLA XXIV: RMN ${ }^{13} \mathrm{C}$ para los compuestos 68,69 y 70 .

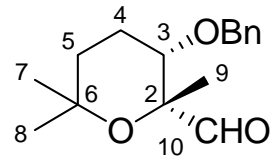

68

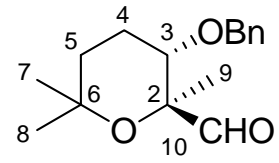

69

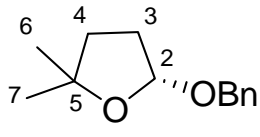

70

\begin{tabular}{|c|c|c|c|}
\hline C & $\delta / p p m$ & $\delta / p p m$ & $\delta /$ ppm \\
\hline 2 & 80.03 & 81.14 & 103.70 \\
\hline 3 & 78.13 & 71.48 & 33.34 \\
\hline 4 & 20.54 & 20.54 & 36.45 \\
\hline 5 & 31.95 & 30.36 & 82.72 \\
\hline 6 & 72.44 & 73.05 & 29.09 \\
\hline 7 & 29.09 & 26.65 & 30.34 \\
\hline 8 & 30.78 & 31.29 & --- \\
\hline 9 & 22.48 & 19.59 & --- \\
\hline 10 & 205.43 & 204.43 & --- \\
\hline $\mathrm{PhCH}_{2} \mathrm{O}$ & 71.29 & 71.34 & 68.68 \\
\hline $\mathbf{P h}_{\text {ipso }}$ & 138.20 & 138.52 & 138.70 \\
\hline $\mathbf{P h}_{\text {orto }}$ & 127.62 & 127.65 & 128.53 \\
\hline $\mathbf{P h}_{\text {meta }}$ & 128.32 & 128.27 & 128.92 \\
\hline $\mathbf{P h}_{\text {para }}$ & 127.62 & 127.53 & 127.62 \\
\hline
\end{tabular}


TABLA XXV: $\mathrm{RMN}{ }^{13} \mathrm{C}$ para los compuestos 71, 73, 74 y 75.

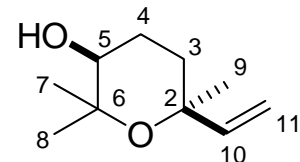

71

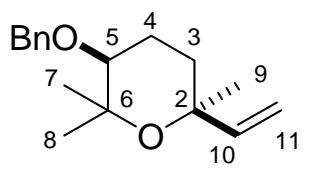

73

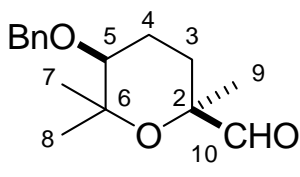

74

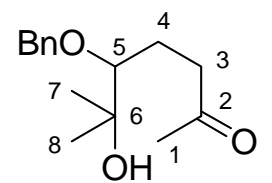

75

\begin{tabular}{|c|c|c|c|c|}
\hline $\mathbf{C}$ & $\delta / \mathbf{p p m}$ & $\delta /$ ppm & $\delta / \mathbf{p p m}$ & $\delta / p p m$ \\
\hline 1 & --- & --- & --- & 27.17 \\
\hline 2 & 73.65 & 68.78 & 78.34 & 209.01 \\
\hline 3 & 32.71 & 30.22 & 29.82 & 40.35 \\
\hline 4 & 25.81 & 19.45 & 21.72 & 22.93 \\
\hline 5 & 74.93 & 79.94 & 81.04 & 85.70 \\
\hline 6 & 76.22 & 73.38 & 76.54 & 73.79 \\
\hline 7 & 20.94 & 19.23 & 24.34 & 24.63 \\
\hline 8 & 29.76 & 29.65 & 29.25 & 24.63 \\
\hline 9 & 31.89 & 27.70 & 21.01 & --- \\
\hline 10 & 146.40 & 144.03 & 204.99 & --- \\
\hline 11 & 110.82 & 108.28 & --- & --- \\
\hline $\mathrm{PhCH}_{2} \mathrm{O}$ & --- & 71.08 & 71.24 & 74.87 \\
\hline $\mathbf{P h}_{\text {ipso }}$ & --- & 136.67 & 138.85 & 138.63 \\
\hline $\mathbf{P h}_{\text {orto }}$ & --- & 125.09 & 127.68 & 128.00 \\
\hline $\mathbf{P h} \mathbf{h}_{\text {meta }}$ & --- & 125.96 & 128.54 & 128.75 \\
\hline $\mathbf{P h}_{\text {para }}$ & --- & 125.09 & 127.76 & 128.00 \\
\hline
\end{tabular}


TABLA XXVI: RMN ${ }^{13} \mathrm{C}$ para los compuestos 76,81 y 82 .

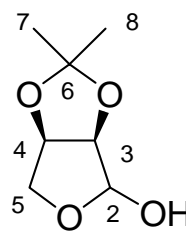

76

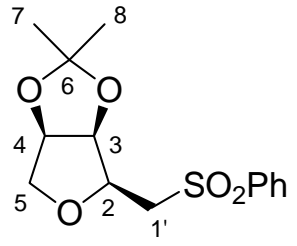

81

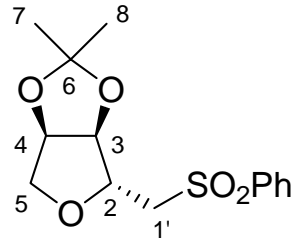

82

\begin{tabular}{cccc}
\hline $\mathbf{C}$ & $\boldsymbol{\delta}(\mathbf{p p m})$ & $\boldsymbol{\delta}(\mathbf{p p m})$ & $\boldsymbol{\delta}(\mathbf{p p m})$ \\
\hline $\mathbf{2}$ & 101.62 & 76.20 & 84.28 \\
$\mathbf{4}$ & 85.27 & 81.27 & 80.46 \\
$\mathbf{5}$ & 80.01 & 80.94 & 79.04 \\
$\mathbf{6}$ & 71.75 & 73.17 & 72.19 \\
$\mathbf{7}$ & 112.37 & 111.76 & 113.35 \\
$\mathbf{8}$ & 26.21 & 26.15 & 26.47 \\
$\mathbf{1}$ & 24.76 & 24.94 & 24.92 \\
$\mathbf{P h}_{\text {ipso }}$ & --- & 56.07 & 136.58 \\
$\mathbf{P h}_{\text {orto }}$ & --- & 140.02 & 139.37 \\
$\mathbf{P h}_{\text {meta }}$ & --- & 128.36 & 129.24 \\
$\mathbf{P h}_{\text {para }}$ & --- & 13.98 & \\
\hline \hline & & & \\
\hline
\end{tabular}


TABLA XXVII: $R M N{ }^{13} \mathrm{C}$ para los compuestos 77 y 78 .

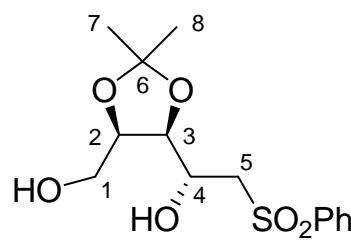

77

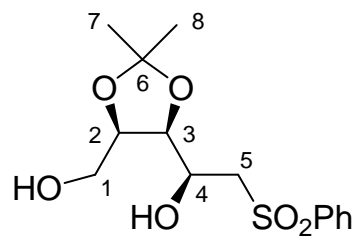

78

\begin{tabular}{ccc}
\hline $\mathbf{C}$ & $\boldsymbol{\delta}(\mathbf{p p m})$ & $\boldsymbol{\delta}(\mathbf{p p m})$ \\
\hline $\mathbf{1}$ & 60.40 & 60.50 \\
$\mathbf{3}$ & 78.04 & 78.85 \\
$\mathbf{4}$ & 77.40 & 77.29 \\
$\mathbf{5}$ & 65.43 & 65.06 \\
$\mathbf{6}$ & 59.73 & 60.43 \\
$\mathbf{7}$ & 109.03 & 108.98 \\
$\mathbf{8}$ & 27.72 & 26.91 \\
$\mathbf{P h}_{\text {ipso }}$ & 139.54 & 25.15 \\
$\mathbf{P h}_{\text {orto }}$ & 128.17 & 139.91 \\
$\mathbf{P h}_{\text {meta }}$ & 129.62 & 128.23 \\
$\mathbf{P h}_{\text {para }}$ & 134.24 & 134.14 \\
\hline
\end{tabular}


TABLA XXVIII: $R M N{ }^{13}$ C para los compuestos 79,80 y 88.

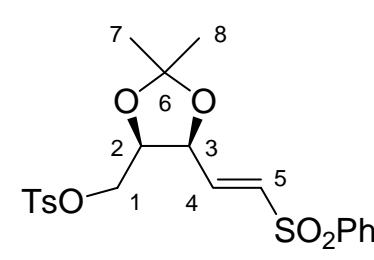

79

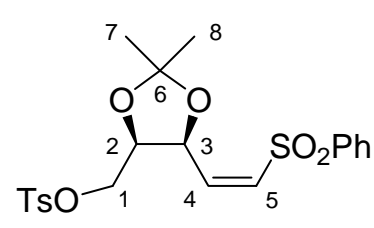

80

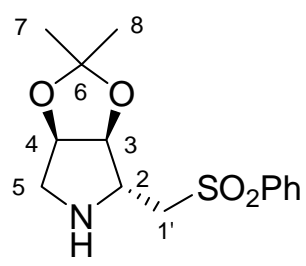

88

\begin{tabular}{|c|c|c|c|}
\hline $\mathbf{C}$ & $\delta(p p m)$ & $\delta(p p m)$ & $\delta($ ppm) \\
\hline 1 & 67.06 & 68.39 & --- \\
\hline 2 & 75.00 & 72.88 & 60.58 \\
\hline 3 & 75.00 & 76.47 & 84.19 \\
\hline 4 & 138.62 & 141.51 & 78.37 \\
\hline 5 & 133.13 & 134.30 & 52.85 \\
\hline 6 & 110.29 & 110.49 & 112.50 \\
\hline 7 & 27.34 & 27.27 & 27.27 \\
\hline 8 & 25.02 & 25.21 & 25.61 \\
\hline 1 ' & --- & --- & 54.18 \\
\hline $\mathbf{S O}_{2} \mathbf{P h}_{\text {ipso }}$ & 139.83 & 140.14 & 139.70 \\
\hline $\mathbf{S O}_{2} \mathbf{P h}_{\text {orto }}$ & 127.91 & 127.67 & 128.43 \\
\hline $\mathbf{S O}_{2} \mathbf{P h}_{\text {meta }}$ & 129.42 & 129.80 & 129.62 \\
\hline $\mathrm{SO}_{2} \mathbf{P h}_{\text {para }}$ & 133.62 & 132.09 & 134.17 \\
\hline Tos $_{i p s o}$ & 145.24 & 145.22 & --- \\
\hline Tos ${ }_{\text {orto }}$ & 128.03 & 128.26 & --- \\
\hline $\operatorname{Tos}_{\text {meta }}$ & 130.07 & 130.12 & --- \\
\hline Tos $_{\text {para }}$ & 132.45 & 132.80 & --- \\
\hline$\underline{\text { Me-Ar }}$ & 21.65 & 21.90 & --- \\
\hline
\end{tabular}


TABLA XXIX: RMN ${ }^{13} \mathrm{C}$ para el compuesto 83.

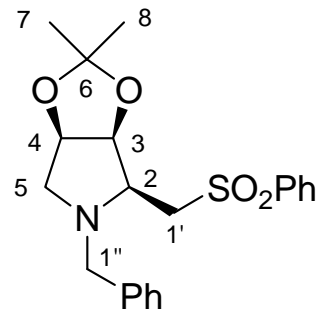

83

\begin{tabular}{|c|c|c|c|c|}
\hline $\mathbf{C}$ & $\delta / \mathbf{p p m}$ & DEPT & $\delta(\mathbf{H}) / \mathbf{p p m}$ & HМBC \\
\hline 2 & 62.10 & $\mathrm{CH}$ & $2.77(1 \mathrm{H}, \mathrm{m})$ & $\mathrm{H}_{\mathrm{A}}-5, \mathrm{H}_{\mathrm{B}}-1$, \\
\hline 3 & 79.90 & $\mathrm{CH}$ & $4.53(1 \mathrm{H}, \mathrm{dd}, J=5.1$ y $10.8 \mathrm{~Hz})$ & $\mathrm{H}-5$ \\
\hline 4 & 77.86 & $\mathrm{CH}$ & $4.57(1 \mathrm{H}, \mathrm{dd}, J=4.4$ y $10.8 \mathrm{~Hz})$ & $\mathrm{H}-2$ \\
\hline 5 & 58.77 & $\mathrm{CH}_{2}$ & $\begin{array}{c}3.01(1 \mathrm{H}, \mathrm{d}, J=11.2 \mathrm{~Hz}) \\
2.03(1 \mathrm{H}, \mathrm{dd}, J=4.4 \text { y } 11.2 \mathrm{~Hz})\end{array}$ & $\mathrm{H}-2$ \\
\hline $1 '$ & 53.79 & $\mathrm{CH}_{2}$ & $\begin{array}{c}3.87(1 \mathrm{H}, \mathrm{dd}, J=8.6 \text { y } 14.5 \mathrm{~Hz}) \\
3.20(1 \mathrm{H}, \mathrm{d}, J=14.5 \mathrm{~Hz}\end{array}$ & $\mathrm{H}-4$ \\
\hline 1, & 56.57 & $\mathrm{CH}_{2}$ & $\begin{array}{l}3.88(1 \mathrm{H}, \mathrm{d}, J=13.9 \mathrm{~Hz}) \\
3.13(1 \mathrm{H}, \mathrm{d}, J=13.9 \mathrm{~Hz})\end{array}$ & \\
\hline 6 & 111.44 & $\mathrm{C}$ & --- & \\
\hline 7 & 26.20 & $\mathrm{CH}_{3}$ & $1.45(3 \mathrm{H}, \mathrm{s})$ & $\mathrm{H}-8$ \\
\hline 8 & 25.37 & $\mathrm{CH}_{3}$ & $1.26(3 \mathrm{H}, \mathrm{s})$ & $\mathrm{H}-7$ \\
\hline $\mathrm{SO}_{2} \mathbf{P h}_{\text {ipso }}$ & 139.83 & $\mathrm{C}$ & --- & \\
\hline $\mathrm{SO}_{2} \mathbf{P h}_{\text {orto }}$ & 128.30 & $\mathrm{CH}$ & & \\
\hline $\mathrm{SO}_{2} \mathbf{P h}_{\text {meta }}$ & 129.15 & $\mathrm{CH}$ & $7.96-7.19(5 \mathrm{H}, \mathrm{m})$ & \\
\hline $\mathrm{SO}_{2} \mathbf{P h}_{\text {para }}$ & 133.63 & $\mathrm{CH}$ & & \\
\hline $\mathbf{P h}_{\text {ipso }}$ & 137.75 & $\mathrm{C}$ & --- & \\
\hline $\mathbf{P h}_{\text {orto }}$ & 128.03 & $\mathrm{CH}$ & & \\
\hline $\mathbf{P h}$ meta & 128.30 & $\mathrm{CH}$ & > 7.96-7.19 $(5 \mathrm{H}, \mathrm{m})$ & \\
\hline $\mathbf{P h}_{\text {para }}$ & 127.05 & $\mathrm{CH}$ & & \\
\hline
\end{tabular}


TABLA XXX: $R M N{ }^{13} \mathrm{C}$ para el compuesto 84.

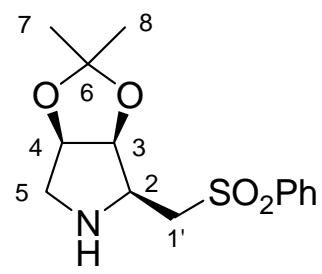

84

\begin{tabular}{|c|c|c|c|c|}
\hline $\mathbf{C}$ & $\delta /$ ppm & DEPT & $\delta(\mathbf{H}) / \mathbf{p p m}$ & НМВС \\
\hline 2 & 57.14 & $\mathrm{CH}$ & $3.22(1 \mathrm{H}, \mathrm{m})$ & $\mathrm{H}_{\mathrm{A}}-5, \mathrm{H}_{\mathrm{B}}-1$ \\
\hline 3 & 81.01 & $\mathrm{CH}$ & $4.54(1 \mathrm{H}, \mathrm{dd}, J=4.2$ y $5.3 \mathrm{~Hz})$ & $\mathrm{H}-5$ \\
\hline 4 & 80.80 & $\mathrm{CH}$ & $4.67(1 \mathrm{H}, \mathrm{dd}, J=4.0$ y $5.3 \mathrm{~Hz})$ & $\mathrm{H}-2$ \\
\hline 5 & 52.57 & $\mathrm{CH}_{2}$ & $\begin{array}{c}3.13(1 \mathrm{H}, \mathrm{d}, J=12.7 \mathrm{~Hz}) \\
2.69(1 \mathrm{H}, \mathrm{dd}, J=4.0 \text { y } 12.7 \mathrm{~Hz})\end{array}$ & \\
\hline 1 ' & 55.91 & $\mathrm{CH}_{2}$ & $\begin{array}{l}3.57(1 \mathrm{H}, \mathrm{dd}, J=5.0 \text { y } 14.0 \mathrm{~Hz}) \\
3.36(1 \mathrm{H}, \mathrm{dd}, J=7.0 \text { y } 14.0 \mathrm{~Hz})\end{array}$ & \\
\hline 6 & 111.10 & $\mathrm{C}$ & --- & \\
\hline 7 & 25.68 & $\mathrm{CH}_{3}$ & $1.41(3 \mathrm{H}, \mathrm{s})$ & $\mathrm{H}-8$ \\
\hline 8 & 24.00 & $\mathrm{CH}_{3}$ & $1.25(3 \mathrm{H}, \mathrm{s})$ & $\mathrm{H}-7$ \\
\hline $\mathbf{S O}_{2} \mathbf{P h}_{\text {ipso }}$ & 139.72 & $\mathrm{C}$ & --- & \\
\hline $\mathrm{SO}_{2} \mathbf{P h}_{\text {orto }}$ & 128.00 & $\mathrm{CH}$ & & \\
\hline $\mathrm{SO}_{2} \mathrm{Ph}_{\text {meta }}$ & 129.21 & $\mathrm{CH}$ & 7.95-7.50 (5H, m) & \\
\hline $\mathrm{SO}_{2} \mathbf{P h}_{\text {para }}$ & 133.71 & $\mathrm{CH}$ & & \\
\hline
\end{tabular}


TABLA XXXI: RMN ${ }^{13} \mathrm{C}$ para el compuesto 85.

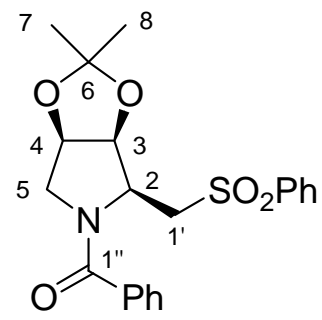

85

\begin{tabular}{|c|c|c|c|c|}
\hline $\mathbf{C}$ & $\delta / \mathbf{p p m}$ & DEPT & $\delta(\mathbf{H}) / \mathbf{p p m}$ & НМВС \\
\hline 2 & 54.77 & $\mathrm{CH}$ & 3.59-3.52 (2H, m) & H-3, H-1' \\
\hline 3 & 78.70 & $\mathrm{CH}$ & $4.83(1 \mathrm{H}, \mathrm{t}, J=5.8 \mathrm{~Hz})$ & $\mathrm{H}-1^{\prime}, \mathrm{H}-4$ \\
\hline 4 & 77.53 & $\mathrm{CH}$ & 4.66-4.61 (2H, m) & $\mathrm{H}-5$ \\
\hline 5 & 54.49 & $\mathrm{CH}_{2}$ & $\begin{array}{l}4.66-4.61(2 \mathrm{H}, \mathrm{m}) \\
3.59-3.52(2 \mathrm{H}, \mathrm{m})\end{array}$ & $\mathrm{H}-4$ \\
\hline 1 ' & 53.18 & $\mathrm{CH}_{2}$ & $\begin{array}{l}3.98(1 \mathrm{H}, \mathrm{dd}, J=14.0 \text { y } 4.7 \mathrm{~Hz}) \\
3.84(1 \mathrm{H}, \mathrm{dd}, J=14.0 \text { y } 9.0 \mathrm{~Hz})\end{array}$ & $\mathrm{H}-2, \mathrm{H}-5$ \\
\hline 1 ', & 171.34 & $\mathrm{C}$ & --- & \\
\hline 6 & 113.07 & $\mathrm{C}$ & --- & $\mathrm{H}-7, \mathrm{H}-8$ \\
\hline 7 & 27.15 & $\mathrm{CH}_{3}$ & $1.54(3 \mathrm{H}, \mathrm{s})$ & $\mathrm{H}-8$ \\
\hline 8 & 25.21 & $\mathrm{CH}_{3}$ & $1.32(3 \mathrm{H}, \mathrm{s})$ & $\mathrm{H}-7$ \\
\hline $\mathrm{SO}_{2} \mathbf{P h}_{\text {ipso }}$ & 139.71 & $\mathrm{C}$ & --- & \\
\hline $\mathrm{SO}_{2} \mathbf{P h}_{\text {orto }}$ & 128.35 & $\mathrm{CH}$ & $8.01(2 \mathrm{H}, \mathrm{d}, J=7.3 \mathrm{~Hz})$ & \\
\hline $\mathbf{S O}_{2} \mathbf{P h}_{\text {meta }}$ & 129.09 & $\mathrm{CH}$ & 7.59-7.55 (2H, m) & \\
\hline $\mathrm{SO}_{2} \mathrm{Ph}_{\text {para }}$ & 133.63 & $\mathrm{CH}$ & 7.65-7.63 (1H, m) & \\
\hline $\mathbf{C}(\mathbf{O}) \mathbf{P h}_{\text {ipso }}$ & 135.28 & $\mathrm{C}$ & --- & \\
\hline $\mathbf{C}(\mathbf{O}) \mathbf{P h} \mathbf{h}_{\text {orto }}$ & 128.15 & $\mathrm{CH}$ & 7.38-7.34 (2H, m) & \\
\hline $\mathbf{C}(\mathbf{O}) \mathbf{P h}_{\text {meta }}$ & 130.85 & $\mathrm{CH}$ & 7.44-7.41 (3H, m) & \\
\hline $\mathbf{C}(\mathbf{O}) \mathbf{P h}_{\text {para }}$ & 127.69 & $\mathrm{CH}$ & 7.44-7.41 (3H, m) & \\
\hline
\end{tabular}


TABLA XXXII: $R M{ }^{13} \mathrm{C}$ para el compuesto 86 .

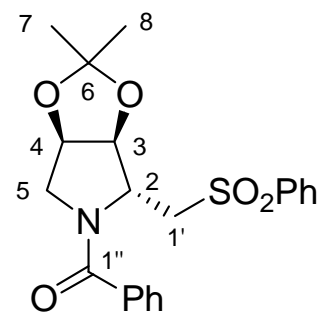

86

\begin{tabular}{|c|c|c|c|c|}
\hline $\mathbf{C}$ & $\delta /$ ppm & DEPT & $\delta(\mathbf{H}) / \mathbf{p p m}$ & HMBC \\
\hline 2 & 60.17 & $\mathrm{CH}$ & $4.79(1 \mathrm{H}, \mathrm{m})$ & $\mathrm{H}-5$ \\
\hline 3 & 82.52 & $\mathrm{CH}$ & $5.25-5.23(1 \mathrm{H}, \mathrm{m})$ & $\mathrm{H}-5$ \\
\hline 4 & 79.58 & $\mathrm{CH}$ & $4.85(1 \mathrm{H}, \mathrm{m})$ & $\mathrm{H}-5$ \\
\hline 5 & 54.84 & $\mathrm{CH}_{2}$ & $3.78-3.71(2 \mathrm{H}, \mathrm{m})$ & \\
\hline $1 '$ & 54.76 & $\mathrm{CH}_{2}$ & $\begin{array}{c}3.89(1 \mathrm{H}, \mathrm{dd}, J=12.8 \text { y } 3.6 \mathrm{~Hz}) \\
3.44(1 \mathrm{H}, \mathrm{d}, J=14.0 \mathrm{~Hz})\end{array}$ & \\
\hline 1 ', & 170.01 & $\mathrm{C}$ & --- & \\
\hline 6 & 112.17 & $\mathrm{C}$ & --- & H-7, H-8 \\
\hline 7 & 26.89 & $\mathrm{CH}_{3}$ & $1.44(3 \mathrm{H}, \mathrm{s})$ & $\mathrm{H}-8$ \\
\hline 8 & 24.89 & $\mathrm{CH}_{3}$ & $1.33(3 \mathrm{H}, \mathrm{s})$ & $\mathrm{H}-7$ \\
\hline $\mathbf{S O}_{2} \mathbf{P h}_{\text {ipso }}$ & 139.62 & $\mathrm{C}$ & --- & \\
\hline $\mathbf{S O}_{2} \mathbf{P h}_{\text {orto }}$ & 128.29 & $\mathrm{CH}$ & 7.69-7.66 (2H, m) & \\
\hline $\mathrm{SO}_{2} \mathbf{P h}_{\text {meta }}$ & 129.41 & $\mathrm{CH}$ & 7.61-7.57 (2H, m) & \\
\hline $\mathrm{SO}_{2} \mathrm{Ph}_{\text {para }}$ & 134.01 & $\mathrm{CH}$ & $7.97(2 \mathrm{H}, \mathrm{d}, J=7.4 \mathrm{~Hz})$ & \\
\hline $\mathbf{C}(\mathbf{O}) \mathbf{P h} \mathbf{h}_{\text {ipso }}$ & 135.50 & $\mathrm{C}$ & --- & \\
\hline $\mathrm{C}(\mathbf{O}) \mathbf{P h}_{\text {orto }}$ & 127.76 & $\mathrm{CH}$ & & \\
\hline $\mathbf{C}(\mathbf{O}) \mathbf{P h}_{\text {meta }}$ & 130.23 & $\mathrm{CH}$ & > 7.46-7.38 $(5 \mathrm{H}, \mathrm{m})$ & \\
\hline $\mathbf{C}(\mathbf{O}) \mathbf{P h}_{\text {para }}$ & 127.22 & $\mathrm{CH}$ & & \\
\hline
\end{tabular}


TABLA XXXIII: RMN ${ }^{13} \mathrm{C}$ para el compuesto 87.

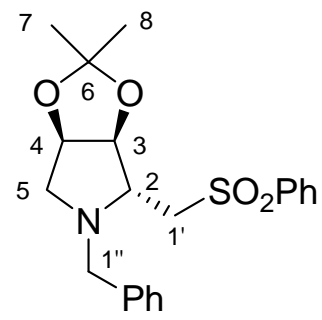

87

\begin{tabular}{|c|c|c|c|c|}
\hline $\mathbf{C}$ & $\delta / p p m$ & DEPT & $\delta(\mathbf{H}) / \mathbf{p p m}$ & НМВС \\
\hline 2 & 63.38 & $\mathrm{CH}$ & $3.32-3.27(2 \mathrm{H}, \mathrm{m})$ & $\mathrm{H}-1^{\prime}$ \\
\hline 3 & 84.29 & $\mathrm{CH}$ & $4.70(1 \mathrm{H}, \mathrm{m})$ & $\mathrm{H}-1^{\prime}$ \\
\hline 4 & 78.69 & $\mathrm{CH}$ & $4.64(1 \mathrm{H}, \mathrm{m})$ & $\mathrm{H}-5$ \\
\hline 5 & 57.28 & $\mathrm{CH}_{2}$ & $\begin{array}{c}2.87(1 \mathrm{H}, \mathrm{dd}, J=10.7 \text { y } 5.3 \mathrm{~Hz}) \\
2.68(1 \mathrm{H}, \mathrm{d}, J=9.0 \mathrm{~Hz})\end{array}$ & \\
\hline $1 '$ & 55.06 & $\mathrm{CH}_{2}$ & $\begin{array}{c}3.32-3.27(2 \mathrm{H}, \mathrm{m}) \\
3.13(1 \mathrm{H}, \mathrm{dd}, J=13.5 \text { y } 9.0 \mathrm{~Hz})\end{array}$ & \\
\hline 1 ', & 56.56 & $\mathrm{CH}_{2}$ & $\begin{array}{l}3.81(1 \mathrm{H}, \mathrm{d}, J=13.3 \mathrm{~Hz}) \\
3.55(1 \mathrm{H}, \mathrm{d}, J=13.3 \mathrm{~Hz})\end{array}$ & \\
\hline 6 & 112.42 & $\mathrm{C}$ & --- & H-7, H-8 \\
\hline 7 & 26.96 & $\mathrm{CH}_{3}$ & $1.50(3 \mathrm{H}, \mathrm{s})$ & $\mathrm{H}-8$ \\
\hline 8 & 24.96 & $\mathrm{CH}_{3}$ & $1.28(3 \mathrm{H}, \mathrm{s})$ & $\mathrm{H}-7$ \\
\hline $\mathbf{S O}_{2} \mathbf{P h}_{\text {ipso }}$ & 139.44 & $\mathrm{C}$ & --- & \\
\hline $\mathrm{SO}_{2} \mathbf{P h}_{\text {orto }}$ & 128.30 & $\mathrm{CH}$ & $7.90-7.87(2 \mathrm{H}, \mathrm{m})$ & \\
\hline $\mathrm{SO}_{2} \mathrm{Ph}_{\text {meta }}$ & 129.21 & $\mathrm{CH}$ & 7.54-7.51 (2H, m) & \\
\hline $\mathrm{SO}_{2} \mathbf{P h}_{\text {para }}$ & 133.66 & $\mathrm{CH}$ & 7.63-7.61 (1H, m) & \\
\hline $\mathbf{P h}_{\text {ipso }}$ & 137.00 & C & --- & \\
\hline $\mathbf{P h}_{\text {orto }}$ & 128.08 & $\mathrm{CH}$ & & \\
\hline $\mathbf{P h}_{\text {meta }}$ & 128.30 & $\mathrm{CH}$ & $7.25-7.15(5 \mathrm{H}, \mathrm{m})$ & \\
\hline $\mathbf{P h}_{\text {para }}$ & 127.13 & $\mathrm{CH}$ & $J$ & \\
\hline
\end{tabular}


TABLA XXXIV: RMN ${ }^{13} \mathrm{C}$ para los compuestos 93 y 94.

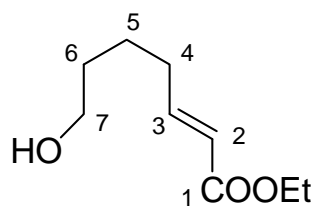

93

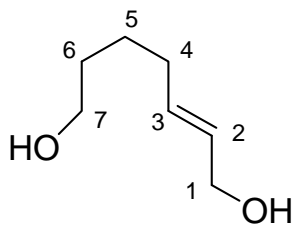

94

\begin{tabular}{|c|c|c|}
\hline $\mathbf{C}$ & $\delta /$ ppm & $\delta /$ ppm \\
\hline 1 & 167.05 & 63.56 \\
\hline 2 & 121.60 & 129.52 \\
\hline 3 & 149.31 & 132.82 \\
\hline 4 & 32.16 & 32.15 \\
\hline 5 & 24.40 & 25.39 \\
\hline 6 & 32.03 & 32.06 \\
\hline 7 & 62.31 & 62.58 \\
\hline $\mathrm{O}-\underline{\mathrm{CH}}_{2}-\mathrm{CH}_{3}$ & 60.42 & --- \\
\hline $\mathrm{O}-\mathrm{CH}_{2}-\underline{\mathrm{CH}} \underline{3}$ & 14.38 & --- \\
\hline
\end{tabular}


TABLA XXXV: $\mathrm{RMN}^{13} \mathrm{C}$ para los compuestos 99, 100 y 101.

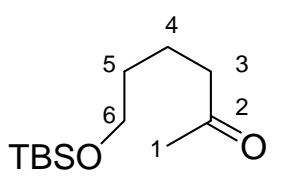

99

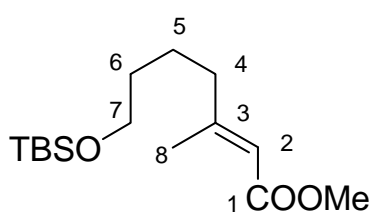

100

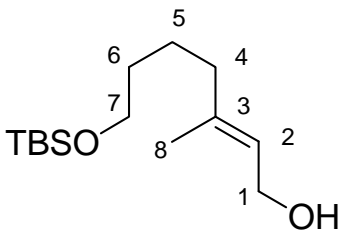

101

\begin{tabular}{|c|c|c|c|}
\hline $\mathbf{C}$ & $\delta(\mathbf{p p m})$ & $\delta(p p m)$ & $\delta(p p m)$ \\
\hline 1 & 29.98 & 167.36 & 59.39 \\
\hline 2 & 209.16 & 115.37 & 123.78 \\
\hline 3 & 43.65 & 160.51 & 139.58 \\
\hline 4 & 20.49 & 40.80 & 39.46 \\
\hline 5 & 32.36 & 23.82 & 24.01 \\
\hline 6 & 62.96 & 32.38 & 32.54 \\
\hline 7 & --- & 62.89 & 63.25 \\
\hline 8 & --- & 18.78 & 16.31 \\
\hline $\mathrm{COOCH}_{3}$ & --- & 50.88 & --- \\
\hline$\left(\underline{\mathrm{CH}}_{3}\right)_{3}(\mathrm{C}) \mathrm{Si}$ & 26.13 & 23.82 & 26.17 \\
\hline$\left(\mathrm{CH}_{3}\right)_{3}(\underline{\mathrm{C}}) \mathrm{Si}$ & 18.50 & 18.49 & 18.56 \\
\hline$\underline{\mathrm{Me}}_{2}(\mathrm{C}) \mathrm{Si}$ & -5.14 & -5.15 & -5.11 \\
\hline
\end{tabular}


TABLA XXXVI: $\mathrm{RMN}^{13} \mathrm{C}$ para los compuestos 103, 104, 129 y 130 .

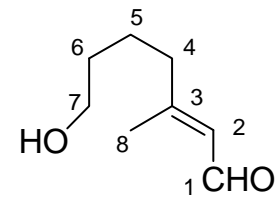

103

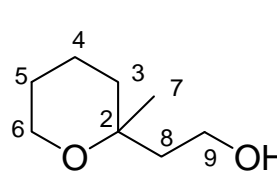

104

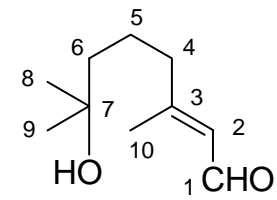

129

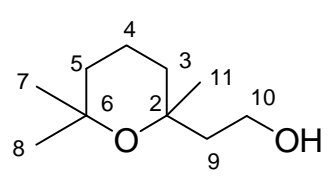

130

\begin{tabular}{ccccc}
\hline $\mathbf{C}$ & $\delta / \mathbf{p p m}$ & $\delta / \mathbf{p p m}$ & $\delta / \mathbf{p p m}$ & $\delta / \mathbf{p p m}$ \\
\hline $\mathbf{1}$ & 191.66 & --- & 191.67 & -- \\
$\mathbf{2}$ & 127.58 & 75.15 & 127.53 & 72.46 \\
$\mathbf{3}$ & 164.34 & 35.37 & 164.62 & 34.74 \\
$\mathbf{4}$ & 40.49 & 19.33 & 41.07 & 16.46 \\
$\mathbf{5}$ & 25.26 & 25.99 & 21.99 & 36.61 \\
$\mathbf{6}$ & 32.43 & 61.77 & 43.27 & 76.09 \\
$\mathbf{7}$ & 62.53 & 21.70 & 70.74 & 27.67 \\
$\mathbf{8}$ & 17.71 & 42.81 & 29.44 & 33.41 \\
$\mathbf{9}$ & --- & -17.67 & 45.91 \\
$\mathbf{1 0}$ & --- & -- & 29.44 & 59.88 \\
\hline \hline
\end{tabular}


TABLA XXXVII: RMN ${ }^{13}$ C para los compuestos 120, 121 y 122.

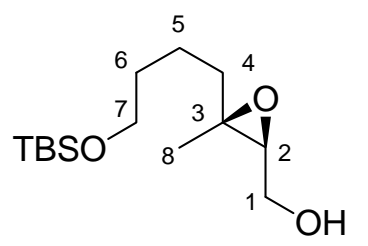

120

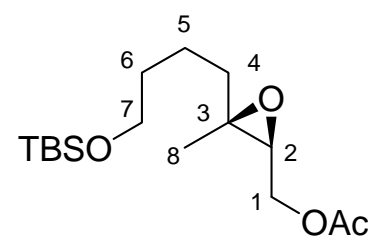

121

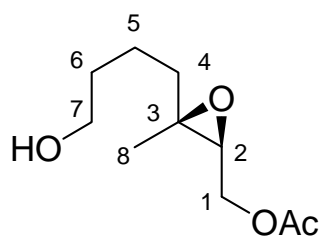

122

\begin{tabular}{|c|c|c|c|}
\hline $\mathrm{C}$ & $\delta(\mathbf{p p m})$ & $\delta(\mathbf{p p m})$ & $\delta(p p m)$ \\
\hline 1 & 61.65 & 63.00 & 62.64 \\
\hline 2 & 63.07 & 59.75 & 59.78 \\
\hline 3 & 61.53 & 60.90 & 60.93 \\
\hline 4 & 38.44 & 38.18 & 38.03 \\
\hline 5 & 21.62 & 21.55 & 21.42 \\
\hline 6 & 32.86 & 32.78 & 32.59 \\
\hline 7 & 63.07 & 63.58 & 63.55 \\
\hline 8 & 16.88 & 16.94 & 16.96 \\
\hline$\underline{\mathrm{CH}}_{3} \mathrm{COO}$ & --- & 20.98 & 20.98 \\
\hline $\mathrm{CH}_{3} \underline{\mathrm{COO}}$ & --- & 171.04 & 171.19 \\
\hline$\left(\underline{\mathrm{CH}}_{3}\right)_{3}(\mathrm{C}) \mathrm{Si}$ & 26.17 & 26.15 & --- \\
\hline$\left(\mathrm{CH}_{3}\right)_{3}(\underline{\mathrm{C}}) \mathrm{Si}$ & 18.56 & 18.53 & --- \\
\hline$\underline{M e}_{2}(C) S i$ & -5.07 & -5.10 & --- \\
\hline
\end{tabular}


TABLA XXXVIII: RMN ${ }^{13}$ C para los compuestos 119, 123 y 124.

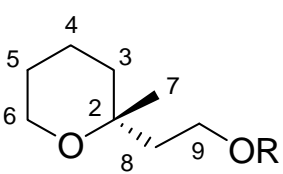

119 (a, b y c)

$\mathrm{R}=(R)-\mathrm{MTPA}$ o $(S)-\mathrm{MTPA}$

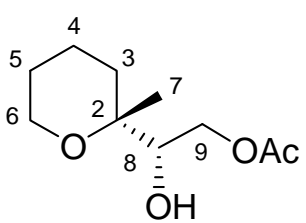

123

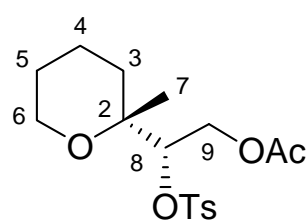

124

\begin{tabular}{|c|c|c|c|}
\hline $\mathrm{C}$ & $\delta(\mathbf{p p m})$ & $\delta(\mathbf{p p m})$ & $\delta(p p m)$ \\
\hline 2 & 71.71 & 74.54 & 73.71 \\
\hline 3 & 35.34 & 29.53 & 32.24 \\
\hline 4 & 19.11 & 18.94 & 18.81 \\
\hline 5 & 25.64 & 26.06 & 25.48 \\
\hline 6 & 61.54 & 61.87 & 62.08 \\
\hline 7 & 23.34 & 17.85 & 18.74 \\
\hline 8 & 37.53 & 76.13 & 83.84 \\
\hline 9 & 62.92 & 65.63 & 63.06 \\
\hline$\underline{\mathrm{CH}}_{3} \mathrm{COO}$ & --- & 21.23 & 20.91 \\
\hline $\mathrm{CH}_{3} \underline{\mathrm{C}} \mathrm{OO}$ & --- & 171.69 & 171.08 \\
\hline Tos $_{i p s o}$ & --- & --- & 144.60 \\
\hline Tos ${ }_{\text {orto }}$ & --- & --- & 127.98 \\
\hline Tos $_{\text {meta }}$ & --- & --- & 129.61 \\
\hline Tos $_{\text {para }}$ & --- & --- & 135.27 \\
\hline
\end{tabular}


TABLA XXXIX: RMN ${ }^{13} \mathrm{C}$ para los compuestos 126, 127 y 128.

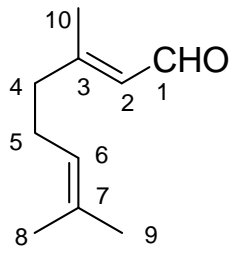

126

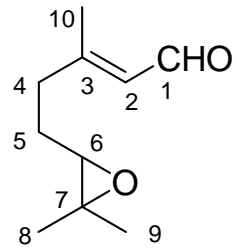

127

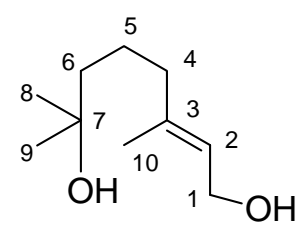

128

\begin{tabular}{llcc}
\hline $\mathbf{C}$ & $\boldsymbol{\delta}(\mathbf{p p m})$ & $\boldsymbol{\delta}(\mathbf{p p m})$ & $\boldsymbol{\delta}(\mathbf{p p m})$ \\
\hline $\mathbf{1}$ & 191.48 & 191.21 & 59.07 \\
$\mathbf{3}$ & 127.59 & 127.54 & 123.96 \\
$\mathbf{4}$ & 164.09 & 162.87 & 138.86 \\
$\mathbf{5}$ & 40.78 & 37.41 & 39.92 \\
$\mathbf{6}$ & 25.91 & 26.78 & 22.43 \\
$\mathbf{7}$ & 122.77 & 63.42 & 43.40 \\
$\mathbf{8}$ & 133.07 & 58.57 & 70.98 \\
$\mathbf{9}$ & 17.90 & 18.82 & 29.24 \\
$\mathbf{1 0}$ & 25.84 & 24.85 & 29.24 \\
\hline
\end{tabular}


TABLA XL: RMN ${ }^{13} \mathrm{C}$ para los compuestos 135, 136, 137 y 138.

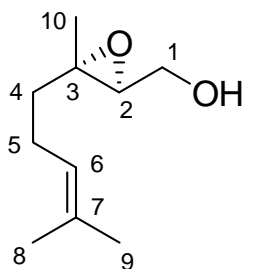

135

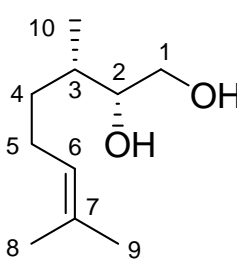

136

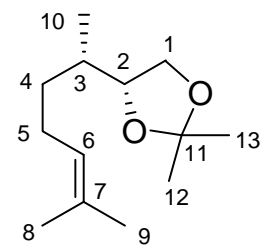

137

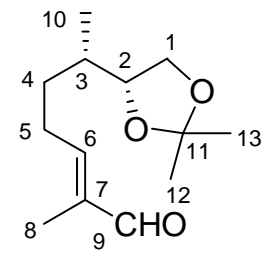

138

\begin{tabular}{|c|c|c|c|c|}
\hline $\mathrm{C}$ & $\delta(\mathbf{p p m})$ & $\delta(\mathbf{p p m})$ & $\delta(\mathbf{p p m})$ & $\delta(p p m)$ \\
\hline 1 & 61.44 & 65.35 & 67.99 & 67.46 \\
\hline 2 & 63.52 & 75.94 & 80.51 & 79.84 \\
\hline 3 & 61.39 & 35.51 & 36.25 & 36.08 \\
\hline 4 & 38.67 & 33.31 & 33.02 & 31.43 \\
\hline 5 & 23.82 & 25.72 & 25.59 & 26.74 \\
\hline 6 & 123.52 & 124.55 & 124.54 & 154.42 \\
\hline 7 & 132.20 & 131.89 & 131.88 & 139.76 \\
\hline 8 & 17.78 & 17.90 & 17.90 & 9.47 \\
\hline 9 & 25.82 & 25.94 & 26.85 & 195.47 \\
\hline 10 & 16.86 & 14.67 & 15.73 & 15.33 \\
\hline 11 & --- & --- & 108.74 & 108.99 \\
\hline 12 & --- & --- & 25.94 & 26.77 \\
\hline 13 & --- & --- & 25.75 & 25.58 \\
\hline
\end{tabular}


TABLA XLI: RMN ${ }^{13} \mathrm{C}$ para los compuestos 140 y 141.

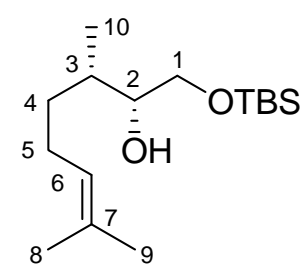

140

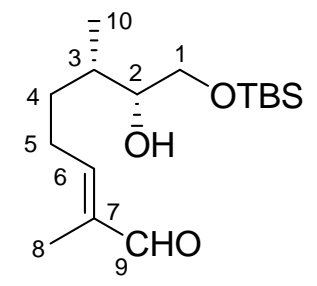

141

\begin{tabular}{|c|c|c|}
\hline $\mathrm{C}$ & $\delta(\mathbf{p p m})$ & $\delta(\mathrm{ppm})$ \\
\hline 1 & 65.64 & 65.38 \\
\hline 2 & 75.21 & 74.75 \\
\hline 3 & 35.11 & 35.22 \\
\hline 4 & 33.31 & 31.92 \\
\hline 5 & 25.77 & 26.94 \\
\hline 6 & 124.76 & 154.88 \\
\hline 7 & 131.66 & 139.64 \\
\hline 8 & 17.89 & 9.47 \\
\hline 9 & 25.94 & 195.58 \\
\hline 10 & 14.80 & 14.55 \\
\hline$\left(\underline{\mathrm{CH}}_{3}\right)_{3}(\mathrm{C}) \mathrm{Si}$ & 26.10 & 26.09 \\
\hline$\left(\mathrm{CH}_{3}\right)_{3}(\underline{\mathrm{C}}) \mathrm{Si}$ & 18.48 & 18.68 \\
\hline$\underline{\mathrm{Me}}_{2}(\mathrm{C}) \mathrm{Si}$ & -5.11 & -5.10 \\
\hline
\end{tabular}





\section{Instrumentación}

1.1. Rotaciones específicas

1.2. Puntos de fusión

1.3. Espectroscopía de IR

1.4. Espectroscopía de RMN

$$
\begin{aligned}
& { }^{1} \mathrm{H} \mathrm{y}{ }^{13} \mathrm{C} \\
& \text { nOe }
\end{aligned}
$$

Experimentos bidimensionales

HMQC

HMBC

COSY

ROESY

1.5. Espectrometría de masas

\section{Técnicas generales cromatográficas}

2.1. Cromatografía de gases (GC)

2.2. Cromatografía en capa fina (CCF)

2.3. Cromatografía en columna (CC)

\section{Purificación de reactivos y disolventes}





\section{INSTRUMENTACIÓN}

\subsection{Rotaciones específicas}

Se midieron en un polarímetro digital Perkin-Elmer 241, en cubetas de $1 \mathrm{dm}$ de paso óptico y en disolución de cloroformo. La concentración a la que se realizó la medida se especifica en cada caso.

\subsection{Puntos de fusión}

Se determinaron en un microscopio de platina caliente (Kofler) y están sin corregir.

\subsection{Espectroscopía de IR}

Las medidas se han realizado en un espectrofotómetro BOMEM FT MB-100 en película capilar sobre cristales de $\mathrm{NaCl}$ y en un espectrofotómetro AVATAR 370 FT-IR Thermo Nicolet en película capilar sobre cristales de $\mathrm{NaCl}$.

\subsection{Espectroscopía de RMN}

$\underline{{ }^{1} H y{ }^{13} \mathrm{C}}$

Se han realizado en un espectrómetro BRUKER AVANCE 400 MHz DRX (400 $\mathrm{MHz}{ }^{1} \mathrm{H}$ y $100 \mathrm{MHz}{ }^{13} \mathrm{C}$ ) (Figura D), equipado con una sonda de detección inversa con bobina de gradientes y una sonda ${ }^{1} \mathrm{H} /{ }^{13} \mathrm{C}$, en un espectrómetro BRUKER WP-200-SY (200 MHz ${ }^{1} \mathrm{H}$ y $50 \mathrm{MHz}{ }^{13} \mathrm{C}$ ) y en un espectrómetro VARIAN $200\left(200 \mathrm{MHz}{ }^{1} \mathrm{H}\right.$ y 50 $\left.\mathrm{MHz}{ }^{13} \mathrm{C}\right)$. 
Los espectros se realizaron en $\mathrm{CDCl}_{3}$ como disolvente habitual y se referencian con respecto al disolvente residual $\mathrm{CHCl}_{3}\left(7.26 \mathrm{ppm}\right.$ en ${ }^{1} \mathrm{H}$ y $77.0 \mathrm{ppm}$ en $\left.{ }^{13} \mathrm{C}\right)$. Los desplazamientos químicos $(\delta)$ se expresan en ppm y las constantes de acoplamiento $(J)$ en $\mathrm{Hz}$.

La multiplicidad de los carbonos se determina utilizando la secuencia de pulsos DEPT (Distorsionless Enhancement by Polarization Transfer). La secuencia distingue los carbonos protonados $\mathrm{CH}, \mathrm{CH}_{2}$ y $\mathrm{CH}_{3}$ utilizando pulsos de protón a través del desacoplador a $90^{\circ}$ y $135^{\circ}$.

$\underline{\text { nOe (nuclear Overhauser effect) }}$

La irradiación de una señal de protón causa variaciones a uno o varios protones. Esta variación está relacionada con el recíproco de la sexta potencia de la distancia entre los núcleos $1 / r^{6}$. Se suele irradiar con baja potencia y de manera continua la señal que interesa. Además, se obtiene un espectro irradiado fuera de la zona de resonancia. Se restan ambos y se observa si hay variaciones en la intensidad de la señal. La secuencia utilizada permite irradiar todos los componentes de un multiplete con una potencia mucho menor que si se irradia el centro.

\section{Experimentos bidimensionales: HMQC (Heteronuclear Multiple Quantum Coherence)}

Los experimentos de correlación heteronuclear ${ }^{1} \mathrm{H} /{ }^{13} \mathrm{C}$ a un enlace se adquieren utilizando la secuencia Bruker inv4gs, con selección de la secuencia de cero cuanto y doble cuanto con una serie de tres pulsos de gradientes sinusoidales. La longitud del pulso de gradiente es de $1.5 \mathrm{~ms}$ y los pulsos guardan una relación de 50:30:40 con respecto a la longitud total del pulso. El intervalo de recuperación del gradiente es de 100 ms.

Un experimento típico adquiere 256 series de uno o dos transientes c/u. El intervalo de reciclado es de tres segundos y la modulación se sintoniza para ${ }^{1} J_{\mathrm{H}, \mathrm{C}}=145$ 
$\mathrm{Hz}$, que corresponde a un intervalo de $3.45 \mathrm{~ms}$, y desacoplando con una secuencia garp en ${ }^{13} \mathrm{C}$ en el momento de la adquisición.

La transformada de Fourier en ambas dimensiones se realiza después de aplicar una función exponencial de $0.3 \mathrm{~Hz}$ en F2 $\left({ }^{1} \mathrm{H}\right)$ y una función sinusoidal en F1 $\left({ }^{13} \mathrm{C}\right)$. Se obtiene un espectro de correlación en magnitud con 1024 puntos en F2 y 512 en F1, que corresponde a una resolución de $4.68 \mathrm{~Hz} / \mathrm{pt}$ en F2 y 45.2 Hz/pt en F1.

\section{Experimentos bidimensionales: HMBC (Heteronuclear Multiple Bond Conectivity)}

Para las correlaciones a larga distancia, 2 ó 3 enlaces, se utiliza la secuencia inv4gslplrnd, que utiliza un filtro de paso largo para la eliminación de la correlación directa en función de la constante de acoplamiento ${ }^{1} J_{\mathrm{H}, \mathrm{C}}=145 \mathrm{~Hz}$. La secuencia de pulsos de gradientes para la selección de la coherencia es la misma que en el caso anterior y se aplica un nuevo intervalo de evolución (función ${ }^{1} J_{\mathrm{H}, \mathrm{C}}$ cuyos valores pueden ser $50 \mathrm{~ms}(10 \mathrm{~Hz}), 83 \mathrm{~ms}(6 \mathrm{~Hz})$ y $110 \mathrm{~ms}(4.5 \mathrm{~Hz}))$ antes de la selección de la coherencia y no se desacopla durante la adquisición. Un acoplamiento típico se adquiere con 256 series de 4 transientes c/u.

La transformada de Fourier (FT) en ambas dimensiones se realiza con las mismas funciones que en el caso anterior y se obtiene un espectro de correlación en magnitud con 1024 puntos en F2 y 512 en F1, que corresponde a una resolución de $4.8 \mathrm{~Hz} / \mathrm{pt}$ en ${ }^{1} \mathrm{H}$ y $45.2 \mathrm{~Hz} / \mathrm{pt}$ en ${ }^{13} \mathrm{C}$.

\section{Experimentos bidimensionales: COSY (COrrelation SpectroscopY)}

La secuencia básica del COSY tiene dos pulsos de $90^{\circ}$ y un tiempo de evolución. Para el procesado se utilizan funciones sinusoidales en ambas direcciones, obteniendo así una matriz simétrica de 512 puntos en ambas dimensiones.

En general se utiliza se utiliza la secuencia con filtro de doble cuanto, que permite la eliminación o disminución de las señales intensas, ya sea de disolventes o singletes en la diagonal y sus correspondientes artefactos. 
Experimentos bidimensionales: ROESY (Rotating frame Overhauser Effect SpectroscopY)

En un experimento ROESY se determinan los valores de la relajación cruzada transversal, en lugar de la longitudinal como en el NOESY. La ventaja es que estos valores son siempre positivos.

Para poder observarlos hay que hacer un experimento tipo "spin-lock” (bloqueo de espines): un pulso no selectivo de $90^{\circ}$ seguido de un tiempo de evolución, que coloca las magnetizaciones en el punto inicial del período de mezcla; el campo o pulso de “spin-lock” se aplica a lo largo del eje X durante la primera parte de la ciclación de fases. Todos los otros componentes se desenfocan o se dispersan, y sólo las magnetizaciones cuyos componentes están en X evolucionan, debido al fenómeno de relajación.

Un experimento habitual se obtiene con 1024 puntos en F2 y 256 en F1, a partir de 256 series de 8 transientes. El intervalo de reciclado entre serie y serie es de $3 \mathrm{~ms}$. El tiempo de "spin-lock" puede variar desde 250 ms hasta $650 \mathrm{~ms}$, dependiendo de las moléculas.

La transformada de Fourier (FT) en ambas dimensiones utiliza una función exponencial en F2 y una sinusoidal desplazada en p/2 en F1 para el modo TPPI (Time Proportional Phase Increment).

\subsection{Espectrometría de masas}

Se realizaron en un espectrómetro VG-TS 250, 70 eV (Figura F), en el que las técnicas empleadas fueron Impacto Electrónico (EI), FAB (Xenon, $10 \mathrm{KV}$ ), empleando como matriz alcohol m-nitrobencílico, o Ionización Química (CI), utilizando $\mathrm{NH}_{3}$ como gas ionizador. Algunas muestras se realizaron en un espectrómetro de masas QSTAR XL, utilizando el Electrospray como técnica de ionización (ESI, positivo) y metanol como disolvente. 


\section{TÉCNICAS GENERALES CROMATOGRÁFICAS}

\subsection{Cromatografía de gases (GC)}

Se utilizó un cromatógrafo de gases (con helio como gas portador) acoplado con un espectrómetro de masas (Impacto Electrónico como técnica) SHIMAZDU QP-5000. La columna quiral empleada fue una CHIRASIL DEX-CB (10m x 0.25mm x 0.25 $\mu \mathrm{m})$.

\subsection{Cromatografía en capa fina (CCF)}

Se realizaron sobre placas de $0.2 \mathrm{~mm}$ de espesor de gel de sílice Merck (60 F254). Para su revelado se utilizaron disoluciones de $\mathrm{H}_{2} \mathrm{SO}_{4} / \mathrm{H}_{2} \mathrm{O} 15 / 75 \mathrm{v} / \mathrm{v}$, pulverizada sobre la placa, o de molibdato amónico en $\mathrm{H}_{2} \mathrm{SO}_{4} / \mathrm{H}_{2} \mathrm{O}$ al $0.05 / 1 \mathrm{p} / \mathrm{v}$, seguido de calentamiento a $120^{\circ}$ durante unos segundos.

Las sustancias que presentan fluorescencia son visualizadas por iluminación con luz ultravioleta de $\mathbf{l}=254$ y $306 \mathrm{~nm}$ antes de ser reveladas.

\subsection{Cromatografía en columna (CC)}

Se realizó en columna de vidrio, llenándola con gel de sílice flash Merck-60 (0.063- $0.040 \mathrm{~mm}$ ) o con una papilla preparada con el mismo gel y el eluyente inicial, agitando suavemente para eliminar el aire. Se emplea normalmente la proporción de 20 g de gel de sílice por gramo de sustancia a cromatografíar.

La elución se realiza con disolventes y mezclas de disolventes de polaridad creciente (generalmente mezclas $n$-hexano/AcOEt) y se sigue la composición de las fracciones eluidas por CCF. 


\section{PURIFICACIÓN DE REACTIVOS Y DISOLVENTES}

AcOEt (AcOEt): Se destila y se almacena con $\mathrm{CaCl}_{2}$.

$\underline{\text { Acetona }\left(\mathrm{Me}_{2}\right.} \underline{\mathrm{CO})}$ : Se somete a ebullición sobre $\mathrm{KMnO}_{4}$ y se destila.

Acetonitrilo (MeCN): Se somete a ebullición sobre $\mathrm{CaH}_{2}$ bajo atmósfera de argon y se destila.

Anhídrido acético ( $\mathrm{Ac}_{2} \mathrm{O}$ ): Se destila a partir del producto comercial.

Benceno $\left(\mathrm{C}_{6} \underline{\mathrm{H}}_{6}\right)$ : Se destila sobre Na y benzofenona bajo atmósfera de argon. Se almacena con $\mathrm{Na}$.

Bencilamina $\left(\mathrm{BnNH}_{2}\right)$ : Se destila y almacena sobre $\mathrm{KOH}$.

Cloroformo $\left(\mathrm{CHCl}_{3}\right)$ : Se destila y se almacena con $\mathrm{P}_{2} \mathrm{O}_{5}$.

Diclorometano $\left(\mathrm{CH}_{2} \underline{\mathrm{Cl}}_{2}\right)$ : Se destila sobre $\mathrm{CaH}_{2}$ bajo atmósfera de argon.

Diisopropilamina ( ${ }^{i} \operatorname{Pr}_{2} \underline{N H}$ ): Se destila y almacena sobre $\mathrm{KOH}$.

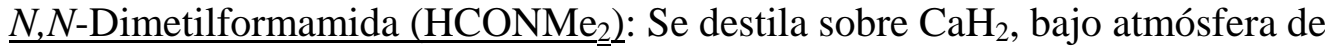
argon y a presión reducida. Se almacena con tamiz molecular (4§̊).

Éter ( $\mathrm{Et}_{2} \underline{\mathrm{O}}$ ): Se somete a ebullición sobre Na y se destila sobre Na y benzofenona.

$\underline{n-H e x a n o}\left(\mathrm{C}_{6} \underline{\mathrm{H}_{12}} \underline{2}\right)$ : Se destila y almacena con $\mathrm{CaCl}_{2}$ o Na.

Metanol (MeOH): Se destila.

Piridina $\left(\mathrm{C}_{5} \underline{H}_{5} \underline{\mathrm{N}}\right)$ : Se destila y almacena con $\mathrm{BaO}$.

Tetrahidrofurano $\left(\mathrm{C}_{4} \underline{\mathrm{H}}_{8} \underline{\mathrm{O}}\right)$ : Se somete a ebullición sobre Na y se destila sobre Na y benzofenona.

Tolueno $\left(\mathrm{MeC}_{6} \mathrm{H}_{5}\right)$ : Se destila y almacena con $\mathrm{Na}$.

Trietilamina ( $\mathrm{Et}_{3} \underline{\mathrm{N}}$ ): Se somete a ebullición sobre $\mathrm{CaH}_{2}$, se destila y almacena con $\mathrm{KOH}$.

El resto de los reactivos líquidos y disolventes se destilaron inmediatamente antes de cada reacción. 


\section{Metodología experimental}

\section{Capítulo I: Síntesis y aplicaciones de tetrahidropiranos y tetrahidrofuranos}

- Síntesis de tetrahidropiranos 3-hidroxi-2,2,6,6-tetrasustituidos de 10 átomos de carbono

- Uso de los nitrilos en síntesis: Síntesis de ent- Sachalinol A

- Síntesis y aplicaciones de tetrahidrofuranos

- Síntesis y aplicaciones de tetrahidropiranos 3-hidroxi-2,2,6,6-tetrasustituidos de 9 átomos de carbono

\section{Capítulo II: Organocatálisis aplicada a la síntesis de tetrahidropiranos}

- Síntesis de pirrolidinas quirales como catalizadores orgánicos

- Síntesis organocatalítica de tetrahidropiranos 

Capítulo I: Síntesis y aplicaciones de tetrahidropiranos

y tetrahidrofuranos 



\section{ADICIÓN DEL ACETILURO DE 3 A ACETONA}

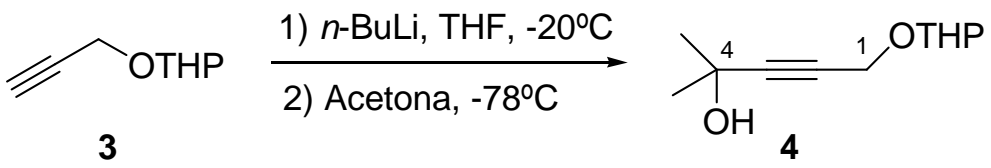

Sobre una disolución de 3 (5.00 g, 35.67 mmoles) en $35 \mathrm{~mL}$ de THF seco, bajo atmósfera de argon y a $-20^{\circ} \mathrm{C}$, se añaden $22.3 \mathrm{~mL}$ de una disolución de $n$-BuLi $1.6 \mathrm{M}$ en hexano. Se deja reaccionando a esta temperatura con buena agitación durante 15 minutos (se observa que la disolución se torna de un color naranja intenso). Pasado este tiempo se baja la temperatura a $-78^{\circ} \mathrm{C}$, se adicionan $3.9 \mathrm{~mL}(53.50 \mathrm{mmoles})$ de acetona y se deja reaccionando a esta temperatura con agitación durante 45 minutos. Seguidamente se deja subir progresivamente la temperatura durante una hora más y se añaden $25 \mathrm{~mL}$ de una disolución saturada de $\mathrm{NH}_{4} \mathrm{Cl}$. Se diluye la fase acuosa con agua y se extrae con AcOEt. La fase orgánica se lava con una disolución saturada de $\mathrm{NaCl}$ y se seca sobre $\mathrm{Na}_{2} \mathrm{SO}_{4}$ anhidro. Se filtra y se evapora el disolvente para obtener $8.05 \mathrm{~g}$ de crudo que se cromatografían en columna sobre sílicagel flash (eluyente: hexano/AcOEt 7:3), separándose $6.93 \mathrm{~g}(98 \%)$ del producto de adición 4, cuyas propiedades espectroscópicas son las siguientes:

\section{2-Metil-5-(tetrahidro-piran-2-iloxi)-pent-3-in-2-ol (4)}

ESPECTRO IR $v_{\max }$ (película) $\mathrm{cm}^{-1}$ (fig. 2a): 3400 (ancha), 2900-2840, 1480, 1350, 950,800 .

ESPECTRO RMN ${ }^{1} \mathbf{H}\left(200 \mathrm{MHz}, \mathrm{CDCl}_{3}, \delta\right.$ ppm) (fig. 2b): 4.81 (1H, m, H-1'), 4.29 $\left(1 \mathrm{H}, \mathrm{d}, J=16.0 \mathrm{~Hz}, \mathrm{H}_{\mathrm{A}}-1\right), 4.25\left(1 \mathrm{H}, \mathrm{d}, J=16.0 \mathrm{~Hz}, \mathrm{H}_{\mathrm{B}}-1\right), 3.83\left(1 \mathrm{H}, \mathrm{m}, \mathrm{H}_{\mathrm{A}}-5^{\prime}\right), 3.54$ $\left(1 \mathrm{H}, \mathrm{m}, \mathrm{H}_{\mathrm{B}}-5^{\prime}\right), 1.52-1.90$ (6H, m, H-2', H-3'y H-4'), 1.52 (6H, s, H-5 y H-6).

ESPECTRO RMN ${ }^{13} \mathbf{C}\left(50 \mathrm{MHz}, \mathrm{CDCl}_{3}, \delta\right.$ ppm) (fig. 2c) (Tabla I).

Nota: Aunque en cada compuesto figura el nombre IUPAC, la asignación de los datos espectroscópicos se realiza siguiendo la numeración mostrada en las figuras, con fines únicamente comparativos. 
LRMS, EI, m/z (\%) (fig. 2d): 67 (100), 77 (42), 85 (100), 101 (100), 125 (76), 139 (72), 163 (10), $181(100), 199(16)(\mathrm{M}+\mathrm{H})^{+}$.

HRMS, EI: Calculado para $\mathrm{C}_{11} \mathrm{H}_{18} \mathrm{O}_{3}\left(M^{+}\right)$, 198.1256. Experimental $\left(\mathrm{M}^{+}\right)$, 198.1269.

\section{HIDROGENACIÓN DE 4}

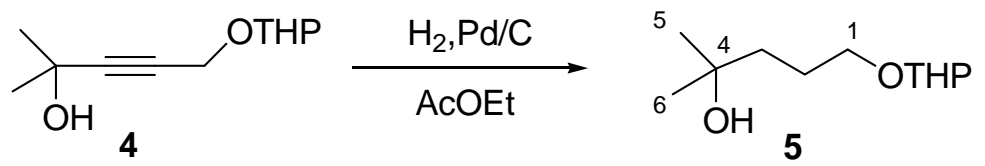

A una disolución de 4 (6.50 g, 32.78 mmoles) en $65 \mathrm{~mL}$ de AcOEt se añade una cantidad catalítica de paladio sobre carbono activado (10\% Pd). Se pone bajo atmósfera de $\mathrm{H}_{2}$ y se deja reaccionando con buena agitación durante 20 horas a temperatura ambiente. Seguidamente se filtra la mezcla resultante por celita y se evapora el disolvente, obteniéndose $5.82 \mathrm{~g}(88 \%)$ de $\mathbf{5}$, cuyas propiedades físicas $\mathrm{y}$ espectroscópicas son las siguientes:

\section{2-Metil-5-(tetrahidro-piran-2-iloxi)-2-pentanol (5)}

ESPECTRO IR $v_{\max }$ (película) $\mathrm{cm}^{-1}$ (fig. 3a): 3400 (ancha), 2900-2800, 1450, 1380, 800.

ESPECTRO RMN ${ }^{1} \mathbf{H}\left(200 \mathrm{MHz}, \mathrm{CDCl}_{3}, \delta\right.$ ppm) (fig. 3b): $4.62\left(1 \mathrm{H}, \mathrm{m}, \mathrm{H}-1^{\prime}\right), 3.83$ (2H, m, $\mathrm{H}_{\mathrm{A}}-1$ y $\left.\mathrm{H}_{\mathrm{A}}-5^{\prime}\right), 3.48$ (2H, m, $\mathrm{H}_{\mathrm{B}}-1$ y $\left.\mathrm{H}_{\mathrm{B}}-5^{\prime}\right)$, 1.90-1.40 (10H, m, H-2, H-3, H-2', H-3'y H-4'), 1.24 (6H, s, H-5 y H-6).

ESPECTRO RMN ${ }^{13} \mathbf{C}\left(50 \mathrm{MHz}, \mathrm{CDCl}_{3}, \delta \mathrm{ppm}\right)$ (fig. 3c) (Tabla I).

LRMS, EI, m/z (\%) (fig. 3d): 85 (100), 101 (20), 154 (15), 203 (10) (M+H) ${ }^{+}$

HRMS, EI: Calculado para $\mathrm{C}_{11} \mathrm{H}_{23} \mathrm{O}_{3}(M+\mathrm{H})^{+}$, 203.1648. Experimental $(\mathrm{M}+\mathrm{H})^{+}$, 203.1660 .

ANÁLISIS ELEMENTAL: Calculado para $\mathrm{C}_{11} \mathrm{H}_{23} \mathrm{O}_{3}$ : \%C: 65.31, \% $\%$ : 10.96; Experimental: \%C: $65.31, \% \mathrm{H}: 11.12$. 


\section{DESPROTECCIÓN DE 5}

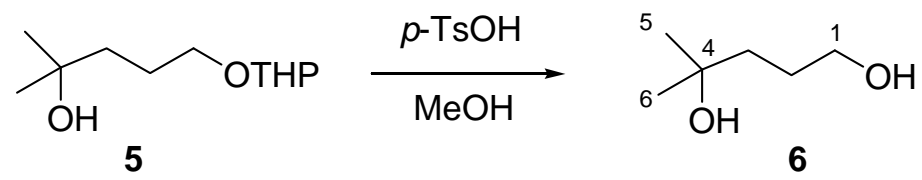

Se disuelve 5 (11.65 g, 57.60 mmoles) en $115 \mathrm{~mL}$ de $\mathrm{MeOH}$ seco y se añade una cantidad catalítica de ácido $p$-toluensulfónico $(p-\mathrm{TsOH})$. Se deja reaccionando con buena agitación a temperatura ambiente durante 5 horas. Transcurrido este tiempo se añaden $1.5 \mathrm{~g}$ de $\mathrm{NaHCO}_{3}$ y se deja agitando 10 minutos. A continuación, se evapora el metanol, se redisuelve el residuo en AcOEt y se filtra para obtener $4.76 \mathrm{~g}$ (70\%) de 6, que presenta las siguientes propiedades espectroscópicas:

\section{4-Metil-1,4-pentanodiol (6)}

ESPECTRO IR $v_{\max }$ (película) $\mathrm{cm}^{-1}$ (fig. 4a): 3390 (ancha), 3000-2840, 1380, 1210, $1150,1050,950$.

ESPECTRO RMN ${ }^{1} \mathbf{H}\left(200 \mathrm{MHz}, \mathrm{CDCl}_{3}, \delta\right.$ ppm) (fig. 4b): $3.67(2 \mathrm{H}, \mathrm{t}, J=6.8 \mathrm{~Hz}, \mathrm{H}-$ 1), 1.75-1.55 (4H, m, H-2 y H-3), 1.24 (6H, s, H-5 y H-6).

ESPECTRO RMN ${ }^{13} \mathbf{C}\left(50 \mathrm{MHz}, \mathrm{CDCl}_{3}, \delta\right.$ ppm) (fig. 4c) (Tabla I).

LRMS, EI, m/z (\%) (fig. 4d): 55 (39), 69 (24), 77 (28), 83 (68), 101 (100), 119 (38) (M $+\mathrm{H})^{+}$.

HRMS, EI: Calculado para $\mathrm{C}_{6} \mathrm{H}_{15} \mathrm{O}_{2}(M+\mathrm{H})^{+}$, 119.1072. Experimental $(\mathrm{M}+\mathrm{H})^{+}$, 119.1055.

\section{OXIDACIÓN DE 6}

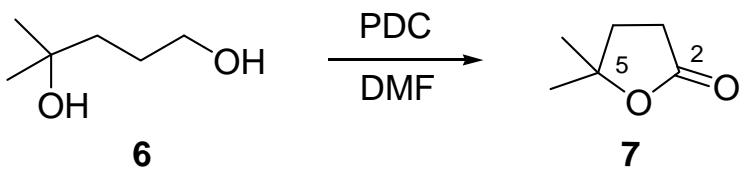


Sobre una disolución de 6 (6.27 g, 53.06 mmoles) en $130 \mathrm{~mL}$ de DMF se añaden $69.86 \mathrm{~g}$ (185.70 mmoles) de PDC y se deja reaccionando la mezcla a temperatura ambiente durante 5 horas. Transcurrido este tiempo se añaden $500 \mathrm{~mL}$ de agua y se extrae con abundante AcOEt (5 veces). La fase orgánica se lava sucesivamente con disoluciones acuosas de $\mathrm{HCl}(10 \%), \mathrm{NaHCO}_{3}(5 \%)$ y $\mathrm{NaCl}$ saturada. Se seca sobre $\mathrm{Na}_{2} \mathrm{SO}_{4}$ anhidro, se filtra y se evapora cuidadosamente, sin calentar, para dar $5.67 \mathrm{~g}$ (94\%) de la lactona volátil 7, cuyas propiedades espectroscópicas son las siguientes:

\section{5,5-Dimetil-dihidro-2-furanona (7)}

ESPECTRO IR $v_{\max }$ (película) $\mathrm{cm}^{-1}$ (fig. 5a): 3000-2840, 1760, 1280, 1140, 940.

ESPECTRO RMN ${ }^{1} \mathbf{H}\left(200 \mathrm{MHz}, \mathrm{CDCl}_{3}, \delta\right.$ ppm) (fig. 5b): $2.60(2 \mathrm{H}, \mathrm{t}, J=8.2 \mathrm{~Hz}, \mathrm{H}-$ 3), 2.04 (2H, t, $J=8.2 \mathrm{~Hz}, \mathrm{H}-4), 1.41$ (6H, s, H-6 y H-7).

ESPECTRO RMN ${ }^{13} \mathbf{C}\left(50 \mathrm{MHz}, \mathrm{CDCl}_{3}, \delta \mathrm{ppm}\right)$ (fig. 5c) (Tabla II).

\section{REDUCCIÓN DE LA LACTONA 7}<smiles>CC1(C)CCC(=O)O1</smiles>

7

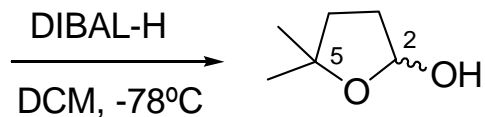

8

Se disuelve 7 (7.10 g, 62.20 mmoles) en $200 \mathrm{~mL}$ de DCM seco, se pone bajo atmósfera de argon con buena agitación y se baja la temperatura a $-78^{\circ} \mathrm{C}$. Seguidamente se añaden cuidadosamente $49.7 \mathrm{~mL}$ (74.64 mmoles) de una disolución $1.5 \mathrm{M}$ de DIBAL-H en tolueno. Se deja reaccionando a $-78^{\circ} \mathrm{C}$ durante una hora. Pasado este tiempo se añaden $8 \mathrm{~mL}$ de agua y se deja la mezcla agitando, permitiendo que alcance progresivamente temperatura ambiente. Entonces se disuelven los productos en abundante éter $\left(2 \mathrm{~L}\right.$ ), se añaden $100 \mathrm{~g}$ de $\mathrm{NaHCO}_{3}, 100 \mathrm{~g}$ de $\mathrm{Na}_{2} \mathrm{SO}_{4}$ anhidro y se deja agitando vigorosamente durante 3 horas. Pasado este tiempo se filtra por celita y se evapora el disolvente, obteniéndose $7.0 \mathrm{~g}$ de crudo con restos de tolueno. Se 
cromatografía en columna sobre sílicagel flash (eluyente: hexano/éter 7:3), aislándose $7.15 \mathrm{~g}(99 \%)$ del lactol 8, cuyas propiedades espectroscópicas son las siguientes:

\section{5,5-Dimetil-tetrahidro-2-furanol (8)}

ESPECTRO IR $v_{\max }$ (película) $\mathrm{cm}^{-1}$ (fig. 6a): 3400 (ancha), 3000-2800, 1450, 1050.

ESPECTRO RMN ${ }^{1} \mathbf{H}\left(200 \mathrm{MHz}, \mathrm{CDCl}_{3}, \delta\right.$ ppm) (fig. 6b): $5.50(1 \mathrm{H}, \mathrm{sa}, \mathrm{H}-2), 2.10-$ 1.60 (4H, m, H-3 y H-4), 1.38 y 1.17 (3H c/u, s, H-6 y H-7).

ESPECTRO RMN ${ }^{13} \mathbf{C}\left(50 \mathrm{MHz}, \mathrm{CDCl}_{3}, \delta\right.$ ppm) (fig. 6c) (Tabla II).

\section{REACCIÓN DE WITTIG DEL LACTOL 8 CON}

\section{(CARBETOXIETILIDEN)TRIFENILFOSFORANO}

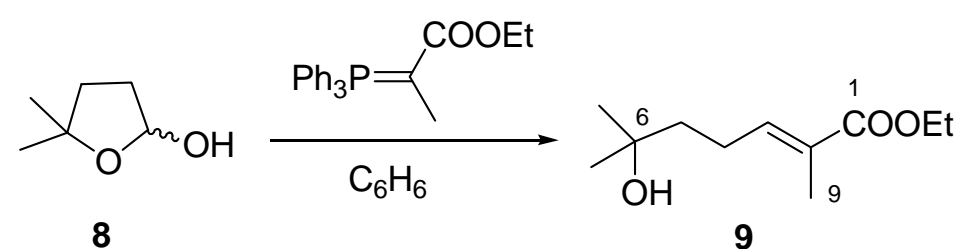

A una disolución de 8 (4.67 g, 40.21 mmoles) en $200 \mathrm{~mL}$ de benceno se añaden $29.14 \mathrm{~g}$ (80.42 mmoles) de $\mathrm{Ph}_{3} \mathrm{PC}(\mathrm{Me}) \mathrm{COOEt}$. Se calienta la mezcla a ebullición $\left(85^{\circ} \mathrm{C}\right)$ y se mantiene a reflujo durante 7 horas. Pasado este tiempo se evapora parcialmente el disolvente (hasta un volumen de aproximadamente $10 \mathrm{~mL}$ ) para evitar así la precipitación del óxido de trifenilfosfina. El crudo obtenido se cromatografía en columna sobre sílicagel flash (eluyente: hexano/AcOEt 8:2), obteniéndose 6.02 g (75\%) de 9, como una mezcla inseparable $E: Z$ 97:3. Las propiedades físicas y espectroscópicas del isómero $E$ mayoritario son las siguientes: 


\section{6-Hidroxi-2,6-dimetil-hept-E-2-enoato de etilo (9)}

ESPECTRO IR $v_{\max }$ (película) $\mathrm{cm}^{-1}$ (fig. 7a): 3440 (ancha), 3000-2840, 1710, 1650, 1360, 1280, 1150, 940, 910, 750 .

ESPECTRO RMN ${ }^{1} \mathbf{H}\left(200 \mathrm{MHz}, \mathrm{CDCl}_{3}, \delta\right.$ ppm) (fig. 7b): $6.78(1 \mathrm{H}, \mathrm{t}, J=7.4 \mathrm{~Hz}, \mathrm{H}-$ 3), $4.20\left(2 \mathrm{H}, \mathrm{c}, J=7.1 \mathrm{~Hz},-\mathrm{O}-\mathrm{CH}_{2}-\mathrm{CH}_{3}\right), 2.35-2.20$ (2H, m, H-4), 1.85 (3H, s, H-9), 1.70-1.50 (2H, m, H-5), 1.29 (3H, t, $\left.J=7.1 \mathrm{~Hz},-\mathrm{O}-\mathrm{CH}_{2}-\underline{\mathrm{CH}}_{3}\right), 1.25$ (6H, s, H-7 y H-8). ESPECTRO RMN ${ }^{13} \mathbf{C}\left(50 \mathrm{MHz}, \mathrm{CDCl}_{3}, \delta \mathrm{ppm}\right)$ (fig. 7c) (Tabla V).

LRMS, EI, m/z (\%) (fig. 7d): 59 (48), 69 (15), 97 (25), 111 (62), 139 (100), 154 (28), $182(25), 200(12)\left(\mathrm{M}^{+}\right)$.

HRMS, EI: Calculado para $\mathrm{C}_{11} \mathrm{H}_{20} \mathrm{O}_{3}\left(M^{+}\right), 200.1412$. Experimental $\left(\mathrm{M}^{+}\right), 200.1421$.

ANÁLISIS ELEMENTAL: Calculado para $\mathrm{C}_{11} \mathrm{H}_{20} \mathrm{O}_{3}$ : \%C: 65.97, \% $\mathrm{H}$ : 10.06; Experimental: \%C: $65.88, \% \mathrm{H}: 10.03$.

\section{PROTECCIÓN DEL ÉSTER 9}

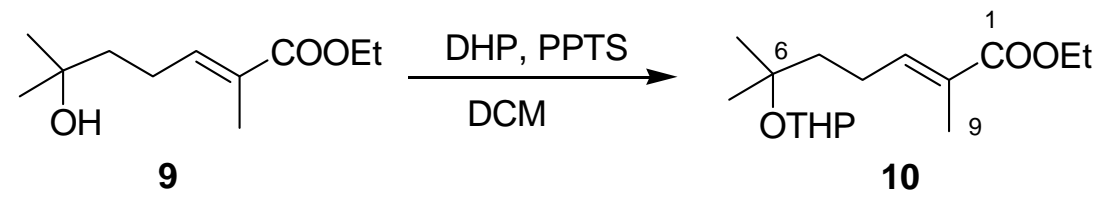

Se disuelven $6.02 \mathrm{~g}$ (30.06 mmoles) de 9 en $300 \mathrm{~mL}$ de DCM seco y se añade una cantidad catalítica de PPTS. Se pone bajo atmósfera de argon y se adicionan 5.48 $\mathrm{mL}$ (60.12 mmoles) de 3,4-dihidro-2H-pirano (DHP). Se deja reaccionando a temperatura ambiente durante 12 horas. Transcurrido este tiempo se evapora parte del DCM (hasta unos $50 \mathrm{~mL}$ aproximadamente), se añade AcOEt y se lava con una disolución acuosa saturada de $\mathrm{NaCl}$. Se seca sobre $\mathrm{Na}_{2} \mathrm{SO}_{4}$ anhidro, se filtra y se evapora el disolvente para dar $10.2 \mathrm{~g}$ de crudo que se cromatografía en columna sobre sílicagel flash (eluyente: hexano/AcOEt 9:1), obteniéndose $7.90 \mathrm{~g}(93 \%)$ de 10, que presenta las siguientes propiedades físicas y espectroscópicas: 


\section{2,6-Dimetil-6-(tetrahidro-piran-2-iloxi)-hept-E-2-enoato de etilo (10)}

ESPECTRO IR $v_{\max }$ (película) $\mathrm{cm}^{-1}$ (fig. 8a): 2970-2870, 1710, 1650, 1370, 1280, $1020,860,750$.

ESPECTRO RMN ${ }^{1} \mathbf{H}\left(200 \mathrm{MHz}, \mathrm{CDCl}_{3}, \delta\right.$ ppm) (fig. 8 b): $6.78(1 \mathrm{H}, \mathrm{t}, J=7.4 \mathrm{~Hz}, \mathrm{H}-$ 3), $4.73\left(1 \mathrm{H}, \mathrm{m}, \mathrm{H}-1^{\prime}\right), 4.16\left(2 \mathrm{H}, \mathrm{c}, J=7.1 \mathrm{~Hz},-\mathrm{O}-\underline{\mathrm{CH}}_{2}-\mathrm{CH}_{3}\right), 3.91$ y $3.48(1 \mathrm{H} \mathrm{c} / \mathrm{u}, \mathrm{m}$, H-5'), 2.25 (2H, m, H-4), 1.84 (3H, s, H-9), 1.70-1.48 (8H, m, H-5, H-2', H-3' y H-4'), $1.29\left(3 \mathrm{H}, \mathrm{t}, J=7.1 \mathrm{~Hz},-\mathrm{O}-\mathrm{CH}_{2}-\underline{\mathrm{CH}}_{3}\right), 1.26$ y $1.23(3 \mathrm{H}$ c/u, s, H-7 y H-8).

ESPECTRO RMN ${ }^{13} \mathbf{C}\left(50 \mathrm{MHz}, \mathrm{CDCl}_{3}, \delta\right.$ ppm) (fig. 8c) (Tabla VI).

LRMS, FAB ${ }^{+}, \mathrm{m} / \mathrm{z}$ (\%) (fig. 8d): 85 (100), 99 (20), 154 (40), 183 (75), 285 (8) (M + $\mathrm{H})^{+}$.

HRMS, FAB ${ }^{+}$: Calculado para $\mathrm{C}_{16} \mathrm{H}_{29} \mathrm{O}_{4}(M+\mathrm{H})^{+}$, 285.2066. Experimental $(\mathrm{M}+\mathrm{H})^{+}$, 285.2033 .

ANÁLISIS ELEMENTAL: Calculado para $\mathrm{C}_{16} \mathrm{H}_{28} \mathrm{O}_{4}$ : \%C: $67.57, \% \mathrm{H}: 9.92$; Experimental: \%C: $67.32, \% \mathrm{H}: 10.29$.

\section{REDUCCIÓN DEL ÉSTER 10}<smiles>CCOC(=O)/C(C)=C/CCC(C)(C)[OH+]</smiles>

10

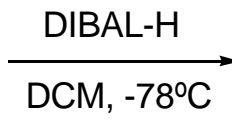

$\mathrm{DCM},-78^{\circ} \mathrm{C}$

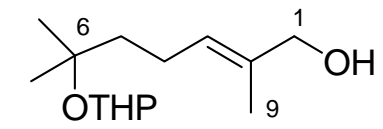

11

Se disuelve 10 (7.58 g, 26.65 mmoles) en $220 \mathrm{~mL}$ de DCM seco, se pone bajo atmósfera de argon con buena agitación y se baja la temperatura a $-78^{\circ} \mathrm{C}$. Seguidamente se añaden $44 \mathrm{~mL}$ (66.63 mmoles) de una disolución 1.5 M de DIBAL-H en tolueno. Se deja reaccionando a $-78^{\circ} \mathrm{C}$ durante 90 minutos. Pasado este tiempo se añaden $5 \mathrm{~mL}$ de agua y se deja la mezcla agitando, permitiendo que alcance progresivamente temperatura ambiente. Entonces se disuelven los productos en abundante éter (1L), se añaden $50 \mathrm{~g}$ de $\mathrm{NaHCO}_{3}, 50 \mathrm{~g}$ de $\mathrm{Na}_{2} \mathrm{SO}_{4}$ anhidro y se deja agitando vigorosamente 
durante 3 horas. A continuación se filtra por celita y se evapora el disolvente, obteniéndose $10 \mathrm{~g}$ de crudo que se cromatografían en columna sobre sílicagel flash (eluyente: hexano/AcOEt 9:1 $\rightarrow$ 8:2). Se obtienen $5.90 \mathrm{~g}(91 \%)$ del alcohol alílico 11, cuyas propiedades físicas y espectroscópicas son las siguientes:

\section{$\underline{\text { 2,6-Dimetil-6-(tetrahidro-piran-2-iloxi)-hept-E-2-en-1-ol (11) }}$}

ESPECTRO IR $v_{\max }$ (película) $\mathrm{cm}^{-1}$ (fig. 9a): 3400 (ancha), 2980-2870, 1450, 1380, $1120,1010,880,820$.

ESPECTRO RMN ${ }^{1} \mathbf{H}\left(200 \mathrm{MHz}, \mathrm{CDCl}_{3}, \delta\right.$ ppm) (fig. 9b): $5.41(1 \mathrm{H}, \mathrm{t}, J=7.4 \mathrm{~Hz}, \mathrm{H}-$ 3), 4.72 (1H, m, H-1' ), 3.96 (2H, s, H-1), 3.91 y 3.48 (1H c/u, m, H-5'), 2.15-1.40 (10H, m, H-4, H-5, H-2', H-3' y H-4'), 1.64 (3H, s, H-9), 1.20 y 1.18 (3H c/u, s, H-7 y H-8).

ESPECTRO RMN ${ }^{13} \mathbf{C}\left(50 \mathrm{MHz}, \mathrm{CDCl}_{3}, \delta \mathrm{ppm}\right)$ (fig. 9c) (Tabla VII).

LRMS, FAB ${ }^{+}, \mathrm{m} / \mathrm{z}$ (\%) (fig. 9d): 67 (8), 85 (100), 123 (40), 140 (8), 154 (11), 225 (5), $243(2)(\mathrm{M}+\mathrm{H})^{+}$.

HRMS, $\mathrm{FAB}^{+}$: Calculado para $\mathrm{C}_{14} \mathrm{H}_{27} \mathrm{O}_{3}(M+\mathrm{H})^{+}$, 243.1932. Experimental $(\mathrm{M}+\mathrm{H})^{+}$, 243.1961.

ANÁLISIS ELEMENTAL: Calculado para $\mathrm{C}_{14} \mathrm{H}_{26} \mathrm{O}_{3}: \quad \% \mathrm{C}: 69.38, \% \mathrm{H}: 10.81$; Experimental: \%C: 69.03 , \%H: 10.95 .

\section{EPOXIDACIÓN DE SHARPLESS DE 11}

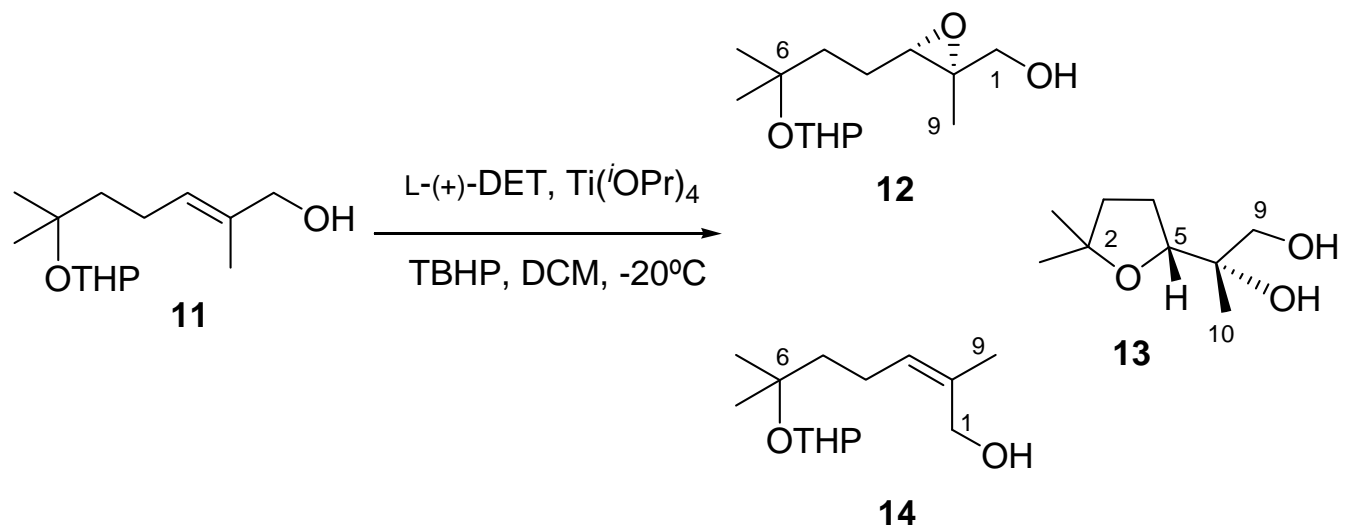


Se disuelven $510 \mathrm{mg}$ (2.47 mmoles) de L-(+)-DET en $12.5 \mathrm{~mL}$ de DCM seco bajo atmósfera de argon. Se baja la temperatura a $-23^{\circ} \mathrm{C}$ y se añaden $0.61 \mathrm{~mL}(2.06$ mmoles $)$ de $\mathrm{Ti}\left({ }^{i} \mathrm{OPr}\right)_{4}$. Pasados 10 minutos en estas condiciones se añaden $500 \mathrm{mg}$ (2.06 mmoles) de 11 disueltos en $7.5 \mathrm{~mL}$ de DCM. Se deja agitando a $-23^{\circ} \mathrm{C}$ durante 5 minutos, y entonces se adicionan $0.42 \mathrm{~mL}$ (4.12 mmoles) de una disolución de TBHP 5.5 M en $n$-decano. Se mantiene la reacción a $-23^{\circ} \mathrm{C}$ durante 20 horas.

Pasado este tiempo se añaden $\left(\mathrm{a}-23^{\circ} \mathrm{C}\right) 5 \mathrm{~mL}$ de una disolución acuosa de ácido tartárico (10\%). Se deja agitando a esa temperatura durante 30 minutos y luego a temperatura ambiente durante una hora más. Se filtra la mezcla por celita, lavando abundantemente con éter $(250 \mathrm{~mL})$. Seguidamente se lava con agua y se evapora parte del éter (hasta $50 \mathrm{~mL}$ aproximadamente). Se baja la temperatura a $0^{\circ} \mathrm{C}$ y se añaden 6.3 $\mathrm{mL}$ de $\mathrm{NaOH} 1 \mathrm{M}$; se deja agitando en estas condiciones durante 45 minutos. A continuación se separa la fase orgánica y se lava con una disolución acuosa de $\mathrm{NaCl}$ saturada. La fase acuosa se extrae con éter ( 2 veces) y se lava con una disolución acuosa de $\mathrm{NaCl}$ saturada. Se reúnen las fases etéreas y se secan sobre $\mathrm{Na}_{2} \mathrm{SO}_{4}$ anhidro. Se filtra y se evapora el éter, obteniéndose $1 \mathrm{~g}$ de crudo que se cromatografía en columna sobre sílicagel flash (eluyente: hexano/AcOEt 8:2 $\rightarrow$ 7:3 $\rightarrow$ 1:1). Se obtienen $35 \mathrm{mg}$ (7\%) del alcohol alílico $Z$ 14, $417 \mathrm{mg}$ (78\%) del epoxialcohol 12 y $49 \mathrm{mg}$ (13\%) del tetrahidrofurano 13. Estos compuestos presentan las siguientes propiedades físicas y espectroscópicas:

$\underline{(2 S, 3 S)-\{2-M e t i l-3-[3-m e t i l-3-(t e t r a h i d r o-p i r a n-2-i l o x i)-b u t i l]-o x i r a n i l\}-m e t a n o l ~}$ $\underline{(12)}$

ESPECTRO IR $v_{\max }$ (película) $\mathrm{cm}^{-1}$ (fig. 10a): 3400 (ancha), 3000-2800, 1450, 1380, $1020,860,800$.

ESPECTRO RMN ${ }^{1} \mathbf{H}\left(200 \mathrm{MHz}, \mathrm{CDCl}_{3}, \delta\right.$ ppm) (fig. 10b): $4.72\left(1 \mathrm{H}, \mathrm{m}, \mathrm{H}-1^{\prime}\right), 3.94$ y 3.43 (1H c/u, m, H-5'), 3.62 (2H, m, H-1), 3.06 (1H, t, $J=6.0 \mathrm{~Hz}, \mathrm{H}-3), 1.9-1.45$ (10H, m, H-4, H-5, H-2', H-3' y H-4'), 1.30 (3H, s, H-9), 1.24 y 1.21 (3H c/u, s, H-7 y H-8). ESPECTRO RMN ${ }^{13} \mathbf{C}\left(50 \mathrm{MHz}, \mathrm{CDCl}_{3}, \delta \mathrm{ppm}\right)$ (fig. 10c) (Tabla IX). 
LRMS, EI, m/z (\%) (fig. 10d): 69 (15), 85 (100), 99 (88), 139 (24), 157 (78), 175 (80), $259(5)(\mathrm{M}+\mathrm{H})^{+}$.

HRMS, EI: Calculado para $\mathrm{C}_{14} \mathrm{H}_{27} \mathrm{O}_{4}(M+\mathrm{H})^{+}, 259.1909$. Experimental $(\mathrm{M}+\mathrm{H})^{+}$, 259.1901 .

ANÁLISIS ELEMENTAL: Calculado para $\mathrm{C}_{14} \mathrm{H}_{26} \mathrm{O}_{4}: \quad \% \mathrm{C}: 65.09$, \% $\mathrm{H}: 10.14$; Experimental: \%C: $64.78, \% \mathrm{H}: 10.42$.

$[\alpha]_{D}^{25}=-9.85^{\circ}\left(\mathrm{c}=1.1, \mathrm{CHCl}_{3}\right)$

\section{$\underline{\left(2 S, 2^{\prime} R\right)-2-\left(5^{\prime}, 5^{\prime} \text {-Dimetil-tetrahidro-furan-2'-il)-1,2-propanodiol (13) }\right.}$}

ESPECTRO IR $v_{\max }$ (película) $\mathrm{cm}^{-1}$ (fig. 11a): 3400 (ancha), 2970-2870, 1460, 1360, $1140,1050,935,890$.

ESPECTRO RMN ${ }^{1} \mathbf{H}\left(200 \mathrm{MHz}, \mathrm{CDCl}_{3}, \delta\right.$ ppm) (fig. $\left.11 \mathrm{~b}\right): 3.96(1 \mathrm{H}, \mathrm{t}, J=6.6 \mathrm{~Hz}$, H-5), $3.71\left(1 \mathrm{H}, \mathrm{d}, J=11.3 \mathrm{~Hz}, \mathrm{H}_{\mathrm{A}}-9\right), 3.37\left(1 \mathrm{H}, \mathrm{d}, J=11.3 \mathrm{~Hz}, \mathrm{H}_{\mathrm{B}}-9\right), 2.0-1.65$ (4H, m, H-3 y H-4), 1.23 y 1.21 (3H c/u, s, H-6 y H-7), 1.08 (3H, s, H-10).

ESPECTRO RMN ${ }^{13} \mathbf{C}\left(50 \mathrm{MHz}, \mathrm{CDCl}_{3}, \delta\right.$ ppm) (fig. 11c) (Tabla II).

LRMS, EI, m/z (\%) (fig. 11d): 57 (8), 70 (9), 76 (12), 82 (48), 100 (100), 125 (15), 143 (25), 157 (72), $174(48)\left(\mathrm{M}^{+}\right)$.

HRMS, EI: Calculado para $\mathrm{C}_{9} \mathrm{H}_{19} \mathrm{O}_{3}(M+\mathrm{H})^{+}$, 175.1334. Experimental $(\mathrm{M}+\mathrm{H})^{+}$, 175.1360 .

$[\alpha]_{D}^{25}=+12.8^{\circ}\left(\mathrm{c}=1.3, \mathrm{CHCl}_{3}\right)$

ANÁLISIS ELEMENTAL: Calculado para $\mathrm{C}_{9} \mathrm{H}_{18} \mathrm{O}_{3}$ : \%C: 62.04, \% $\mathrm{H}: 10.41$; Experimental: \%C: 62.49 , \%H: 10.52 .

P.F.: $53-55^{\circ} \mathrm{C}$ (Recristalizado en AcOEt-hexano)

\section{$\underline{\text { 2,6-Dimetil-6-(tetrahidro-piran-2-iloxi)-hept-Z-2-en-1-ol (14) }}$}

ESPECTRO IR $v_{\max }$ (película) $\mathrm{cm}^{-1}$ (fig. 12a): 3400 (ancha), 3000-2800, 1454, 1368, 1260, 1200, 1130, 1076, 1024, 993, 868, 812. 
ESPECTRO RMN ${ }^{1} \mathbf{H}\left(200 \mathrm{MHz}, \mathrm{CDCl}_{3}, \delta\right.$ ppm) (fig. 12b): $5.30(1 \mathrm{H}, \mathrm{t}, J=6.7 \mathrm{~Hz}$, H-3), $4.72\left(1 \mathrm{H}, \mathrm{m}, \mathrm{H}-1^{\prime}\right), 4.18\left(1 \mathrm{H}, \mathrm{d}, J=11.1 \mathrm{~Hz}, \mathrm{H}_{\mathrm{A}}-1\right), 4.10(1 \mathrm{H}, \mathrm{d}, J=11.1 \mathrm{~Hz}$, $\left.\mathrm{H}_{\mathrm{B}}-1\right), 3.91$ y 3.48 (1H c/u, m, H-5'), 2.20-1.30 (10H, m, H-4, H-5, H-2', H-3' y H-4'), 1.79 (3H, s, H-9), 1.22 y 1.19 (3H c/u, s, H-7 y H-8).

ESPECTRO RMN ${ }^{13} \mathbf{C}\left(50 \mathrm{MHz}, \mathrm{CDCl}_{3}, \delta \mathrm{ppm}\right)$ (fig. 12c) (Tabla VII).

LRMS, EI, m/z (\%) (fig. 12d): 67 (62), 85 (100), 97 (23), 107 (38), 123 (98), 140 (86), 159 (15), $225(8), 243(4)(\mathrm{M}+\mathrm{H})^{+}$.

HRMS, EI: Calculado para $\mathrm{C}_{14} \mathrm{H}_{27} \mathrm{O}_{3}(M+\mathrm{H})^{+}, 243.1960$. Experimental $(\mathrm{M}+\mathrm{H})^{+}$, 243.1978.

\section{TOSILACIÓN DEL EPOXIALCOHOL 12}

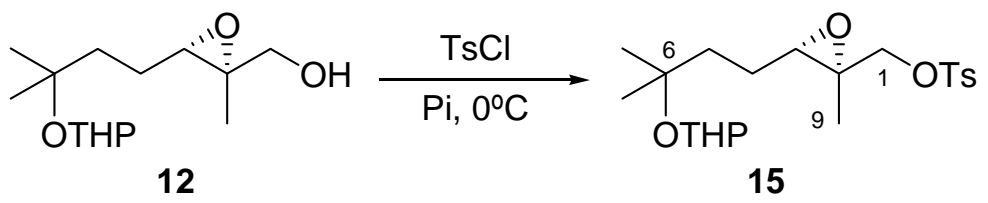

A una disolución de 12 (158 mg, 0.61 mmoles) en $1.3 \mathrm{~mL}$ de piridina se añaden $152 \mathrm{mg}$ ( $0.80 \mathrm{mmoles}) \mathrm{de} \mathrm{TsCl}$ a $0^{\circ} \mathrm{C}$ y se mantiene la reacción a esa temperatura y con buena agitación durante 12 horas. Pasado este tiempo, se vierte la mezcla de reacción sobre hielo y se extrae con éter (4 veces). La combinación de las fases etéreas se lava sucesivamente con agua y disoluciones acuosas de $\mathrm{CuSO}_{4}(20 \%), \mathrm{NaHCO}_{3}(5 \%)$ y $\mathrm{NaCl}$ (saturada). Se seca sobre $\mathrm{Na}_{2} \mathrm{SO}_{4}$ anhidro, se filtra y se evapora el éter para obtener $232 \mathrm{mg}$ de crudo que se cromatografían en columna sobre sílicagel flash (eluyente: hexano/AcOEt 8:2). Se aíslan $206 \mathrm{mg}$ (81\%) de 15, cuyas propiedades físicas y espectroscópicas son las siguientes:

Toluen-4-sulfonato de (2S,3S)-2-metil-3-[3-metil-3-(tetrahidro-piran-2-iloxi)-butil]oxiranilmetilo (15)

ESPECTRO IR $v_{\max }$ (película) $\mathrm{cm}^{-1}$ (fig. 13a): 3000-2840, 1600, 1460, 1380, 1190, 810,680 . 
ESPECTRO RMN ${ }^{1} \mathbf{H}\left(200 \mathrm{MHz}, \mathrm{CDCl}_{3}, \delta\right.$ ppm) (fig. 13b): $7.75(2 \mathrm{H}, \mathrm{d}, J=8.3 \mathrm{~Hz}$, $\left.\mathrm{H}_{\text {orto }} \underline{\mathrm{Ar}}-\mathrm{Me}\right), 7.31$ (2H, d, J = 8.3 Hz, Heta $\left.\underline{\mathrm{Ar}}-\mathrm{Me}\right), 4.65$ (1H, m, H-1'), 3.93 (2H, s, H1), 3.93 у 3.45 (1H c/u, m, H-5'), 2.78 (1H, sa, H-3), 2.46 (3H, s, Ar-Me), 1.90-1.40 (10H, m, H-4, H-5, H-2', H-3'y H-4'), 1.30 (3H, s, H-9), 1.23 y 1.19 (3H c/u, s, H-7 y H-8).

ESPECTRO RMN ${ }^{13} \mathbf{C}\left(50 \mathrm{MHz}, \mathrm{CDCl}_{3}, \delta\right.$ ppm) (fig. 13c) (Tabla X).

LRMS, FAB ${ }^{+}, \mathrm{m} / \mathrm{z}$ (\%) (fig. 13d): 85 (100), 139 (62), 329 (5) (M-THP+H) ${ }^{+}$.

HRMS, $\mathrm{FAB}^{+}$: Calculado para $\mathrm{C}_{16} \mathrm{H}_{25} \mathrm{O}_{5} \mathrm{~S}(M-\mathrm{THP}+\mathrm{H})^{+}$, 329.1423. Experimental (M$\mathrm{THP}+\mathrm{H})^{+}, 329.1426$.

ANÁLISIS ELEMENTAL: Calculado para $\mathrm{C}_{21} \mathrm{H}_{32} \mathrm{O}_{6} \mathrm{~S}: \% \mathrm{C}: 61.14, \% \mathrm{H}: 7.82, \% \mathrm{~S}$ : 7.77; Experimental: \%C: 60.96, \%H: 7.79, \%S: 7.56.

$[\alpha]_{D}^{25}=-16.6^{\circ}\left(\mathrm{c}=1.0, \mathrm{CHCl}_{3}\right)$

\section{YODACIÓN DEL TOSILATO 15}

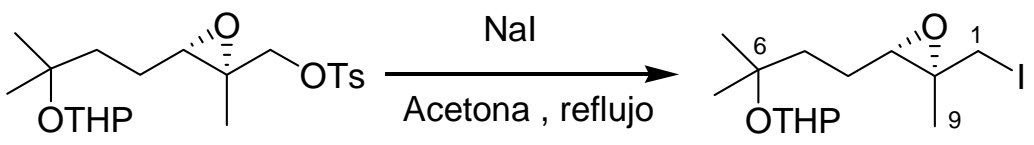

15

16

Sobre una disolución de 15 (192 $\mathrm{mg}, 0.47 \mathrm{mmoles})$ en $2.3 \mathrm{~mL}$ de acetona se añaden $245 \mathrm{mg}$ (1.63 mmoles) de NaI. Se calienta la mezcla a ebullición y se deja reaccionando a reflujo durante 2 horas. Pasado este tiempo se evapora la acetona y se disuelve el residuo en $20 \mathrm{~mL}$ de agua. Se extrae 3 veces con éter y el combinado de fases etéreas se lava sucesivamente con disoluciones acuosas de $\mathrm{Na}_{2} \mathrm{~S}_{2} \mathrm{O}_{3} \quad(10 \%)$, $\mathrm{NaHCO}_{3} \quad(5 \%)$ y $\mathrm{NaCl}$ (saturada). Se seca sobre $\mathrm{Na}_{2} \mathrm{SO}_{4}$ anhidro, se filtra y se evapora el éter obteniéndose $164 \mathrm{mg}$ de crudo. Se cromatografían en columna sobre sílicagel flash (eluyente: hexano/ AcOEt 9:1), aislándose $145 \mathrm{mg}$ (85\%) del yododerivado 16, el cual presenta las siguientes propiedades físicas y espectroscópicas: 


\section{$\underline{\left(2^{\prime} S, 3^{\prime} S\right)-2-\left[3-\left(3^{\prime}-Y o d o m e t i l-3 '-m e t i l-o x i r a n i l\right)-1,1-d i m e t i l-p r o p o x i\right]-t e t r a h i d r o-~}$}

pirano (16)

ESPECTRO IR $v_{\max }$ (película) $\mathrm{cm}^{-1}$ (fig. 14a): 3000-2840, 1455, 1390, 1125, 1085, $1020,860,810$.

ESPECTRO RMN ${ }^{1} \mathbf{H}\left(200 \mathrm{MHz}, \mathrm{CDCl}_{3}, \delta\right.$ ppm) (fig. 14b): 4.75 (1H, m, H-1'), 3.95 y $3.45\left(1 \mathrm{H} \mathrm{c} / \mathrm{u}, \mathrm{m}, \mathrm{H}-5^{\prime}\right), 3.25\left(1 \mathrm{H}, \mathrm{d}, J=10.9 \mathrm{~Hz}, \mathrm{H}_{\mathrm{A}}-1\right), 3.11\left(1 \mathrm{H}, \mathrm{d}, J=10.9 \mathrm{~Hz}, \mathrm{H}_{\mathrm{B}^{-}}\right.$ 1), 2.90 (1H, m, H-3), 1.90-1.48 (10H, m, H-4, H-5, H-2', H-3' y H-4'), 1.46 (3H, s, H9), 1.24 y $1.21(3 \mathrm{H} \mathrm{c} / \mathrm{u}, \mathrm{s}, \mathrm{H}-7$ y $\mathrm{H}-8)$.

ESPECTRO RMN ${ }^{13} \mathbf{C}\left(50 \mathrm{MHz}, \mathrm{CDCl}_{3}, \delta\right.$ ppm) (fig. 14c) (Tabla X).

HRMS, FAB ${ }^{+}$: Calculado para $\mathrm{C}_{14} \mathrm{H}_{26} \mathrm{O}_{3} \mathrm{I}(M+\mathrm{H})^{+}, 369.0926$. Experimental $(\mathrm{M}+\mathrm{H})^{+}$, 369.0943 .

ANÁLISIS ELEMENTAL: Calculado para $\mathrm{C}_{14} \mathrm{H}_{25} \mathrm{O}_{3} \mathrm{I}: \quad \% \mathrm{C}: 45.66$, \% $\mathrm{H}: \quad 6.83$; Experimental: \%C: 45.85, \%H: 6.96 .

$[\alpha]_{D}^{25}=+6.98^{\circ}\left(\mathrm{c}=1.4, \mathrm{CHCl}_{3}\right)$

\section{DESPLAZAMIENTO DEL YODO DE 16 POR CIANURO CON ELIMINACIÓN} Y APERTURA DEL EPÓXIDO<smiles>CC(C)([OH2+])CCC(=O)C(C)(C)CI</smiles>

16

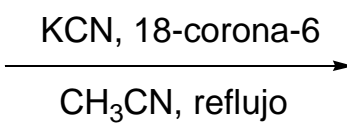

$\mathrm{CH}_{3} \mathrm{CN}$, reflujo

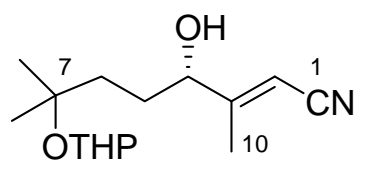

17

Se disuelven $46 \mathrm{mg}$ (0.13 mmoles) de 16 en $1 \mathrm{~mL}$ de $\mathrm{CH}_{3} \mathrm{CN}$ bajo atmósfera de argon y se añaden $3 \mathrm{mg}$ (0.013 mmoles) del éter 18-corona-6. A continuación se adiciona esta disolución sobre $25 \mathrm{mg}(0.38$ mmoles $)$ de $\mathrm{KCN}$ y se deja reaccionando a reflujo $\left(90^{\circ} \mathrm{C}\right)$ durante 20 horas. Pasado este tiempo se diluye la mezcla de reacción con $150 \mathrm{~mL}$ de agua y se extrae 3 veces con DCM. Se seca sobre $\mathrm{Na}_{2} \mathrm{SO}_{4}$ anhidro. Se 
filtra y se evapora el disolvente para obtener $37 \mathrm{mg}$ de crudo que se cromatografían en columna sobre sílicagel flash (eluyente: hexano/AcOEt 85:15). Finalmente se aíslan 11 mg (33\%) del nitrilo 17 que presenta las siguientes propiedades espectroscópicas:

\section{(4S)-4-Hidroxi-3,7-dimetil-7-(tetrahidro-piran-2-iloxi)-oct-E-2-en-nitrilo (17)}

ESPECTRO IR $v_{\max }$ (película) $\mathrm{cm}^{-1}$ (fig. 15a): 3420 (ancha), 2970-2870, 2220, 1634, $1441,1385,1128,1074,1024,991,866,812$.

ESPECTRO RMN ${ }^{1} \mathbf{H}\left(400 \mathrm{MHz}, \mathrm{CDCl}_{3}, \delta\right.$ ppm) (fig. 15b): 5.59-5.57 (1H c/u, s, H2), 4.77-4.73 (1H c/u, m, H-1'), 4.26-4.08 (1H c/u, sa, H-4), $3.94\left(2 \mathrm{H}, \mathrm{m}, \mathrm{H}_{\mathrm{A}}-5^{\prime}\right), 3.47$ (2H, m, H $\mathrm{B}^{-} 5^{\prime}$ ), 2.00-1.99 (3H c/u, s, H-10), 1.95-1.35 (20 H, m, H-5, H-6, H-2', H-3'y H-4'), 1.26-1.25 (3H c/u, s, H-8), 1.19-1.18 (3H c/u, s, H-9).

ESPECTRO RMN ${ }^{13} \mathbf{C}\left(100 \mathrm{MHz}, \mathrm{CDCl}_{3}, \delta\right.$ ppm) (fig. 15c) (Tabla XI).

LRMS, EI, m/z (\%) (fig. 15d): 41 (90), 55 (78), 85 (100), 96 (28), 121 (12), 148 (22), 166 (40) (M - OTHP) ${ }^{+}$.

\section{DESPROTECCIÓN DE 17}

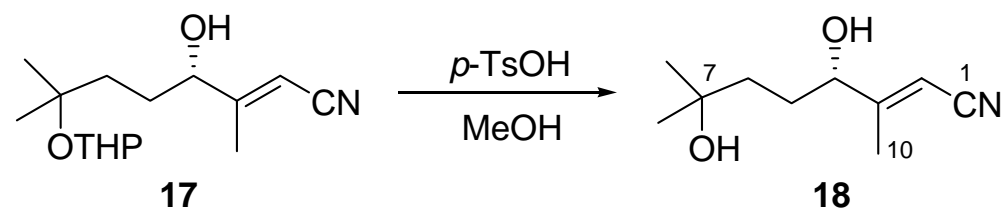

Se disuelven $51 \mathrm{mg}$ (0.19 mmoles) de 17 en $1 \mathrm{~mL}$ de $\mathrm{MeOH}$ y se añade una cantidad catalítica de ácido $p$-toluensulfónico $(p-\mathrm{TsOH})$. Se deja reaccionando con buena agitación a temperatura ambiente durante 2 horas, transcurridas las cuales se añaden $50 \mathrm{mg}$ de $\mathrm{NaHCO}_{3}$ y se deja agitando durante 10 minutos. Seguidamente se evapora el $\mathrm{MeOH}$, se redisuelve el residuo en AcOEt y se filtra. Tras evaporar el disolvente se obtienen $29 \mathrm{mg}(81 \%)$ de 18, cuyas propiedades físicas y espectroscópicas son las siguientes: 
(4S)-4,7-Dihidroxi-3,7-dimetil-oct-E-2-en-nitrilo (18)

ESPECTRO IR $v_{\max }$ (película) $\mathrm{cm}^{-1}$ (fig. 16a): 3400 (ancha), 2970-2870, 2222, 1632, 1441, 1381, 1215, 1152, 1090, 910.

ESPECTRO RMN ${ }^{1} \mathbf{H}\left(200 \mathrm{MHz}, \mathrm{CDCl}_{3}, \delta\right.$ ppm) (fig. 16b): 5.55 (1H, s, H-2), 4.18 (1H, m, H-4), 2.01 (3H, s, H-10), 1.9-1.2 (4H, m, H-5 y H-6), 1.24 (6H, s, H-8 y H-9).

ESPECTRO RMN ${ }^{13} \mathbf{C}\left(100 \mathrm{MHz}, \mathrm{CDCl}_{3}, \delta \mathrm{ppm}\right)$ (fig. 16c) (Tabla XI).

LRMS, EI, m/z (\%) (fig. 16d): 131 (32), 139 (11), 150 (45), 166 (100), 182 (25), 183 (5) $\left(\mathrm{M}^{+}\right)$.

HRMS, EI: Calculado para $\mathrm{C}_{10} \mathrm{H}_{17} \mathrm{O}_{2} \mathrm{~N}(M)^{+}, 183.1259$. Experimental (M) ${ }^{+}, 183.1237$.

ANÁLISIS ELEMENTAL: Calculado para $\mathrm{C}_{10} \mathrm{H}_{17} \mathrm{O}_{2} \mathrm{~N}$ : \%C: $65.54, \% \mathrm{H}: 9.35, \% \mathrm{~N}$ : 7.64; Experimental: \%C: $65.27, \% \mathrm{H}: 9.15, \% \mathrm{~N}: 7.65$.

$[\alpha]_{D}^{25}=-27.0^{\circ}\left(\mathrm{c}=2.0, \mathrm{CHCl}_{3}\right)$

\section{DESPLAZAMIENTO DEL TOSILO DE 15 POR CIANURO CON ELIMINACIÓN Y APERTURA DEL EPÓXIDO}<smiles>CC(C)([OH+])CC[C@@H](O)[C@@](C)(O)C[O+]</smiles>

15 $\frac{\text { 1) } \mathrm{NaCN}, \mathrm{HMPA}}{\text { 2) } p-\mathrm{TsOH}, \mathrm{MeOH}}$<smiles>CC=C(C)[C@@H](O)CCC(C)(C)O</smiles>

18

Se disuelven 660 mg (1.60 mmoles) de 15 en 3.2 mL de HMPA. A continuación se añaden $236 \mathrm{mg}$ (4.81 mmoles) de $\mathrm{NaCN}$ y se deja reaccionando con buena agitación a temperatura ambiente durante 3 horas. Transcurrido este tiempo se diluye la mezcla con agua $(50 \mathrm{~mL})$ y se extrae 5 veces con AcOEt. El combinado de fases orgánicas se lava sucesivamente con disoluciones acuosas de $\mathrm{HCl}(10 \%), \mathrm{NaHCO}_{3}(5 \%)$ y $\mathrm{NaCl}$ (saturada). Se seca sobre $\mathrm{Na}_{2} \mathrm{SO}_{4}$ anhidro, se filtra, y se evapora el disolvente para obtener $441 \mathrm{mg}$ de un crudo que se redisuelve en $5.5 \mathrm{~mL}$ de $\mathrm{MeOH}$. Se añade una cantidad catalítica de $p$-TsOH y se deja reaccionando con buena agitación a 
temperatura ambiente durante 2 horas, transcurridas las cuales se añaden $50 \mathrm{mg}$ de $\mathrm{NaHCO}_{3}$. Se mantiene agitando durante 10 minutos, luego se evapora el MeOH y se redisuelve el residuo en AcOEt. Tras filtrar y evaporar se obtienen $336 \mathrm{mg}$ de crudo que se cromatografían en columna sobre sílicagel flash (eluyente: hexano/AcOEt 1:1). Finalmente se obtienen $239 \mathrm{mg}(81 \%)$ del nitrilo 18, cuyas propiedades físicas y espectroscópicas ya han sido descritas.

\section{BENCILACIÓN DE 18}<smiles>C/C(=C\C(=N)Br)[C@@H](O)CCC(C)(C)O</smiles>

18

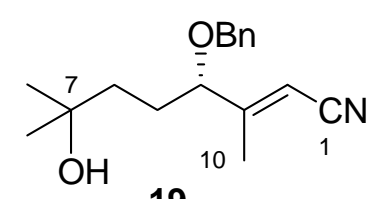

19

Sobre una suspensión de $\mathrm{NaH}$ (14 mg, 0.58 mmoles, 60\% en parafina y previamente lavado con dos porciones de THF de $1 \mathrm{~mL}$ ) en $1 \mathrm{~mL}$ de THF se añaden 89 mg (0.48 mmoles) de 18 disueltos en $1.5 \mathrm{~mL}$ de THF, bajo atmósfera de argon. A continuación se añaden $18 \mathrm{mg}(0.05$ mmoles $)$ de TBAI y por último $0.12 \mathrm{~mL}(0.97$ mmoles) de $\mathrm{BnBr}$. Se mantiene la reacción a temperatura ambiente durante 15 horas. Transcurrido este tiempo se añade $1 \mathrm{~mL}$ de agua $\left(\right.$ a $\left.0^{\circ} \mathrm{C}\right)$ y se deja agitando 15 minutos. Seguidamente se diluye la mezcla con $50 \mathrm{~mL}$ de agua, se extrae con AcOEt (3 veces) y las fases orgánicas combinadas se lavan con una disolución acuosa de $\mathrm{NaCl}$ (saturada). Se seca sobre $\mathrm{Na}_{2} \mathrm{SO}_{4}$ anhidro, se filtra y se evapora el disolvente para obtener $176 \mathrm{mg}$ de crudo que se cromatografían en columna sobre sílicagel flash (eluyente: hexano/AcOEt 8:2), aislándose $100 \mathrm{mg}$ (77\%) del bencilderivado 19, cuyas propiedades físicas y espectroscópicas son las siguientes:

\section{(4S)-4-Benciloxi-7-hidroxi-3,7-dimetil-oct-E-2-en-nitrilo (19)}

ESPECTRO IR $v_{\max }$ (película) $\mathrm{cm}^{-1}$ (fig. 17a): 3470 (ancha), 3065, 3032, 2970-2870, 2220, 1636, 1456, 1379, 1217, 1096, 909, 739, 698. 
ESPECTRO RMN ${ }^{1} \mathbf{H}\left(200 \mathrm{MHz}, \mathrm{CDCl}_{3}, \delta\right.$ ppm) (fig. 17b): 7.49-7.30 (5H, m, -Ph), $5.42(1 \mathrm{H}, \mathrm{s}, \mathrm{H}-2), 4.47\left(1 \mathrm{H}, \mathrm{d}, J=11.7 \mathrm{~Hz}, \mathrm{O}-\underline{\mathrm{CH}}_{2}-\mathrm{Ph}, \mathrm{H}_{\mathrm{A}}\right), 4.30(1 \mathrm{H}, \mathrm{d}, J=11.7 \mathrm{~Hz}$, $\left.\mathrm{O}-\underline{\mathrm{CH}}_{2}-\mathrm{Ph}, \mathrm{H}_{\mathrm{B}}\right), 3.81(1 \mathrm{H}, \mathrm{t}, J=5.8 \mathrm{~Hz}, \mathrm{H}-4), 2.03(3 \mathrm{H}, \mathrm{s}, \mathrm{H}-10), 1.8-1.2(4 \mathrm{H}, \mathrm{m}, \mathrm{H}-5 \mathrm{y}$ H-6), 1.21 (6H, s, H-8 y H-9).

ESPECTRO RMN ${ }^{13} \mathbf{C}\left(50 \mathrm{MHz}, \mathrm{CDCl}_{3}, \delta \mathrm{ppm}\right)$ (fig. 17c) (Tabla XII).

LRMS, EI, m/z (\%) (fig. 17d): 59 (35), 77 (22), 91 (100), 105 (22), 149 (149), 258 (3), $274(1)(\mathrm{M}+\mathrm{H})^{+}$.

HRMS, EI: Calculado para $\mathrm{C}_{17} \mathrm{H}_{23} \mathrm{O}_{2} \mathrm{~N}\left(M^{+}, 273.1729\right.$. Experimental (M) ${ }^{+}, 273.1741$.

ANÁLISIS ELEMENTAL: Calculado para $\mathrm{C}_{17} \mathrm{H}_{23} \mathrm{O}_{2} \mathrm{~N}: \% \mathrm{C}: 74.69, \% \mathrm{H}: 8.48, \% \mathrm{~N}$ :

5.12; Experimental: \%C: $74.14, \% \mathrm{H}: 8.52, \% \mathrm{~N}: 5.32$.

$[\alpha]_{D}^{25}=-31.8^{\circ}\left(\mathrm{c}=1.2, \mathrm{CHCl}_{3}\right)$

\section{$\underline{\text { ACETILACIÓN DE } 18}$}<smiles>CC(=O)OC(C)CC[C@H](OC(C)=O)/C(C)=C/C#N</smiles>

Se disuelve 18 (18.6 mg, 0.10 mmoles) en $1 \mathrm{~mL}$ de piridina destilada bajo atmósfera de argon y se añaden $0.5 \mathrm{~mL}$ de anhídrido acético. Se deja reaccionando a temperatura ambiente durante 20 horas. Pasado este tiempo se añade hielo y se deja agitando durante 10 minutos. Se extrae 3 veces con éter y el combinado de fases orgánicas se lava sucesivamente con disoluciones acuosas de $\mathrm{HCl}(10 \%), \mathrm{NaHCO}_{3}$ $(5 \%)$ y $\mathrm{NaCl}$ (saturada). Se seca sobre $\mathrm{Na}_{2} \mathrm{SO}_{4}$ anhidro, se filtra y se evapora el disolvente para obtener $18 \mathrm{mg}$ (78\%) de $\mathbf{2 0}$, cuyas propiedades espectroscópicas son las siguientes: 
(4S)-4-Acetoxi-7-hidroxi-3,7-dimetil-oct-E-2-en-nitrilo (20)

ESPECTRO RMN ${ }^{1} \mathbf{H}\left(200 \mathrm{MHz}, \mathrm{CDCl}_{3}, \delta\right.$ ppm) (fig. 18): 5.36-5.20 (2H, m, H-2 y H-

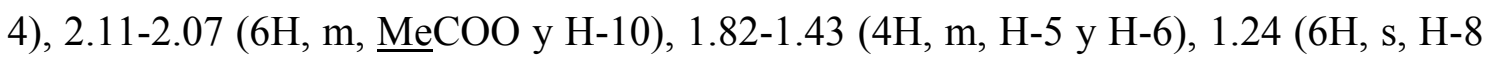
y $\mathrm{H}-9)$

\section{REDUCCIÓN DEL NITRILO 19 HASTA ALDEHIDO}

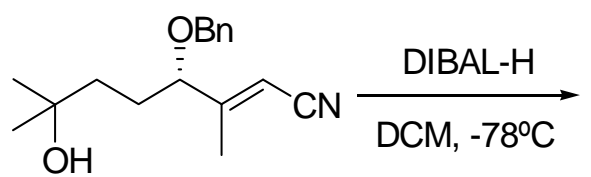

19

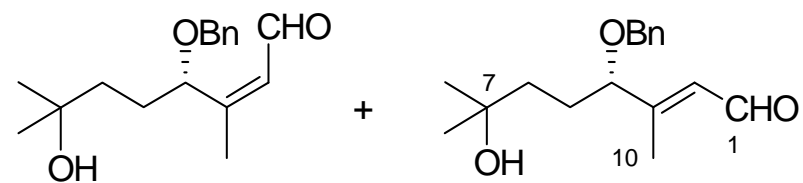

21
$15: 85$

Se disuelven $126 \mathrm{mg}$ (0.46 mmoles) de 19 en $4.6 \mathrm{~mL}$ de DCM seco y se pone bajo atmósfera de argon. Se baja la temperatura a $-78^{\circ} \mathrm{C}$ y se añaden $0.67 \mathrm{~mL}(1.01$ mmoles) de una disolución de DIBAL-H 1.5 M en tolueno. Se mantiene la rección a esa temperatura y con buena agitación durante 90 minutos, transcurridos los cuales se vierte la mezcla de reacción sobre $65 \mathrm{~mL}$ de una disolución acuosa de $\mathrm{NH}_{4} \mathrm{Cl}$ (saturada). Se deja agitando a temperatura ambiente durante 20 minutos y seguidamente se extrae con AcOEt (4 veces). La fase orgánica se seca sobre $\mathrm{Na}_{2} \mathrm{SO}_{4}$ anhidro, se filtra y se evapora el disolvente, obteniéndose $163 \mathrm{mg}$ de una mezcla con restos de tolueno que se cromatografía en columna sobre sílicagel (eluyente: hexano/AcOEt 8:2). Se aíslan 13 mg (10\%) del aldehído Z 21 y $73 \mathrm{mg}$ (57\%) del aldehído E 22, que presentan las siguientes propiedades físicas y espectroscópicas:

\section{(4S)-4-Benciloxi-7-hidroxi-3,7-dimetil-oct-Z-2-enal (21)}

ESPECTRO IR $v_{\max }$ (película) $\mathrm{cm}^{-1}$ (fig. 19a): 3447 (ancha), 3069, 3034, 2970-2870, 1674, 1456, 1375, 1072, 739, 698.

ESPECTRO RMN ${ }^{1} \mathbf{H}\left(400 \mathrm{MHz}, \mathrm{CDCl}_{3}, \delta\right.$ ppm) (fig. 19b): 9.96 (1H, d, $J=7.8 \mathrm{~Hz}$, CHO), 7.37-7.29 (5H, m, -Ph), 6.05 (1H, d, J= 7.8 Hz, H-2), 4.76 (1H, m, H-4), 4.54 
$\left(1 \mathrm{H}, \mathrm{d}, J=11.7 \mathrm{~Hz}, \mathrm{O}-\underline{\mathrm{CH}}_{2}-\mathrm{Ph}, \mathrm{H}_{\mathrm{A}}\right), 4.32\left(1 \mathrm{H}, \mathrm{d}, J=11.7 \mathrm{~Hz}, \mathrm{O}-\underline{\mathrm{CH}}_{2}-\mathrm{Ph}, \mathrm{H}_{\mathrm{B}}\right), 1.98$ (3H, s, H-10), 2.0-1.3 (4H, m, H-5 y H-6), 1.21 (6H, s, H-8 y H-9).

ESPECTRO RMN ${ }^{13} \mathbf{C}\left(100 \mathrm{MHz}, \mathrm{CDCl}_{3}, \delta\right.$ ppm) (fig. 19c) (Tabla XII).

$[\alpha]_{D}^{25}=-22.4^{\circ}\left(\mathrm{c}=0.6, \mathrm{CHCl}_{3}\right)$

(4S)-4-Benciloxi-7-hidroxi-3,7-dimetil-oct-E-2-enal (22)

ESPECTRO IR $v_{\max }$ (película) $\mathrm{cm}^{-1}$ (fig. 20a): 3445 (ancha), 3065, 3032, 2970-2870, 1674, 1456, 1377, 1198, 1094, 739, 698.

ESPECTRO RMN ${ }^{1} \mathbf{H}\left(200 \mathrm{MHz}, \mathrm{CDCl}_{3}, \delta\right.$ ppm) (fig. 20b): 10.08 (1H, d, J=7.8 Hz, CHO), 7.38-7.30 (5H, m, -Ph), 6.05 (1H, d, $J=7.8 \mathrm{~Hz}, \mathrm{H}-2)$, , 4.50 (1H, d, $J=11.8 \mathrm{~Hz}$, $\left.\mathrm{O}-\underline{\mathrm{CH}}_{2}-\mathrm{Ph}, \mathrm{H}_{\mathrm{A}}\right), 4.29\left(1 \mathrm{H}, \mathrm{d}, J=11.8 \mathrm{~Hz}, \mathrm{O}-\underline{\mathrm{CH}}_{2}-\mathrm{Ph}, \mathrm{H}_{\mathrm{B}}\right), 3.81(1 \mathrm{H}, \mathrm{m}, \mathrm{H}-4), 2.16(3 \mathrm{H}$, s, H-10), 1.9-1.3 (4H, m, H-5 y H-6), 1.20 (6H, s, H-8 y H-9).

ESPECTRO RMN ${ }^{13} \mathbf{C}\left(50 \mathrm{MHz}, \mathrm{CDCl}_{3}, \delta \mathrm{ppm}\right)$ (fig. 20c) (Tabla XII).

HRMS, $\mathrm{FAB}^{+}$(fig. 20d): Calculado para $\mathrm{C}_{17} \mathrm{H}_{25} \mathrm{O}_{3}(M+\mathrm{H})^{+}$, 277.1804. Experimental $(\mathrm{M}+\mathrm{H})^{+}, 277.1840$.

$[\alpha]_{D}^{25}=-27.3^{\circ}\left(\mathrm{c}=0.7, \mathrm{CHCl}_{3}\right)$

REACCIÓN DE ELIMINACIÓN DEL TOSILATO 15 Y APERTURA DEL EPÓXIDO

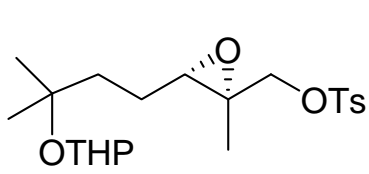

15

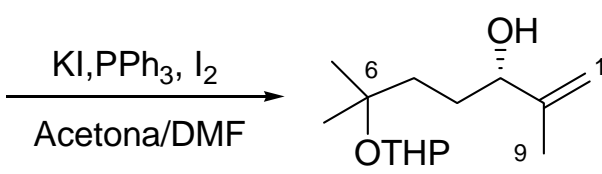

23<smiles>C=C(C)[C@H](O)CCC(C)(C)O</smiles>

1 
Se disuelve 15 (93 mg, 0.24 mmoles) en $1.75 \mathrm{~mL}$ de acetona/DMF 6:1 y se añaden $121 \mathrm{mg}(0.73 \mathrm{mmoles})$ de $\mathrm{KI}$. Se deja la mezcla reflujando $\left(65-70^{\circ} \mathrm{C}\right)$ durante 1 hora. Pasado este tiempo se enfría hasta que alcanza temperatura ambiente y se añaden, a $0^{\circ} \mathrm{C}, 64 \mathrm{mg}$ (0.24 mmoles) de $\mathrm{PPh}_{3}$ y $6 \mathrm{mg}$ (0.024 mmoles) de $\mathrm{I}_{2}$. Se deja agitando a esta temperatura durante 3 horas, transcurridas las cuales se añaden $17 \mathrm{~mL}$ de agua. Se extrae 3 veces con éter y el combinado de fases orgánicas se lava sucesivamente con disoluciones acuosas de $\mathrm{Na}_{2} \mathrm{~S}_{2} \mathrm{O}_{3}(10 \%)$ y $\mathrm{NaCl}$ (saturada). Se seca sobre $\mathrm{Na}_{2} \mathrm{SO}_{4}$ anhidro, se filtra y se evapora el disolvente para obtener $139 \mathrm{mg}$ de crudo que se cromatografían en columna sobre sílicagel flash (eluyente: hexano/AcOEt 8:2). Se aíslan $26 \mathrm{mg}(44 \%)$ de 23 y $5 \mathrm{mg}(13 \%)$ de 1, que presentan las siguientes propiedades físicas y espectroscópicas:

(3S)-2,6-Dimetil-6-(tetrahidro-piran-2-iloxi)-hept-1-en-3-ol (23)

ESPECTRO IR $v_{\max }$ (película) $\mathrm{cm}^{-1}$ (fig. 21a): 3400 (ancha), 3050, 3000-2800, 1650, 1450, 1360, 1120, 1020, 910, 820 .

ESPECTRO RMN ${ }^{1} \mathbf{H}\left(200 \mathrm{MHz}, \mathrm{CDCl}_{3}, \delta\right.$ ppm) (fig. 21b): 4.92 (2H, sa, H-1), 4.55 $\left(1 \mathrm{H}, \mathrm{m}, \mathrm{H}-1^{\prime}\right), 4.20$ (1H, m, H-3), 3.90 y 3.50 (1H c/u, m, H-5'), 1.85-1.40 (10H, m, H4, H-5, H-2', H-3' y H-4'), 1.64 (3H, s, H-9), 1.22 (6H, s, H-7 y H-8).

ESPECTRO RMN ${ }^{13} \mathbf{C}\left(50 \mathrm{MHz}, \mathrm{CDCl}_{3}, \delta\right.$ ppm) (fig. 21c) (Tabla XIII).

LRMS, EI, m/z (\%) (fig. 21d): 67 (28), 85 (100), 98 (8), 109 (16), 123 (84), 141 (38), 155 (12), 224 (2), $243(1)(\mathrm{M}+\mathrm{H})^{+}$.

ANÁLISIS ELEMENTAL: Calculado para $\mathrm{C}_{14} \mathrm{H}_{26} \mathrm{O}_{3}$ : \%C: 69.39, \% $\mathrm{H}: 10.81$; Experimental: \%C: $69.06, \% \mathrm{H}: 10.79$.

$[\alpha]_{D}^{25}=-14.0^{\circ}\left(\mathrm{c}=0.7, \mathrm{CHCl}_{3}\right)$

\section{(5S)-2,6-Dimetil-hept-6-en-2,5-diol (1)}

ESPECTRO IR $v_{\max }$ (película) $\mathrm{cm}^{-1}$ (fig. 1a): 3400 (ancha), 3050, 3000-2800, 1650, $1450,1380,1060,900$. 
ESPECTRO RMN ${ }^{1} \mathbf{H}\left(200 \mathrm{MHz}, \mathrm{CDCl}_{3}, \delta\right.$ ppm) (fig. 1b): $4.93\left(1 \mathrm{H}, \mathrm{sa}, \mathrm{H}_{\mathrm{A}}-1\right), 4.82$ $\left(1 \mathrm{H}, \mathrm{sa}, \mathrm{H}_{\mathrm{B}}-1\right), 4.05(1 \mathrm{H}, \mathrm{t}, J=7.1 \mathrm{~Hz}, \mathrm{H}-3), 1.71(3 \mathrm{H}, \mathrm{s}, \mathrm{H}-9), 1.70-1.40$ (4H, m, H-4 y H-5), 1.21 (6H, s, H-7 y H-8).

ESPECTRO RMN ${ }^{13} \mathbf{C}\left(50 \mathrm{MHz}, \mathrm{CDCl}_{3}, \delta\right.$ ppm) (fig. 1c) (Tabla XIII).

LRMS, CI ( $\mathrm{NH}_{3}$ ), m/z (\%) (fig. 1d): 58 (3), 82 (4), 105 (3), 123 (63), 141 (100), 158 (54) $\left(\mathrm{M}^{+}\right), 176(59)\left(\mathrm{M}+\mathrm{NH}_{4}\right)^{+}$.

HRMS, CI $\left(\mathrm{NH}_{3}\right)$ : Calculado para $\mathrm{C}_{9} \mathrm{H}_{22} \mathrm{NO}_{2}\left(M+\mathrm{NH}_{4}\right)^{+}$, 176.1650. Experimental (M $\left.+\mathrm{NH}_{4}\right)^{+}, 176.1651$.

$[\alpha]_{D}^{25}=-10.6^{\circ}\left(\mathrm{c}=0.7, \mathrm{CHCl}_{3}\right)$

P.F. : $40-42{ }^{\circ} \mathrm{C}$ (Recristalizado en AcOEt-hexano)

\section{REACCIÓN DE ELIMINACIÓN DE 16 CON ZINC EN ACOH Y POSTERIOR DESPROTECCIÓN}
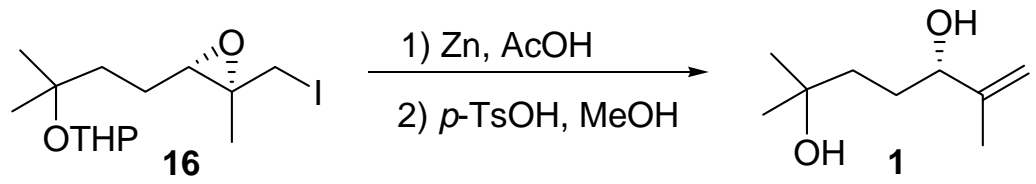

Se disuelve 16 (150 mg, 0.40 mmoles $)$ en $0.7 \mathrm{~mL}$ de ácido acético glacial a $0^{\circ} \mathrm{C}$ y se añaden con agitación $106 \mathrm{mg}$ (1.62 mmoles) de Zn activado (lavado previamente con $\mathrm{HCl} 2 \mathrm{M}, \mathrm{H}_{2} \mathrm{O}, \mathrm{MeOH}$ y éter). Se deja reaccionar a temperatura ambiente y bajo atmósfera de argon durante 1 hora. Transcurrido este tiempo se diluye la mezcla de reacción con éter y se filtra por celita, lavando abundantemente con éter $(250 \mathrm{~mL})$. Luego se lava el filtrado sucesivamente con agua y con disoluciones acuosas de $\mathrm{Na}_{2} \mathrm{~S}_{2} \mathrm{O}_{3}(10 \%), \mathrm{NaHCO}_{3}(5 \%)$ y $\mathrm{NaCl}$ (saturada). Se seca sobre $\mathrm{Na}_{2} \mathrm{SO}_{4}$ anhidro, se filtra y se evapora el éter, obteniéndose $75 \mathrm{mg}$ de crudo que se redisuelven en $1.5 \mathrm{~mL}$ de $\mathrm{MeOH}$. Se añade a esta mezcla una candidad catalítica de $p$-TsOH y se deja reaccionando a temperatura ambiente con buena agitación durante 1 hora. Pasado este tiempo se añade una pequeña cantidad de $\mathrm{NaHCO}_{3}$ y se esperan 10 minutos. Seguidamente se evapora el $\mathrm{MeOH}$, se redisuelve en AcOEt, se filtra y se evapora el 
AcOEt para obtener $40 \mathrm{mg}(63 \%)$ de 1 , cuyas propiedades físicas y espectroscópicas ya han sido descritas anteriormente.

\section{REACCIÓN DE OZONOLISIS DE 23}

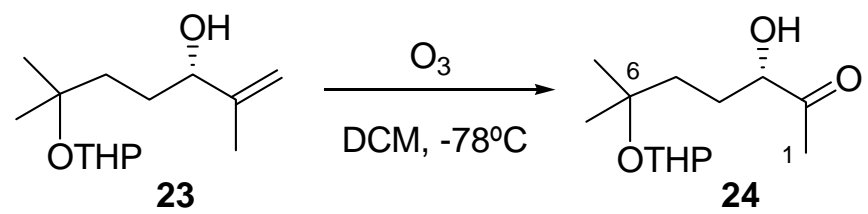

Se disuelven $20 \mathrm{mg}$ (0.08 mmoles) de $\mathbf{2 3}$ en $2 \mathrm{~mL}$ de DCM seco y se baja la temperatura a $-78^{\circ} \mathrm{C}$. Seguidamente se pasa una corriente de $\mathrm{O}_{3}$ hasta que la disolución se vuelve de color azul-violeta (10 minutos). Entonces se añade una gota de dimetilsulfuro y se deja agitando a temperatura ambiente durante 90 minutos. Transcurrido este tiempo se evapora el disolvente y se obtienen $22 \mathrm{mg}$ de crudo que se cromatografían en columna sobre sílicagel flash (eluyente: hexano/AcOEt 8:2). Se aíslan $8 \mathrm{mg}(40 \%)$ de $\mathbf{2 4}$, cuyas propiedades espectroscópicas son las siguientes:

\section{(3S)-3-Hidroxi-6-metil-6-(tetrahidro-piran-2-iloxi)-heptan-2-ona (24)}

ESPECTRO RMN ${ }^{1} \mathbf{H}\left(200 \mathrm{MHz}, \mathrm{CDCl}_{3}, \delta\right.$ ppm) (fig. 22): 4.46 (1H, m, H-1'), 4.22 $(1 \mathrm{H}, \mathrm{t}, J=7.0 \mathrm{~Hz}, \mathrm{H}-3), 3.86$ y 3.45 (1H c/u, m, H-5'), 1.83-1.37 (10H, m, H-4, H-5, H-2', H-3' y H-4'), 2.16 (3H, s, H-1), 1.22 (6H, s, H-7 y H-8).

\section{REACCIÓN DE WITTIG DE 24 CON}

\section{(CARBETOXIMETILEN)TRIFENILFOSFORANO}<smiles>[Z4]C(=O)[C@H](O)CCC(C)(C)[OH2+]</smiles>

24

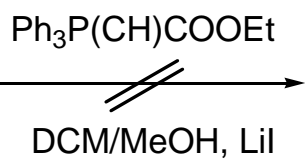

$\mathrm{DCM} / \mathrm{MeOH}$, Lil 
A una disolución de 24 (8 mg, 0.03 mmoles) en $1 \mathrm{~mL}$ de DCM/MeOH (15:85) a temperatura ambiente y bajo atmósfera de argon, se añaden sucesivamente $11 \mathrm{mg}$ de (carbetoximetilen)trifenilfosforano y $6 \mathrm{mg}$ de LiI trihidrato. Se deja reaccionando a esta temperatura durante 12 horas, transcurridas las cuales se evapora el disolvente, recuperándose el material de partida inalterado.

\section{OZONOLISIS DE 1 Y POSTERIOR OLEFINACIÓN DE HORNER- WADSWORTH-EMMONS}

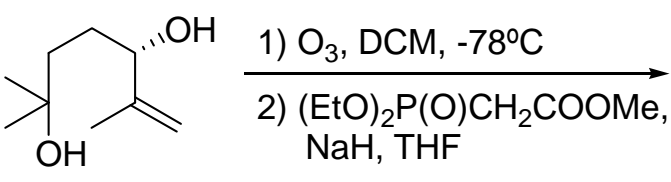

1<smiles>COC(=O)/C=C(\C)[C@H](O)CCC(C)(C)O</smiles>

26<smiles>CC(=O)C=C1CC(C)(C)CC[C@H]1O</smiles>

27

Se disuelven $47 \mathrm{mg}$ (0.30 mmoles) de 1 en $2 \mathrm{~mL}$ de DCM seco y se baja la temperatura a $-78^{\circ} \mathrm{C}$. Entonces se pasa una corriente de $\mathrm{O}_{3}$ hasta que la disolución se pone de color azul-violeta (10 minutos). Transcurrido este tiempo, se añade una gota de dimetilsulfuro y se deja agitando a temperatura ambiente durante 90 minutos. Seguidamente se evapora el disolvente para obtener un crudo que se redisuelve en $2 \mathrm{~mL}$ de THF seco bajo atmósfera de argon y se añade sobre una disolución del carbanión estabilizado del fosfonato $(\mathrm{EtO})_{2} \mathrm{P}(\mathrm{O}) \mathrm{CH}_{2} \mathrm{COOMe}$ (previamente formado por adición de $0.26 \mathrm{~mL}$ (1.47 mmoles) del fosfonato sobre una suspensión de $\mathrm{NaH}$ (58 mg, 1.47 mmoles), anteriormente lavado, en $1 \mathrm{~mL}$ de $\mathrm{THF}$ seco a $0^{\circ} \mathrm{C}$ ) en THF seco. Se deja reaccionando a temperatura ambiente durante 20 horas, transcurridas las cuales se añaden $4 \mathrm{~mL}$ de $\mathrm{H}_{2} \mathrm{O}$ y se extrae con éter (x3). El combinado de fases orgánicas se lava sucesivamente con $\mathrm{H}_{2} \mathrm{O}$ y disolución acuosa de $\mathrm{NaCl}$ (saturada). Se seca sobre $\mathrm{Na}_{2} \mathrm{SO}_{4}$ anhidro, se filtra y se evapora el disolvente, obteniéndose $70 \mathrm{mg}$ de crudo que se cromatografian en columna sobre sílicagel flash (eluyente: hexano/AcOEt 8:2). Finalmente se obtienen 6 mg (10\%) de la mezcla de ésteres 26 y 27. 


\section{REACCIÓN DE BENCILACIÓN DE 1}<smiles>C=C(C)[C@H](O)CCC(C)(C)O</smiles>

1

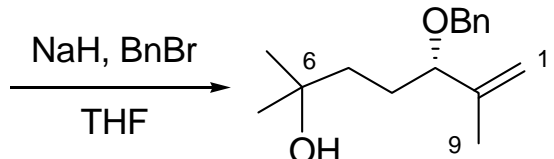

28

Se añade una disolución de 1 (50 mg, 0.31 mmoles) en $1.5 \mathrm{~mL}$ de THF sobre 15 $\mathrm{mg}$ de $\mathrm{NaH}$ (0.65 mmoles, $60 \%$ en parafina y previamente lavado con 2 porciones de THF de $1 \mathrm{~mL}$ ) a $0^{\circ} \mathrm{C}$. Se deja reaccionando con buena agitación a temperatura ambiente durante 50 minutos, transcurridos los cuales se añaden $40.5 \mu \mathrm{L}$ de $\mathrm{BnBr}$. Se deja reaccionando durante 15 horas. A continuación se baja la temperatura a $0^{\circ} \mathrm{C}$, se añaden $0.5 \mathrm{~mL}$ de $\mathrm{H}_{2} \mathrm{O}$ y se deja 15 minutos agitando a temperatura ambiente. Se vierte la mezcla sobre $10 \mathrm{~mL}$ de una disolución acuosa de $\mathrm{NaCl}$ (saturada) y se extrae varias veces con AcOEt. Se seca sobre $\mathrm{Na}_{2} \mathrm{SO}_{4}$, se filtra y se evapora el disolvente, obteniéndose $70 \mathrm{mg}$ de crudo que se cromatografían en columna sobre sílicagel flash (eluyente: hexano/AcOEt 85:15). Finalmente se aíslan $51 \mathrm{mg}$ (67\%) del bencilderivado 28, cuyas propiedades físicas y espectroscópicas se detallan a continuación:

\section{(5S)-5-Benciloxi-2,6-dimetil-hept-6-en-2-ol (28)}

ESPECTRO IR $v_{\max }$ (película) $\mathrm{cm}^{-1}$ (fig. 23a): 3430, 3071, 3032, 2971, 2864, 1649, 1454, 1373, 1069, 905, 735, 696.

ESPECTRO RMN ${ }^{1} \mathbf{H}\left(200 \mathrm{MHz}, \mathrm{CDCl}_{3}, \delta\right.$ ppm) (fig. 23b): $7.34-7.32$ (5 H, m, -Ph), $4.99\left(1 \mathrm{H}, \mathrm{sa}, \mathrm{H}_{\mathrm{A}}-1\right), 4.94\left(1 \mathrm{H}, \mathrm{sa}, \mathrm{H}_{\mathrm{B}}-1\right), 4.50\left(1 \mathrm{H}, \mathrm{d}, J=11.8 \mathrm{~Hz}, \mathrm{O}-\underline{\mathrm{CH}}_{2}-\mathrm{Ph}, \mathrm{H}_{\mathrm{A}}\right), 4.27$ $\left(1 \mathrm{H}, \mathrm{d}, J=11.8 \mathrm{~Hz}, \mathrm{O}-\underline{\mathrm{CH}}_{2}-\mathrm{Ph}, \mathrm{H}_{\mathrm{B}}\right), 3.72(1 \mathrm{H}, \mathrm{t}, J=5.7 \mathrm{~Hz}, \mathrm{H}-3), 1.8-1.3$ (4H, m, H-4 y H-5), 1.70 (3H, s, H-9), 1.20 (6H, s, H-7 y H-8).

ESPECTRO RMN ${ }^{13} \mathbf{C}\left(50 \mathrm{MHz}, \mathrm{CDCl}_{3}, \delta\right.$ ppm) (fig. 23c) (Tabla XXII ).

ANÁLISIS ELEMENTAL: Calculado para $\mathrm{C}_{16} \mathrm{H}_{24} \mathrm{O}_{2}$ : \%C: 77.37, \% $\mathrm{H}$ : 9.74; Experimental: \%C: $77.54, \% \mathrm{H}: 9.68$.

$[\alpha]_{D}^{25}=-38.3^{\circ}\left(\mathrm{c}=1.0, \mathrm{CHCl}_{3}\right)$ 


\section{REACCIÓN DE OZONOLISIS DEL BENCILDERIVADO 28}<smiles>C=C(C)[C@@H](CCC(C)(C)O)OBr</smiles>

28

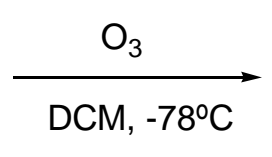

DCM, $-78^{\circ} \mathrm{C}$<smiles>CC(=O)[C@H](Br)CCC(C)(C)O</smiles>

29

Se disuelven $43 \mathrm{mg}$ ( 0.17 mmoles) de $\mathbf{2 8}$ en $2.5 \mathrm{~mL}$ de DCM seco y se enfría a $78^{\circ} \mathrm{C}$. Seguidamente se pasa una corriente de $\mathrm{O}_{3}$ hasta que la disolución se torna de color azul-violeta (5 minutos) y entonces se añade una gota de dimetilsulfuro. Se deja agitando a temperatura ambiente durante 90 minutos. A continuación se evapora el disolvente y se obtienen $67 \mathrm{mg}$ de crudo que se cromatografían en columna sobre sílicagel flash (eluyente: hexano/AcOEt 8:2), aislándose $20 \mathrm{mg}$ (50\%) de 29, que posee las siguientes propiedades físicas y espectroscópicas:

(3S)-3-Benciloxi-6-hidroxi-6-metil-heptan-2-ona (29)

ESPECTRO IR $v_{\max }$ (película) $\mathrm{cm}^{-1}$ (fig. 24a): 3426, 2973, 2918, 1725, 1447, 1364, $1175,1105$.

ESPECTRO RMN ${ }^{1} \mathbf{H}\left(200 \mathrm{MHz}, \mathrm{CDCl}_{3}, \delta\right.$ ppm) (fig. 24b): 7.35 (5H, m, Ph), 4.58 $\left(1 \mathrm{H}, \mathrm{d}, J=11.6 \mathrm{~Hz},-\mathrm{O}-\underline{\mathrm{CH}}_{2}-\mathrm{Ph}, \mathrm{H}_{\mathrm{A}}\right), 4.43\left(1 \mathrm{H}, \mathrm{d}, J=11.6 \mathrm{~Hz},-\mathrm{O}-\underline{\mathrm{CH}}_{2}-\mathrm{Ph}, \mathrm{H}_{\mathrm{B}}\right), 3.80$ $(1 \mathrm{H}, \mathrm{t}, J=6.4 \mathrm{~Hz}, \mathrm{H}-3), 1.80-1.40$ (4H, m, H-4 y H-5), 2.20 (3H, s, H-1), 1.21 (6H, s, H-7 y H-8).

ESPECTRO RMN ${ }^{13} \mathbf{C}\left(50 \mathrm{MHz}, \mathrm{CDCl}_{3}, \delta\right.$ ppm) (fig. 24c) (Tabla XXII ).

$[\alpha]_{D}^{25}=-43.5^{\circ}\left(\mathrm{c}=1.2, \mathrm{CHCl}_{3}\right)$ 


\section{RUPTURA OXIDATIVA DEL BENCILDERIVADO 28}

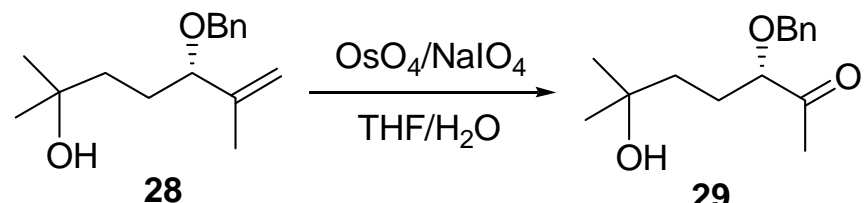

Se disuelven $32 \mathrm{mg}(0.13$ mmoles $)$ de 28 en $1.3 \mathrm{~mL}$ de $\mathrm{THF} / \mathrm{H}_{2} \mathrm{O}(3: 1)$ y se añaden $3 \mathrm{mg}(0.013$ mmoles $)$ de $\mathrm{OsO}_{4}$ y $83 \mathrm{mg}(0.39$ mmoles $)$ de $\mathrm{NaIO}_{4}$. Se deja agitando a temperatura ambiente durante 3 horas. Después se diluye la mezcla con AcOEt y se extrae la fase acuosa varias veces con AcOEt. El combinado de fases orgánicas se junta y se añade sobre $20 \mathrm{~mL}$ de una disolución acuosa saturada de $\mathrm{Na}_{2} \mathrm{~S}_{2} \mathrm{O}_{3}$. Se deja agitando durante 45 minutos. Pasado este tiempo se separa la fase orgánica y se lava con $\mathrm{H}_{2} \mathrm{O}$ y una disolución acuosa de $\mathrm{NaCl}$ (saturada). Se seca sobre $\mathrm{Na}_{2} \mathrm{SO}_{4}$ anhidro, se filtra y se evapora el disolvente para obtener $30 \mathrm{mg}$ de crudo que se cromatografían en columna sobre sílicagel flash (eluyente: hexano/AcOEt 8:2). Se aíslan $23 \mathrm{mg}(70 \%)$ de $\mathbf{2 9}$, cuyas propiedades físicas y espectroscópicas ya han sido descritas anteriormente.

\section{REACCIÓN DE HORNER-WADSWORTH-EMMONS DE LA CETONA 29}

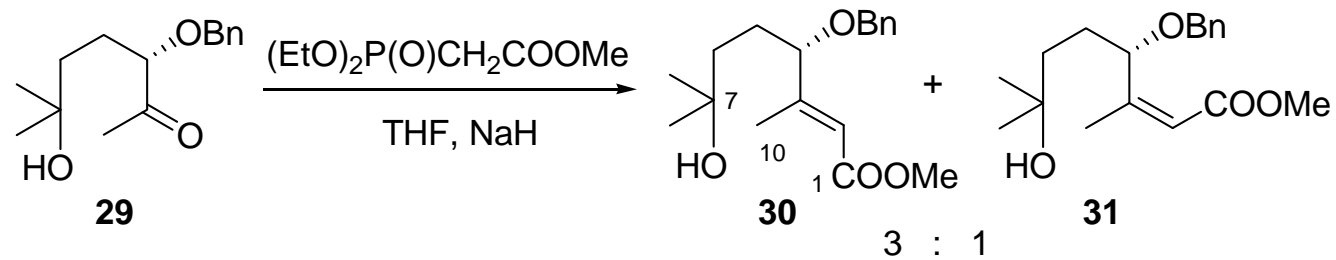

Sobre una suspensión de $\mathrm{NaH}$ (5 mg, 0.22 mmoles, $60 \%$ en parafina, previamente lavado con 2 porciones de $0.5 \mathrm{~mL}$ de THF) en $0.3 \mathrm{~mL}$ de $\mathrm{THF}$, se añaden lentamente $41 \mu \mathrm{L}$ del fosfonato correspondiente. Se mantiene agitando a temperatura ambiente durante 30 minutos, transcurridos los cuales se añade una disolución de 29 (14 $\mathrm{mg}, 0.056$ mmoles) en $1 \mathrm{~mL}$ de THF. Se deja reaccionando a temperatura ambiente 
durante 20 horas. A continuación se añaden $4 \mathrm{~mL}$ de agua y se extrae varias veces con éter. Se juntan las fases orgánicas y se lavan con agua y con una disolución acuosa de $\mathrm{NaCl}$ (saturada). Se seca sobre $\mathrm{Na}_{2} \mathrm{SO}_{4}$ anhidro, se filtra y se evapora el éter para obtener $14 \mathrm{mg}$ de crudo que se cromatografían en columna sobre sílicagel flash (eluyente: hexano/AcOEt 8:2). Se obtienen $9 \mathrm{mg}$ (54\%) de una mezcla de los ésteres $E$ y $Z 30$ y 31 en una proporción 3:1. Las propiedades espectroscópicas del isómero $E$ mayoritario, son las siguientes:

\section{(4S)-4-Benciloxi-7-hidroxi-3,7-dimetiloct-E-2-enoato de metilo (30)}

ESPECTRO RMN ${ }^{1} \mathbf{H}\left(200 \mathrm{MHz}, \mathrm{CDCl}_{3}, \delta\right.$ ppm) (fig. 25): 7.34-7.32 (5H, m, Ph), 5.89 $(1 \mathrm{H}, \mathrm{s}, \mathrm{H}-2), 4.51\left(1 \mathrm{H}, \mathrm{d}, J=11.6 \mathrm{~Hz},-\mathrm{O}-\underline{\mathrm{CH}}_{2}-\mathrm{Ph}, \mathrm{H}_{\mathrm{A}}\right), 4.25(1 \mathrm{H}, \mathrm{d}, J=11.6 \mathrm{~Hz},-\mathrm{O}-$ $\left.\underline{\mathrm{CH}}_{2}-\mathrm{Ph}, \mathrm{H}_{\mathrm{B}}\right), 3.73(1 \mathrm{H}, \mathrm{s},-\mathrm{COOMe}), 3.71(1 \mathrm{H}, \mathrm{m}, \mathrm{H}-4), 2.14(3 \mathrm{H}, \mathrm{s}, \mathrm{H}-10), 1.57-1.25$ (4H, m, H-5 y H-6), 1.20 (6H, s, H-8 y H-9).

\section{REDUCCIÓN DEL ALDEHÍDO 21}

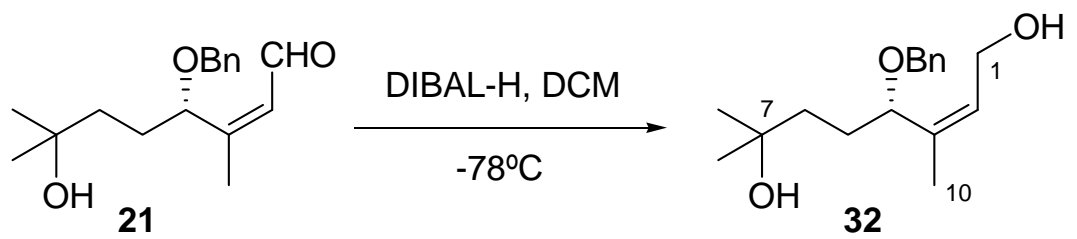

Se disuelven $67 \mathrm{mg}$ (0.24 mmoles) de 21 en $2.5 \mathrm{~mL}$ de DCM y se añaden, bajo atmósfera de argon y a $-78{ }^{\circ} \mathrm{C}, 0.24 \mathrm{~mL}(0.36$ mmoles $)$ de una disolución $1.5 \mathrm{M}$ de DIBAL-H en tolueno. Se mantiene la agitación a esa temperatura durante una hora, tras la cual se adicionan $0.3 \mathrm{~mL}$ de $\mathrm{H}_{2} \mathrm{O}$ y se agita durante 10 minutos más a temperatura ambiente. A continuación se añade la mezcla sobre $100 \mathrm{~mL}$ de éter y se agita con $2 \mathrm{~g}$ de $\mathrm{NaHCO}_{3}$ y 2 g de $\mathrm{Na}_{2} \mathrm{SO}_{4}$ durante 3 horas. Pasado este tiempo se filtra por celita y se evapora el disolvente, obteniéndose $80 \mathrm{mg}$ de crudo con restos de tolueno que se cromatografían en columna sobre sílicagel flash (eluyente: hexano/AcOEt 6:4), para 
obtener $52 \mathrm{mg}(78 \%)$ del alcohol alílico 32, cuyas propiedades físicas y espectroscópicas son las siguientes:

\section{(4S)-4-Benciloxi-3,7-dimetil-oct-2-Z-en-1,7-diol (32)}

ESPECTRO IR $v_{\max }$ (película) $\mathrm{cm}^{-1}$ (fig. 26a): 3380 (ancha), 3065, 3032, 2970-2870, 1454, 1377, 1217, 1157, 1069, 1028, 737, 698.

ESPECTRO RMN ${ }^{1} \mathbf{H}\left(200 \mathrm{MHz}, \mathrm{CDCl}_{3}, \delta\right.$ ppm) (fig. 26b): 7.38-7.30 (5H, m, -Ph), $5.68(1 \mathrm{H}, \mathrm{t}, J=6.4 \mathrm{~Hz}, \mathrm{H}-2), 4.48\left(1 \mathrm{H}, \mathrm{d}, J=11.8 \mathrm{~Hz}, \mathrm{O}-\underline{\mathrm{CH}}_{2}-\mathrm{Ph}, \mathrm{H}_{\mathrm{A}}\right), 4.24(1 \mathrm{H}, \mathrm{d}, J=$ $\left.11.8 \mathrm{~Hz}, \mathrm{O}-\underline{\mathrm{CH}}_{2}-\mathrm{Ph}, \mathrm{H}_{\mathrm{B}}\right), 4.19$ (1H, m, H-4), 4.07 (2H, t, J=6.4 Hz, H-1), 1.9-1.3 (4H, m, H-5 y H-6), 1.73 (3H, s, H-10), 1.19 (6H, s, H-8 y H-9).

ESPECTRO RMN ${ }^{13} \mathbf{C}\left(50 \mathrm{MHz}, \mathrm{CDCl}_{3}, \delta\right.$ ppm) (fig. 26c) (Tabla XIV).

HRMS, EI: Calculado para $\mathrm{C}_{17} \mathrm{H}_{27} \mathrm{O}_{3}(M+\mathrm{H})^{+}, 279.1960$. Experimental $(\mathrm{M}+\mathrm{H})^{+}$, 279.1955.

$$
[\alpha]_{D}^{25}=-20.9^{\circ}\left(\mathrm{c}=1.2, \mathrm{CHCl}_{3}\right)
$$

\section{REDUCCIÓN DEL ALDEHÍDO 22}

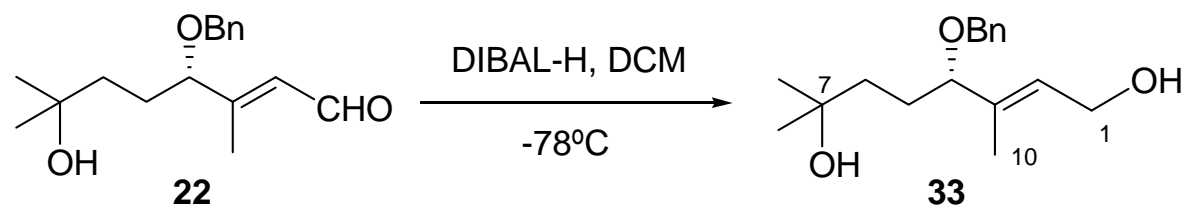

Sobre una disolución de 22 (110 mg, 0.40 mmoles) en $4 \mathrm{~mL}$ de DCM se añaden, a $-78{ }^{\circ} \mathrm{C}$ y bajo atmósfera de argon, $0.4 \mathrm{~mL}$ de una disolución 1.5 $\mathrm{M}$ de DIBAL-H en tolueno. Se mantiene la mezcla de reacción con agitación a $-78^{\circ} \mathrm{C}$ durante 90 minutos. Transcurrido este periodo de tiempo se añaden $0.5 \mathrm{~mL}$ de agua y se deja que la mezcla alcance progresivamente la temperatura ambiente. Entonces se disuelven los productos en $300 \mathrm{~mL}$ de éter, se añaden $3.5 \mathrm{~g}$ de $\mathrm{NaHCO}_{3}, 5 \mathrm{~g}$ de $\mathrm{Na}_{2} \mathrm{SO}_{4}$ anhidro y se deja agitando durante 14 horas. Después de este tiempo se filtra por celita y se evapora el 
éter, obteniéndose $110 \mathrm{mg}$ de una mezcla con restos de tolueno que se cromatografía en columna sobre sílicagel flash (eluyente: hexano/AcOEt $(6 / 4 \rightarrow 8 / 2)$, aislándose $107 \mathrm{mg}$ (97\%) del alcohol alílico 33, cuyas propiedades físicas y espectroscópicas son las siguientes:

\section{(4S)-4-Benciloxi-3,7-dimetil-oct-2-E-en-1,7-diol (33)}

ESPECTRO IR $v_{\max }$ (película) $\mathrm{cm}^{-1}$ (fig. 27a): 3400 (ancha), 3032, 2970-2870, 1456, 1377, 1211, 1157, 1072, 737, 698.

ESPECTRO RMN ${ }^{1} \mathbf{H}\left(200 \mathrm{MHz}, \mathrm{CDCl}_{3}, \delta\right.$ ppm) (fig. 27b): 7.35-7.30 (5H, m, Ph), $5.60(1 \mathrm{H}, \mathrm{t}, J=6.3 \mathrm{~Hz}, \mathrm{H}-2), 4.46\left(1 \mathrm{H}, \mathrm{d}, J=11.8 \mathrm{~Hz}, \mathrm{O}-\underline{\mathrm{CH}}_{2}-\mathrm{Ph}, \mathrm{H}_{\mathrm{A}}\right), 4.26(1 \mathrm{H}, \mathrm{d}, J=$ $\left.11.8 \mathrm{~Hz}, \mathrm{O}-\underline{\mathrm{CH}}_{2}-\mathrm{Ph}, \mathrm{H}_{\mathrm{B}}\right), 4.22$ (2H, m, H-1), 3.67 (1H, m, H-4), 1.90-1.30 (4H, m, H-5, H-6), 1.65 (3H, s, H-10), 1.19 (6H, s, H-8 y H-9).

ESPECTRO RMN ${ }^{13} \mathbf{C}\left(50 \mathrm{MHz}, \mathrm{CDCl}_{3}, \delta\right.$ ppm) (fig. 27c) (Tabla XIV).

HRMS, $\mathrm{FAB}^{+}$: Calculado para $\mathrm{C}_{17} \mathrm{H}_{27} \mathrm{O}_{3}(M+\mathrm{H})^{+}, 279.1960$. Experimental $(\mathrm{M}+\mathrm{H})^{+}$, 279.1948 .

$$
[\alpha]_{D}^{25}=-28.0^{\circ}\left(\mathrm{c}=0.8, \mathrm{CHCl}_{3}\right)
$$

\section{YODOCICLACIÓN DEL ALDEHÍDO 33}<smiles>CC(C)(O)CC[C@H](/C=C/CO)OCc1ccccc1</smiles>

33

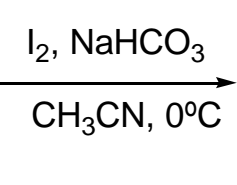

Se disuelven $1.46 \mathrm{~g}$ (5.25 mmoles) de 33 en $52 \mathrm{~mL}$ de $\mathrm{CH}_{3} \mathrm{CN}$ y se añaden, a 0 ${ }^{\circ} \mathrm{C}, 3.99 \mathrm{~g}$ (15.75 mmoles) de $\mathrm{I}_{2}$ resublimado y $1.32 \mathrm{~g}$ (15.75 mmoles) de $\mathrm{NaHCO}_{3}$. Se deja agitando permitiendo subir la temperatura lentamente. Transcurridos 90 minutos se diluye la mezcla con AcOEt $(900 \mathrm{~mL})$ y se lava sucesivamente con disoluciones acuosas de $\mathrm{Na}_{2} \mathrm{~S}_{2} \mathrm{O}_{3}(10 \%), \mathrm{NaHCO}_{3}(5 \%)$ y $\mathrm{NaCl}$ (saturado). Se seca sobre $\mathrm{Na}_{2} \mathrm{SO}_{4}$ anhidro, se filtra y se evapora el disolvente obteniéndose $2.13 \mathrm{~g}$ de crudo que se 
cromatografían sobre sílicagel flash (eluyente: hexano/AcOEt 95:5) aislándose $1.74 \mathrm{~g}$ (82\%) del tetrahidropirano 34 y $136 \mathrm{mg}$ (6\%) del diastereoisómero 35, cuyas propiedades físicas y espectroscópicas son las siguientes:

\section{$\underline{\left(2 S, 2^{\prime} R, 3^{\prime} S\right)-2-\left(3^{\prime}-\text { Benciloxi-2', } 6^{\prime}, 6^{\prime} \text {-trimetil-tetrahidro-piran-2'-il)-2-yodoetanol }\right.}$}

$\underline{(34)}$

ESPECTRO IR $v_{\max }$ (película) $\mathrm{cm}^{-1}$ (fig.28a): 3460 (ancha), 2970-2870, 1454, 1377, 1221, 1069, 974, 731, 696.

ESPECTRO RMN ${ }^{1} \mathbf{H}\left(400 \mathrm{MHz}, \mathrm{CDCl}_{3}, \delta\right.$ ppm) (fig. 28b): 7.46-7.30 (5H, m, Ph), $4.85(1 \mathrm{H}, \mathrm{dd}, J=3.4 \mathrm{~Hz}$ y $10.1 \mathrm{~Hz}, \mathrm{H}-10), 4.58\left(1 \mathrm{H}, \mathrm{d}, J=10.8 \mathrm{~Hz}, \mathrm{O}-\underline{\mathrm{CH}}_{2}-\mathrm{Ph}, \mathrm{H}_{\mathrm{A}}\right)$, $4.48\left(1 \mathrm{H}, \mathrm{d}, J=10.8 \mathrm{~Hz}, \mathrm{O}-\underline{\mathrm{CH}}_{2}-\mathrm{Ph}, \mathrm{H}_{\mathrm{B}}\right), 4.09$ (1H, m, H $\left.\mathrm{H}_{\mathrm{A}}-11\right), 3.94$ (1H, m, $\left.\mathrm{H}_{\mathrm{B}}-11\right)$, 3.43 (1H, m, H-3), 2.05-1.85 (4H, m, H-4, H-5), 1.51 (3H, s, H-9), 1.26 y 1.22 (3H c/u, s, H-7 y H-8).

ESPECTRO RMN ${ }^{13} \mathbf{C}\left(100 \mathrm{MHz}, \mathrm{CDCl}_{3}, \delta\right.$ ppm) (fig. 28c) (Tabla XVI).

HRMS, EI: Calculado para $\mathrm{C}_{17} \mathrm{H}_{26} \mathrm{O}_{3} \mathrm{I}(\mathrm{M}+\mathrm{H})^{+}$, 405.0927. Experimental $(\mathrm{M}+\mathrm{H})^{+}$, 405.0944 .

$[\alpha]_{D}^{25}=+22.5^{\circ}\left(\mathrm{c}=1.0, \mathrm{CHCl}_{3}\right)$

$\underline{\left(2 R, 2^{\prime} S, 3^{\prime} S\right)-2-\left(3^{\prime}-\text { Benciloxi-2', } 6^{\prime}, 6^{\prime} \text {-trimetil-tetrahidro-piran-2'-il)-2-yodoetanol }\right.}$ (35)

ESPECTRO IR $v_{\max }$ (película) $\mathrm{cm}^{-1}$ (fig. 29a): 3450 (ancha), 2970-2870, 1454, 1366, 1221, 1098, 1028, 737, 698.

ESPECTRO RMN ${ }^{1} \mathbf{H}\left(400 \mathrm{MHz}, \mathrm{CDCl}_{3}, \delta \mathrm{ppm}\right)$ (fig.29b): 7.40-7.30 (5H, m, Ph), $4.69\left(1 \mathrm{H}, \mathrm{d}, J=11.7 \mathrm{~Hz}, \mathrm{O}-\underline{\mathrm{CH}}_{2}-\mathrm{Ph}, \mathrm{H}_{\mathrm{A}}\right), 4.44\left(1 \mathrm{H}, \mathrm{d}, J=11.7 \mathrm{~Hz}, \mathrm{O}-\underline{\mathrm{CH}}_{2}-\mathrm{Ph}, \mathrm{H}_{\mathrm{B}}\right)$, $4.44(1 \mathrm{H}, \mathrm{m}, \mathrm{H}-10), 3.89\left(1 \mathrm{H}, \mathrm{m}, \mathrm{H}_{\mathrm{A}}-11\right), 3.74(1 \mathrm{H}, \mathrm{dd}, J=4.2 \mathrm{~Hz}$ y $10.5 \mathrm{~Hz}, \mathrm{H}-3)$, $3.66\left(1 \mathrm{H}, \mathrm{m}, \mathrm{H}_{\mathrm{B}}-11\right), 2.10-1.30$ (4H, m, H-4, H-5), 1.49 (3H, s, H-9), 1.29 y 1.25 (3H c/u, s, H-7 y H-8). 
ESPECTRO RMN ${ }^{13} \mathbf{C}\left(100 \mathrm{MHz}, \mathrm{CDCl}_{3}, \delta\right.$ ppm) (fig. 29c) (Tabla XV).

HRMS, EI: Calculado para $\mathrm{C}_{17} \mathrm{H}_{26} \mathrm{O}_{3} \mathrm{I}(\mathrm{M}+\mathrm{H})^{+}$, 405.0927. Experimental $(\mathrm{M}+\mathrm{H})^{+}$, 405.0952 .

$[\alpha]_{D}^{25}=+6.7^{\circ}\left(\mathrm{c}=1.0, \mathrm{CHCl}_{3}\right)$

\section{YODOCICLACIÓN DEL ALDEHÍDO 32}<smiles>C/C(=C/CO)[C@H](CCC(C)(C)O)OCc1ccccc1</smiles>

32

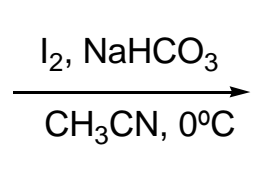

$0^{\circ} \mathrm{C}$

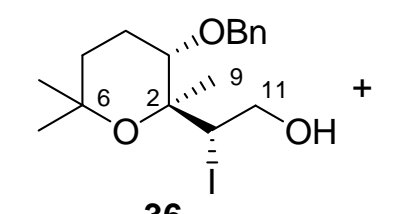

36<smiles>CC1(C)CC[C@@H](OBr)[C@@](CO)(CI)O1</smiles>

37

Se disuelven $26 \mathrm{mg}$ (0.09 mmoles) de 32 en $1 \mathrm{~mL}$ de $\mathrm{CH}_{3} \mathrm{CN}$ y se añaden $70 \mathrm{mg}$ (0.27 mmoles) de $\mathrm{I}_{2}$ y $23 \mathrm{mg}(0.27$ mmoles $)$ de $\mathrm{NaHCO}_{3}$ a $0{ }^{\circ} \mathrm{C}$. Se mantiene la agitación durante 2 horas dejando calentar lentamente hasta temperatura ambiente. Transcurrido este tiempo se diluye la mezcla con AcOEt $(200 \mathrm{~mL})$ y se lava con disoluciones acuosas de $\mathrm{Na}_{2} \mathrm{~S}_{2} \mathrm{O}_{3}(10 \%), \mathrm{NaHCO}_{3}(5 \%)$ y $\mathrm{NaCl}$ (saturada). Se seca sobre $\mathrm{Na}_{2} \mathrm{SO}_{4}$, se filtra y evapora el disolvente para obtener $40 \mathrm{mg}$ de un crudo que se cromatografían en columna sobre sílicagel flash (eluyente: $\mathrm{CHCl}_{3}$ ) para obtener 10 $\mathrm{mg}$ del tetrahidropirano 36, $8 \mathrm{mg}$ del tetrahidropirano $37 \mathrm{y} 11 \mathrm{mg}$ de mezcla 36/37, con un rendimiento global del $83 \%$. Las propiedades físicas y espectroscópicas de de estos compuestos son las que se muestran a continuación:

\section{$\underline{\left(2 S, 2^{\prime} S, 3^{\prime} S\right)-2-\left(3^{\prime}-B e n c i l o x i-2^{\prime}, 6^{\prime}, 6^{\prime} \text {-trimetil-tetrahidro-piran-2'-il)-2-yodoetanol }\right.}$} (36)

ESPECTRO IR $v_{\max }$ (película) $\mathrm{cm}^{-1}$ (fig. 30a): 3496, 2926, 2854, 1458, 1364, 1090, $1030,698$. 
ESPECTRO RMN ${ }^{1} \mathbf{H}\left(400 \mathrm{MHz}, \mathrm{CDCl}_{3}, \delta\right.$ ppm) (fig. 30b): 7.33-7.27 (5H, m, Ph), $4.64\left(1 \mathrm{H}, \mathrm{d}, J=11.5 \mathrm{~Hz}, \mathrm{O}-\underline{\mathrm{CH}}_{2}-\mathrm{Ph}, \mathrm{H}_{\mathrm{A}}\right), 4.50\left(1 \mathrm{H}, \mathrm{d}, J=11.5 \mathrm{~Hz}, \mathrm{O}-\underline{\mathrm{CH}}_{2}-\mathrm{Ph}, \mathrm{H}_{\mathrm{B}}\right)$, $4.58(1 \mathrm{H}, \mathrm{t}, J=3.2 \mathrm{~Hz}, \mathrm{H}-10), 4.18\left(1 \mathrm{H}, \mathrm{dd}, J=12.8\right.$ y $\left.3.2 \mathrm{~Hz}, \mathrm{H}_{\mathrm{A}}-11\right), 3.80(1 \mathrm{H}, \mathrm{dd}, J$ $=12.8$ y $\left.3.2 \mathrm{~Hz}, \mathrm{H}_{\mathrm{B}}-11\right), 3.83-3.76(1 \mathrm{H}, \mathrm{m}, \mathrm{H}-3), 1.68-1.57$ (2H, m, H-5), 1.35-1.20 (2H, m, H-4), 1.46 (3H, s, H-9), 1.24 y 1.20 (3H c/u, s, H-7 y H-8).

ESPECTRO RMN ${ }^{13} \mathbf{C}\left(100 \mathrm{MHz}, \mathrm{CDCl}_{3}, \delta\right.$ ppm) (fig. 30c) (Tabla XV).

LRMS, FB ${ }^{+}, \mathrm{m} / \mathrm{z}$ (\%) (fig. 30d): 91 (95), 154 (90), 204 (15), 259 (5), 307 (10), 405 (3) $\left(\mathrm{M}^{+}\right)$.

HRMS, FAB ${ }^{+}$: Calculado para $\mathrm{C}_{17} \mathrm{H}_{26} \mathrm{O}_{3} \mathrm{I},\left(M^{+}\right)$405,0927. Experimental, $\left(\mathrm{M}^{+}\right)$, 405.0916 .

$[\alpha]_{D}^{25}=+2.8^{\circ}\left(\mathrm{c}=0.8, \mathrm{CHCl}_{3}\right)$

$\underline{\left(2 R, 2^{\prime} R, 3^{\prime} S\right)-2-\left(3^{\prime} \text {-Benciloxi-2',6',6'-trimetil-tetrahidro-piran-2'-il)-2-yodoetanol }\right.}$ $\underline{(37)}$

ESPECTRO IR $v_{\max }$ (película) $\mathrm{cm}^{-1}$ (fig. 31a): 3436 (ancha), 2975, 2926, 2871, 1463, 1375, 1359, 1216, 1101, 1074, 1030, 970, 833.

ESPECTRO RMN ${ }^{1} \mathbf{H}\left(400 \mathrm{MHz}, \mathrm{CDCl}_{3}, \delta\right.$ ppm) (fig. 31b): 7.40-7.28 (5H, m, Ph), $4.58\left(1 \mathrm{H}, \mathrm{d}, J=10.8 \mathrm{~Hz}, \mathrm{O}-\underline{\mathrm{CH}_{2}}-\mathrm{Ph}, \mathrm{H}_{\mathrm{A}}\right), 4.48\left(1 \mathrm{H}, \mathrm{d}, J=10.8 \mathrm{~Hz}, \mathrm{O}-\underline{\mathrm{CH}}_{2}-\mathrm{Ph}, \mathrm{H}_{\mathrm{B}}\right)$, $4.43(1 \mathrm{H}, \mathrm{t}, J=5.5 \mathrm{~Hz}, \mathrm{H}-10), 4.08-4.04\left(1 \mathrm{H}, \mathrm{m}, \mathrm{H}_{\mathrm{A}}-11\right), 3.89-3.83\left(1 \mathrm{H}, \mathrm{m}, \mathrm{H}_{\mathrm{B}}-11\right)$, $3.22(1 \mathrm{H}, \mathrm{t}, J=6.3 \mathrm{~Hz}, \mathrm{H}-3), 2.01-1.86$ (4H, m, H-4, H-5), 1.42 (3H, s, H-9), $1.27 \mathrm{y}$ $1.25(3 \mathrm{H} \mathrm{c} / \mathrm{u}, \mathrm{s}, \mathrm{H}-7$ y H-8).

ESPECTRO RMN ${ }^{13} \mathbf{C}\left(100 \mathrm{MHz}, \mathrm{CDCl}_{3}, \delta\right.$ ppm) (fig. 31c) (Tabla XVII).

HRMS, ESI: Calculado para $\mathrm{C}_{17} \mathrm{H}_{26} \mathrm{O}_{3} \mathrm{I}(\mathrm{M}+\mathrm{Na})^{+}$, 427.0740. Experimental $(\mathrm{M}+\mathrm{Na})^{+}$, 427.0741 .

$[\alpha]_{D}^{25}=+18.3^{\circ}\left(\mathrm{c}=0.9, \mathrm{CHCl}_{3}\right)$ 


\section{REDUCCIÓN DE 34 CON Bu 33 SnH}

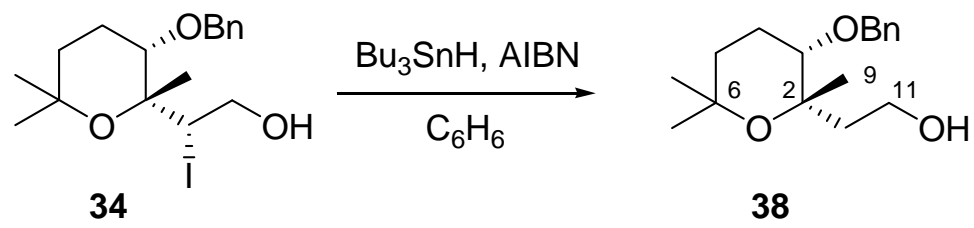

Sobre una disolución de 34 (1.74 g, 4.30 mmoles) en $50 \mathrm{~mL}$ de benceno seco se añaden $100 \mathrm{mg}$ de AIBN y $4.6 \mathrm{~mL}$ (17.18 mmoles) de $\mathrm{Bu}_{3} \mathrm{SnH}$. Se calienta la mezcla a ebullición $\left(80^{\circ} \mathrm{C}\right)$ y se mantiene a reflujo durante dos horas y media. A continuación se añaden $100 \mathrm{mg}$ de ácido oxálico y se agita la reacción durante otros 10 minutos, transcurridos los cuales se diluye la mezcla en AcOEt $(900 \mathrm{~mL})$ y se lava con disoluciones acuosas de $\mathrm{NaHCO}_{3}(5 \%)$ y $\mathrm{NaCl}$ (saturado). Se seca sobre $\mathrm{Na}_{2} \mathrm{SO}_{4}$ anhidro, se filtra y se evapora el disolvente obteniéndose $10 \mathrm{~g}$ de un crudo que se cromatografía sobre sílicagel flash (eluyente: hexano/AcOEt 9/1 $\rightarrow$ 8:2) aislándose 1.12 g (94\%) del alcohol $\mathbf{3 8}$ que presenta las siguientes propiedades físicas $\mathrm{y}$ espectroscópicas:

\section{$\underline{\left(2^{\prime} S, 3^{\prime} S\right)-2-\left(3^{\prime}-B^{\prime} \text { enciloxi-2',6 } 6^{\prime}, 6^{\prime} \text {-trimetil-tetrahidro-piran-2'-il)-etanol (38) }\right.}$}

ESPECTRO IR $\boldsymbol{v}_{\max }$ (película) $\mathrm{cm}^{-1}$ (fig. 32a): 3400 (ancha), 2970-2870, 1454, 1371, 1227, 1109, 1003, 737, 698 .

ESPECTRO RMN ${ }^{1} \mathbf{H}\left(400 \mathrm{MHz}, \mathrm{CDCl}_{3}, \delta\right.$ ppm) (fig. 32b): 7.40-7.30 (5H, m, Ph), $4.69\left(1 \mathrm{H}, \mathrm{d}, J=11.8 \mathrm{~Hz}, \mathrm{O}-\underline{\mathrm{CH}_{2}}-\mathrm{Ph}, \mathrm{H}_{\mathrm{A}}\right), 4.46\left(1 \mathrm{H}, \mathrm{d}, J=11.8 \mathrm{~Hz}, \mathrm{O}-\underline{\mathrm{CH}}_{2}-\mathrm{Ph}, \mathrm{H}_{\mathrm{B}}\right)$, $3.90\left(1 \mathrm{H}, \mathrm{m}, \mathrm{H}_{\mathrm{A}}-11\right), 3.80\left(1 \mathrm{H}, \mathrm{m}, \mathrm{H}_{\mathrm{B}}-11\right), 3.18(1 \mathrm{H}, \mathrm{dd}, J=3.1 \mathrm{~Hz}$ y $6.6 \mathrm{~Hz}, \mathrm{H}-3)$, 2.35-2.25 (1H, m, $\left.\mathrm{H}_{\mathrm{A}}-10\right), 2.0-1.30$ (5H, m, H-4, H-5 y $\left.\mathrm{H}_{\mathrm{B}}-10\right), 1.33$ (3H, s, H-9), 1.28 y $1.25(3 \mathrm{H} \mathrm{c} / \mathrm{u}, \mathrm{s}, \mathrm{H}-7$ y H-8).

ESPECTRO RMN ${ }^{13} \mathbf{C}\left(100 \mathrm{MHz}, \mathrm{CDCl}_{3}, \delta\right.$ ppm) (fig. 32c) (Tabla XV).

HRMS, EI: Calculado para $\mathrm{C}_{17} \mathrm{H}_{27} \mathrm{O}_{3}(M+\mathrm{H})^{+}, 279.1960$. Experimental $(\mathrm{M}+\mathrm{H})^{+}$, 279.1956 .

$[\alpha]_{D}^{25}=+28.2^{\circ}\left(\mathrm{c}=0.9, \mathrm{CHCl}_{3}\right)$ 


\section{OXIDACIÓN DE SWERN DE 38}

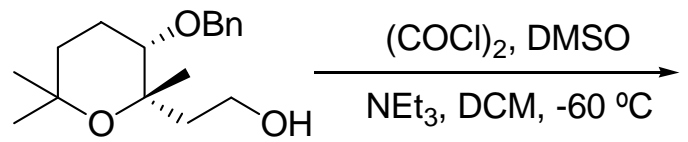

38

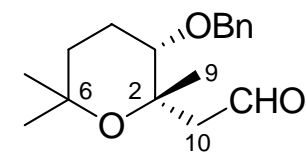

39

Sobre $0.39 \mathrm{~mL}(4.43$ mmoles $)$ de $(\mathrm{COCl})_{2}$ disueltos en $18 \mathrm{~mL}$ de $\mathrm{DCM}$ se añaden, a $-60{ }^{\circ} \mathrm{C}$ y bajo atmósfera de argon, $0.63 \mathrm{~mL}$ (8.86 mmoles) de DMSO. Pasados cinco minutos se adicionan $1.12 \mathrm{~g}$ (4.03 mmoles) de 38 disueltos en $9 \mathrm{~mL}$ de DCM y se mantiene la agitación a esa temperatura durante 30 minutos, transcurridos los cuales se añaden $2.8 \mathrm{~mL}$ (20.14 mmoles) de $\mathrm{NEt}_{3}$. Se mantiene la agitación a $-60{ }^{\circ} \mathrm{C}$ durante cinco minutos y a temperatura ambiente durante 15 minutos más. A continuación se disuelve la mezcla en $400 \mathrm{~mL}$ de $\mathrm{H}_{2} \mathrm{O}$ y se extrae con AcOEt (x 4). El combinado de fases orgánicas se lava con una disolución acuosa de $\mathrm{NaCl}$ (saturada). Se seca sobre $\mathrm{Na}_{2} \mathrm{SO}_{4}$ anhidro, se filtra y se evapora el disolvente obteniéndose $1.17 \mathrm{~g}$ de una mezcla que se cromatografía en columna sobre sílicagel flash (eluyente: hexano/AcOEt 95/5 $\rightarrow$ 9/1), para aislar $1.06 \mathrm{~g}(95 \%)$ del aldehído 39, cuyas propiedades físicas y espectroscópicas son las siguientes:

$\underline{\left(2^{\prime} S, 3^{\prime} S\right)-\left(3^{\prime}-\text { Benciloxi-2',6',6'-trimetil-tetrahidro-piran-2'-il)-acetaldehído (39) }\right.}$

ESPECTRO IR $v_{\max }$ (película) $\mathrm{cm}^{-1}$ (fig. 33a): 2980-2860, 2745, 1717, 1456, 1373, $1229,1109,1028,737,698$.

ESPECTRO RMN ${ }^{1} \mathbf{H}\left(200 \mathrm{MHz}, \mathrm{CDCl}_{3}, \delta\right.$ ppm) (fig. 33b): $9.82(1 \mathrm{H}, \mathrm{t}, J=2.9 \mathrm{~Hz}, \mathrm{H}-$ 11), 7.35-7.30 (5H, m, Ph), $4.56\left(1 \mathrm{H}, \mathrm{d}, J=11.8 \mathrm{~Hz}, \mathrm{O}-\underline{\mathrm{CH}}_{2}-\mathrm{Ph}, \mathrm{H}_{\mathrm{A}}\right), 4.40(1 \mathrm{H}, \mathrm{d}, J=$ $\left.11.8 \mathrm{~Hz}, \mathrm{O}-\underline{\mathrm{CH}}_{2}-\mathrm{Ph}, \mathrm{H}_{\mathrm{B}}\right), 3.21(1 \mathrm{H}, \mathrm{dd}, J=2.8 \mathrm{~Hz}$ y $6.4 \mathrm{~Hz}, \mathrm{H}-3), 2.50\left(1 \mathrm{H}, \mathrm{m}, \mathrm{H}_{\mathrm{A}}-10\right)$, 2.0-1.30 (5H, m, H-4, H-5 y HB-10), 1.33 (3H, s, H-9), 1.23 (6H, s, H-7 y H-8).

ESPECTRO RMN ${ }^{13} \mathbf{C}\left(50 \mathrm{MHz}, \mathrm{CDCl}_{3}, \delta\right.$ ppm) (fig. 33c) (Tabla XVIII).

LRMS, EI, m/z (\%) (fig. 33d): 77 (18), 91 (100), 134 (10), 275 (2) (M - H) .

HRMS, $\mathrm{FAB}^{+}$: Calculado para $\mathrm{C}_{17} \mathrm{H}_{24} \mathrm{O}_{3}(M+\mathrm{H})^{+}, 277.1804$. Experimental $(\mathrm{M}+\mathrm{H})^{+}$, 277.1783 . 


$$
[\alpha]_{D}^{25}=+46.7^{\circ}\left(\mathrm{c}=0.8, \mathrm{CHCl}_{3}\right)
$$

\section{FORMACIÓN DEL ÁCIDO 40}<smiles>CC1(C)CC[C@@H](OBr)C(CC=O)(CC=O)O1</smiles>

39
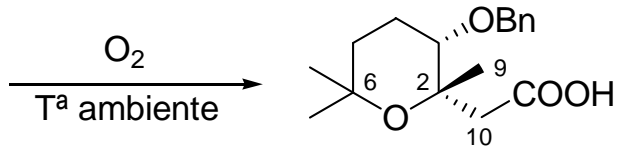

40

Se mantienen $28 \mathrm{mg}$ (0.10 mmoles) del aldehído 39 a temperatura ambiente en contacto con el oxígeno atmosférico durante 24 horas, transcurridas las cuales se cromatografía la mezcla por sílicagel flash (eluyente: hexano/AcOEt 9/1 $\rightarrow 8 / 2$ ) para aislar $12 \mathrm{mg}(41 \%)$ del ácido 40, que presenta las siguientes propiedades físicas y espectroscópicas:

\section{Ácido-(2S,3S)-(3-Benciloxi-2,6,6-trimetil-tetrahidro-piran-2-il)-acético (40)}

ESPECTRO IR $v_{\max }$ (película) $\mathrm{cm}^{-1}$ (fig. 34a): 3600-3100 (ancha), 2970-2870, 1738, 1454, 1379, 1227, 1094, 978, 750, 698.

ESPECTRO RMN ${ }^{1} \mathbf{H}\left(200 \mathrm{MHz}, \mathrm{CDCl}_{3}, \delta\right.$ ppm) (fig. 34b): 7.36-7.30 (5H, m, -Ph), $4.60\left(1 \mathrm{H}, \mathrm{d}, J=12.1 \mathrm{~Hz}, \mathrm{O}-\underline{\mathrm{CH}}_{2}-\mathrm{Ph}, \mathrm{H}_{\mathrm{A}}\right), 4.45\left(1 \mathrm{H}, \mathrm{d}, J=12.1 \mathrm{~Hz}, \mathrm{O}-\underline{\mathrm{CH}}_{2}-\mathrm{Ph}, \mathrm{H}_{\mathrm{B}}\right)$, $3.20(1 \mathrm{H}, \mathrm{m}, \mathrm{H}-3), 2.67\left(1 \mathrm{H}, \mathrm{d}, J=16.0 \mathrm{~Hz}, \mathrm{H}_{\mathrm{A}}-10\right), 2.45\left(1 \mathrm{H}, \mathrm{d}, J=16.0 \mathrm{~Hz}, \mathrm{H}_{\mathrm{B}}-10\right)$, 2.0-1.3 (4H, m, H-4 y H-5), 1.33, 1.32 y 1.31 (3H c/u, s, H-9, H-7 y H-8).

LRMS, EI, m/z (\%) (fig. 34c): 65 (15), 77 (16), 91 (100), 105 (18), 185 (5), 275 (2), $293(4)(\mathrm{M}+\mathrm{H})^{+}$.

HRMS, EI: Calculado para $\mathrm{C}_{17} \mathrm{H}_{25} \mathrm{O}_{4}(M+\mathrm{H})^{+}$, 293.1753. Experimental $(\mathrm{M}+\mathrm{H})^{+}$, 293.1794.

$[\alpha]_{D}^{25}=+27.1^{\circ}\left(\mathrm{c}=1.3, \mathrm{CHCl}_{3}\right)$ 


\section{DESPROTECCIÓN DEL BENCILO DE 40 Y FORMACIÓN DE LA LACTONA}

$\underline{41}$

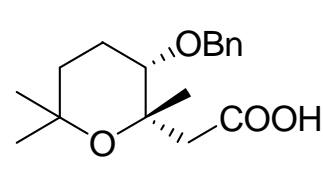

40

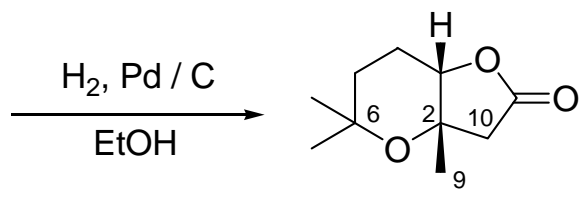

41

Se disuelven $12 \mathrm{mg}$ (0.04 mmoles) de $\mathbf{4 0}$ en $1.5 \mathrm{~mL}$ de EtOH absoluto y se añaden $3 \mathrm{mg}$ de $\mathrm{Pd} / \mathrm{C}$. A continuación se evacúa el oxígeno del sistema y se introduce una atmósfera de hidrógeno, manteniendo la reacción a temperatura ambiente y con buena agitación durante 2 horas. Después se filtra la mezcla por una pequeña cantidad de celita, lavando con AcOEt. Se evapora el disolvente, obteniéndose $9 \mathrm{mg}$ de un crudo que se cromatografía por sílicagel flash (eluyente: hexano/AcOEt 8:2). Se aíslan $5 \mathrm{mg}$ $(66 \%)$ de la lactona 41, cuyas propiedades físicas y espectroscópicas son las siguientes:

$\underline{(3 a S, 7 a S)-3 a, 5,5-T r i m e t i l-h e x a h i d r o-f u r o[3,2-b]-2-p i r a n o n a ~(41) ~}$

ESPECTRO IR $v_{\max }$ (película) $\mathrm{cm}^{-1}$ (fig. 35a): 2980-2870, 1771, 1458, 1370, 1246, $1184,1123,1045,995,976,945,808,743$.

ESPECTRO RMN ${ }^{1} \mathbf{H}\left(200 \mathrm{MHz}, \mathrm{CDCl}_{3}, \delta\right.$ ppm) (fig. 35b): 4.27 (1H, t, $J=3.0 \mathrm{~Hz}, \mathrm{H}-$ 3), $2.61\left(1 \mathrm{H}, \mathrm{d}, J=17.0 \mathrm{~Hz}, \mathrm{H}_{\mathrm{A}}-10\right), 2.46\left(1 \mathrm{H}, \mathrm{d}, J=17.0 \mathrm{~Hz}, \mathrm{H}_{\mathrm{B}}-10\right), 2.2-1.3(4 \mathrm{H}, \mathrm{m}$, H-4 y H-5), 1.45 (3H, s, H-9), 1.24 y 1.18 (3H c/u, s, H-7 y H-8).

ESPECTRO RMN ${ }^{13} \mathbf{C}\left(100 \mathrm{MHz}, \mathrm{CDCl}_{3}, \delta\right.$ ppm) (fig. 35c) (Tabla XIX).

LRMS, EI, m/z (\%) (fig. 35d): 55 (100), 69 (82), 77 (99), 98 (78), 107 (35), 141 (45), $151(11), 169(52), 185(7)(\mathrm{M}+\mathrm{H})^{+}$.

HRMS, EI: Calculado para $\mathrm{C}_{10} \mathrm{H}_{17} \mathrm{O}_{3}(M+\mathrm{H})^{+}$, 185.1178. Experimental $(\mathrm{M}+\mathrm{H})^{+}$, 185.1176

ANÁLISIS ELEMENTAL: Calculado para $\mathrm{C}_{10} \mathrm{H}_{16} \mathrm{O}_{3}: \quad \% \mathrm{C}: 65.19, \quad \% \mathrm{H}: \quad 8.75$; Experimental: \%C: $64.97, \% \mathrm{H}: 8.70$. 


$$
[\alpha]_{D}^{25}=+39.5^{\circ}\left(\mathrm{c}=0.4, \mathrm{CHCl}_{3}\right)
$$

\section{REDUCCIÓN DE 35 CON Bü3}

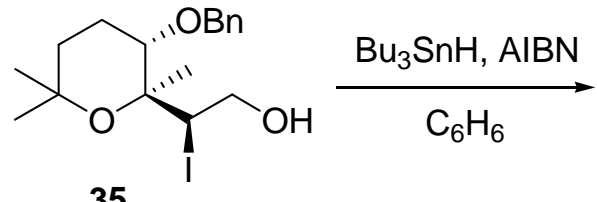

35

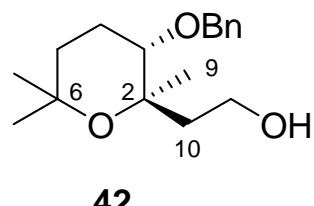

42

Sobre una disolución de 35 ( $29 \mathrm{mg}, 0.07$ mmoles) en $2 \mathrm{~mL}$ de benceno seco se añaden $10 \mathrm{mg}$ de $\mathrm{AIBN}$ y $0.08 \mathrm{~mL}(0.29$ mmoles $)$ de $\mathrm{Bu}_{3} \mathrm{SnH}$. Se calienta la mezcla a ebullición $\left(80^{\circ} \mathrm{C}\right)$ durante una hora. A continuación se añaden $20 \mathrm{mg}$ de ácido oxálico y se agita la reacción durante otros 10 minutos, transcurridos los cuales se diluye la mezcla en AcOEt $(100 \mathrm{~mL})$ y se lava con disoluciones acuosas de $\mathrm{NaHCO}_{3}(5 \%)$ y $\mathrm{NaCl}$ (saturado). Se seca sobre $\mathrm{Na}_{2} \mathrm{SO}_{4}$ anhidro, se filtra y se evapora el disolvente obteniéndose $134 \mathrm{mg}$ de un crudo que se cromatografían en columna sobre sílicagel flash (eluyente: hexano/AcOEt 9/1) aislándose $12 \mathrm{mg}$ (60\%) del alcohol 42 que presenta las siguientes propiedades físicas y espectroscópicas:

\section{$\underline{\left(2^{\prime} R, 3^{\prime} S\right)-2-\left(3^{\prime}-\text { Benciloxi-2', } 6^{\prime}, 6^{\prime} \text {-trimetil-tetrahidro-piran-2'-il)-etanol (42) }\right.}$}

ESPECTRO IR $v_{\max }$ (película) $\mathrm{cm}^{-1}$ (fig. 36a): 3400 (ancha), 2970-2870, 1454, 1366, 1225, 1096, 993, 737, 698.

ESPECTRO RMN ${ }^{1} \mathbf{H}\left(400 \mathrm{MHz}, \mathrm{CDCl}_{3}, \delta\right.$ ppm) (fig. 36b): 7.34-7.30 (5H, m, Ph), $4.65\left(1 \mathrm{H}, \mathrm{d}, J=11.9 \mathrm{~Hz}, \mathrm{O}-\underline{\mathrm{CH}}_{2}-\mathrm{Ph}, \mathrm{H}_{\mathrm{A}}\right), 4.42\left(1 \mathrm{H}, \mathrm{d}, J=11.9 \mathrm{~Hz}, \mathrm{O}-\underline{\mathrm{CH}}_{2}-\mathrm{Ph}, \mathrm{H}_{\mathrm{B}}\right)$, 3.72-3.68 (2H, m, H-11), 3.37 (1H, dd, $J=4.3$ Hz y 11.3 Hz, H-3), 2.0-1.30 (6H, m, H4, H-5 y H-10), 1.33 (3H, s, H-9), 1.28 y 1.18 (3H c/u, s, H-7 y H-8).

ESPECTRO RMN ${ }^{13} \mathbf{C}\left(100 \mathrm{MHz}, \mathrm{CDCl}_{3}, \delta\right.$ ppm) (fig. 36c) (Tabla XV).

HRMS, EI: Calculado para $\mathrm{C}_{17} \mathrm{H}_{27} \mathrm{O}_{3}(M+\mathrm{H})^{+}, 279.1960$. Experimental $(\mathrm{M}+\mathrm{H})^{+}$, 279.1946 . 


$$
[\alpha]_{D}^{25}=+36.2^{\circ}\left(\mathrm{c}=0.5, \mathrm{CHCl}_{3}\right)
$$

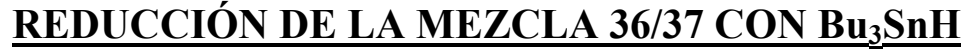

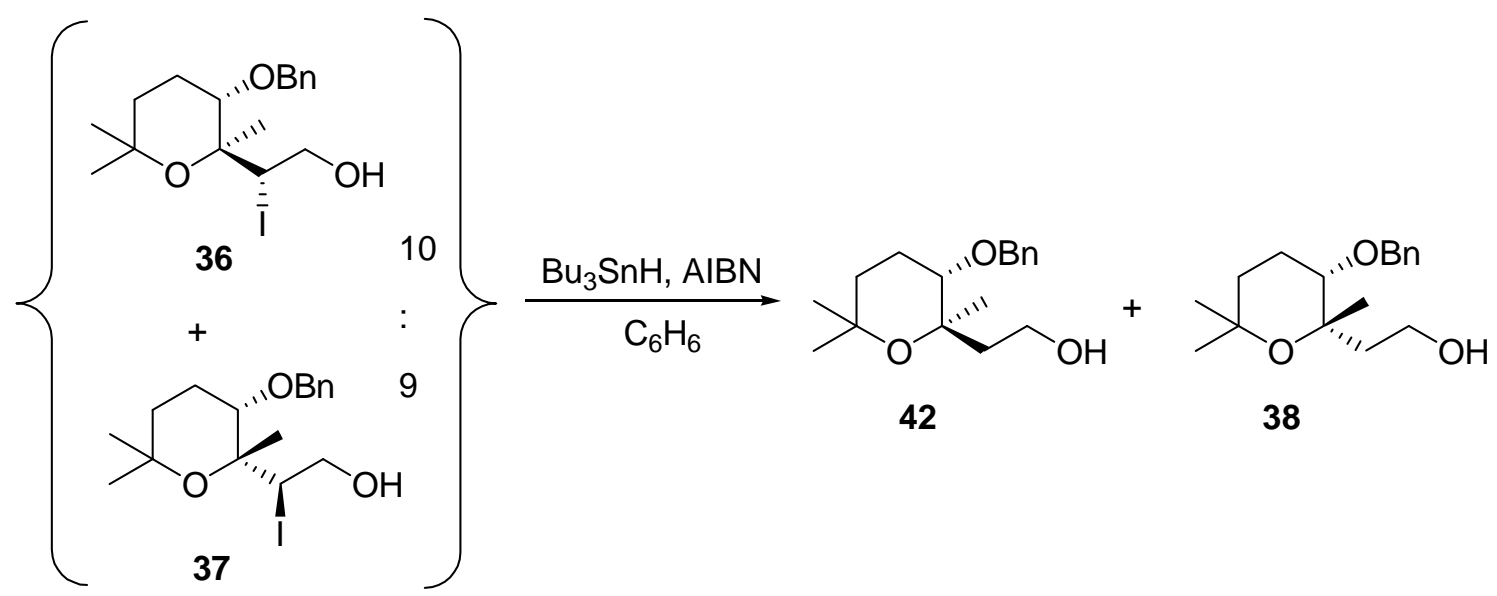

Sobre una disolución de la mezcla de tetrahidropiranos 36 y 37 (11 mg, 0.03 mmoles) en $1 \mathrm{~mL}$ de benceno seco se añaden $10 \mathrm{mg}$ de AIBN y $29 \mu \mathrm{L}(0.11$ mmoles $)$ de $\mathrm{Bu}_{3} \mathrm{SnH}$. Se calienta la mezcla a ebullición $\left(80^{\circ} \mathrm{C}\right)$ durante una hora. A continuación se añaden $20 \mathrm{mg}$ de ácido oxálico y se agita la reacción durante otros 10 minutos, transcurridos los cuales se diluye la mezcla en AcOEt $(150 \mathrm{~mL})$ y se lava con disoluciones acuosas de $\mathrm{NaHCO}_{3}(5 \%)$ y $\mathrm{NaCl}$ (saturado). Se seca sobre $\mathrm{Na}_{2} \mathrm{SO}_{4}$ anhidro, se filtra y se evapora el disolvente obteniéndose $10 \mathrm{mg}$ de un crudo que se cromatografía en columna sobre sílicagel flash (eluyente: hexano/AcOEt 9/1 $\rightarrow 8: 2$ ) aislándose $2 \mathrm{mg}(26 \%)$ del alcohol 42 y $5 \mathrm{mg}(66 \%)$ del alcohol 38, cuyas propiedades físicas y espectroscópicas ya han sido descritas anteriormente. 


\section{$\underline{\text { REACCIÓN DEL NITRILO } 19 \text { CON I }} \underline{2} \underline{\mathrm{Y} \mathrm{NaHCO}_{3}}$}

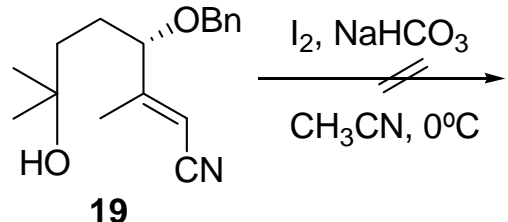

Sobre una disolución de 19 (18 mg, 0.07 mmoles) en $1 \mathrm{~mL}$ de $\mathrm{CH}_{3} \mathrm{CN}$ a $0^{\circ} \mathrm{C}$ se añaden $51 \mathrm{mg}$ (0.20 mmoles) de $\mathrm{I}_{2}$ y $17 \mathrm{mg}(0.20$ mmoles $)$ de $\mathrm{NaHCO}_{3}$. Se mantiene la agitación durante 19 horas dejando calentar progresivamente hasta temperatura ambiente. Al no observar evolución alguna del producto de partida por CCF, se diluye la mezcla con AcOEt $(50 \mathrm{~mL})$ y se lava con disoluciones acuosas de $\mathrm{Na}_{2} \mathrm{~S}_{2} \mathrm{O}_{3}(10 \%)$, $\mathrm{NaHCO}_{3}(5 \%)$ y $\mathrm{NaCl}$ (saturada). Se seca sobre $\mathrm{Na}_{2} \mathrm{SO}_{4}$, se filtra y se evapora el disolvente obteniéndose el material de partida sin reaccionar.

\section{$\underline{\text { REACCIÓN DEL NITRILO } 19 \mathrm{CON}_{2}}$}

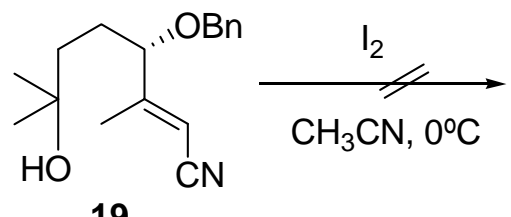

Sobre una disolución de 19 (18 mg, 0.07 mmoles) en $1 \mathrm{~mL}$ de $\mathrm{CH}_{3} \mathrm{CN}$ a $0^{\circ} \mathrm{C}$ se añaden $51 \mathrm{mg}(0.20$ mmoles$)$ de $\mathrm{I}_{2}$. Se mantiene la agitación durante 72 horas dejando calentar progresivamente hasta temperatura ambiente. Durante este tiempo no se observa evolución del producto de partida por CCF, así pues, se diluye la mezcla con AcOEt $(50 \mathrm{~mL})$ y se lava con disoluciones acuosas de $\mathrm{Na}_{2} \mathrm{~S}_{2} \mathrm{O}_{3}(10 \%), \mathrm{NaHCO}_{3}(5 \%)$ y $\mathrm{NaCl}$ (saturada). Se seca sobre $\mathrm{Na}_{2} \mathrm{SO}_{4}$, se filtra y se evapora el disolvente obteniéndose el material de partida en su totalidad sin reaccionar. 


\section{$\underline{\text { REACCIÓN DEL NITRILO } 19 \text { CON IPi }} \underline{B F}_{4}$}

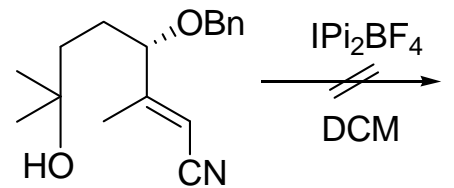

19

Sobre una disolución de 19 (35 mg, 0.13 mmoles) en $1.3 \mathrm{~mL}$ de DCM seco y bajo atmósfera de argon se añaden $52 \mathrm{mg}(0.14$ mmoles $)$ de $\mathrm{IPi}_{2} \mathrm{BF}_{4}$. Se deja agitando a temperatura ambiente durante 20 horas. A no observarse evolución del producto de partida por CCF, se diluye la mezcla con DCM $(50 \mathrm{~mL})$ y se lava con disolución acuosa de $\mathrm{Na}_{2} \mathrm{~S}_{2} \mathrm{O}_{3}(10 \%), \mathrm{H}_{2} \mathrm{O}$ y disolución acuosa saturada de $\mathrm{NaCl}$ (saturada). Se seca sobre $\mathrm{Na}_{2} \mathrm{SO}_{4}$, se filtra y se evapora el disolvente obteniéndose el material de partida en su totalidad sin reaccionar.

\section{REACCIÓN DEL NITRILO 19 CON NaH}

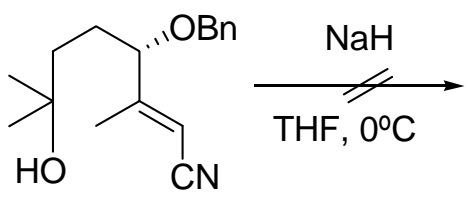

19

Sobre una suspensión de $\mathrm{NaH}(2.4 \mathrm{mg}, 0.10$ mmoles, $60 \%$ en parafina $\mathrm{y}$ previamente lavado con dos porciones de THF de $1 \mathrm{~mL}$ ) en $0.3 \mathrm{~mL}$ de THF se añaden a $0^{\circ} \mathrm{C} 18 \mathrm{mg}$ ( 0.07 mmoles) de 19 disueltos en $0.5 \mathrm{~mL}$ de THF, bajo atmósfera de argon. Se mantiene la agitación durante 17 horas dejando calentar progresivamente hasta temperatura ambiente. Al no observar evolución alguna del producto de partida por $\mathrm{CCF}$, se para la reacción añadiendo $1 \mathrm{~mL}$ de THF húmedo a $0^{\circ} \mathrm{C}$. Se deja agitando durante 15 minutos y se extrae con éter. Las fases orgánicas combinadas se lavan con una disolución acuosa de $\mathrm{NaCl}$ (saturada). Se seca sobre $\mathrm{Na}_{2} \mathrm{SO}_{4}$ anhidro, se filtra y se evapora el disolvente obteniéndose el producto de partida sin reaccionar. 


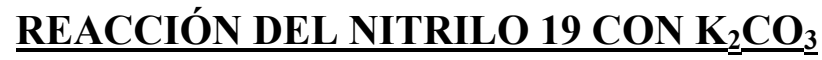

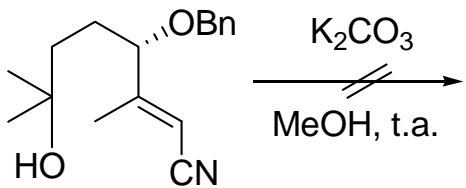

19

Sobre una disolución de 19 (18 mg, 0.07 mmoles) en $1 \mathrm{~mL}$ de $\mathrm{MeOH}$ se añaden $100 \mathrm{mg}$ de $\mathrm{K}_{2} \mathrm{CO}_{3}$ y se deja agitando a temperatura ambiente durante 48 horas. Pasado este tiempo se para la reacción añadiendo $\mathrm{HCl} 2 \mathrm{M}$ hasta alcanzar $\mathrm{pH}$ neutro. Seguidamente se extrae con AcOEt y las fases orgánicas combinadas se lavan con una disolución acuosa de $\mathrm{NaCl}$ (saturada). Se seca sobre $\mathrm{Na}_{2} \mathrm{SO}_{4}$ anhidro, se filtra y se evapora el disolvente obteniéndose el producto de partida sin reaccionar.

\section{REACCIÓN DEL NITRILO $20 \mathrm{CON}_{2} \underline{\mathrm{Y} \mathrm{NaHCO}}_{3}$}

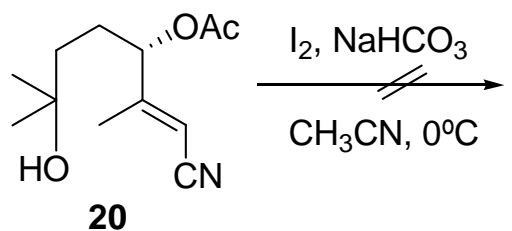

Sobre una disolución de 20 (18 mg, 0.08 mmoles) en $1 \mathrm{~mL}$ de $\mathrm{CH}_{3} \mathrm{CN}$ a $0^{\circ} \mathrm{C}$ se añaden $60 \mathrm{mg}$ (0.24 mmoles) de $\mathrm{I}_{2}$ y $20 \mathrm{mg}(0.24$ mmoles $)$ de $\mathrm{NaHCO}_{3}$. Se mantiene la agitación durante 48 horas dejando calentar progresivamente hasta temperatura ambiente. Al no observar evolución alguna del producto de partida por $\mathrm{CCF}$, se diluye la mezcla con AcOEt (50 mL) y se lava con disoluciones acuosas de $\mathrm{Na}_{2} \mathrm{~S}_{2} \mathrm{O}_{3}(10 \%)$, $\mathrm{NaHCO}_{3}(5 \%)$ y $\mathrm{NaCl}$ (saturada). Se seca sobre $\mathrm{Na}_{2} \mathrm{SO}_{4}$, se filtra y se evapora el disolvente obteniéndose el material de partida sin reaccionar. 


\section{YODOCICLACIÓN DEL ALDEHÍDO 21}

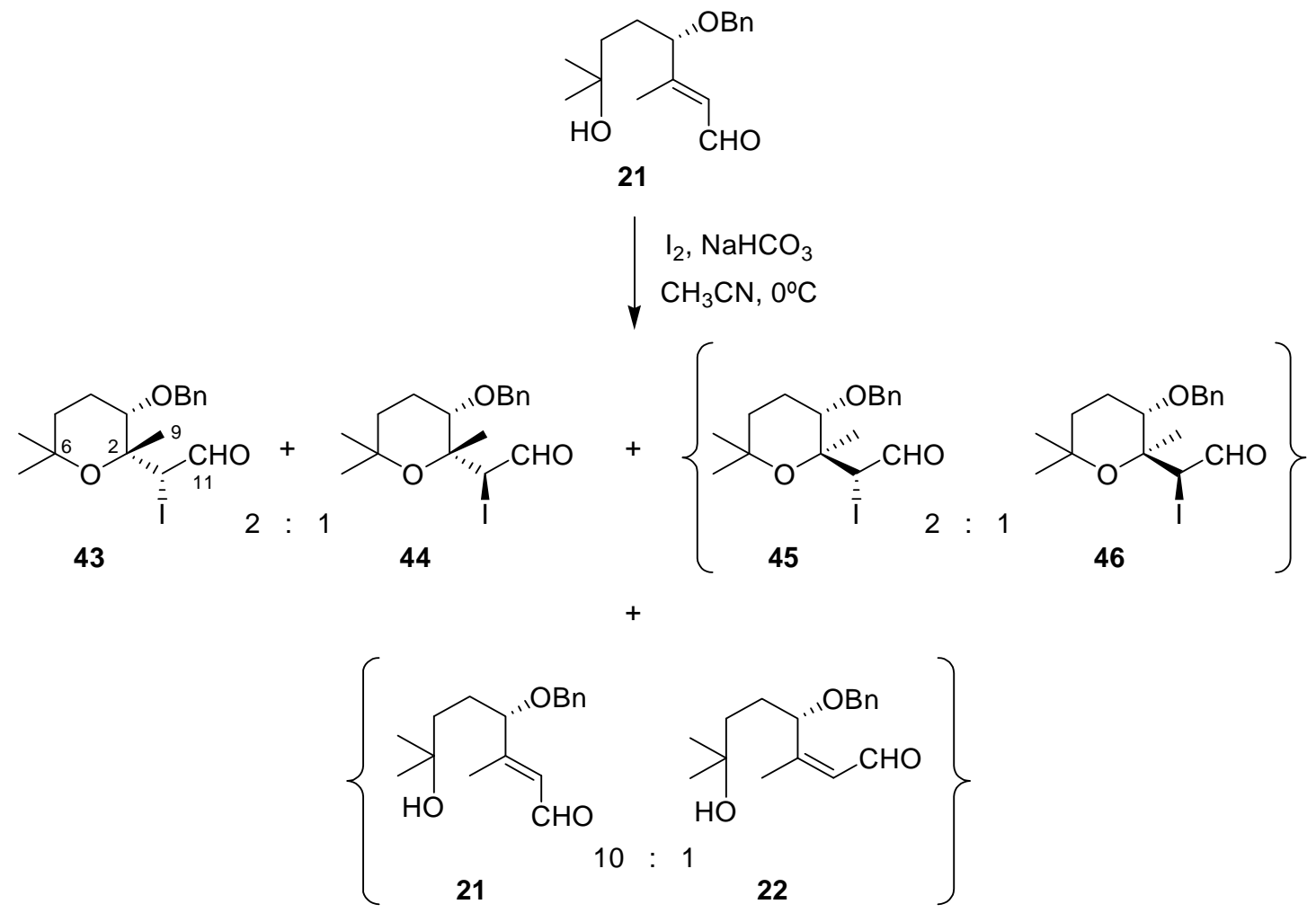

Se disuelven $48 \mathrm{mg}(0.17$ mmoles $)$ de 21 en $1.7 \mathrm{~mL}$ de $\mathrm{CH}_{3} \mathrm{CN}$ y se añaden 132 mg (0.52 mmoles) de $\mathrm{I}_{2}$ resublimado y $44 \mathrm{mg}(0.52 \mathrm{mmoles})$ de $\mathrm{NaHCO}_{3}$ a $0^{\circ} \mathrm{C}$. Se mantiene la agitación durante 5 horas dejando calentar progresivamente hasta temperatura ambiente. Pasado este tiempo se diluye la mezcla con AcOEt (200 mL) y se lava con disoluciones acuosas de $\mathrm{Na}_{2} \mathrm{~S}_{2} \mathrm{O}_{3}(10 \%), \mathrm{NaHCO}_{3}(5 \%)$ y $\mathrm{NaCl}$ (saturada). Se seca sobre $\mathrm{Na}_{2} \mathrm{SO}_{4}$, se filtra y se evapora el disolvente para obtener $60 \mathrm{mg}$ de crudo que se cromatografían en columna sobre sílicagel flash (eluyente: hexano/AcOEt 98:2). Se aíslan $27 \mathrm{mg}$ de una mezcla de los tetrahidropiranos 45 y 46 en una proporción 2:1, 6 $\mathrm{mg}$ de una mezcla de dichos tetrahidropiranos y de 44, $3 \mathrm{mg}$ del tetrahidropirano $44 \mathrm{y}$ $10 \mathrm{mg}$ del tetrahidropirano 43 (como un sólido cristalino), con un rendimiento global del 66\%. Asimismo, se separaron $11 \mathrm{mg}(23 \%)$ de una mezcla del aldehído de partida 21 y de su isómero 22 en una proporción 10:1. Las propiedades físicas y espectroscópicas de estos compuestos se muestran a continuación: 
$\underline{\left(2 R, 2^{\prime} R, 3^{\prime} S\right)-\left(3^{\prime} \text {-Benciloxi-2',6', } 6^{\prime} \text {-trimetil-tetrahidro-piran-2'-il)-yodo- }\right.}$ acetaldehído (43)

ESPECTRO IR $v_{\max }$ (película) $\mathrm{cm}^{-1}$ (fig. 37a): 3065, 3032, 2970-2870, 2731, 1705, $1454,1373,1225,1115,1071,1028,974,750,698$.

ESPECTRO RMN ${ }^{1} \mathbf{H}\left(400 \mathrm{MHz}, \mathrm{CDCl}_{3}, \delta\right.$ ppm) (fig. 37b): $9.27(1 \mathrm{H}, \mathrm{d}, J=5.7 \mathrm{~Hz}$, $\mathrm{H}-11), 7.36-7.30$ (5H, m, Ph), $4.54(1 \mathrm{H}, \mathrm{d}, J=5.7 \mathrm{~Hz}, \mathrm{H}-10), 4.47$ (1H, d, $J=11.6 \mathrm{~Hz}$, $\left.\mathrm{O}-\underline{\mathrm{CH}}_{2}-\mathrm{Ph}, \mathrm{H}_{\mathrm{A}}\right), 4.43\left(1 \mathrm{H}, \mathrm{d}, J=11.6 \mathrm{~Hz}, \mathrm{O}-\underline{\mathrm{CH}}_{2}-\mathrm{Ph}, \mathrm{H}_{\mathrm{B}}\right), 3.36(1 \mathrm{H}, \mathrm{t}, J=2.1 \mathrm{~Hz}, \mathrm{H}-3)$, 1.95-1.80 (3H, m, H-4 y H-5), 1.44 (3H, s, H-9), 1.30-1.20 (1H, m, H-5), 1.22 у 1.21 $(3 \mathrm{H}, \mathrm{c} / \mathrm{u}, \mathrm{s}, \mathrm{H}-7$ y H-8).

ESPECTRO RMN ${ }^{13} \mathbf{C}\left(100 \mathrm{MHz}, \mathrm{CDCl}_{3}, \delta\right.$ ppm) (fig. 37c) (Tabla XVIII).

LRMS, FAB ${ }^{+}$, m/z (\%) (fig. 37d): 69 (15), 91 (100), 154 (16), 295 (20), 403 (3) (M + $\mathrm{H})^{+}$.

HRMS, FAB ${ }^{+}$: Calculado para $\mathrm{C}_{17} \mathrm{H}_{24} \mathrm{O}_{3} \mathrm{I}(M+\mathrm{H})^{+}$, 403.0770. Experimental $(\mathrm{M}+\mathrm{H})^{+}$, 403.0753.

$[\alpha]_{D}^{25}=-84.5^{\circ}\left(\mathrm{c}=0.7, \mathrm{CHCl}_{3}\right)$

P.F. : $70-72{ }^{\circ} \mathrm{C}$ (Recristalizado en AcOEt-hexano)

$\underline{\left(2 S, 2^{\prime} R, 3^{\prime} S\right)-\left(3^{\prime} \text {-Benciloxi-2',6', } 6^{\prime} \text {-trimetil-tetrahidro-piran-2'-il)-yodo- }\right.}$ acetaldehído (44)

ESPECTRO IR $v_{\max }$ (película) $\mathrm{cm}^{-1}$ (fig. 38a): 3065, 3032, 2970-2870, 2731, 1713, 1454, 1373, 1223, 1098, 976, 737, 698.

ESPECTRO RMN ${ }^{1} \mathbf{H}\left(400 \mathrm{MHz}, \mathrm{CDCl}_{3}, \delta\right.$ ppm) (fig. 38b): $9.20(1 \mathrm{H}, \mathrm{d}, J=3.7 \mathrm{~Hz}$, H-11), 7.35-7.30 (5H, m, Ph), 4.75 (1H, d, J=3.7 Hz, H-10), $4.53(1 \mathrm{H}, \mathrm{d}, J=11.2 \mathrm{~Hz}$, $\left.\mathrm{O}-\underline{\mathrm{CH}}_{2}-\mathrm{Ph}, \mathrm{H}_{\mathrm{A}}\right), 4.42\left(1 \mathrm{H}, \mathrm{d}, J=11.2 \mathrm{~Hz}, \mathrm{O}-\underline{\mathrm{CH}}_{2}-\mathrm{Ph}, \mathrm{H}_{\mathrm{B}}\right), 3.63(1 \mathrm{H}, \mathrm{t}, J=4.2 \mathrm{~Hz}, \mathrm{H}-3)$, 1.90-1.30 (4H, m, H-4 y H-5), 1.47 (3H, s, H-9), 1.27 y 1.24 (3H, c/u, s, H-7 y H-8).

ESPECTRO RMN ${ }^{13} \mathbf{C}\left(100 \mathrm{MHz}, \mathrm{CDCl}_{3}, \delta \mathrm{ppm}\right)$ (fig. 38c) (Tabla XVIII).

LRMS, FAB ${ }^{+}, \mathrm{m} / \mathrm{z}$ (\%) (fig. 38d): 69 (31), 91 (100), 137 (8), 233 (8), 295 (12), 403 (1) $(\mathrm{M}+\mathrm{H})^{+}$. 
$[\alpha]_{D}^{25}=+35.5^{\circ}\left(\mathrm{c}=0.4, \mathrm{CHCl}_{3}\right)$

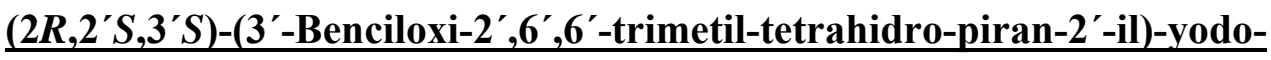
acetaldehído (45) y (2S,2'S,3'S)-(3'-Benciloxi-2', $6^{\prime}, 6^{\prime}$-trimetil-tetrahidro-piran-2'il)-yodo-acetaldehído (46)

ESPECTRO RMN ${ }^{1} \mathbf{H}\left(400 \mathrm{MHz}, \mathrm{CDCl}_{3}, \delta\right.$ ppm) (fig. 39): $9.33(1 \mathrm{H}, \mathrm{d}, J=7.0 \mathrm{~Hz}, \mathrm{H}-$ 11), 7.37-7.27 (5H, m, Ph), $4.62\left(1 \mathrm{H}, \mathrm{d}, J=11.4 \mathrm{~Hz}, \mathrm{O}-\mathrm{CH}_{2}-\mathrm{Ph}, \mathrm{H}_{\mathrm{A}}\right), 4.44(1 \mathrm{H}, \mathrm{d}, J=$ $\left.11.4 \mathrm{~Hz}, \mathrm{O}-\mathrm{CH}_{2}-\mathrm{Ph}, \mathrm{H}_{\mathrm{B}}\right), 4.53(1 \mathrm{H}, \mathrm{d}, J=7.0 \mathrm{~Hz}, \mathrm{H}-10), 3.60-3.55$ (1H, m, H-3), 2.001.50 (4H, m, H-4 y H-5), 1.46 (3H, s, H-9), 1.31 y 1.29 (3H c/u, s, H-7 y H-8).

\section{OXIDACIÓN DE 36 CON TPAP}<smiles>CC1(C)CC[C@@H](Br)[C@](C)(C(I)CO)O1</smiles>

36

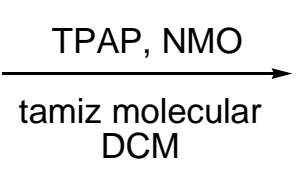

DCM<smiles>CC1(C)CC[C@@H](OBr)[C@](C)(C(I)C=O)O1</smiles>

44

Sobre una disolución agitada de 36 (9 $\mathrm{mg}, 0.02 \mathrm{mmoles})$ en $0.3 \mathrm{~mL}$ de DCM se añade tamiz molecular ( $3 \AA$, activado), NMO (9 mg, 0.07 mmoles) y una cantidad catalítica de TPAP. Tras agitar la mezcla de reacción a temperatura ambiente durante una hora, se filtra por sílice, lavando abundantemente con DCM, para obtener $7 \mathrm{mg}$ (79\%) del aldehído 44, cuyas propiedades físicas y espectroscópicas ya han sido descritas. 


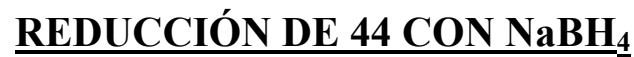

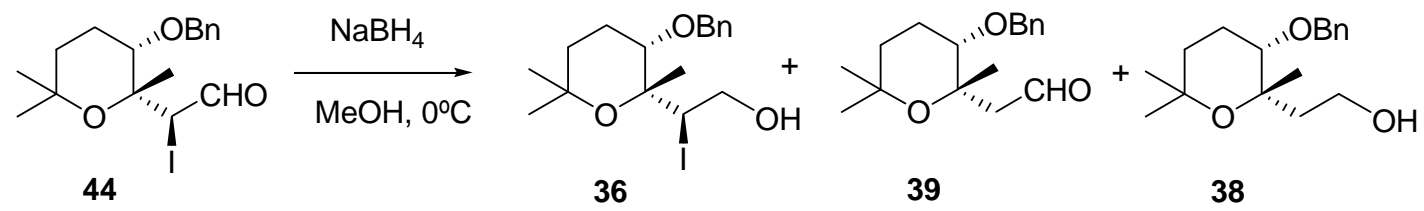

Se disuelven $6 \mathrm{mg}$ (0.015 mmoles) de 44 en $0.3 \mathrm{~mL}$ de $\mathrm{MeOH}$ seco bajo atmósfera de argon. Se añaden con agitación $0.7 \mathrm{mg}(0.018 \mathrm{mmoles}) \mathrm{de} \mathrm{NaBH}_{4}$ a $0^{\circ} \mathrm{C}$ y se deja calentar lentamente hasta temperatura ambiente durante 30 minutos. Pasado este tiempo se evapora el $\mathrm{MeOH}$, se diluye con agua, se extrae varias veces con AcOEt y el combinado de fases orgánicas se lava sucesivamente con agua y una disolución acuosa de $\mathrm{NaCl}$ (saturada). Se seca sobre $\mathrm{Na}_{2} \mathrm{SO}_{4}$, se filtra y se evapora el disolvente. Se obtienen $7 \mathrm{mg}$ de crudo que se cromatografían en columna sobre sílicagel flash (eluyente: hexano/AcOEt 95:5 $\rightarrow$ 8:2), aislándose $1 \mathrm{mg}(25 \%)$ de 39, $1 \mathrm{mg}(24 \%)$ de 38 y trazas de 36. Las propiedades físicas y espectroscópicas de estos compuestos ya han sido descritas anteriormente.

\section{REDUCCIÓN DE 43 CON Bu 33 SnH}<smiles>CC1(C)CC[C@@H](Br)[C@](C(I)C=O)(C(I)CBr)O1</smiles>

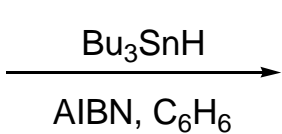

AIBN, $\mathrm{C}_{6} \mathrm{H}_{6}$<smiles>CC1(C)CC[C@@H](OBr)[C@](C)(CC=O)O1</smiles>

39

Sobre una disolución de $\mathbf{4 3}$ (5 mg, 0.012 mmoles) en $1 \mathrm{~mL}$ de benceno seco se añaden $3 \mathrm{mg}$ de AIBN y $0.02 \mathrm{~mL}(0.074$ mmoles $)$ de $\mathrm{Bu}_{3} \mathrm{SnH}$. Se calienta la mezcla a ebullición $\left(80^{\circ} \mathrm{C}\right)$ durante 1 hora. A continuación se añaden $5 \mathrm{mg}$ de ácido oxálico y se agita la reacción durante otros 10 minutos, transcurridos los cuales se diluye la mezcla en AcOEt (100 mL) y se lava con disoluciones acuosas de $\mathrm{NaHCO}_{3}(5 \%)$ y $\mathrm{NaCl}$ (saturado). Se seca sobre $\mathrm{Na}_{2} \mathrm{SO}_{4}$ anhidro, se filtra y se evapora el disolvente obteniéndose $86 \mathrm{mg}$ de un crudo que se cromatografían sobre sílicagel flash 
(eluyente: hexano/AcOEt 95/5), aislándose $3 \mathrm{mg}$ (87\%) del aldehído 39, cuyas propiedades físicas y espectroscópicas ya han sido descritas anteriormente.

\section{$\underline{\text { REDUCCIÓN DEL ALDEHÍDO } 43 \text { CON NaBH }} 4$}<smiles>CC1(C)CC[C@@H](OBr)[C@](C)(C(I)C=O)O1</smiles>

43<smiles>CCOC(=O)C1(C)CC[C@@H](OBr)[C@](C)([C@H](I)CO)O1</smiles>

34<smiles>CC1(C)CC[C@@H](Br)[C@](C)(CCO)O1</smiles>

38

Se disuelven $25 \mathrm{mg}$ (0.062 mmoles) de 43 en $1 \mathrm{~mL}$ de EtOH absoluto bajo atmósfera de argon. Se añaden con agitación $3 \mathrm{mg}(0.075 \mathrm{mmoles}) \mathrm{de} \mathrm{NaBH}_{4}$ a $0^{\circ} \mathrm{C}$ y se deja reaccionando permitiendo que suba la temperatura lentamente hasta temperatura ambiente durante 20 horas. Pasado este tiempo se evapora el EtOH, se diluye con agua, se extrae varias veces con AcOEt y el combinado de fases orgánicas se lava sucesivamente con agua y una disolución acuosa de $\mathrm{NaCl}$ (saturada). Se seca sobre $\mathrm{Na}_{2} \mathrm{SO}_{4}$, se filtra y se evapora el disolvente. Se obtienen $23 \mathrm{mg}$ de crudo que se cromatografían en columna sobre sílicagel flash (eluyente: hexano/AcOEt 8:2), aislándose $5 \mathrm{mg}(20 \%)$ de 34 y $9 \mathrm{mg}(52 \%)$ de 38 . Las propiedades físicas y espectroscópicas de estos compuestos ya han sido descritas anteriormente. 


\section{REDUCCIÓN DE LA MEZCLA DE ALDEHÍDOS 45/46 CON NaBH${ }_{4}$}
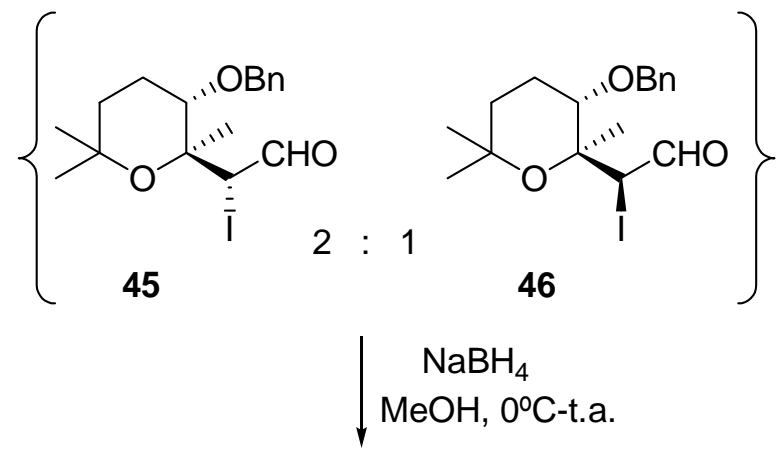<smiles>CC1(C)CC[C@@H](Br)[C@](C)(C(I)CO)O1</smiles>

37

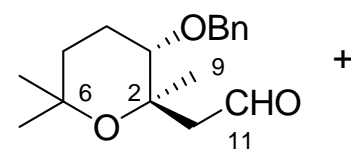

47<smiles>CC1(C)CC[C@@H](Br)[C@](C)(CCO)O1</smiles>

42

Se disuelven $27 \mathrm{mg}$ (0.07 mmoles) de la mezcla 45/46 en $1 \mathrm{~mL}$ de $\mathrm{MeOH}$ seco bajo atmósfera de argon. Se añaden $3.0 \mathrm{mg}(0.08$ mmoles $)$ de $\mathrm{NaBH}_{4}$ a $0^{\circ} \mathrm{C}$ y se deja reaccionando con buena agitación permitiendo que suba la temperatura lentamente hasta temperatura ambiente durante 1 hora. Pasado este tiempo se evapora el $\mathrm{MeOH}$, se diluye con agua, se extrae varias veces con AcOEt y el combinado de fases orgánicas se lava sucesivamente con agua y una disolución acuosa de $\mathrm{NaCl}$ (saturada). Se seca sobre $\mathrm{Na}_{2} \mathrm{SO}_{4}$, se filtra y se evapora el disolvente. Se obtienen $20 \mathrm{mg}$ de crudo que se cromatografían en columna sobre sílicagel flash (eluyente: hexano/AcOEt 95:5 8:2), aislándose $2 \mathrm{mg}$ (11\%) de 47, $5 \mathrm{mg}$ (20\%) de 37 y $7 \mathrm{mg}$ (40\%) de 42. Las propiedades espectroscópicas de $\mathbf{3 7}$ y $\mathbf{4 2}$ ya han sido descritas anteriormente y las del aldehído $\mathbf{4 7}$ son las que se indican a continuación:

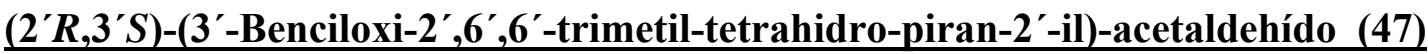

ESPECTRO RMN ${ }^{1} \mathbf{H}\left(200 \mathrm{MHz}, \mathrm{CDCl}_{3}, \delta \mathrm{ppm}\right)($ fig. 40$): 9.75(1 \mathrm{H}, \mathrm{t}, J=3.0 \mathrm{~Hz}, \mathrm{H}-$ 11), 7.30 (5H, m, Ph), $4.60\left(1 \mathrm{H}, \mathrm{d}, J=11.8 \mathrm{~Hz}, \mathrm{O}-\underline{\mathrm{CH}}_{2}-\mathrm{Ph}, \mathrm{H}_{\mathrm{A}}\right), 4.38(1 \mathrm{H}, \mathrm{d}, J=11.8$ $\left.\mathrm{Hz}, \mathrm{O}-\underline{\mathrm{CH}}_{2}-\mathrm{Ph}, \mathrm{H}_{\mathrm{B}}\right), 3.29(1 \mathrm{H}, \mathrm{dd}, J=4.2 \mathrm{~Hz}$ y $10.4 \mathrm{~Hz}, \mathrm{H}-3), 2.46(1 \mathrm{H}, \mathrm{d}, J=3.0 \mathrm{~Hz}$, $\left.\mathrm{H}_{\mathrm{A}}-10\right), 2.0-1.30$ (5H, m, H-4, H-5 y $\left.\mathrm{H}_{\mathrm{B}}-10\right), 1.35,1.25$ y 1.13 (3H c/u, s, H-7, H-8 у H9). 


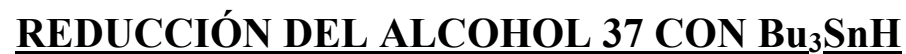<smiles>CC1(C)CC[C@@H](OBr)[C@H](CO)[C@H]1I</smiles>

37

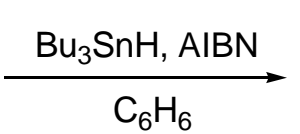

42

Se disuelven $7 \mathrm{mg}$ (0.017 mmoles) de 37 en $1 \mathrm{~mL}$ de benceno seco y se añaden $19 \mu \mathrm{L}(0.07$ mmoles $)$ de $\mathrm{Bu}_{3} \mathrm{SnH}$ y una cantidad catalítica de AIBN. Se calienta la mezcla a ebullición $\left(80^{\circ} \mathrm{C}\right)$ durante 2 horas. A continuación se añaden $5 \mathrm{mg}$ de ácido oxálico y se agita la reacción durante otros 10 minutos, transcurridos los cuales se diluye la mezcla en AcOEt (100 mL) y se lava éste con disoluciones acuosas de $\mathrm{NaHCO}_{3}(5 \%)$ y $\mathrm{NaCl}$ (saturado). Se seca sobre $\mathrm{Na}_{2} \mathrm{SO}_{4}$ anhidro, se filtra y se evapora el disolvente obteniéndose un crudo que se cromatografía sobre sílicagel flash (eluyente: hexano/AcOEt 9/1) aislándose $3 \mathrm{mg}$ (63\%) del alcohol 42 cuyas propiedades físicas y espectroscópicas ya han sido descritas con anterioridad. 


\section{REDUCCIÓN DEL NITRILO 18 CON DIBAL-H}

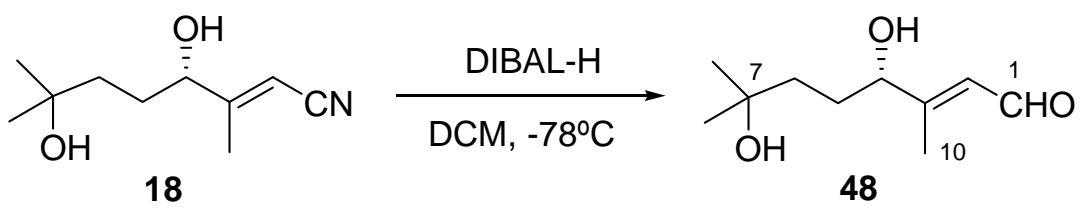

Se disuelve 18 (150 mg, 0.81 mmoles) en $9 \mathrm{~mL}$ de DCM seco, se baja la temperatura a $-78^{\circ} \mathrm{C}$ y se pone bajo atmósfera de argon. Entonces se añaden $2.5 \mathrm{~mL}$ de una disolución 1.5 M de DIBAL-H en tolueno y se deja reaccionar a esa temperatura durante una hora. Pasado este tiempo se añade la mezcla de reacción sobre $30 \mathrm{~mL}$ de una disolución acuosa saturada de $\mathrm{NH}_{4} \mathrm{Cl}$ y se deja agitando a temperatura ambiente durante 10 minutos. A continuación se extrae varias veces con AcOEt. Las fases orgánicas combinadas se lavan con una disolución acuosa de $\mathrm{NaCl}$ (saturada) y se secan sobre $\mathrm{Na}_{2} \mathrm{SO}_{4}$ anhidro. Se filtra y se evapora el disolvente para obtener $90 \mathrm{mg}$ de crudo que se cromatografían en columna sobre sílicagel flash (eluyente: hexano/AcOEt $7: 3 \rightarrow 6: 4)$, recuperándose $25 \mathrm{mg}(17 \%)$ de producto de partida y aislándose $23 \mathrm{mg}$ (15\%) del aldehído 48, cuyas propiedades físicas y espectroscópicas se muestran a continuación:

\section{(4S)-4,7-Dihidroxi-3,7-dimetil-oct-E-2-enal (48)}

ESPECTRO IR $v_{\max }$ (película) $\mathrm{cm}^{-1}$ (fig. 41a): 3389, 2969, 2918, 2849, 1664, 1383.

ESPECTRO RMN ${ }^{1} \mathbf{H}\left(200 \mathrm{MHz}, \mathrm{CDCl}_{3}, \delta\right.$ ppm) (fig. 4lb): $10.07(1 \mathrm{H}, \mathrm{d}, J=7.8 \mathrm{~Hz}$, H-1), 6.15 (1H, d, J = 7.8 Hz, H-2), 4.18 (1H, m, H-4), 2.16 (3H, s, H-10), 1.86-1.55 (4H, m, H-5 y H-6), 1.26 (6H, s, H-8 y H-9).

ESPECTRO RMN ${ }^{13} \mathbf{C}\left(50 \mathrm{MHz}, \mathrm{CDCl}_{3}, \delta\right.$ ppm) (fig. 41c) (Tabla XX).

$[\alpha]_{D}^{25}=+3.7^{\circ}\left(\mathrm{c}=0.4, \mathrm{CHCl}_{3}\right)$ 


\section{REDUCCIÓN DEL ALDEHIDO 48 CON DIBAL-H}<smiles>CC(=CC=O)[C@@H](O)CCC(C)(C)O</smiles>

Se disuelve 48 (17 mg, 0.09 mmoles) en $1.5 \mathrm{~mL}$ de DCM seco bajo atmósfera de argon, se baja la temperatura a $-78^{\circ} \mathrm{C}$ y se añaden con buena agitación $2.5 \mathrm{~mL}$ de una disolución 1.5 M de DIBAL-H en tolueno. Se deja reaccionar a esa temperatura durante una hora y luego se deja calentar lentamente hasta temperatura ambiente. A continuación se para la reacción añadiendo una gota de $\mathrm{HCl} 2 \mathrm{M}$. Se añaden $10 \mathrm{~mL}$ de DCM, $0.5 \mathrm{~g}$ de $\mathrm{NaHCO}_{3}$ y $0.5 \mathrm{~g}$ de $\mathrm{Na}_{2} \mathrm{SO}_{4}$ anhidro a la mezcla de reacción y se deja agitando durante 2 horas, transcurridas las cuales se filtra por celita. El crudo obtenido se cromatografía en columna sobre sílicagel (eluyente: $\mathrm{CHCl}_{3} / \mathrm{MeOH}$ 95:5), pudiéndose aislar únicamente $3 \mathrm{mg}(18 \%)$ de 49 , cuyas propiedades físicas y espectroscópicas se muestran a continuación:

\section{(4S)-3,7-Dimetil-oct-E-2-en-1,4,7-triol, ent-Sachalinol A (49)}

ESPECTRO IR $v_{\max }$ (película) $\mathrm{cm}^{-1}$ (fig. 42a): 3348 (ancha), 2964, 2866, 1375, 1310, $1211,1156,1058,1003,904$.

ESPECTRO RMN ${ }^{1} \mathbf{H}\left(200 \mathrm{MHz}, \mathrm{CD}_{3} \mathrm{OD}, \delta\right.$ ppm) (fig. $\left.42 \mathrm{~b}\right): 5.54(1 \mathrm{H}, \mathrm{t}, J=6.2 \mathrm{~Hz}$, H-2), 4.13 (2H, d, J=6.2 Hz, H-1), 3.91 (1H, t, $J=6.6 \mathrm{~Hz}, \mathrm{H}-4), 1.64$ (3H, s, H-10), 1.58-1.41 (4H, m, H-5 y H-6), 1.17 (6H, s, H-8 y H-9).

ESPECTRO RMN ${ }^{13} \mathbf{C}\left(50 \mathrm{MHz}, \mathrm{CD}_{3} \mathrm{OD}, \delta\right.$ ppm) (fig. 42c) (Tabla XX).

HRMS, ESI (fig. 42d): Calculado para $\mathrm{C}_{10} \mathrm{H}_{20} \mathrm{O}_{3} \mathrm{Na}(M+\mathrm{Na})^{+}$, 211.1304. Experimental $(\mathrm{M}+\mathrm{Na})^{+}, 211.1298$.

$[\alpha]_{D}^{25}=-1.2^{\circ}(\mathrm{c}=1.0, \mathrm{MeOH})$ 


\section{PROTECCIÓN DE 18 CON TBDMSOTf}<smiles>CC(=CC#N)[C@@H](O)CCC(C)(C)O</smiles>

18

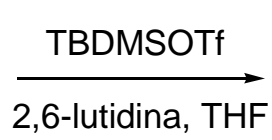

2,6-lutidina, THF

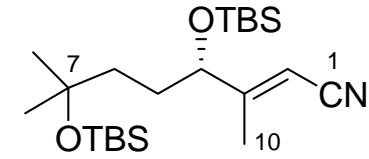

50

Sobre una disolución de $\mathbf{1 8}(47 \mathrm{mg}, 0.26 \mathrm{mmoles})$ en $\mathrm{THF}$ seco a $0^{\circ} \mathrm{C}$, se añade 2,6-lutidina (90 $\mu \mathrm{L}, 0.77$ mmoles), TBDMSOTf (176 $\mu \mathrm{L}, 0.77$ mmoles) y se deja reaccionando a esa temperatura durante dos horas. Pasado este tiempo, la reacción se para añadiendo una disolución saturada de $\mathrm{NaHCO}_{3}$ hasta alcanzar $\mathrm{pH}$ neutro y seguidamente se extrae con AcOEt (x3). Las fases orgánicas combinadas se lavan con una disolución acuosa saturada de $\mathrm{NaCl}$. Se seca sobre $\mathrm{Na}_{2} \mathrm{SO}_{4}$ anhidro, se filtra y se evapora el disolvente para obtener $200 \mathrm{mg}$ de crudo que se cromatografían en columna sobre sílicagel flash (eluyente: hexano/AcOEt 95:5), aislándose $86 \mathrm{mg}$ (85\%) del compuesto diprotegido 50, cuyas propiedades físicas y espectroscópicas son las siguientes:

\section{$\underline{(4 S)-4,7-B i s(t e r c-b u t i l-d i m e t i l-s i l a n i l o x i)-3,7-d i m e t i l-o c t-E-2-e n-n i t r i l o ~(50) ~}$}

ESPECTRO IR $v_{\max }$ (película) $\mathrm{cm}^{-1}$ (fig. 43a): 2956, 2930, 2887, 2858, 2220, 1640, $1463,1382,1364,1254,1218,1150,1103,938$.

ESPECTRO RMN ${ }^{1} \mathbf{H}\left(200 \mathrm{MHz}, \mathrm{CDCl}_{3}, \delta\right.$ ppm) (fig. 43b): 5.43 (1H, s, H-2), 4.13 $(1 \mathrm{H}, \mathrm{t}, J=5.2 \mathrm{~Hz}, \mathrm{H}-4), 1.98$ (3H, s, H-10), 1.70-1.30 (4H, m, H-5 y H-6), 1.17 (6H, s, H-8 y H-9), 0.89 y 0.84 (9H c/u, s, $\left.{ }^{t} \underline{B u M e}_{2} \mathrm{Si}\right), 0.053$ (6H, s, $\left.{ }^{t} \mathrm{BuMe} 2{ }_{2} \mathrm{Si}\right), 0.009$ y -0.002 $\left(3 \mathrm{H} \mathrm{c} / \mathrm{u}, \mathrm{s},{ }^{t} \mathrm{BuMe}{ }_{2} \mathrm{Si}\right)$.

ESPECTRO RMN ${ }^{13} \mathbf{C}\left(50 \mathrm{MHz}, \mathrm{CDCl}_{3}, \delta\right.$ ppm) (fig. 43c) (Tabla XXI).

HRMS, ESI (fig. 43d): Calculado para $\mathrm{C}_{22} \mathrm{H}_{45} \mathrm{NO}_{2} \mathrm{NaSi}_{2}(M+\mathrm{Na})^{+}, 434.2881$. Experimental $(\mathrm{M}+\mathrm{Na})^{+}, 434.2901$.

$[\alpha]_{D}^{25}=-5.7^{\circ}\left(\mathrm{c}=1.6, \mathrm{CHCl}_{3}\right)$ 


\section{REDUCCIÓN DE 50 CON DIBAL-H}

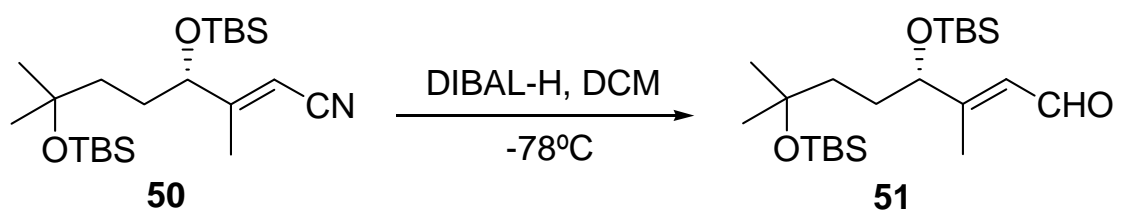

Se disuelven $85 \mathrm{mg}$ (0.21 mmoles) de $\mathbf{5 0}$ en $2 \mathrm{~mL}$ de DCM seco bajo atmósfera de argon. Se baja la temperatura a $-78^{\circ} \mathrm{C}$ y se añaden $0.30 \mathrm{~mL}(0.46$ mmoles $)$ de una disolución de DIBAL-H 1.5 M en tolueno. Se mantiene la reacción a esa temperatura durante 1 hora, transcurrida la cual se vierte la mezcla de reacción sobre $50 \mathrm{~mL}$ de una disolución acuosa saturada de $\mathrm{NH}_{4} \mathrm{Cl}$. Se deja agitando a temperatura ambiente durante 20 minutos y seguidamente se extrae con AcOEt (x4). La fase orgánica se seca sobre $\mathrm{Na}_{2} \mathrm{SO}_{4}$ anhidro, se filtra y se evapora el disolvente, obteniéndose $73 \mathrm{mg}$ (85\%) del aldehído 51 que se utiliza sin previa purificación en la siguiente reacción de reducción.

\section{REDUCCIÓN DE 51 CON DIBAL-H}

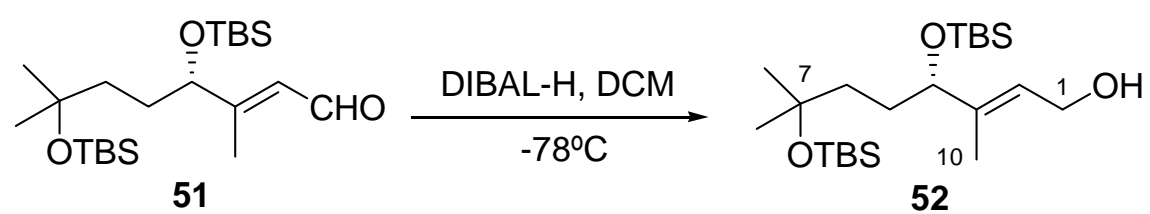

Se disuelven $73 \mathrm{mg}$ (0.17 mmoles) de $\mathbf{5 1}$ en $2 \mathrm{~mL}$ de DCM seco bajo atmósfera de argon. Se baja la temperatura a $-78^{\circ} \mathrm{C}$ y se añaden $0.22 \mathrm{~mL}(0.33$ mmoles $)$ de una disolución de DIBAL-H 1.5 M en tolueno. Se deja reaccionando a $-78^{\circ} \mathrm{C}$ durante una hora. Pasado este tiempo se para la reacción añadiendo $0.2 \mathrm{~mL}$ de agua y se deja la mezcla agitando, permitiendo que alcance progresivamente temperatura ambiente. Entonces se disuelven los productos en $200 \mathrm{~mL}$ de éter, se añaden $2 \mathrm{~g}$ de $\mathrm{NaHCO}_{3}, 2 \mathrm{~g}$ de $\mathrm{Na}_{2} \mathrm{SO}_{4}$ anhidro y se deja agitando vigorosamente durante 3 horas. Seguidamente se filtra por celita y se evapora el disolvente, obteniéndose $80 \mathrm{mg}$ de crudo con 
restos de tolueno. Se cromatografía en columna sobre sílicagel flash (eluyente: hexano/AcOEt 95:5), aislándose $46 \mathrm{mg}$ (65\%) del alcohol 52, cuyas propiedades físicas y espectroscópicas son las siguientes:

\section{$\underline{(4 S)-4,7-B i s(t e r c-b u t i l-d i m e t i l-s i l a n i l o x i)-3,7-d i m e t i l-o c t-E-2-e n-1-o l ~(52) ~}$}

ESPECTRO IR $v_{\max }$ (película) $\mathrm{cm}^{-1}$ (fig. 44a): 3336 (ancha), 2956, 2930, 2886, 2857, $1472,1381,1363,1253,1216,1153,1076,1005,835$.

ESPECTRO RMN ${ }^{1} \mathbf{H}\left(200 \mathrm{MHz}, \mathrm{CDCl}_{3}, \delta\right.$ ppm) (fig. 44b): $5.53(1 \mathrm{H}, \mathrm{t}, J=6.6 \mathrm{~Hz}, \mathrm{H}-$ 2), 4.18 (2H, d, $J=6.6$ Hz, H-1), 3.92 (1H, t, $J=7.0$ Hz, H-4), 1.60 (3H, s, H-10), 1.56$1.22\left(4 \mathrm{H}, \mathrm{m}, \mathrm{H}-5\right.$ y H-6), $1.16\left(6 \mathrm{H}, \mathrm{s}, \mathrm{H}-8\right.$ y H-9), 0.88 y $0.84\left(9 \mathrm{H} \mathrm{c} / \mathrm{u}, \mathrm{s},{ }^{t} \mathrm{BuMe}_{2} \mathrm{Si}\right)$, $0.051\left(6 \mathrm{H}, \mathrm{s},{ }^{t} \mathrm{BuMe} \underline{\underline{M}}_{2} \mathrm{Si}\right), 0.031$ y $-0.015\left(3 \mathrm{H} \mathrm{c} / \mathrm{u}, \mathrm{s},{ }^{t} \mathrm{BuMe}{ }_{2} \mathrm{Si}\right)$.

ESPECTRO RMN ${ }^{13} \mathbf{C}\left(50 \mathrm{MHz}, \mathrm{CDCl}_{3}, \delta\right.$ ppm) (fig. 44c) (Tabla XXI).

HRMS, ESI (fig. 44d): Calculado para $\mathrm{C}_{22} \mathrm{H}_{48} \mathrm{O}_{3} \mathrm{NaSi}_{2}(M+\mathrm{Na})^{+}, 439.3034$. Experimental $(\mathrm{M}+\mathrm{Na})^{+}, 439.3036$.

$[\alpha]_{D}^{25}=-1.7^{\circ}\left(\mathrm{c}=0.9, \mathrm{CHCl}_{3}\right)$

\section{DESPROTECCIÓN DE 52 PARA OBTENER ent-SACHALINOL A, 49}

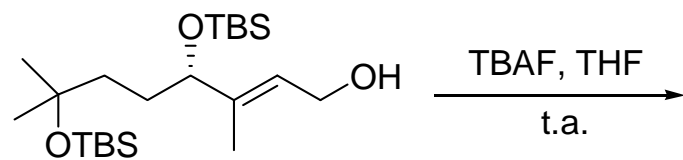

52<smiles>C/C(=C\CO)[C@@H](O)CCC(C)(C)O</smiles>

49

Sobre una disolución de 52 (30 mg, 0.07 mmoles) en THF seco a temperatura ambiente y bajo atmósfera de argon, se añaden $180 \mu \mathrm{L}(0.18 \mathrm{mmoles})$ de una disolución de TBAF $1.0 \mathrm{M}$ en THF. Se mantiene agitando a esta temperatura durante 72 horas, transcurridas las cuales se evapora el disolvente y se cromatografía el crudo en columna sobre sílicagel flash (eluyente: hexano/ AcOEt 1:9), aislándose $10 \mathrm{mg}$ (75\%) de entsachalinol A 49, cuyas propiedades físicas y espectroscópicas ya se han descrito anteriormente. 


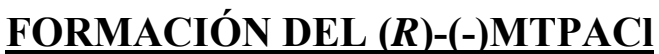<smiles>CO[C@](C(=O)O)(c1ccccc1)C(F)(F)F</smiles>

(S)-(-)-MTPA

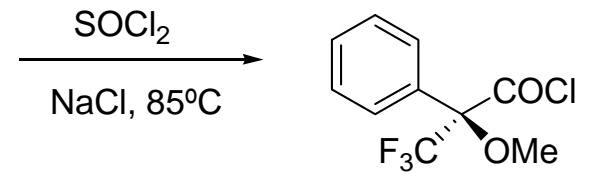

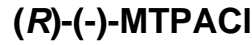

Se disuelven $1.08 \mathrm{~g}$ (4.61 mmoles) de (S)-(-)-MTPA y $45 \mathrm{mg}$ de $\mathrm{NaCl}$ en $4 \mathrm{~mL}$ de $\mathrm{SOCl}_{2}$ previamente destilado y se calienta a $85^{\circ} \mathrm{C}$ durante dos días bajo atmósfera de argon. Transcurrido este tiempo se evapora el exceso de $\mathrm{SOCl}_{2}$ y se purifica el (R)-(-)$\mathrm{MTPACl}$ por destilación a presión reducida en un Kügelrhor $\left(110{ }^{\circ} \mathrm{C}, 18 \mathrm{mmHg}\right)$ obteniéndose $805 \mathrm{mg}(69 \%)$ de (R)-(-)-MTPACl.

\section{FORMACIÓN DE LOS ÉSTERES DE MOSHER DE 49}
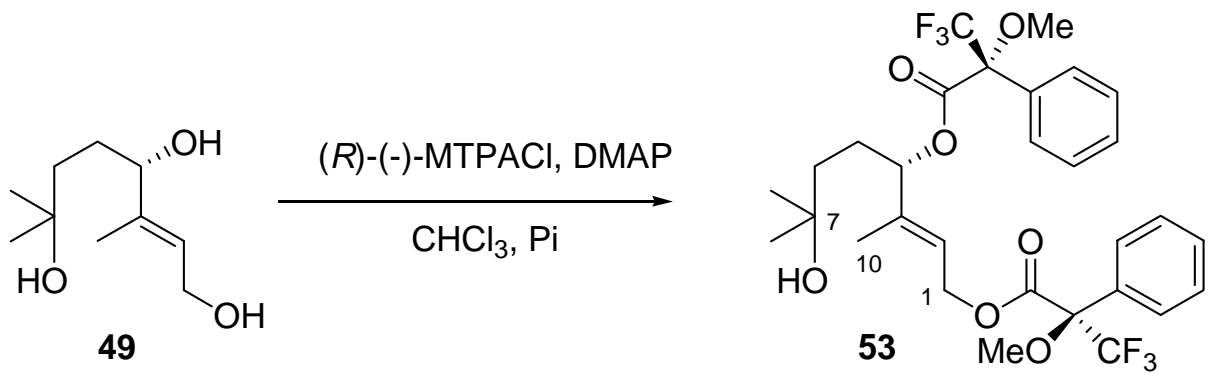

A una disolución agitada de 49 (10 $\mathrm{mg}, 0.05$ mmoles $)$ en $0.8 \mathrm{~mL}$ de $\mathrm{CHCl}_{3}$ se añaden sucesivamente $0.8 \mathrm{~mL}$ de piridina, una cantidad catalítica de DMAP y $100 \mu \mathrm{L}$ (0.53 mmoles) de (R)-(-)-MTPACl a $0^{\circ} \mathrm{C}$. Se deja la mezcla reaccionando a temperatura ambiente bajo atmósfera de argon durante 5 horas. Transcurrido este tiempo se añade AcOEt (100 mL) y se lava sucesivamente con disoluciones acuosas de $\mathrm{CuSO}_{4}(20 \%)$, $\mathrm{NaHCO}_{3}(5 \%)$ y $\mathrm{NaCl}$ (saturada). Se seca sobre $\mathrm{NaSO}_{4}$ anhidro, se filtra y evapora el disolvente obteniéndose $100 \mathrm{mg}$ de crudo con restos de piridina que se cromatografían en columna sobre sílicagel flash (eluyente: hexano/ AcOEt 8:2) para obtener $20 \mathrm{mg}$ (61\%) del compuesto 53, el cual presenta las siguientes propiedades físicas y espectroscópicas: 
(4'S,2R)-Bis-(3,3,3-trifluoro-2-metoxi-2-fenilpropanoato) de (7'-hidroxi-3',7'dimetil-oct-E-2'-en-1',4'-diilo) (53)

ESPECTRO IR $v_{\max }$ (película) $\mathrm{cm}^{-1}$ (fig. 45a): 3452 (ancha), 2970, 2844, 1748, 1496, 1452, 1375, 1271, 1173, 1118, 1025, 992.

ESPECTRO RMN ${ }^{1} \mathbf{H}\left(400 \mathrm{MHz}, \mathrm{CDCl}_{3}, \delta\right.$ ppm) (fig. 45b): 7.49-7.36 (10H, m, -Ph), $5.70(1 \mathrm{H}, \mathrm{t}, J=7.0 \mathrm{~Hz}, \mathrm{H}-2), 5.36(1 \mathrm{H}, \mathrm{t}, J=6.5 \mathrm{~Hz}, \mathrm{H}-4), 4.90(1 \mathrm{H}, \mathrm{dd}, J=12.5$ y 7.0 $\left.\mathrm{Hz}, \mathrm{H}_{\mathrm{A}}-1\right), 4.78\left(1 \mathrm{H}, \mathrm{dd}, J=12.5\right.$ y $\left.7.0 \mathrm{~Hz}, \mathrm{H}_{\mathrm{B}}-1\right), 3.52$ y $3.48\left(3 \mathrm{H}\right.$ c/u, s, $\left.\underline{\mathrm{CH}}_{3} \mathrm{O}\right), 1.79-$ 1.64 y $1.27-1.23$ (2H c/u, m, H-5 y H-6), 1.74 (3H, s, H-10), 1.13 y 1.11 (3H c/u, s, H-8 y H-9).

ESPECTRO RMN ${ }^{13} \mathbf{C}\left(100 \mathrm{MHz}, \mathrm{CDCl}_{3}, \delta \mathrm{ppm}\right)$ (fig. 45c) (Tabla XX).

HRMS, ESI (fig. 45d): Calculado para $\mathrm{C}_{30} \mathrm{H}_{34} \mathrm{O}_{7} \mathrm{~F}_{6} \mathrm{Na}(M+\mathrm{Na})^{+}, \quad 643.2101$. Experimental $(\mathrm{M}+\mathrm{Na})^{+}, 643.2078$.

$[\alpha]_{D}^{25}=-48.0^{\circ}\left(\mathrm{c}=1.1, \mathrm{CHCl}_{3}\right)$ 



\section{PROTECCIÓN DE 13 COMO ACETÓNIDO}

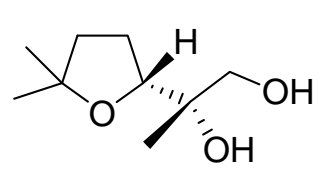

13

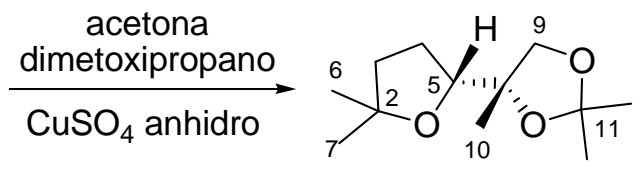

54

Se disuelve 13 (200 mg, 1.15 mmoles) en $6 \mathrm{~mL}$ de acetona seca bajo atmósfera de argon, y se adiciona una pequeña cantidad de $\mathrm{CuSO}_{4}$ anhidro. A continuación se añaden $1.1 \mathrm{~mL}$ de dimetoxipropano y se deja agitando a temperatura ambiente durante 20 horas. Pasado este tiempo se filtra por celita, lavando abundantemente con AcOEt. Por último se evapora el disolvente, obteniéndose $250 \mathrm{mg}$ de crudo que se cromatografían en columna sobre sílicagel flash (eluyente: hexano/AcOEt 9:1). Se aíslan $170 \mathrm{mg}(\mathbf{7 0 \% )}$ de $\mathbf{5 4}$, el cual presenta las siguientes propiedades espectroscópicas:

$\underline{(4 S, 2 ' R)-4-(5,, 5 '-D i m e t i l-t e t r a h i d r o-f u r a n-2 '-i l)-2,2,4-t r i m e t i l-1,3-d i o x o l a n o ~(54) ~}$

ESPECTRO IR $v_{\max }$ (película) $\mathrm{cm}^{-1}$ (fig. 46a): 2975, 2934, 2872, 1464, 1371, 1262, 1205, 1123, 1061, 993, 900, 833.

ESPECTRO RMN ${ }^{1} \mathbf{H}\left(400 \mathrm{MHz}, \mathrm{CDCl}_{3}, \delta\right.$ ppm) (fig. 46b): $3.97(1 \mathrm{H}, \mathrm{d}, J=8.5 \mathrm{~Hz}$, $\left.\mathrm{H}_{\mathrm{A}}-9\right), 3.69\left(1 \mathrm{H}, \mathrm{dd}, J=8.5\right.$ y $\left.0.8 \mathrm{~Hz}, \mathrm{H}_{\mathrm{B}}-9\right), 3.91(1 \mathrm{H}, \mathrm{t}, J=7.0 \mathrm{~Hz}, \mathrm{H}-5), 1.98-1.93$ $\left(1 \mathrm{H}, \mathrm{m}, \mathrm{H}_{\mathrm{A}}-4\right), 1.84-1.79\left(1 \mathrm{H}, \mathrm{m}, \mathrm{H}_{\mathrm{B}}-4\right), 1.70-1.63(1 \mathrm{H}, \mathrm{m}, \mathrm{H}-3), 1.36(3 \mathrm{H}, \mathrm{s}, \mathrm{H}-12)$, 1.35 (3H, s, H-13), 1.20 (6H, s, H-6 y H-10), 1.17 (3H, s, H-7).

ESPECTRO RMN ${ }^{13} \mathbf{C}\left(100 \mathrm{MHz}, \mathrm{CDCl}_{3}, \delta\right.$ ppm) (fig. 46c) (Tabla III).

HRMS, ESI (fig. 46d): Calculado para $\mathrm{C}_{12} \mathrm{H}_{22} \mathrm{O}_{3} \mathrm{Na}(M+\mathrm{Na})^{+}, 237.1461$. Experimental $(\mathrm{M}+\mathrm{Na})^{+}, 237.1460$. 


\section{REACCIÓN DE WITTIG DEL LACTOL 8 CON (CARBETOXIMETILEN)TRIFENILFOSFORANO}<smiles>CCOC(=O)C=CCCCC(C)(O)CC(=O)OCC</smiles>

A una disolución de 8 (5.0 g, 43.80 mmoles) en $150 \mathrm{~mL}$ de benceno se añaden $22.8 \mathrm{~g}$ (65.70 mmoles) de $\mathrm{Ph}_{3}$ PCHCOOEt. Se calienta la mezcla a ebullición $\left(85^{\circ} \mathrm{C}\right) \mathrm{y}$ se mantiene a reflujo durante 20 horas. Pasado este tiempo se evapora el disolvente parcialmente (hasta un volumen de aproximadamente $10 \mathrm{~mL}$ ) para evitar así la precipitación del óxido de trifenilfosfina. El crudo obtenido se cromatografía en columna sobre sílicagel flash (eluyente: hexano/AcOEt 7:3), obteniéndose $4.9 \mathrm{~g} \mathrm{(60 \% )}$ de 55, cuyas propiedades espectroscópicas son las siguientes:

\section{6-Hidroxi-6-metil-hept-E-2-enoato de etilo (55)}

ESPECTRO IR $v_{\max }$ (película) $\mathrm{cm}^{-1}$ (fig. 47a): 3430, 2970, 2926, 1715, 1655, 1463, 1364, 1273, 1174, 1040, 988, 926, 854.

ESPECTRO RMN ${ }^{1} \mathbf{H}\left(200 \mathrm{MHz}, \mathrm{CDCl}_{3}, \delta \mathrm{ppm}\right)$ (fig. 47b): $7.00(1 \mathrm{H}, \mathrm{dt}, J=15.6 \mathrm{y}$ $6.8 \mathrm{~Hz}, \mathrm{H}-3), 5.84(1 \mathrm{H}, \mathrm{dt}, J=15.6$ y $1.6 \mathrm{~Hz}, \mathrm{H}-2), 4.18\left(2 \mathrm{H}, \mathrm{c}, J=7.2 \mathrm{~Hz}, \mathrm{O}-\underline{\mathrm{CH}}_{2}-\right.$ $\left.\mathrm{CH}_{3}\right), 2.37-2.25$ (2H, m, H-4), 1.66- 1.58 (2H, m, H-5), 1.28 (3H, t, J= 7.2 Hz, O-CH ${ }_{2}^{-}$ $\left.\underline{\mathrm{CH}}_{3}\right), 1.25(6 \mathrm{H}, \mathrm{s}, \mathrm{H}-7$ y H-8).

ESPECTRO RMN ${ }^{13} \mathbf{C}\left(50 \mathrm{MHz}, \mathrm{CDCl}_{3}, \delta\right.$ ppm) (fig. 47c) (Tabla V).

LRMS, EI, m/z (\%) (fig. 47d): 59 (100), 69 (22), 81 (23), 95 (28), 125 (26), 168 (13), $186(2)(\mathrm{M})^{+}$.

HRMS, EI: Calculado para $\mathrm{C}_{10} \mathrm{H}_{18} \mathrm{O}_{3}(M)^{+}, 186.1256$. Experimental (M) ${ }^{+}, 186.1237$. 


\section{REDUCCIÓN DEL ÉSTER 55}

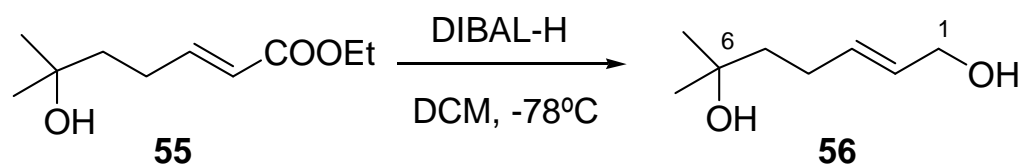

Sobre una disolución agitada de 55 (3.0 g, 16.10 mmoles) en $150 \mathrm{~mL}$ de DCM seco a $-78^{\circ} \mathrm{C}$ se añaden bajo atmósfera de argon $26.6 \mathrm{~mL}$ de una disolución de DIBAL$\mathrm{H}$ 1.5 $\mathrm{M}$ en tolueno. Se deja reaccionando a esa temperatura durante 2 horas, transcurridas las cuales se añaden $5 \mathrm{~mL}$ de agua y se deja agitando hasta que la mezcla alcanza temperatura ambiente. A continuación se añade la mezcla de reacción sobre $1 \mathrm{~L}$ de éter, se adicionan $25 \mathrm{~g}$ de $\mathrm{NaHCO}_{3}, 25 \mathrm{~g}$ de $\mathrm{Na}_{2} \mathrm{SO}_{4}$ anhidro y se deja agitando a temperatura ambiente durante 3 horas. Pasado este tiempo, se filtra por celita, lavando abundantemente con éter. Tras evaporar el disolvente se obtienen $3 \mathrm{~g}$ de crudo que se cromatografían en columna sobre sílicagel flash (eluyente: hexano/AcOEt 1:1). Finalmente se aíslan $2 \mathrm{~g}(87 \%)$ de 56, que presenta las siguientes propiedades espectroscópicas:

\section{6-Metil-hept-E-2-en-1,6-diol (56)}

ESPECTRO IR $v_{\max }$ (película) $\mathrm{cm}^{-1}$ (fig. 48a): 3348, 2970, 2921, 2860, 1666, 1381, 1211, 1149, 1092, 998, 967, 916.

ESPECTRO RMN ${ }^{1} \mathbf{H}\left(200 \mathrm{MHz}, \mathrm{CDCl}_{3}, \delta\right.$ ppm) (fig. 48b): 5.82-5.58 (2H, m, H-2 y H-3), 4.09 (2H, d, J = 3.6 Hz, H-1), 2.18-2.09 (2H, m, H-4), 1.61-1.52 (2H, m, H-5), $1.23(6 \mathrm{H}, \mathrm{s}, \mathrm{H}-7$ y H-8).

ESPECTRO RMN ${ }^{13} \mathbf{C}\left(50 \mathrm{MHz}, \mathrm{CDCl}_{3}, \delta\right.$ ppm) (fig. 48c) (Tabla VIII).

LRMS, EI, m/z (\%) (fig. 48d): 59 (100), 82 (30), 93 (18), 111 (24), 126 (10), 144 (1) $(\mathrm{M})^{+}$.

HRMS, EI: Calculado para $\mathrm{C}_{8} \mathrm{H}_{16} \mathrm{O}_{2}(M)^{+}, 144.1150$. Experimental (M) ${ }^{+}, 144.1138$. 


\section{EPOXIDACIÓN DE SHARPLESS DE 56 Y POSTERIOR PROTECCIÓN COMO ACETÓNIDO}

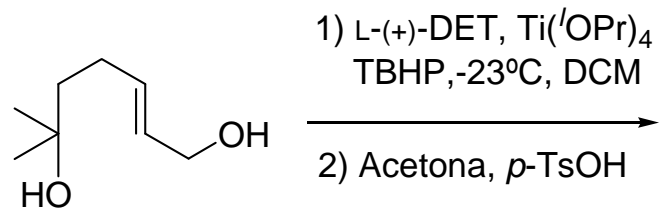

56

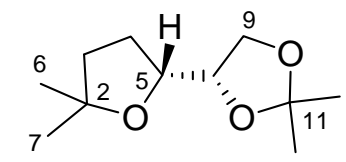

58

Se disuelven $923 \mathrm{mg}$ (4.47 mmoles) de L-(+)-DET en $20 \mathrm{~mL}$ de DCM destilado y seco bajo atmósfera de argon. Se baja la temperatura a $-23^{\circ} \mathrm{C}$ y se añaden $1.1 \mathrm{~mL}(3.73$ mmoles) de $\mathrm{Ti}\left({ }^{i} \mathrm{OPr}\right)_{4}$. Pasados 10 minutos en estas condiciones se añaden $537 \mathrm{mg}$ (3.73 mmoles) de 56 disueltos en $17 \mathrm{~mL}$ de DCM. Se deja agitando a $-23^{\circ} \mathrm{C}$ durante 5 minutos, y entonces se añaden $1.3 \mathrm{~mL}$ (7.46 mmoles) de una disolución de TBHP $5.5 \mathrm{M}$ en $n$-decano. Se mantiene la reacción a $-23^{\circ} \mathrm{C}$ durante 23 horas.

Pasado este tiempo se añaden $\left(\mathrm{a}-23^{\circ} \mathrm{C}\right) 5 \mathrm{~mL}$ de una disolución acuosa de ácido tartárico (10\%). Se deja agitando a esa temperatura durante 30 minutos y luego a temperatura ambiente durante una hora más. Se filtra la mezcla por celita, lavando abundantemente con éter $(300 \mathrm{~mL})$. Posteriormente se lava con agua y se evapora parte del éter (hasta $50 \mathrm{~mL}$ aproximadamente). Se baja la temperatura a $0^{\circ} \mathrm{C}$ y se añaden $7 \mathrm{~mL}$ de $\mathrm{NaOH} 1 \mathrm{M}$; se deja agitando en estas condiciones durante 45 minutos. A continuación se separa la fase orgánica y se lava con una disolución acuosa de $\mathrm{NaCl}$ saturada. La fase acuosa se extrae con éter ( 2 veces) y se lava con una disolución acuosa $\mathrm{NaCl}$ saturada. Se reúnen las fases etéreas y se secan sobre $\mathrm{Na}_{2} \mathrm{SO}_{4}$ anhidro. Se filtra y se evapora el éter, obteniéndose un crudo que se redisuelve en acetona destilada (10 $\mathrm{mL}$ ). Tras añadir una cantidad catalítica de $p-\mathrm{TsOH}$ se deja reaccionando a temperatura ambiente durante 5 horas. Pasado este tiempo se añade una disolución acuosa de $\mathrm{NaHCO}_{3}(5 \%)$ hasta $\mathrm{pH}$ neutro y se extrae con éter. Las fases etéreas combinadas se lavan con $\mathrm{H}_{2} \mathrm{O}$ y con disolución acuosa saturada de $\mathrm{NaCl}$. Se seca sobre $\mathrm{Na}_{2} \mathrm{SO}_{4}$ anhidro, se filtra y se evapora el éter, obteniéndose un crudo que se cromatografía en columna sobre sílicagel flash (eluyente: hexano/AcOEt 3:7). Se aíslan $75 \mathrm{mg}$ (10\%) del compuesto 58, el cual presenta las siguientes propiedades espectroscópicas: 
ESPECTRO IR $v_{\max }$ (película) $\mathrm{cm}^{-1}$ (fig. 50a): 2971, 2929, 2874, 1733, 1459, 1380, $1250,1214,1144,1062,842$.

ESPECTRO RMN ${ }^{1} \mathbf{H}\left(400 \mathrm{MHz}, \mathrm{CDCl}_{3}, \delta\right.$ ppm) (fig. 50b): 4.06 (1H, dd, $J=8.2$ y 5.8 $\left.\mathrm{Hz}, \mathrm{H}_{\mathrm{A}}-9\right), 3.81\left(1 \mathrm{H}, \mathrm{dd}, J=8.2\right.$ y $\left.5.8 \mathrm{~Hz}, \mathrm{H}_{\mathrm{B}}-9\right), 3.91-3.87$ (2H, m, H-5 y H-8), 1.73$1.69(2 \mathrm{H}, \mathrm{m}, \mathrm{H}-3), 2.13-2.07\left(1 \mathrm{H}, \mathrm{m}, \mathrm{H}_{\mathrm{A}}-4\right), 1.90-1.86\left(1 \mathrm{H}, \mathrm{m}, \mathrm{H}_{\mathrm{B}}-4\right), 1.38(3 \mathrm{H}, \mathrm{s}, \mathrm{H}-$ 12), 1.33 (3H, s, H-13), 1.22 (3H, s, H-6), 1.19 (3H, s, H-7).

ESPECTRO RMN ${ }^{13} \mathbf{C}\left(100 \mathrm{MHz}, \mathrm{CDCl}_{3}, \delta\right.$ ppm) (fig. 50c) (Tabla IV).

LRMS, ESI, m/z (\%) (fig. 50d): 101 (22), 137 (40), 141 (14), 199 (36), 210(25), 223 (100) $(\mathrm{M}+\mathrm{Na})^{+}$.

HRMS, ESI: Calculado para $\mathrm{C}_{11} \mathrm{H}_{20} \mathrm{O}_{3} \mathrm{Na}(M+\mathrm{Na})^{+}$, 223.1304. Experimental $(\mathrm{M}+$ $\mathrm{Na})^{+}, 223.1297$.

\section{REACCIÓN DE PROTECCIÓN DEL ÉSTER 55}

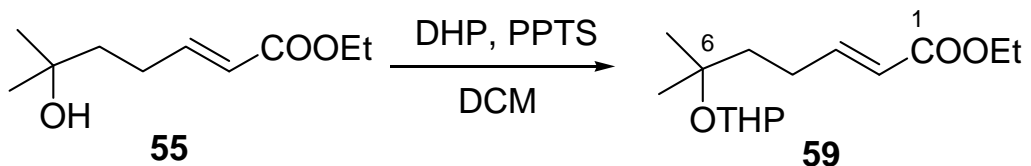

Se disuelven 4.0 g (21.47 mmoles) de 55 en $200 \mathrm{~mL}$ de DCM seco. A continuación se añade una cantidad catalítica de PPTS. Se pone bajo atmósfera de argon y se adicionan $4.9 \mathrm{~mL}$ (53.68 mmoles) de DHP. Se deja reaccionando a temperatura ambiente durante 20 horas. Transcurrido este tiempo se evapora parte del DCM (hasta unos $50 \mathrm{~mL}$ aproximadamente), se añade AcOEt y se lava con una disolución acuosa saturada de $\mathrm{NaCl}$. Se seca sobre $\mathrm{Na}_{2} \mathrm{SO}_{4}$ anhidro, se filtra y se evapora el disolvente para dar $7 \mathrm{~g}$ de crudo que se cromatografían en columna sobre sílicagel (eluyente: hexano/AcOEt 9:1), obteniéndose $5.1 \mathrm{~g}(88 \%)$ de 59, que presenta las siguientes propiedades espectroscópicas: 


\section{6-Metil-6-(tetrahidro-piran-2-iloxi)-hept-E-2-enoato de etilo (59)}

ESPECTRO IR $v_{\max }$ (película) $\mathrm{cm}^{-1}$ (fig. 51a): 2937, 2860, 1721, 1644, 1452, 1370, $1260,1185,1133,1024,993$.

ESPECTRO RMN ${ }^{1} \mathbf{H}\left(200 \mathrm{MHz}, \mathrm{CDCl}_{3}, \delta\right.$ ppm) (fig. 51b): $6.97(1 \mathrm{H}, \mathrm{dt}, J=15.6 \mathrm{y}$ 6.8, H-3), 5.78 (1H, dt, $J=15.6$ y $1.6 \mathrm{~Hz}, \mathrm{H}-2), 4.67$ (1H, m, H-1'), 4.14 (2H, c, $J=7.2$, $\left.-\mathrm{O}-\underline{\mathrm{CH}}_{2}-\mathrm{CH}_{3}\right), 3.90$ y 3.42 (1H c/u, m, H-5'), 2.30-2.24 (2H, m, H-4), 1.70-1.42 (8H, m,

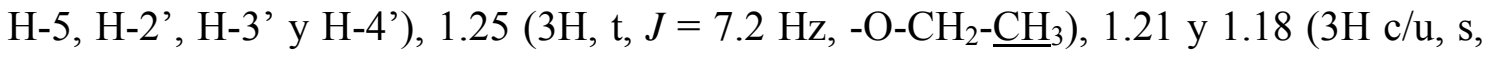
H-7 y H-8).

ESPECTRO RMN ${ }^{13} \mathbf{C}\left(50 \mathrm{MHz}, \mathrm{CDCl}_{3}, \delta\right.$ ppm) (fig. 51c) (Tabla VI).

LRMS, ESI, m/z (\%) (fig. 51d): 102 (40), 123 (40), 141 (13), 169 (81), 187 (22), 246 (9), $271(5)(\mathrm{M}+\mathrm{H})^{+}, 290(27), 297(16), 293(100)(\mathrm{M}+\mathrm{Na})^{+}$.

\section{REACCIÓN DE REDUCCIÓN DEL ÉSTER 59 CON DIBAL-H}

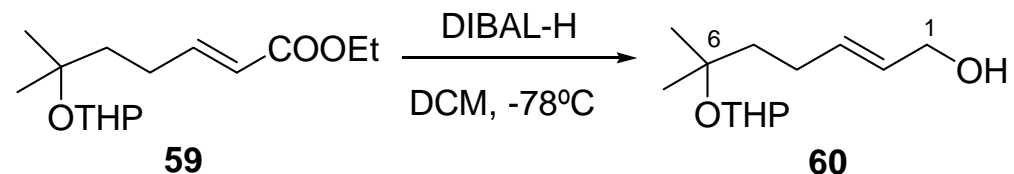

Se disuelve 59 (2.9 g, 10.72 mmoles) en $110 \mathrm{~mL}$ de DCM seco, se pone bajo atmósfera de argon y se baja la temperatura a $-78^{\circ} \mathrm{C}$. Seguidamente se añaden $18 \mathrm{~mL}$ (26.81 mmoles) de una disolución 1.5 M de DIBAL-H en tolueno. Se deja reaccionando a $-78^{\circ} \mathrm{C}$ durante 1 hora. Pasado este tiempo se añaden $2 \mathrm{~mL}$ de agua y se deja la mezcla agitando, permitiendo que alcance progresivamente temperatura ambiente. Entonces se disuelven los productos en $1 \mathrm{~L}$ de éter, se añaden $30 \mathrm{~g}$ de $\mathrm{NaHCO}_{3}, 30 \mathrm{~g}$ de $\mathrm{Na}_{2} \mathrm{SO}_{4}$ anhidro y se deja agitando vigorosamente durante 3 horas. Pasado este tiempo se filtra por celita, se evapora el disolvente y el crudo se cromatografía en columna sobre sílicagel flash (eluyente: hexano/AcOEt 8:2). Se obtienen $2 \mathrm{~g}$ (82\%) del alcohol alílico 60, cuyas propiedades espectroscópicas son las siguientes: 
ESPECTRO IR $v_{\max }$ (película) $\mathrm{cm}^{-1}$ (fig. 52a): 3396, 2941, 2867, 1676, 1454, 1383, 1199, 1130, 1076, 1024, 988, 942, 869, 812.

ESPECTRO RMN ${ }^{1} \mathbf{H}\left(200 \mathrm{MHz}, \mathrm{CDCl}_{3}, \delta\right.$ ppm) (fig. 52b): 5.80-5.57 (2H, m, H-2 y H-3), 4.72 (1H, m, H-1'), 4.08 (2H, d, J=4.4 Hz, H-1), 4.00-3.90 y 3.50-3.39 (1H c/u, m, H-5'), 2.19-2.07 (2H, m, H-4), 1.61-1.50 (8H, m, H-5, H-2', H-3', H-4'), 1.22-1.20 $(3 \mathrm{H} \mathrm{c} / \mathrm{u}, \mathrm{s}, \mathrm{H}-7$ y $\mathrm{H}-8)$.

ESPECTRO RMN ${ }^{13} \mathbf{C}\left(50 \mathrm{MHz}, \mathrm{CDCl}_{3}, \delta \mathrm{ppm}\right)$ (fig. 52c) (Tabla VIII).

LRMS, ESI, m/z (\%) (fig. 52d): 109 (63), 127 (29), 193 (7), 229 (13) (M + H) ${ }^{+}, 251$ (100) $(\mathrm{M}+\mathrm{Na})^{+}$.

HRMS, ESI: Calculado para $\mathrm{C}_{13} \mathrm{H}_{25} \mathrm{O}_{3}(M+\mathrm{H})^{+}$, 229.1798. Experimental $(\mathrm{M}+\mathrm{H})^{+}$, 229.1792 .

\section{REACCIÓN DE EPOXIDACIÓN DE SHARPLESS DE 60}

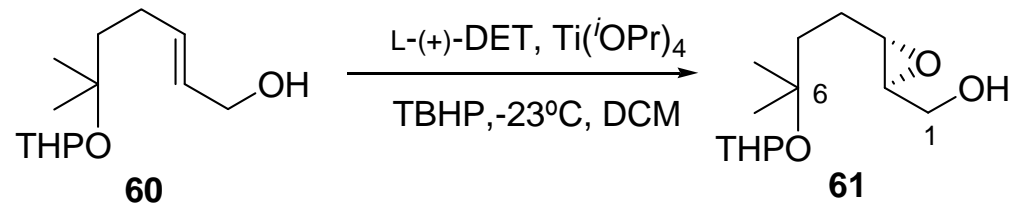

Se disuelven $1.1 \mathrm{~g}$ (5.19 mmoles) de L-(+)-DET en $30 \mathrm{~mL}$ de DCM destilado y seco bajo atmósfera de argon. Se baja la temperatura a $-23^{\circ} \mathrm{C}$ y se añaden $1.27 \mathrm{~mL}(4.33$ mmoles) de $\mathrm{Ti}\left({ }^{i} \mathrm{OPr}\right)_{4}$. Pasados 10 minutos en estas condiciones se añaden $986 \mathrm{mg}$ (4.33 mmoles) de 60 disueltos en $13 \mathrm{~mL}$ de DCM. Se deja agitando a $-23^{\circ} \mathrm{C}$ durante 5 minutos y entonces se añaden $1.6 \mathrm{~mL}$ (8.65 mmoles) de una disolución de TBHP 5.5M en $n$ decano. Se mantiene la reacción a $-23^{\circ} \mathrm{C}$ durante 23 horas.

Pasado este tiempo se añaden $\left(\mathrm{a}-23^{\circ} \mathrm{C}\right) 10 \mathrm{~mL}$ de una disolución acuosa de ácido tartárico (10\%). Se deja agitando a esa temperatura durante 30 minutos y luego a temperatura ambiente durante una hora más. Se filtra la mezcla por celita, lavando abundantemente con éter $(500 \mathrm{~mL})$. Luego se lava con agua y se evapora parte del éter (hasta $50 \mathrm{~mL}$ aproximadamente). Se baja la temperatura a $0^{\circ} \mathrm{C}$ y se añaden $14 \mathrm{~mL}$ de 
$\mathrm{NaOH} 1 \mathrm{M}$; se deja agitando en estas condiciones durante 45 minutos. A continuación se separa la fase orgánica y se lava con una disolución acuosa de $\mathrm{NaCl}$ saturada. La fase acuosa se extrae con éter ( 2 veces) y se lava con una disolución acuosa $\mathrm{NaCl}$ saturada. Se reúnen las fases etéreas y se secan sobre $\mathrm{Na}_{2} \mathrm{SO}_{4}$ anhidro. Se filtra y se evapora el éter, obteniéndose $1 \mathrm{~g}$ de crudo que se cromatografía en columna sobre sílicagel flash (eluyente: hexano/AcOEt 1:1). Se recuperan $100 \mathrm{mg}$ (10\%) de producto de partida y se aíslan $200 \mathrm{mg}(20 \%)$ del epóxido 61, que presenta las siguientes propiedades físicas y espectroscópicas:

\section{$\underline{(2 S, 3 S)-\{3-[3-m e t i l-3-(t e t r a h i d r o-p i r a n-2-i l o x i)-b u t i l]-o x i r a n i l\}-m e t a n o l ~(61) ~}$}

ESPECTRO IR $v_{\max }$ (película) $\mathrm{cm}^{-1}$ (fig. 53a): 3441, 2944, 2872, 1475, 1361, 1133, 1076, 1024, 993, 869.

ESPECTRO RMN ${ }^{1} \mathbf{H}\left(200 \mathrm{MHz}, \mathrm{CDCl}_{3}, \delta\right.$ ppm) (fig. 53b): 4.69 (1H, m, H-1'), $3.91 \mathrm{y}$ 3.43 (1H c/u, m, H-5'), 3.61 (2H, m, H-1), 2.95 (2H, m, H-2 y H-3), 2.20-1.48 (10H, m, H-4, H-5, H-2', H-3' y H-4'), 1.21 y 1.18 (3H c/u, s, H-7 y H-8).

ESPECTRO RMN ${ }^{13} \mathbf{C}\left(100 \mathrm{MHz}, \mathrm{CDCl}_{3}, \delta \mathrm{ppm}\right)$ (fig. 53c) (Tabla IX).

LRMS, ESI, m/z (\%) (fig. 53d): 125 (8), 143 (19), 161 (38), 267 (100) (M) ${ }^{+}$. $[\alpha]_{D}^{25}=-13.9^{\circ}\left(\mathrm{c}=1.3, \mathrm{CHCl}_{3}\right)$

\section{REACCIÓN DE DESPROTECCIÓN DE 61}<smiles>CC(C)(O)CCC(=O)CO</smiles>

61

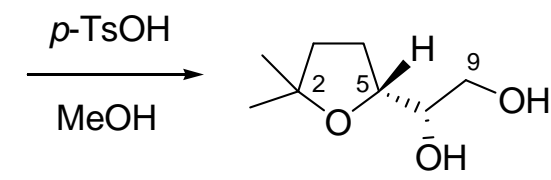

57 
A una disolución agitada de 61 (200 mg, 0.82 mmoles) en $4 \mathrm{~mL}$ de $\mathrm{MeOH}$ seco se añaden $15 \mathrm{mg}$ (0.082 mmoles) de $p$-TsOH. Se deja agitando a temperatura ambiente durante 2 horas, transcurridas las cuales se añaden $10 \mathrm{mg}$ de $\mathrm{NaHCO}_{3}$ y se deja agitando durante 15 minutos. A continuación se evapora el $\mathrm{MeOH}$, se redisuelve el residuo en AcOEt, se filtra y se evapora el disolvente para obtener $140 \mathrm{mg}$ de crudo que se cromatografían en columna sobre sílicagel flash (eluyente: hexano/AcOEt 1:1). Se aíslan $90 \mathrm{mg}(70 \%)$ de $\mathbf{5 7}$, cuyas propiedades físicas y espectroscópicas se detallan a continuación:

$\underline{(2 S, 2 ' R)-2-\left(5^{\prime}, 5 ' \text { 'Dimetil-tetrahidro-furan-2'-il)-1,2-etanodiol (57) }\right.}$

ESPECTRO IR $v_{\max }$ (película) $\mathrm{cm}^{-1}$ (fig. 49a): 3385, 2970, 2932, 2874, 1651, 1460, $1367,1316,1235,1130,1056,902,856$.

ESPECTRO RMN ${ }^{1} \mathbf{H}\left(200 \mathrm{MHz}, \mathrm{CDCl}_{3}, \delta\right.$ ppm) (fig. 49b): 3.94 (1H, m, H-5), 3.63 (3H, m, H-8 y H-9), 2.01-1.70 (4H, m, H-3 y H-4), 1.22 y 1.20 (3H c/u, s, H-6 y H-7).

ESPECTRO RMN ${ }^{13} \mathbf{C}\left(50 \mathrm{MHz}, \mathrm{CDCl}_{3}, \delta\right.$ ppm) (fig. 49c) (Tabla II).

LRMS, ESI, m/z (\%) (fig. 49d): $161(18)(\mathrm{M}+\mathrm{H})^{+}, 180(45), 183(100)(\mathrm{M}+\mathrm{Na})^{+}$.

HRMS, ESI: Calculado para $\mathrm{C}_{8} \mathrm{H}_{16} \mathrm{O}_{3} \mathrm{Na}(M+\mathrm{Na})^{+}$, 183.0997. Experimental $(\mathrm{M}+$ $\mathrm{Na})^{+}, 183.0981$.

$[\alpha]_{D}^{25}=+3.3^{\circ}\left(\mathrm{c}=0.8, \mathrm{CHCl}_{3}\right)$

\section{REACCIÓN DE PROTECCIÓN DE 57}

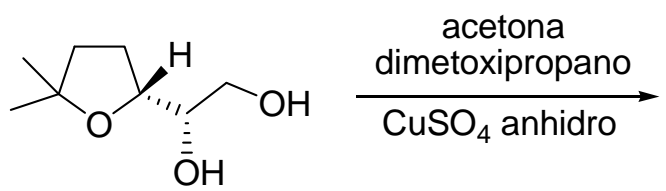

57

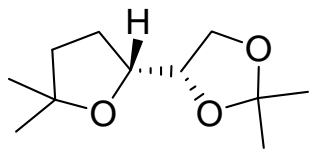

58 
Se disuelve 57 (90 mg, 0.56 mmoles) en $3 \mathrm{~mL}$ de acetona destilada y seca bajo atmósfera de argon, y se adiciona una pequeña cantidad de $\mathrm{CuSO}_{4}$ anhidro. A continuación se añaden $0.5 \mathrm{~mL}$ de dimetoxipropano y se deja agitando a temperatura ambiente durante 20 horas. Pasado este tiempo se filtra por celita, lavando abundantemente con AcOEt. Por último se evapora el disolvente, obteniéndose $100 \mathrm{mg}$ de crudo que se cromatografían en columna sobre sílicagel flash (eluyente: hexano/AcOEt 8:2). Se aíslan $76 \mathrm{mg}$ (70\%) de 58, cuyas propiedades espectroscópicas ya han sido descritas anteriormente. 


\section{EPOXIDACIÓN DE 28 CON m-CPBA}

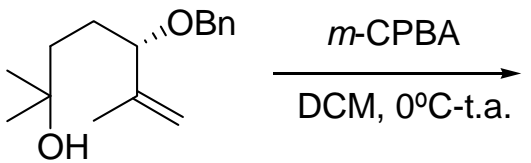

28

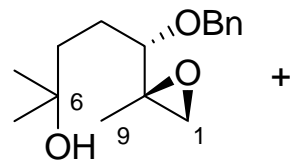

62<smiles>CC1(C)CC[C@@H](OBr)C(C)(O)C1</smiles>

63

Se disuelven $528 \mathrm{mg}$ ( 2.13 mmoles) de 28 en $21 \mathrm{~mL}$ de DCM, se añaden $550 \mathrm{mg}$ (3.20 mmoles) de $m$-CPBA a $0^{\circ} \mathrm{C}$ y se deja agitando a temperatura ambiente durante 14 horas. Transcurrido este tiempo se añaden $50 \mathrm{~mL}$ de $\mathrm{H}_{2} \mathrm{O}$ y se extrae con AcOEt $(4 \mathrm{x}$ $100 \mathrm{~mL}$ ). Las fases orgánicas combinadas se lavan con disoluciones acuosas de $\mathrm{NaHCO}_{3}(5 \%)$ y $\mathrm{NaCl}$ (saturada). Se seca sobre $\mathrm{Na}_{2} \mathrm{SO}_{4}$ anhidro, se filtra y se evapora el disolvente, obteniéndose $700 \mathrm{mg}$ de una mezcla que se cromatografía sobre sílicagel flash (eluyente: hexano/AcOEt 8:2 $\rightarrow$ 7:3). Se aíslan $230 \mathrm{mg}$ (41\%) del epóxido anti 62 y $230 \mathrm{mg}(41 \%)$ del epóxido syn 63. Estos compuestos presentan las siguientes propiedades físicas y espectroscópicas:

\section{$\underline{(5 S, 2 ' S)-5-B e n c i l o x i-2-m e t i l-5-\left(2^{\prime}-\text { metil-oxiranil)-2-pentanol (62) }\right.}$}

ESPECTRO IR $v_{\max }$ (película) $\mathrm{cm}^{-1}$ (fig. 55a): 3400 (ancha), 3032, 2971-2870, 1454, 1375, 1101, 1072, 909, 739, 698.

ESPECTRO RMN ${ }^{1} \mathbf{H}\left(200 \mathrm{MHz}, \mathrm{CDCl}_{3}, \delta\right.$ ppm) (fig. 55b): 7.35-7.32 (5H, m, -Ph), $4.67\left(1 \mathrm{H}, \mathrm{d}, J=11.5 \mathrm{~Hz}, \mathrm{O}-\underline{\mathrm{CH}}_{2}-\mathrm{Ph}, \mathrm{H}_{\mathrm{A}}\right), 4.46\left(1 \mathrm{H}, \mathrm{d}, J=11.5 \mathrm{~Hz}, \mathrm{O}-\underline{\mathrm{CH}}_{2}-\mathrm{Ph}, \mathrm{H}_{\mathrm{B}}\right)$, $3.04(1 \mathrm{H}, \mathrm{t}, J=6.0 \mathrm{~Hz}, \mathrm{H}-3), 2.74\left(1 \mathrm{H}, \mathrm{d}, J=5.0 \mathrm{~Hz}, \mathrm{H}_{\mathrm{A}}-1\right), 2.67(1 \mathrm{H}, \mathrm{d}, J=5.0 \mathrm{~Hz}$, $\left.\mathrm{H}_{\mathrm{B}}-1\right), 1.8-1.2$ (4H, m, H-4 y H-5), 1.34 (3H, s, H-9), 1.22 (6H, s, H-7 y H-8).

ESPECTRO RMN ${ }^{13} \mathbf{C}\left(50 \mathrm{MHz}, \mathrm{CDCl}_{3}, \delta\right.$ ppm) (fig. 55c) (Tabla XXII).

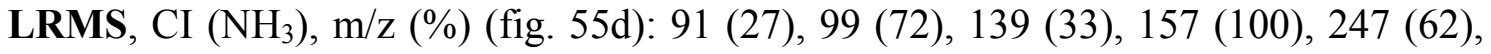
$265(23)(\mathrm{M}+\mathrm{H})^{+}$

HRMS, CI $\left(\mathrm{NH}_{3}\right)$ : Calculado para $\mathrm{C}_{16} \mathrm{H}_{25} \mathrm{O}_{3}(M+\mathrm{H})^{+}$, 265.1804. Experimental $(\mathrm{M}+$ $\mathrm{H})^{+}, 265.1800$.

ANÁLISIS ELEMENTAL: Calculado para $\mathrm{C}_{16} \mathrm{H}_{24} \mathrm{O}_{3}$ : \%C: 69.20, \% $\mathrm{H}: 10.32$; Experimental: \%C: $69.16, \% \mathrm{H}: 10.08$. 
$[\alpha]_{D}^{25}=-20.6^{\circ}\left(\mathrm{c}=0.9, \mathrm{CHCl}_{3}\right)$

$\underline{\left(5 S, 2^{\prime} R\right)-5-B e n c i l o x i-2-m e t i l-5-\left(2^{\prime}-m e t i l-o x i r a n i l\right)-2-p e n t a n o l ~(63) ~}$

ESPECTRO IR $v_{\max }$ (película) $\mathrm{cm}^{-1}$ (fig. 54a): 3400 (ancha), 3032, 2971-2870, 1454, 1377, 1096, 1072, 909, 737, 698.

ESPECTRO RMN ${ }^{1} \mathbf{H}\left(200 \mathrm{MHz}, \mathrm{CDCl}_{3}, \delta\right.$ ppm) (fig. 54b): 7.37-7.30 (5H, m, -Ph), $4.82\left(1 \mathrm{H}, \mathrm{d}, J=11.8 \mathrm{~Hz}, \mathrm{O}-\underline{\mathrm{CH}_{2}}-\mathrm{Ph}, \mathrm{H}_{\mathrm{A}}\right), 4.52\left(1 \mathrm{H}, \mathrm{d}, J=11.8 \mathrm{~Hz}, \mathrm{O}-\underline{\mathrm{CH}}_{2}-\mathrm{Ph}, \mathrm{H}_{\mathrm{B}}\right)$, $2.98(1 \mathrm{H}, \mathrm{dd}, J=10.0$ y $5.0 \mathrm{~Hz}, \mathrm{H}-3), 2.62\left(1 \mathrm{H}, \mathrm{d}, J=4.5 \mathrm{~Hz}, \mathrm{H}_{\mathrm{A}}-1\right), 2.54(1 \mathrm{H}, \mathrm{d}, J=$ 4.5 Hz, HB-1), 1.8-1.2 (4H, m, H-4 y H-5), 1.37 (3H, s, H-9), 1.21 (6H, s, H-7 y H-8).

ESPECTRO RMN ${ }^{13} \mathbf{C}\left(50 \mathrm{MHz}, \mathrm{CDCl}_{3}, \delta\right.$ ppm) (fig. 54c) (Tabla XXII).

ANÁLISIS ELEMENTAL: Calculado para $\mathrm{C}_{16} \mathrm{H}_{24} \mathrm{O}_{3}$ : \%C: $69.20, \% \mathrm{H}: 10.32$; Experimental: \%C: $69.59, \% \mathrm{H}: 10.23$.

$[\alpha]_{D}^{25}=-43.9^{\circ}\left(\mathrm{c}=0.8, \mathrm{CHCl}_{3}\right)$

\section{CICLACIÓN DE 62 CON CSA}

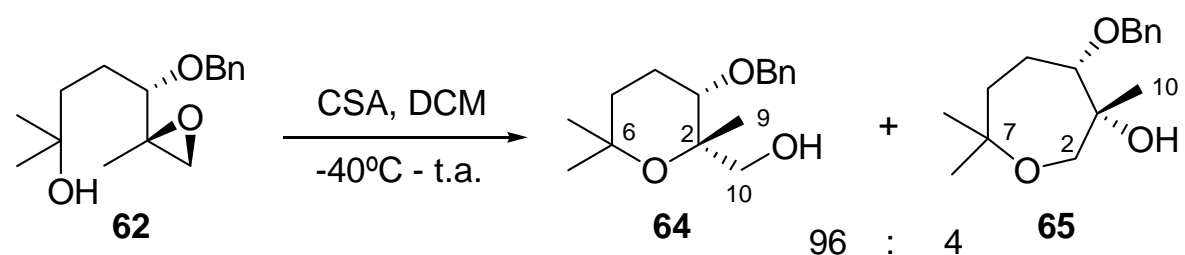

Se disuelven $134 \mathrm{mg}$ (0.51 mmoles) de 62 en $5 \mathrm{~mL}$ de DCM y se añaden $12 \mathrm{mg}$ (0.051 mmoles) de CSA a $-40{ }^{\circ} \mathrm{C}$. Se mantiene la mezcla agitando bajo atmósfera de argon dejando subir lentamente la temperatura. Transcurridas 48 horas se añaden 0.4 $\mathrm{mL}$ de $\mathrm{NEt}_{3}$ y se agita durante 10 minutos. A continuación se evapora el disolvente y se cromatografía el residuo por sílicagel flash (eluyente: hexano/AcOEt 9:1) para obtener $115 \mathrm{mg}(86 \%)$ del tetrahidropirano 64 y $5 \mathrm{mg}(4 \%)$ del oxepano $\mathbf{6 5}$, que presentan las siguientes propiedades físicas y espectroscópicas: 


\section{$\underline{(2 S, 3 S)-(3-B e n c i l o x i-2,6,6-t r i m e t i l-t e t r a h i d r o-p i r a n-2-i l)-m e t a n o l ~(64) ~}$}

ESPECTRO IR $v_{\max }$ (película) $\mathrm{cm}^{-1}$ (fig. 56a): 3400 (ancha), 2970-2870, 1454, 1366, 1101, 1072, 1030, 997, 737, 698.

ESPECTRO RMN ${ }^{1} \mathbf{H}$ (400 MHz, $\mathrm{CDCl}_{3}, \delta$ ppm) (fig. 56b): 7.35-7.31 (5H, m, -Ph), $4.66\left(1 \mathrm{H}, \mathrm{d}, J=11.7 \mathrm{~Hz}, \mathrm{O}-\underline{\mathrm{CH}}_{2}-\mathrm{Ph}, \mathrm{H}_{\mathrm{A}}\right), 4.42\left(1 \mathrm{H}, \mathrm{d}, J=11.7 \mathrm{~Hz}, \mathrm{O}-\underline{\mathrm{CH}}_{2}-\mathrm{Ph}, \mathrm{H}_{\mathrm{B}}\right)$, $3.74\left(1 \mathrm{H}, \mathrm{d}, J=11.7 \mathrm{~Hz}, \mathrm{H}_{\mathrm{A}}-10\right), 3.61\left(1 \mathrm{H}, \mathrm{d}, J=11.7 \mathrm{~Hz}, \mathrm{H}_{\mathrm{B}}-10\right), 3.37(1 \mathrm{H}, \mathrm{dd}, J=$ 3.7 y 8.2 Hz, H-3), 2.0-1.8 (2H, m, H-4), 1.8-1.4 (2H, m, H-5), 1.27 (3H, s, H-9), 1.26 y $1.22(3 \mathrm{H} \mathrm{c} / \mathrm{u}, \mathrm{s}, \mathrm{H}-7$ y H-8).

ESPECTRO RMN ${ }^{13} \mathbf{C}\left(100 \mathrm{MHz}, \mathrm{CDCl}_{3}, \delta\right.$ ppm) (fig. 56c) (TablaXXIII). $[\alpha]_{D}^{25}=+46.4^{\circ}\left(\mathrm{c}=0.7, \mathrm{CHCl}_{3}\right)$

\section{$\underline{(3 R, 4 S)-4-B e n c i l o x i-3,7,7-t r i m e t i l-o x e p a n-3-o l ~(65) ~}$}

ESPECTRO IR $v_{\max }$ (película) $\mathrm{cm}^{-1}$ (fig. 57a): 3400 (ancha), 2970-2870, 1456, 1375, $1098,737,698$.

ESPECTRO RMN ${ }^{1} \mathbf{H}\left(400 \mathrm{MHz}, \mathrm{CDCl}_{3}, \delta\right.$ ppm) (fig. 57b): 7.36-7.29 (5H, m, -Ph), $4.68\left(1 \mathrm{H}, \mathrm{d}, J=11.3 \mathrm{~Hz}, \mathrm{O}-\underline{\mathrm{CH}_{2}}-\mathrm{Ph}, \mathrm{H}_{\mathrm{A}}\right), 4.63\left(1 \mathrm{H}, \mathrm{d}, J=11.3 \mathrm{~Hz} \mathrm{O}-\underline{\mathrm{CH}}_{2}-\mathrm{Ph}, \mathrm{H}_{\mathrm{B}}\right)$, $3.81\left(1 \mathrm{H}, \mathrm{d}, J=11.1 \mathrm{~Hz}, \mathrm{H}_{\mathrm{A}}-2\right), 3.57\left(1 \mathrm{H}, \mathrm{d}, J=11.1 \mathrm{~Hz}, \mathrm{H}_{\mathrm{B}}-2\right), 3.51(1 \mathrm{H}, \mathrm{dd}, J=3.3$ y $7.9 \mathrm{~Hz}, \mathrm{H}-4), 1.9-1.2$ (4H, m, H-5 y H-6), 1.28 (3H, s, H-10), 1.23 y $1.22(3 \mathrm{H}$ c/u, s, H-8 y H-9)

ESPECTRO RMN ${ }^{13} \mathbf{C}\left(100 \mathrm{MHz}, \mathrm{CDCl}_{3}, \delta\right.$ ppm) (fig. 57c) (Tabla XXIII).

\section{CICLACIÓN DE 63 CON CSA}

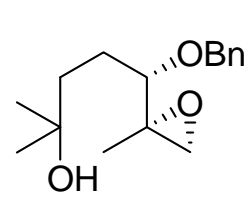

63

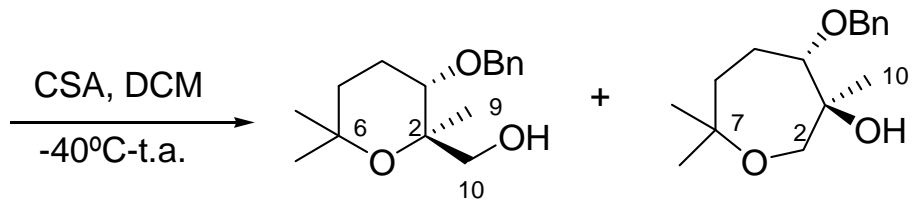

$66 \quad 85: 15$

67 
Se disuelven $135 \mathrm{mg}$ (0.51 mmoles) de $\mathbf{6 3}$ en $5 \mathrm{~mL}$ de DCM y se añaden $12 \mathrm{mg}$ (0.051 mmoles) de CSA a $-40{ }^{\circ} \mathrm{C}$. Se mantiene la mezcla agitando bajo atmósfera de argon dejando subir lentamente la temperatura. Transcurridas 48 horas se añaden 0.4 $\mathrm{mL}$ de $\mathrm{NEt}_{3}$ y se agita durante 10 minutos. A continuación se evapora el disolvente y se cromatografía el residuo $(155 \mathrm{mg}$ ) por sílicagel flash (eluyente: hexano/AcOEt 9:1) para obtener $102 \mathrm{mg}(76 \%)$ del tetrahidropirano 66 y $15 \mathrm{mg}$ (11\%) del oxepano 67, que presentan las siguientes propiedades físicas y espectroscópicas:

\section{$\underline{(2 R, 3 S)-(3-B e n c i l o x i-2,6,6-t r i m e t i l-t e t r a h i d r o-p i r a n-2-i l)-m e t a n o l ~(66) ~}$}

ESPECTRO IR $v_{\max }$ (película) $\mathrm{cm}^{-1}$ (fig. 58a): 3400 (ancha), 2970-2870, 1454, 1364, 1127, 1099, 1049, 993, 735, 698.

ESPECTRO RMN ${ }^{1} \mathbf{H}\left(200 \mathrm{MHz}, \mathrm{CDCl}_{3}, \delta\right.$ ppm) (fig. 58b): 7.35-7.31 (5H, m, -Ph), $4.65\left(1 \mathrm{H}, \mathrm{d}, J=11.7 \mathrm{~Hz}, \mathrm{O}-\underline{\mathrm{CH}_{2}}-\mathrm{Ph}, \mathrm{H}_{\mathrm{A}}\right), 4.51\left(1 \mathrm{H}, \mathrm{d}, J=11.7 \mathrm{~Hz}, \mathrm{O}-\underline{\mathrm{CH}}_{2}-\mathrm{Ph}, \mathrm{H}_{\mathrm{B}}\right)$, $3.63(1 \mathrm{H}, \mathrm{dd}, J=4.4$ y $10.8 \mathrm{~Hz}, \mathrm{H}-3), 3.48\left(1 \mathrm{H}, \mathrm{d}, J=10.5 \mathrm{~Hz}, \mathrm{H}_{\mathrm{A}}-10\right), 3.31(1 \mathrm{H}, \mathrm{d}, J=$ 10.5 Hz, HB-10), 2.0-1.4 (4H, m, H-4 y H-5), 1.30 (3H, s, H-9), 1.19 (6H, s, H-7 y H-8).

ESPECTRO RMN ${ }^{13} \mathbf{C}\left(50 \mathrm{MHz}, \mathrm{CDCl}_{3}, \delta \mathrm{ppm}\right)$ (fig. 58c) (Tabla XXIII).

LRMS, CI ( $\mathrm{NH}_{3}$ ), m/z (\%) (fig. 58d): 91 (4), 108 (4), 157 (43), 174 (11), 233 (23), 247 (51), $265(100)(\mathrm{M}+\mathrm{H})^{+}, 282(58)\left(\mathrm{M}+\mathrm{NH}_{4}\right)^{+}$.

HRMS, CI $\left(\mathrm{NH}_{3}\right)$ : Calculado para $\mathrm{C}_{16} \mathrm{H}_{25} \mathrm{O}_{3}(M+\mathrm{H})^{+}$, 265.1804. Experimental $(\mathrm{M}+$ $\mathrm{H})^{+}, 265.1807$.

$$
[\alpha]_{D}^{25}=+41.4^{\circ}\left(\mathrm{c}=0.7, \mathrm{CHCl}_{3}\right)
$$

\section{$\underline{(3 S, 4 S)-4-B e n c i l o x i-3,7,7-t r i m e t i l-o x e p a n-3-o l ~(67) ~}$}

ESPECTRO IR $v_{\max }$ (película) $\mathrm{cm}^{-1}$ (fig. 59a): 3400 (ancha), 2970-2870, 1454, 1377, $1092,737,698$.

ESPECTRO RMN ${ }^{1} \mathbf{H}\left(400 \mathrm{MHz}, \mathrm{CDCl}_{3}, \delta\right.$ ppm) (fig. 59b): 7.37-7.30 (5H, m, -Ph), $4.71\left(1 \mathrm{H}, \mathrm{d}, J=11.1 \mathrm{~Hz}, \mathrm{O}-\underline{\mathrm{CH}_{2}}-\mathrm{Ph}, \mathrm{H}_{\mathrm{A}}\right), 4.65\left(1 \mathrm{H}, \mathrm{d}, J=11.1 \mathrm{~Hz}, \mathrm{O}-\underline{\mathrm{CH}}_{2}-\mathrm{Ph}, \mathrm{H}_{\mathrm{B}}\right)$, $3.65(1 \mathrm{H}, \mathrm{m}, \mathrm{H}-4), 4.64\left(1 \mathrm{H}, \mathrm{d}, J=10.8 \mathrm{~Hz}, \mathrm{H}_{\mathrm{A}}-2\right), 4.45\left(1 \mathrm{H}, \mathrm{d}, J=10.8 \mathrm{~Hz}, \mathrm{H}_{\mathrm{B}}-2\right)$, 1.8-1.5 (4H, m, H-5 y H-6), 1.28 (3H, s, H-10), 1.23 y 1.22 (3H c/u, s, H-8 y H-9). 
ESPECTRO RMN ${ }^{13} \mathbf{C}\left(100 \mathrm{MHz}, \mathrm{CDCl}_{3}, \delta\right.$ ppm) (fig. 59c) (Tabla XXIII).

LRMS, CI (NH 3 ), m/z (\%) (fig. 59d): 81 (9), 91 (57), 99 (87), 108 (60), 157 (17), 175 (99), $191(44), 265(15)(\mathrm{M}+\mathrm{H})^{+}$.

\section{OXIDACIÓN DE 64 CON TPAP}

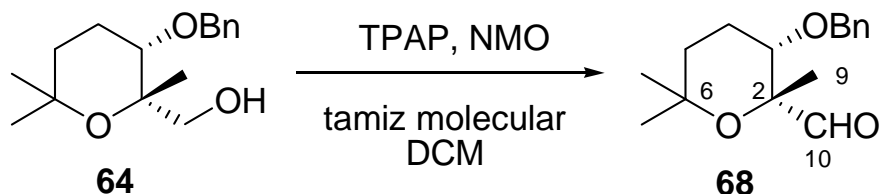

Sobre una disolución de 64 (103 mg, 0.39 mmoles) en 4 mL de DCM se añade tamiz molecular ( $3 \AA$, activado), NMO (158 mg, 1.17 mmoles) y una cantidad catalítica de TPAP. Tras agitar la mezcla a temperatura ambiente durante una hora, se filtra por sílice lavando abundantemente con DCM para obtener $65 \mathrm{mg}$ (64\%) del aldehído 68, que presenta las siguientes propiedades físicas y espectroscópicas:

\section{$\underline{(2 R, 3 S)-3-B e n c i l o x i-2,6,6-t r i m e t i l-t e t r a h i d r o-p i r a n-2-c a r b a l d e h i ́ d o ~(68) ~}$}

ESPECTRO IR $v_{\max }$ (película) $\mathrm{cm}^{-1}$ (fig. 60a): 2970-2870,1736, 1452, 1370, 1258, $1111,737,698$.

ESPECTRO RMN ${ }^{1} \mathbf{H}\left(200 \mathrm{MHz}, \mathrm{CDCl}_{3}, \delta\right.$ ppm) (fig. 60b): 9.71 (1H, s, H-10), 7.35$7.30(5 \mathrm{H}, \mathrm{m},-\mathrm{Ph}), 4.58\left(1 \mathrm{H}, \mathrm{d}, J=11.8 \mathrm{~Hz}, \mathrm{O}-\underline{\mathrm{CH}}_{2}-\mathrm{Ph}, \mathrm{H}_{\mathrm{A}}\right), 4.37(1 \mathrm{H}, \mathrm{d}, J=11.8 \mathrm{~Hz}$, $\left.\mathrm{O}-\underline{\mathrm{CH}}_{2}-\mathrm{Ph}, \mathrm{H}_{\mathrm{B}}\right), 3.48(1 \mathrm{H}, \mathrm{dd}, J=2.7$ y $5.9 \mathrm{~Hz}, \mathrm{H}-3), 1.9-1.3(4 \mathrm{H}, \mathrm{m}, \mathrm{H}-4$ y H-5), 1.28 (3H, s, H-9), 1.27 (6H, s, H-7 y H-8).

ESPECTRO RMN ${ }^{13} \mathbf{C}\left(50 \mathrm{MHz}, \mathrm{CDCl}_{3}, \delta \mathrm{ppm}\right)$ (fig. 60c) (Tabla XXIV).

HRMS, ESI (fig. 60d): Calculado para $\mathrm{C}_{16} \mathrm{H}_{22} \mathrm{O}_{3} \mathrm{Na}(M+\mathrm{Na})^{+}, 285.1461$. Experimental $(\mathrm{M}+\mathrm{Na})^{+}, 285.1474$.

$[\alpha]_{D}^{25}=+65.5^{\circ}\left(\mathrm{c}=0.9, \mathrm{CHCl}_{3}\right)$ 


\section{OXIDACIÓN DE 66 CON TPAP}<smiles>CC1(C)CC[C@@H](Br)[C@H](CO)C1</smiles>

66

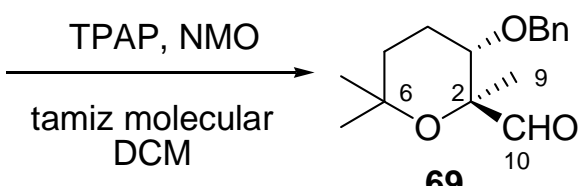

69

Sobre una disolución de 66 (70 mg, 0.26 mmoles) en $2.5 \mathrm{~mL}$ de DCM se añade tamiz molecular ( $3 \AA$, activado), NMO (107 mg, 0.79 mmoles) y una cantidad catalítica de TPAP. Tras agitar la mezcla a temperatura ambiente durante una hora, se filtra por sílice lavando abundantemente con DCM para obtener $51 \mathrm{mg}$ (73\%) del aldehído 69, que presenta las siguientes propiedades físicas y espectroscópicas:

\section{$\underline{(2 S, 3 S)-3-B e n c i l o x i-2,6,6-t r i m e t i l-t e t r a h i d r o-p i r a n-2-c a r b a l d e h i ́ d o ~(69) ~}$}

ESPECTRO IR $v_{\max }$ (película) $\mathrm{cm}^{-1}$ (fig. 61a): 2970-2870, 1736, 1452, 1370, 1258, 1213, 1111, 1026, 737, 698.

ESPECTRO RMN ${ }^{1} \mathbf{H}\left(200 \mathrm{MHz}, \mathrm{CDCl}_{3}, \delta\right.$ ppm) (fig.61b): 9.56 (1H, s, H-10), 7.35$7.30(5 \mathrm{H}, \mathrm{m},-\mathrm{Ph}), 4.63\left(1 \mathrm{H}, \mathrm{d}, J=11.8 \mathrm{~Hz}, \mathrm{O}-\underline{\mathrm{CH}}_{2}-\mathrm{Ph}, \mathrm{H}_{\mathrm{A}}\right), 4.46(1 \mathrm{H}, \mathrm{d}, J=11.8 \mathrm{~Hz}$, O- $\left.\underline{\mathrm{CH}}_{2}-\mathrm{Ph}, \mathrm{H}_{\mathrm{B}}\right), 3.75$ (1H, sa, H-3), 2.0-1.5 (4H, m, H-4 y H-5), 1.30 (3H, s, H-9), 1.20 y $1.15(3 \mathrm{H} \mathrm{c} / \mathrm{u}, \mathrm{s}, \mathrm{H}-7$ y H-8).

ESPECTRO RMN ${ }^{13} \mathbf{C}\left(50 \mathrm{MHz}, \mathrm{CDCl}_{3}, \delta\right.$ ppm) (fig. 61c) (Tabla XXIV).

HRMS, ESI (fig. 61d): Calculado para $\mathrm{C}_{16} \mathrm{H}_{22} \mathrm{O}_{3} \mathrm{Na}(M+\mathrm{Na})^{+}, 285.1461$. Experimental $(\mathrm{M}+\mathrm{Na})^{+}, 285.1457$.

$[\alpha]_{D}^{25}=+76.3^{\circ}\left(\mathrm{c}=0.9, \mathrm{CHCl}_{3}\right)$

\section{REORDENAMIENTO OXIDATIVO DEL ALDEHÍDO 68}

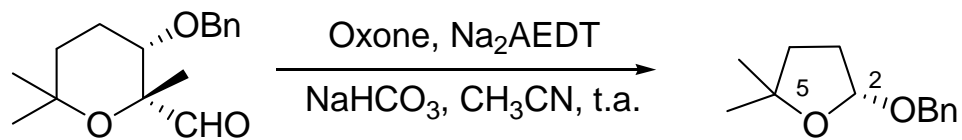

68 
Sobre una disolución de 68 (13 mg, $0.05 \mathrm{mmol})$ en $\mathrm{CH}_{3} \mathrm{CN}(0.8 \mathrm{~mL})$ a temperatura ambiente, se añaden $0.5 \mathrm{~mL}$ de una disolución acuosa $0.4 \mathrm{mM}$ de $\mathrm{Na}_{2}$ AEDT. Seguidamente, se añade una mezcla de Oxone ${ }^{\circledR}(150 \mathrm{mg}, 0.25 \mathrm{mmol}$ $\left.\mathrm{KHSO}_{5}\right)$ y $\mathrm{NaHCO}_{3}(66 \mathrm{mg}, 0.77 \mathrm{mmol})$ en pequeñas porciones durante 30 minutos. Se deja agitando vigorosamente la mezcla de reacción a temperatura ambiente durante 12 horas. Pasado este tiempo se diluye con $\mathrm{H}_{2} \mathrm{O}(10 \mathrm{~mL})$ y se extrae con AcOEt $(3 \mathrm{x} 15$ $\mathrm{mL}$ ). Las fases orgánicas combinadas se lavan con disolución acuosa saturada de $\mathrm{NaCl}$ y se secan sobre $\mathrm{Na}_{2} \mathrm{SO}_{4}$ anhidro. Tras filtrar y evaporar el disolvente, el crudo se purifica por cromatografía en columna sobre sílicagel flash (eluyente: hexano/AcOEt, 95:5), obteniéndose $6 \mathrm{mg}(60 \%)$ del producto de reordenamiento 70, cuyas propiedades físicas y espectroscópicas se muestran a continuación:

$\underline{(2 R)-2-(B e n c i l o x i)-t e t r a h i d r o-5,5-d i m e t i l f u r a n o ~(70) ~}$

ESPECTRO IR $v_{\max }$ (película) $\mathrm{cm}^{-1}$ (fig. 62a): 2970, 2924, 1454, 1361, 1262, 1138, 1091, 1042, 1026, 1008, 962.

ESPECTRO RMN ${ }^{1} \mathbf{H}\left(200 \mathrm{MHz}, \mathrm{CDCl}_{3}, \delta\right.$ ppm) (fig. 62b): 7.34-7.25 (5H, m, -Ph), 5.15-5.17 (1H, m, H-2), $4.75\left(1 \mathrm{H}, \mathrm{d}, J=11.7 \mathrm{~Hz}, \mathrm{O}-\underline{\mathrm{CH}}_{2}-\mathrm{Ph}, \mathrm{H}_{\mathrm{A}}\right), 4.42(1 \mathrm{H}, \mathrm{d}, J=11.7$ $\left.\mathrm{Hz}, \mathrm{O}-\underline{\mathrm{CH}}_{2}-\mathrm{Ph}, \mathrm{H}_{\mathrm{B}}\right), 2.07-1.72$ (4H, m, H-3 y H-4), 1.40 y 1.24 (3H c/u, s, H-6).

ESPECTRO RMN ${ }^{13} \mathbf{C}\left(50 \mathrm{MHz}, \mathrm{CDCl}_{3}, \delta\right.$ ppm) (fig. 62c) (Tabla XXIV).

HRMS, ESI (fig. 62d): Calculado para $\mathrm{C}_{13} \mathrm{H}_{18} \mathrm{O}_{2} \mathrm{Na}(M+\mathrm{Na})^{+}, 229.1199$. Experimental $(\mathrm{M}+\mathrm{Na})^{+}, 229.1200$.

$[\alpha]_{D}^{25}=+79.4^{\circ}\left(\mathrm{c}=0.5, \mathrm{CHCl}_{3}\right)$

ee $=78 \%$ (Determinado por HPLC en una columna ChiralPak AD-H, $25 \mathrm{~cm} \mathrm{x} 10 \mathrm{~mm})$

\section{BENCILACIÓN DEL LACTOL 8}<smiles>CC1(C)CC[C@@H](O)O1</smiles>

8

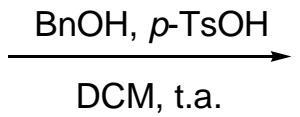

DCM, t.a<smiles>CC1(C)CC[C@@H](OCc2ccccc2)O1</smiles>

rac-70 
Se disuelve 8 (348 mg, $3.0 \mathrm{mmol}$ ) en DCM y se añade alcohol bencílico (3.24 g, $30.0 \mathrm{mmol}$ ) y una cantidad catalítica de $p$-TsOH. Se deja agitando a temperatura ambiente durante 30 minutos y posteriormente se para añadiendo disolución acuosa saturada de $\mathrm{NaHCO}_{3}(20 \mathrm{~mL})$ y DCM $(100 \mathrm{~mL})$. Se separan las fases, se lava la orgánica con disolución acuosa saturada de $\mathrm{NaCl}$ y se seca sobre $\mathrm{Na}_{2} \mathrm{SO}_{4}$ anhidro. Después de filtrar y evaporar el disolvente, se purifica el crudo por cromatografía en columna sobre sílicagel flash (eluyente: hexano/AcOEt 95:5) obteniendo $430 \mathrm{mg}$ (70\%) de rac-70, cuyas propiedades espectroscópicas ya han sido descritas.

\section{CICLACIÓN DE LINALOOL CON m-CPBA}

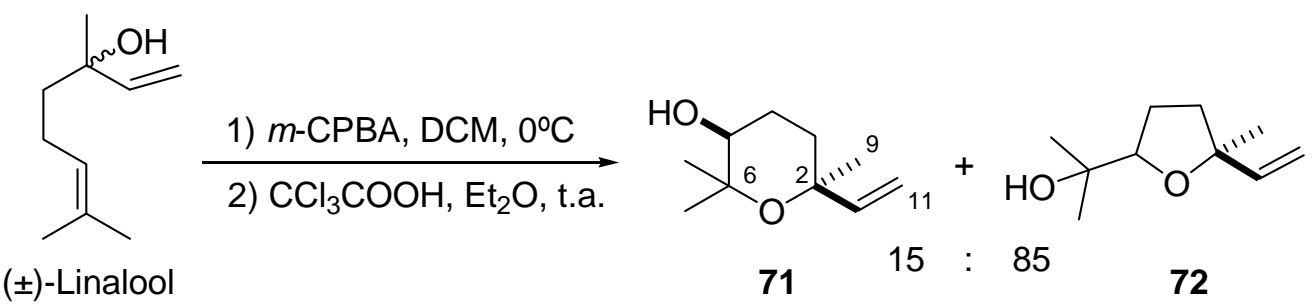

Sobre una disolución de ( \pm -linalool $(4.0 \mathrm{~g}, 25.9 \mathrm{mmol})$ en $\mathrm{DCM}(52 \mathrm{~mL})$ a $0^{\circ} \mathrm{C}$ se añaden $7.7 \mathrm{~g}(31.1 \mathrm{mmol})$ de $m$-CPBA $70 \%$. Se deja agitando la mezcla a esta temperatura durante 3 horas. Posteriormente se diluye con éter y se lava sucesivamente con disoluciones acuosas de $\mathrm{Na}_{2} \mathrm{SO}_{3}(10 \%), \mathrm{NaHCO}_{3}(5 \%)$ y $\mathrm{NaCl}$ (saturada). Se seca sobre $\mathrm{Na}_{2} \mathrm{SO}_{4}$ anhidro, se filtra y se evapora el éter obteniéndose $4.4 \mathrm{~g}$ de crudo que se redisuelven en $60 \mathrm{~mL}$ de éter. Se añaden $0.2 \mathrm{~mL}$ de ácido tricloroacético y se deja reaccionando la mezcla a temperatura ambiente durante 12 horas. Transcurrido este tiempo, se diluye con más éter $(200 \mathrm{~mL})$ y se lava con disoluciones acuosas de $\mathrm{Na}_{2} \mathrm{CO}_{3}$ $(10 \%)$ y $\mathrm{NaCl}$ (saturada). Tras secar sobre $\mathrm{Na}_{2} \mathrm{SO}_{4}$ anhidro, filtrar y evaporar el éter, se obtienen $4.1 \mathrm{~g}$ de crudo que se cromatografían en columna sobre sílicagel flash (eluyente: hexano/éter 4:1), obteniéndose una mezcla de 71/72 (3.5 g, 80\%) en una proporción 15:85. Dicha mezcla se volvió a cromatografiar (eluyente: hexano/AcOEt $9: 1 \rightarrow 85: 15)$ y se consiguieron aislar $130 \mathrm{mg}(4 \%)$ del diastereoisómero $\mathbf{7 1}$, cuyas propiedades espectroscópicas son las siguientes: 


\section{$\underline{\text { 2,2,6-Trimetil-6-vinil-tetrahidropiran-3-ol (71) }}$}

ESPECTRO IR $v_{\max }$ (película) $\mathrm{cm}^{-1}$ (fig. 63a): 3415 (ancha), 2976, 2943, 2874, 1452, 1410, 1365, 1229, 1156, 1078, 1001, 182, 911.

ESPECTRO RMN ${ }^{1} \mathbf{H}\left(200 \mathrm{MHz}, \mathrm{CDCl}_{3}, \delta\right.$ ppm) (fig. 63b): $5.92(1 \mathrm{H}, \mathrm{dd}, J=18.4 \mathrm{~Hz}$ y $11.0 \mathrm{~Hz}, \mathrm{H}-10), 4.93\left(1 \mathrm{H}, \mathrm{d}, J=11.0 \mathrm{~Hz}, \mathrm{H}-11_{\text {cis }}\right), 4.92(1 \mathrm{H}, \mathrm{d}, J=18.4 \mathrm{~Hz}, \mathrm{H}-$ 11trans), 3.41-3.34 (1H, m, H-5), 2.11-1.50 (4H, m, H-3 y H-4), 1.19 (3H, s, H-9), 1.11 $(6 \mathrm{H}, \mathrm{s}, \mathrm{H}-7$ y $\mathrm{H}-8)$.

ESPECTRO RMN ${ }^{13} \mathbf{C}\left(50 \mathrm{MHz}, \mathrm{CDCl}_{3}, \delta\right.$ ppm) (fig. 63c) (Tabla XXV).

HRMS, ESI (fig. 63d): Calculado para $\mathrm{C}_{10} \mathrm{H}_{18} \mathrm{O}_{2} \mathrm{Na}(M+\mathrm{Na})^{+}$, 193.1199. Experimental $(\mathrm{M}+\mathrm{Na})^{+}, 193.1210$.

\section{BENCILACIÓN DE 71}

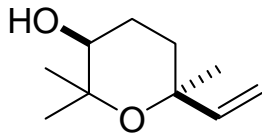

71

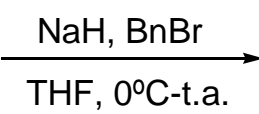

THF, $0^{\circ} \mathrm{C}-\mathrm{t} . \mathrm{a}$.

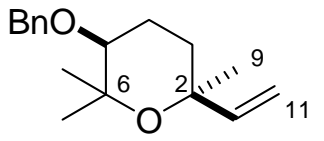

73

Sobre una suspension de $\mathrm{NaH}$ (37 mg, 0.92 mmoles, $60 \%$ en parafina y previamente lavado con dos porciones de THF de $2 \mathrm{~mL}$ ) en $3 \mathrm{~mL}$ de THF, se añaden $130 \mathrm{mg}(0.76 \mathrm{mmol})$ de 71 disueltos en $1 \mathrm{~mL}$ de THF bajo atmósfera de argon a $0^{\circ} \mathrm{C}$. A continuación se añaden $0.18 \mathrm{~mL}(1.53 \mathrm{mmol})$ de $\mathrm{BnBr}$ y se deja reaccionando a temperatura ambiente durante 12 horas. Pasado este tiempo se para la reacción añadiendo $1 \mathrm{~mL}$ de $\mathrm{H}_{2} \mathrm{O}$. Seguidamente se diluye la mezcla con $40 \mathrm{~mL}$ de agua, se extrae con AcOEt (x3) y las fases orgánicas combinadas se lavan con una disolución acuosa de $\mathrm{NaCl}$ (saturada). Se seca sobre $\mathrm{Na}_{2} \mathrm{SO}_{4}$ anhidro, se filtra y se evapora el disolvente para obtener $300 \mathrm{mg}$ de crudo que se cromatografían en columna sobre sílicagel flash (eluyente: hexano/AcOEt 95:15). Se aíslan $180 \mathrm{mg}$ (90\%) del bencilderivado $\mathbf{7 3}$, cuyas propiedades espectroscópicas son las siguientes: 


\section{$\underline{\text { 3-Benciloxi-2,2,6-trimetil-6-vinil-tetrahidropirano (73) }}$}

ESPECTRO IR $v_{\max }$ (película) $\mathrm{cm}^{-1}$ (fig. 64a): 2974, 2942, 2871, 1496, 1454, 1365, 1238, 1164, 1092, 986, 911.

ESPECTRO RMN ${ }^{1} \mathbf{H}\left(200 \mathrm{MHz}, \mathrm{CDCl}_{3}, \delta\right.$ ppm) (fig. 64b): 7.40-7.27 (5H, m, -Ph), $6.01(1 \mathrm{H}, \mathrm{dd}, J=17.2$ y $11.0 \mathrm{~Hz}, \mathrm{H}-10), 5.00(1 \mathrm{H}, \mathrm{d}, J=11.0 \mathrm{~Hz}, \mathrm{H}-11$ cis $), 4.99$ (1H, d, $\left.J=17.2 \mathrm{~Hz}, \mathrm{H}-11_{\text {trans }}\right), 4.67\left(1 \mathrm{H}, \mathrm{d}, J=11.7 \mathrm{~Hz}, \mathrm{O}-\underline{\mathrm{CH}_{2}}-\mathrm{Ph}, \mathrm{HA}_{\mathrm{A}}\right), 4.48(1 \mathrm{H}, \mathrm{d}, J=11.7$ Hz, O- $\left.\mathrm{CH}_{2}-\mathrm{Ph}, \mathrm{Hв}\right), 3.21$ (1H, dd, $J=11.0$ у $\left.4.2 \mathrm{~Hz}, \mathrm{H}-5\right), 2.21-1.51$ (4H, m, H-3 у H4), $1.27,1.24$ y 1.18 (3H c/u, s, H-7, H-8 y H-9).

ESPECTRO RMN ${ }^{13} \mathbf{C}\left(50 \mathrm{MHz}, \mathrm{CDCl}_{3}, \delta\right.$ ppm) (fig. 64c) (Tabla XXV).

HRMS, ESI (fig. 64d): Calculado para $\mathrm{C}_{17} \mathrm{H}_{24} \mathrm{O}_{2} \mathrm{Na}(M+\mathrm{Na})^{+}$, 283.1668. Experimental $(\mathrm{M}+\mathrm{Na})^{+}, 283.1657$.

\section{RUPTURA OXIDATIVA DEL BENCILDERIVADO 73}

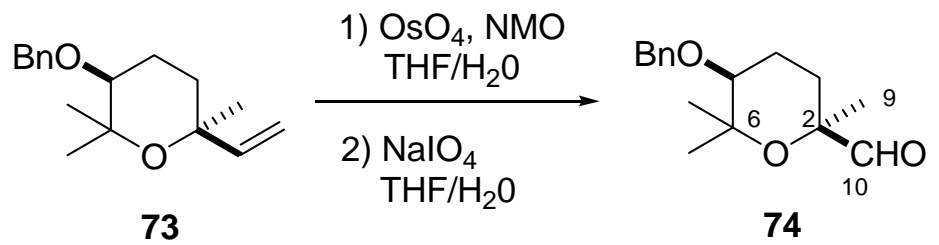

Sobre una disolución de 73 (100 mg, 0.38 mmoles) en $1 \mathrm{~mL}$ de THF/ $\mathrm{H}_{2} \mathrm{O}(2: 1)$ se añade una cantidad catalítica de $\mathrm{OsO}_{4}(0.1 \mathrm{~mL}$ de una disolución $2.5 \% \mathrm{p} / \mathrm{v}$ en $t$ butanol) y $183 \mathrm{mg}(1.34 \mathrm{mmol})$ de NMO y se deja agitando a temperatura ambiente durante 20 horas. Pasado este tiempo se para la reacción añadiendo $3 \mathrm{~mL}$ de una disolución acuosa saturada de $\mathrm{Na}_{2} \mathrm{SO}_{3}$. Tras dejar agitando durante 30 minutos, se extrae la fase acuosa con AcOEt (50 mL x 3). El combinado de fases orgánicas se lava sucesivamente con disolución acuosa de $\mathrm{Na}_{2} \mathrm{~S}_{2} \mathrm{O}_{3}(10 \%), \mathrm{H}_{2} \mathrm{O}$ y con disolución acuosa de $\mathrm{NaCl}$ (saturada). Se seca sobre $\mathrm{Na}_{2} \mathrm{SO}_{4}$ anhidro, se filtra y se evapora el disolvente para obtener $100 \mathrm{mg}$ de un crudo que se disuelve en $3 \mathrm{~mL}$ de $\mathrm{THF} / \mathrm{H}_{2} \mathrm{O}$ (5:1). Se añade $\mathrm{NaIO}_{4}(182 \mathrm{mg}, 0.85 \mathrm{mmol})$ y se deja reaccionando a temperatura ambiente durante 20 minutos, transcurridos los cuales se diluye la mezcla con $10 \mathrm{~mL}$ de $\mathrm{H}_{2} \mathrm{O}$. Se extrae con $\mathrm{Et}_{2} \mathrm{O}$ (x3) y se lavan las fases orgánicas con $\mathrm{H}_{2} \mathrm{O}$ y disolución acuosa 
saturada de $\mathrm{NaCl}$. Tras secar sobre $\mathrm{Na}_{2} \mathrm{SO}_{4}$ anhidro, filtrar y evaporar el disolvente se obtienen $86 \mathrm{mg}(84 \%)$ del aldehído 74, cuyas propiedades espectroscópicas son las siguientes:

\section{5-(Benciloxi)-2,6,6-trimetil-tetrahidro-piran-2-carbaldehído (74)}

ESPECTRO IR $v_{\max }$ (película) $\mathrm{cm}^{-1}$ (fig. 65a): 2975, 2929, 2867, 2789, 1728, 1454, 1361, 1257, 1097, 1009.

ESPECTRO RMN ${ }^{1} \mathbf{H}\left(200 \mathrm{MHz}, \mathrm{CDCl}_{3}, \delta\right.$ ppm) (fig. 65b): $9.60(1 \mathrm{H}, \mathrm{s}, \mathrm{H}-10), 7.34-$ $7.26(5 \mathrm{H}, \mathrm{m},-\mathrm{Ph}), 4.63\left(1 \mathrm{H}, \mathrm{d}, J=12.0 \mathrm{~Hz}, \mathrm{O}-\underline{\mathrm{CH}_{2}}-\mathrm{Ph}, \mathrm{HA}\right), 4.43(1 \mathrm{H}, \mathrm{d}, J=12.0 \mathrm{~Hz}$, $\left.\mathrm{O}-\mathrm{CH}_{2}-\mathrm{Ph}, \mathrm{Hв}\right), 3.21-3.15$ (1H, m, H-5), 2.41-1.35 (4H, m, H-3 у H-4), 1.31, 1.12 у 1.09 (3H c/u, s, H-7, H-8 y H-9).

ESPECTRO RMN ${ }^{13} \mathbf{C}\left(50 \mathrm{MHz}, \mathrm{CDCl}_{3}, \delta\right.$ ppm) (fig. 65c) (Tabla XXV).

\section{REORDENAMIENTO OXIDATIVO DEL ALDEHÍDO 74}<smiles>CC1(C)O[C@](C)(C=O)CCC1OBr</smiles>

74

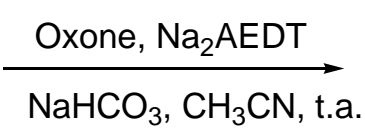

$\mathrm{NaHCO}_{3}, \mathrm{CH}_{3} \mathrm{CN}$, t.a.<smiles>CC(=O)CCC(OBr)C(C)(C)O</smiles>

75

Sobre una disolución de 74 (38 mg, $0.14 \mathrm{mmol})$ en $\mathrm{CH}_{3} \mathrm{CN}(2.4 \mathrm{~mL})$ a temperatura ambiente, se añaden $1.5 \mathrm{~mL}$ de una disolución acuosa $0.4 \mathrm{mM}$ de $\mathrm{Na}_{2}$ AEDT. Seguidamente, se añade una mezcla de Oxone ${ }^{\circledR}(450 \mathrm{mg}, 0.72 \mathrm{mmol}$ $\left.\mathrm{KHSO}_{5}\right)$ y $\mathrm{NaHCO}_{3}(190 \mathrm{mg}, 2.25 \mathrm{mmol})$ en pequeñas porciones durante 30 minutos. Se deja agitando vigorosamente la mezcla de reacción a temperatura ambiente durante 12 horas. Pasado este tiempo se diluye con $\mathrm{H}_{2} \mathrm{O}(10 \mathrm{~mL})$ y se extrae con AcOEt $(3 \mathrm{x} 15$ $\mathrm{mL}$ ). Las fases orgánicas combinadas se lavan con disolución acuosa saturada de $\mathrm{NaCl}$ y se secan sobre $\mathrm{Na}_{2} \mathrm{SO}_{4}$ anhidro. Tras filtrar y evaporar el disolvente, el crudo se purifica por cromatografía en columna sobre sílicagel flash (eluyente: hexano/AcOEt, 7:3), obteniéndose $18 \mathrm{mg}(50 \%)$ del producto de reordenamiento $\mathbf{7 5}$, cuyas propiedades espectroscópicas se muestran a continuación: 
5-(Benciloxi)-6-hidroxi-6-metilheptan-2-ona (75)

ESPECTRO IR $v_{\max }$ (película) $\mathrm{cm}^{-1}$ (fig. 66a): 3452, 2926, 2855, 1715, 1458, 1364, $1260,1096,1030$.

ESPECTRO RMN ${ }^{1} \mathbf{H}\left(200 \mathrm{MHz}, \mathrm{CDCl}_{3}, \delta\right.$ ppm) (fig. 66b): 7.33-7.31 (5H, m, -Ph), $4.62\left(2 \mathrm{H}, \mathrm{s}, \mathrm{O}-\mathrm{CH}_{2}-\mathrm{Ph}\right), 3.24$ (1H, dd, $J=8.2$ y $\left.3.4 \mathrm{~Hz}, \mathrm{H}-5\right), 2.5-2.48$ (2H, m, H-3), 2.08 (3H, s, H-1), 1.87-1.66 (2H, m, H-4), 1.23 (6H, s, H-7 y H-8).

ESPECTRO RMN ${ }^{13} \mathbf{C}\left(50 \mathrm{MHz}, \mathrm{CDCl}_{3}, \delta\right.$ ppm) (fig. 66c) (Tabla XXV).

HRMS, ESI (fig. 66d): Calculado para $\mathrm{C}_{15} \mathrm{H}_{22} \mathrm{O}_{3} \mathrm{Na}(M+\mathrm{Na})^{+}, 273.1461$. Experimental $(\mathrm{M}+\mathrm{Na})^{+}, 273.1451$. 
Capítulo II: Organocatálisis aplicada a la síntesis de tetrahidropiranos 



\section{SÍNTESIS DE $(S)-(-)-\alpha, \alpha$-DIFENIL-2-PIRROLIDINMETANOL TRIMETILSILIL ETER, 106}<smiles>OC(c1ccccc1)(c1ccccc1)C1CCCN1</smiles>

(S)-(-)- $\alpha, \alpha-$ difenil-2pirrolidinmetanol
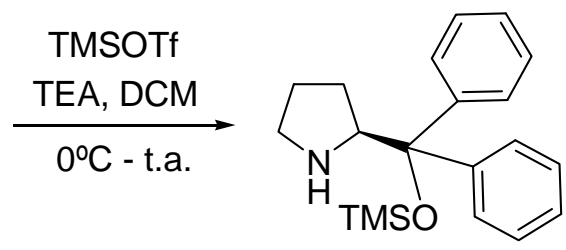

106

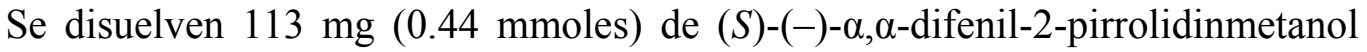
en $2 \mathrm{~mL}$ de DCM destilado y seco bajo atmósfera de argon y se baja la temperatura a $0^{\circ} \mathrm{C}$. Entonces se añaden sucesivamente $80 \mu \mathrm{L}(0.58$ mmoles $)$ de TEA y $105 \mu \mathrm{L}(0.58$ mmoles) de TMSOTf y se deja calentando lentamente hasta temperatura ambiente durante 17 horas. Transcurrido este tiempo se para la reacción añadiendo $0.5 \mathrm{~mL}$ de $\mathrm{H}_{2} \mathrm{O}$ y se extrae con DCM. El combinado de fases orgánicas se agita con $\mathrm{NaHCO}_{3}$ durante 15 minutos y posteriormente se filtra y se seca sobre $\mathrm{Na}_{2} \mathrm{SO}_{4}$ anhidro. Tras filtrar y evaporar el disolvente, se obtiene un crudo que se cromatografía en columna sobre sílicagel (eluyente: hexano/AcOEt 7:1 $\rightarrow$ 3:1). Se aíslan $135 \mathrm{mg}(91 \%)$ de (S)-(-)a, $\alpha$-difenil-2-pirrolidinmetanol trimetilsilil éter 106, cuyas propiedades espectroscópicas coinciden con las descritas en bibliografía. ${ }^{227}$

\section{SÍNTESIS DEL SULFAMIDATO CÍCLICO 143 A PARTIR DE (S)-PROLINOL}<smiles>OCC1CCCN1</smiles>

(S)-prolinol

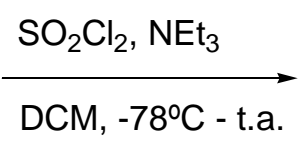

DCM, $-78^{\circ} \mathrm{C}$ - t.a.<smiles>O=S1(=O)OC[C@H]2CCCN21</smiles>

143

\footnotetext{
${ }^{227}$ Para la obtención de 106, ver: (a) Marigo, M.; Wabnitz, T. C.; Fielenbach, D.; Jørgensen, K. A.; Angew. Chem. Int. Ed. 2005, 44, 794; (b) Sundén, H.; Ibrahem, I.; Córdova, A. Tetrahedron Lett 2006, 47, 99; Para la obtención de 110, ver: Ishii, T.; Fujioka, S.; Sekiguchi, Y.; Kotsuki, H. J. Am. Chem. Soc. 2004, 126, 9558 y referencias allí citadas.
} 
Se disuelve (S)-prolinol (553 mg, 5.47 mmoles) y NEt 3 (1.5 mL, 10.95 mmoles) en $27 \mathrm{~mL}$ de DCM seco bajo atmósfera de argon y se baja la temperatura a $-78^{\circ} \mathrm{C}$. Entonces se añaden $5.5 \mathrm{~mL}$ de una disolución de $\mathrm{SO}_{2} \mathrm{Cl}_{2}$ en $\mathrm{DCM}$ y se deja agitando a esta temperatura durante 3 horas. Seguidamente se calienta lentamente hasta que alcanza temperatura ambiente y se deja reaccionando 10 horas más. Pasado este tiempo se diluye la mezcla con AcOEt y se lava con disoluciones acuosas de $\mathrm{HCl}(10 \%)$, $\mathrm{NaHCO}_{3}(5 \%)$ y $\mathrm{NaCl}$ (saturada). Se seca sobre $\mathrm{Na}_{2} \mathrm{SO}_{4}$ anhidro, se filtra y se evapora el disolvente, obteniéndose $500 \mathrm{mg}(56 \%)$ de 143, que se utiliza en la siguiente reacción sin previa purificación. Las propiedades espectroscópicas de este compuesto coinciden con las descritas en bibliografía. ${ }^{227}$

\section{SÍNTESIS DE (S)-2-(PIRROLIDIN-2-IL-METIL)PIRIDINA, 110}

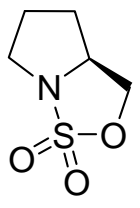

143
1. 2-bromopiridina

$n$-BuLi, THF

$-78^{\circ} \mathrm{C}-\mathrm{t} . \mathrm{a}$.

2. $\mathrm{HCl} / \mathrm{H}_{2} \mathrm{O}$

$\mathrm{EtOH}, \Delta$

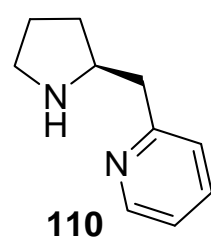

110

Sobre una disolución de 2-bromopiridina (126 mg, 0.79 mmoles) en $1 \mathrm{~mL}$ de THF seco a $-78^{\circ} \mathrm{C}$ se añaden $0.5 \mathrm{~mL}$ de una disolución de $n$-BuLi $1.6 \mathrm{M}$ en hexano y se deja la mezcla agitando a esta temperatura durante 1 hora. Pasado este tiempo se añade a $-78^{\circ} \mathrm{C}$ una disolución del sulfamidato 143 (100 mg, $\left.0.61 \mathrm{mmoles}\right)$ en $2 \mathrm{~mL}$ de THF y se agita la mezcla durante 12 horas dejando calentar progresivamente hasta temperatura ambiente. Tras evaporar el disolvente, se añaden sobre el residuo $1 \mathrm{~mL}$ de $\mathrm{HCl} 6 \mathrm{M}$ caliente y $1 \mathrm{~mL}$ de EtOH y se deja reaccionando durante 12 horas. Transcurrido este tiempo se lleva la mezcla hasta $\mathrm{pH}$ básico por adición de una disolución acuosa de $\mathrm{NaOH}$ al $50 \%$ y se extrae con DCM. Las fases orgánicas combinadas se lavan con $\mathrm{H}_{2} \mathrm{O}$ y disolución acuosa saturada de $\mathrm{NaCl}$. Se seca sobre $\mathrm{Na}_{2} \mathrm{SO}_{4}$ anhidro, se filtra y se evapora el disolvente, obteniéndose un crudo que se cromatografía en columna sobre sílicagel flash (eluyente: $\mathrm{CHCl}_{3} / \mathrm{i}-\mathrm{PrNH}_{2}$ 19:1). Se aíslan $60 \mathrm{mg}$ (47\%) del catalizador 110, cuyas propiedades espectroscópicas coinciden con las descritas en bibliografía. ${ }^{227}$ 


\section{REDUCCIÓN DE (-)-2,3-O-ISOPROPILIDEN-D-ERITRONOLACTONA}

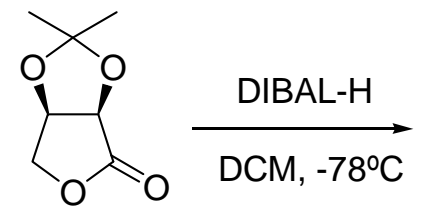

(-)-2,3-O-isopropilidenD-eritronolactona

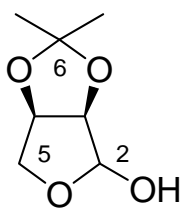

76

Sobre una disolución de (-)-2,3-O-isopropiliden-D-eritronolactona (3.00 g, 18.98 mmol) en $190 \mathrm{~mL}$ de DCM se añaden $15.2 \mathrm{~mL}(22.78 \mathrm{mmol})$ de una disolución $1.5 \mathrm{M}$ de DIBAL-H en tolueno. Se mantiene la reacción a esta temperatura con buena agitación durante 30 minutos. Pasado este tiempo se añaden $5 \mathrm{~mL}$ de agua y se deja calentar lentamente hasta temperatura ambiente. A continuación se diluye la mezcla en $1 \mathrm{~L}$ de éter, se añaden $10 \mathrm{~g}$ de $\mathrm{NaHCO}_{3}, 10 \mathrm{~g}$ de $\mathrm{Na}_{2} \mathrm{SO}_{4}$ anhidro y se deja agitando a temperatura ambiente durante 3 horas, transcurridas las cuales se filtra por celita y se evapora el éter aislándose el lactol $76(2.80 \mathrm{~g}, 92 \%)$. Las propiedades físicas y espectroscópicas de este compuesto son las siguientes:

\section{$\underline{\text { 2,3-O-isopropiliden-D-eritronolactol (76) }}$}

ESPECTRO IR $v_{\max }$ (película) $\mathrm{cm}^{-1}$ (fig. 67a): 3500 (ancha), 2944, 1375, 1211, 1099, $1069,988$.

ESPECTRO RMN ${ }^{1} \mathbf{H}\left(200 \mathrm{MHz}, \mathrm{CDCl}_{3}, \delta\right.$ ppm) (fig. 67b): $5.43(1 \mathrm{H}, \mathrm{d}, J=2.2 \mathrm{~Hz}$, H-2), $4.84(1 \mathrm{H}, \mathrm{m}, \mathrm{H}-3), 4.59(1 \mathrm{H}, \mathrm{d}, J=5.8 \mathrm{~Hz}, \mathrm{H}-4), 4.10(1 \mathrm{H}, \mathrm{dd}, J=5.8$ y $10.6 \mathrm{~Hz}$, $\left.\mathrm{H}_{\mathrm{A}}-5\right), 4.04\left(1 \mathrm{H}, \mathrm{d}, J=10.6 \mathrm{~Hz}, \mathrm{H}_{\mathrm{B}}-5\right), 1.47$ y 1.31 (3H c/u, s, H-7 y H-8).

ESPECTRO RMN ${ }^{13} \mathbf{C}\left(50 \mathrm{MHz}, \mathrm{CDCl}_{3}, \delta\right.$ ppm) (fig. 67c) (Tabla XXVI).

$[\alpha]_{D}^{25}=-10.5^{\circ}\left(\mathrm{c}=0.1, \mathrm{CHCl}_{3}\right)$ 


\section{$\underline{\text { REACCIÓN DE } 76 \text { CON MeSO }} 2 \underline{\text { Ph/n-BuLi }}$}

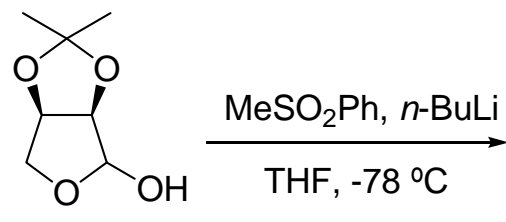

76

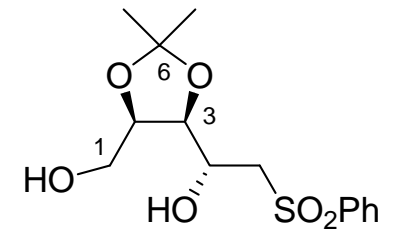

77

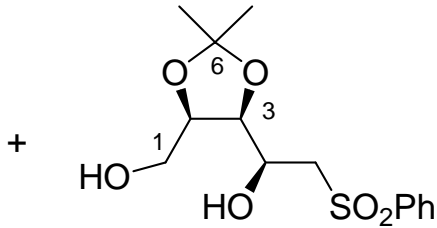

78

Sobre una disolución de $\mathrm{MeSO}_{2} \mathrm{Ph}(4.10 \mathrm{~g}, 26.3 \mathrm{mmol})$ en $40 \mathrm{~mL}$ de THF se añaden lentamente $16.4 \mathrm{~mL}(26.3 \mathrm{mmol})$ de una disolución de $n$-BuLi 1.6M en hexano, bajo atmósfera de argon y a $0{ }^{\circ} \mathrm{C}$. La mezcla se mantiene agitando durante 10 minutos a esta temperaratura. Pasado este tiempo, se enfría a $-78{ }^{\circ} \mathrm{C}$ y se añade sobre una disolución del lactol 76 (2.80 g, $17.5 \mathrm{mmol})$ en $60 \mathrm{~mL}$ de THF, a $-78^{\circ} \mathrm{C}$. Después de 30 minutos de reacción, se retira el baño frío y la mezcla se agita durante $2 \mathrm{~h}$, dejando alcanzar temperatura ambiente. La reacción se para adicionando unas gotas de una disolución acuosa saturada de $\mathrm{NH}_{4} \mathrm{Cl}$ y se extrae con AcOEt. La fase orgánica se lava con disolución acuosa saturada de $\mathrm{NaCl}$, se seca sobre $\mathrm{Na}_{2} \mathrm{SO}_{4}$ y se evapora el disolvente, obteniéndose un crudo que se cromatografía en columna sobre sílicagel flash (eluyente: hexano/AcOEt 7:3). Se consiguen aislar $3.97 \mathrm{~g}(72 \%)$ del compuesto $77 \mathrm{y}$ $1.33 \mathrm{~g}(23 \%)$ del compuesto 78 en una relación 75/25. Las propiedades físicas y espectroscópicas de estos compuestos son las siguientes:

\section{$\underline{(2 R, 3 S, 4 R)-5-F e n i l s u l f o n i l-2,3-i s o p r o p i l i d e n d i o x i-p e n t a n o-1,4-d i o l ~(77) ~}$}

ESPECTRO IR $v_{\max }$ (película) $\mathrm{cm}^{-1}$ (fig. 68a): 3500 (ancha), 1306, 1142, 1071, 855.

ESPECTRO RMN ${ }^{1} \mathbf{H}\left(200 \mathrm{MHz}, \mathrm{CDCl}_{3}, \delta\right.$ ppm) (fig. 68b): 7.95-7.40 (5H, m, -Ar), 4.36-4.19 (2H, m, H-2 y H-3), 3.95-3.74 (3H, m, H-4 y H-1), 3.59 (1H, d, J=14.4 Hz, $\left.\mathrm{H}_{\mathrm{A}}-5\right), 3.19$ (1H, dd, $J=10.0$ y $\left.14.4 \mathrm{~Hz}, \mathrm{H}_{\mathrm{B}}-5\right), 1.41$ y 1.26 (3H c/u, s, H-7 y H-8).

ESPECTRO RMN ${ }^{13} \mathbf{C}\left(50 \mathrm{MHz}, \mathrm{CDCl}_{3}, \delta \mathrm{ppm}\right)$ (fig. 68c) (Tabla XXVII). $[\alpha]_{D}^{25}=-58.3^{\circ}\left(\mathrm{c}=0.9, \mathrm{CHCl}_{3}\right)$ 


\section{$\underline{(2 R, 3 S, 4 S)-5-F e n i l s u l f o n i l-2,3-i s o p r o p i l i d e n d i o x i-p e n t a n o-1,4-d i o l ~(78) ~}$}

ESPECTRO IR $v_{\max }$ (película) $\mathrm{cm}^{-1}$ (fig. 69a): 3500 (ancha), 1449, 1304, 1217, 1146.

ESPECTRO RMN ${ }^{1} \mathbf{H}\left(200 \mathrm{MHz}, \mathrm{CDCl}_{3}, \delta\right.$ ppm) (fig. 69b): 7.95-7.40 (5H, m, -Ar), 4.37 (1H, ddd, $J=2.6,3.6$ y 7.8 Hz, H-4), 4.23 (1H, m, H-2), 4.12 (1H, dd, $J=2.6$ y 6.6 Hz, H-3), $3.83(2 \mathrm{H}, \mathrm{t}, J=4.0 \mathrm{~Hz}, \mathrm{H}-1), 3.42\left(1 \mathrm{H}, \mathrm{dd}, J=8.2\right.$ y $\left.14.4 \mathrm{~Hz}, \mathrm{H}_{\mathrm{A}}-5\right), 3.30$ $\left(1 \mathrm{H}, \mathrm{dd}, J=3.6\right.$ y $\left.14.4 \mathrm{~Hz}, \mathrm{H}_{\mathrm{B}}-5\right), 1.48$ y 1.34 (3H c/u, s, H-7 y H-8).

ESPECTRO RMN ${ }^{13} \mathbf{C}\left(50 \mathrm{MHz}, \mathrm{CDCl}_{3}, \delta\right.$ ppm) (fig. 69c) (Tabla XXVII). $[\alpha]_{D}^{25}=-14.2^{\circ}\left(\mathrm{c}=1.2, \mathrm{CHCl}_{3}\right)$

\section{REACCIÓN DE 77 Y 78 CON TsCl}

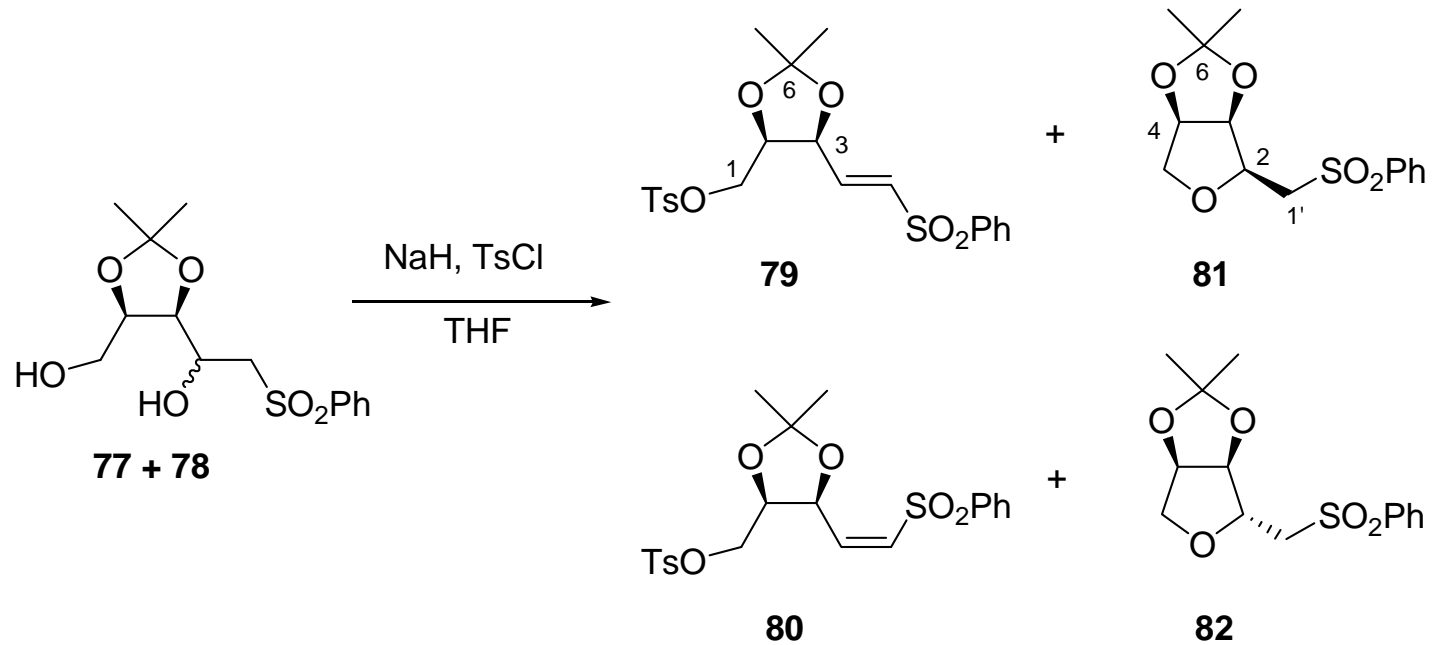

Una disolución de la mezcla dioles 77 y 78 (5.30 g, $16.80 \mathrm{mmol})$ en $20 \mathrm{~mL}$ de THF se añade sobre $\mathrm{NaH}(2.7 \mathrm{~g}, 67.1 \mathrm{mmol})$, previamente lavado con THF, a $0^{\circ} \mathrm{C}$. La mezcla se mantiene agitando a esta temperatura durante 40 minutos, transcurridos los cuales se enfría a $-78{ }^{\circ} \mathrm{C}$ y se añade una disolución de $\mathrm{TsCl}(19.20 \mathrm{~g}, 100.6 \mathrm{mmol})$ en THF (30 mL). Pasados 10 minutos se para la reacción añadiendo $\mathrm{HCl} 2 \mathrm{M}$ y se extrae con AcOEt. La fase orgánica se lava con agua y disolución acuosa saturada de $\mathrm{NaCl}$. Se seca sobre $\mathrm{Na}_{2} \mathrm{SO}_{4}$, se filtra y se evapora el disolvente obteniéndose un crudo que se cromatografía en columna sobre sílicagel flash (eluyente: hexano/AcOEt 85:15). Se 
obtiene la mezcla de olefinas $79(5.11$ g, 68\%) y $80(1.70$ g, 22\%) y de tetrahidrofuranos $81(100 \mathrm{mg}, 2 \%)$ y $82(150 \mathrm{mg}, 3 \%)$. Las propiedades físicas y espectroscópicas de estos compuestos se detallan a continuación:

\section{$\underline{(2 R, 3 S)}$-Tosilato de 5-fenilsulfonil-2,3-isopropilidendioxi-pent-E-4-en-1-ilo (79)}

ESPECTRO IR $v_{\max }$ (película) $\mathrm{cm}^{-1}$ (fig. 70a): 2990, 1368, 1177, 1150, 980.

ESPECTRO RMN ${ }^{1} \mathbf{H}\left(200 \mathrm{MHz}, \mathrm{CDCl}_{3}, \delta\right.$ ppm) (fig. 70b): 7.91-7.39 (9H, m, -Ar), $6.91(1 \mathrm{H}, \mathrm{dd}, J=3.8$ y $15.0 \mathrm{~Hz}, \mathrm{H}-4), 6.63(1 \mathrm{H}, \mathrm{dd}, J=1.4$ y $15.0 \mathrm{~Hz}, \mathrm{H}-5), 4.85(1 \mathrm{H}$, m, H-3), 4.44 (1H, ddd, $J=5.5,6.7$ y $6.7 \mathrm{~Hz}, \mathrm{H}-2), 3.93\left(1 \mathrm{H}, \mathrm{dd}, J=5.5\right.$ y $10.3 \mathrm{~Hz}, \mathrm{H}_{\mathrm{A}^{-}}$ 1), $3.79\left(1 \mathrm{H}, \mathrm{dd}, J=6.7\right.$ y $\left.10.3 \mathrm{~Hz}, \mathrm{H}_{\mathrm{B}}-1\right), 2.46(3 \mathrm{H}, \mathrm{s}, \mathrm{Ar}-\underline{\mathrm{Me}}), 1.37$ y $1.31(3 \mathrm{H} \mathrm{c} / \mathrm{u}, \mathrm{s}$, H-7 y H-8).

ESPECTRO RMN ${ }^{13} \mathbf{C}\left(50 \mathrm{MHz}, \mathrm{CDCl}_{3}, \delta \mathrm{ppm}\right)$ (fig. 70c) (Tabla XXVIII).

LRMS, EI, m/z (\%) (fig.70d): 452 (28) $\left(\mathrm{M}^{+}\right), 426$ (55), 414 (100).

HMRS, EI (fig. 70e): Calculado para $\mathrm{C}_{21} \mathrm{H}_{24} \mathrm{O}_{7} \mathrm{~S}_{2}\left(M^{+}\right)$, 452.0963. Experimental $\left(\mathrm{M}^{+}\right)$, 452.0945 .

$[\alpha]_{D}^{25}=-3.2^{\circ}\left(\mathrm{c}=0.8, \mathrm{CHCl}_{3}\right)$.

\section{$\underline{(2 R, 3 S) \text {-Tosilato de 5-fenilsulfonil-2,3-isopropilidendioxi-pent-Z-4-en-1-ilo (80) }}$}

ESPECTRO IR $v_{\max }$ (película) $\mathrm{cm}^{-1}$ (fig. 71a): 1456, 1364, 1308, 1177, 988.

ESPECTRO RMN ${ }^{1} \mathbf{H}\left(200 \mathrm{MHz}, \mathrm{CDCl}_{3}, \delta\right.$ ppm) (fig. 71b): 7.95-7.31 (9H, m, -Ar), 6.34-6.20 (2H, m, H-4 y H-5), $5.72(1 \mathrm{H}, \mathrm{dd}, J=5.4$ y $7.4 \mathrm{~Hz}, \mathrm{H}-3), 4.62$ (1H, ddd, $J=$ $3.8,4.8$ y $7.4 \mathrm{~Hz}, \mathrm{H}-2), 4.11\left(1 \mathrm{H}, \mathrm{dd}, J=3.8\right.$ y $\left.10.6 \mathrm{~Hz}, \mathrm{H}_{\mathrm{A}}-5\right), 3.94(1 \mathrm{H}, \mathrm{dd}, J=4.8$ y $\left.10.6 \mathrm{~Hz}, \mathrm{H}_{\mathrm{B}}-5\right), 2.44$ (3H, s, Ar-Me), 1.44 y 1.36 (3H c/u, s, H-7 y H-8).

ESPECTRO RMN ${ }^{13} \mathbf{C}\left(50 \mathrm{MHz}, \mathrm{CDCl}_{3}, \delta \mathrm{ppm}\right)$ (fig. 71c) (Tabla XXVIII).

LRMS, EI, m/z (\%) (fig. 71d): 452 (5) (M+), 437 (25), 267 (10), 238 (20), 209 (30), 155 (50), 125 (60), 91 (100).

HMRS, EI (fig. 71e): Calculado para $\mathrm{C}_{21} \mathrm{H}_{24} \mathrm{O}_{7} \mathrm{~S}_{2}\left(M^{+}\right)$, 452.0963. Experimental $\left(\mathrm{M}^{+}\right)$, 452.0964 .

$[\alpha]_{D}^{25}=+184.0^{\circ}\left(\mathrm{c}=1.3, \mathrm{CHCl}_{3}\right)$. 


\section{$\underline{(2 S, 3 S, 4 R)-2-F e n i l s u l f o n i l m e t i l-3,4-i s o p r o p i l i d e n d i o x i-t e t r a h i d r o f u r a n o ~(81) ~}$}

ESPECTRO IR $v_{\max }$ (película) $\mathrm{cm}^{-1}$ (fig. 72a): 2932, 1308, 1148, 1086.

ESPECTRO RMN ${ }^{1} \mathbf{H}\left(200 \mathrm{MHz}, \mathrm{CDCl}_{3}, \delta\right.$ ppm) (fig. 72b): 7.96-7.19 (5H, m, -Ar), $4.73(1 \mathrm{H}, \mathrm{dd}, J=3.2$ y $5.8 \mathrm{~Hz}, \mathrm{H}-4), 4.60(1 \mathrm{H}, \mathrm{dd}, J=3.6$ y $5.8 \mathrm{~Hz}, \mathrm{H}-3), 3.97$ (1H, m, H-2), $3.95\left(1 \mathrm{H}, \mathrm{d}, J=11.0 \mathrm{~Hz}, \mathrm{H}_{\mathrm{A}}-5\right), 3.60\left(1 \mathrm{H}, \mathrm{dd}, J=4.8\right.$ y $14.8 \mathrm{~Hz}, \mathrm{H}_{\mathrm{A}}-1$ '), 3.46 $\left(1 \mathrm{H}, \mathrm{d}, J=14.8 \mathrm{~Hz}, \mathrm{H}_{\mathrm{B}}-1^{\prime}\right), 3.44\left(1 \mathrm{H}, \mathrm{dd}, J=3.2\right.$ y $\left.11.0 \mathrm{~Hz}, \mathrm{H}_{\mathrm{B}}-5\right), 1.41$ y $1.28(3 \mathrm{H} \mathrm{c} / \mathrm{u}$, s, H-7 y H-8).

ESPECTRO RMN ${ }^{13} \mathbf{C}\left(50 \mathrm{MHz}, \mathrm{CDCl}_{3}, \delta\right.$ ppm) (fig.72c) (Tabla XXVI).

LRMS, $\mathrm{FAB}^{+}, \mathrm{m} / \mathrm{z}$ (\%) (fig. $\left.72 \mathrm{~d}\right): 299$ (5) (M + H) ${ }^{+}, 154$ (100), 107 (22), 69 (28).

HMRS, $\mathrm{FAB}^{+}$(fig. 72e): Calculado para $\mathrm{C}_{14} \mathrm{H}_{19} \mathrm{O}_{5} \mathrm{~S}(M+\mathrm{H})^{+}$, 299. 0953. Experimental $(\mathrm{M}+\mathrm{H})^{+}, 299.0958$.

$[\alpha]_{D}^{25}=-17.8^{\circ}\left(\mathrm{c}=0.7, \mathrm{CHCl}_{3}\right)$.

$\underline{(2 R, 3 S, 4 R)-2-F e n i l s u l f o n i l m e t i l-3,4-i s o p r o p i l i d e n d i o x i-t e t r a h i d r o f u r a n o ~(82) ~}$

ESPECTRO IR $v_{\max }$ (película) $\mathrm{cm}^{-1}$ (fig. 73a): 2932,1308, 1144, 1080.

ESPECTRO RMN ${ }^{1} \mathbf{H}\left(200 \mathrm{MHz}, \mathrm{CDCl}_{3}, \delta\right.$ ppm) (fig. 73b): 7.96-7.19 (5H, m, -Ar), $4.77(1 \mathrm{H}, \mathrm{m}, \mathrm{H}-4), 4.68(1 \mathrm{H}, \mathrm{dd}, J=1.6$ y $6.2 \mathrm{~Hz}, \mathrm{H}-3), 4.39(1 \mathrm{H}, \mathrm{dt}, J=1.6$ y $6.6 \mathrm{~Hz}$, H-2), $3.86\left(1 \mathrm{H}, \mathrm{d}, J=10.9 \mathrm{~Hz}, \mathrm{H}_{\mathrm{A}}-5\right), 3.65\left(1 \mathrm{H}, \mathrm{dd}, J=4.3\right.$ y $\left.10.9 \mathrm{~Hz}, \mathrm{H}_{\mathrm{B}}-5\right), 3.28(1 \mathrm{H}$, dd, $J=6.8$ y $\left.14.4 \mathrm{~Hz}, \mathrm{H}_{\mathrm{A}}-1^{\prime}\right), 3.20\left(1 \mathrm{H}, \mathrm{dd}, J=6.6\right.$ y $14.4 \mathrm{~Hz}, \mathrm{H}_{\mathrm{B}}-1$ ') 1.41 y $1.28(3 \mathrm{H}$ c/u, s, H-7 y H-8).

ESPECTRO RMN ${ }^{13} \mathbf{C}\left(50 \mathrm{MHz}, \mathrm{CDCl}_{3}, \delta\right.$ ppm) (fig. 73c) (Tabla XXVI).

$[\alpha]_{D}^{25}=-14.0^{\circ}\left(\mathrm{c}=0.3, \mathrm{CHCl}_{3}\right)$. 


\section{CICLACIÓN DE 79 CON BnNH $2 \underline{2}$}
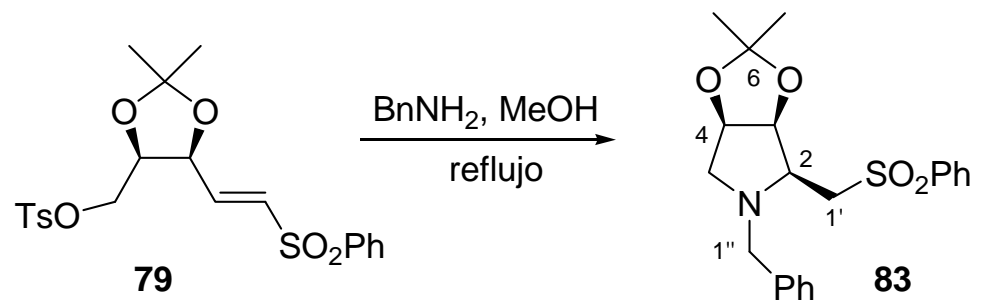

Sobre una disolución de 79 (48 mg, $0.10 \mathrm{mmol})$ en $1.5 \mathrm{~mL}$ de $\mathrm{MeOH}$ se añade $\mathrm{BnNH}_{2}(45 \mu \mathrm{L}, 0.40 \mathrm{mmol})$. La disolución se calienta a reflujo $\left(65^{\circ} \mathrm{C}\right)$ bajo atmósfera de argon durante 12 horas. Pasado este tiempo, se evapora el $\mathrm{MeOH}$, y el residuo obtenido se diluye con agua y se extrae con AcOEt. La fase orgánica se lava con agua y disolución acuosa saturada de $\mathrm{NaCl}$. Se seca sobre $\mathrm{Na}_{2} \mathrm{SO}_{4}$, se filtra y se evapora el disolvente, obteniéndose un crudo que se cromatografía en columna sobre sílicagel flash (eluyente: hexano/AcOEt 85:15), aislándose $30 \mathrm{mg}$ (78\%) del compuesto 83, el cual presenta las siguientes propiedades físicas y espectroscópicas:

\section{$\underline{(2 S, 3 S, 4 R)-N \text {-Bencil-2-fenilsulfonilmetil-3,4-isopropilidendioxipirrolidina (83) }}$}

ESPECTRO IR $v_{\max }$ (película) $\mathrm{cm}^{-1}$ (fig. 74a): 2938, 2805, 1447, 1306, 1150, 1086.

ESPECTRO RMN ${ }^{1} \mathbf{H}\left(200 \mathrm{MHz}, \mathrm{CDCl}_{3}, \delta\right.$ ppm) (fig. 74b): 7.96-7.19 (10H, m, -Ar), $4.57(1 \mathrm{H}, \mathrm{dd}, J=4.4$ y $10.8 \mathrm{~Hz}, \mathrm{H}-4), 4.53(1 \mathrm{H}, \mathrm{dd}, J=5.1$ y $10.8 \mathrm{~Hz}, \mathrm{H}-3), 3.88(1 \mathrm{H}$, d, $J=13.9 \mathrm{~Hz}, \mathrm{H}_{\mathrm{A}}-1$ '’), $3.87\left(1 \mathrm{H}, \mathrm{dd}, J=8.6\right.$ y $\left.14.5 \mathrm{~Hz}, \mathrm{H}_{\mathrm{A}}-1^{\prime}\right), 3.20(1 \mathrm{H}, \mathrm{d}, J=14.5$ $\left.\mathrm{Hz}, \mathrm{H}_{\mathrm{B}}-1^{\prime}\right), 3.13$ (1H, d, J=13.9 Hz, $\mathrm{H}_{\mathrm{B}}{ }^{\prime}$ '’ $), 3.01$ (1H, d, J=11.2 Hz, $\left.\mathrm{H}_{\alpha}-5\right), 2.77(1 \mathrm{H}$, m, H-2), 2.03 (1H, dd, J=4.4 y $\left.11.2 \mathrm{~Hz}, \mathrm{H}_{\beta}-5\right) .1 .45$ y 1.26 (3H c/u, s, H-7 y H-8).

ESPECTRO RMN ${ }^{13} \mathbf{C}\left(50 \mathrm{MHz}, \mathrm{CDCl}_{3}, \delta\right.$ ppm) (fig. 74c) (Tabla XXIX).

LRMS, EI, m/z (\%) (fig. 74d): 388 (21) (M+H) ${ }^{+}, 376$ (100), 370 (30), 364 (25).

HMRS, EI (fig. 74e): Calculado para $\mathrm{C}_{21} \mathrm{H}_{26} \mathrm{O}_{4} \mathrm{SN}(M+\mathrm{H})^{+}, 388.1582$. Experimental $(\mathrm{M}+\mathrm{H})^{+}, 388.1588$.

$[\alpha]_{D}^{25}=-37.3^{\circ}\left(\mathrm{c}=0.5, \mathrm{CHCl}_{3}\right)$. 


\section{DESBENCILACIÓN DE 83}
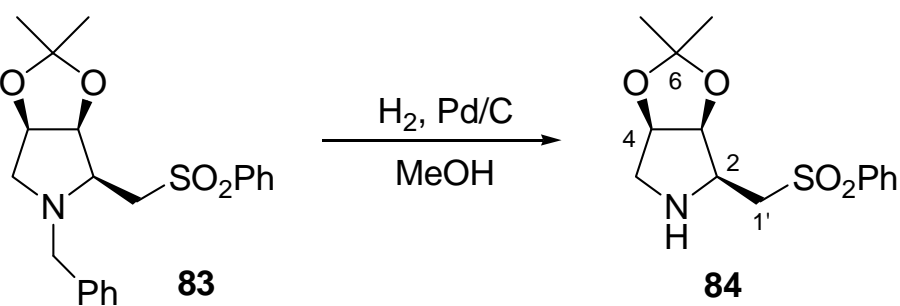

Sobre una disolución de $\mathbf{8 3}$ (500 mg, 1.29 mmoles) en $5 \mathrm{~mL}$ de $\mathrm{MeOH}$ se añade una cantidad catalítica de $\mathrm{Pd} / \mathrm{C}$. Se purga el sistema con $\mathrm{H}_{2}$ y se mantiene agitando bajo atmósfera de hidrógeno durante $24 \mathrm{~h}$. Transcurrido este tiempo, se filtra la mezcla sobre celita y se evapora el disolvente obteniéndose $313 \mathrm{mg}$ (95\%) del compuesto 84, cuyas propiedades físicas y espectroscópicas se detallan a continuación:

\section{$\underline{(2 S, 3 S, 4 R)-2-F e n i l s u l f o n i l m e t i l-3,4-i s o p r o p i l i d e n d i o x i-p i r r o l i d i n a ~(84) ~}$}

ESPECTRO IR $v_{\max }$ (película) $\mathrm{cm}^{-1}$ (fig. 75a): 3000, 2936, 1447, 1381, 1308, 1148, 1086,650 .

ESPECTRO RMN ${ }^{1} \mathbf{H}\left(200 \mathrm{MHz}, \mathrm{CDCl}_{3}, \delta\right.$ ppm) (fig. 75b): 7.95-7.50 (5H, m, -Ar), $4.67(1 \mathrm{H}, \mathrm{dd}, J=4.0$ y $5.3 \mathrm{~Hz}, \mathrm{H}-4), 4.54(1 \mathrm{H}, \mathrm{dd}, J=4.2$ y $5.3 \mathrm{~Hz}, \mathrm{H}-3), 3.57(1 \mathrm{H}, \mathrm{dd}$, $J=5.0$ y $14.0 \mathrm{~Hz}, \mathrm{H}_{\mathrm{A}}{ }^{-1}$ '), $3.36\left(1 \mathrm{H}, \mathrm{dd}, J=7.0\right.$ y $\left.14.0 \mathrm{~Hz}, \mathrm{H}_{\mathrm{B}}-1^{\prime}\right), 3.22$ (1H, m, H-2), $3.13\left(1 \mathrm{H}, \mathrm{d}, J=12.7 \mathrm{~Hz}, \mathrm{H}_{\alpha^{-}}-5\right), 2.69\left(1 \mathrm{H}, \mathrm{dd}, J=4.0\right.$ y $\left.12.7 \mathrm{~Hz}, \mathrm{H}_{\beta}-5\right), 2.20(1 \mathrm{H}, \mathrm{sa}, \mathrm{H}-$ 1), 1.41 y 1.25 (3H c/u, s, H-7 y H-8).

ESPECTRO RMN ${ }^{13} \mathbf{C}\left(50 \mathrm{MHz}, \mathrm{CDCl}_{3}, \delta\right.$ ppm) (fig. 75c) (Tabla XXX).

LRMS, FAB ${ }^{+}, \mathrm{m} / \mathrm{z}$ (\%) (fig. 75d): 298 (100) (M+ H) ${ }^{+}, 154$ (55), 136 (50), 107 (25), 80 (45).

HMRS, $\mathrm{FAB}^{+}$(fig. 75e): Calculado para $\mathrm{C}_{14} \mathrm{H}_{20} \mathrm{NO}_{4} \mathrm{~S}(M+\mathrm{H})^{+}, \quad 298.1113$. Experimental $(\mathrm{M}+\mathrm{H})^{+}, 298.1128$.

$[\alpha]_{D}^{25}=-25.8^{\circ}\left(\mathrm{c}=1.0, \mathrm{CHCl}_{3}\right)$. 


\section{REACCIÓN DE 83 CON n-BuLi}

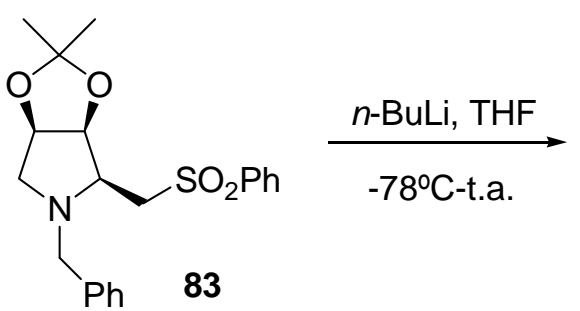

Sobre una disolución de 83 (40 mg, 0.10 mmoles) en $1 \mathrm{~mL}$ de THF seco, bajo atmósfera de argon y a $-78^{\circ} \mathrm{C}$, se añaden $75 \mu \mathrm{L}$ de una disolución de $n$-BuLi $1.6 \mathrm{M}$ en hexano. Se agita la mezcla durante 3 horas dejando alcanzar temperatura ambiente. Pasado este tiempo se para la reacción añadiendo unas gotas de disolución acuosa saturada de $\mathrm{NH}_{4} \mathrm{Cl}$ y se extrae con AcOEt. Las fases orgánicas combinadas se lavan con disolución acuosa saturada de $\mathrm{NaCl}$, se seca sobre $\mathrm{Na}_{2} \mathrm{SO}_{4}$ anhidro, se filtra y evapora el disolvente recuperándose el compuesto $\mathbf{8 3}$ en su totalidad.

\section{BENZOILACIÓN DE 84}

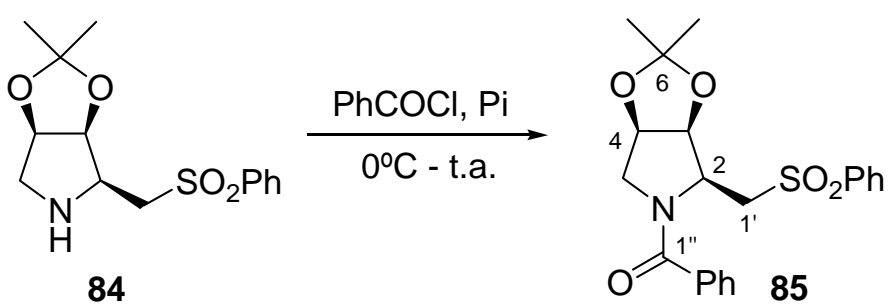

Sobre una disolución de 84 (40 mg, 0.13 mmoles) en $0.5 \mathrm{~mL}$ de piridina destilada, a $0^{\circ} \mathrm{C}$ y bajo atmósfera de argon, se añaden $20 \mu \mathrm{L}$ de $\mathrm{PhCOCl}$ y se agita durante 3 horas dejando alcanzar temperatura ambiente. Pasado este tiempo se para la reacción añadiendo hielo. Se extrae con AcOEt y las fases orgánicas combinadas se lavan sucesivamente con disoluciones acuosas de $\mathrm{CuSO}_{4}(20 \%), \mathrm{NaHCO}_{3}(5 \%)$ y $\mathrm{NaCl}$ (saturada). Se seca sobre $\mathrm{Na}_{2} \mathrm{SO}_{4}$, se filtra y se evapora el disolvente, obteniéndose un crudo que se cromatografía en columna sobre sílicagel flash (eluyente: hexano/AcOEt 
8:2), aislándose $52 \mathrm{mg}(97 \%)$ del compuesto 85, el cual presenta las siguientes propiedades físicas y espectroscópicas:

\section{$\underline{(2 S, 3 S, 4 R)-N \text {-Benzoil-2-fenilsulfonilmetil-3,4-isopropilidendioxi-pirrolidina (85) }}$}

ESPECTRO IR $v_{\max }$ (película) $\mathrm{cm}^{-1}$ (fig. 76a): 3066, 2987, 2939, 1738, 1643, 1584, 1447, 1383, 1307, 1249, 1215, 1153, 1085, 970.

ESPECTRO RMN ${ }^{1} \mathbf{H}\left(400 \mathrm{MHz}, \mathrm{CDCl}_{3}, \delta\right.$ ppm) (fig. 76b): 8.03-7.34 (10H, m, $\mathrm{C}(\mathrm{O})$ - $\underline{\mathrm{Ar}} \mathrm{y}-\mathrm{SO}_{2}$ - $\left.\underline{\mathrm{Ar}}\right), 4.83(1 \mathrm{H}, \mathrm{t}, J=5.8 \mathrm{~Hz}, \mathrm{H}-3), 4.66-4.61\left(2 \mathrm{H}, \mathrm{m}, \mathrm{H}-4\right.$ y H$\left.{ }^{-}-5\right), 3.98$ $\left(1 \mathrm{H}, \mathrm{dd}, J=14.0\right.$ y $\left.3.7 \mathrm{~Hz}, \mathrm{H}_{\mathrm{A}}-1^{\prime}\right), 3.84\left(1 \mathrm{H}, \mathrm{dd}, J=14.0\right.$ y $9.0 \mathrm{~Hz}, \mathrm{H}_{\mathrm{B}}-1$ ') 3.59 (2H, m, H-2 y $\left.\mathrm{H}_{\beta}-5\right), 1.54$ y 1.32 (3H c/u, s, H-7 y H-8).

ESPECTRO RMN ${ }^{13} \mathbf{C}\left(100 \mathrm{MHz}, \mathrm{CDCl}_{3}, \delta\right.$ ppm) (fig. 76c) (Tabla XXXI).

HRMS, ESI (fig. 76d): Calculado para $\mathrm{C}_{21} \mathrm{H}_{24} \mathrm{NO}_{5} \mathrm{~S}(M+\mathrm{H})^{+}, 402.1369$. Experimental $(\mathrm{M}+\mathrm{H})^{+}, 402.1364$.

$[\alpha]_{D}^{25}=-67.1^{\circ}\left(\mathrm{c}=1.4, \mathrm{CHCl}_{3}\right)$

\section{EPIMERIZACIÓN DE 85 EN C-2 CON n-BuLi}

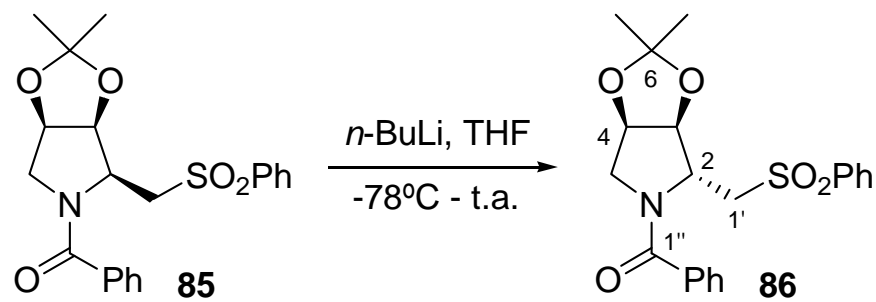

Sobre una disolución de 85 (40 mg, 0.10 mmoles) en $1 \mathrm{~mL}$ de THF seco, bajo atmósfera de argon y a $-78^{\circ} \mathrm{C}$, se añaden $75 \mu \mathrm{L}$ de una disolución de $n$-BuLi $1.6 \mathrm{M}$ en hexano. Se agita la mezcla durante 3 horas dejando alcanzar temperatura ambiente. Pasado este tiempo se para la reacción añadiendo unas gotas de disolución acuosa saturada de $\mathrm{NH}_{4} \mathrm{Cl}$ y se extrae con AcOEt. Las fases orgánicas combinadas se lavan con disolución acuosa saturada de $\mathrm{NaCl}$ y se secan sobre $\mathrm{Na}_{2} \mathrm{SO}_{4}$ anhidro. Posteriormente 
se filtra y evapora el disolvente para obtener un crudo que se cromatografían en columna sobre sílicagel flash (eluyente: hexano/AcOEt 7:3 $\rightarrow$ 6:4). Se aíslan $20 \mathrm{mg}$ (50\%) de 86, el cual presenta las siguientes propiedades físicas y espectroscópicas:

\section{$\underline{(2 R, 3 S, 4 R)-N \text {-Benzoil-2-fenilsulfonilmetil-3,4-isopropilidendioxi-pirrolidina (86) }}$}

ESPECTRO IR $v_{\max }$ (película) $\mathrm{cm}^{-1}$ (fig. 77a): 3064, 2978, 2938, 1634, 1577, 1413, 1319, 1217, 1152, 1074, 1046, 858.

ESPECTRO RMN ${ }^{1} \mathbf{H}\left(400 \mathrm{MHz}, \mathrm{CDCl}_{3}, \delta\right.$ ppm) (fig. 77b): 7.98-7.38 (10H, m, $\mathrm{C}(\mathrm{O})$ - $\left.\underline{\mathrm{Ar}} \mathrm{y}-\mathrm{SO}_{2}-\underline{\mathrm{Ar}}\right), 5.25-5.23(1 \mathrm{H}, \mathrm{m}, \mathrm{H}-3), 4.85$ (1H, m, H-4), 4.79 (1H, m, H-2), $3.89\left(1 \mathrm{H}, \mathrm{dd}, J=14.0\right.$ y $\left.3.6 \mathrm{~Hz}, \mathrm{H}_{\mathrm{A}}-1^{\prime}\right), 3.78-3.71(2 \mathrm{H}, \mathrm{m}, \mathrm{H}-5), 3.44(1 \mathrm{H}, \mathrm{d}, J=14.0$ $\mathrm{Hz}, \mathrm{H}_{\mathrm{B}}-1$ '), 1.44 y 1.33 (3H c/u, s, H-7 y H-8).

ESPECTRO RMN ${ }^{13} \mathbf{C}\left(100 \mathrm{MHz}, \mathrm{CDCl}_{3}, \delta\right.$ ppm) (fig. 77c) (Tabla XXXII).

HRMS, ESI (fig. 77d): Calculado para $\mathrm{C}_{21} \mathrm{H}_{23} \mathrm{NO}_{5} \mathrm{NaS}(M+\mathrm{Na})^{+}, 424.1189$. Experimental $(\mathrm{M}+\mathrm{Na})^{+}, 424.1195$.

$[\alpha]_{D}^{25}=+33.9^{\circ}\left(\mathrm{c}=1.1, \mathrm{CHCl}_{3}\right)$

\section{$\underline{\text { REACCIÓN DE } 86 \text { CON NH}} 2$}

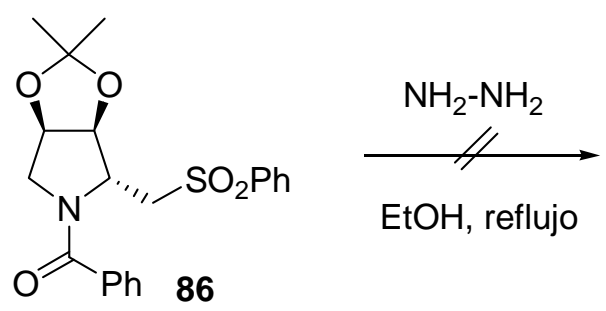

Sobre una disolución de 86 (5 mg, 0.01 mmoles) en $0.1 \mathrm{~mL}$ de EtOH seco se añade $1 \mathrm{~mL}$ de $\mathrm{NH}_{2}-\mathrm{NH}_{2}$ y se refluja durante 24 horas. Pasado este tiempo se deja enfriar hasta temperatura ambiente y se para añadiendo $10 \mathrm{~mL}$ de $\mathrm{H}_{2} \mathrm{O}$. Se extrae con AcOEt y las fases orgánicas combinadas se lavan con disolución acuosa saturada de $\mathrm{NaCl}$. Se seca sobre $\mathrm{Na}_{2} \mathrm{SO}_{4}$ anhidro, se filtra y evapora el disolvente obteniéndose el material de partida sin reaccionar. 


\section{REACCIÓN DE 86 CON HCI}

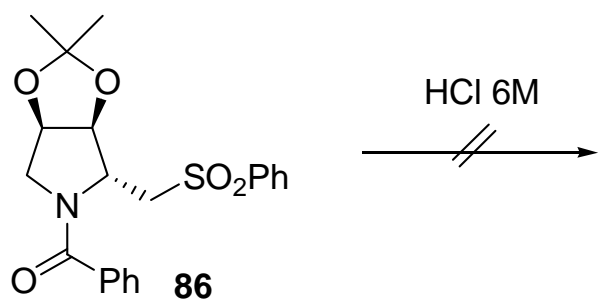

Sobre una disolución de $\mathbf{8 6}$ (22 mg, 0.055 mmoles) en $1 \mathrm{~mL}$ de $\mathrm{MeOH}$ se añaden 4 gotas de una disolución acuosa de $\mathrm{HCl} 6 \mathrm{M}$ y se pone la mezcla a reflujo durante 1 hora. Pasado este tiempo, se añade la mezcla sobre hielo, se neutraliza con disolución acuosa de $\mathrm{NaOH} 1 \mathrm{M}$ y se extrae con éter. Tras lavar las fases orgánicas combinadas con disolución acuosa saturada de $\mathrm{NaCl}$, se seca sobre $\mathrm{Na}_{2} \mathrm{SO}_{4}$ anhidro, se filtra y evapora el disolvente. El crudo obtenido no se trata del producto de desbenzoilación deseado, sino del producto de desprotección parcial del acetónido.

\section{$\underline{\text { REDUCCIÓN DE } 86 \text { CON LiAlH }} 4$}
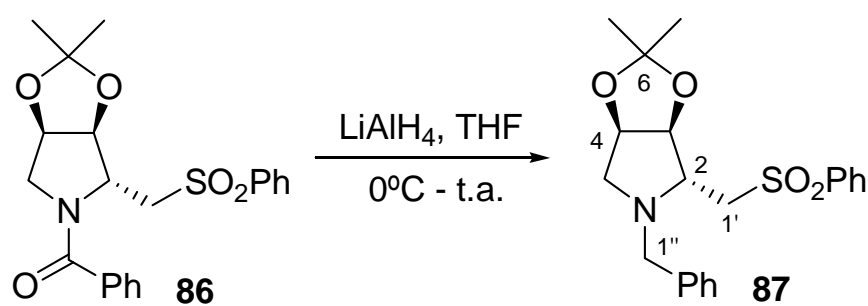

Se disuelve 86 ( $38 \mathrm{mg}, 0.09$ mmoles) en $1 \mathrm{~mL}$ de THF seco y se añaden a $0^{\circ} \mathrm{C} 7$ mg (0.189 mmoles) de $\mathrm{LiAlH}_{4}$. Se deja reaccionando durante 1 hora permitiendo que vaya subiendo lentamente la temperatura hasta la ambiente. Pasado este tiempo se para la reacción añadiendo éter húmedo. Se seca sobre $\mathrm{Na}_{2} \mathrm{SO}_{4}$ anhidro, se filtra y se evapora el disolvente obteniéndose un crudo que se cromatografía en columna sobre sílicagel flash (eluyente: hexano/AcOEt 8:2 $\rightarrow$ 7:3). Se aíslan $10 \mathrm{mg}$ (30\%) del compuesto 87, cuyas propiedades físicas y espectroscópicas son las siguientes: 


\section{$\underline{(2 R, 3 S, 4 R)-N \text {-Bencil-2-fenilsulfonilmetil-3,4-isopropilidendioxi-pirrolidina (87) }}$}

ESPECTRO IR $v_{\max }$ (película) $\mathrm{cm}^{-1}$ (fig. 78a): 2983, 2942, 1454, 1377, 1307, 1209, $1148,1086,1054,849$.

ESPECTRO RMN ${ }^{1} \mathbf{H}\left(400 \mathrm{MHz}, \mathrm{CDCl}_{3}, \delta\right.$ ppm) (fig. 78b): 7.90-7.15 (10H, m, - $\mathrm{CH}_{2}$ -

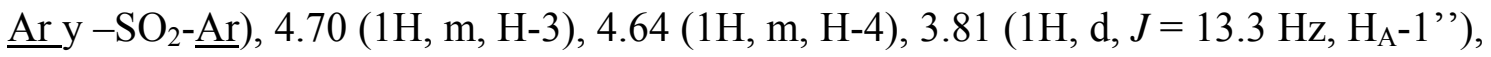
$3.55\left(1 \mathrm{H}, \mathrm{d}, J=13.3 \mathrm{~Hz}, \mathrm{H}_{\mathrm{B}}-1^{\prime}\right.$ '), $3.32-3.27$ (2H, m, H-2 y $\mathrm{H}_{\mathrm{A}}-1$ '), $3.13(1 \mathrm{H}, \mathrm{dd}, J=$ 13.5 y $\left.9.0 \mathrm{~Hz}, \mathrm{H}_{\mathrm{B}}-1^{\prime}\right), 2.87\left(1 \mathrm{H}, \mathrm{dd}, J=10.7\right.$ y $\left.5.3 \mathrm{~Hz}, \mathrm{H}_{\alpha}-5\right), 2.68(1 \mathrm{H}, \mathrm{d}, J=10.7 \mathrm{~Hz}$, $\left.\mathrm{H}_{\beta}-5\right), 1.50$ y 1.28 (3H c/u, s, H-7 y H-8).

ESPECTRO RMN ${ }^{13} \mathbf{C}\left(100 \mathrm{MHz}, \mathrm{CDCl}_{3}, \delta\right.$ ppm) (fig. 78c) (Tabla XXXIII).

HRMS, ESI (fig. 78d): Calculado para $\mathrm{C}_{21} \mathrm{H}_{25} \mathrm{NO}_{4} \mathrm{NaS}(M+\mathrm{Na})^{+}, 410.1396$. Experimental $(\mathrm{M}+\mathrm{Na})^{+}, 410.1397$.

$[\alpha]_{D}^{25}=+20.2^{\circ}\left(\mathrm{c}=1.0, \mathrm{CHCl}_{3}\right)$

\section{REDUCCIÓN DE 86 CON BH $3 \underline{3}^{\cdot T H F}$}

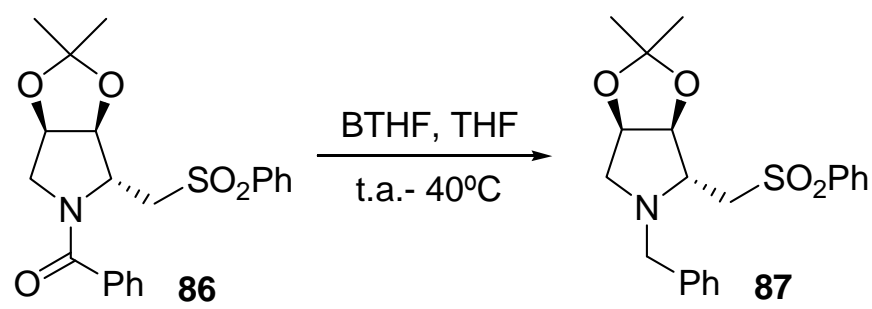

Sobre una disolución de 86 (38 mg, 0.09 mmoles) en $1 \mathrm{~mL}$ de THF seco bajo atmósfera de argon y a temperatura ambiente se añaden $0.12 \mathrm{~mL}$ de una disolución de $\mathrm{BH}_{3} \cdot \mathrm{THF} 1 \mathrm{M}$ en THF. Se sube la temperatura a $40^{\circ} \mathrm{C}$ y se deja reaccionando durante 2 horas, transcurridas las cuales se para añadiendo unas gotas de agua. Se extrae con $\mathrm{Et}_{2} \mathrm{O}$ y las fases orgánicas combinadas se lavan con agua y disolución acuosa saturada de $\mathrm{NaCl}$. Se seca sobre $\mathrm{Na}_{2} \mathrm{SO}_{4}$ anhidro, se filtra y se evapora el disolvente obteniéndose un crudo que se cromatografía en columna sobre sílicagel flash (eluyente: hexano/AcOEt 8:2 $\rightarrow$ 7:3). Se aíslan $5 \mathrm{mg}(15 \%)$ del compuesto 87 y $10 \mathrm{mg}$ (26\%) de 
producto de partida 86. Las propiedades físicas y espectroscópicas de estos compuestos ya se han descrito anteriormente.

\section{DESBENCILACIÓN DE 87}
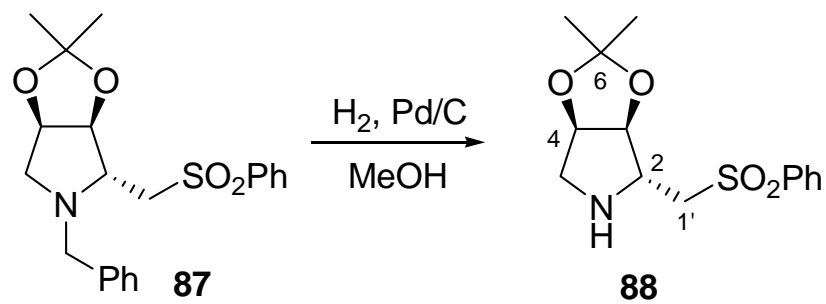

Sobre una disolución de 87 (10 mg, 0.03 mmoles) en $0.5 \mathrm{~mL}$ de $\mathrm{MeOH}$ se añade una cantidad catalítica de $\mathrm{Pd} / \mathrm{C}$. Se purga el sistema con $\mathrm{H}_{2}$ y se mantiene agitando bajo atmósfera de hidrógeno durante $24 \mathrm{~h}$. Transcurrido este tiempo, se filtra la mezcla sobre celita y se evapora el disolvente obteniéndose $6 \mathrm{mg}$ (80\%) del compuesto $\mathbf{8 8}$, cuyas propiedades espectroscópicas se detallan a continuación:

\section{$\underline{(2 R, 3 S, 4 R)-2-F e n i l s u l f o n i l m e t i l-3,4-i s o p r o p i l i d e n d i o x i-p i r r o l i d i n a ~(88) ~}$}

ESPECTRO IR $v_{\max }$ (película) $\mathrm{cm}^{-1}$ (fig. 79a): 2976, 2934, 1448, 1382, 1307, 1210, $1149,1086,1056,858$.

ESPECTRO RMN ${ }^{1} \mathbf{H}\left(200 \mathrm{MHz}, \mathrm{CDCl}_{3}, \delta\right.$ ppm) (fig.79b): 7.98-7.58 (5H, m, -Ar), 4.67 (2H, m, H-3 y H-4), 3.57-2.70 (5H, m, H-2, H-5 y H-1'), 1.48 y 1.27 (3H c/u, s, H7 y H-8).

ESPECTRO RMN ${ }^{13} \mathbf{C}\left(50 \mathrm{MHz}, \mathrm{CDCl}_{3}, \delta\right.$ ppm) (fig. 79c) (Tabla XXVIII).

HMRS, ESI (fig.79d): Calculado para $\mathrm{C}_{14} \mathrm{H}_{20} \mathrm{NO}_{4} \mathrm{~S}(M+\mathrm{H})^{+}, 298.1113$. Experimental $(\mathrm{M}+\mathrm{H})^{+}, 298.1130$. 



\section{OXIDACIÓN DE 56 CON TPAP}

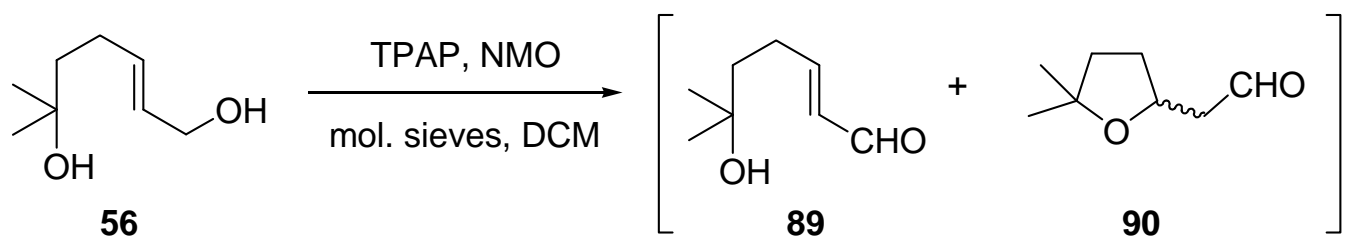

Sobre una disolución de 56 (55 mg, 0.38 mmoles) en $4 \mathrm{~mL}$ de DCM se añade tamiz molecular de $3 \AA$, NMO (154 mg, 1.14 mmoles) y una cantidad catalítica de TPAP. Tras agitar a temperatura ambiente durante una hora, se filtra la mezcla de reacción y se evapora el disolvente, obteniéndose una mezcla de los aldehídos 89 y 90 en una proporción variable dependiendo del agente filtrante utilizado (sílice, celita o Fluorisil), llegando a ser del $\mathbf{9 8 \%}$ de $\mathbf{9 0}$ cuando se filtra a través de Fluorisil. Esta mezcla es inseparable por cromatografía en columna sobre sílicagel, ya que en el medio ácido de la sílice el aldehído 89 cicla para dar $\mathbf{9 0}$.

\section{REDUCCIÓN DE $\delta$-VALEROLACTONA CON DIBAL-H}

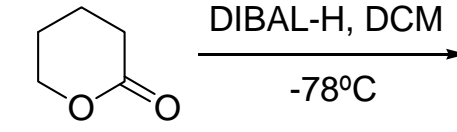

$\delta$-valerolactona<smiles>O[C@@H]1CCCCO1</smiles>

91

A una disolución de $\delta$-valerolactona (1g, 10.0 mmoles) en $50 \mathrm{~mL}$ de DCM seco bajo atmósfera de argon y a $-78^{\circ} \mathrm{C}$, se añaden $8 \mathrm{~mL}$ de una disolución $1.5 \mathrm{M}$ de DIBAL$\mathrm{H}$ en tolueno. Se mantiene la reacción en estas condiciones con buena agitación durante una hora. Pasado este tiempo se añaden $1.5 \mathrm{~mL}$ de agua y se deja calentar lentamente hasta temperatura ambiente. A continuación se diluye la mezcla en $500 \mathrm{~mL}$ de éter, se añaden $5 \mathrm{~g}$ de $\mathrm{NaHCO}_{3}, 5 \mathrm{~g}$ de $\mathrm{Na}_{2} \mathrm{SO}_{4}$ anhidro y se deja agitando a temperatura ambiente durante 14 horas, transcurridas las cuales se filtra por celita y se evapora el éter. Se obtiene el lactol 91 con restos de tolueno que se utiliza sin previa purificación en la siguiente reacción. 


\section{REACCIÓN DEL LACTOL 91 CON}

\section{(CARBETOXIMETILEN)TRIFENILFOSFORANO}

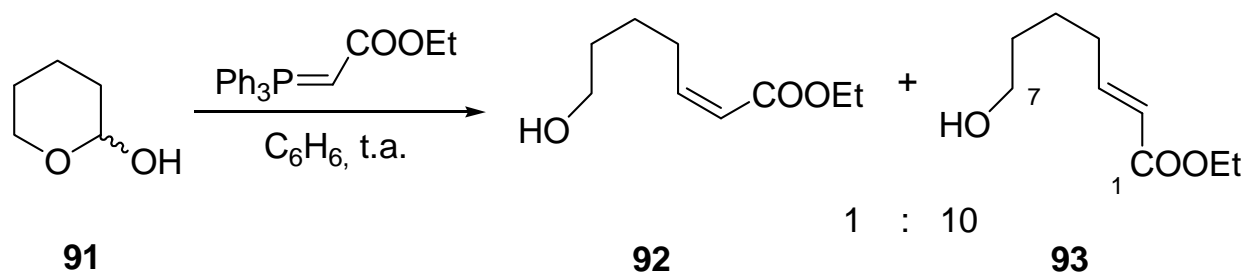

A una disolución de 91 (10.0 mmoles) en $50 \mathrm{~mL}$ de benceno seco se añaden 7.0 g (20.0 mmoles) de $\mathrm{Ph}_{3} \mathrm{PCHCOOEt}$ y se calienta a $50^{\circ} \mathrm{C}$ durante 2 horas. Posteriormente se deja enfriar hasta temperatura ambiente durante 12 horas. Pasado este tiempo se evapora el benceno y se redisuelve la mezcla en éter. Se baja la temperatura a $-18^{\circ} \mathrm{C}$ y se deja en estas condiciones durante 1 hora para facilitar la precipitación del óxido de trifenilfosfina. Tras filtrar y evaporar el disolvente, el crudo obtenido se cromatografía en columna sobre sílicagel (eluyente: hexano/AcOEt 8:2), aislándose 19 mg de 92, $812 \mathrm{mg}$ de 93 y $276 \mathrm{mg}$ de mezcla $\mathbf{9 2 / 9 3}$ con un rendimiento global del 65\% en dos pasos. Las propiedades espectroscópicas del compuesto $E$ mayoritario son las siguientes:

\section{7-Hidroxi-hept-E-2-enoato de etilo (93)}

ESPECTRO IR $v_{\max }$ (película) $\mathrm{cm}^{-1}$ (fig. 80a): 3423 (ancha), 2982, 2937, 2866, 1720, 1654, 1452, 1369, 1313, 1270, 1191, 1044, 984.

ESPECTRO RMN ${ }^{1} \mathbf{H}\left(200 \mathrm{MHz}, \mathrm{CDCl}_{3}, \delta\right.$ ppm) (fig. 80b): $6.90(1 \mathrm{H}, \mathrm{dt}, J=16.0 \mathrm{y}$ $7.0 \mathrm{~Hz}, \mathrm{H}-3), 5.81,(1 \mathrm{H}, \mathrm{d}, J=16.0 \mathrm{~Hz}, \mathrm{H}-2), 4.16\left(2 \mathrm{H}, \mathrm{c}, J=7.0 \mathrm{~Hz},-\mathrm{O}-\underline{\mathrm{CH}}_{2}-\mathrm{CH}_{3}\right)$, $3.64(2 \mathrm{H}, \mathrm{t}, J=6.0 \mathrm{~Hz}, \mathrm{H}-7), 2.25-2.21$ (2H, m, H-4), 1.58-1.51 (4H, m, H-5 y H-6), $1.27\left(3 \mathrm{H}, \mathrm{t}, J=7.0 \mathrm{~Hz},-\mathrm{O}-\mathrm{CH}_{2}-\underline{\mathrm{CH}}_{3}\right)$.

ESPECTRO RMN ${ }^{13} \mathbf{C}\left(50 \mathrm{MHz}, \mathrm{CDCl}_{3}, \delta\right.$ ppm) (fig. 80c) (Tabla XXXIV).

HRMS, ESI (fig. 80d): Calculado para $\mathrm{C}_{9} \mathrm{H}_{16} \mathrm{O}_{3} \mathrm{Na}(M+\mathrm{Na})^{+}$, 195.0991. Experimental $(\mathrm{M}+\mathrm{Na})^{+}, 195.0995$. 


\section{REDUCCIÓN DEL ÉSTER 93 CON DIBAL-H}

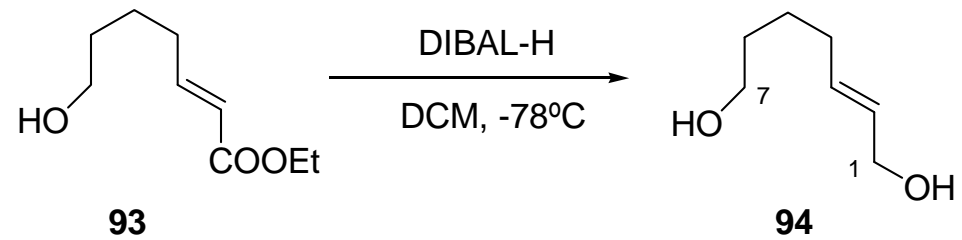

Sobre una disolución de 93 (580 mg, 3.37 mmoles) en 34 mL de DCM destilado y seco bajo atmósfera de argon y a $-78^{\circ} \mathrm{C}$, se añaden $5.6 \mathrm{~mL}$ ( $\left.8.43 \mathrm{mmoles}\right)$ de una disolución 1.5 M de DIBAL-H en tolueno. Se mantiene la reacción a esta temperatura con buena agitación durante 90 minutos. Pasado este tiempo se añaden $5 \mathrm{~mL}$ de agua y se deja calentar lentamente hasta temperatura ambiente. A continuación se diluye la mezcla en $250 \mathrm{~mL}$ de éter, se añaden $5 \mathrm{~g}$ de $\mathrm{NaHCO}_{3}, 5 \mathrm{~g}$ de $\mathrm{Na}_{2} \mathrm{SO}_{4}$ anhidro y se deja agitando a temperatura ambiente durante 3 horas, transcurridas las cuales se filtra por celita y se evapora el éter. Se obtiene un crudo con restos de tolueno que se purifica por cromatografía en columna sobre sílica gel flash (eluyente: hexano/AcOEt 1:1), aislándose $380 \mathrm{mg}(87 \%)$ del diol 94, cuyas propiedades espectroscópicas son las siguientes:

\section{Hept-E-2-en-1,7-diol (94)}

ESPECTRO IR $v_{\max }$ (película) $\mathrm{cm}^{-1}$ (fig. 81a): 3331 (ancha), 2933, 2861, 1438, 1060, 1002,970 .

ESPECTRO RMN ${ }^{1} \mathbf{H}\left(200 \mathrm{MHz}, \mathrm{CDCl}_{3}, \delta\right.$ ppm) (fig. 81b): 5.60 (2H, m, H-2 y H-3), $4.01(2 \mathrm{H}, \mathrm{d}, J=3.6 \mathrm{~Hz}, \mathrm{H}-1), 3.56(2 \mathrm{H}, \mathrm{t}, J=6.0 \mathrm{~Hz}, \mathrm{H}-7), 3.00$ (2H, sa, $-\mathrm{OH}), 2.03$ (2H, m, H-4), 1.52-1.40 (4H, m, H-5 y H-6).

ESPECTRO RMN ${ }^{13} \mathbf{C}\left(50 \mathrm{MHz}, \mathrm{CDCl}_{3}, \delta\right.$ ppm) (fig. 81c) (Tabla XXXIV).

HRMS, ESI (fig. 81d): Calculado para $\mathrm{C}_{7} \mathrm{H}_{14} \mathrm{O}_{2} \mathrm{Na}(\mathrm{M}+\mathrm{Na})^{+}, 153.0886$. Experimental $(\mathrm{M}+\mathrm{Na})^{+}, 153.0875$. 


\section{OXIDACIÓN ALÍLICA DEL DIOL 94 CON MnO}<smiles>OC/C=C/CCCCO</smiles><smiles>COC(C)(C)C</smiles><smiles>O=CC[C@@H]1CCCCO1</smiles>

Se disuelven $53 \mathrm{mg}$ (0.41 mmoles) del diol 94 en $8 \mathrm{~mL}$ de DCM seco y se añaden $708 \mathrm{mg}$ ( 8.15 mmoles) de $\mathrm{MnO}_{2}$. Se deja reaccionando con buena agitación durante 1 hora. Pasado este tiempo se filtra la mezcla por celita, obteniéndose tras evaporar el disolvente una mezcla de los aldehídos 95 y 96 inseparable por cromatografía en columna sobre sílicagel, ya que en el medio ácido de la sílice el aldehído 95 cicla para dar 96.

\section{ADICIÓN DE MeMgBr AL LACTOL 91}

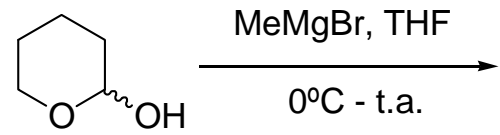

91<smiles>C[C@@H](O)CCCCO</smiles>

97

Sobre una disolución del lactol 91 (500 mg, 4.90 mmoles) en $25 \mathrm{~mL}$ de THF seco se añaden lentamente, bajo atmósfera de argon y a $0^{\circ} \mathrm{C}, 6.5 \mathrm{~mL}$ de una disolución 3.0 $\mathrm{M}$ de bromuro de metilmagnesio en $\mathrm{Et}_{2} \mathrm{O}$. Se mantiene la agitación durante 2 horas dejando calentar lentamente hasta temperatura ambiente. Transcurrido este tiempo se para la reacción añadiendo unas gotas de disolución acuosa saturada de $\mathrm{NH}_{4} \mathrm{Cl}$. Posteriormente se extrae con AcOEt (3 x $200 \mathrm{~mL}$ ) y las fases orgánicas combinadas se lavan con disolución acuosa saturada de $\mathrm{NaCl}$. Se seca sobre $\mathrm{Na}_{2} \mathrm{SO}_{4}$ anhidro, se filtra y se evapora el disolvente para obtener $407 \mathrm{mg}$ (70\%) de 97, cuyas propiedades espectroscópicas coinciden con las descritas en bibliografía. ${ }^{238}$ Este compuesto se utiliza en la siguiente reacción sin previa purificación.

\footnotetext{
${ }^{238}$ Black, G. P.; Murphy, P. J.; Thornhill, A. J.; Walshe, N. D. A.; Zanetti, C. Tetrahedron 1999, 55, 6547.
} 


\section{PROTECCIÓN DE 97 CON TBDMSCI}

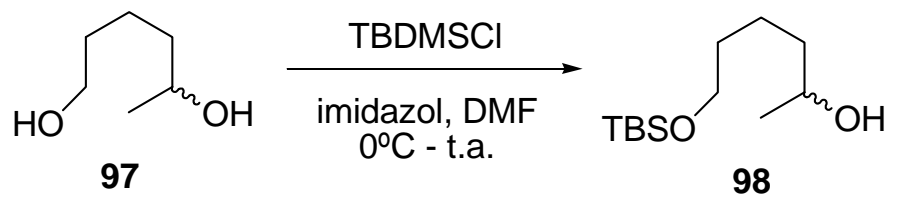

Sobre una disolución de 97 (407 mg, 3.45 mmoles) en 9 mL de DMF destilada, a $0^{\circ} \mathrm{C}$ y bajo atmósfera de argon, se añaden sucesivamente $470 \mathrm{mg}$ (6.9 mmoles) de imidazol y $521 \mathrm{mg}$ (3.45 mmoles) de TBDMSCl. Se mantiene la agitación durante 3 horas dejando calentar lentamente hasta temperatura ambiente. Transcurrido este tiempo se diluye la mezcla de reacción con éter $(100 \mathrm{~mL})$ y se lava con $\mathrm{H}_{2} \mathrm{O}(3 \times 20 \mathrm{~mL})$. Las aguas de lavado se combinan y se extraen con $50 \mathrm{~mL}$ de éter. Posteriormente, las fases etéreas combinadas se lavan con disolución acuosa saturada de $\mathrm{NaCl}$ y se secan sobre $\mathrm{Na}_{2} \mathrm{SO}_{4}$ anhidro. Se filtra y se evapora el disolvente, obteniéndose un crudo que se cromatografía en columna sobre sílicagel flash (eluyente: hexano/AcOEt 9:1). Se aíslan $640 \mathrm{mg}(80 \%)$ del producto monoprotegido 98, cuyas propiedades espectroscópicas coinciden con las descritas en bibliografía. ${ }^{238}$

\section{OXIDACIÓN DE 98 CON TPAP}

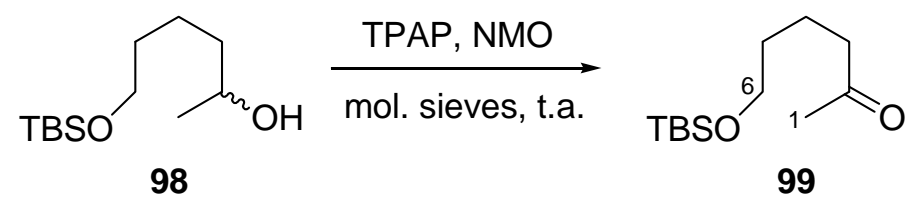

Sobre una disolución de 98 (640 mg, 2.76 mmoles) en 28 mL de DCM se añade tamiz molecular (3 $\AA$ ), NMO (1.12 g, 8.27 mmoles) y una cantidad catalítica de TPAP. Tras agitar a temperatura ambiente durante 90 minutos, se filtra la mezcla de reacción a través de celita. Después de evaporar el disolvente, se obtiene un crudo que se cromatografía en columna sobre sílicagel flash (eluyente: hexano/AcOEt 8:2). Se aíslan $597 \mathrm{mg}(94 \%)$ de la metilcetona 99, cuyas propiedades espectroscópicas se describen a continuación: 


\section{6-(terc-Butil-dimetil-silaniloxi)-hexan-2-ona (99)}

ESPECTRO IR $v_{\max }$ (película) $\mathrm{cm}^{-1}$ (fig. 82a): 2955, 2930, 2887, 2858, 1720, 1472, $1361,1255,1162,1100,837$.

ESPECTRO RMN ${ }^{1} \mathbf{H}\left(200 \mathrm{MHz}, \mathrm{CDCl}_{3}, \delta\right.$ ppm) (fig. 82b): 3.54 (2H, t, J=6.0 Hz, H6), 2.38 (2H, t, J = 7.0 Hz, H-3), 2.06 (3H, s, H-1), 1.57-1.44 (4H, m, H-4 y H-5), 0.82 $\left(9 \mathrm{H}, \mathrm{s},{ }^{t} \underline{\mathrm{BuMe}} \mathrm{S}_{2} \mathrm{Si}\right),-0.02\left(6 \mathrm{H}, \mathrm{s},{ }^{t} \mathrm{BuMe} \underline{2}_{2} \mathrm{Si}\right)$.

ESPECTRO RMN ${ }^{13} \mathbf{C}\left(50 \mathrm{MHz}, \mathrm{CDCl}_{3}, \delta\right.$ ppm) (fig. 82c) (Tabla XXXV).

HRMS, ESI (fig. 82d): Calculado para $\mathrm{C}_{12} \mathrm{H}_{26} \mathrm{O}_{2} \mathrm{NaSi}(M+\mathrm{Na})^{+}, \quad 253.1594$. Experimental $(\mathrm{M}+\mathrm{Na})^{+}, 253.1577$.

\section{REACCIÓN DE HORNER-WADSWORTH-EMMONS DE 99}<smiles>CC(=O)CCCCO[AsH3+]</smiles>

99

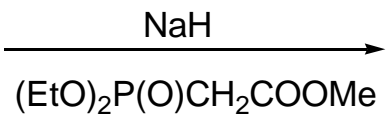

monoglime, $60^{\circ} \mathrm{C}$

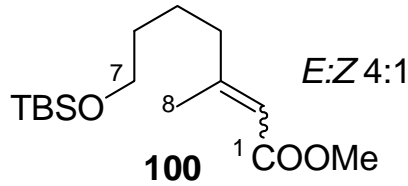

Sobre una suspensión de $\mathrm{NaH}$ (1.0 g, 26 mmoles, $60 \%$ en parafina) en $16 \mathrm{~mL}$ de monoglime bajo atmósfera de argon, se añade el metildietilfosfonoacetato (4.6 mL, 26 mmoles) a $0^{\circ} \mathrm{C}$. Se deja agitando a temperatura ambiente durante 40 minutos. A continuación se adiciona una disolución de 99 (597 mg, 2.6 mmoles) en $10 \mathrm{~mL}$ de monoglime y se calienta la mezcla de reacción a $60^{\circ} \mathrm{C}$ durante una hora. Transcurrido este tiempo se deja enfriar hasta temperatura ambiente y posteriormente se baja hasta $0^{\circ} \mathrm{C}$. Entonces se añaden $25 \mathrm{~mL}$ de $\mathrm{H}_{2} \mathrm{O}$ y se extrae con AcOEt $(3 \times 200 \mathrm{~mL})$. Las fases orgánicas combinadas se lavan con disolución acuosa saturada de $\mathrm{NaCl}$. Se seca sobre $\mathrm{Na}_{2} \mathrm{SO}_{4}$ anhidro, se filtra y se evapora el disolvente para obtener $1.5 \mathrm{~g}$ de un crudo que se cromatografía en columna sobre sílicagel flash (eluyente: hexano/AcOEt 9:1). Se consiguen aislar $720 \mathrm{mg}(96 \%)$ de la mezcla inseparable de diastereoisómeros 100 en una proporción E/Z 4:1. Las propiedades espectroscópicas del diastereoisómero $E$ mayoritario son las siguientes: 


\section{$\underline{\text { 3-Metil-7-(terc-butil-dimetil-silaniloxi)-hept-E-2-enoato de metilo (100) }}$}

ESPECTRO IR $v_{\max }$ (película) $\mathrm{cm}^{-1}$ (fig. 83a): 2951, 2931, 2858, 1723, 1649, 1472, $1435,1387,1360,1255,1224,1150,1101,1033,837$.

ESPECTRO RMN ${ }^{1} \mathbf{H}\left(200 \mathrm{MHz}, \mathrm{CDCl}_{3}, \delta\right.$ ppm) (fig. 83b): 5.65 (1H, s, H-2), 3.67 (3H, s, -COOMe), 3.65-3.59 (2H, m, H-7), 2.14 (3H, s, H-8), 2.15-2.13 (2H, m, H-4), 1.56-1.48 (4H, m, H-5 y H-6), 0.87 (9H, s, $\left.{ }^{t} \underline{\mathrm{BuMe}}_{2} \mathrm{Si}\right),-0.03\left(6 \mathrm{H}, \mathrm{s},{ }^{t} \mathrm{BuMe} \underline{2}_{2} \mathrm{Si}\right)$.

ESPECTRO RMN ${ }^{13} \mathbf{C}\left(50 \mathrm{MHz}, \mathrm{CDCl}_{3}, \delta\right.$ ppm) (fig. 83c) (Tabla XXXV).

HRMS, ESI (fig. 83d): Calculado para $\mathrm{C}_{15} \mathrm{H}_{30} \mathrm{O}_{3} \mathrm{NaSi}(M+\mathrm{Na})^{+}, 309.1856$. Experimental $(\mathrm{M}+\mathrm{Na})^{+}, 309.1840$.

\section{REDUCCIÓN DE LA MEZCLA DE ÉSTERES 100 CON DIBAL-H}

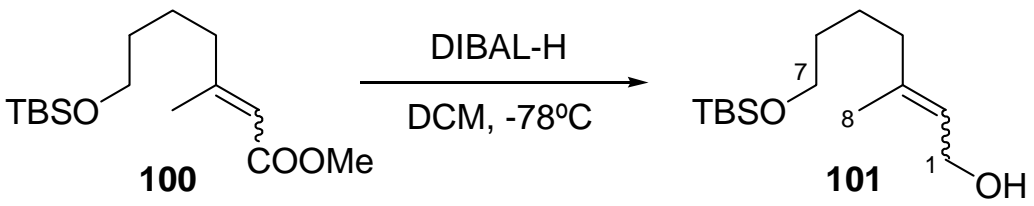

Sobre una disolución de 100 (720 mg, 2.5 mmoles) en 25 mL de DCM destilado y seco bajo atmósfera de argon y a $-78^{\circ} \mathrm{C}$, se añaden $4.2 \mathrm{~mL}(6.3 \mathrm{mmoles})$ de una disolución 1.5 M de DIBAL-H en tolueno. Se mantiene la reacción a esta temperatura con buena agitación durante dos horas. Pasado este tiempo se añaden $5 \mathrm{~mL}$ de agua y se deja calentar lentamente hasta temperatura ambiente. A continuación se diluye la mezcla en $500 \mathrm{~mL}$ de éter, se añaden $10 \mathrm{~g}$ de $\mathrm{NaHCO}_{3}, 10 \mathrm{~g}$ de $\mathrm{Na}_{2} \mathrm{SO}_{4}$ anhidro y se deja agitando a temperatura ambiente durante 12 horas, transcurridas las cuales se filtra por celita y se evapora el éter. Se obtiene un crudo con restos de tolueno que se purifica por cromatografía en columna sobre sílica gel flash (eluyente: hexano/ AcOEt 8:2), aislándose $600 \mathrm{mg}(93 \%)$ de la mezcla inseparable de alcoholes alílicos 101. Las propiedades espectroscópicas del diastereoisómero $E$ mayoritario son las siguientes: 


\section{$\underline{\text { 7-(terc-Butil-dimetil-silaniloxi)-3-metil-hept-E-2-en-1-ol (101) }}$}

ESPECTRO IR $v_{\max }$ (película) $\mathrm{cm}^{-1}$ (fig. 84a): 3346 (ancha), 2930, 2858, 1668, 1472, $1387,1361,1255,1101,1006,836$.

ESPECTRO RMN ${ }^{1} \mathbf{H}\left(200 \mathrm{MHz}, \mathrm{CDCl}_{3}, \delta\right.$ ppm) (fig. 84b): 5.34 (1H, t, J=7.0 Hz, H2), 4.10-4.05 (2H, m, H-1), 3.55 (2H, t, $J=6.0 \mathrm{~Hz}, \mathrm{H}-7)$, 2.03-1.94 (2H, m, H-4), 1.67 $(3 \mathrm{H}, \mathrm{s}, \mathrm{H}-8), 1.44-1.38\left(4 \mathrm{H}, \mathrm{m}, \mathrm{H}-5\right.$ y H-6), $0.84\left(9 \mathrm{H}, \mathrm{s},{ }^{t} \mathrm{BuMe}_{2} \mathrm{Si}\right),-0.01(6 \mathrm{H}, \mathrm{s}$, $\left.{ }^{t} \mathrm{BuMe}{ }_{2} \mathrm{Si}\right)$.

ESPECTRO RMN ${ }^{13} \mathbf{C}\left(50 \mathrm{MHz}, \mathrm{CDCl}_{3}, \delta \mathrm{ppm}\right)$ (fig. 84c) (Tabla XXXV).

HRMS, ESI (fig. 84d): Calculado para $\mathrm{C}_{14} \mathrm{H}_{30} \mathrm{O}_{2} \mathrm{NaSi}(M+\mathrm{Na})^{+}, 281.1907$. Experimental $(\mathrm{M}+\mathrm{Na})^{+}, 281.1901$.

\section{DESPROTECCIÓN DE 101 CON TBAF Y POSTERIOR OXIDACIÓN ALÍLICA}

\section{$\underline{\mathrm{CON} \mathrm{MnO}} 2$}
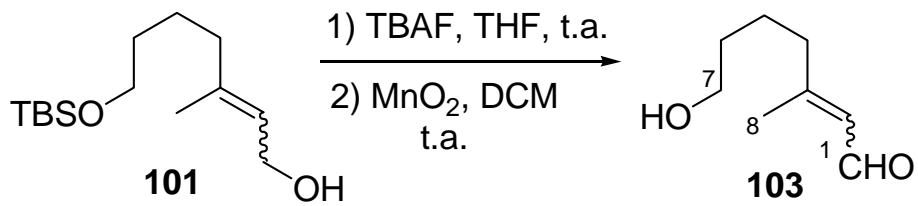

Se disuelven $1.58 \mathrm{~g}$ (6.12 mmoles) de 101 en $61 \mathrm{~mL}$ de THF bajo atmósfera de argon, se añaden $7.4 \mathrm{~mL}$ (7.40 mmoles) de una disolución de TBAF 1.0 M en THF y se deja reaccionando a temperatura ambiente durante una hora. Pasado este tiempo se añaden $20 \mathrm{~mL}$ de $\mathrm{H}_{2} \mathrm{O}$, se extrae con $\operatorname{AcOEt}(3 \mathrm{x} 300 \mathrm{~mL})$ y el combinado de fases orgánicas se lava con $\mathrm{H}_{2} \mathrm{O}$ y disolución acuosa saturada de $\mathrm{NaCl}$. Se seca sobre $\mathrm{Na}_{2} \mathrm{SO}_{4}$ anhidro, se filtra y se evapora el disolvente para obtener un crudo que se redisuelve en $61 \mathrm{~mL}$ de DCM. Se añaden $10.6 \mathrm{~g}$ de $\mathrm{MnO}_{2}$ y se deja reaccionando con buena agitación a temperatura ambiente durante dos horas. Pasado este tiempo se filtra la mezcla de reaccción a través de celita lavando abundantemente con AcOEt. Tras evaporar el disolvente se obtienen $1.2 \mathrm{~g}$ de crudo que se cromatografían en columna sobre sílicagel (eluyente: hexano/AcOEt 1:1), aislándose $600 \mathrm{mg}$ (70\% en dos pasos) de la mezcla 
inseparable de aldehídos $\alpha, \beta$-insaturados 103. Las propiedades espectroscópicas del diastereoisómero $E$ mayoritario son las siguientes:

\section{7-Hidroxi-3-metil-hept-E-2-en-1-al (103)}

ESPECTRO IR $v_{\max }$ (película) $\mathrm{cm}^{-1}$ (fig. 85a): 3431 (ancha), 2938, 1667, 1442, 1380, $1196,1128,1066,859$.

ESPECTRO RMN ${ }^{1} \mathbf{H}\left(200 \mathrm{MHz}, \mathrm{CDCl}_{3}, \delta\right.$ ppm) (fig. 85b): $9.96(1 \mathrm{H}, \mathrm{d}, J=8.0 \mathrm{~Hz}$, H-1), 5.85 (1H, d, J = 8.0 Hz, H-2), 3.67-3.62 (2H, m, H-7), 2.26-2.19 (2H, m, H-4), 2.14 (3H, s, H-8), 1.63-1.53 (4H, m, H-5 y H-6).

ESPECTRO RMN ${ }^{13} \mathbf{C}\left(50 \mathrm{MHz}, \mathrm{CDCl}_{3}, \delta \mathrm{ppm}\right)$ (fig. 85c) (Tabla XXXVI).

HRMS, ESI (fig. 85d): Calculado para $\mathrm{C}_{8} \mathrm{H}_{14} \mathrm{O}_{2} \mathrm{Na}(M+\mathrm{Na})^{+}, 165.0886$. Experimental $(\mathrm{M}+\mathrm{Na})^{+}, 165.0885$.

\section{PROCEDIMIENTO GENERAL DE ADICIÓN oXo-MICHAEL} ORGANOCATALÍTICA DEL SUSTRATO 103 Y POSTERIOR REDUCCIÓN<smiles>CC(=CC=O)CCCCO</smiles><smiles>CC1(CO)CCCCO1</smiles>

Sobre una disolución del sustrato $\mathbf{1 0 3}$ en el disolvente y a la temperatura de elección, bajo atmósfera de argon, se añade el catalizador correspondiente. Se deja reaccionando a esa temperatura hasta que el seguimiento por $\mathrm{CCF}$ indica que ha finalizado. Entonces se añade, en caso necesario, el codisolvente $(\mathrm{MeOH})$ y el reductor $\left(\mathrm{NaBH}_{4}\right.$ o DIBAL-H) correspondientes. Pasada media hora se para la reacción de la forma habitual en cada caso y se cromatografía el crudo obtenido en columna sobre sílicagel flash (eluyente: hexano/AcOEt 8:2) para obtener el tetrahidropirano 104, el cual presenta las siguientes propiedades espectroscópicas: 
$\underline{\text { 2-(2'-Metil-tetrahidro-piran-2'-il)-etanol (104) }}$

ESPECTRO IR $v_{\max }$ (película) $\mathrm{cm}^{-1}$ (fig. 86a): 3407 (ancha), 2935, 2864, 1454, 1373, 1283, 1221, 1087, 1045, 964.

ESPECTRO RMN ${ }^{1} \mathbf{H}\left(200 \mathrm{MHz}, \mathrm{CDCl}_{3}, \delta\right.$ ppm) (fig. 86b): 3.85-3.78 (2H, m, H-6), 3.74-3.65 (2H, m, H-9), 1.91-1.32 (8H, m, H-3, H-4, H-5 y H-8), 1.26 (3H, s, H-7).

ESPECTRO RMN ${ }^{13} \mathbf{C}\left(50 \mathrm{MHz}, \mathrm{CDCl}_{3}, \delta\right.$ ppm) (fig. 86c) (Tabla XXXVI).

HRMS, ESI (fig. 86d): Calculado para $\mathrm{C}_{8} \mathrm{H}_{16} \mathrm{O}_{2} \mathrm{Na}(M+\mathrm{Na})^{+}, 167.1042$. Experimental $(\mathrm{M}+\mathrm{Na})^{+}, 167.1035$.

\section{YODOCICLACIÓN DE 103}
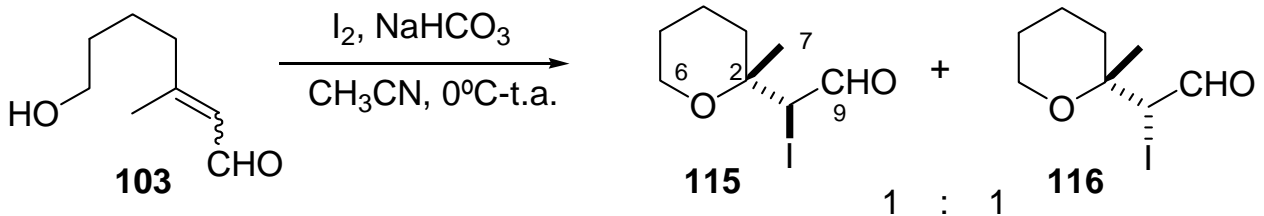

Se disuelven $47 \mathrm{mg}(0.33$ mmoles $)$ de $\mathbf{1 0 3}$ en $3.5 \mathrm{~mL}$ de $\mathrm{CH}_{3} \mathrm{CN}$ y se añaden a $0^{\circ} \mathrm{C} 252 \mathrm{mg}$ (0.99 mmoles) de $\mathrm{I}_{2}$ resublimado y $84 \mathrm{mg}(0.99 \mathrm{mmoles})$ de $\mathrm{NaHCO}_{3}$. Se mantiene la reacción agitando durante 3 horas dejando calentar progresivamente hasta temperatura ambiente. Pasado este tiempo se diluye la mezcla con AcOEt (100 mL) y se lava con disoluciones acuosas de $\mathrm{Na}_{2} \mathrm{~S}_{2} \mathrm{O}_{3}(10 \%), \mathrm{NaHCO}_{3}(5 \%)$ y $\mathrm{NaCl}$ (saturada). Se seca sobre $\mathrm{Na}_{2} \mathrm{SO}_{4}$, se filtra y se evapora el disolvente para obtener $77 \mathrm{mg}(86 \%)$ de la mezcla de diastereoisómeros 115 y 116, cuyas propiedades espectroscópicas son las siguientes:

\section{$\underline{\text { (2'-Metil-tetrahidro-piran-2'-il)-yodo-acetaldehído (115 y 116) }}$}

ESPECTRO IR $v_{\max }$ (película) $\mathrm{cm}^{-1}$ (fig. 88a): 2940, 2866, 1712, 1449, 1377, 1283, 1217, 1082, 1046, 962. 
ESPECTRO RMN ${ }^{1} \mathbf{H}\left(200 \mathrm{MHz}, \mathrm{CDCl}_{3}, \delta\right.$ ppm) (fig. 88b): 9.34 y $9.31(1 \mathrm{H} \mathrm{c} / \mathrm{u}, \mathrm{d}, J=$ 5.8 y $6.4 \mathrm{~Hz}, \mathrm{H}-9), 4.52$ y 4.43 (1H c/u, d, J= 5.8 y $6.4 \mathrm{~Hz}, \mathrm{H}-8), 3.71-3.59$ (2H, m, H6), 1.68-1.36 (6H, m, H-3, H-4 y H-5), 1.43 y 1.35 (3H c/u, s, H-7).

ESPECTRO RMN ${ }^{13} \mathbf{C}\left(50 \mathrm{MHz}, \mathrm{CDCl}_{3}, \delta\right.$ ppm) (fig. 88c).

HRMS, ESI (fig. 88d): Calculado para $\mathrm{C}_{8} \mathrm{H}_{13} \mathrm{O}_{2} \mathrm{NaI}(M+\mathrm{Na})^{+}$, 290.9852. Experimental $(\mathrm{M}+\mathrm{Na})^{+}, 290.9845$.

\section{REDUCCIÓN DE LA MEZCLA 115/116 CON NaBH}

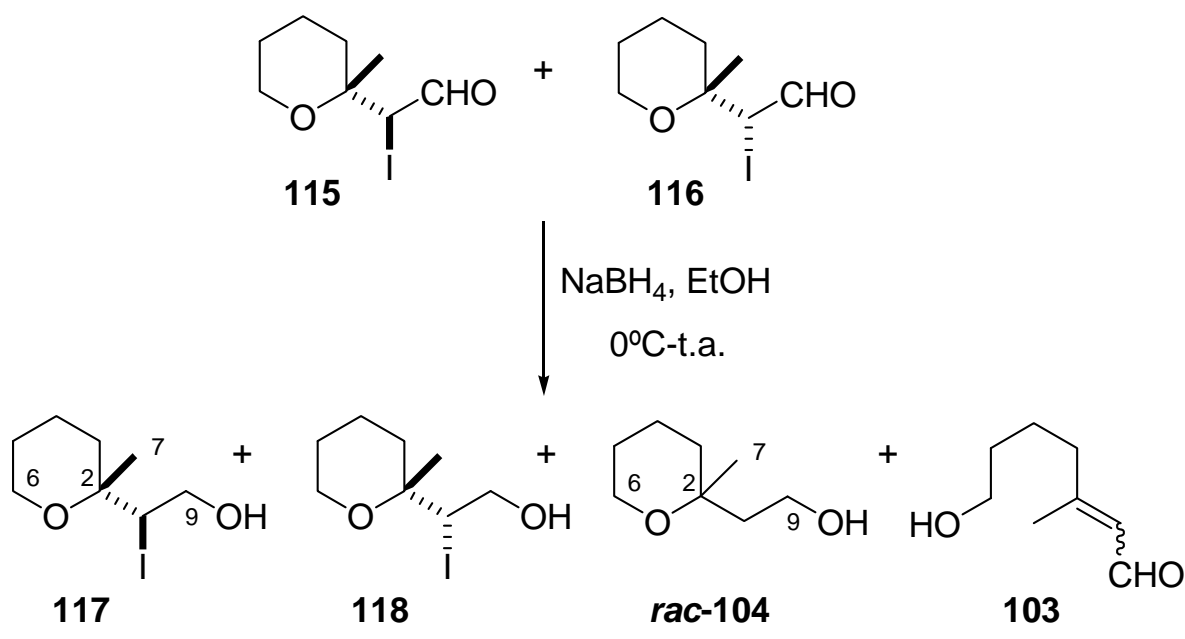

Se disuelven $77 \mathrm{mg}$ (0.28 mmoles) de la mezcla 115/116 en $3 \mathrm{ml}$ de EtOH seco bajo atmósfera de argon. Se añaden $24 \mathrm{mg}(0.63$ mmoles $)$ de $\mathrm{NaBH}_{4}$ a $0^{\circ} \mathrm{C}$ y se agita dejando calentar lentamente hasta temperatura ambiente durante 4 horas. Pasado este tiempo se evapora el EtOH, se diluye con agua, se extrae varias veces con AcOEt y el combinado de fases orgánicas se lava sucesivamente con agua y una disolución acuosa de $\mathrm{NaCl}$ (saturada). Se seca sobre $\mathrm{Na}_{2} \mathrm{SO}_{4}$, se filtra y se evapora el disolvente. Se obtiene un crudo que se cromatografía en columna sobre sílicagel flash (eluyente: hexano/AcOEt $9: 1 \rightarrow 8: 2 \rightarrow 1: 1)$, aislándose $21 \mathrm{mg}(27 \%)$ de la mezcla de diastereoisómeros 117/118, $5 \mathrm{mg}(12 \%)$ del producto de reducción rac-104 y $14 \mathrm{mg}$ (35\%) del producto de apertura 103. Las propiedades espectroscópicas de la mezcla de diastereoisómeros $\mathbf{1 1 7 / 1 1 8}$ son las siguientes: 


\section{$\underline{\text { 2-(2'-Metil-tetrahidro-piran-2'-il)-2-yodoetanol (117/118) }}$}

ESPECTRO IR $v_{\max }$ (película) $\mathrm{cm}^{-1}$ (fig. 89a): 3416, 2937, 2867, 1448, 1378, 1206, $1078,1047,960,859$.

ESPECTRO RMN ${ }^{1} \mathbf{H}\left(200 \mathrm{MHz}, \mathrm{CDCl}_{3}, \delta\right.$ ppm) (fig. 89b): $4.36(1 \mathrm{H}, \mathrm{t}, J=6.0 \mathrm{~Hz}, \mathrm{H}-$ 8), 4.02-3.80 (2H, m, H-9), 3.71-3.65 (2H, m, H-6), 1.73-1.40 (6H, m, H-3, H-4 y H-5), 1.40 y 1.37 (3H c/u, s, H-7).

ESPECTRO RMN ${ }^{13} \mathbf{C}\left(50 \mathrm{MHz}, \mathrm{CDCl}_{3}, \delta\right.$ ppm) (fig. 89c).

HRMS, ESI (fig. 88d): Calculado para $\mathrm{C}_{8} \mathrm{H}_{15} \mathrm{O}_{2} \mathrm{NaI}(M+\mathrm{Na})^{+}, 293.0009$. Experimental $(\mathrm{M}+\mathrm{Na})^{+}, 293.0011$.

\section{FORMACIÓN DE LOS ÉSTERES DE MOSHER DE 104 Y rac-104*}

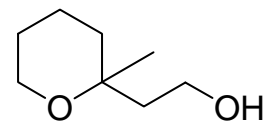

rac-104

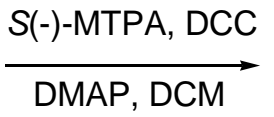

DMAP, DCM

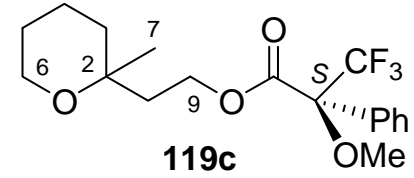

A una disolución de rac-104 (9 mg, 0.062 mmoles) en $2 \mathrm{~mL}$ de DCM se añaden sucesivamente a $0^{\circ} \mathrm{C}$ una cantidad catalítica de DMAP, $70 \mu \mathrm{L}$ (0.068 mmoles) de una disolución 1M de DCC en DCM y 16 mg (0.068 mmoles) de S(-)-MTPA. Se deja la mezcla reaccionando bajo atmósfera de argon durante 12 horas. Transcurrido este periodo de tiempo se diluye la mezcla de reacción con AcOEt y se lava sucesivamente con disoluciones acuosas de $\mathrm{HCl}(2 \mathrm{M}), \mathrm{NaHCO}_{3}(5 \%)$ y $\mathrm{NaCl}$ (sat.). Se seca sobre $\mathrm{Na}_{2} \mathrm{SO}_{4}$ anhidro, se filtra y evapora el disolvente obteniéndose un crudo que se cromatografía en columna sobre sílicagel flash (eluyente: hexano/AcOEt 95:5). Se obtienen $13 \mathrm{mg}(70 \%)$ de la mezcla de diastereoisómeros 119, cuyas propiedades espectroscópicas son las siguientes:

\footnotetext{
* Se muestra únicamente el procedimiento de obtención de 119c a partir del producto racémico de 104, ya que la obtención de 119a y 119b es absolutamente similar y las propiedades espectroscópicas de todos los productos 119 coinciden (Ver esquema 124 del apartado Discusión y resultados. Capítulo 2).
} 
(2S)-3,3,3-Trifluoro-2-metoxi-2-fenilpropanoato de 2-(2'-metil-tetrahidro-piran-2'il)-etilo (119c)

ESPECTRO RMN ${ }^{1} \mathbf{H}\left(400 \mathrm{MHz}, \mathrm{CDCl}_{3}, \delta\right.$ ppm) (fig. 92a): 7.53-7.38 (5H, m, -Ar), 4.44 (2H, t, J = 7.2 Hz, H-9), 3.65-3.60 (2H, m, H-6), 3.55 (3H, s, -OMe), 2.05-1.40 (8H, m, H-3, H-4, H-5 y H-8), 1.17 (3H, s, H-7).

ESPECTRO RMN ${ }^{13} \mathbf{C}\left(100 \mathrm{MHz}, \mathrm{CDCl}_{3}, \delta\right.$ ppm) (fig. 92b) (Tabla XXXVIII).

\section{EPOXIDACIÓN DE SHARPLESS DE 101}
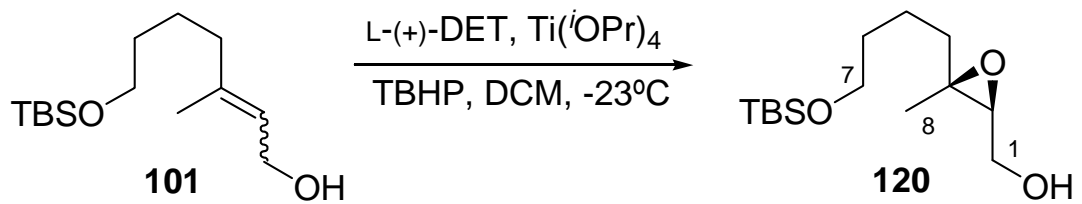

Se disuelven $331 \mathrm{mg}$ (1.61 mmoles) de L-(+)-DET en $8 \mathrm{~mL}$ de DCM seco bajo atmósfera de argon. Se baja la temperatura a $-23^{\circ} \mathrm{C}$ y se añaden $0.40 \mathrm{~mL}$ (1.34 mmoles) de $\operatorname{Ti}\left({ }^{i} \mathrm{OPr}\right){ }_{4}$. Pasados 10 minutos en estas condiciones se añaden $346 \mathrm{mg}$ (1.34 mmoles) de 101 disueltos en $5 \mathrm{~mL}$ de DCM. Se deja agitando a $-23^{\circ} \mathrm{C}$ durante 5 minutos, y entonces se añaden $0.5 \mathrm{~mL}$ (2.68 mmoles) de una disolución de TBHP $5.5 \mathrm{M}$ en $n$ decano. Se mantiene la reacción a $-23^{\circ} \mathrm{C}$ durante 20 horas.

Pasado este tiempo se añaden, a $-23^{\circ} \mathrm{C}, 2 \mathrm{~mL}$ de una disolución acuosa de ácido tartárico (10\%). Se deja agitando a esa temperatura durante 30 minutos y luego a temperatura ambiente durante una hora más. Se filtra la mezcla por celita, lavando abundantemente con éter $(125 \mathrm{~mL})$. Luego se lava con agua y se evapora parte del éter. Se baja la temperatura a $0^{\circ} \mathrm{C}$, se añaden $3 \mathrm{~mL}$ de $\mathrm{NaOH} 1 \mathrm{M}$ y se deja agitando en estas condiciones durante 45 minutos. A continuación se separa la fase orgánica y se lava con una disolución acuosa de $\mathrm{NaCl}$ saturada. La fase acuosa se extrae 2 veces con éter y se lava con una disolución acuosa $\mathrm{NaCl}$ saturada. Se reúnen las fases etéreas y se secan sobre $\mathrm{Na}_{2} \mathrm{SO}_{4}$ anhidro. Se filtra y se evapora el éter, obteniéndose $600 \mathrm{mg}$ de crudo que se cromatografía en columna sobre sílicagel (eluyente: hexano/AcOEt 9:1). Se obtienen 330 mg (90\%) del alcohol alílico 120 como diastereoisómero y enantiómero 
mayoritario, no recuperándose el material de partida Z-101. Las propiedades físicas y espectroscópicas de este compuesto son las siguientes:

\section{$\underline{\text { (2S,3S)-3-Metil-3-[4'-(terc-butil-dimetil-silaniloxi)-butil]-oxiranilmetanol (120) }}$}

ESPECTRO IR $v_{\max }$ (película) $\mathrm{cm}^{-1}$ (fig. 93a): 3424 (ancha), 2930, 2858, 1472, 1463, 1386, 1361, 1255, 1101, 1034, 837.

ESPECTRO RMN ${ }^{1} \mathbf{H}\left(200 \mathrm{MHz}, \mathrm{CDCl}_{3}, \delta\right.$ ppm) (fig. 93b): 3.82-3.57 (4H, m, H-1 y H-7), 2.95 (1H, dd, $J=6.2$ y 4.2 Hz, H-2), 1.87-1.44 (6H, m, H-4, H-5 y H-6), 1.28 $(3 \mathrm{H}, \mathrm{s}, \mathrm{H}-8), 0.88\left(9 \mathrm{H}, \mathrm{s},{ }^{t} \underline{\mathrm{BuMe}} \mathrm{S}_{2} \mathrm{Si}\right), 0.03\left(6 \mathrm{H}, \mathrm{s},{ }^{t} \mathrm{BuMe} \underline{2}_{2} \mathrm{Si}\right)$.

ESPECTRO RMN ${ }^{13} \mathbf{C}\left(50 \mathrm{MHz}, \mathrm{CDCl}_{3}, \delta\right.$ ppm) (fig. 93c) (Tabla XXXVII).

HRMS, ESI (fig. 93d): Calculado para $\mathrm{C}_{14} \mathrm{H}_{30} \mathrm{O}_{3} \mathrm{NaSi}(M+\mathrm{Na})^{+}, 297.1856$. Experimental $(\mathrm{M}+\mathrm{Na})^{+}, 297.1853$.

$[\alpha]_{D}^{25}=-4.3^{\circ}\left(\mathrm{c}=1.2, \mathrm{CHCl}_{3}\right)$

\section{ACETILACIÓN DEL EPOXIALCOHOL 120}

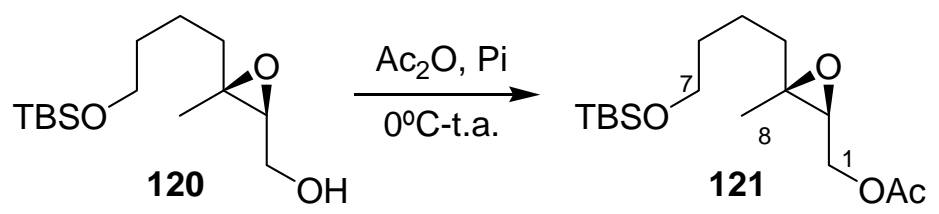

Se disuelve 120 (134 mg, 0.49 mmoles) en $1 \mathrm{~mL}$ de piridina y se añade $1 \mathrm{~mL}$ de anhídrido acético a $0^{\circ} \mathrm{C}$. Se agita durante 20 horas dejando calentar lentamente hasta temperatura ambiente. Pasado este tiempo se añade hielo picado y se deja agitando durante 10 minutos. Se extrae 3 veces con AcOEt y el combinado de fases orgánicas se lava sucesivamente con disoluciones acuosas de $\mathrm{CuSO}_{4}(20 \%), \mathrm{NaHCO}_{3}(5 \%)$ y $\mathrm{NaCl}$ (saturada). Se seca sobre $\mathrm{Na}_{2} \mathrm{SO}_{4}$ anhidro, se filtra y se evapora el disolvente obteniéndose $150 \mathrm{mg}$ de crudo que se cromatografían en columna sobre sílicagel flash (eluyente: hexano/AcOEt 9:1). Se aíslan $142 \mathrm{mg}$ (92\%) del compuesto 121 como diastereoisómero y enantiómero mayoritario. Las propiedades físicas y espectroscópicas de este compuesto son las siguientes: 
$\underline{\text { Acetato de (2S,3S)-3-Metil-3-[4-(terc-butil-dimetil-silaniloxi)-butil]-oxiranilmetilo }}$ $\underline{(121)}$

ESPECTRO IR $v_{\max }$ (película) $\mathrm{cm}^{-1}$ (fig. 94a): 2931, 2858, 1747, 1472, 1376, 1233, 1101, 1036, 837.

ESPECTRO RMN ${ }^{1} \mathbf{H}\left(200 \mathrm{MHz}, \mathrm{CDCl}_{3}, \delta\right.$ ppm) (fig. 94b): $4.29(1 \mathrm{H}, \mathrm{dd}, J=12.2 \mathrm{y}$ $\left.4.4 \mathrm{~Hz}, \mathrm{H}_{\mathrm{A}}-1\right), 4.02\left(1 \mathrm{H}, \mathrm{dd}, J=12.2\right.$ y $\left.6.6 \mathrm{~Hz}, \mathrm{H}_{\mathrm{B}}-1\right), 3.58(2 \mathrm{H}, \mathrm{t}, J=5.8 \mathrm{~Hz}, \mathrm{H}-7)$, 2.95 (2H, dd, J=6.6 y 4.4 Hz, H-2), 2.07 (3H, s, $\underline{\text { MeCOO- }), ~ 1.56-1.30 ~(6 H, ~ m, ~ H-4, ~ H-~}$ 5 y H-6), 1.28 (3H, s, H-8), $0.87\left(9 \mathrm{H}, \mathrm{s},{ }^{t} \underline{\mathrm{BuMe}}_{2} \mathrm{Si}\right), 0.02\left(6 \mathrm{H}, \mathrm{s},{ }^{t} \mathrm{BuMe} \underline{2}_{2} \mathrm{Si}\right)$.

ESPECTRO RMN ${ }^{13} \mathbf{C}\left(50 \mathrm{MHz}, \mathrm{CDCl}_{3}, \delta\right.$ ppm) (fig. 94c) (Tabla XXXVII).

HRMS, ESI (fig. 94d): Calculado para $\mathrm{C}_{16} \mathrm{H}_{32} \mathrm{O}_{4} \mathrm{NaSi}(M+\mathrm{Na})^{+}, 339.1962$. Experimental $(\mathrm{M}+\mathrm{Na})^{+}, 339.1941$.

$[\alpha]_{D}^{25}=-15.0^{\circ}\left(\mathrm{c}=1.6, \mathrm{CHCl}_{3}\right)$

\section{DESPROTECCIÓN DE 121 CON TBAF}

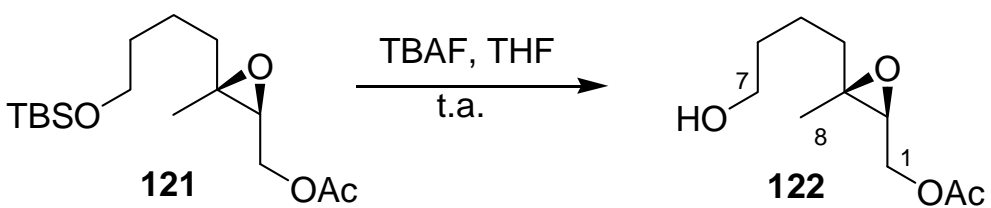

Se disuelven $220 \mathrm{mg}$ ( 0.69 mmoles) de 121 en $7 \mathrm{~mL}$ de THF y se añaden $0.8 \mathrm{~mL}$ (0.83 mmoles) de una disolución de TBAF 1.0 M en THF. Se deja reaccionando a temperatura ambiente durante una hora, transcurrida la cual se añaden $4 \mathrm{~mL}$ de $\mathrm{H}_{2} \mathrm{O}$ y se extrae con AcOEt ( 3 x $50 \mathrm{~mL}$ ). El combinado de fases orgánicas se lava con $\mathrm{H}_{2} \mathrm{O}$ y disolución acuosa saturada de $\mathrm{NaCl}$. Se seca sobre $\mathrm{Na}_{2} \mathrm{SO}_{4}$ anhidro, se filtra y se evapora el disolvente para obtener un crudo que se cromatografía en columna sobre sílicagel flash (eluyente: hexano/AcOEt 6:4). Se aíslan $112 \mathrm{mg}$ (80\%) del compuesto 122 como diastereoisómero y enantiómero mayoritario. Las propiedades físicas y espectroscópicas de este compuesto son las siguientes: 
Acetato de [(2S,3S)-3-(4-hidroxibutil)-3-metil-oxiran-2-il]-metilo (122)

ESPECTRO IR $v_{\max }$ (película) $\mathrm{cm}^{-1}$ (fig. 95a): 3466 (ancha), 2938, 2867, 1741, 1440, 1371, 1247, 1108, 1081, 1047, 975, 913.

ESPECTRO RMN ${ }^{1} \mathbf{H}\left(200 \mathrm{MHz}, \mathrm{CDCl}_{3}, \delta\right.$ ppm) (fig. 95b): $4.28(1 \mathrm{H}, \mathrm{dd}, J=12.2 \mathrm{y}$ $\left.4.4 \mathrm{~Hz}, \mathrm{H}_{\mathrm{A}}-1\right), 3.99\left(1 \mathrm{H}, \mathrm{dd}, J=12.2\right.$ y $\left.6.6 \mathrm{~Hz}, \mathrm{H}_{\mathrm{B}}-1\right), 3.59$ (2H, t, $\left.J=5.8 \mathrm{~Hz}, \mathrm{H}-7\right)$,

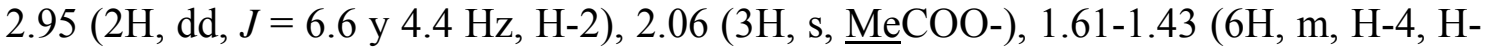
5 y H-6), 1.29 (3H, s, H-8).

ESPECTRO RMN ${ }^{13} \mathbf{C}\left(50 \mathrm{MHz}, \mathrm{CDCl}_{3}, \delta\right.$ ppm) (fig. 95c) (Tabla XXXVII).

HRMS, ESI (fig. 95d): Calculado para $\mathrm{C}_{10} \mathrm{H}_{18} \mathrm{O}_{4} \mathrm{Na}(M+\mathrm{Na})^{+}$, 225.1097. Experimental $(\mathrm{M}+\mathrm{Na})^{+}, 225.1104$.

$[\alpha]_{D}^{25}=-27.5^{\circ}\left(\mathrm{c}=1.4, \mathrm{CHCl}_{3}\right)$

\section{CICLACIÓN DE 122 CON CSA}
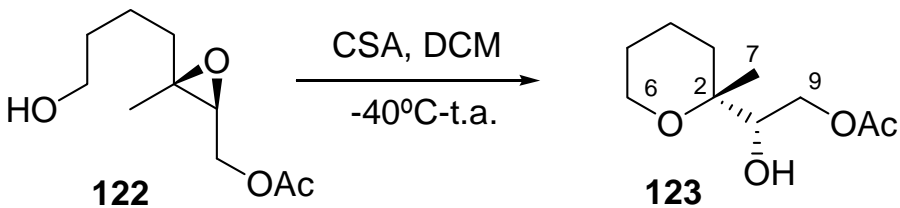

Se disuelven $52 \mathrm{mg}$ (0.26 mmoles) de 122 en $2.5 \mathrm{~mL}$ de DCM y se añaden $6 \mathrm{mg}$ (0.026 mmoles) de CSA a $-40{ }^{\circ} \mathrm{C}$. Se mantiene la mezcla con agitación bajo atmósfera de argon dejando subir lentamente la temperatura. Transcurridas 12 horas se añaden 0.2 $\mathrm{mL}$ de $\mathrm{NEt}_{3}$ y se agita durante 10 minutos. A continuación se evapora el disolvente y se cromatografía el residuo sobre sílicagel flash (eluyente: hexano/AcOEt 85:15) para obtener $30 \mathrm{mg}(60 \%)$ del tetrahidropirano 123 como diastereoisómero y enantiómero mayoritario. Las propiedades físicas y espectroscópicas de este compuesto son las siguientes: 
Acetato de (2S,2'R)-2-(2'-tetrahidro-2'-metil-tetrahidro-piran-2'-il)-2-hidroxietilo $\underline{(123)}$

ESPECTRO IR $v_{\max }$ (película) $\mathrm{cm}^{-1}$ (fig. 96a): 3466 (ancha), 2938, 2867, 1741, 1440, 1371, 1247, 1108, 1081, 1047, 975, 913.

ESPECTRO RMN ${ }^{1} \mathbf{H}\left(200 \mathrm{MHz}, \mathrm{CDCl}_{3}, \delta\right.$ ppm) (fig. 96b): $4.30(1 \mathrm{H}, \mathrm{dd}, J=11.4 \mathrm{y}$ $\left.2.2 \mathrm{~Hz}, \mathrm{H}_{\mathrm{A}}-9\right), 4.00$ (1H, dd, $J=11.4$ y $\left.8.5 \mathrm{~Hz}, \mathrm{H}_{\mathrm{B}}-9\right)$, 3.73-3.70 (3H, m, H-6 y H-8), 2.10 (3H, s, MeCOO-), 1.70-1.25 (6H, m, H-3, H-4 y H-5), 1.22 (3H, s, H-7).

ESPECTRO RMN ${ }^{13} \mathbf{C}\left(50 \mathrm{MHz}, \mathrm{CDCl}_{3}, \delta\right.$ ppm) (fig. 96c) (Tabla XXXVIII)

HRMS, ESI (fig. 96d): Calculado para $\mathrm{C}_{10} \mathrm{H}_{18} \mathrm{O}_{4} \mathrm{Na}(M+\mathrm{Na})^{+}$, 225.1097. Experimental $(\mathrm{M}+\mathrm{Na})^{+}, 225.1112$.

$[\alpha]_{D}^{25}=-9.1^{\circ}\left(\mathrm{c}=0.7, \mathrm{CHCl}_{3}\right)$

\section{TOSILACIÓN DE 123}

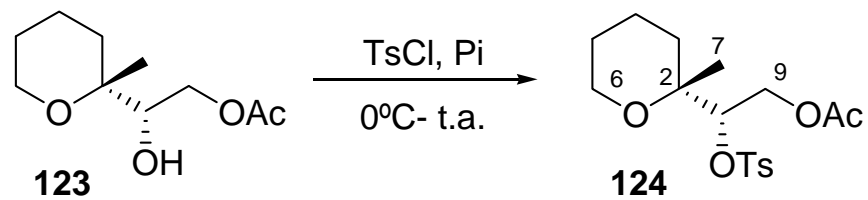

A una disolución de 123 (50 $\mathrm{mg}, 0.25$ mmoles) en $0.5 \mathrm{~mL}$ de piridina se añaden $94 \mathrm{mg}$ (0.49 mmoles) de $\mathrm{TsCl}$ a $0^{\circ} \mathrm{C}$. Se agita durante 12 horas dejando calentar lentamente hasta temperatura ambiente. Pasado este tiempo se añade hielo picado y se extrae la fase acuosa con AcOEt (4 veces). El combinado de fases orgánicas se lava sucesivamente con disoluciones acuosas de $\mathrm{CuSO}_{4}(20 \%), \mathrm{NaHCO}_{3}(5 \%), \mathrm{H}_{2} \mathrm{O}$ y NaCl (saturada). Se seca sobre $\mathrm{Na}_{2} \mathrm{SO}_{4}$ anhidro, se filtra y se evapora el disolvente para obtener $100 \mathrm{mg}$ de crudo que se cromatografían en columna sobre sílicagel flash (eluyente: hexano/AcOEt 9:1). Se aíslan $54 \mathrm{mg}$ (61\%) de 124 como diastereoisómero y enantiómero mayoritario y se recuperan $15 \mathrm{mg}$ (30\%) de producto de partida. Las propiedades físicas y espectroscópicas del tosilderivado 124 son las siguientes: 
Toluen-4-sulfonato de $(2 S, 2$ ' $R)-2$-acetoxi-1-(2'-tetrahidro-2'-metil-tetrahidropiran-2'-il)-etilo (124)

ESPECTRO IR $v_{\max }$ (película) $\mathrm{cm}^{-1}$ (fig. 97a): 2941, 2868, 1744, 1598, 1451, 1366, $1235,1176,1081,1047,925$.

ESPECTRO RMN ${ }^{1} \mathbf{H}\left(200 \mathrm{MHz}, \mathrm{CDCl}_{3}, \delta\right.$ ppm) (fig. 97b): $7.80(2 \mathrm{H}, \mathrm{d}, J=8.4 \mathrm{~Hz}$, $\left.\mathrm{H}_{\text {orto }} \underline{\mathrm{Ar}}-\mathrm{Me}\right), 7.30$ (2H, d, J=8.4 Hz, H $\left.\mathrm{H}_{\text {meta }} \underline{\mathrm{Ar}}-\mathrm{Me}\right), 4.92(1 \mathrm{H}, \mathrm{dd}, J=8.4$ y $1.8 \mathrm{~Hz}, \mathrm{H}-$ 8), $4.45\left(1 \mathrm{H}, \mathrm{dd}, J=12.6\right.$ y $\left.1.8 \mathrm{~Hz}, \mathrm{H}_{\mathrm{A}}-9\right), 4.11\left(1 \mathrm{H}, \mathrm{dd}, \mathrm{J}=12.6\right.$ y $\left.8.4 \mathrm{~Hz}, \mathrm{H}_{\mathrm{B}}-9\right), 3.60$

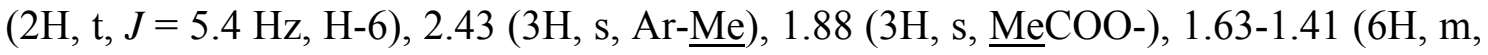
H-3, H-4 y H-5), 1.21 (3H, s, H-7).

ESPECTRO RMN ${ }^{13} \mathbf{C}\left(50 \mathrm{MHz}, \mathrm{CDCl}_{3}, \delta \mathrm{ppm}\right)$ (fig.97c) (Tabla XXXVIII)

HRMS, ESI (fig. 97d): Calculado para $\mathrm{C}_{17} \mathrm{H}_{24} \mathrm{O}_{6} \mathrm{NaS}(M+\mathrm{Na})^{+}, 379.1185$. Experimental $(\mathrm{M}+\mathrm{Na})^{+}, 379.1206$.

$[\alpha]_{D}^{25}=-34.7^{\circ}\left(\mathrm{c}=1.1, \mathrm{CHCl}_{3}\right)$

\section{$\underline{\text { REDUCCIÓN DE } 124 \text { CON LiAlH }}_{4}$}

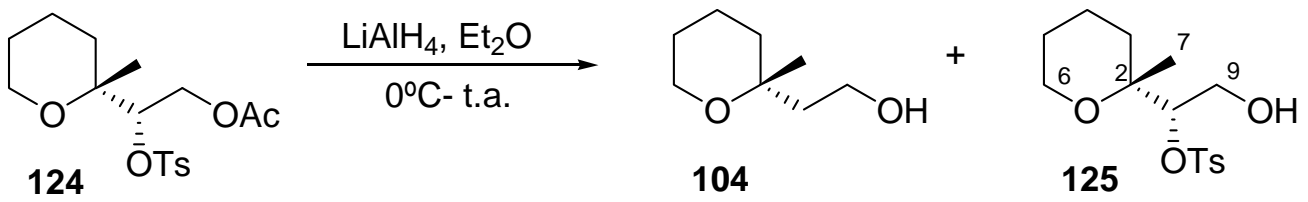

Se disuelve 124 (95 mg, 0.27 mmoles) en $3 \mathrm{~mL}$ de $\mathrm{Et}_{2} \mathrm{O}$ seco y se añaden a $0^{\circ} \mathrm{C}$ $50 \mathrm{mg}$ (1.33 mmoles) de $\mathrm{LiAlH}_{4}$. Se agita durante cinco horas dejando calentar lentamente hasta temperatura ambiente. Pasado este tiempo se para la reacción añadiendo éter húmedo. Se seca sobre $\mathrm{Na}_{2} \mathrm{SO}_{4}$ anhidro, se filtra y se evapora el disolvente obteniéndose $50 \mathrm{mg}$ de crudo que se cromatografían en columna sobre sílicagel flash (eluyente: hexano/AcOEt 9:1). Se aíslan $12 \mathrm{mg}$ (32\%) del alcohol 104 como enantiómero mayoritario, cuyas propiedades espectroscópicas ya han sido descritas con anterioridad y $15 \mathrm{mg}$ (18\%) del compuesto 125 como diastereoisómero y enantiómero mayoritario, que presenta las siguientes propiedades espectroscópicas: 
$\underline{\text { Toluen-4-sulfonato de }\left(2 S, 2^{\prime} R\right)-1-\left(2^{\prime} \text {-tetrahidro-2'-metil-tetrahidro-piran-2'-il)-2- }\right.}$ hidroxietilo (125)

ESPECTRO RMN ${ }^{1} \mathbf{H}\left(200 \mathrm{MHz}, \mathrm{CDCl}_{3}, \delta\right.$ ppm) (fig. 98): $7.83(2 \mathrm{H}, \mathrm{d}, J=8.2 \mathrm{~Hz}$, $\left.\mathrm{H}_{\text {orto }} \underline{\mathrm{Ar}}-\mathrm{Me}\right), 7.34$ (2H, d, J = 8.2 Hz, H $\left.\mathrm{H}_{\text {meta }} \underline{\mathrm{Ar}}-\mathrm{Me}\right), 4.59$ (1H, m, H-8), 3.88-3.47 (4H, m, H-6 y H-9), 2.45 (3H, s, Ar-Me), 1.67-1.31 (6H, m, H-3, H-4 y H-5), 1.18 (3H, s, H$7)$.

\section{OXIDACIÓN ALÍLICA DE GERANIOL CON MnO 2}

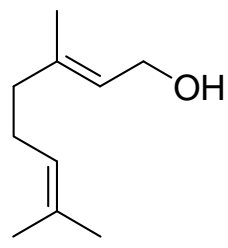

Geraniol
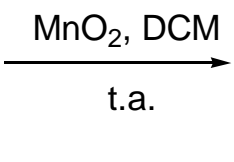

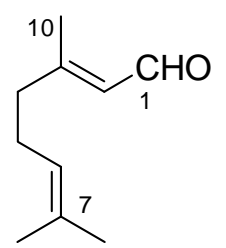

126

Se disuelven 3 g (19.45 mmoles) de geraniol en $195 \mathrm{~mL}$ de DCM seco, se añaden $34 \mathrm{~g}$ (389 mmoles) de $\mathrm{MnO}_{2}$ y se deja reaccionando con agitación a temperatura ambiente durante 4 horas. Transcurrido este tiempo se filtra la mezcla de reacción a través de celita lavando abundantemente con AcOEt. Tras evaporar el disolvente se obtienen 2.9 g (97\%) de 126, que se utiliza en la siguiente reacción sin previa purificación. Este compuesto presenta las siguientes propiedades espectroscópicas:

\section{$\underline{\text { 3,7-Dimetil-octa-E-2,6-dien-1-al (126) }}$}

ESPECTRO IR $v_{\max }$ (película) $\mathrm{cm}^{-1}$ (fig. 99a): 2969, 2917, 2856, 1672, 1444, 1380, 1196, 1124, 910.

ESPECTRO RMN ${ }^{1} \mathbf{H}\left(200 \mathrm{MHz}, \mathrm{CDCl}_{3}, \delta\right.$ ppm) (fig. 99b): $9.97(1 \mathrm{H}, \mathrm{d}, J=8.0 \mathrm{~Hz}$, H-1), 5.85 (1H, d, J=8.0 Hz, H-2), 5.09-5.04 (1H, m, H-6), 2.14 (3H, s, H-10), 2.242.00 (4H, m, H-4 y H-5), 1.66 y 1.58 (3H c/u, H-8 y H-9). 
ESPECTRO RMN ${ }^{13} \mathbf{C}\left(50 \mathrm{MHz}, \mathrm{CDCl}_{3}, \delta\right.$ ppm) (fig. 99c) (Tabla XXXIX).

\section{EPOXIDACIÓN DE 126 CON m-CPBA}<smiles>CC=CC=C(C)CCC=C(C)C</smiles>

126

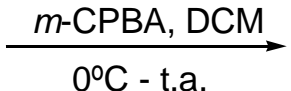

Sobre una disolución de $126(1.0 \mathrm{~g}, 6.57 \mathrm{mmol})$ en $\mathrm{DCM}(65 \mathrm{~mL})$ a $0^{\circ} \mathrm{C}$ se añaden $1.7 \mathrm{~g}(9.85 \mathrm{mmol})$ de $m$-CPBA al 70\%. Se agita la mezcla dejando que alcance temperatura ambiente durante 90 minutos. Pasado este tiempo se para añadiendo $10 \mathrm{~mL}$ de una disolución acuosa de $\mathrm{NaHCO}_{3}$ (5\%). Se extrae con AcOEt (x3) y se lava sucesivamente con disoluciones acuosas de $\mathrm{Na}_{2} \mathrm{SO}_{3}(10 \%), \mathrm{NaHCO}_{3}(5 \%)$ y $\mathrm{NaCl}$ (saturada). Se seca sobre $\mathrm{Na}_{2} \mathrm{SO}_{4}$ anhidro, se filtra y se evapora el disolvente obteniéndose un crudo que se cromatografía en columna sobre sílicagel flash (eluyente: hexano/AcOEt 8:2). Se aíslan $910 \mathrm{mg}$ (84\%) del epóxido 127, que se utiliza en la siguiente reacción sin previa purificación. Este compuesto presenta las siguientes propiedades espectroscópicas:

\section{$\underline{\text { 3-Metil-5-(3,3-dimetiloxiran-2-il)-pent-E-2-en-1-al (127) }}$}

ESPECTRO IR $v_{\max }$ (película) $\mathrm{cm}^{-1}$ (fig. 100a): 2963, 2927, 2863, 2774, 1676, 1448, $1379,1325,1250,1196,1126,878$.

ESPECTRO RMN ${ }^{1} \mathbf{H}\left(200 \mathrm{MHz}, \mathrm{CDCl}_{3}, \delta\right.$ ppm) (fig. 100b): $9.85(1 \mathrm{H}, \mathrm{d}, J=9.2 \mathrm{~Hz}$, H-1), 5.77 (1H, d, J = 9.2 Hz, H-2), 2.58 (1H, t, $J=6.8$ Hz, H-6), 2.27-2.19 (2H, m, H4), 2.06 (3H, s, H-10), 1.60 (2H, dt, J=14.8 y 6.8 Hz, H-5), 1.16 y 1.13 (3H c/u, s, H-8 y H-9).

ESPECTRO RMN ${ }^{13} \mathbf{C}\left(50 \mathrm{MHz}, \mathrm{CDCl}_{3}, \delta\right.$ ppm) (fig. 100c) (Tabla XXIX). 
HRMS, ESI (fig. 100d): Calculado para $\mathrm{C}_{10} \mathrm{H}_{16} \mathrm{O}_{2} \mathrm{Na}(M+\mathrm{Na})^{+}, 191.1042$. Experimental $(\mathrm{M}+\mathrm{Na})^{+}, 191.1024$.

\section{REDUCCIÓN DE 127 CON LiAlH 4}

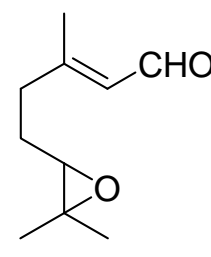

127
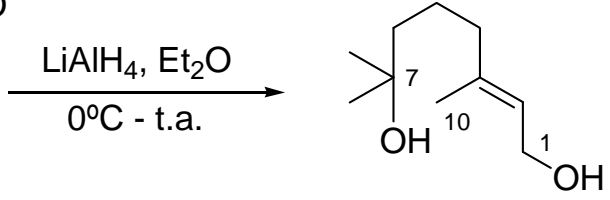

128

Se disuelve 127 (254 mg, 1.51 mmoles) en $15 \mathrm{~mL}$ de $^{2} t_{2} \mathrm{O}$ seco y se añaden a $0^{\circ} \mathrm{C} 143 \mathrm{mg}$ (3.78 mmoles) de $\mathrm{LiAlH}_{4}$. Se agita durante 30 minutos dejando calentar lentamente hasta temperatura ambiente. Pasado este tiempo se para la reacción añadiendo éter húmedo. Se seca sobre $\mathrm{Na}_{2} \mathrm{SO}_{4}$ anhidro, se filtra y se evapora el disolvente obteniéndose $210 \mathrm{mg}(80 \%)$ del diol 128 que se utiliza en la siguiente reacción sin previa purificación. Las propiedades espectroscópicas de este compuesto son las siguientes:

\section{$\underline{\text { 3,7-Dimetil-oct-E-2-en-1,7-diol (128) }}$}

ESPECTRO RMN ${ }^{1} \mathbf{H}\left(200 \mathrm{MHz}, \mathrm{CDCl}_{3}, \delta\right.$ ppm) (fig. 101a): $5.29(1 \mathrm{H}, \mathrm{t}, J=6.8 \mathrm{~Hz}$, H-2), 4.02 (2H, d, J=6.8 Hz, H-1), 1.95-1.88 (2H, m, H-4), 1.40-1.32 (4H, m, H-5 у H6), 1.58 (3H, s, H-10), 1.10 (6H, s, H-8 y H-9).

ESPECTRO RMN ${ }^{13} \mathbf{C}\left(50 \mathrm{MHz}, \mathrm{CDCl}_{3}, \delta\right.$ ppm) (fig. 101b) (Tabla XXXIX). 


\section{$\underline{\text { OXIDACIÓN ALÍLICA DE } 128 \mathrm{CON} \mathrm{MnO}_{2}}$}

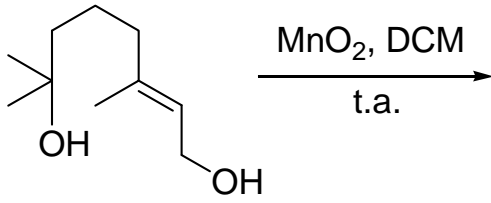

128

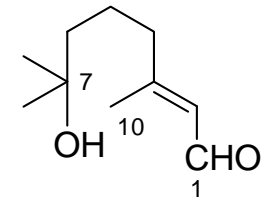

129

Se disuelven $509 \mathrm{mg}$ (2.96 mmoles) de 128 en $30 \mathrm{~mL}$ de DCM seco, se añaden 5 g (59.20 mmoles) de $\mathrm{MnO}_{2}$ y se deja reaccionando con agitación a temperatura ambiente durante 3 horas. Transcurrido este tiempo se filtra la mezcla de reacción a través de celita lavando abundantemente con AcOEt. Tras evaporar el disolvente se obtienen $500 \mathrm{mg}$ de crudo que se cromatografían en columna sobre sílicagel (eluyente: hexano/AcOEt 7:3). Se aíslan $460 \mathrm{mg}$ (91\%) del compuesto 129, el cual presenta las siguientes propiedades espectroscópicas:

\section{7-Hidroxi-3,7-dimetil-oct-E-2-en-1-al (129)}

ESPECTRO IR $v_{\max }$ (película) $\mathrm{cm}^{-1}$ (fig. 102a): 3419 (ancha), 2969, 1670, 1450, 1380, 1196, 1151, 911, 870 .

ESPECTRO RMN ${ }^{1} \mathbf{H}\left(200 \mathrm{MHz}, \mathrm{CDCl}_{3}, \delta\right.$ ppm) (fig. 102b): 9.90 (1H, d, $J=8.0 \mathrm{~Hz}$, H-1), 5.81 (1H, d, J = 8.0 Hz, H-2), 2.19-2.00 (3H, m, H-4 y-OH), 2.10 (3H, s, H-10), 1.61-1.34 (4H, m, H-5 y H-6), 1.15 (6H, s, H-8 y H-9)

ESPECTRO RMN ${ }^{13} \mathbf{C}\left(50 \mathrm{MHz}, \mathrm{CDCl}_{3}, \delta\right.$ ppm) (fig. 102c) (Tabla XXXVI).

HRMS, ESI (fig. 102d): Calculado para $\mathrm{C}_{10} \mathrm{H}_{18} \mathrm{O}_{2} \mathrm{Na}(M+\mathrm{Na})^{+}, \quad 193.1199$. Experimental $(\mathrm{M}+\mathrm{Na})^{+}, 193.1199$. 


\section{PROCEDIMIENTO GENERAL DE ADICIÓN oXo-MICHAEL}

\section{ORGANOCATALÍTICA DEL SUSTRATO 129 Y POSTERIOR REDUCCIÓN}
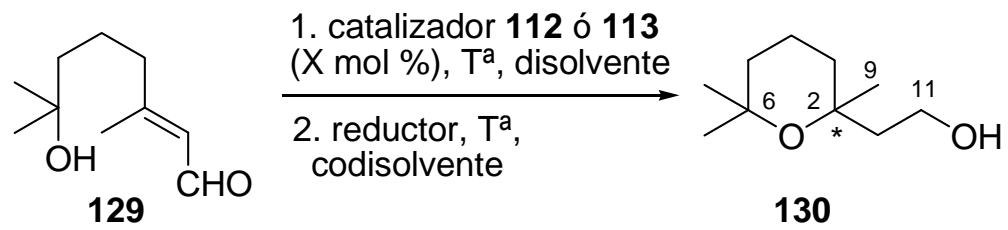

Sobre una disolución del sustrato $\mathbf{1 2 9}$ en el disolvente y a la temperatura de elección, bajo atmósfera de argon, se añade el catalizador correspondiente. Se deja reaccionando a esa temperatura hasta que el seguimiento por $\mathrm{CCF}$ indica que ha terminado. Entonces se añade en caso necesario el codisolvente $(\mathrm{MeOH})$ y el reductor $\left(\mathrm{NaBH}_{4}\right.$ o DIBAL-H) correspondientes. Pasada media hora se para la reacción de la forma habitual para cada caso y se cromatografía el crudo en columna sobre sílicagel flash (eluyente: hexano/AcOEt 8:2) para obtener el tetrahidropirano 130, el cual presenta las siguientes propiedades espectroscópicas:

\section{$\underline{\text { 2-(Tetrahidro-2', 6',6'-trimetil-piran-2'-il)-etanol (130) }}$}

ESPECTRO IR $v_{\max }$ (película) $\mathrm{cm}^{-1}$ (fig. 103a): 3424 (ancha), 2971, 2935, 1444, 1373, 1352, 1226, 1122, 1078, 1004, 982.

ESPECTRO RMN ${ }^{1} \mathbf{H}\left(200 \mathrm{MHz}, \mathrm{CDCl}_{3}, \delta\right.$ ppm) (fig. 103b): 3.83-3.76 (2H, m, H-11), 1.84-1.35, (8H, m, H-3, H-4, H-5 у H-8), 1.28, 1.22 у 1.17 (3H c/u, H-7, H-8 у H-9).

ESPECTRO RMN ${ }^{13} \mathbf{C}\left(50 \mathrm{MHz}, \mathrm{CDCl}_{3}, \delta\right.$ ppm) (fig. 103c) (Tabla XXXVI).

HRMS, ESI (fig. 103d): Calculado para $\mathrm{C}_{10} \mathrm{H}_{20} \mathrm{O}_{2} \mathrm{Na}(M+\mathrm{Na})^{+}, \quad 195.1355$. Experimental $(\mathrm{M}+\mathrm{Na})^{+}, 195.1341$. 


\section{YODOCICLACIÓN DE 129}

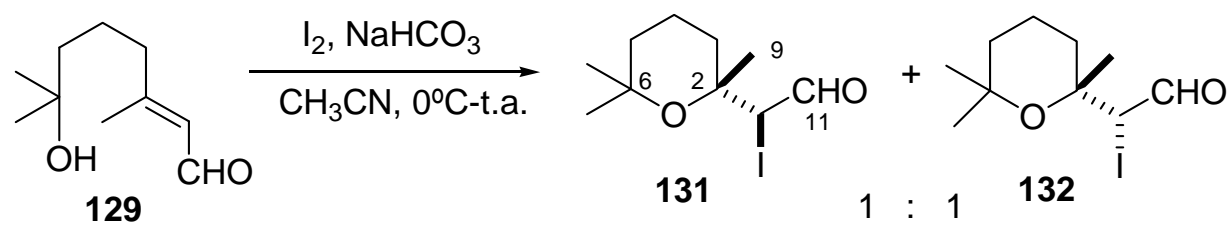

Se disuelven $53 \mathrm{mg}$ (0.31 mmoles) de 129 en $3 \mathrm{~mL}$ de $\mathrm{CH}_{3} \mathrm{CN}$ y se añaden 237 mg (0.93 mmoles) de $\mathrm{I}_{2}$ resublimado y $79 \mathrm{mg}(0.93$ mmoles $)$ de $\mathrm{NaHCO}_{3}$ a $0^{\circ} \mathrm{C}$. Se mantiene la agitación durante 1 hora dejando calentar progresivamente hasta temperatura ambiente. Pasado este tiempo se diluye la mezcla con AcOEt (100 mL) y se lava con disoluciones acuosas de $\mathrm{Na}_{2} \mathrm{~S}_{2} \mathrm{O}_{3}(10 \%), \mathrm{NaHCO}_{3}(5 \%)$ y $\mathrm{NaCl}$ (saturada). Se seca sobre $\mathrm{Na}_{2} \mathrm{SO}_{4}$, se filtra y se evapora el disolvente para obtener $75 \mathrm{mg}(80 \%)$ de la mezcla de diastereoisómeros 131 y 132, cuyas propiedades espectroscópicas son las siguientes:

\section{2-(Tetrahidro-2',6',6'-trimetil-piran-2'-il)-2-yodo-acetaldehído (131 y 132)}

ESPECTRO IR $v_{\max }$ (película) $\mathrm{cm}^{-1}$ (fig. 104a): 2973, 2938, 1712, 1471, 1375, 1222, 1120, 1059, 1024, 987.

ESPECTRO RMN ${ }^{1} \mathbf{H}\left(200 \mathrm{MHz}, \mathrm{CDCl}_{3}, \delta\right.$ ppm) (fig. 104b): $9.35(1 \mathrm{H}, \mathrm{d}, J=6.0 \mathrm{~Hz}$, H-11), 4.36 y 4.29 (1H c/u, d, $J=6.0$ Hz, H-10), 1.76-1.33 (6H, m, H-3, H-4 у H-5), 1.50 y 1.43 (3H c/u, s, H-9), 1.21 (6H, s, H-7 y H-8).

ESPECTRO RMN ${ }^{13} \mathbf{C}\left(50 \mathrm{MHz}, \mathrm{CDCl}_{3}, \delta\right.$ ppm) (fig. 104c).

HRMS, ESI (fig. 104d): Calculado para $\mathrm{C}_{10} \mathrm{H}_{17} \mathrm{O}_{2} \mathrm{NaI}(M+\mathrm{Na})^{+}, 319.0171$. Experimental $(\mathrm{M}+\mathrm{Na})^{+}, 319.0160$. 


\section{$\underline{\text { REDUCCIÓN DE LA MEZCLA 131/132 CON NaBH }}$}

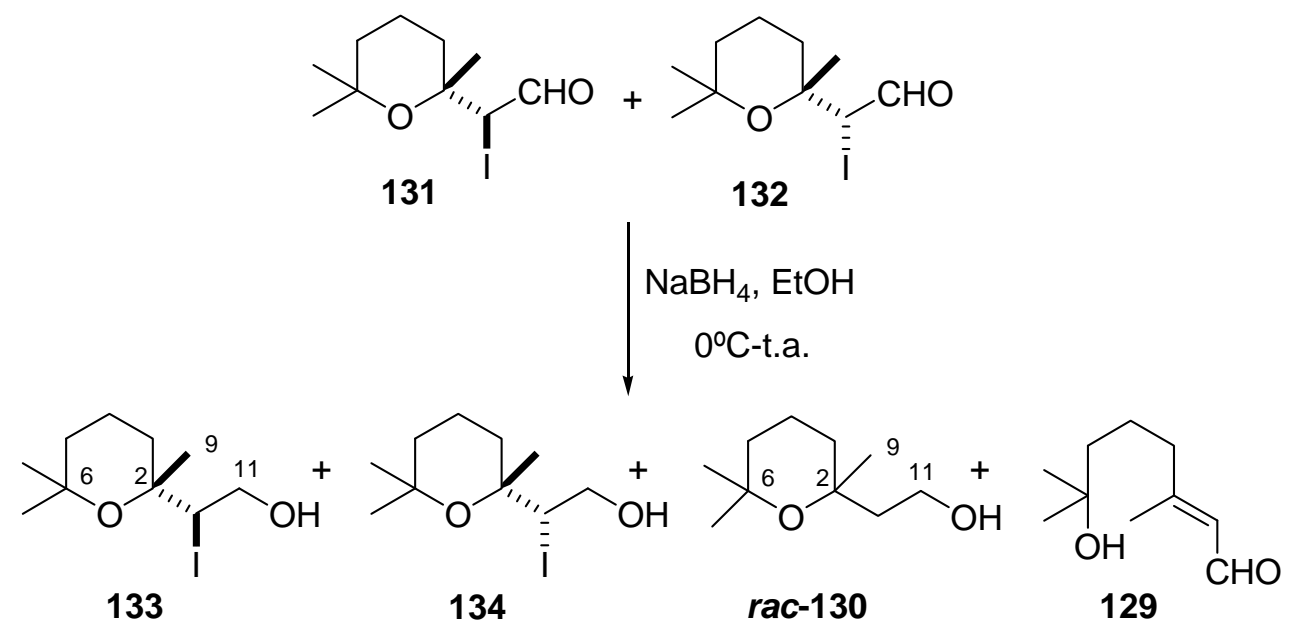

Se disuelven $30 \mathrm{mg}(0.10 \mathrm{mmoles})$ de la mezcla 131/132 en $1 \mathrm{ml}$ de EtOH seco bajo atmósfera de argon. Se añaden $9 \mathrm{mg}(2.20$ mmoles $)$ de $\mathrm{NaBH}_{4}$ a $0^{\circ} \mathrm{C}$ y se agita dejando calentar lentamente hasta temperatura ambiente durante 2 horas. Pasado este tiempo se evapora el EtOH, se diluye con agua, se extrae varias veces con AcOEt y el combinado de fases orgánicas se lava sucesivamente con agua y una disolución acuosa de $\mathrm{NaCl}$ (saturada). Se seca sobre $\mathrm{Na}_{2} \mathrm{SO}_{4}$, se filtra y se evapora el disolvente. Se obtiene un crudo que se cromatografía en columna sobre sílicagel flash (eluyente: hexano/AcOEt $9: 1 \rightarrow 8: 2 \rightarrow 1: 1)$, aislándose $5 \mathrm{mg}(17 \%)$ de la mezcla de diastereoisómeros 133/134, $3 \mathrm{mg}$ (18\%) del producto de reducción rac-130 y $4 \mathrm{mg}$ (23\%) del producto de apertura 129. Las propiedades espectroscópicas de la mezcla de diastereoisómeros 133/134 son las siguientes:

\section{$\underline{\text { 2-(Tetrahidro-2',6',6'-trimetil-piran-2'-il)-2-yodoetanol (133/134) }}$}

ESPECTRO IR $v_{\max }$ (película) $\mathrm{cm}^{-1}$ (fig. 105a): 3449 (ancha), 2954, 2929, 2871, 1464, 1376, 1218, 1120, 1062, 1009, 984.

ESPECTRO RMN ${ }^{1} \mathbf{H}\left(200 \mathrm{MHz}, \mathrm{CDCl}_{3}, \delta\right.$ ppm) (fig. 105b): $4.20(1 \mathrm{H}, \mathrm{dd}, J=8.0 \mathrm{y}$ 4.0 Hz, H-10), 4.05-3.91 (2H, m, H-11), 1.68-1.30 (6H, m, H-3, H-4 у H-5), 1.48 у 1.45 (3H c/u, s, H-9), 1.24 (6H, s, H-7 y H-8). 
ESPECTRO RMN ${ }^{13} \mathbf{C}\left(50 \mathrm{MHz}, \mathrm{CDCl}_{3}, \delta\right.$ ppm) (fig. 105c).

HRMS, ESI (fig. 105d): Calculado para $\mathrm{C}_{10} \mathrm{H}_{19} \mathrm{O}_{2} \mathrm{NaI}(M+\mathrm{Na})^{+}, 321.0322$. Experimental $(\mathrm{M}+\mathrm{Na})^{+}, 321.0319$.

\section{EPOXIDACIÓN DE SHARPLESS DE GERANIOL}

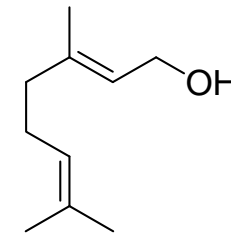

Geraniol

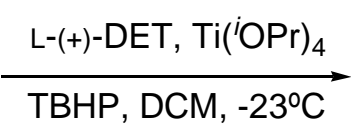

TBHP, DCM, $-23^{\circ} \mathrm{C}$

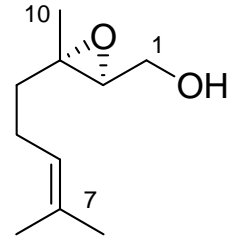

135

Se disuelven $3.2 \mathrm{~g}$ (15.56 mmoles) de L-(+)-DET en $80 \mathrm{~mL}$ de DCM seco bajo atmósfera de argon. Se baja la temperatura a $-23^{\circ} \mathrm{C}$ y se añaden $3.8 \mathrm{~mL}$ (12.96 mmoles) de $\operatorname{Ti}\left({ }^{i} \mathrm{OPr}\right)_{4}$. Pasados 10 minutos en estas condiciones se añaden $2 \mathrm{~g}(12.96 \mathrm{mmoles}) \mathrm{de}$ geraniol disueltos en $50 \mathrm{~mL}$ de DCM. Se deja agitando a $-23^{\circ} \mathrm{C}$ durante 5 minutos, $\mathrm{y}$ entonces se añaden $4.7 \mathrm{~mL}$ (25.93 mmoles) de una disolución de TBHP 5.5 M en $n$ decano. Se mantiene la reacción a $-23^{\circ} \mathrm{C}$ durante 15 horas.

Pasado este tiempo se añaden, a $-23^{\circ} \mathrm{C}, 30 \mathrm{~mL}$ de una disolución acuosa de ácido tartárico (10\%). Se deja agitando a esa temperatura durante 30 minutos y luego a temperatura ambiente durante una hora más. Se filtra la mezcla por celita, lavando abundantemente con éter $(125 \mathrm{~mL})$. Luego se lava con agua y se evapora parte del éter. Se baja la temperatura a $0^{\circ} \mathrm{C}$, se añaden $40 \mathrm{~mL}$ de $\mathrm{NaOH} 1 \mathrm{M}$ y se deja agitando en estas condiciones durante 45 minutos. A continuación se separa la fase orgánica y se lava con una disolución acuosa de $\mathrm{NaCl}$ saturada. La fase acuosa se extrae con éter ( 2 veces) y se lava con una disolución acuosa saturada de $\mathrm{NaCl}$. Se reúnen las fases etéreas y se secan sobre $\mathrm{Na}_{2} \mathrm{SO}_{4}$ anhidro. Se filtra y se evapora el éter, obteniéndose $4 \mathrm{~g}$ de crudo que se cromatografía en columna sobre sílicagel flash (eluyente: hexano/AcOEt 8:2). Se obtienen $1.86 \mathrm{~g}(85 \%)$ del alcohol alílico 135, cuyas propiedades físicas $\mathrm{y}$ espectroscópicas son las siguientes: 


\section{$\underline{(2 S, 3 S)-3-M e t i l-3-(4 '-m e t i l-p e n t-3 '-e n i l)-o x i r a n-2-i l-m e t a n o l ~(135) ~}$}

ESPECTRO IR $v_{\max }$ (película) $\mathrm{cm}^{-1}$ (fig. 106a): 3415 (ancha), 2968, 2927, 2859, 1451, $1384,1034,874$.

ESPECTRO RMN ${ }^{1} \mathbf{H}\left(200 \mathrm{MHz}, \mathrm{CDCl}_{3}, \delta\right.$ ppm) (fig. 106b): 4.99 (1H, t, $J=7.0 \mathrm{~Hz}$, H-6), 3.72-3.66 (1H, m, H $\left.\mathrm{A}_{\mathrm{A}}-1\right), 3.62-3.57\left(1 \mathrm{H}, \mathrm{m}, \mathrm{H}_{\mathrm{B}}-1\right), 2.90(1 \mathrm{H}, \mathrm{dd}, J=6.6$ y $4.0 \mathrm{~Hz}$, H-2), 2.05-1.94 (2H, m, H-5), 1.65-1.34 (2H, m, H-4), 1.59 y 1.54 (3H c/u, s, H-8 y H9), $1.20(3 \mathrm{H}, \mathrm{s}, \mathrm{H}-10)$.

ESPECTRO RMN ${ }^{13} \mathbf{C}\left(50 \mathrm{MHz}, \mathrm{CDCl}_{3}, \delta\right.$ ppm) (fig. 106c) (Tabla XL).

HRMS, ESI (fig. 106d): Calculado para $\mathrm{C}_{10} \mathrm{H}_{18} \mathrm{O}_{2} \mathrm{Na}(M+\mathrm{Na})^{+}, \quad 193.1199$. Experimental $(\mathrm{M}+\mathrm{Na})^{+}, 193.1199$.

$[\alpha]_{D}^{25}=-5.4^{\circ}\left(\mathrm{c}=1.6, \mathrm{CHCl}_{3}\right)$

ee $=92 \%$ (Determinado por GCMS en una columna Xterra C8 de $2.1 \times 20 \mathrm{~mm}$ )

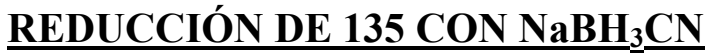

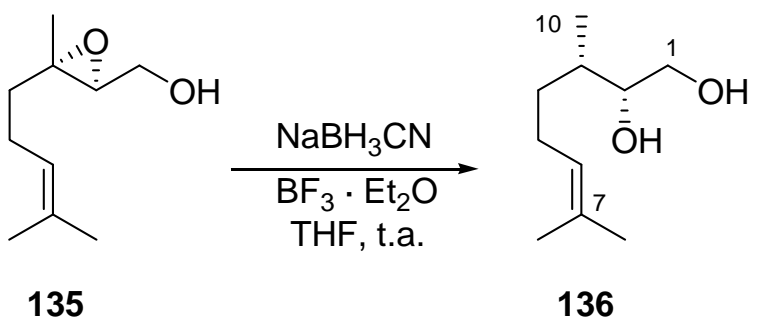

A una disolución de 135 (200 mg, 1.18 mmoles) en $6 \mathrm{~mL}$ de THF con una pequeña cantidad de verde de bromocresol se añaden con agitación $186 \mathrm{mg}$ (2.95 mmoles) de $\mathrm{NaBH}_{3} \mathrm{CN}$ a temperatura ambiente. Seguidamente se añade gota a gota el $\mathrm{BF}_{3} \cdot \mathrm{Et}_{2} \mathrm{O}$ hasta que el indicador vira de verde a amarillo y este color se mantiene $(\approx 0.3$ $\mathrm{mL}$ ). Transcurridas 3 horas se para la reacción añadiendo unas gotas de $\mathrm{HCl} 2 \mathrm{M}$ y se deja agitando 20 minutos. Se filtra la mezcla obtenida y el filtrado se neutraliza con disolución de $\mathrm{NaOH}$ (10\%). Posteriormente se extrae con AcOEt (x3) y las fases orgánicas combinadas se lavan con disolución acuosa saturada de $\mathrm{NaCl}$. Se seca sobre $\mathrm{Na}_{2} \mathrm{SO}_{4}$ anhidro, se filtra y se evapora el disolvente para obtener un crudo que se 
cromatografía en columna sobre sílicagel flash (eluyente: hexano/AcOEt 8:2). Finalmente se aíslan $100 \mathrm{mg}(50 \%)$ del diol 136, el cual presenta las siguientes propiedades físicas y espectroscópicas:

\section{$\underline{(2 R, 3 S)-3,7-D i m e t i l-o c t-6-e n-1,2-d i o l ~(136) ~}$}

ESPECTRO IR $v_{\max }$ (película) $\mathrm{cm}^{-1}$ (fig. 107a): 3373 (ancha), 2966, 2925, 1451, 1377, 1068 .

ESPECTRO RMN ${ }^{1} \mathbf{H}\left(200 \mathrm{MHz}, \mathrm{CDCl}_{3}, \delta\right.$ ppm) (fig. 107b): $5.07(1 \mathrm{H}, \mathrm{t}, J=7.0 \mathrm{~Hz}$, H-6), 3.65-3.51 (3H, m, H-1 y H-2), 2.10-1.85 (2H, m, H-5), 1.67 y 1.59 (3H c/u, s, H-8 y H-9), 1.55-1.13 (3H, m, H-3 y H-4), 0.890 (3H, d, $J=6.6$ Hz, H-10).

ESPECTRO RMN ${ }^{13} \mathbf{C}\left(50 \mathrm{MHz}, \mathrm{CDCl}_{3}, \delta\right.$ ppm) (fig. 107c) (Tabla XL).

HRMS, ESI (fig. 107d): Calculado para $\mathrm{C}_{10} \mathrm{H}_{20} \mathrm{O}_{2} \mathrm{Na}(M+\mathrm{Na})^{+}, \quad$ 195.1355. Experimental $(\mathrm{M}+\mathrm{Na})^{+}, 195.1356$.

$[\alpha]_{D}^{25}=-16.4^{\circ}\left(\mathrm{c}=1.1, \mathrm{CHCl}_{3}\right)$

\section{PROTECCIÓN DE 136 COMO ACETÓNIDO}<smiles>CC(C)=CCC[C@H](C)[C@H](O)CO</smiles>

136

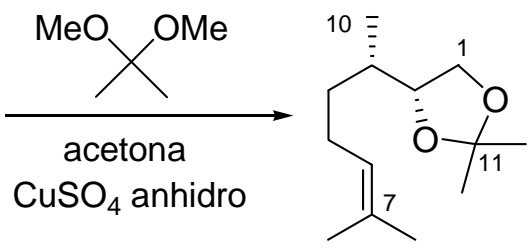

137

Se disuelve 136 (22 mg, 0.13 mmoles) en $1 \mathrm{~mL}$ de acetona seca bajo atmósfera de argon, y se adiciona una pequeña cantidad de $\mathrm{CuSO}_{4}$ anhidro. A continuación se añaden $0.12 \mathrm{~mL}$ de dimetoxipropano y se deja agitando a temperatura ambiente durante 15 horas. Pasado este tiempo se filtra por celita, lavando abundantemente con AcOEt. Por último se evapora el disolvente, obteniéndose $30 \mathrm{mg}$ de crudo que se cromatografían en columna sobre sílicagel flash (eluyente: hexano). Se aíslan $23 \mathrm{mg}$ ( 85 \%) de 137, el cual presenta las siguientes propiedades físicas y espectroscópicas: 
(4R, 6'S)-2,2-Dimetil-4-(2'-metilhept-2'-en-6'-il)-1,3-dioxolano (137)

ESPECTRO IR $v_{\max }$ (película) $\mathrm{cm}^{-1}$ (fig. 108a): 2984, 2929, 2877, 1455, 1378, 1369, $1248,1214,1158,1067,861$.

ESPECTRO RMN ${ }^{1} \mathbf{H}\left(200 \mathrm{MHz}, \mathrm{CDCl}_{3}, \delta\right.$ ppm) (fig. 108b): 5.08 (1H, t, $J=6.0 \mathrm{~Hz}$, H-6), 4.00 (1H, dd, $\left.J=7.2 \mathrm{~Hz}, \mathrm{H}_{\mathrm{A}}-1\right), 3.90(1 \mathrm{H}, \mathrm{ddd}, J=7.0 \mathrm{~Hz}, \mathrm{H}-2), 3.59$ (1H, dd, $J=$ $\left.7.2 \mathrm{~Hz}, \mathrm{H}_{\mathrm{B}}-1\right), 2.04-1.82$ (2H, m, H-5), 1.68 y 1.60 (3H c/u, s, H-8 y H-9), 1.40 y 1.35 (3H c/u, s, H-12 y H-13), 1.65-1.30 (3H, m, H-3 y H-4), 0.97 (3H, d, J = 6.6 Hz, H-10). ESPECTRO RMN ${ }^{13} \mathbf{C}\left(50 \mathrm{MHz}, \mathrm{CDCl}_{3}, \delta\right.$ ppm) (fig. 108c) (Tabla XL).

$[\alpha]_{D}^{25}=-25.4^{\circ}\left(\mathrm{c}=0.8, \mathrm{CHCl}_{3}\right)$

\section{OXIDACIÓN ALÍLICA DE 137 CON SeO 2}<smiles>CC(C)=CCC[C@@H](C)[C@H]1COC(C)(C)O1</smiles>

137

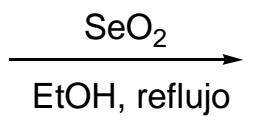

138

Se disuelve 137 (23 mg, 0.11 mmoles) en $1 \mathrm{~mL}$ de EtOH seco, se añaden $18 \mathrm{mg}$ (0.16 mmoles) de $\mathrm{SeO}_{2}$ y se pone la mezcla a reflujo. Pasadas 24 horas se deja enfriar hasta temperatura ambiente y se filtra por sílice lavando abundantemente con EtOH. Seguidamente se evapora el EtOH, se redisuelve en AcOEt y se lava con disolución acuosa saturada de $\mathrm{NaCl}$. Se seca sobre $\mathrm{Na}_{2} \mathrm{SO}_{4}$ anhidro, se filtra y se evapora el disolvente obteniéndose un crudo que se cromatografía en columna sobre sílicagel flash (eluyente: hexano/AcOEt 9:1). Finalmente se aíslan $10 \mathrm{mg}$ (41\%) del aldehído 138, el cual presenta las siguientes propiedades físicas y espectroscópicas: 
$\underline{\left(6 S, 4^{\prime} R\right)-2-M e t i l-6-\left(2^{\prime}, 2^{\prime} \text {-dimetil-1,3-dioxolan-4'-il)-hept-E-2-en-1-al (138) }\right.}$

ESPECTRO IR $v_{\max }$ (película) $\mathrm{cm}^{-1}$ (fig. 109a): 2984, 2932, 2877, 1688, 1646, 1454, $1379,1247,1214,1157,1065,861$.

ESPECTRO RMN ${ }^{1} \mathbf{H}\left(200 \mathrm{MHz}, \mathrm{CDCl}_{3}, \delta\right.$ ppm) (fig. 109b): 9.39 (1H, s, H-9), 6.46 $(1 \mathrm{H}, \mathrm{t}, J=7.2 \mathrm{~Hz}, \mathrm{H}-6), 4.04-3.90\left(2 \mathrm{H}, \mathrm{m}, \mathrm{H}_{\mathrm{A}}-1\right.$ y H-2), 3.65-3.59 (1H, m, $\left.\mathrm{H}_{\mathrm{B}}-1\right)$, 2.442.25 (2H, m, H-5), 1.75 (3H, s, H-8), 1.65-1.30 (3H, m, H-3 y H-4), 1.41 у 1.35 (3H c/u, s, H-12 y H-13), 1.00 (3H, d, $J=6.6 \mathrm{~Hz}, \mathrm{H}-10)$.

ESPECTRO RMN ${ }^{13} \mathbf{C}\left(50 \mathrm{MHz}, \mathrm{CDCl}_{3}, \delta\right.$ ppm) (fig. 109c) (Tabla XL).

HRMS, ESI (fig. 109d): Calculado para $\mathrm{C}_{13} \mathrm{H}_{22} \mathrm{O}_{3} \mathrm{Na}(M+\mathrm{Na})^{+}, \quad 249.1461$. Experimental $(\mathrm{M}+\mathrm{Na})^{+}, 249.1475$.

$[\alpha]_{D}^{25}=-18.8^{\circ}\left(\mathrm{c}=0.6, \mathrm{CHCl}_{3}\right)$

\section{REACCIÓN DE 138 CON p-TsOH}<smiles>CC(C)=CCC[C@@H](C)[C@H]1COC(C)(C)O1</smiles>

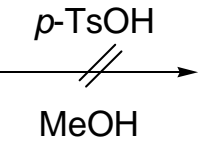

138

A una disolución de 138 (10 mg, 0.044 mmoles) en $0.2 \mathrm{~mL}$ de $\mathrm{MeOH}$ seco se le añade una cantidad catalítica de $p$-TsOH y se deja reaccionando a temperatura ambiente durante 20 horas. Pasado este tiempo se añade $\mathrm{NaHCO}_{3}$ hasta alcanzar $\mathrm{pH}$ neutro, se evapora el $\mathrm{MeOH}$ y se redisuelve en AcOEt. Tras filtrar y evaporar el disolvente se obtiene el producto de partida sin reaccionar. 


\section{REACCIÓN DE 138 CON HCI}

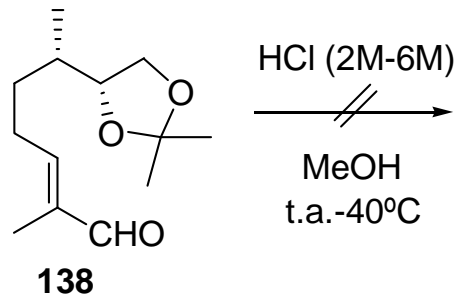

A una disolución de 138 (10 mg, 0.04 mmoles) en $0.2 \mathrm{~mL}$ de $\mathrm{MeOH}$ seco se le añade una gota de una disolución acuosa de $\mathrm{HCl} 2 \mathrm{M}$ y se deja reaccionando a temperatura ambiente durante 2 horas. Al no observar evolución alguna del producto de partida por $\mathrm{CCF}$, se añade una gota de una disolución acuosa de $\mathrm{HCl} 6 \mathrm{M}$ y se calienta a $40^{\circ} \mathrm{C}$ durante 2 horas. Pasado este tiempo se añade $\mathrm{NaHCO}_{3}$ hasta alcanzar $\mathrm{pH}$ neutro, se evapora el $\mathrm{MeOH}$ y se redisuelve en AcOEt. Tras filtrar y evaporar el disolvente se recupera el producto de partida sin reaccionar.

\section{PROTECCIÓN DE 136 CON TBDMSCI}<smiles>CC(C)=CCC[C@H](C)CO</smiles>

136

$$
\underset{\text { DMF, } 0^{\circ} \mathrm{C} \text { - t.a. }}{\stackrel{\text { TBSCl, imidazol }}{\longrightarrow}}
$$<smiles>CC(C)=CCC[C@@H](C)[C@H](O)CO[SbH2]</smiles>

140

Sobre una disolución de 136 (70 mg, 0.41 mmoles) en $1 \mathrm{~mL}$ de $\mathrm{DMF}$, a $0^{\circ} \mathrm{C}$ y bajo atmósfera de argon, se añaden sucesivamente $55 \mathrm{mg}(0.81 \mathrm{mmoles})$ de imidazol y $61 \mathrm{mg}$ (0.41 mmoles) de TBDMSCl. Se mantiene la agitación durante 1 hora dejando calentar lentamente hasta temperatura ambiente. Transcurrido este tiempo se diluye la mezcla de reacción con éter $(100 \mathrm{~mL})$ y se lava con $\mathrm{H}_{2} \mathrm{O}$. Las aguas de lavado se combinan y se extraen con $20 \mathrm{~mL}$ de éter. Posteriormente, las fases etéreas combinadas se lavan con disolución acuosa saturada de $\mathrm{NaCl}$ y se secan sobre $\mathrm{Na}_{2} \mathrm{SO}_{4}$ anhidro. $\mathrm{Se}$ 
filtra y se evapora el disolvente, obteniéndose un crudo que se cromatografía en columna sobre sílicagel flash (eluyente: hexano/AcOEt 99:1). Finalmente se aíslan $90 \mathrm{mg}(77 \%)$ del producto monoprotegido 140, cuyas propiedades físicas y espectroscópicas se muestran a continuación:

\section{$\underline{(2 R, 3 S)-1-(t e r c-B u t i l-d i m e t i l-s i l a n i l o x i)-3,7-d i m e t i l o c t-6-e n-2-o l ~(140) ~}$}

ESPECTRO IR $v_{\max }$ (película) $\mathrm{cm}^{-1}$ (fig. 110a): 3473 (ancha), 2956, 2929, 2858, 1463, $1381,1256,1098,837$.

ESPECTRO RMN ${ }^{1} \mathbf{H}\left(200 \mathrm{MHz}, \mathrm{CDCl}_{3}, \delta\right.$ ppm) (fig. $\left.110 \mathrm{~b}\right): 5.09$ (1H, t, $J=6.0 \mathrm{~Hz}$, H-6), 3.64 (1H, dd, $J=14.0$ y $\left.8.0 \mathrm{~Hz}, \mathrm{H}_{\mathrm{A}}-1\right)$, 3.54-3.44 (2H, m, $\mathrm{H}_{\mathrm{B}}-1$ y H-2), 2.15-1.85 (2H, m, H-5), 1.68 y 1.60 (3H c/u, s, H-8 y H-9), 1.56-1.10 (3H, m, H-3 y H-4), 0.93 $(3 \mathrm{H}, \mathrm{d}, J=7.0 \mathrm{~Hz}, \mathrm{H}-10), 0.90\left(9 \mathrm{H}, \mathrm{s},{ }^{t} \underline{\mathrm{BuMe}}_{2} \mathrm{Si}\right), 0.07\left(6 \mathrm{H}, \mathrm{s},{ }^{t} \mathrm{BuMe}_{2} \mathrm{Si}\right)$.

ESPECTRO RMN ${ }^{13} \mathbf{C}\left(50 \mathrm{MHz}, \mathrm{CDCl}_{3}, \delta\right.$ ppm) (fig. 110c) (Tabla XLI).

HRMS, ESI (fig. 110d): Calculado para $\mathrm{C}_{16} \mathrm{H}_{34} \mathrm{O}_{2} \mathrm{NaSi}(M+\mathrm{Na})^{+}, 309.2220$. Experimental $(\mathrm{M}+\mathrm{Na})^{+}, 309.2208$.

$[\alpha]_{D}^{25}=-16.7^{\circ}\left(\mathrm{c}=1.3, \mathrm{CHCl}_{3}\right)$

\section{OXIDACIÓN ALÍLICA DE 140 CON SeO 2}

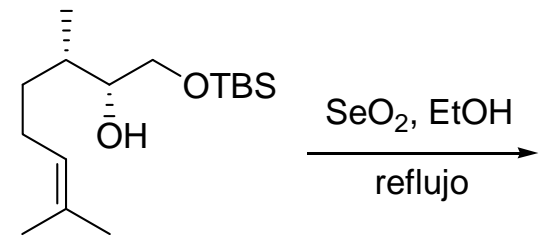

140<smiles>CC(C=O)=CCC[C@H](C)[C@H](O)C[OH+]</smiles>

141

Se disuelve 140 ( $73 \mathrm{mg}, 0.25$ mmoles) en $2.5 \mathrm{~mL}$ de EtOH seco, se añaden 42 mg (0.38 mmoles) de $\mathrm{SeO}_{2}$ y se pone la mezcla a reflujo. Pasadas 24 horas se deja enfriar la mezcla de reacción hasta temperatura ambiente y se filtra por sílice lavando abundantemente con EtOH. Seguidamente se evapora el EtOH, se redisuelve en AcOEt 
y se lava con disolución acuosa saturada de $\mathrm{NaCl}$. Se seca sobre $\mathrm{Na}_{2} \mathrm{SO}_{4}$ anhidro, se filtra y se evapora el disolvente obteniéndose un crudo que se cromatografía en columna sobre sílicagel flash (eluyente: hexano/AcOEt 96:4). Finalmente se aíslan 20 mg (27\%) del aldehído 141, el cual presenta las siguientes propiedades físicas y espectroscópicas:

\section{$\underline{(6 S, 7 R)-8-(t e r c-B u t i l-d i m e t i l-s i l a n i l o x i)-7-h i d r o x i-2,6-d i m e t i l o c t-E-2-e n-1-a l ~(141) ~}$}

ESPECTRO IR $v_{\max }$ (película) $\mathrm{cm}^{-1}$ (fig. 111a): 3449 (ancha), 2955, 2928, 2857, 1689, $1463,1255,1096,1006,837$.

ESPECTRO RMN ${ }^{1} \mathbf{H}\left(200 \mathrm{MHz}, \mathrm{CDCl}_{3}, \delta\right.$ ppm) (fig. $\left.11 \mathrm{~b}\right): 9.39$ (1H, s, H-9), 6.48 $(1 \mathrm{H}, \mathrm{t}, J=7.0 \mathrm{~Hz}, \mathrm{H}-6), 3.78-3.47$ (3H, m, H-1 y H-2), 2.46-2.33 (2H, m, H-5), 1.75 (3H, s, H-8), 1.71-1.33 (3H, m, H-3 y H-4), 0.97 (3H, d, $J=6.6$ Hz, H-10), 0.90 (9H, s, $\underline{{ }^{t} \mathrm{BuMe}} \mathrm{Si}_{2} \mathrm{Si}, 0.08\left(6 \mathrm{H}, \mathrm{s},{ }^{\mathrm{t}} \mathrm{BuMe} \underline{\underline{M}}_{2} \mathrm{Si}\right)$.

ESPECTRO RMN ${ }^{13} \mathbf{C}\left(50 \mathrm{MHz}, \mathrm{CDCl}_{3}, \delta\right.$ ppm) (fig. 111c) (Tabla XLI).

HRMS, ESI (fig. 111d): Calculado para $\mathrm{C}_{16} \mathrm{H}_{32} \mathrm{O}_{3} \mathrm{NaSi}(M+\mathrm{Na})^{+}, 323.2013$. Experimental $(\mathrm{M}+\mathrm{Na})^{+}, 323.2017$.

$[\alpha]_{D}^{25}=-10.2^{\circ}\left(\mathrm{c}=0.8, \mathrm{CHCl}_{3}\right)$

\section{$\underline{\text { REACCIÓN DE } 141 \text { CON EL CATALIZADOR } 113}$}

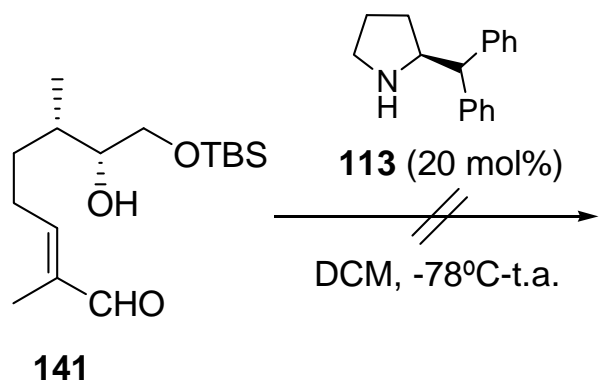

Sobre una disolución de 141 (16 mg, 0.053 mmoles) en $1.3 \mathrm{~mL}$ de $\mathrm{DCM}$ a $-78^{\circ} \mathrm{C}$ y bajo atmósfera de argon se añaden $2 \mathrm{mg}$ (0.011 mmoles) del catalizador 113 y se deja reaccionando a esta temperatura. Al no observarse evolución del producto de partida por CCF se sube la temperatura paulatinamente hasta $-40^{\circ} \mathrm{C},-20^{\circ} \mathrm{C}, 0^{\circ} \mathrm{C}$ y temperatura 
ambiente. Sin embargo, no hay evolución del sustrato en ningún caso. Así pues, se evapora el disolvente y tras una percolación se recupera 141 inalterado. 
ESPECTROSCOPÍA 

Fig. 1a

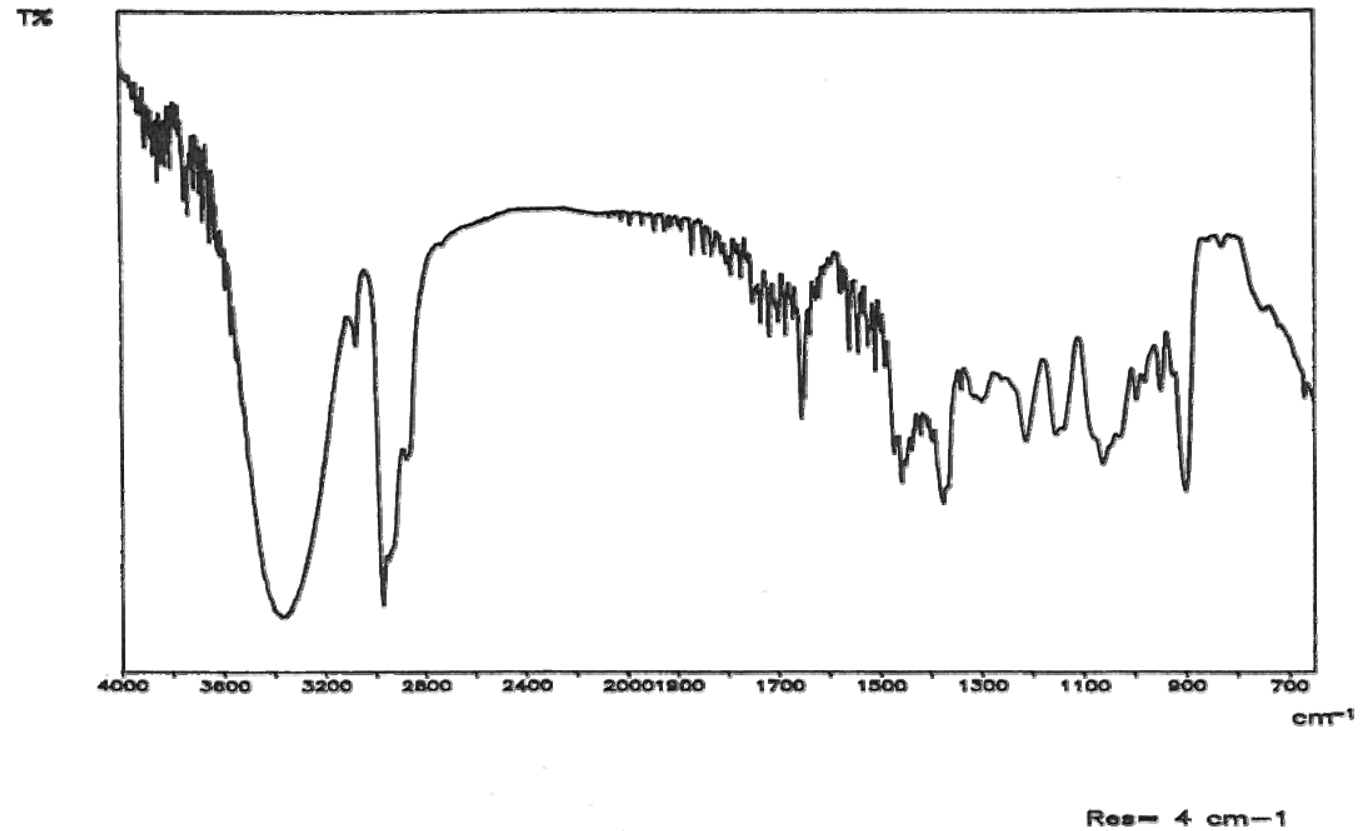

Fig. 1b

$\underline{\Sigma}$

影

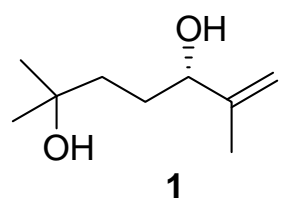

羿

1

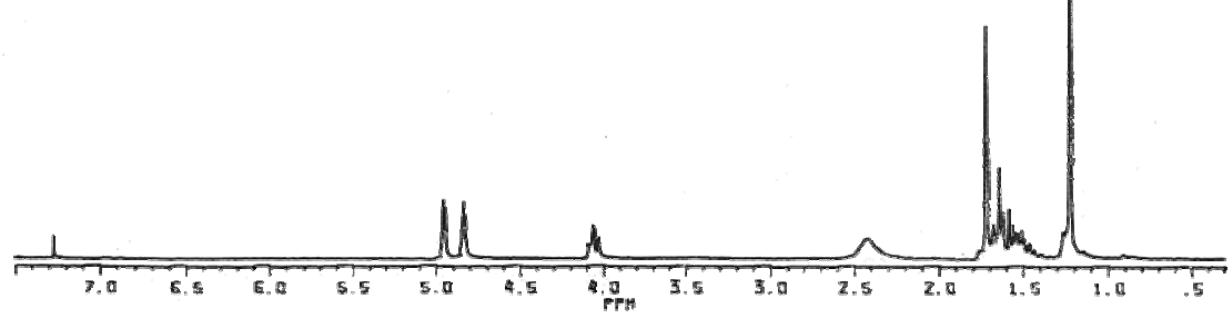


Fig. 1c

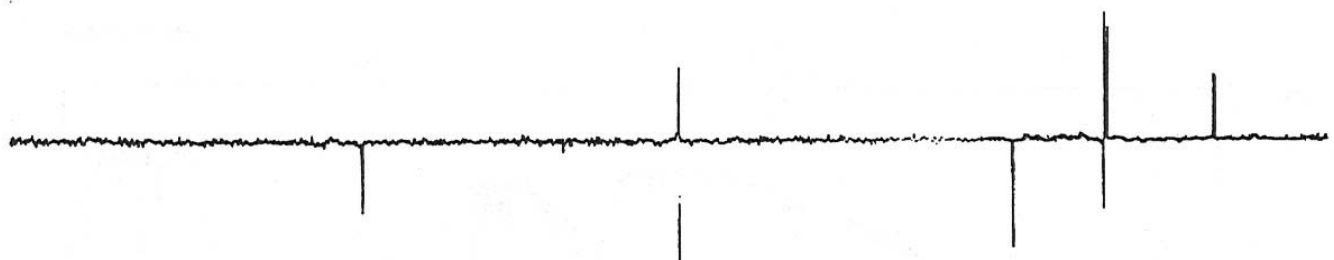

(2)

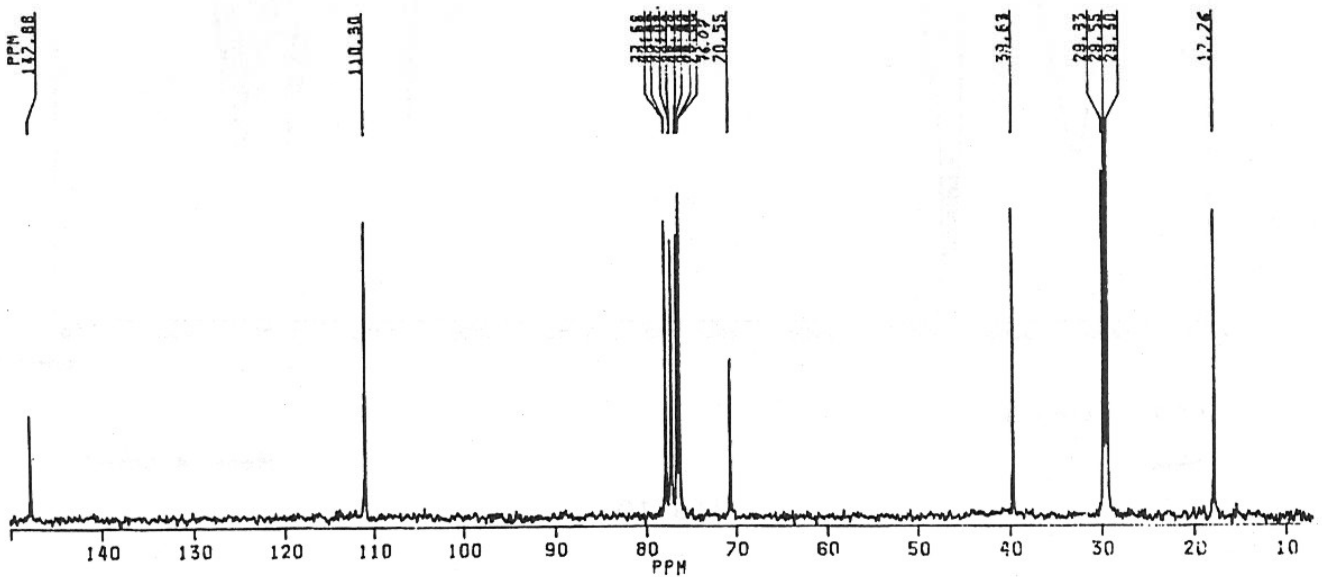

Fig. 1d

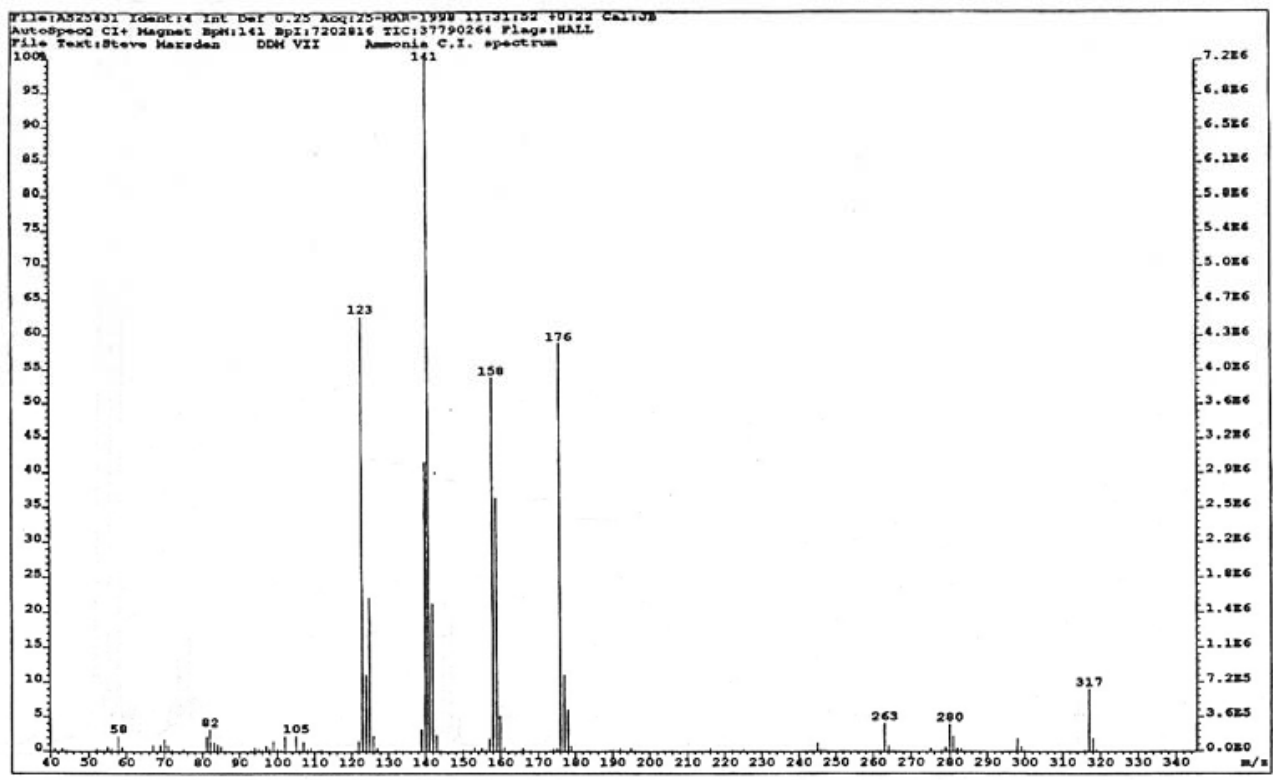


Fig. 2a

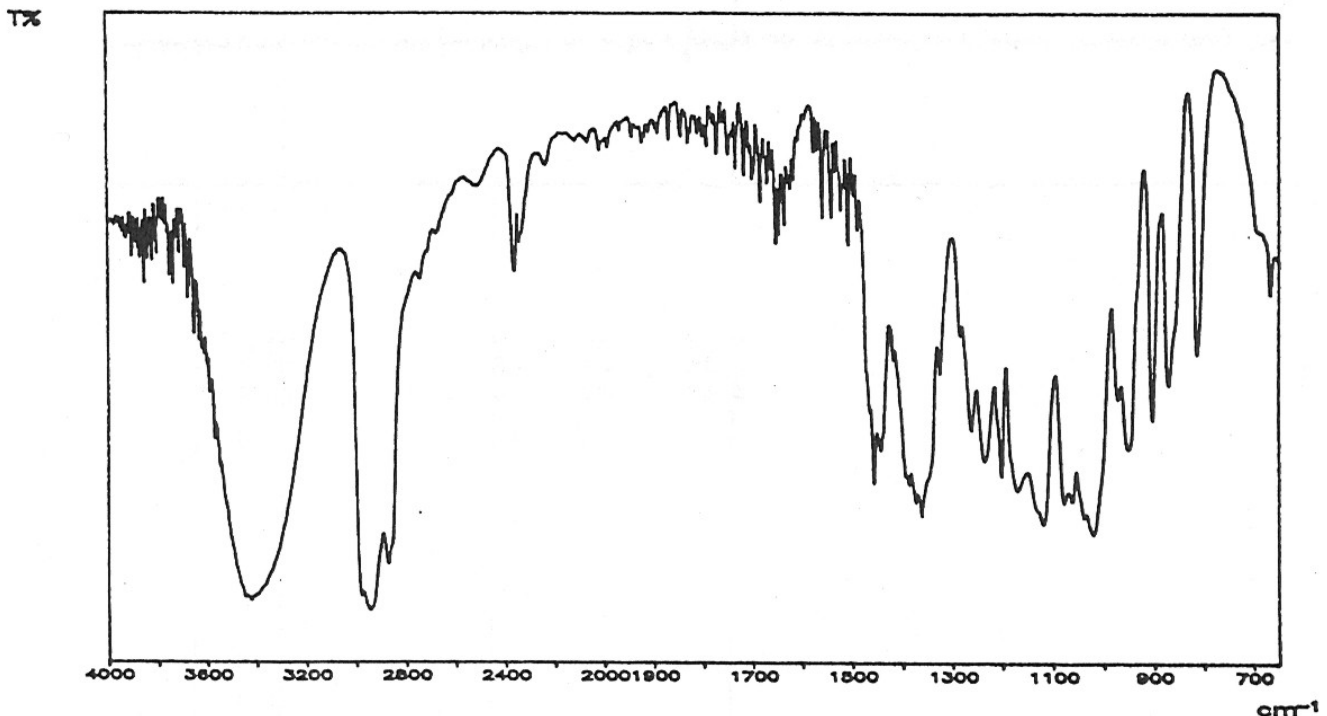

Fig. $2 b$

․ํำ

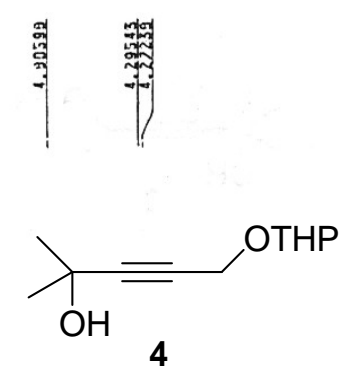

अौ

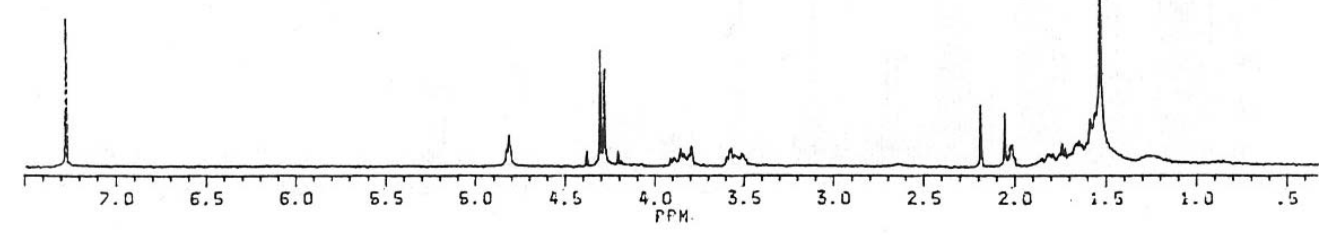


Fig. 2c

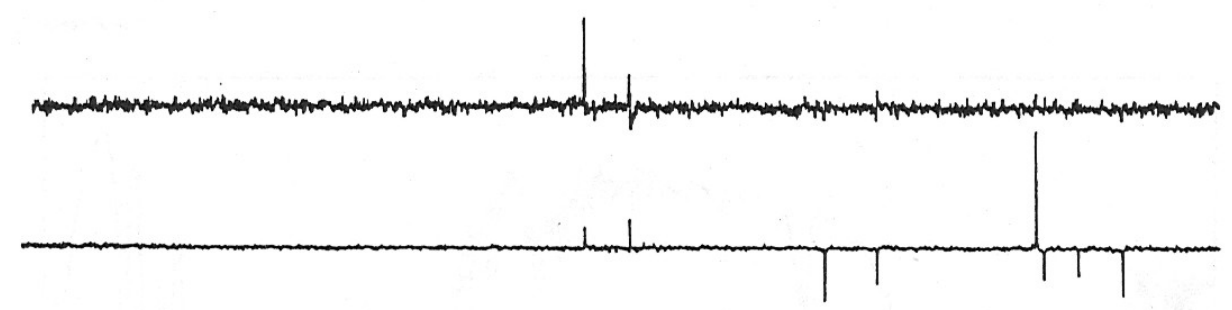

ذ.

|ֶ

Fig. 2d

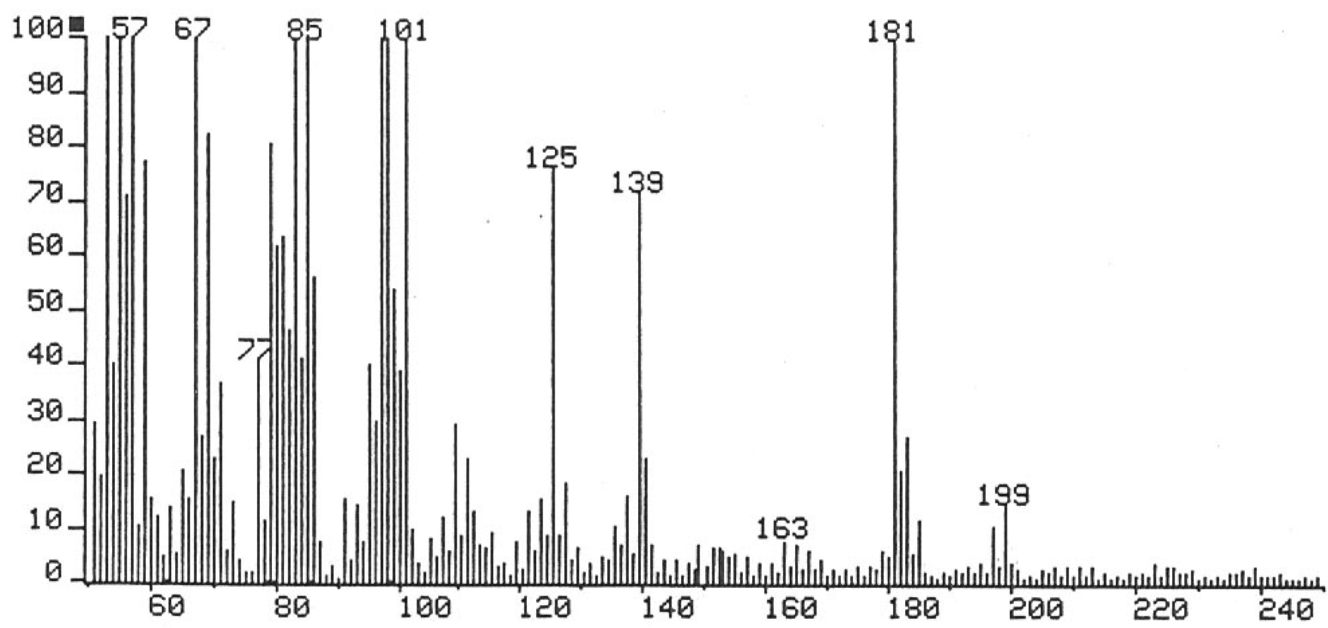

MASS 
Fig. 3a

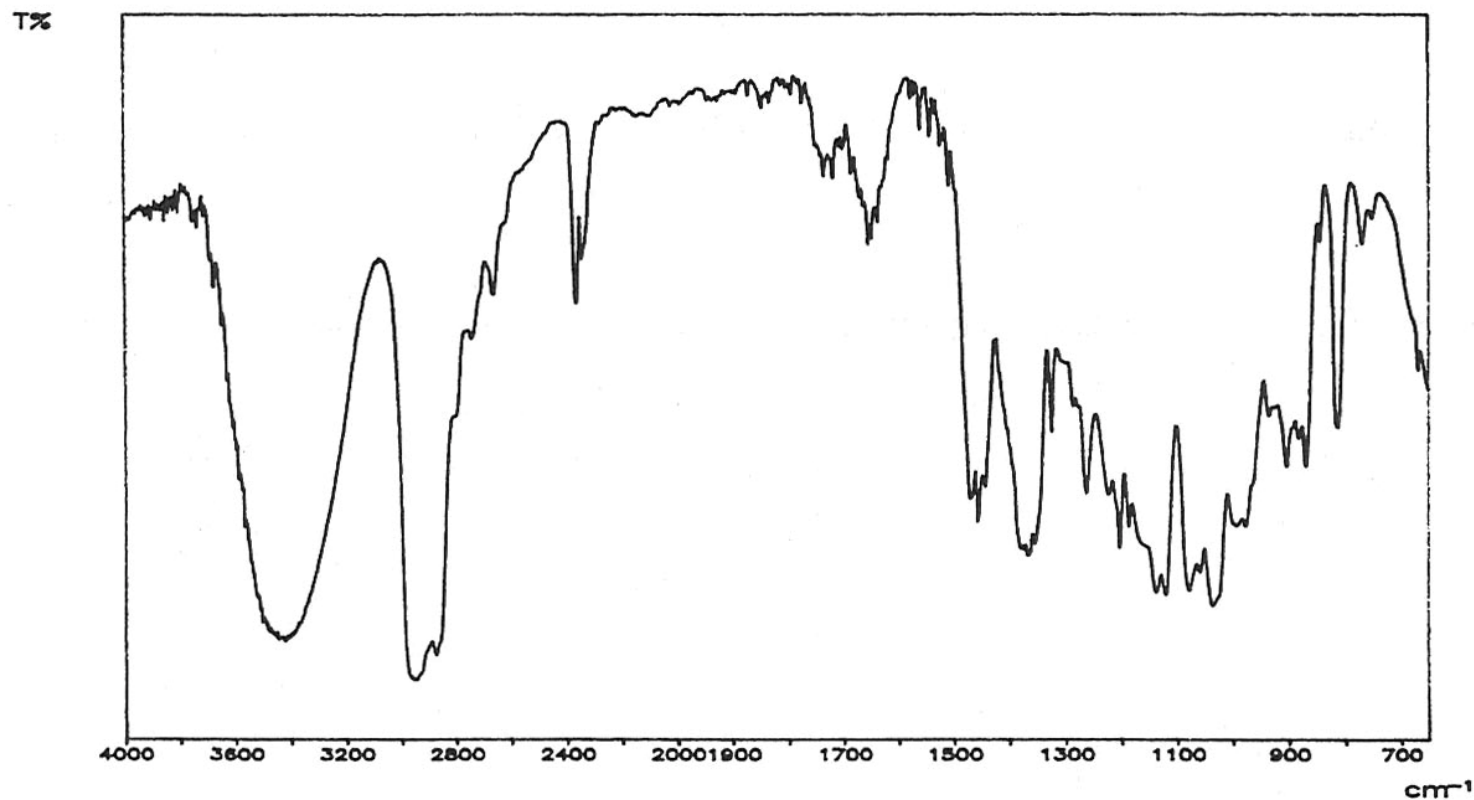

Fig. 3b

ฐ

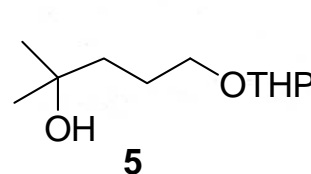

영ㅁํㄱ

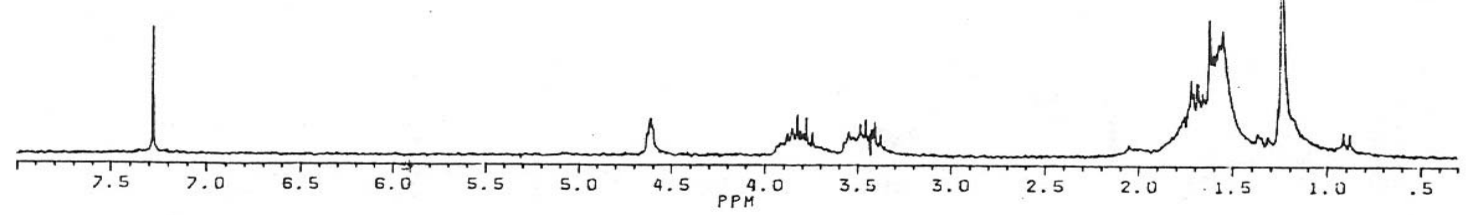


Fig. 3c

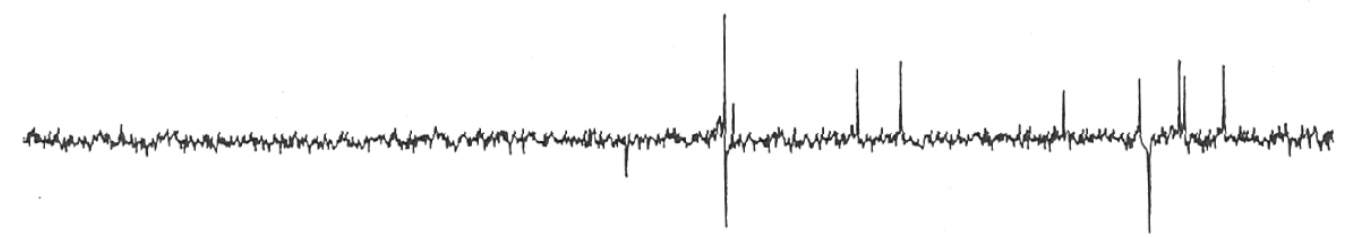

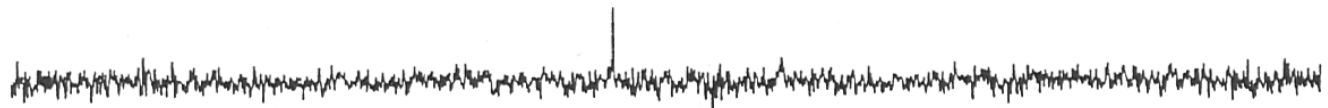

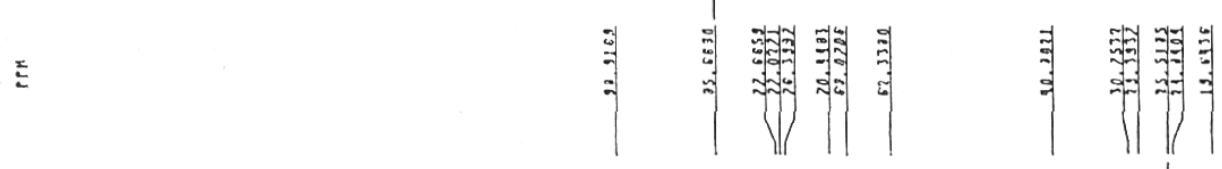

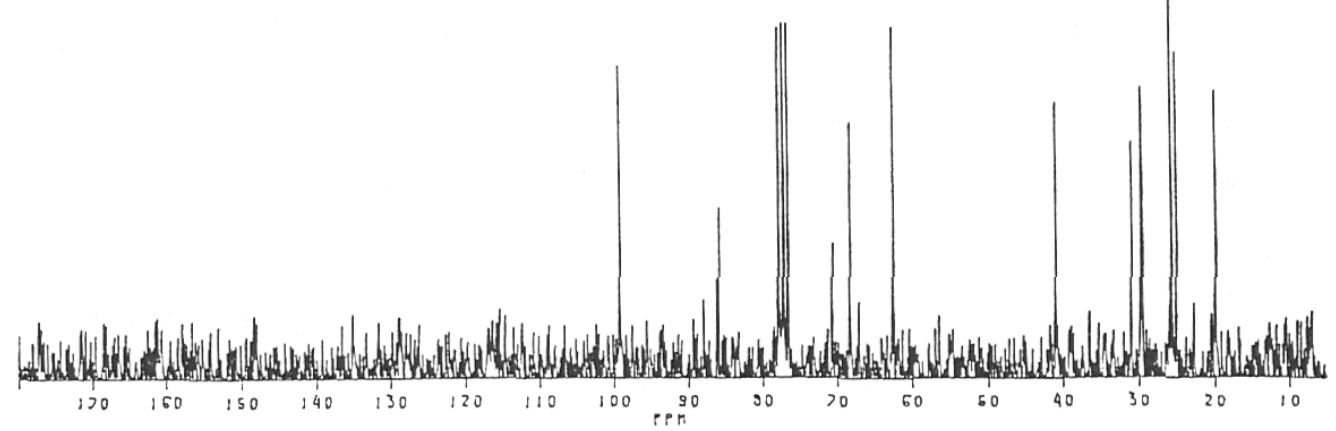

Fig 3d

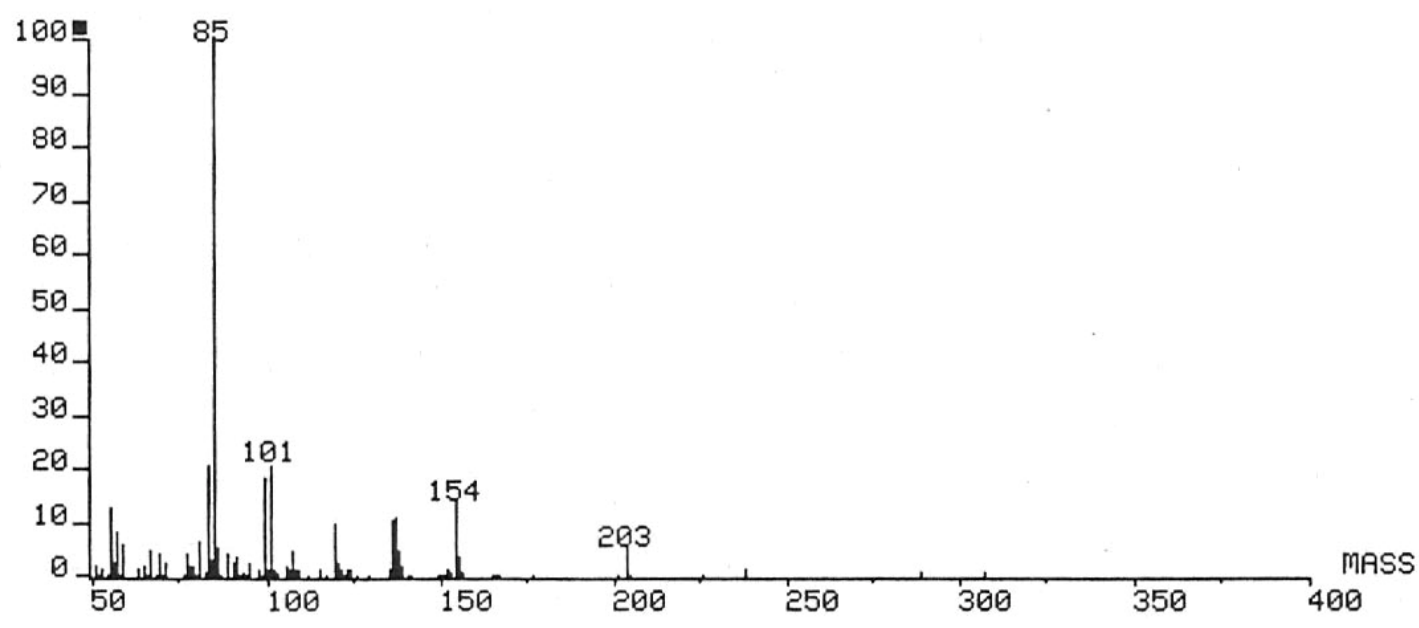


Fig. 4a

Tx

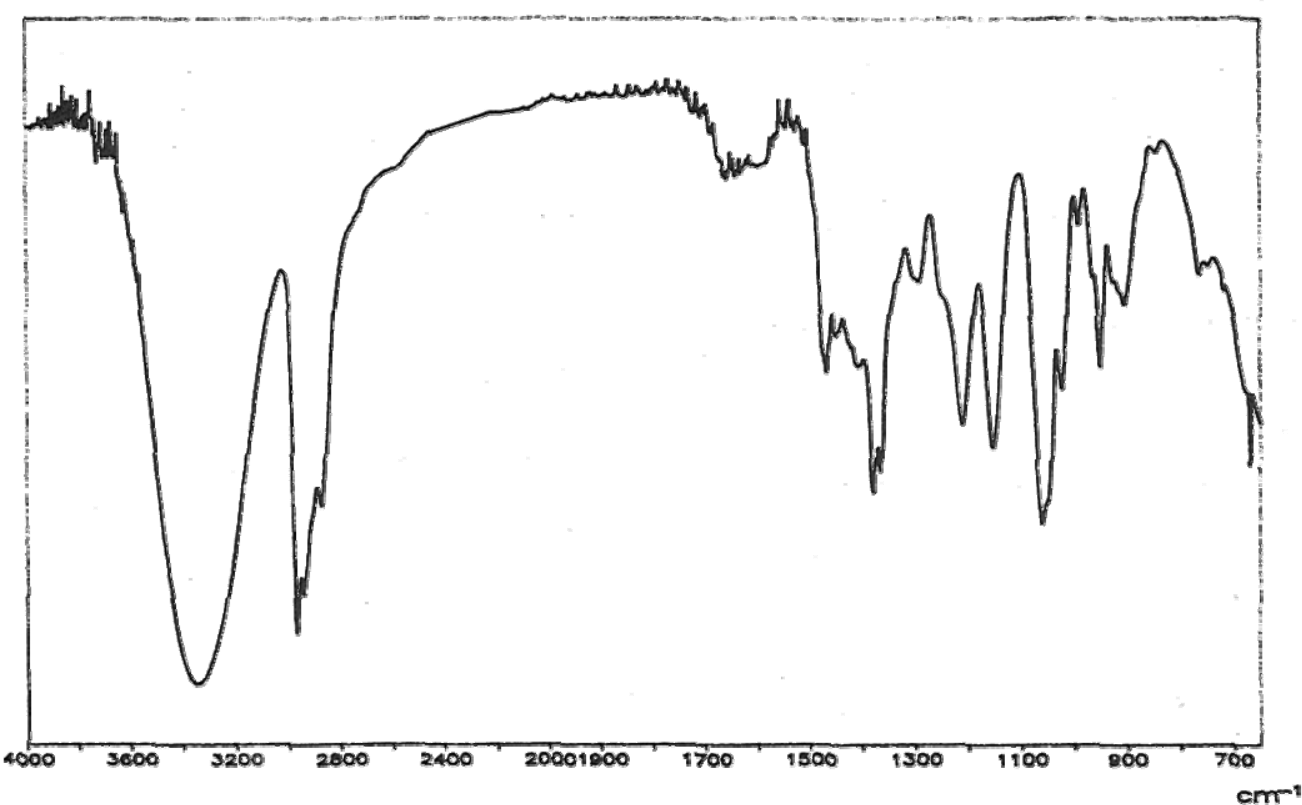

Fig. 4b

ล.

함<smiles>CC(C)(O)CCCO</smiles>

Res $=4 \mathrm{~cm}-1$ 
Fig. 4c

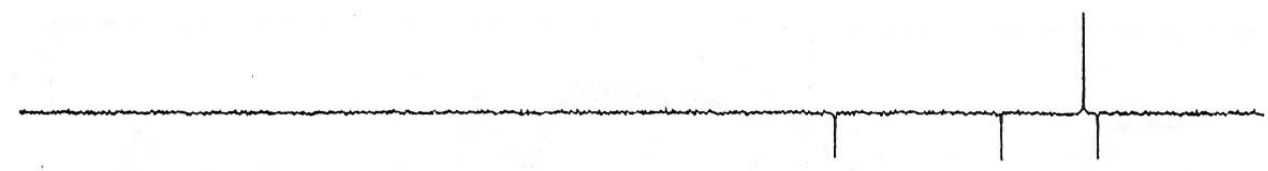

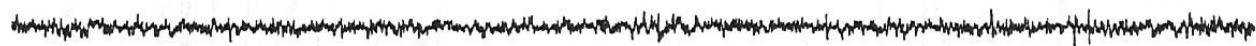
$\frac{x}{2}$
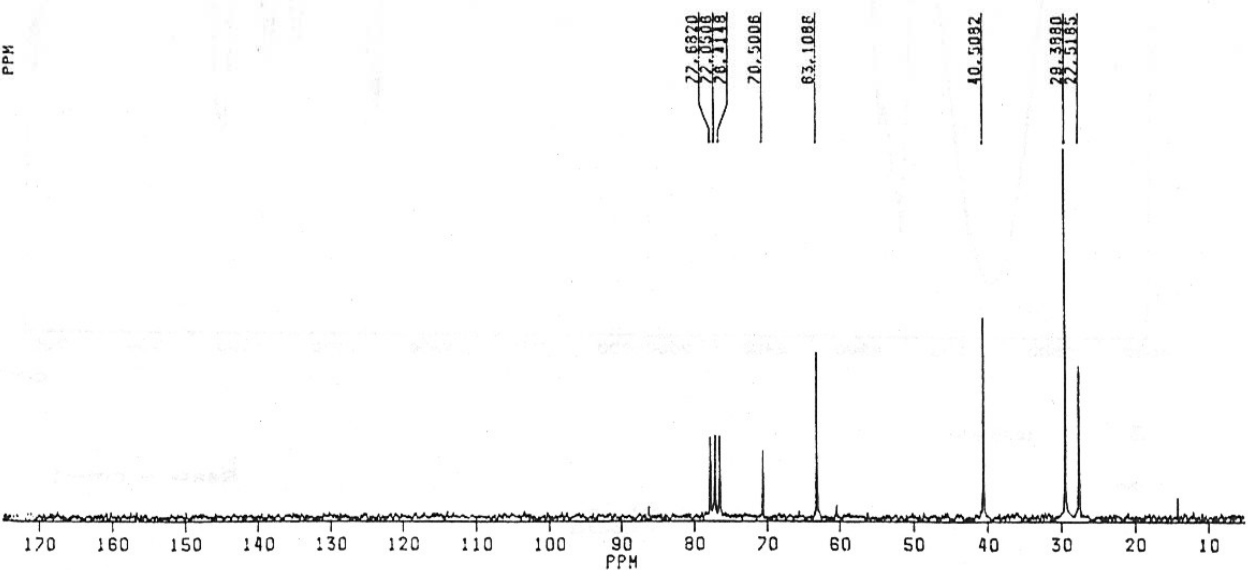

Fig. 4d

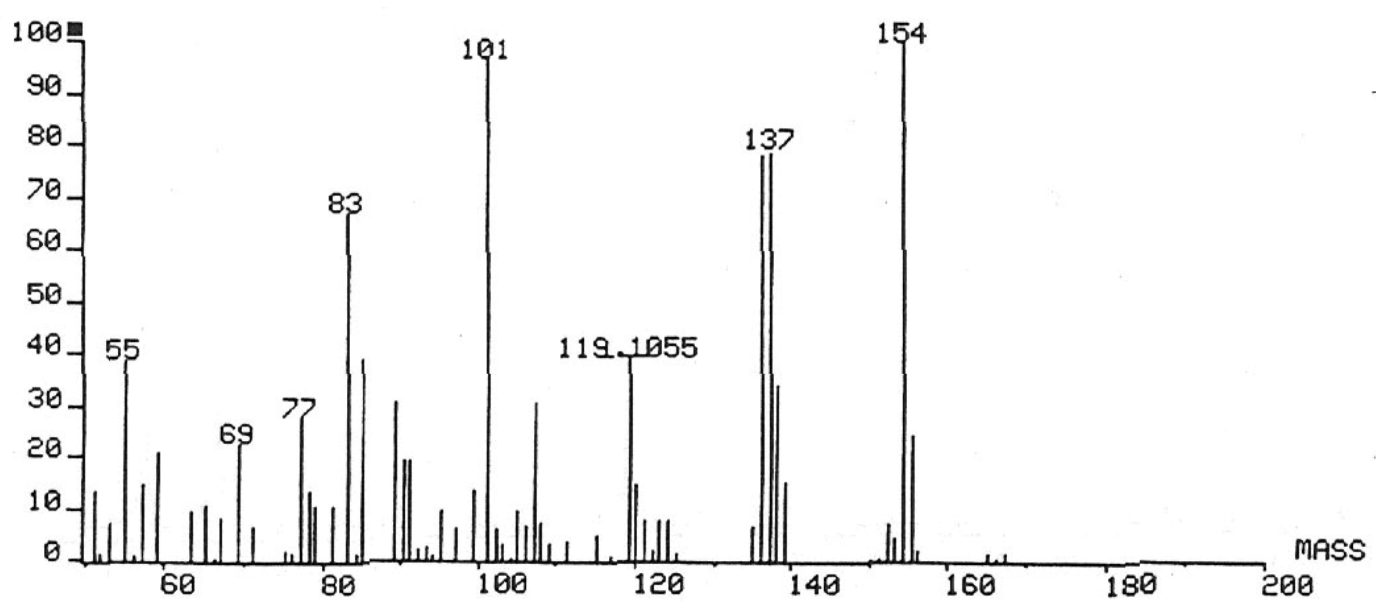


Fig. 5a

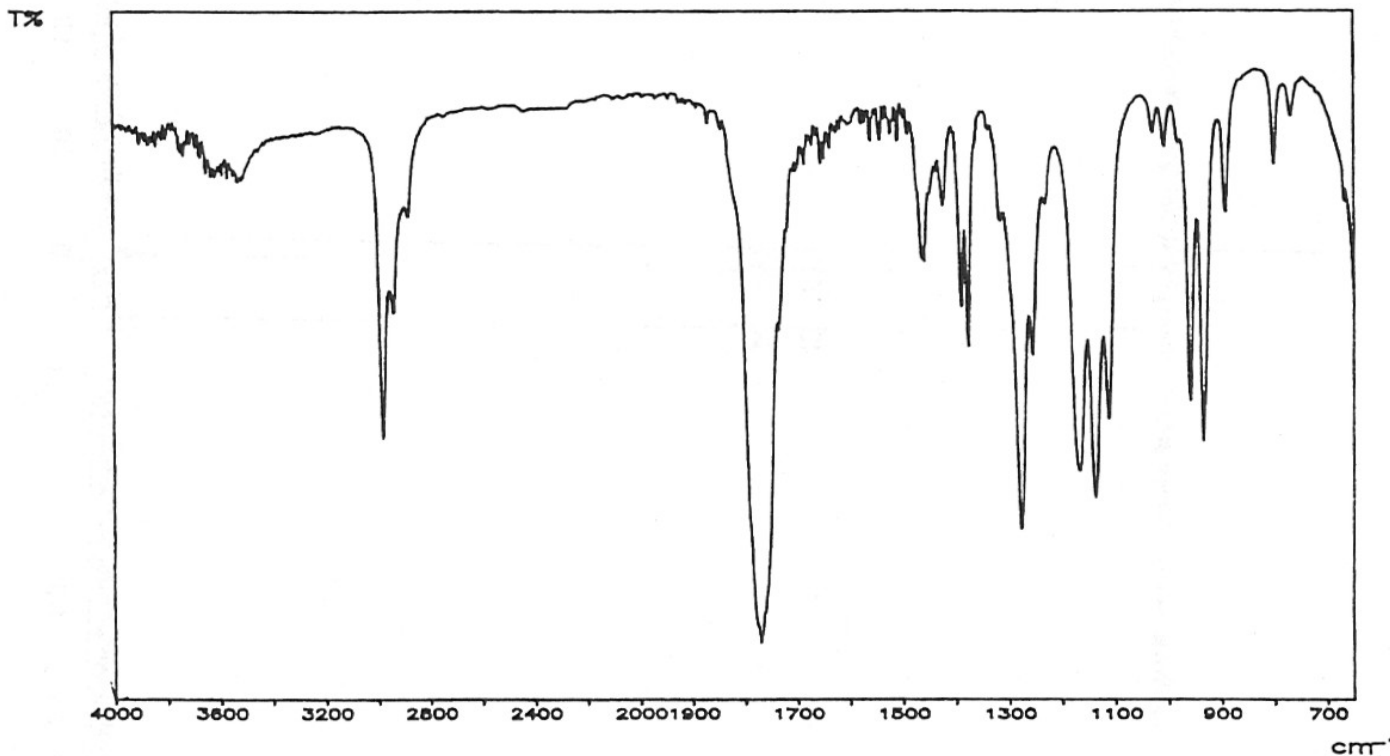

Fig. 5b

ธุํํ
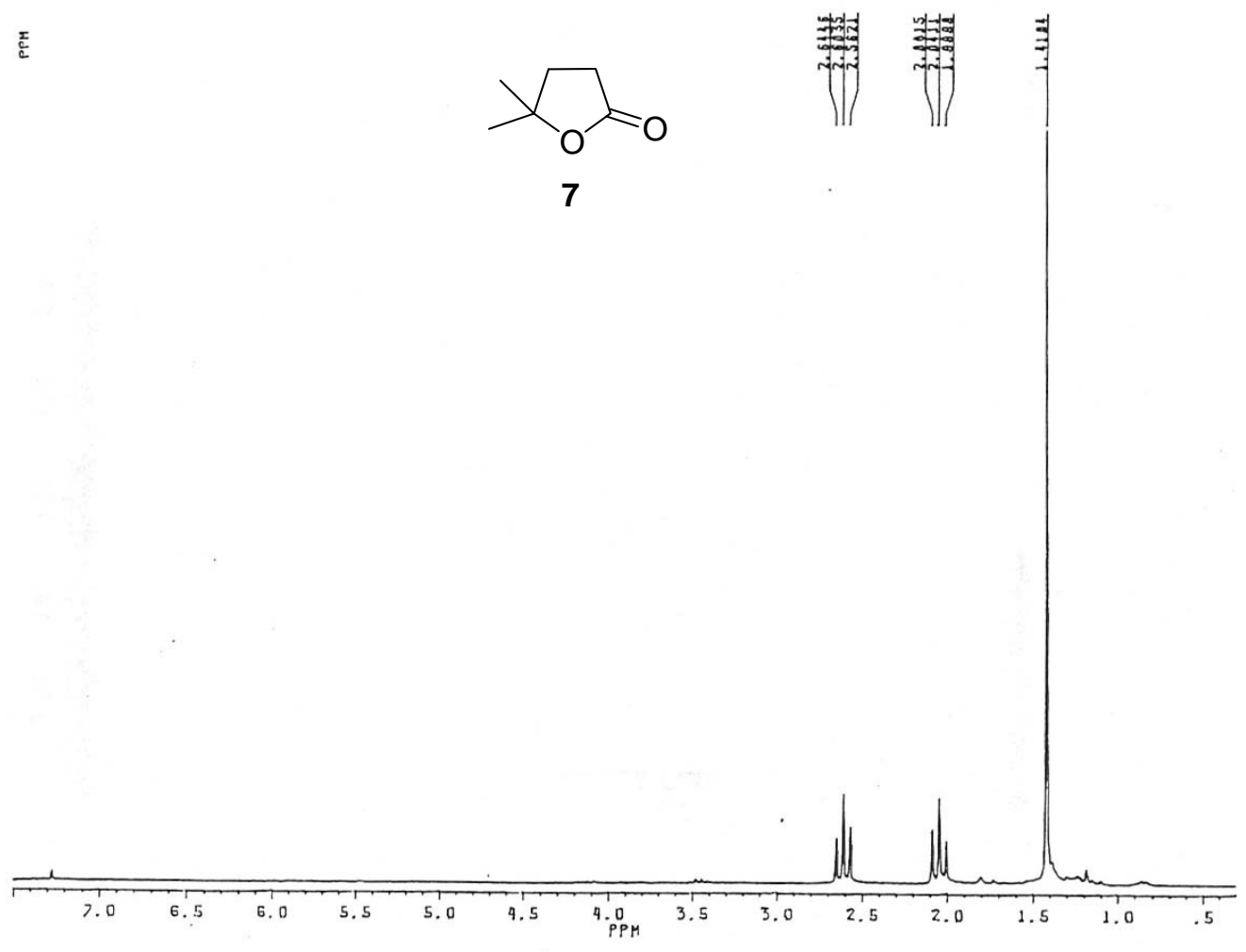
Fig. 5c

2.

ขึำ:

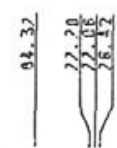

ำ

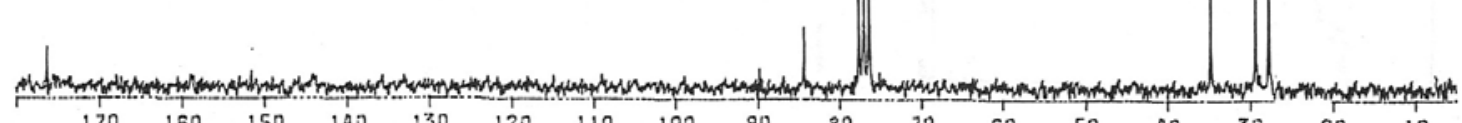

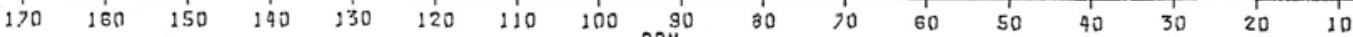


Fig. 6a

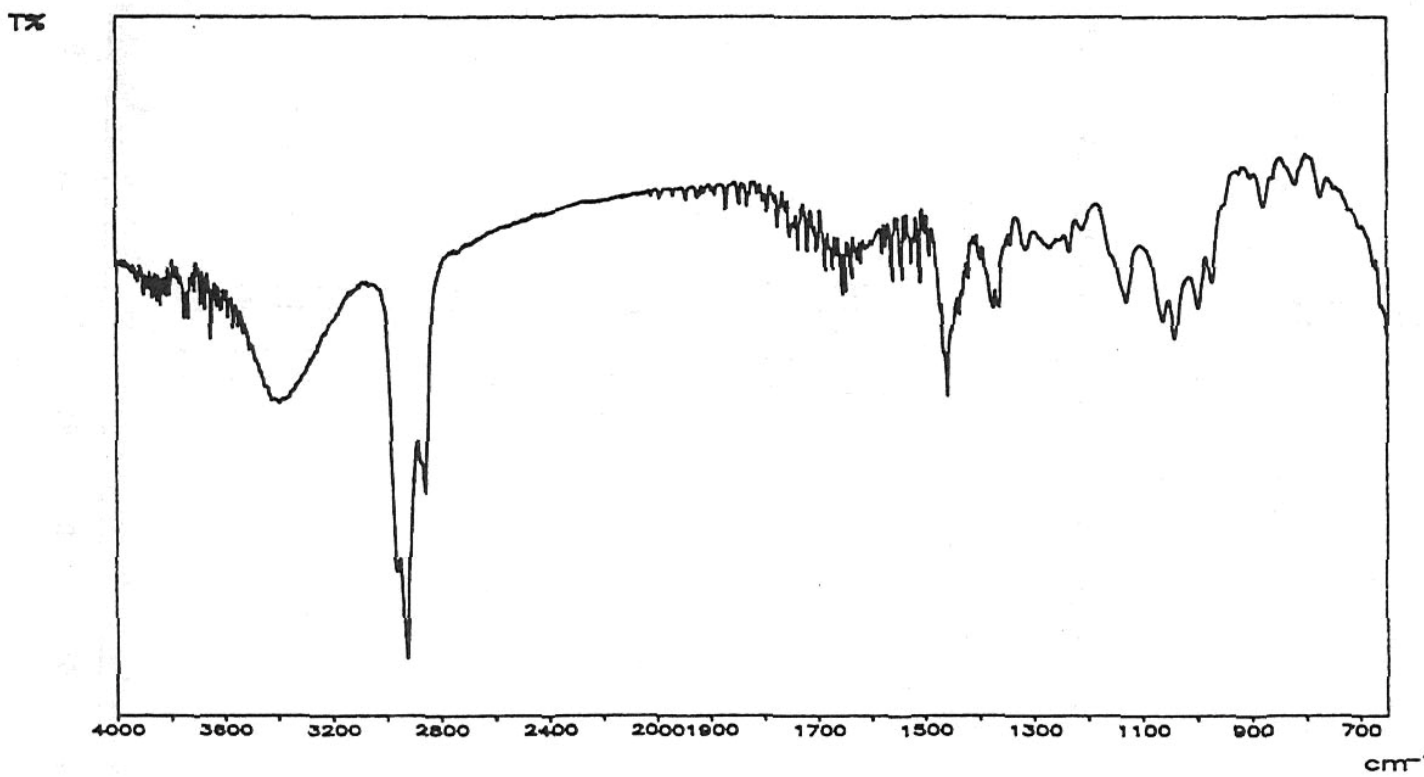

Fig. 6b

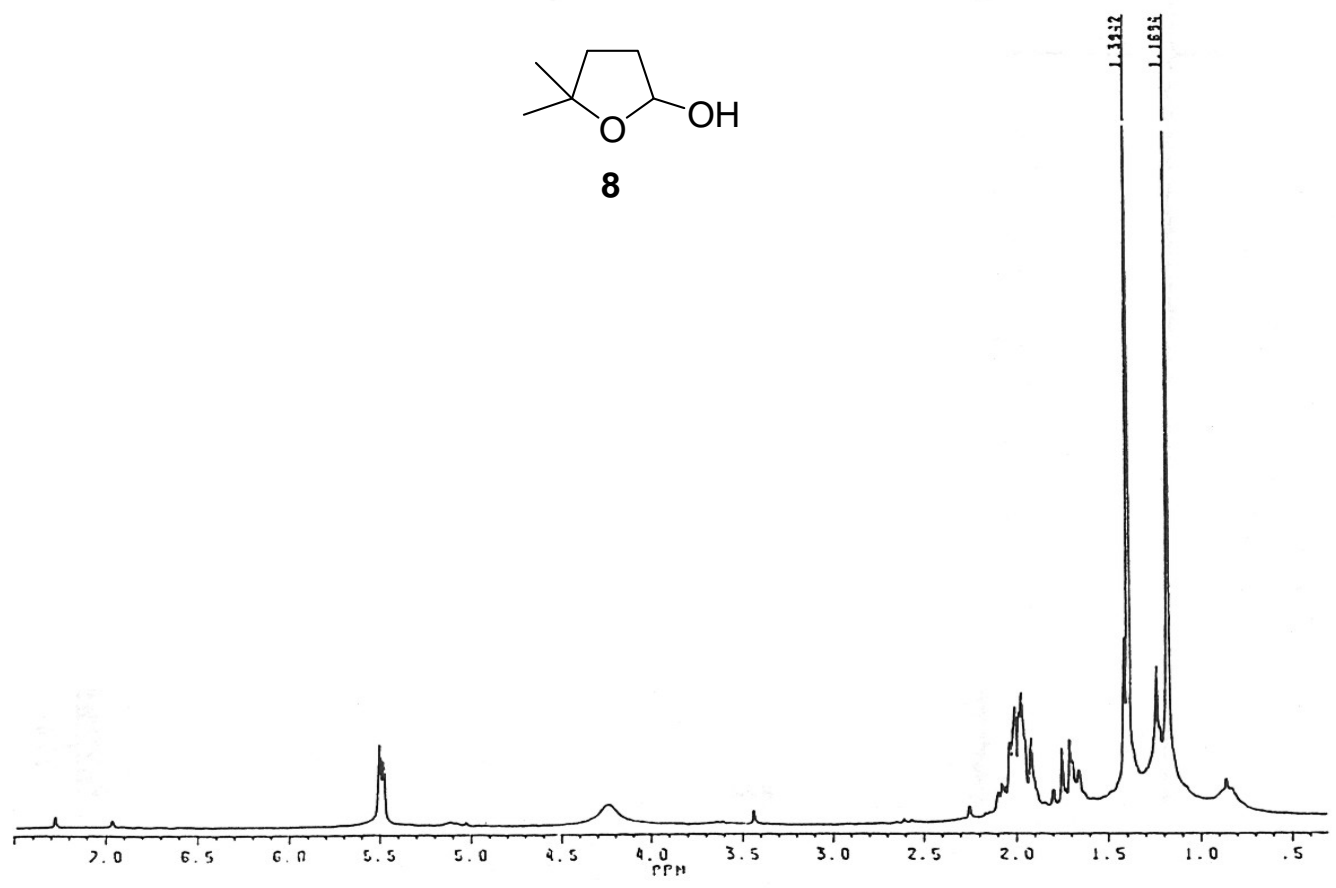


Fig. 6c

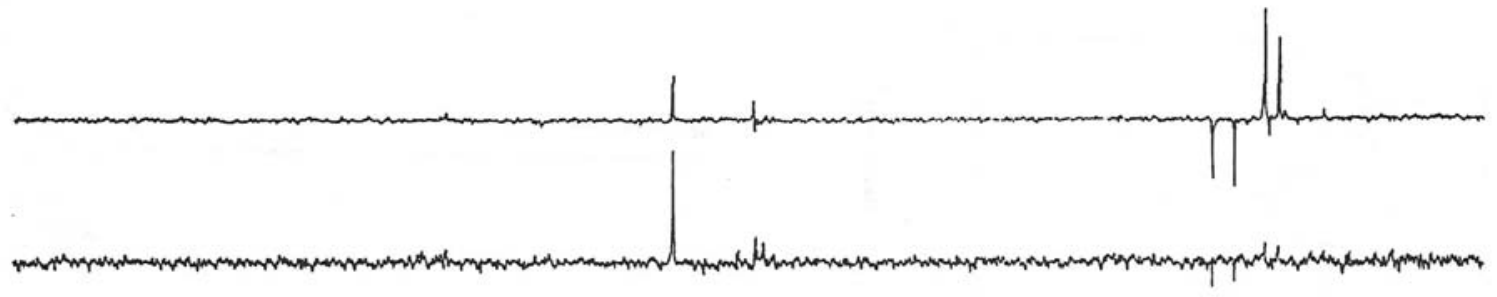

¿
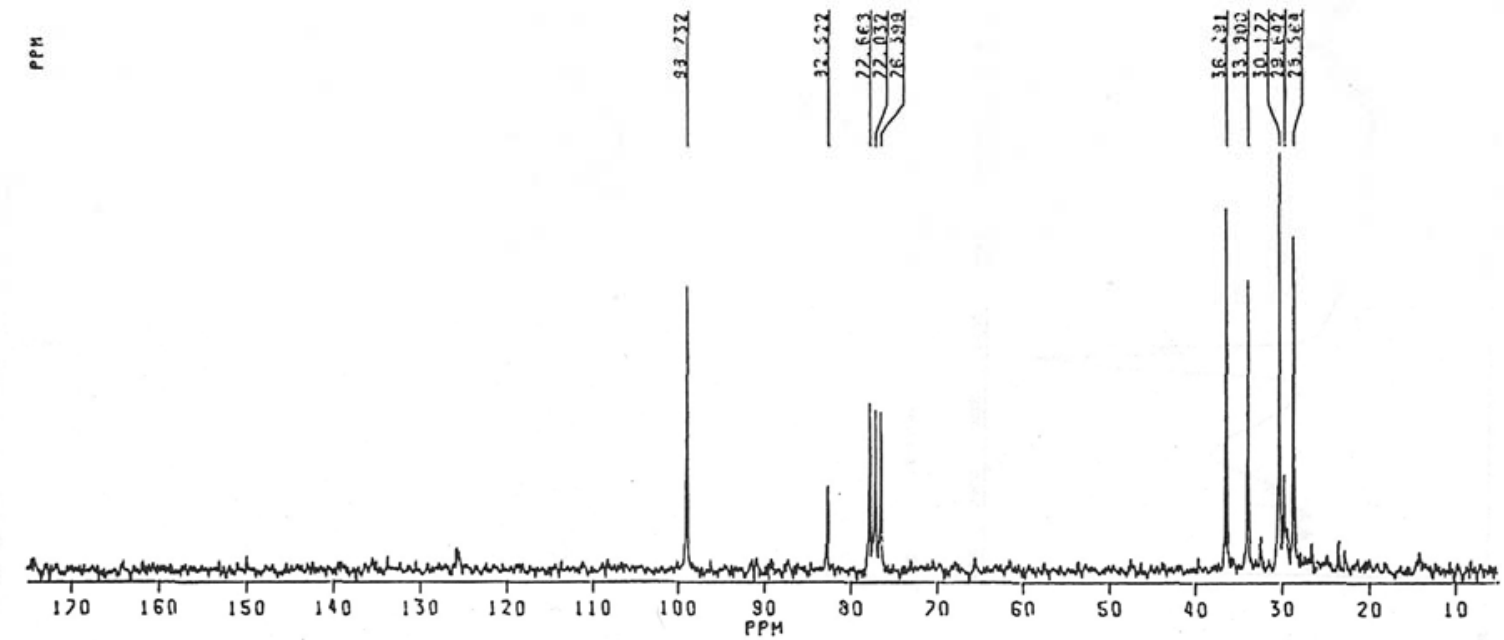
Fig. 7a

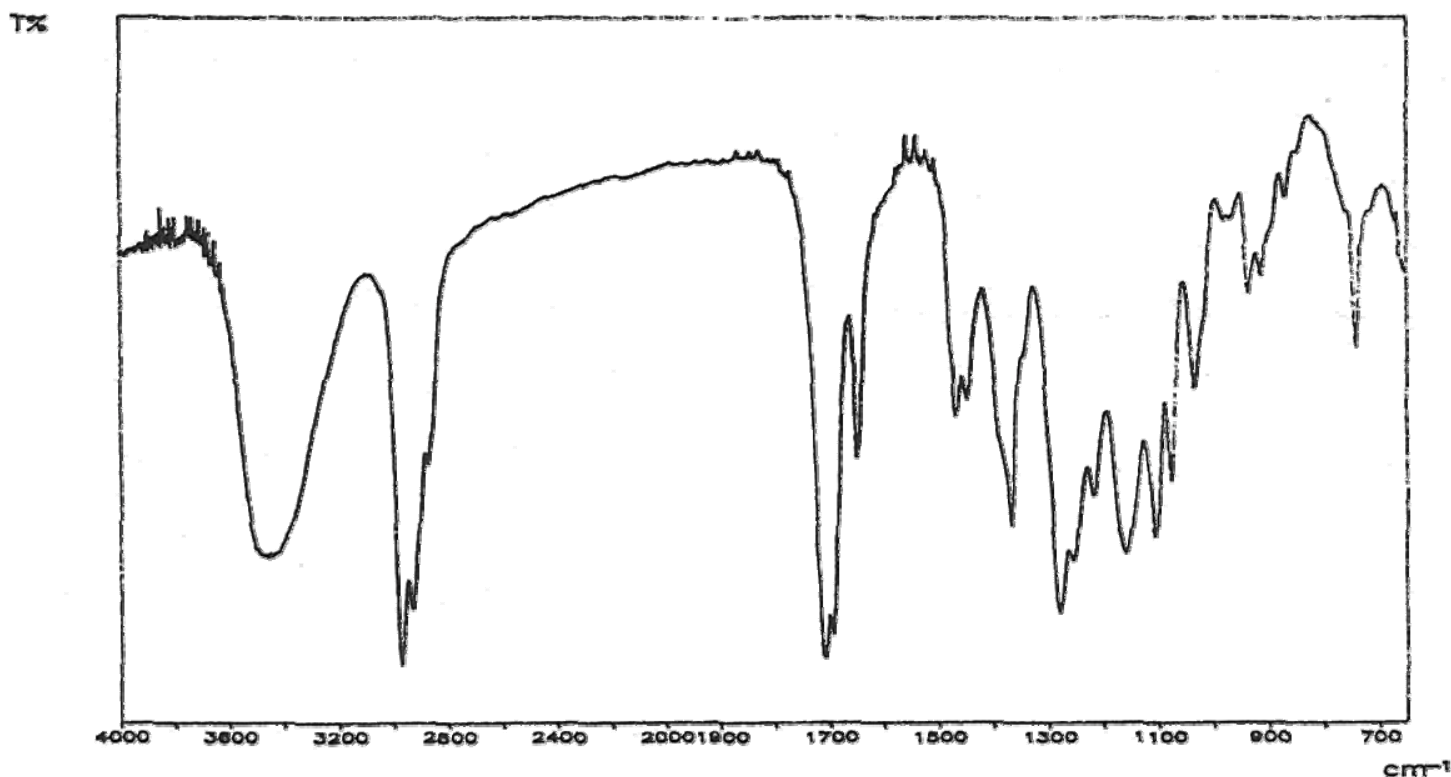

Fig. 7b

졸

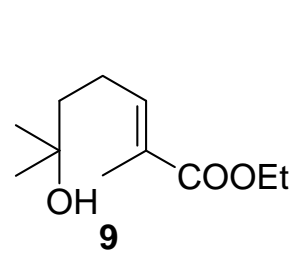

ำ 
Fig.7c
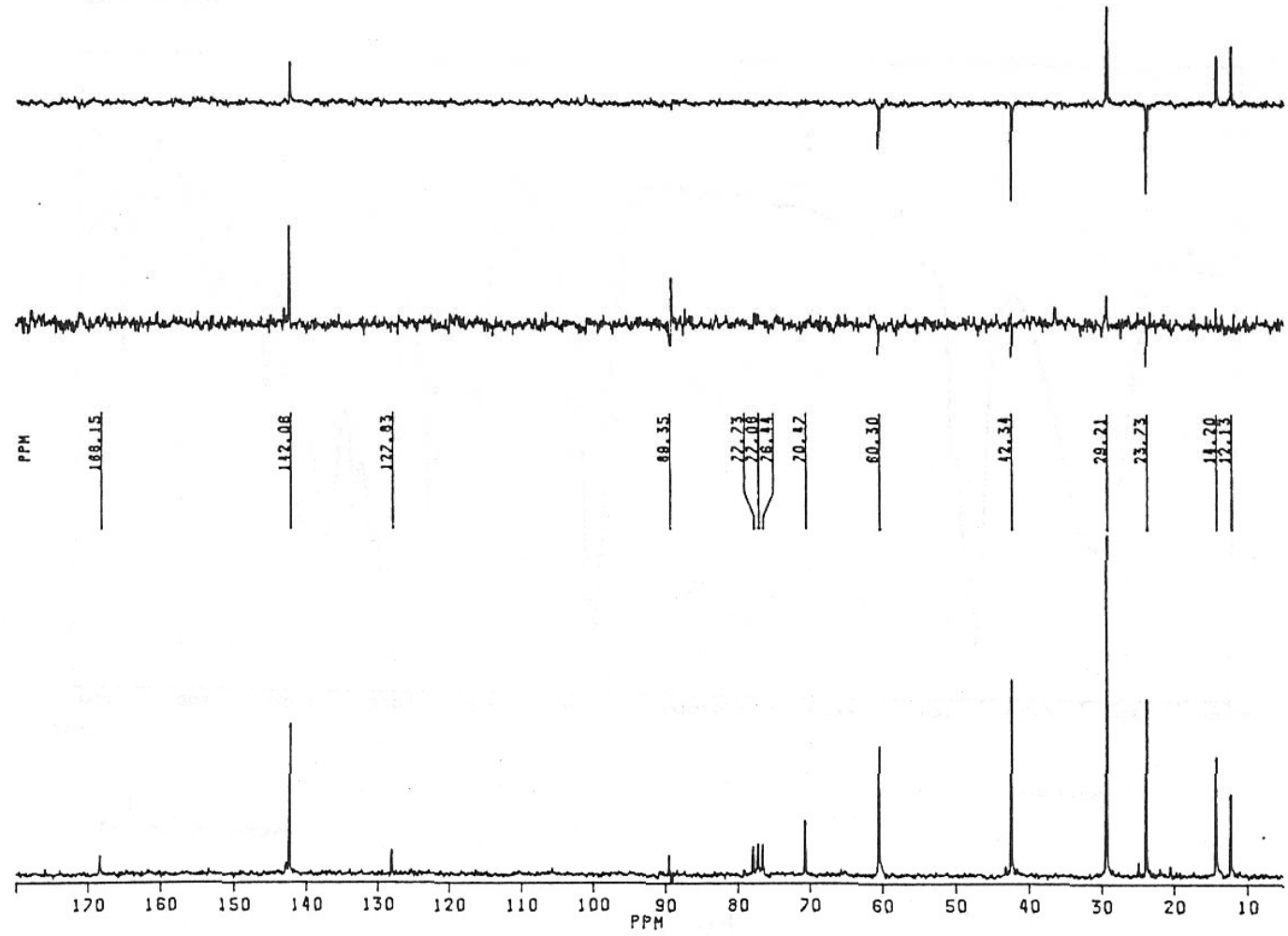

Fig. 7d

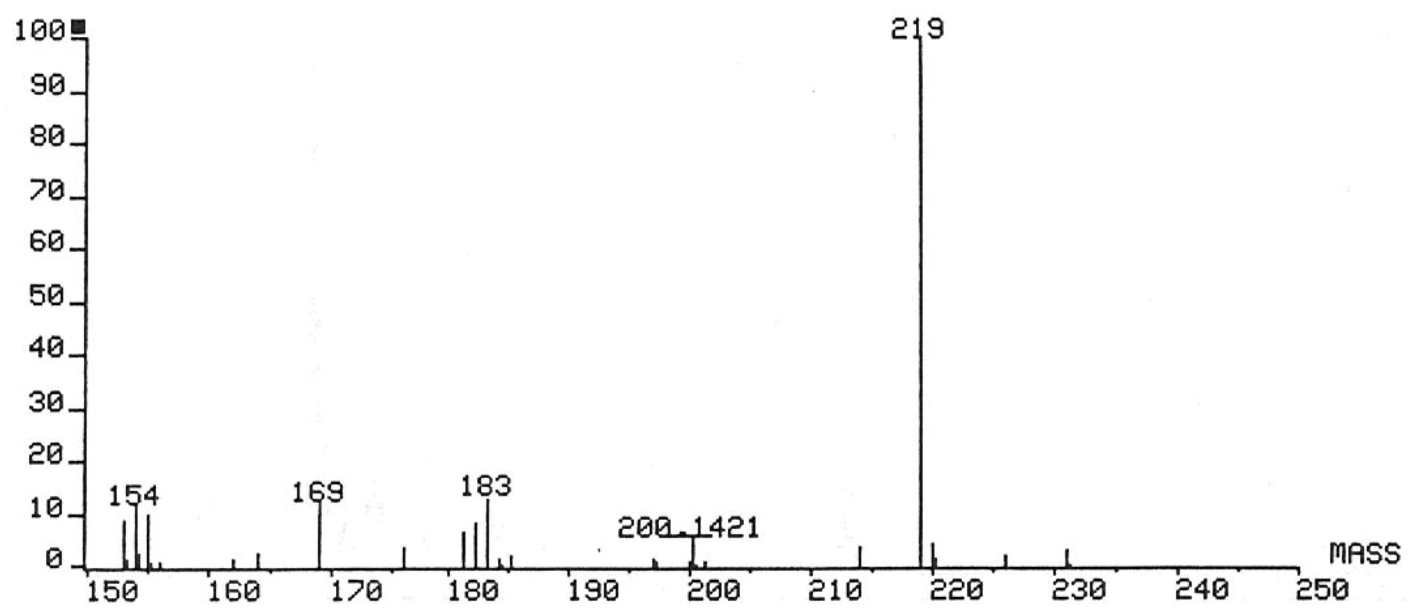


Fig. 8a

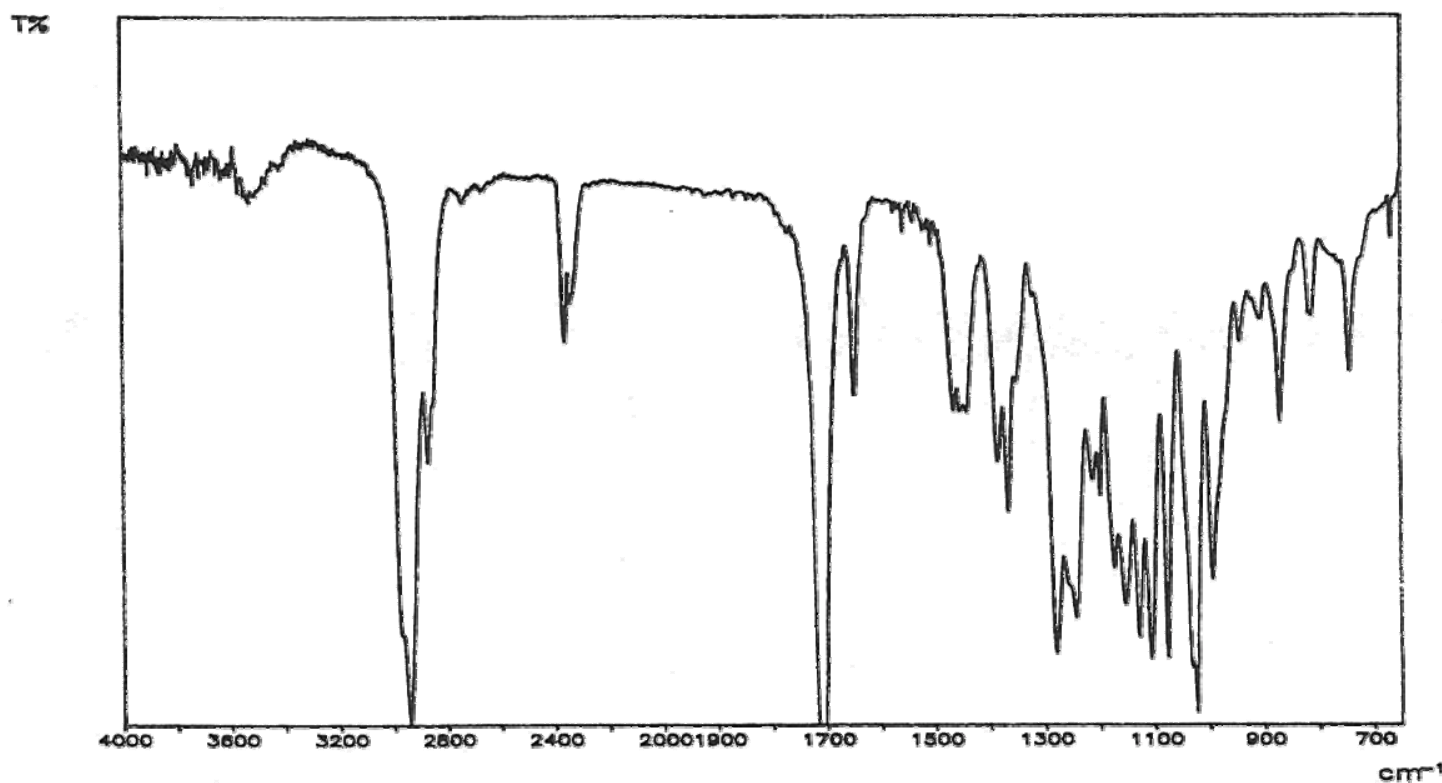

Fig. $8 b$

萡

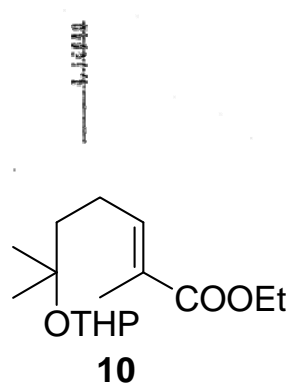

t

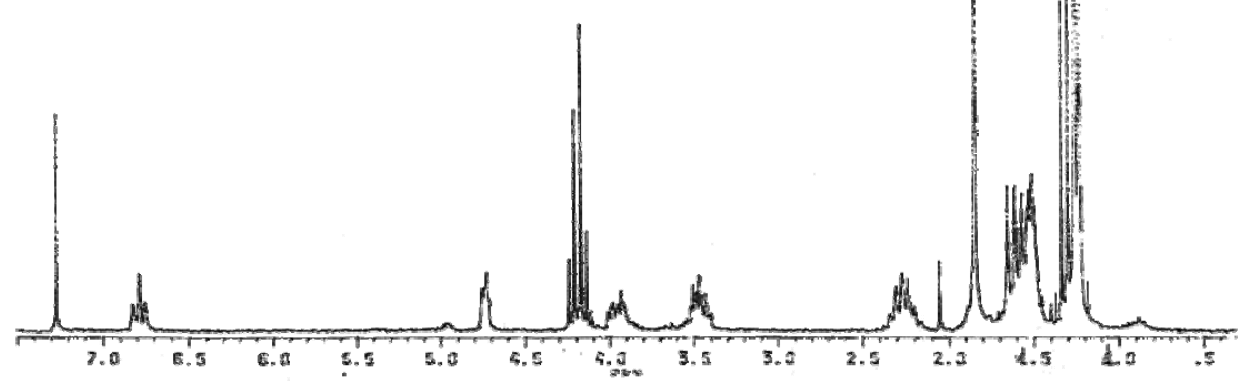


Fig. 8c
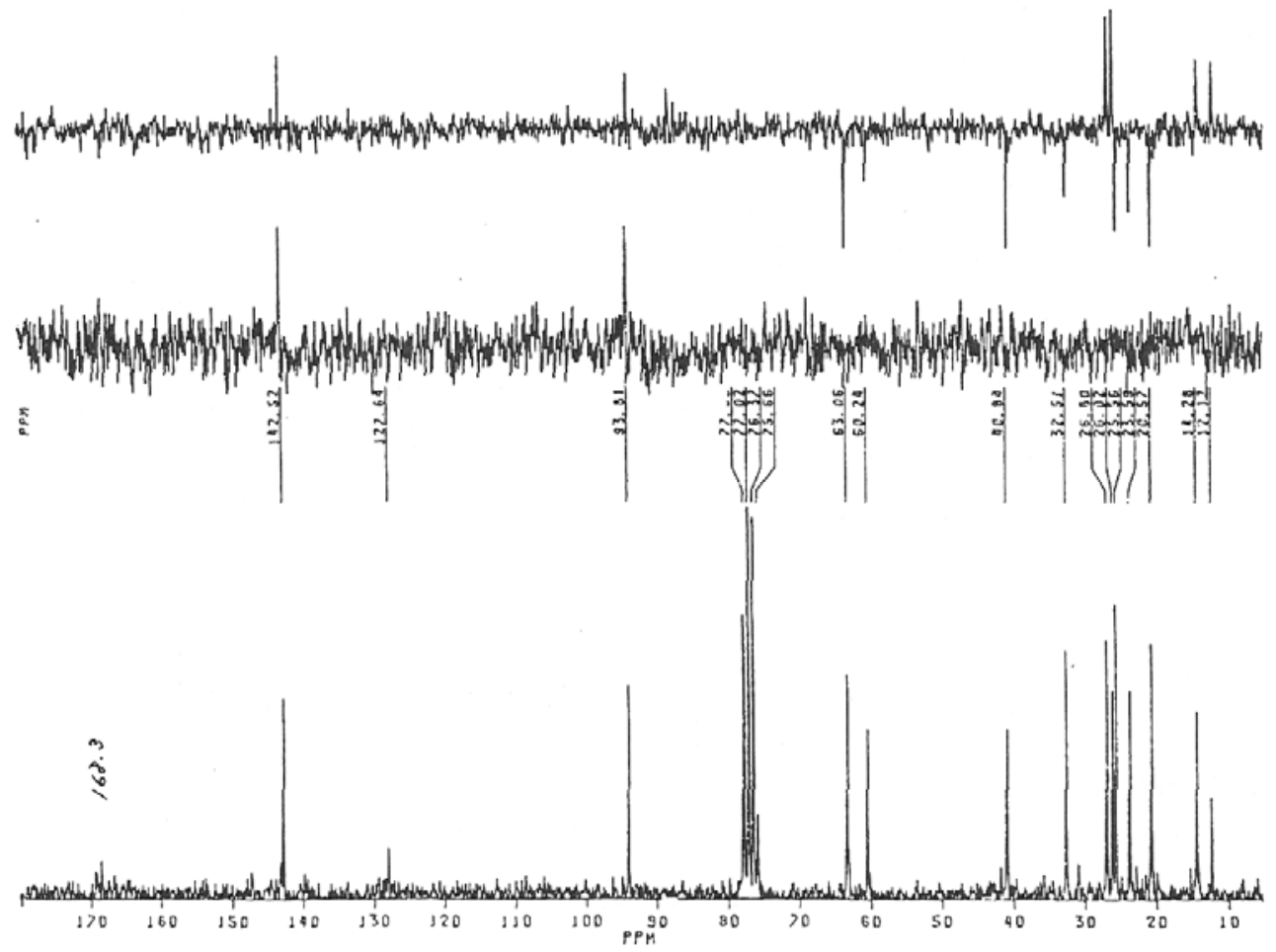

Fig. 8d

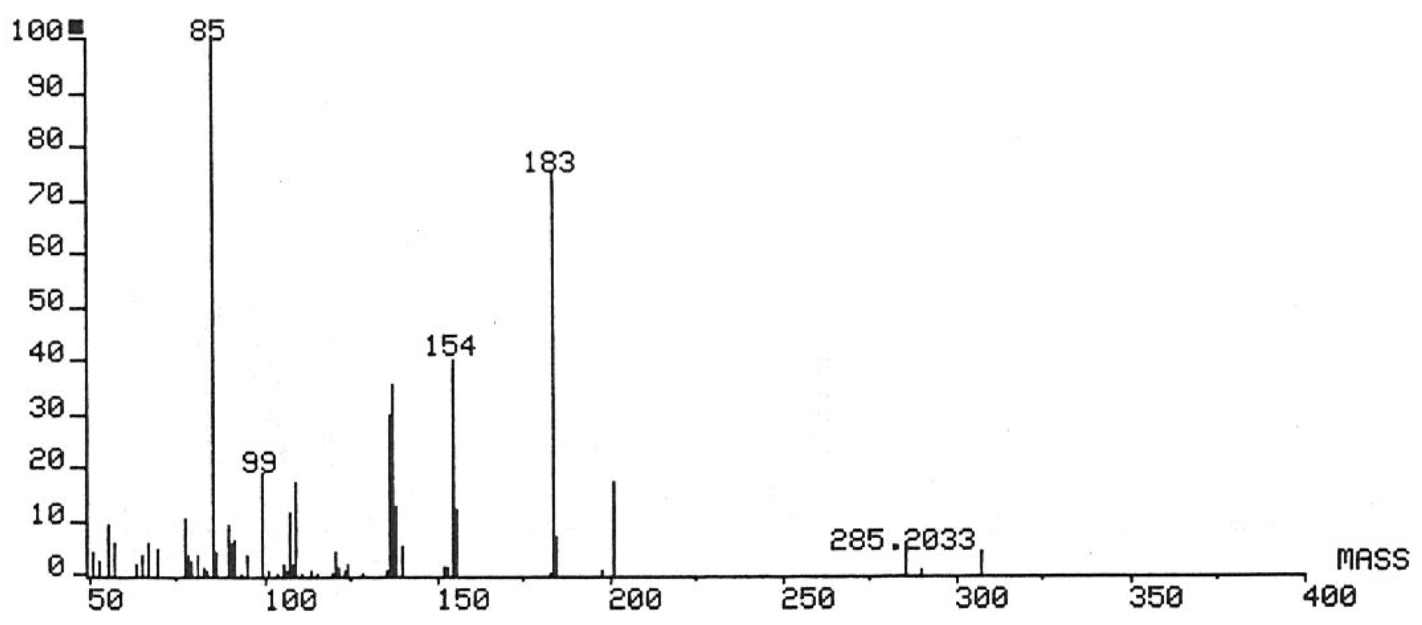


Fig. 9a

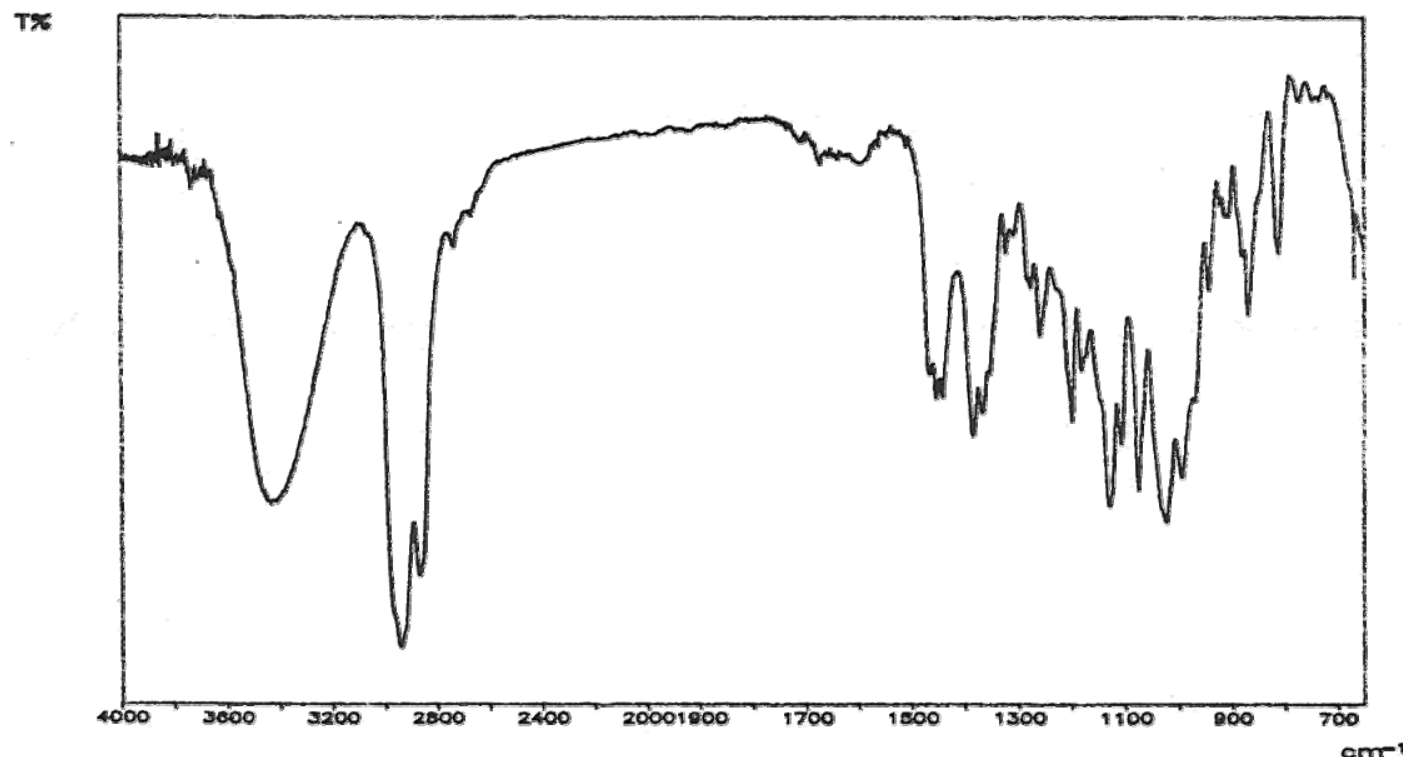

Fig. 9b
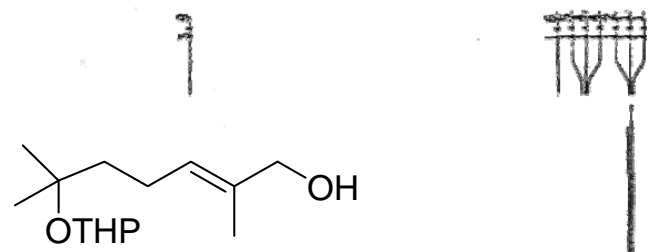

11

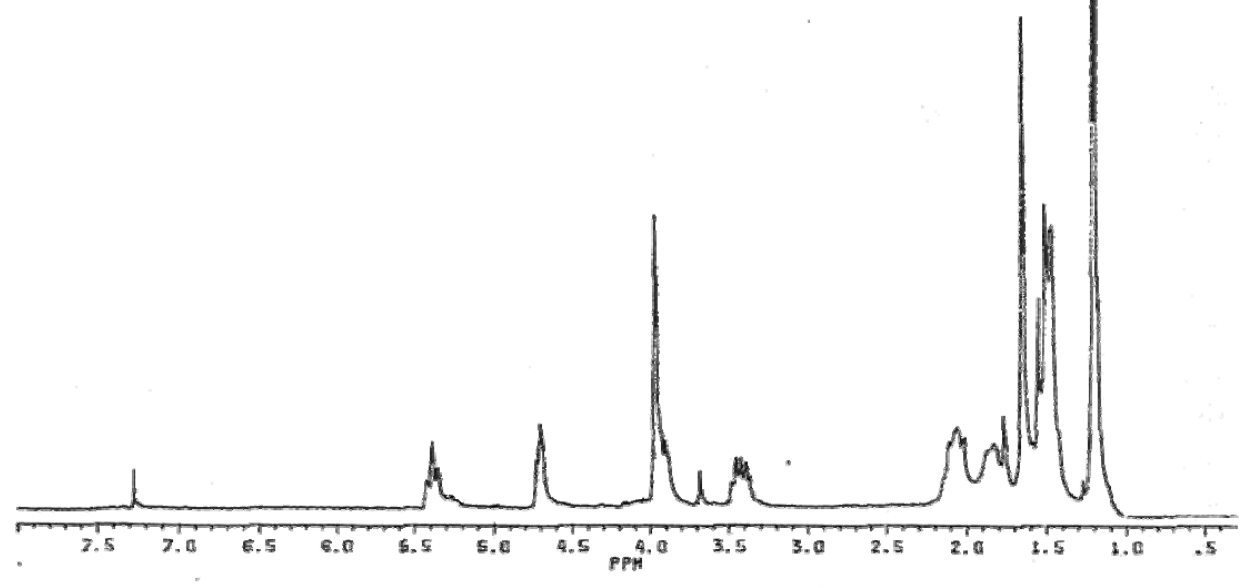


Fig. 9c

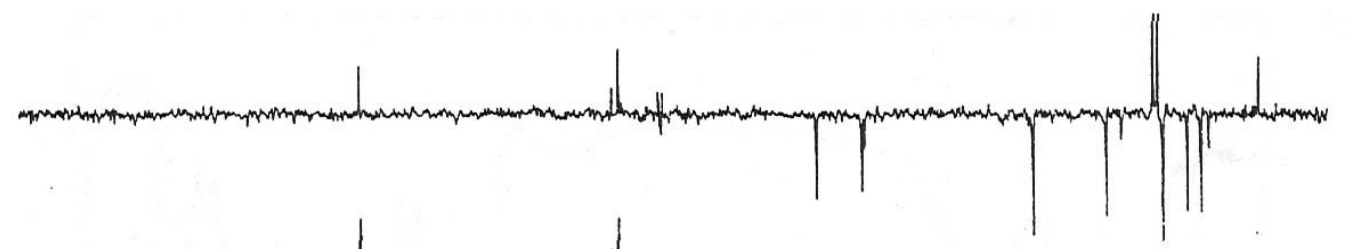

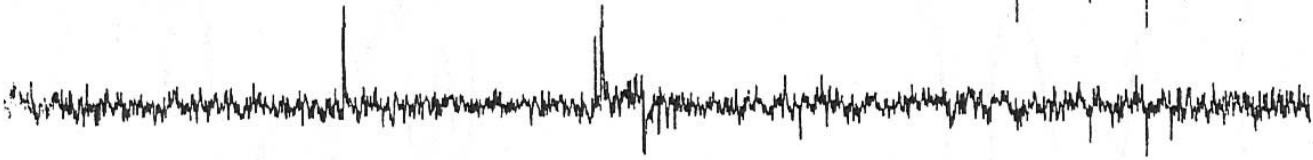

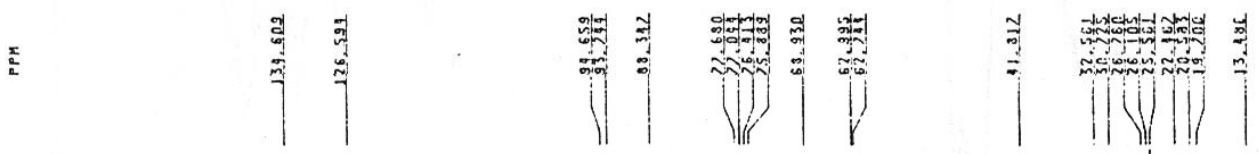

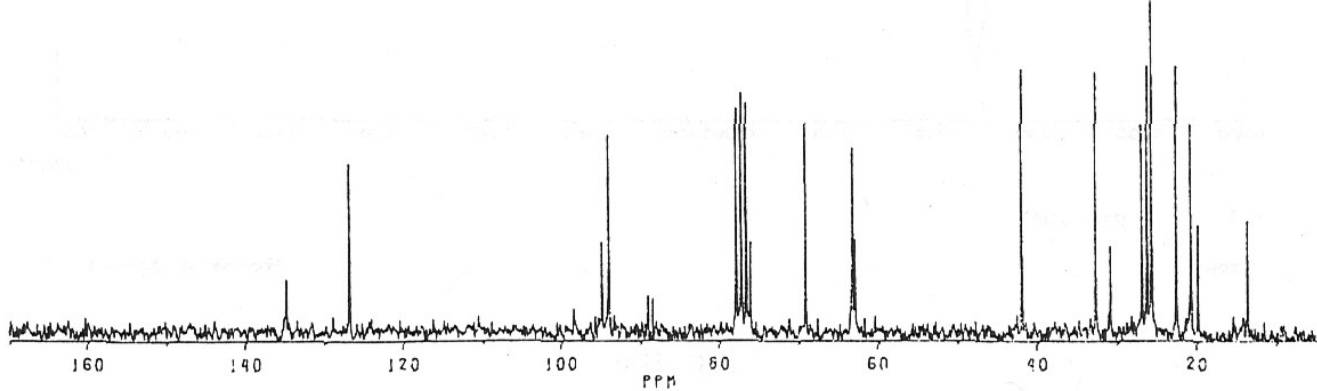

Fig. 9d

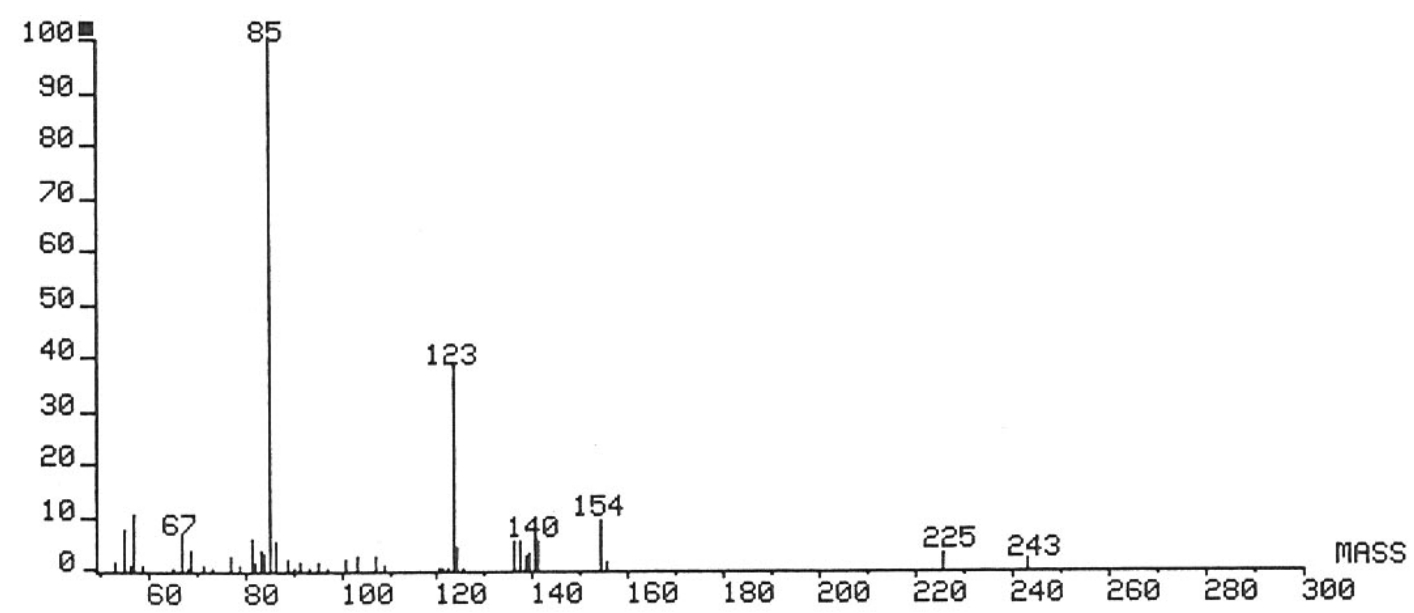


Fig. 10a

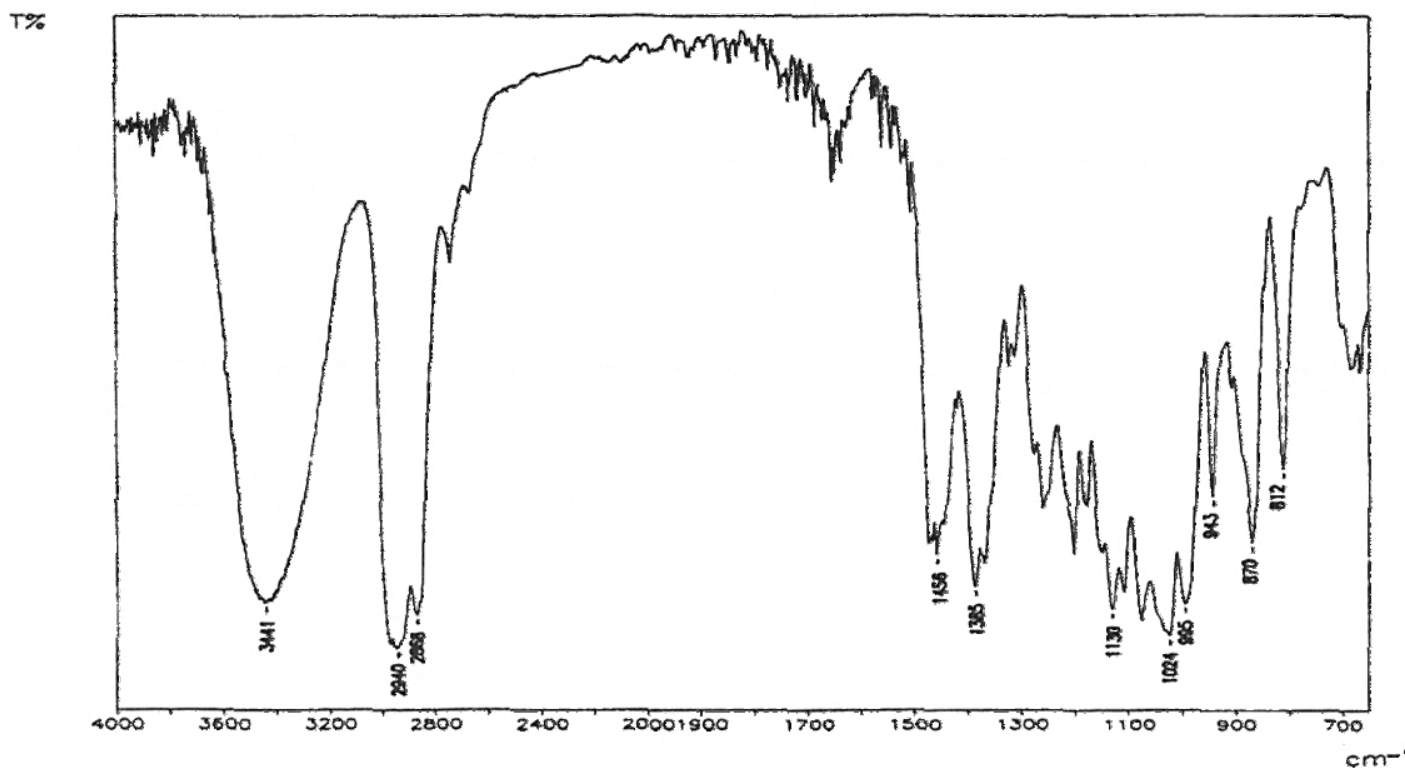

Fig. 10b

ํㅡㄹ
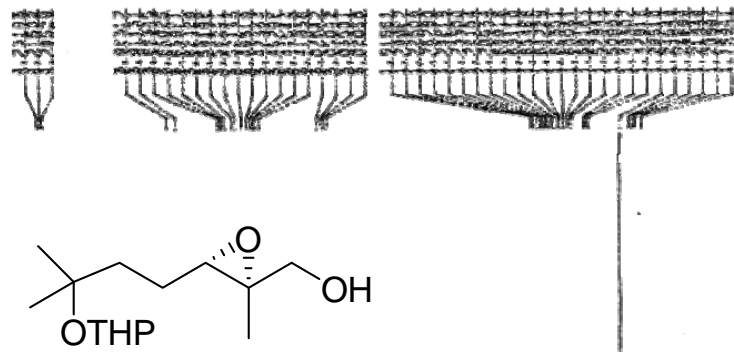

12

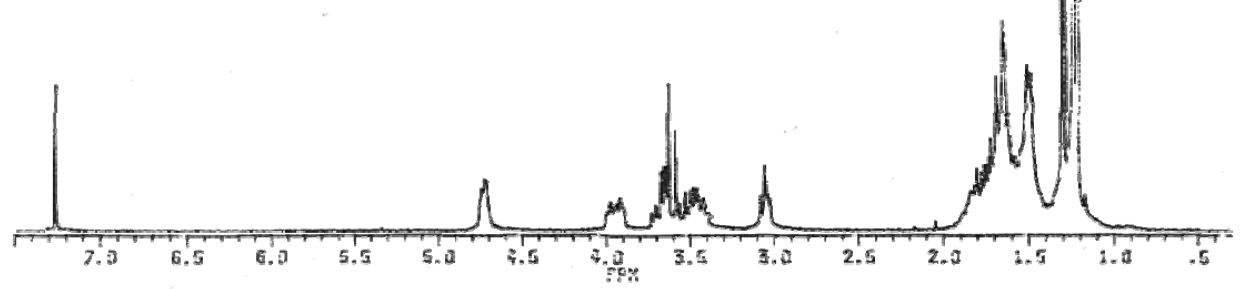


Fig. 10c

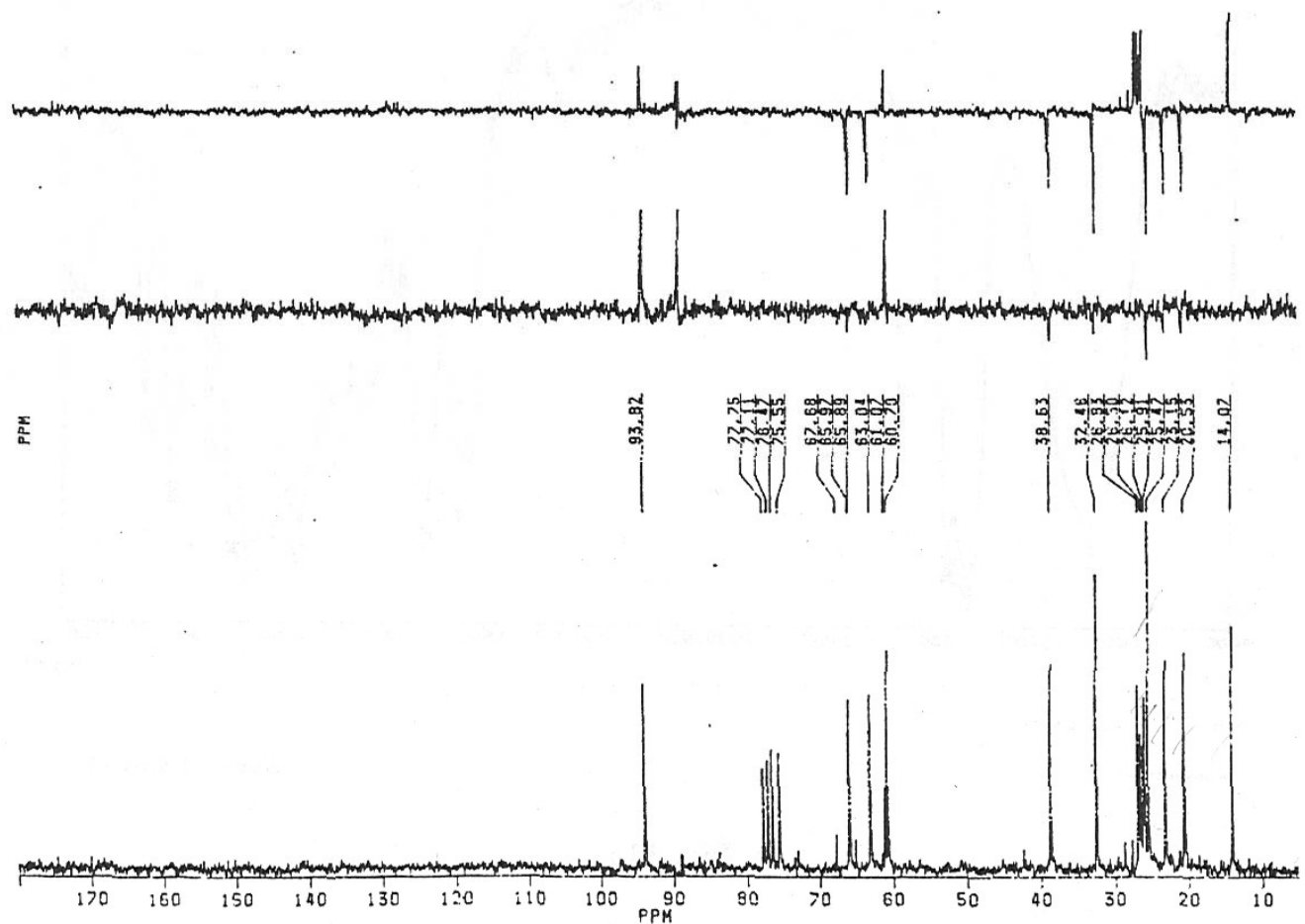

Fig. 10d

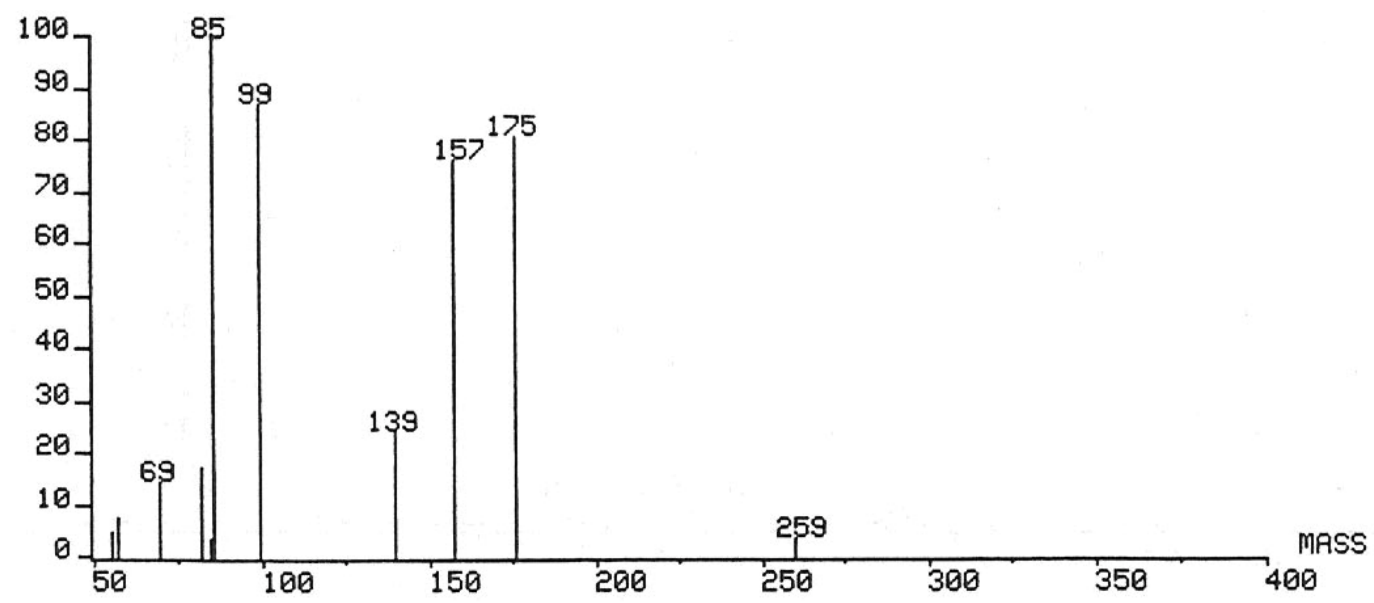


Fig. 11a

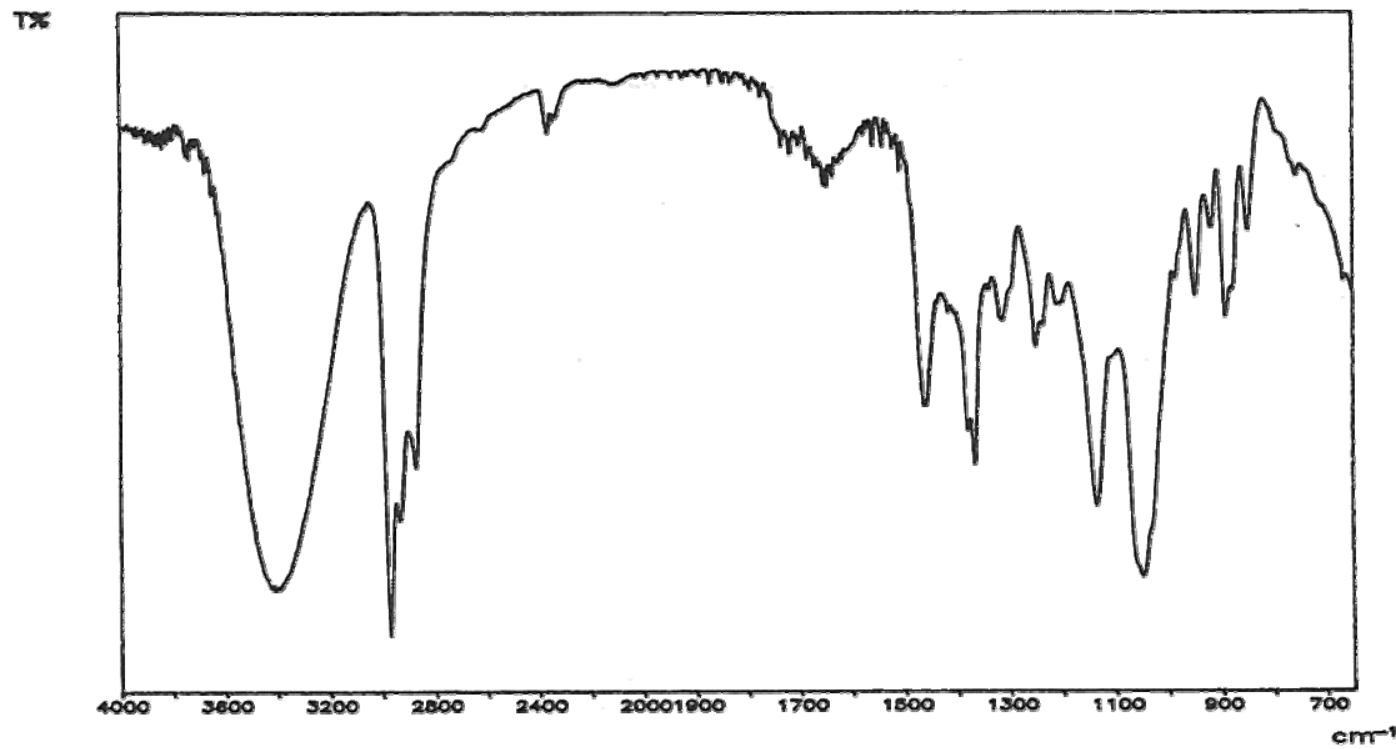

Fig. 11b

$\frac{x}{2}$

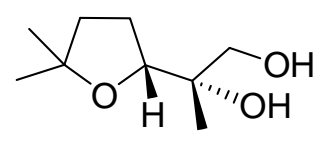

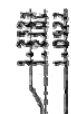

13

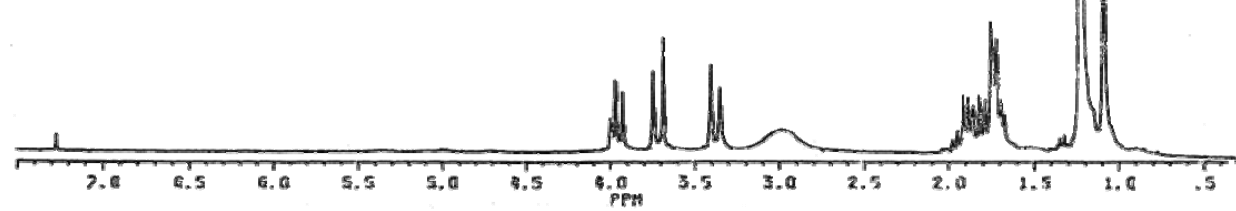


Fig. 11c
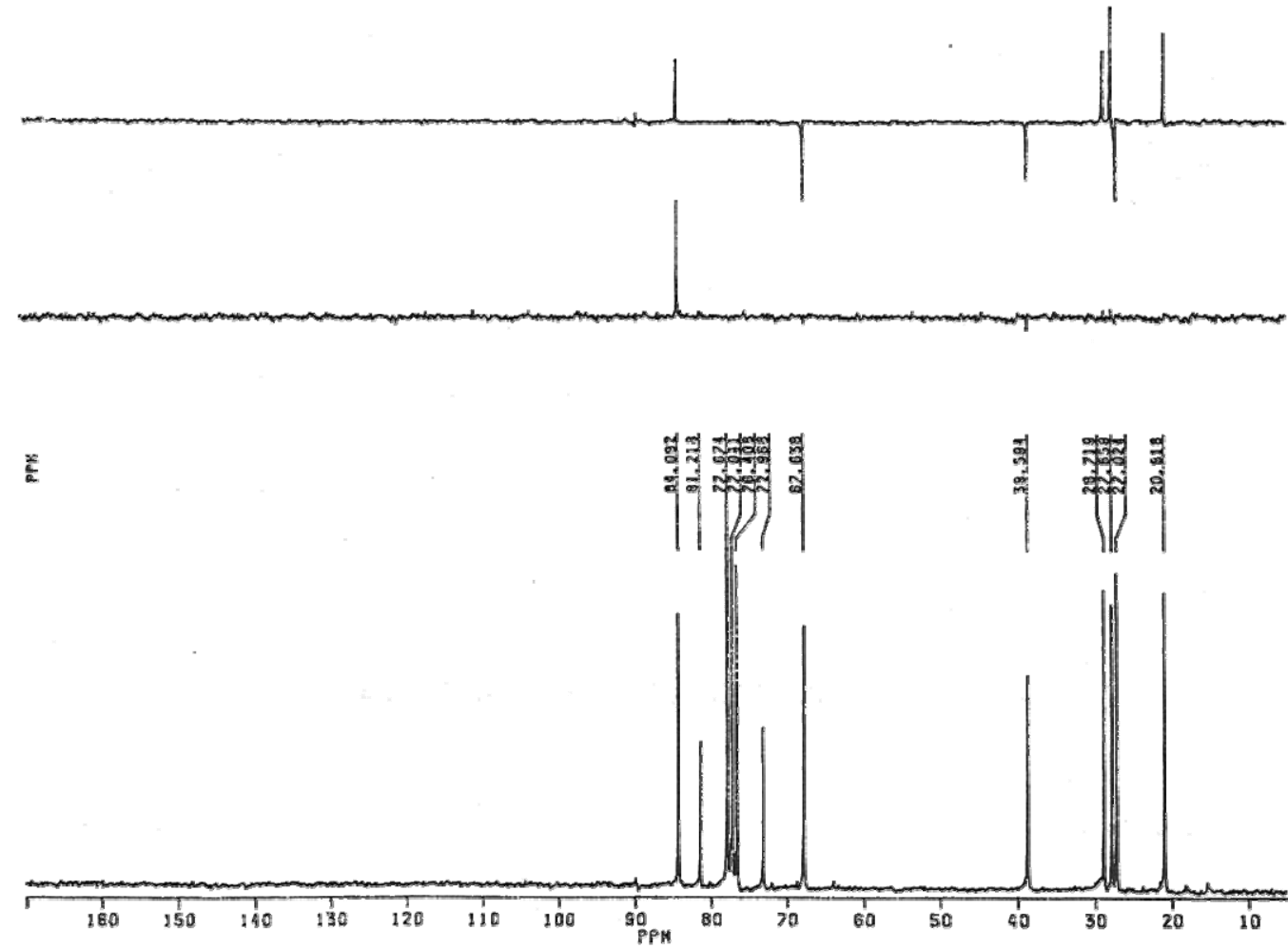

Fig. 11d

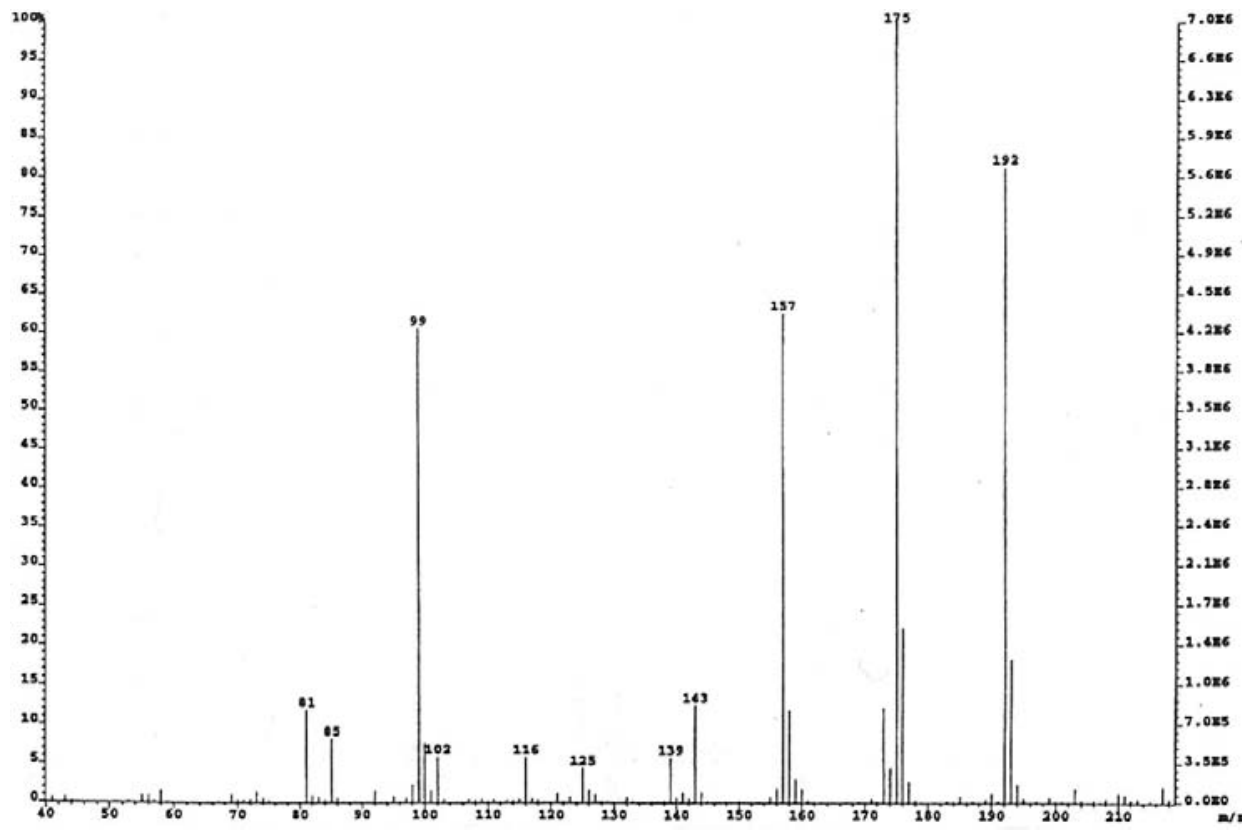


Fig. 12a

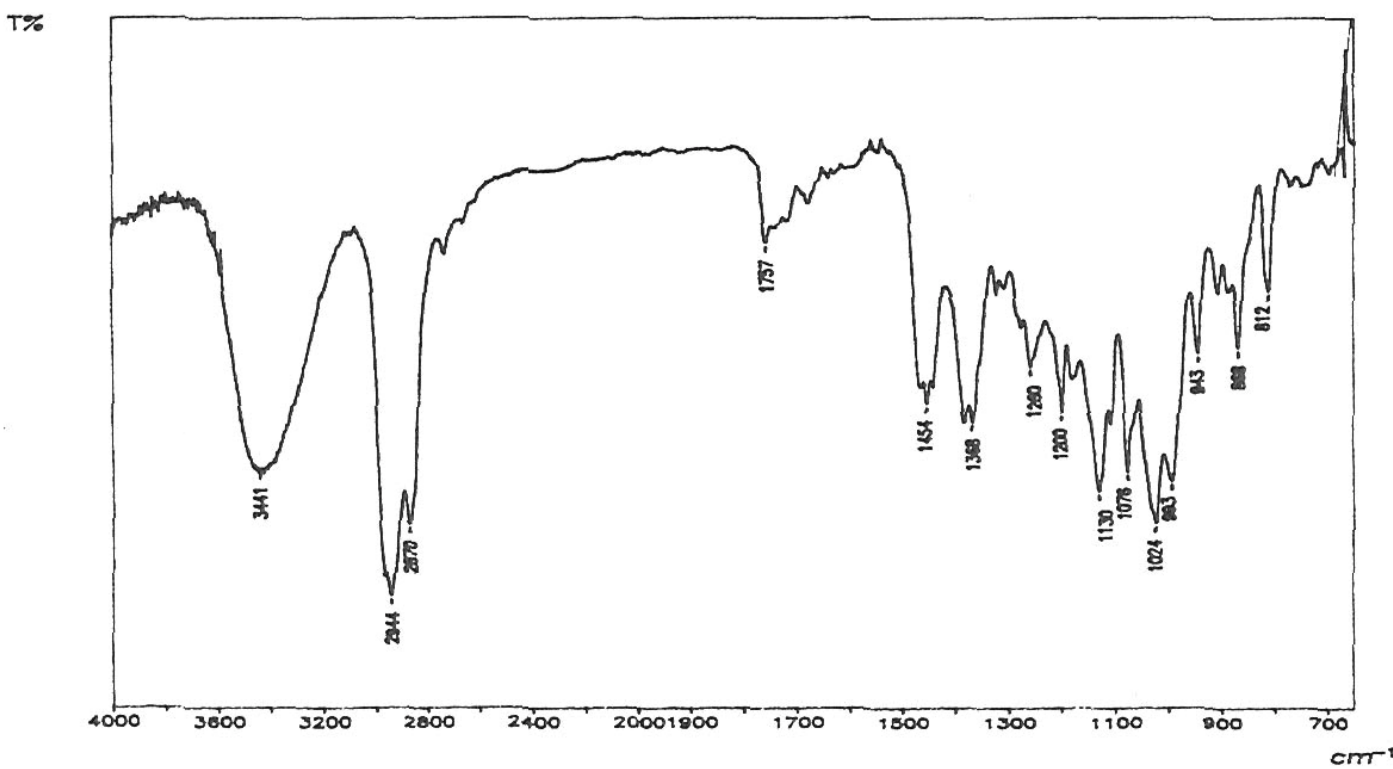

Fig. 12b

害

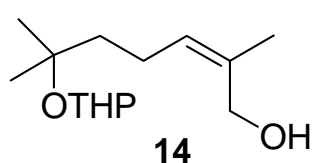

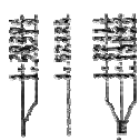

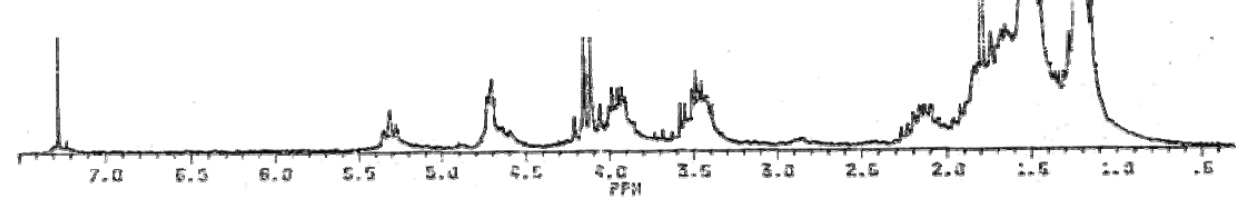


Fig. 12c

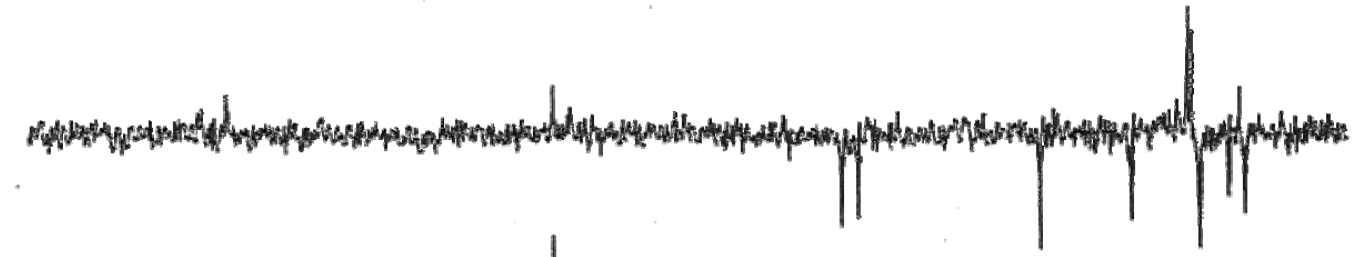

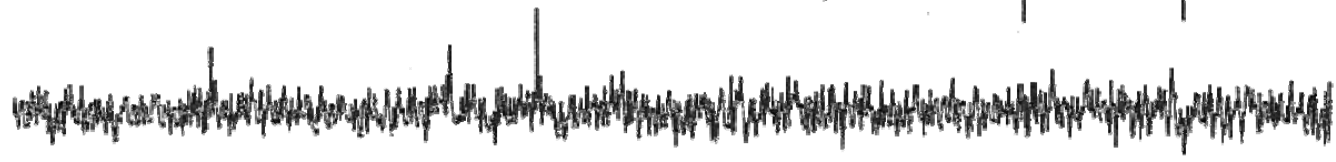

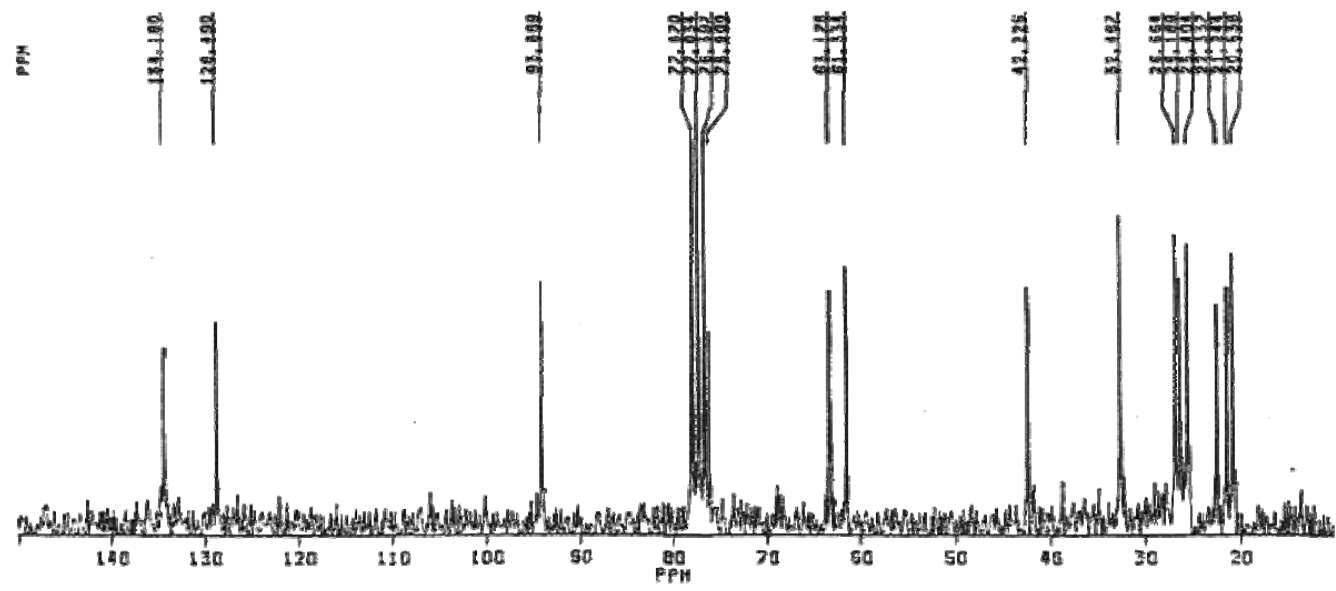

Fig. 12d

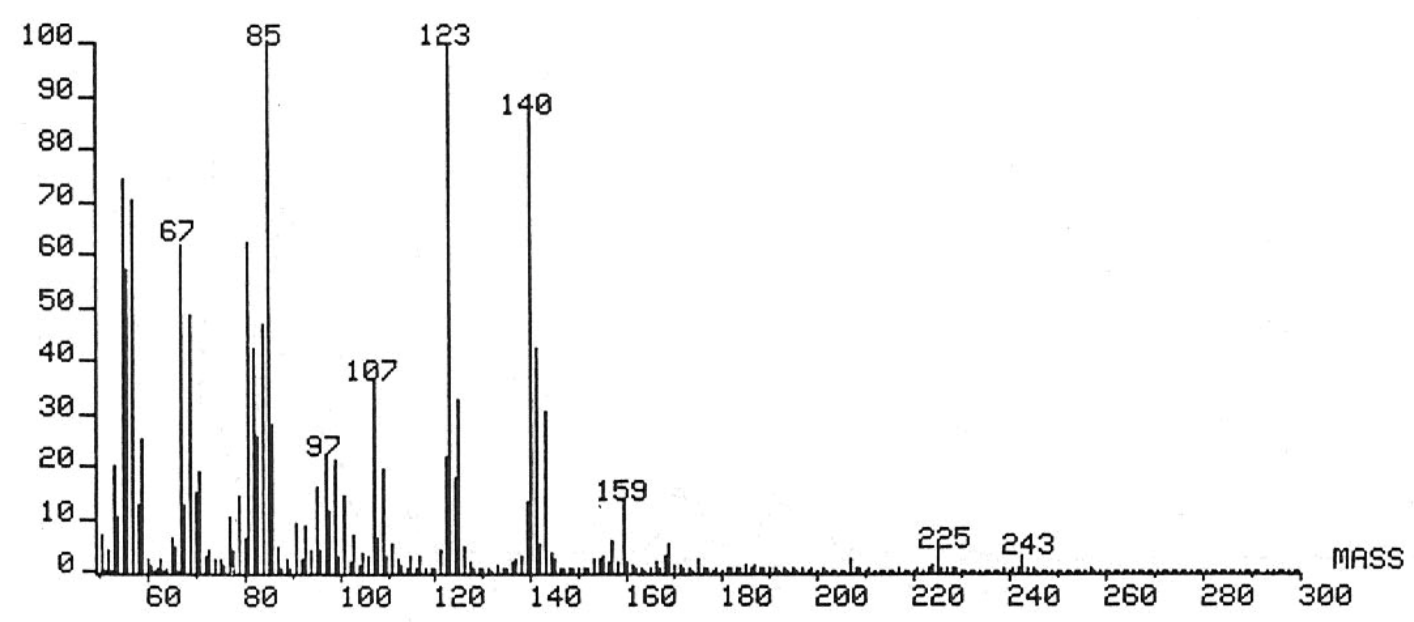


Fig. 13a

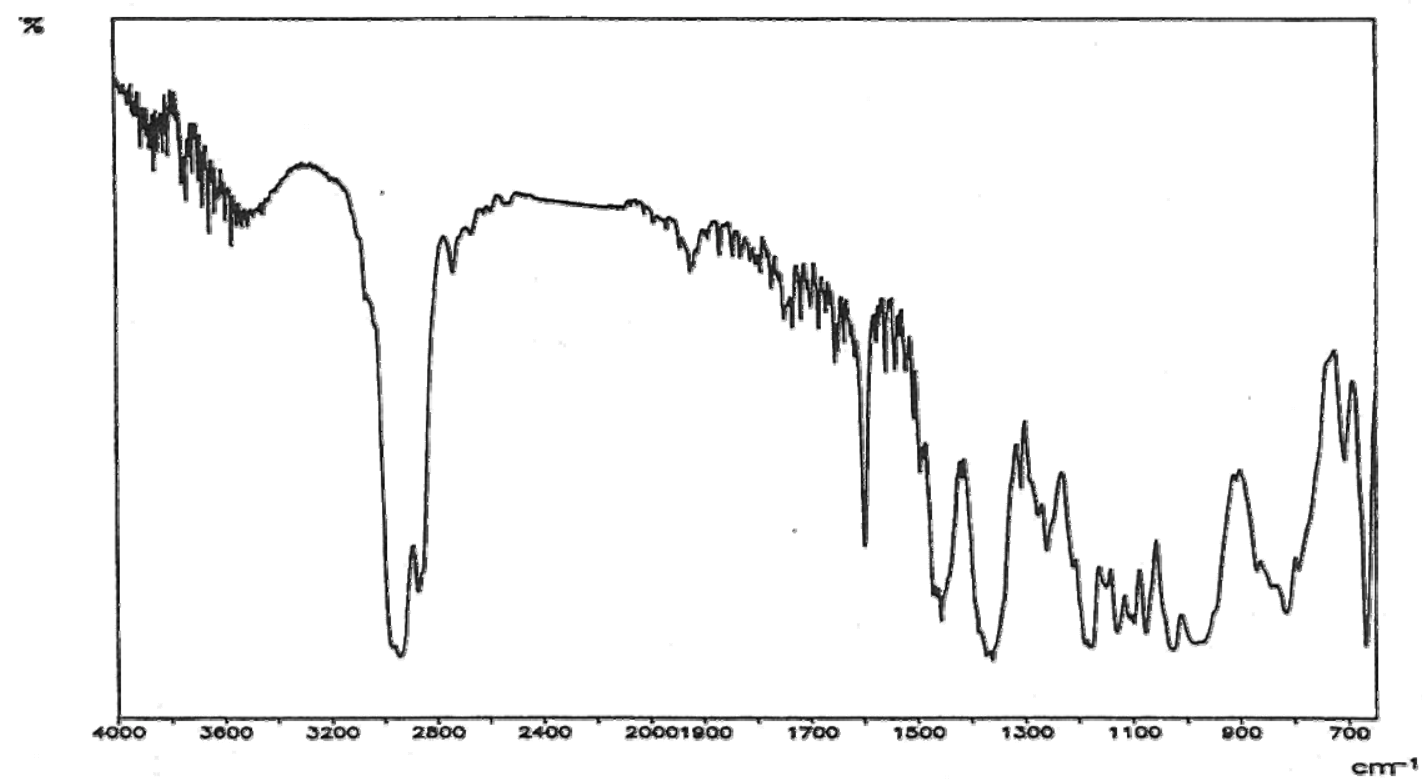

Fig. 13b

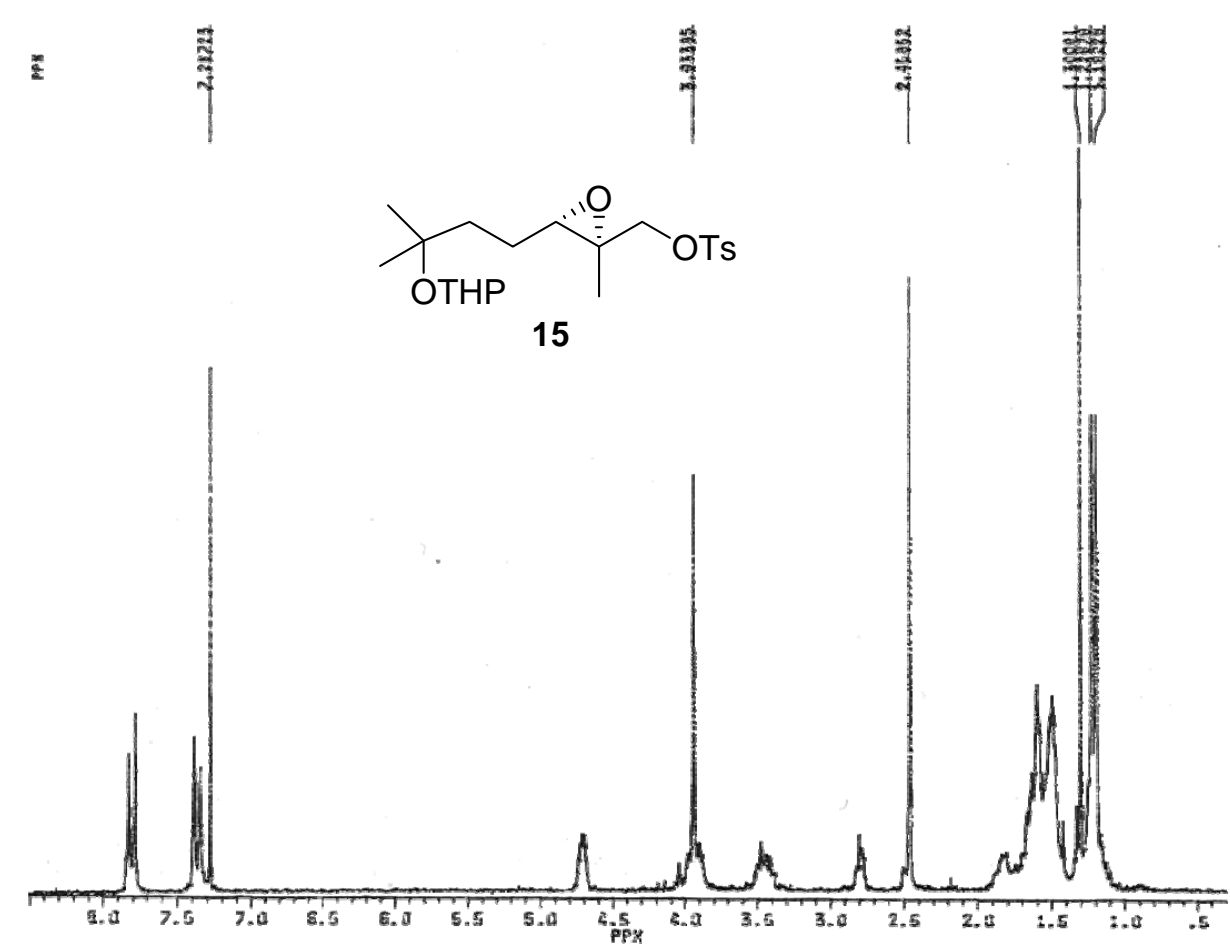


Fig. 13c

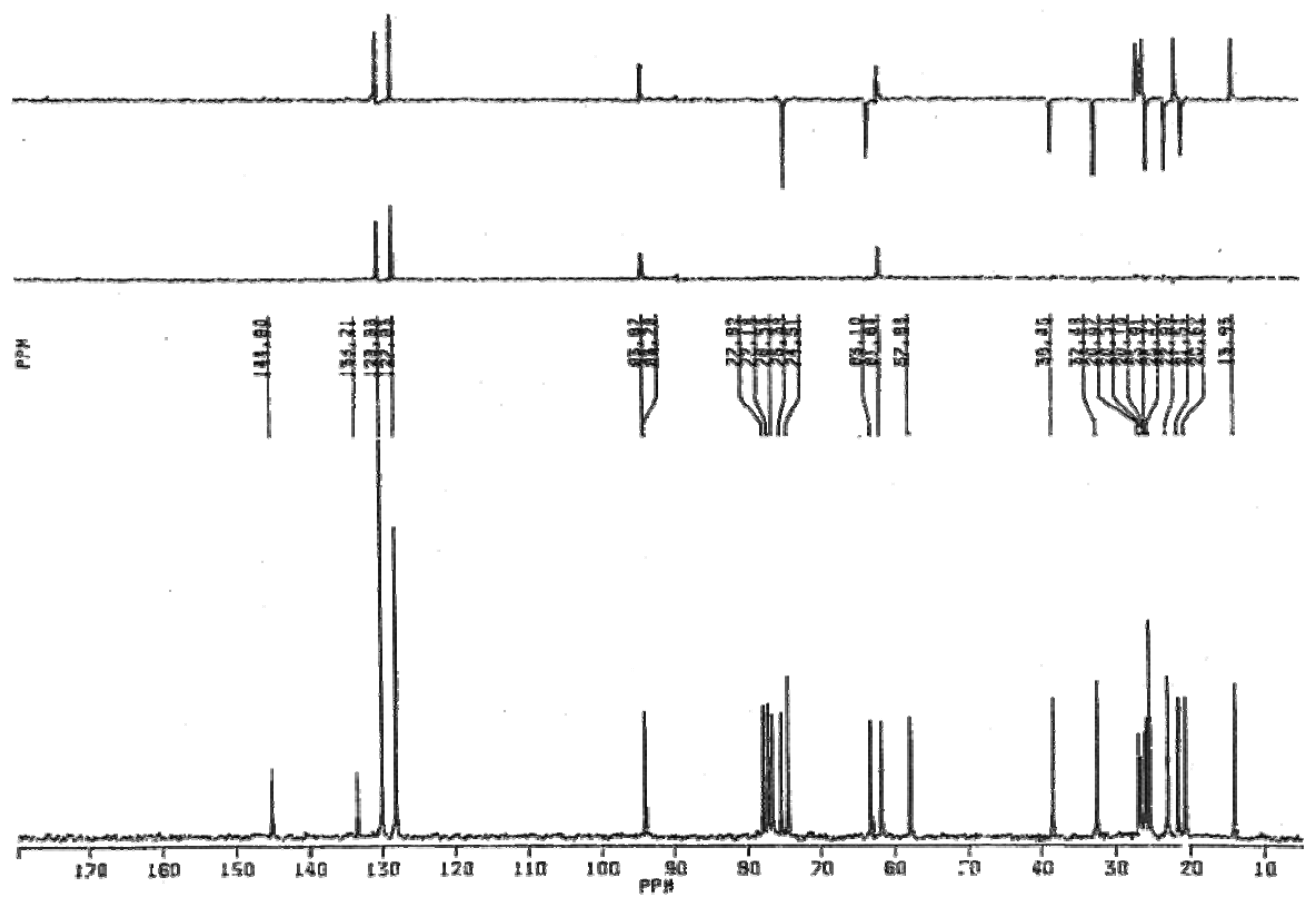

Fig. 13d

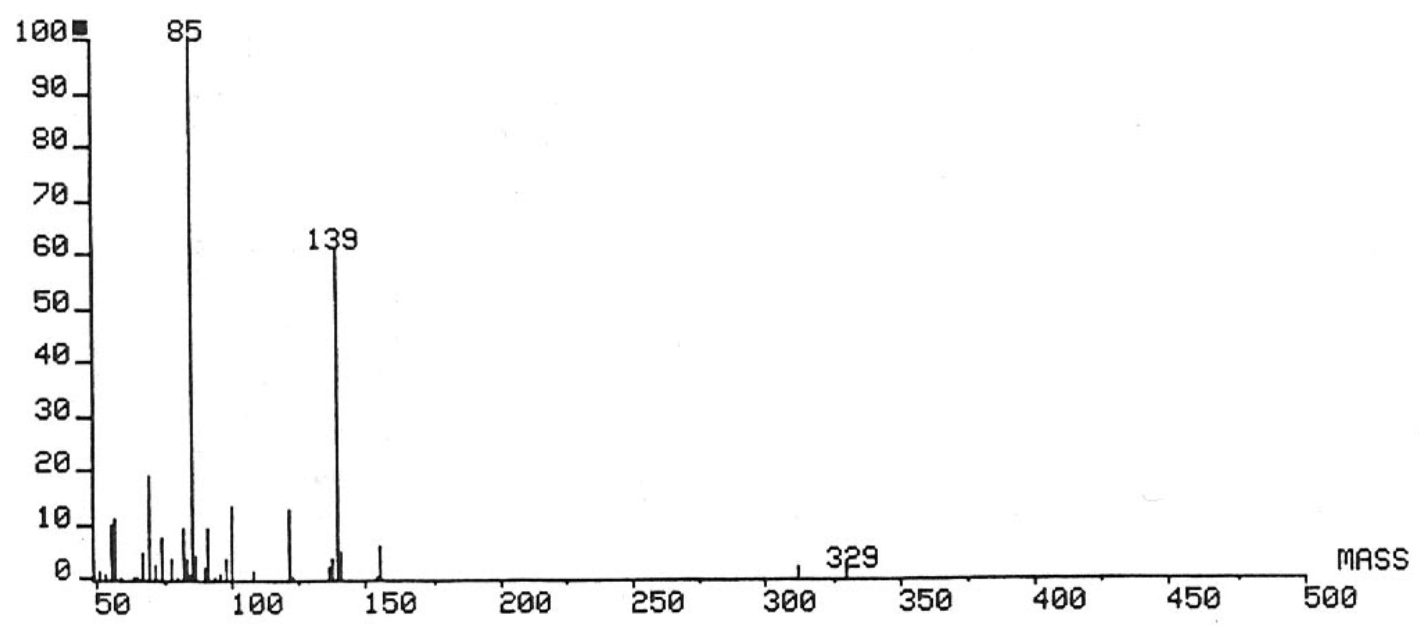


Fig. 14a

$T \pi$

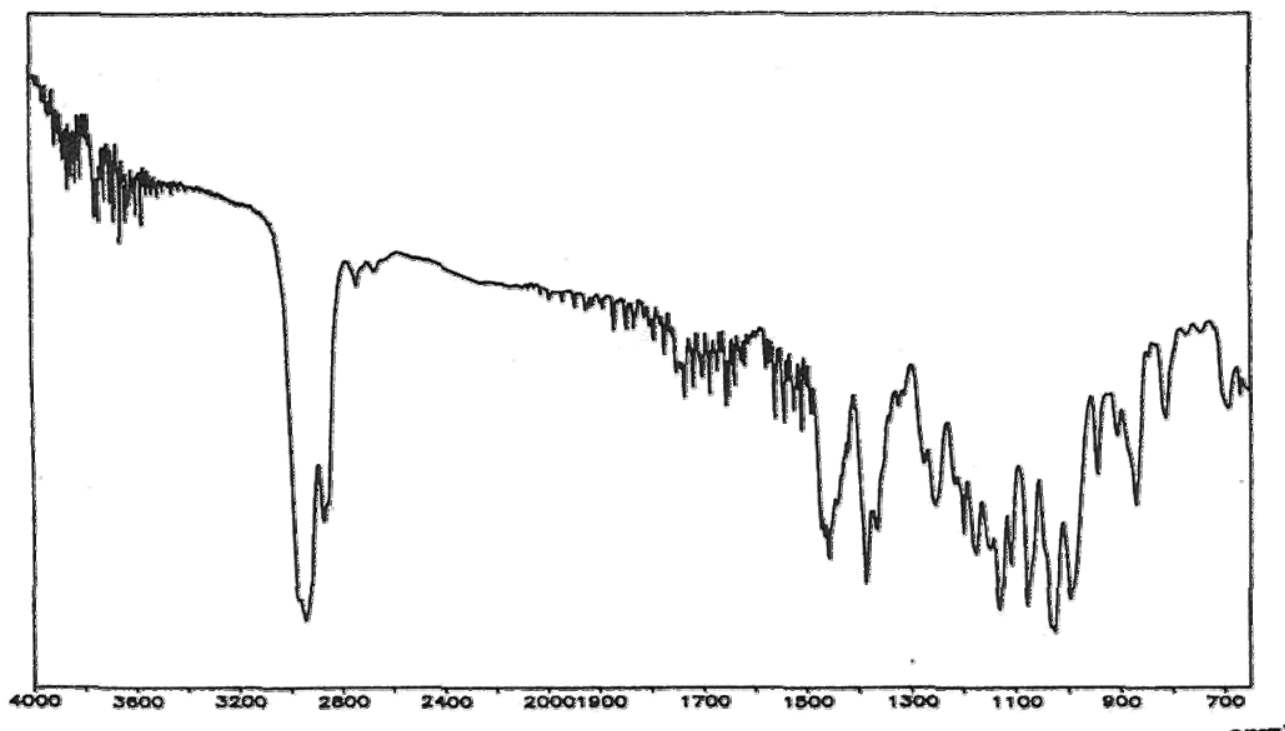

Fig. 14b

$\underline{2}$

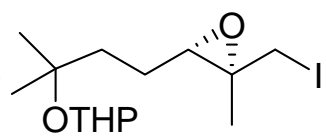

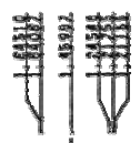

16

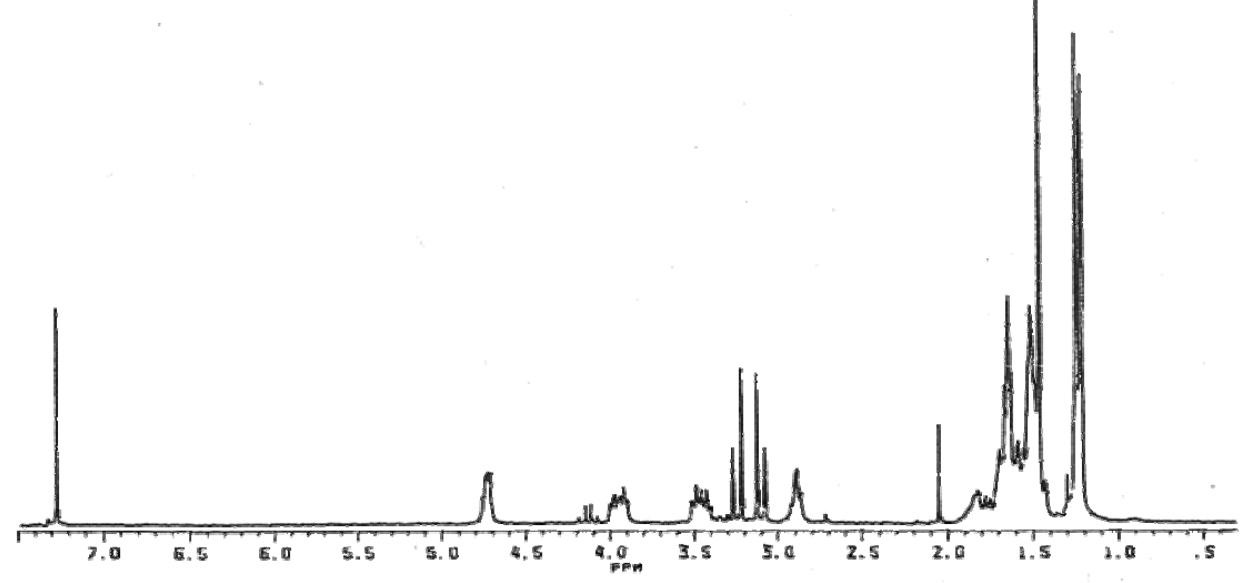


Fig. 14c

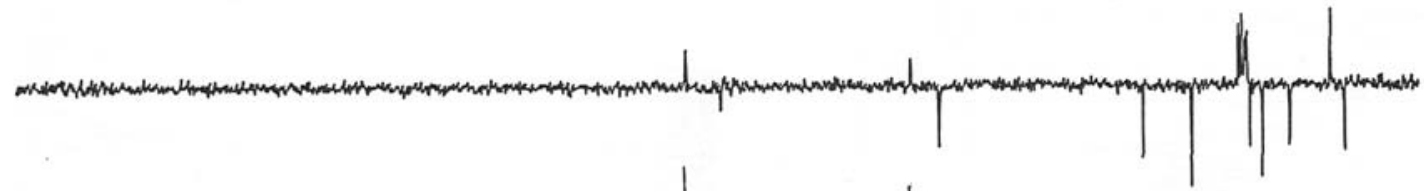
How $\stackrel{\Sigma}{\varepsilon}$

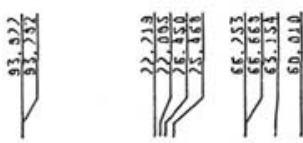

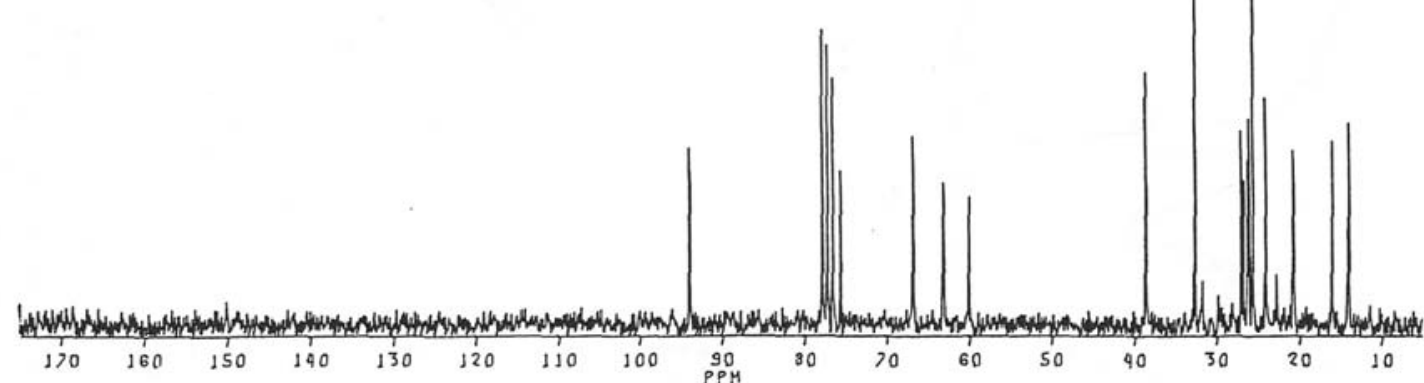


Fig. 15a

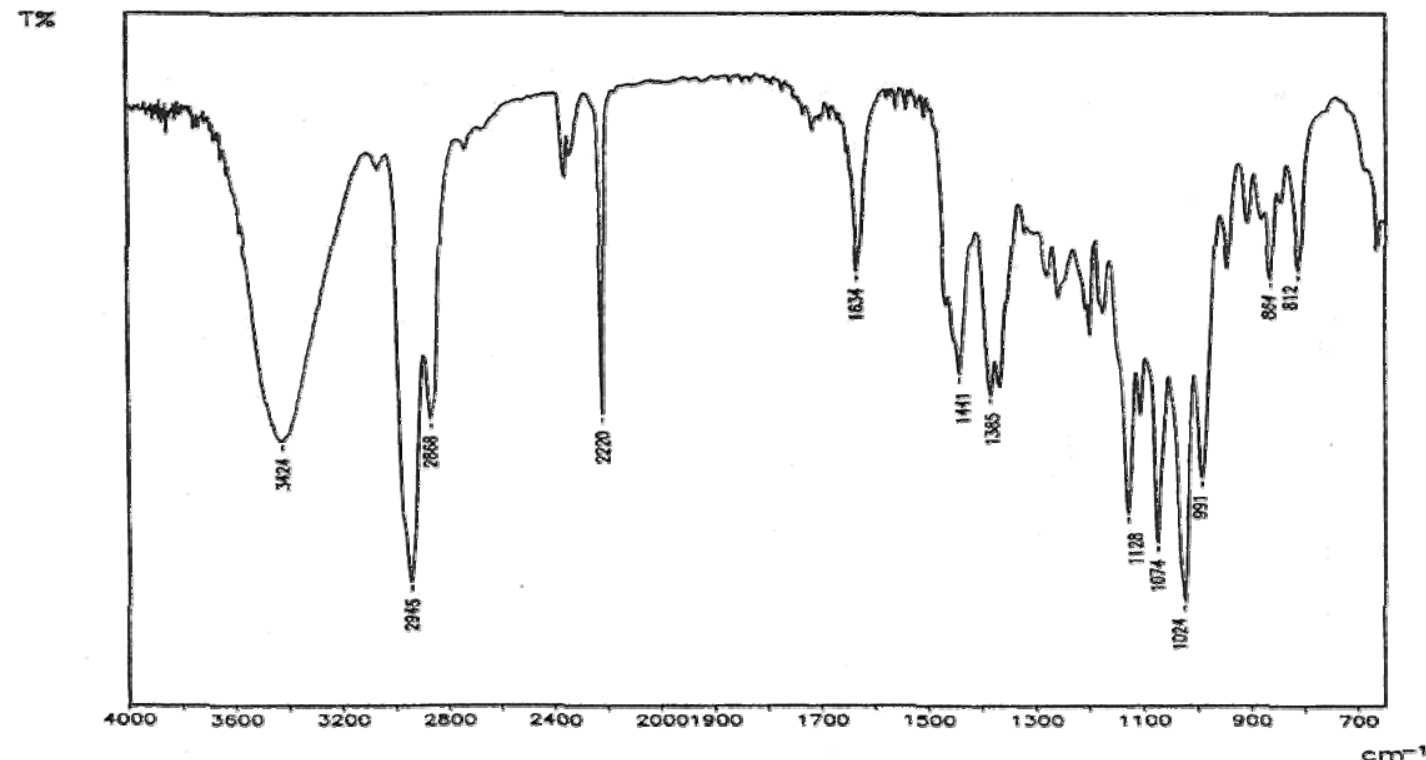

Fig. 15b

ะ<smiles>C/C(=C\C#N)[C@@H](O)CCC(C)(C)[OH+]</smiles>

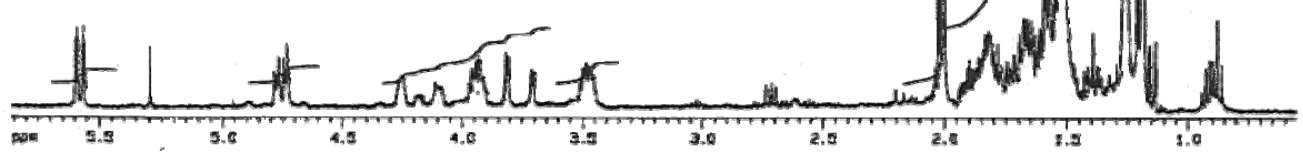


Fig. 15c

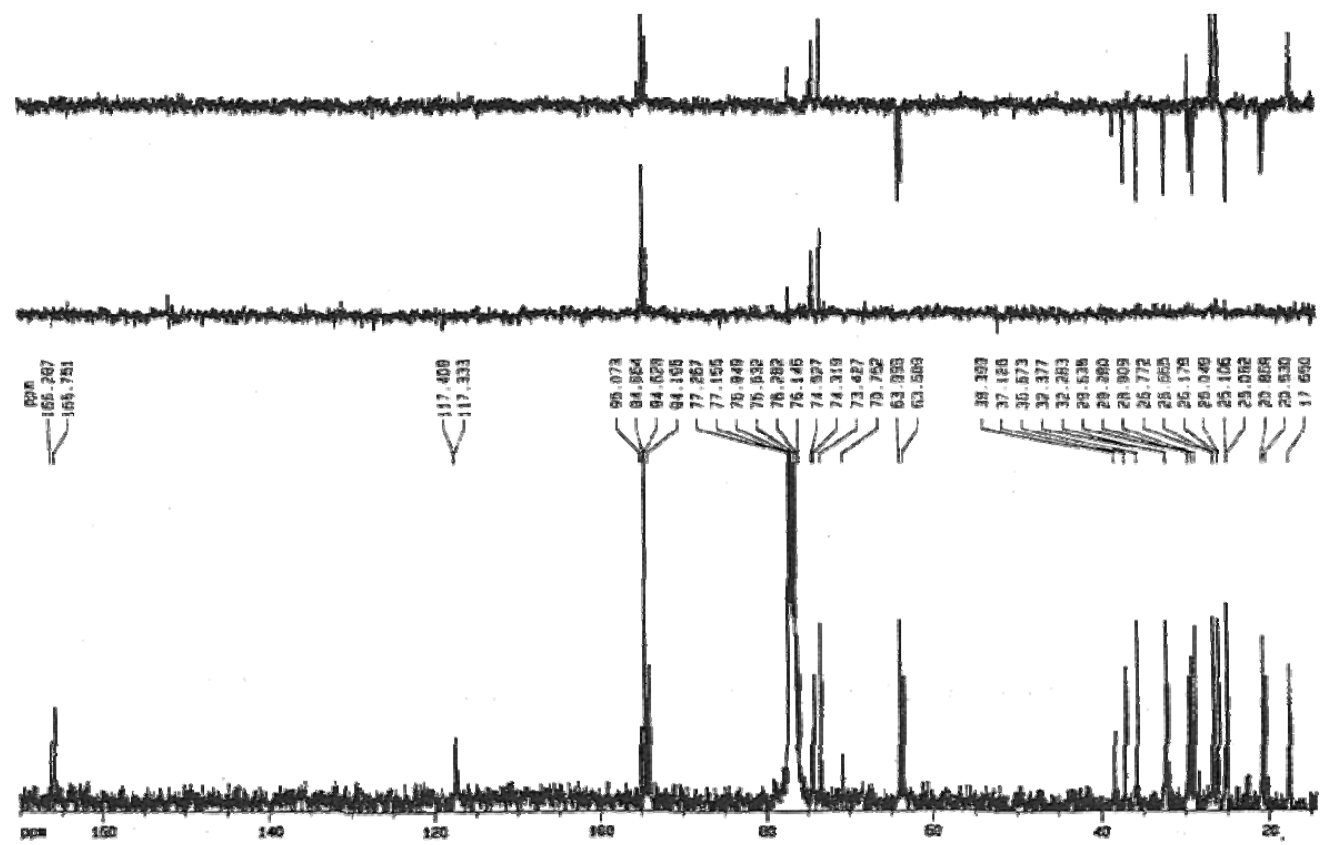

Fig. 15d

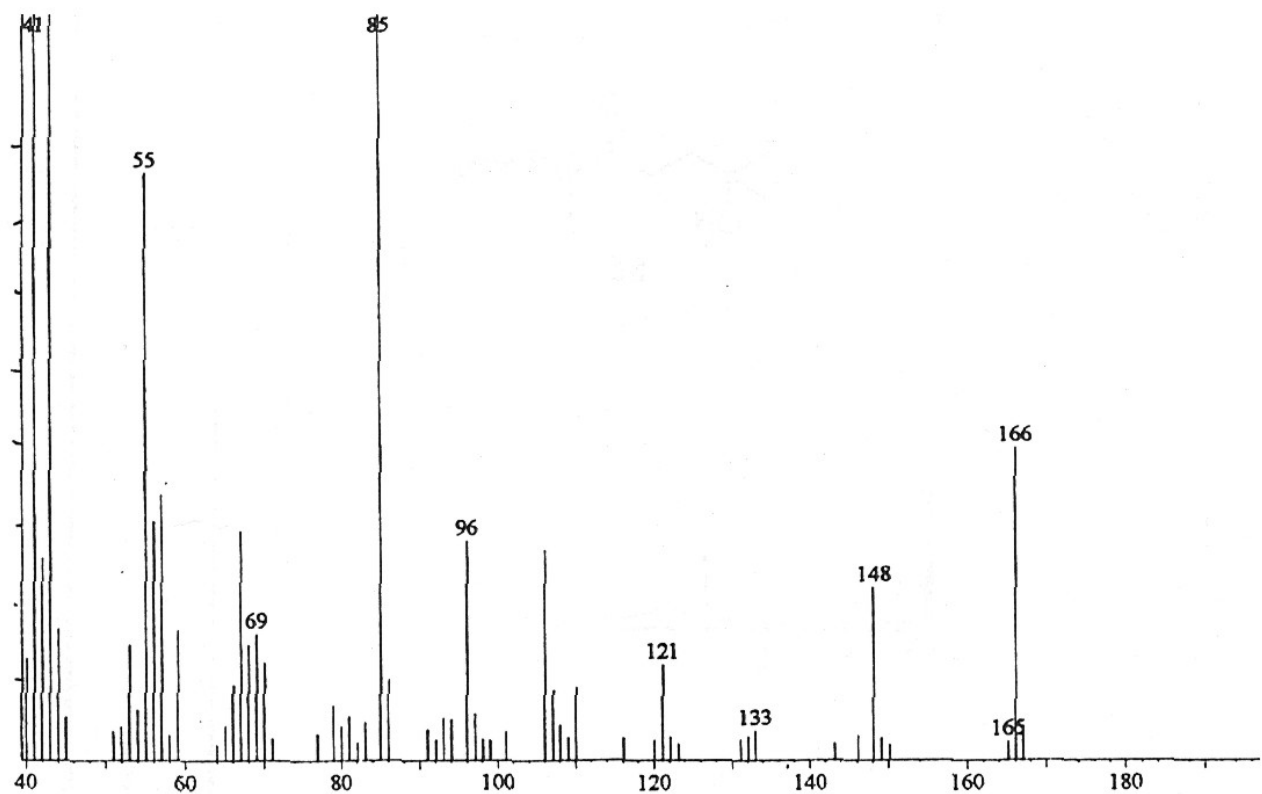


Fig. 16a

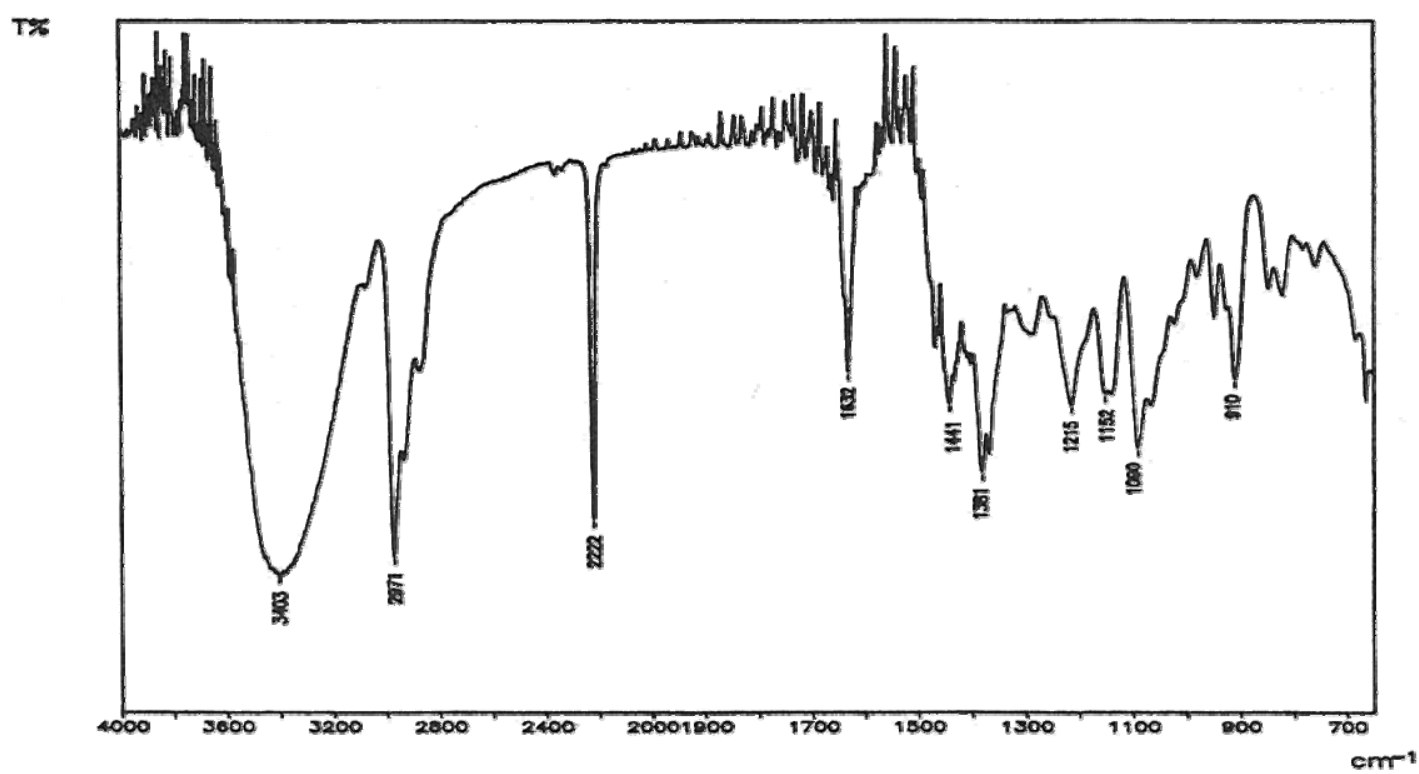

Fig. 16b
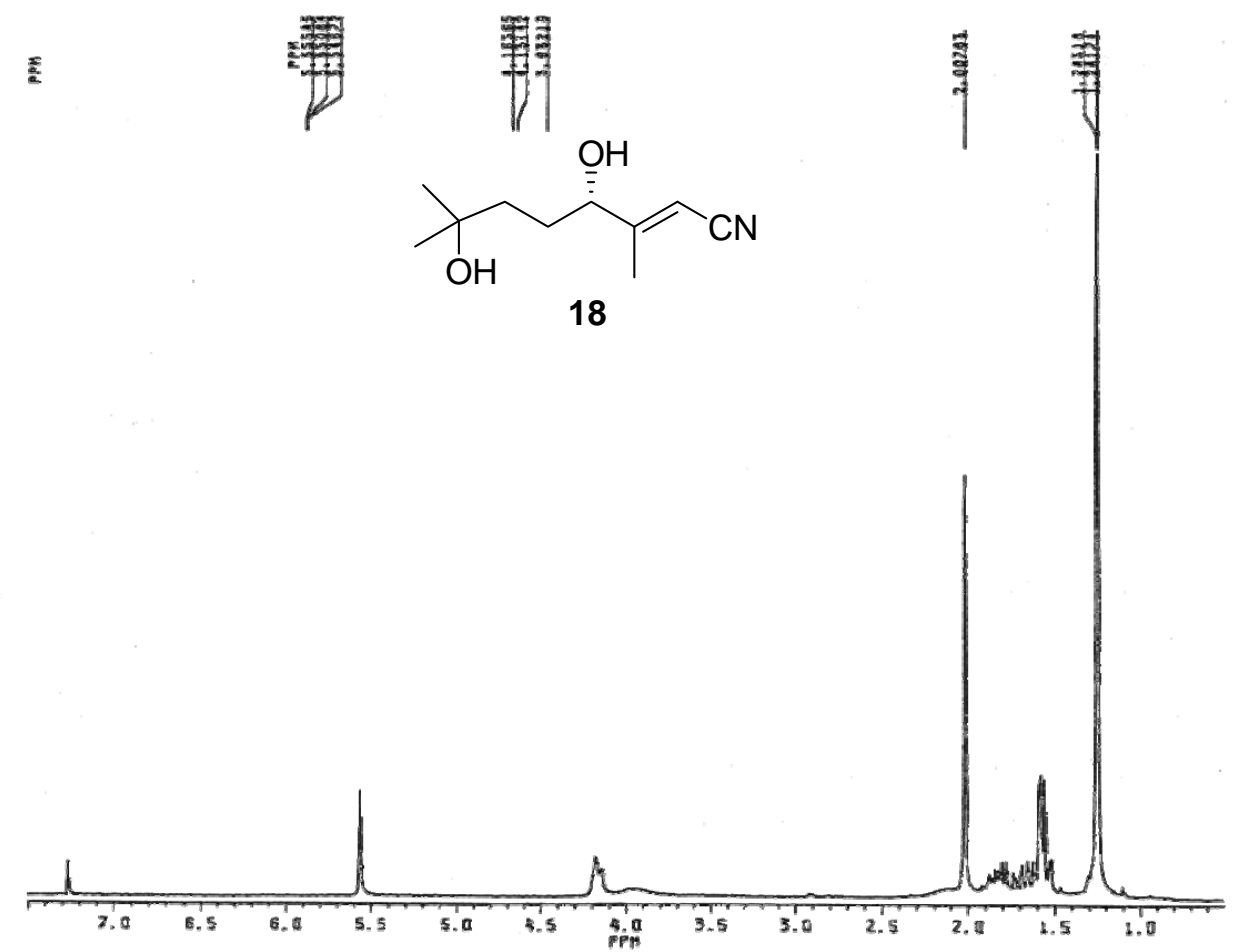
Fig. 16c

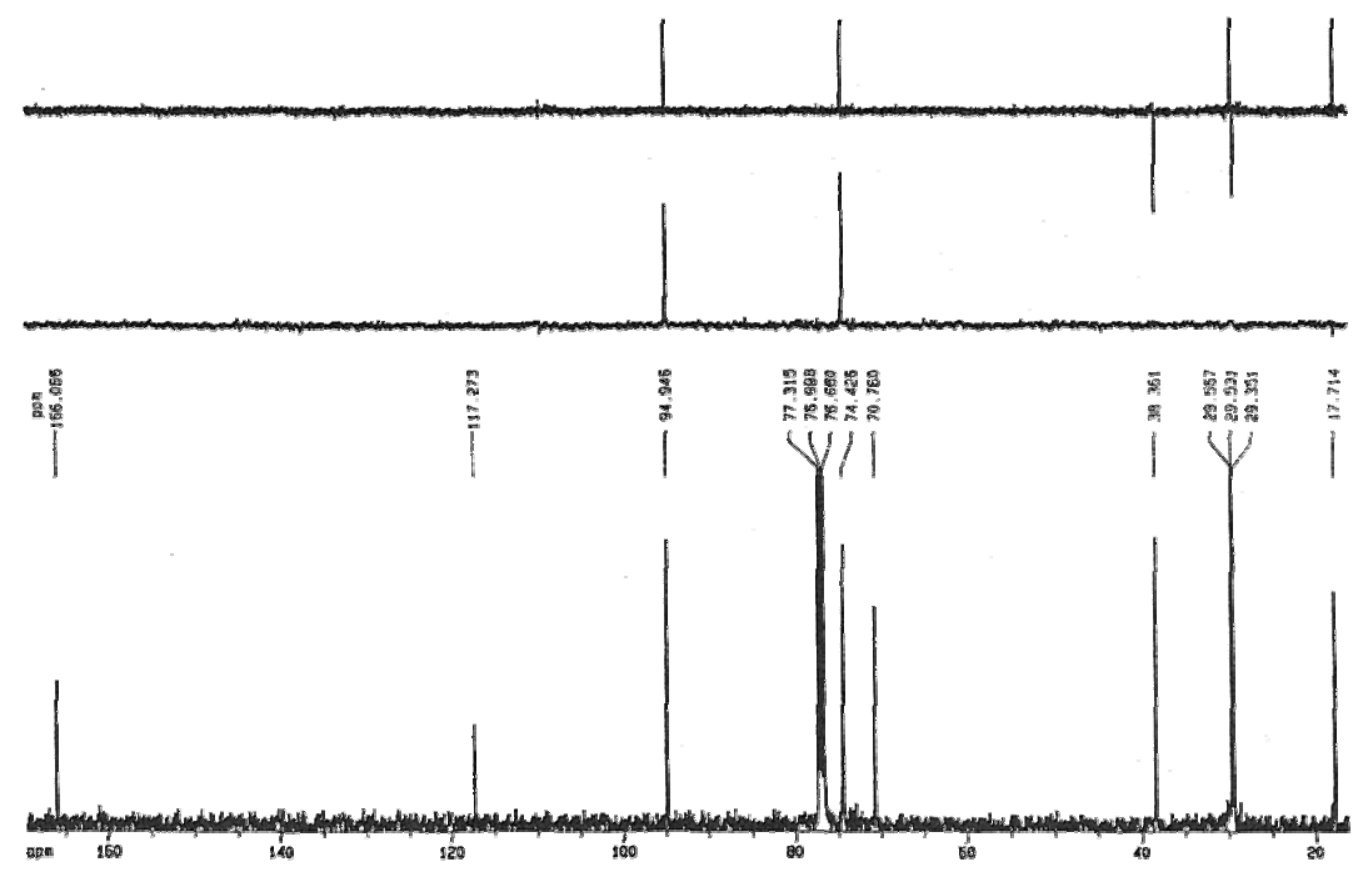

Fig. 16d

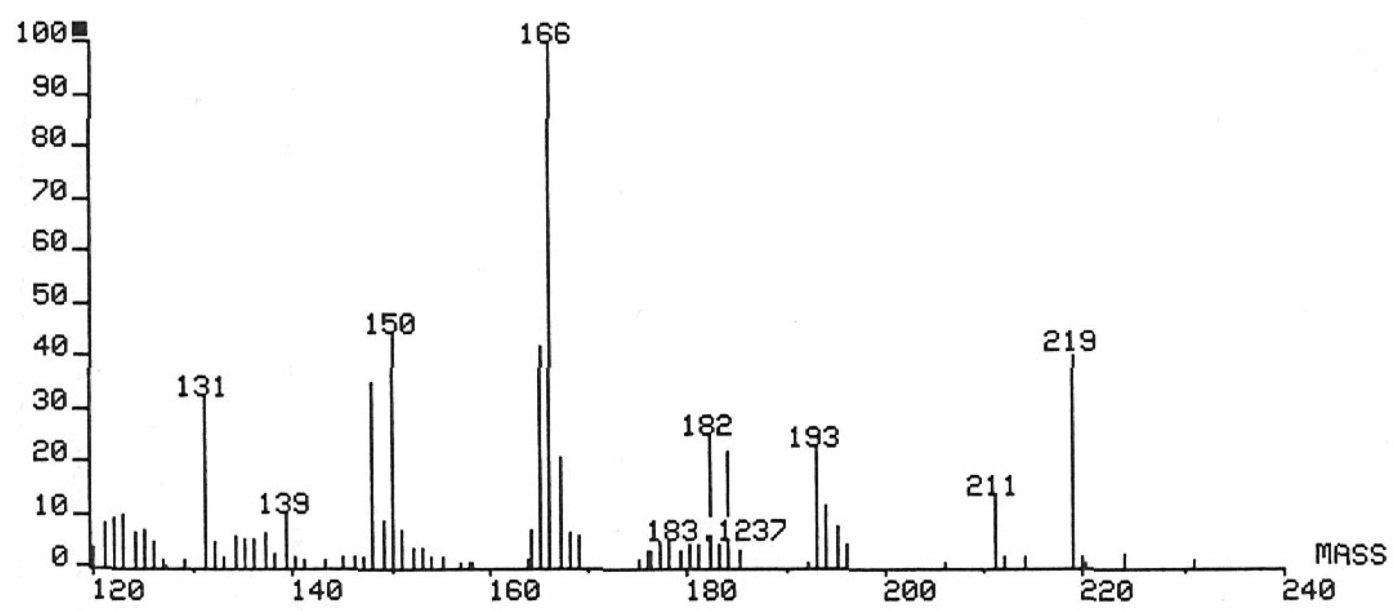


Fig. 17a

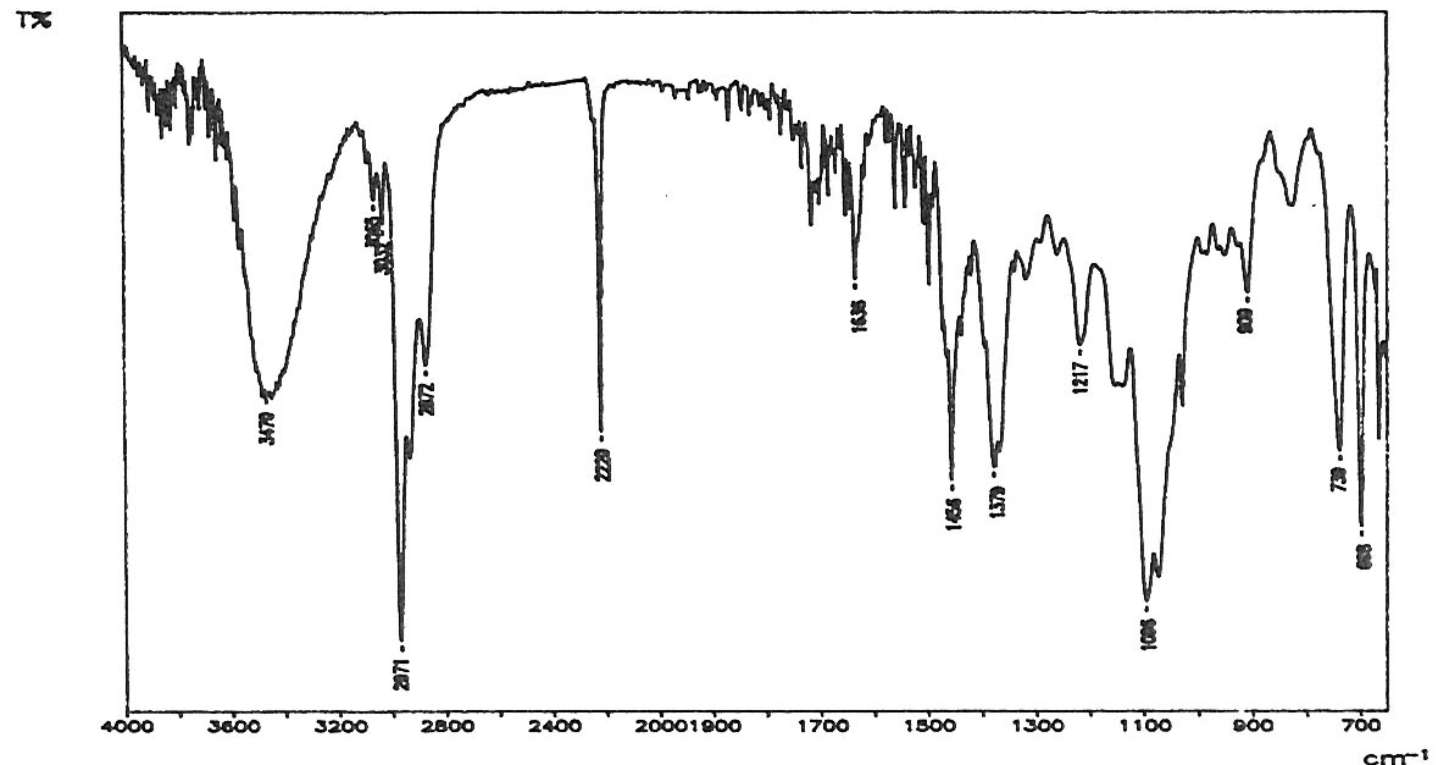

Fig. 17b
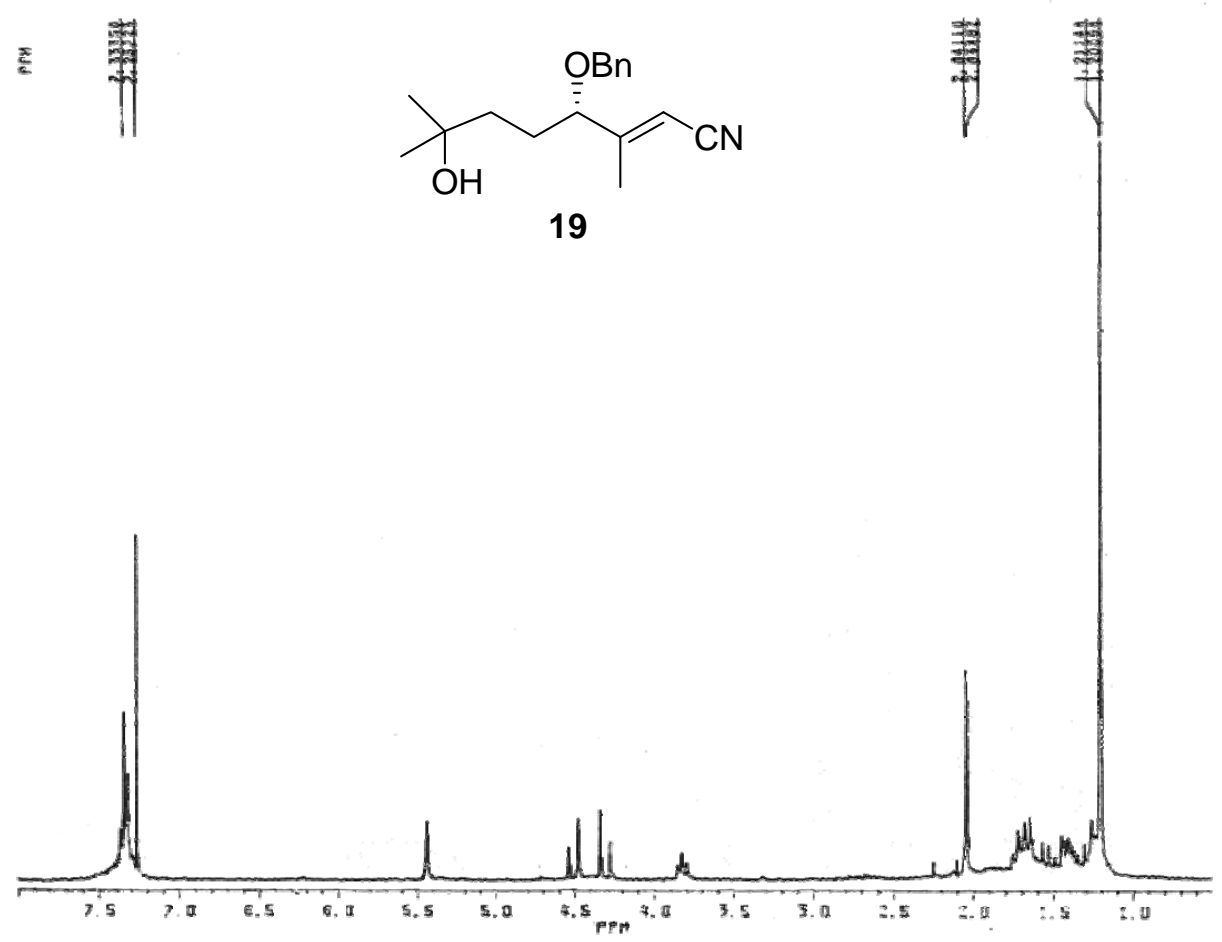
Fig. 17c

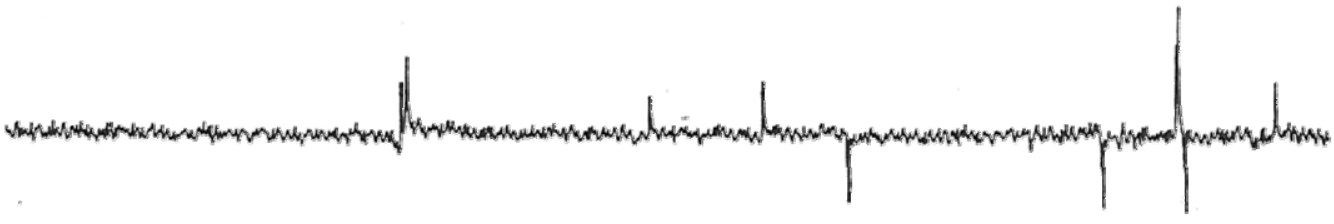

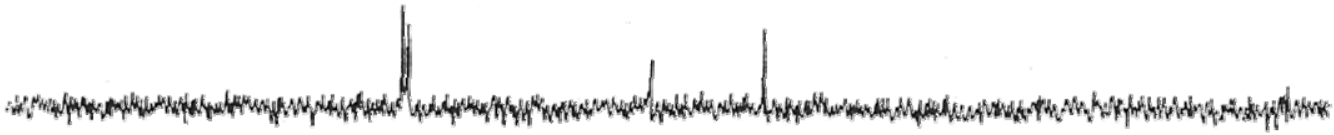

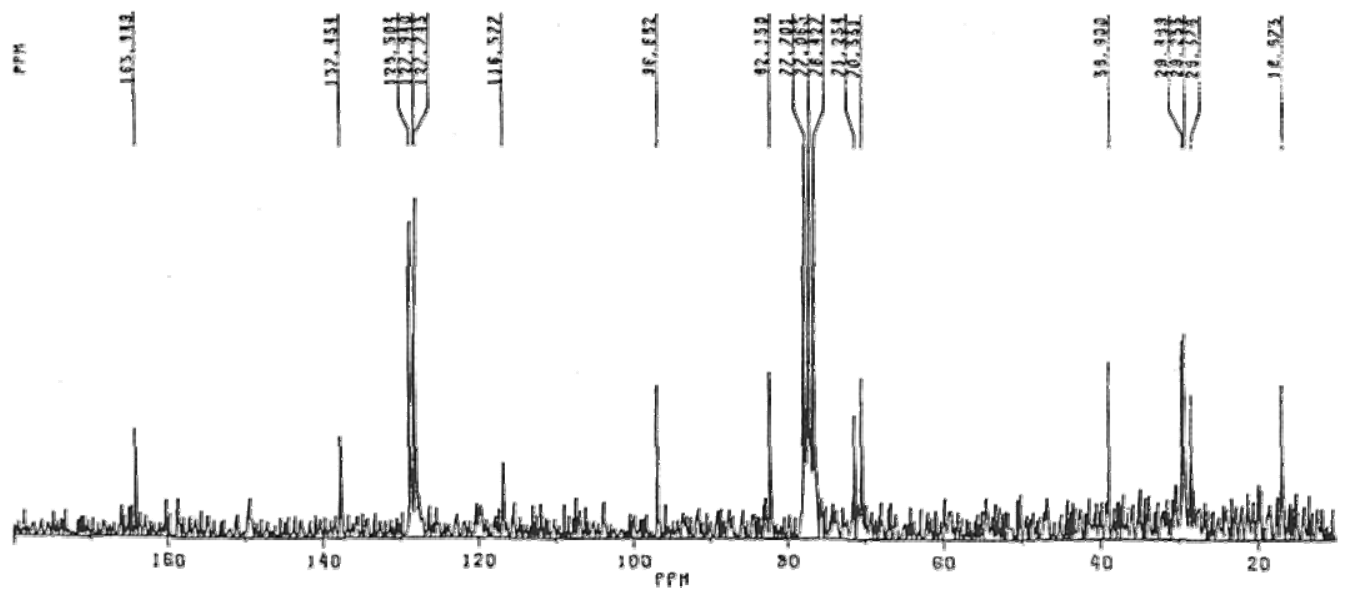

Fig. 17d

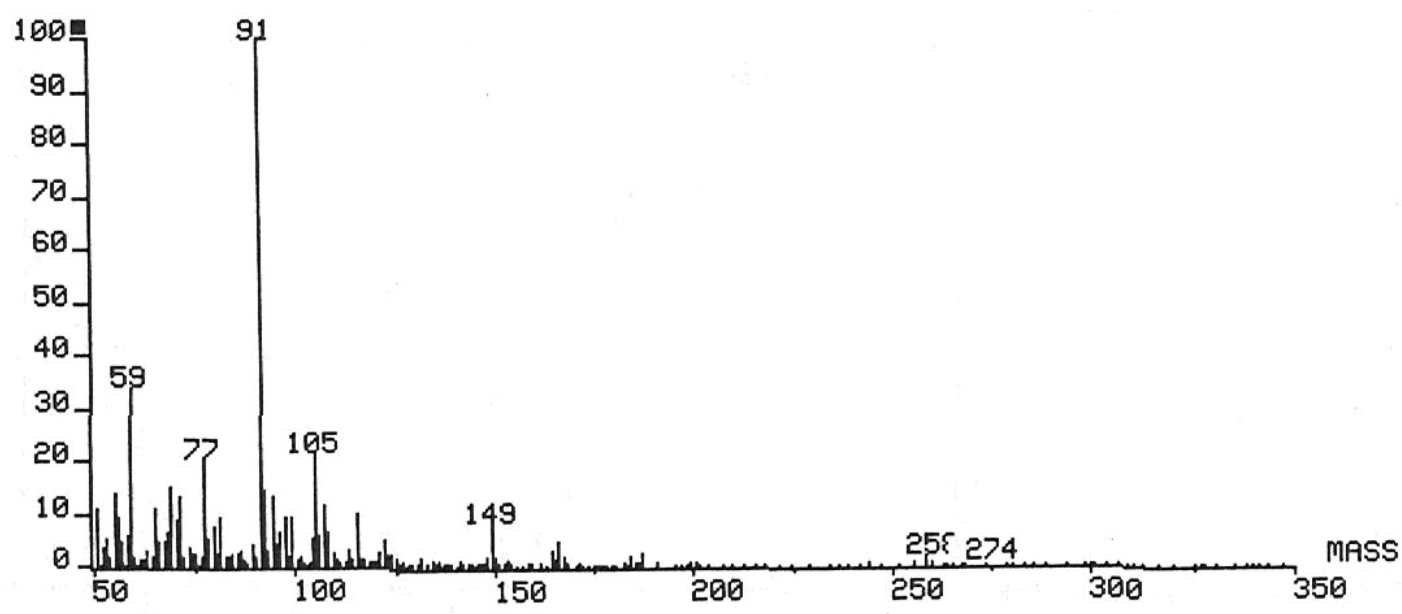


Fig. 18
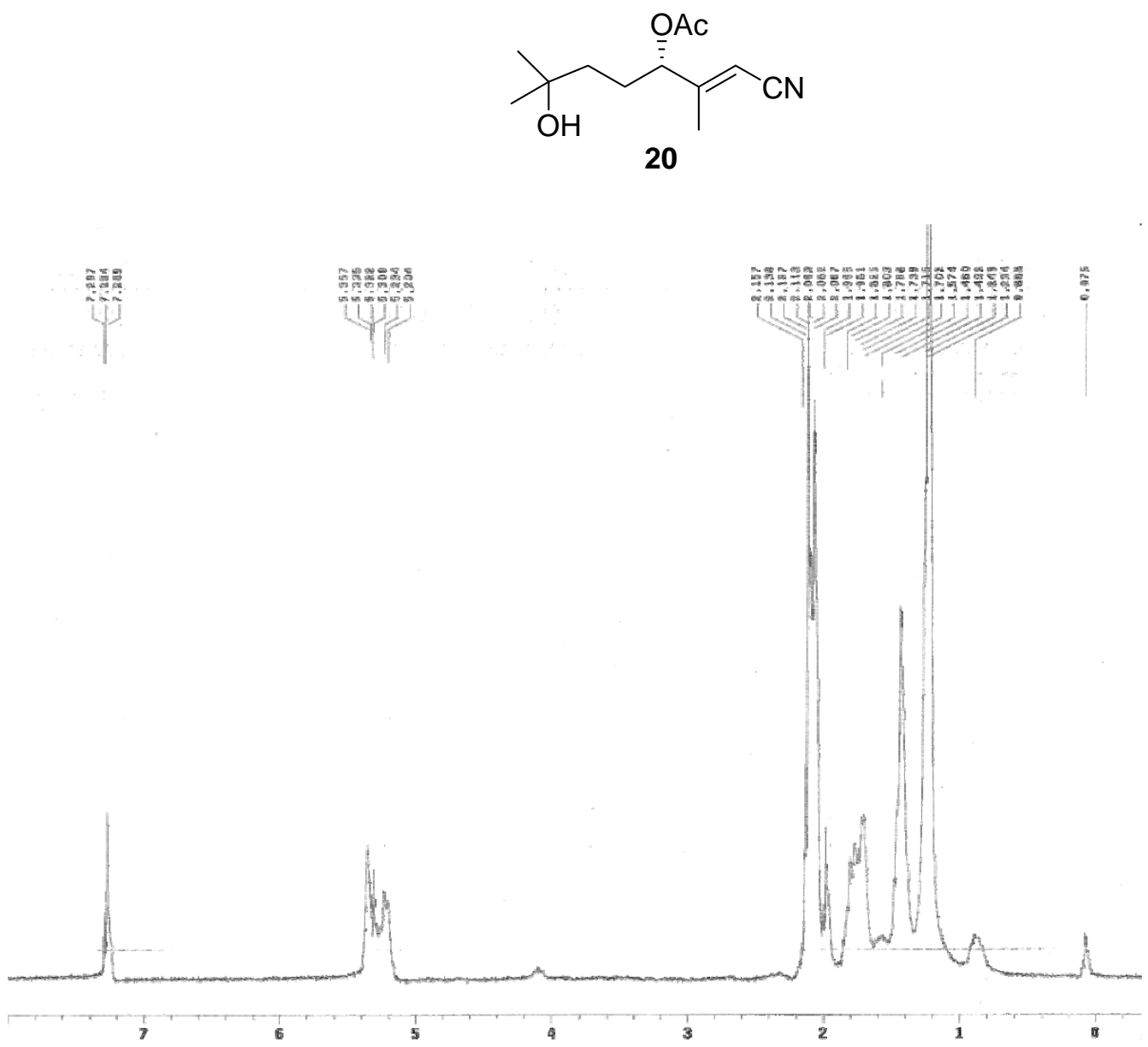
Fig. 19a

Tx

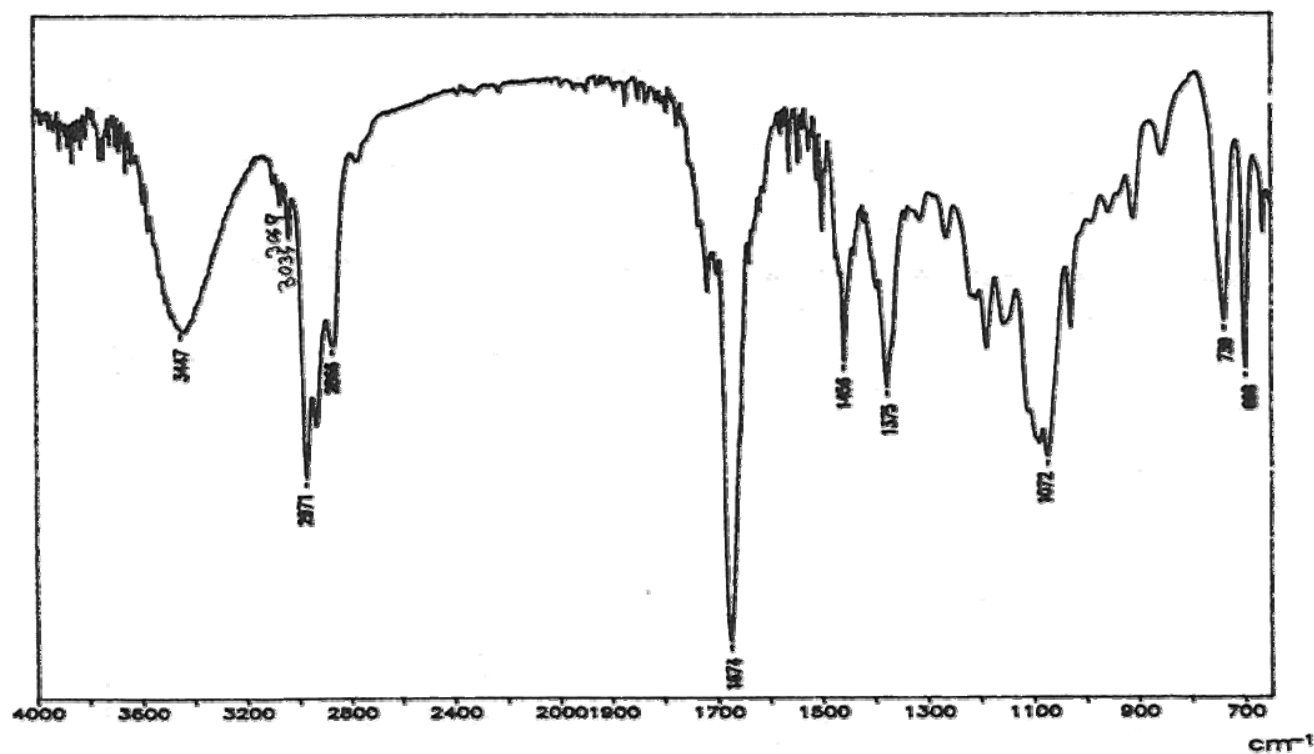

Fig. 19b

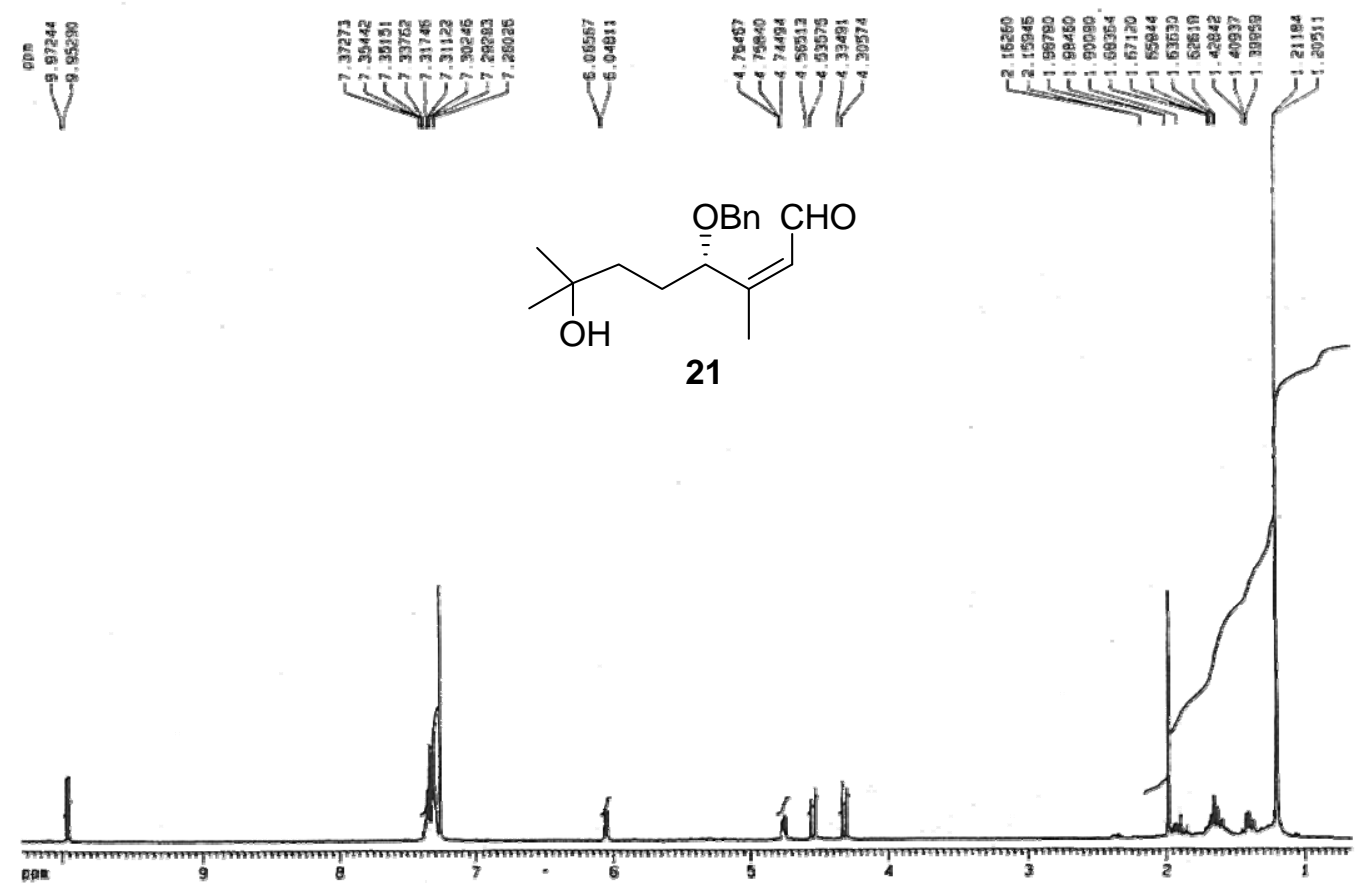


Fig. 19c

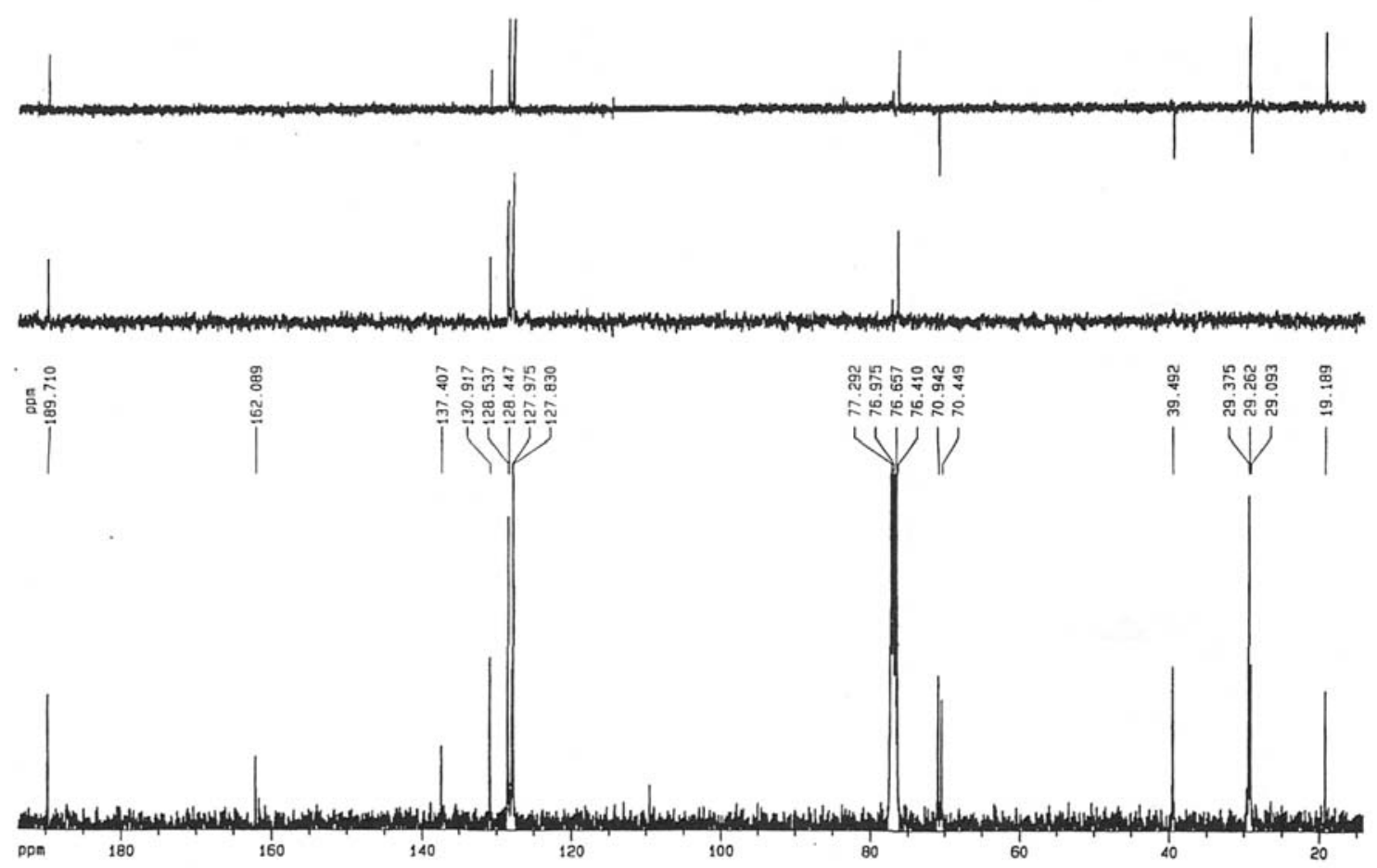


Fig. 20a

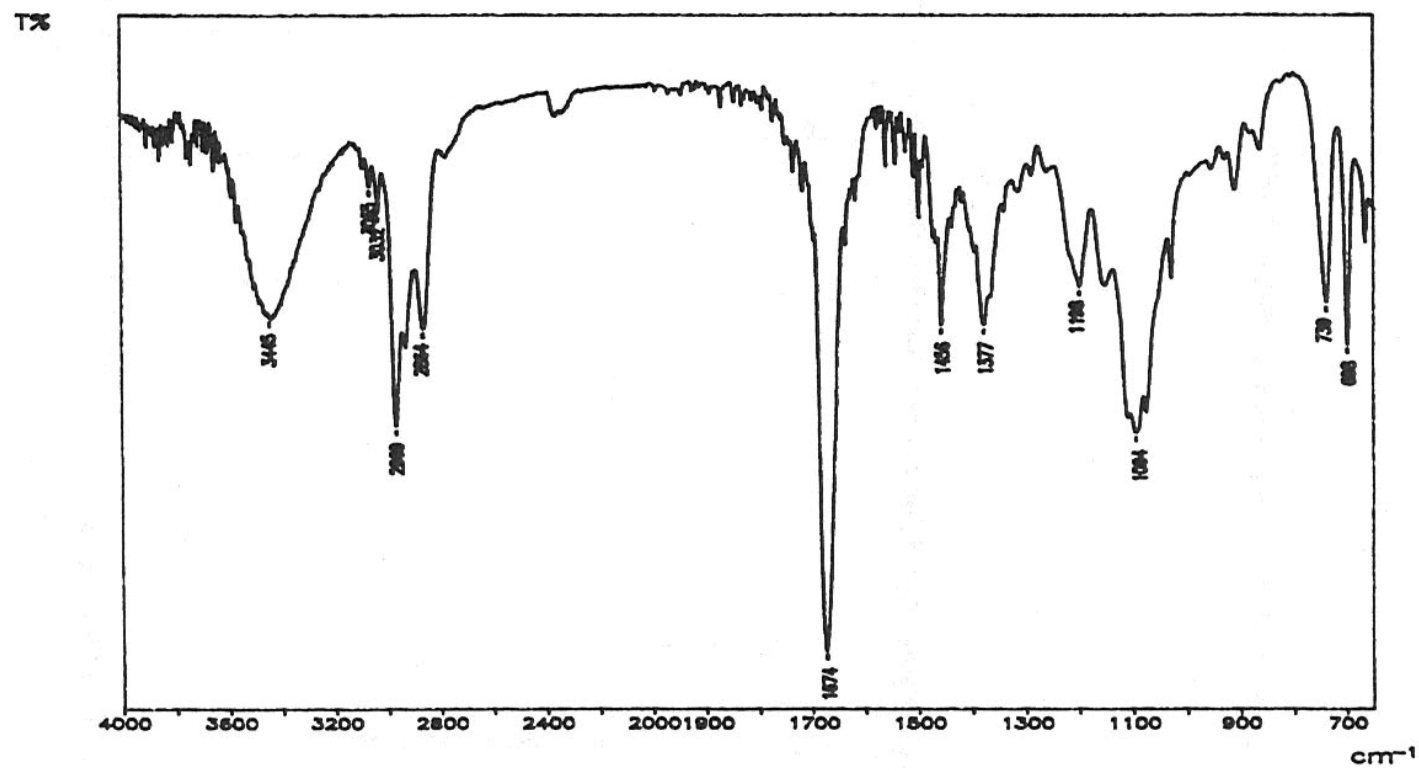

Fig. 20b
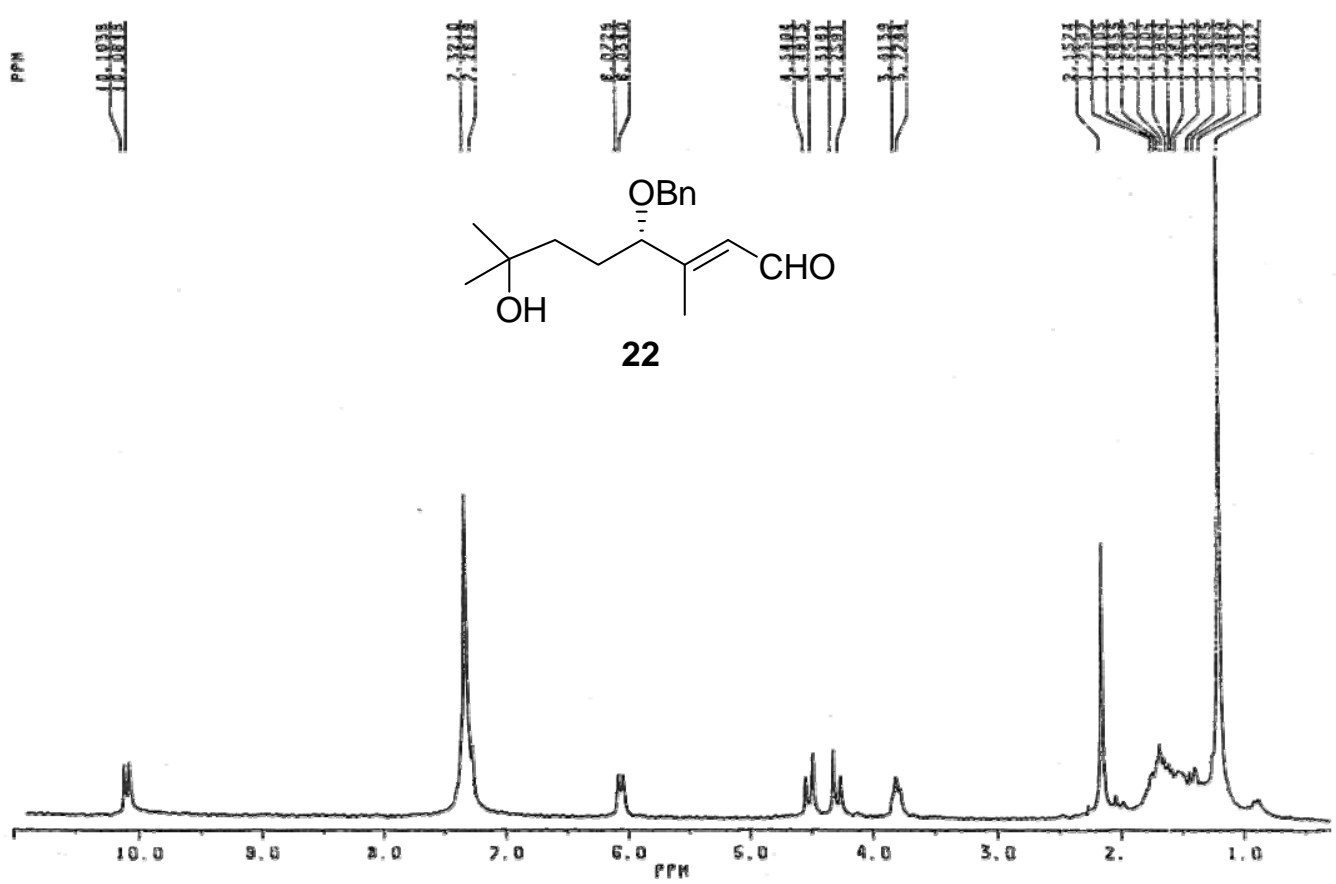
Fig. 20c

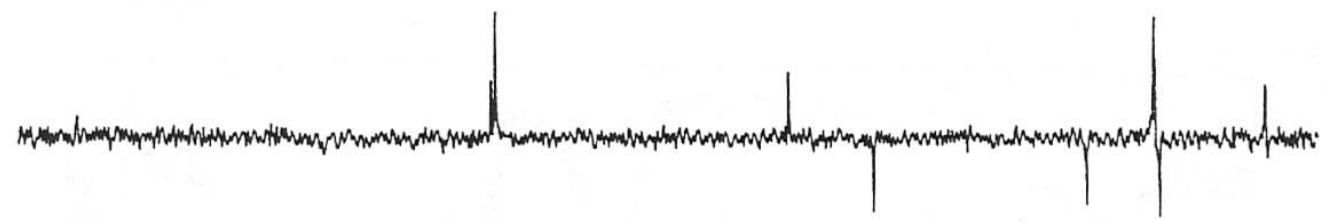

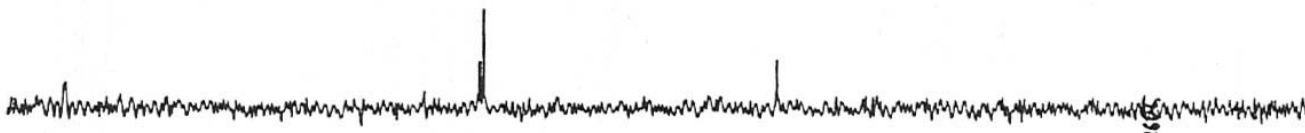

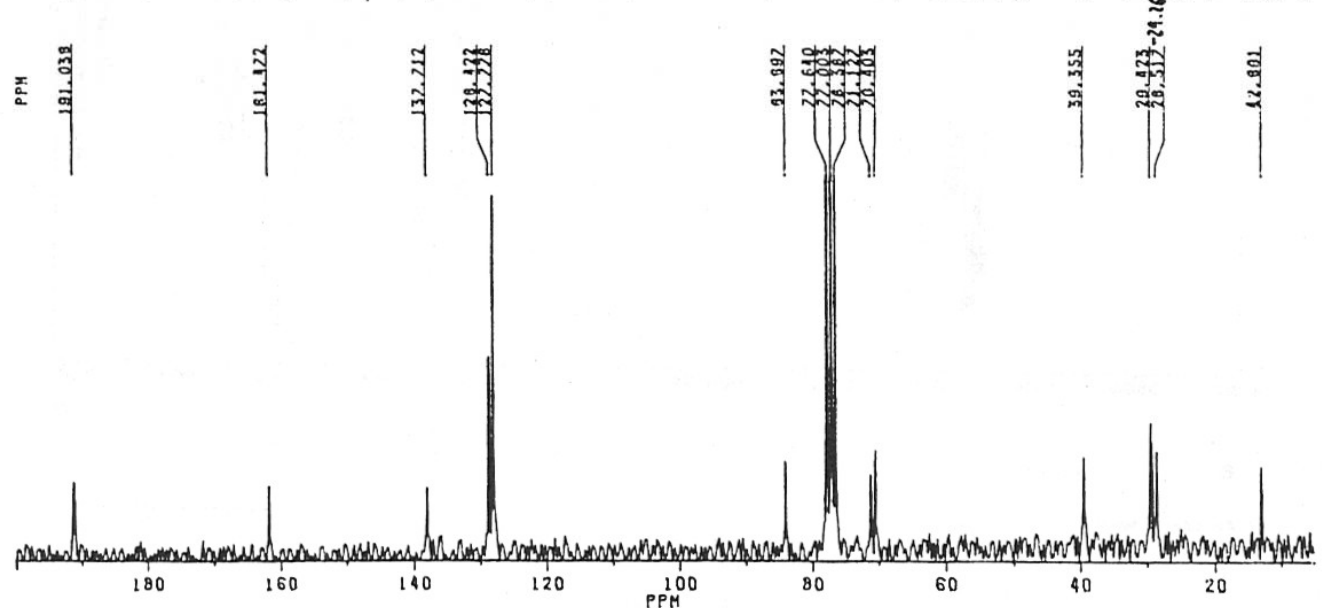

Fig. 20d

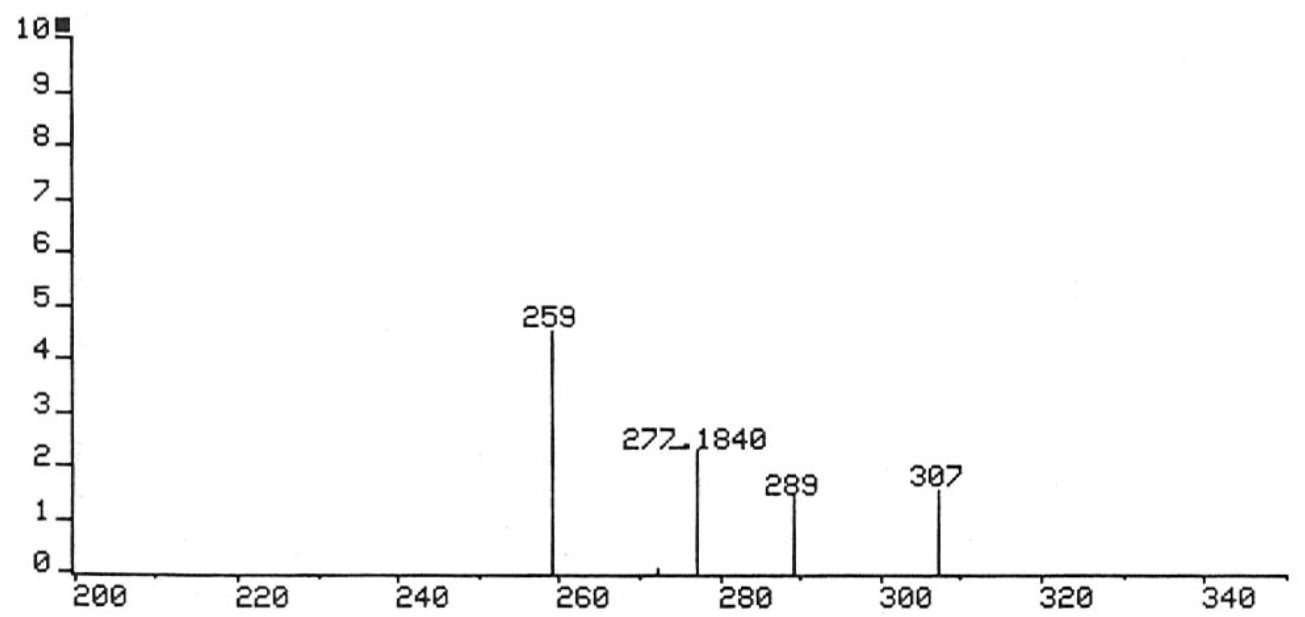
MASS 
Fig. 21a

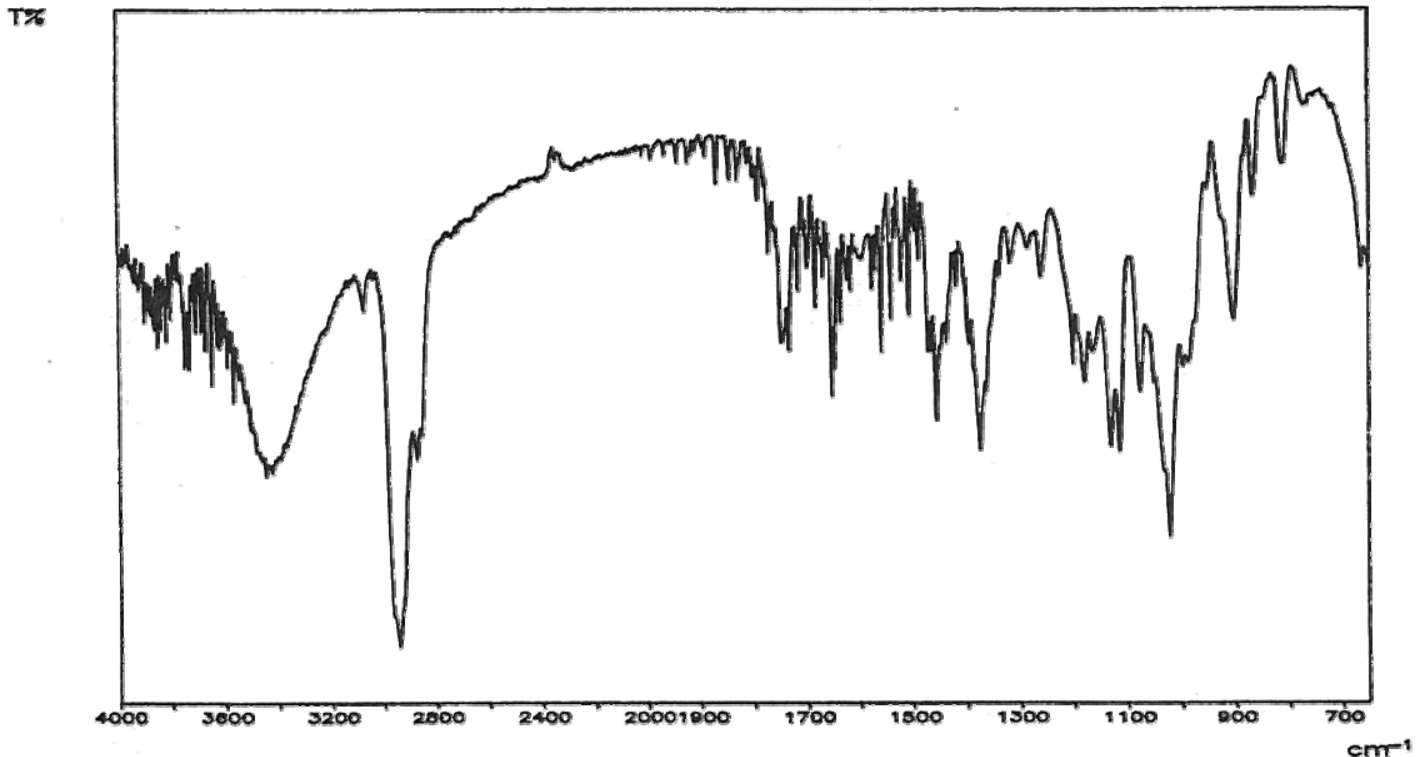

Fig. 21b

ำ

寻
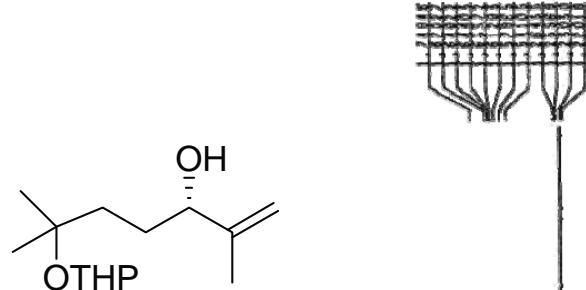

23

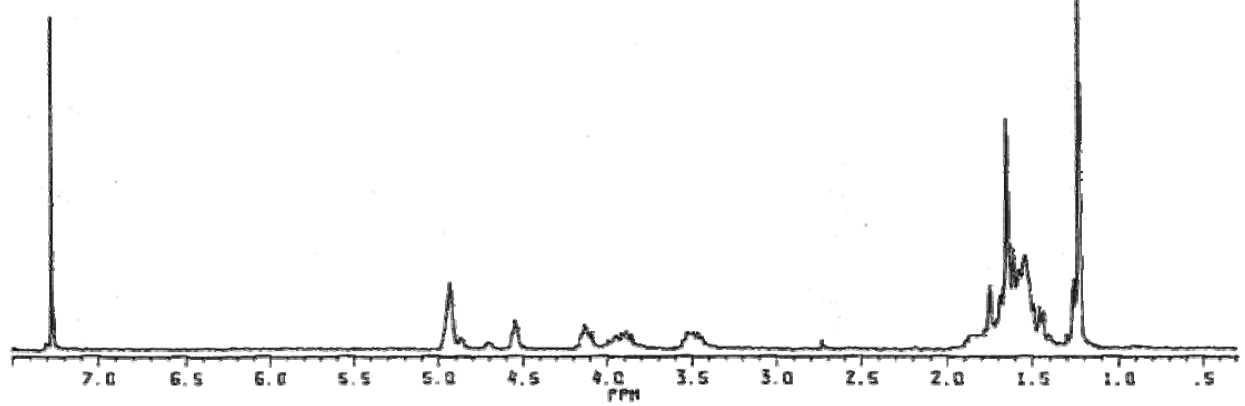


Fig. 21c

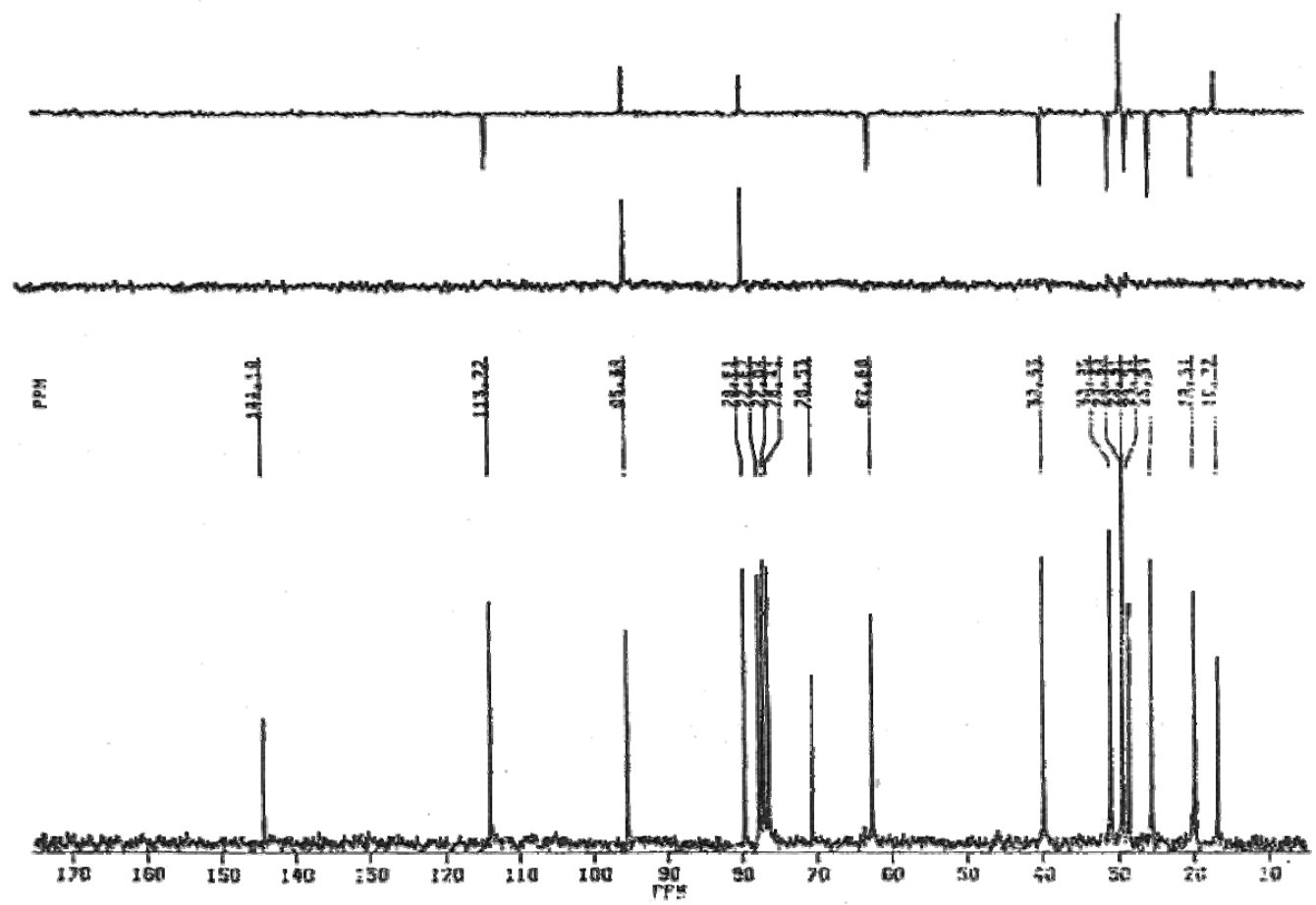

Fig. 21d

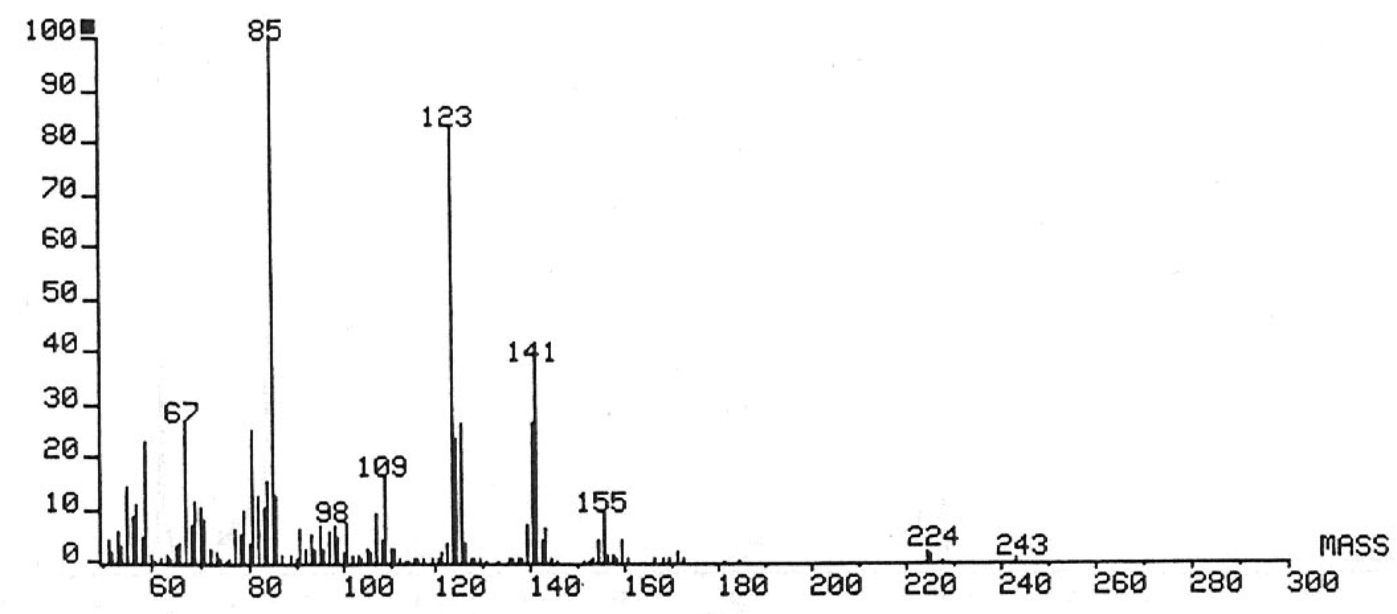


Fig. 22

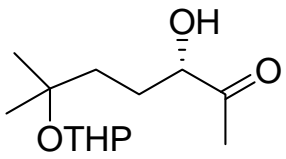

24

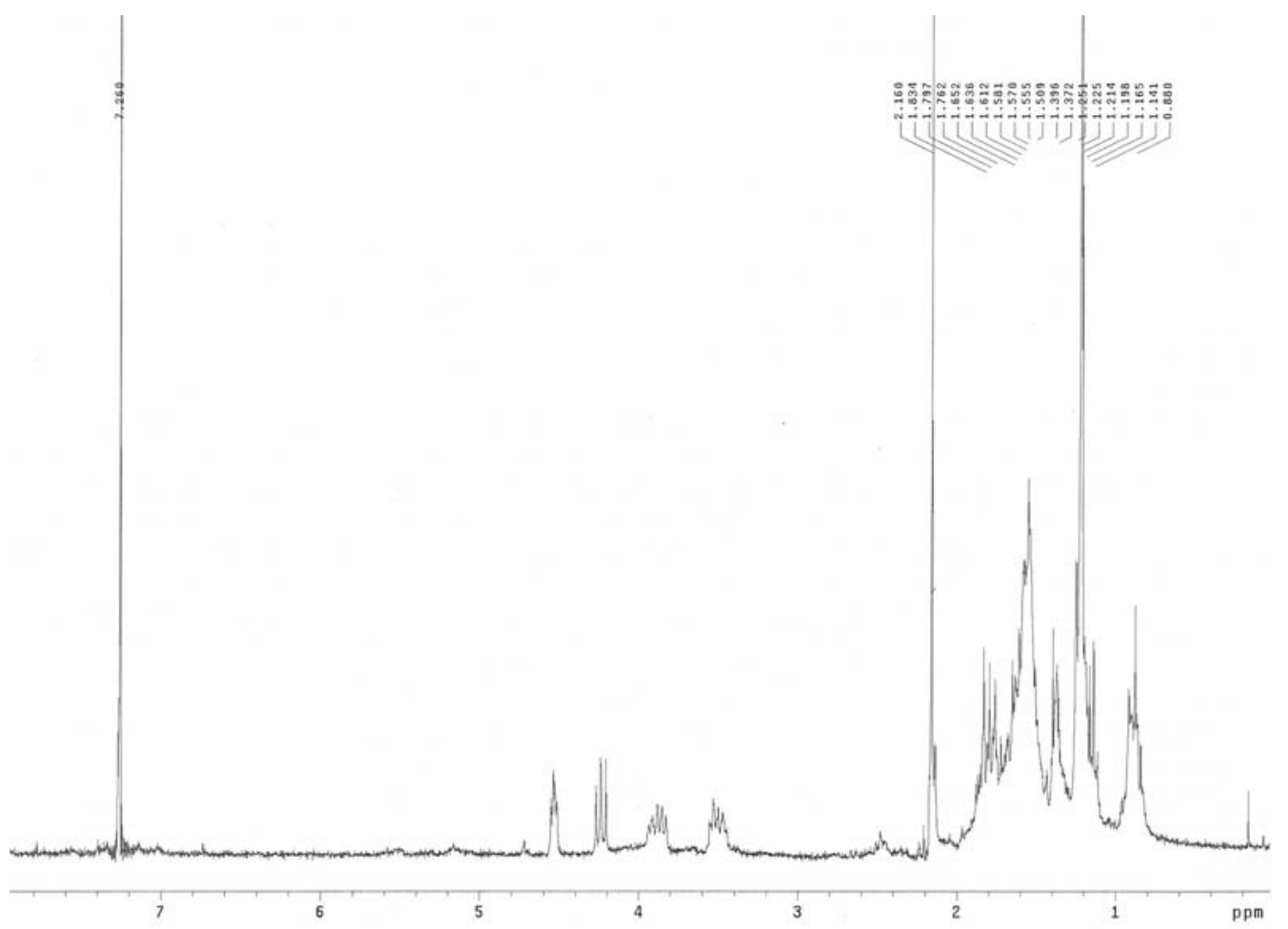


Fig. 23a

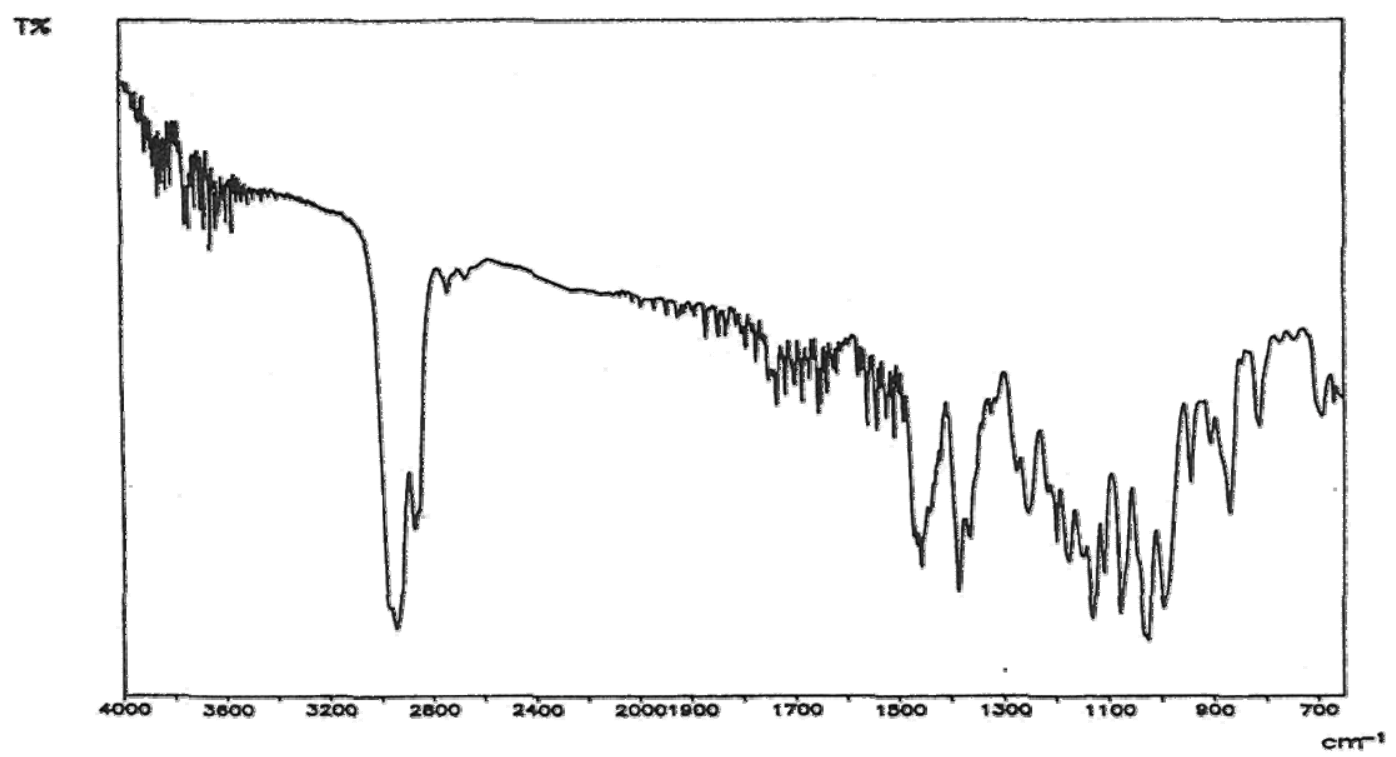

Fig. 23b

琶算

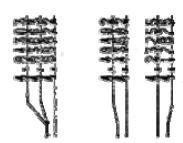<smiles>C=C(C)[C@H](Br)CCC(C)(C)O</smiles>

28

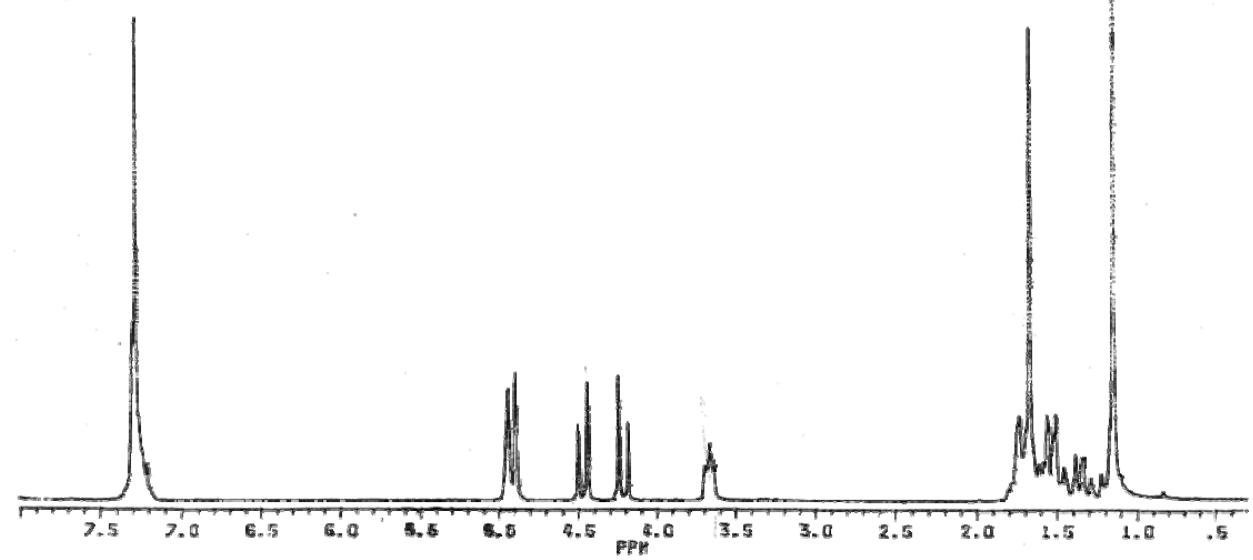


Fig. 23c
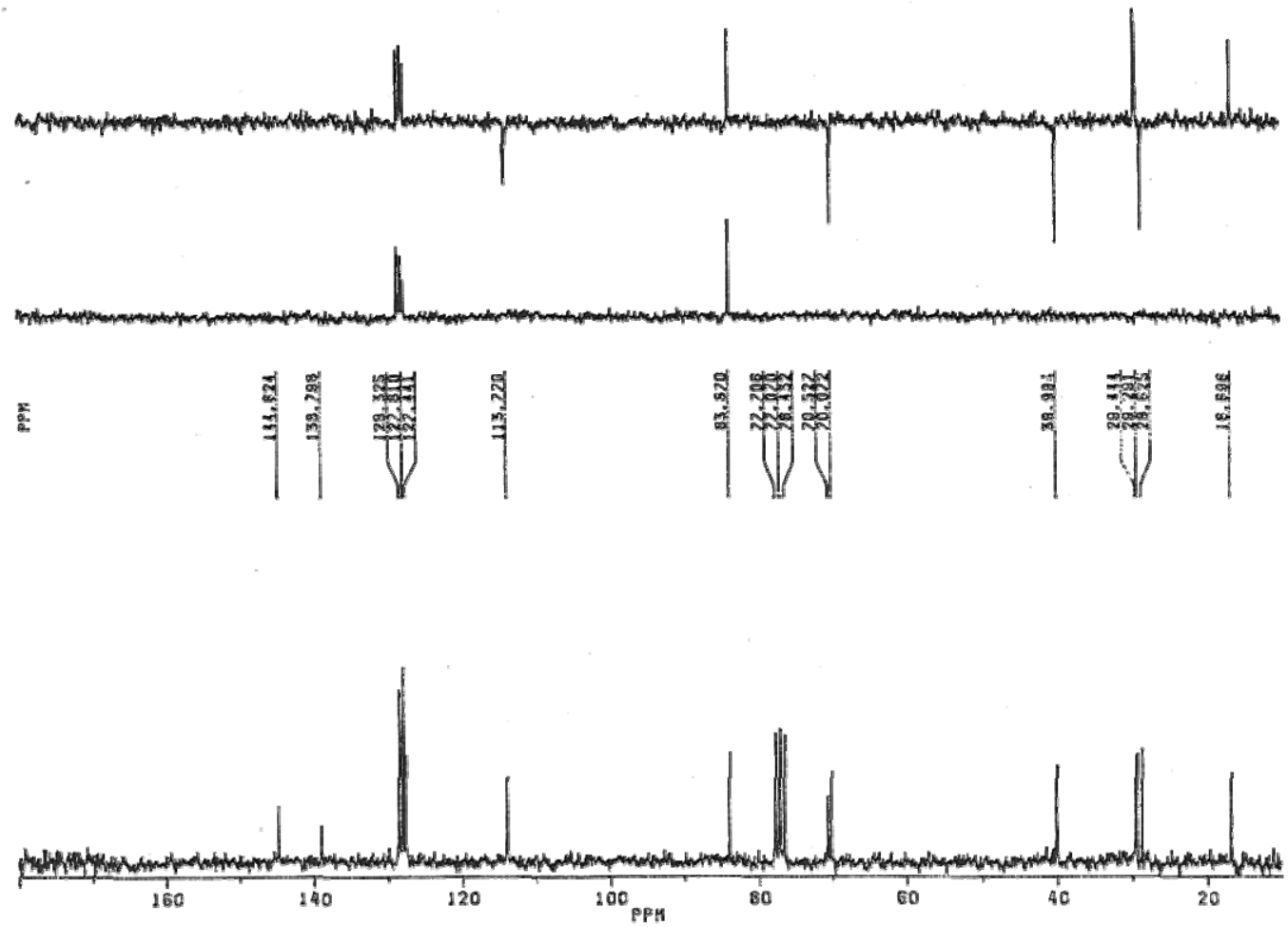
Fig. 24a

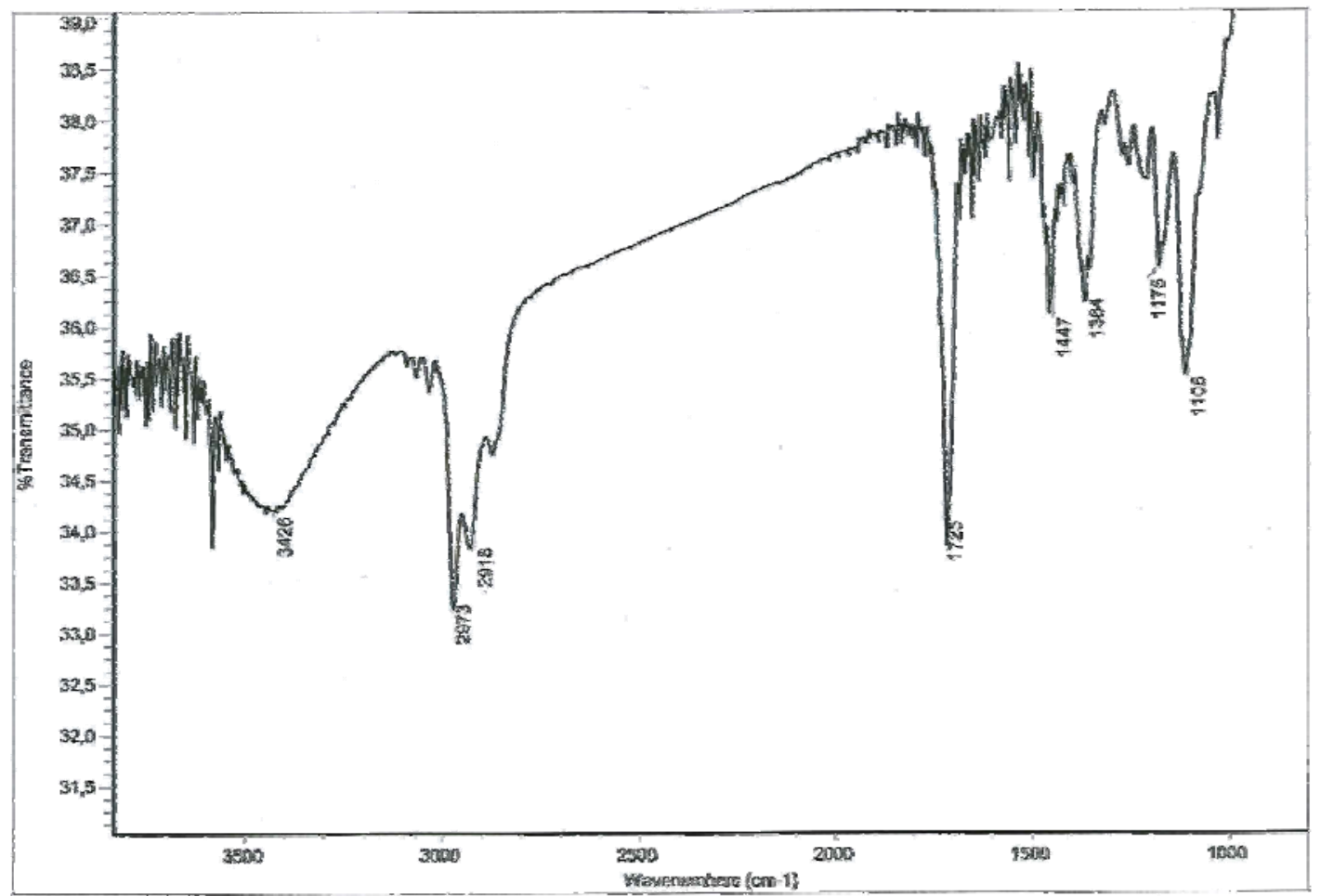

Fig. 24b
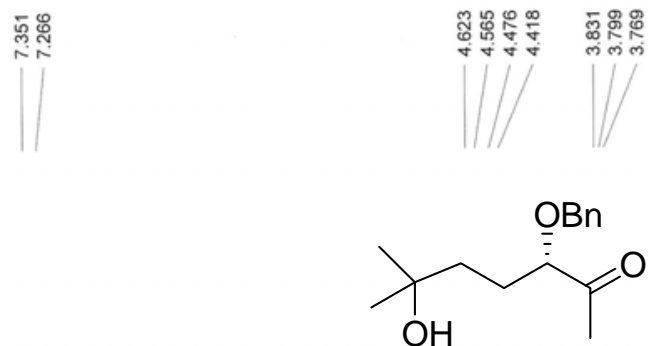

29

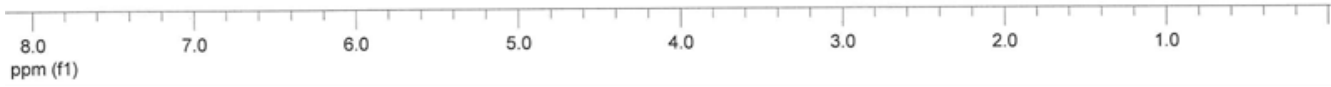


Fig. 24c
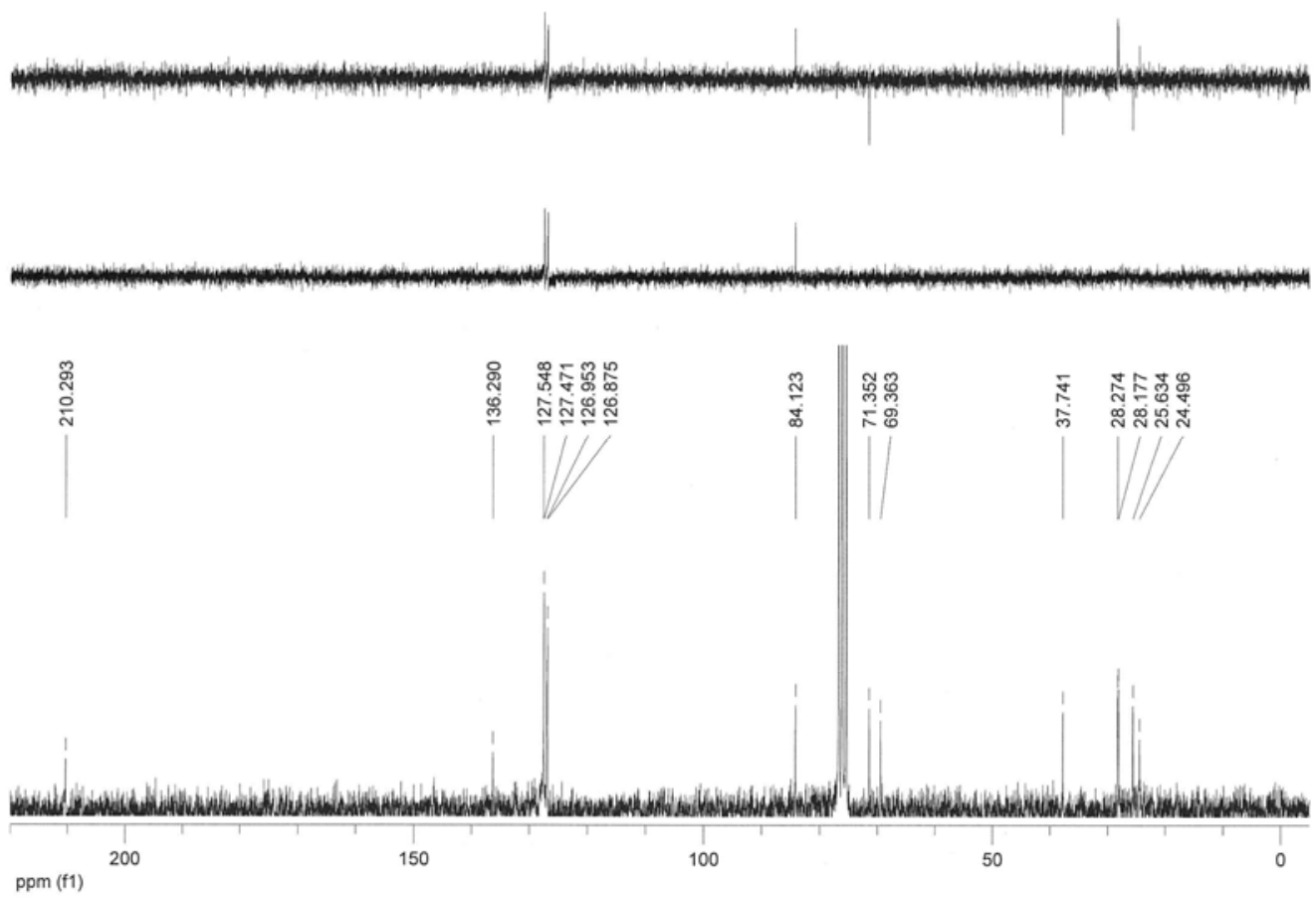
Fig. 25
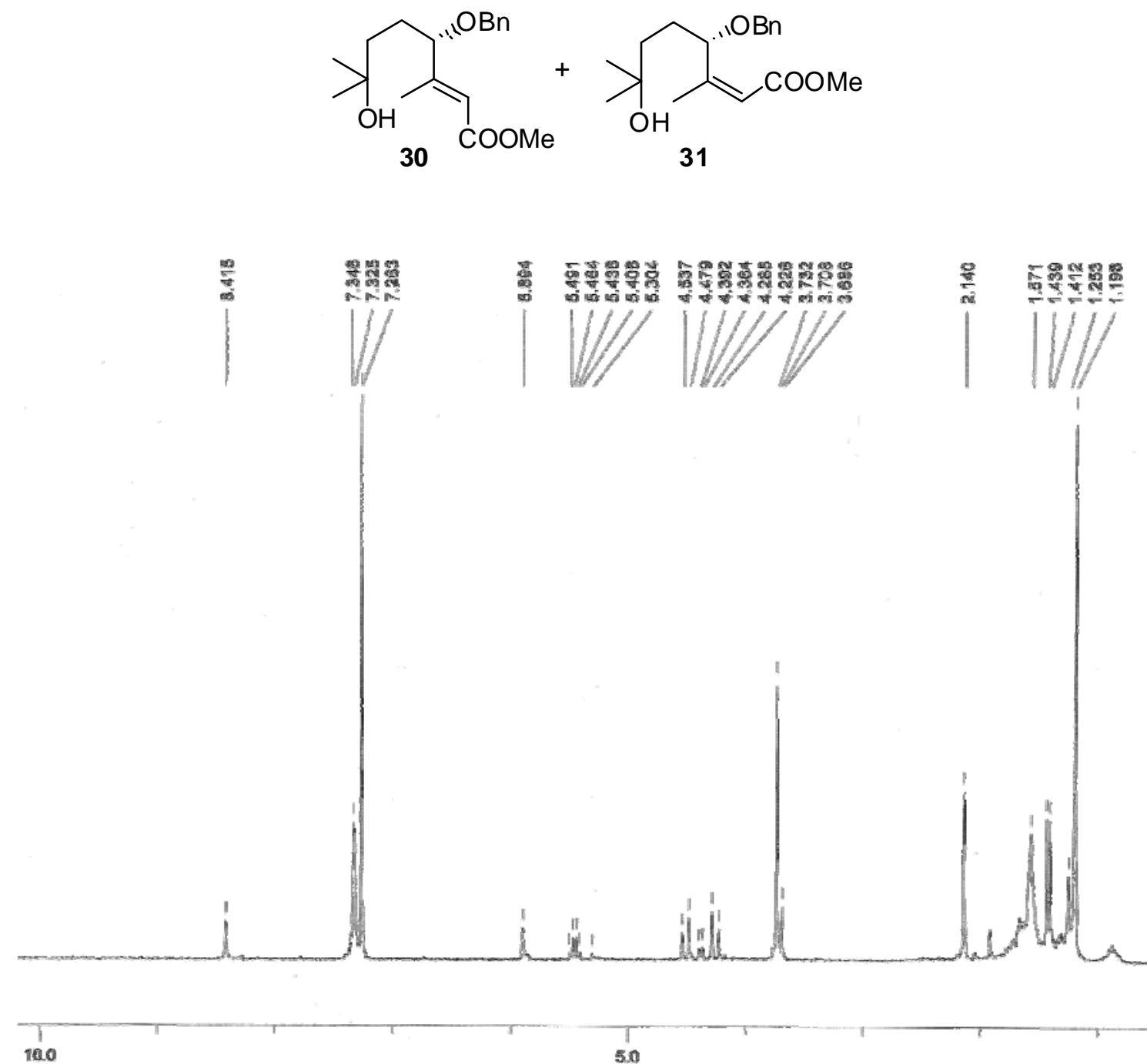
Fig. 26a

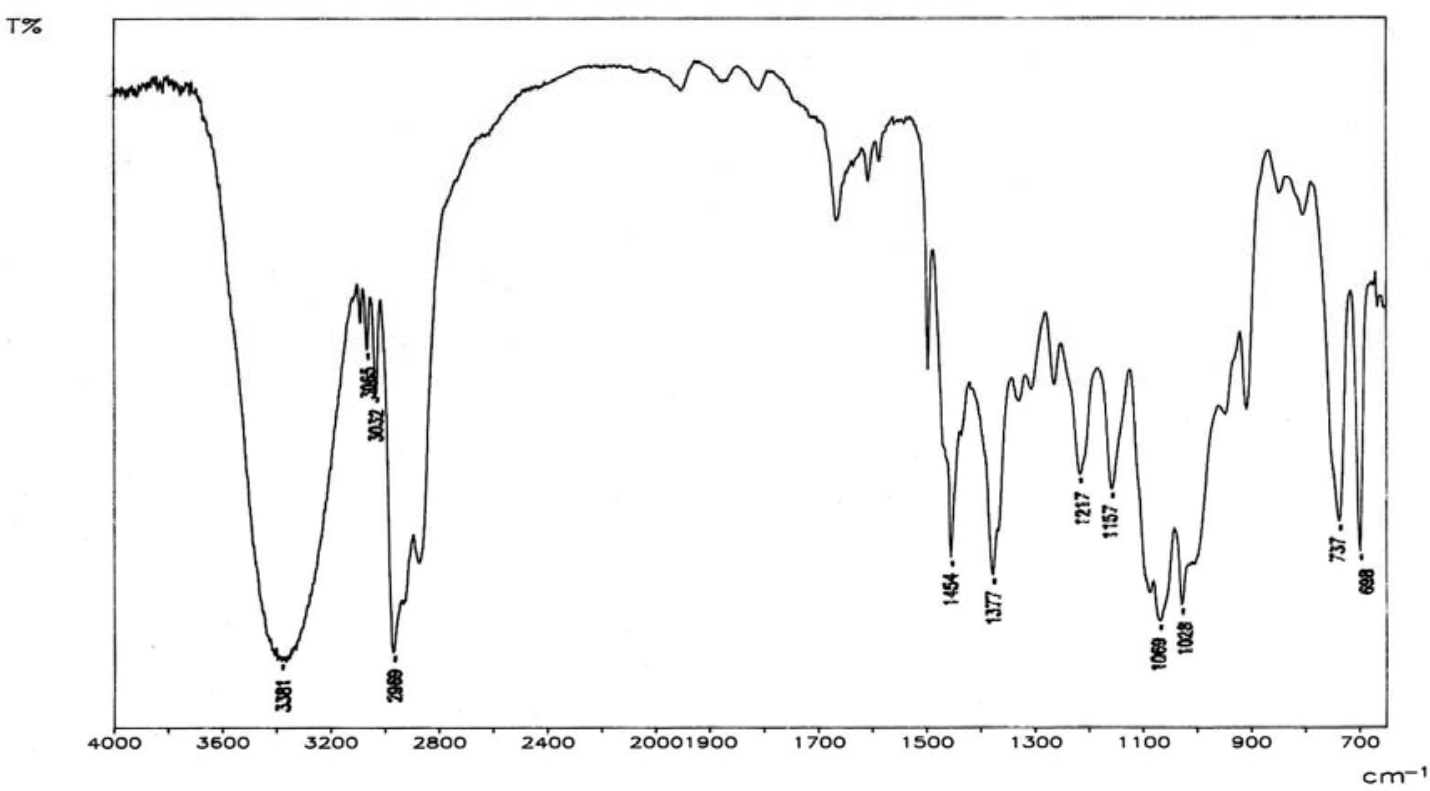

Fig. 26b
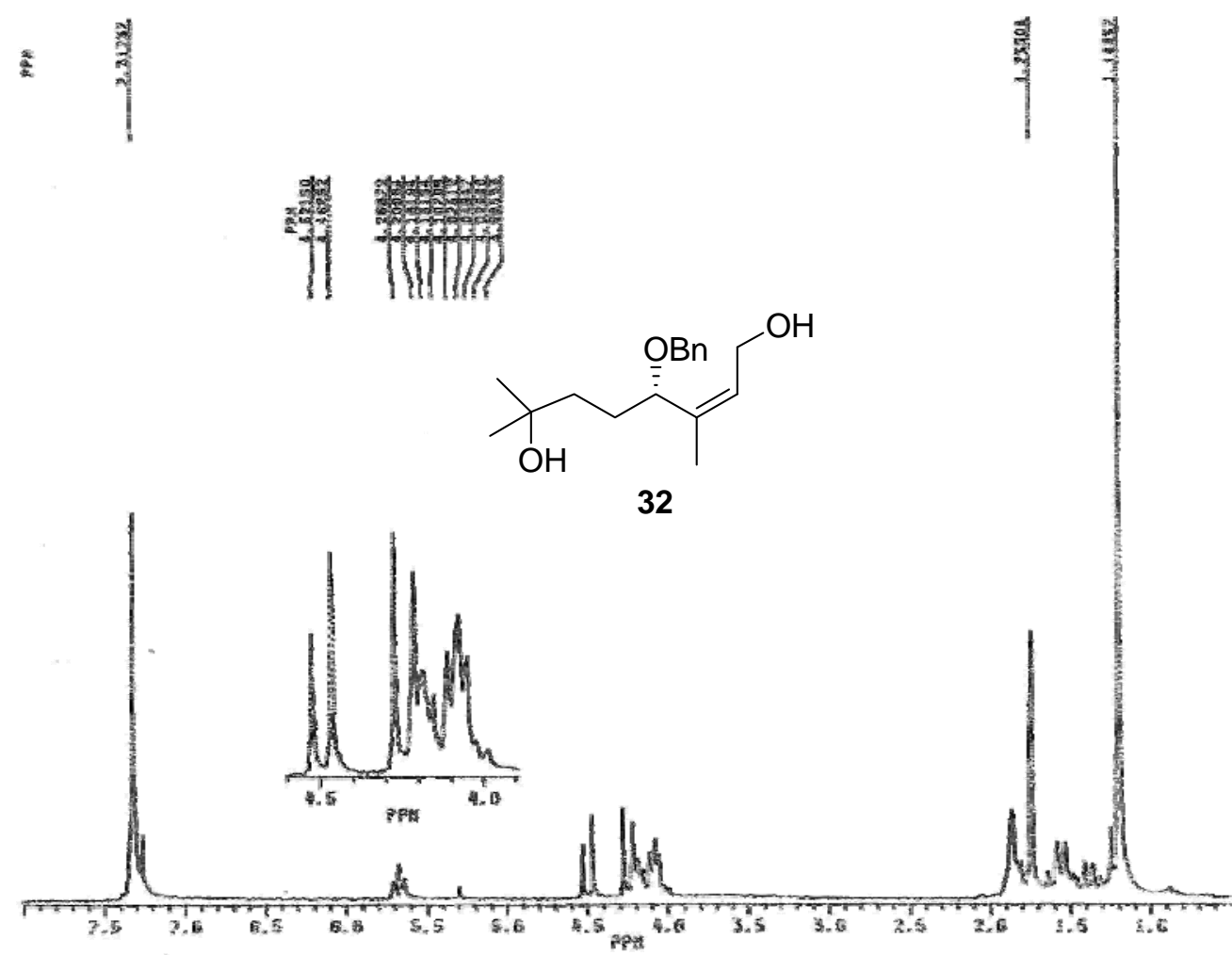
Fig. 26c
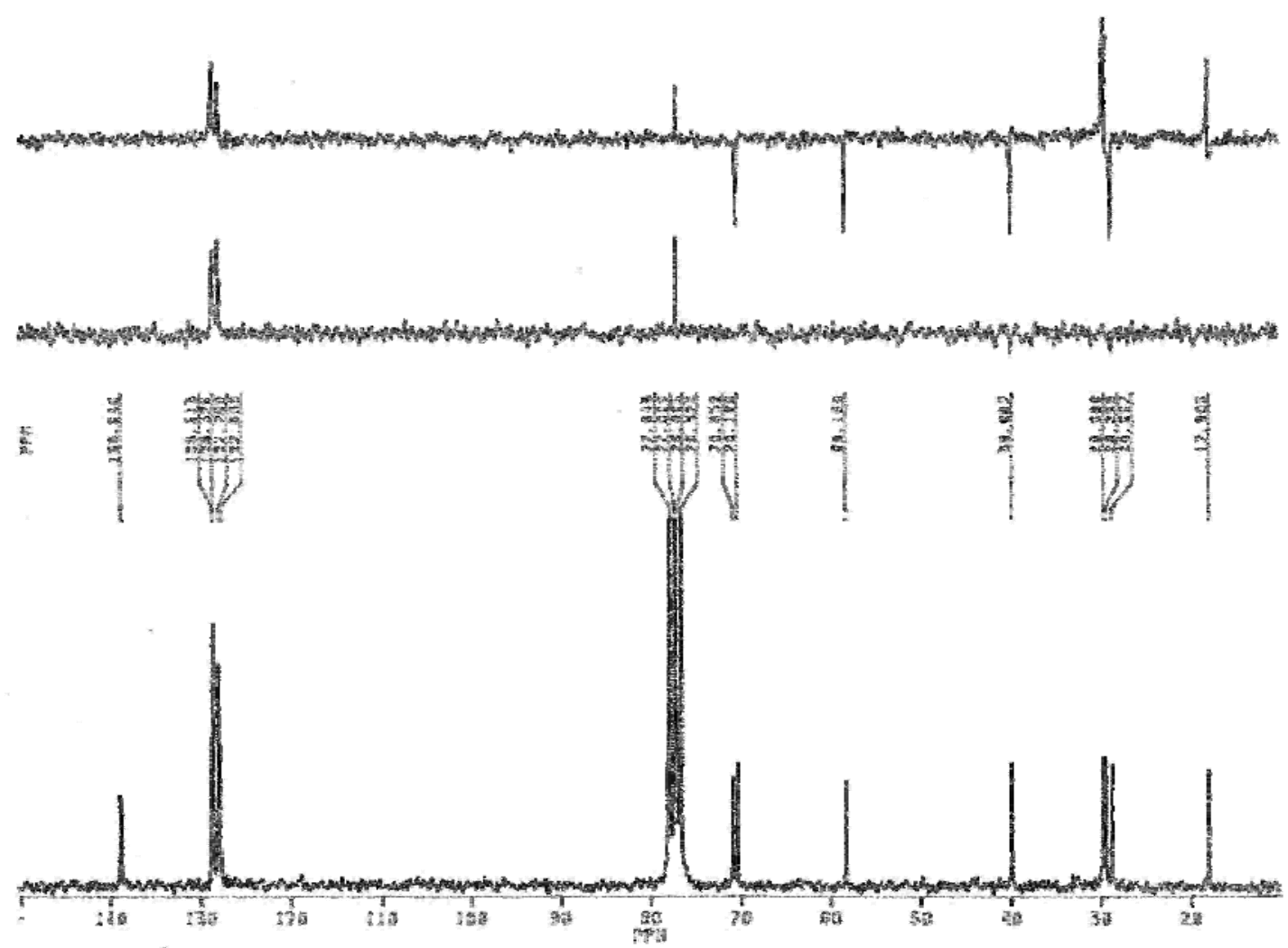

Fig. 26d

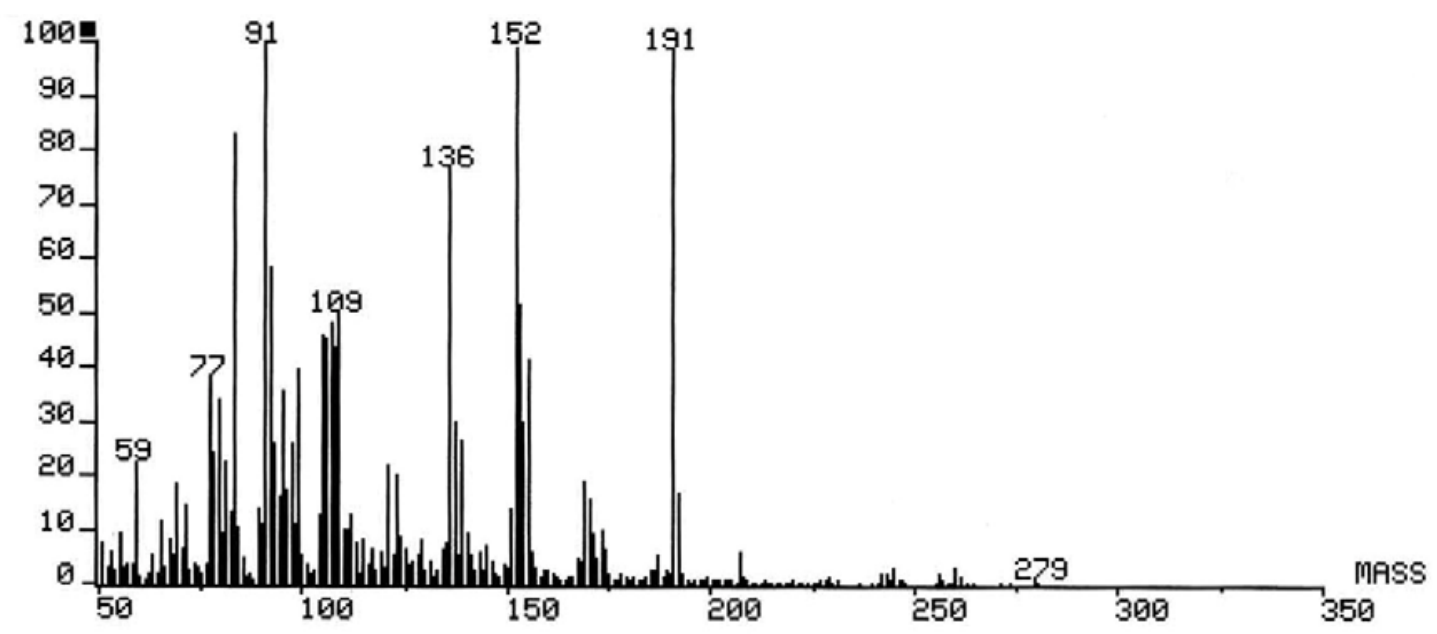


Fig. 27a

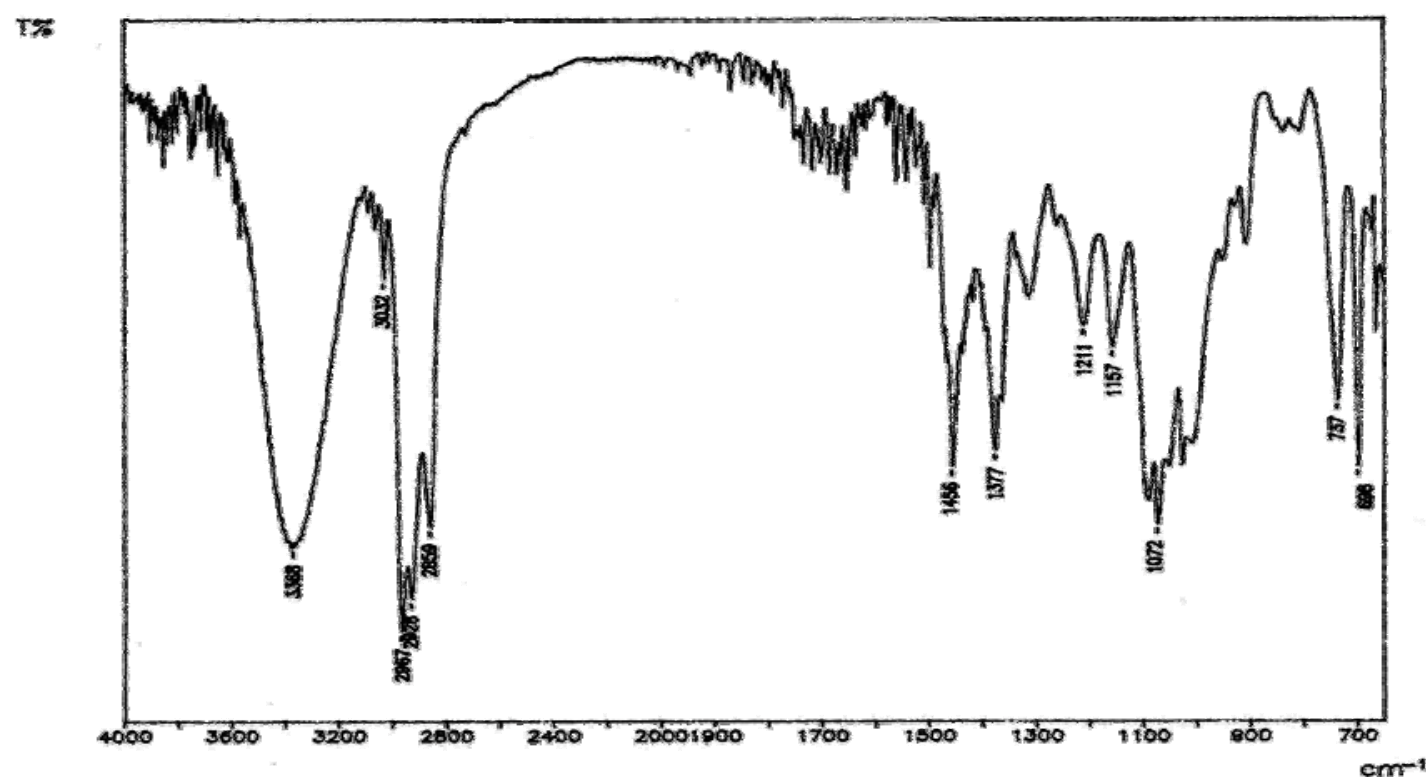

Fig. 27b

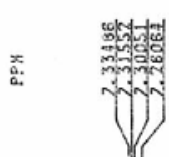
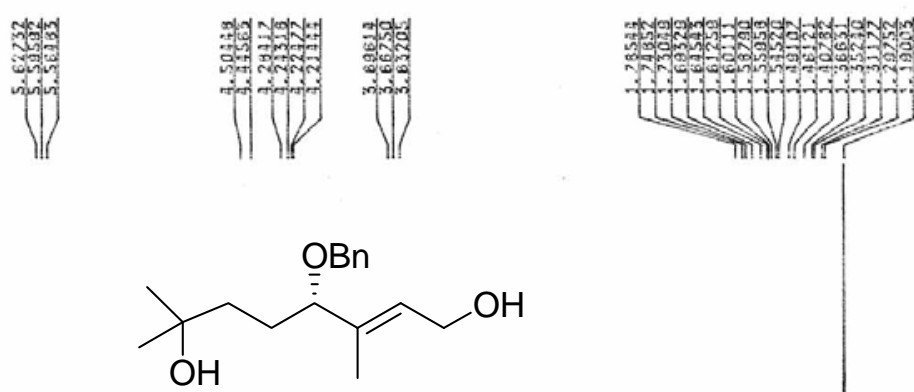

33

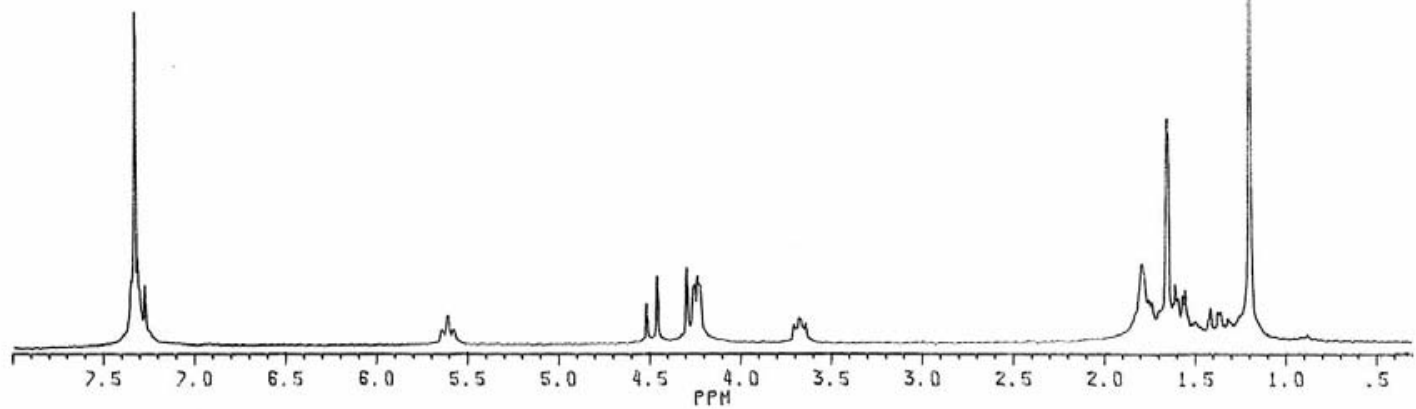


Fig. 27c

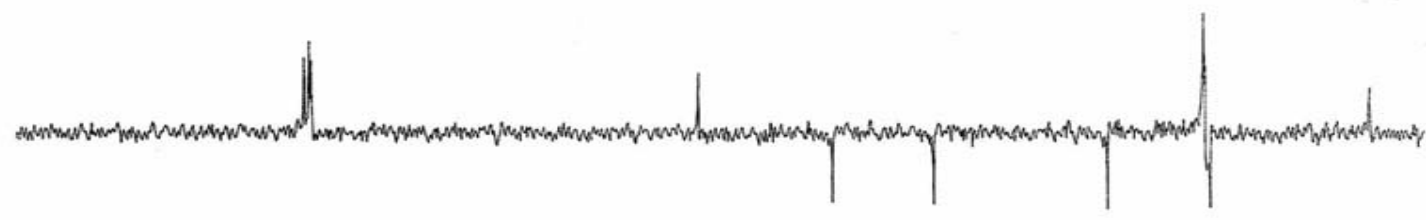

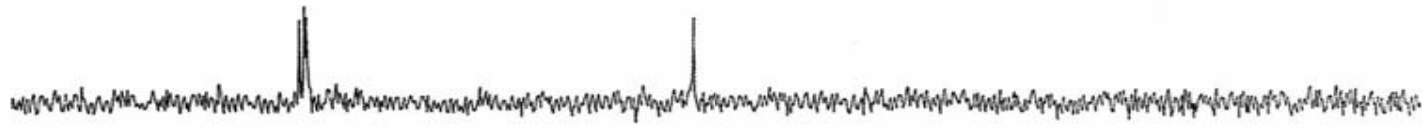
à․<smiles>C#CCCCC1CCCC1</smiles>

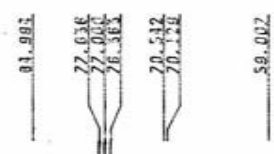

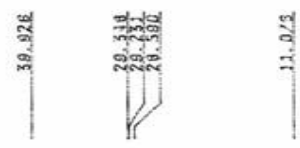

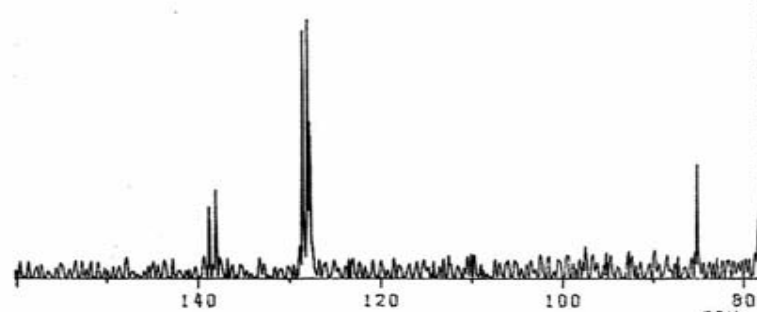

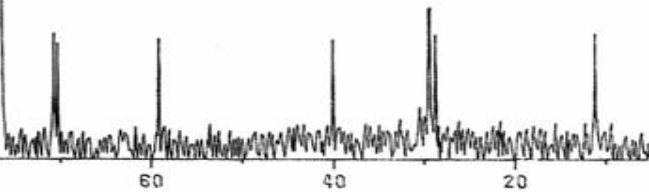


Fig. 28a

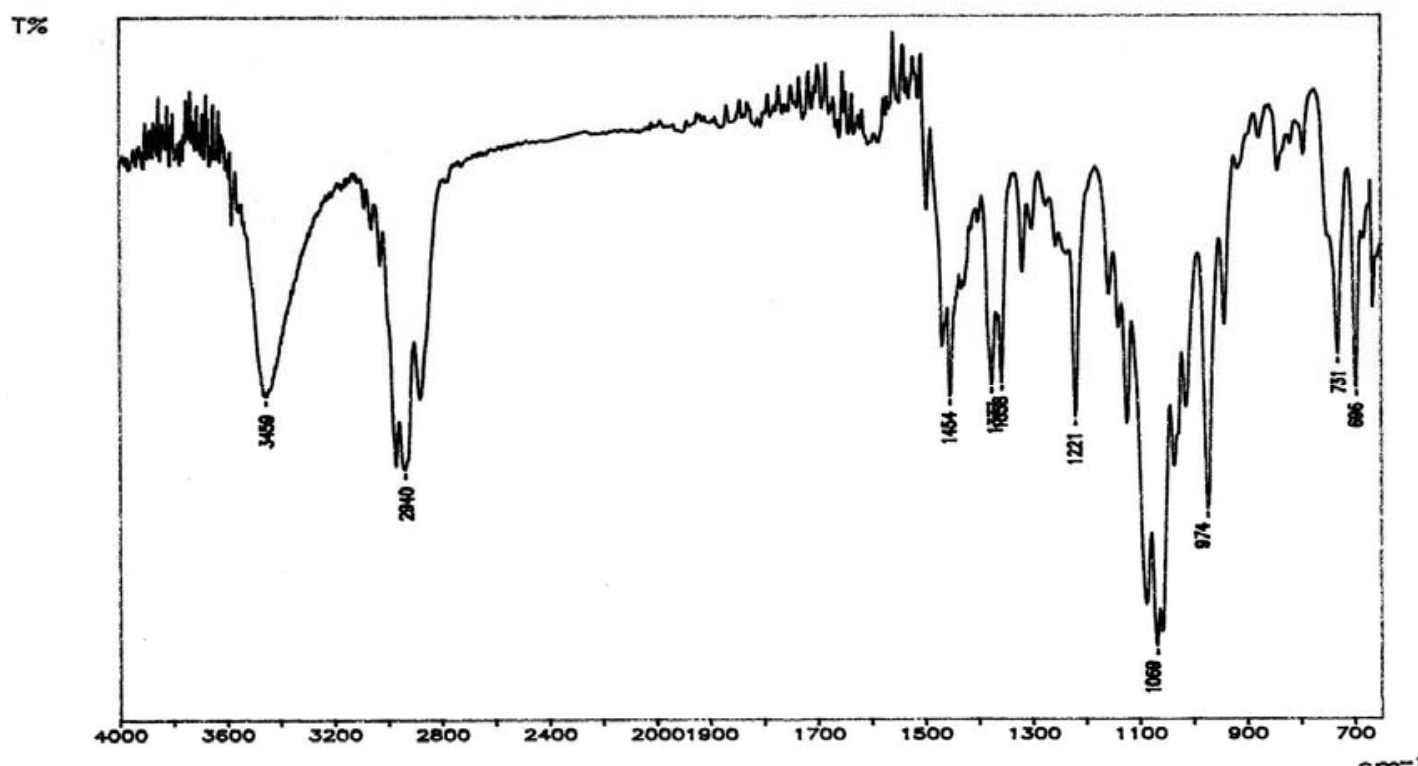

Fig. 28b

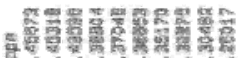

vivisis

ำำ

WUive
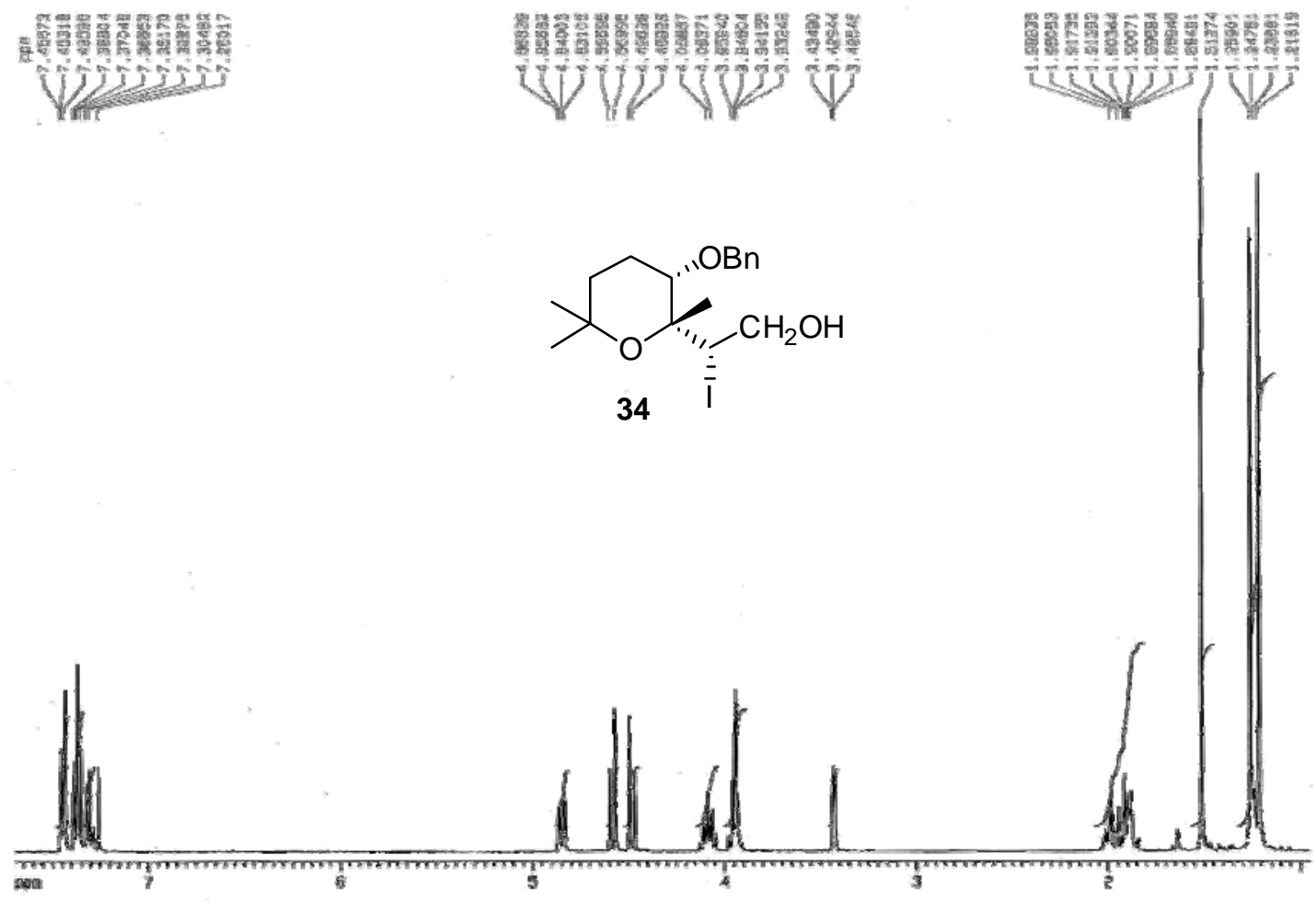
Fig. 28c

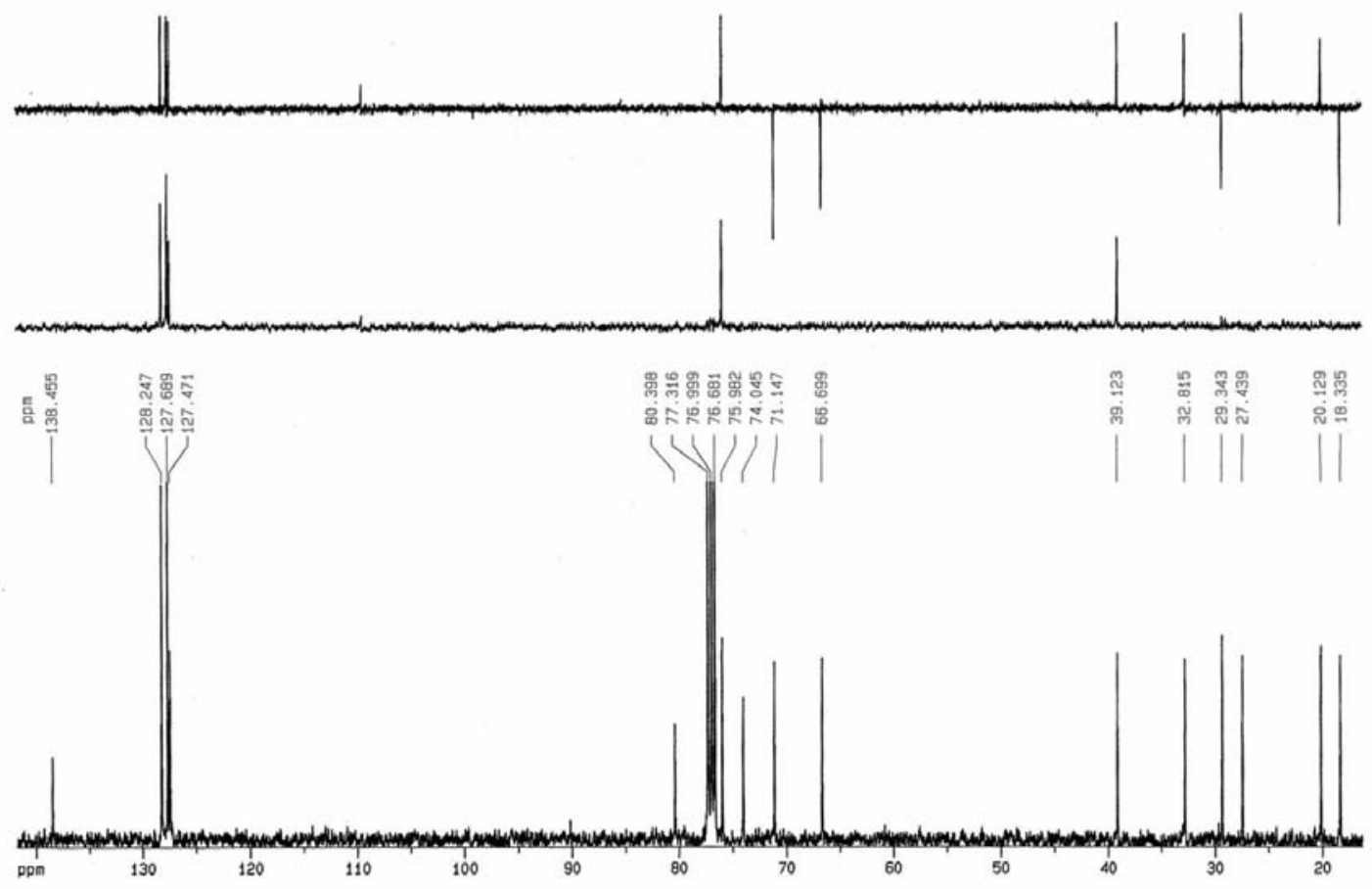

Fig. 28d

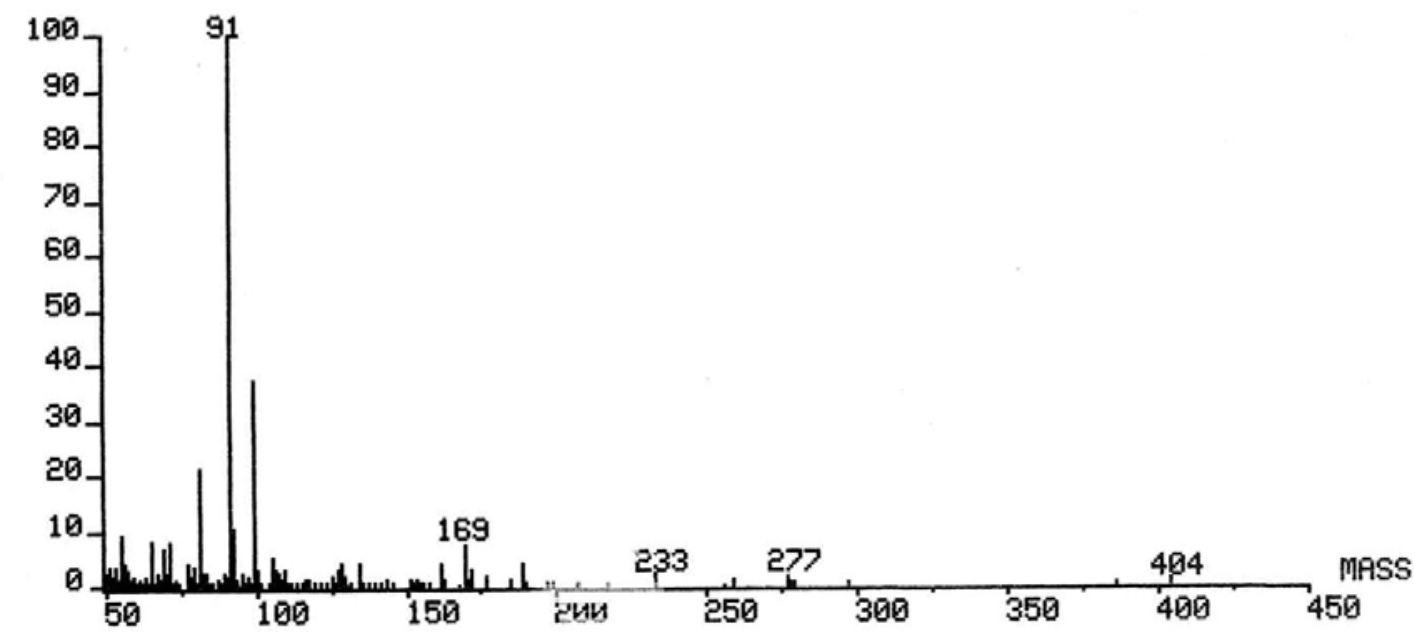


Fig. 28e

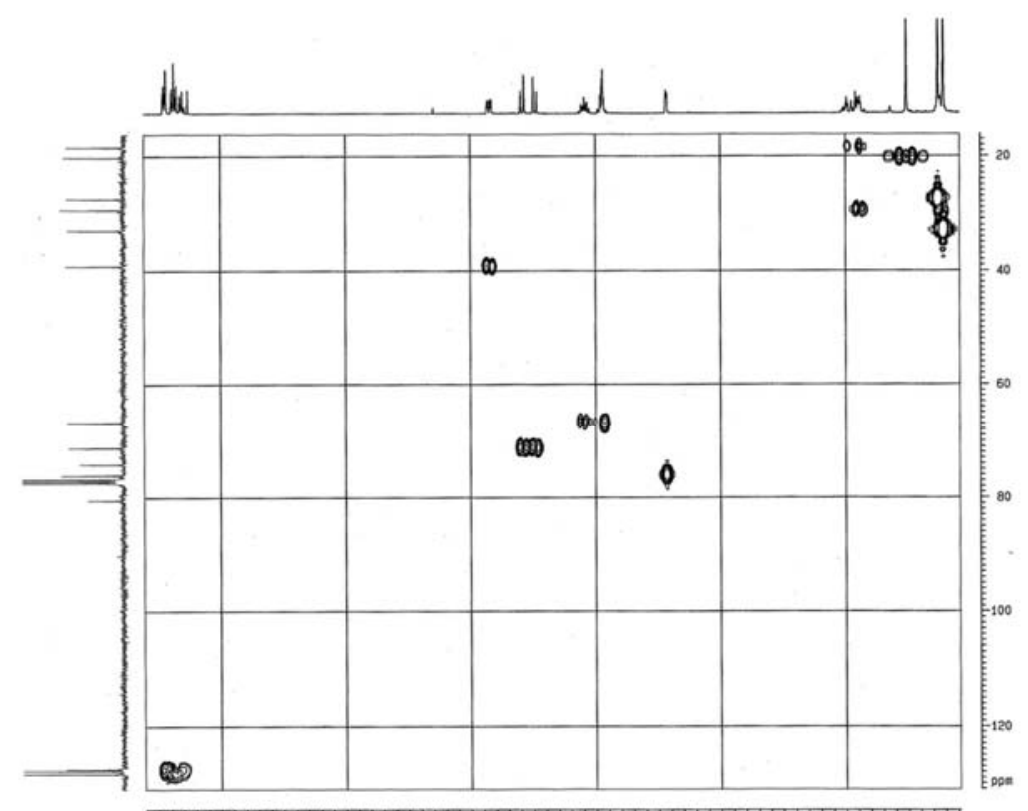

Fig. $28 f$

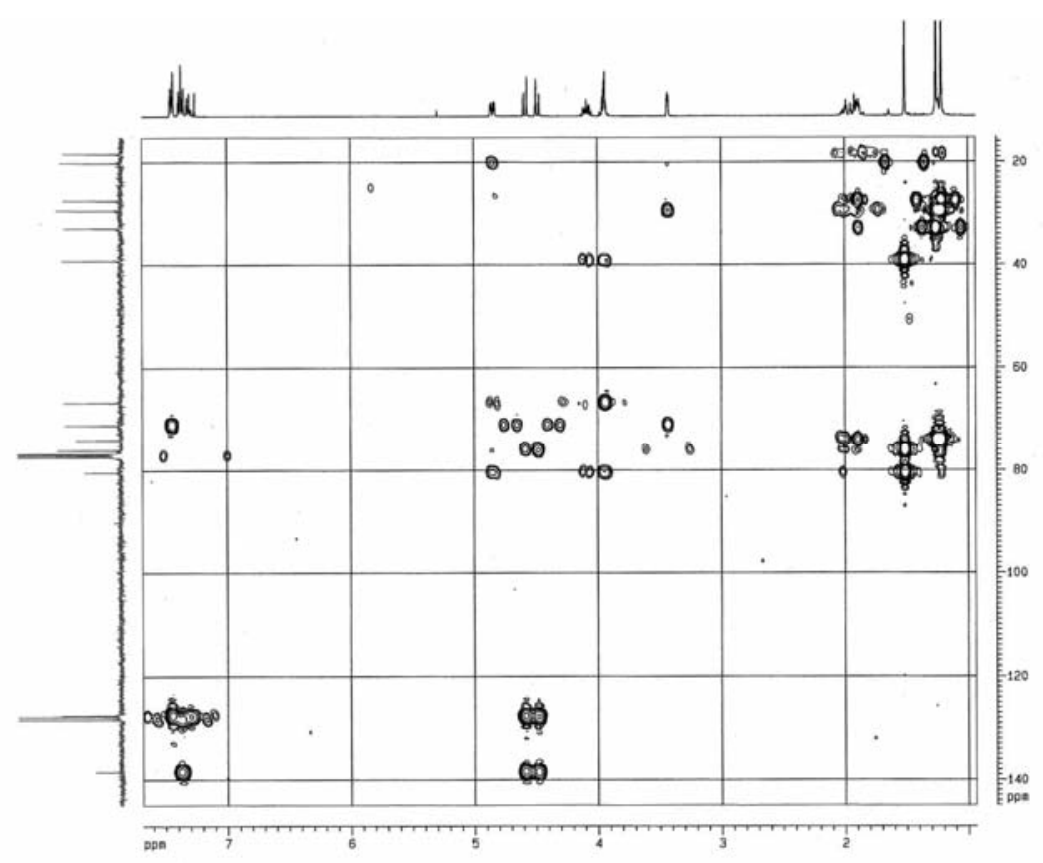


Fig. 28g
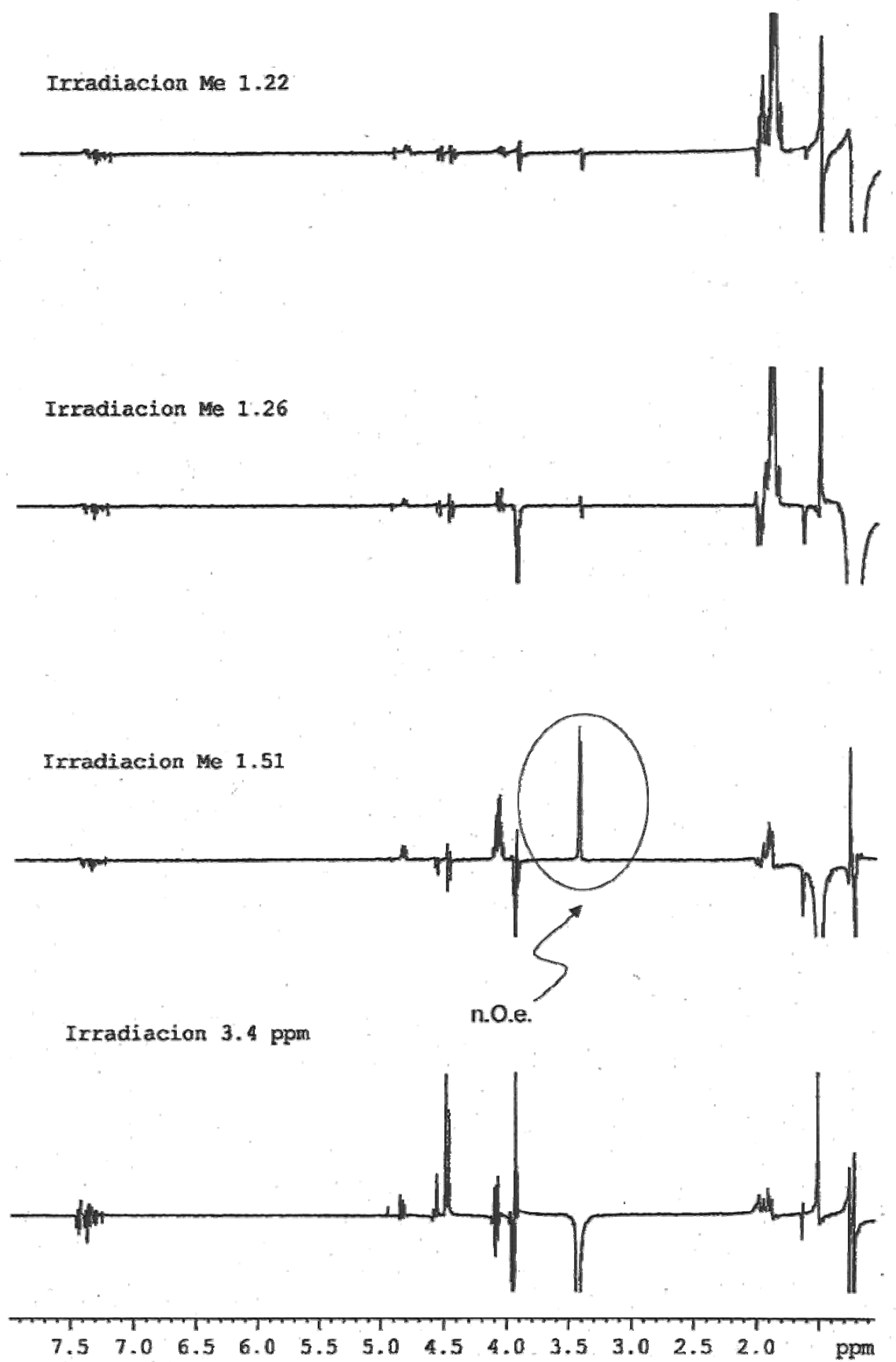
Fig. 29a

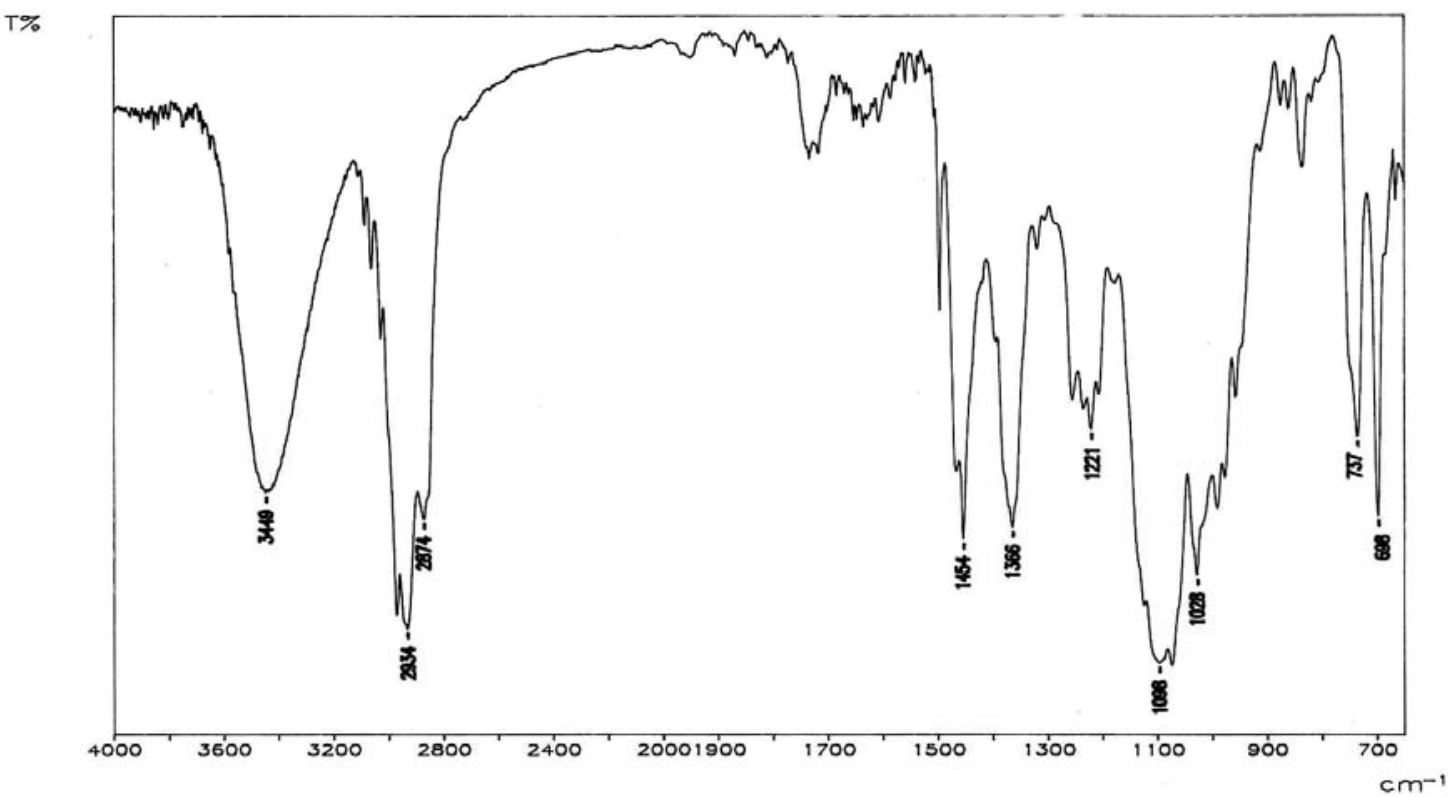

Fig. 29b

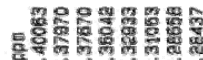

iving

Uni
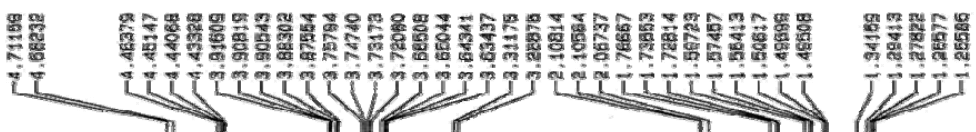<smiles>CC1(C)CC[C@@H](OBr)[C@](C)(C(I)CO)O1</smiles>

35

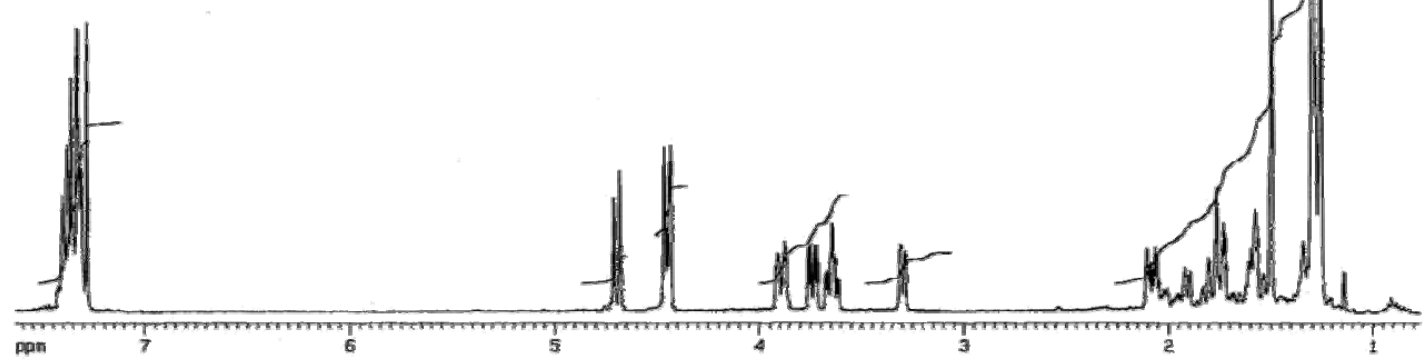


Fig. 29c

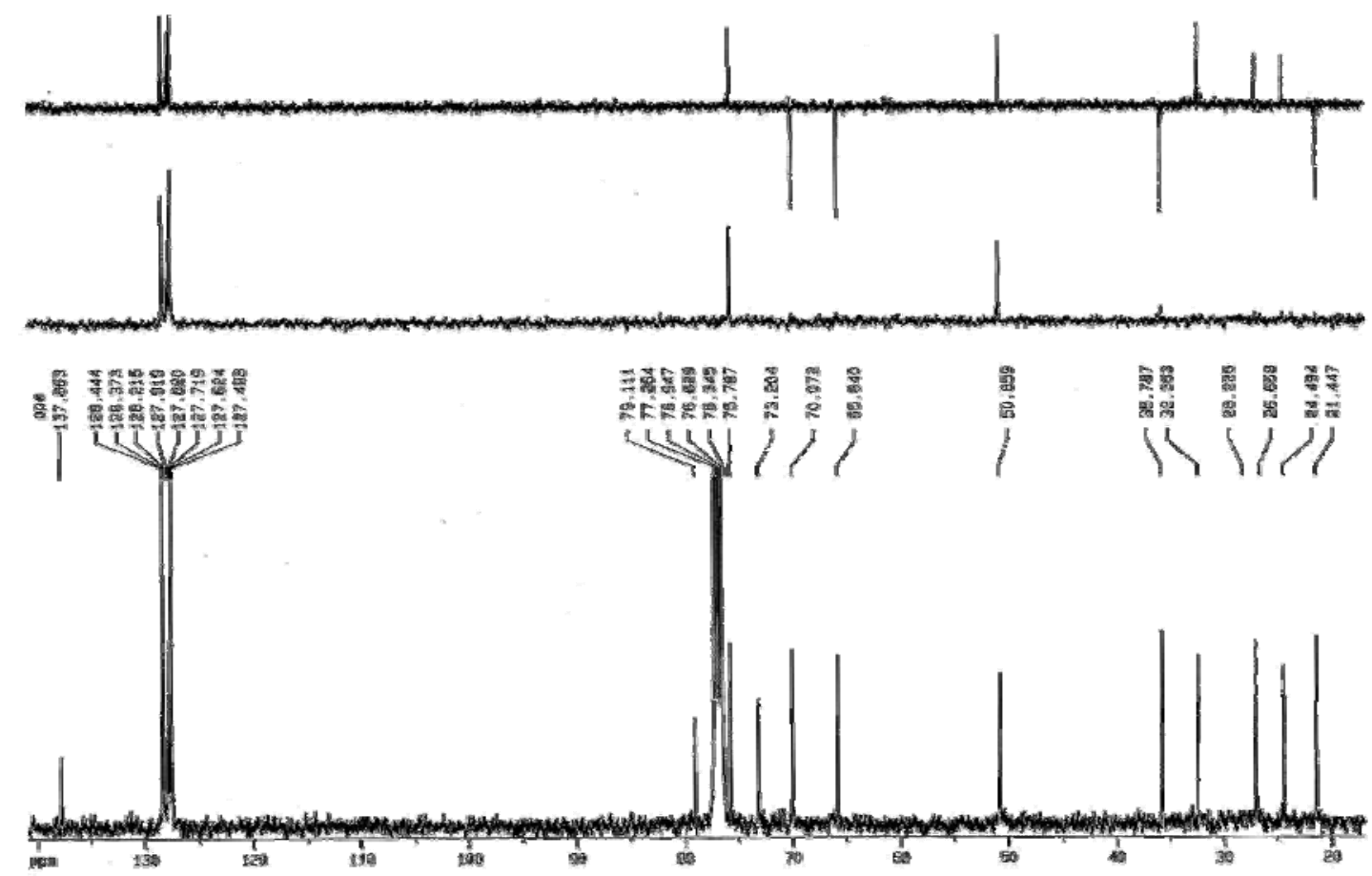

Fig. 29d

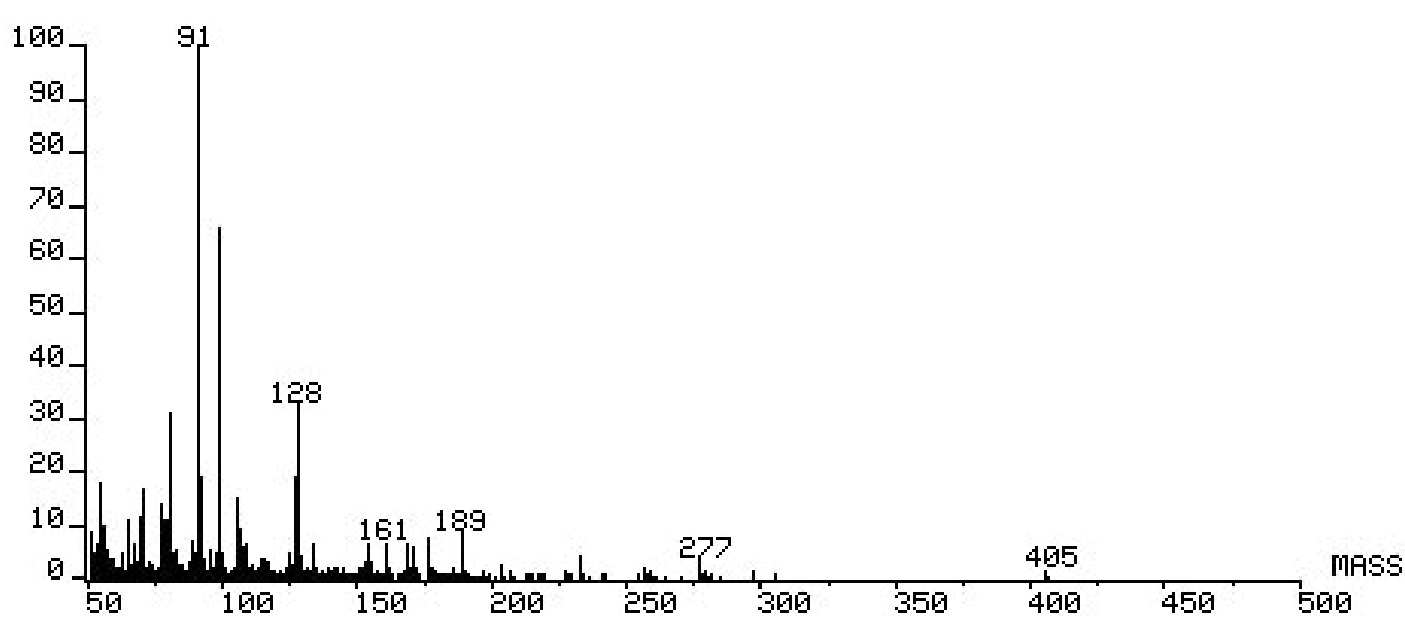


Fig. 30a

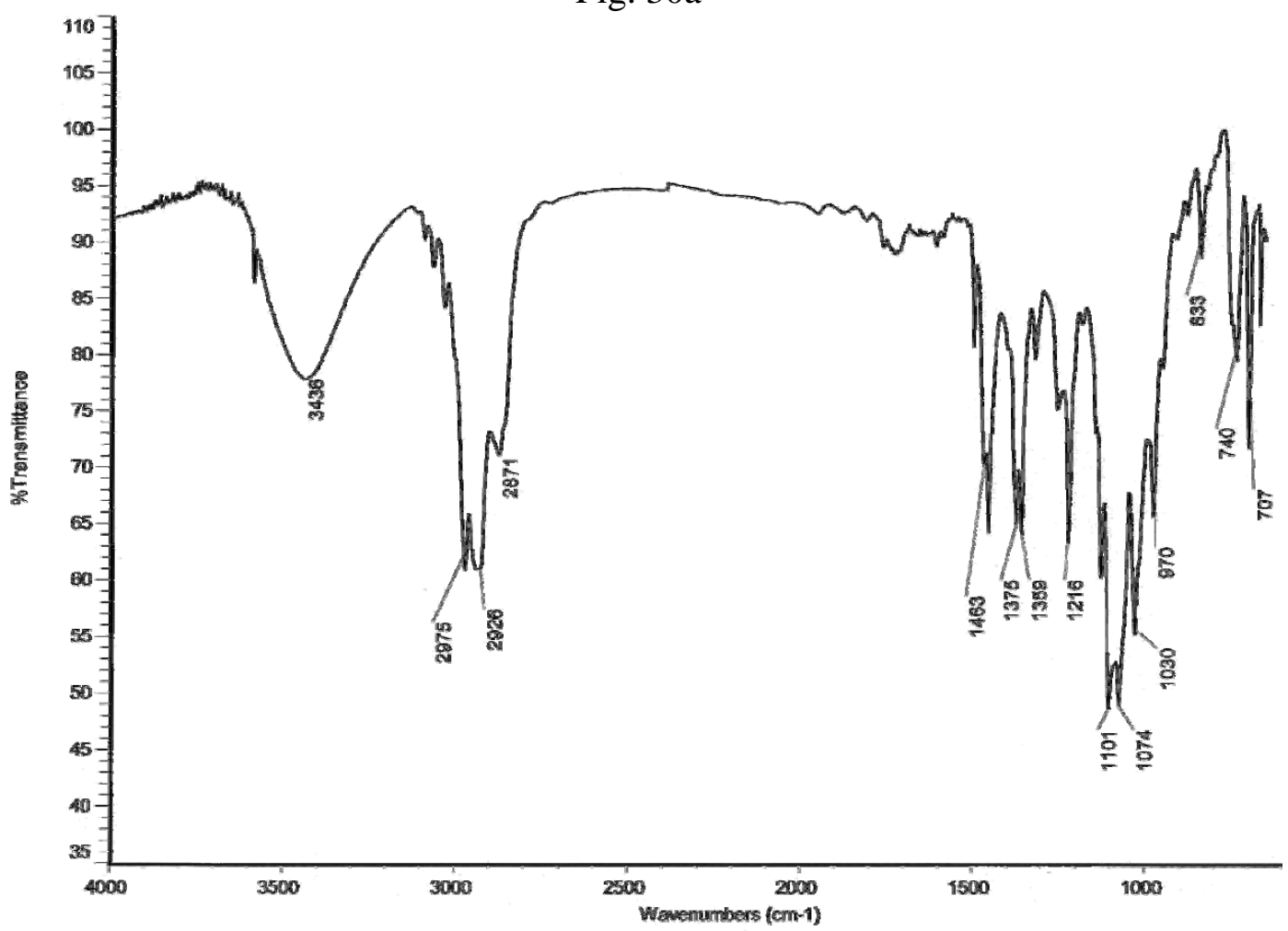

Fig. 30b
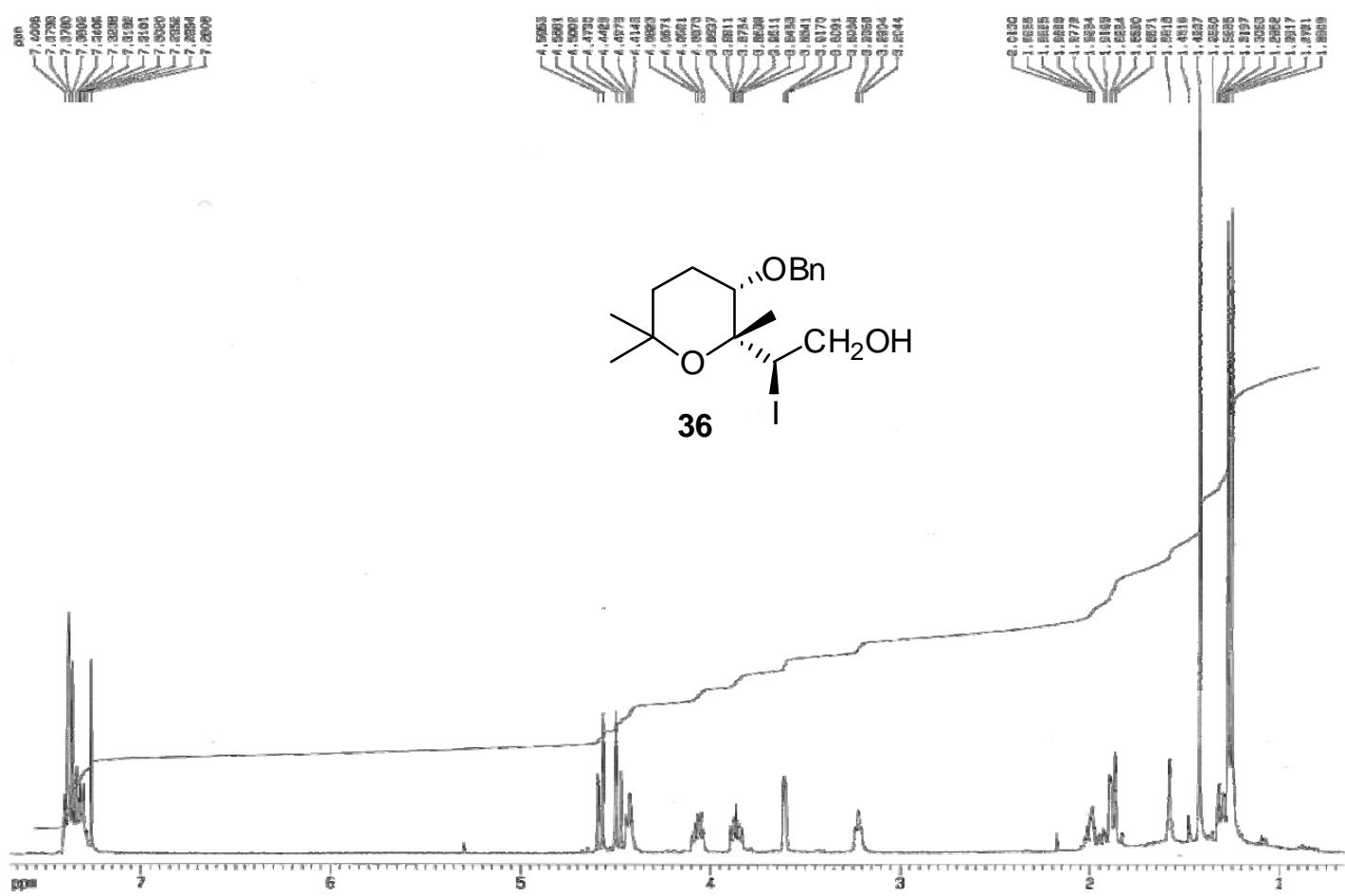
Fig. 30c

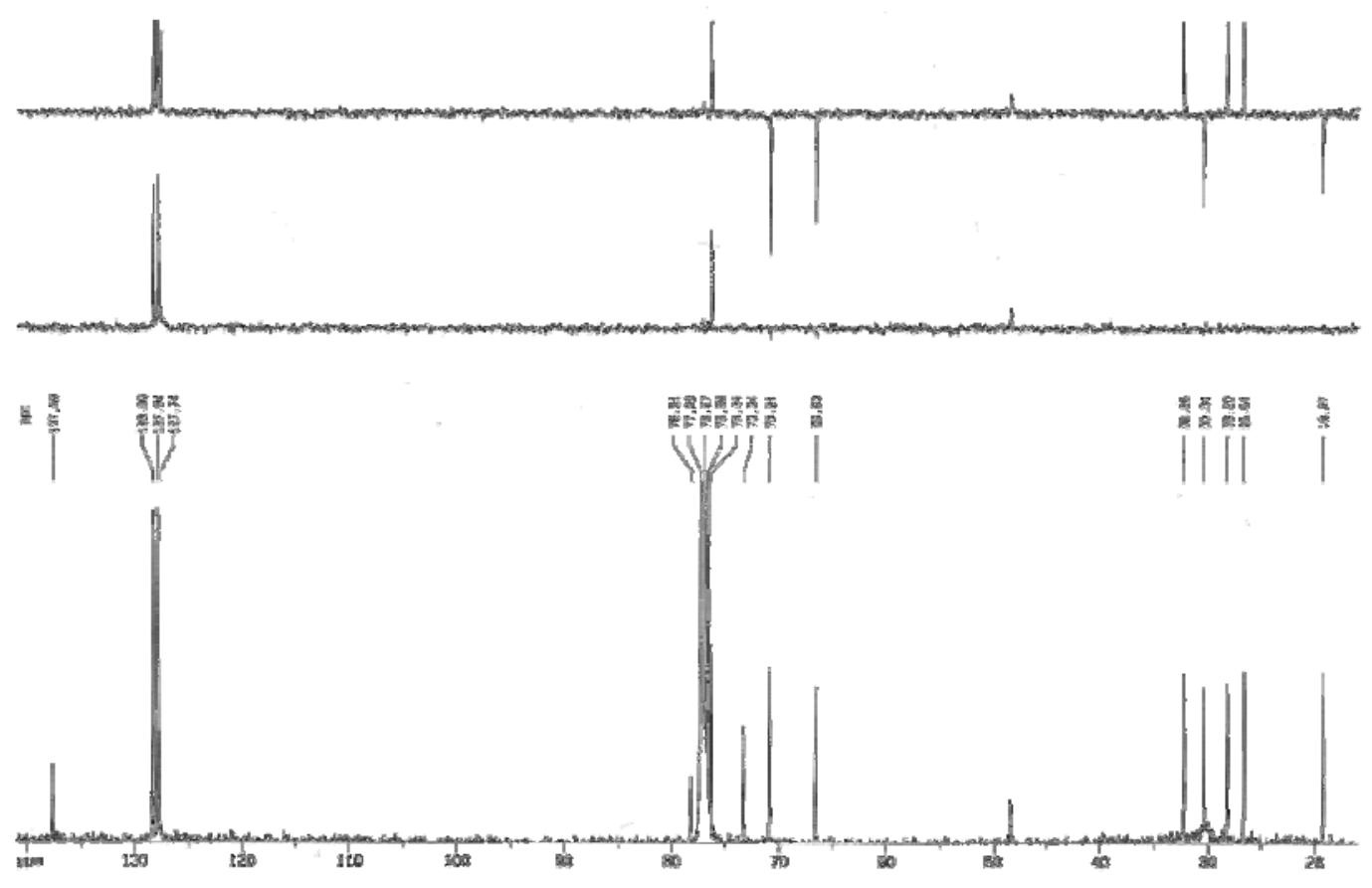

Fig. 30d

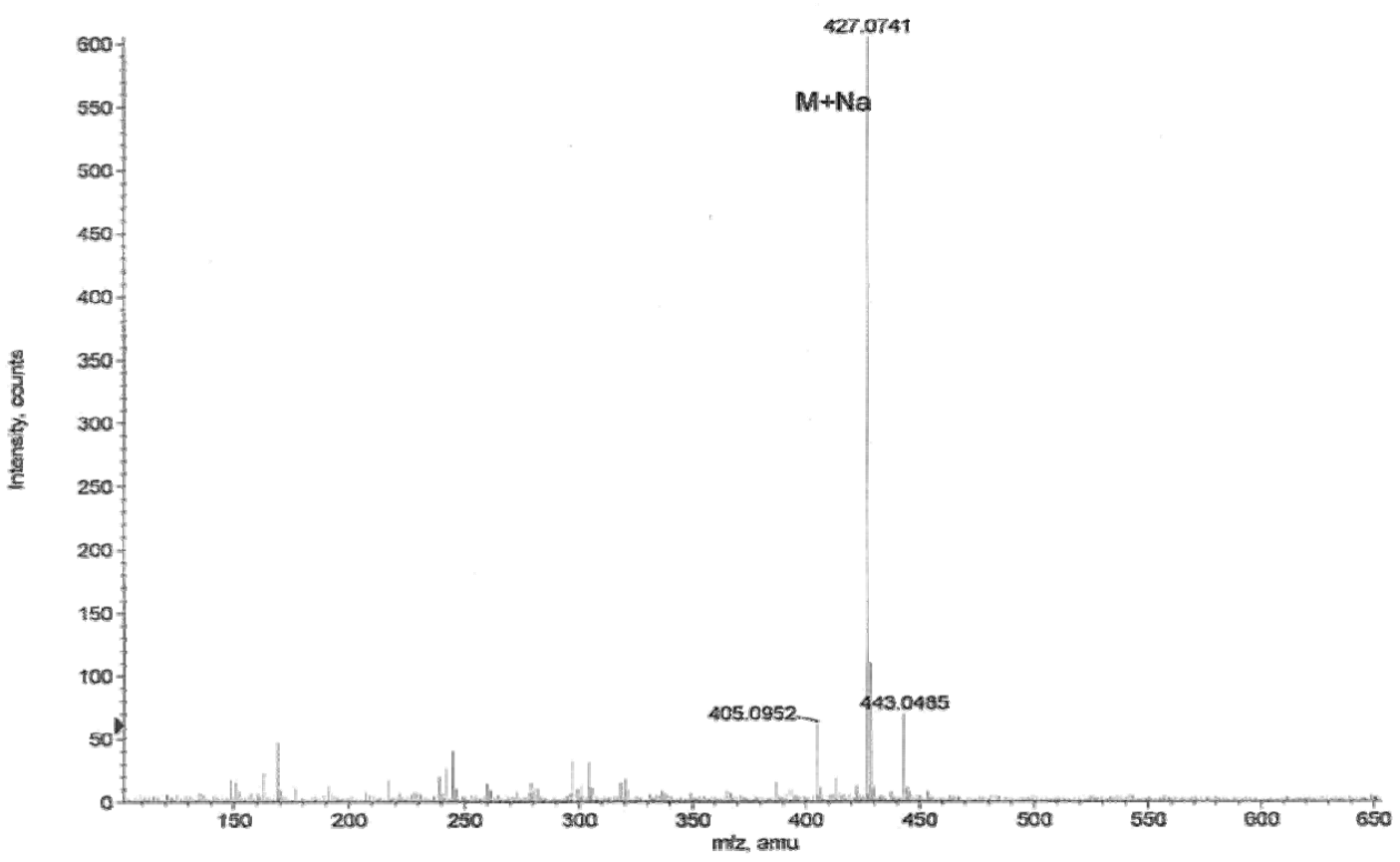


Fig. 31a

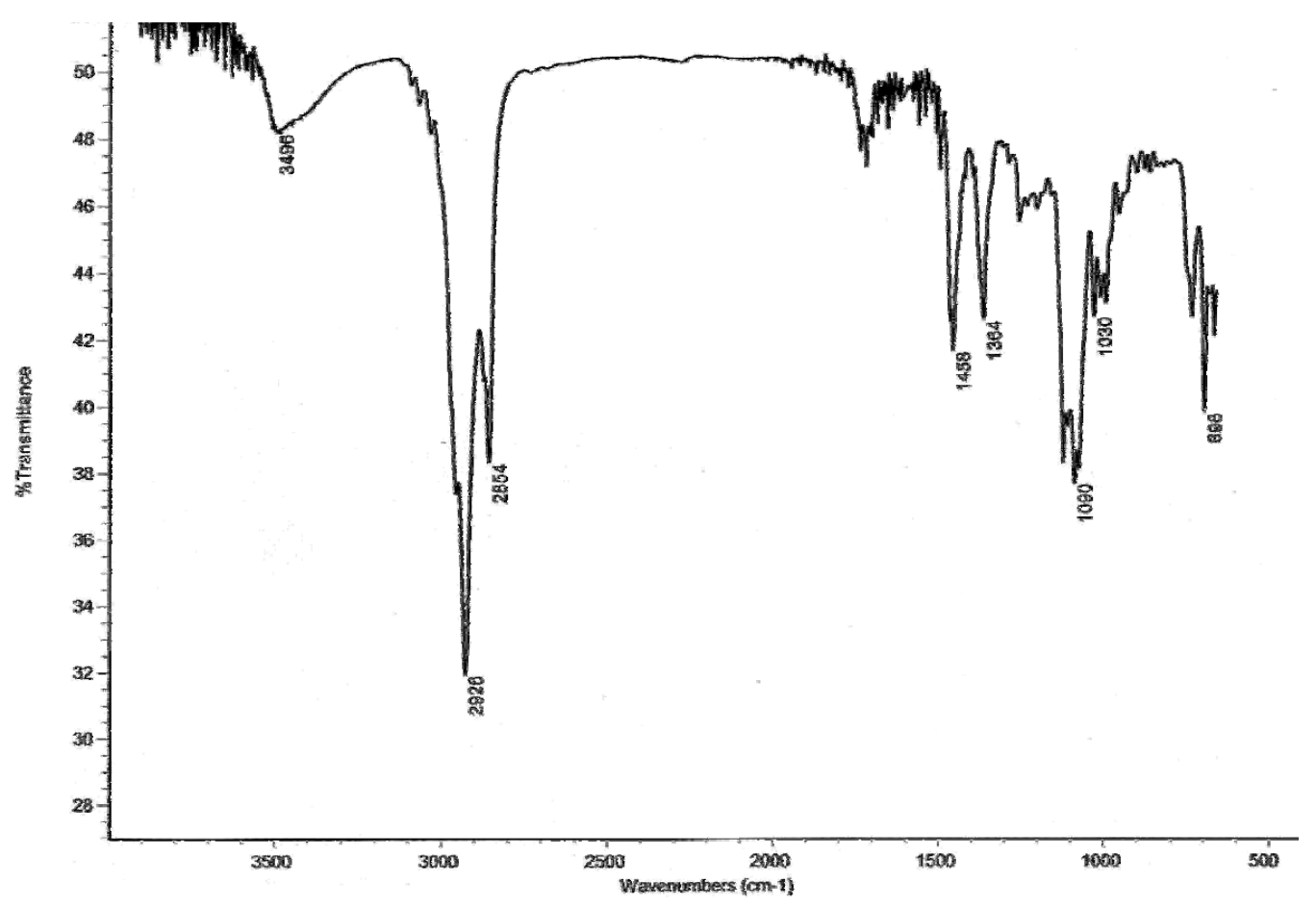

Fig. 31b

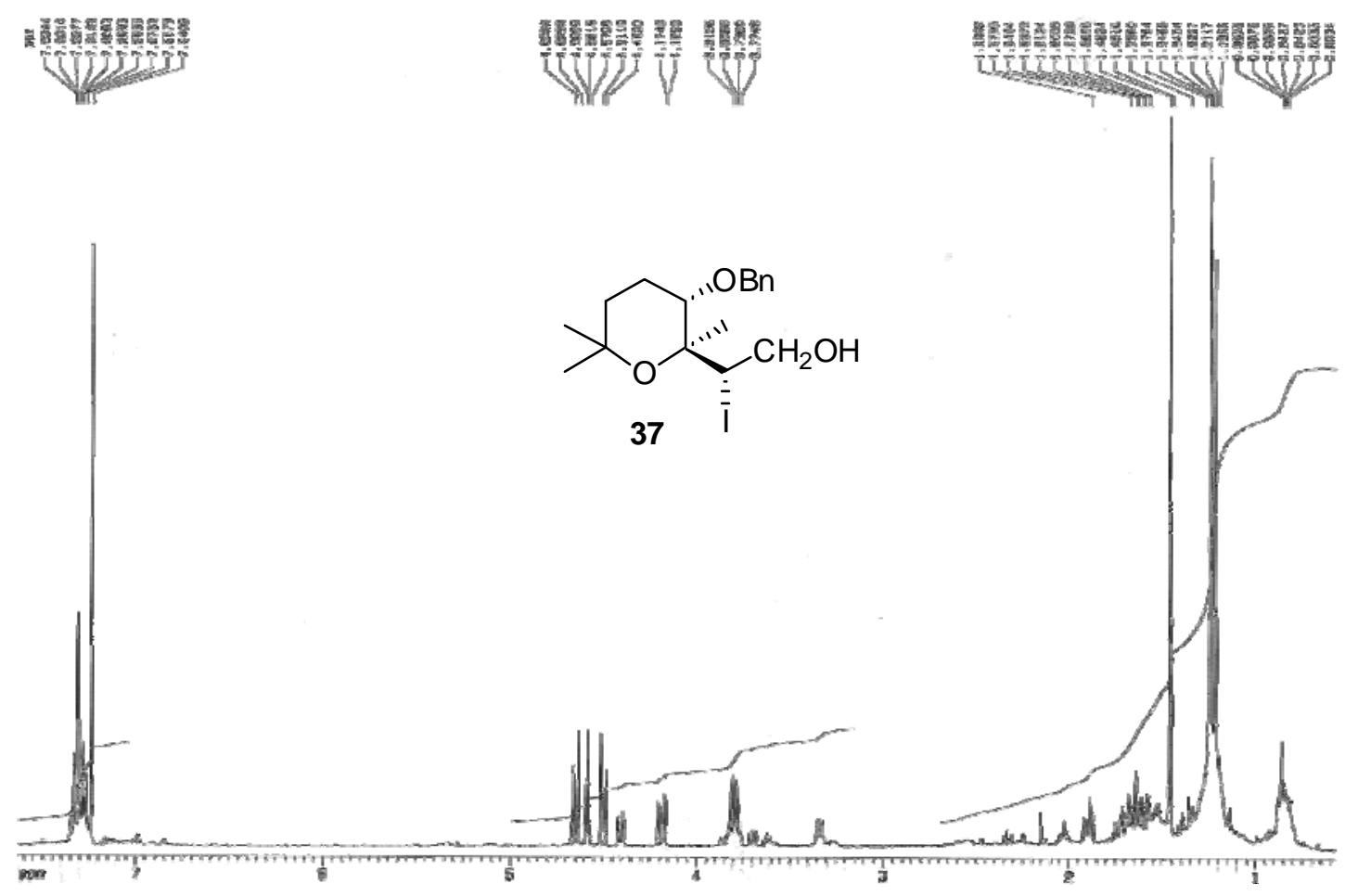


Fig. 31c
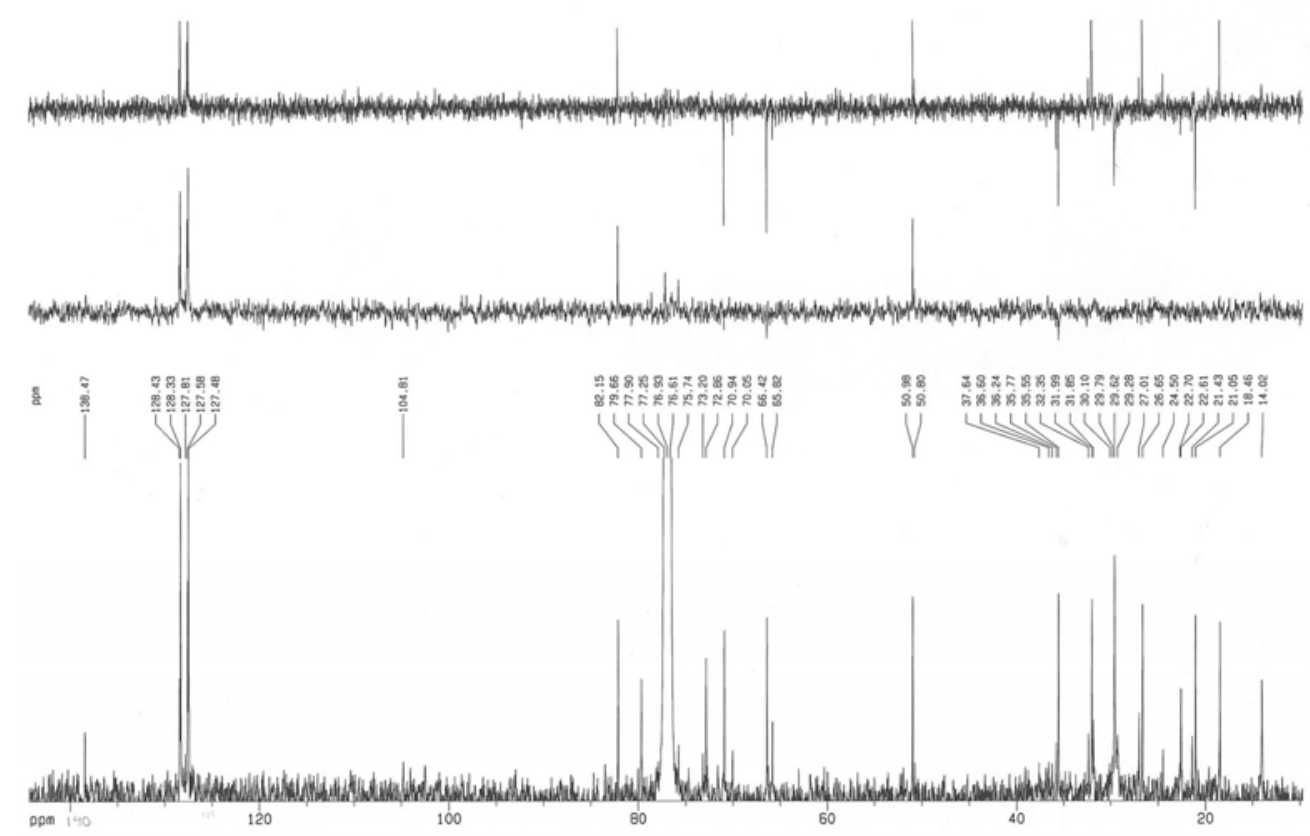

Fig. 31d

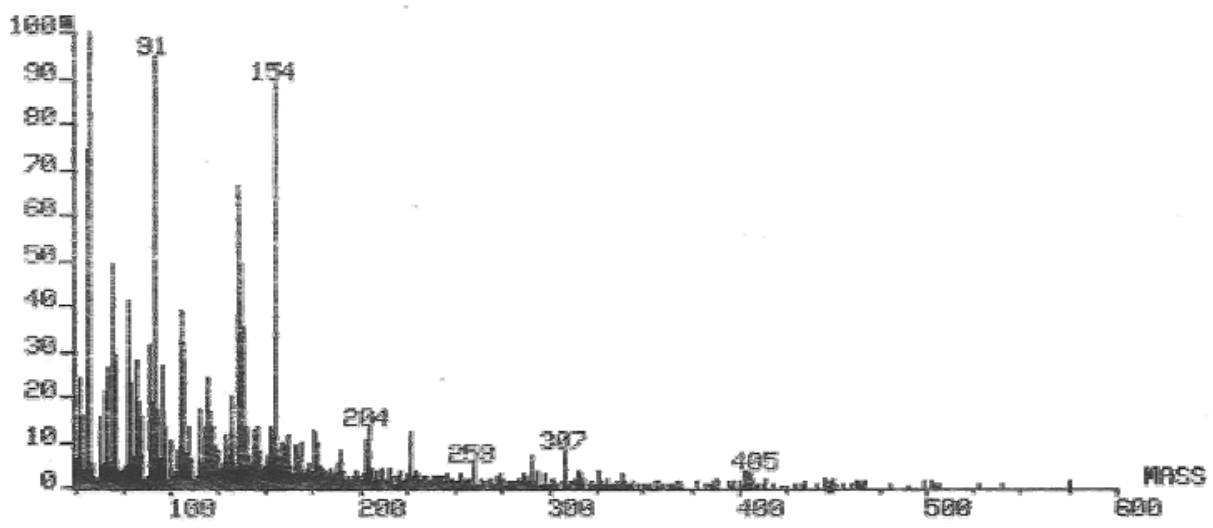

Fig. 31e

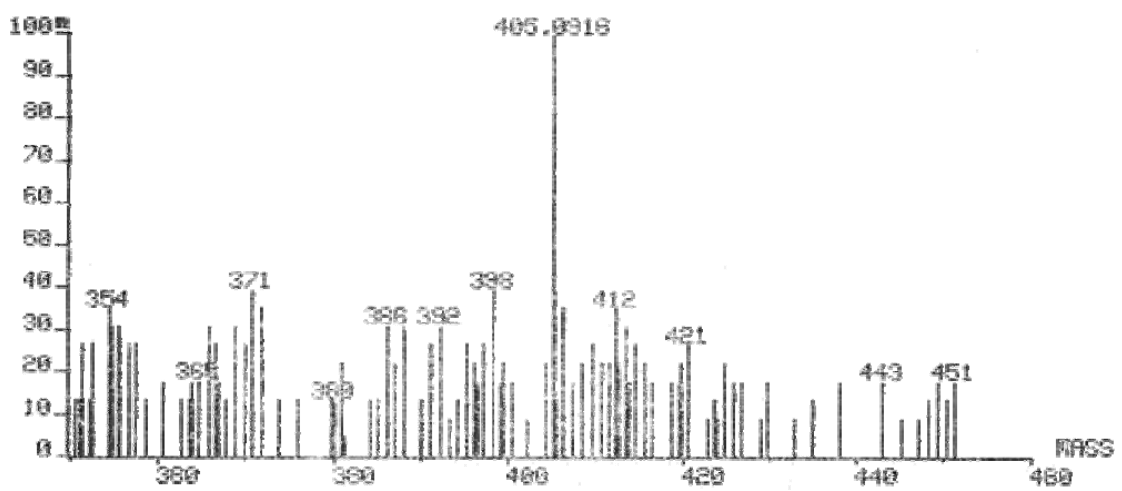


Fig. 31f

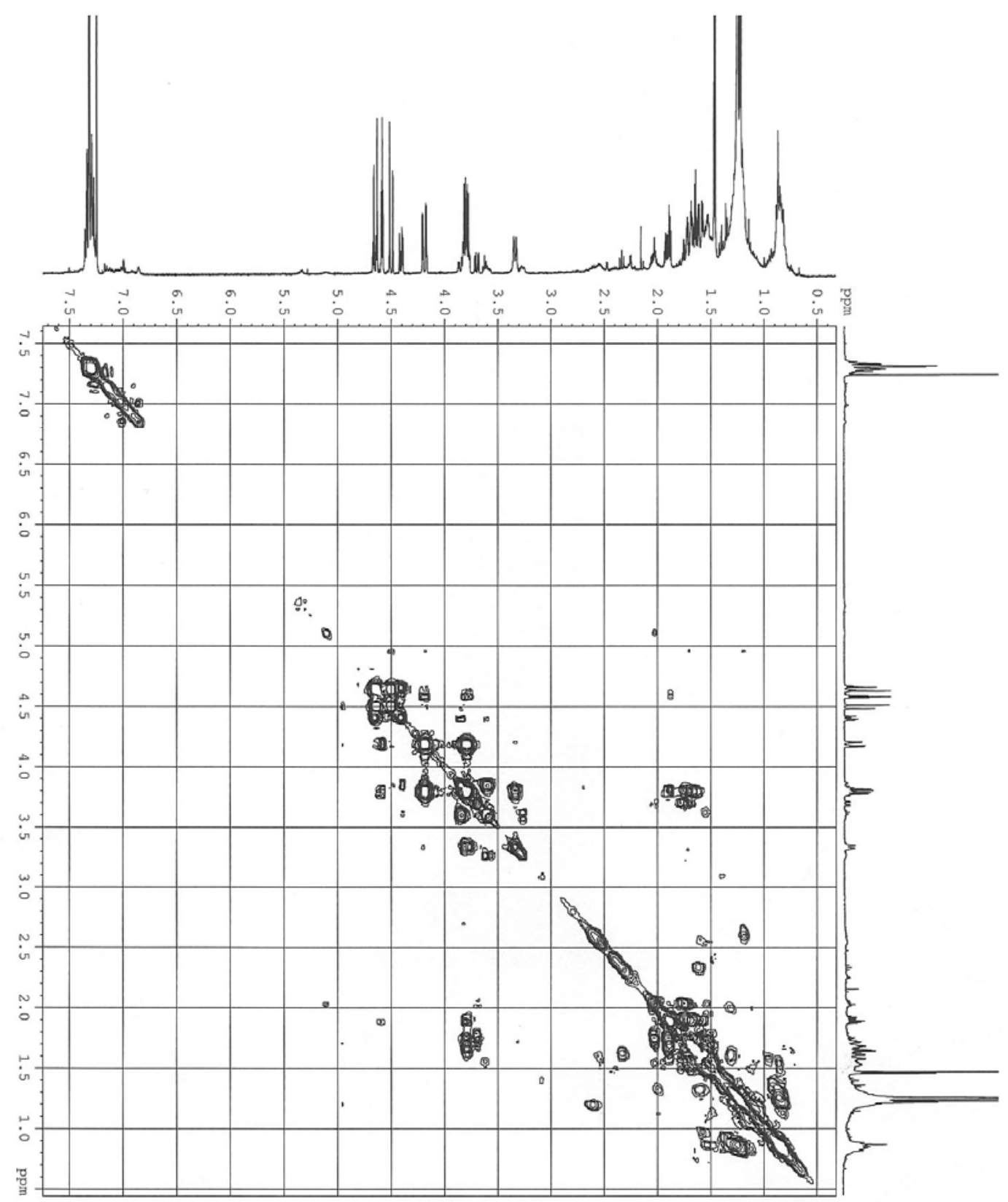


Fig. 31g

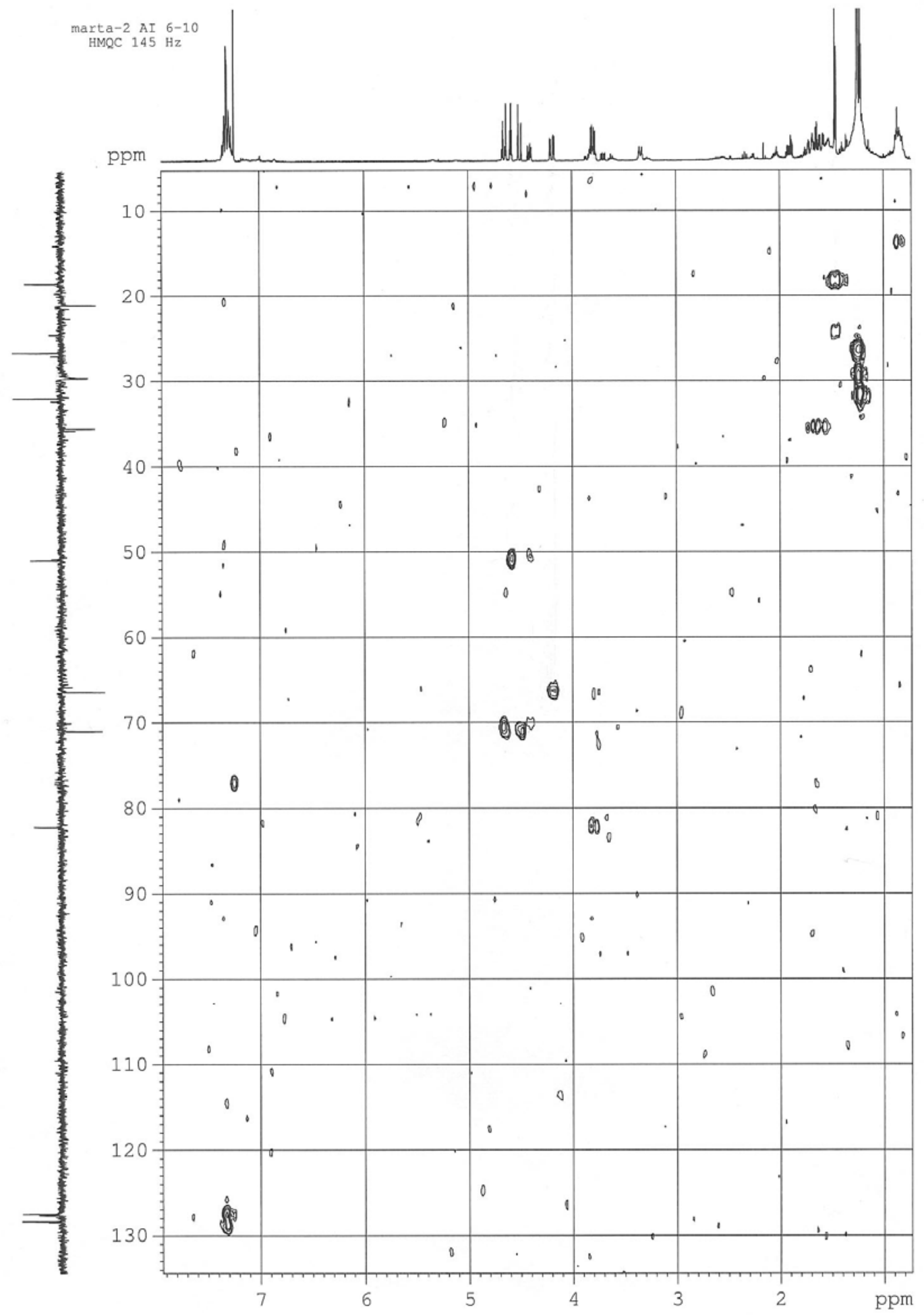


Fig. 31h

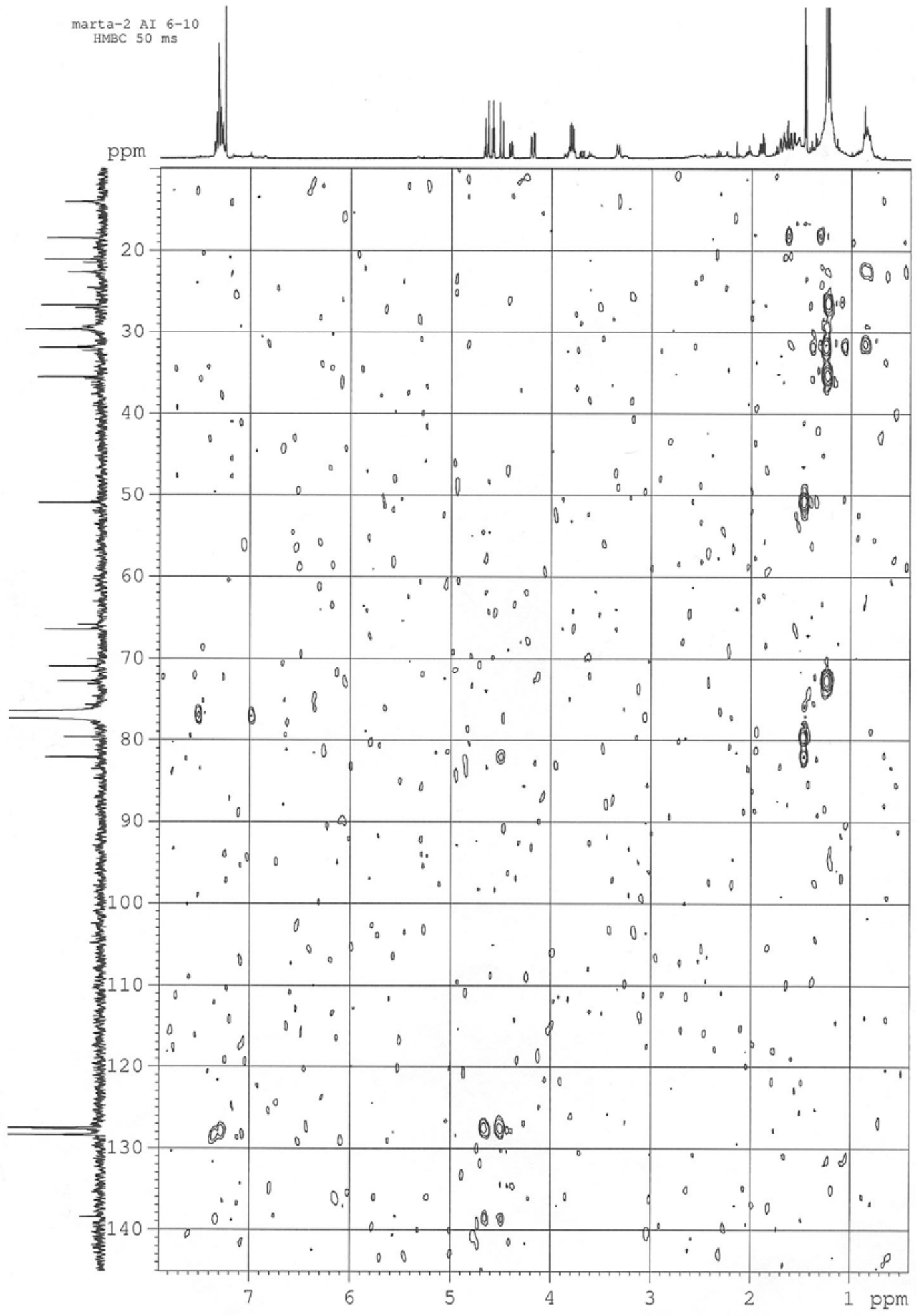


Fig. 31i
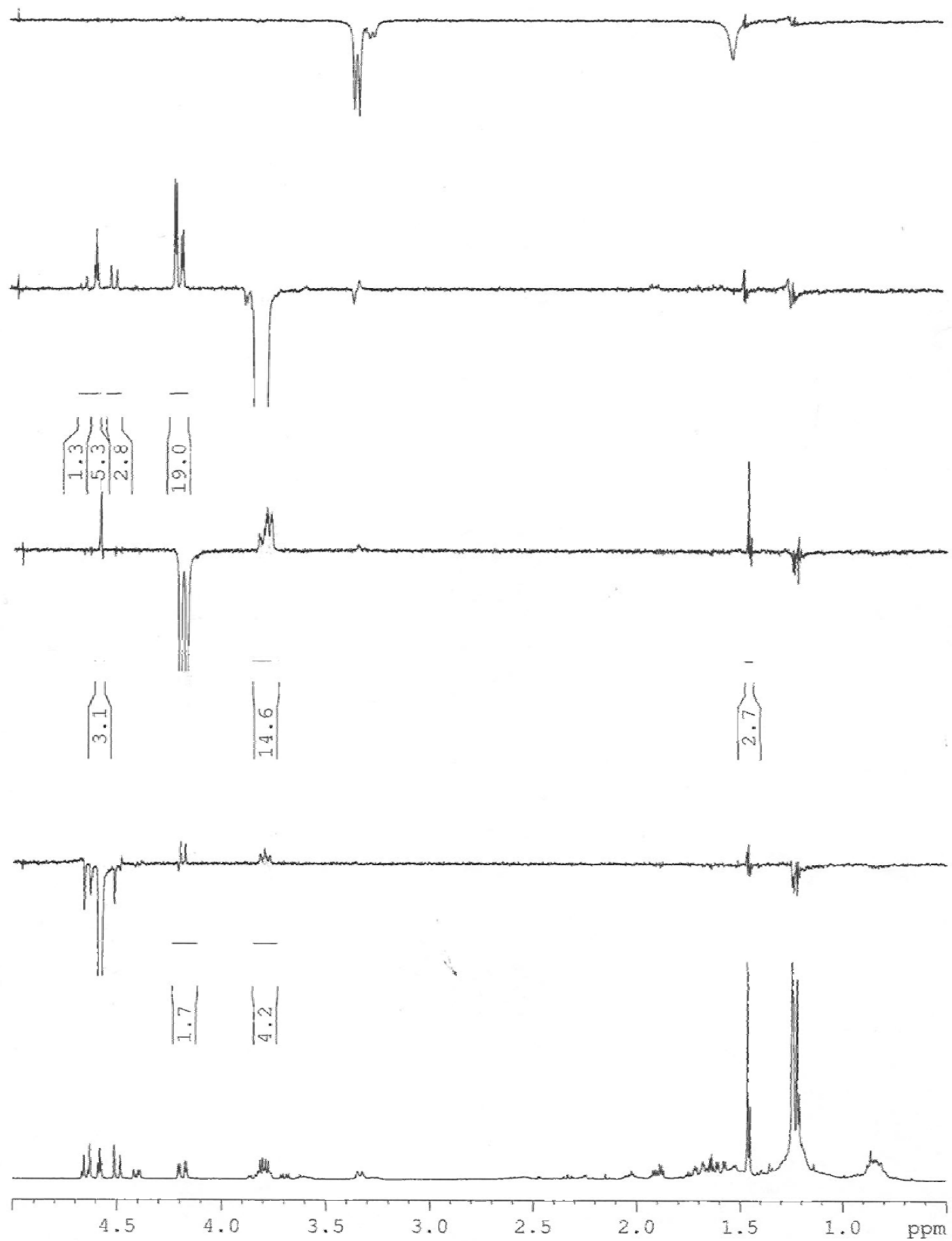
Fig. 32a

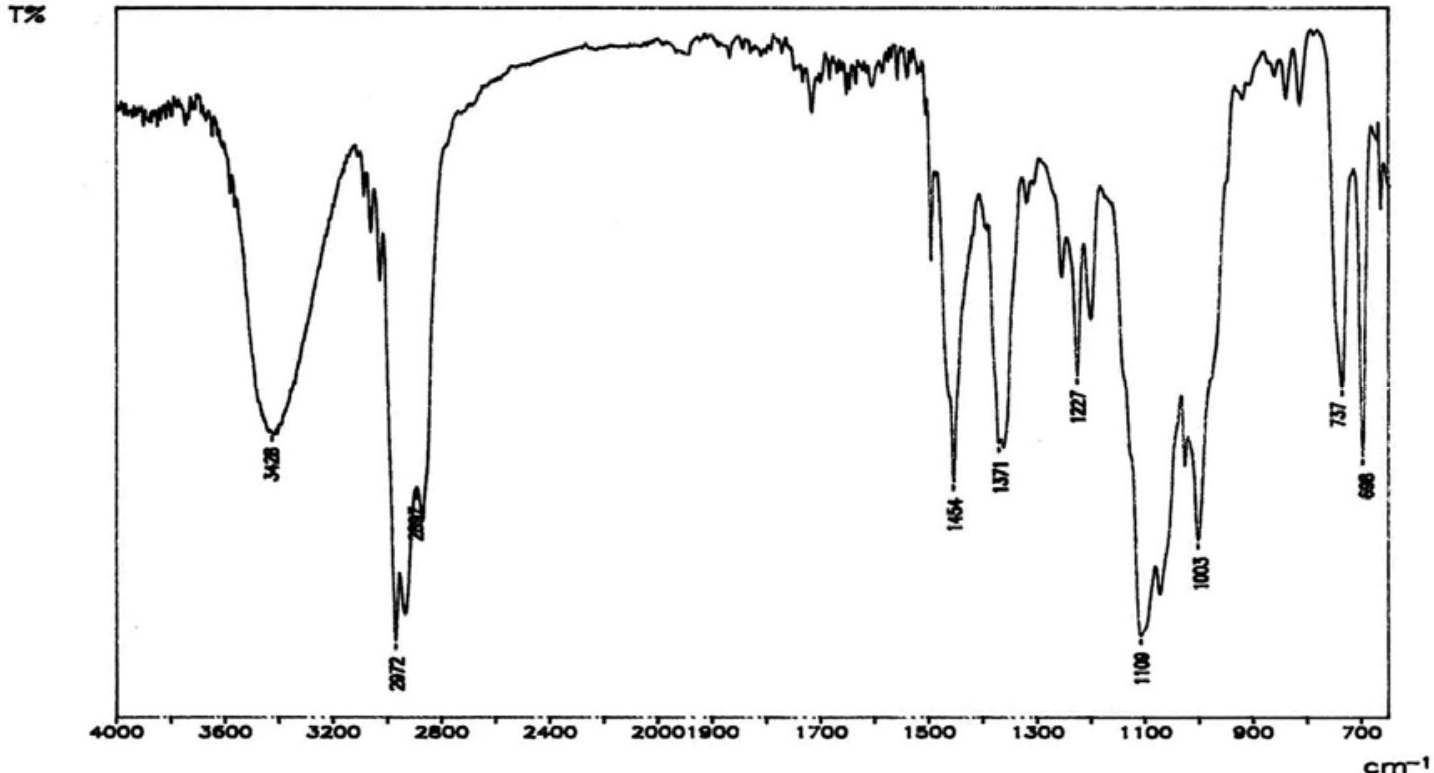

Fig. 32b

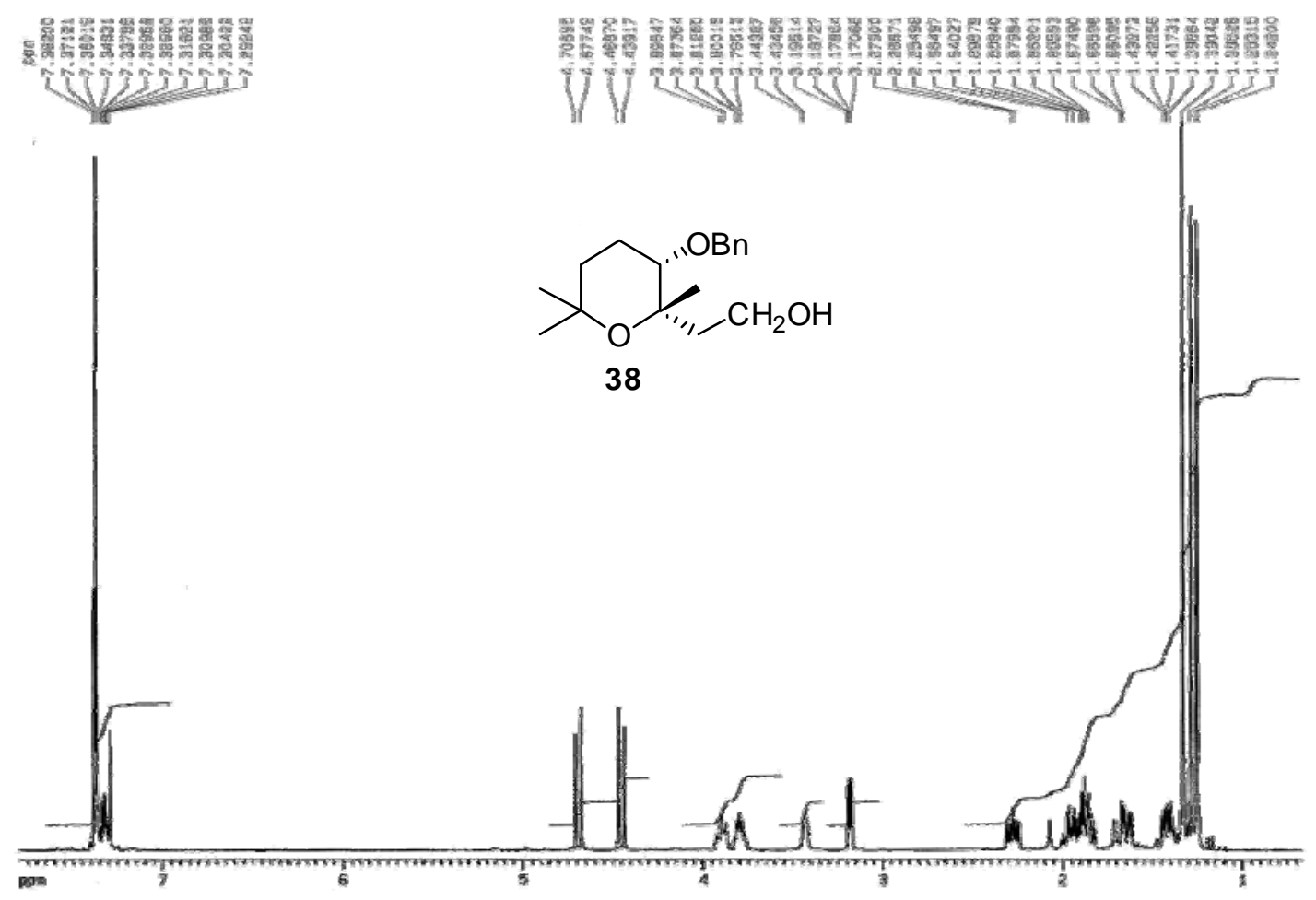


Fig. 32c

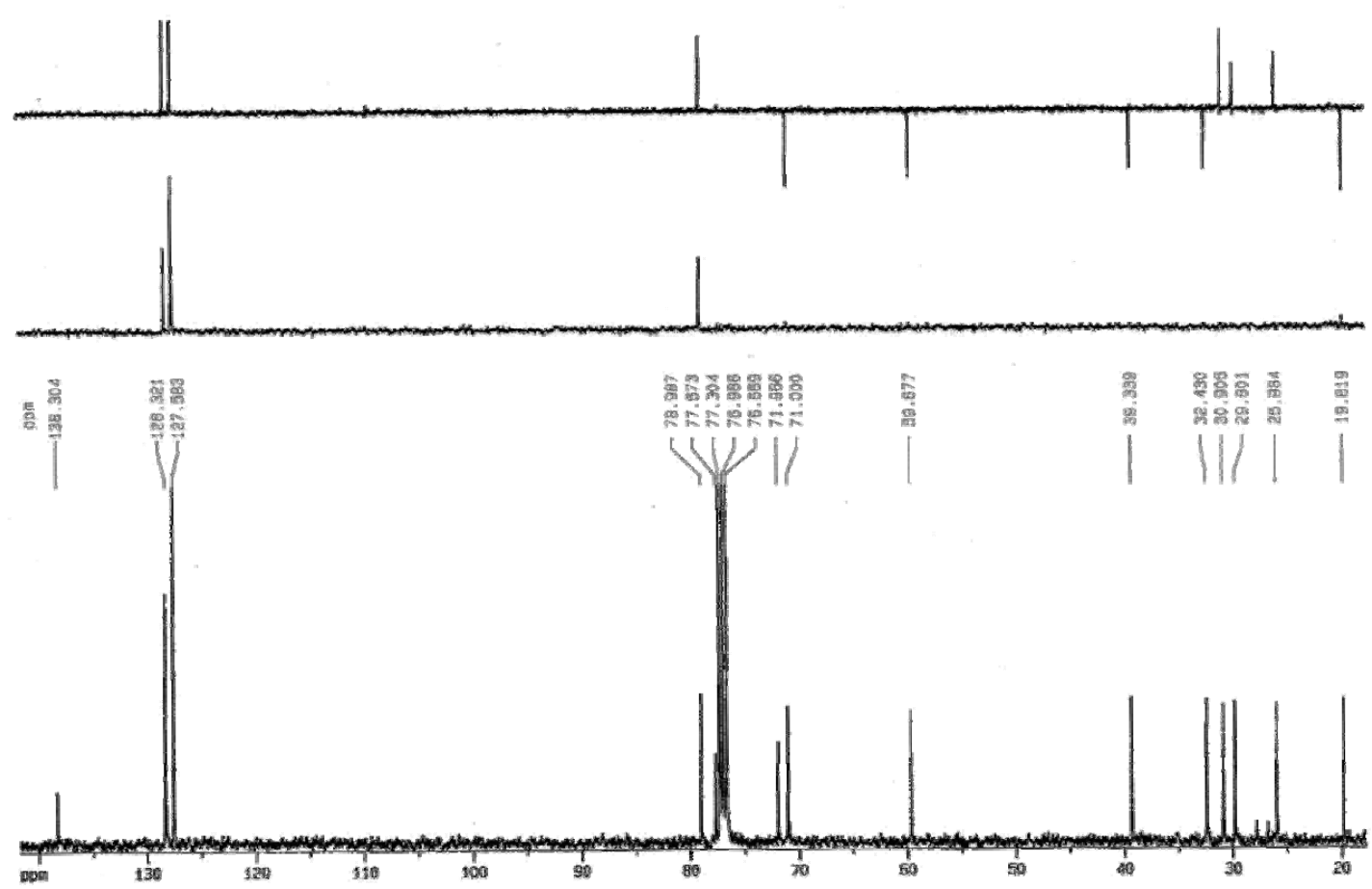

Fig. 32d

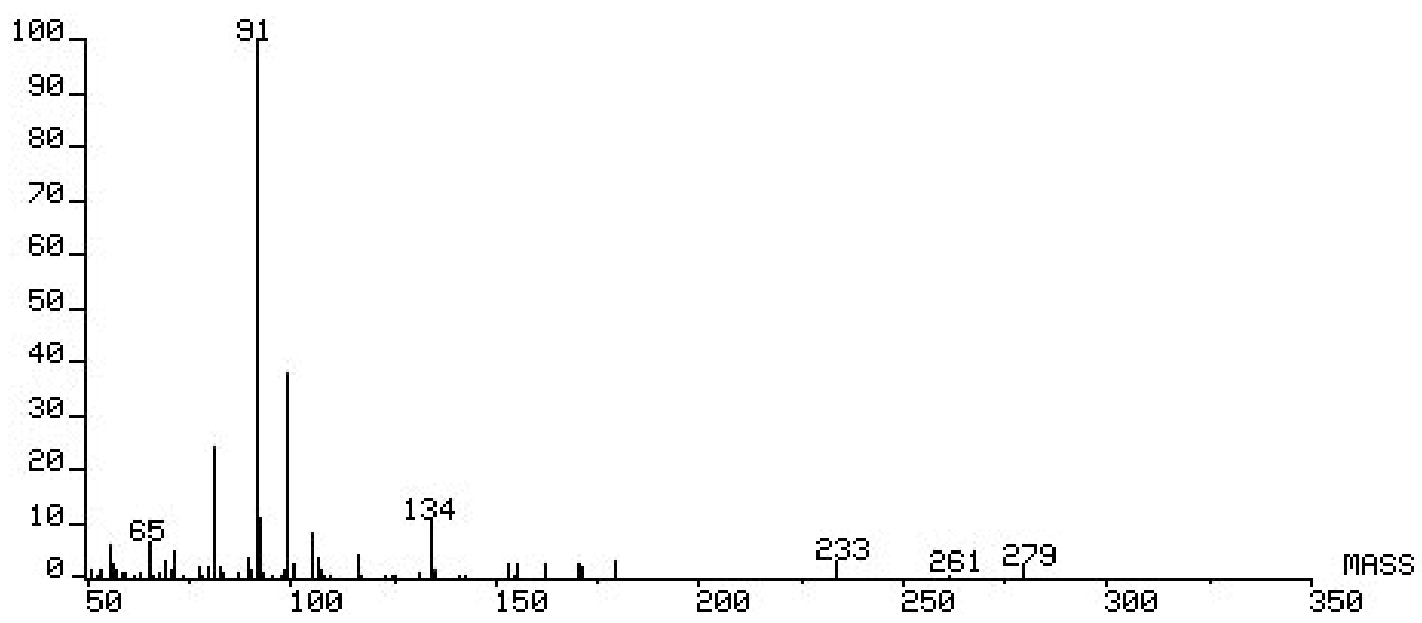


Fig. 33a

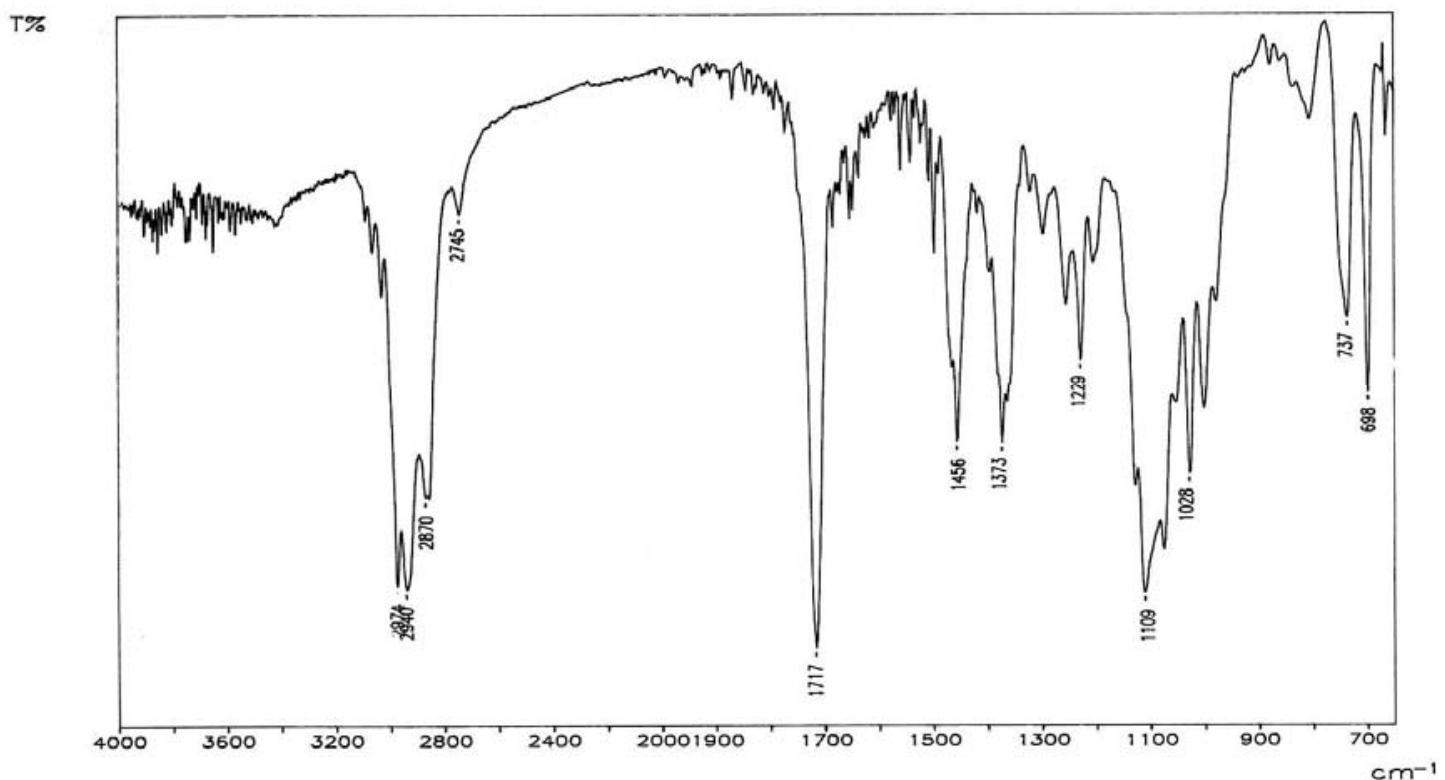

Fig. 33b
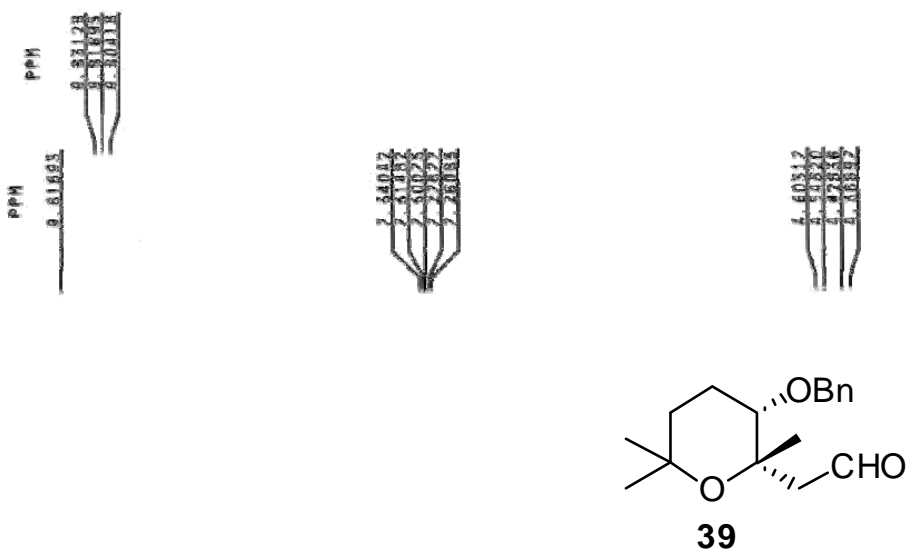

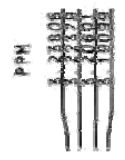
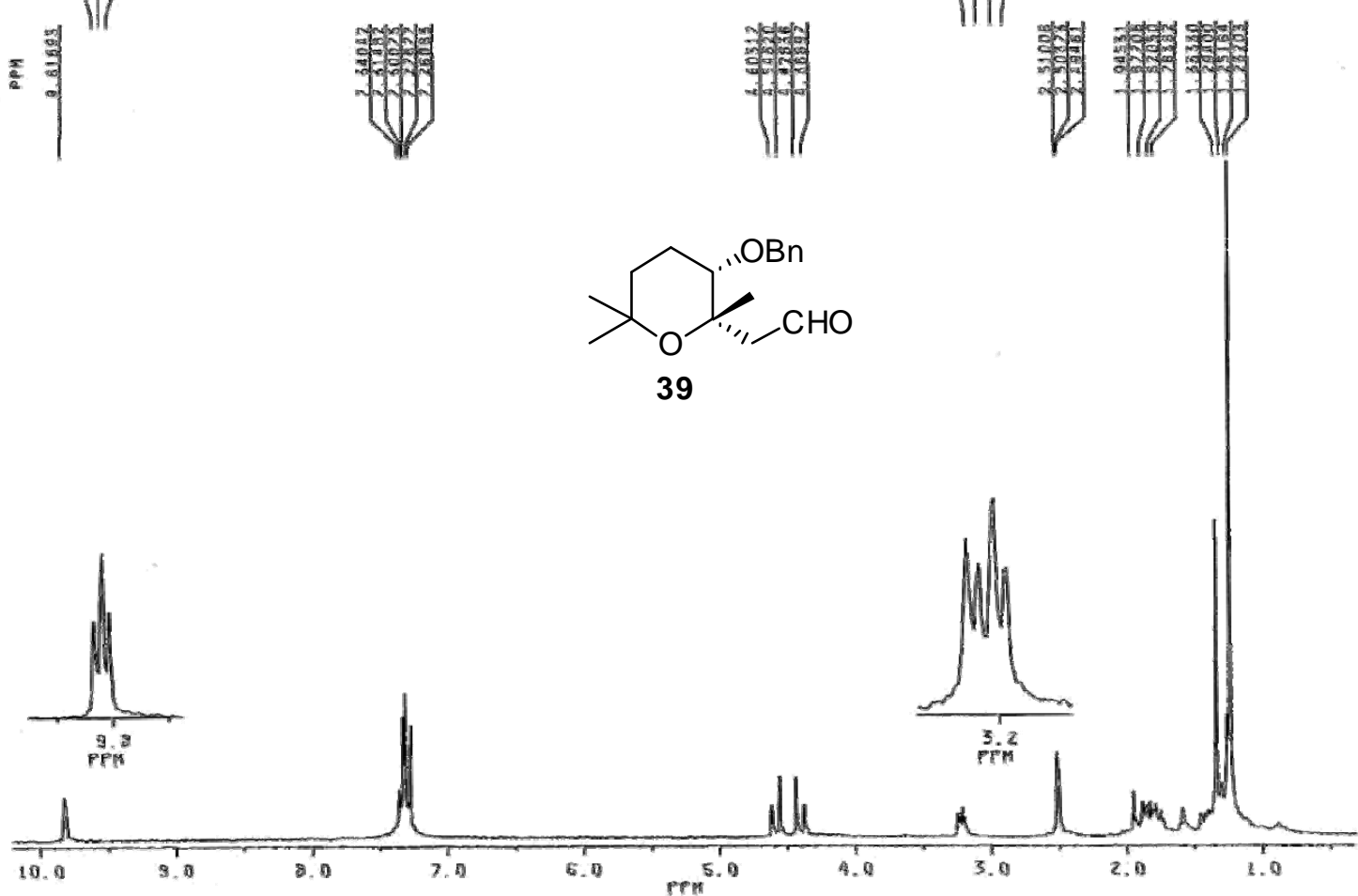
Fig. 33c

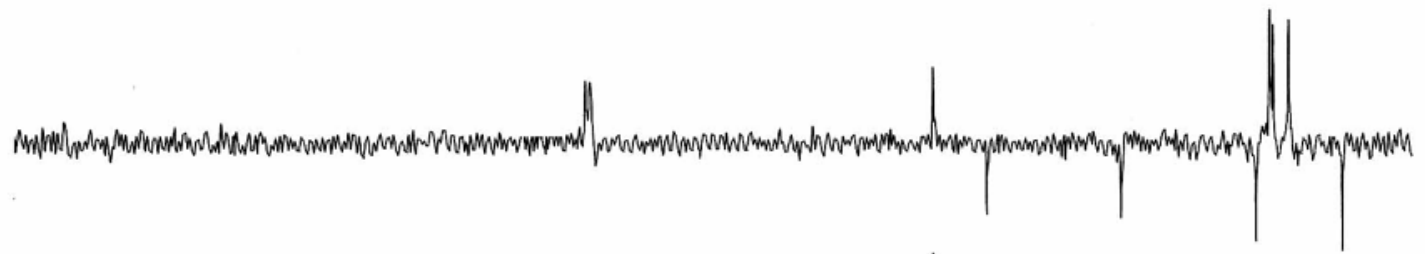

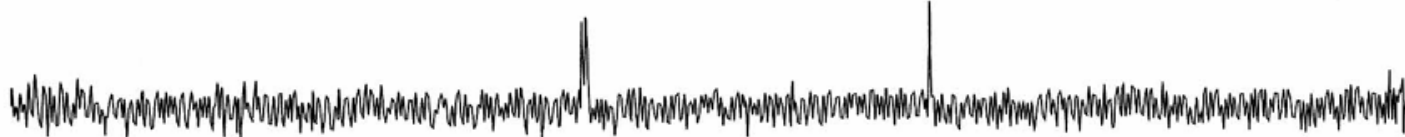
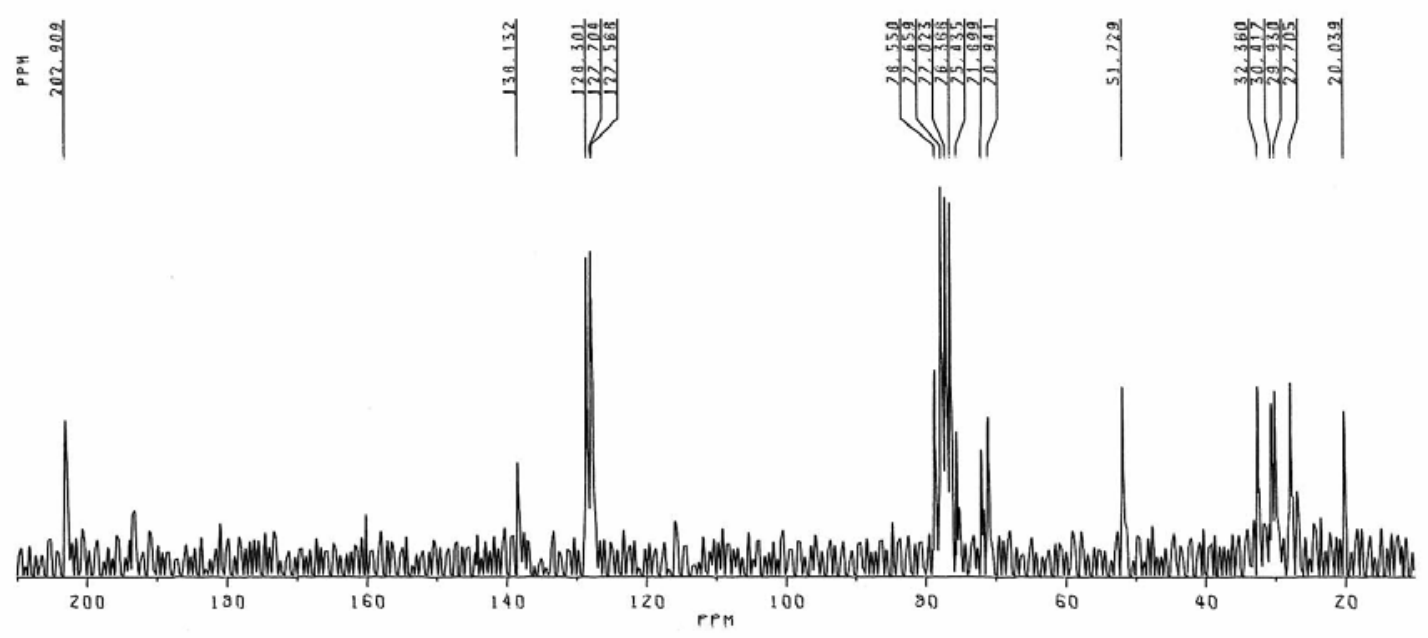

Fig. 33d

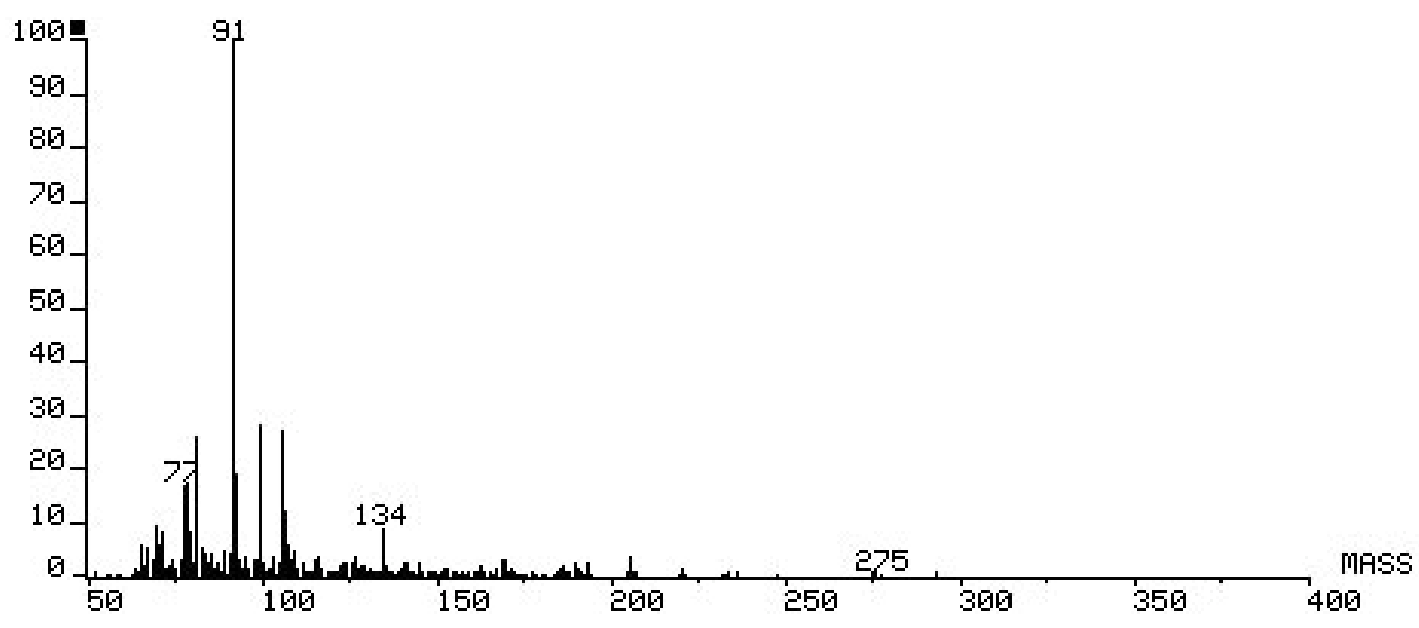


Fig. 34a

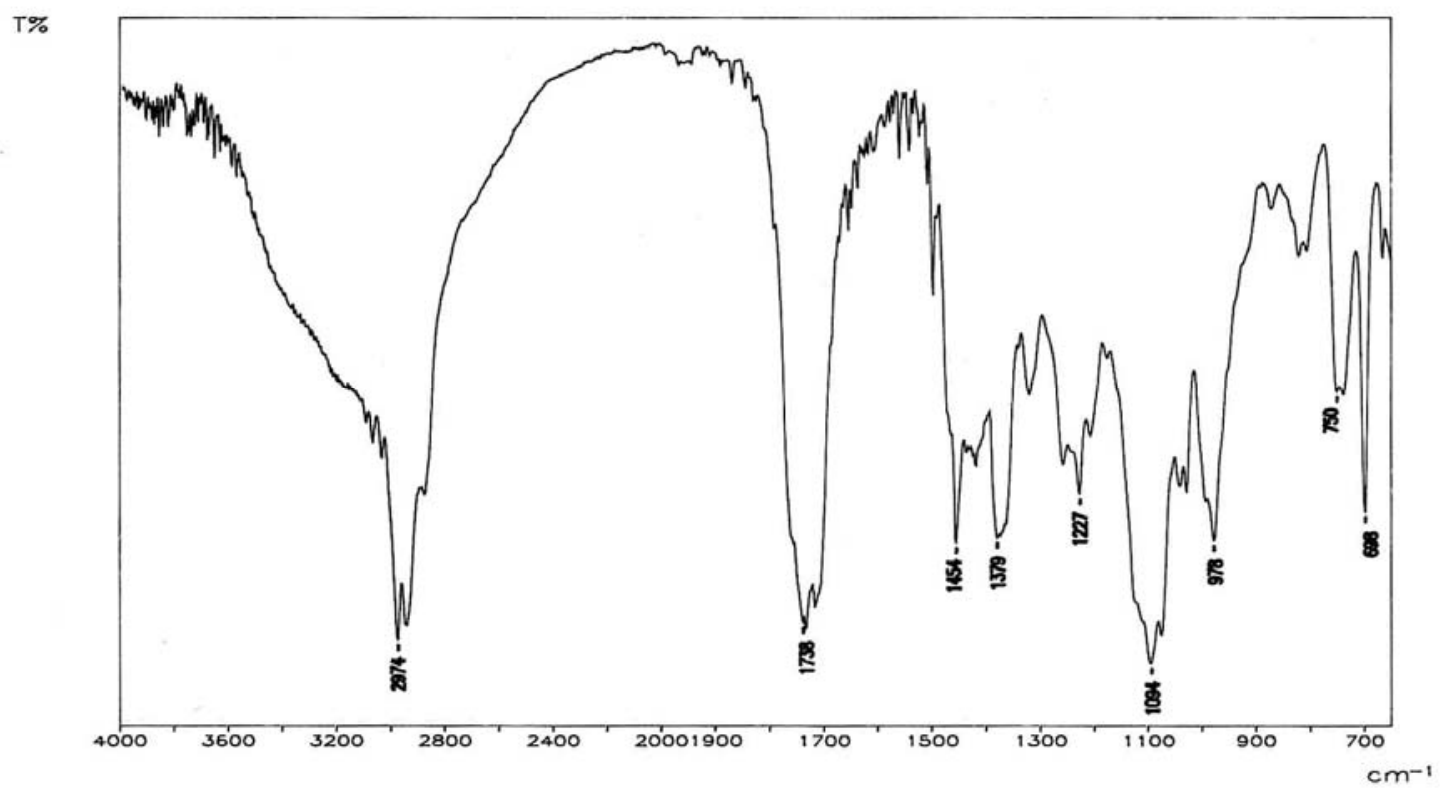

Fig. 34b

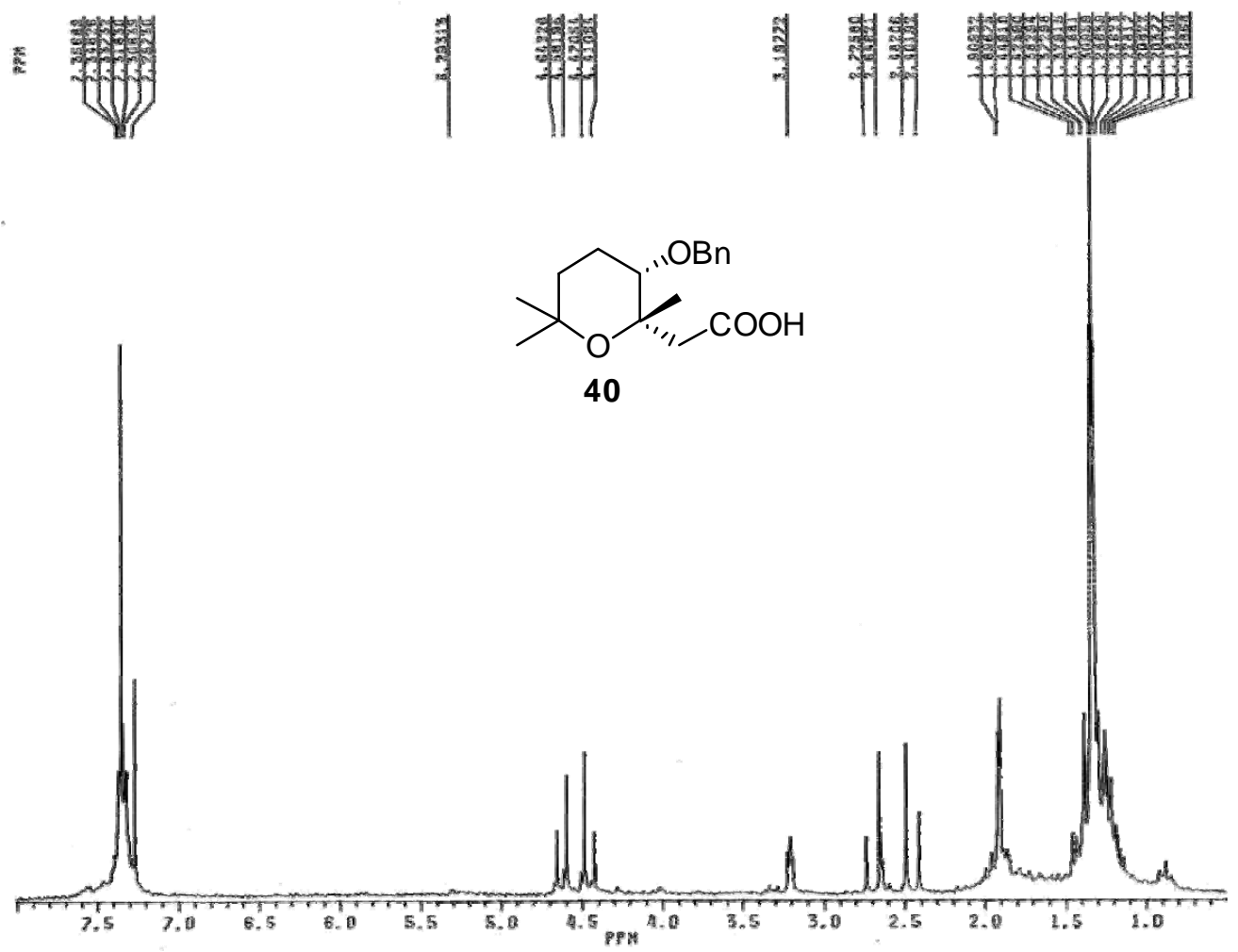


Fig. 34c

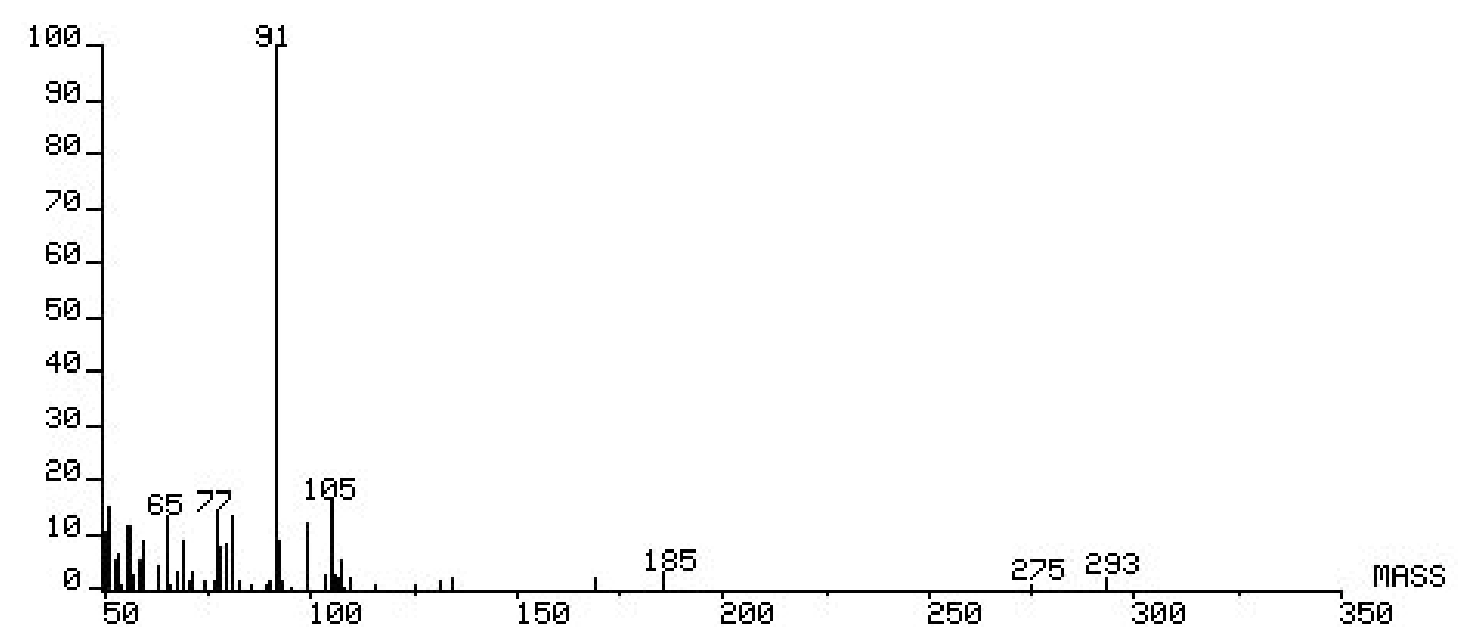


Fig. 35a

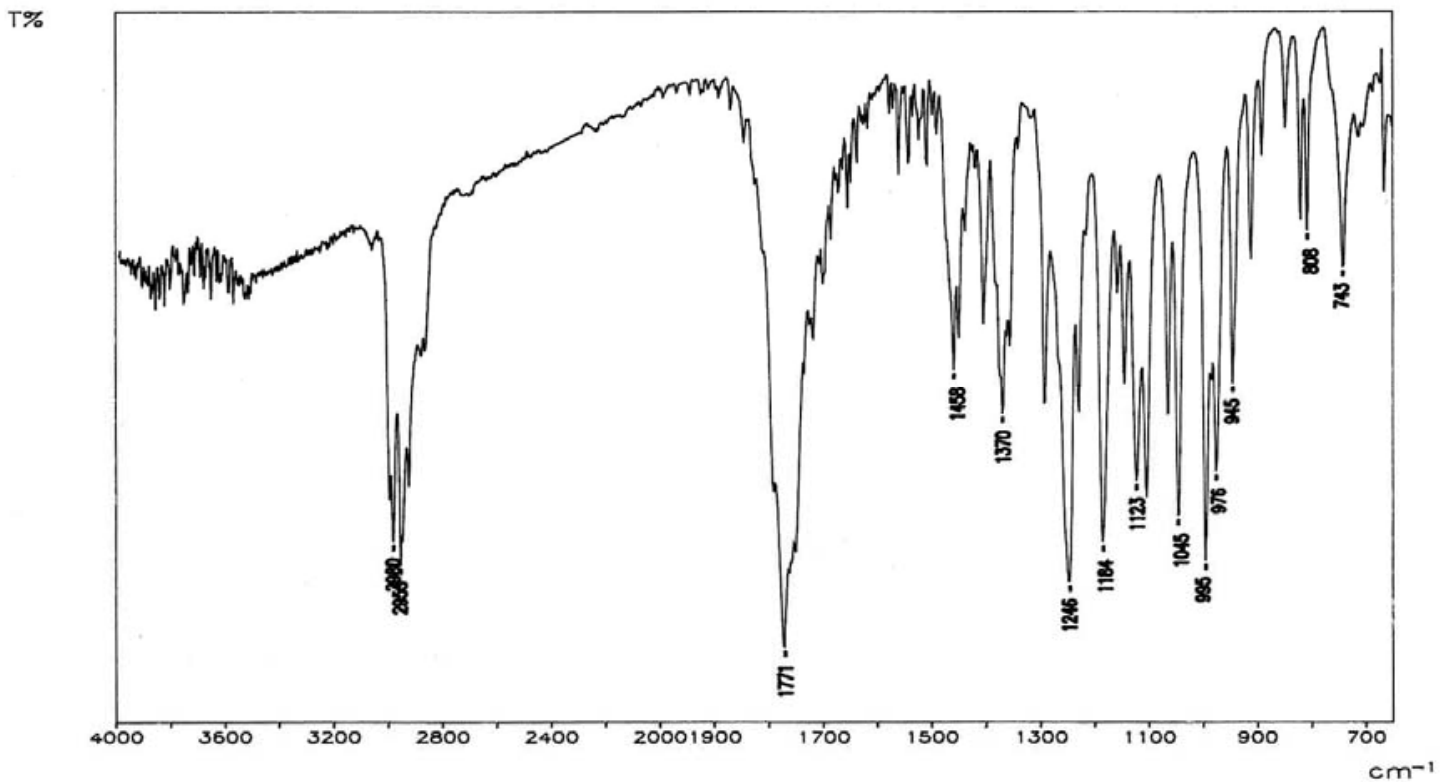

Fig. 35b

연
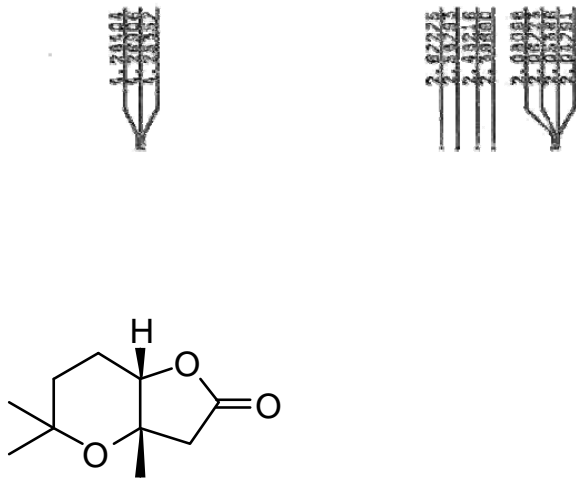

41

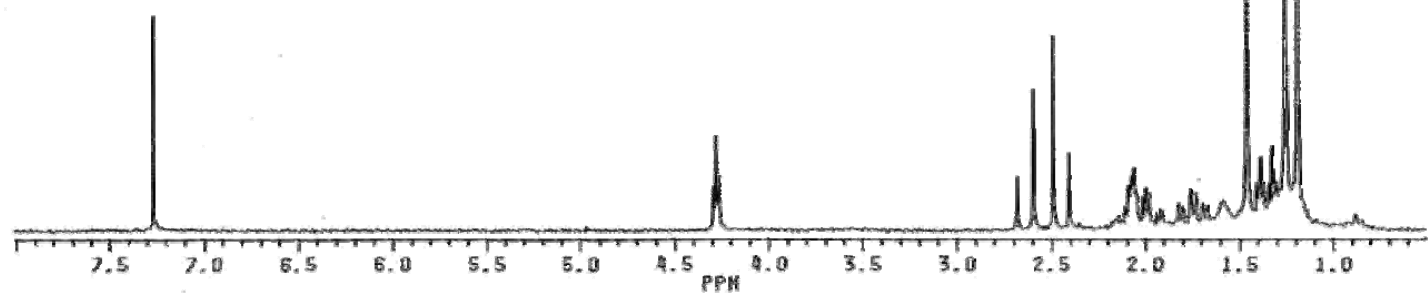


Fig. 35c

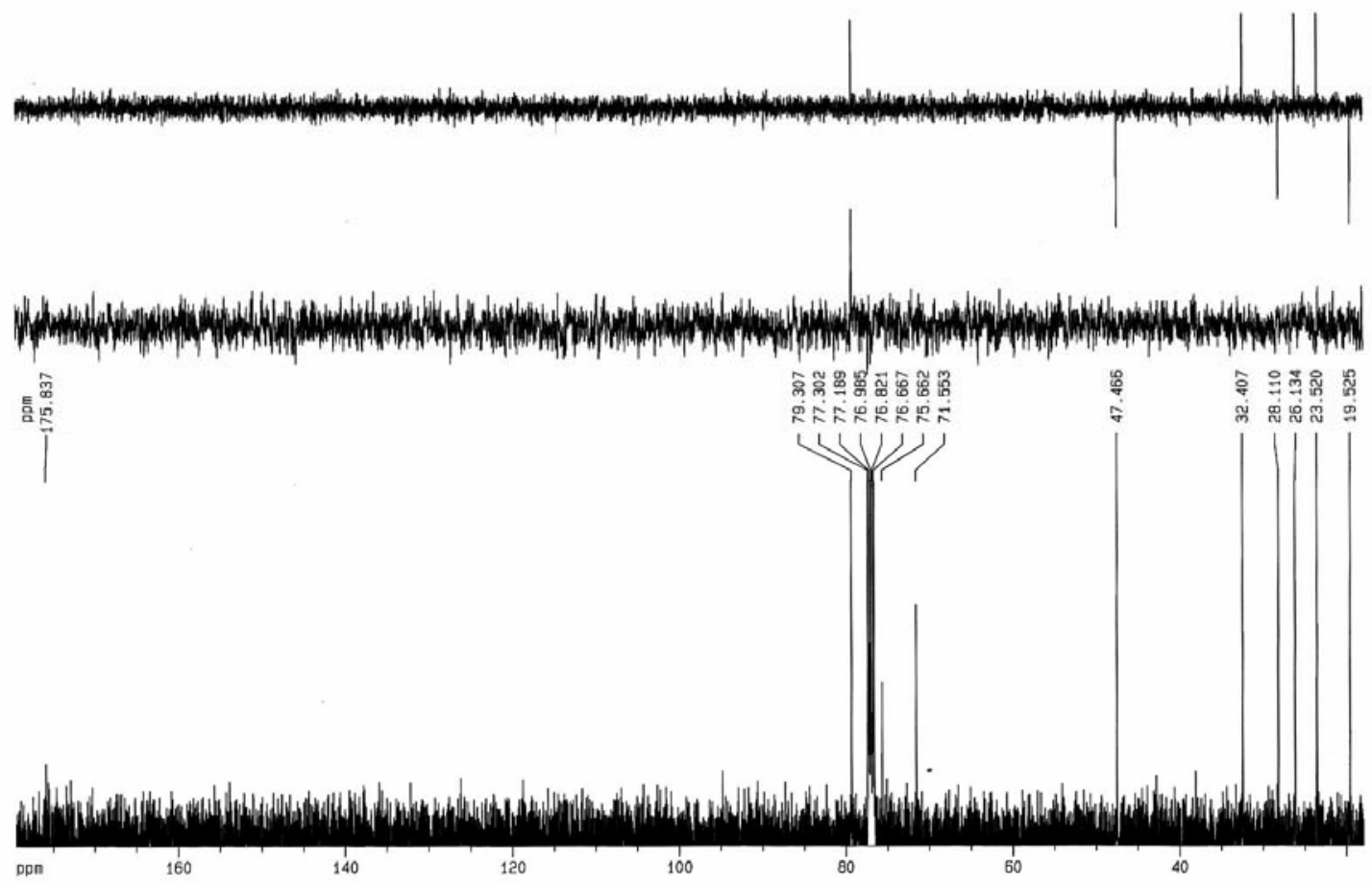

Fig. 35d

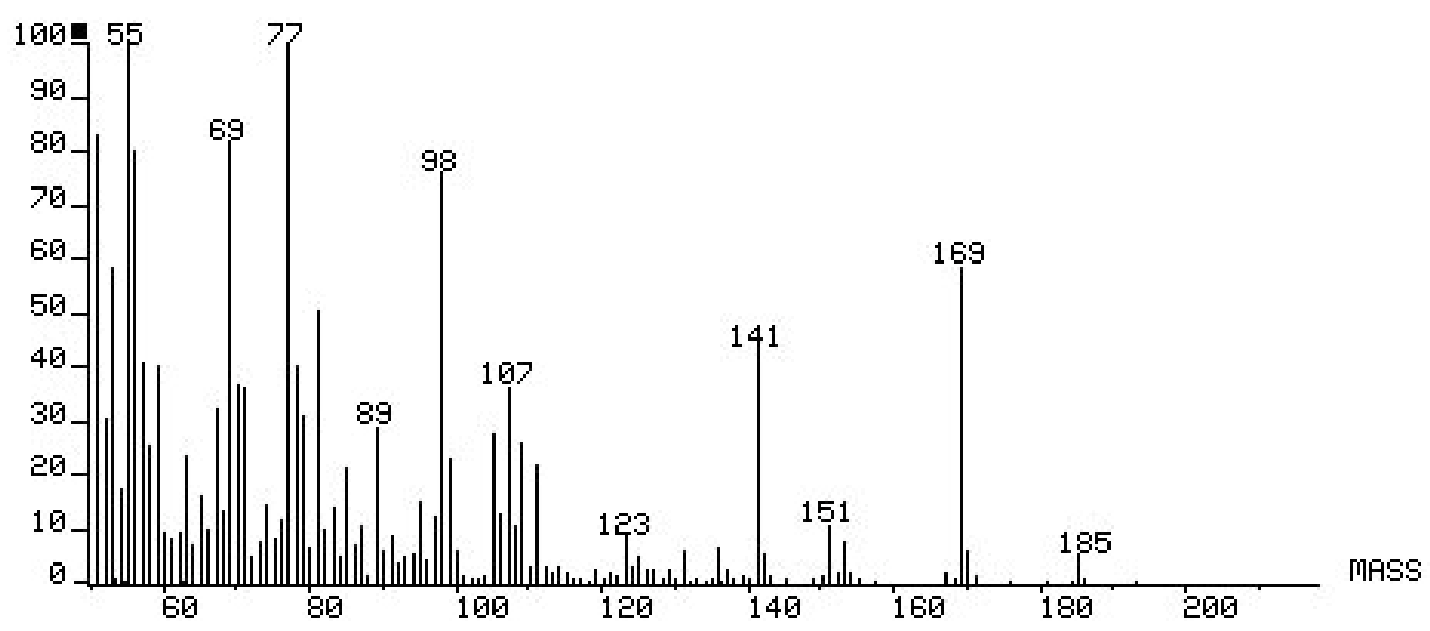


Fig. 35e

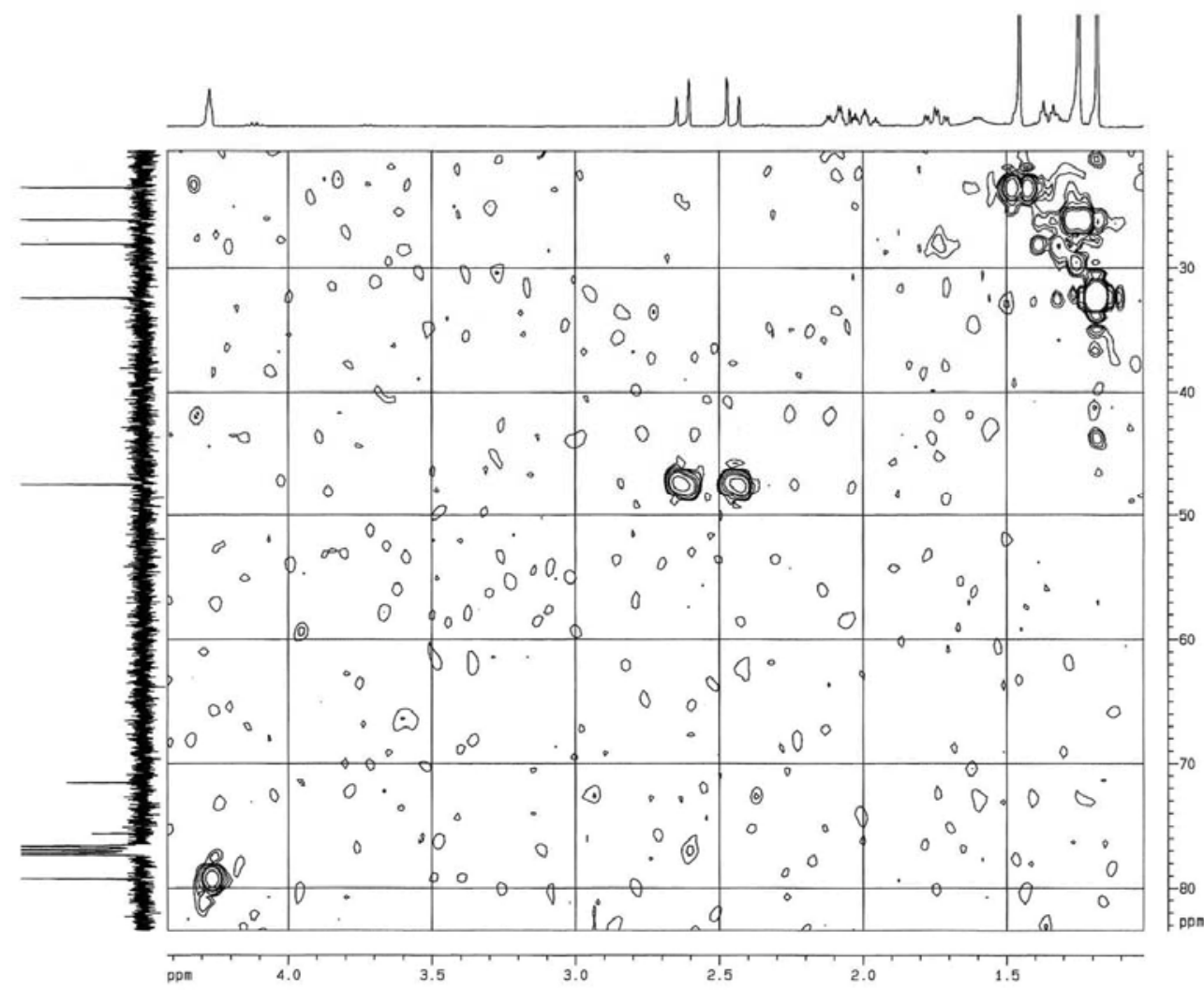

Fig. 35f

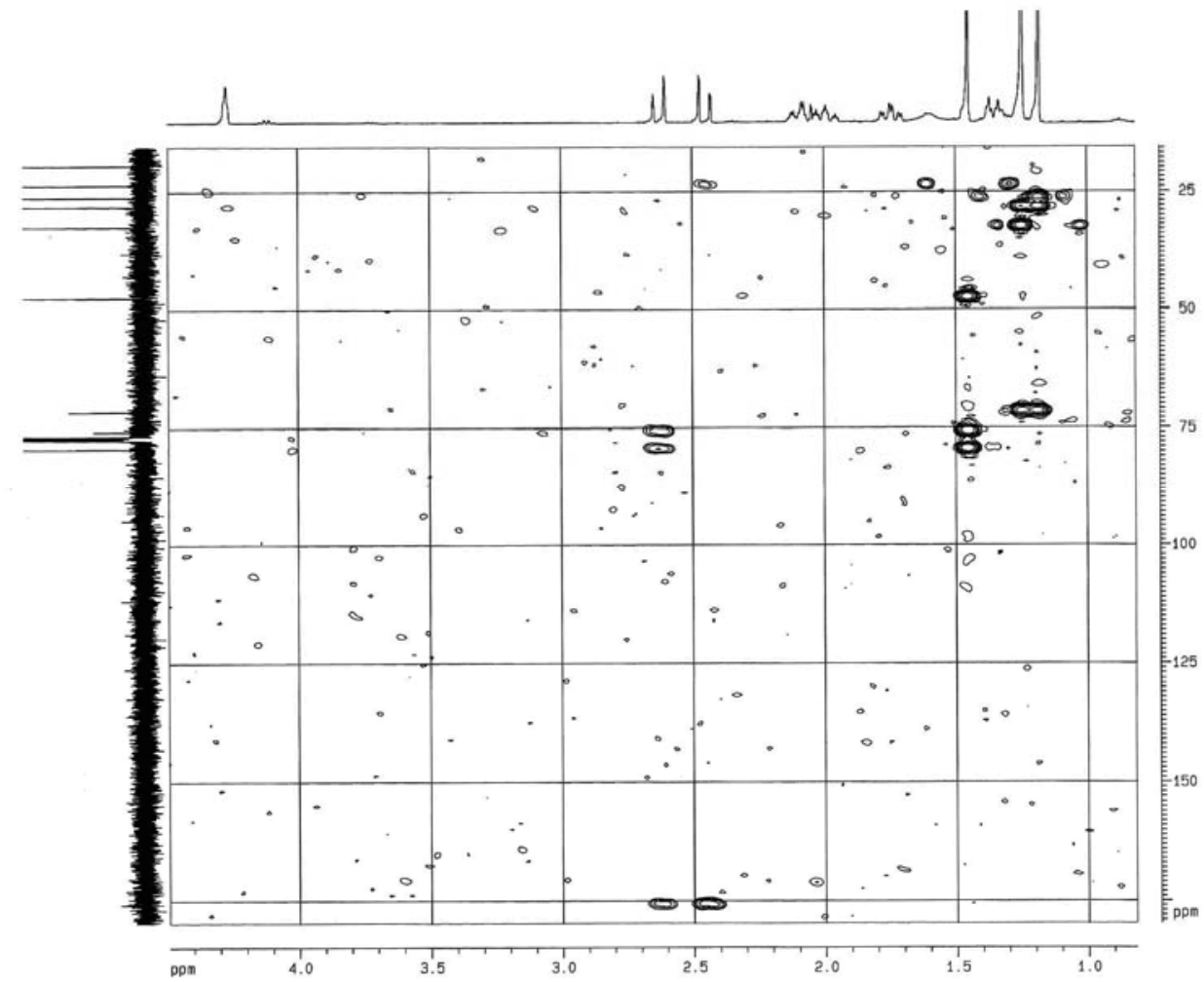


Fig. 35g

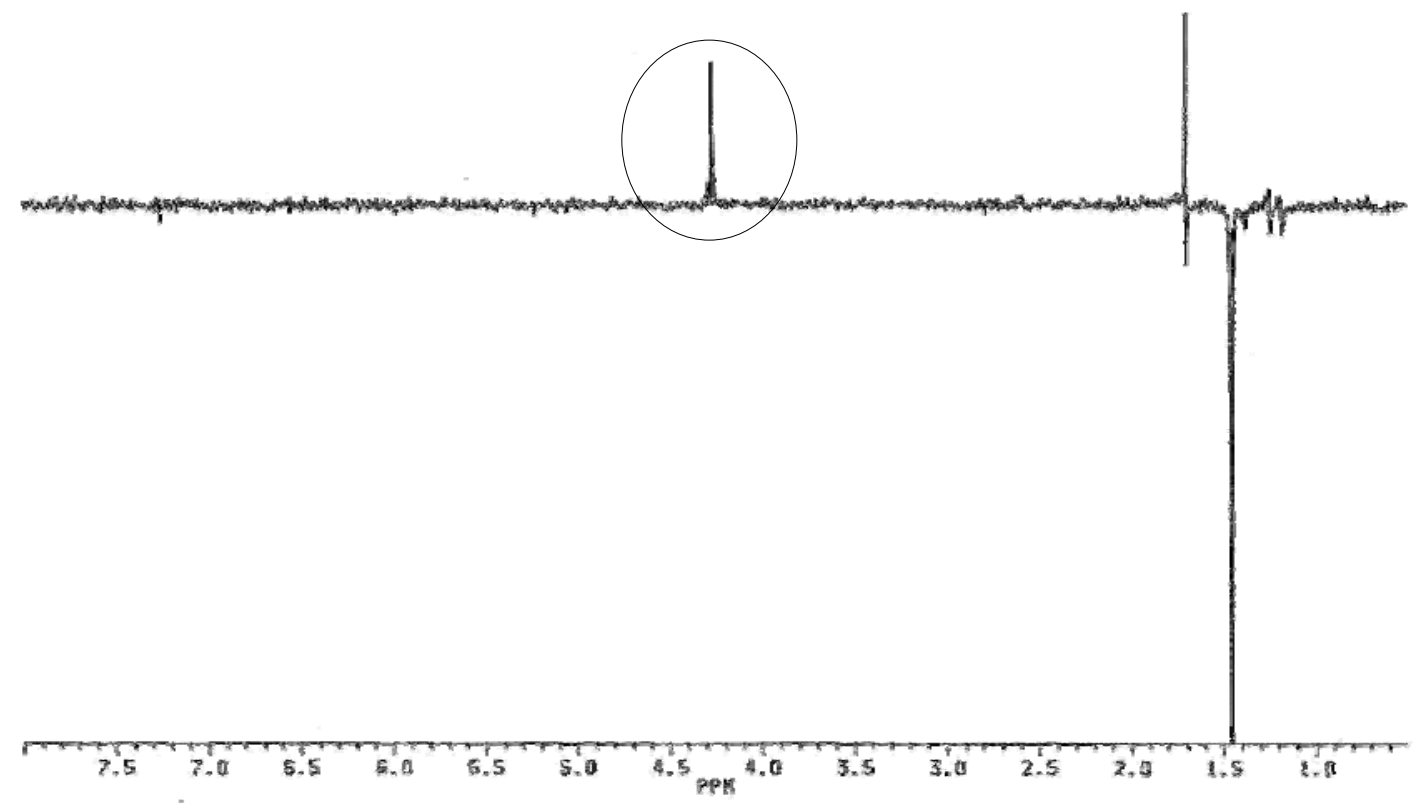


Fig. 36a

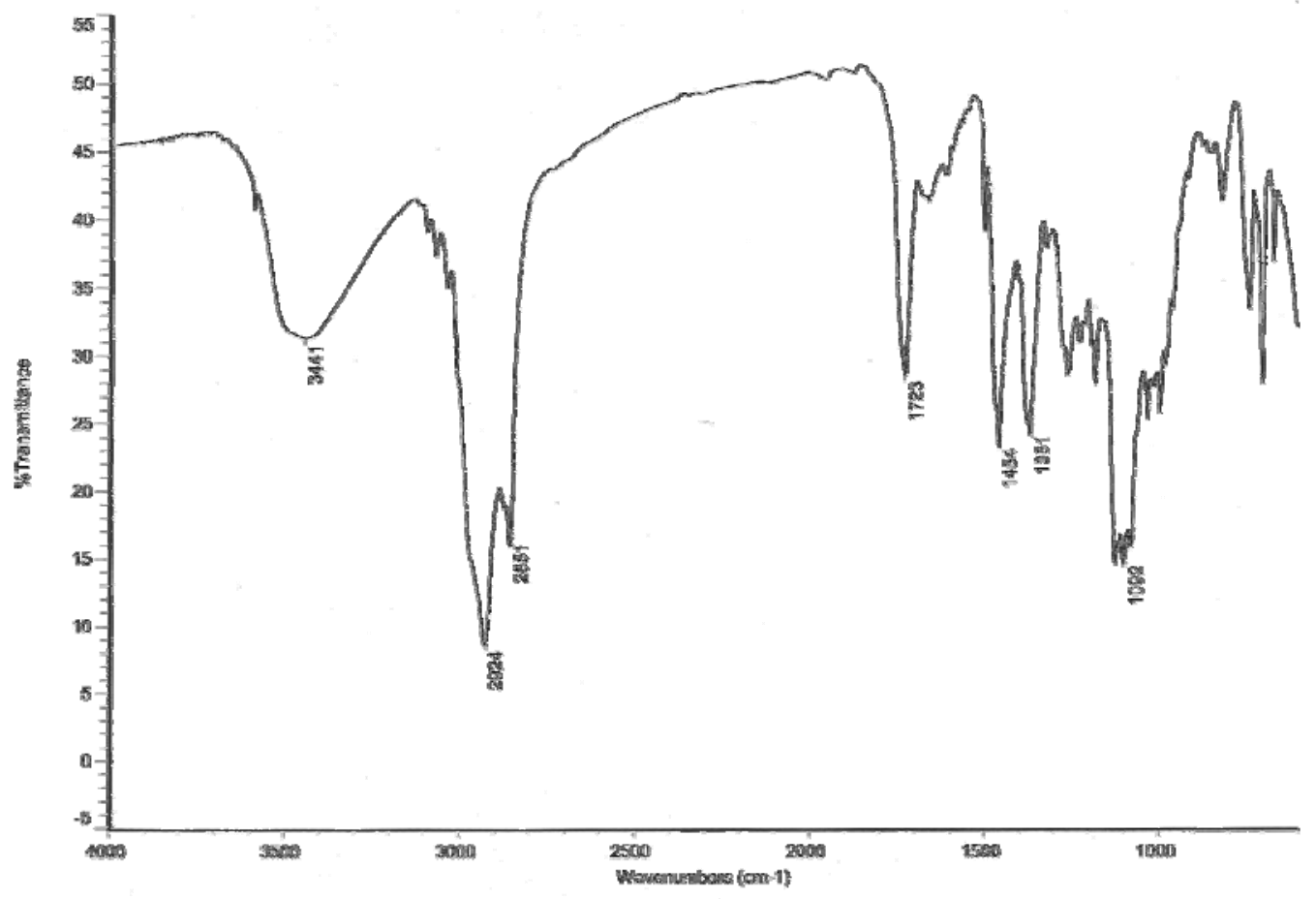

Fig. 36b

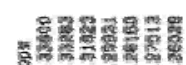

visis

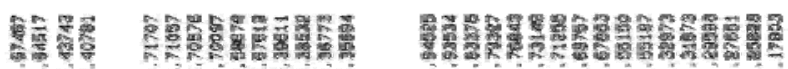

VI

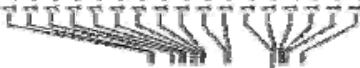

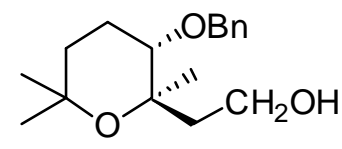

42

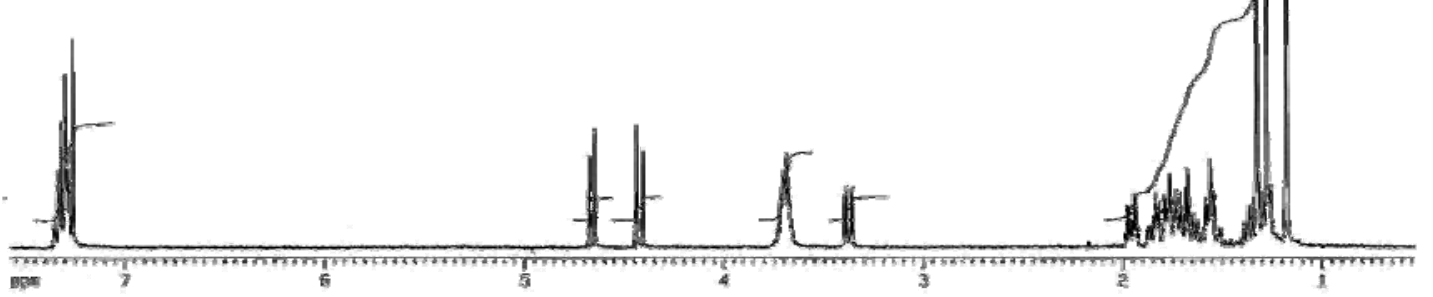


Fig. 36c
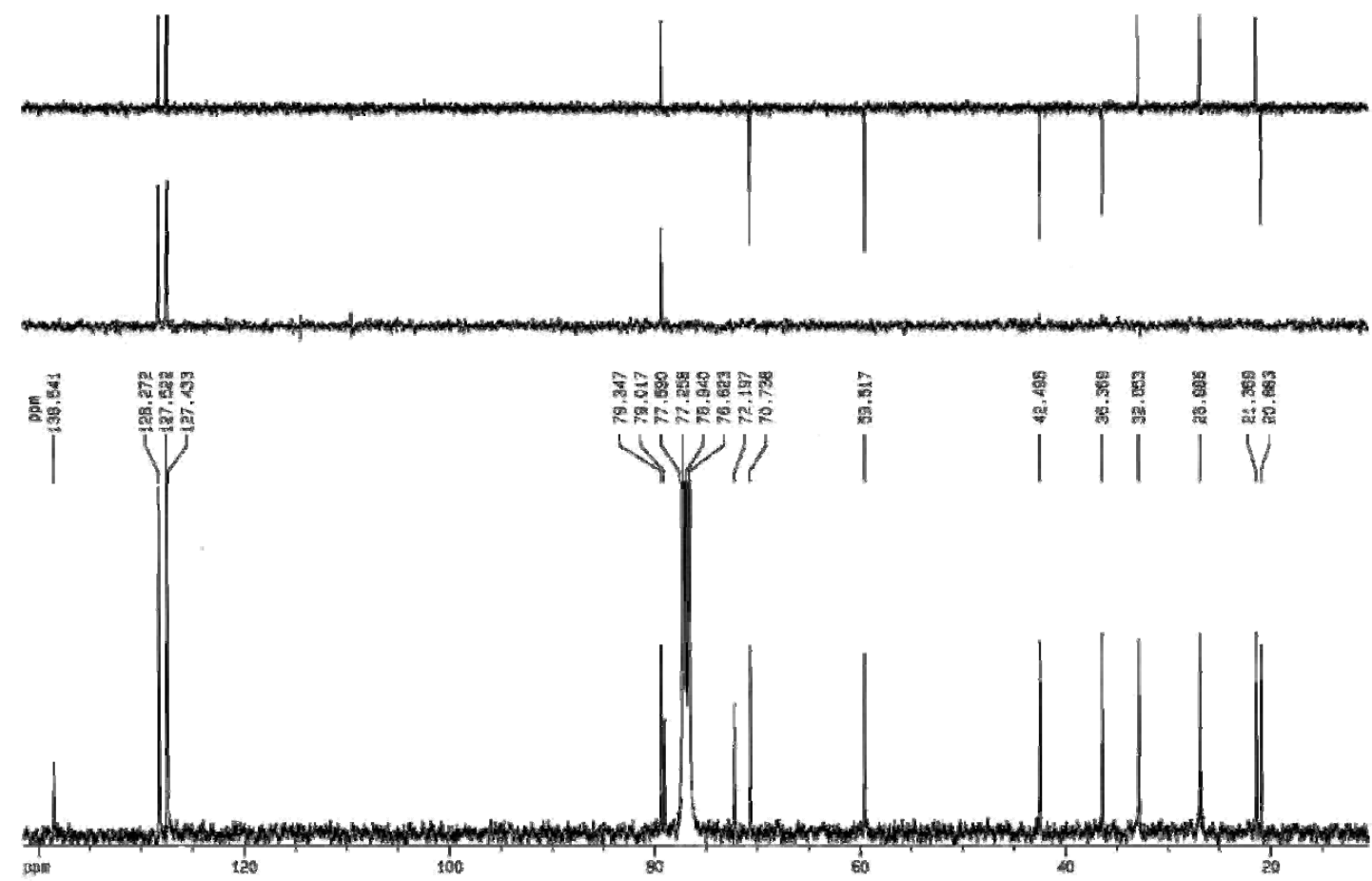

Fig. 36d

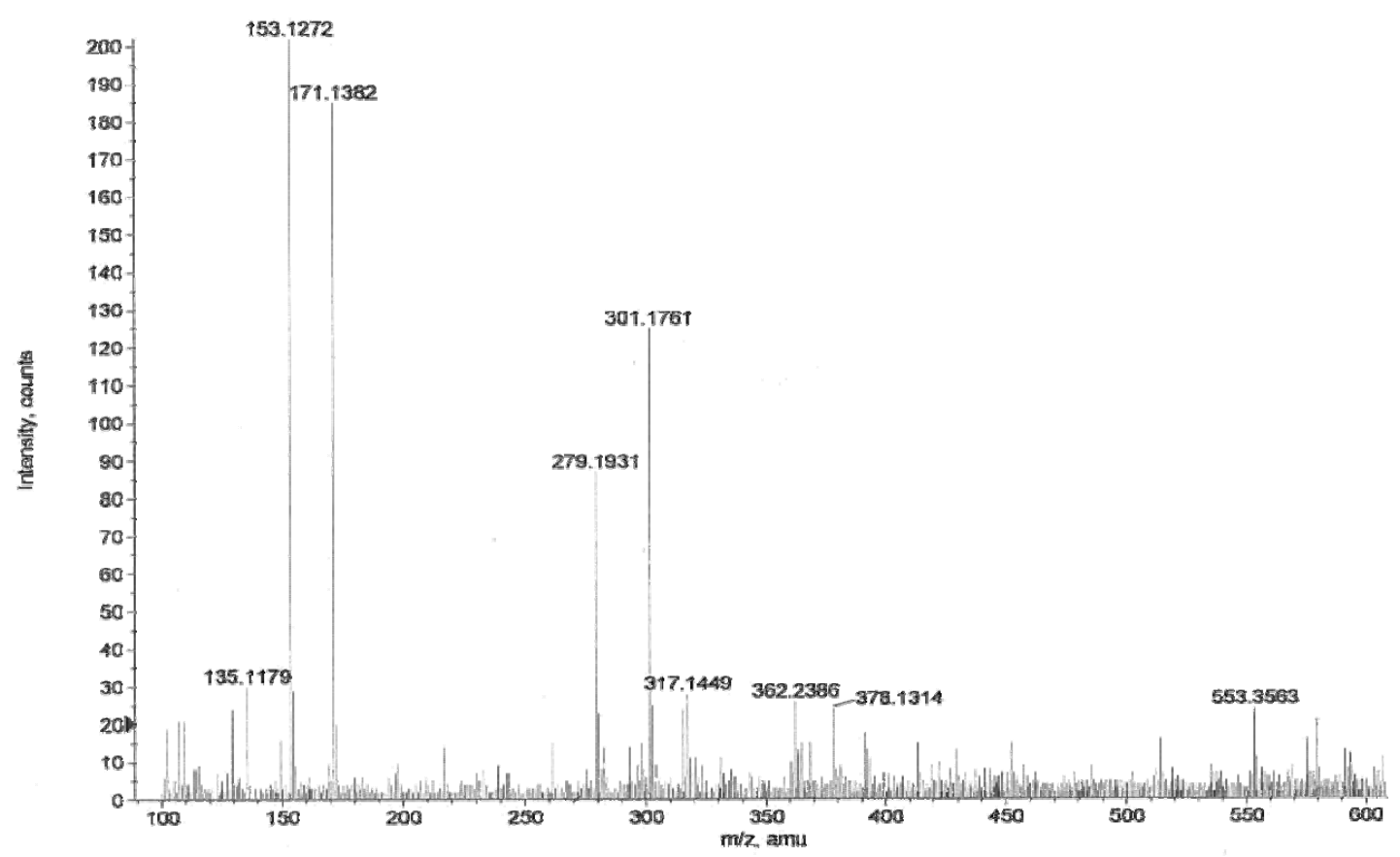


Fig. 37a

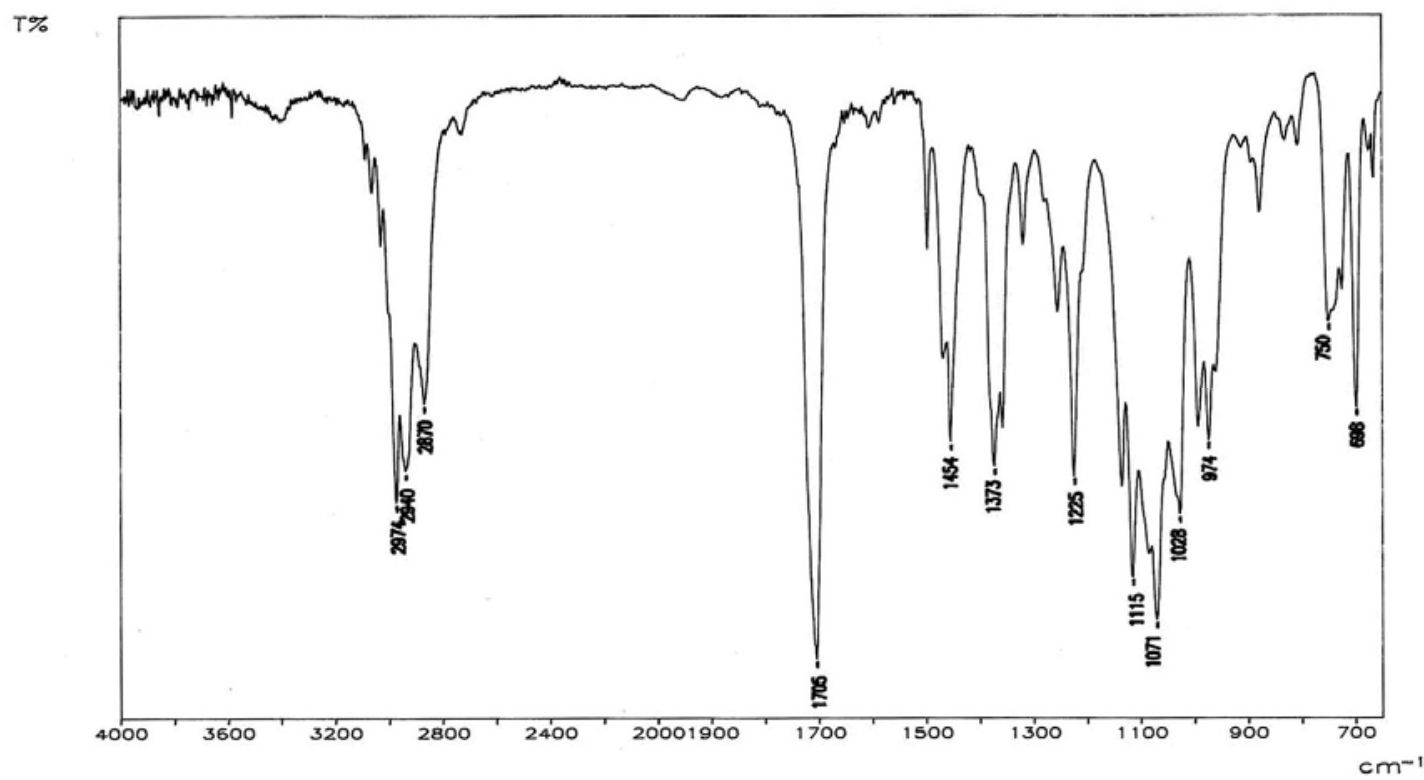

Fig.37b

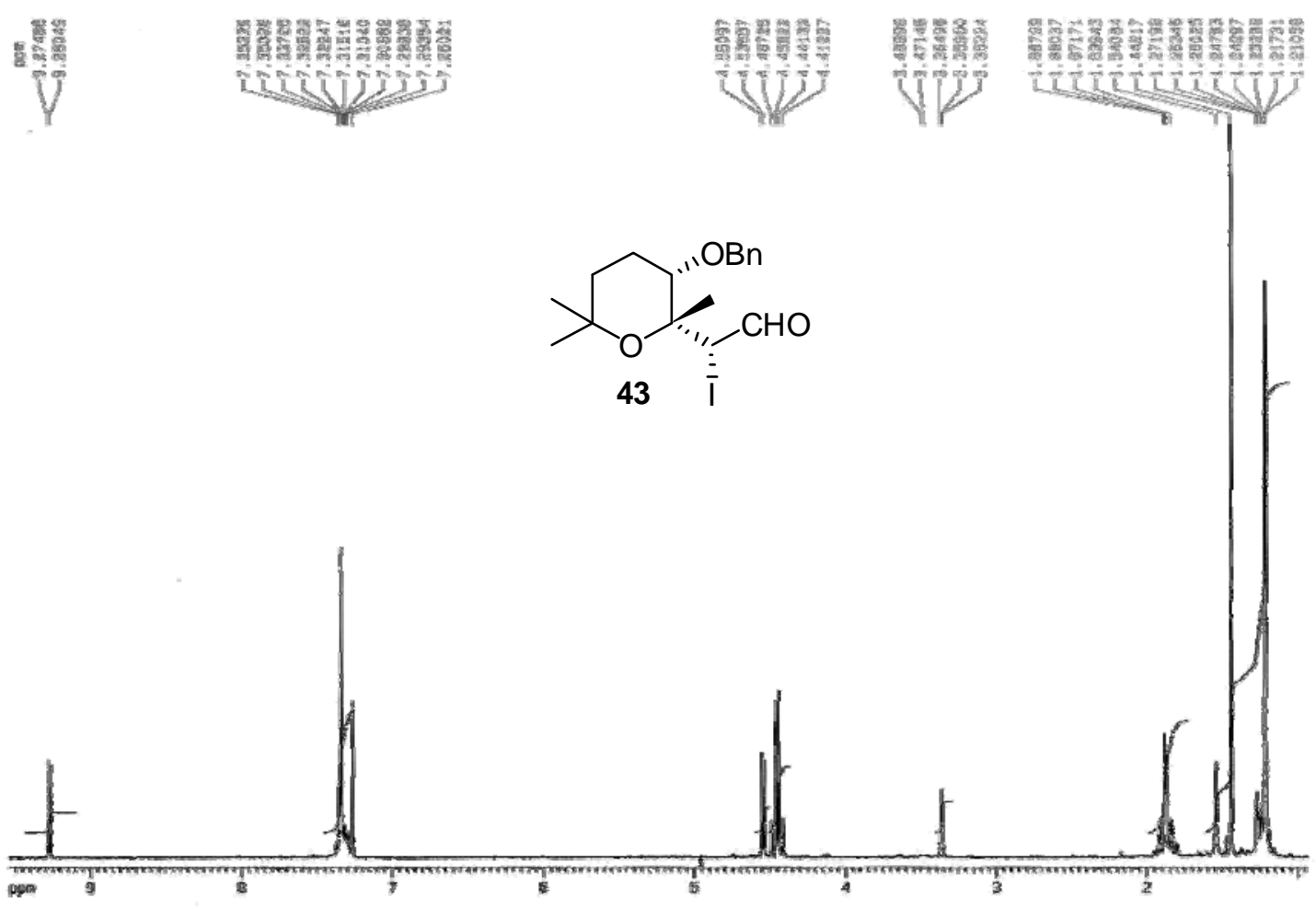


Fig. 37c

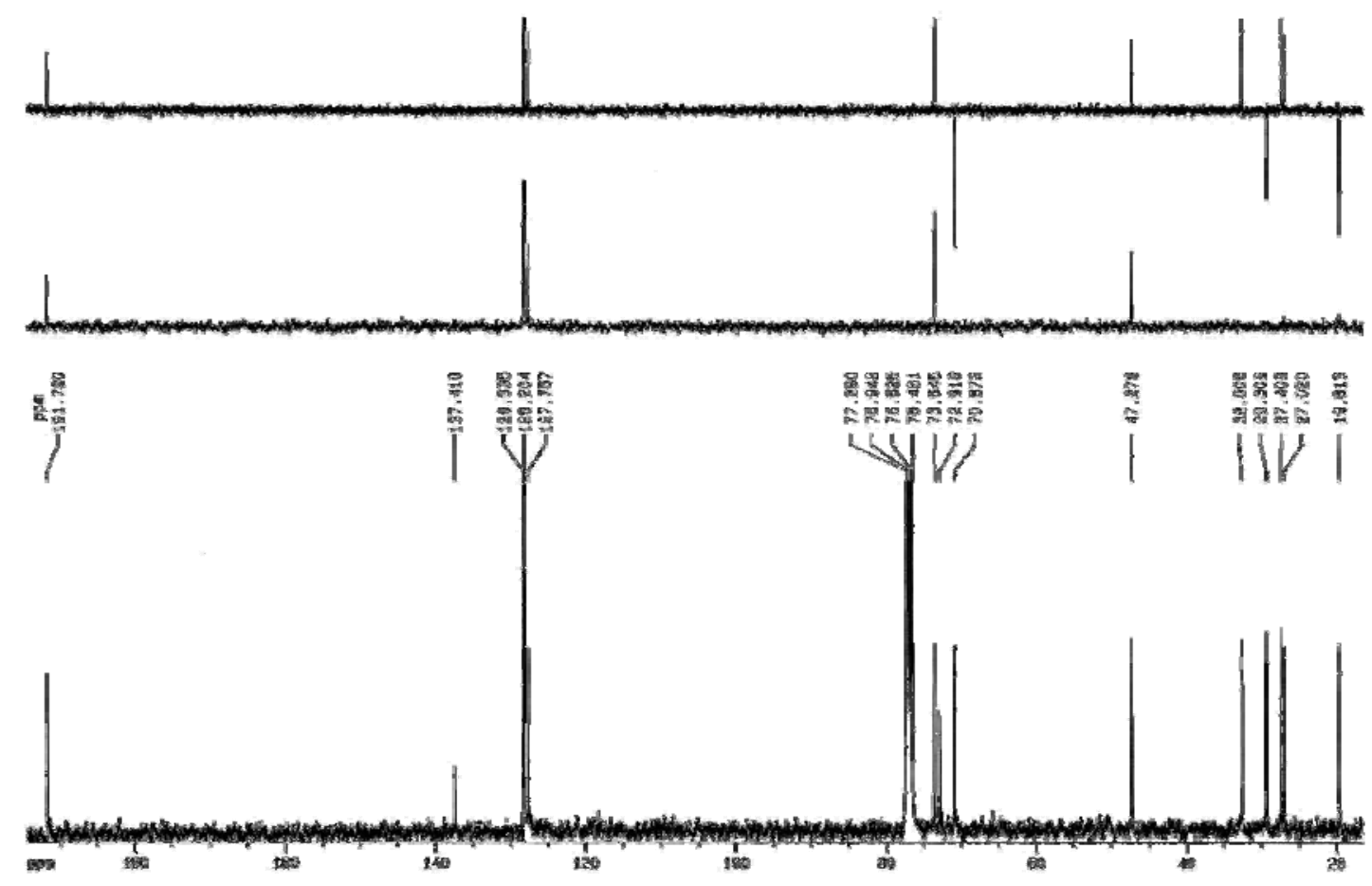

Fig. 37d

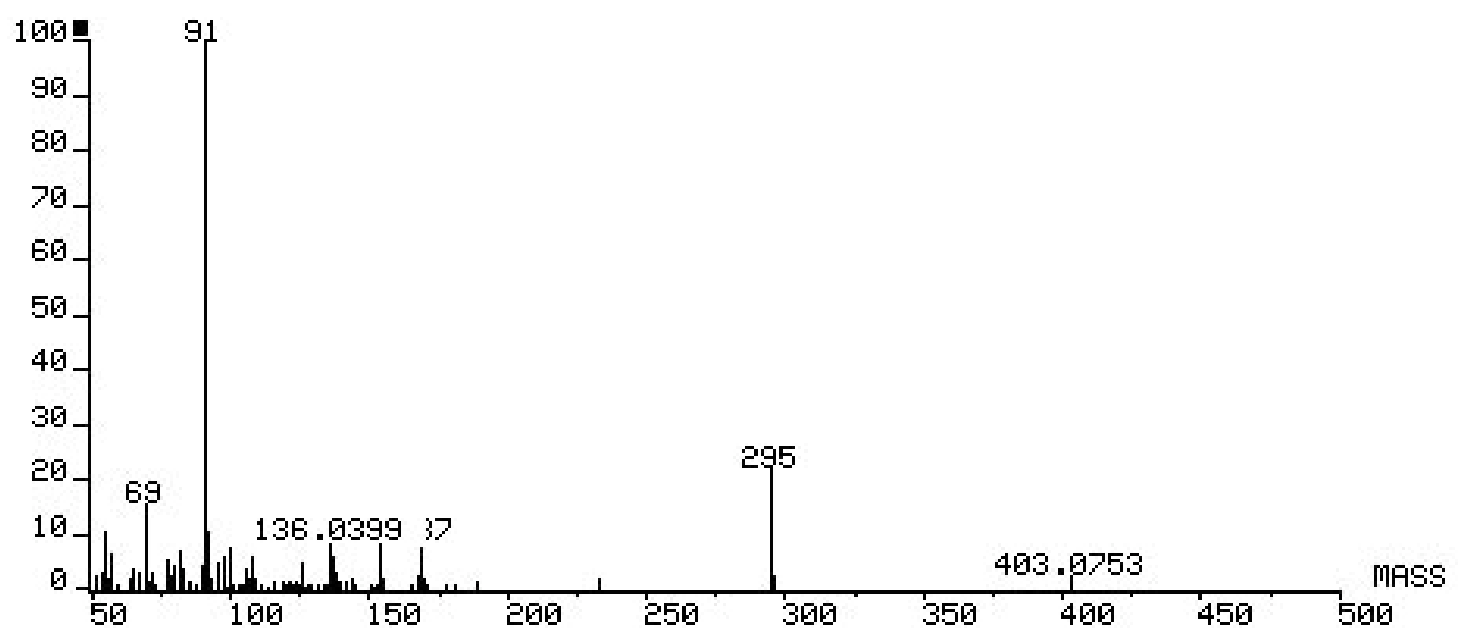


Fig. 37e

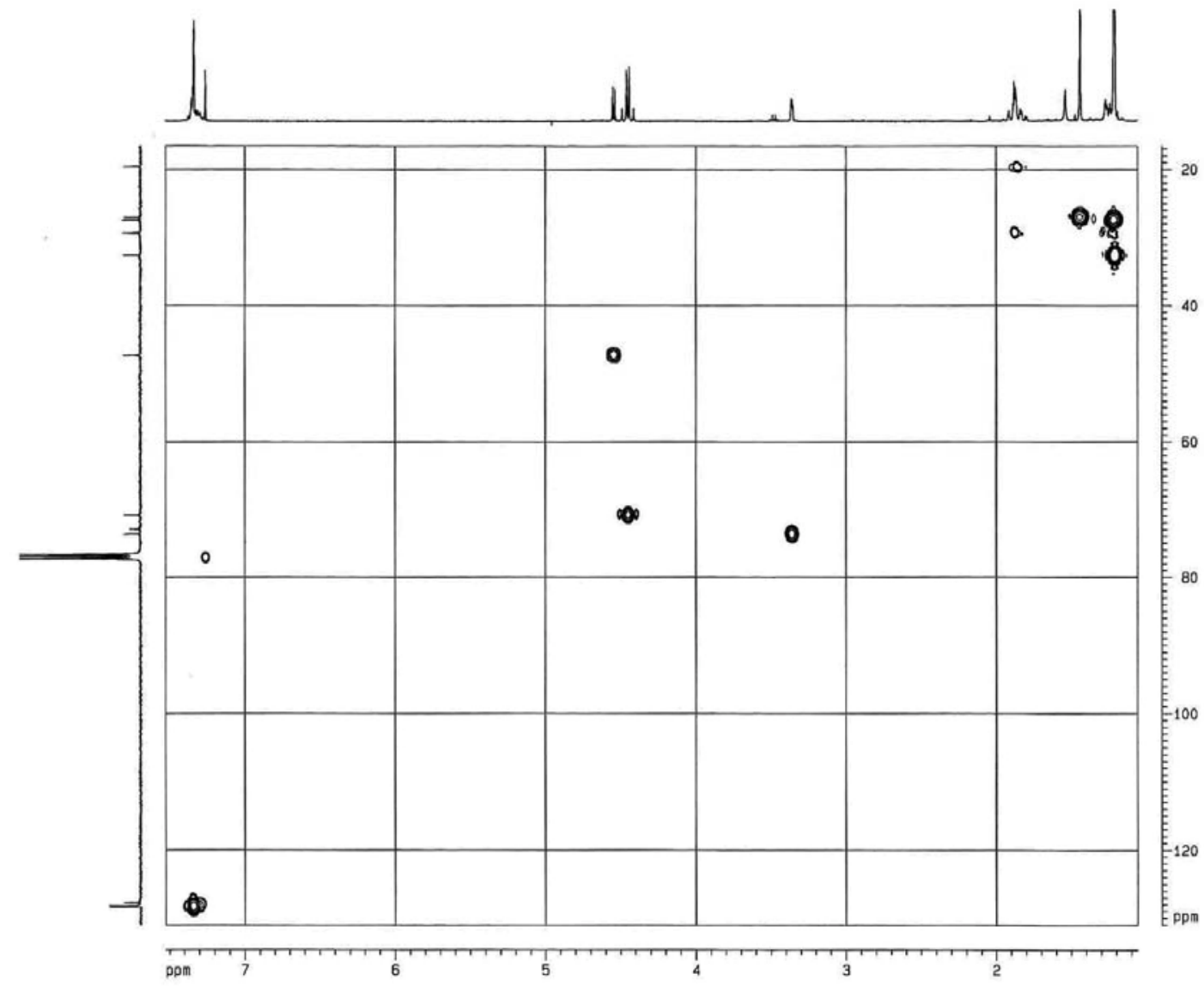

Fig. 37f

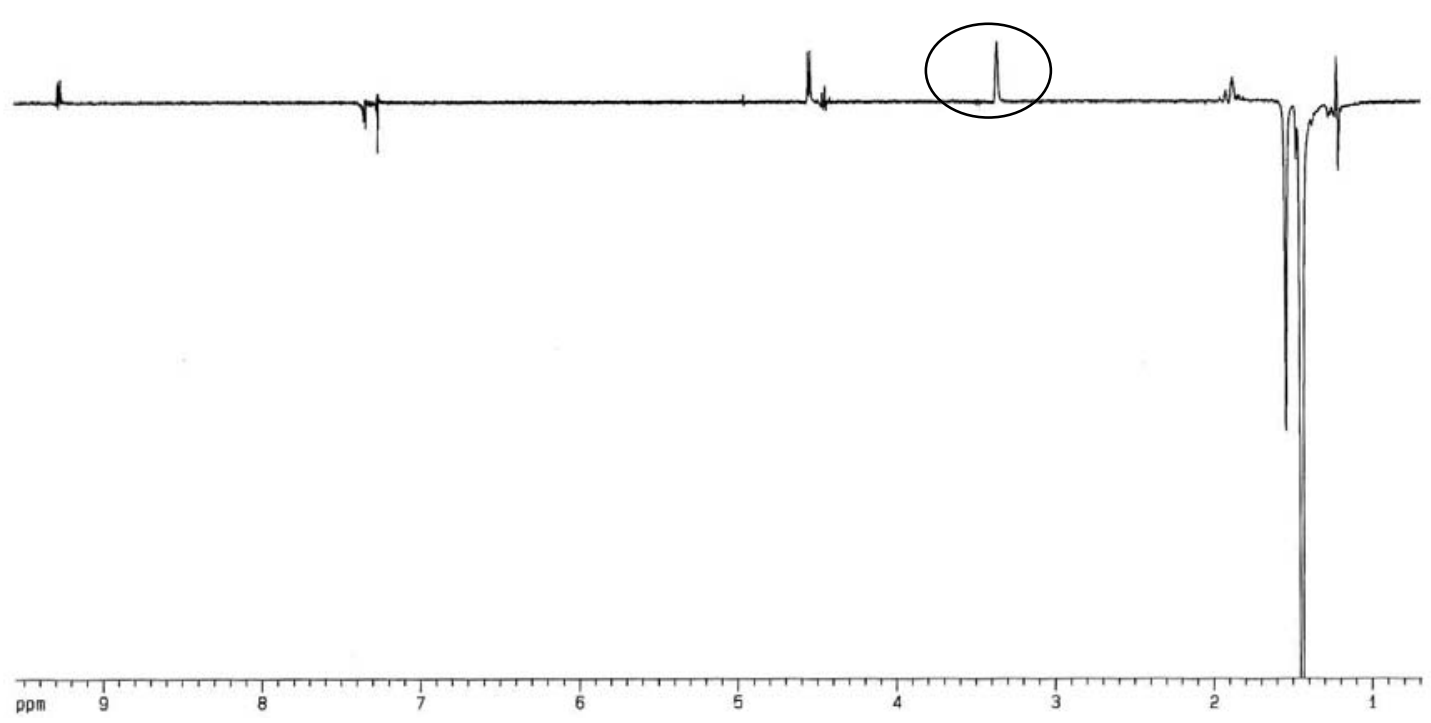


Fig. 38a

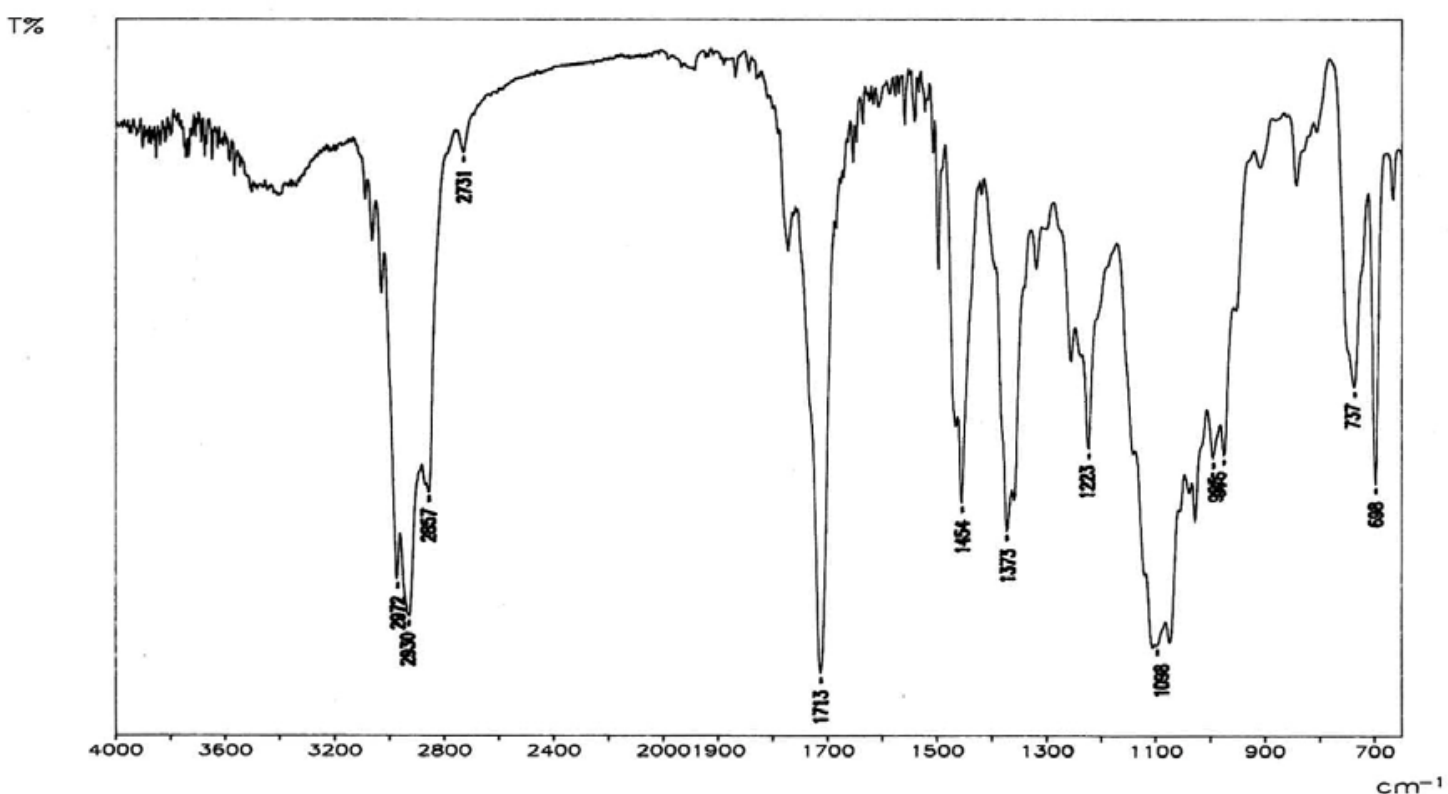

Fig. 38b

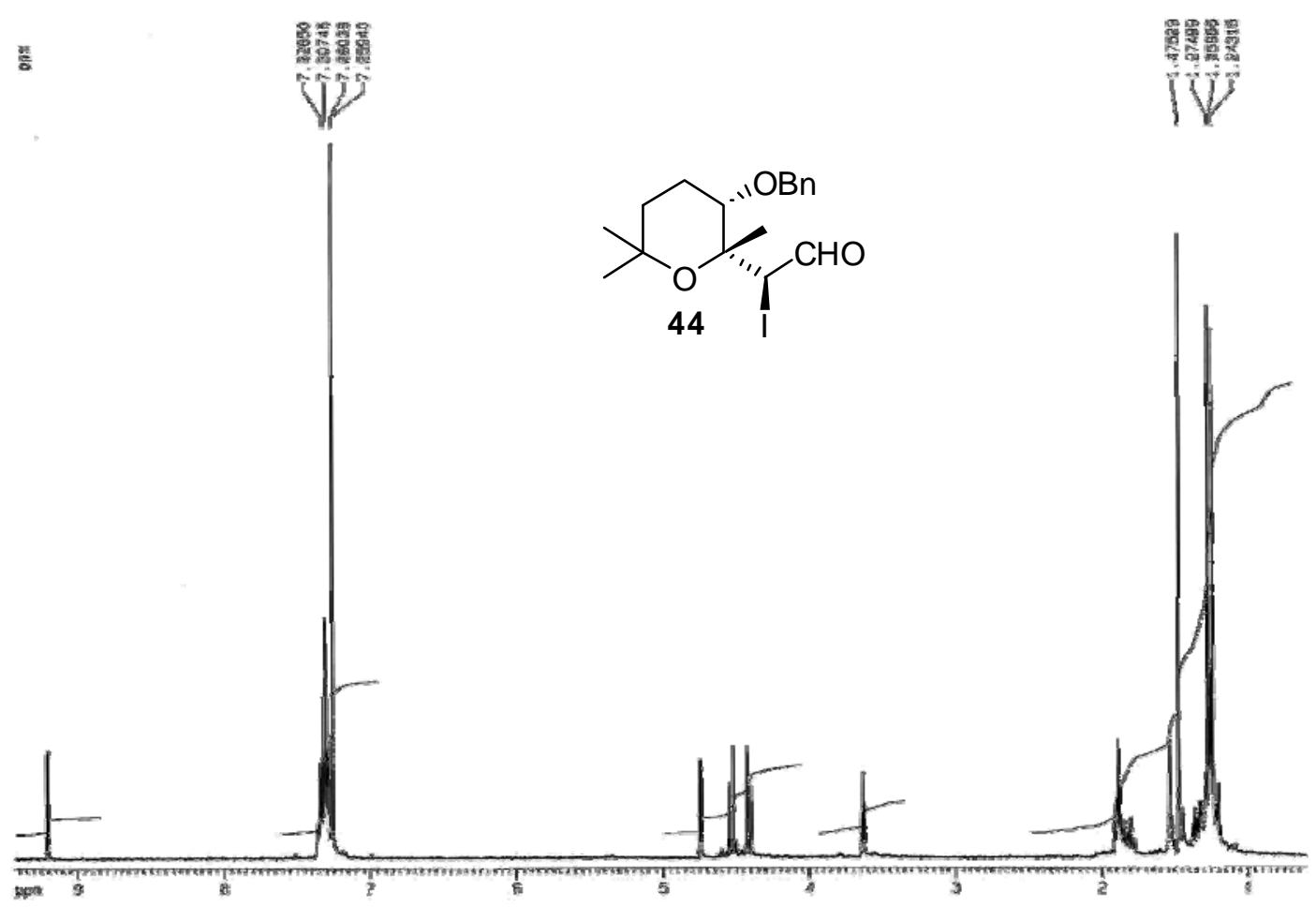


Fig. 38c

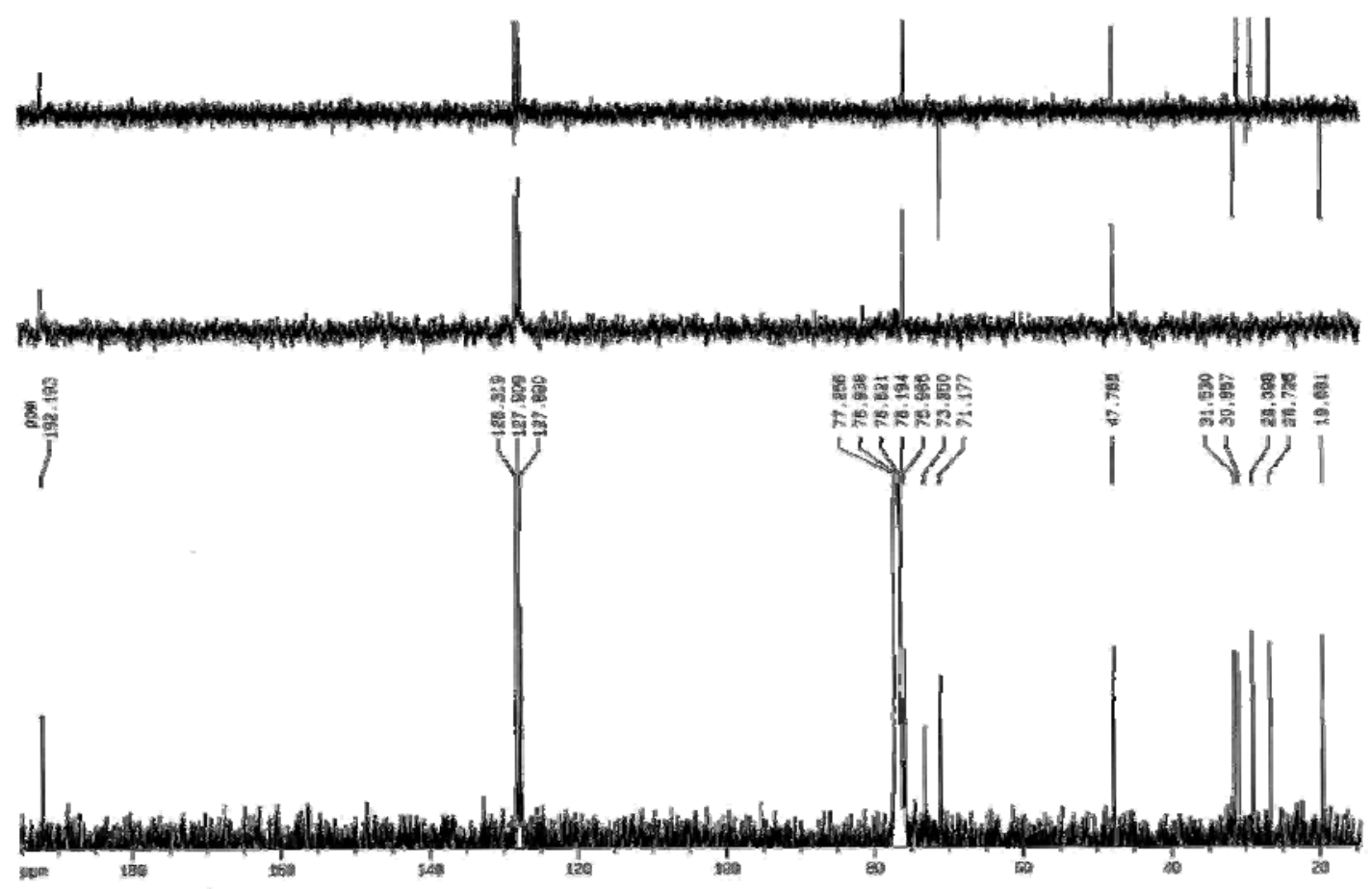

Fig. 38d

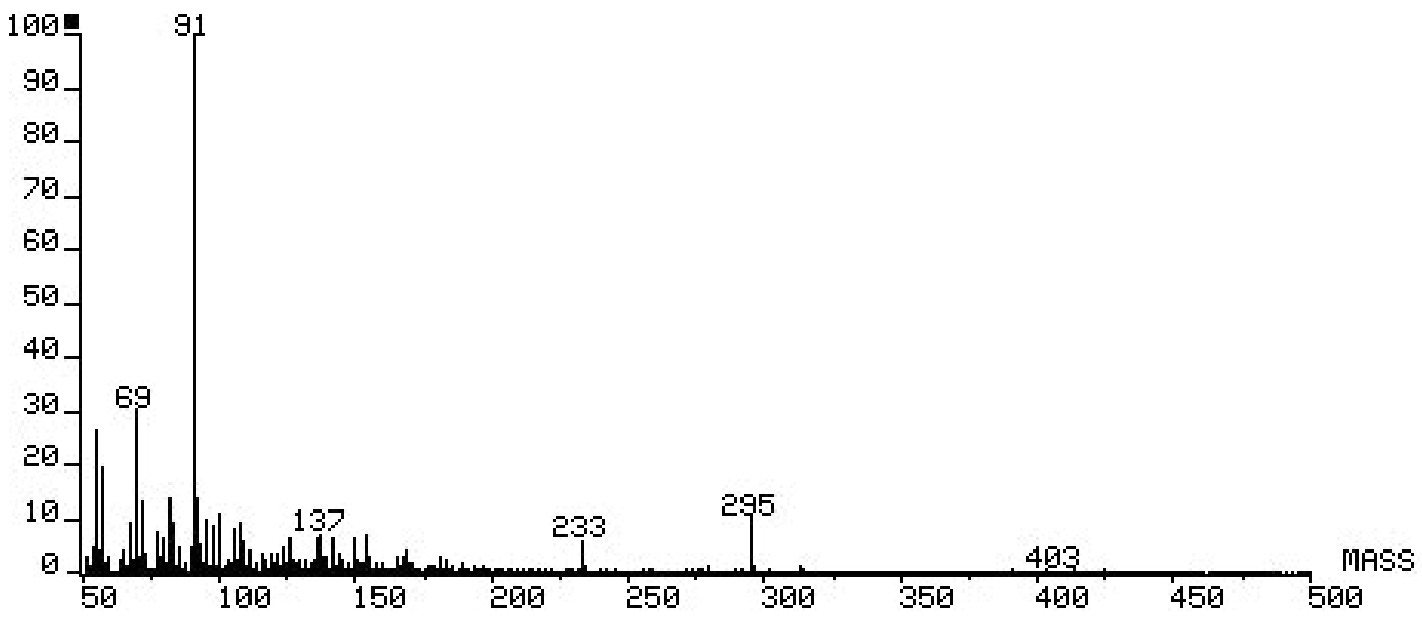


Fig. 39a

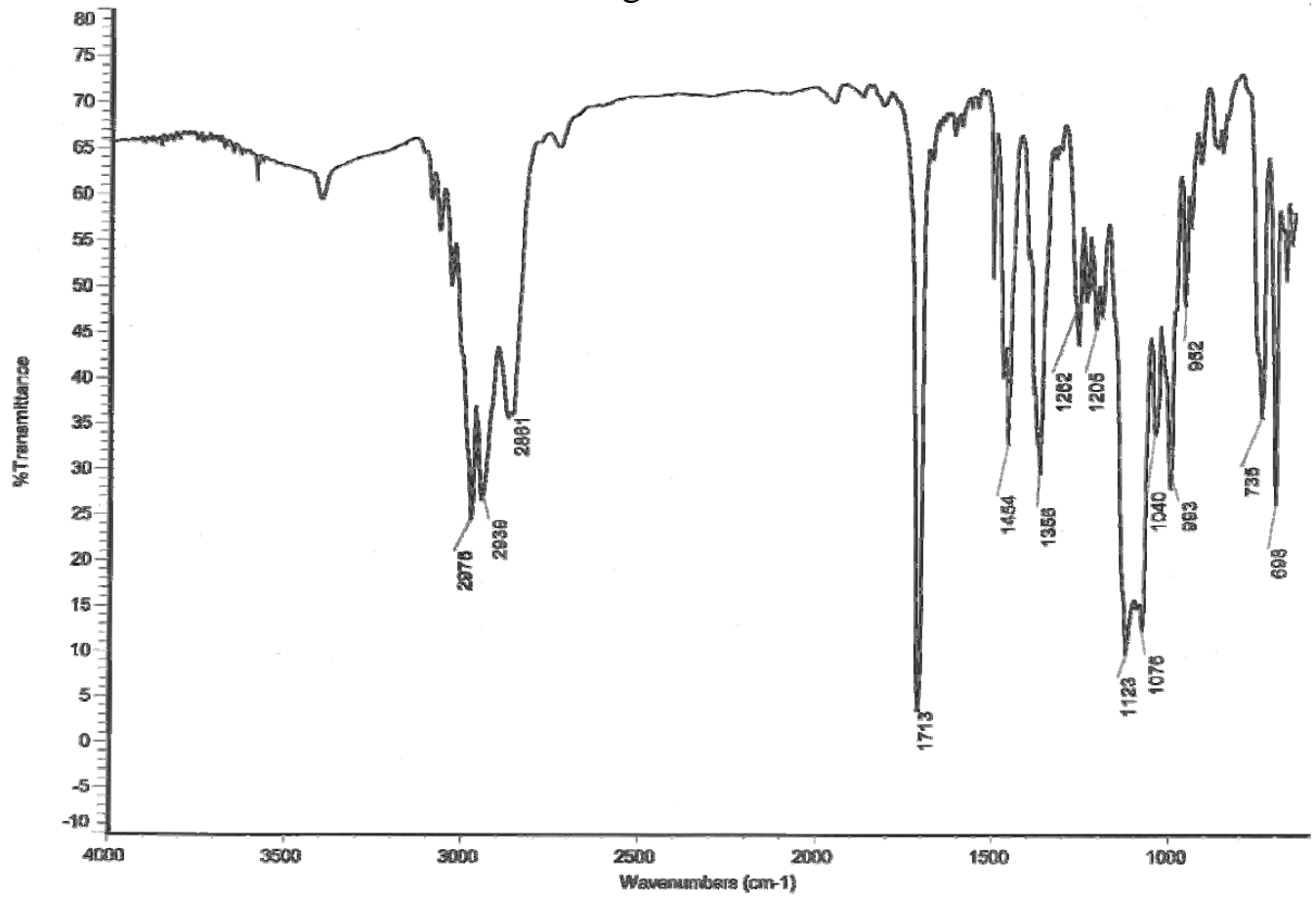

Fig. 39b

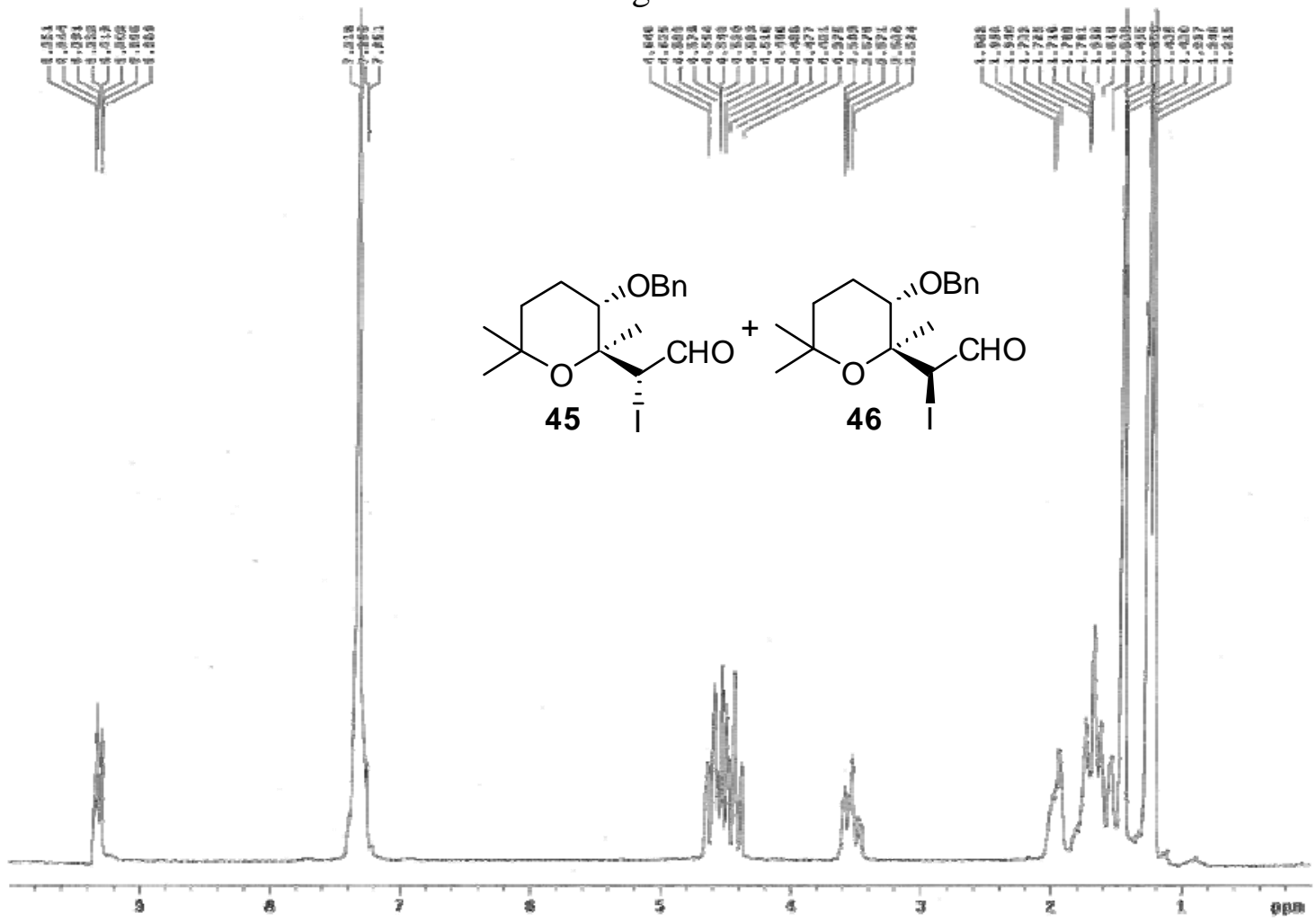


Fig. 39c
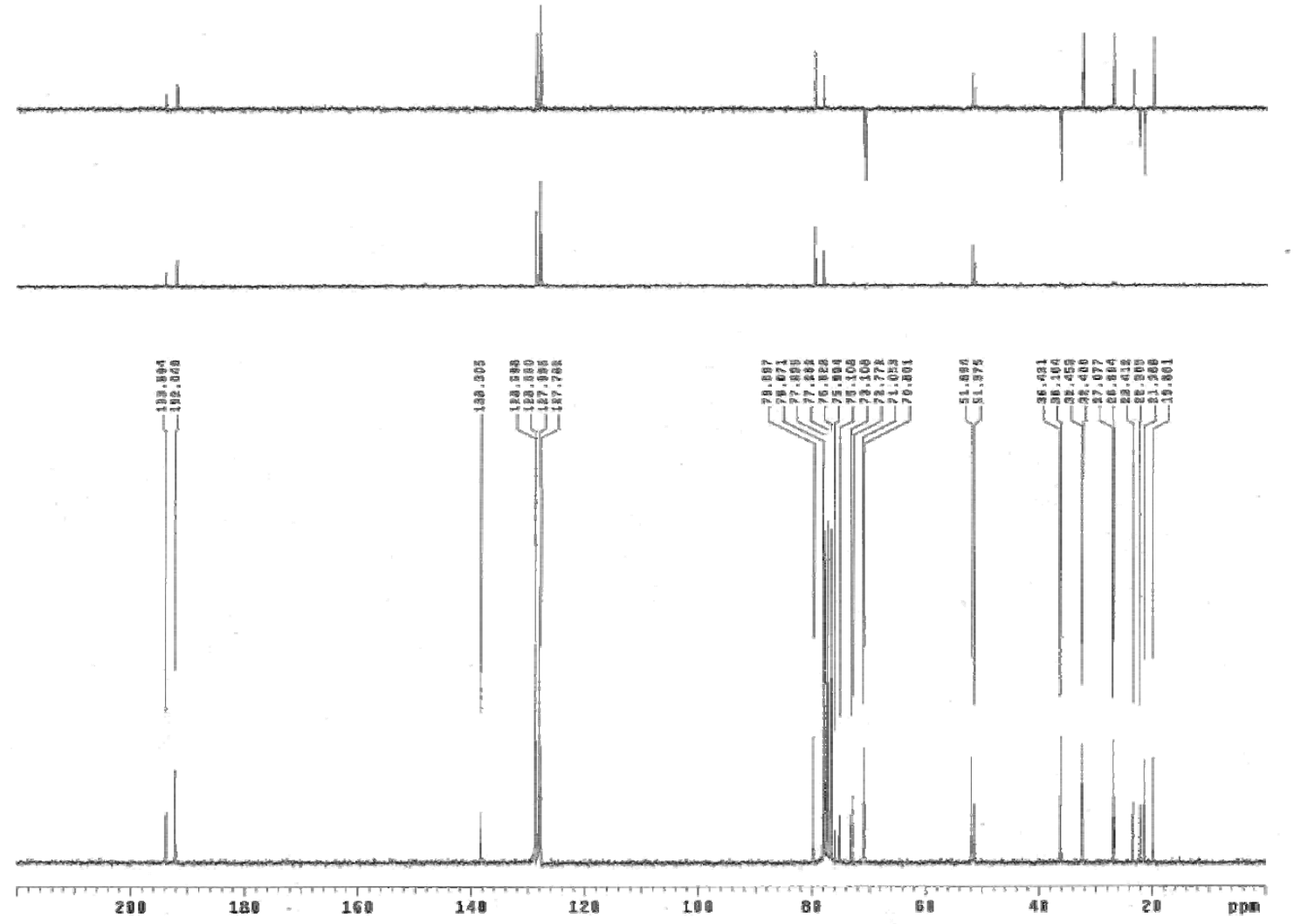
Fig. 40

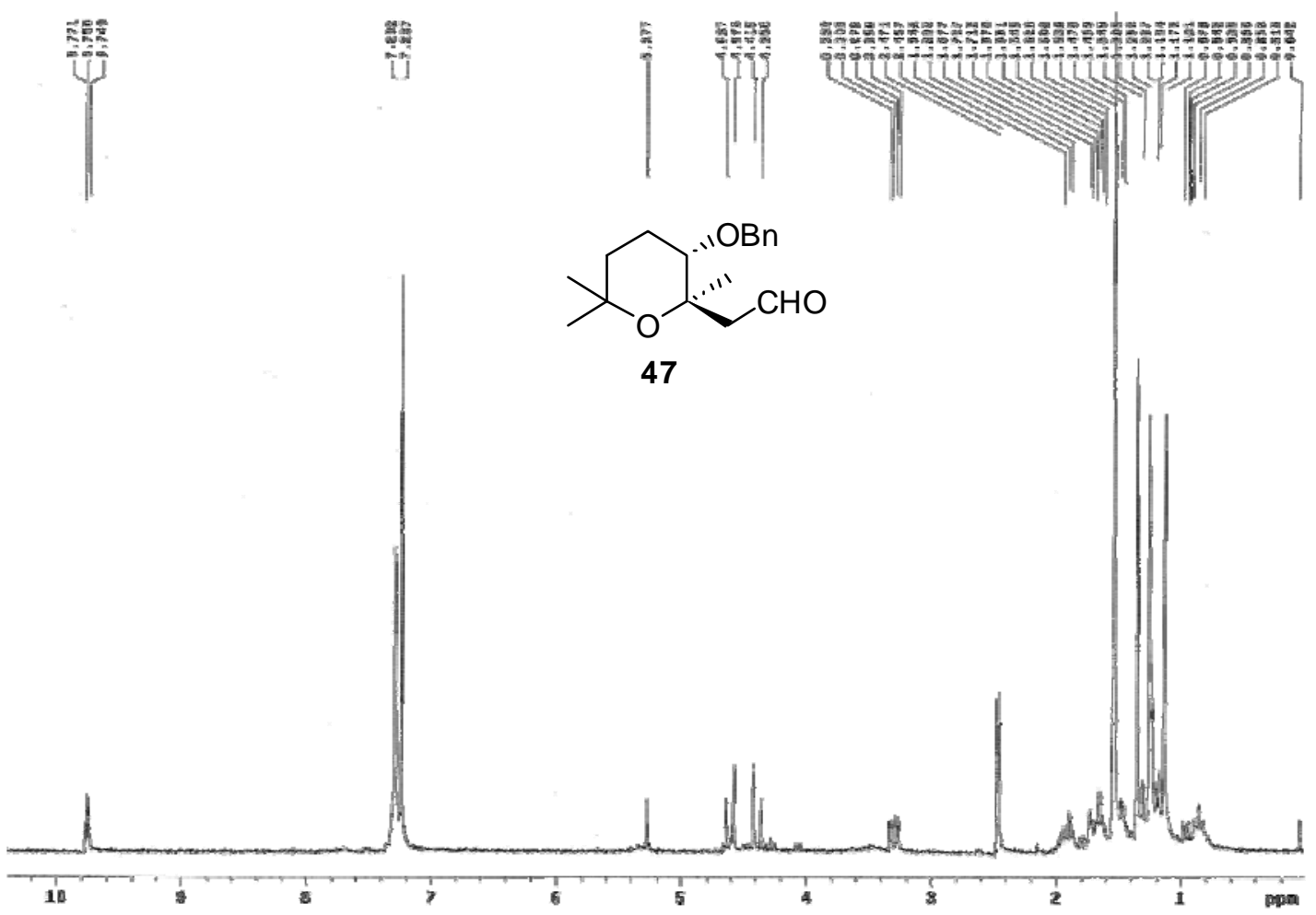


Fig. 41a

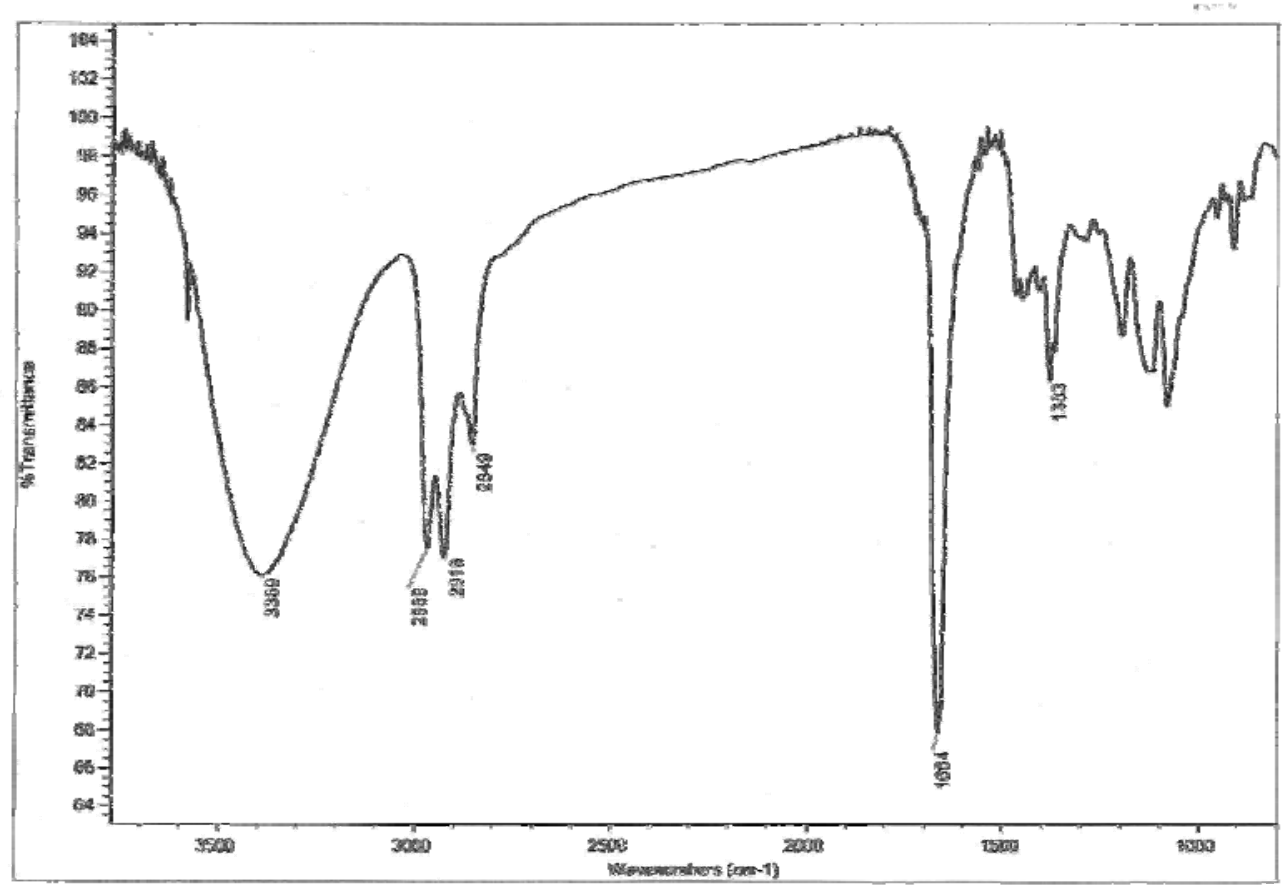

Fig. 41b
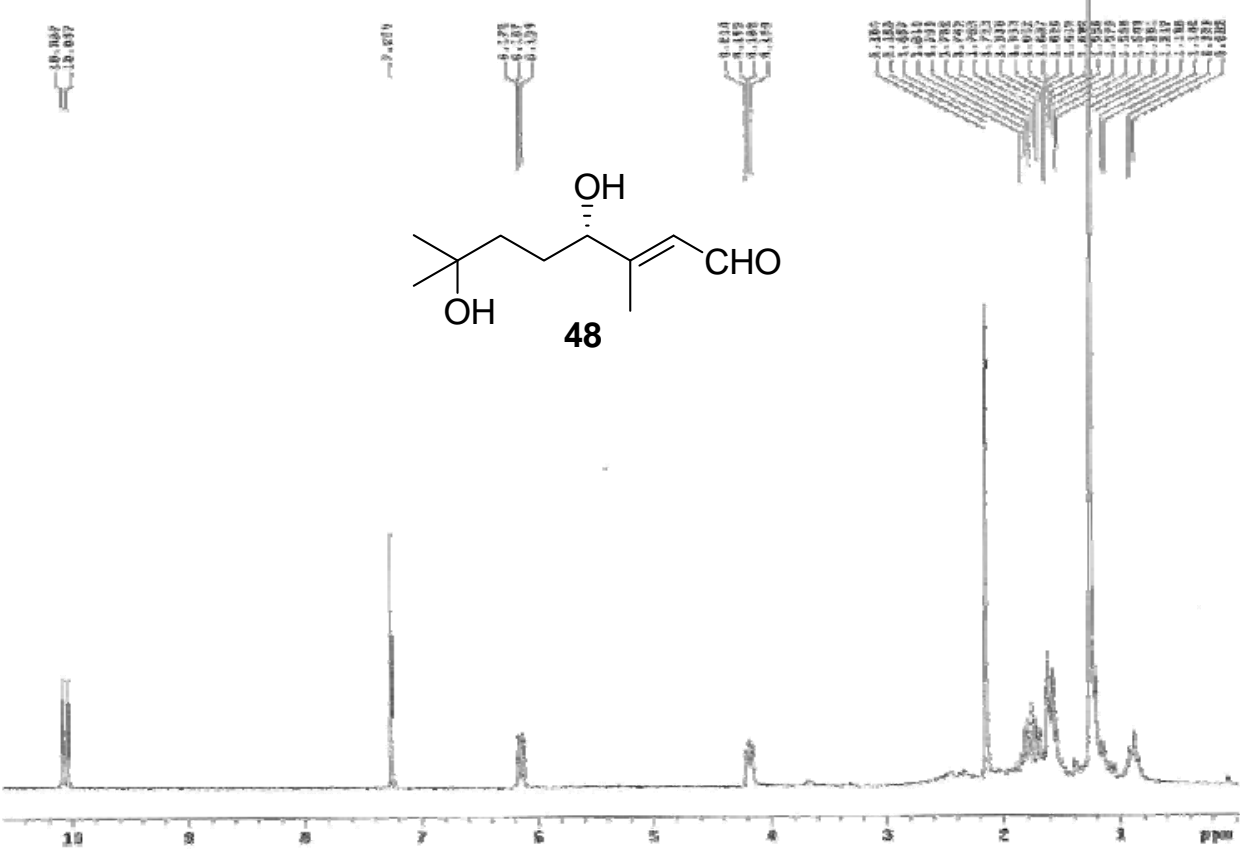
Fig. 41c

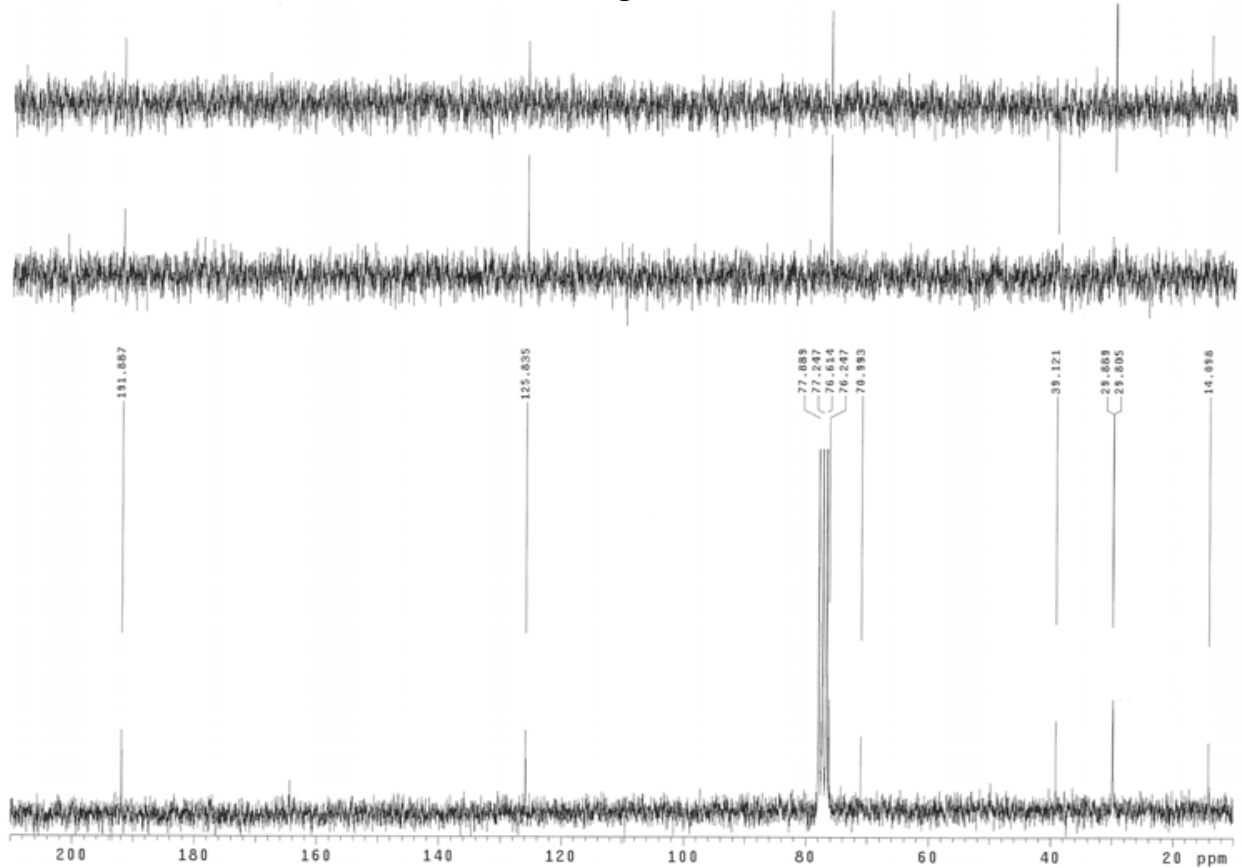


Fig. 42a

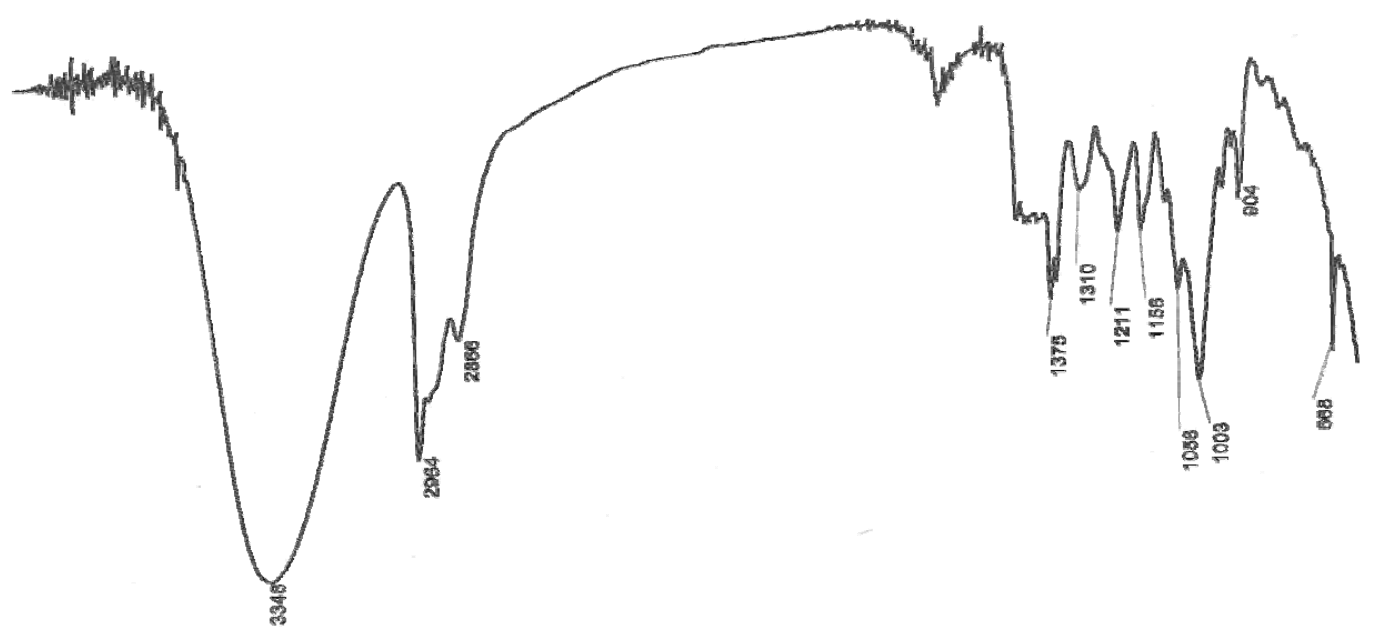

3500

3000

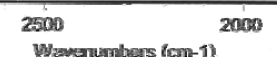

1500

1000

Fig. 42b
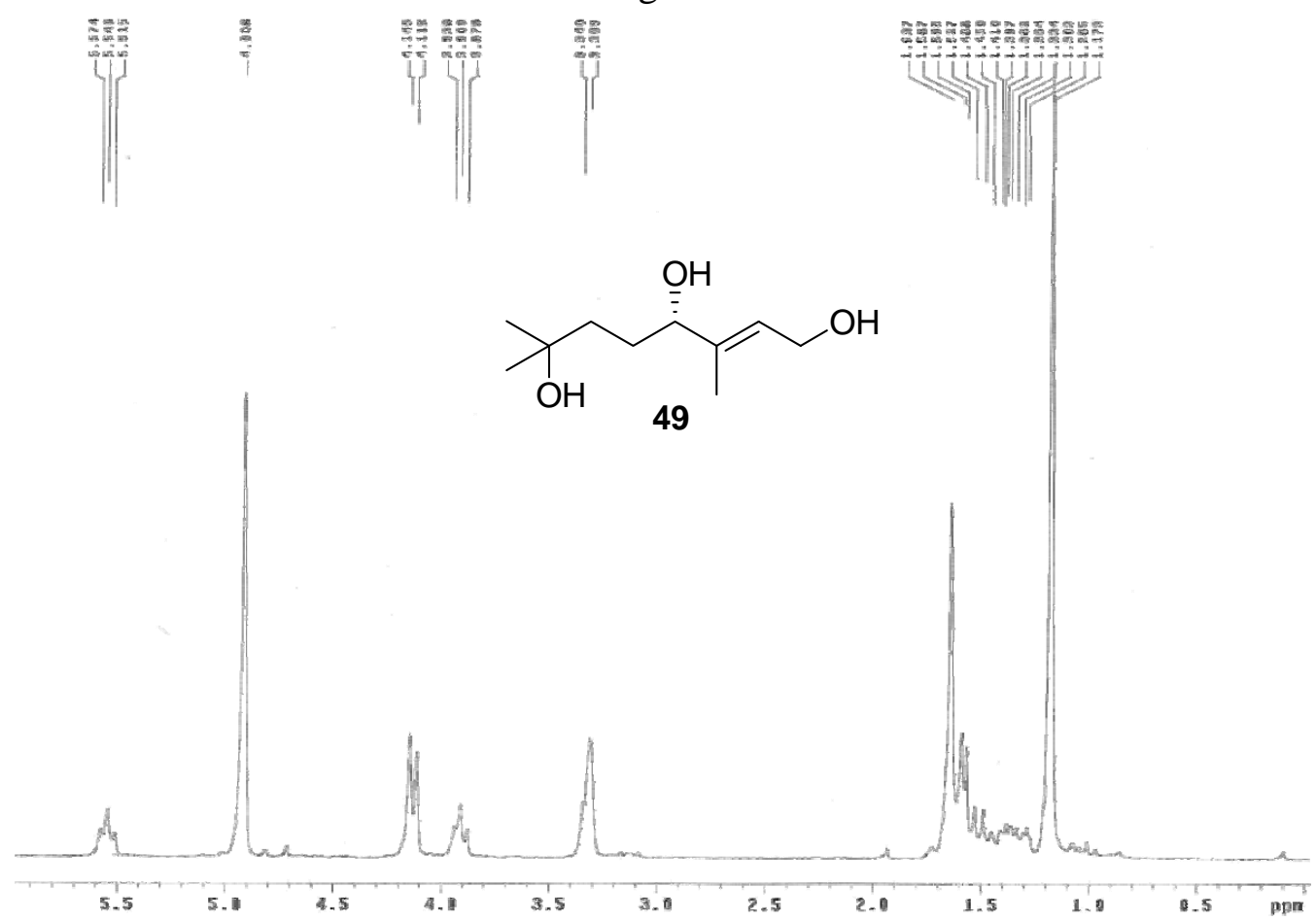
Fig. 42c
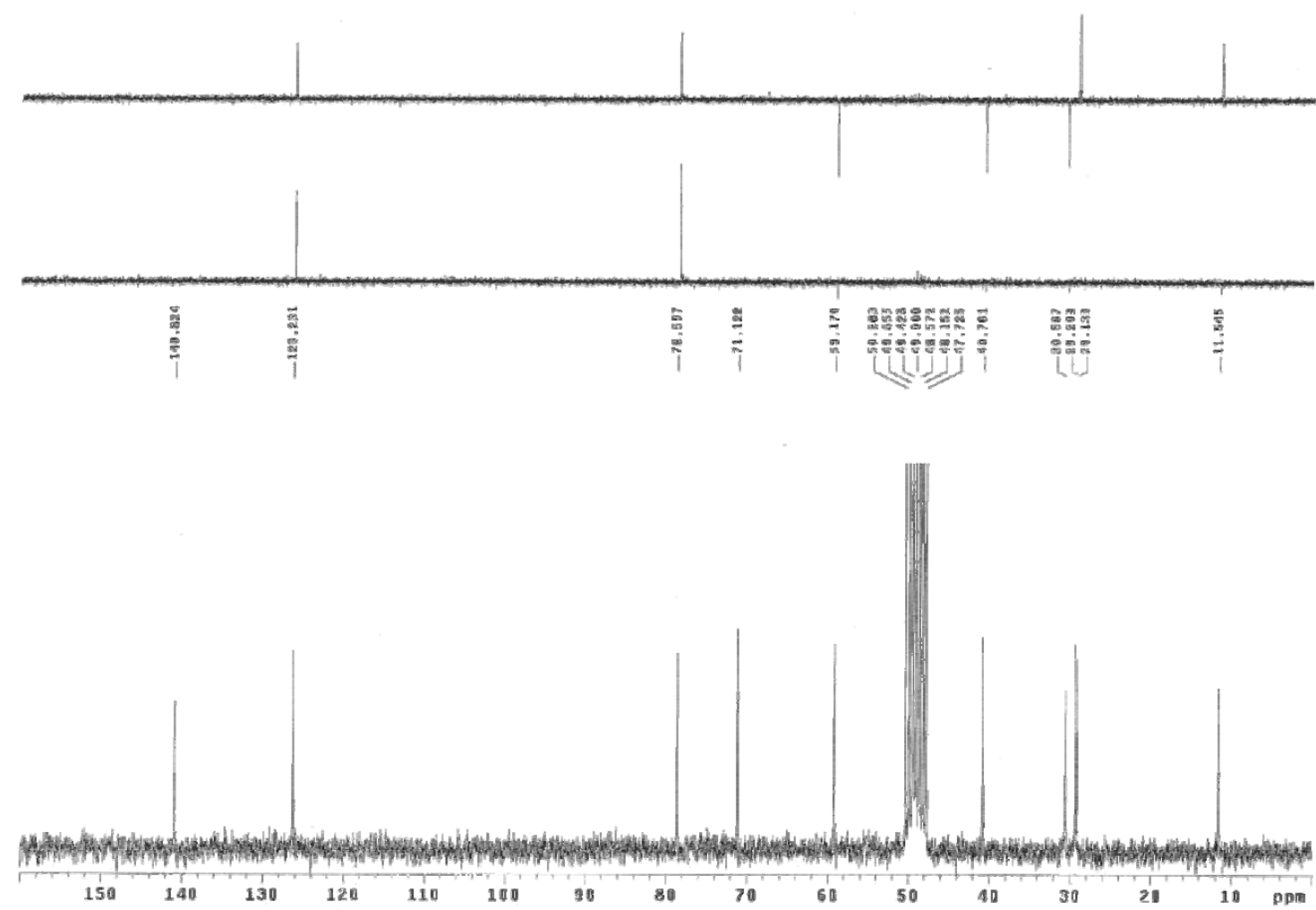

Fig. 42d

+TOF MS: 0.284 min from Sample 3 (RAGN DI(24-41)) of dic15052 witi

$a=3.56443429121948660 \mathrm{e}-004, t 0=1.56965204566804460 \mathrm{e}+001 \mathrm{R}$; subtracted $(0.0 .17$ to 0.

Masx, 683.6 counts.

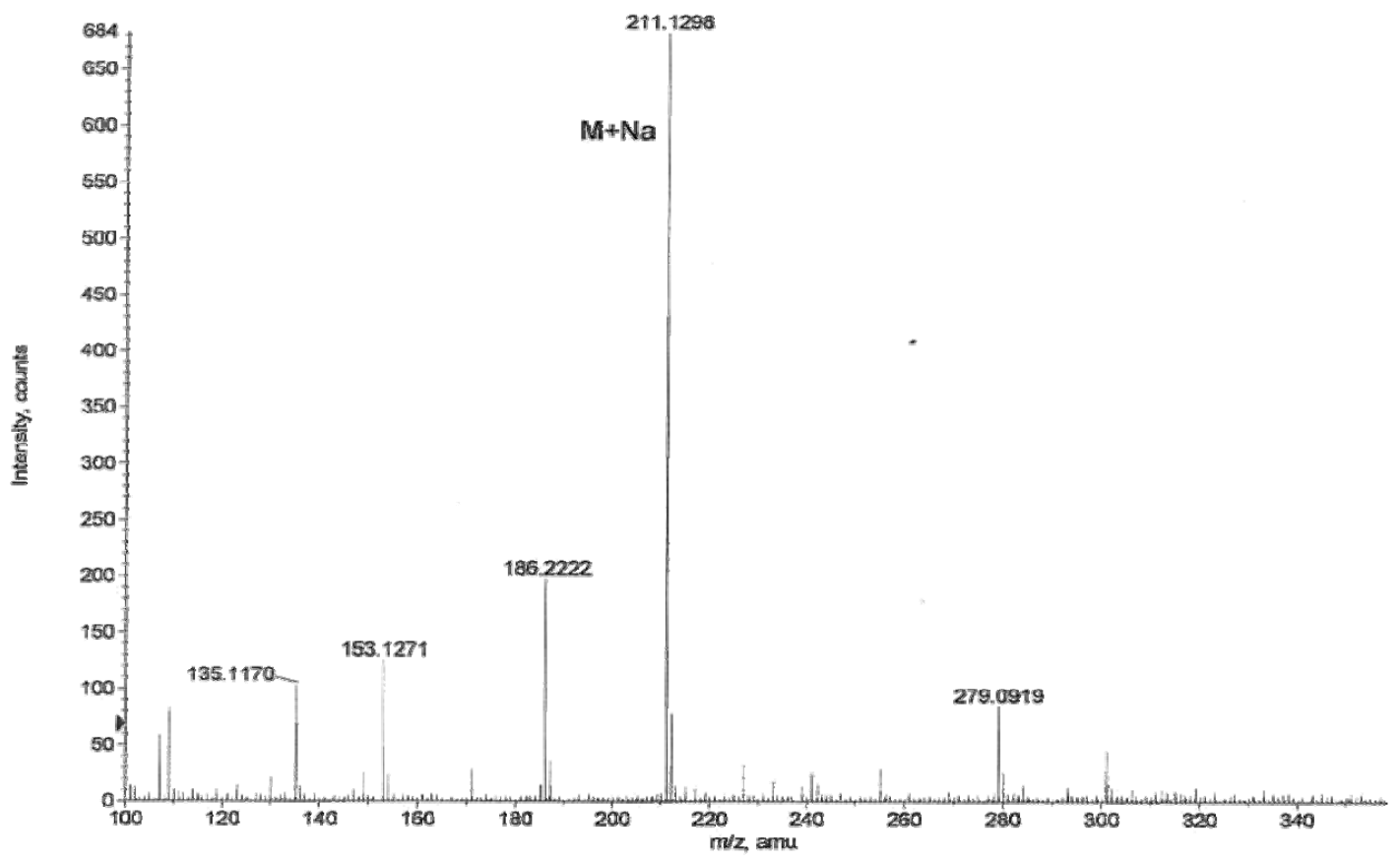


Fig. 43a

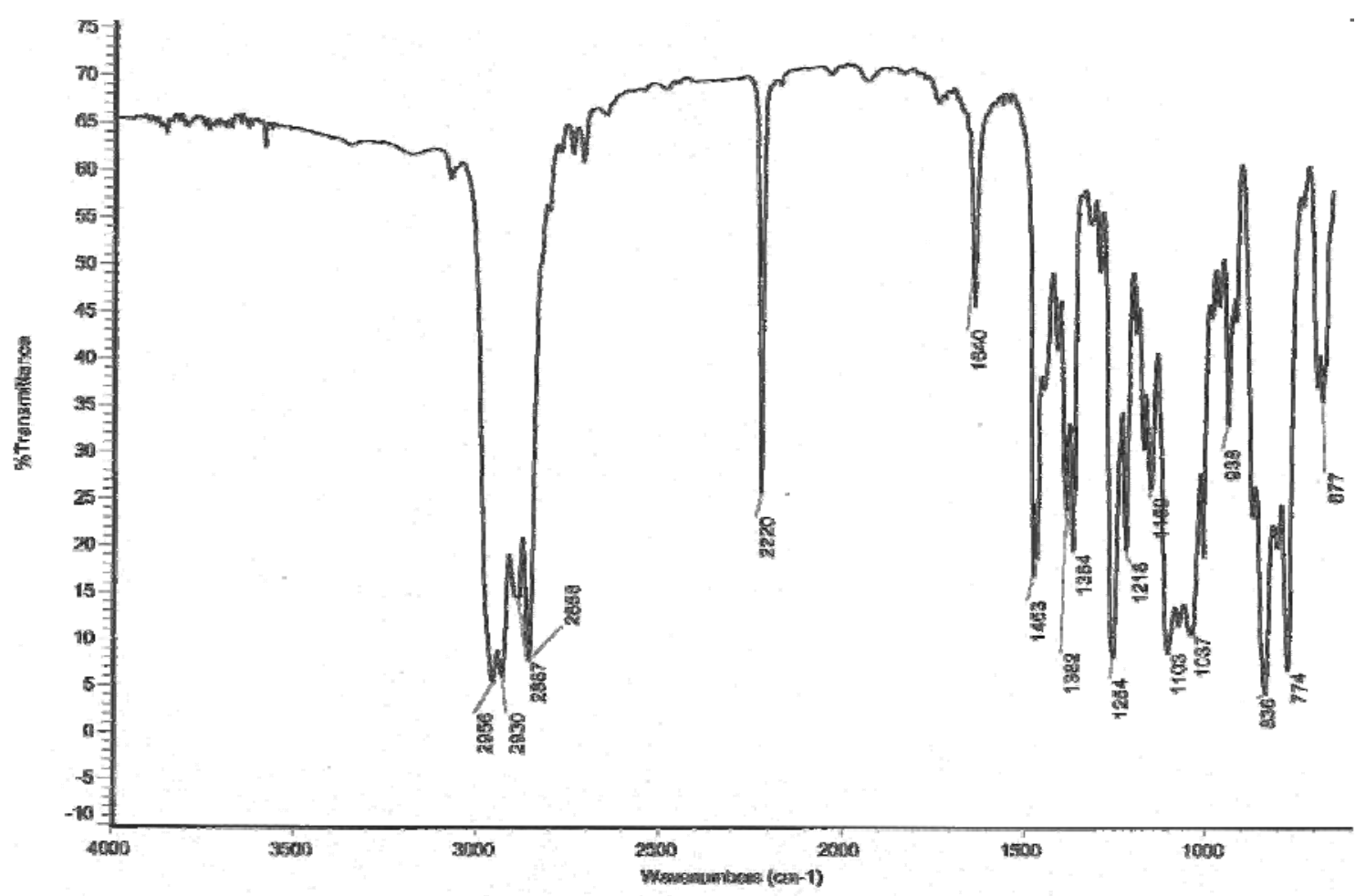

Fig. 43b

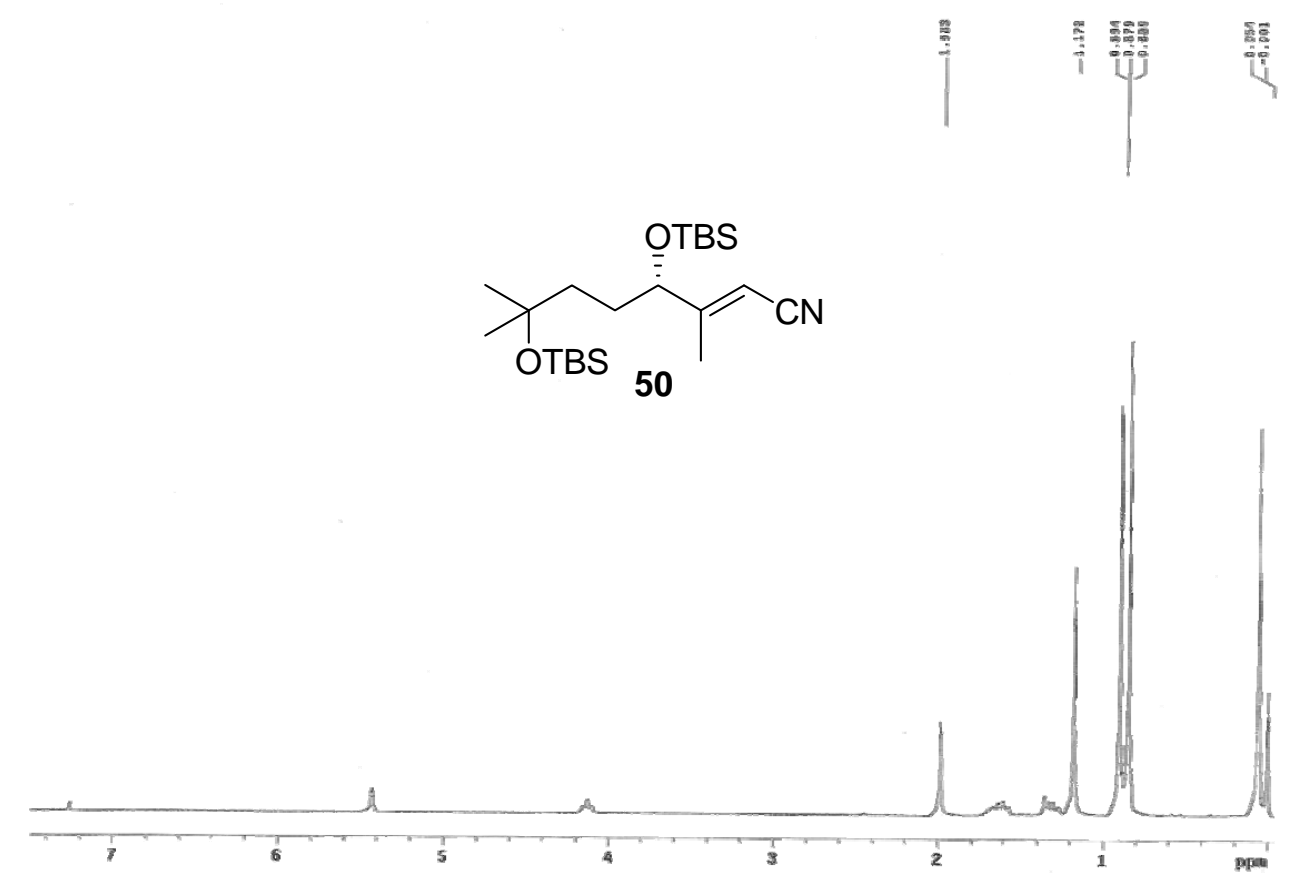


Fig. 43c

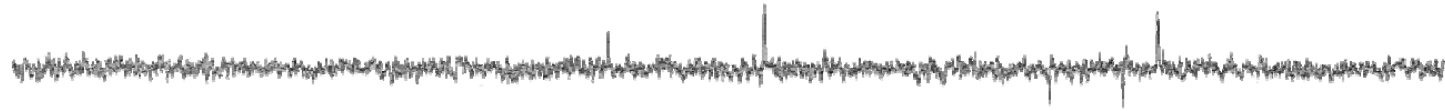

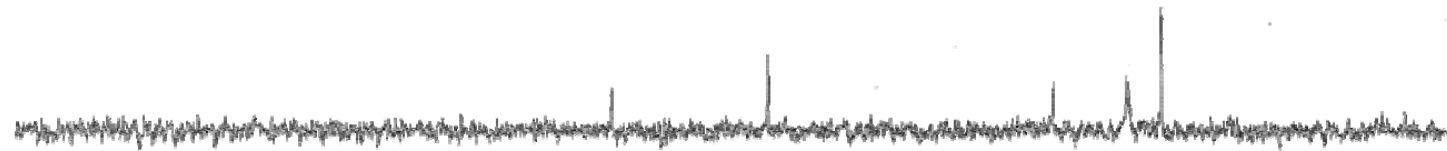

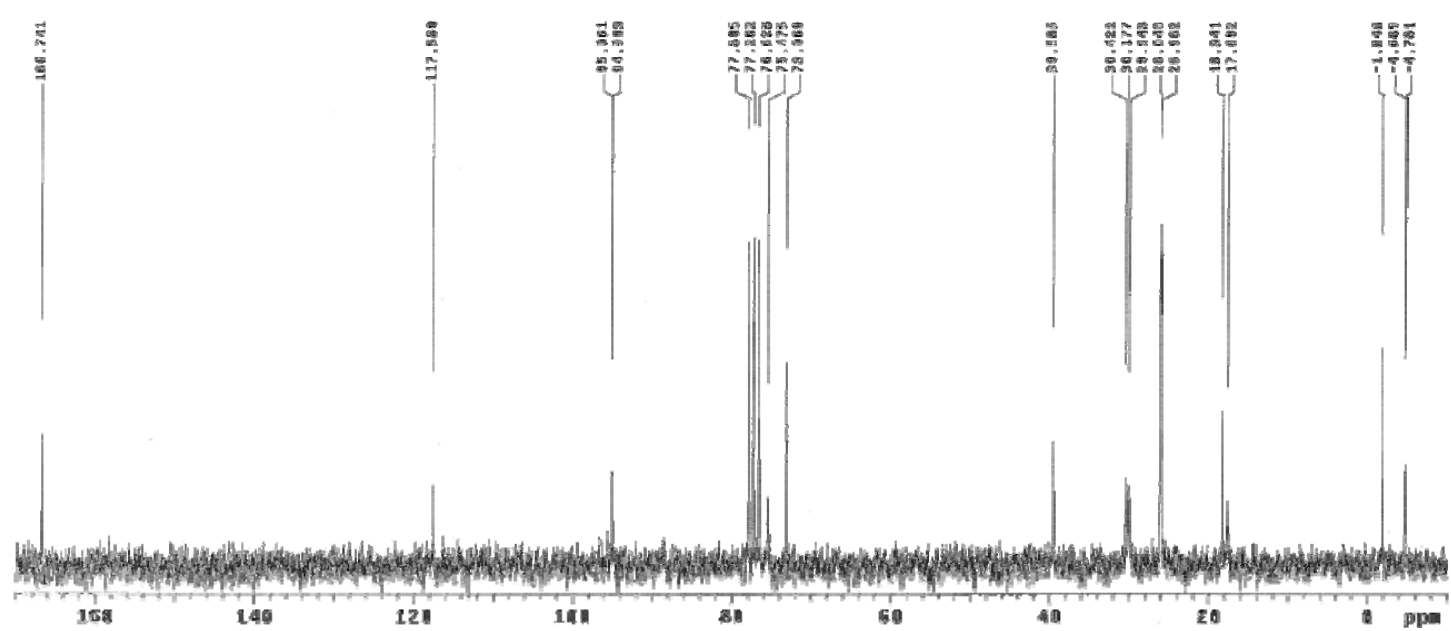

Fig. 43d

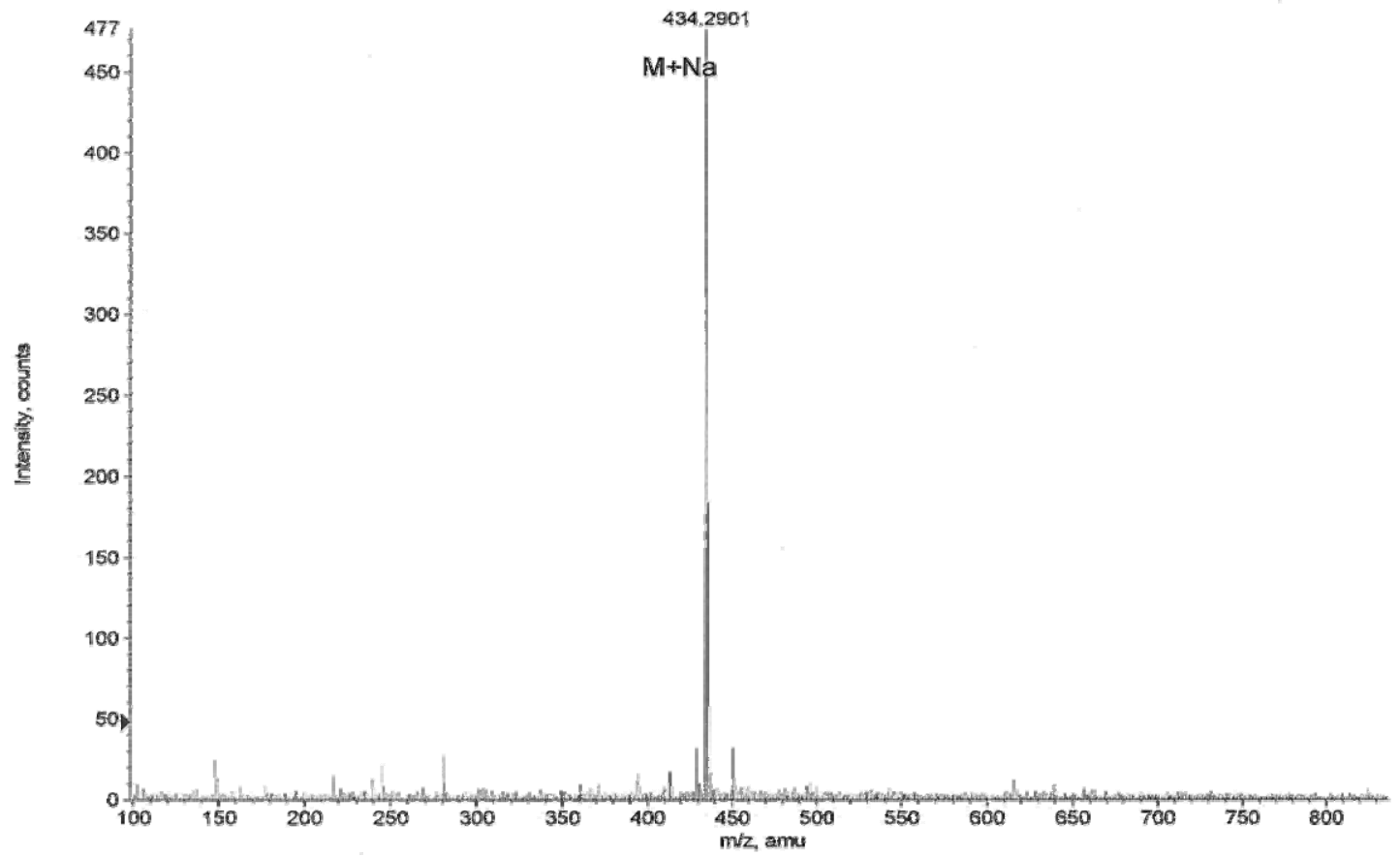


Fig. 44a

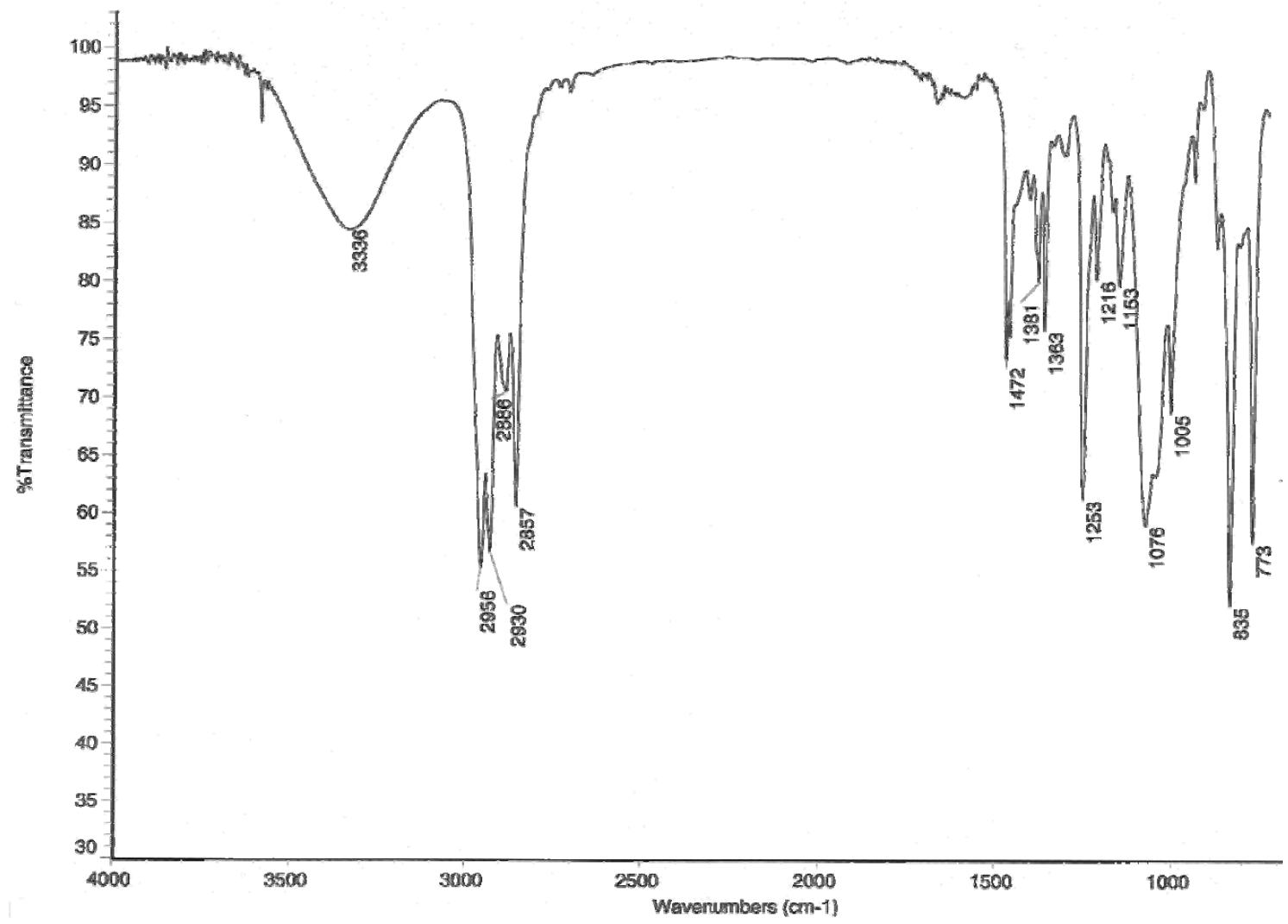

Fig. 44b

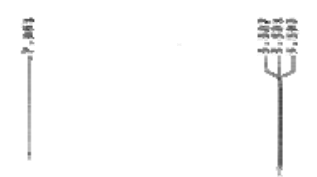

ํㅜㄴ

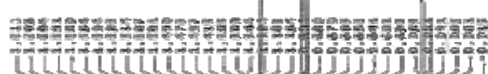

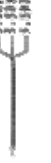

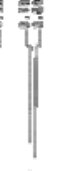

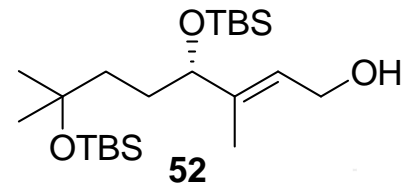

52

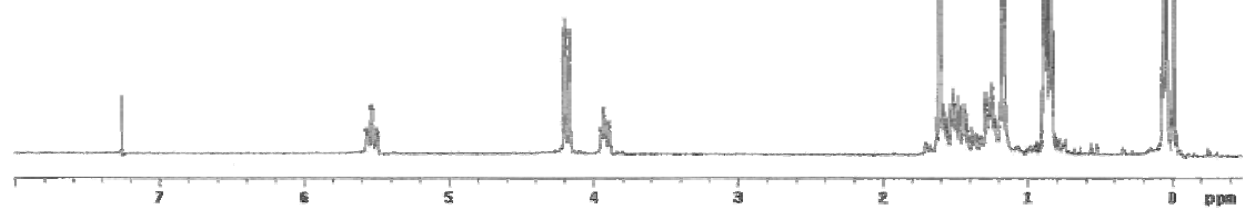


Fig. 44c
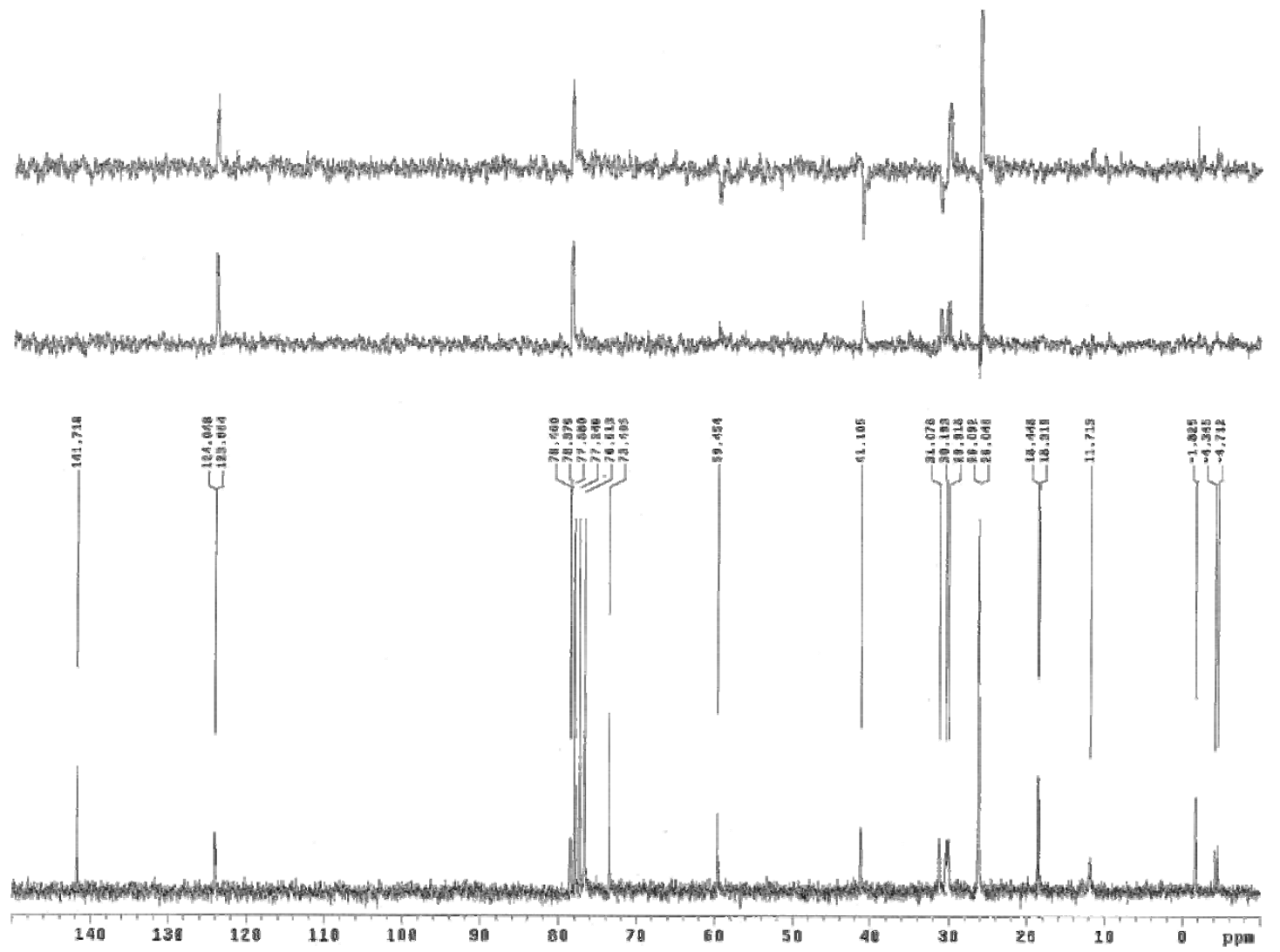

Fig. 44d

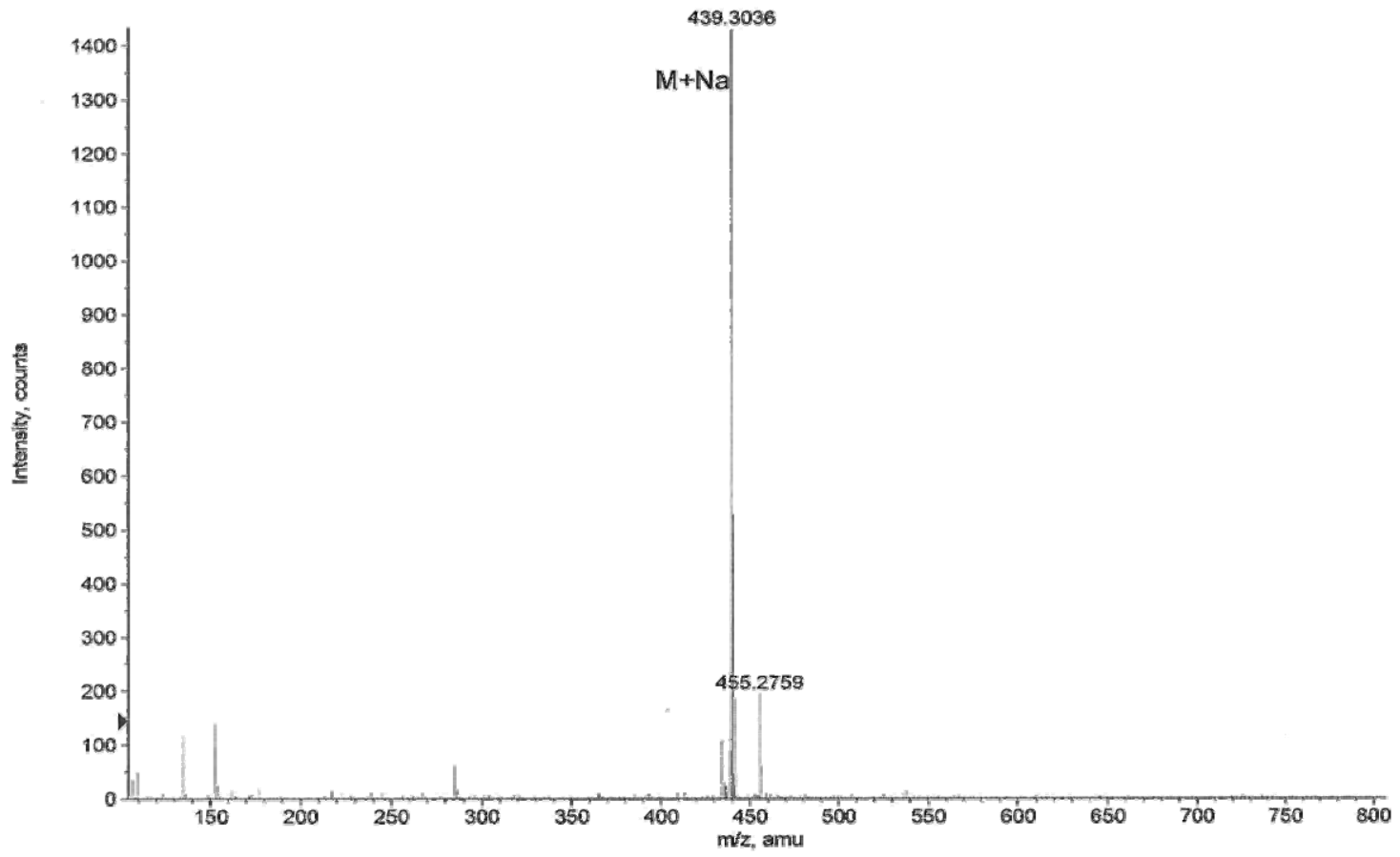


Fig. 45a

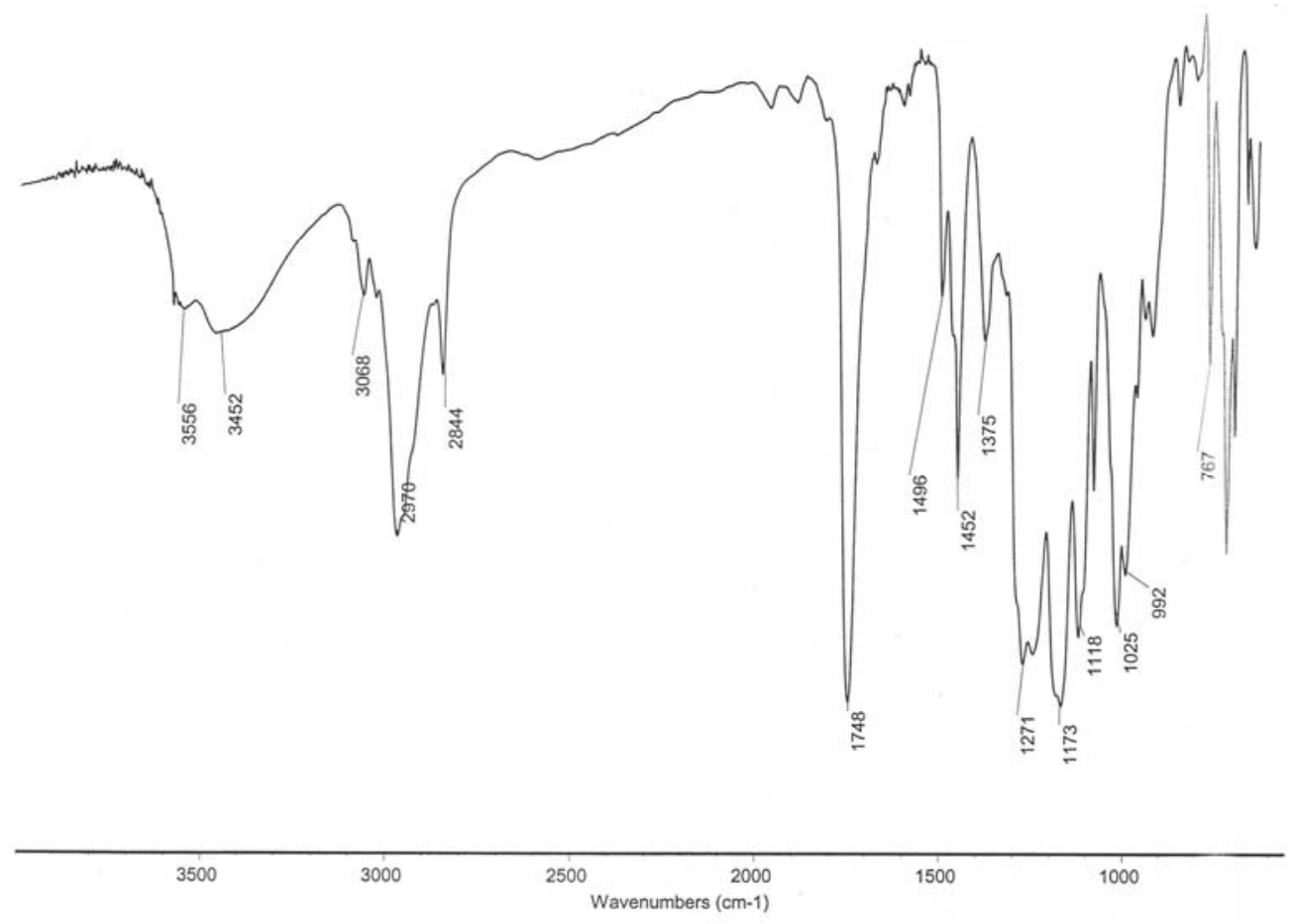

Fig. 45b

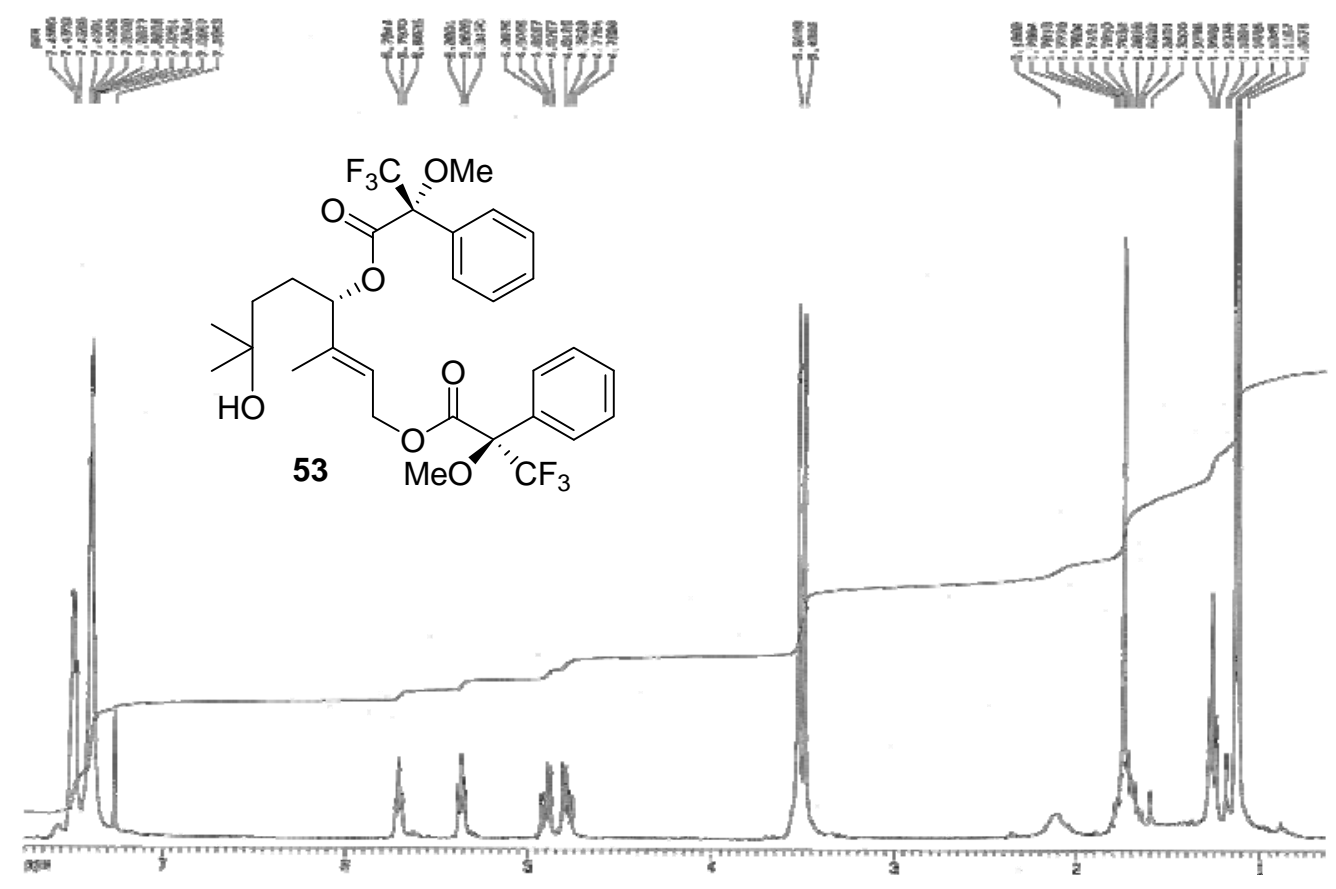


Fig. 45c
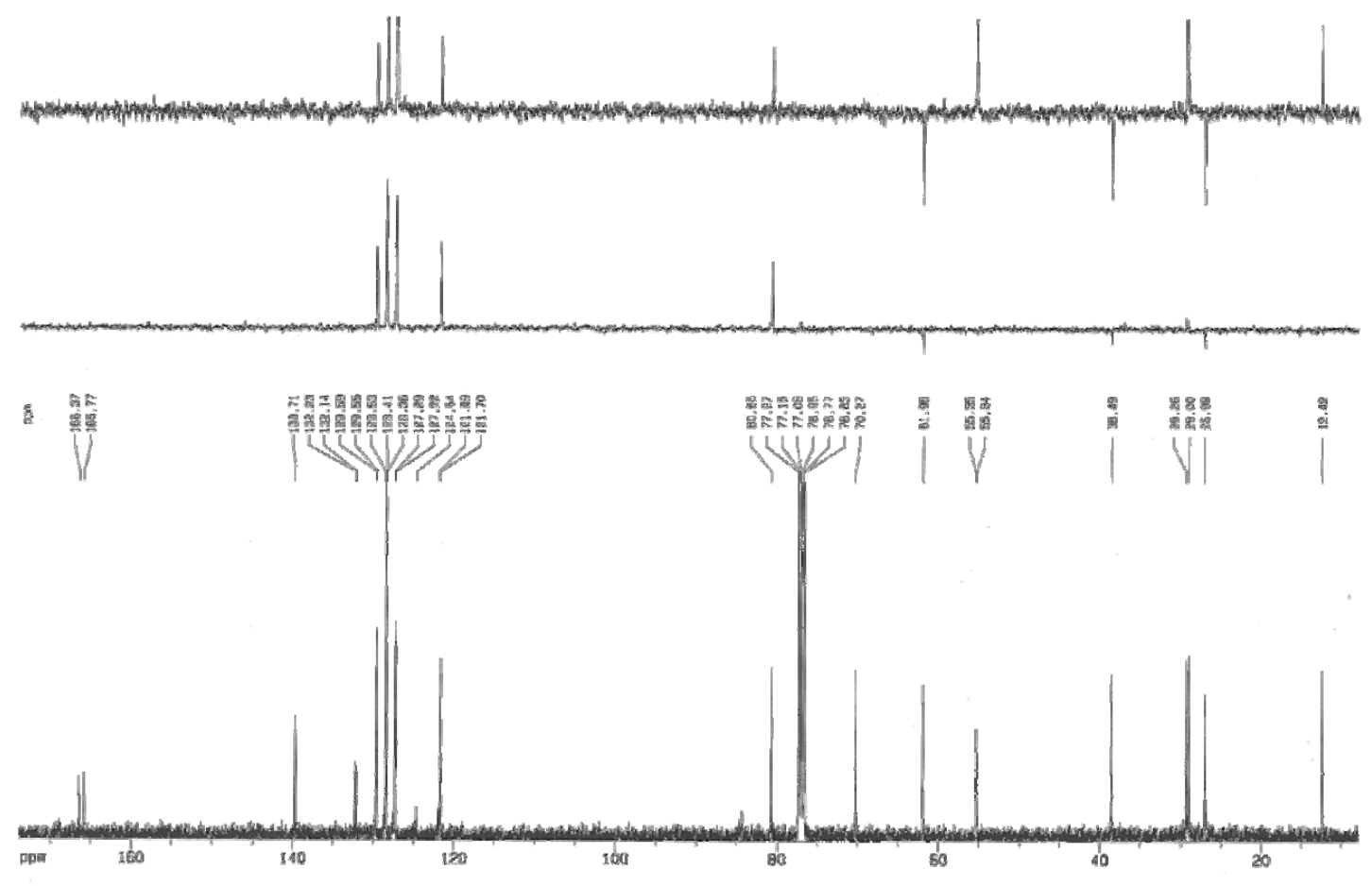

Fig. 45d

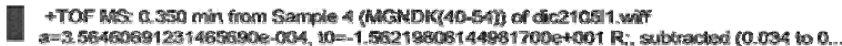

Max 547 a counts

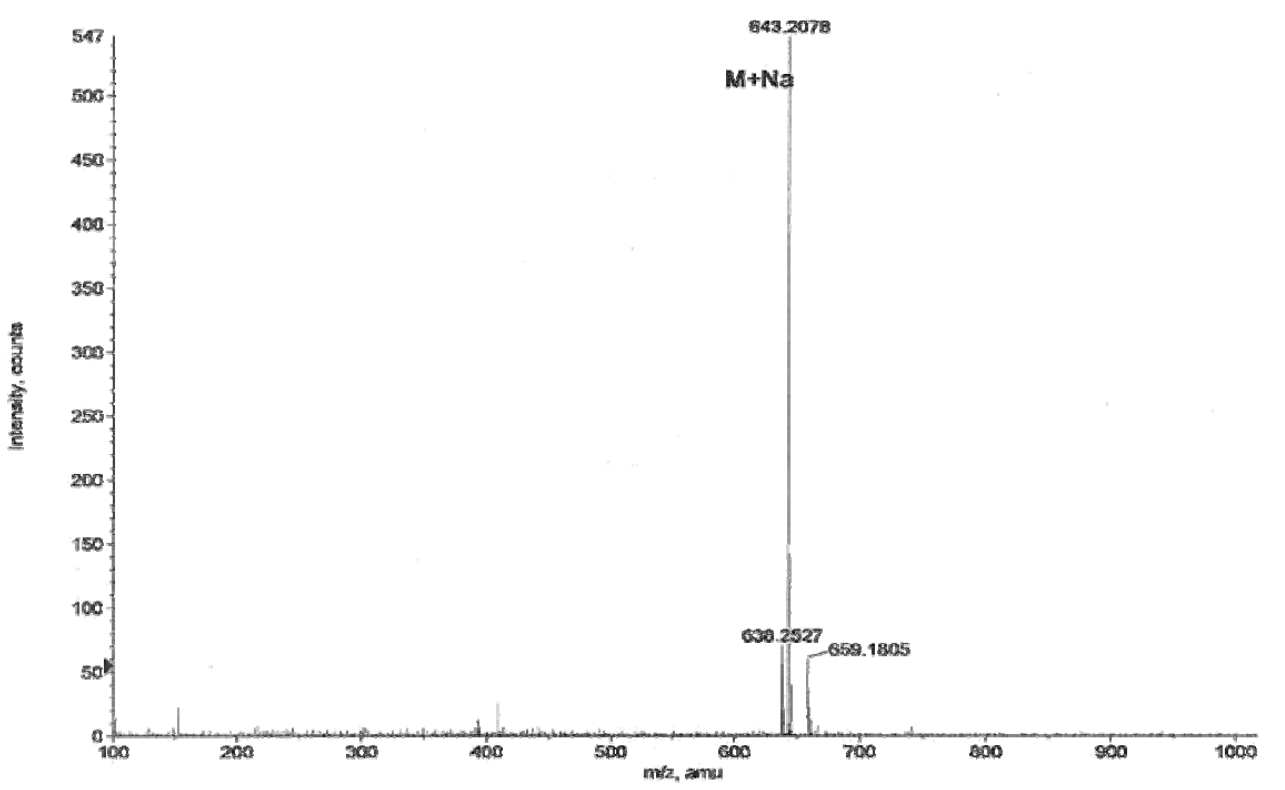


Fig. 46a

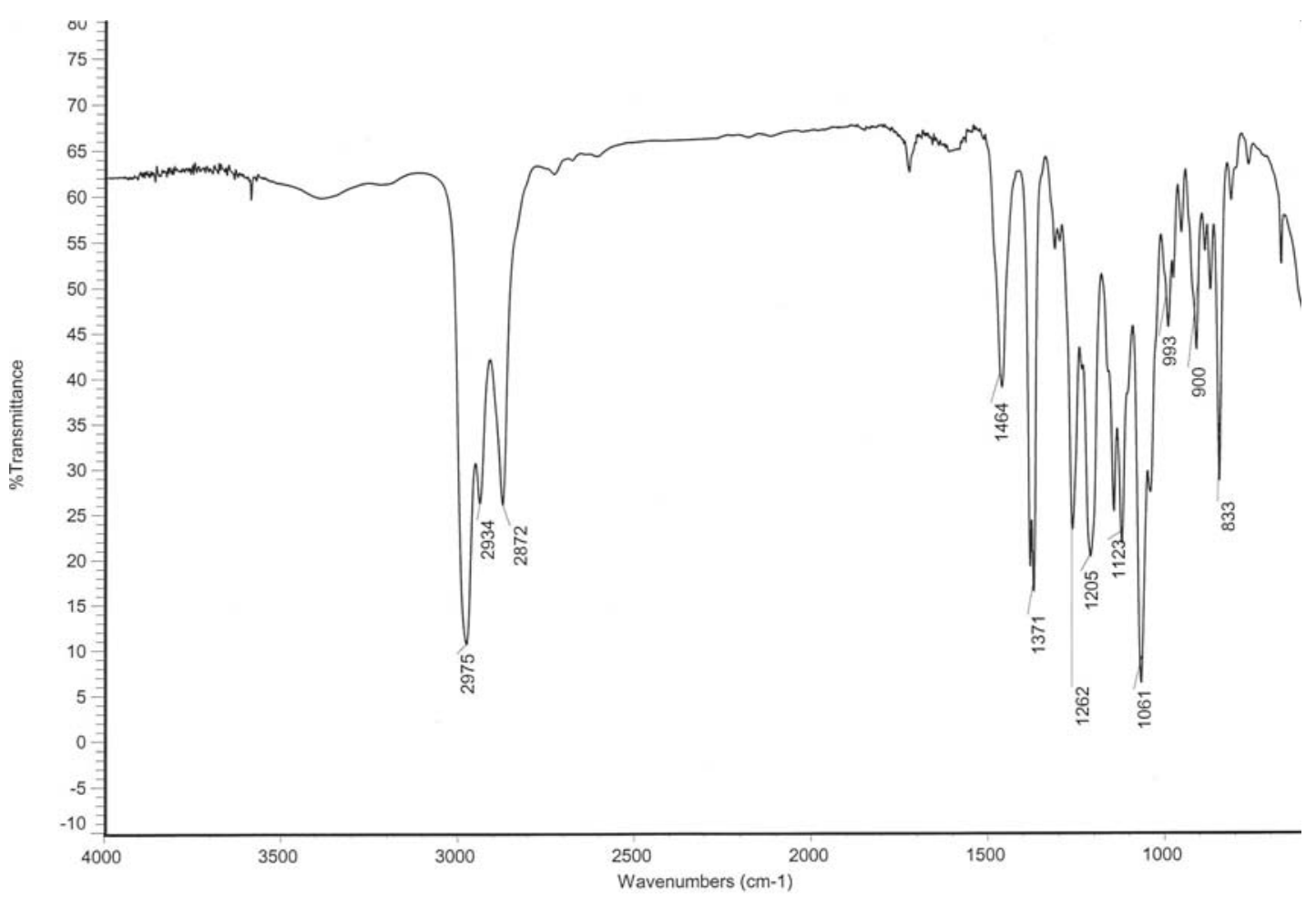

Fig. 46b

8

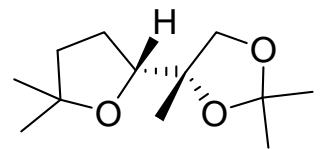

54

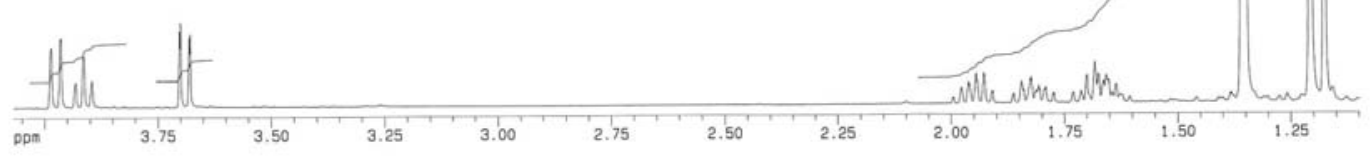


Fig. $46 \mathrm{c}$

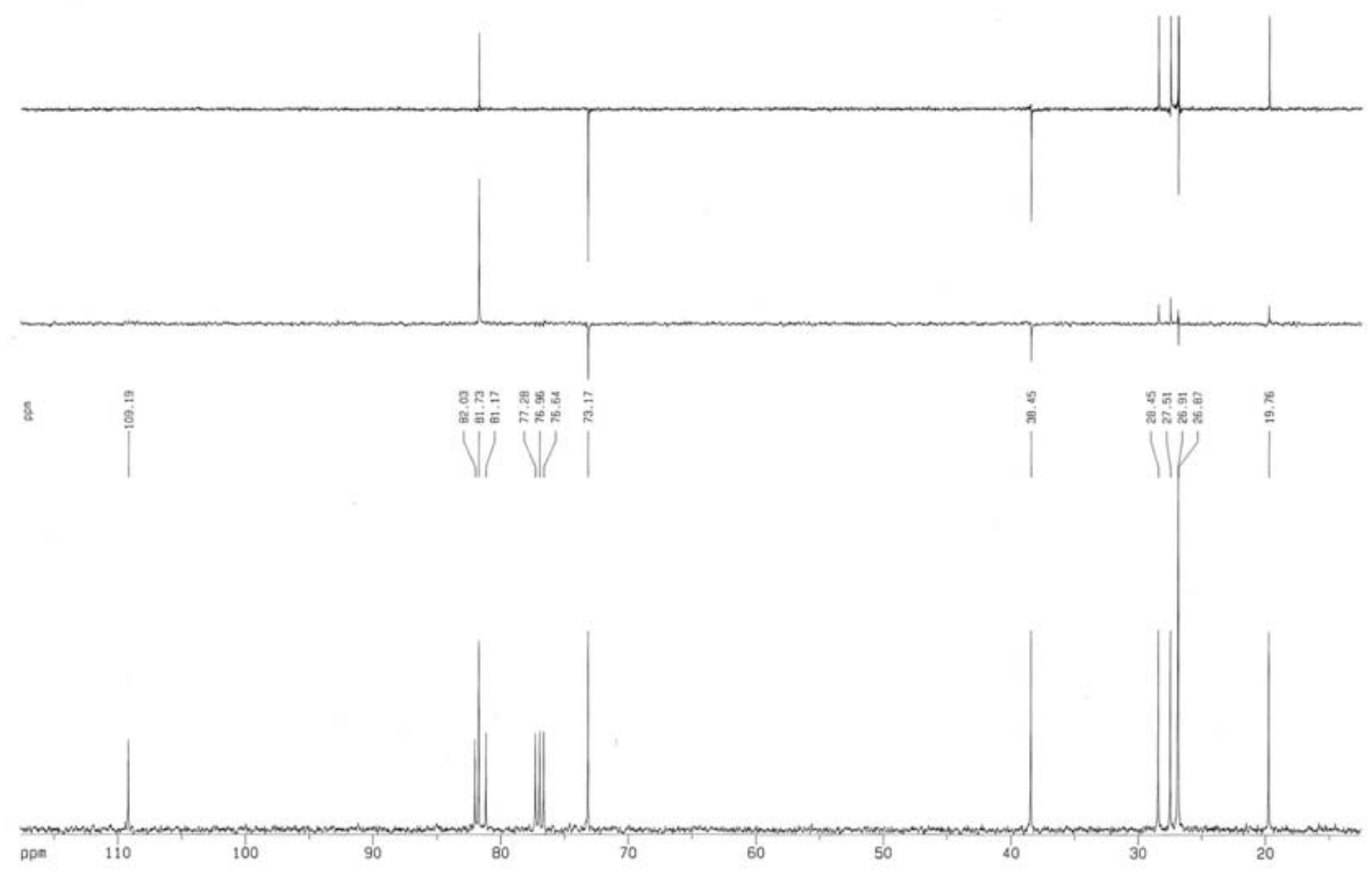

Fig. 46d

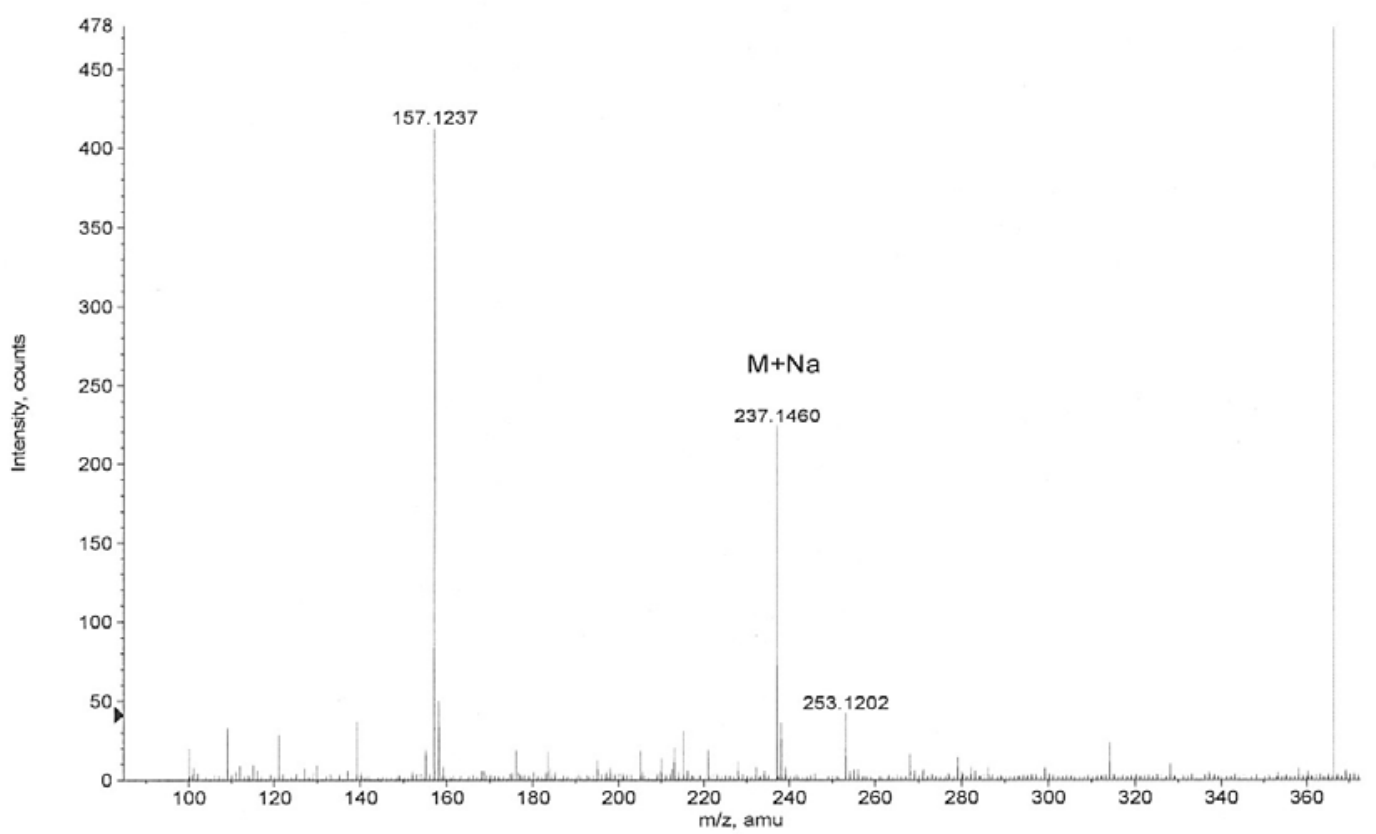


Fig. 46e-COSY

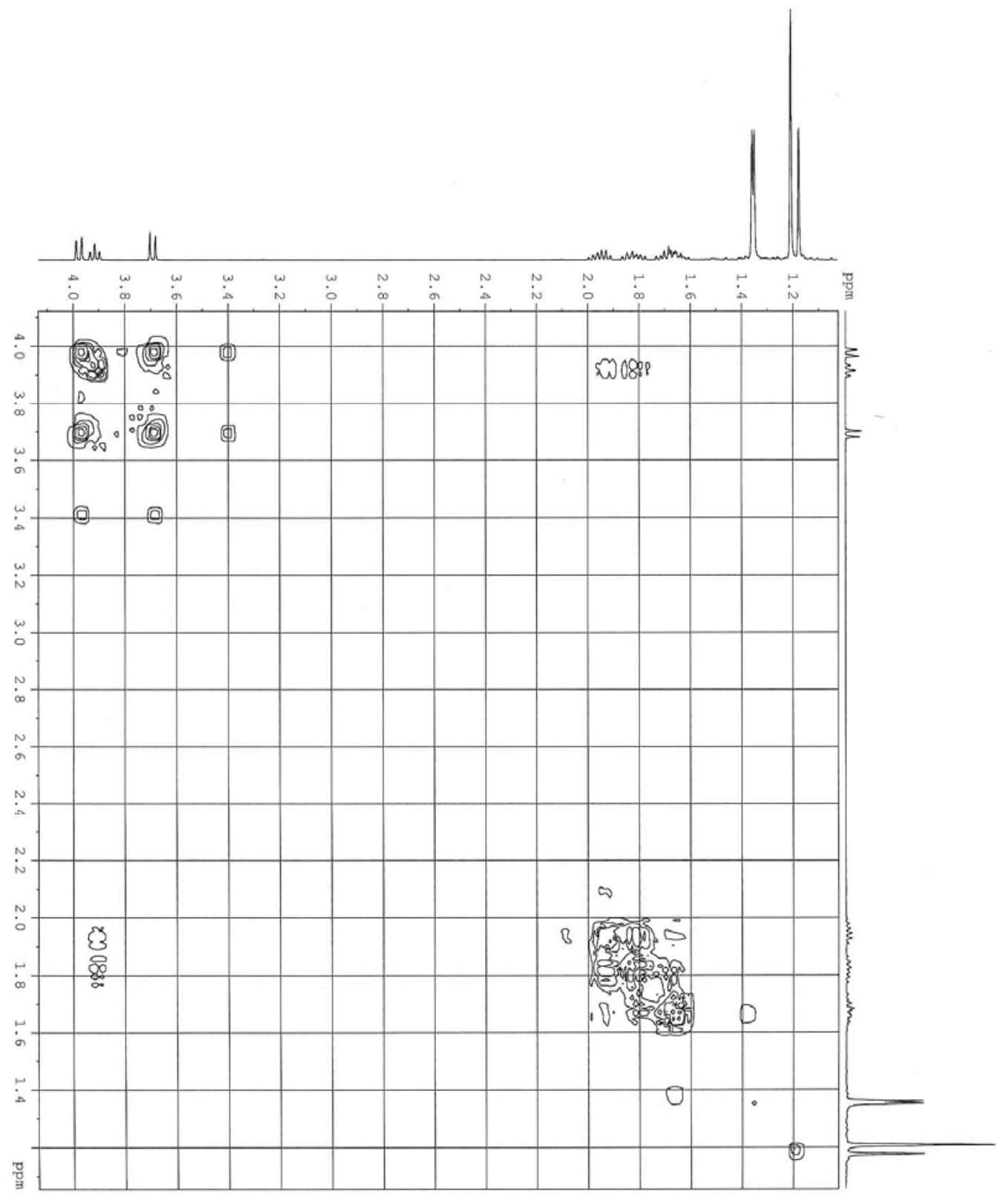


Fig. 46f-HMQC

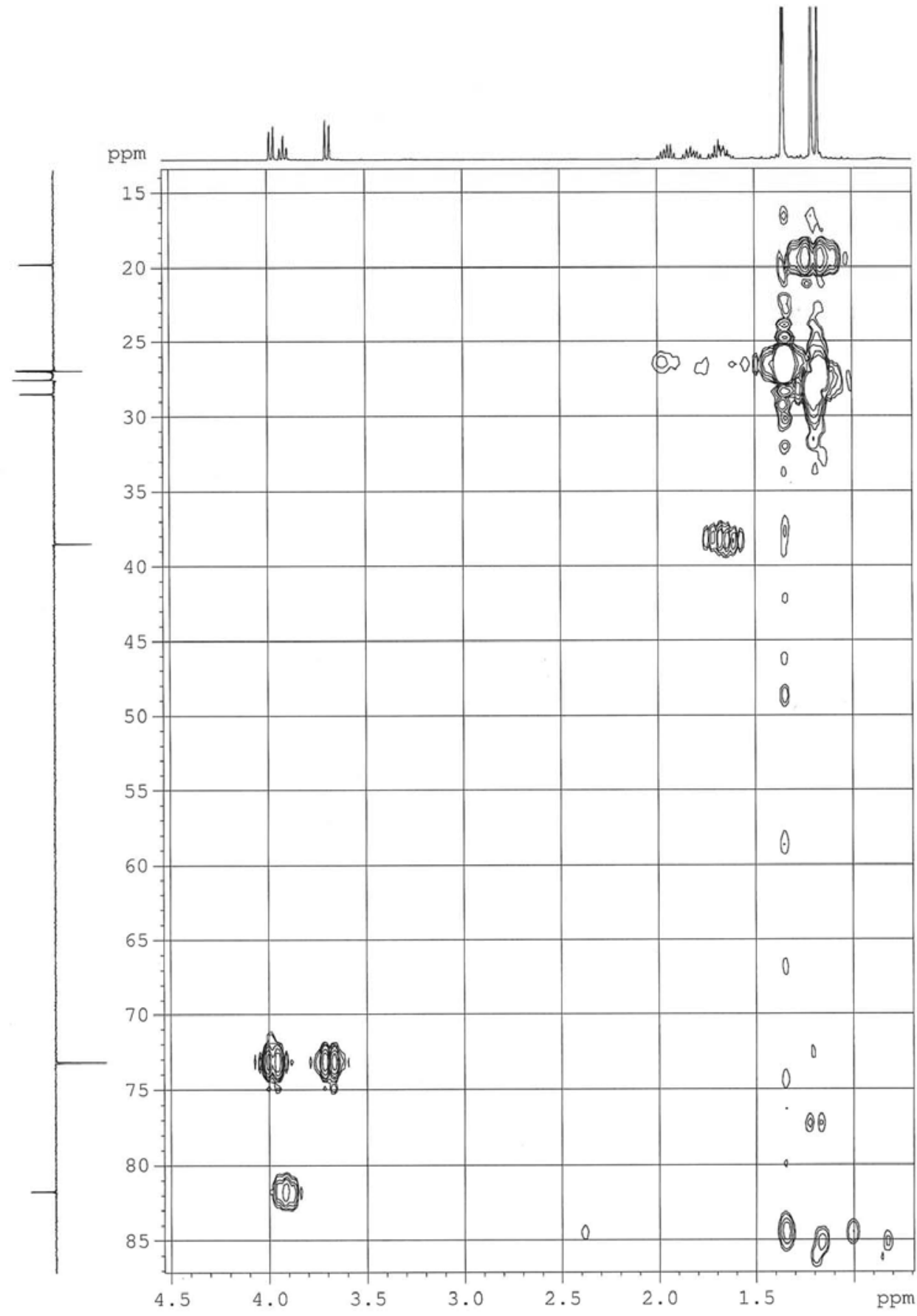


Fig. 46g-HMBC

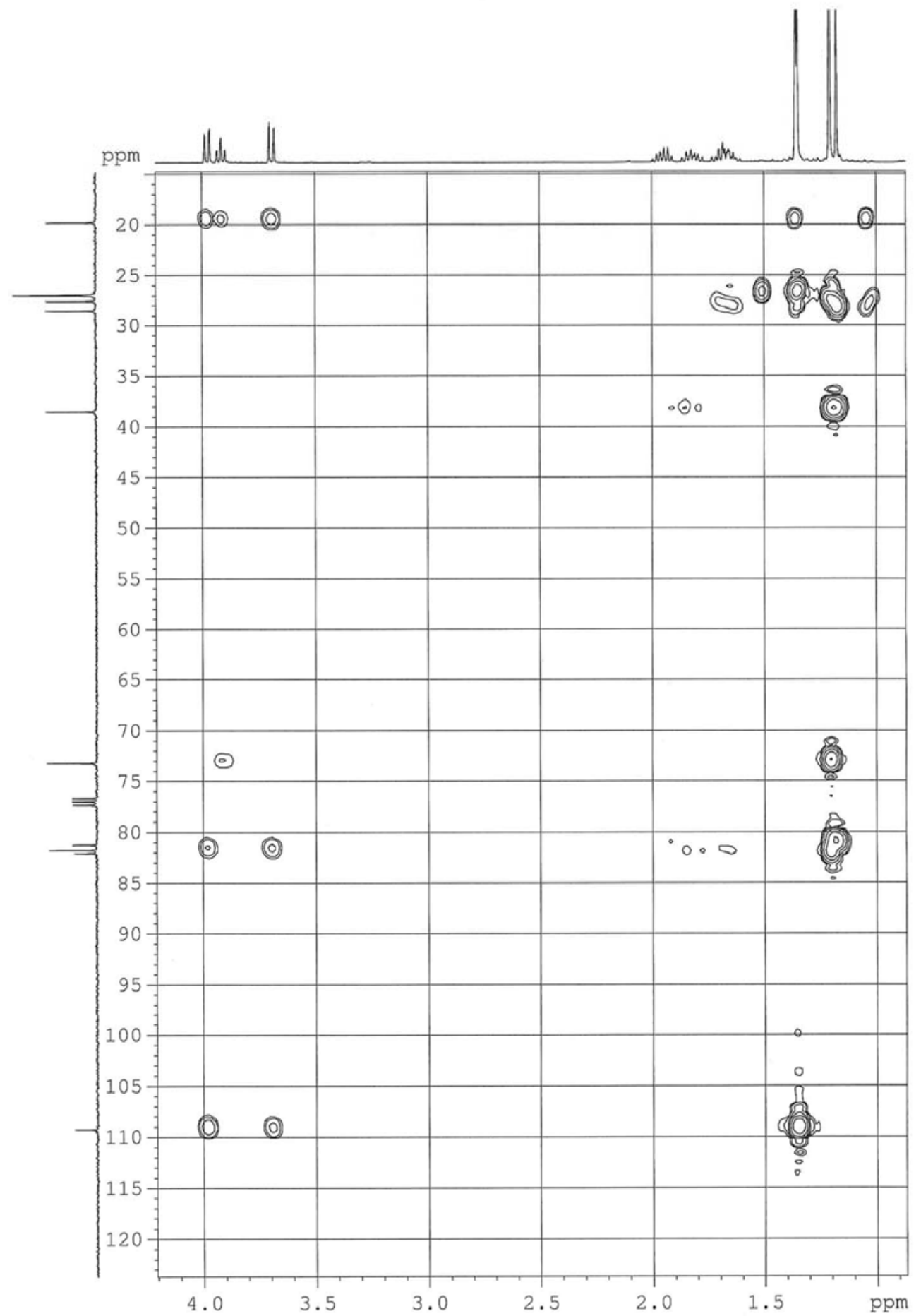


Fig. 47a

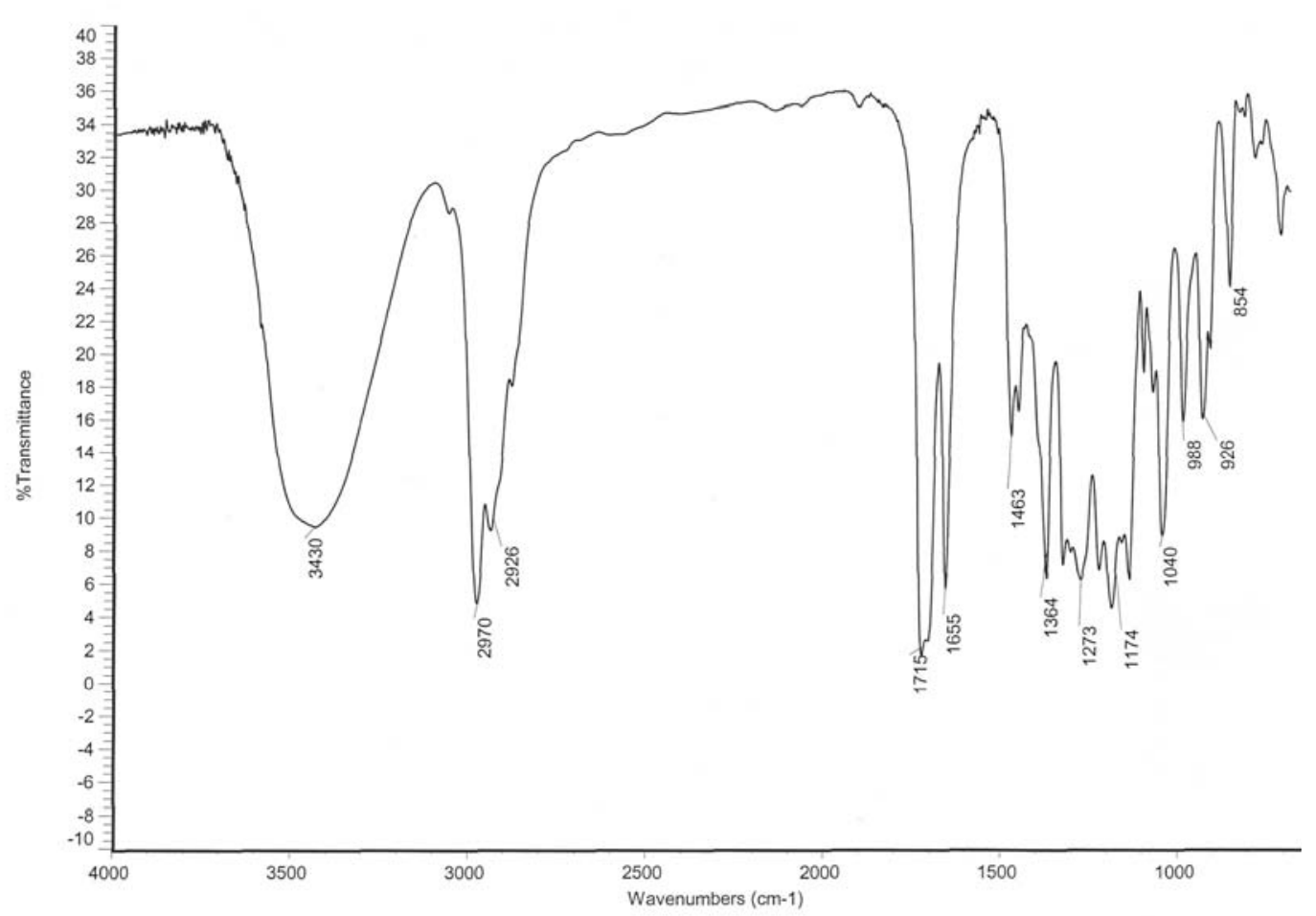

Fig. 47b

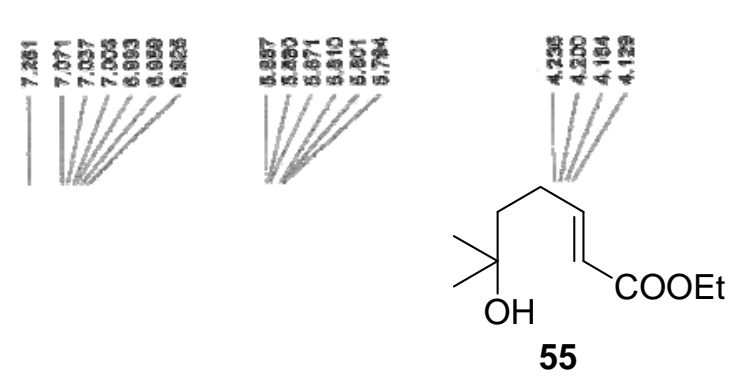

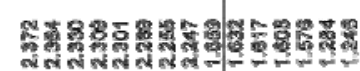

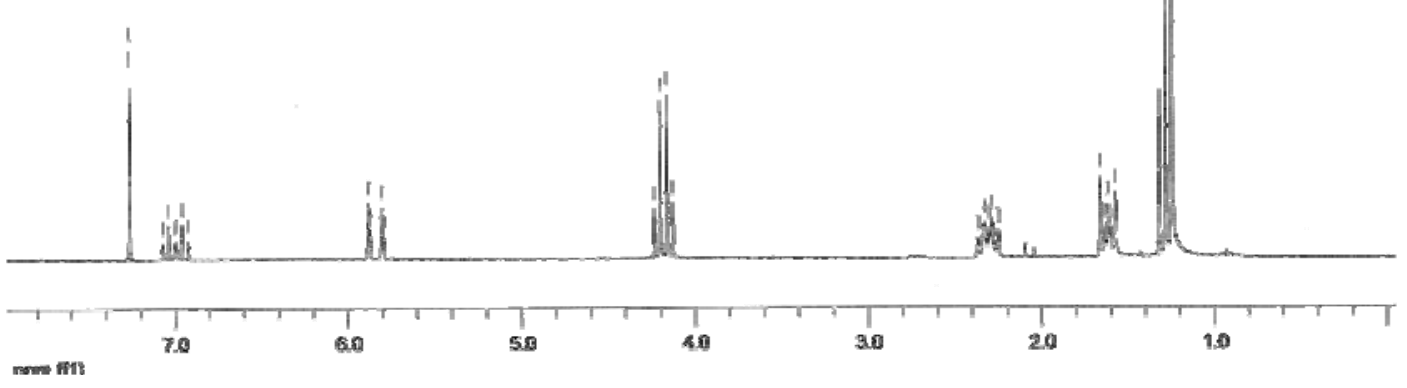


Fig. 47c
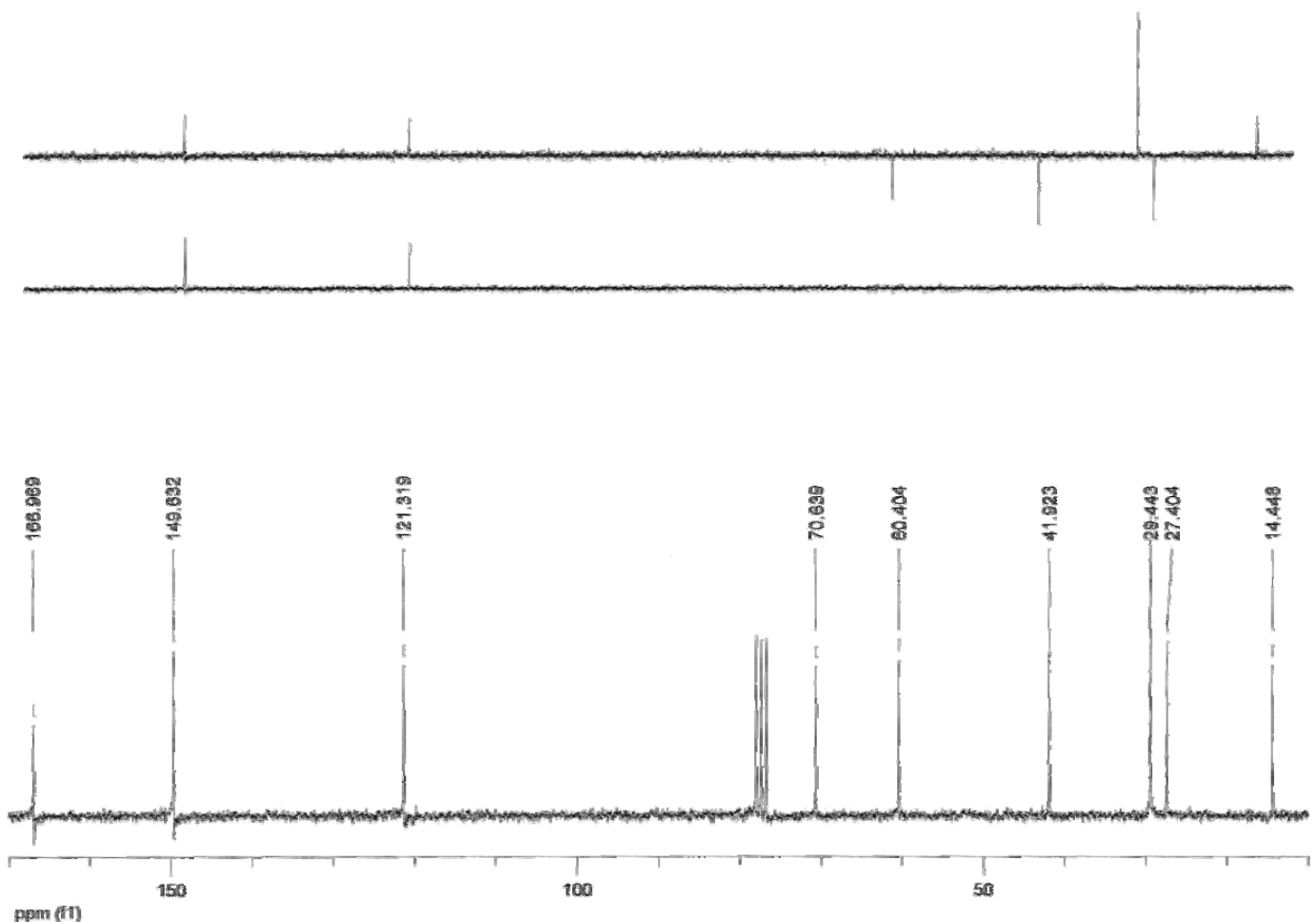

Fig. 47d

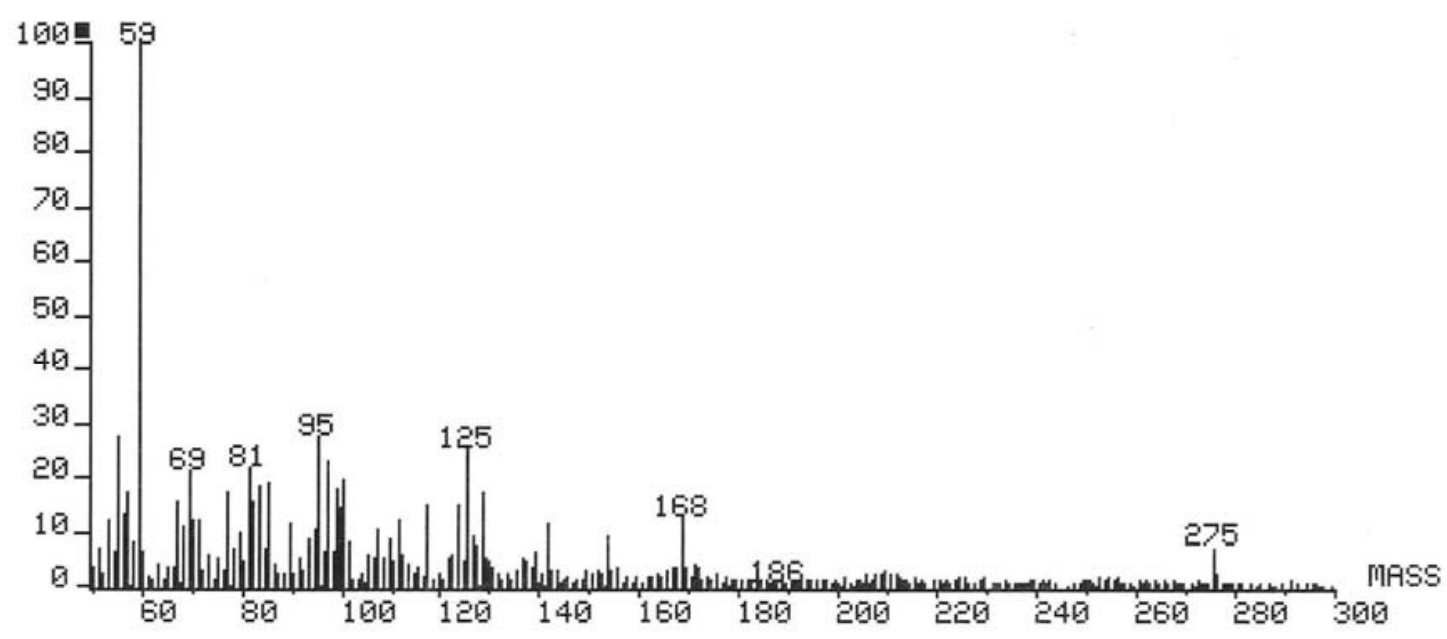


Fig. 48a

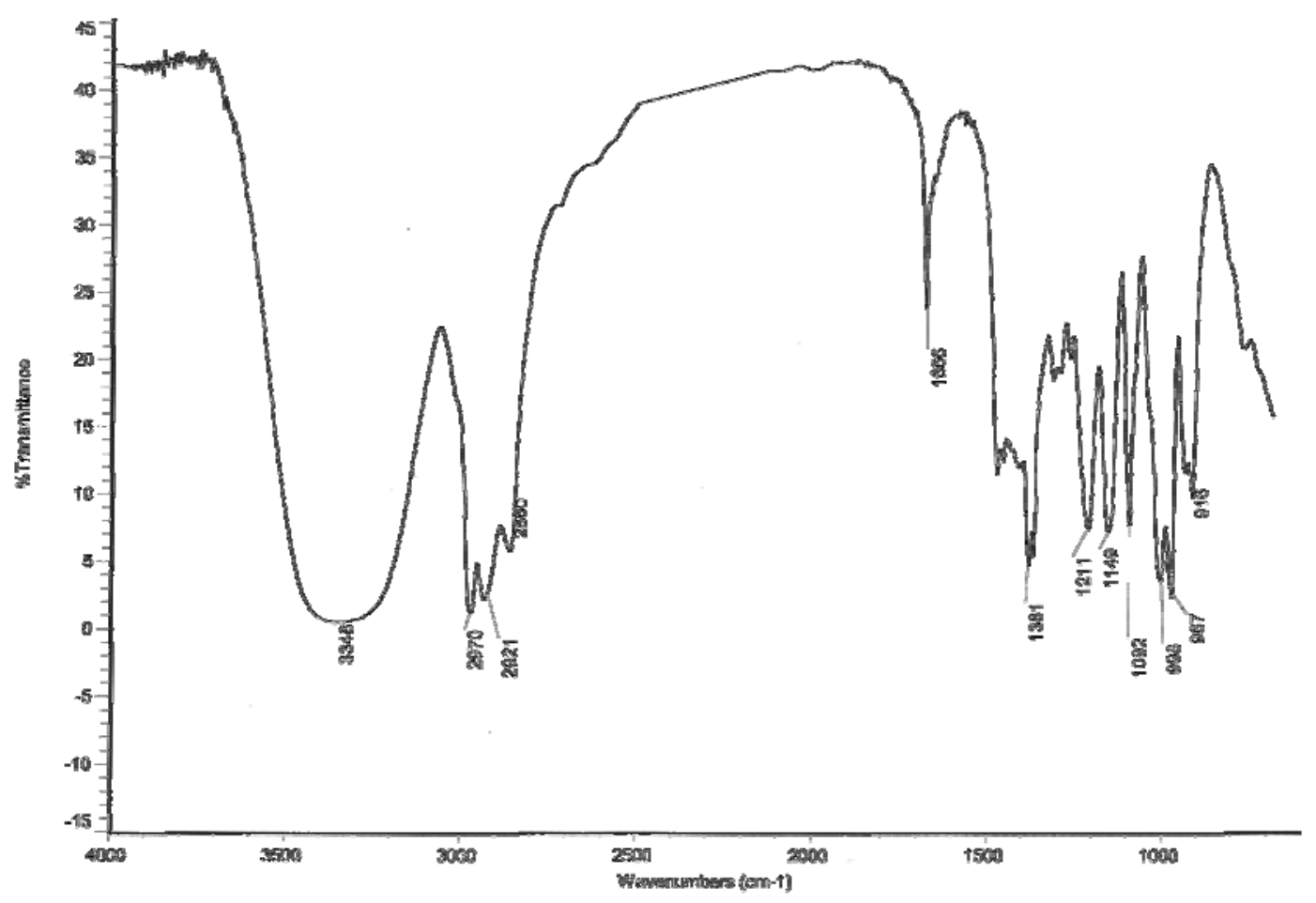

Fig. 48b

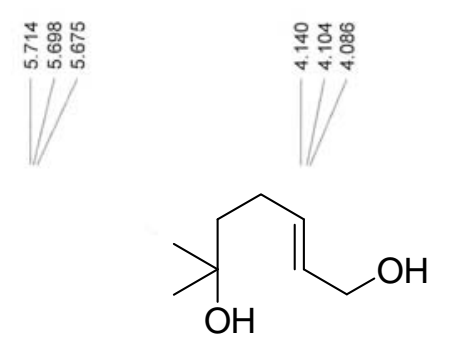

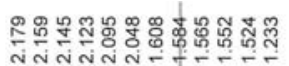

56 
Fig. 48c
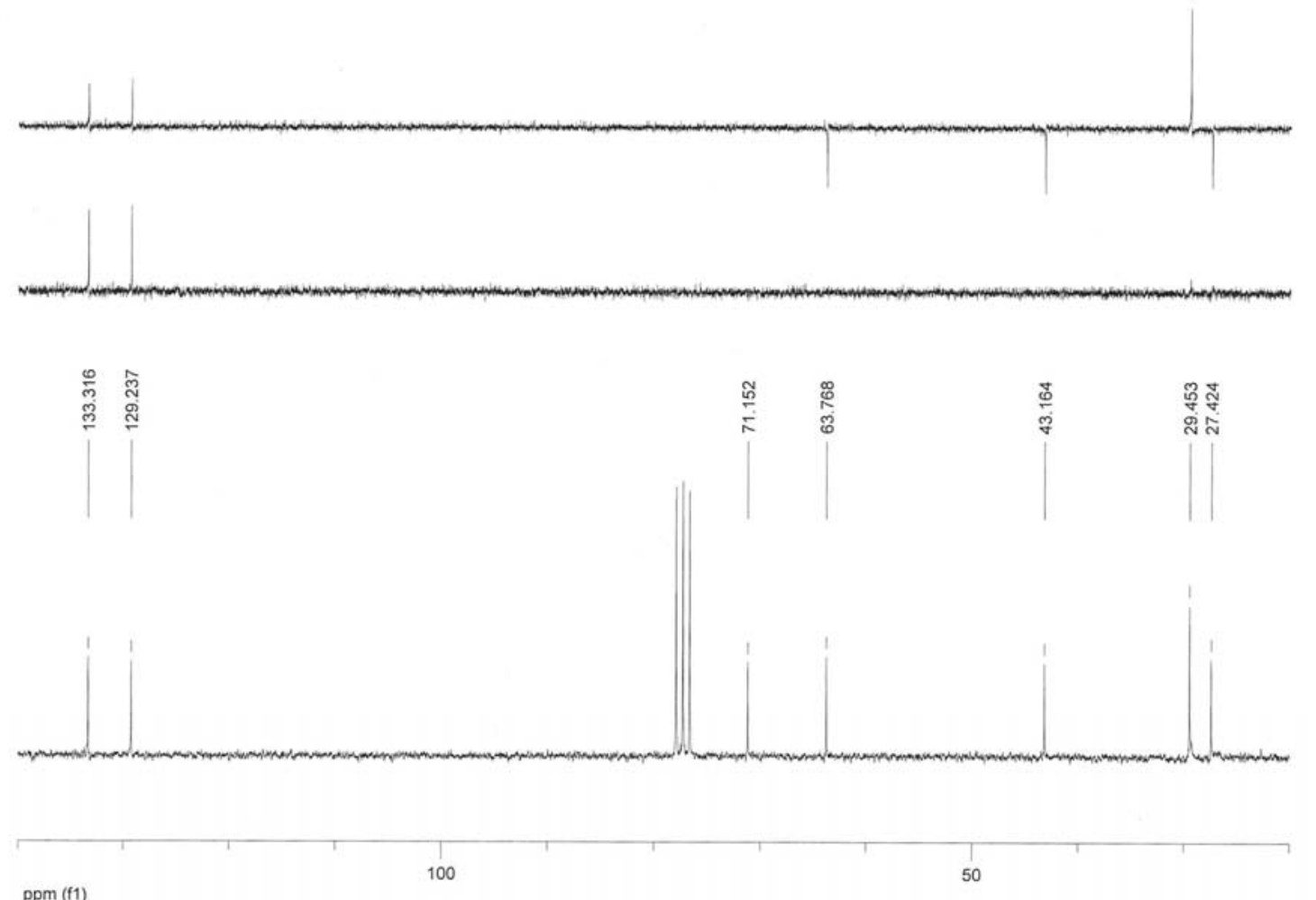

Fig. 48d

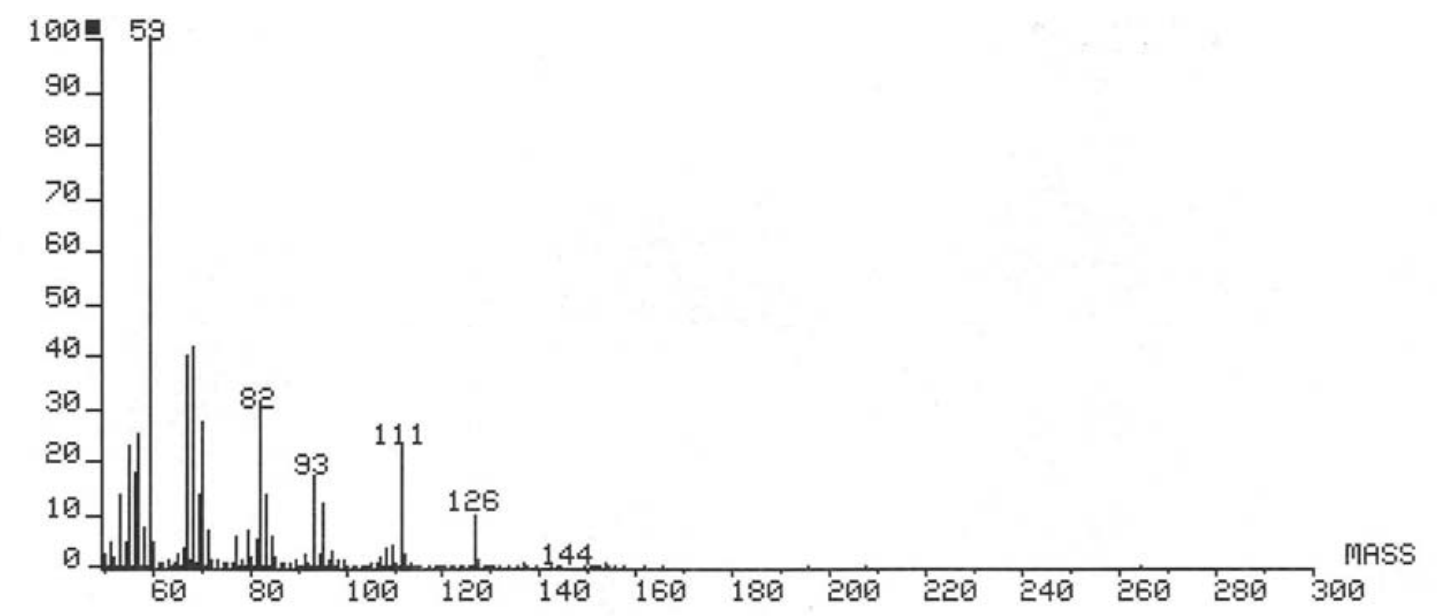


Fig. 49a

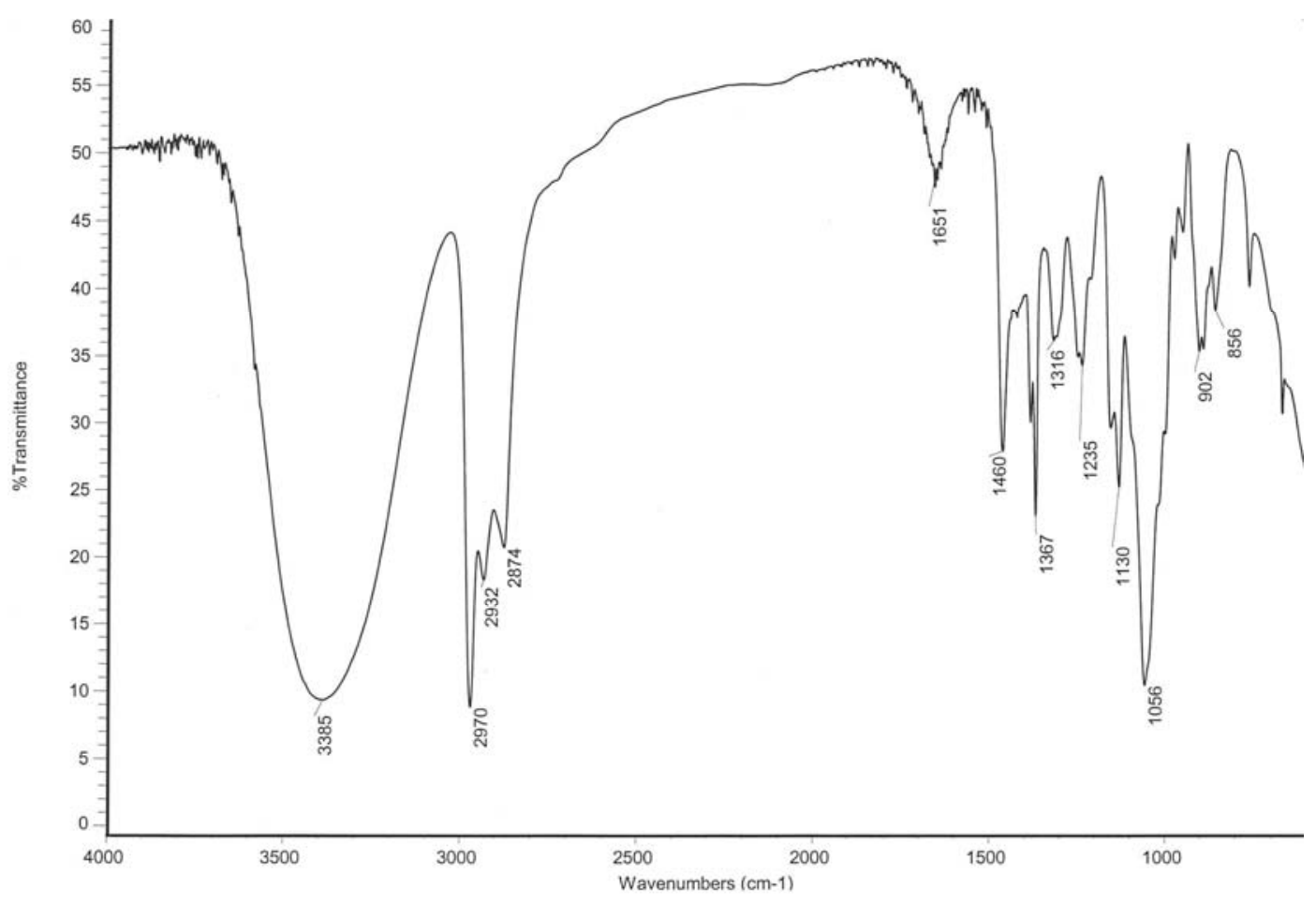

Fig. 49b
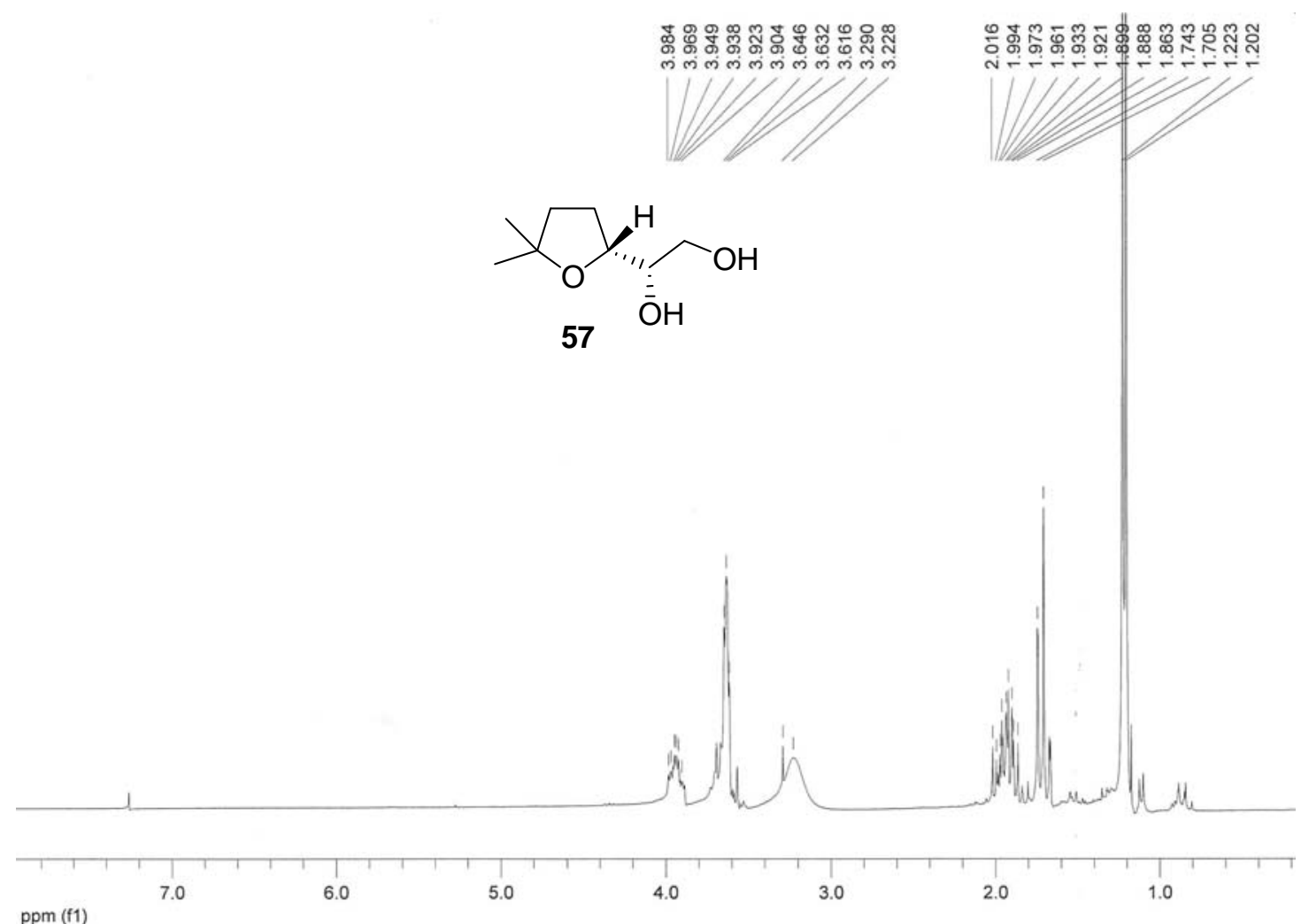
Fig. 49c

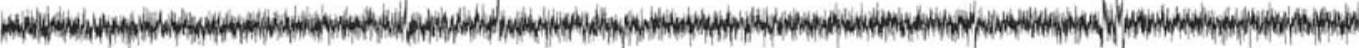
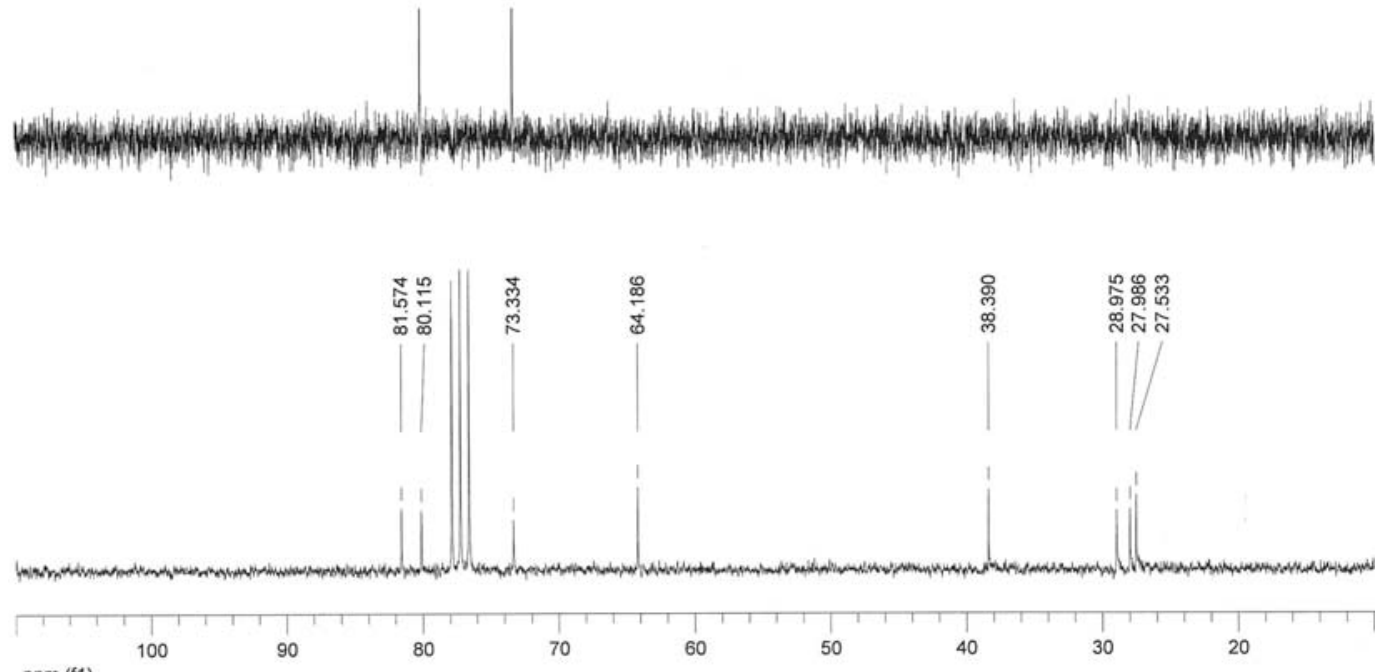

Fig. 49d

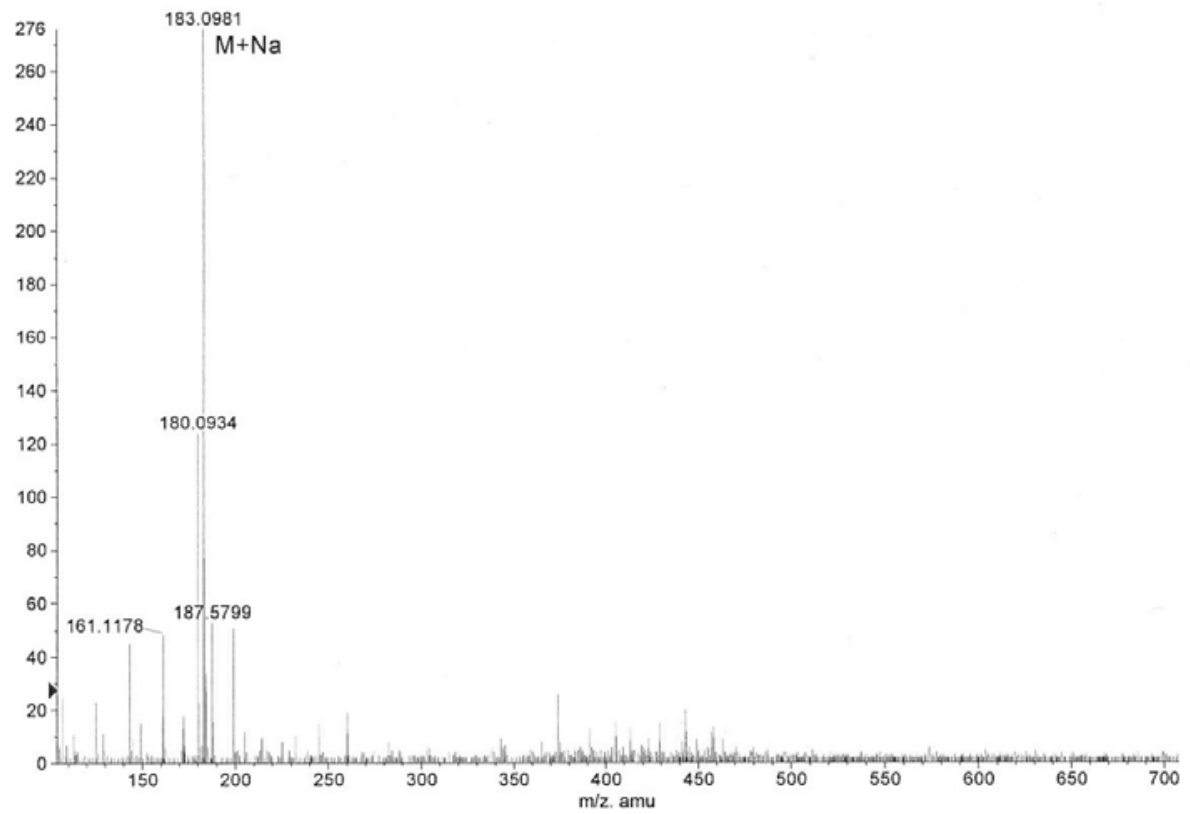


Fig. 50a

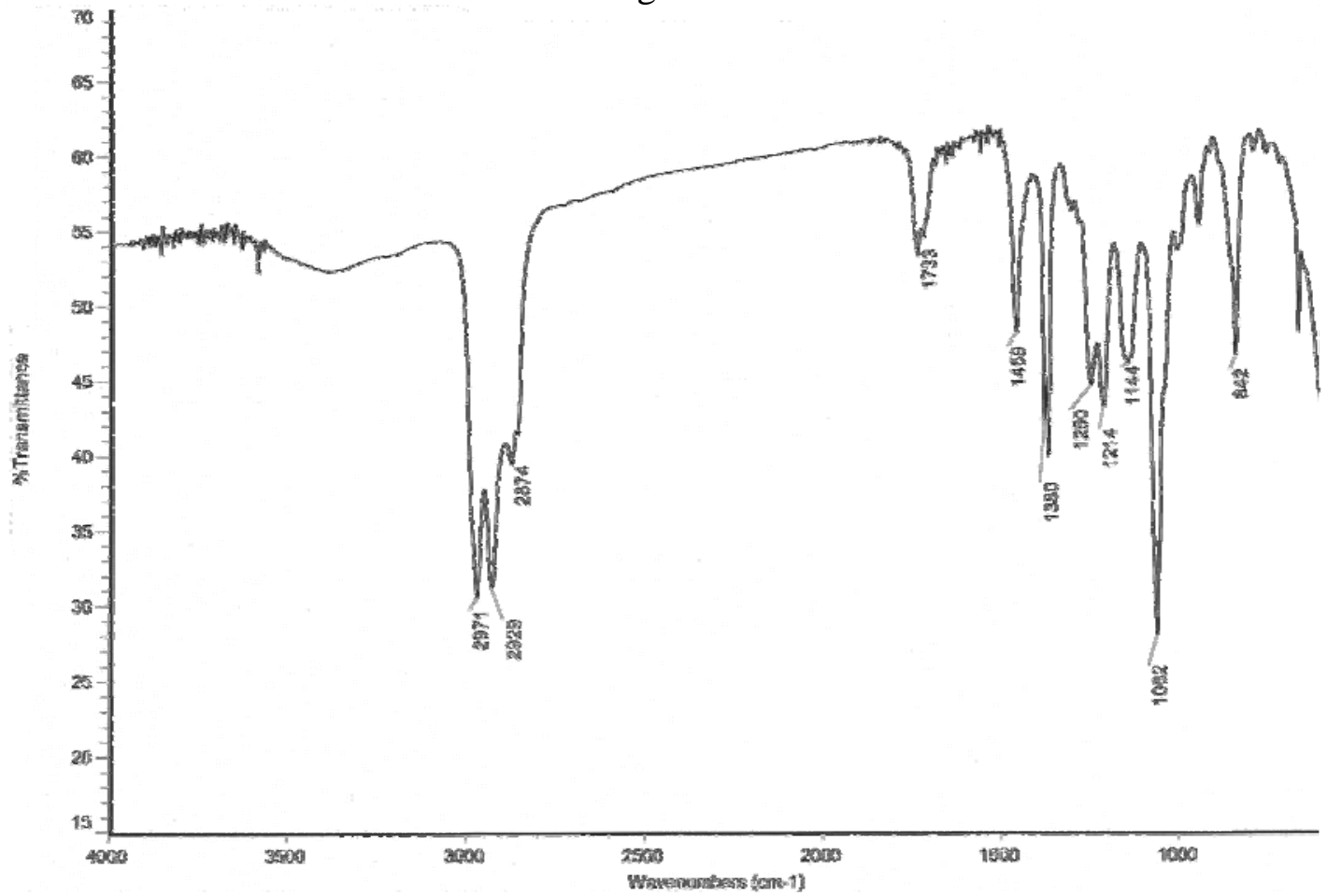

Fig. 50b

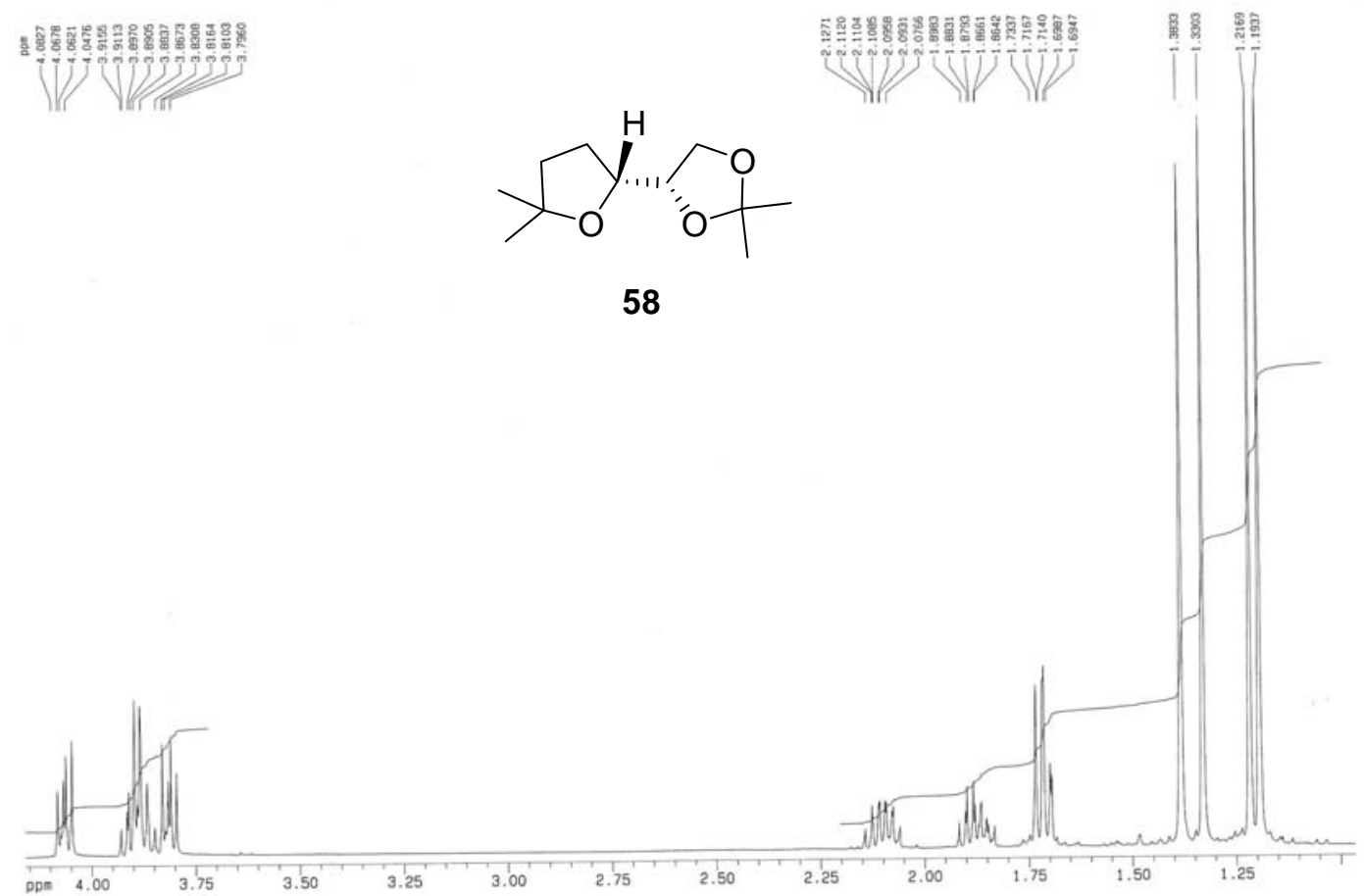


Fig. 50c

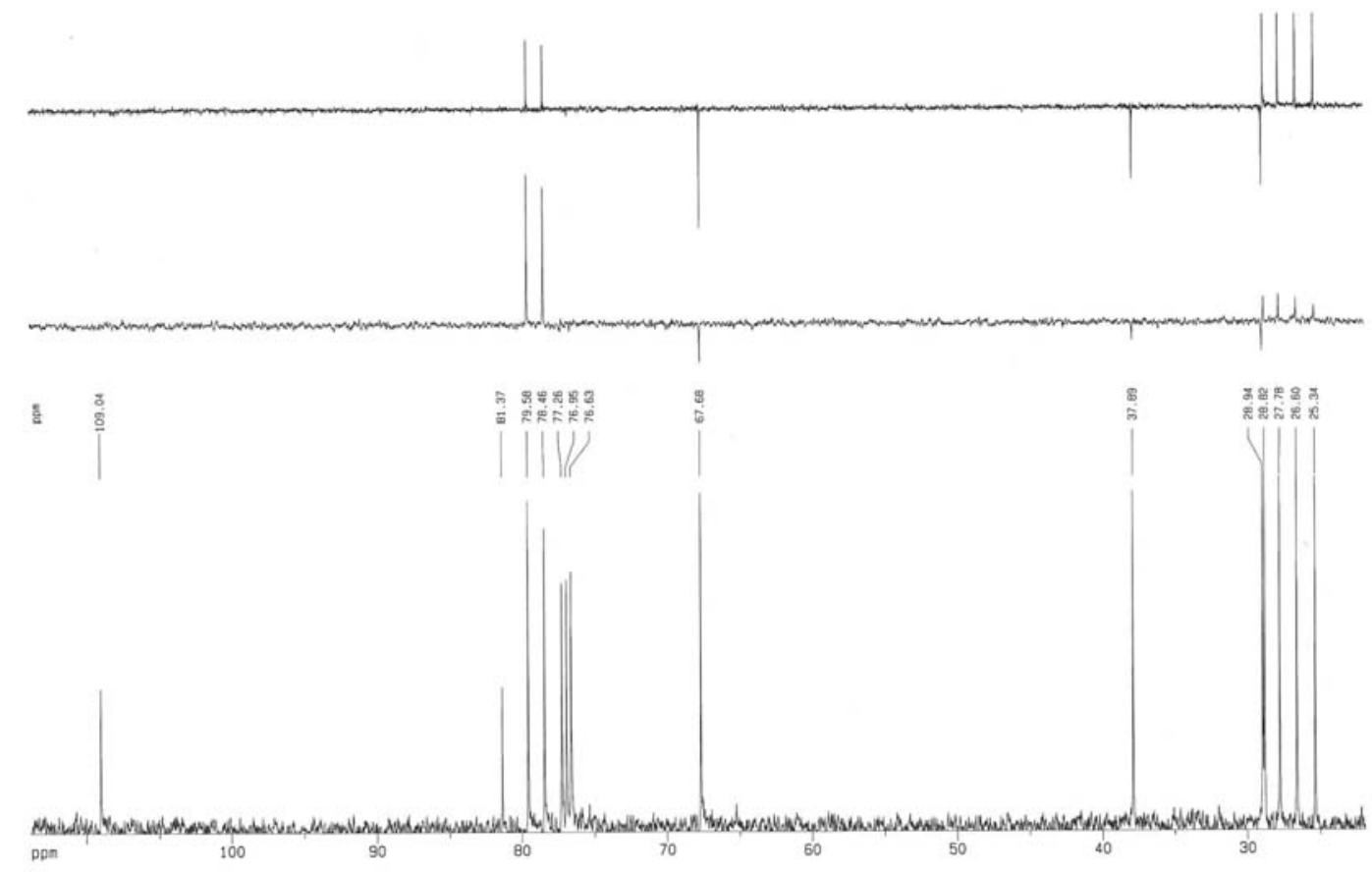

Fig. 50d

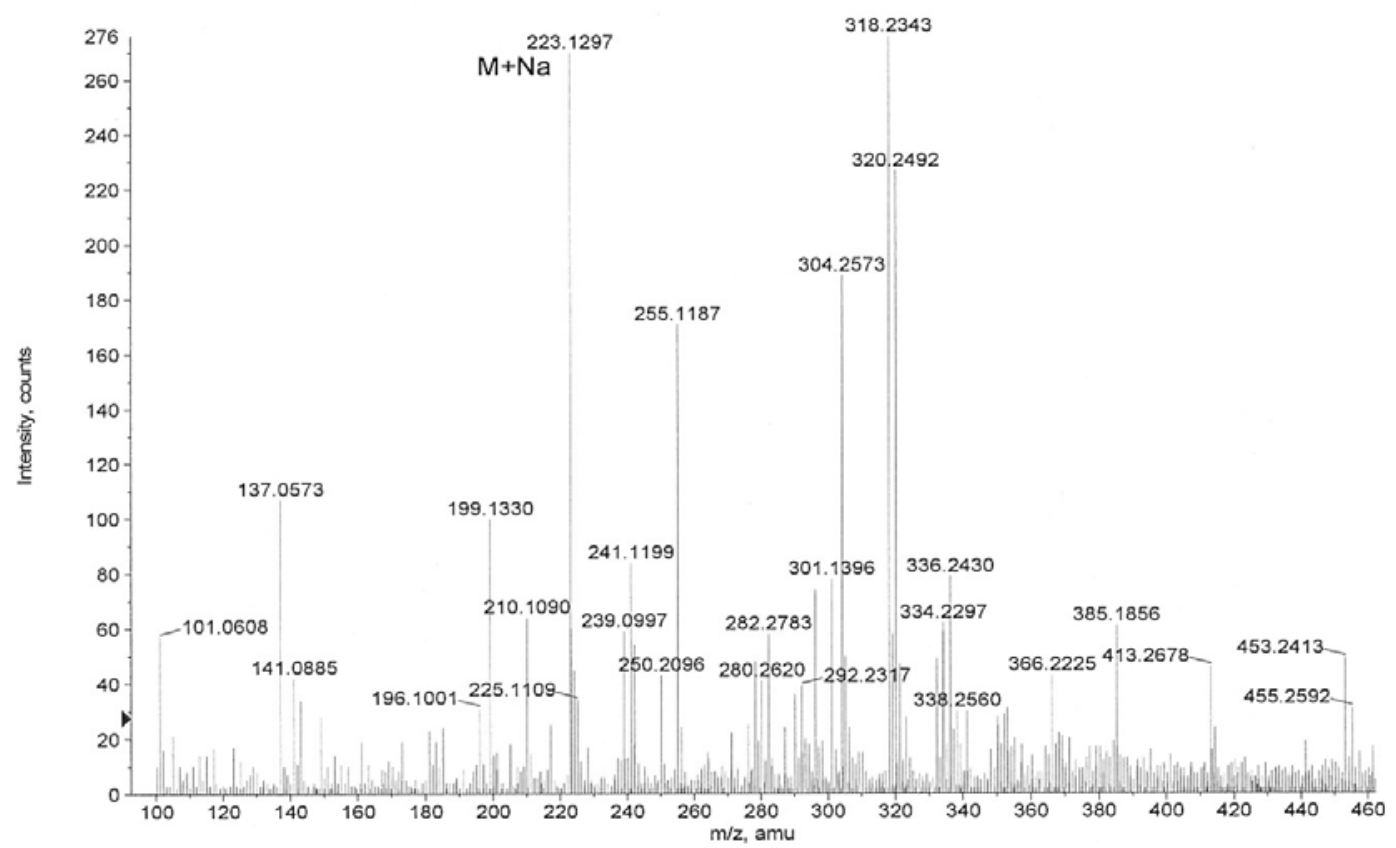


Fig. 50e-COSY

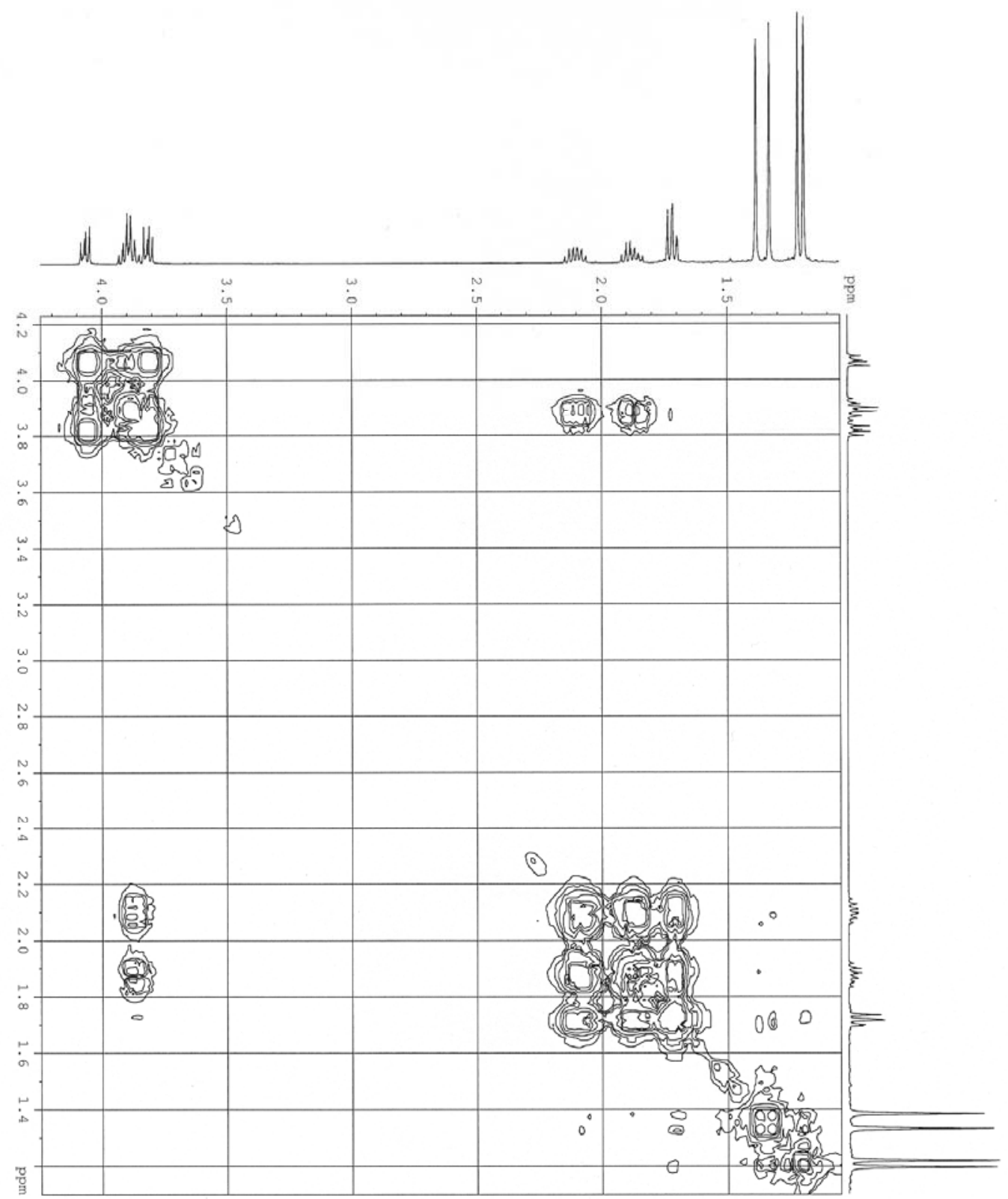


Fig. 50f-HMQC

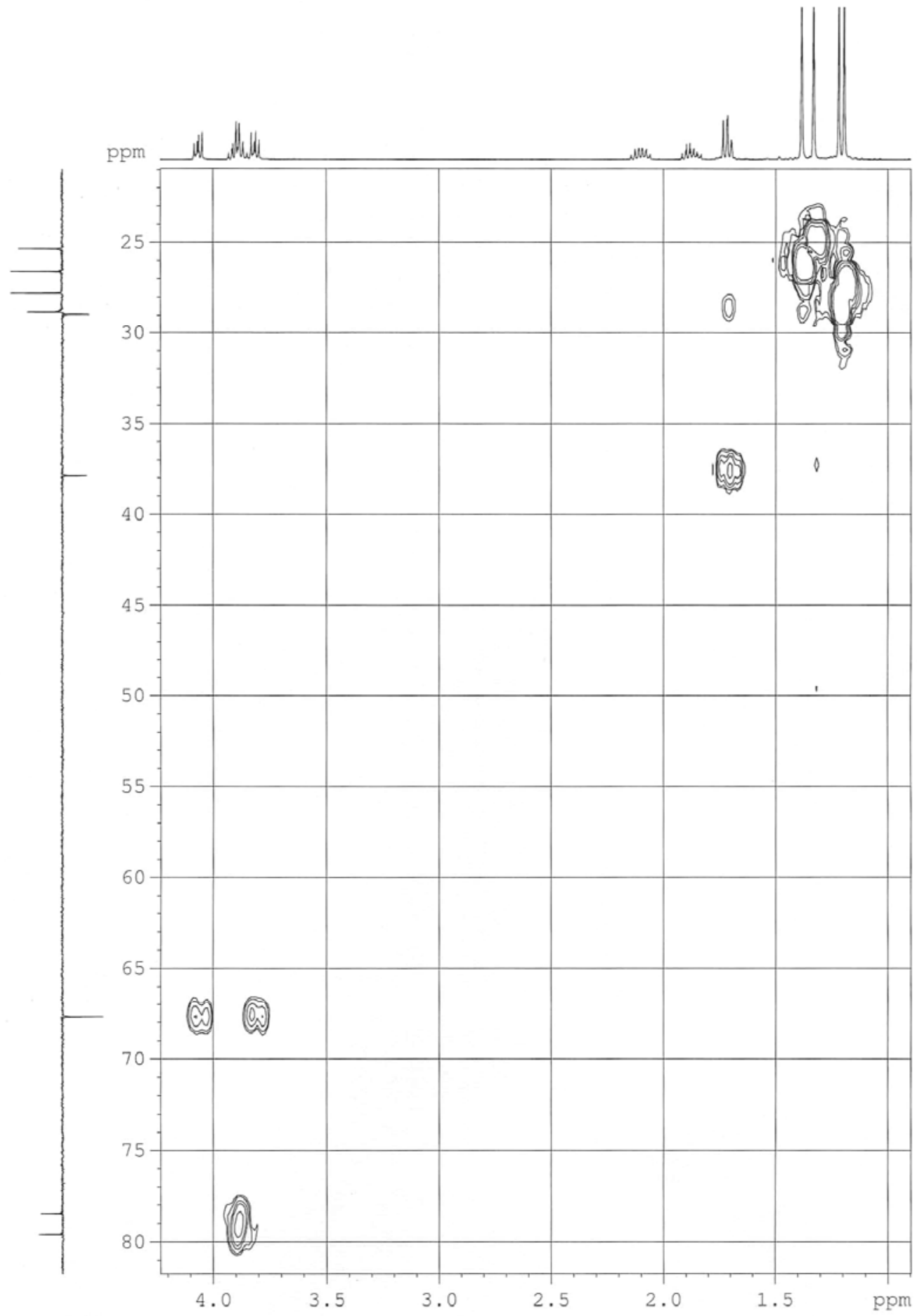


Fig. 50g-HMBC

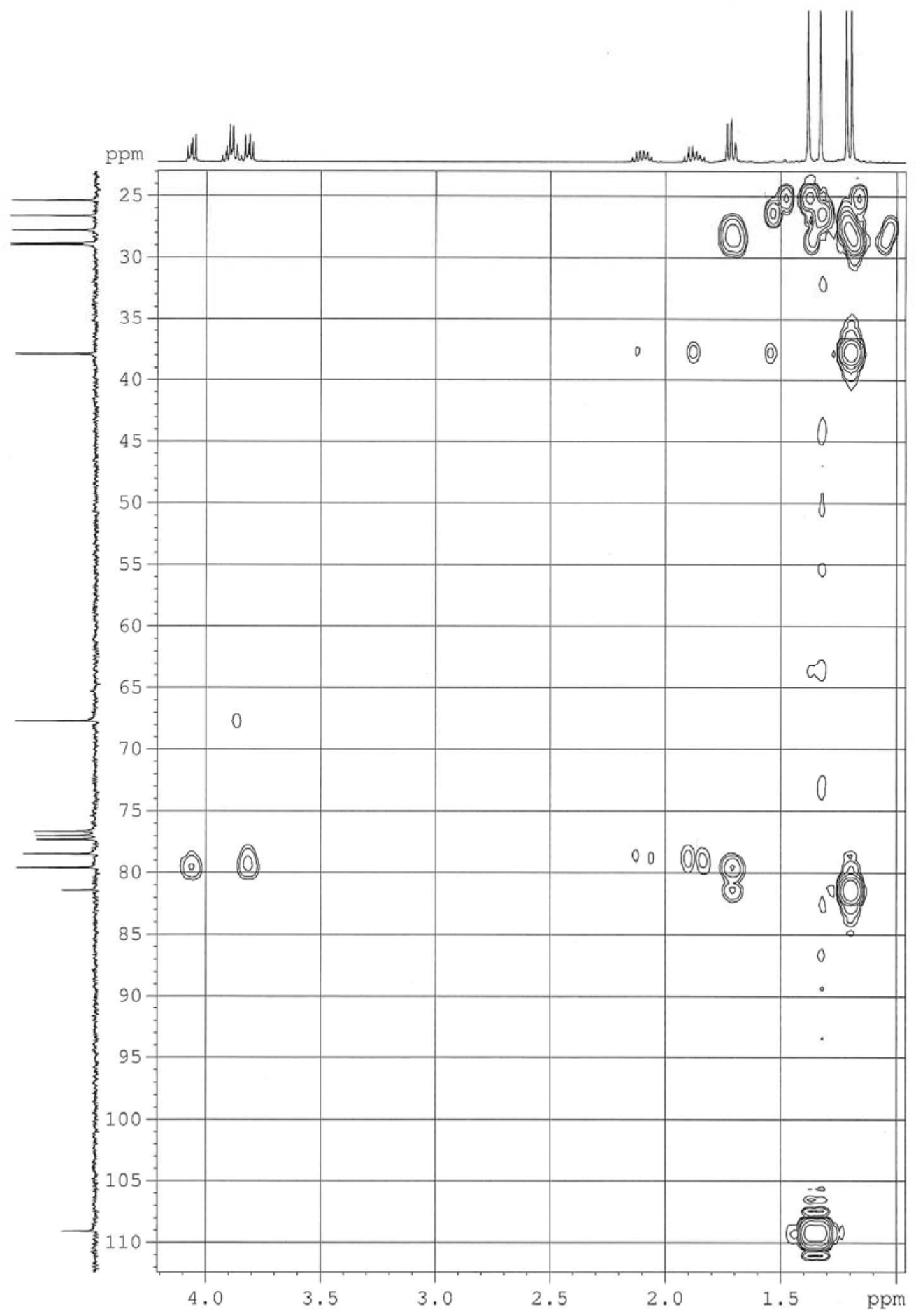


Fig. 51a

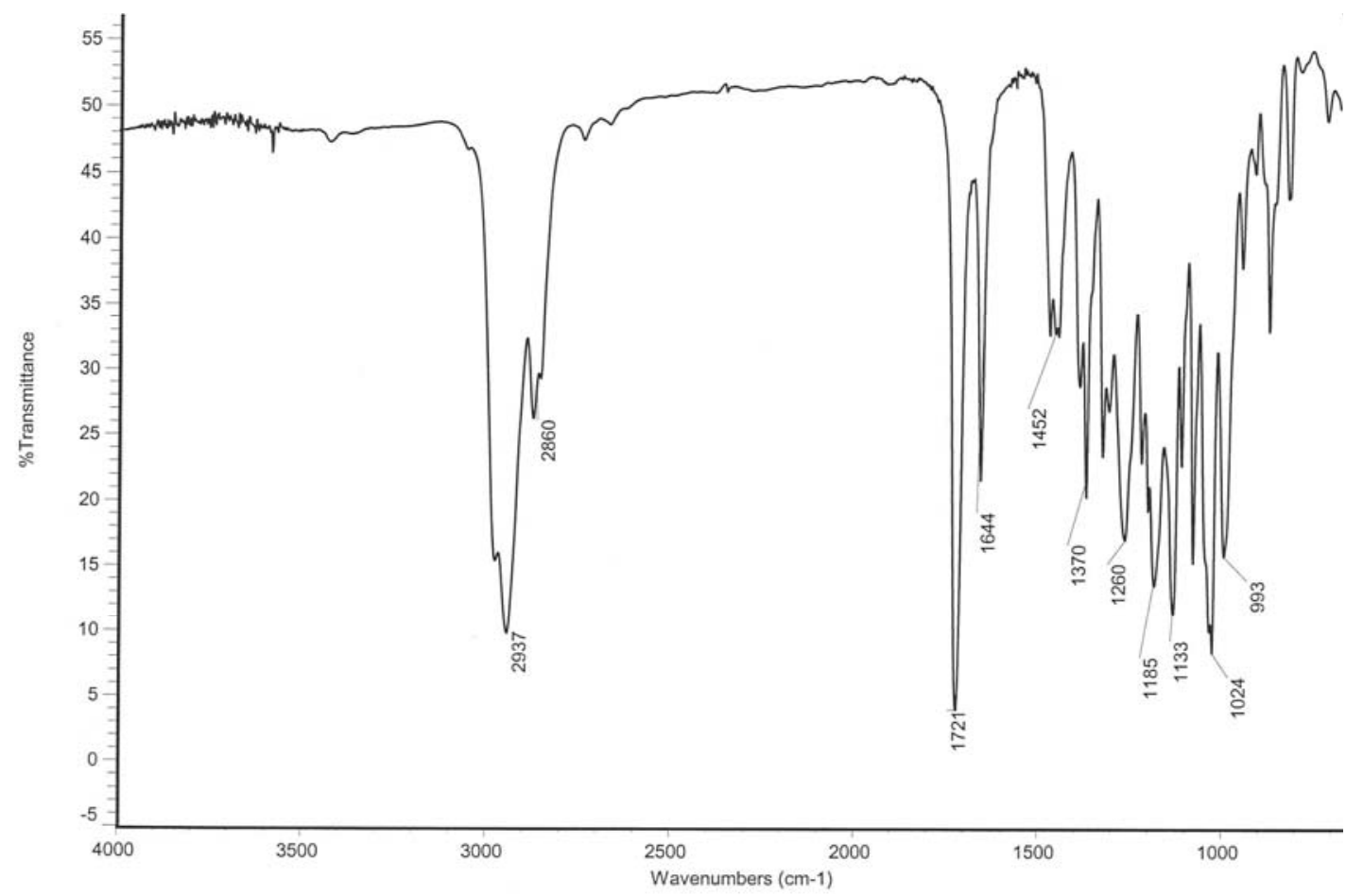

Fig. 51b
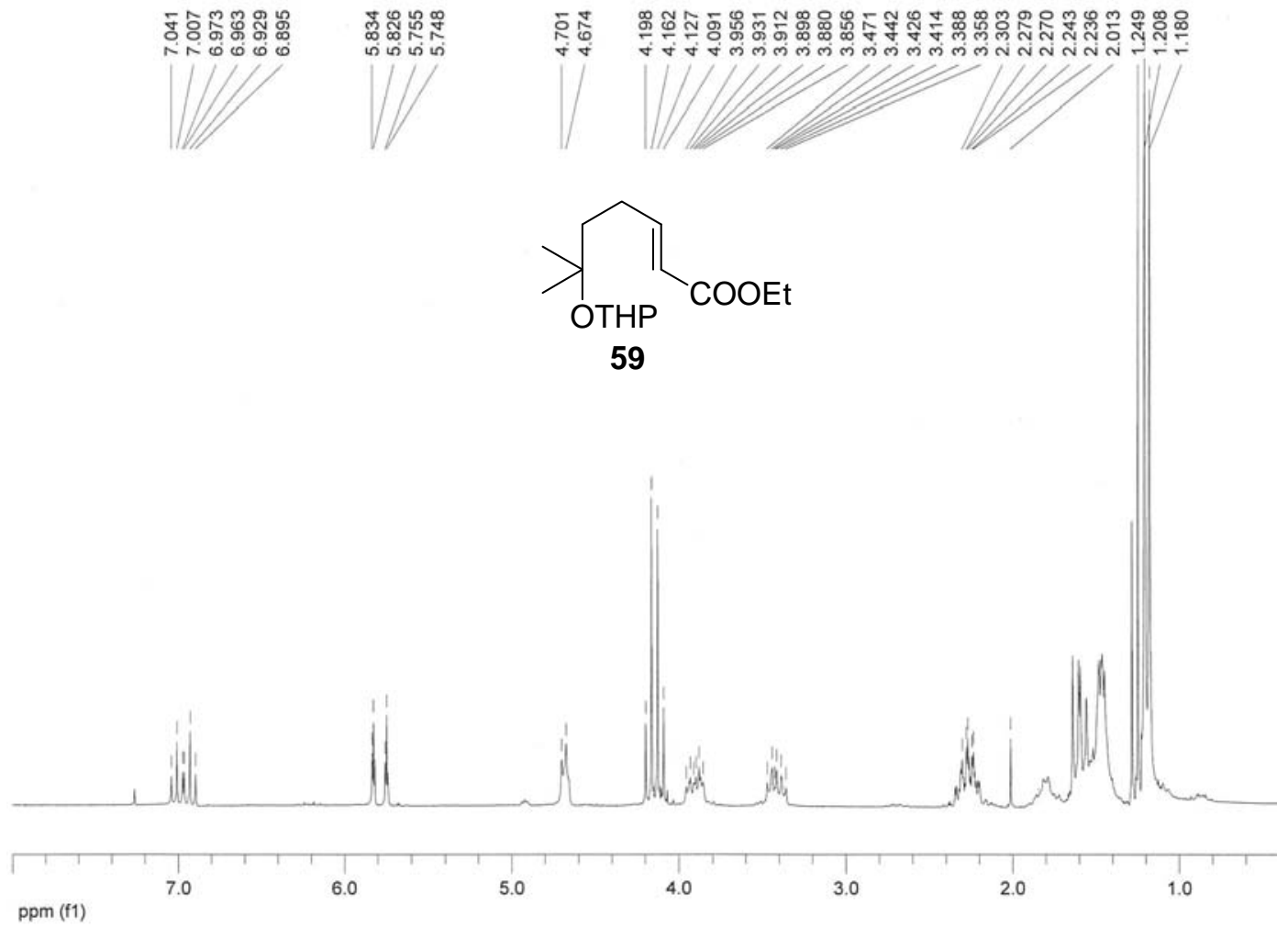
Fig. 51c
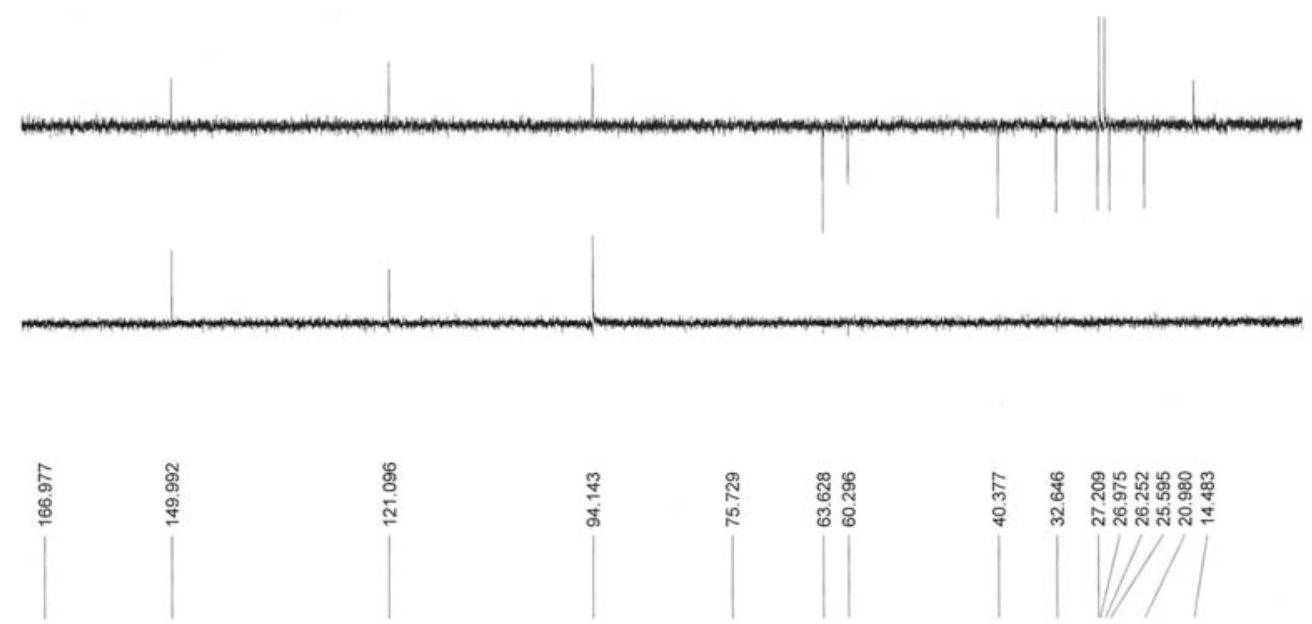

Fig. 51d

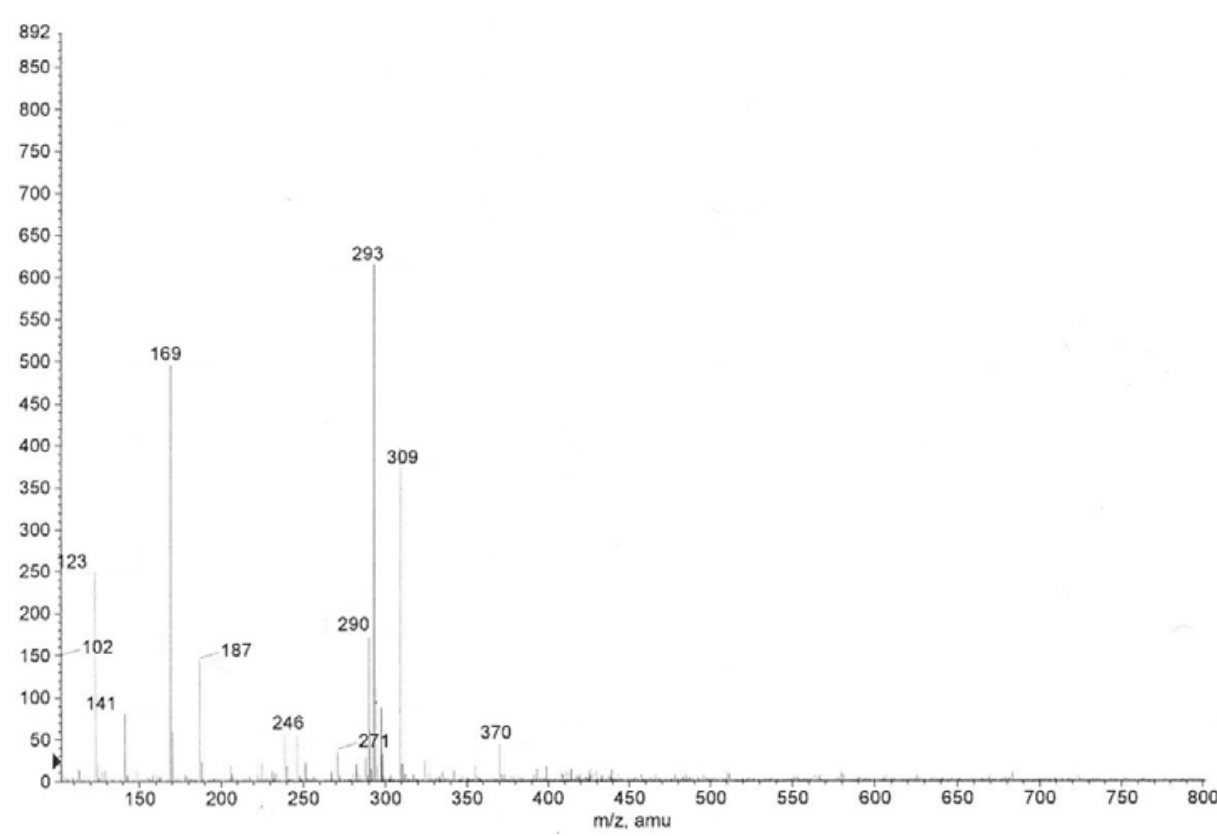


Fig. 52a

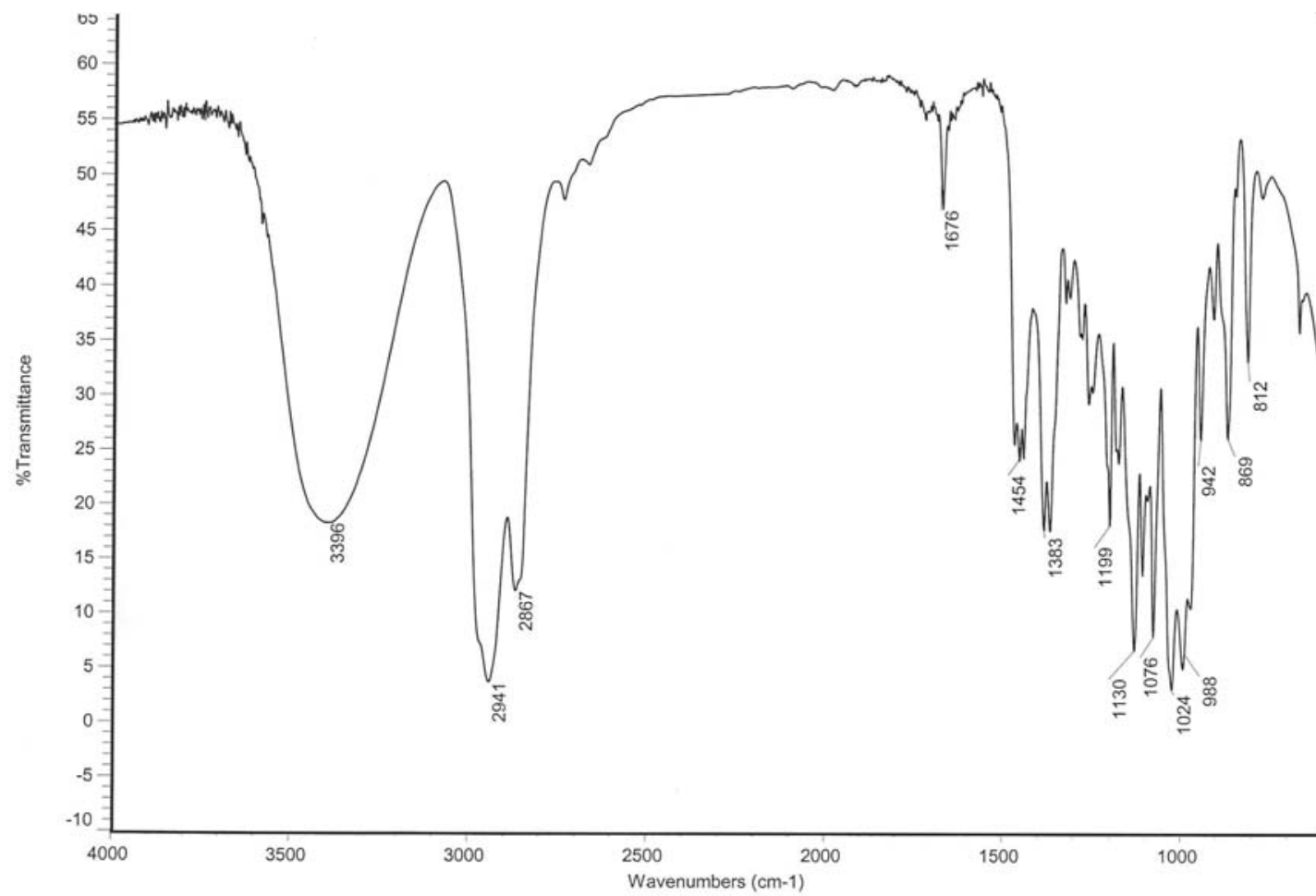

Fig. 52b

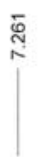

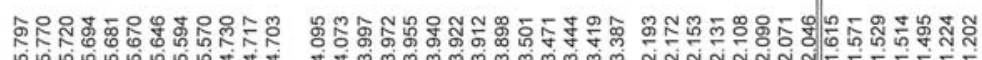

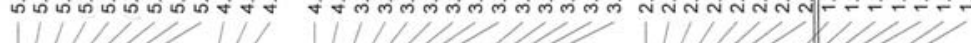<smiles>CC(C)([OH+])CC/C=C/CO</smiles>

60

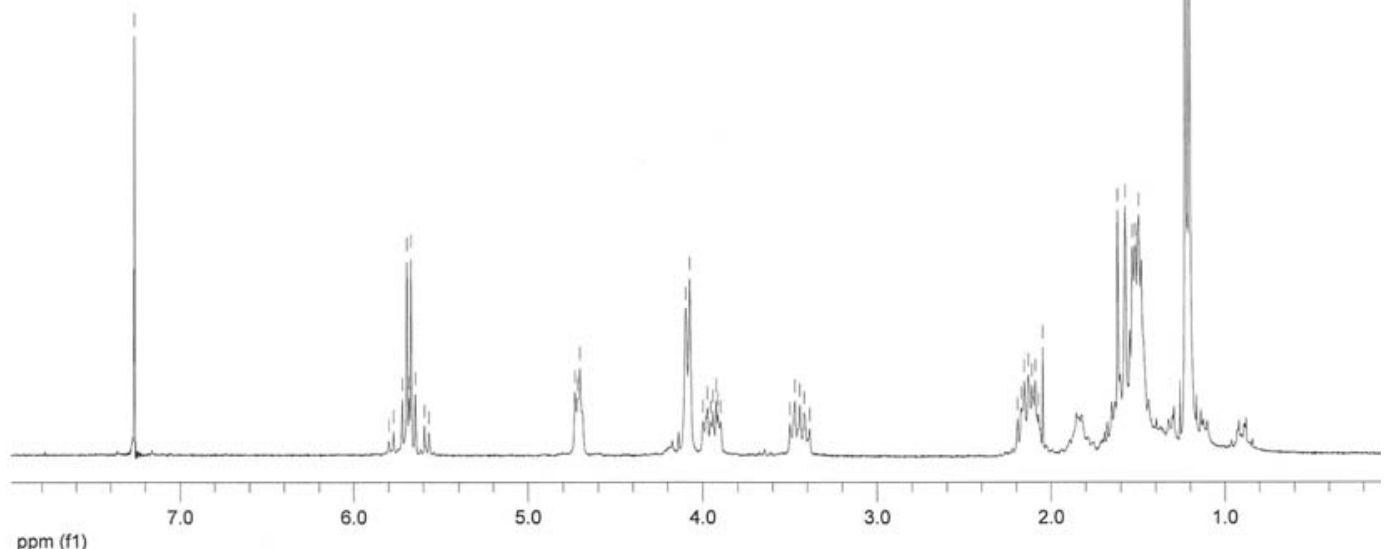


Fig. 52c
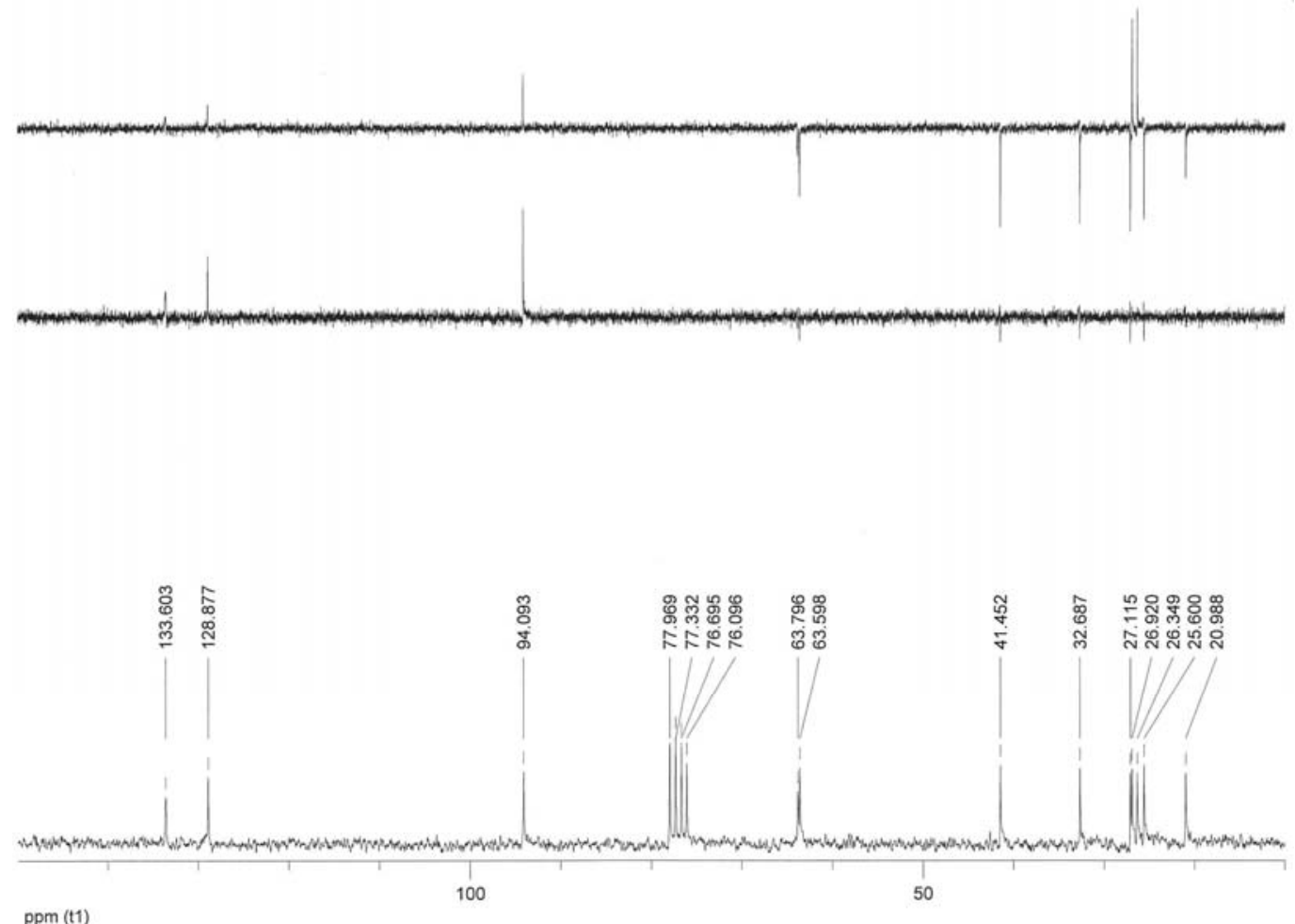

Fig. 52d

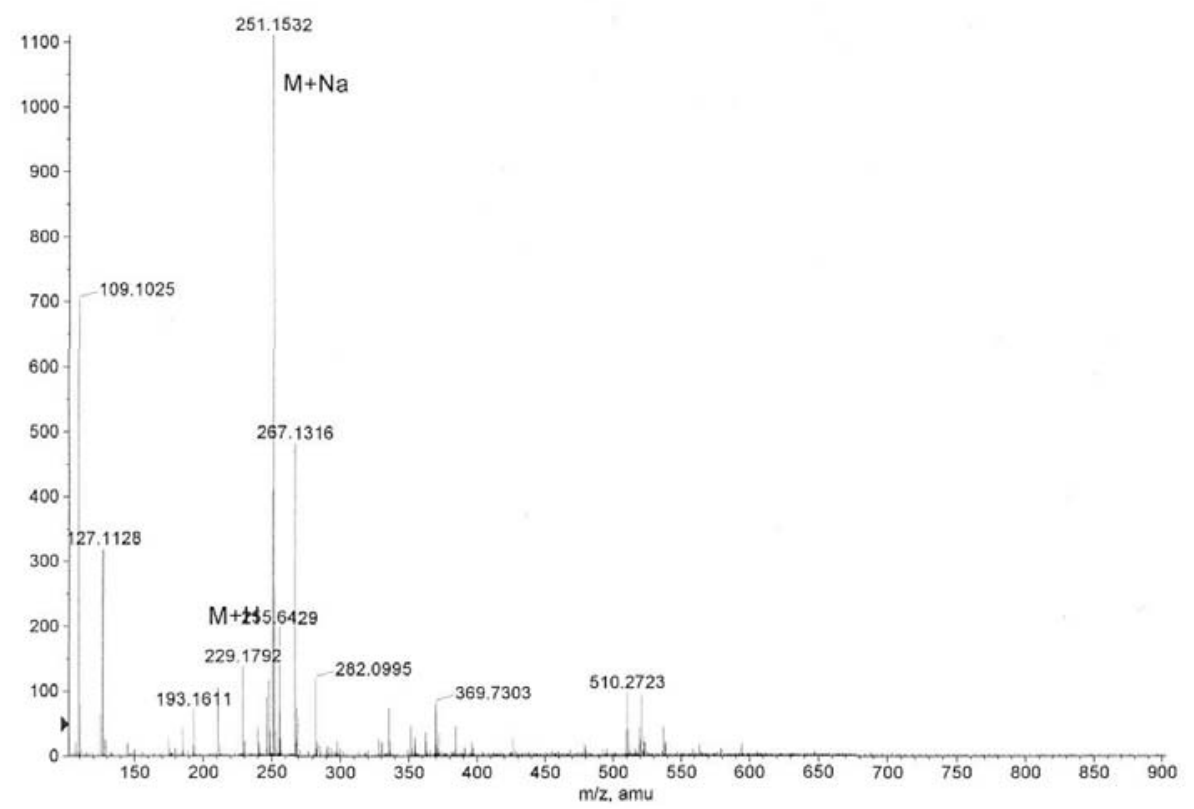


Fig. 53a

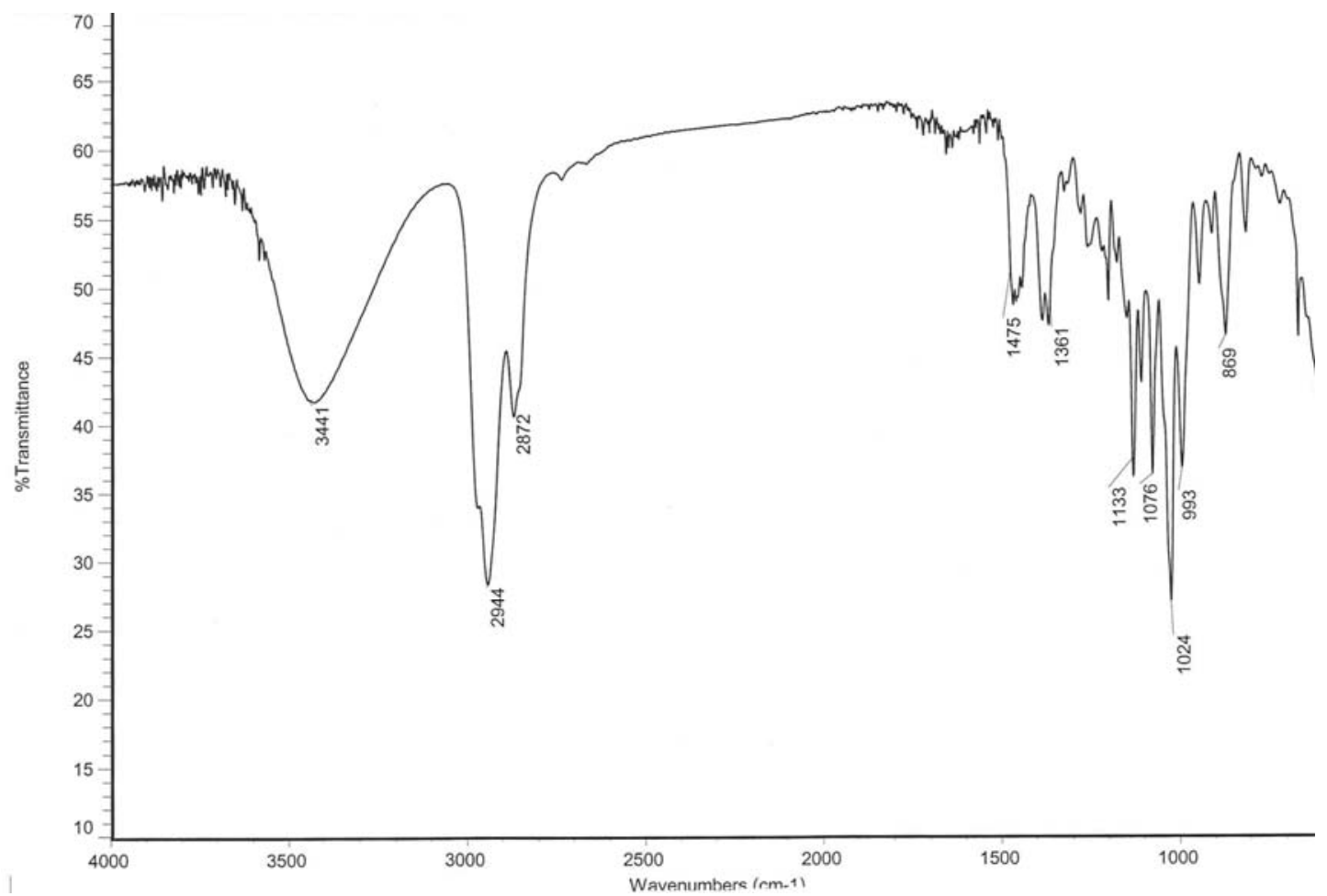

Fig. 53b

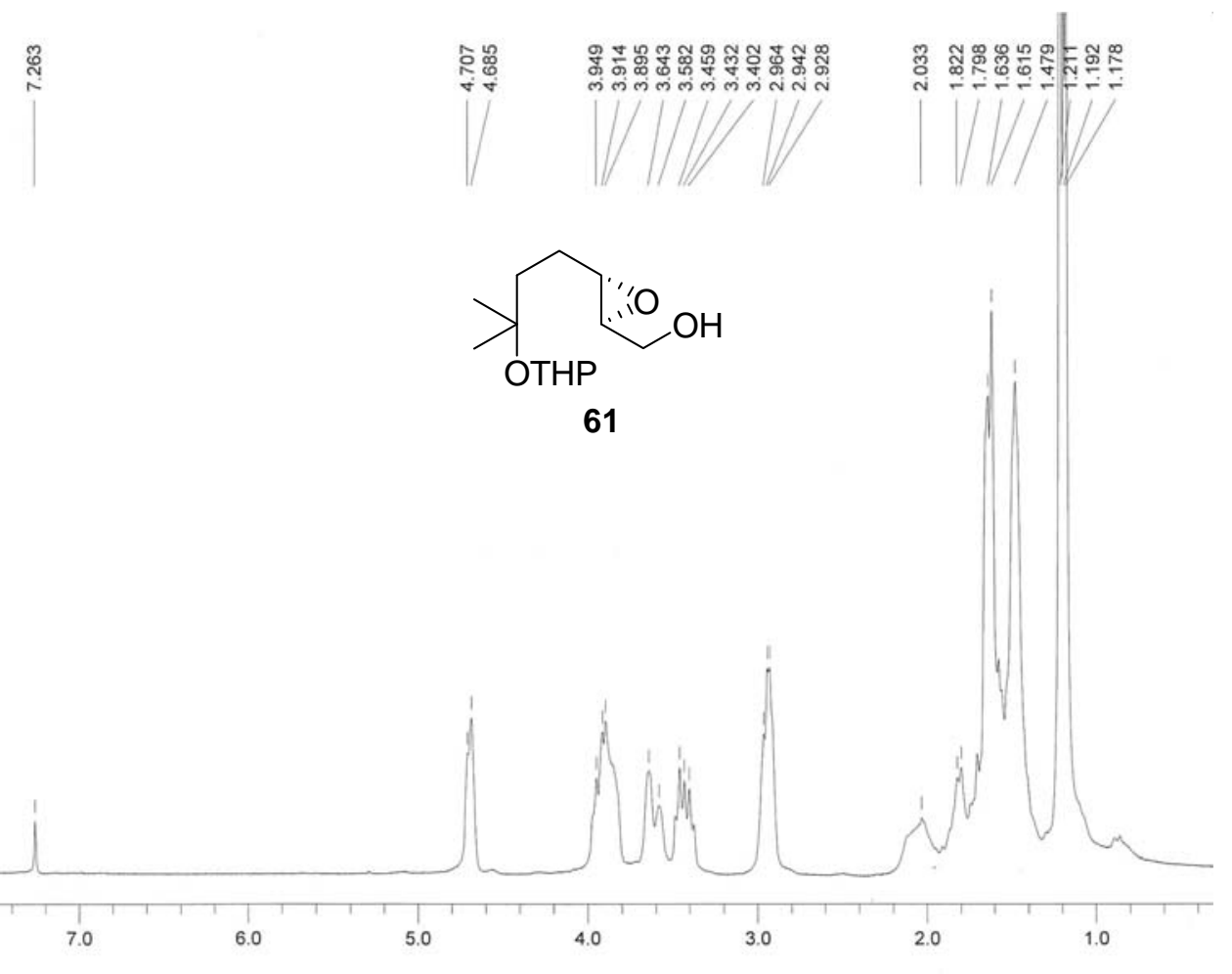


Fig. 53c

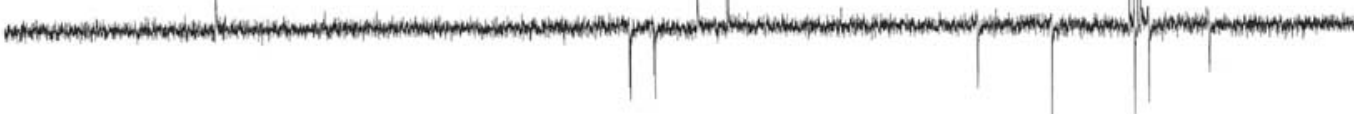

m.

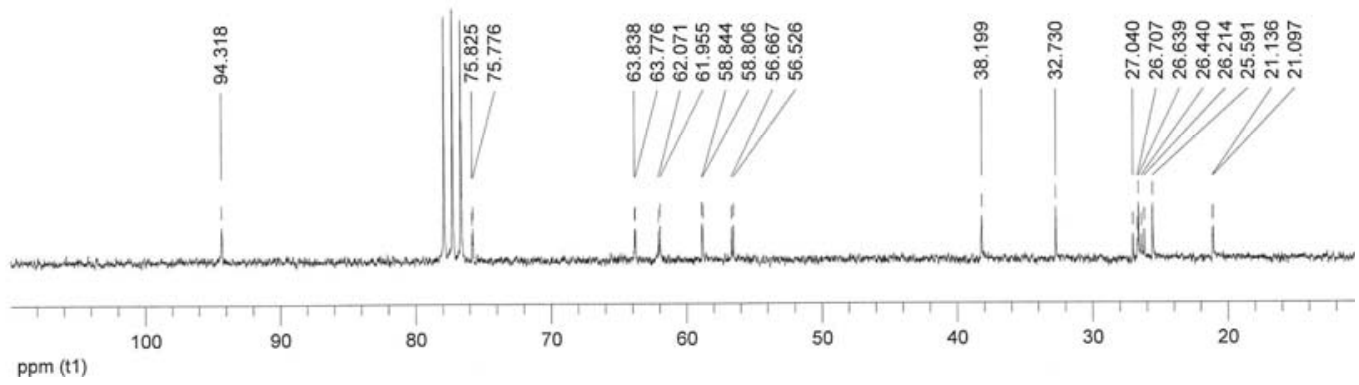

Fig. 53d

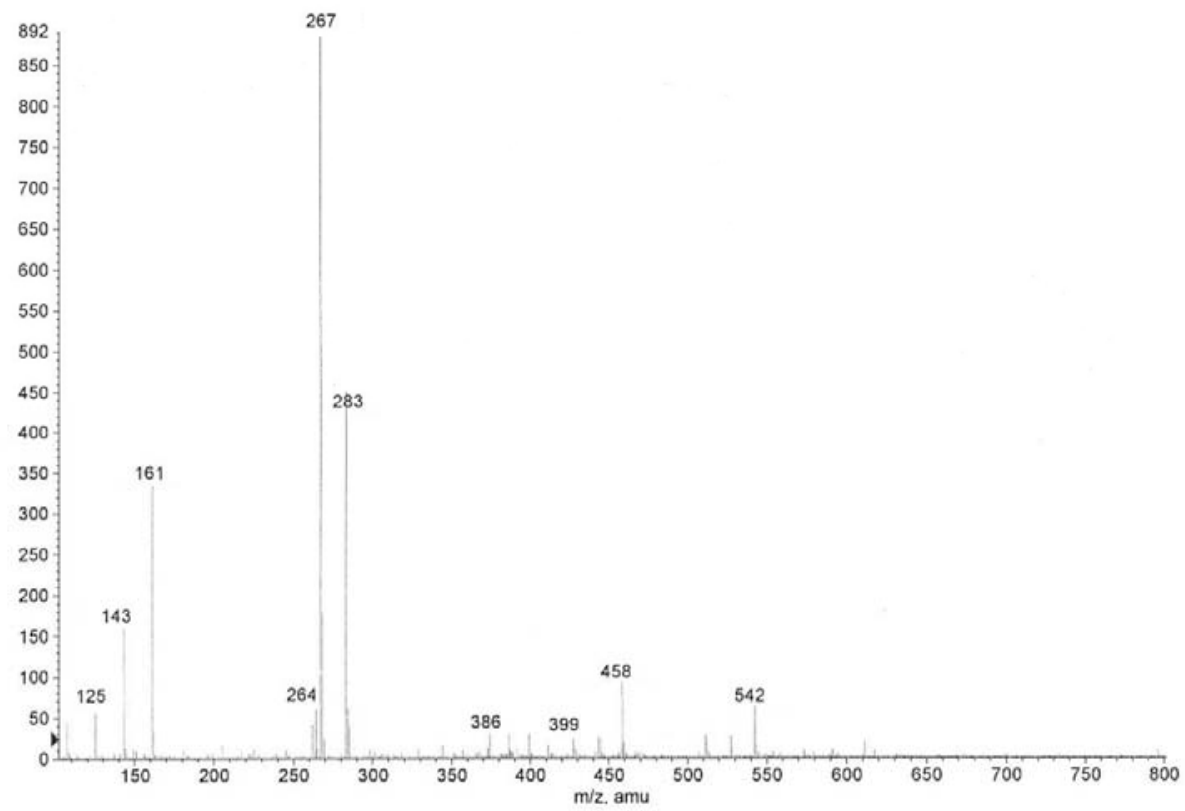


Fig. 54a

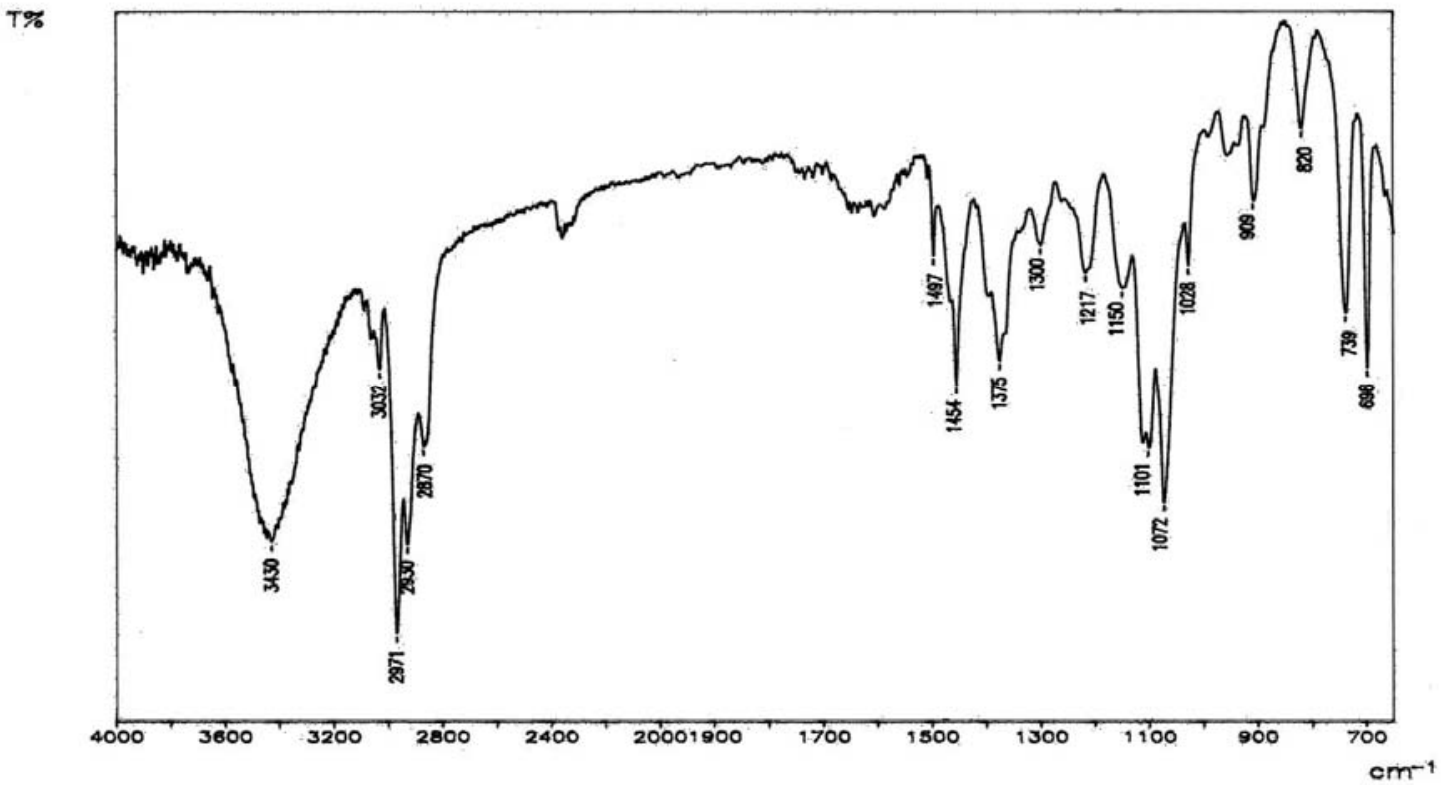

Fig. 54b

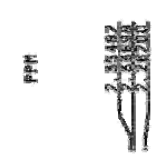

정
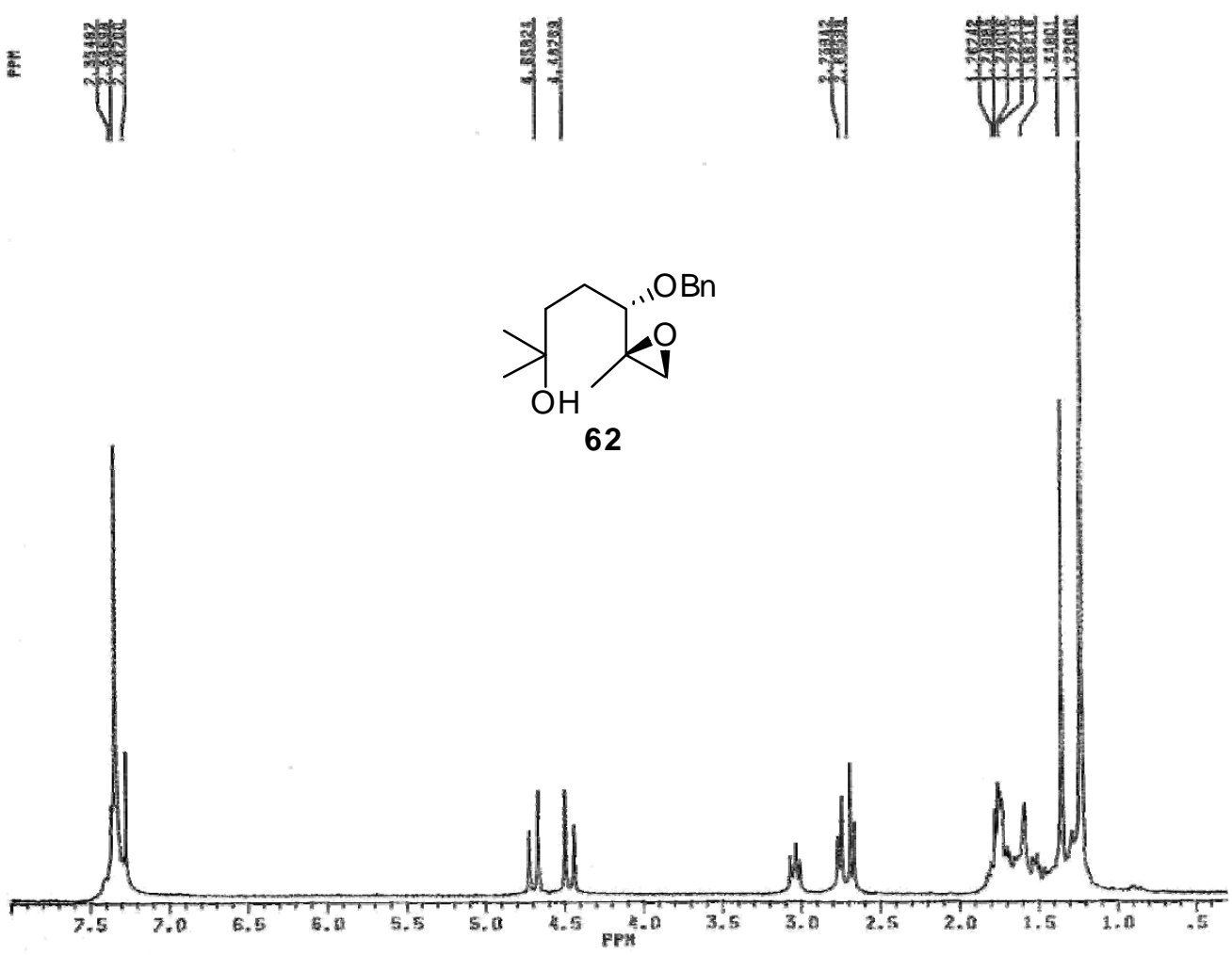
Fig. 54c

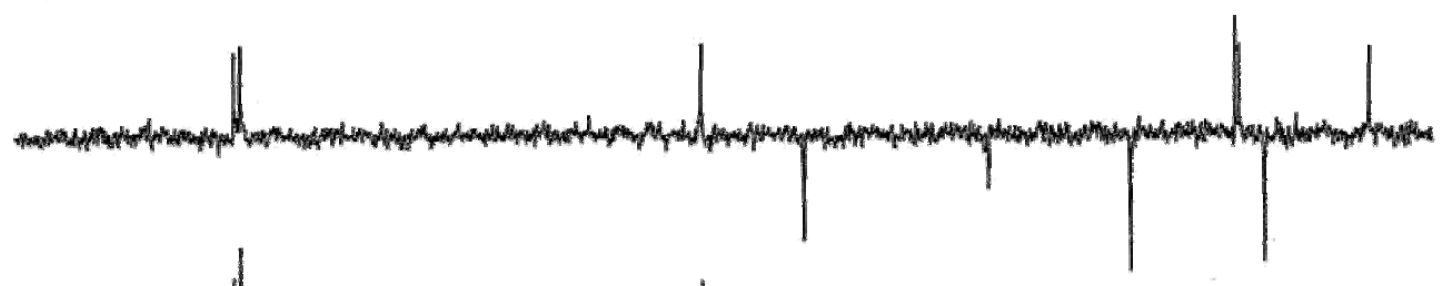
What

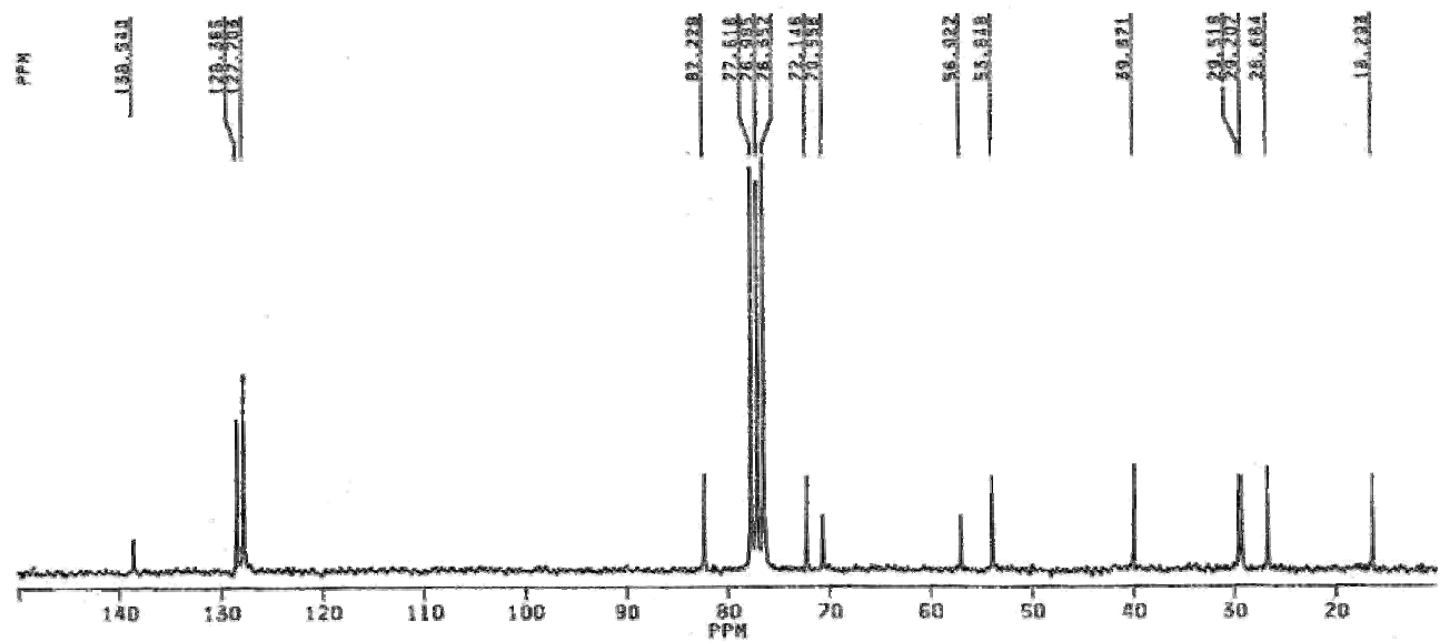

Fig. 54d

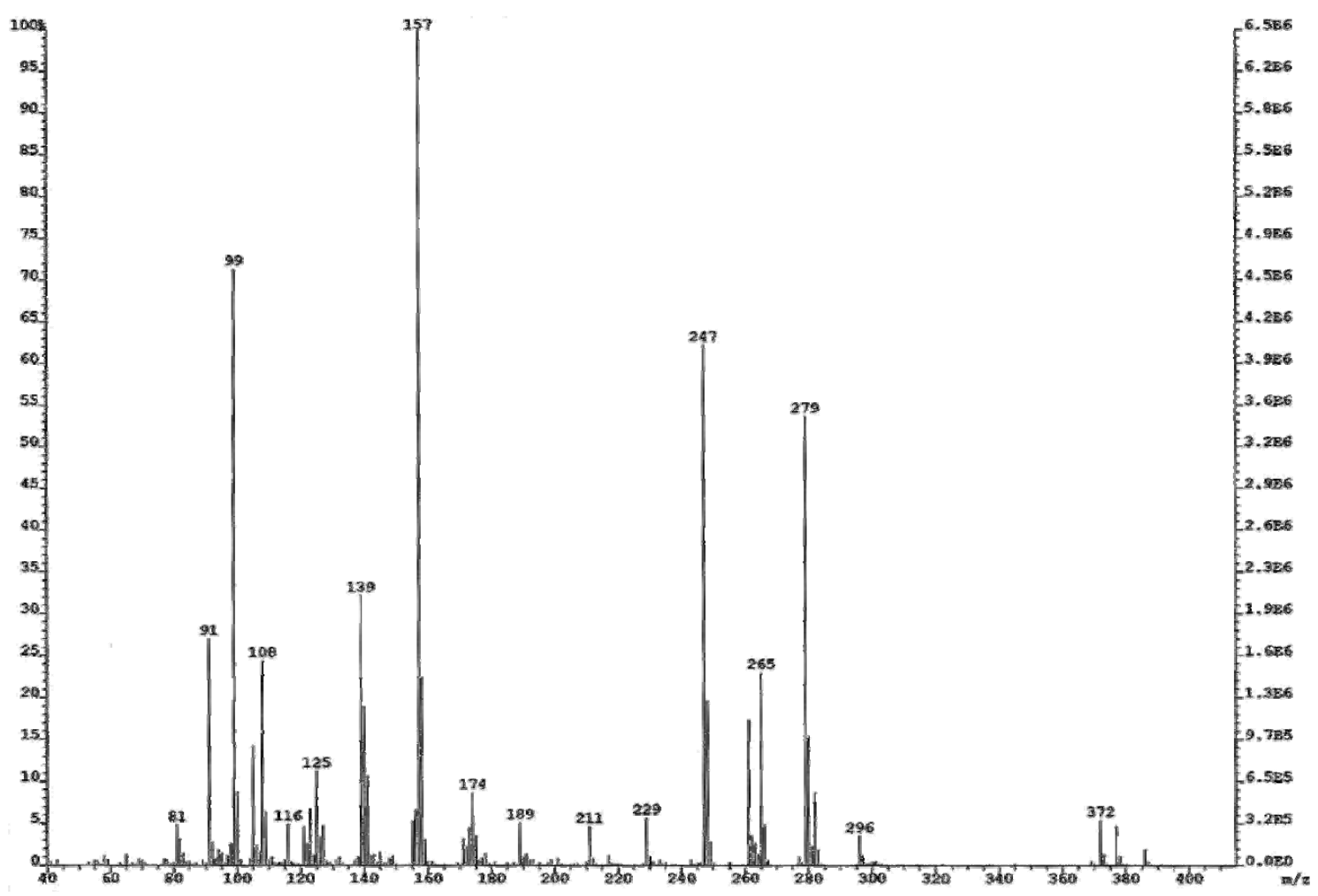


Fig. 55a

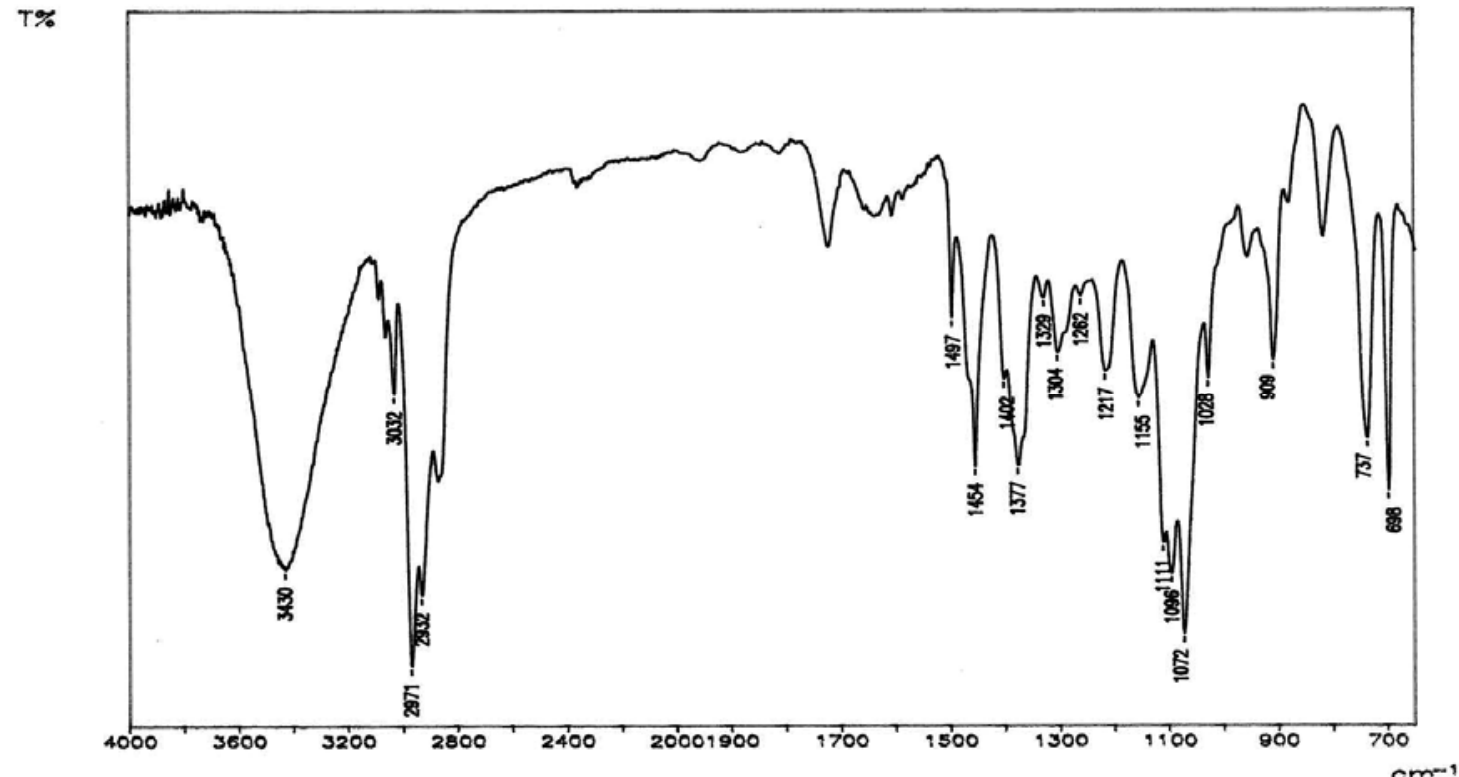

Fig. 55b

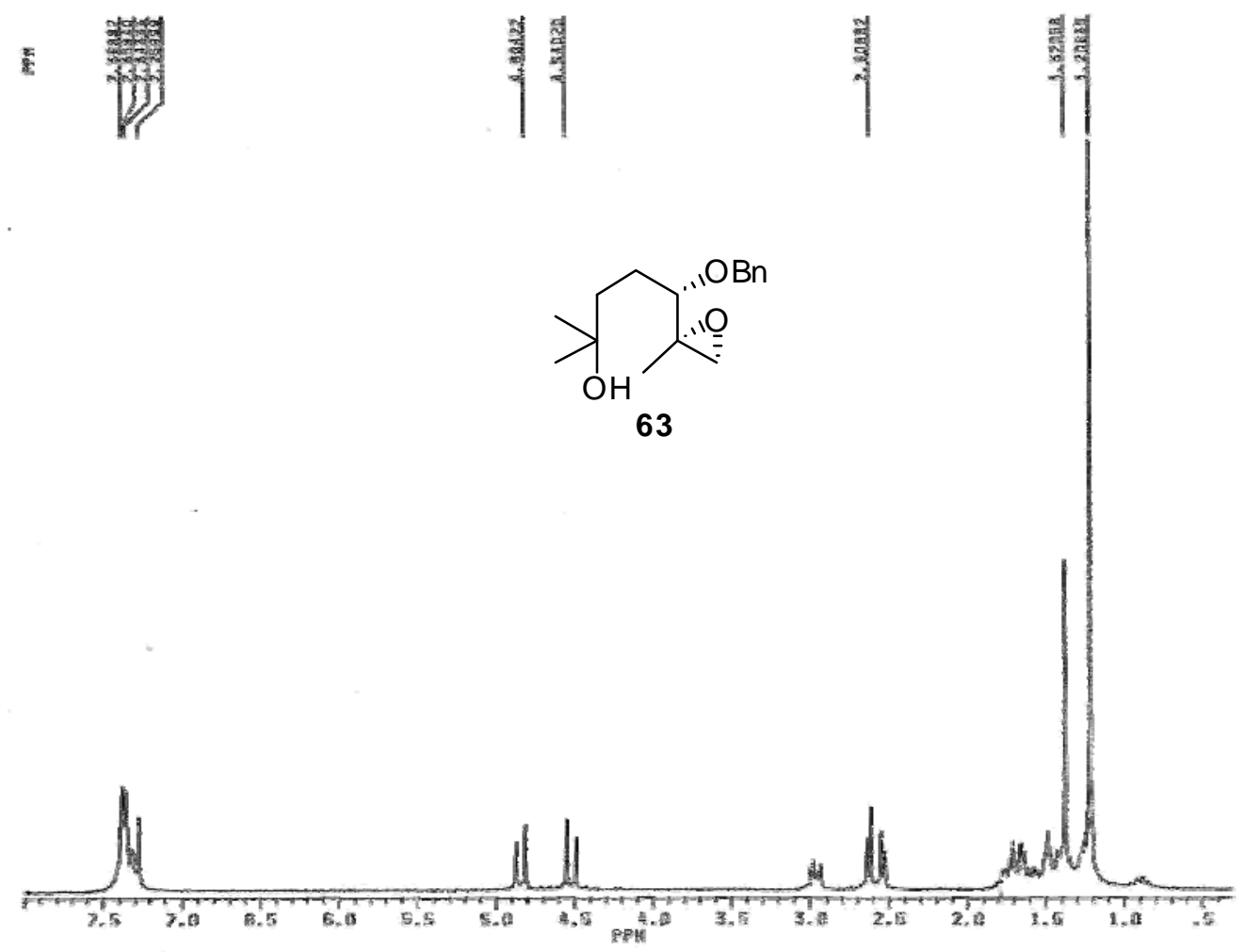


Fig. 55c

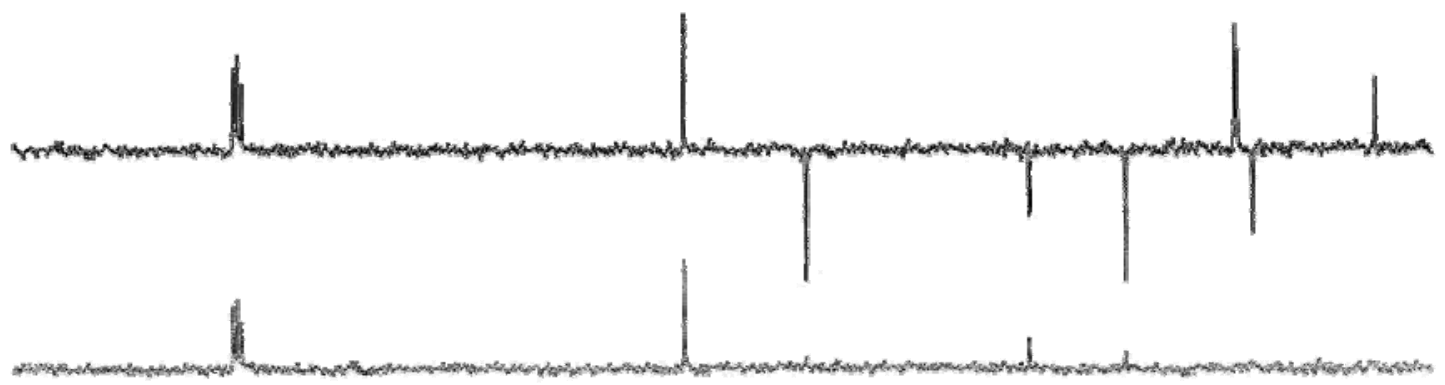

1
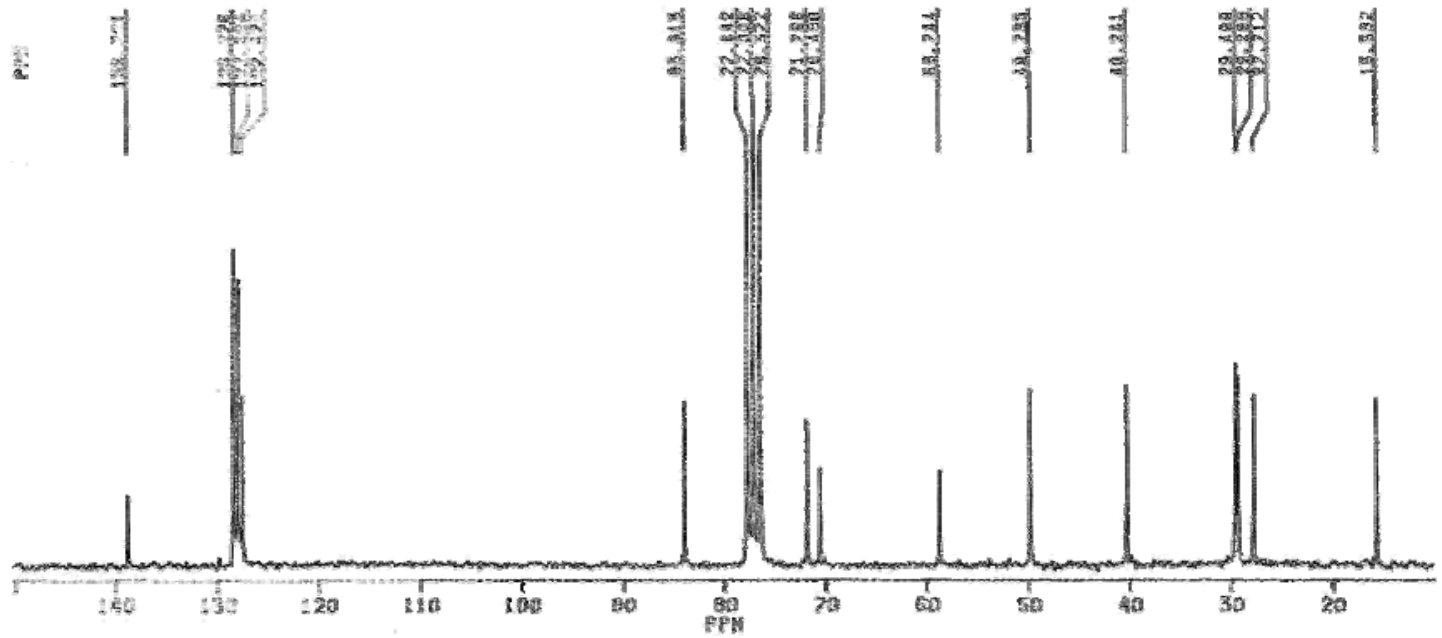
Fig. 56a

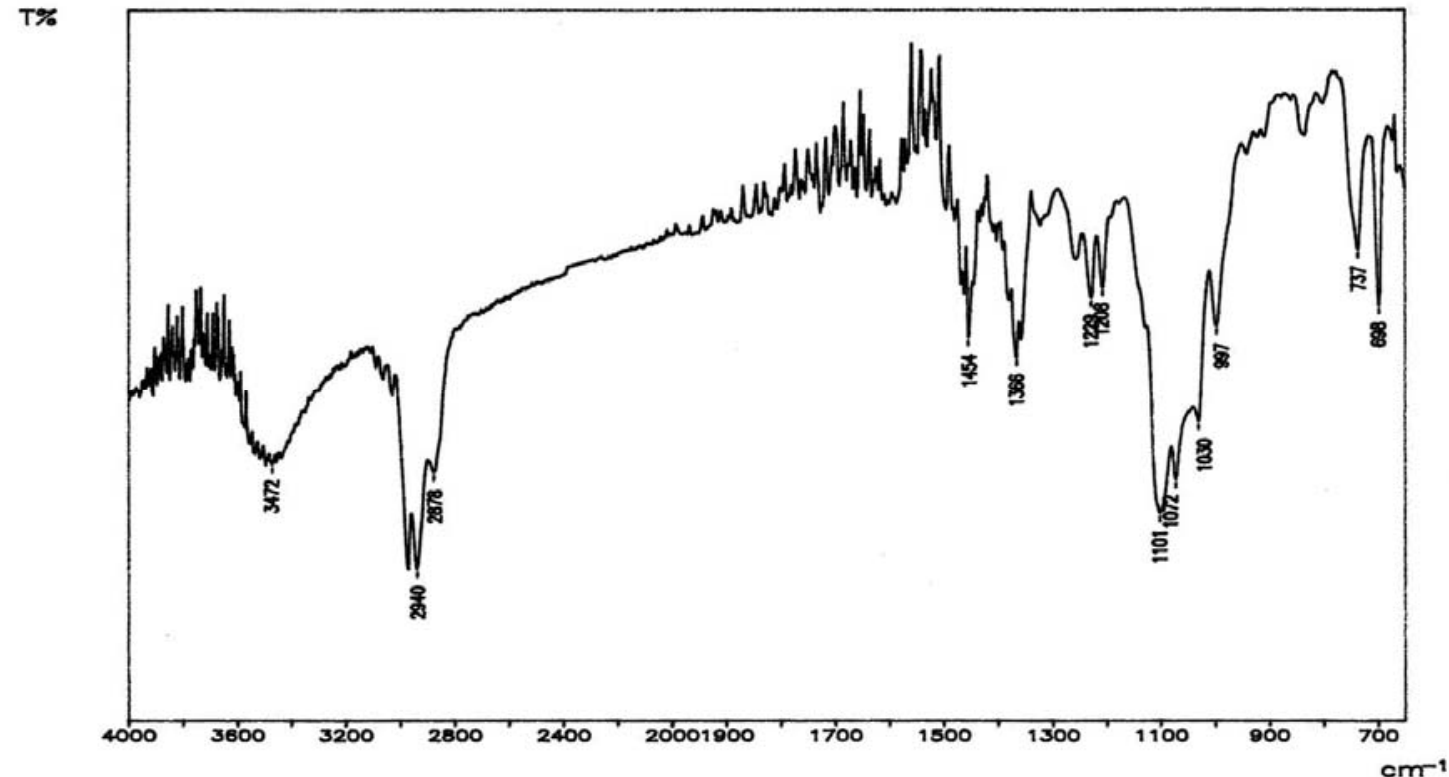

Fig. 56b

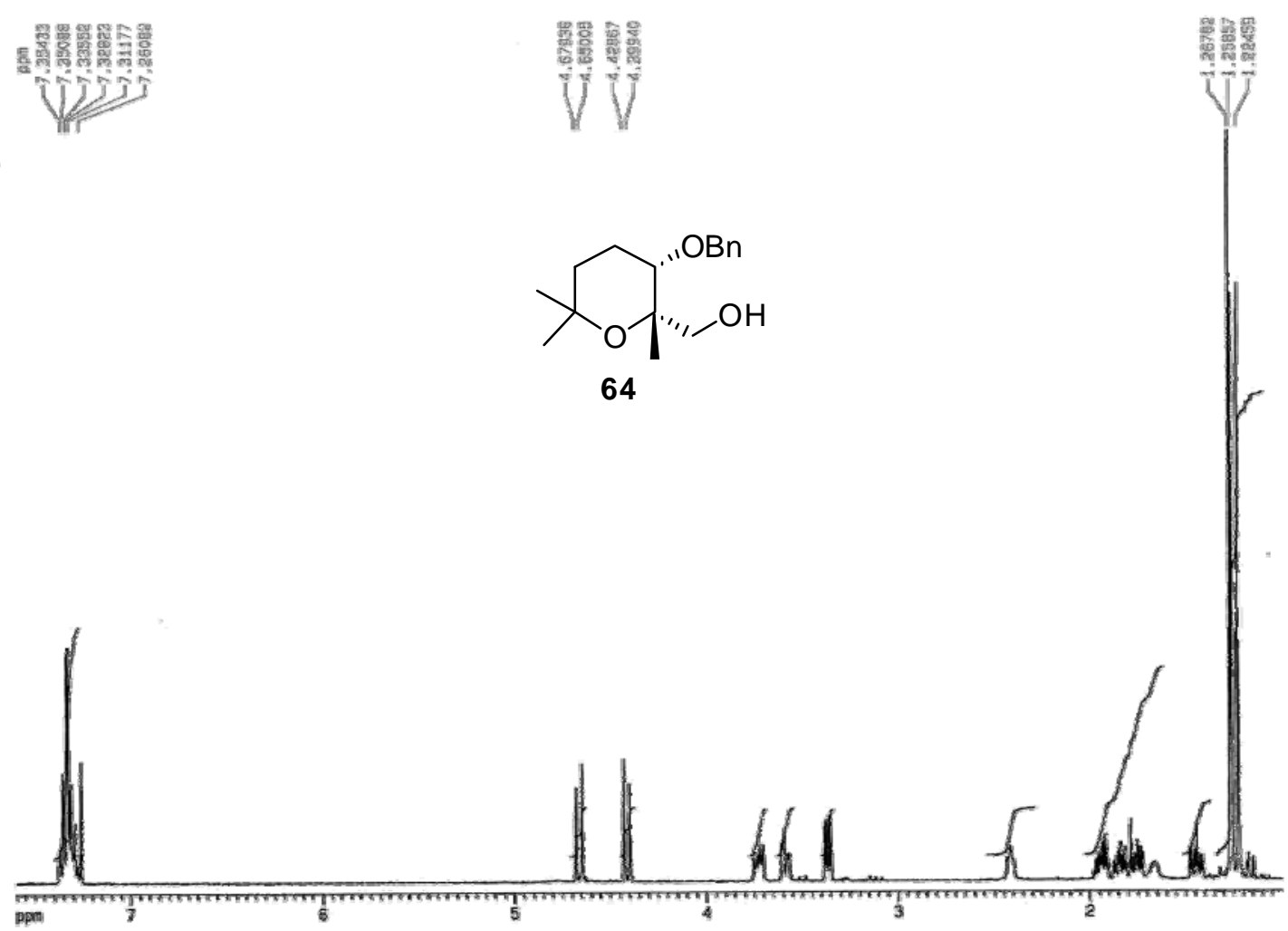


Fig. 56c

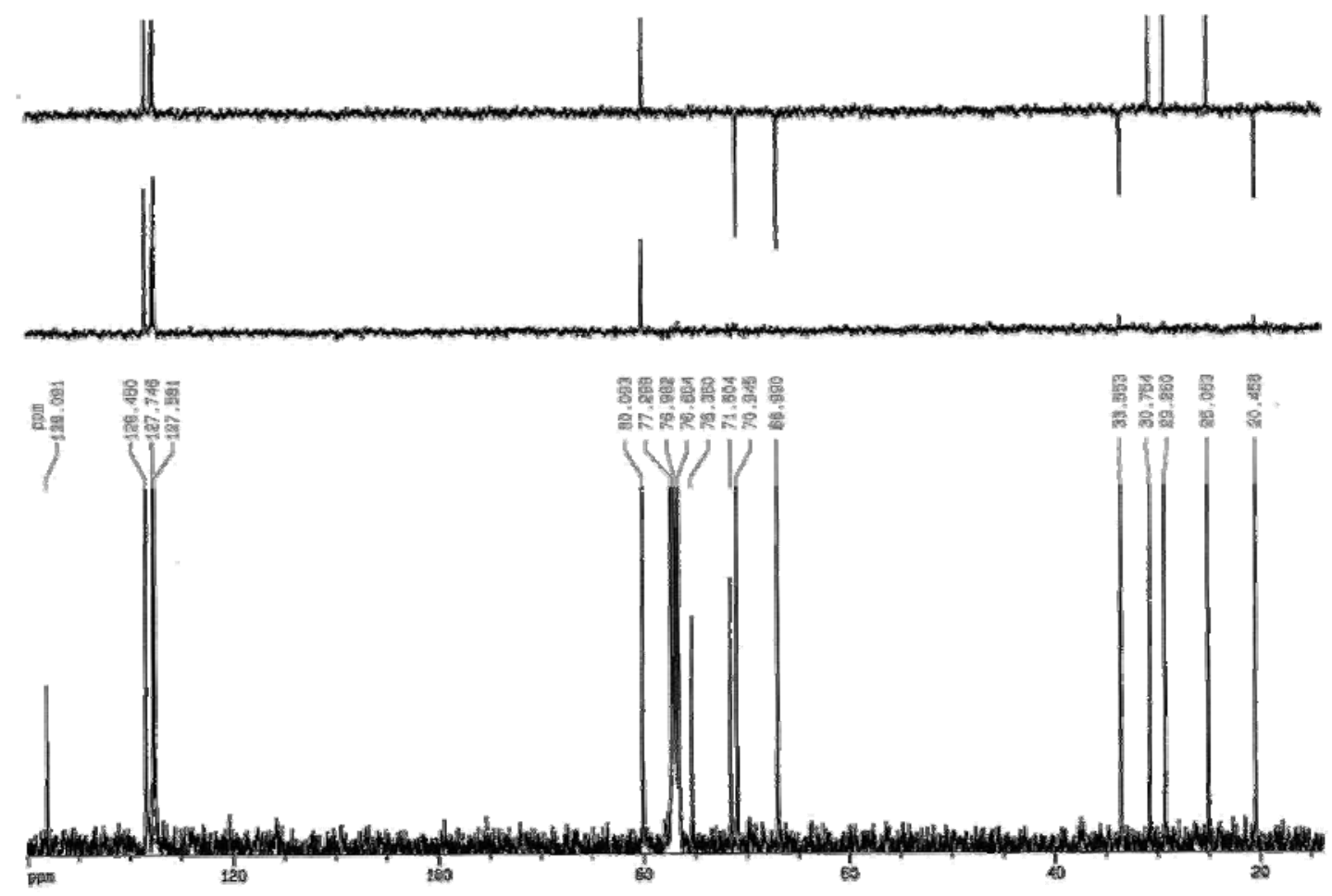

Fig. 56d

NOE id
Irradiacion Me 1.26

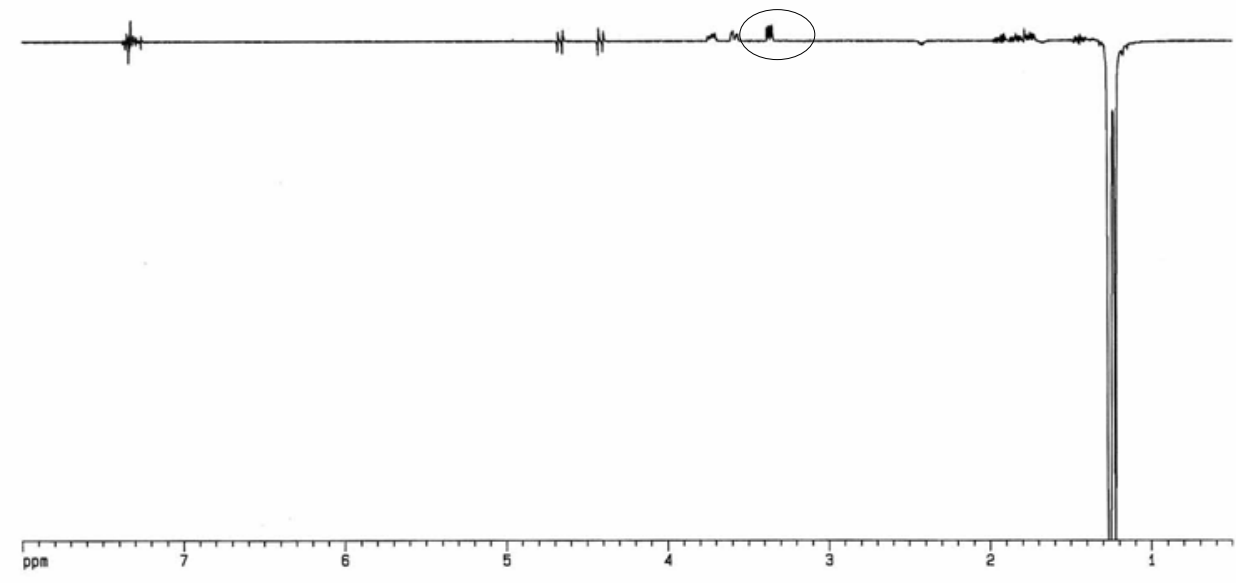


Fig. 57a

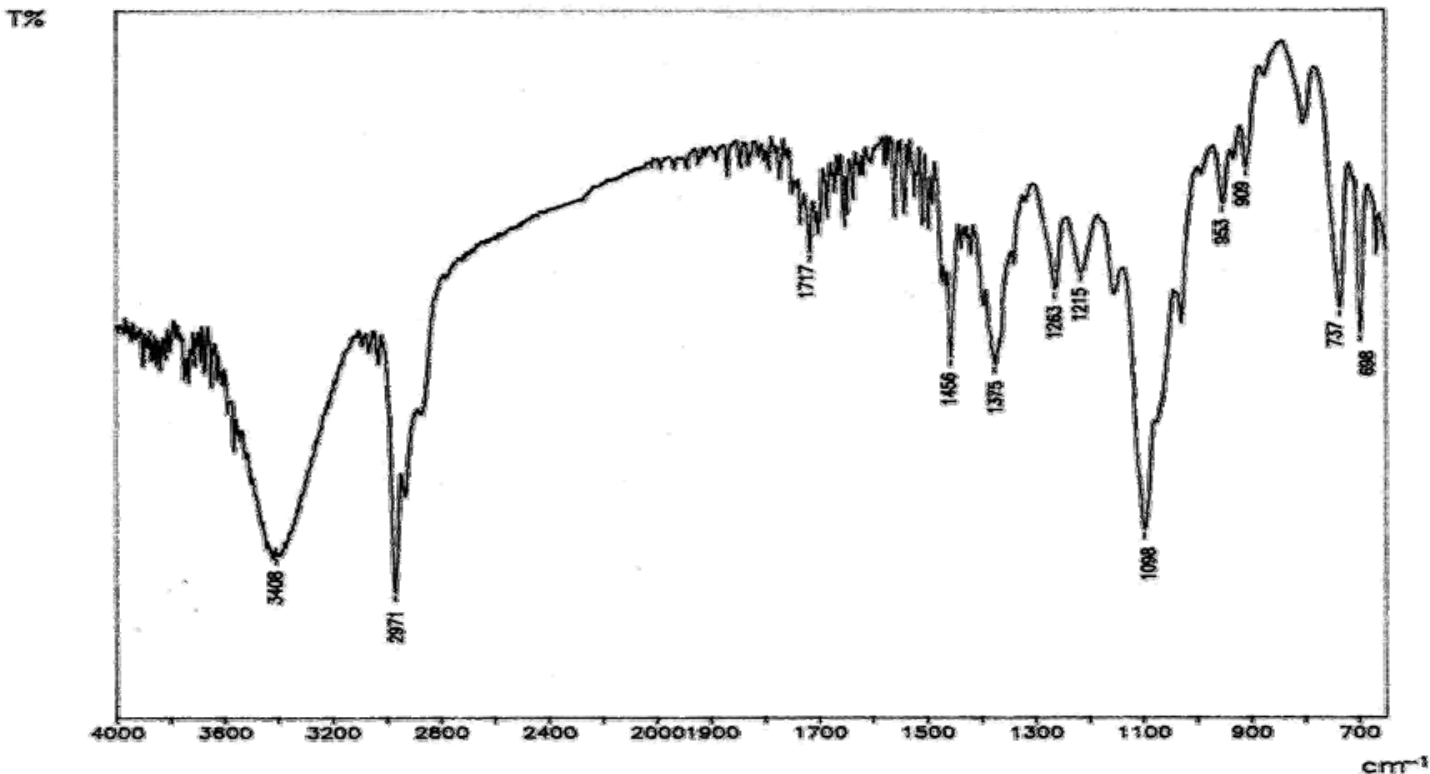

Fig. 57b
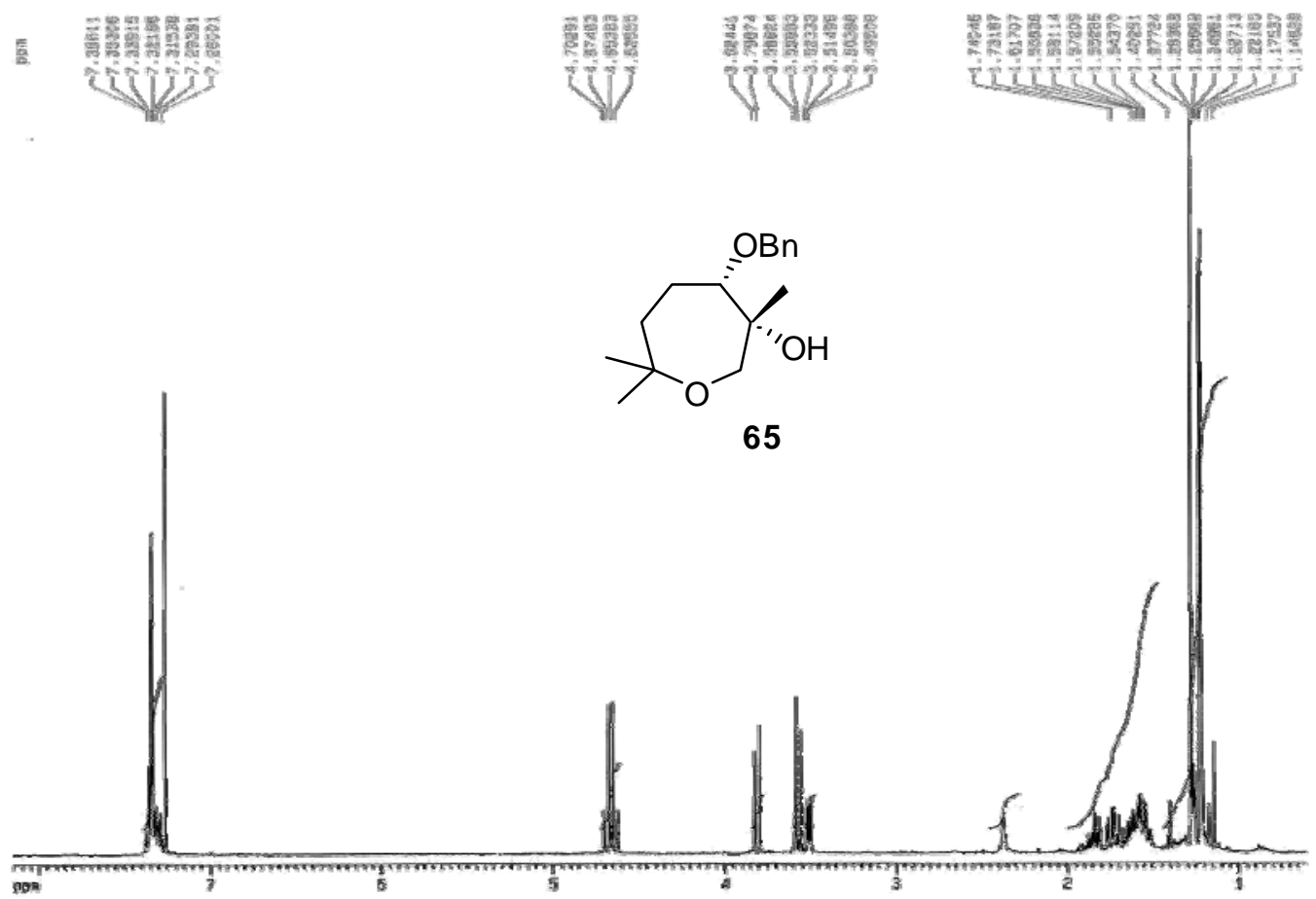

65 
Fig. 57c
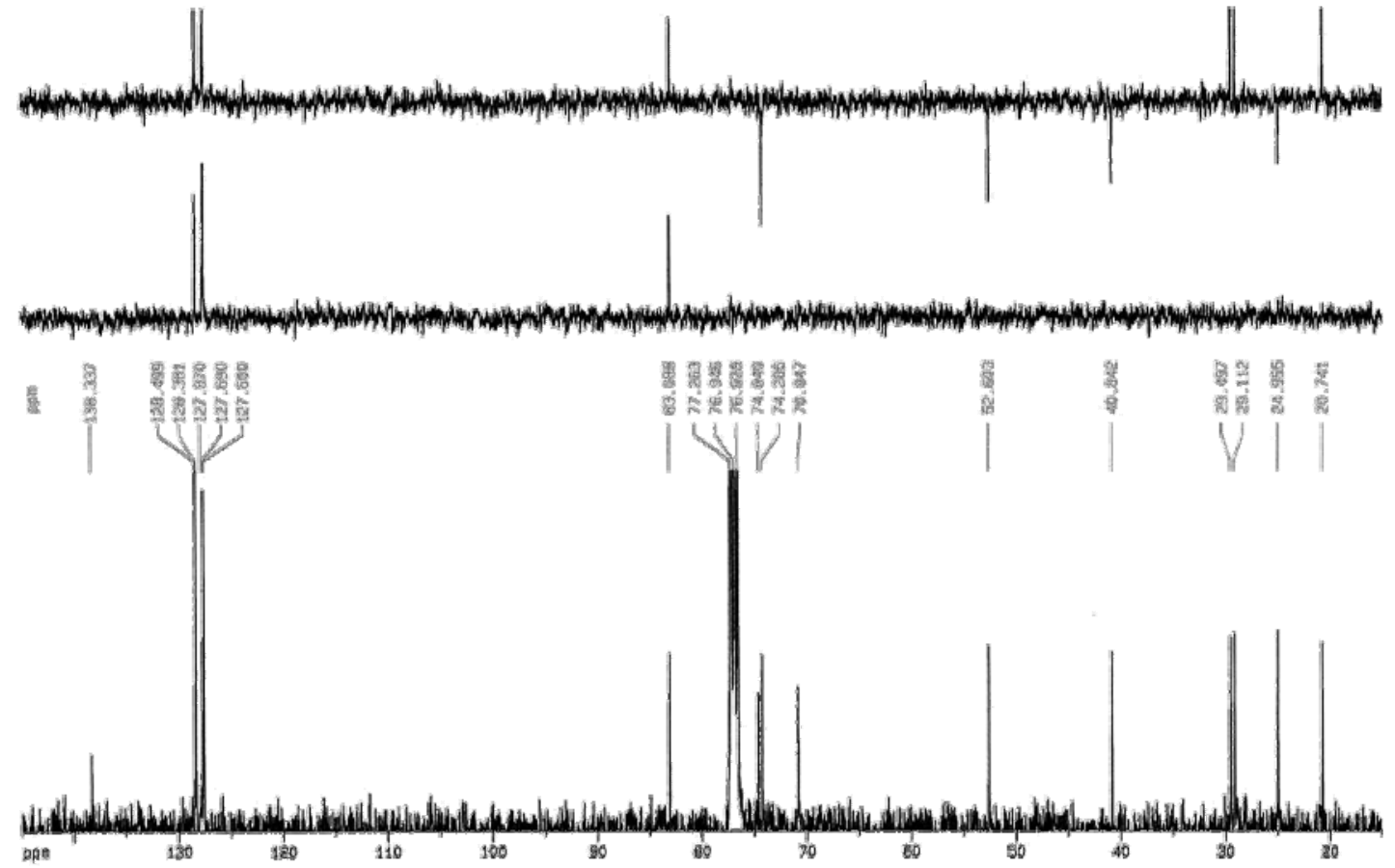
Fig. 58a

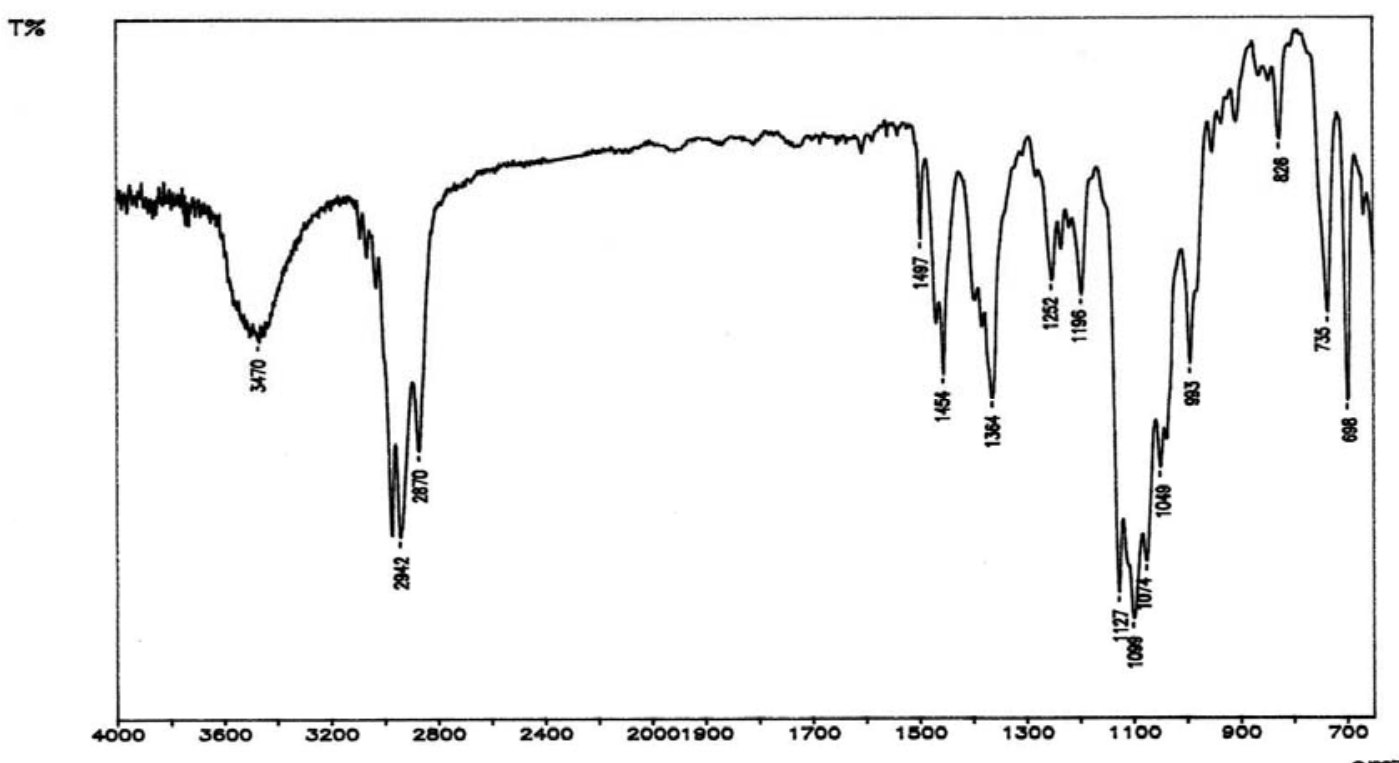

Fig. 58b
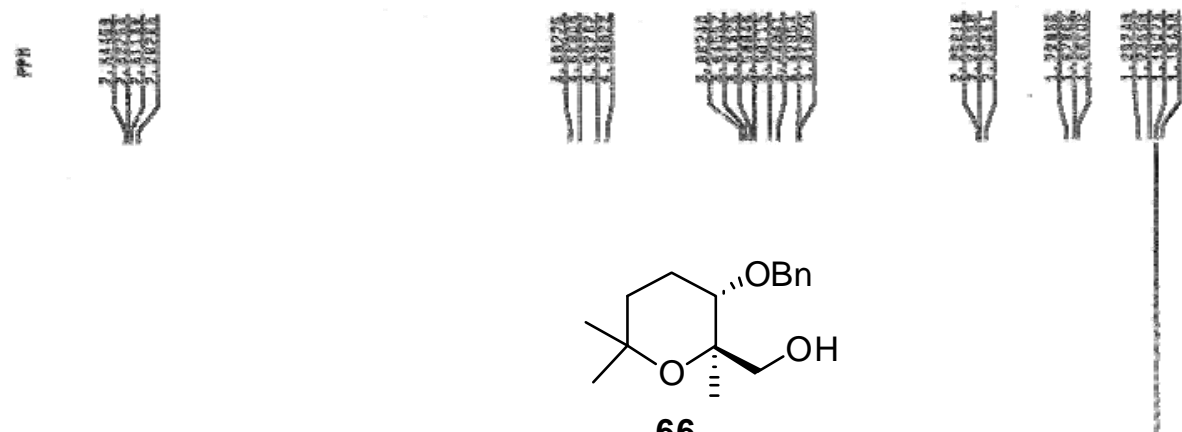

66

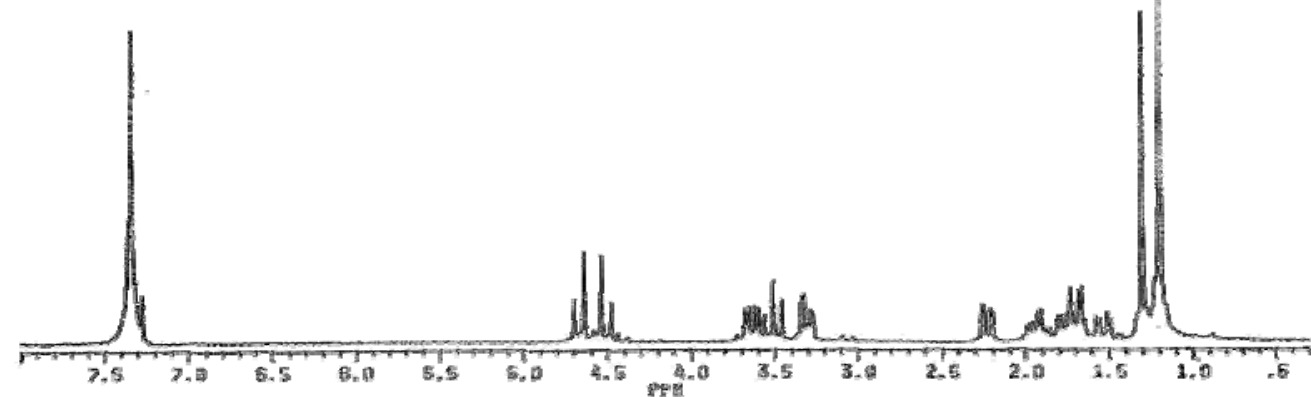


Fig. 58c

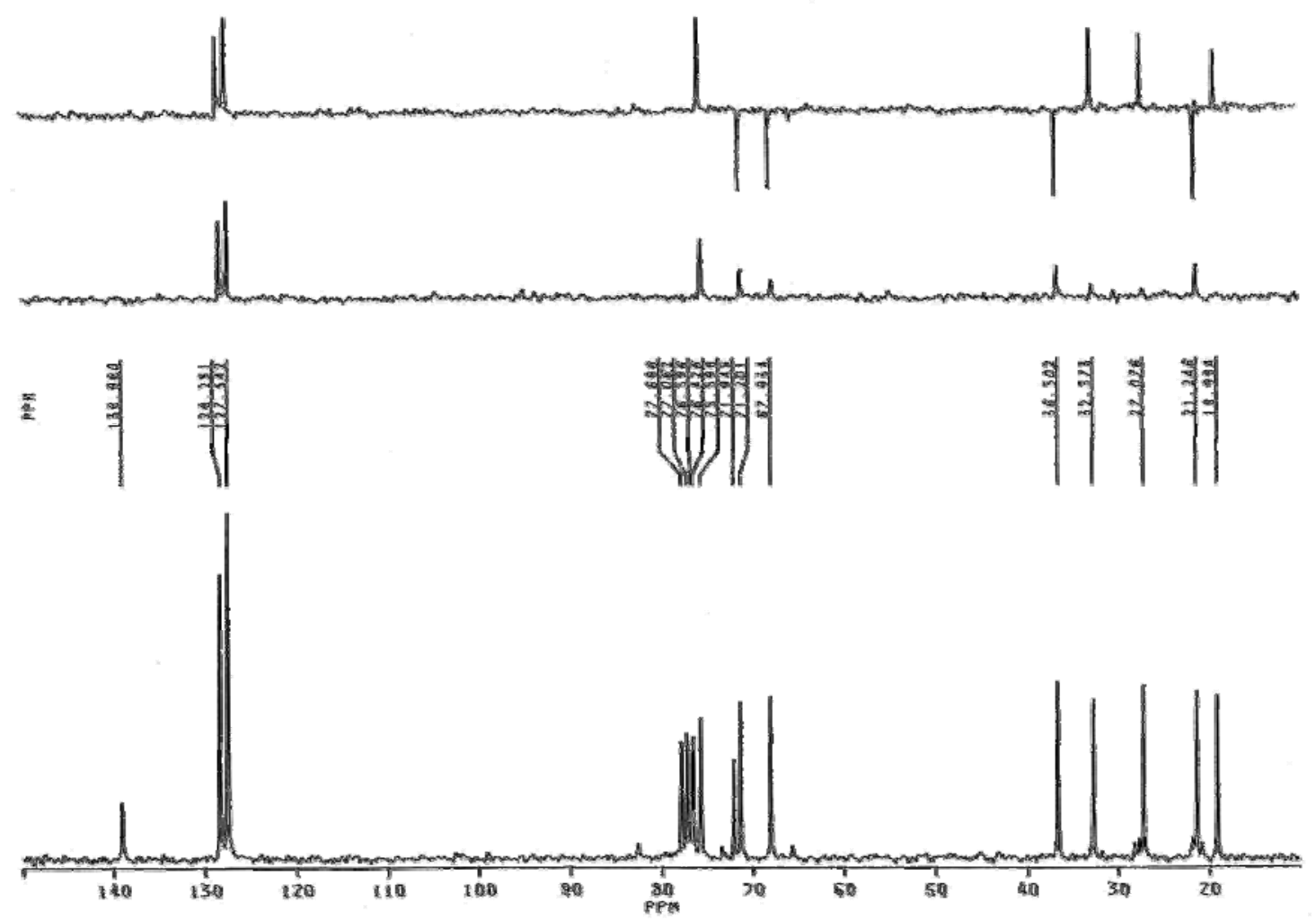

Fig. 58d

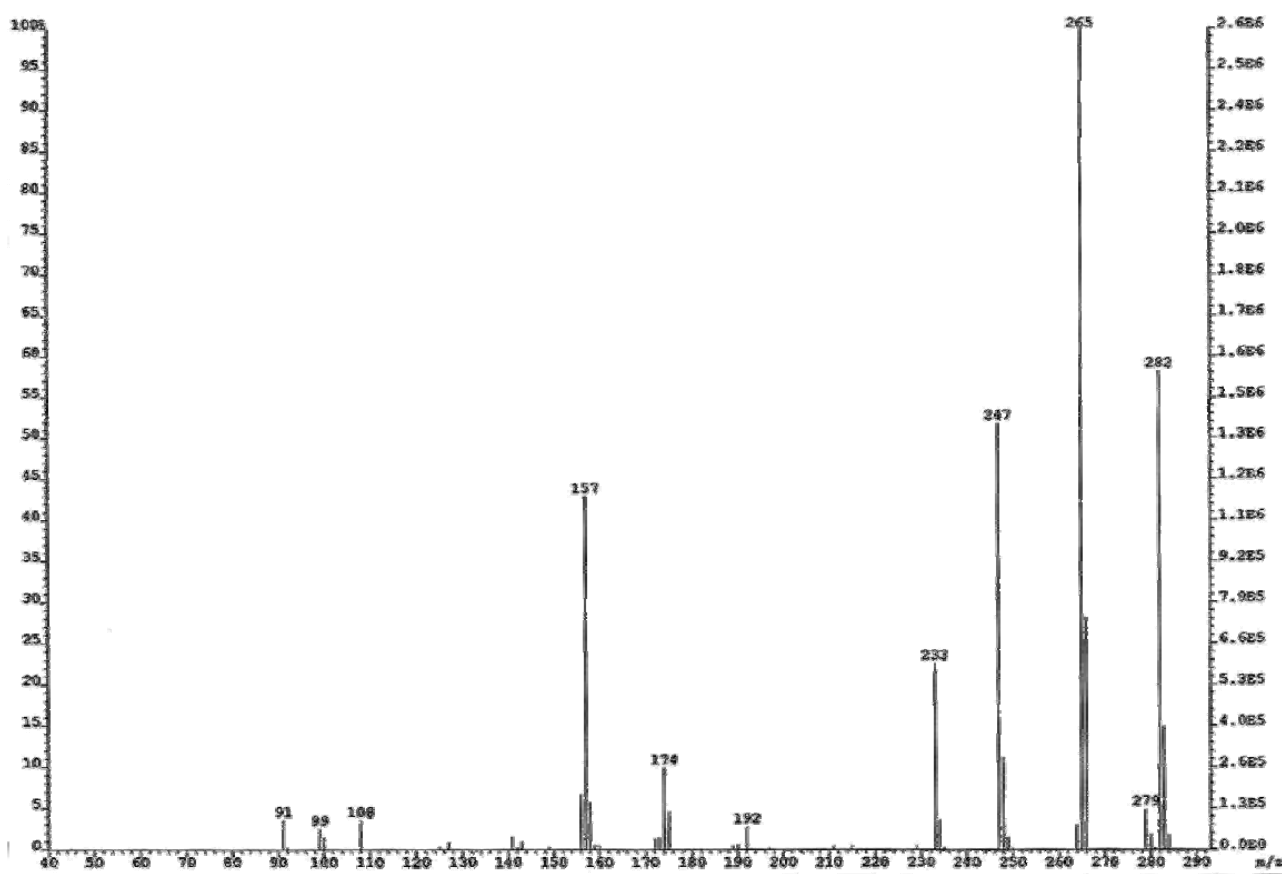


Fig. 59a

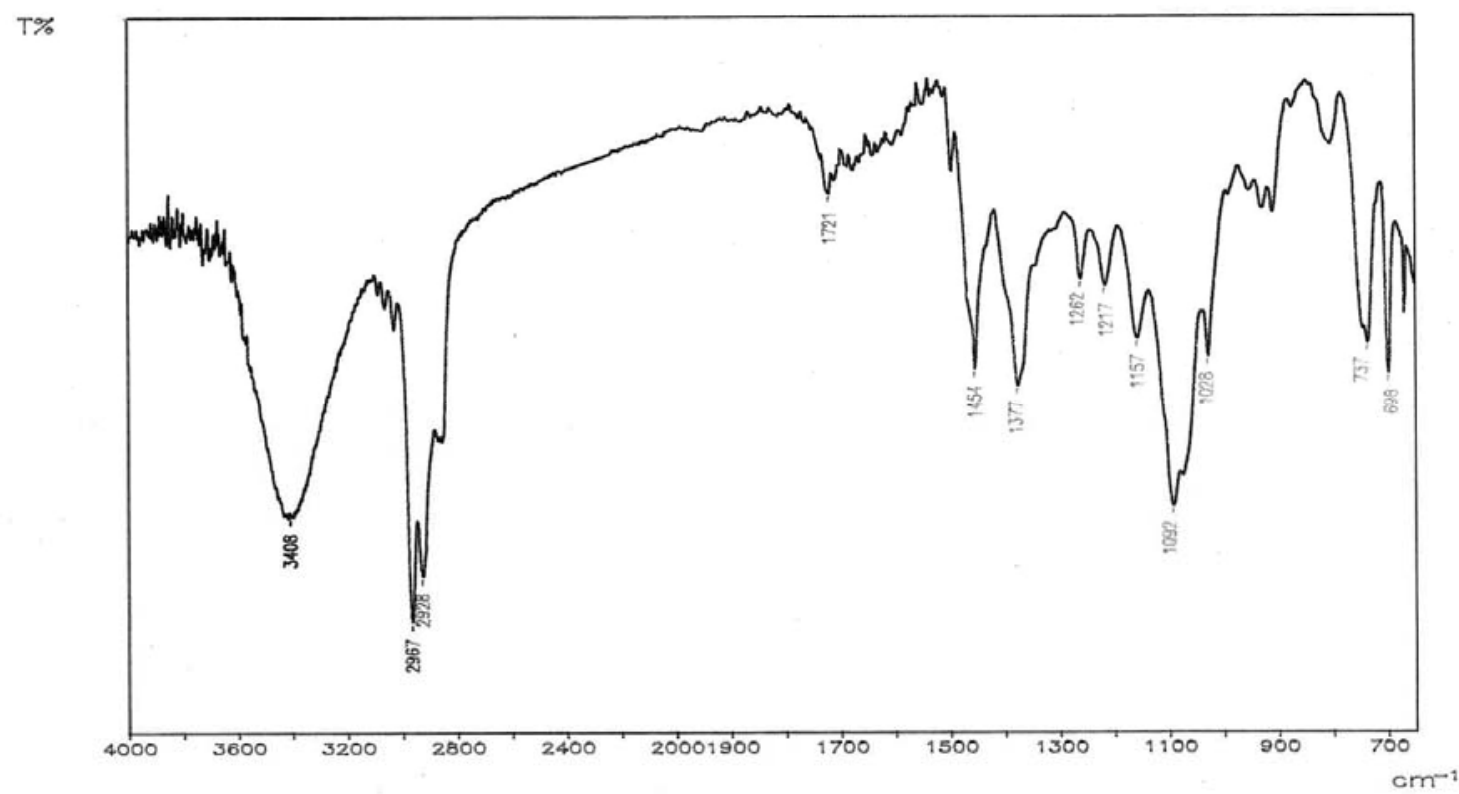

Fig. 59b

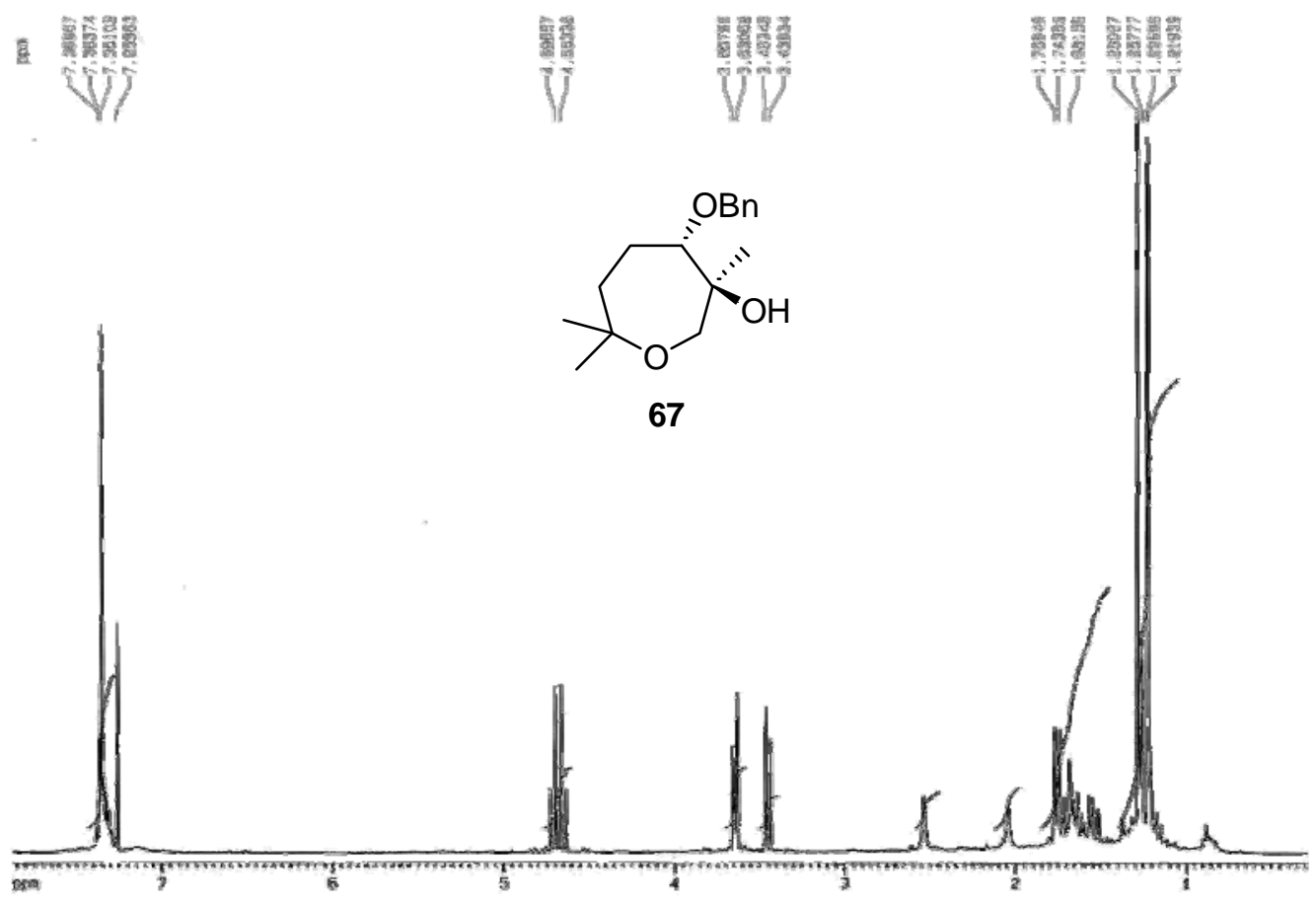


Fig. 59c

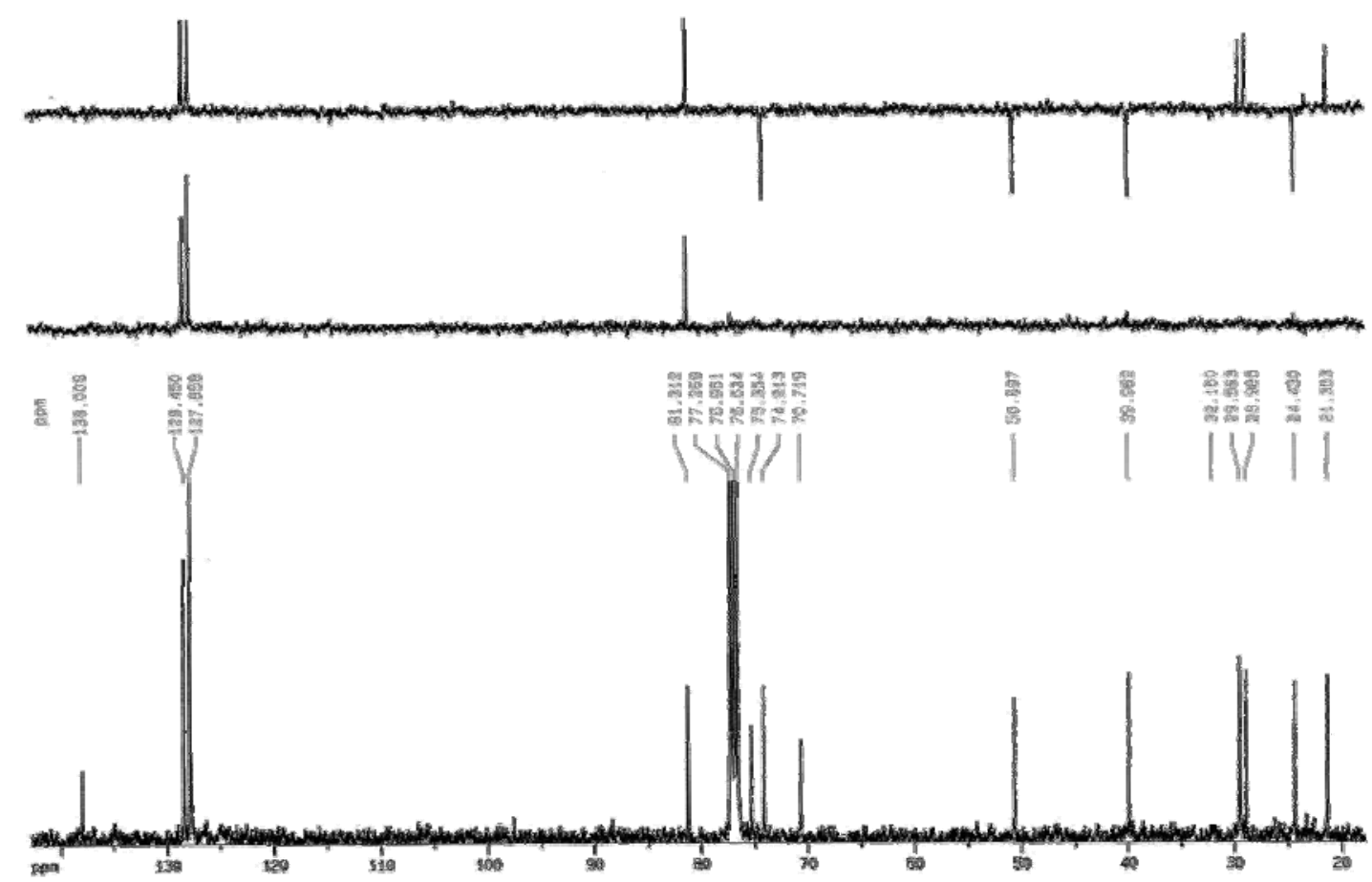

Fig. 59d

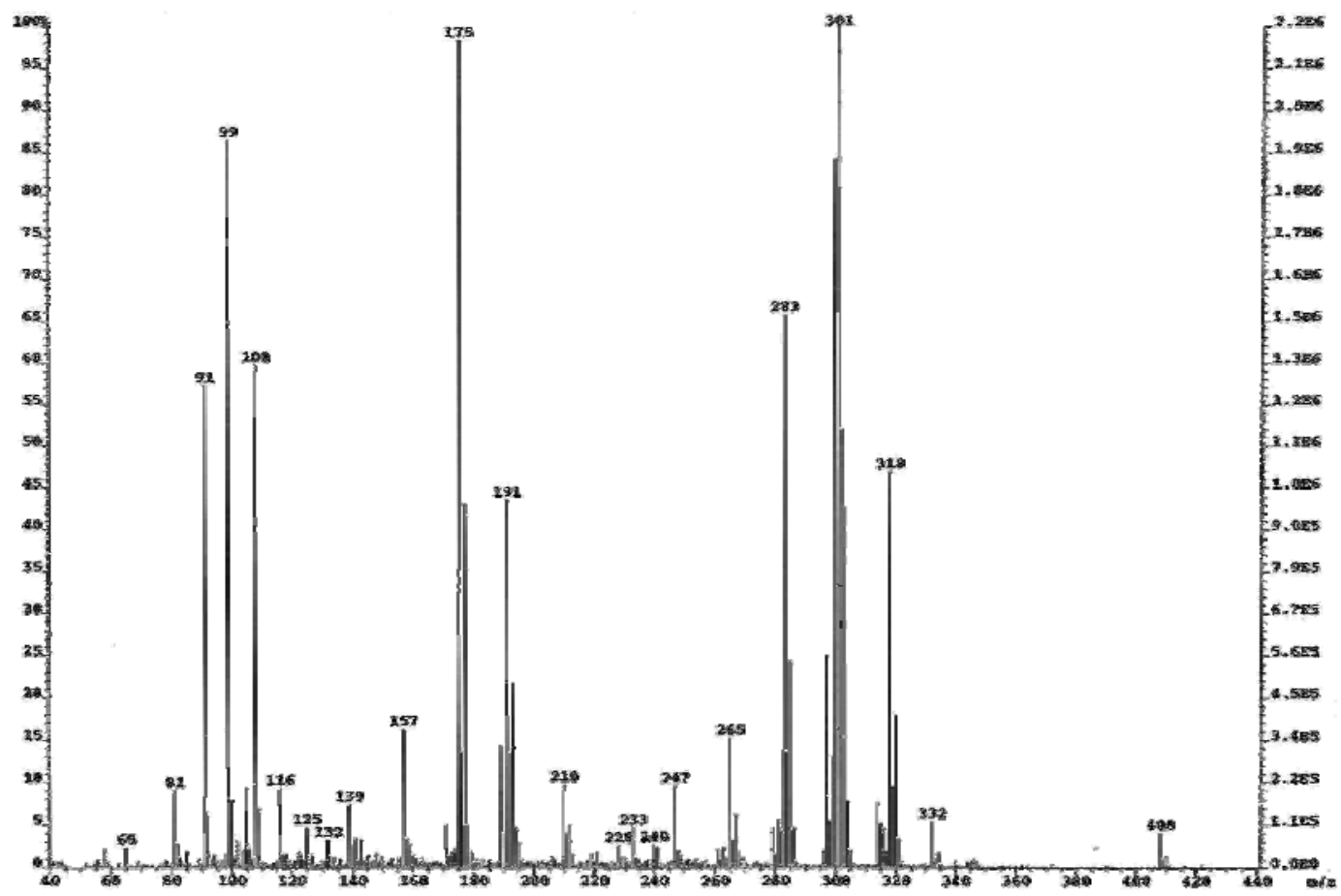


Fig. 60a

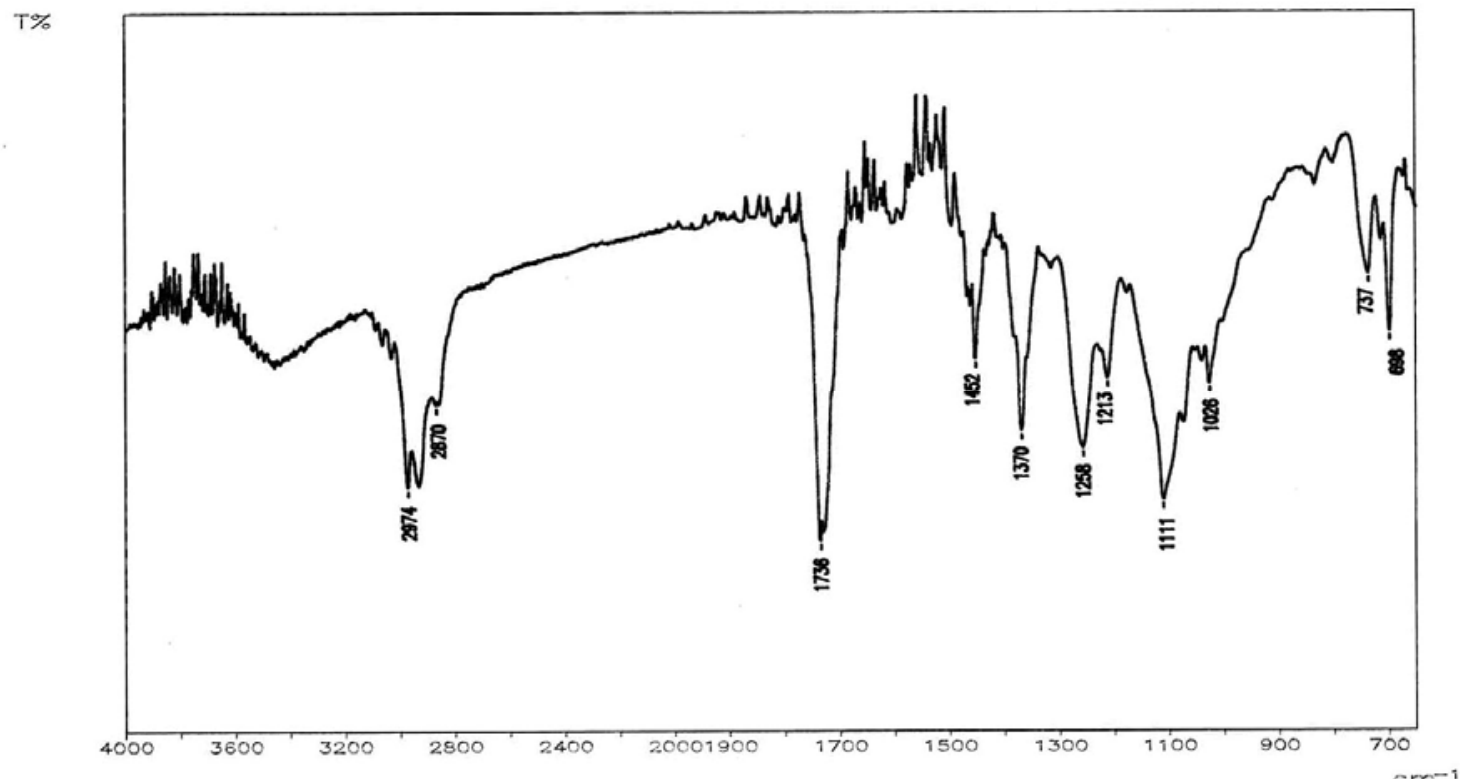

Fig. $60 \mathrm{~b}$
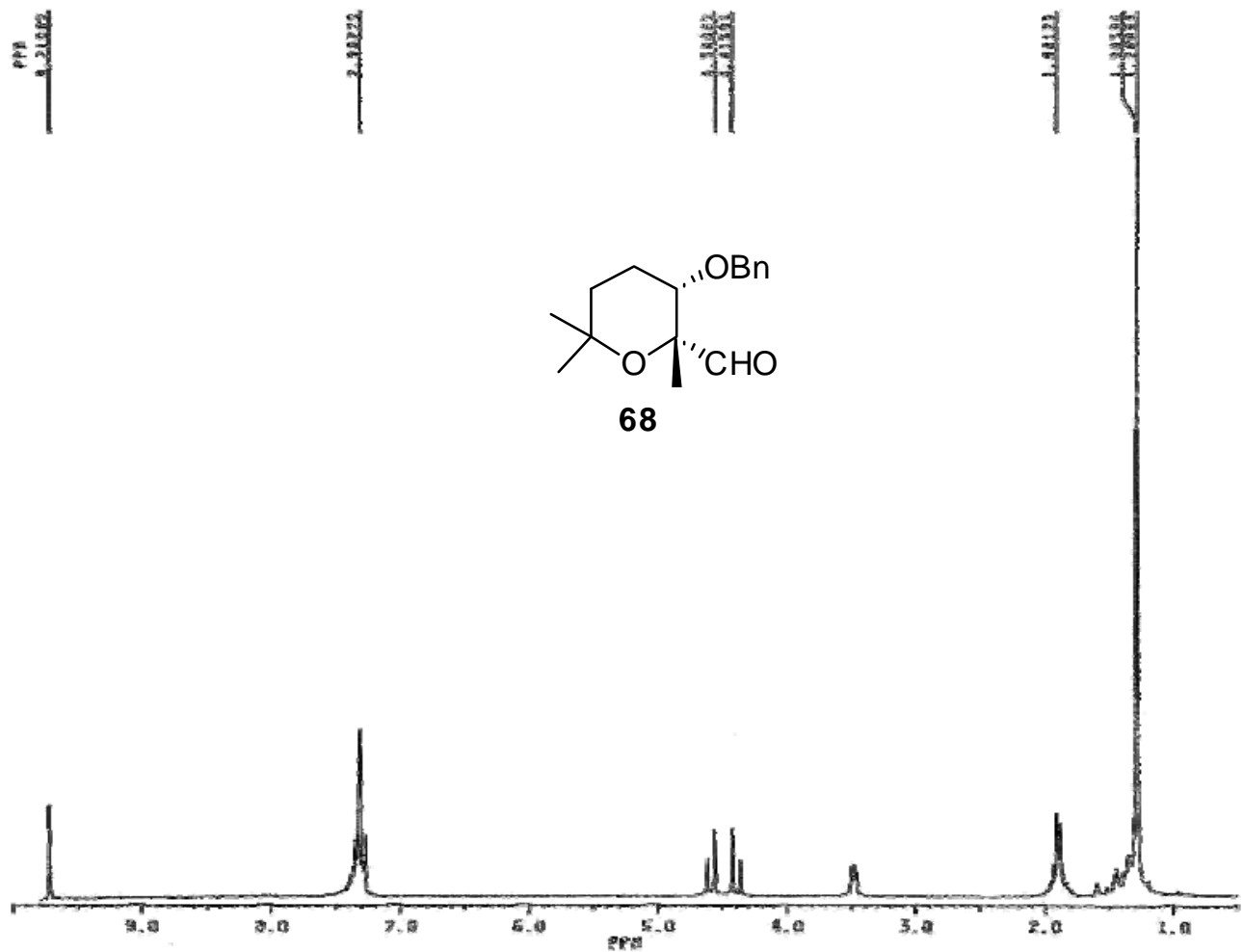
Fig. 60c

7.

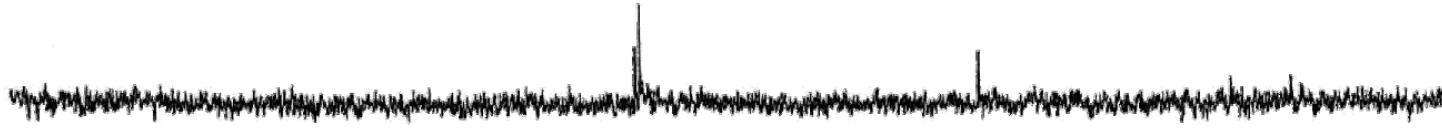

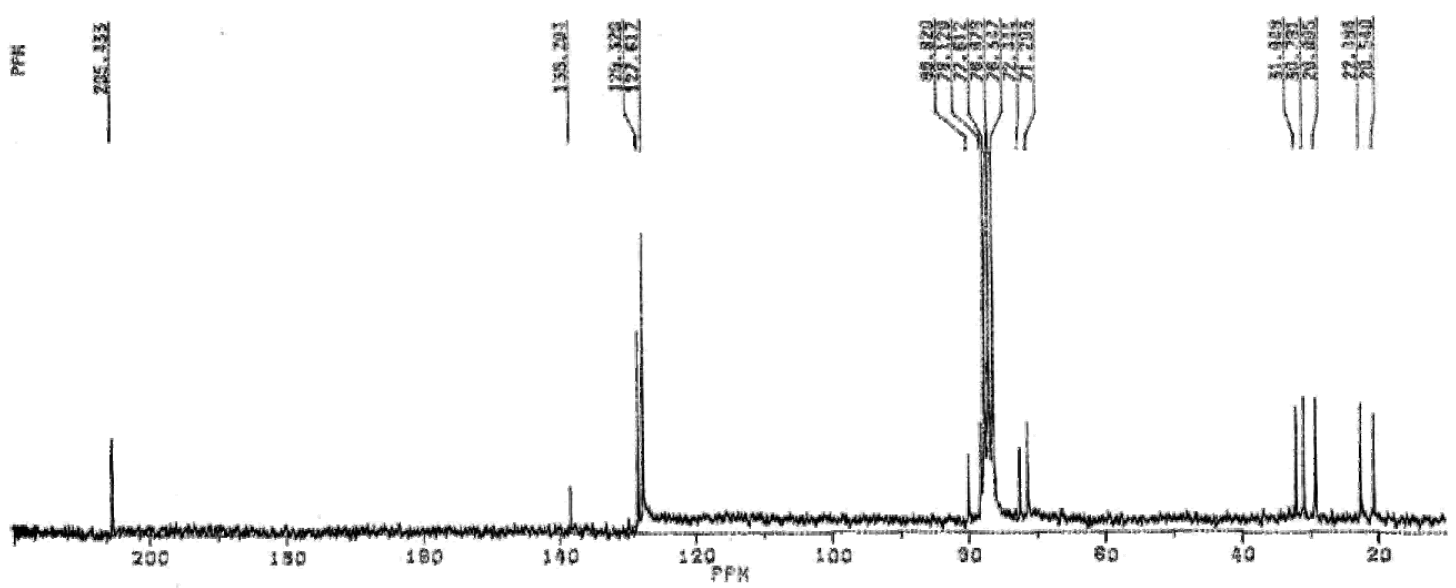

Fig. 60d

+TOF MS: $0.284 \mathrm{~min}$ from Sample 2 (mgn r204) of may030611 wiff

$a=3.56004543858948270 \mathrm{e}-004,10=1.02516170529052030 \mathrm{e}+001: R:$ subtracted 0.034 to 0

Max. 673.0 counts.

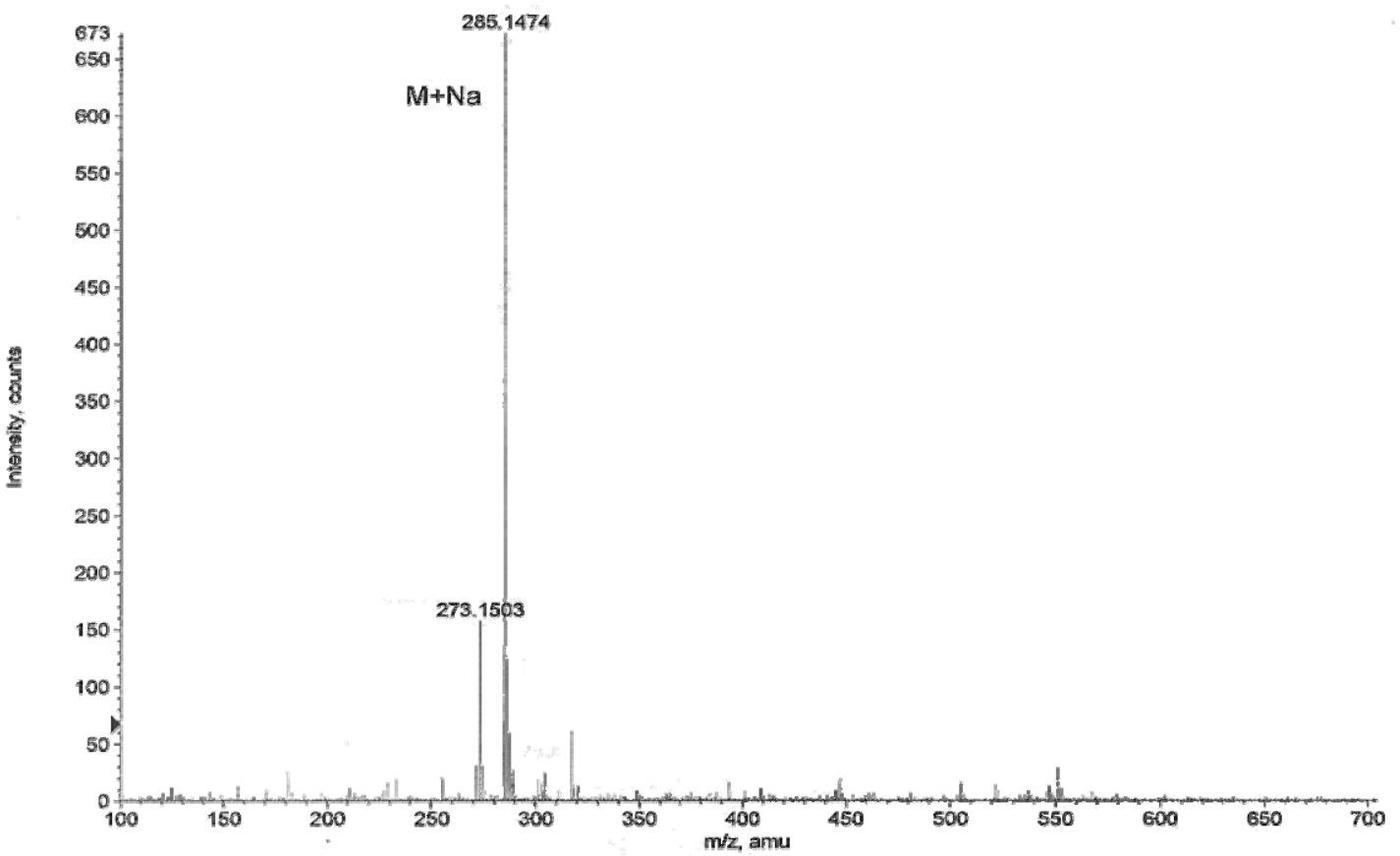


Fig. 61a

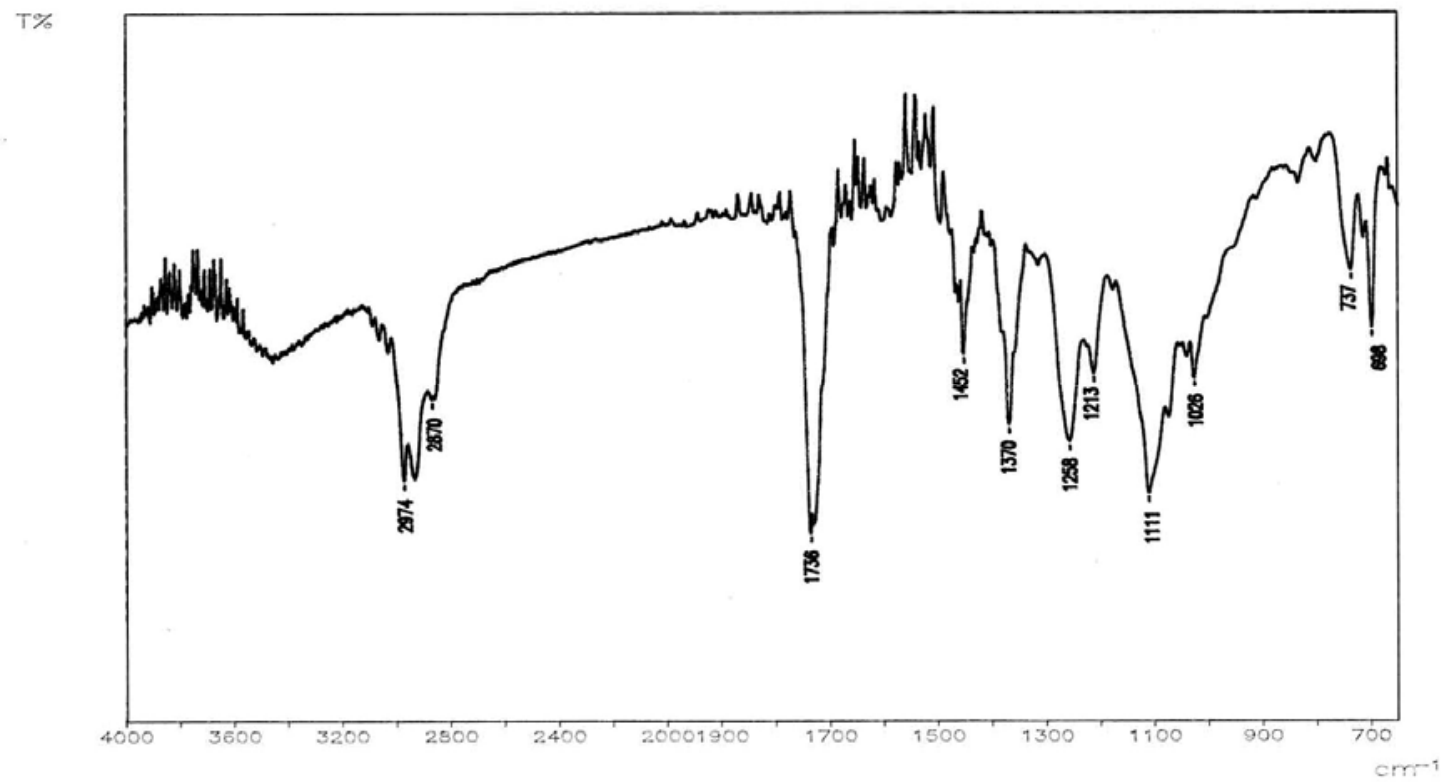

Fig. 61b

$$
\text { 홍 }
$$

7
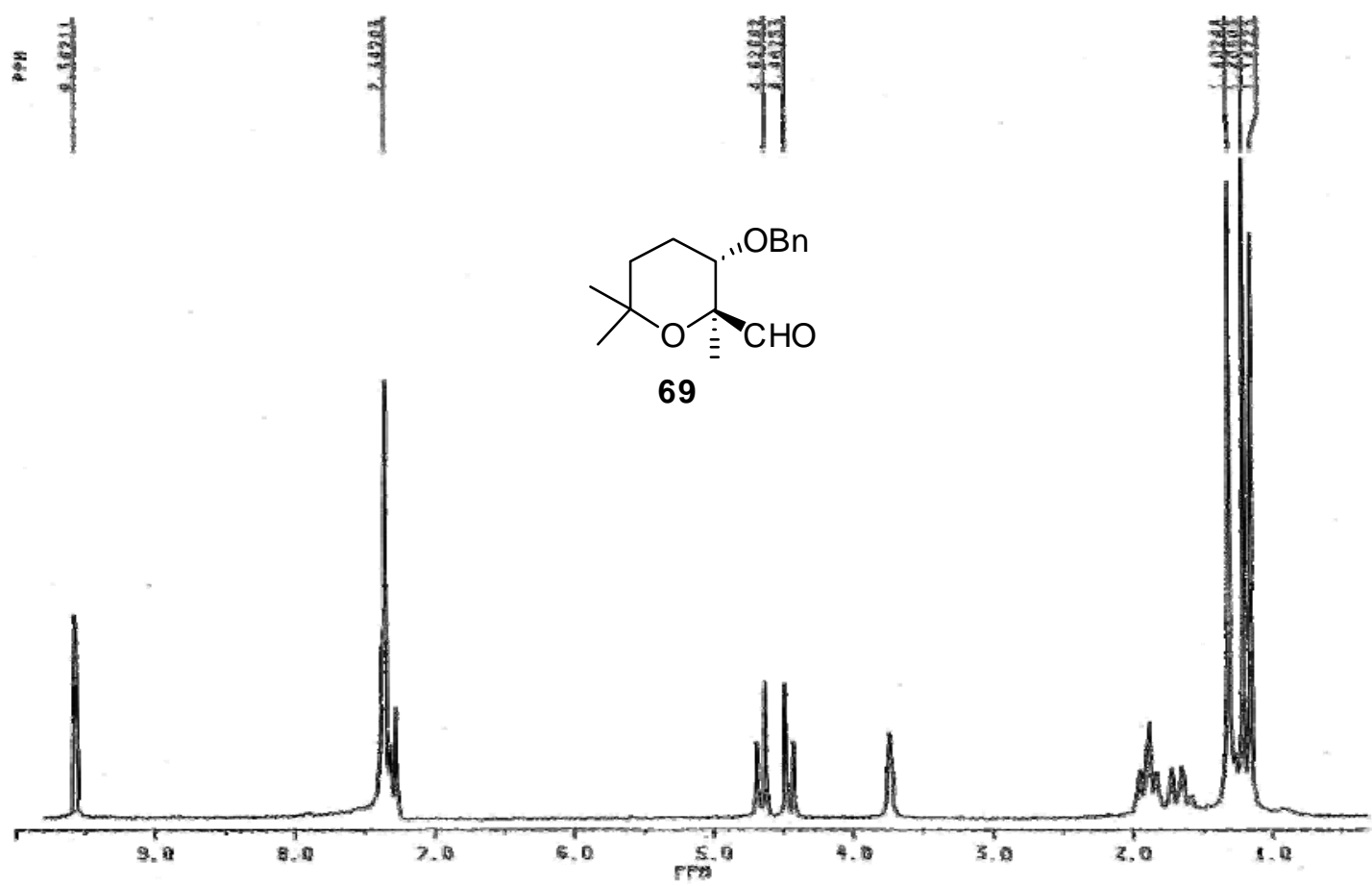
Fig. 61c

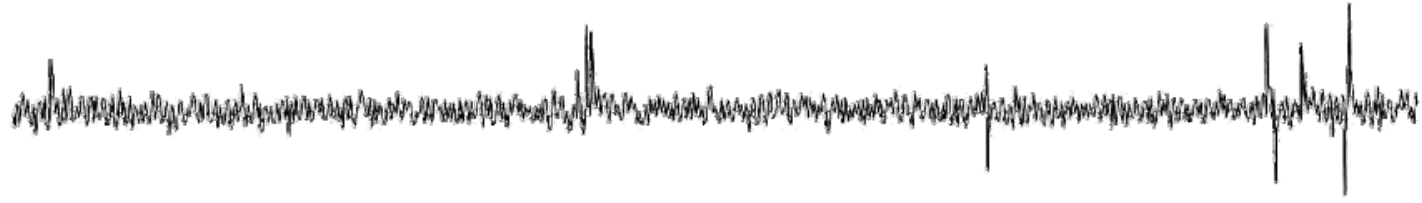

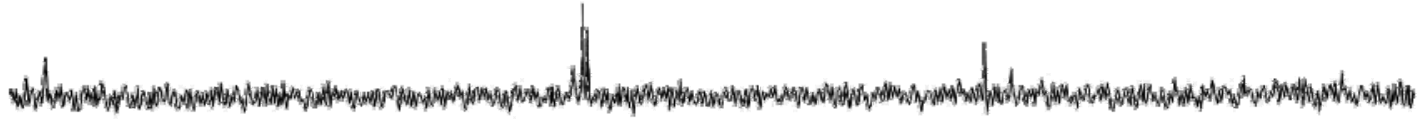
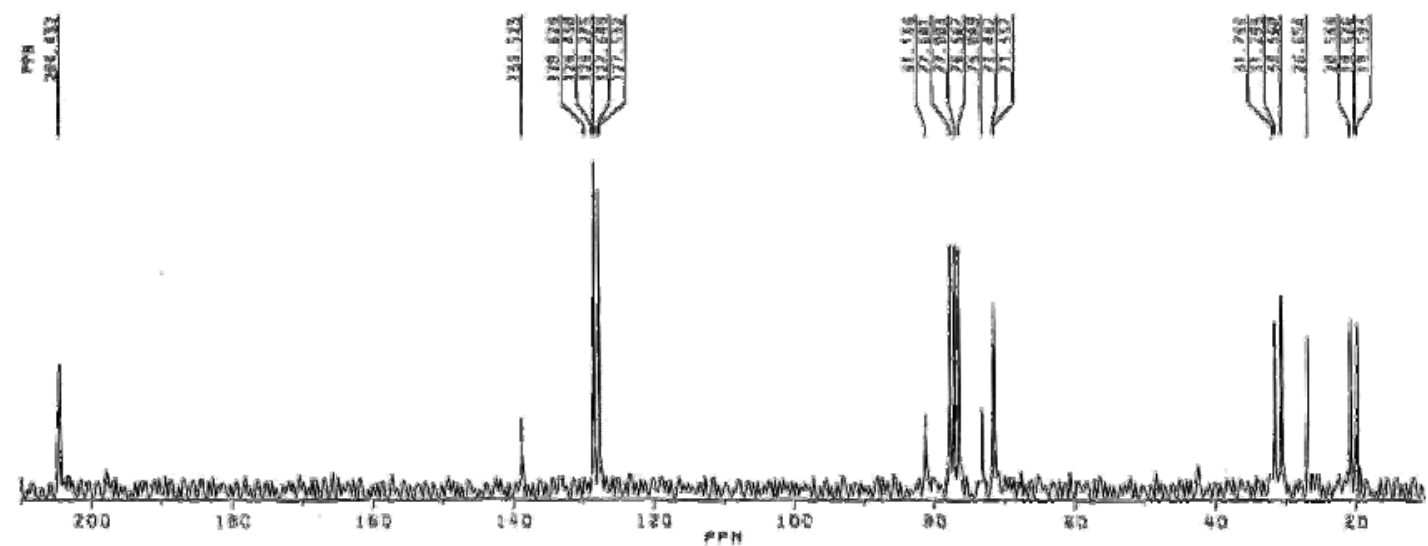

Fig. 61d

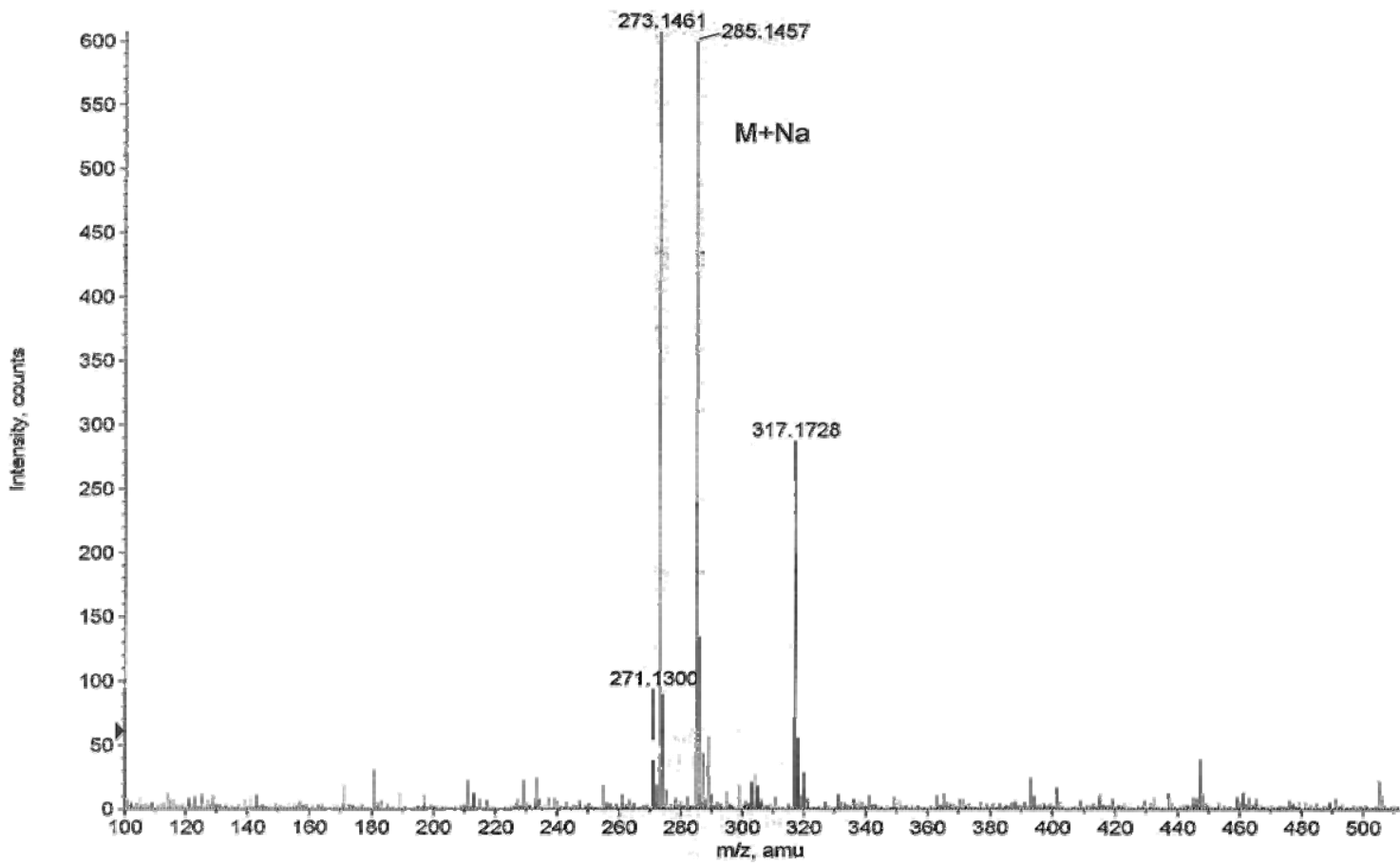


Fig. 62a

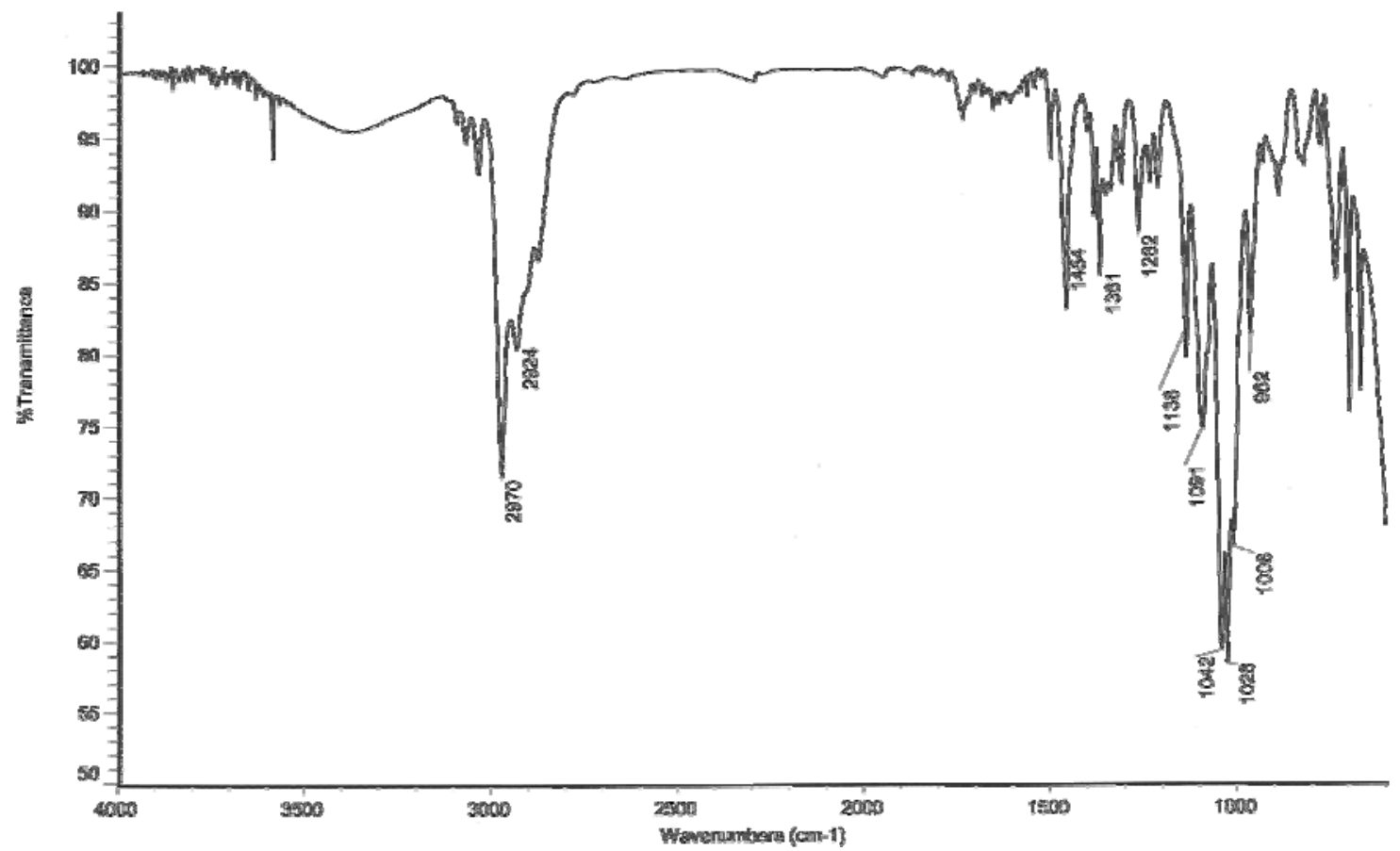

Fig. 62b
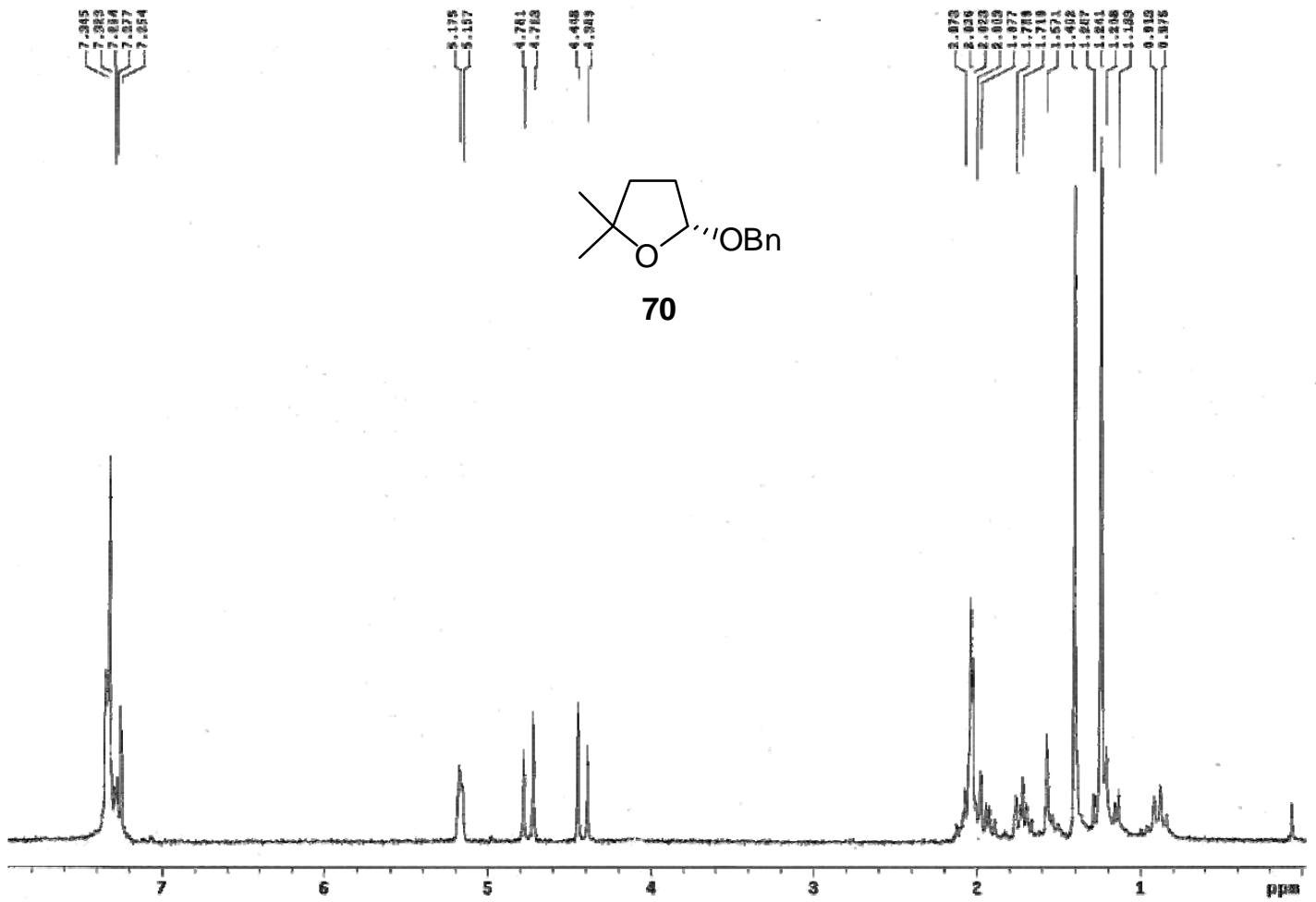
Fig. 62c
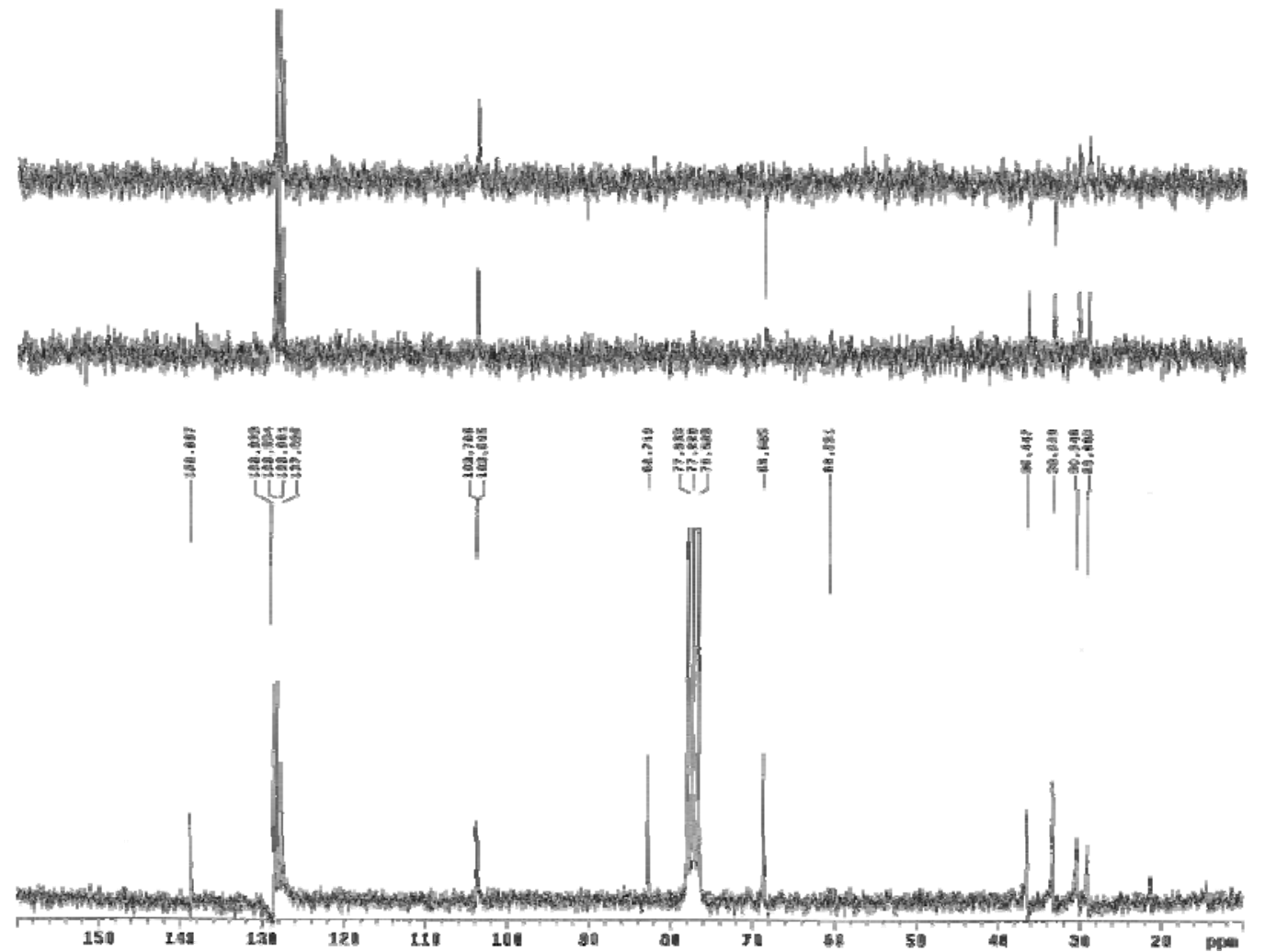

Fig. 62d

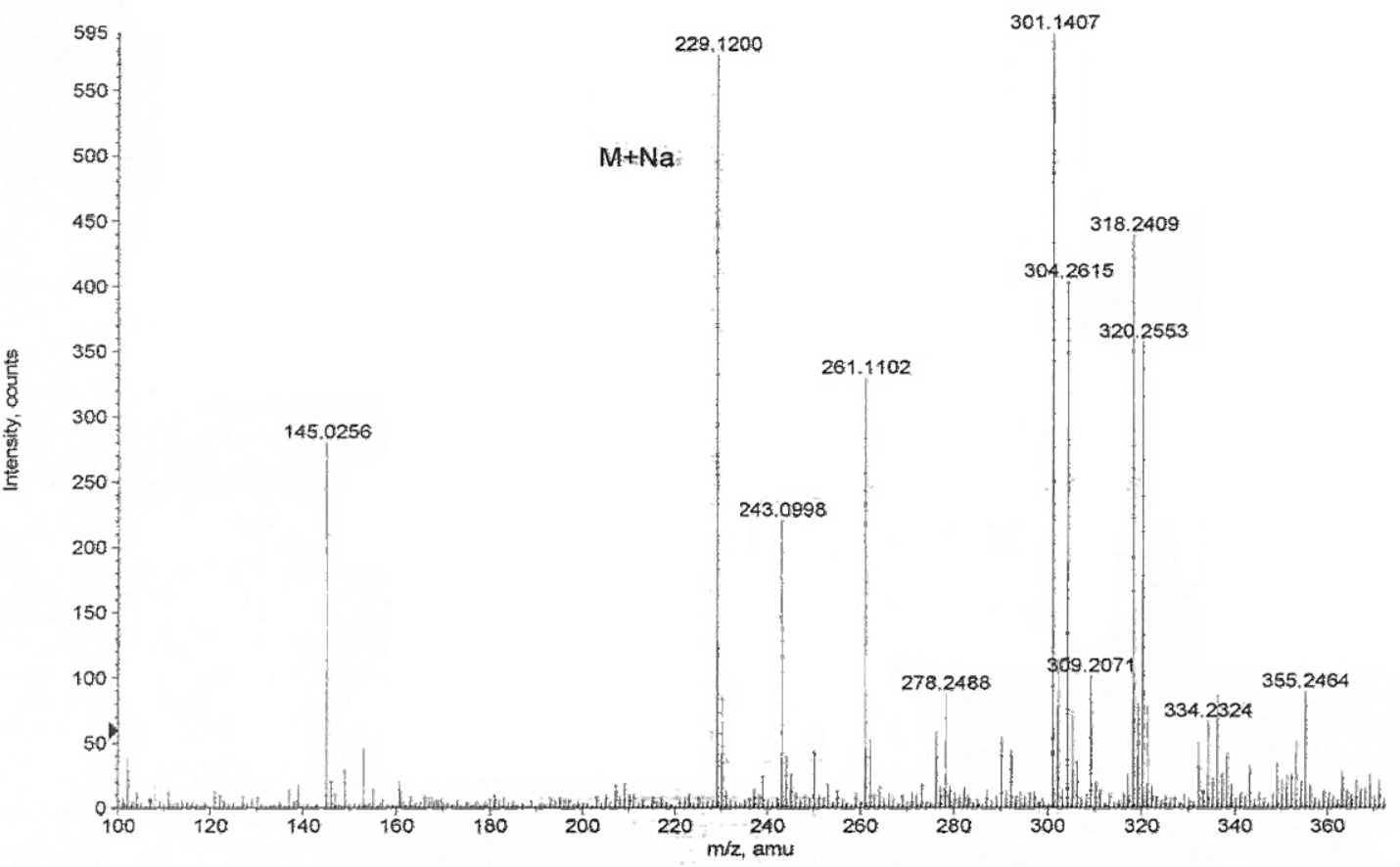


Fig. 62e-HPLC racémico

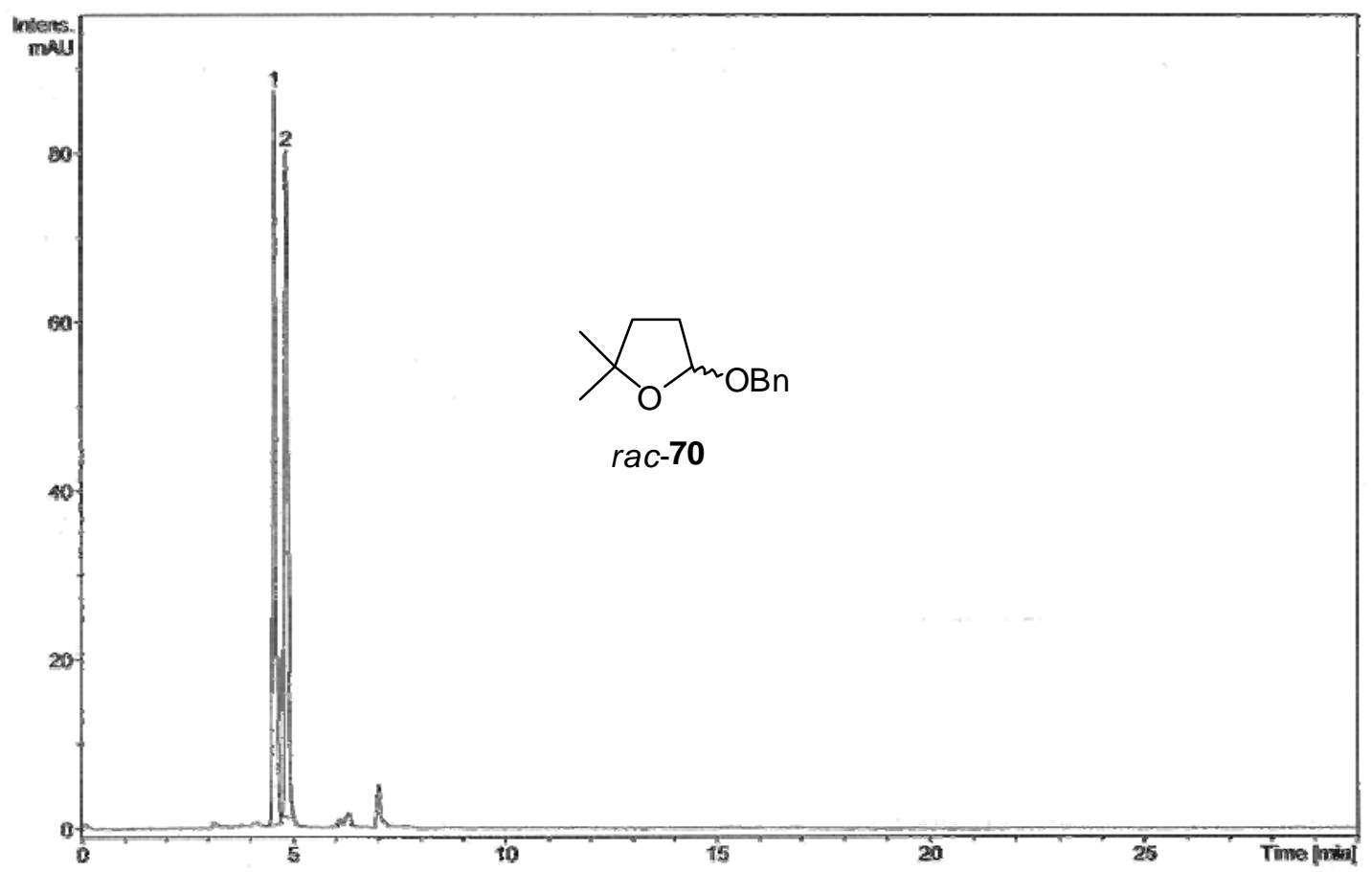

Fig. 62f- HPLC quiral

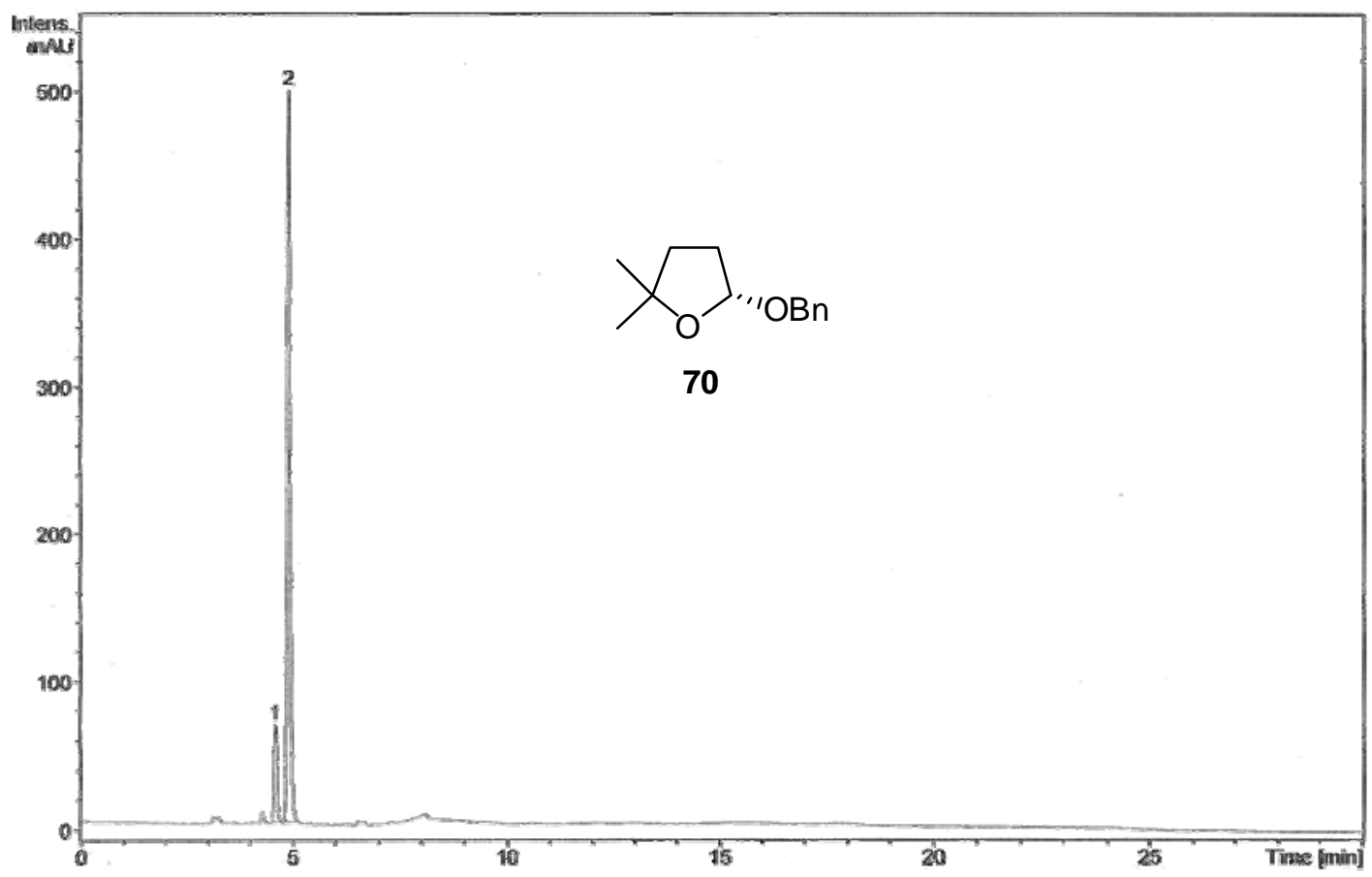


Fig. 63a

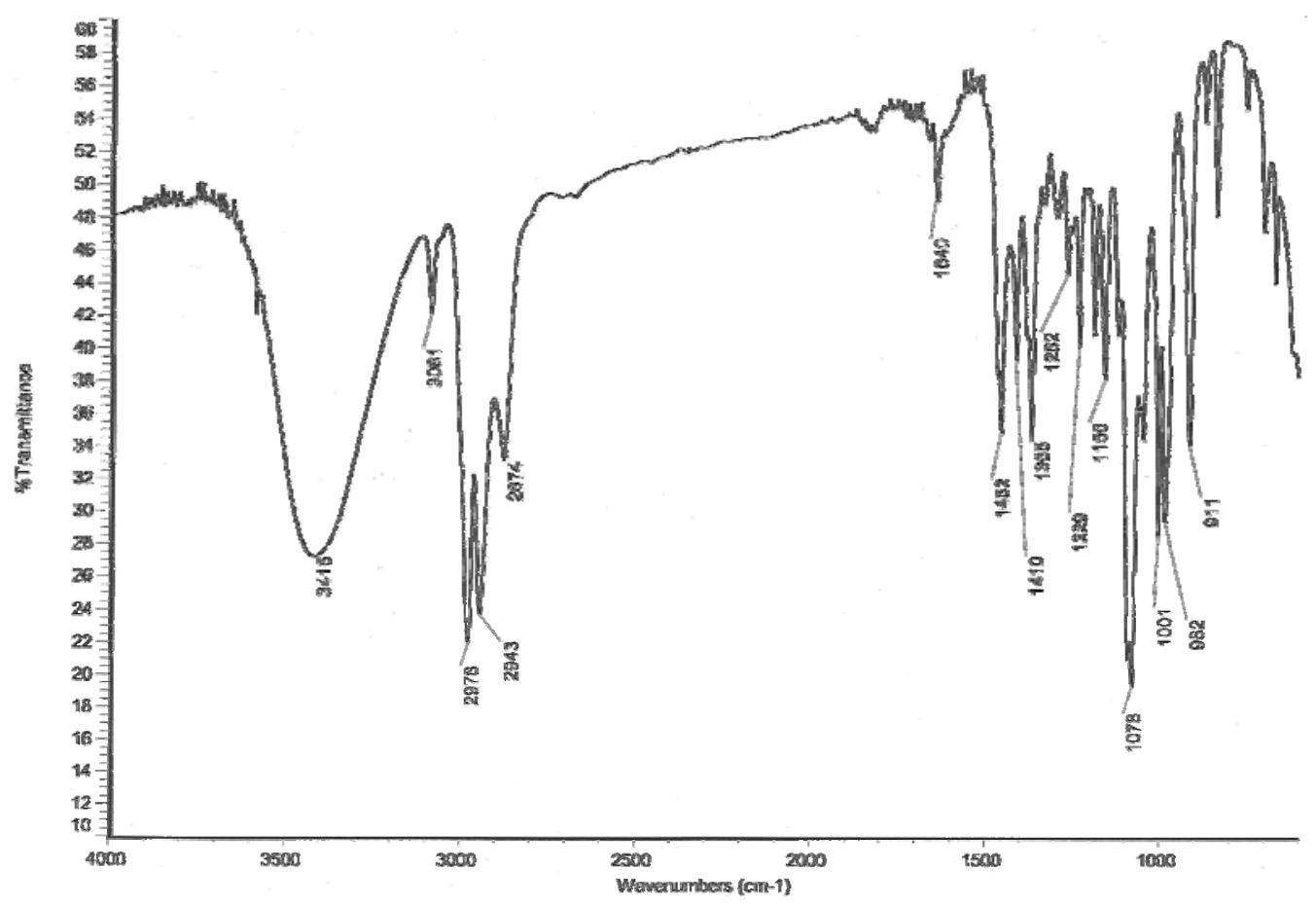

Fig. $63 b$
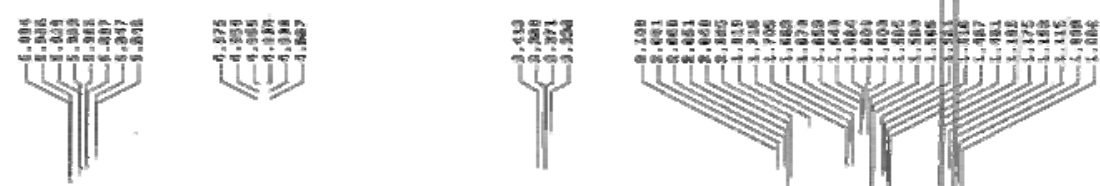

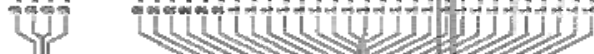

|

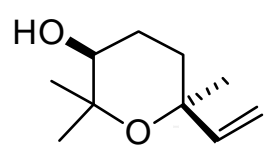

71

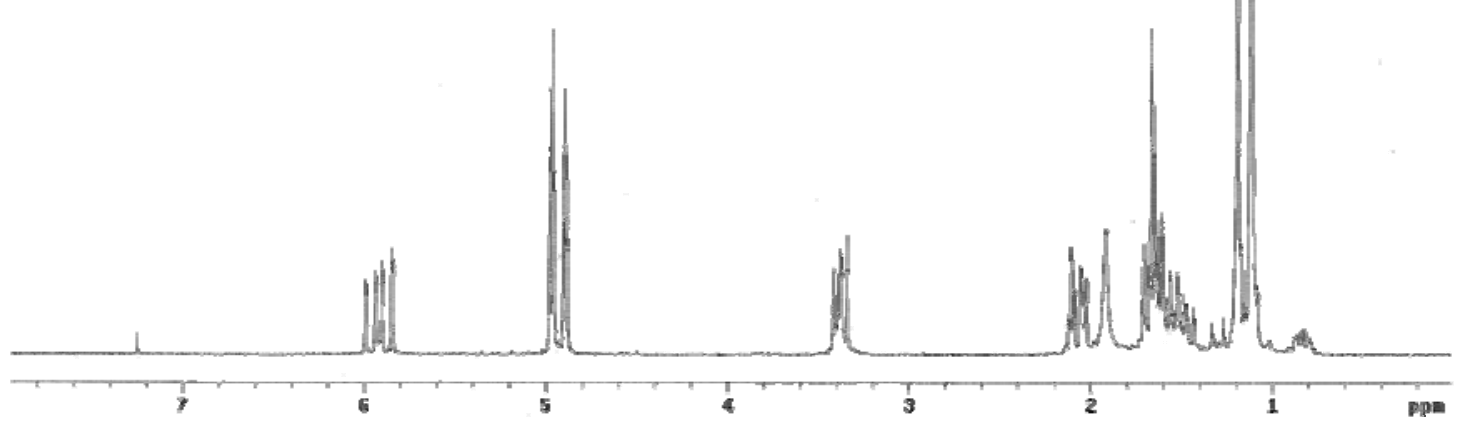


Fig. 63c
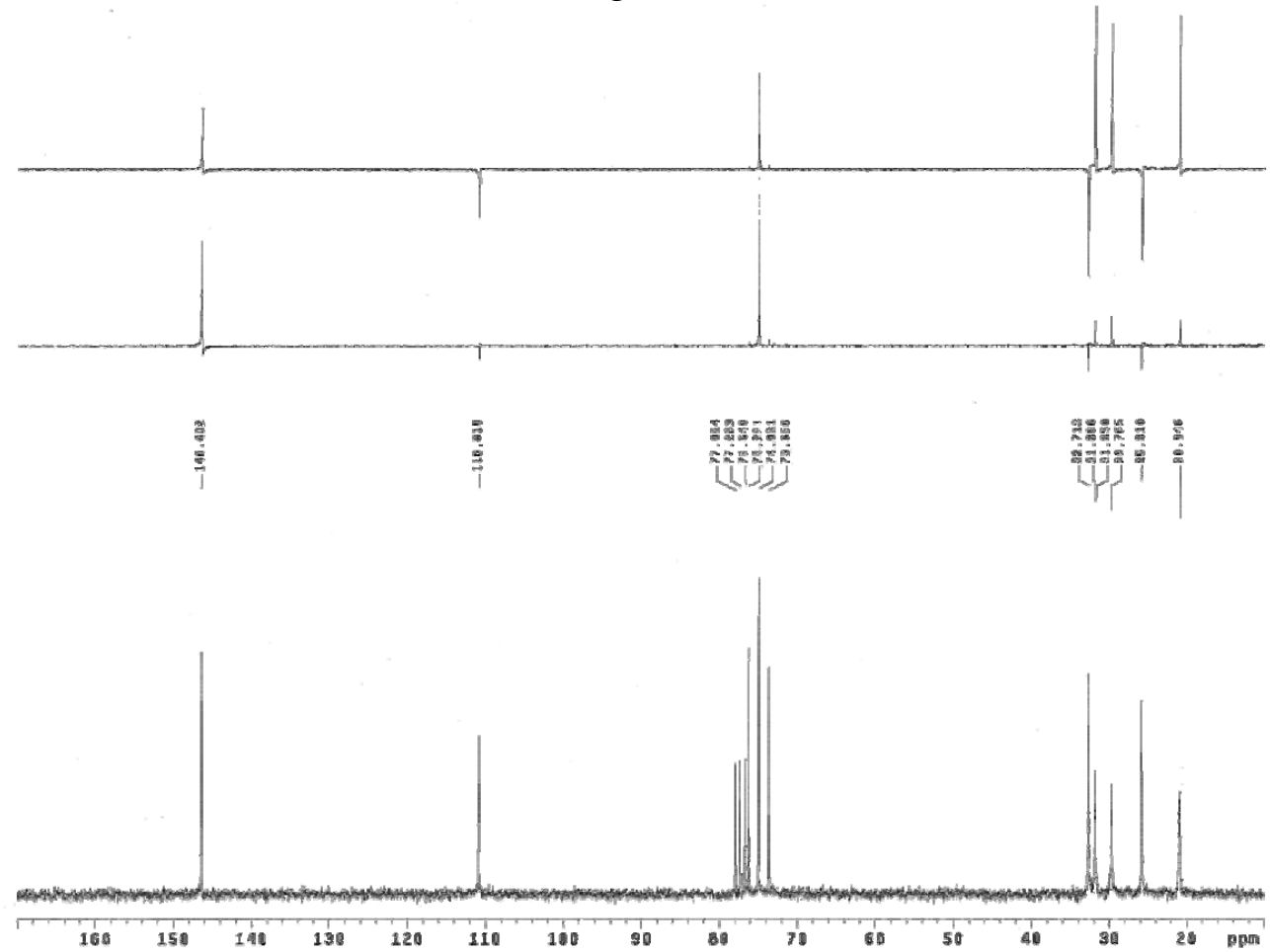

Fig. 63d

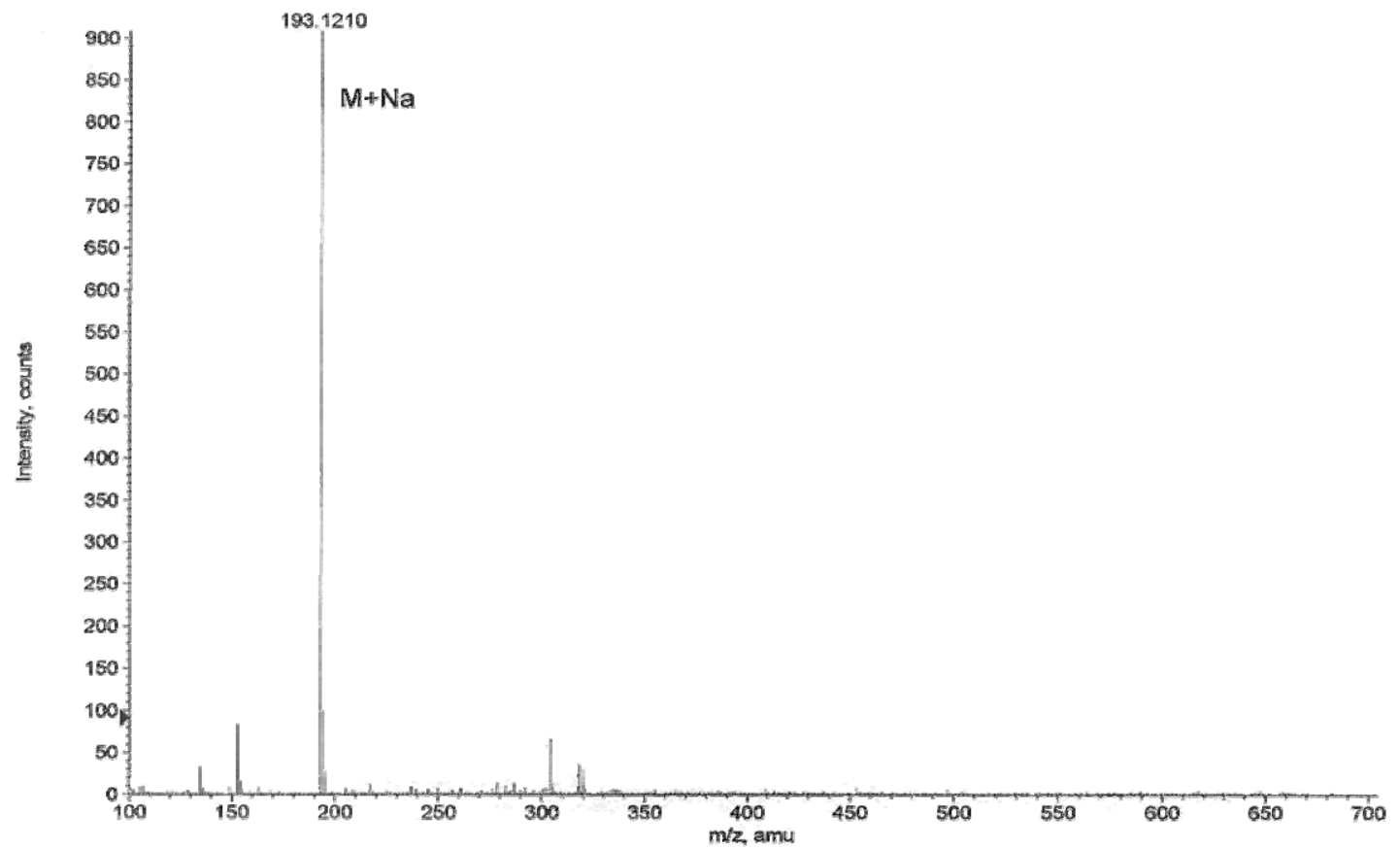


Fig. 64a

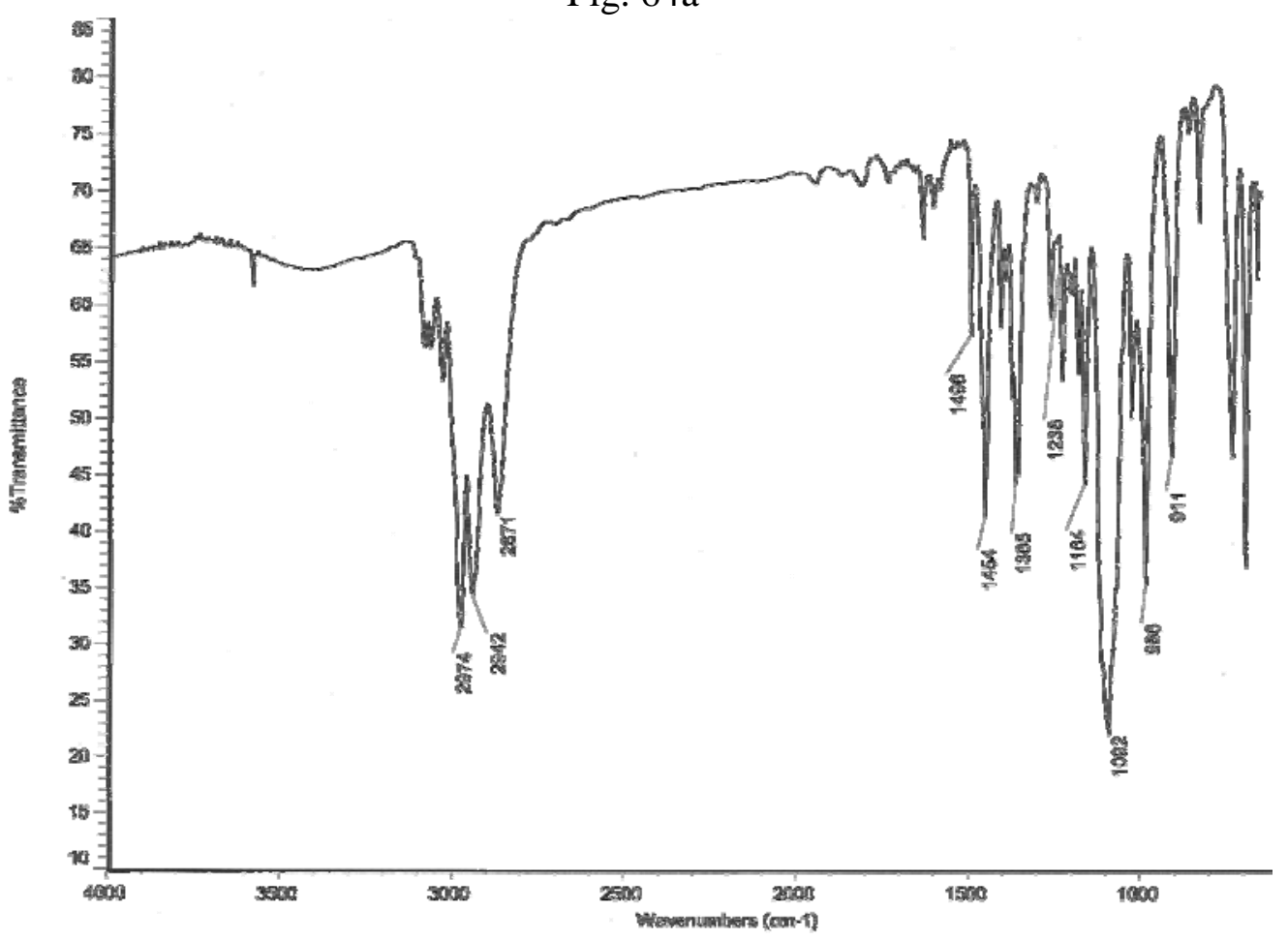

Fig. 64b

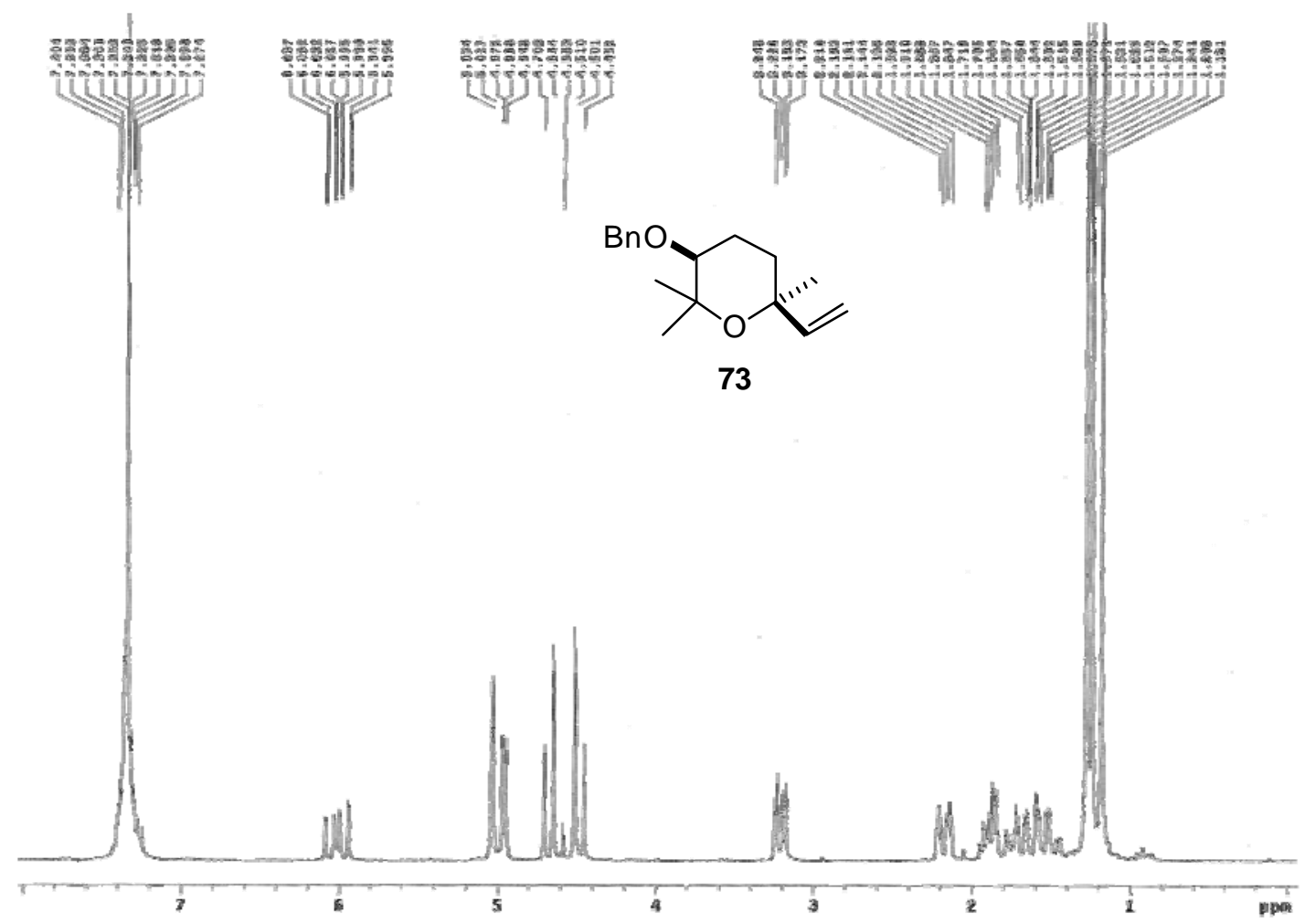


Fig. 64c
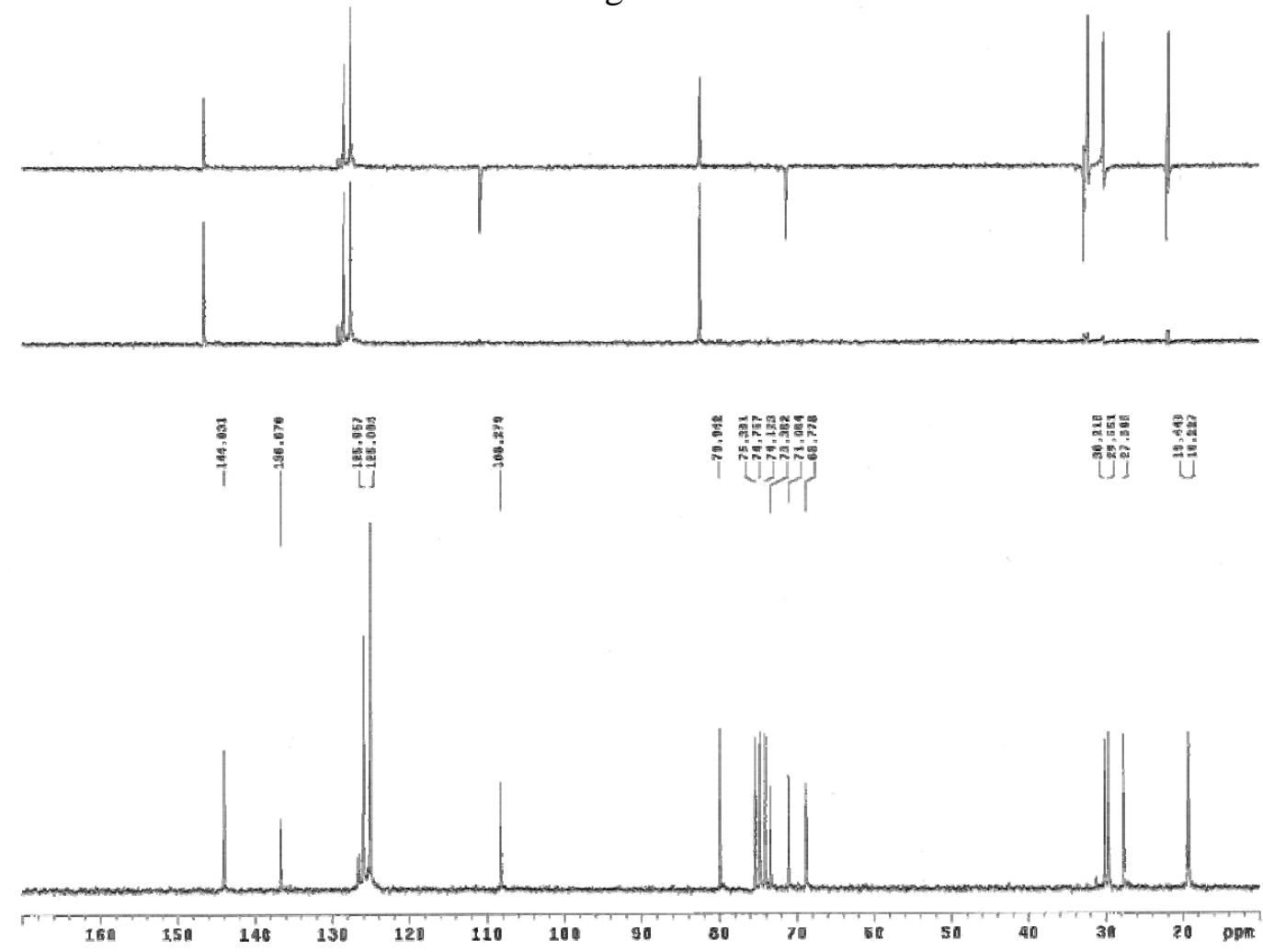

Fig. 64d

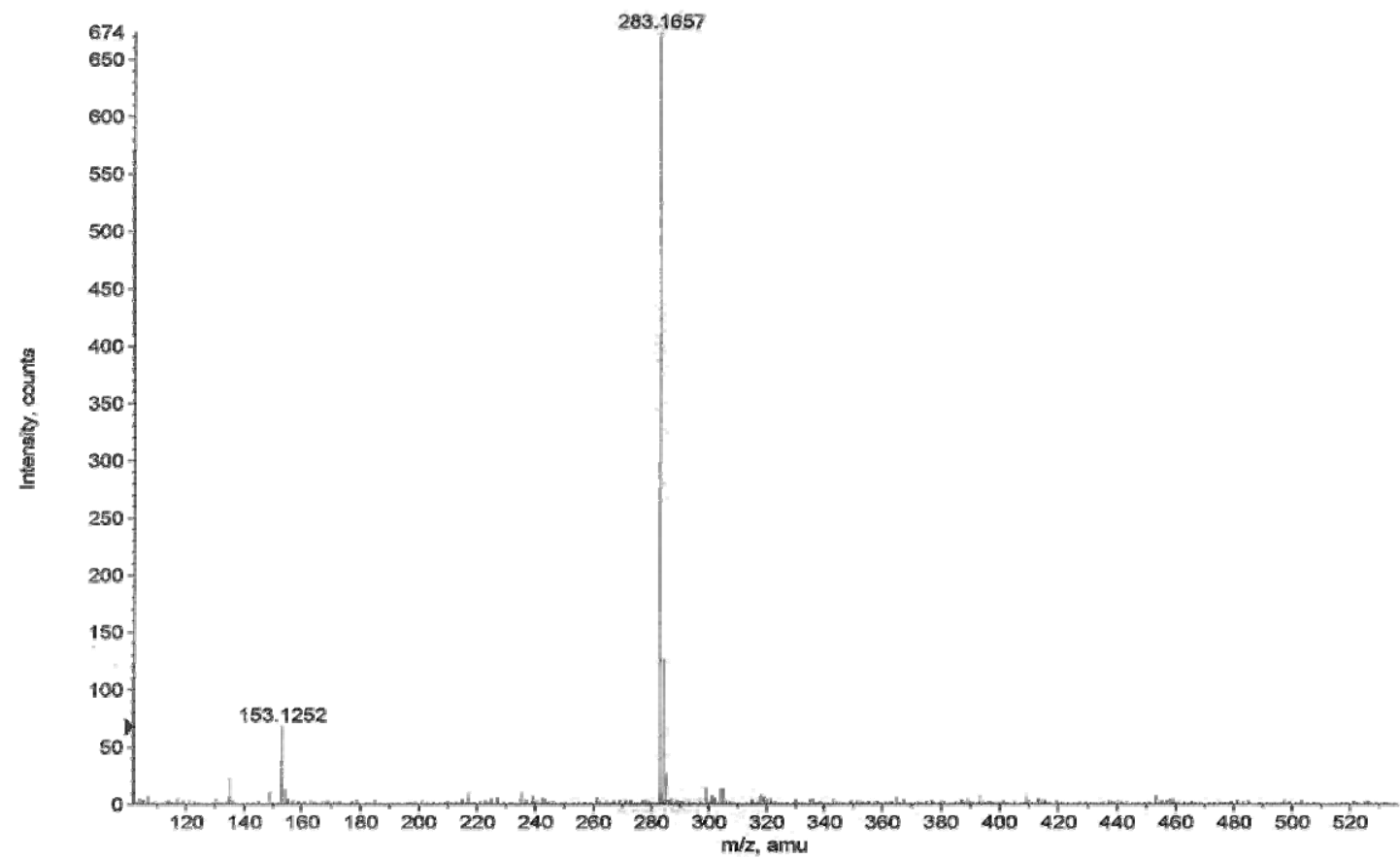


Fig. 65a

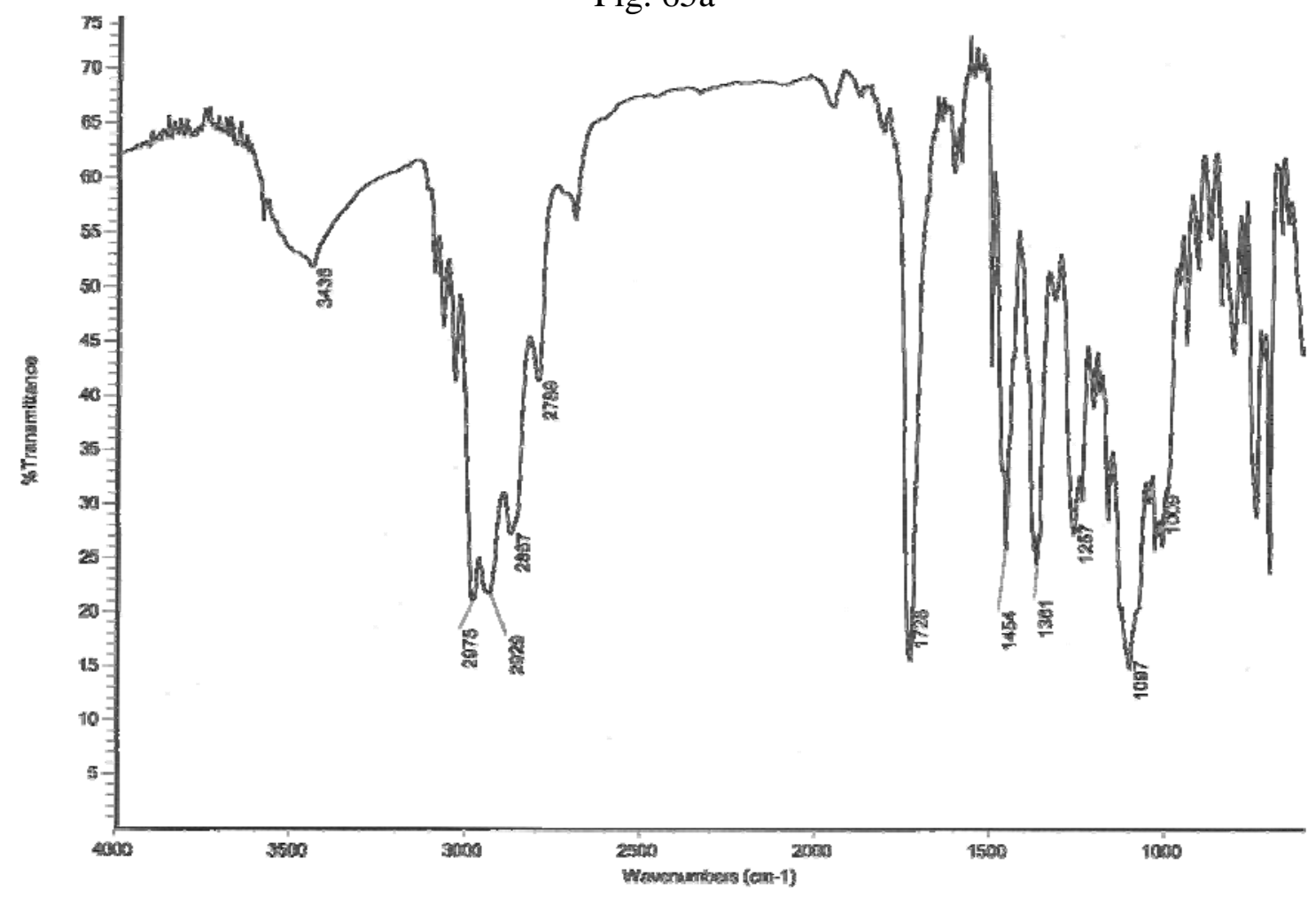

Fig. 65b

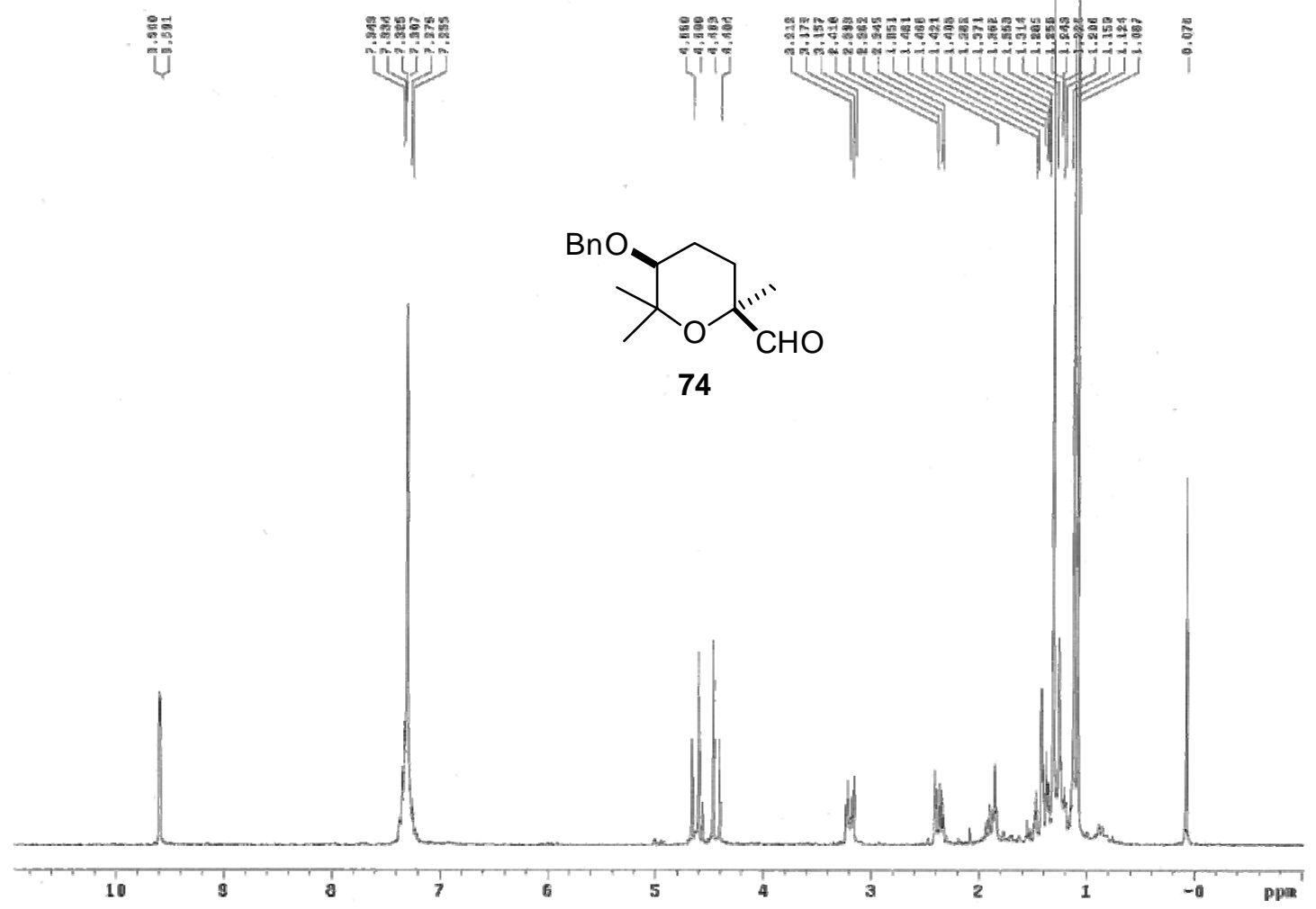


Fig. $65 c$

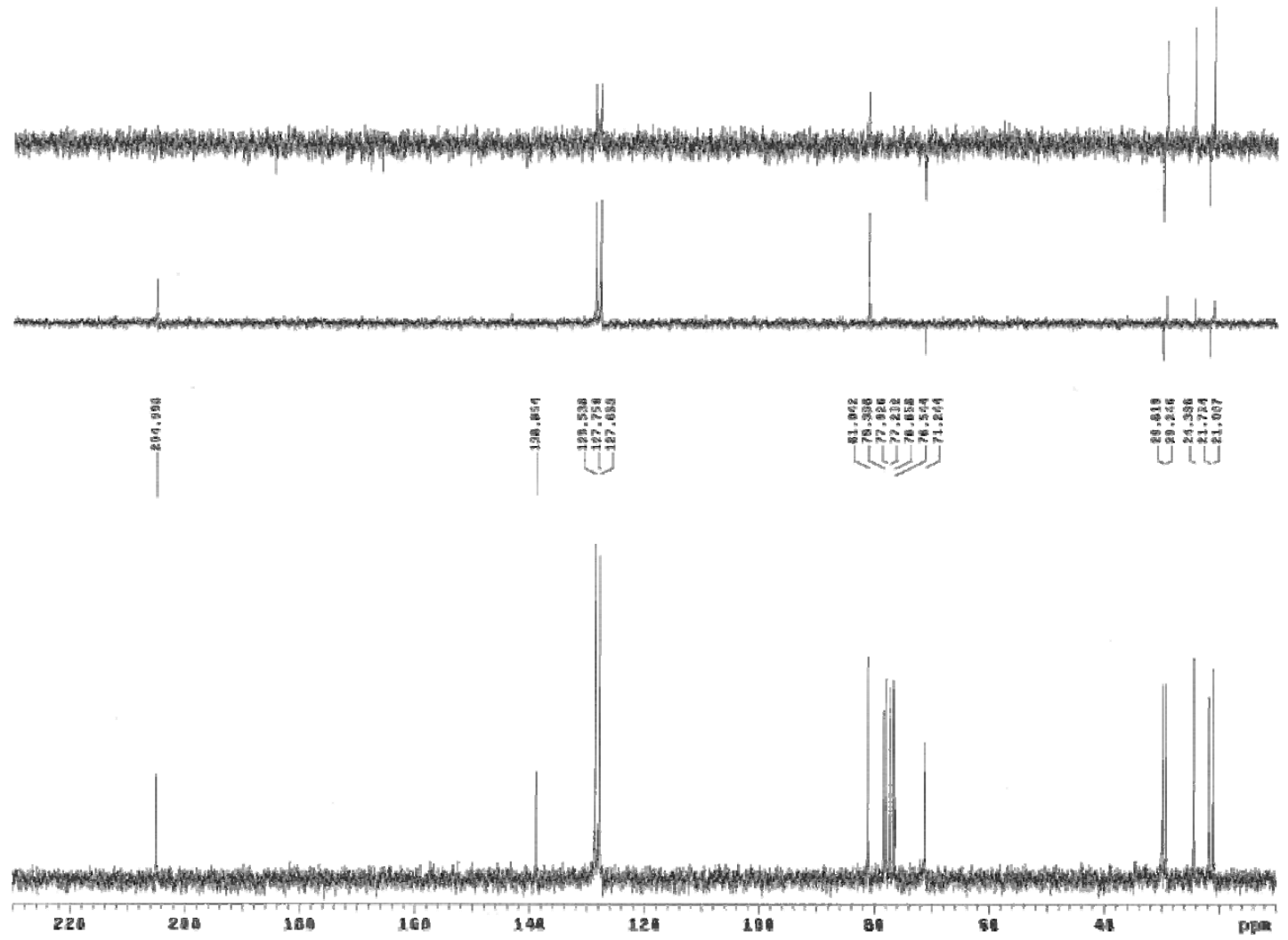


Fig. 66a

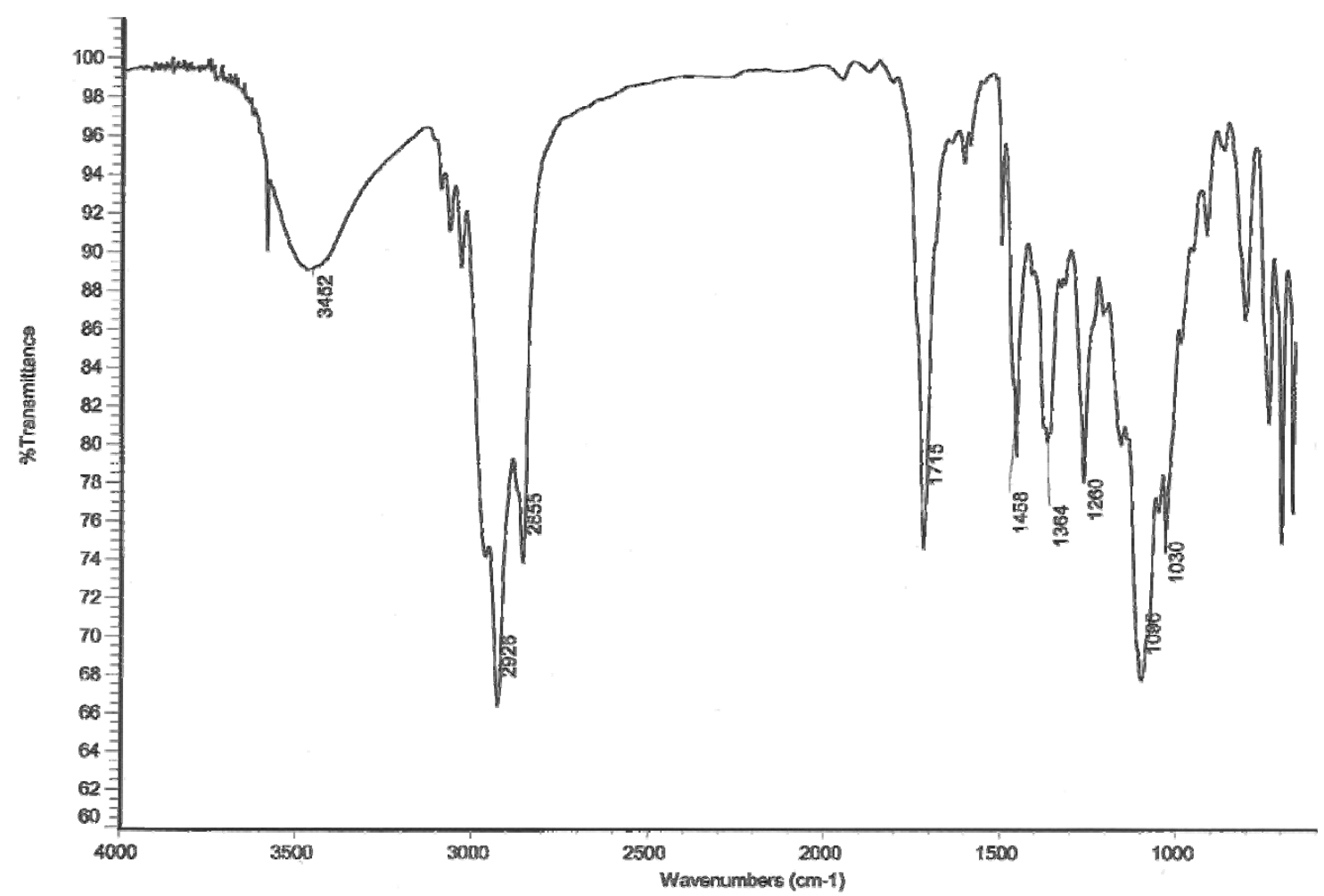

Fig. 66b

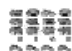

羟

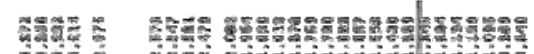

(19) [บ ใบ

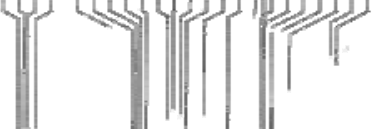

$\mathrm{BnO}$

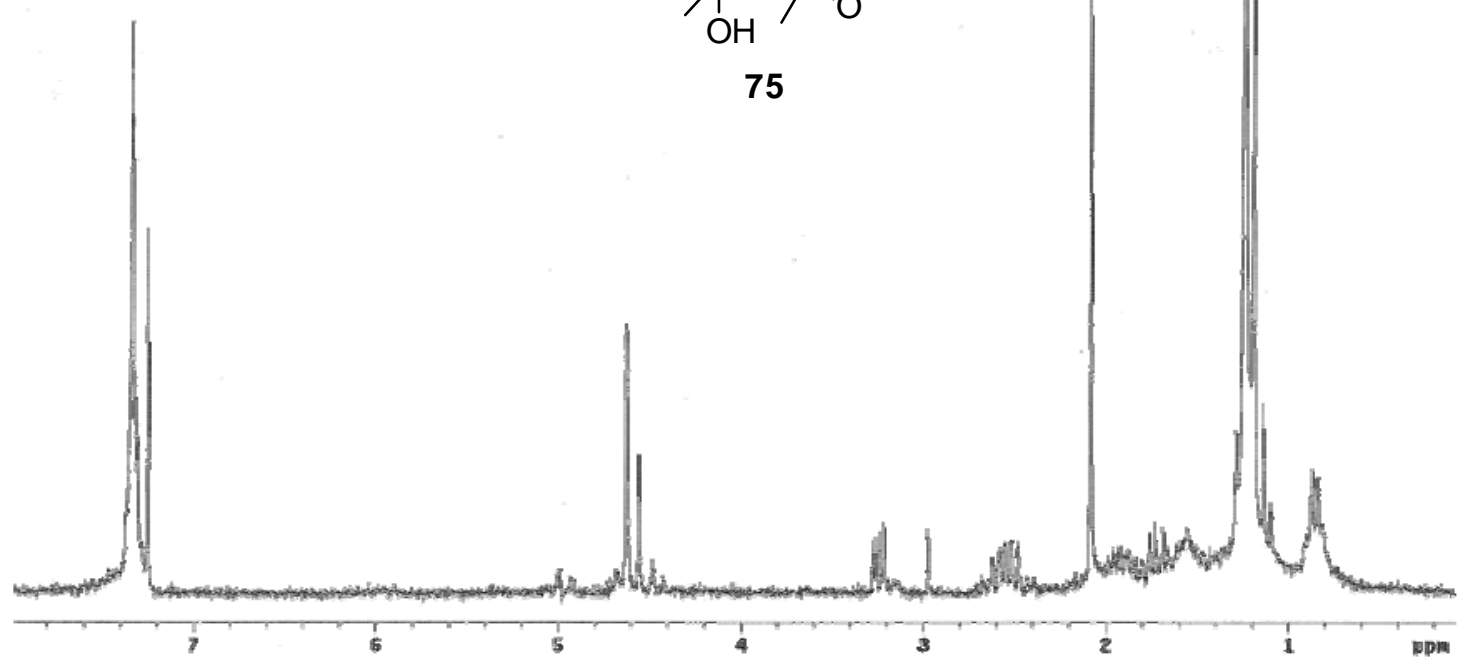


Fig. 66c
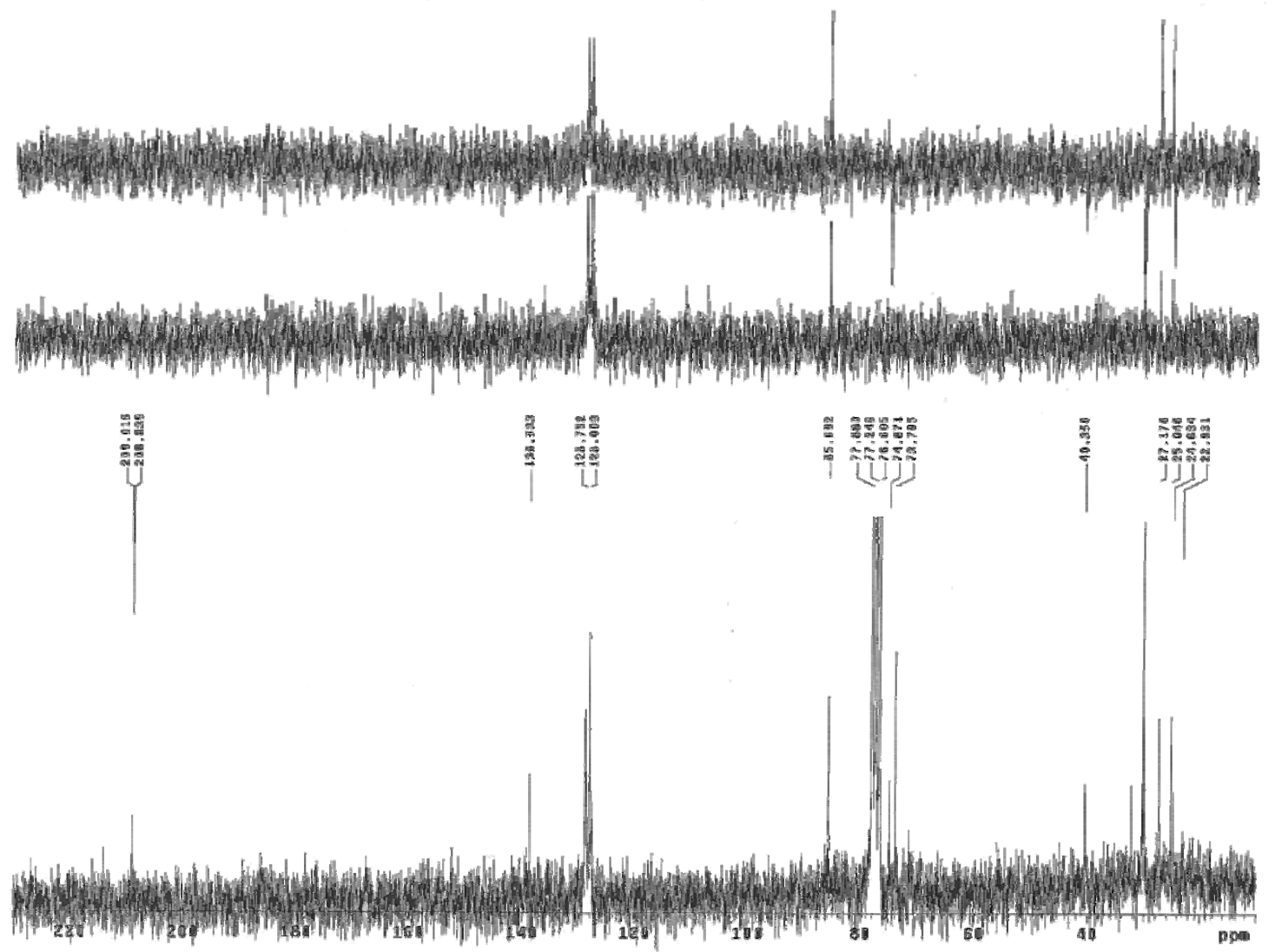

Fig. 66d

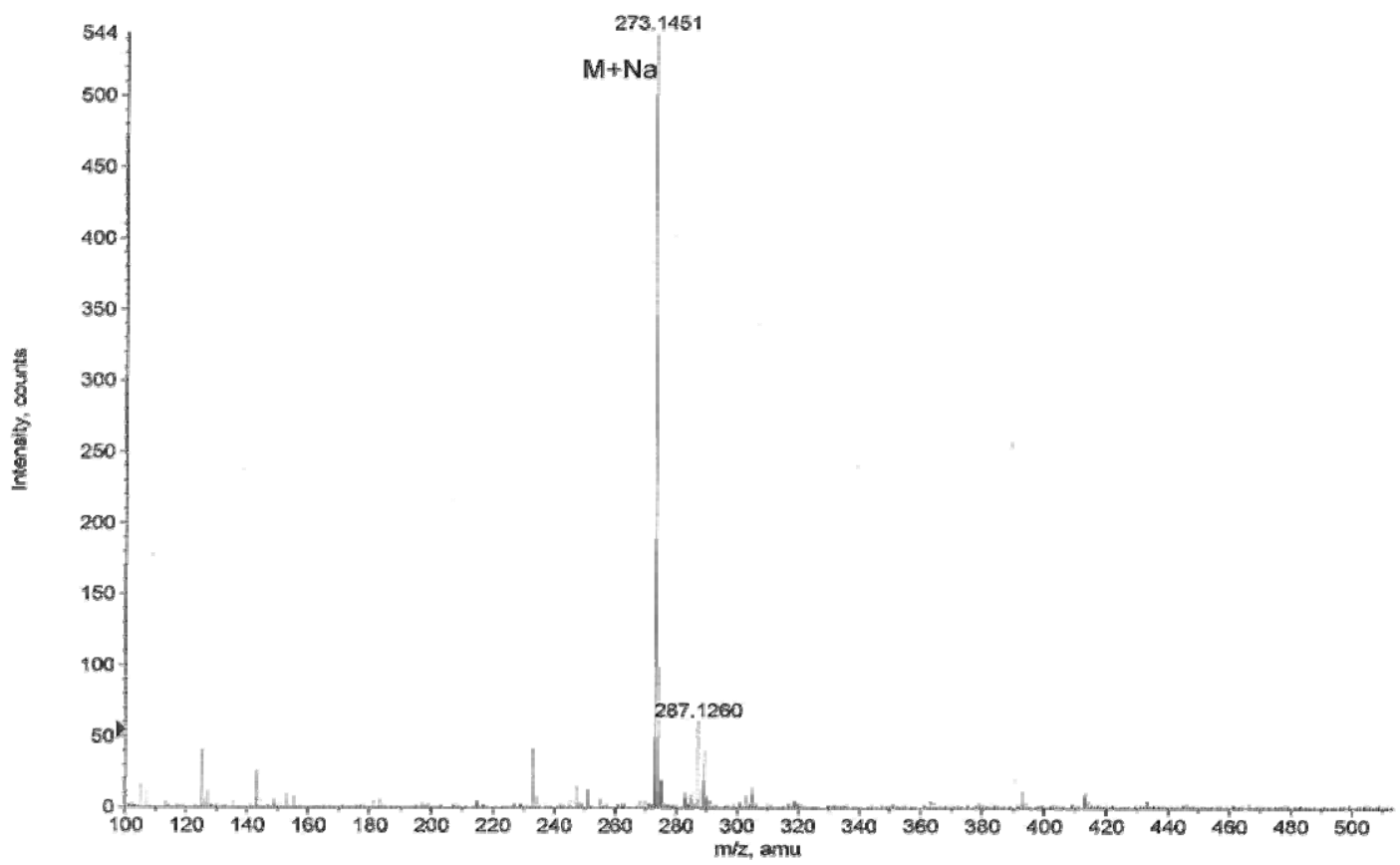


Fig. 67a

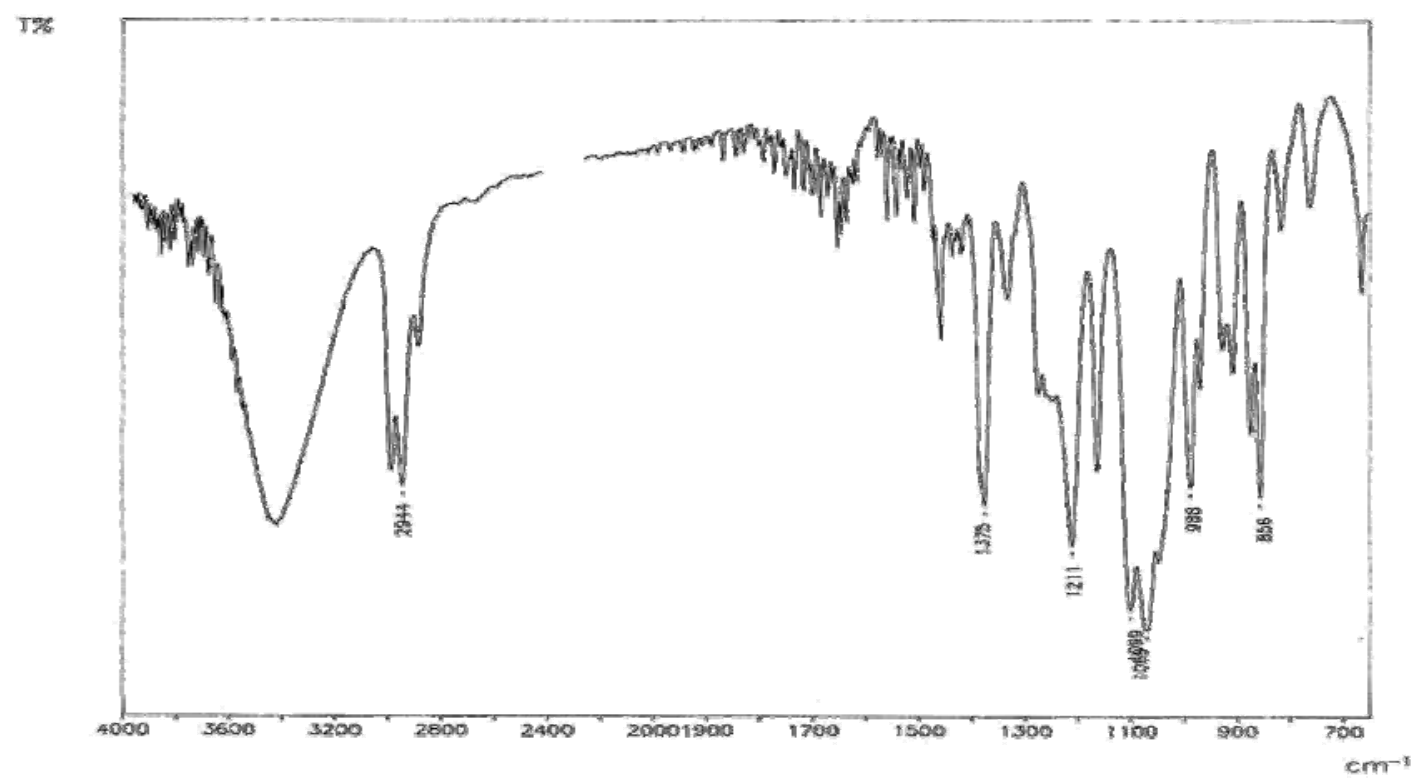

Fig. 67b

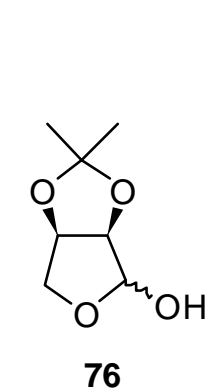


Fig. 67c

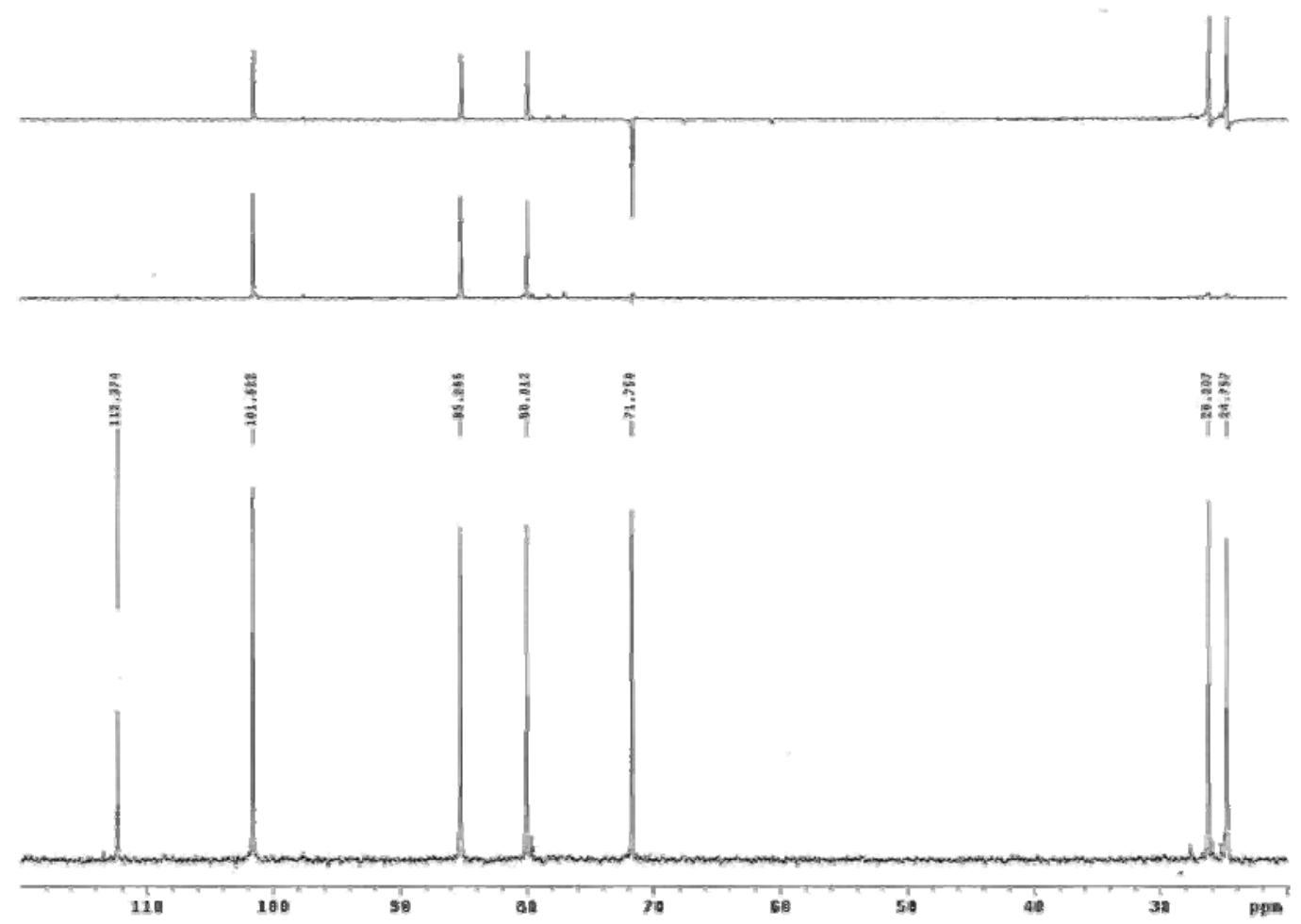


Fig. 68a

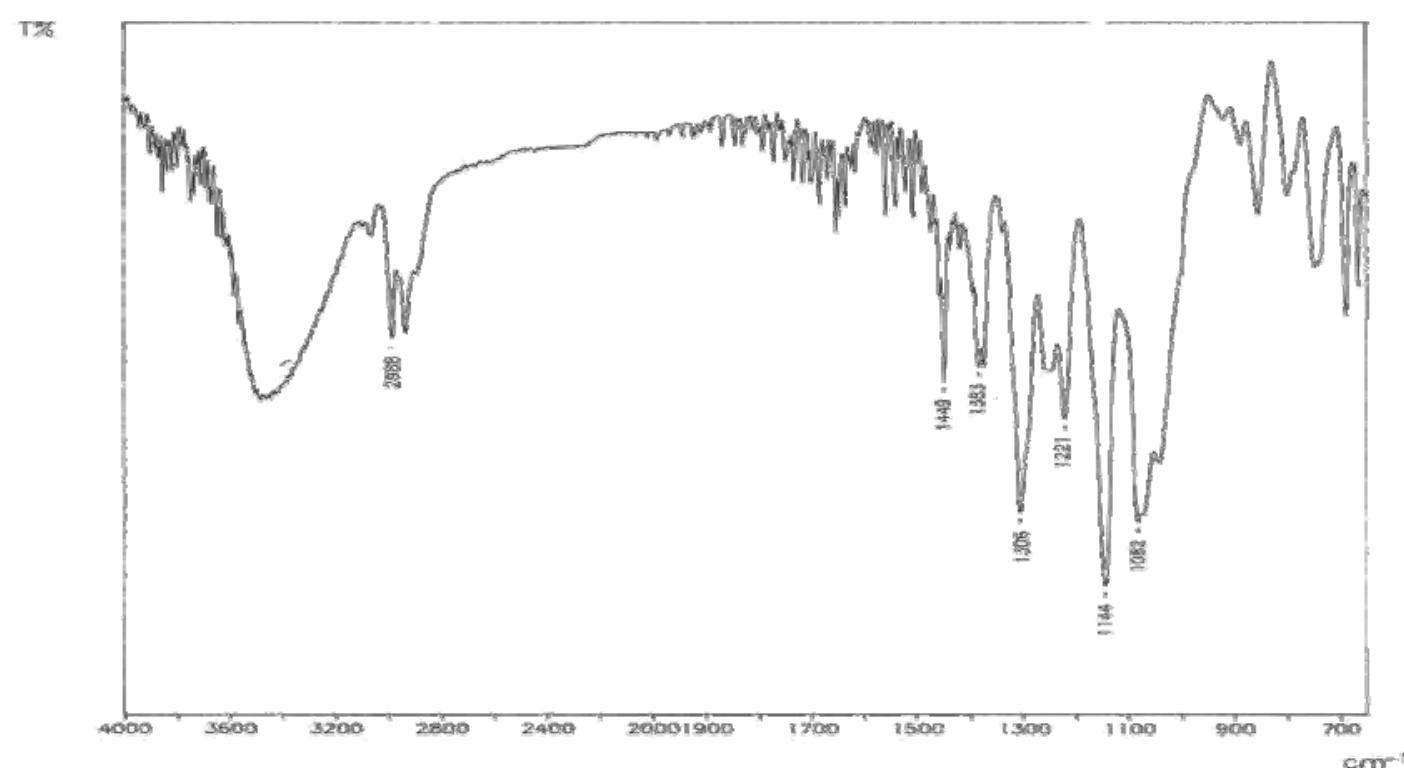

Fig. $68 \mathrm{~b}$

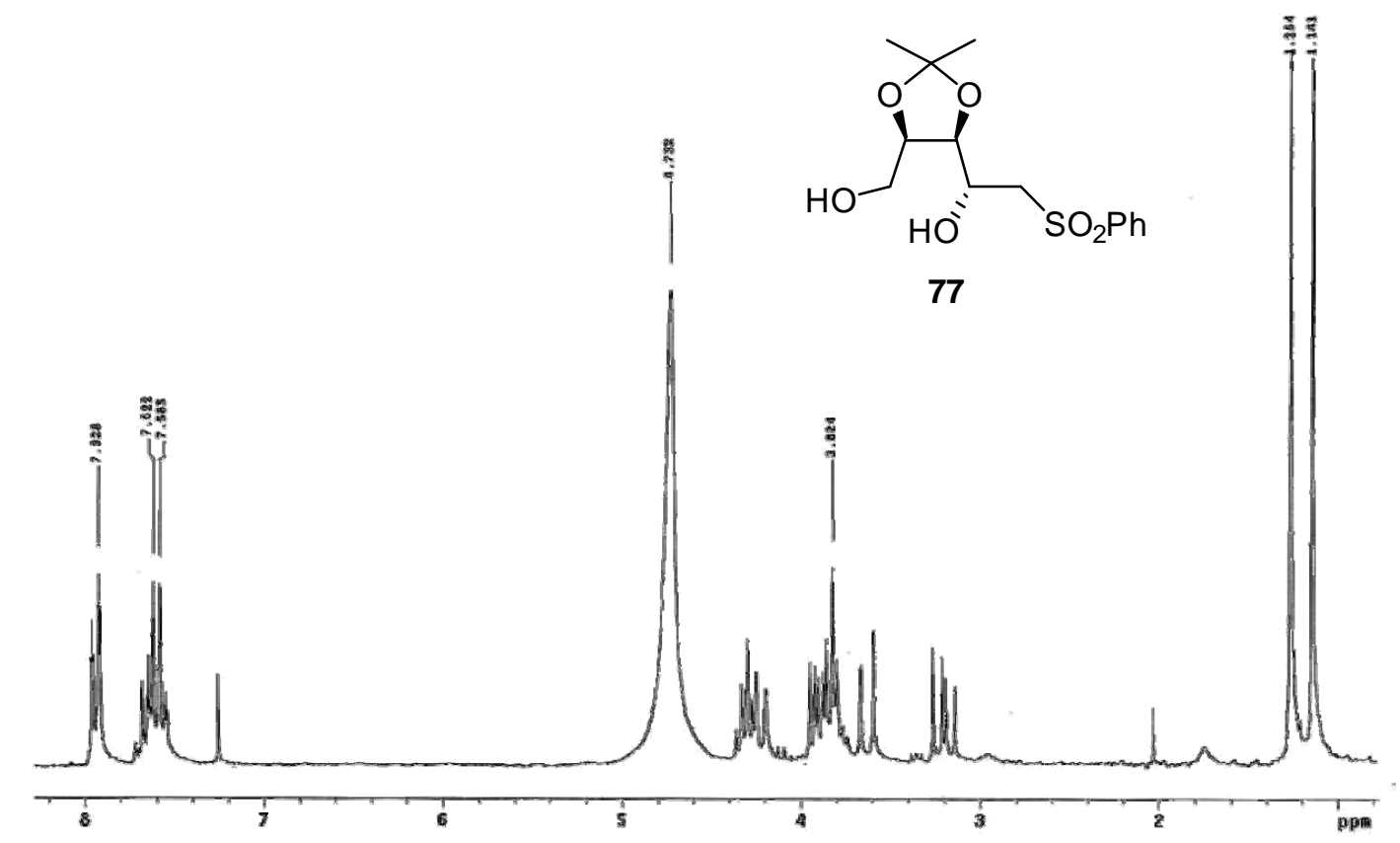


Fig. 68c
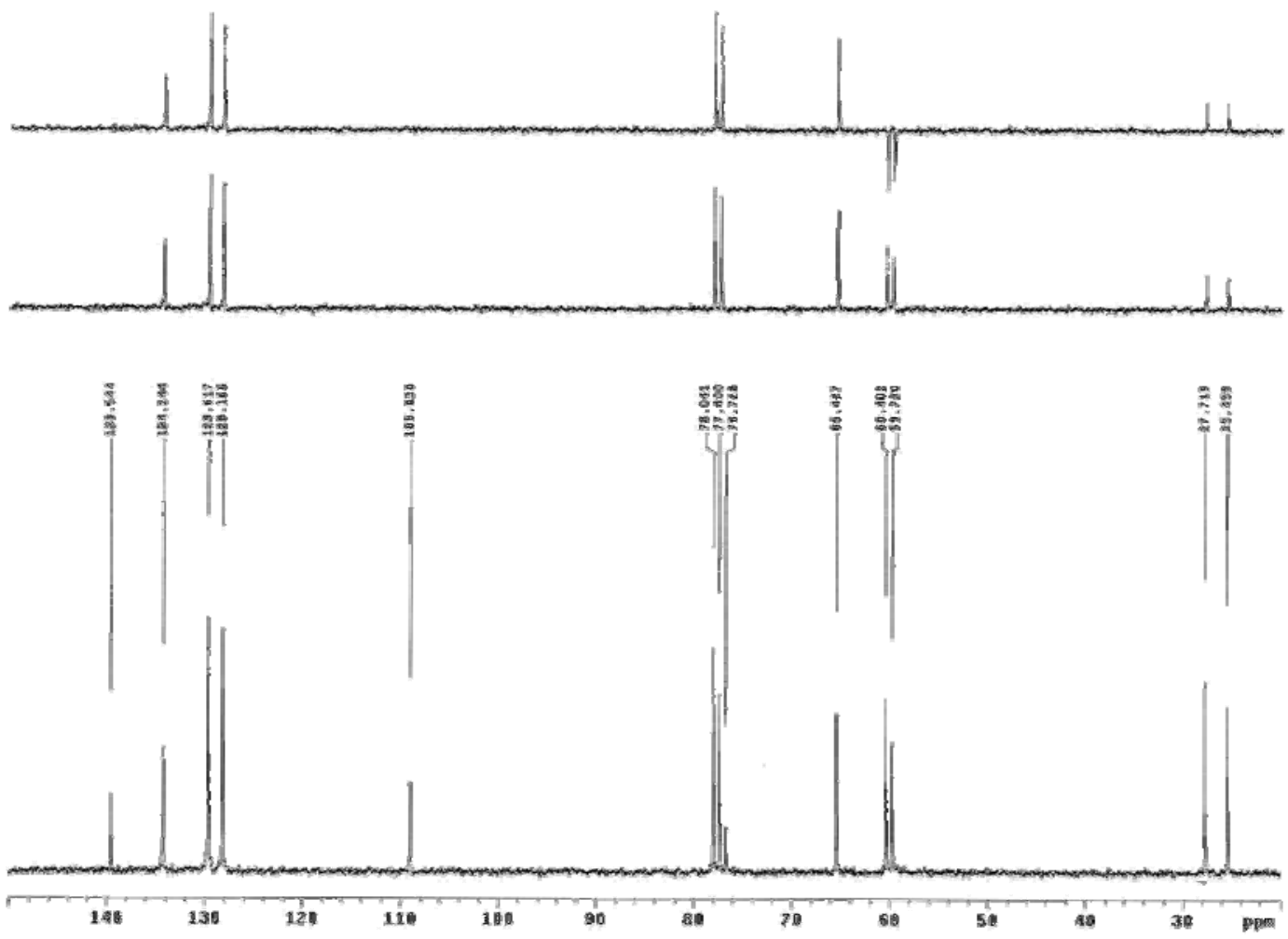
Fig. 69a

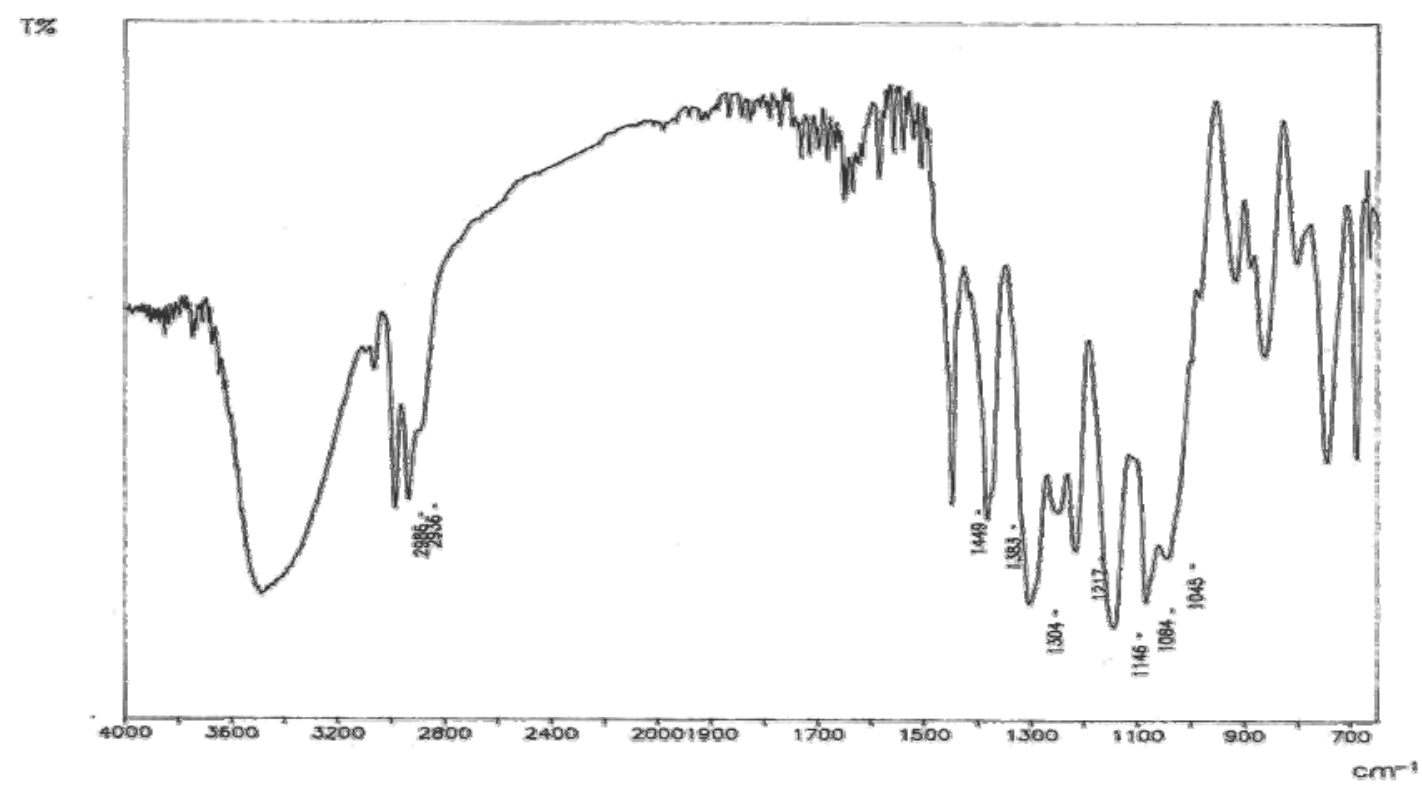

Fig. 69b
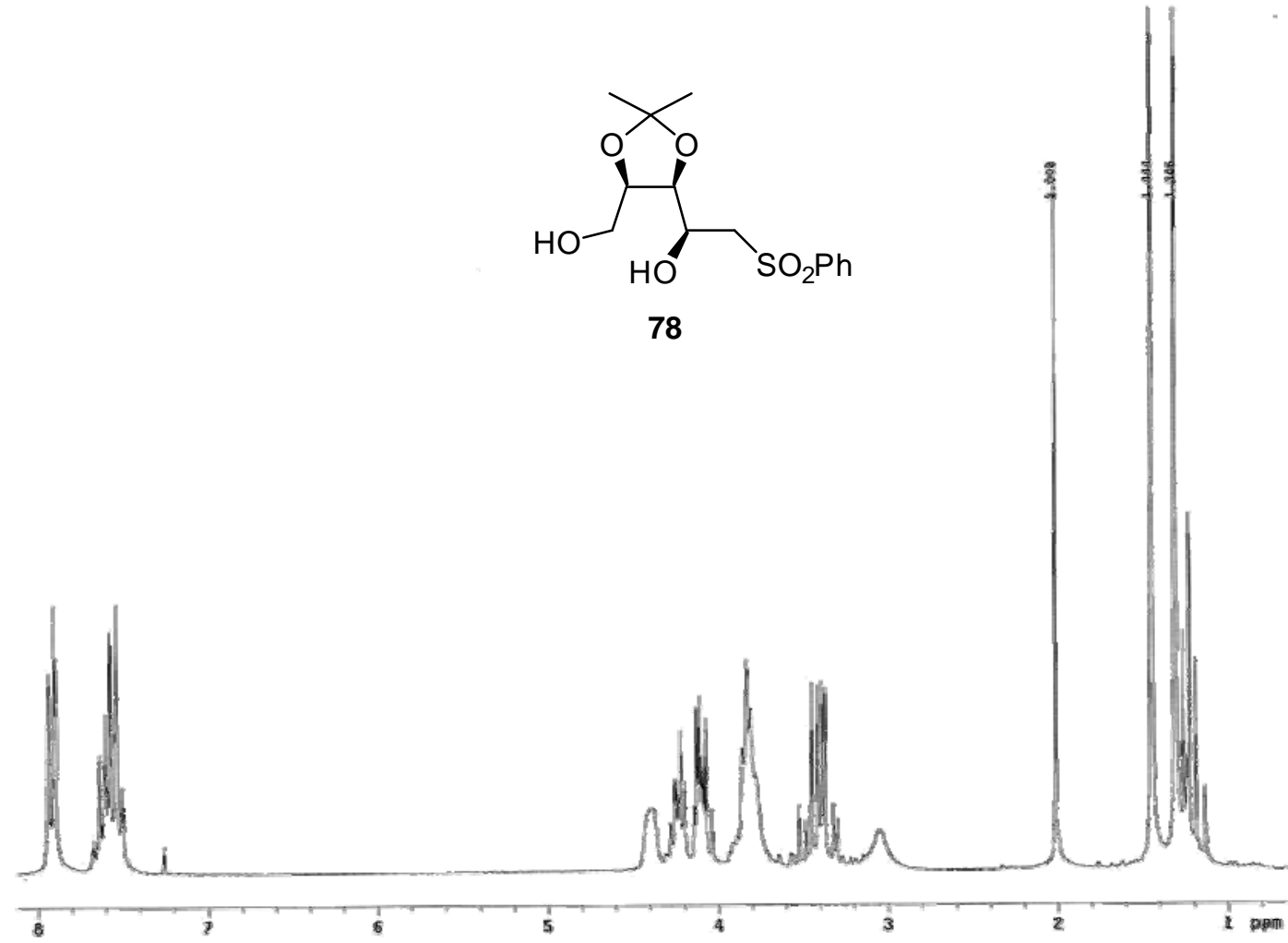
Fig. 69c
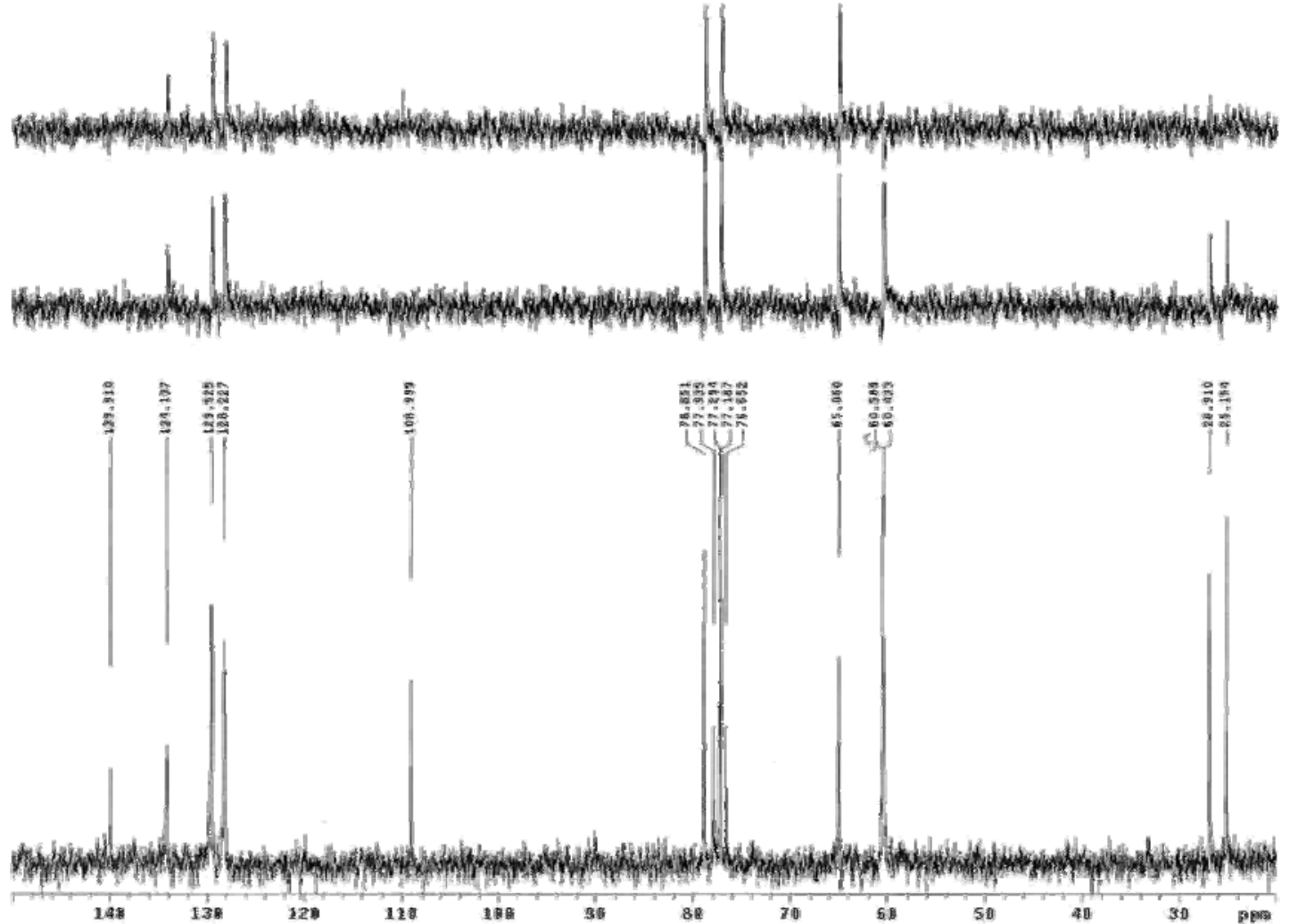
Fig. 70a

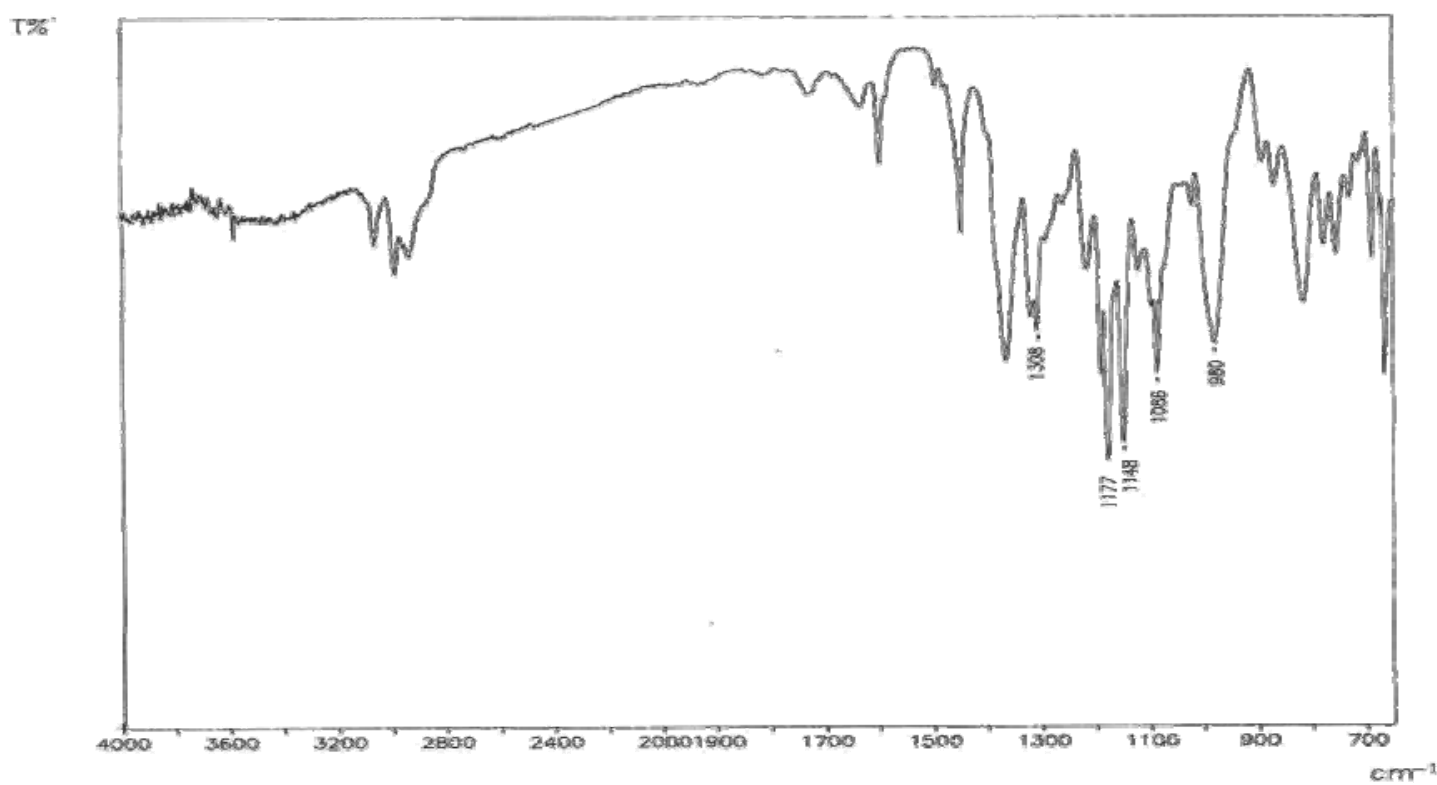

Fig. $70 \mathrm{~b}$

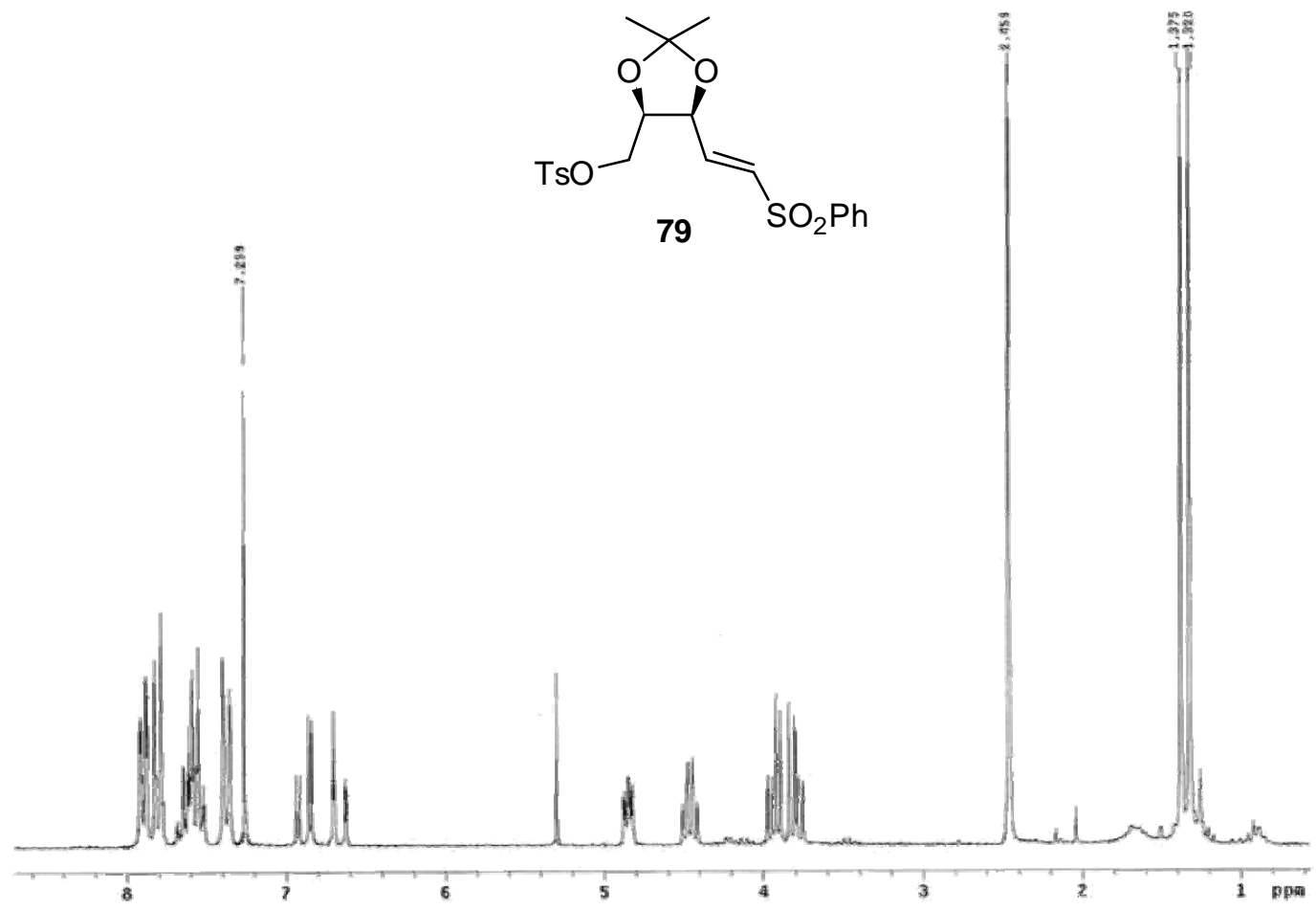


Fig. 70c

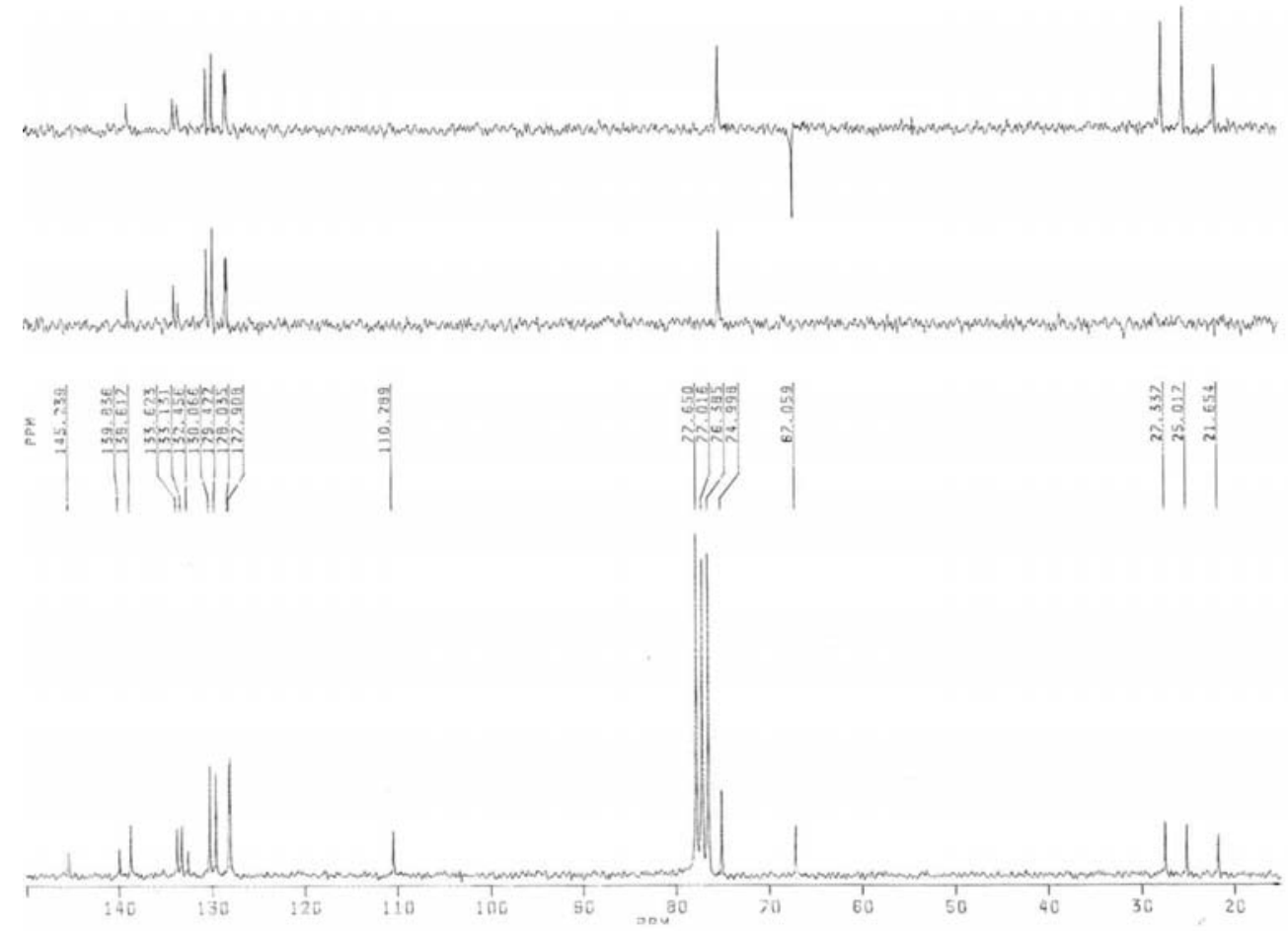

Fig. 70d

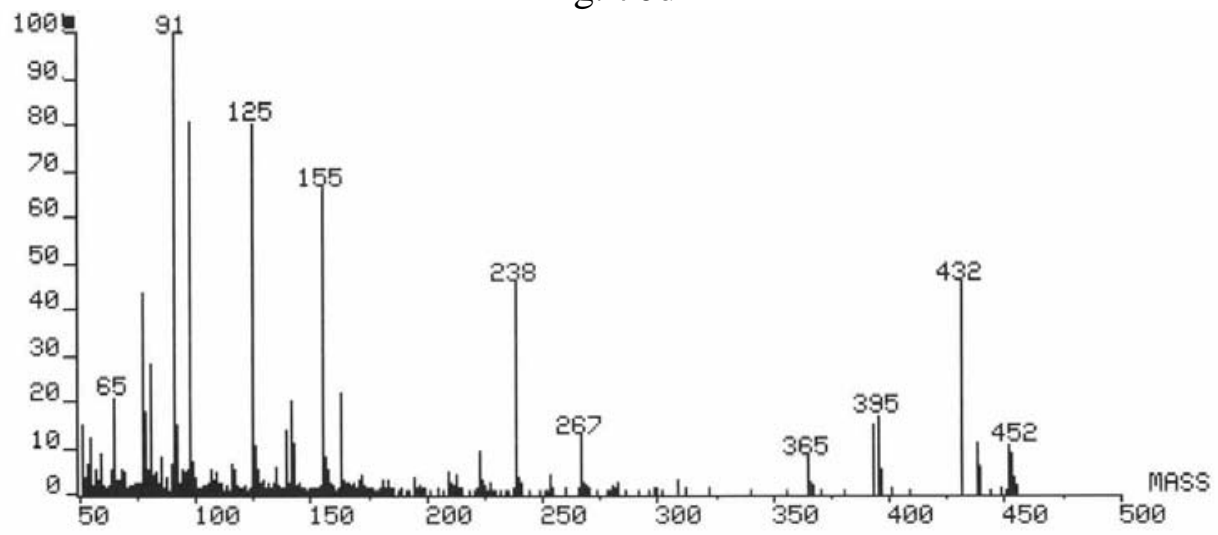

Fig. 70e

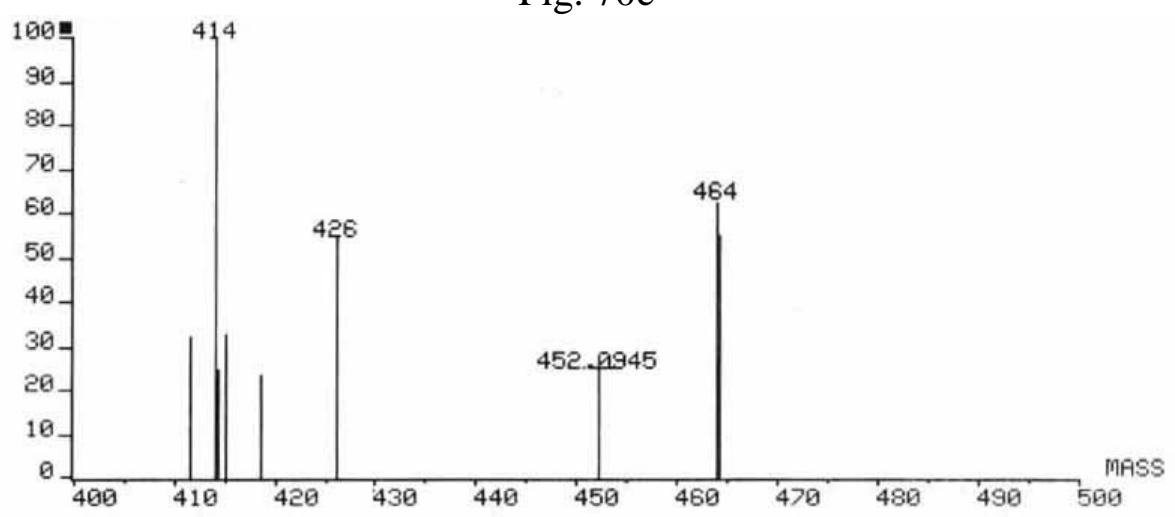


Fig. 71a

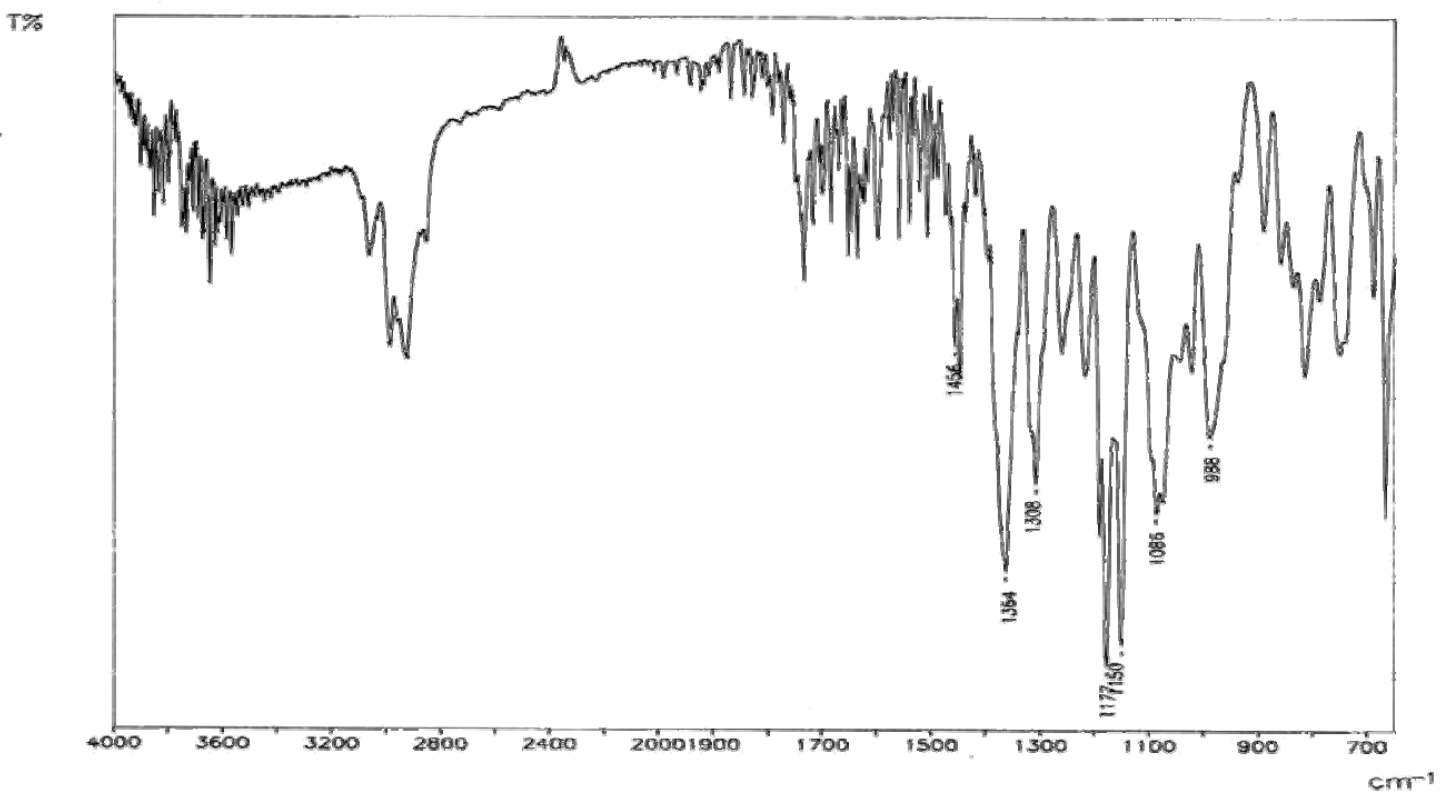

Fig. 71b

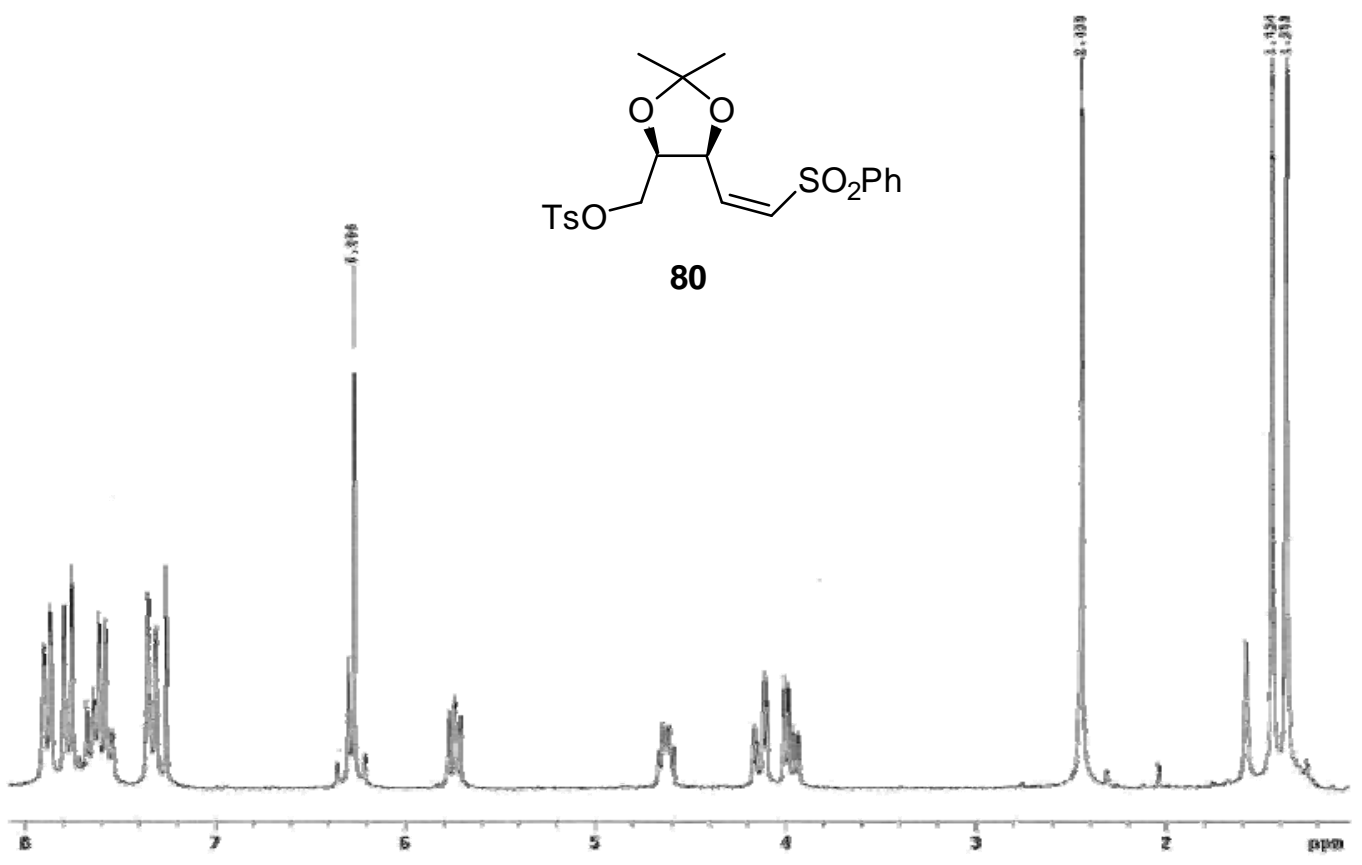


Fig. 71c
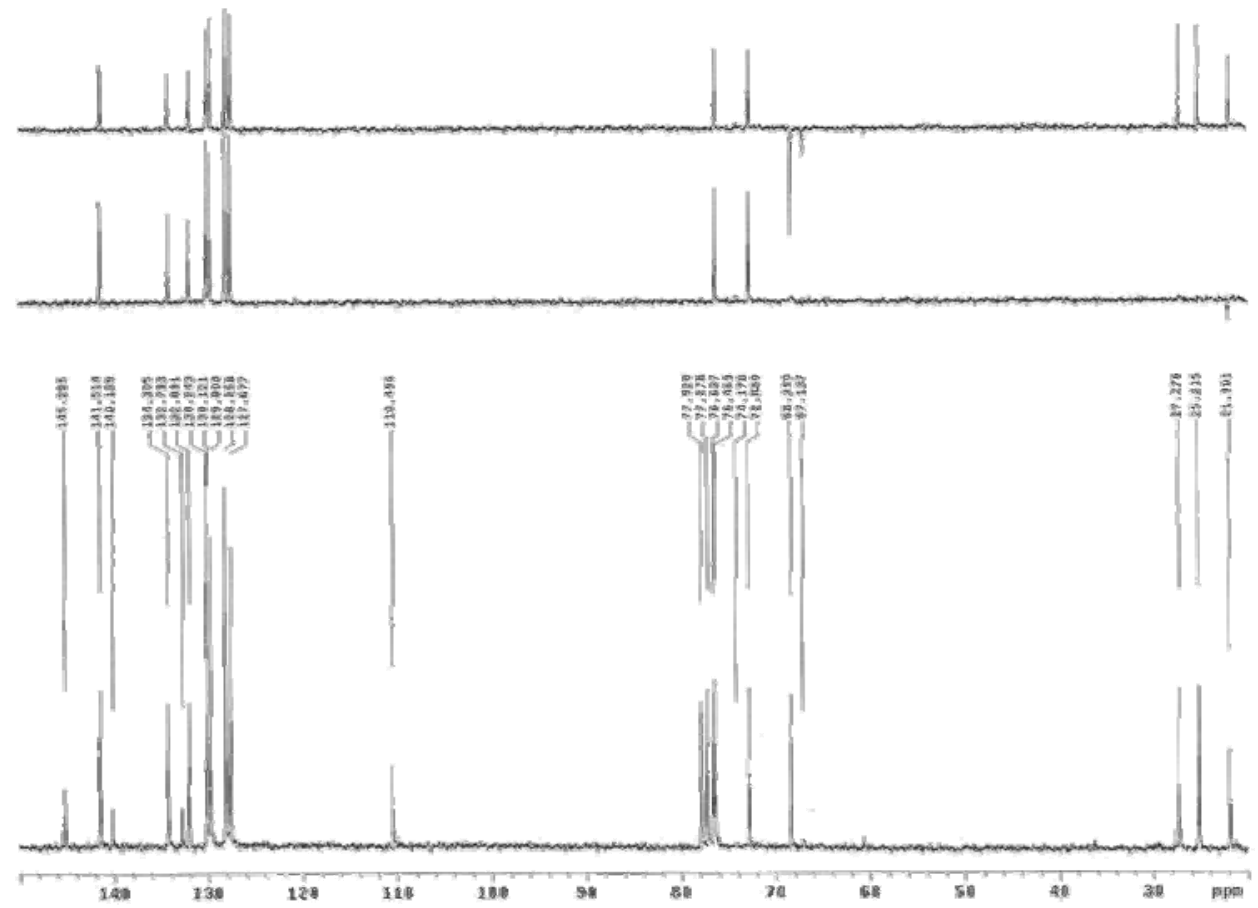

Fig. 71d

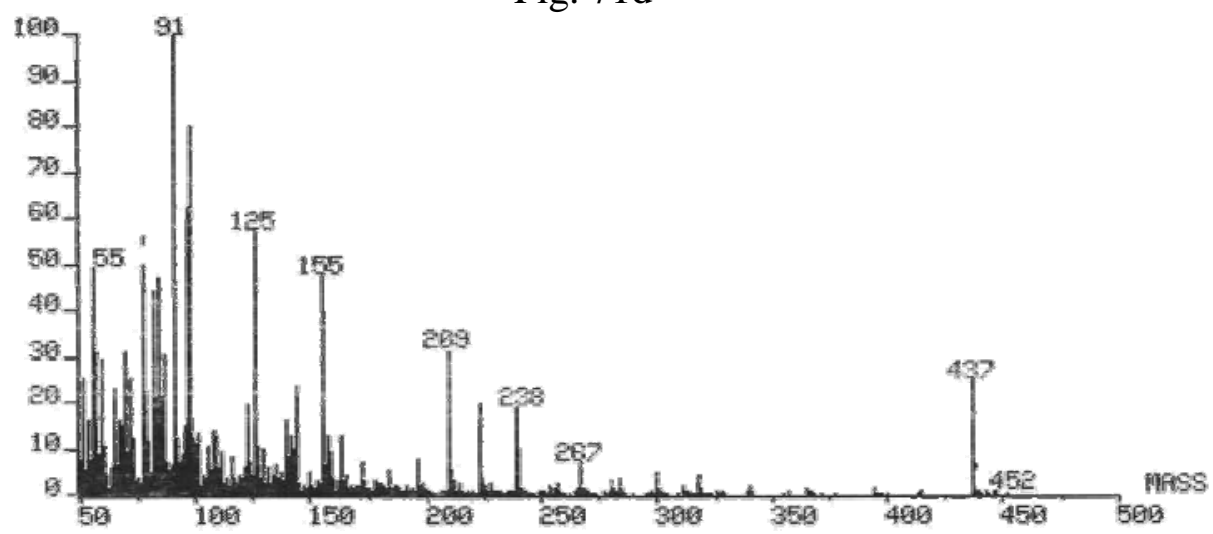

Fig. 71e

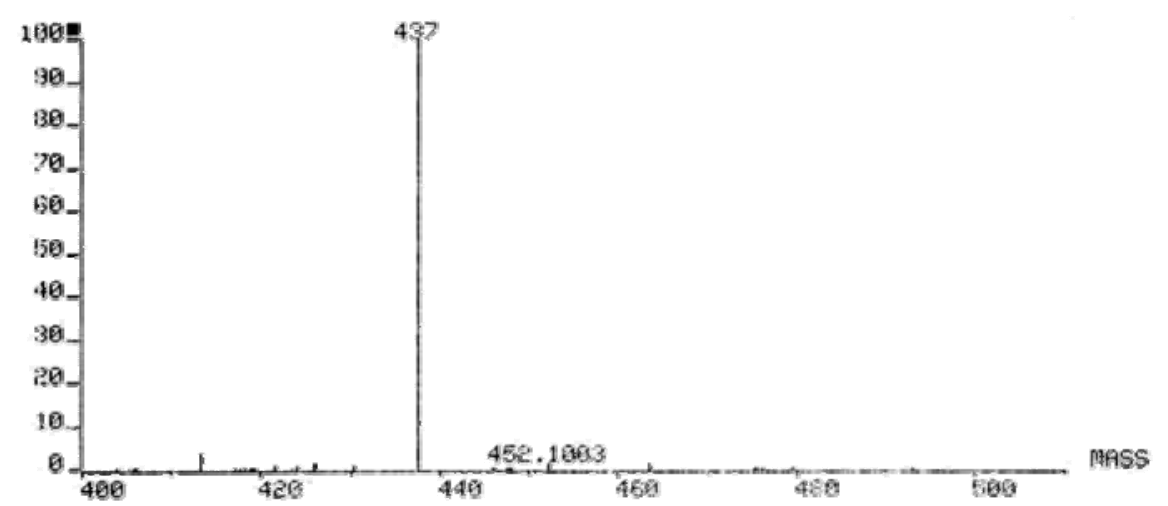


Fig. $72 \mathrm{a}$

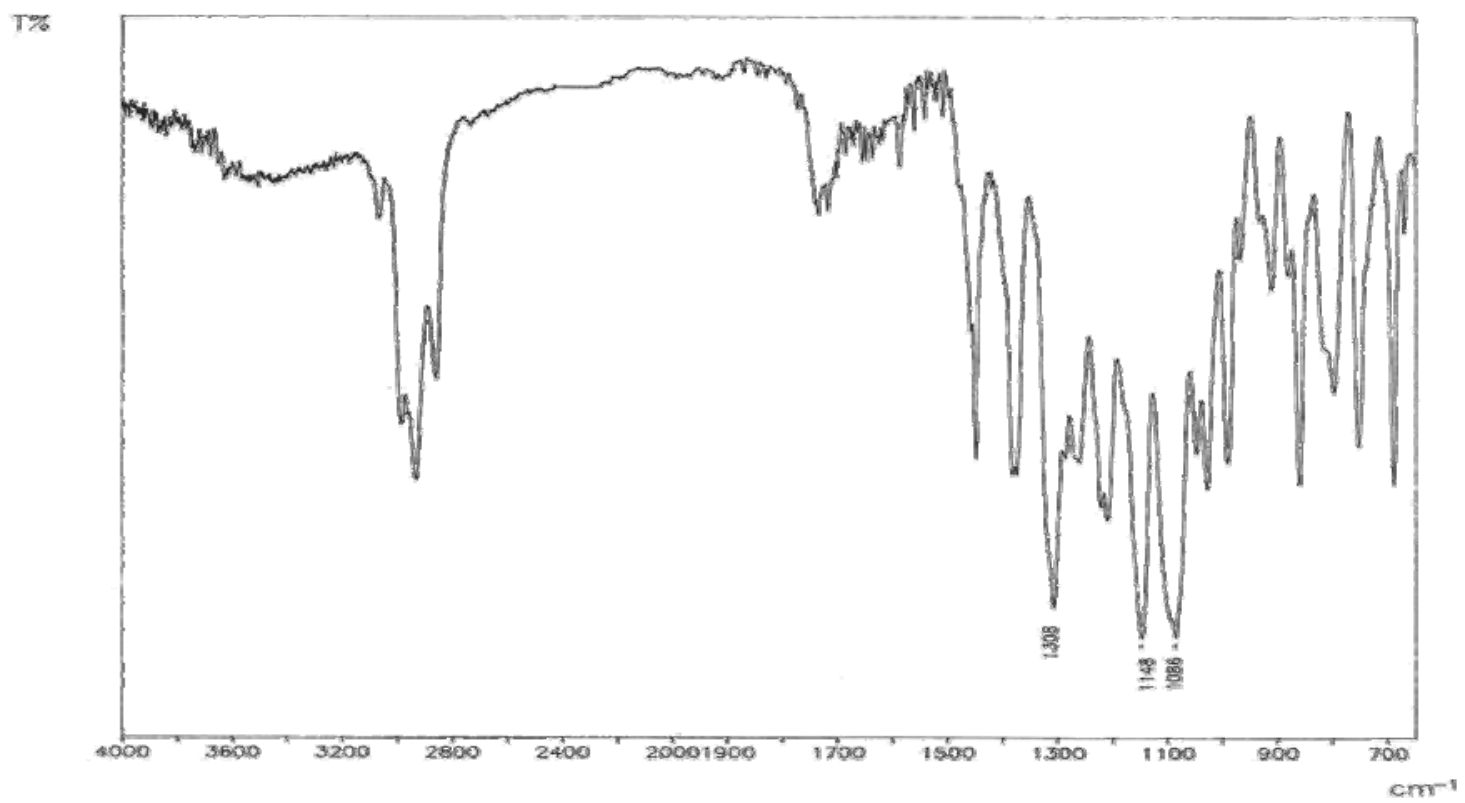

Fig. $72 b$

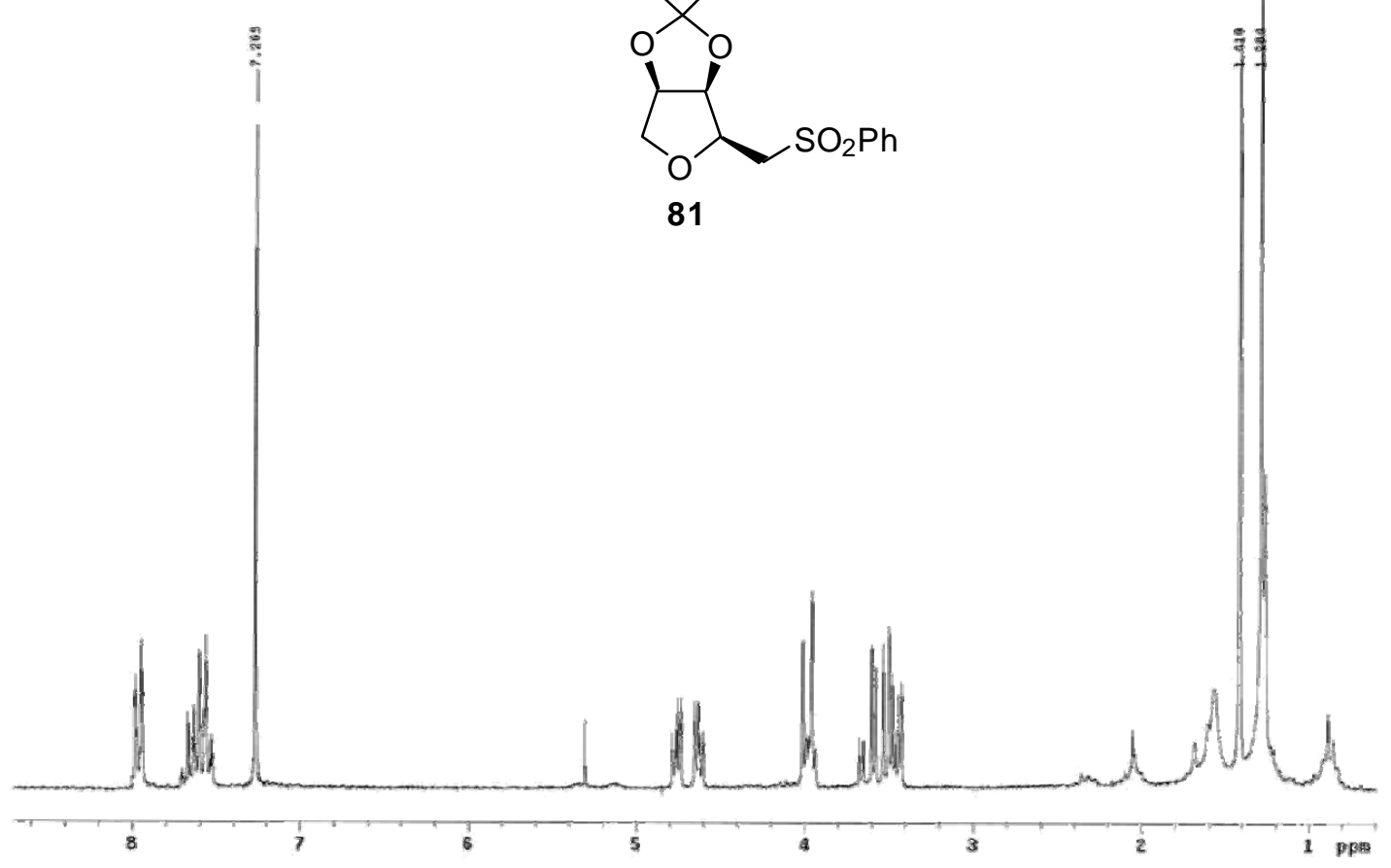


Fig. 72c
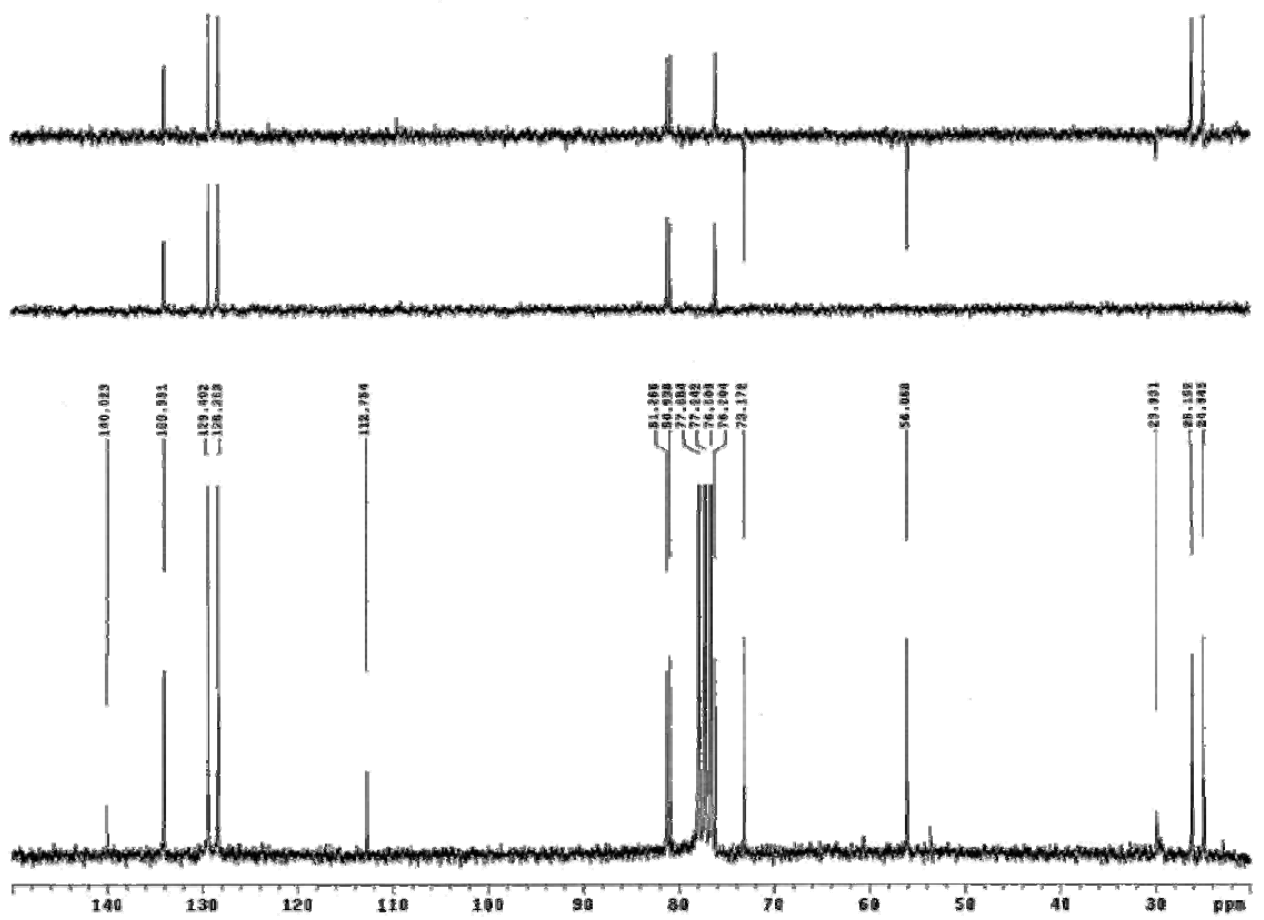

Fig. $72 d$

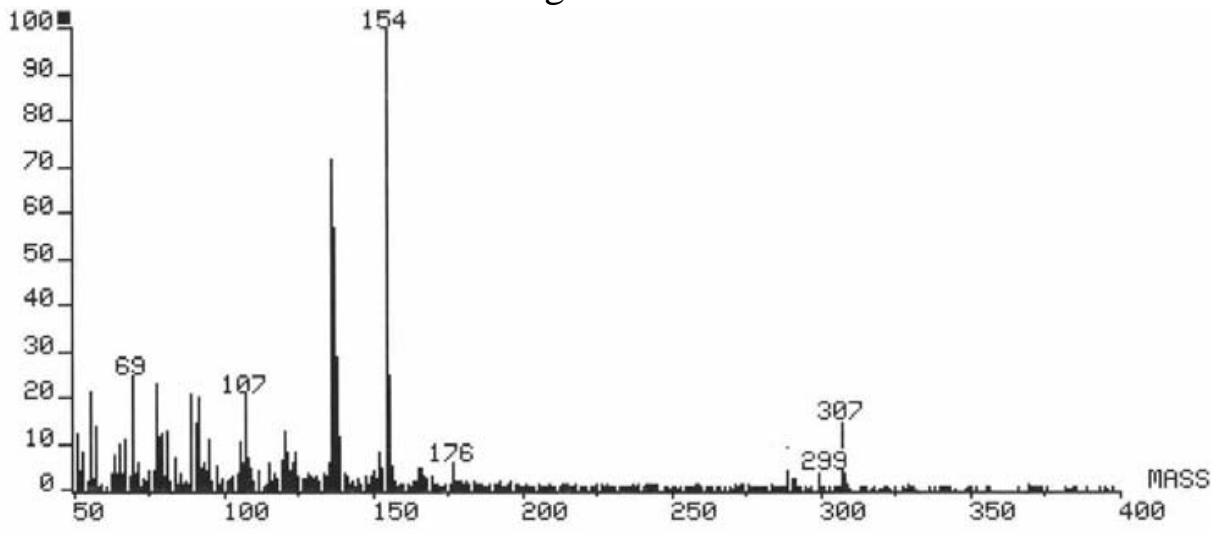

Fig. 72e

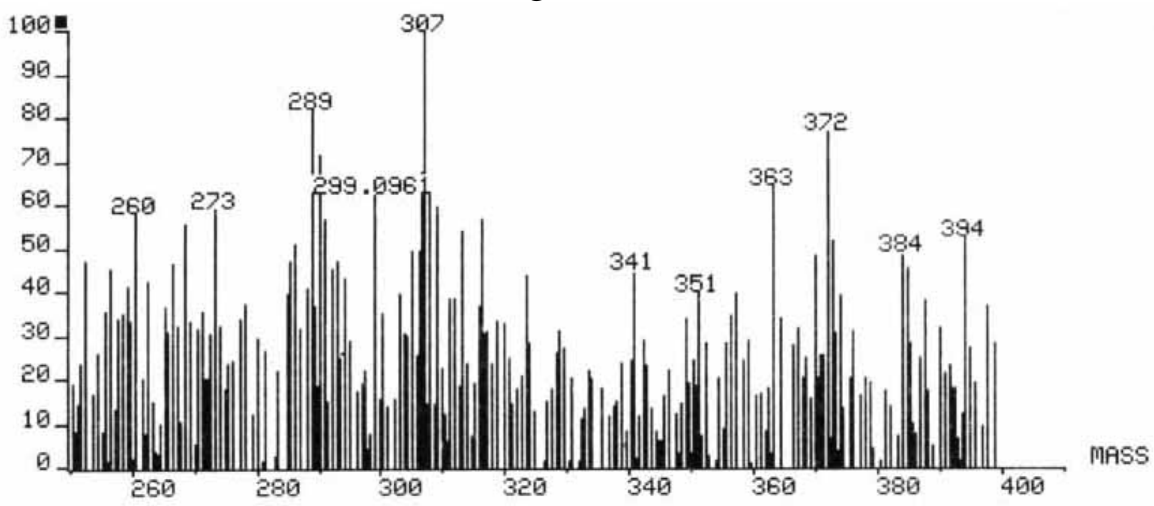


Fig. 73a

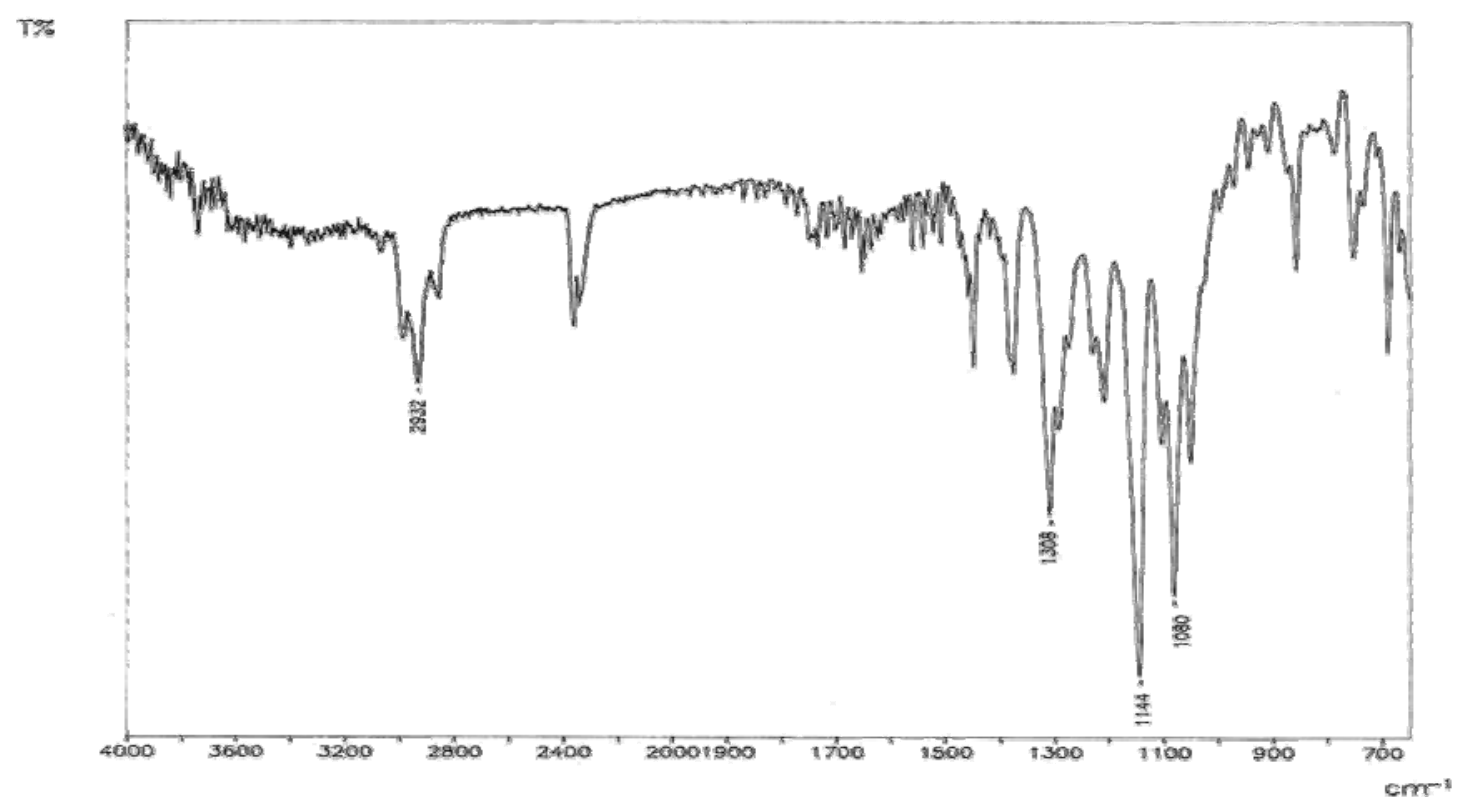

Fig. 73b

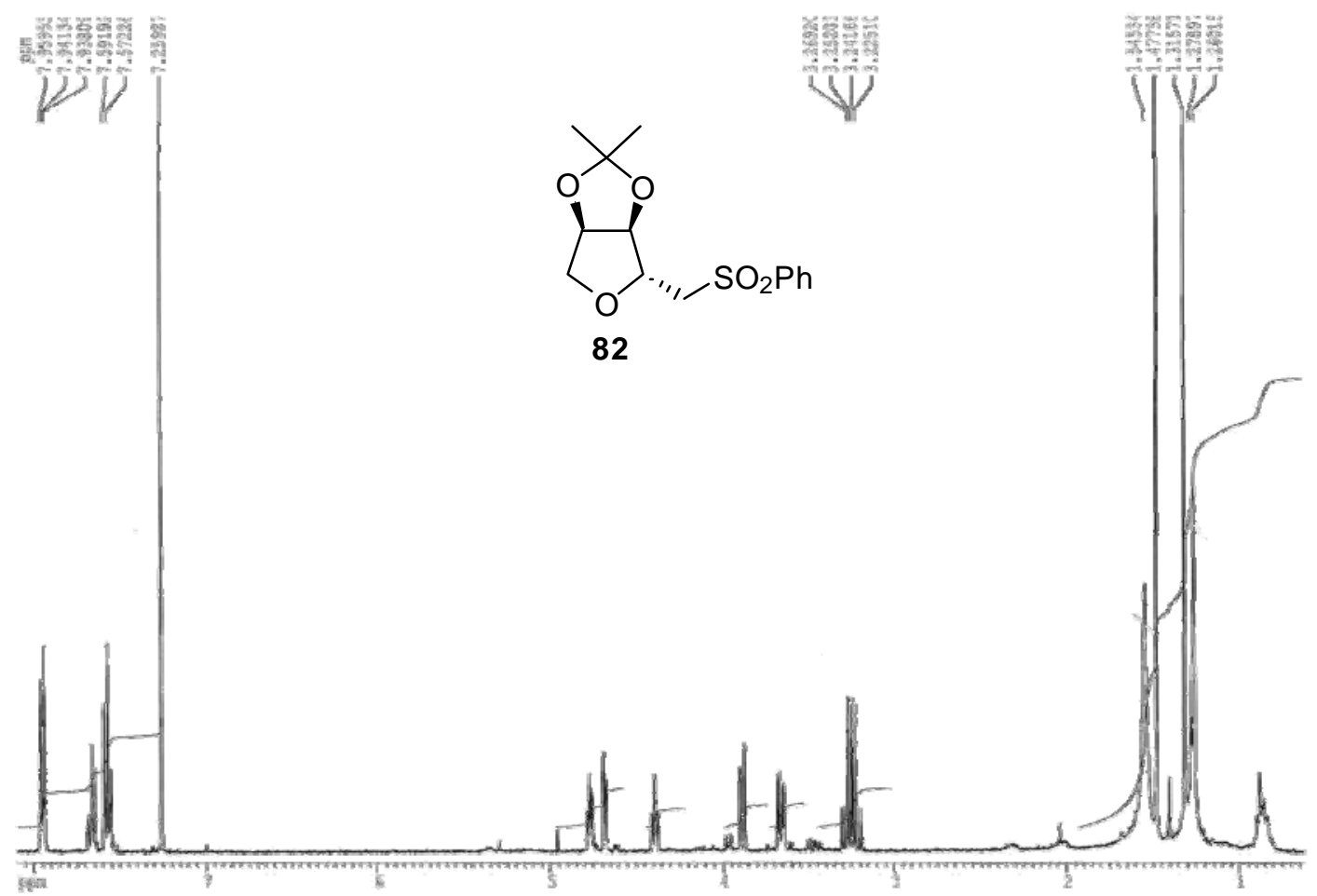


Fig. $73 c$
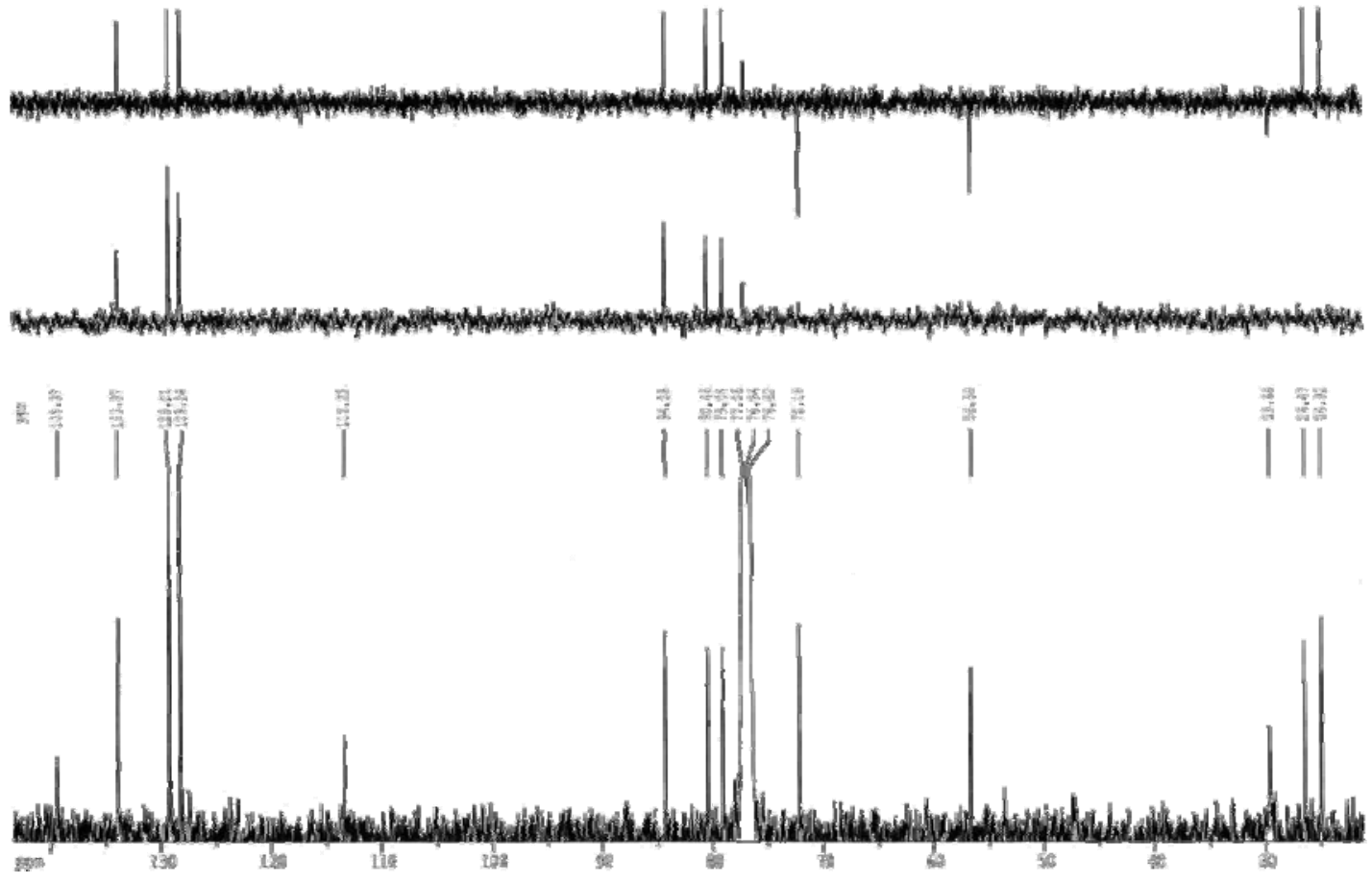
Fig. 74a

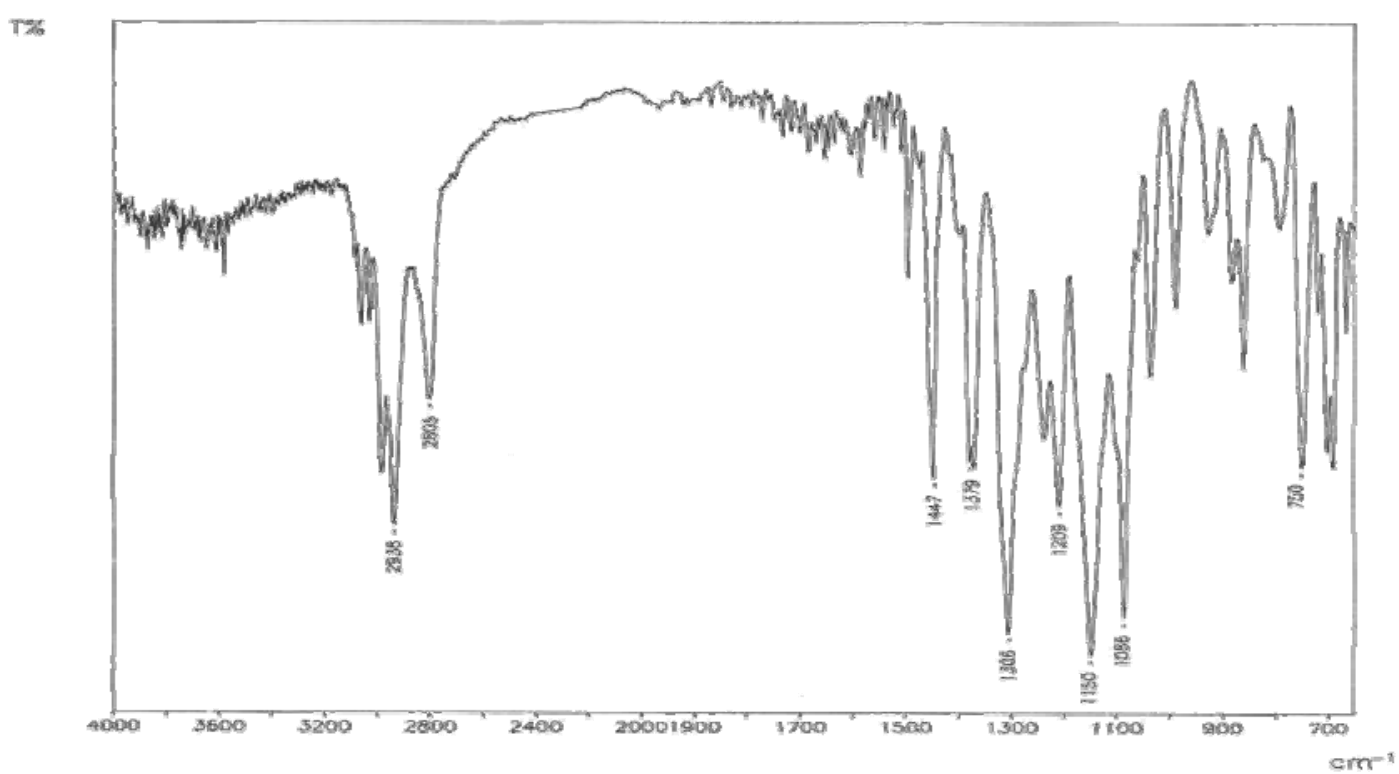

Fig. 74b

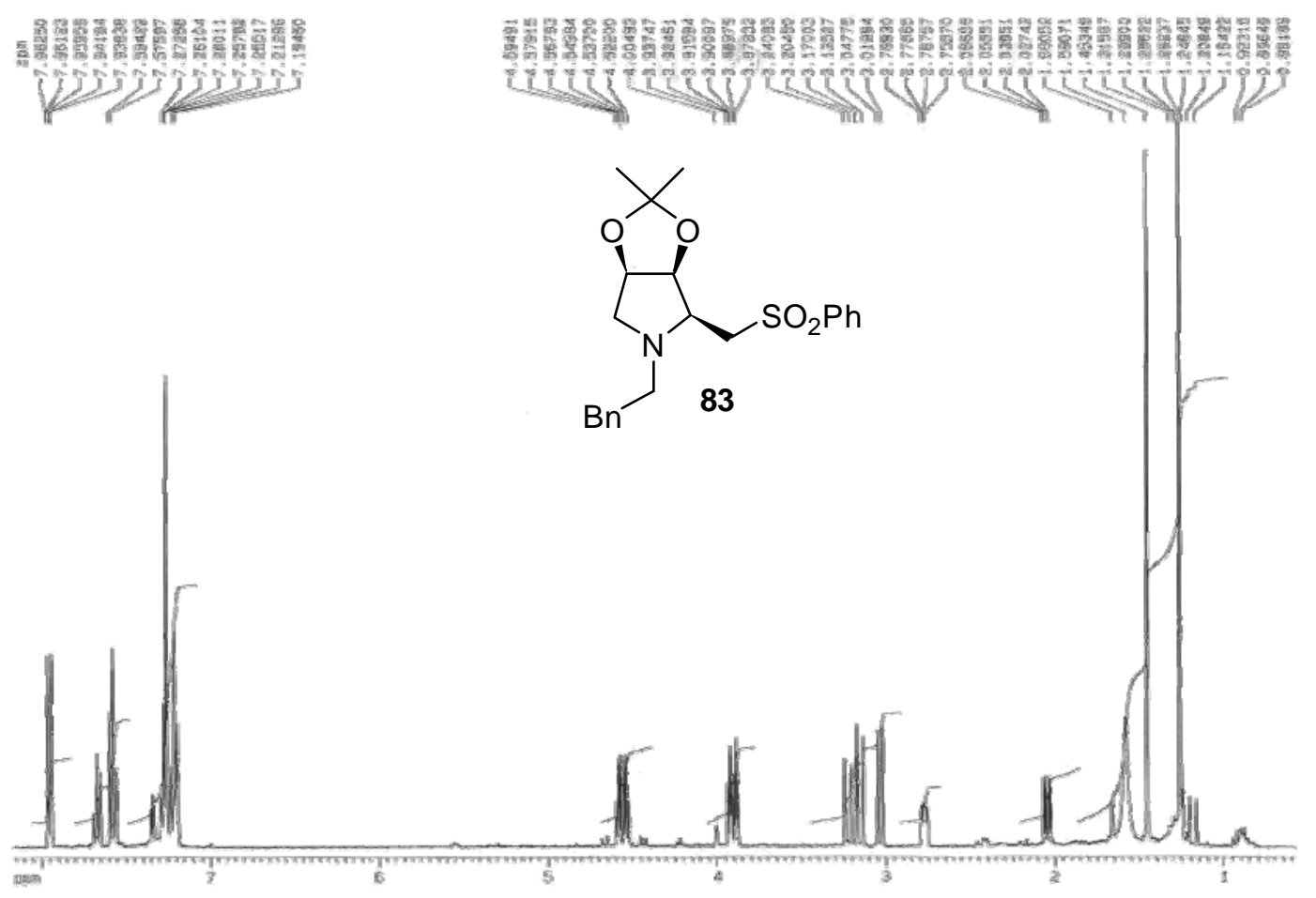


Fig. 74c

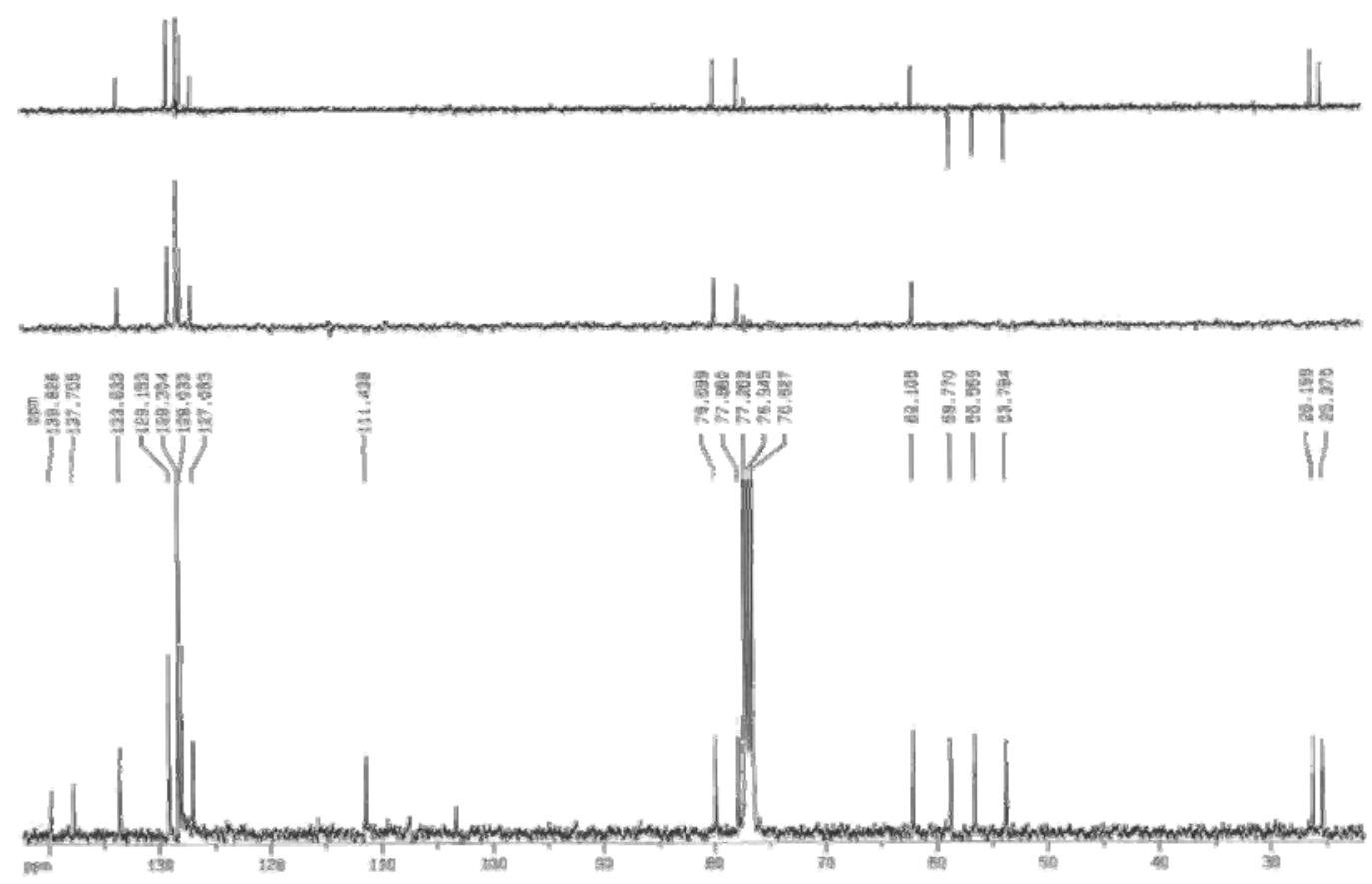

Fig. 74d

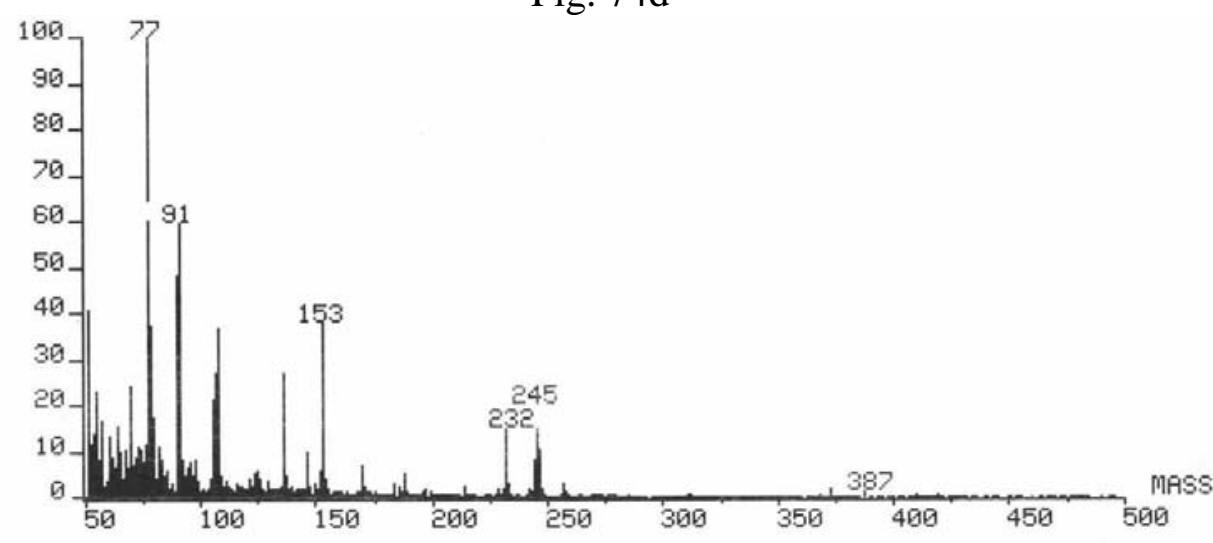

Fig. $74 \mathrm{e}$

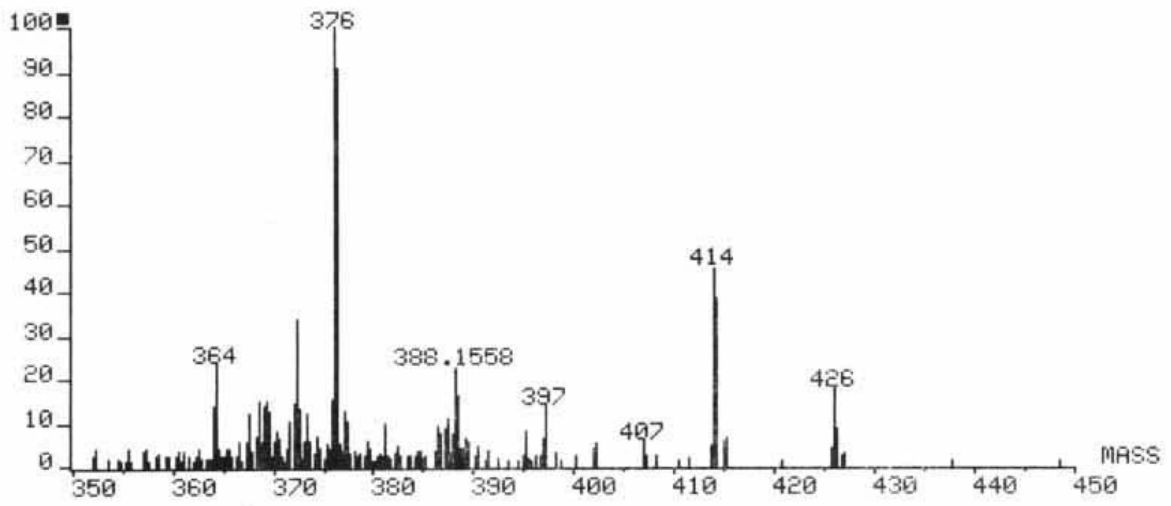


Fig. 74f-COSY

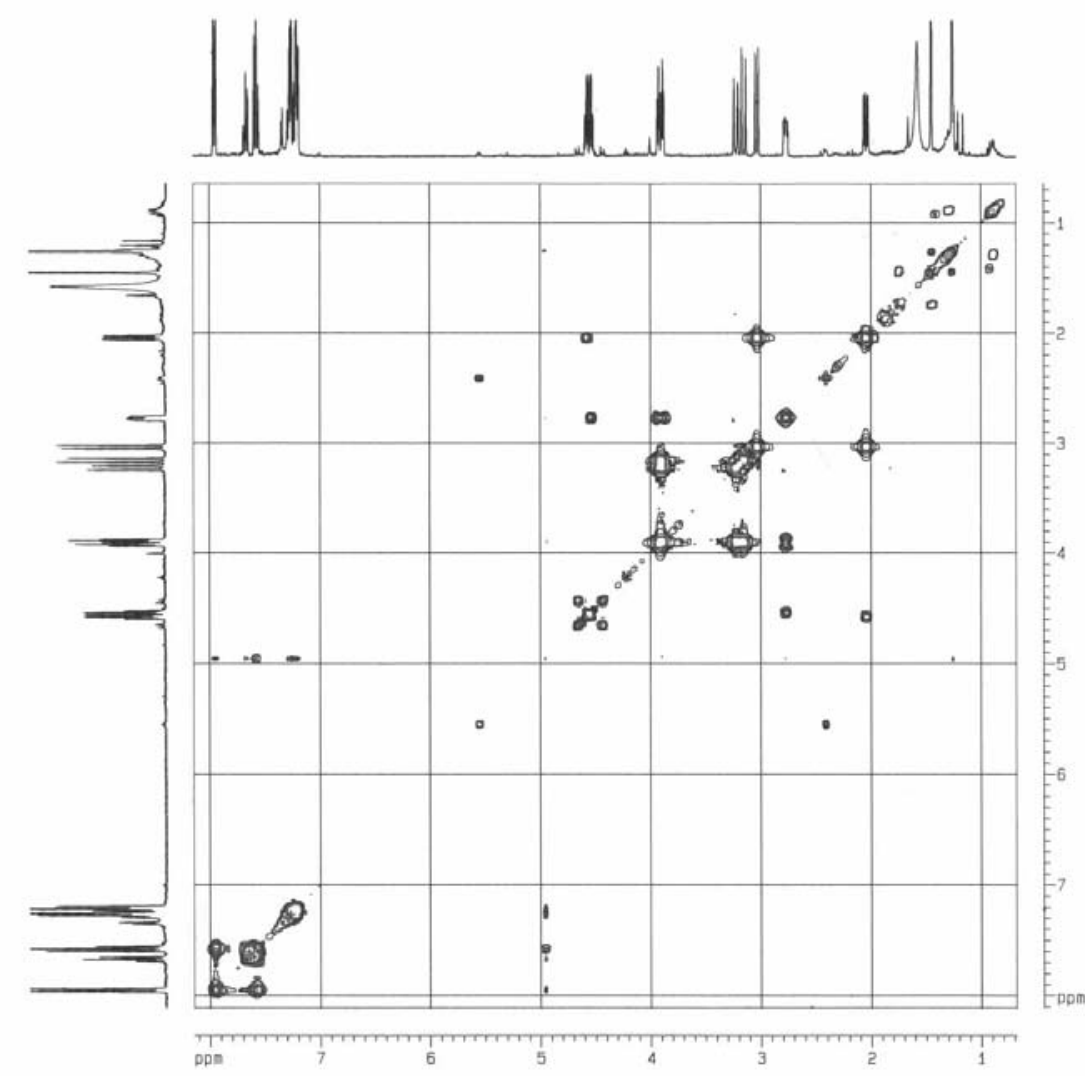

Fig. 74g-HMQC

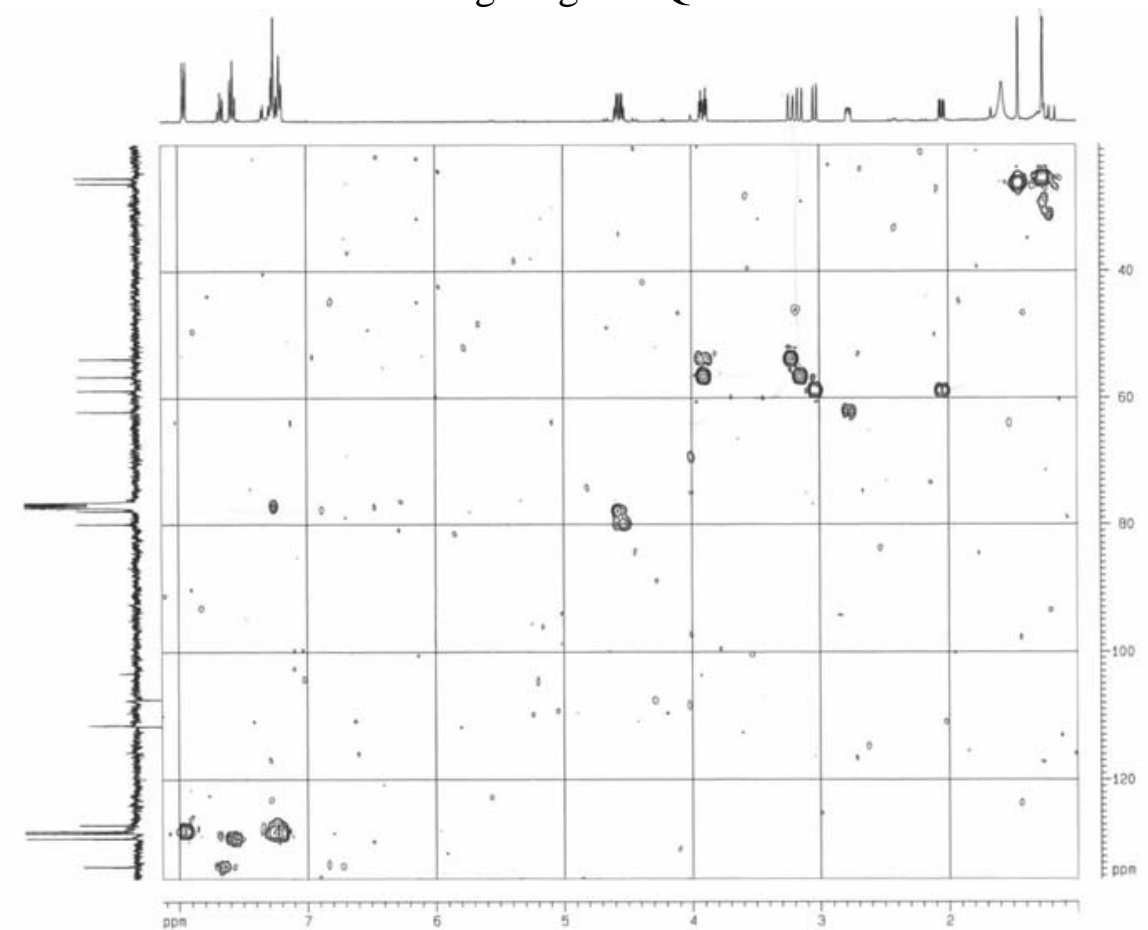


Fig. $75 a$

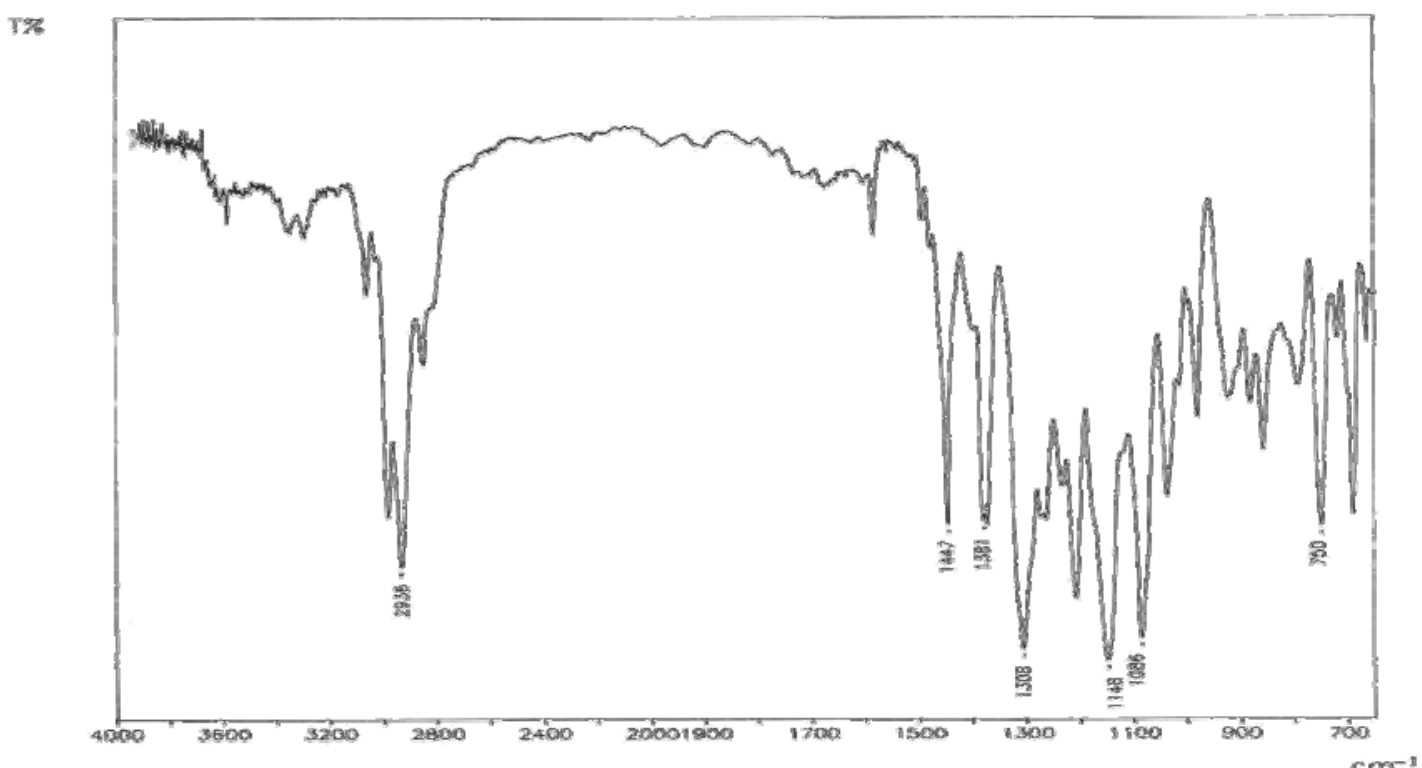

Fig. $75 b$
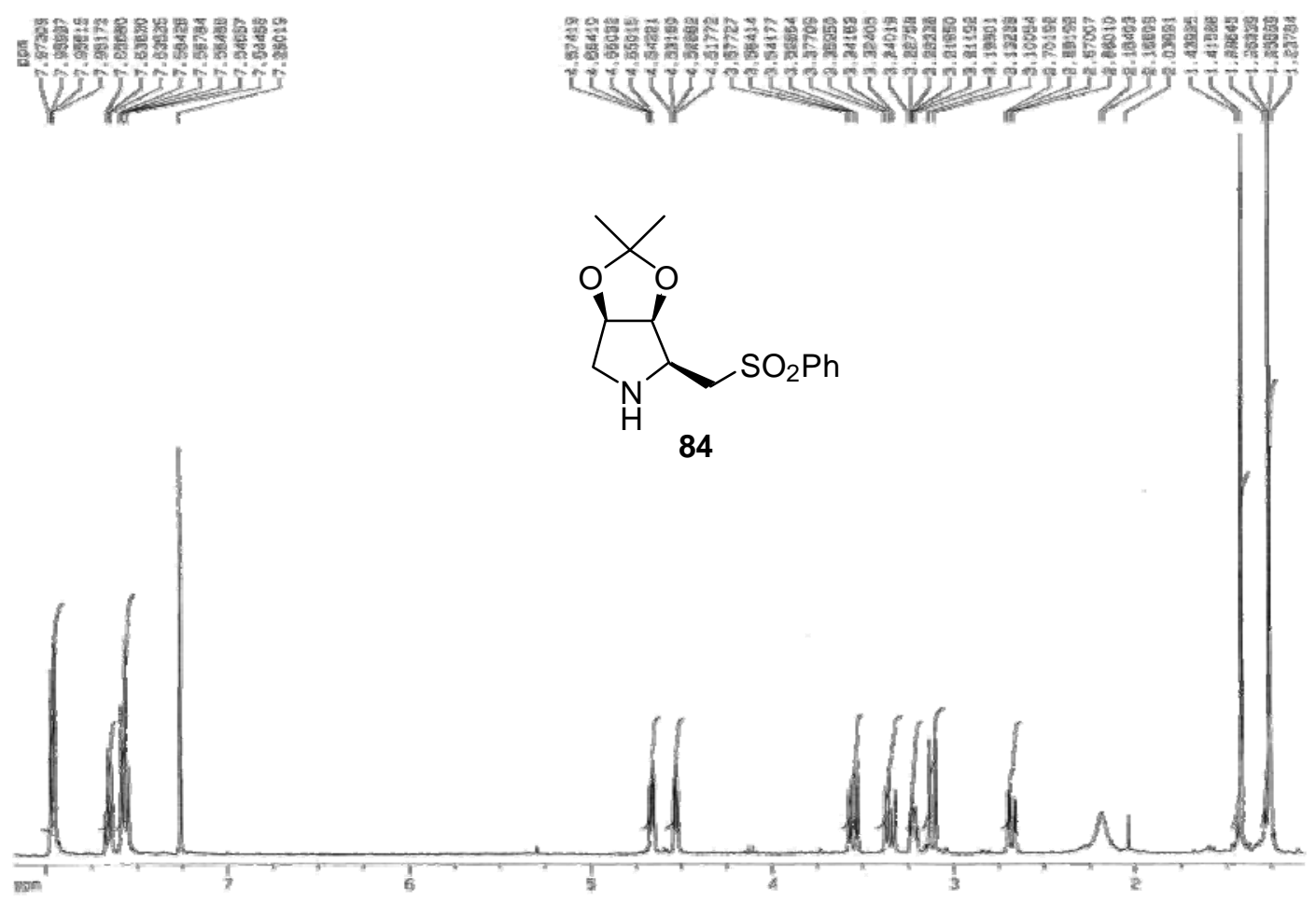
Fig. $75 c$

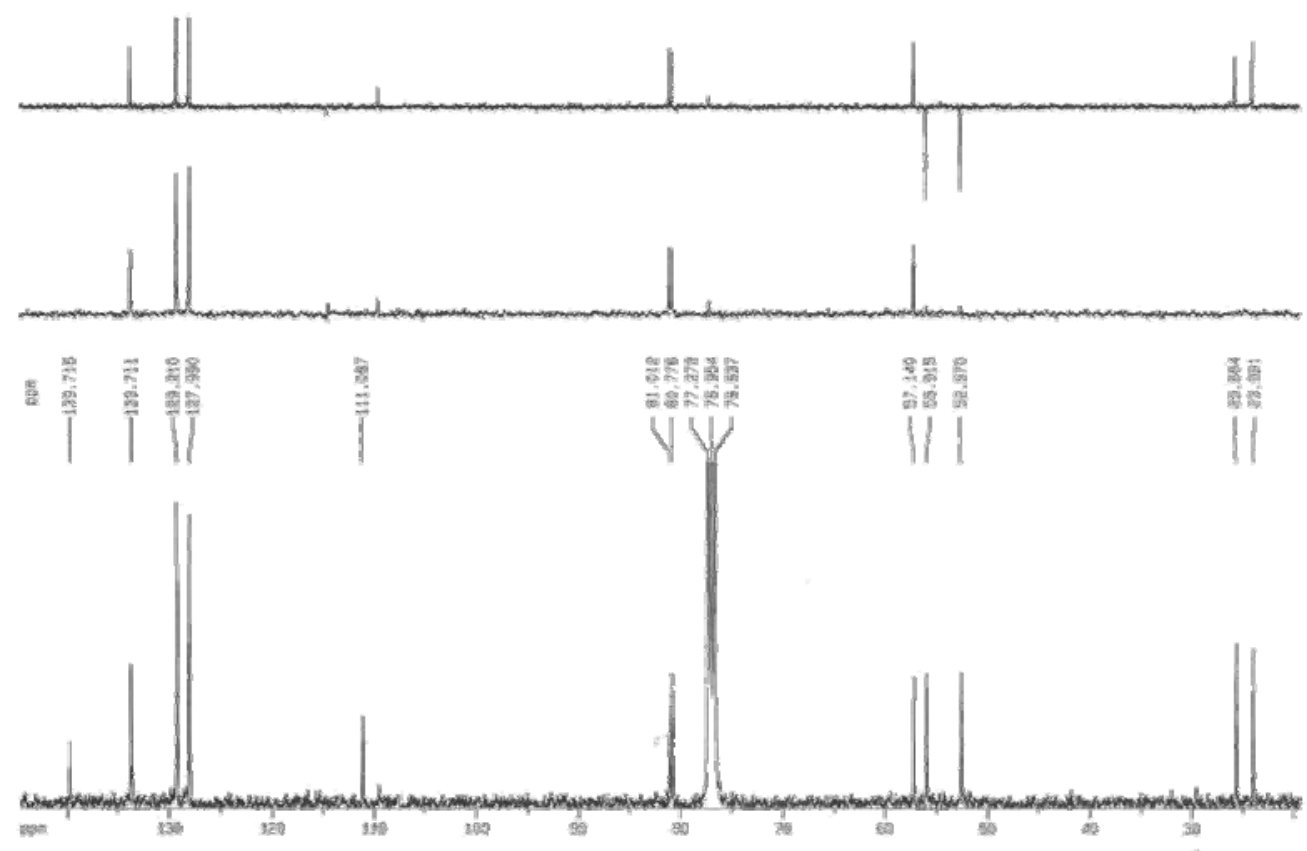

Fig. 75d

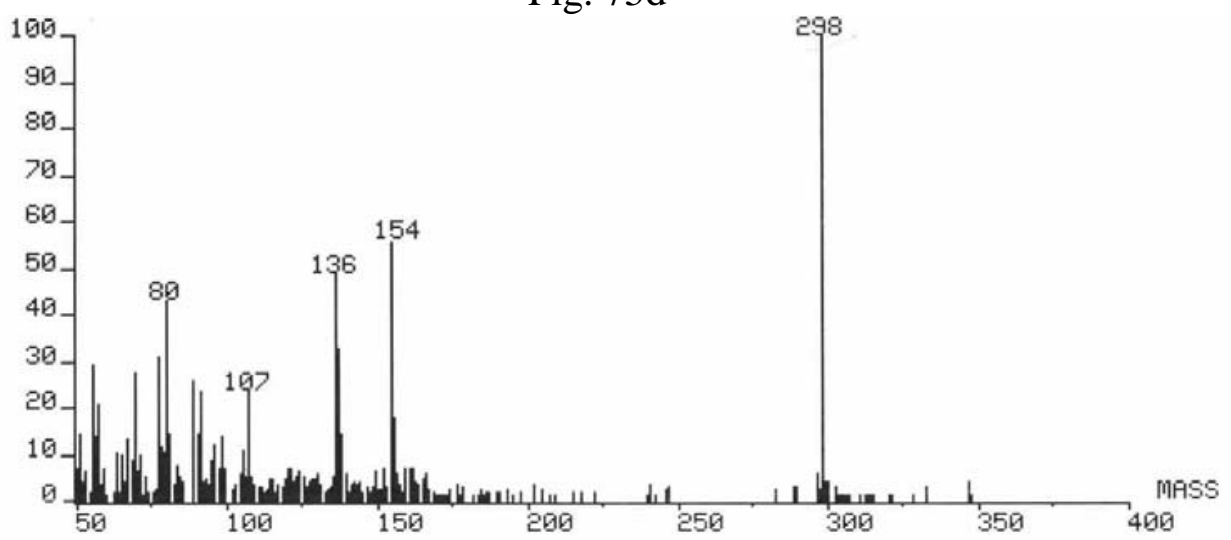

Fig. 75e

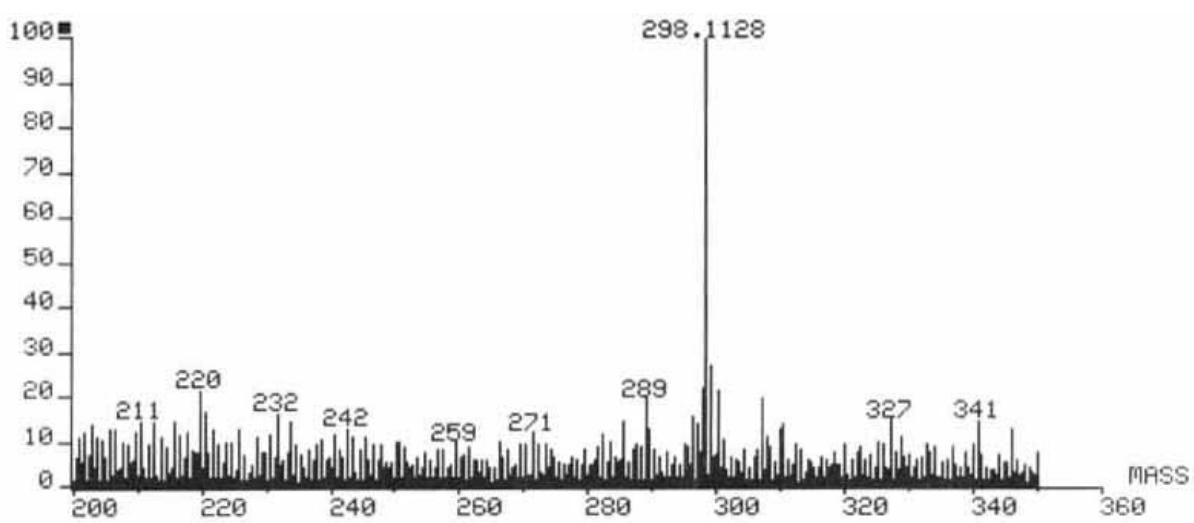


Fig. 75f-COSY

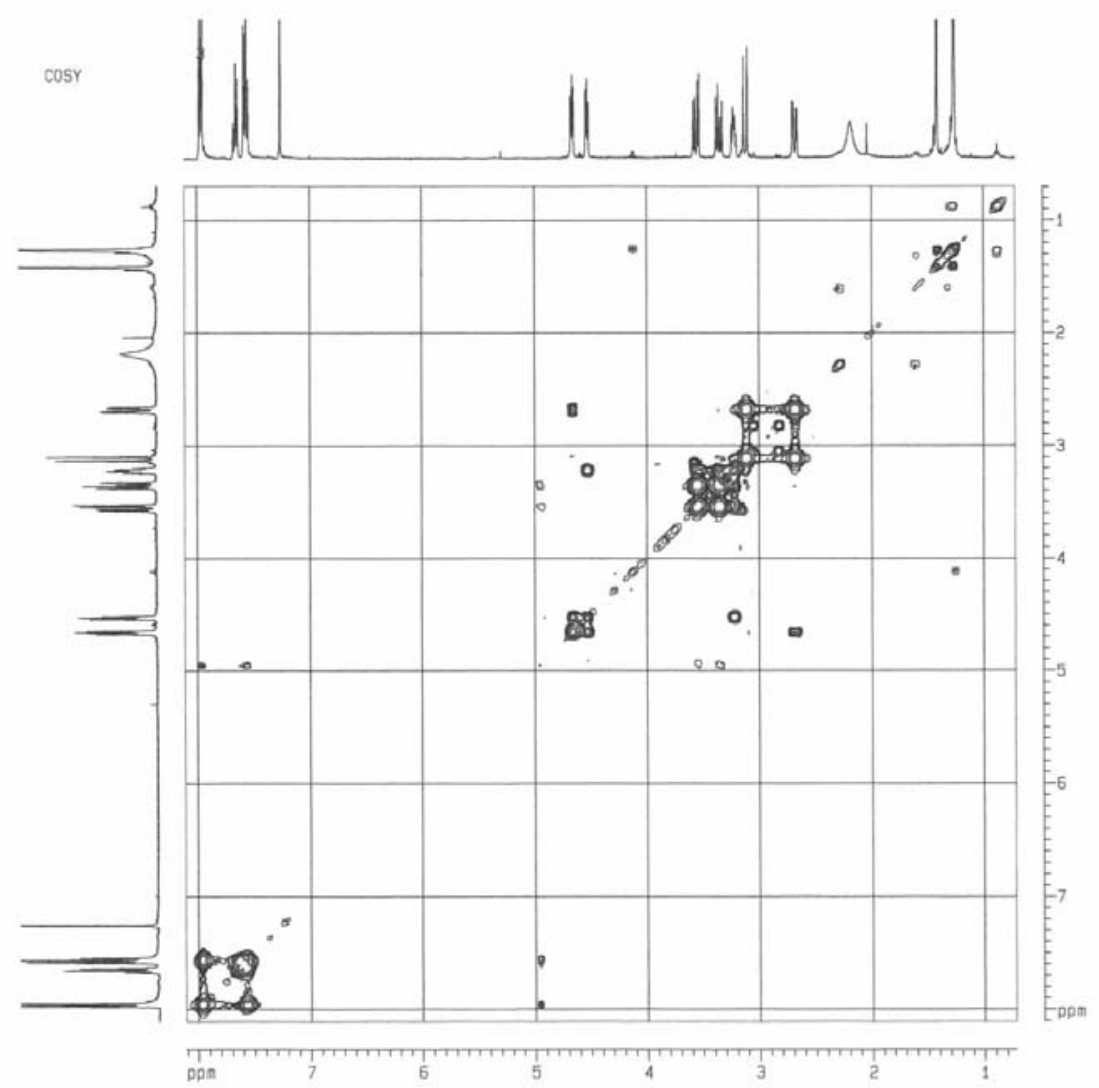

Fig. 75g-HMQC

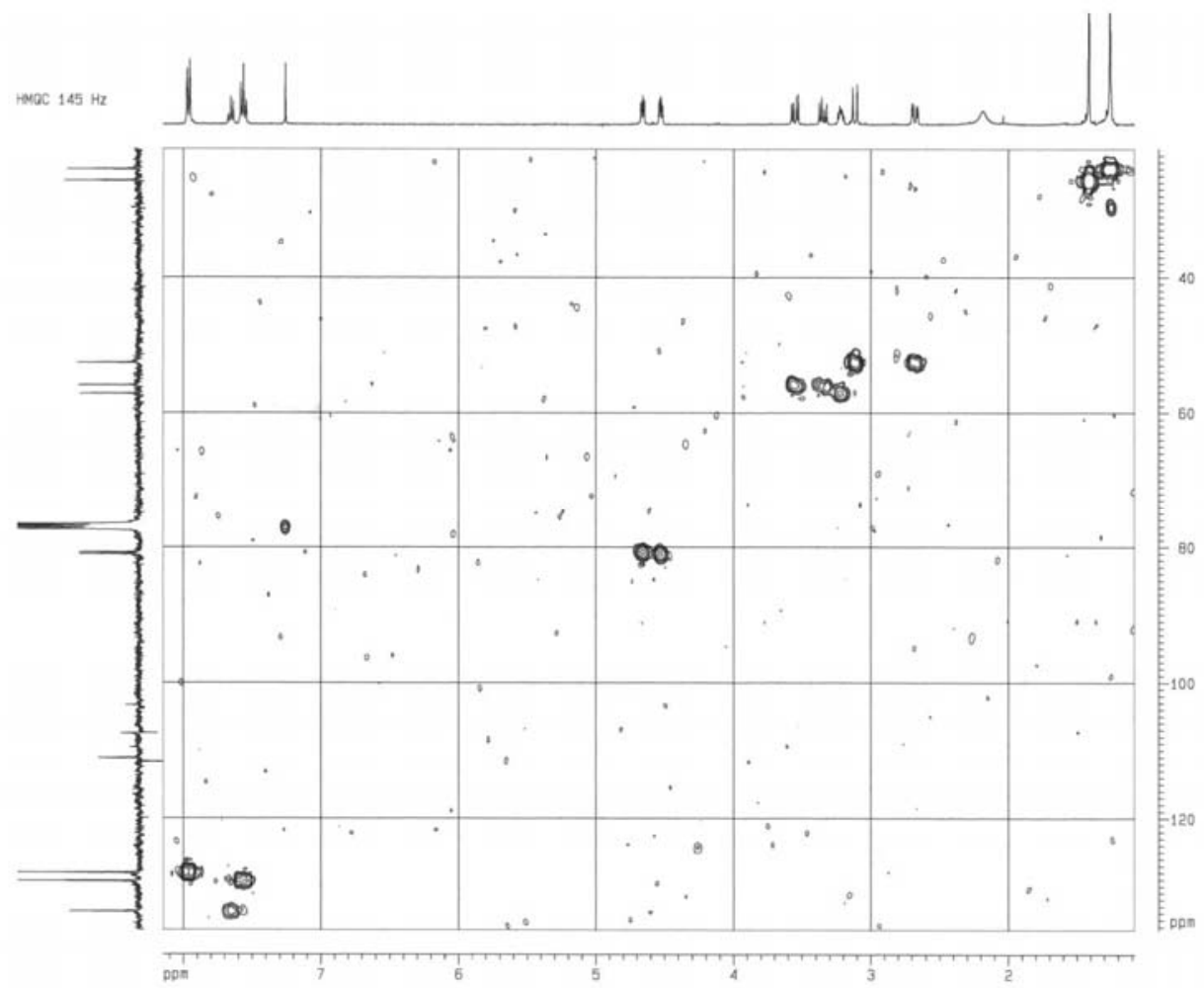


Fig. 75h-HMBC

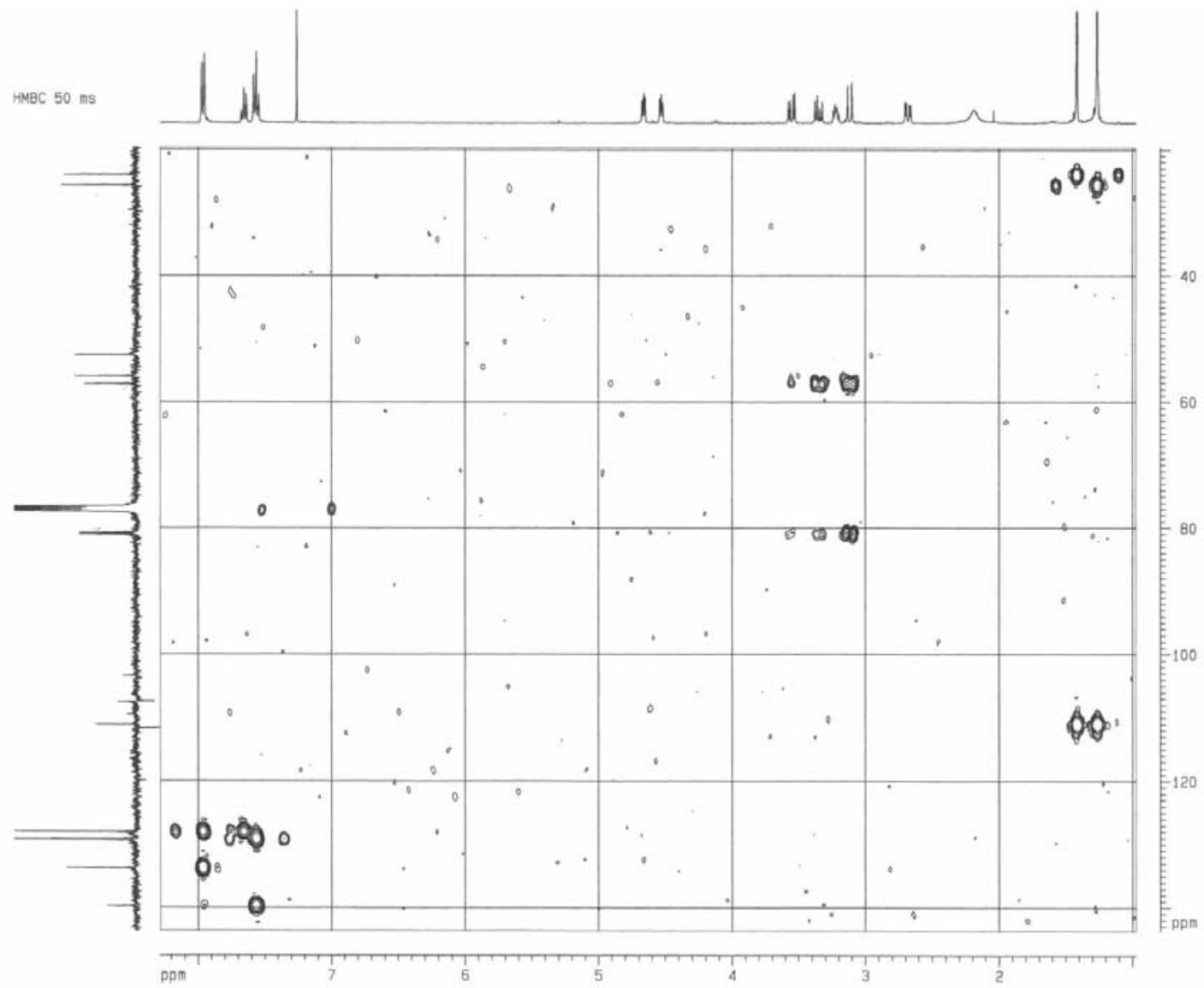


Fig. $76 a$

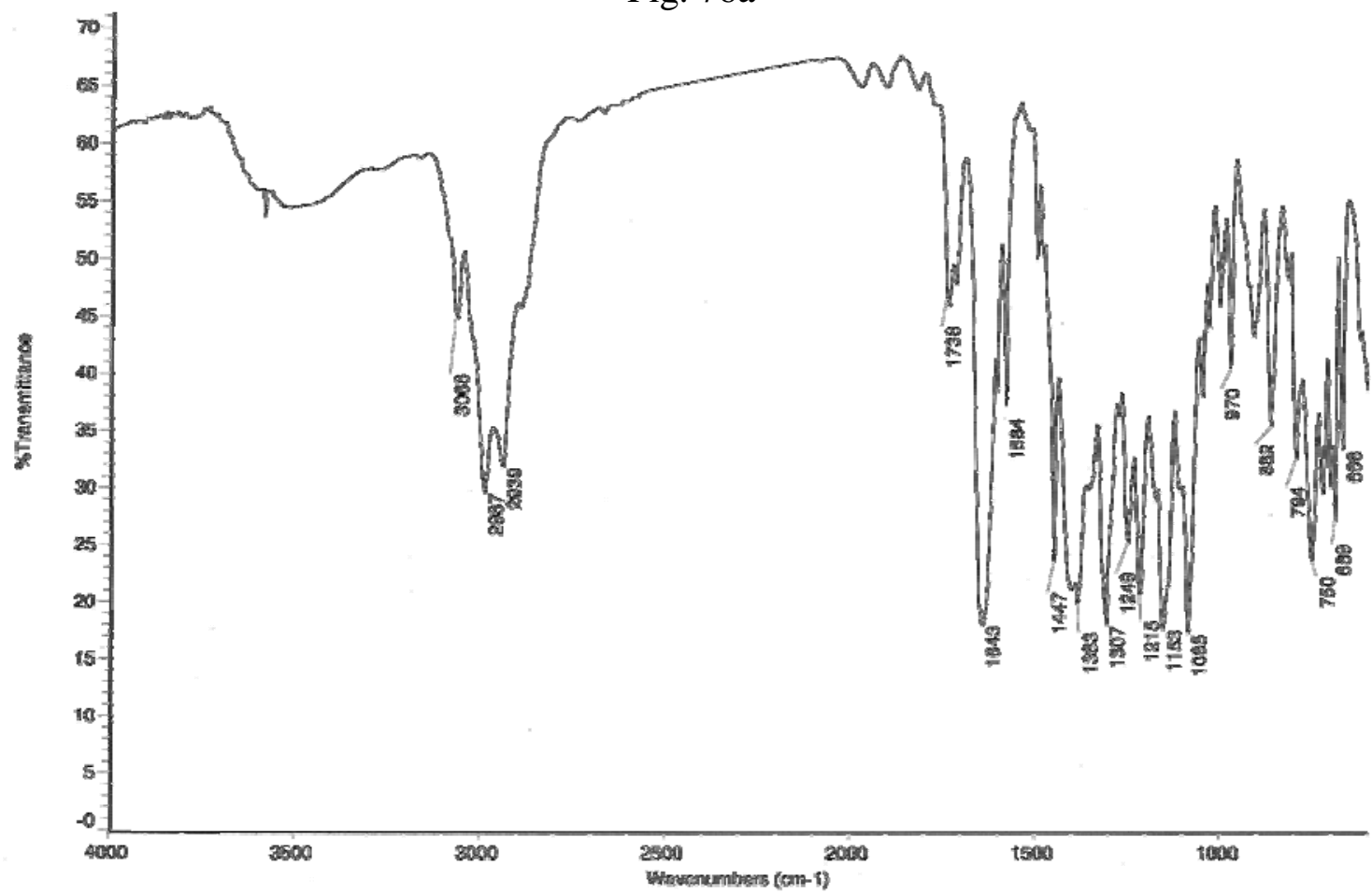

Fig. $76 b$

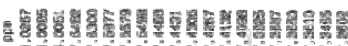

wis

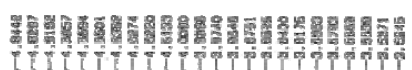

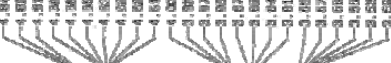

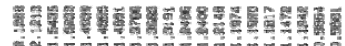
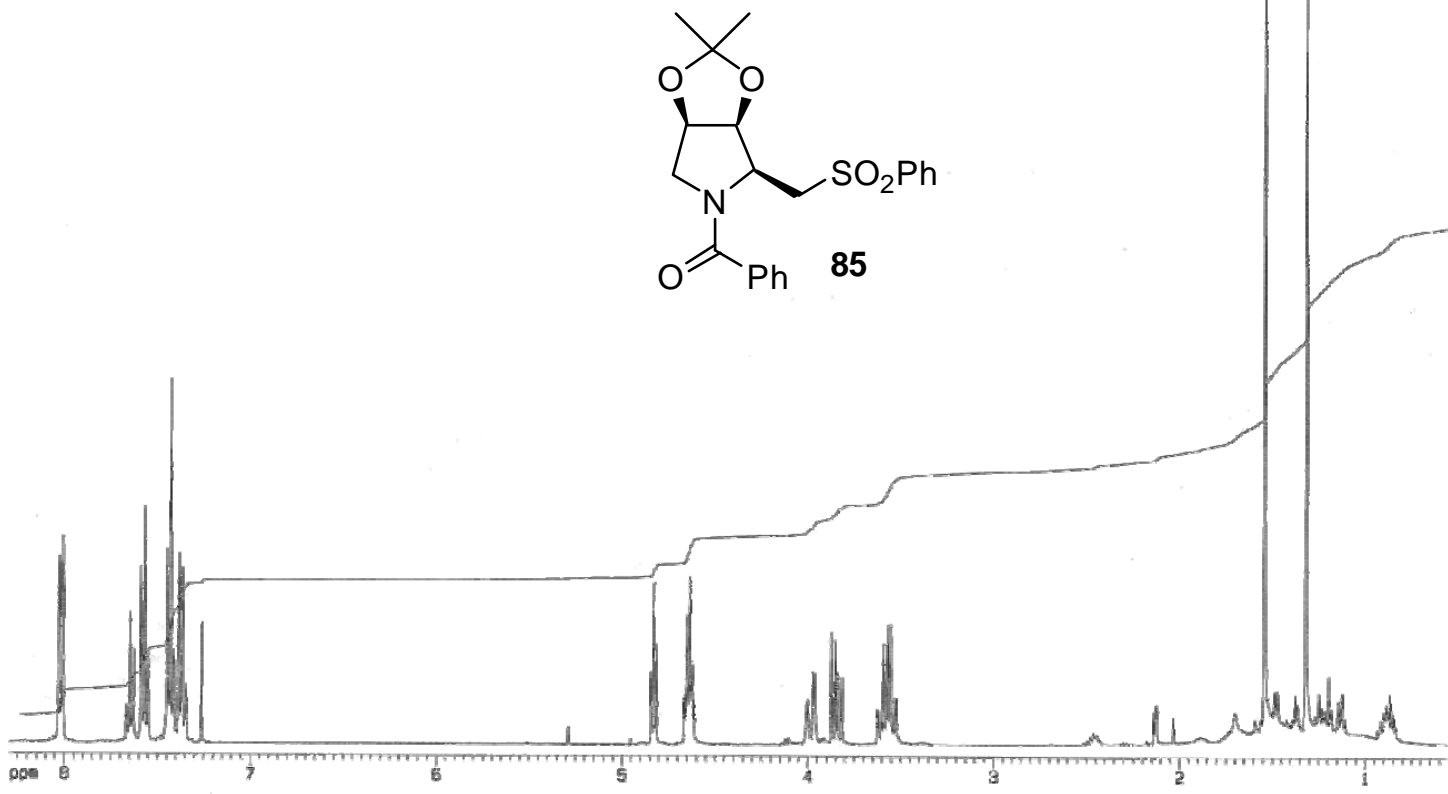
Fig. 76c
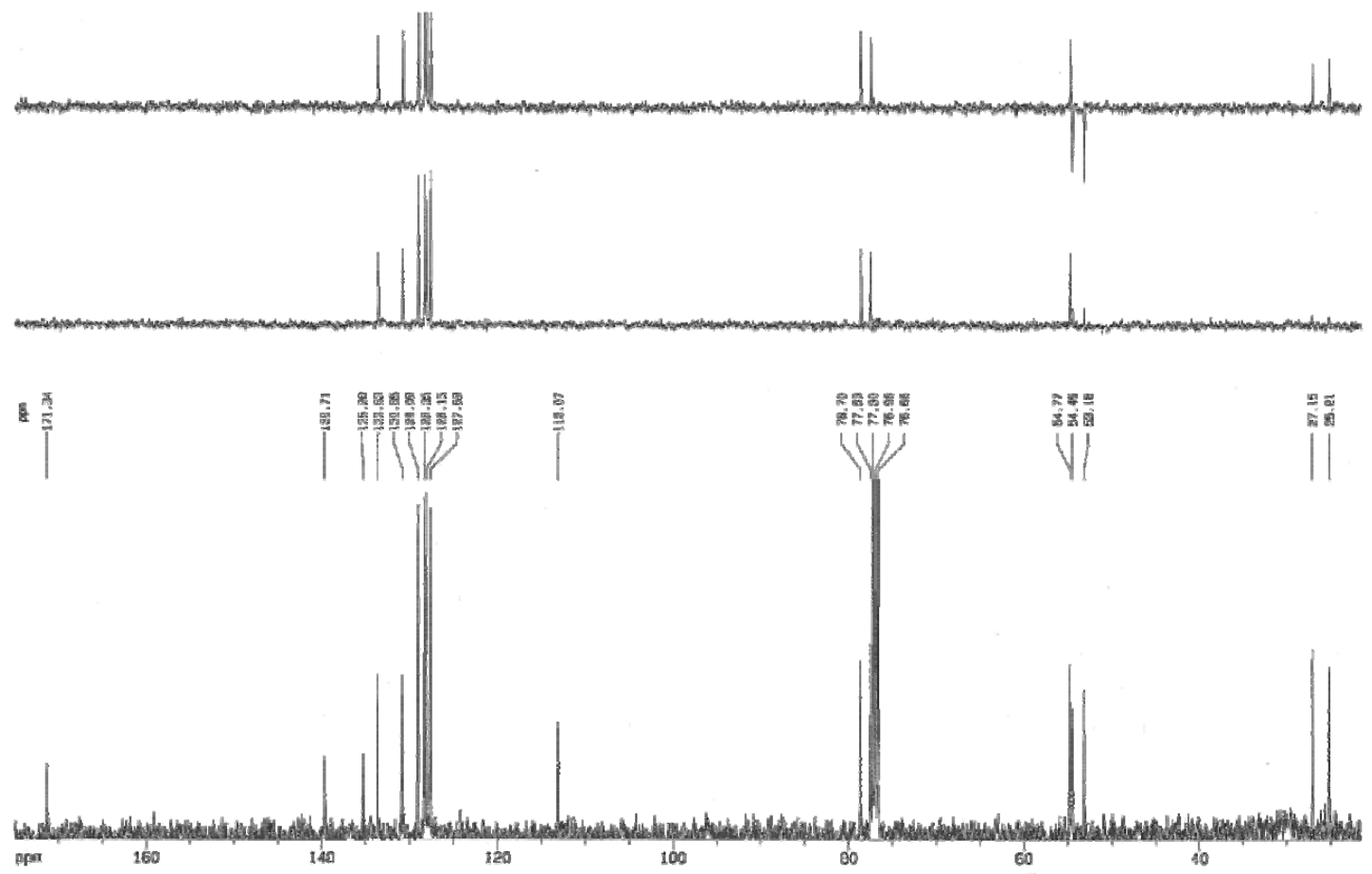

Fig. 76d

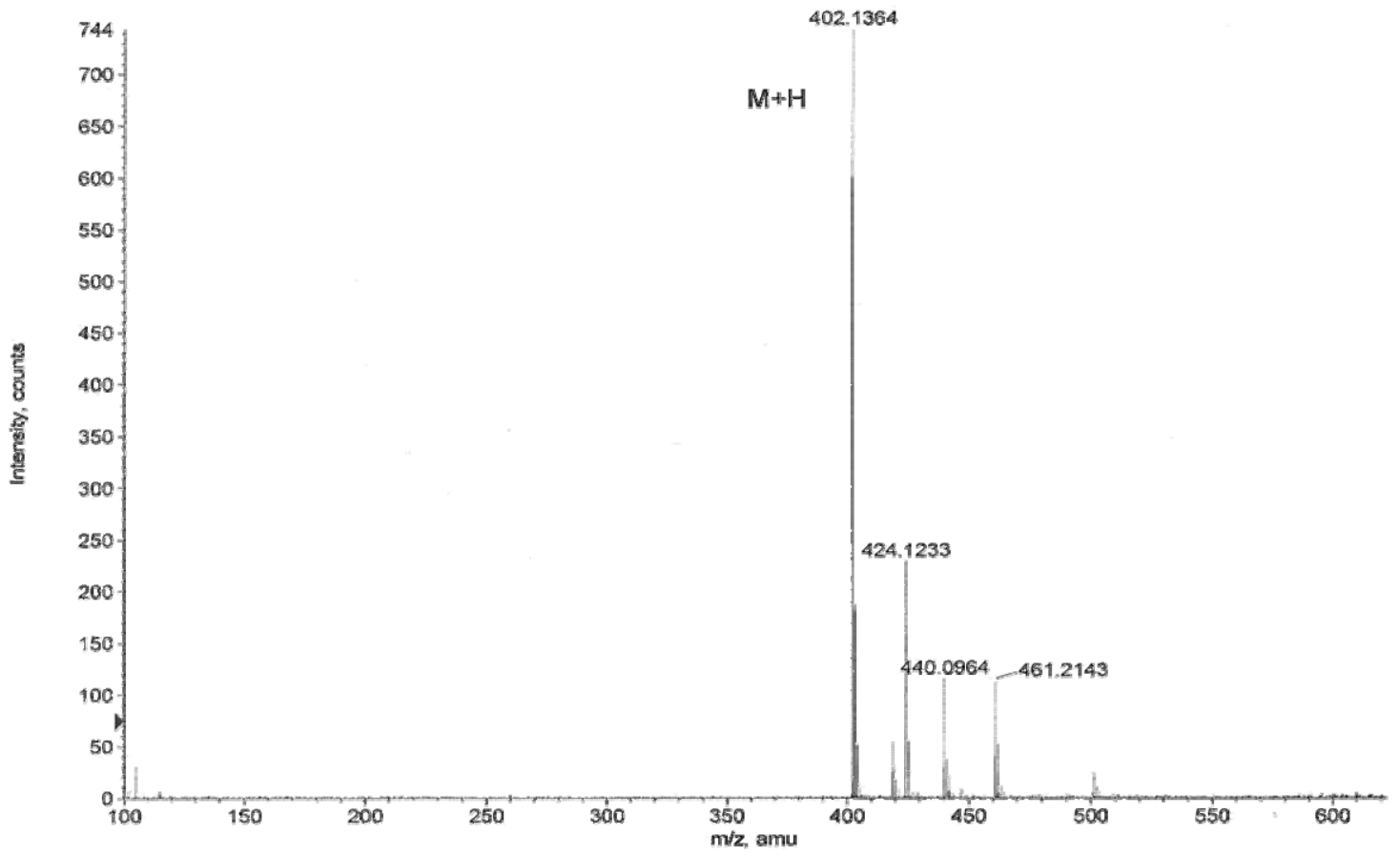


Fig. 76e-HMQC

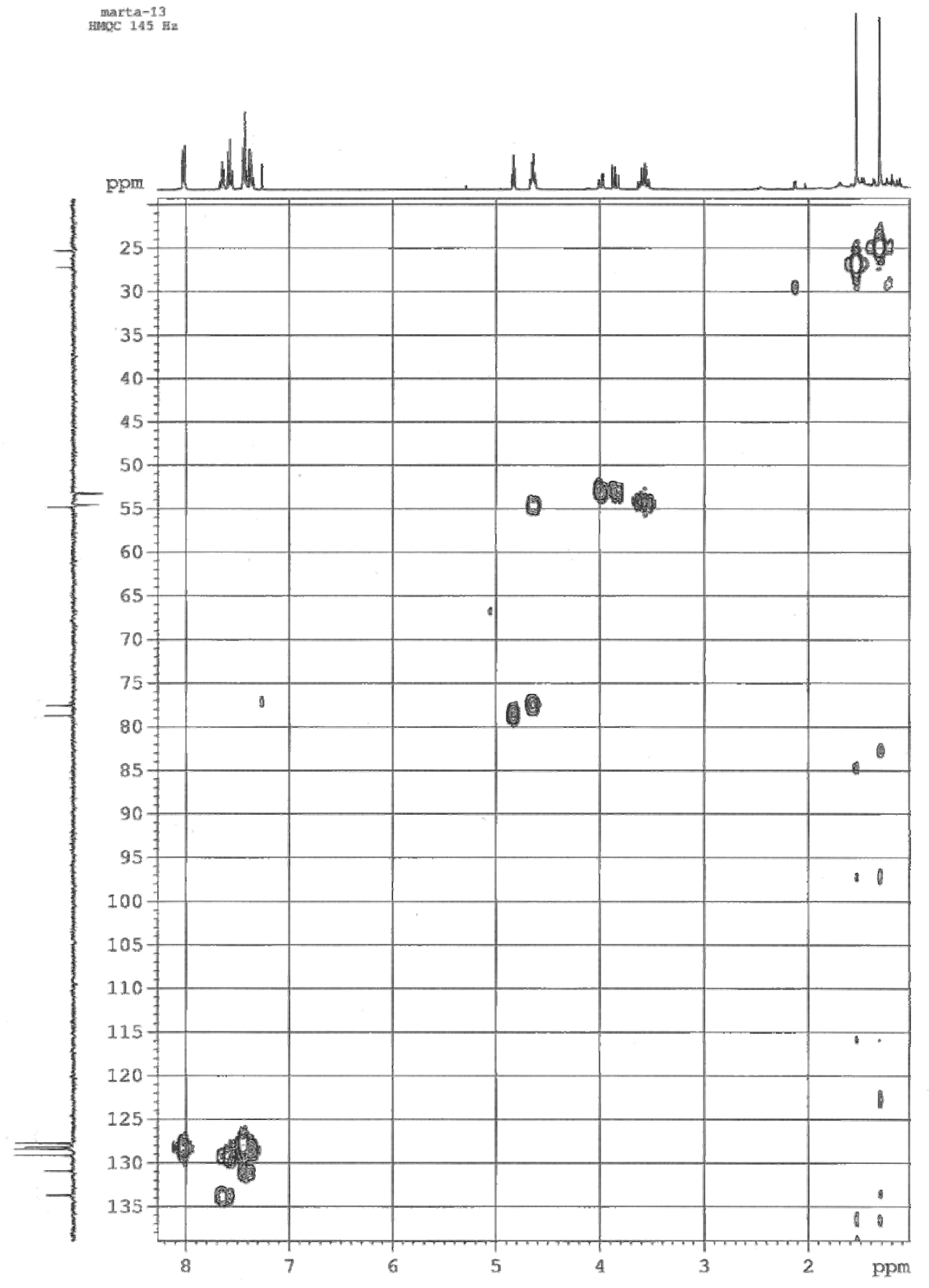


Fig. 76f-HMBC

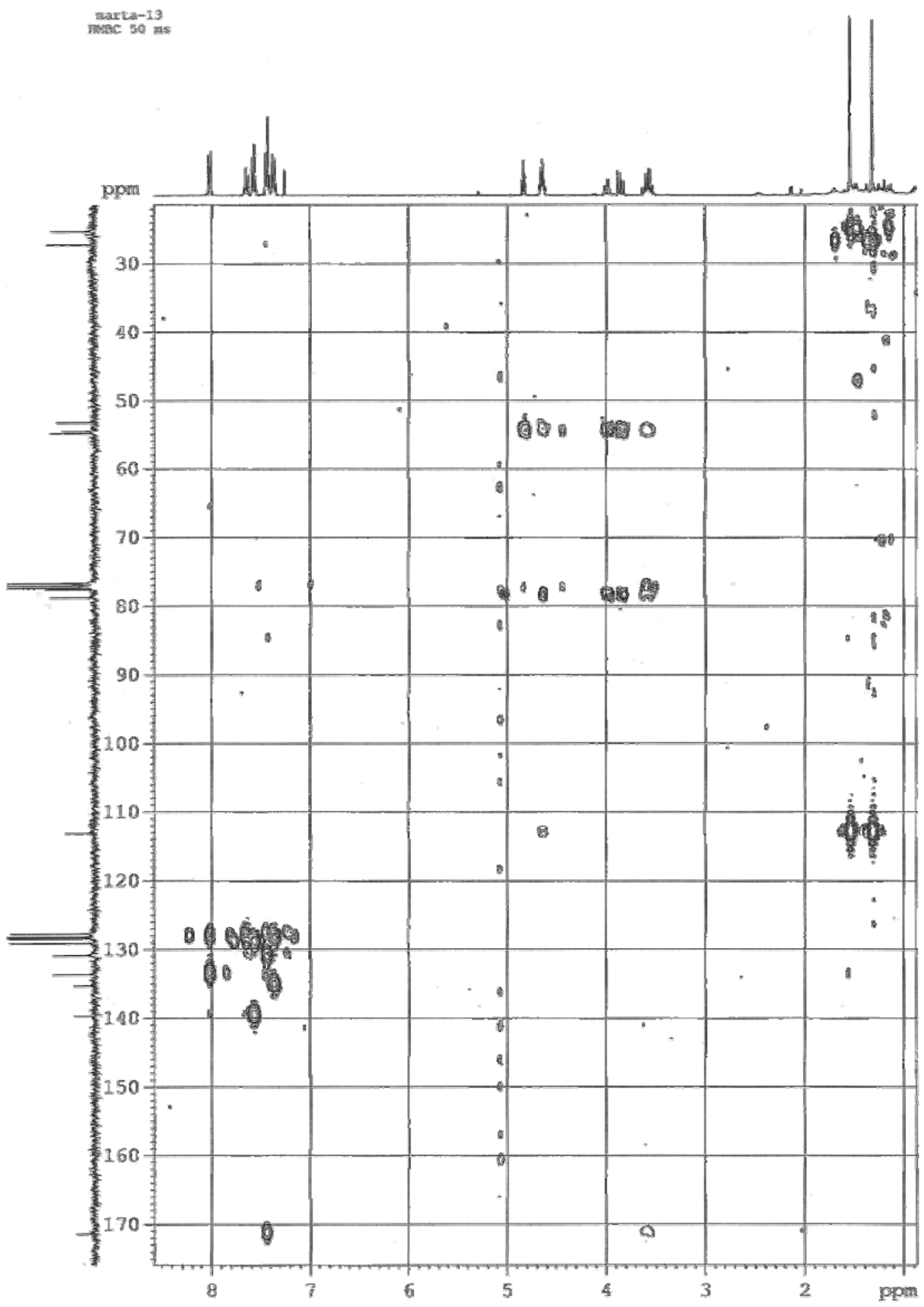


Fig. $77 \mathrm{a}$

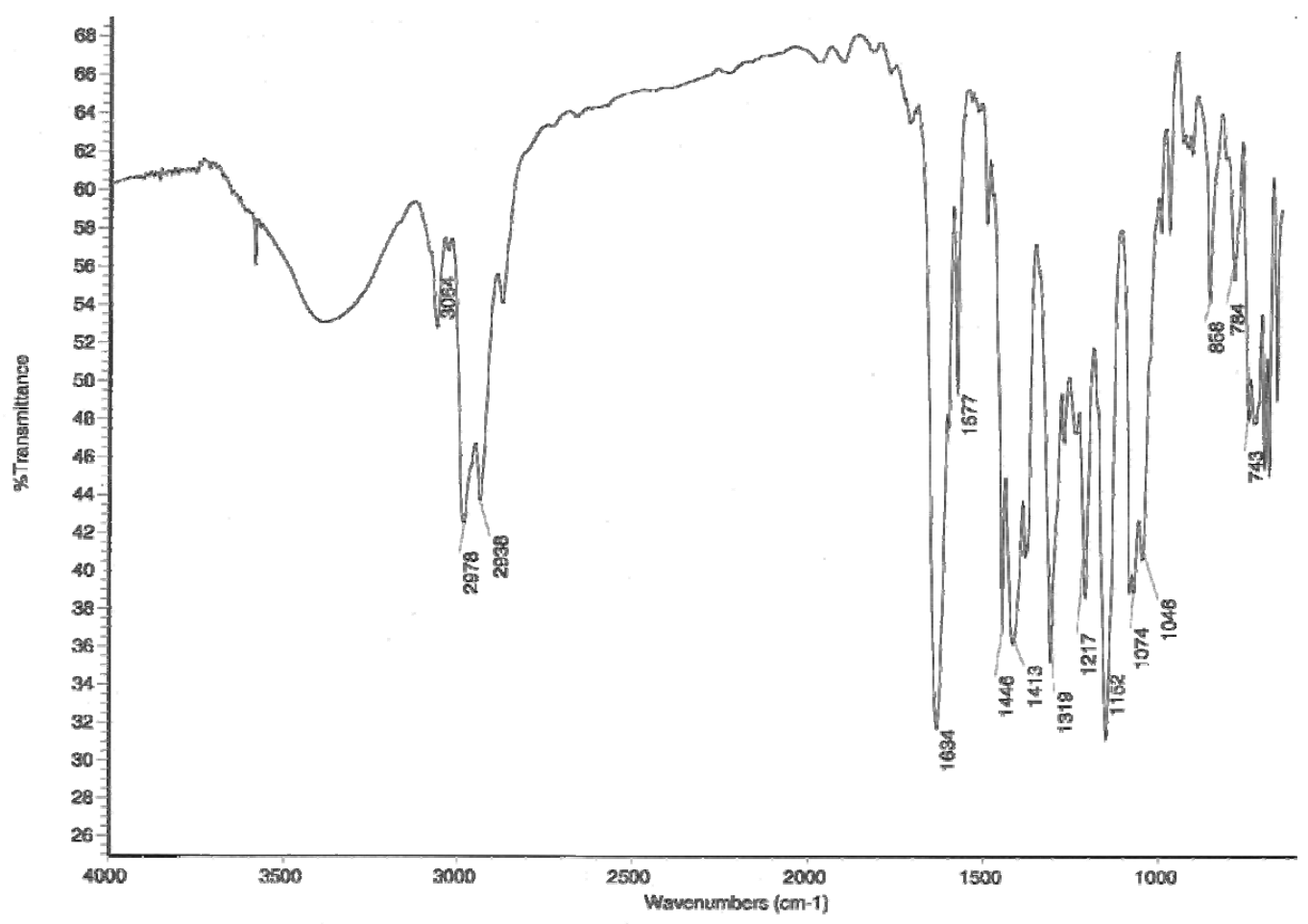

Fig. $77 \mathrm{~b}$

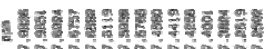

VUVisinisis

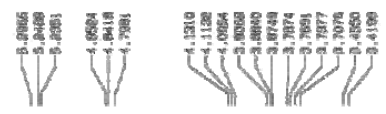

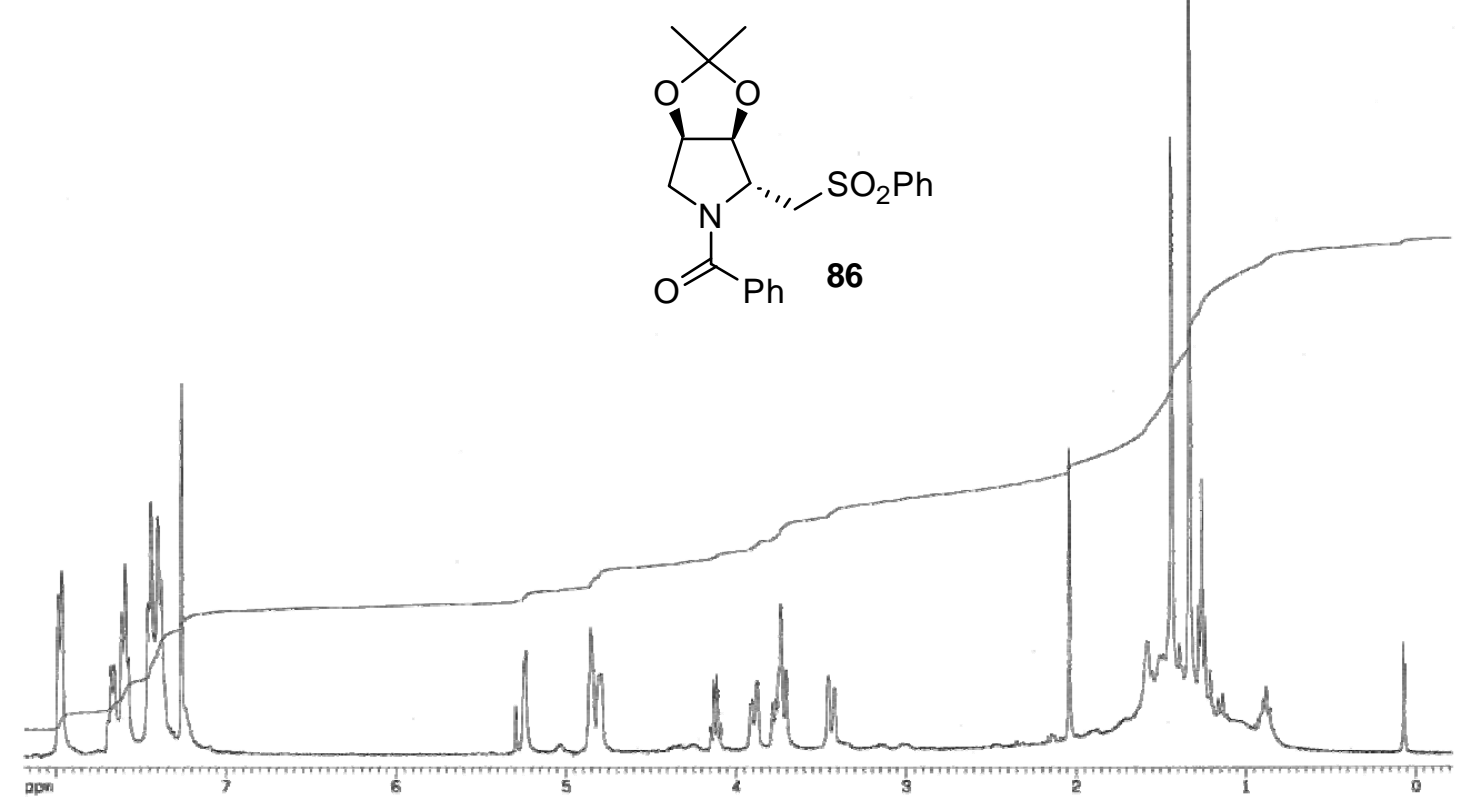

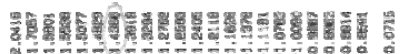

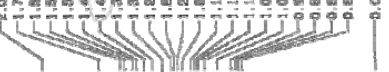


Fig. 77c
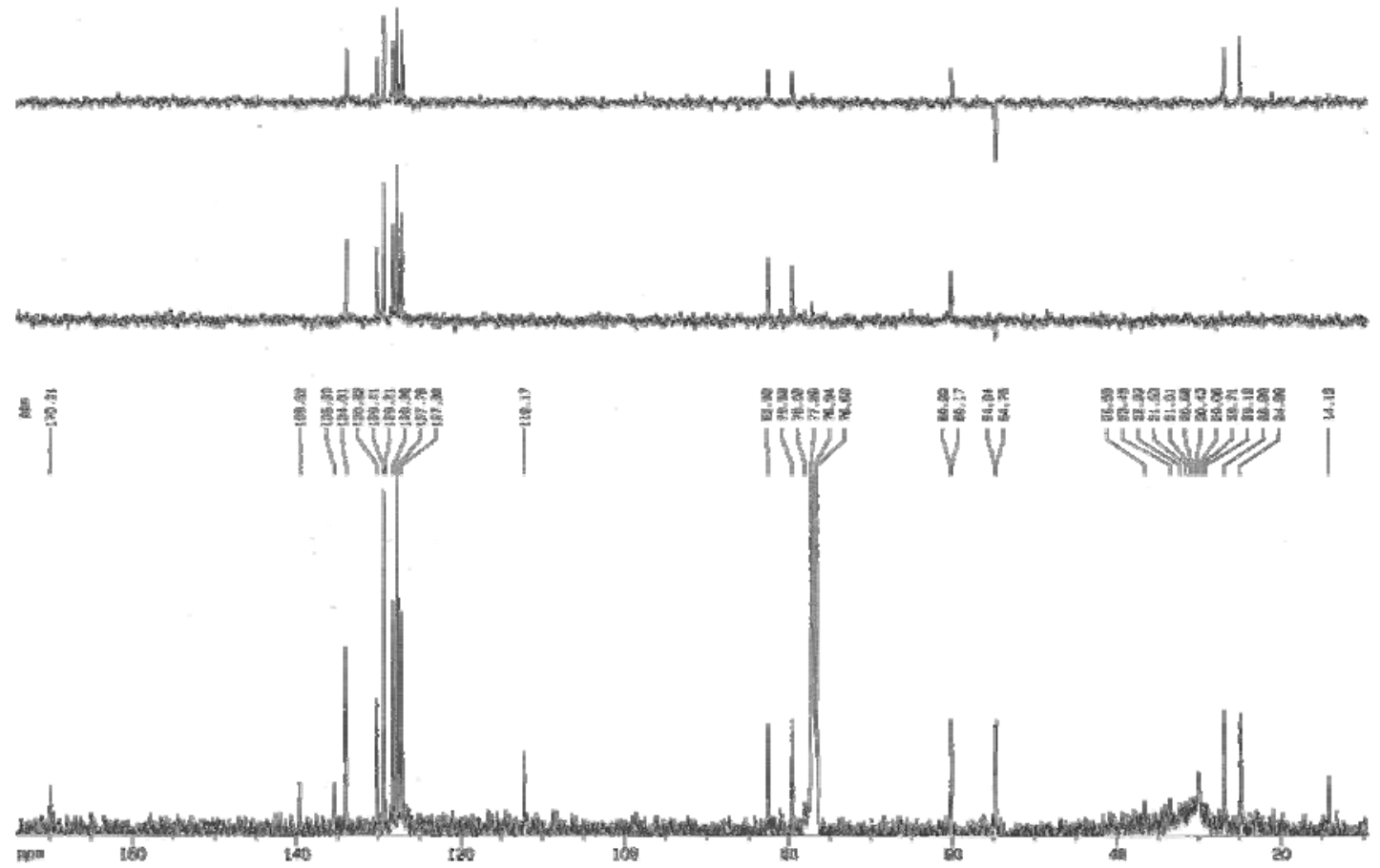

Fig. 77d

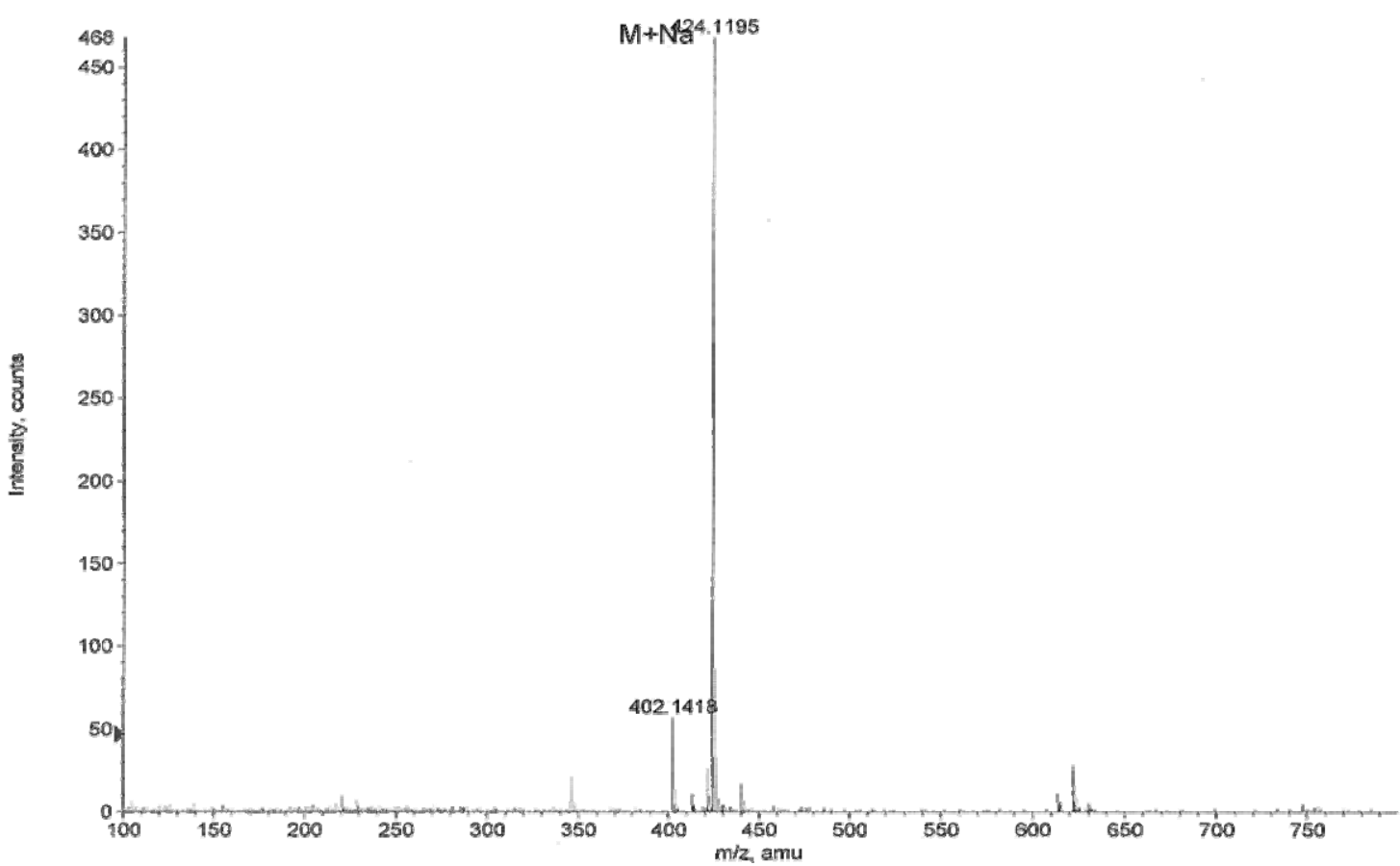


Fig. 77e-HMQC

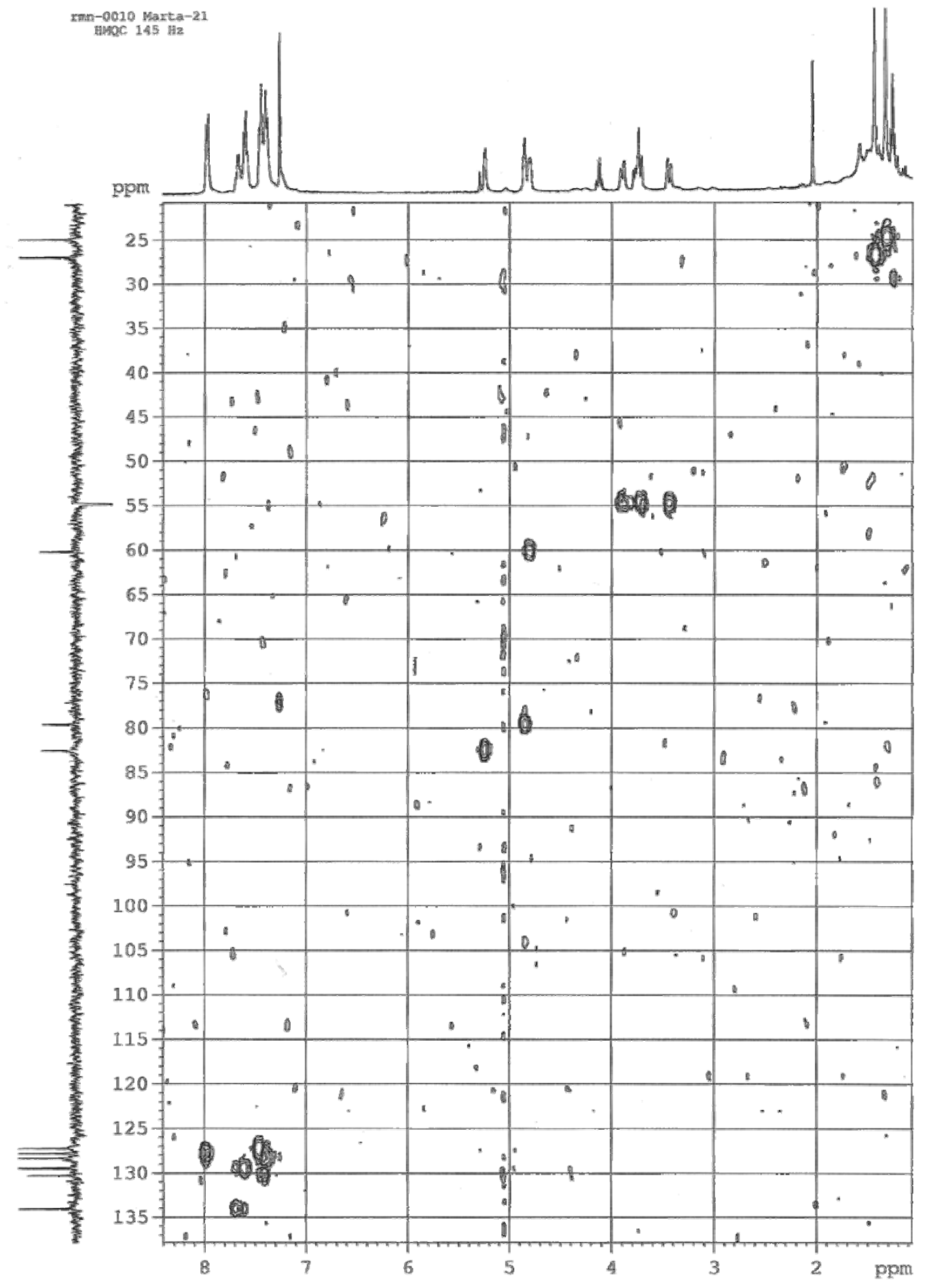


Fig. 77f-HMBC

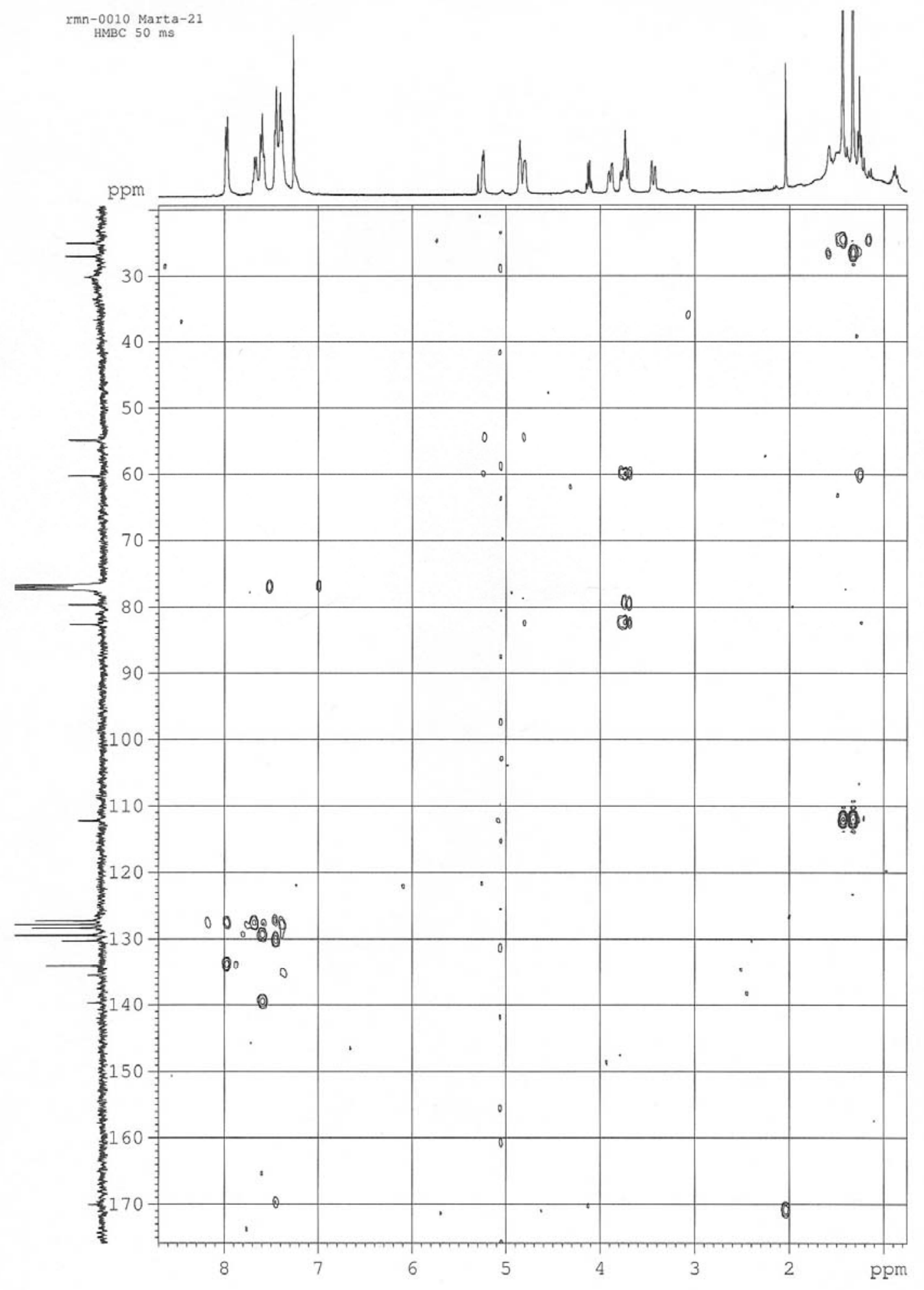


Fig. 78a

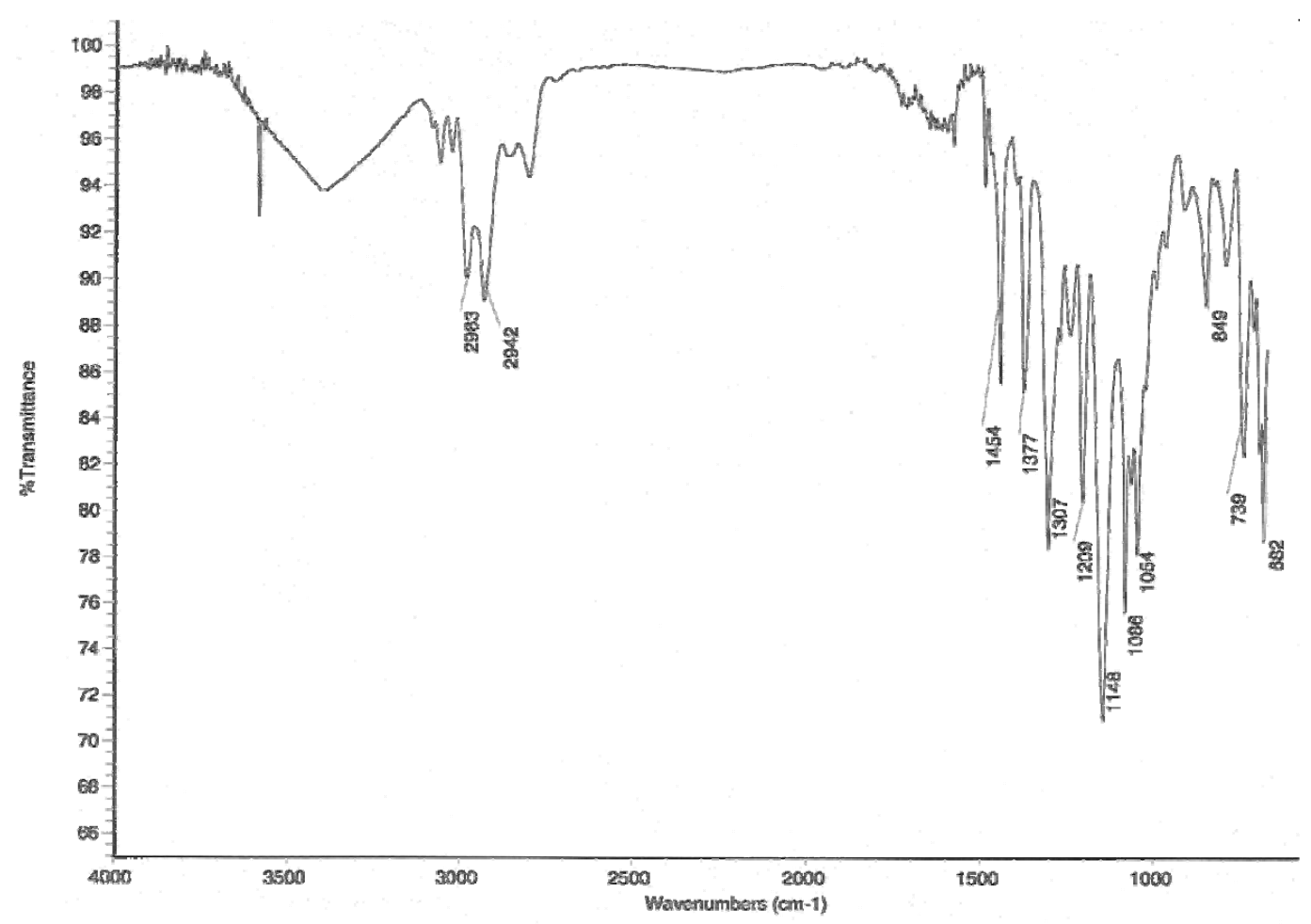

Fig. 78b

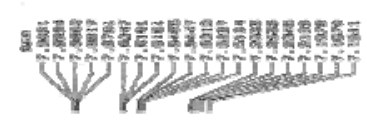

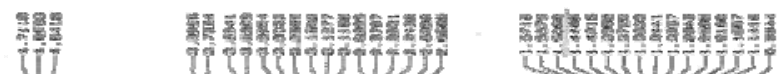
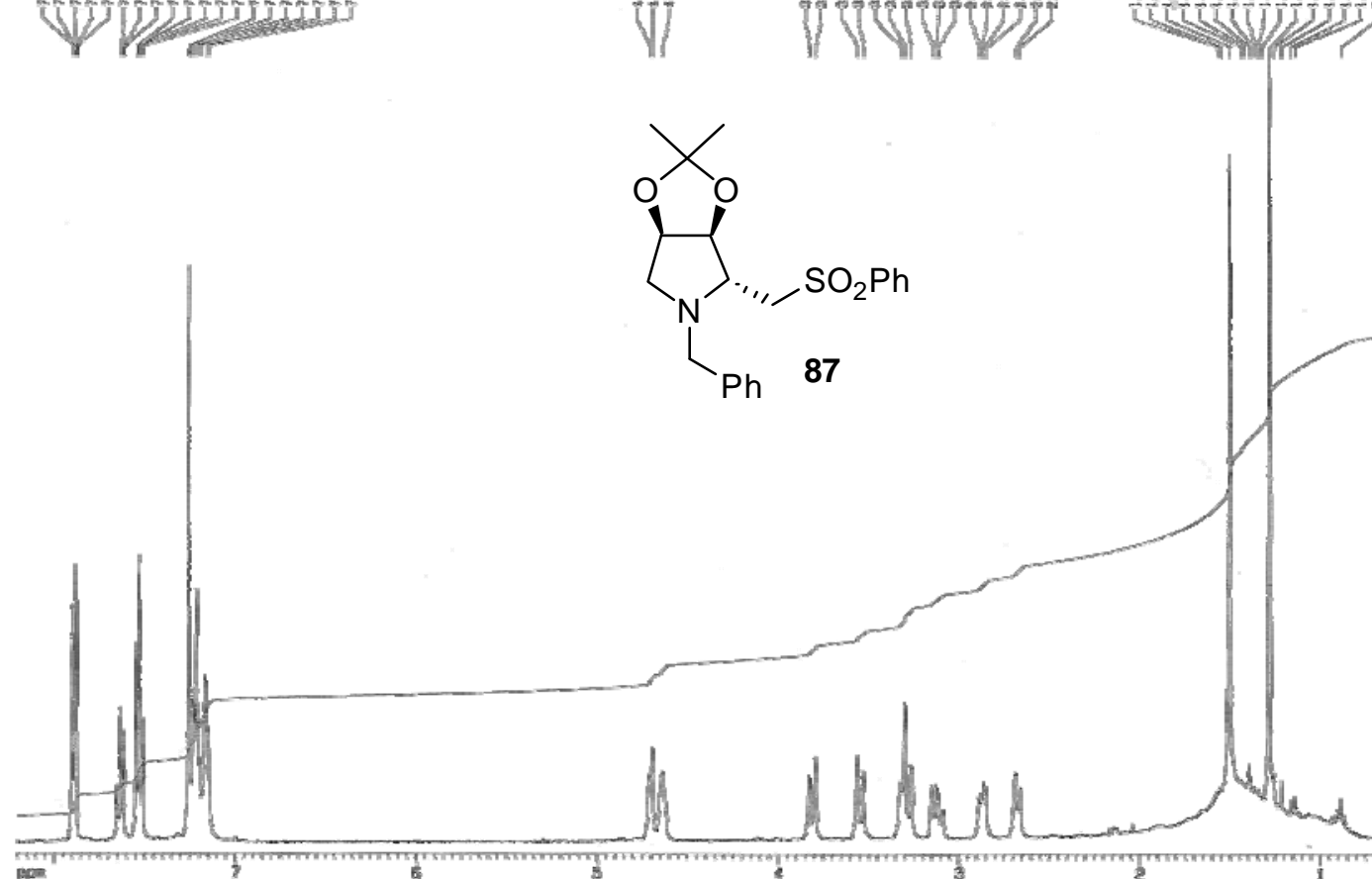
Fig. 78c
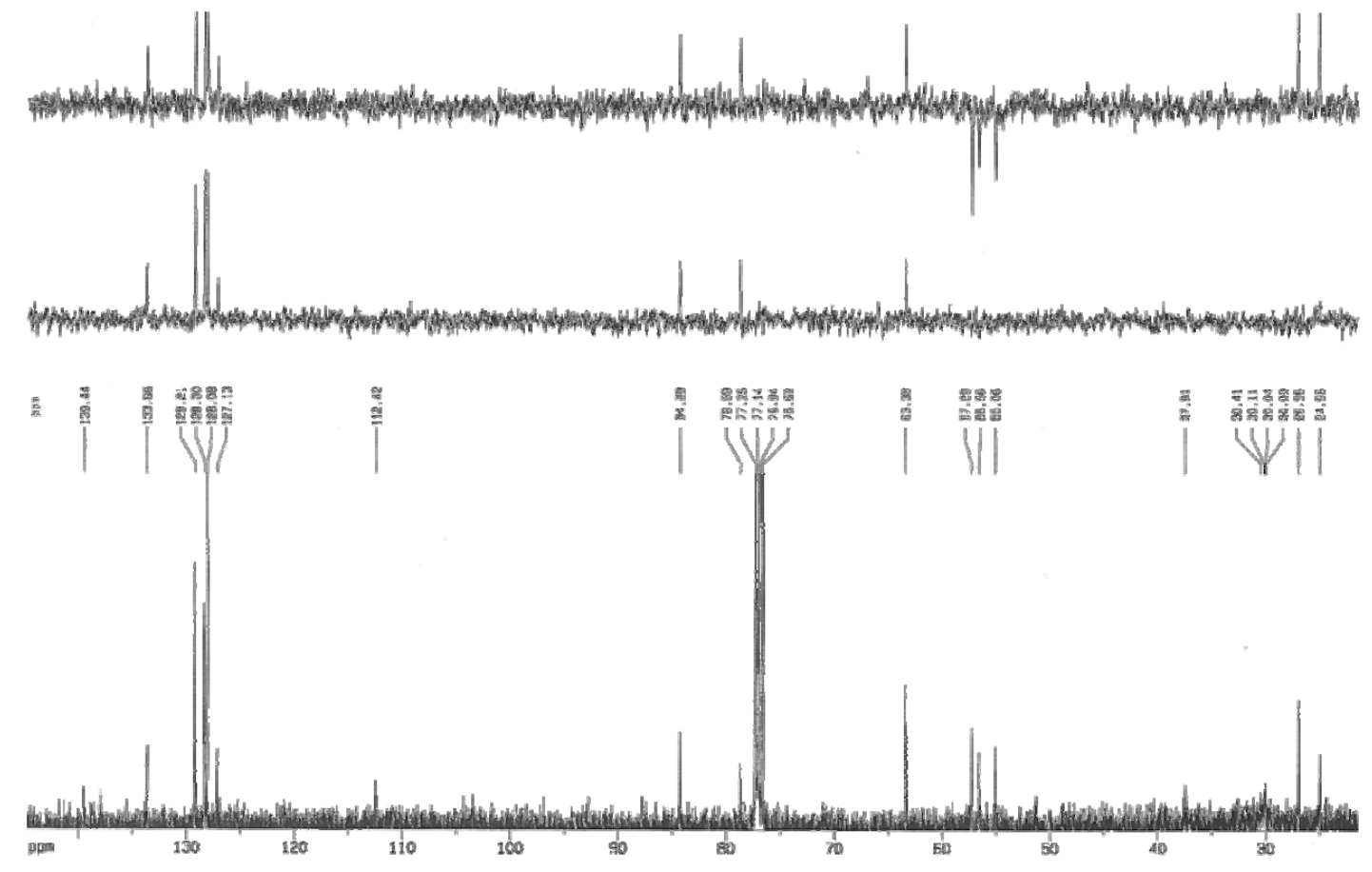

Fig. 78d

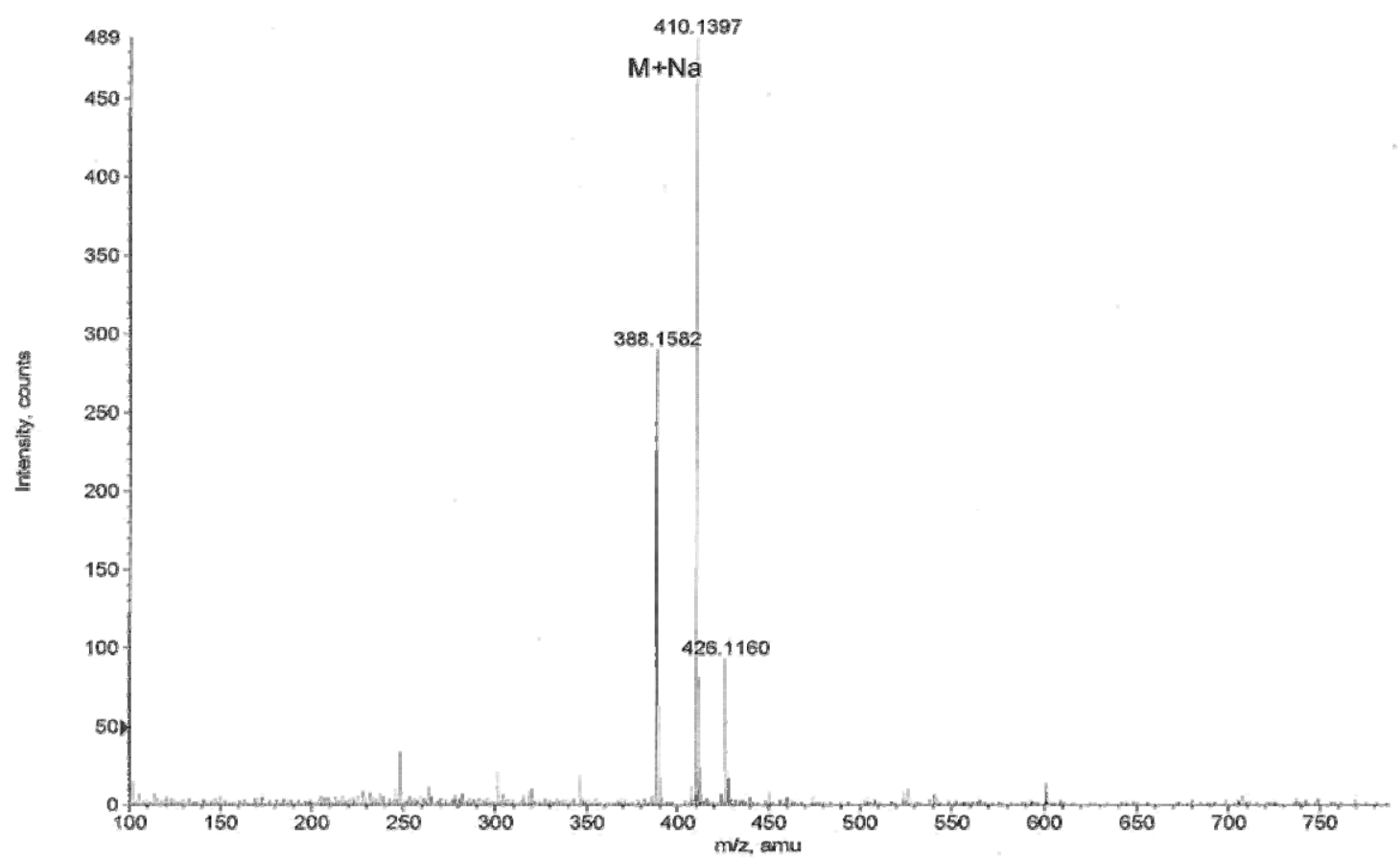


Fig. 78e-COSY

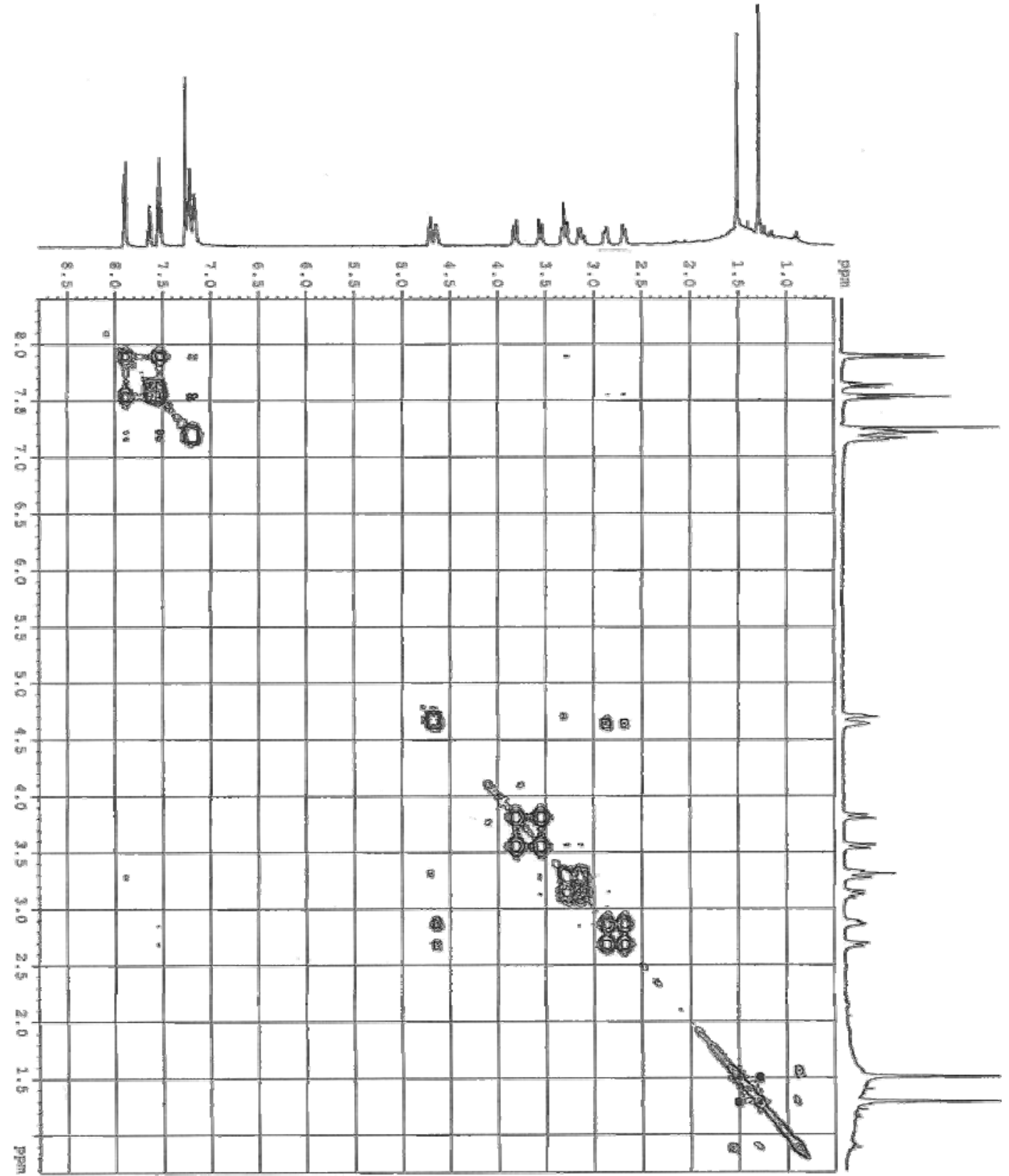


Fig. 78f-HMQC

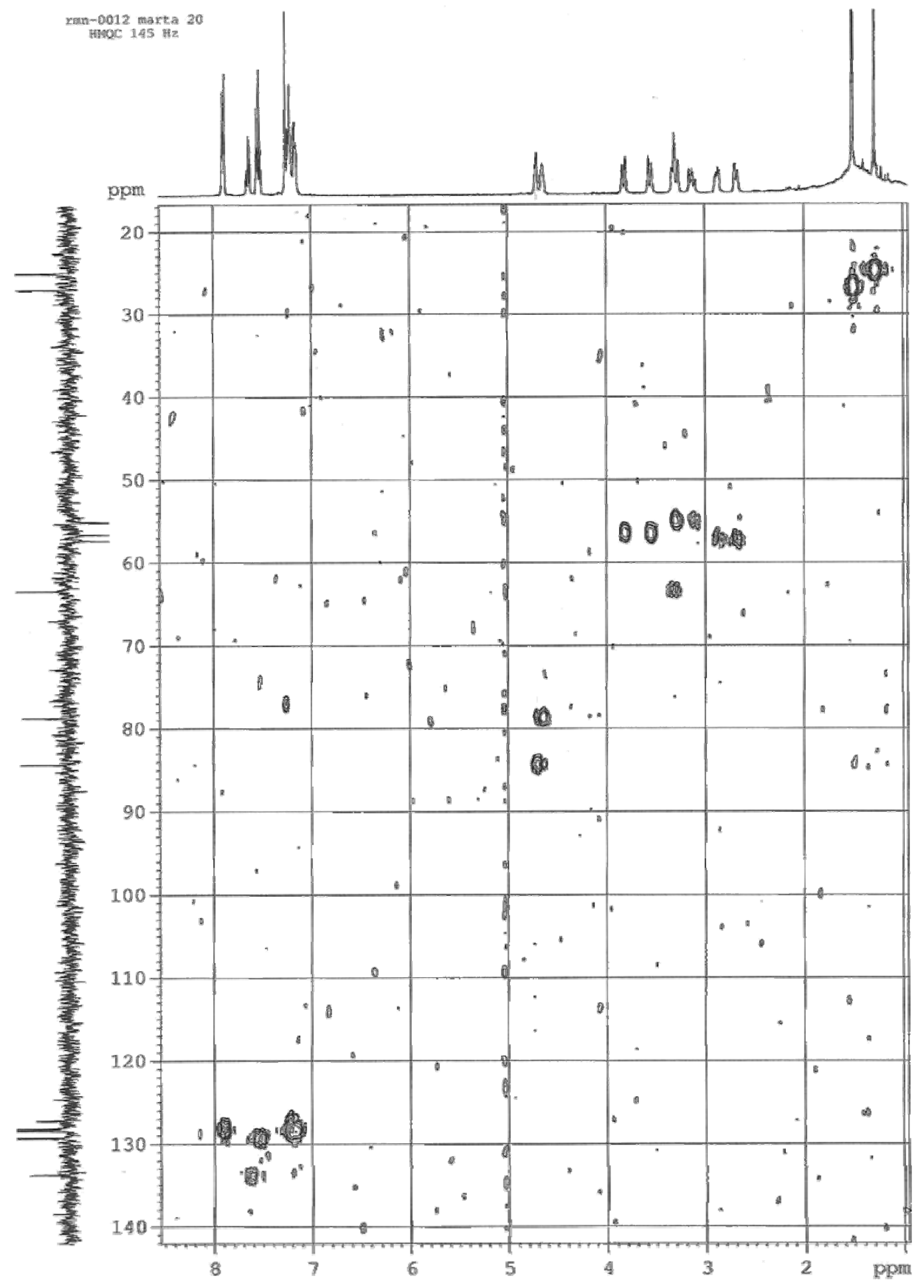


Fig. 78g-HMBC

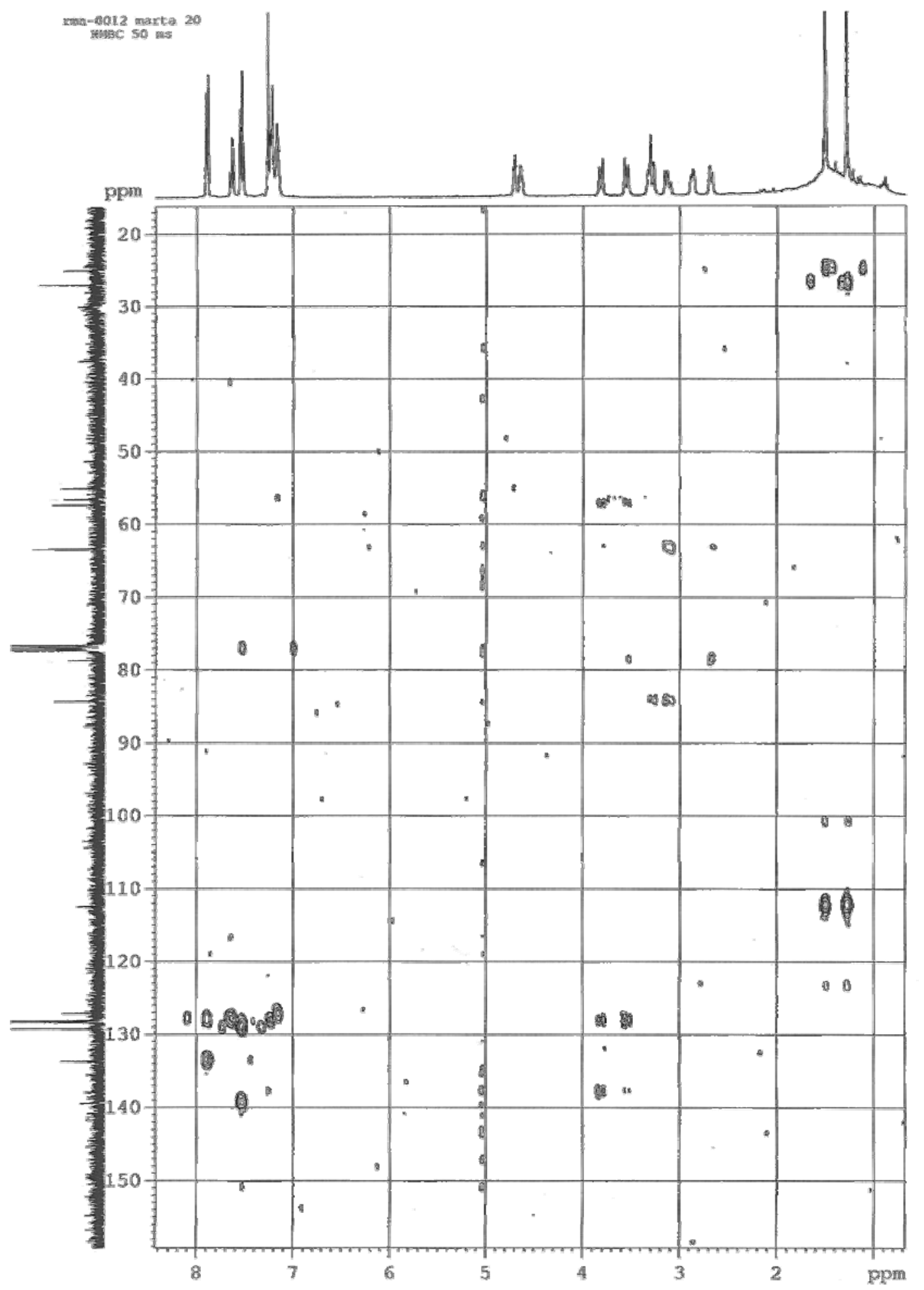


Fig. 78h-ROESY

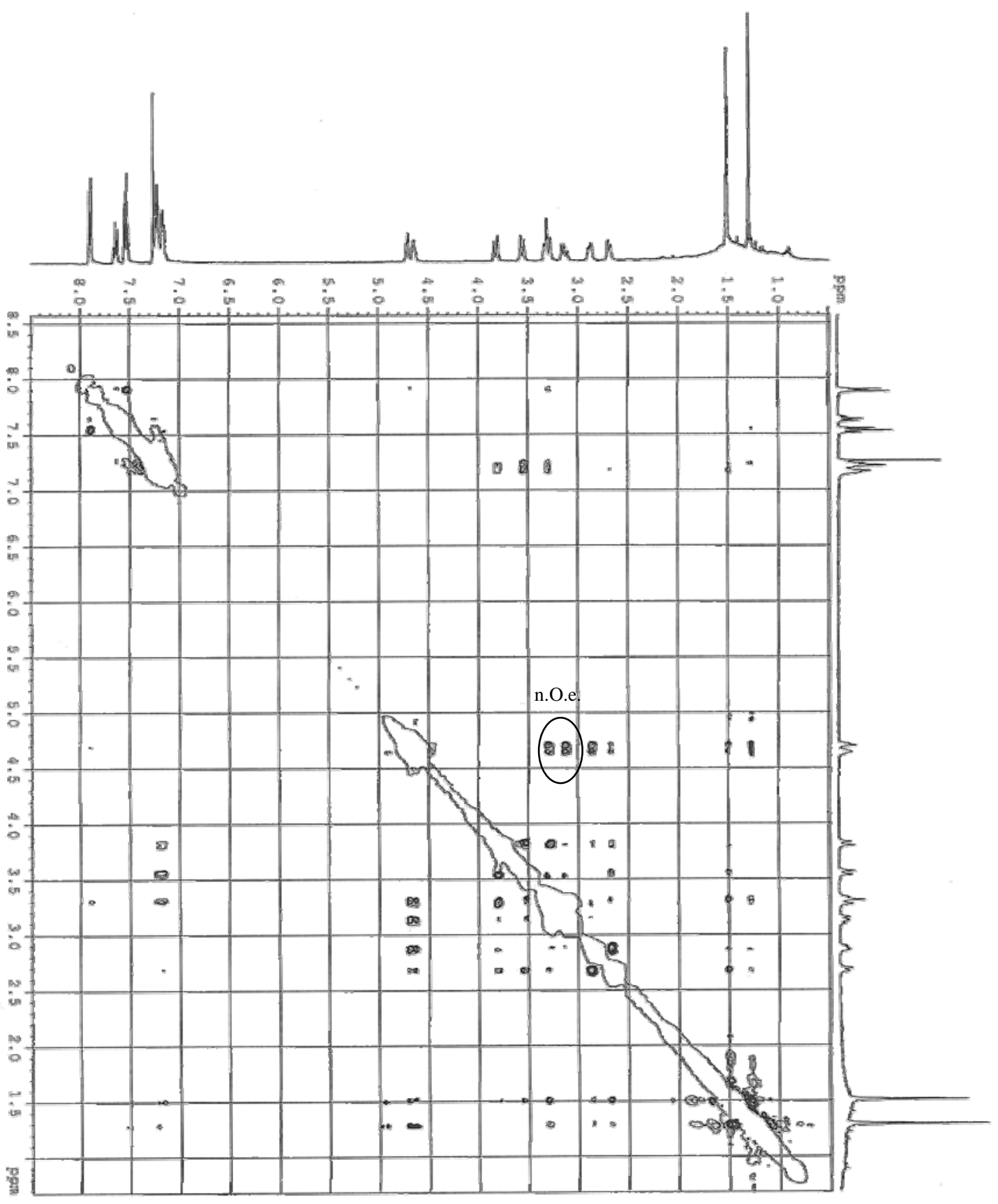


Fig. 79a

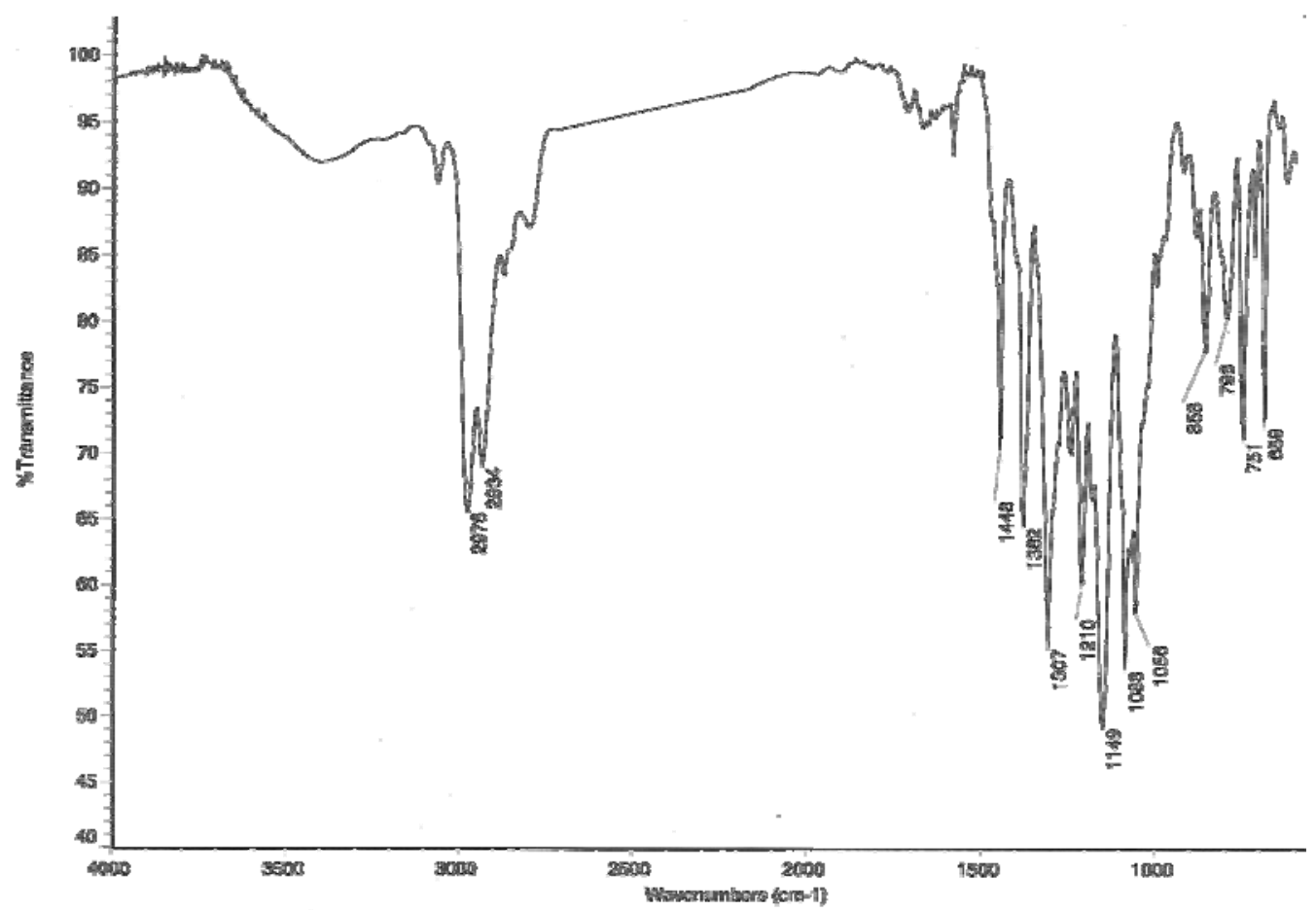

Fig. 79b

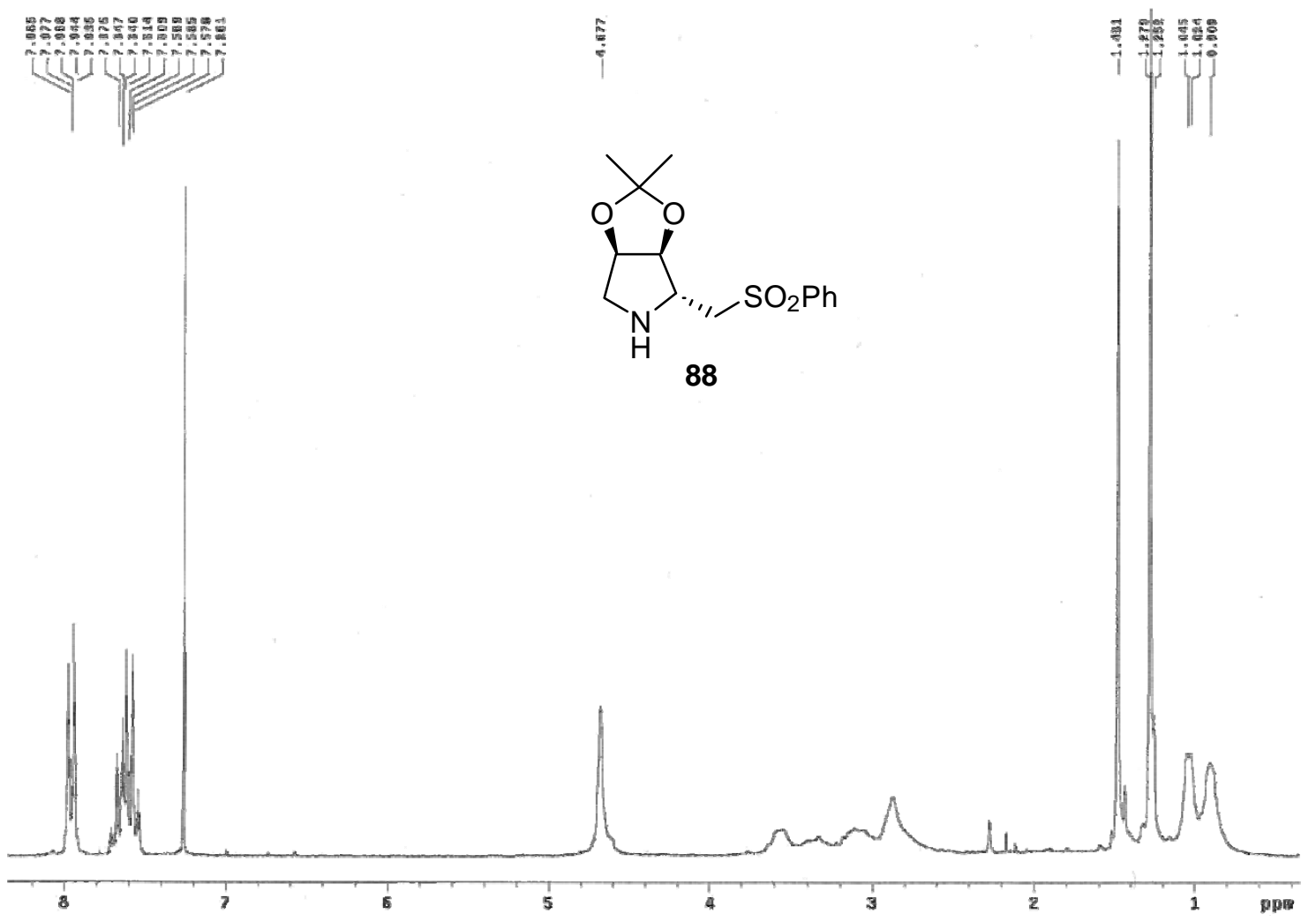


Fig. 79c

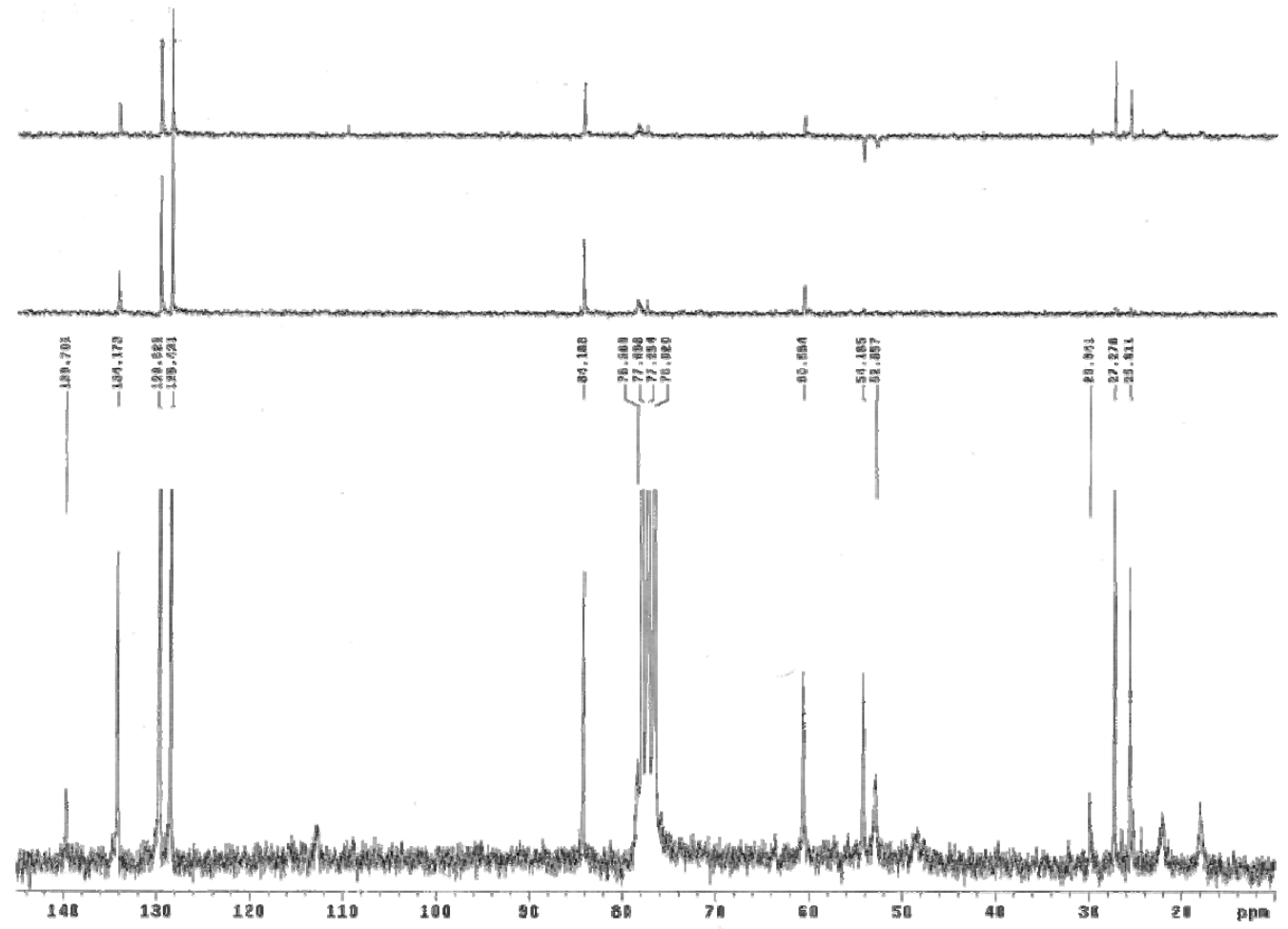

Fig. 79d

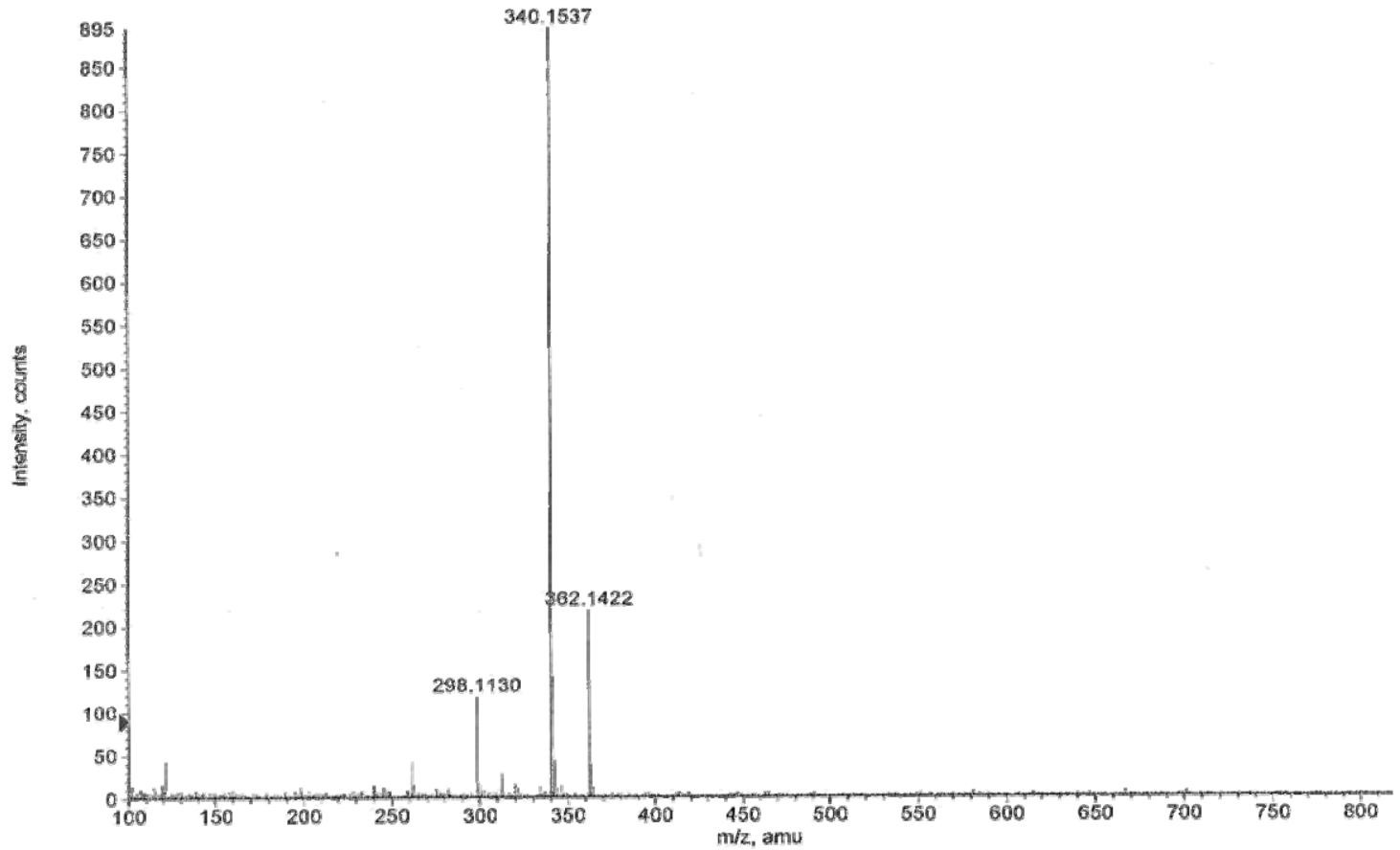


Fig. 80a

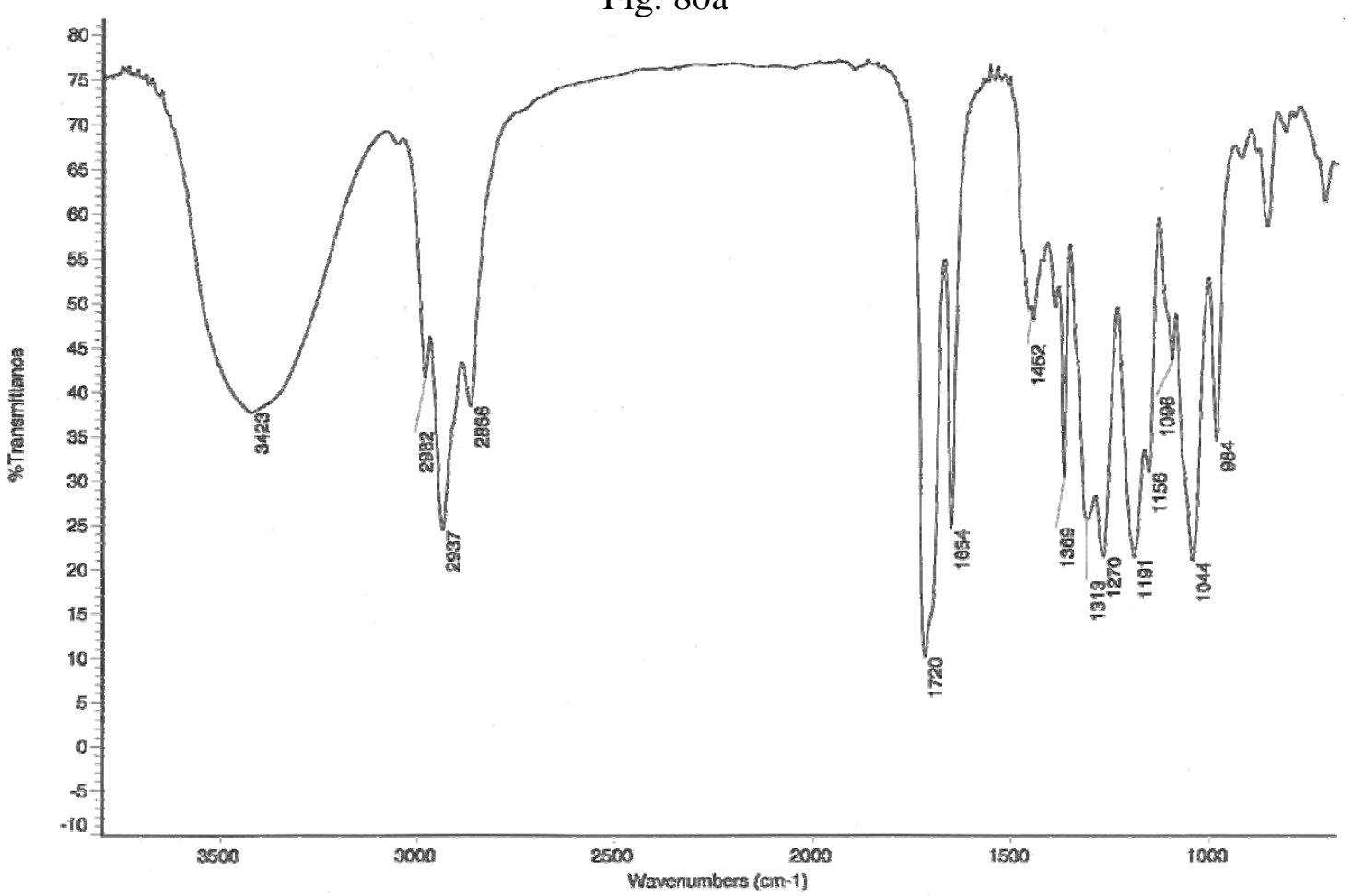

Fig. 80b

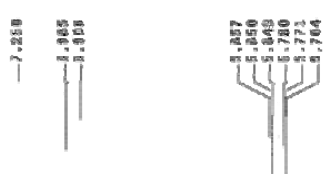

路里等

ifj

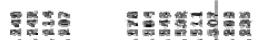

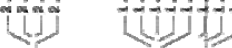<smiles>CCOC(=O)/C=C/CCCCO</smiles>

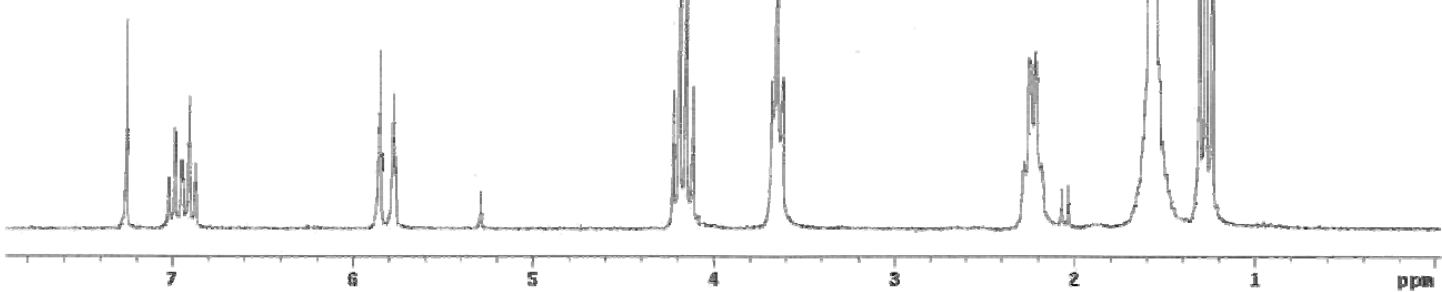


Fig. 80c
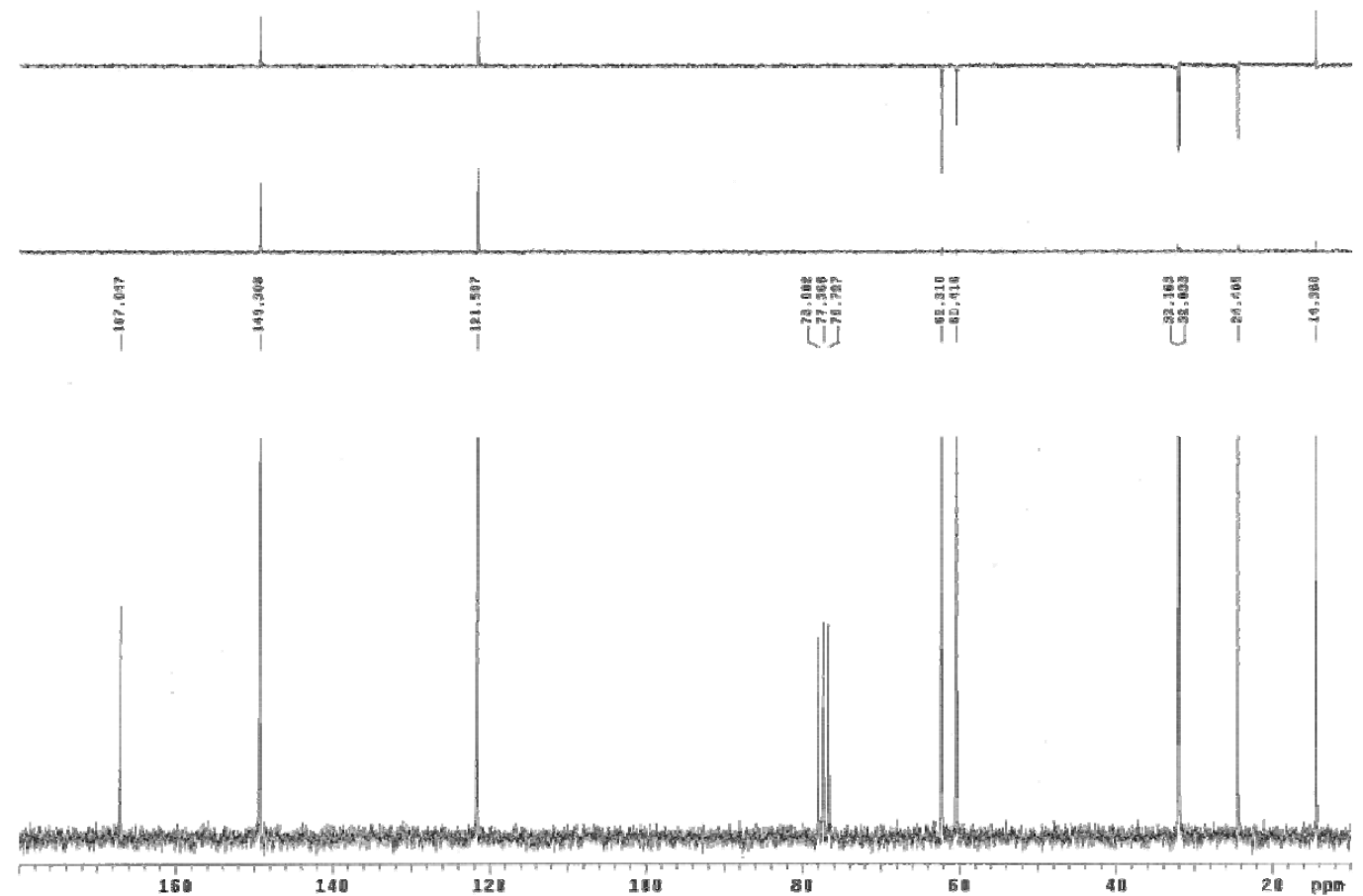

Fig. 80d

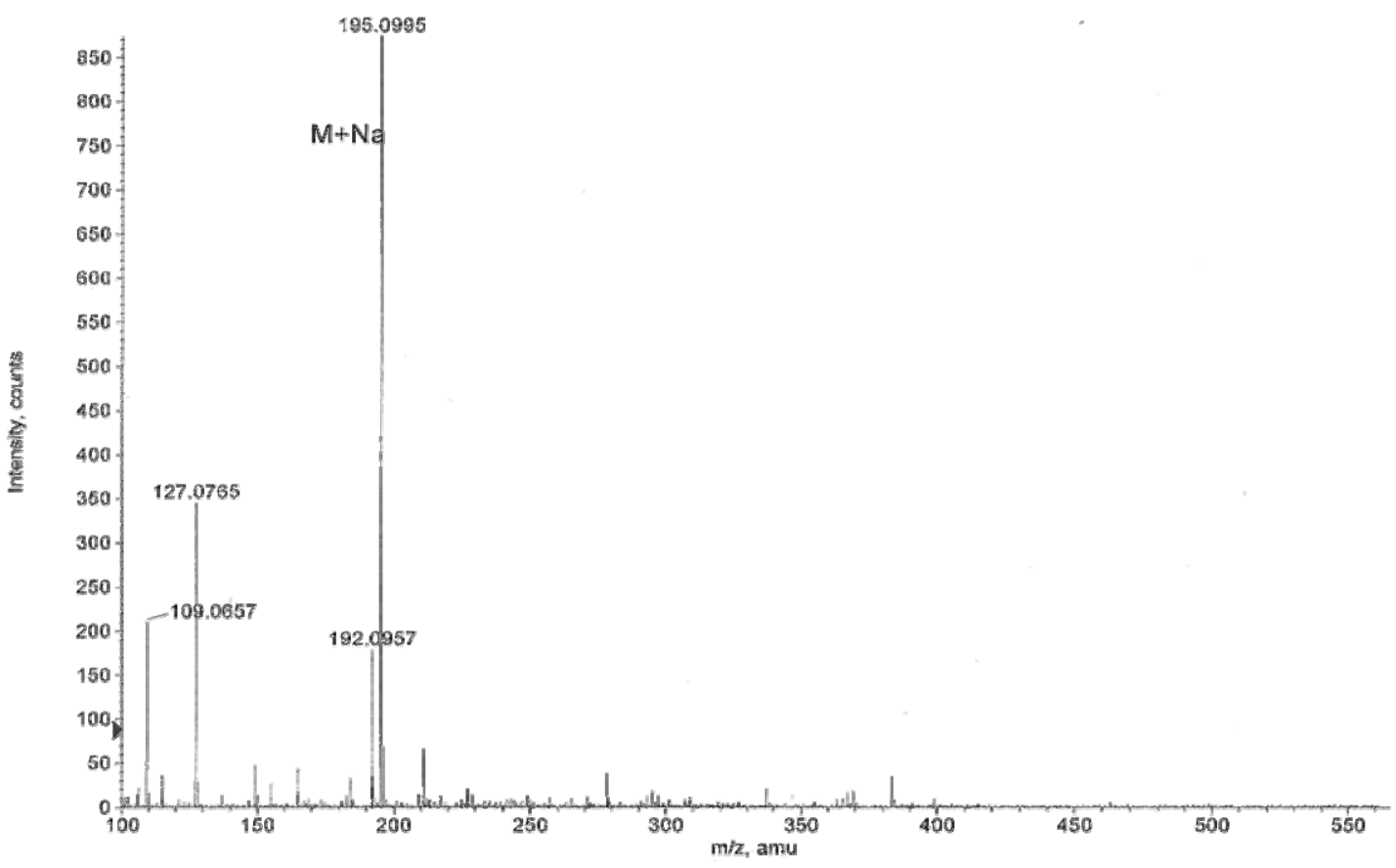


Fig. 81a

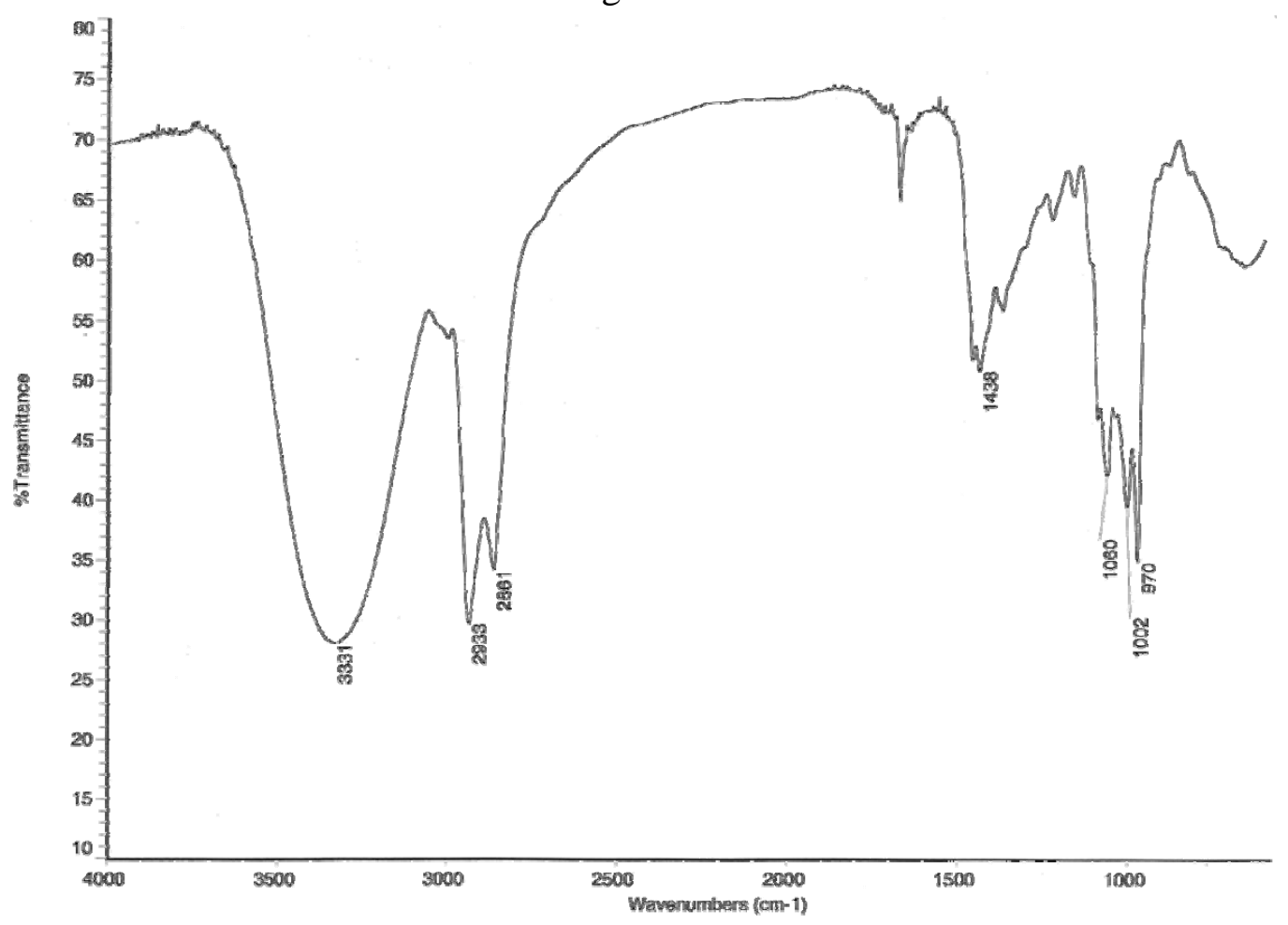

Fig. $81 \mathrm{~b}$

这

器器

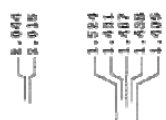
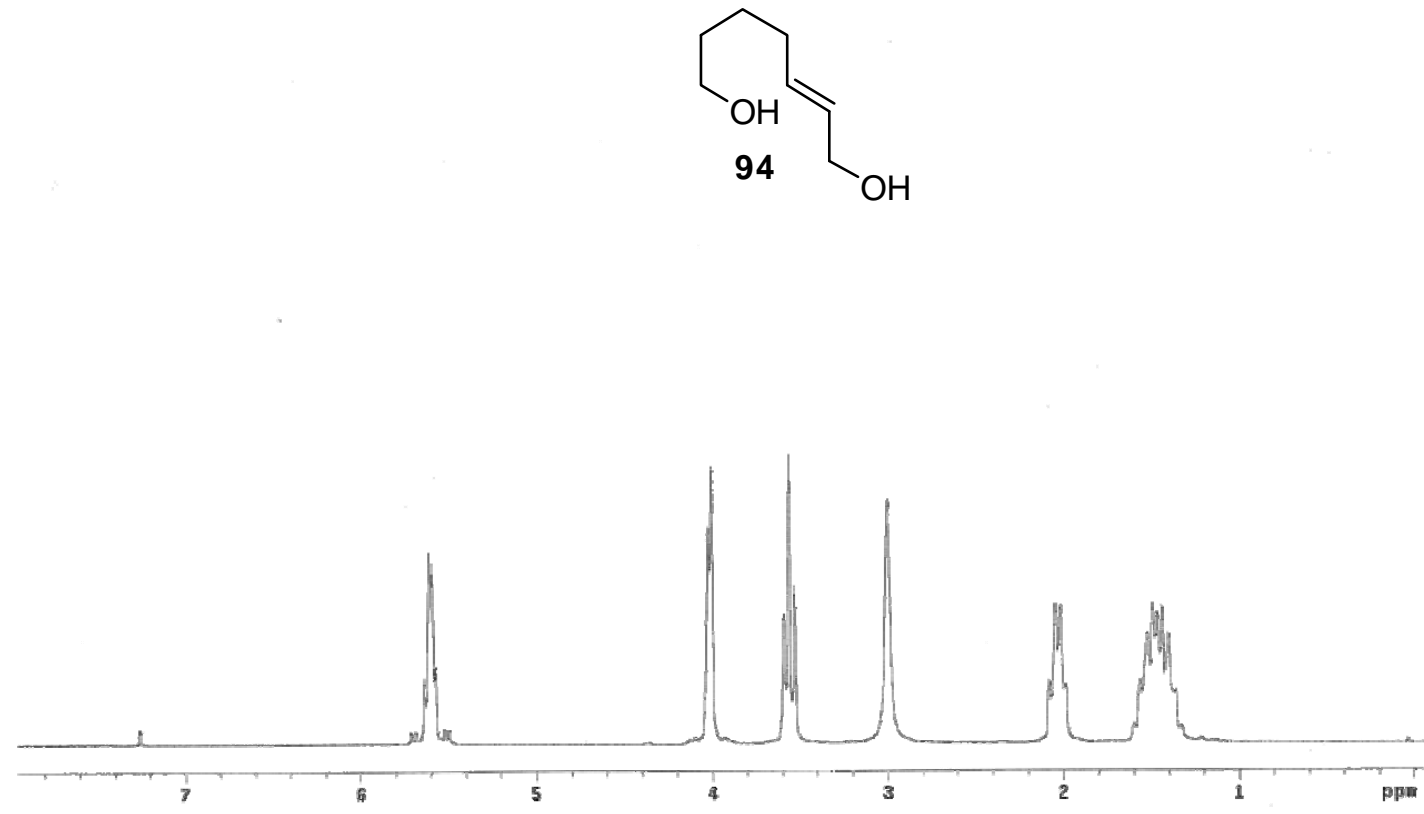
Fig. 81c
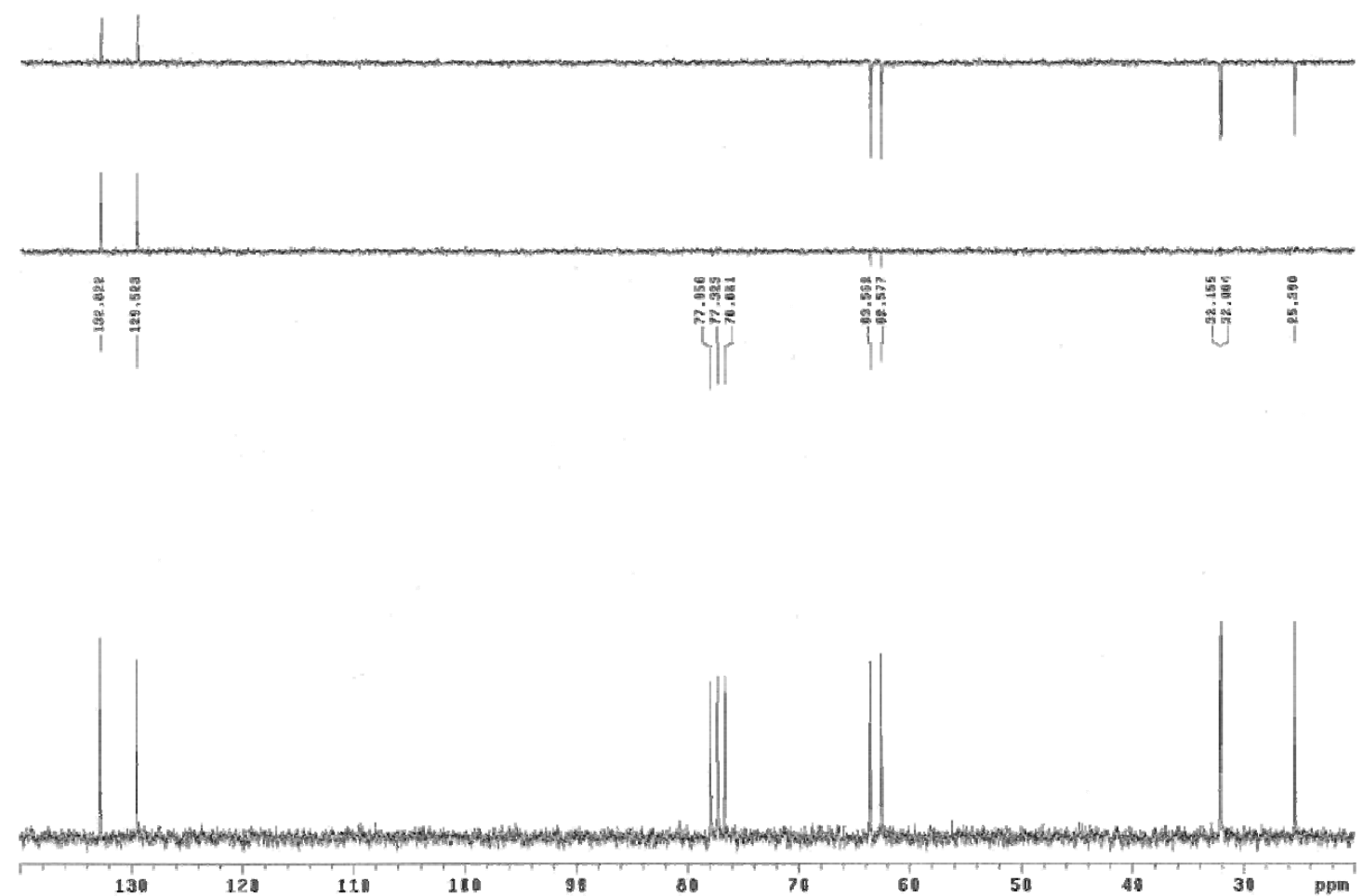

Fig. 81d

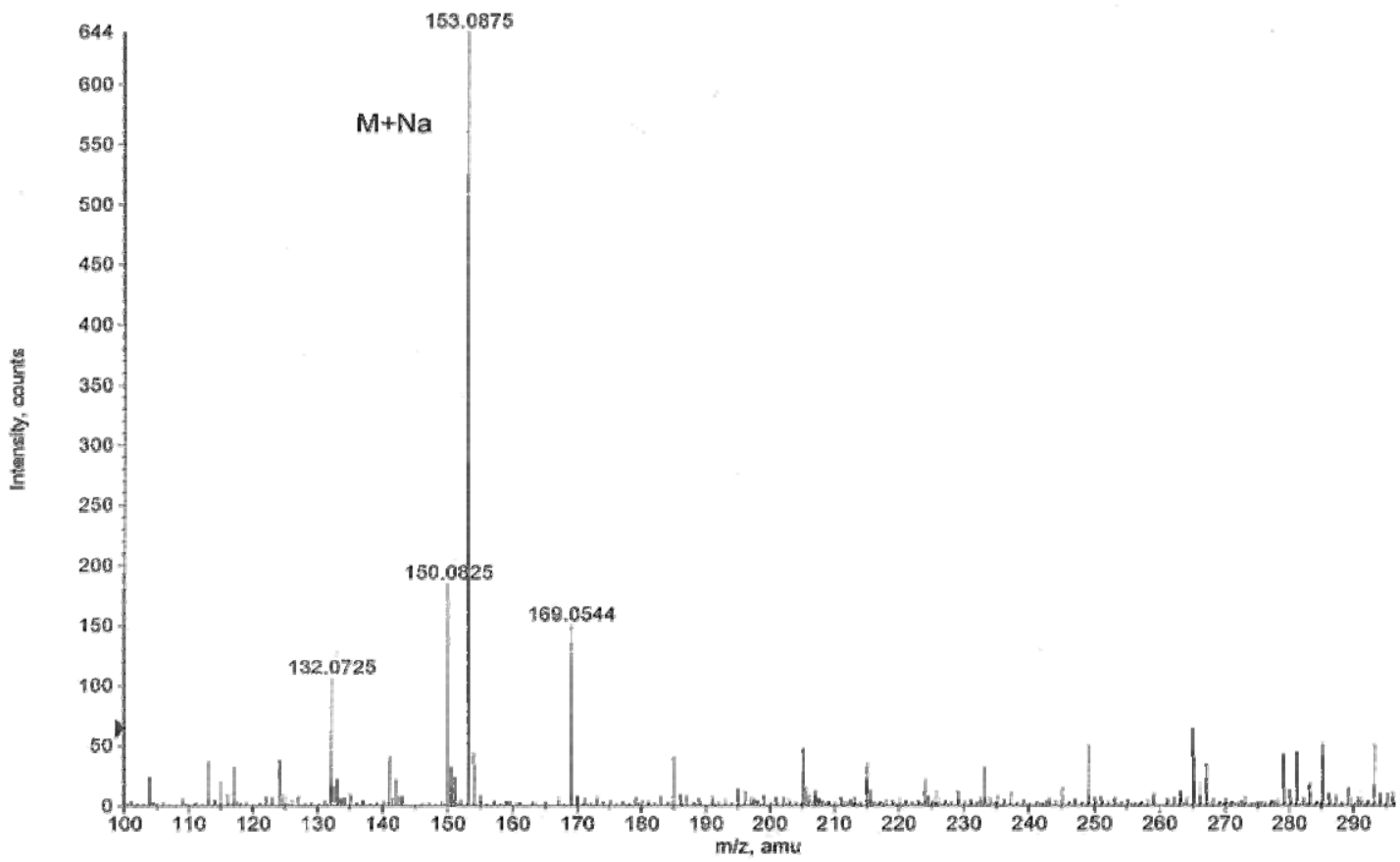


Fig. $82 \mathrm{a}$

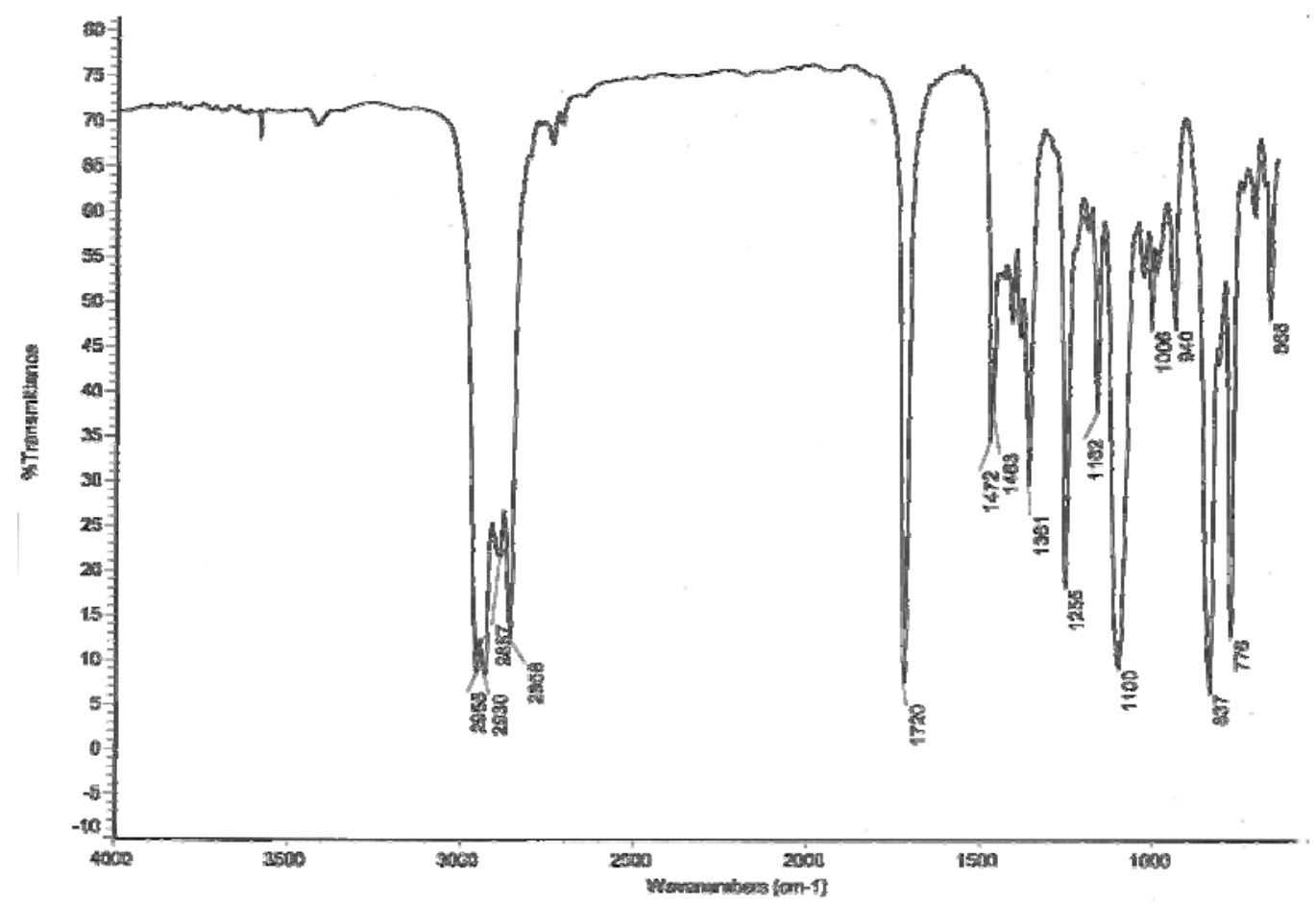

Fig. 82b

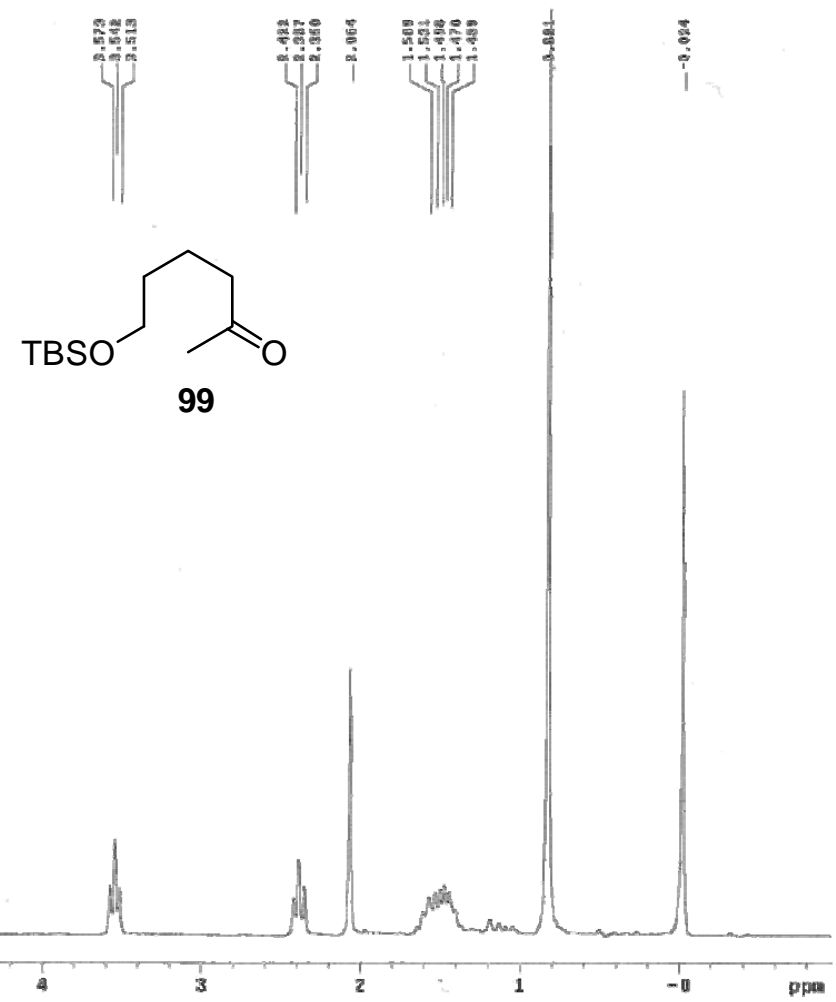


Fig. 82c
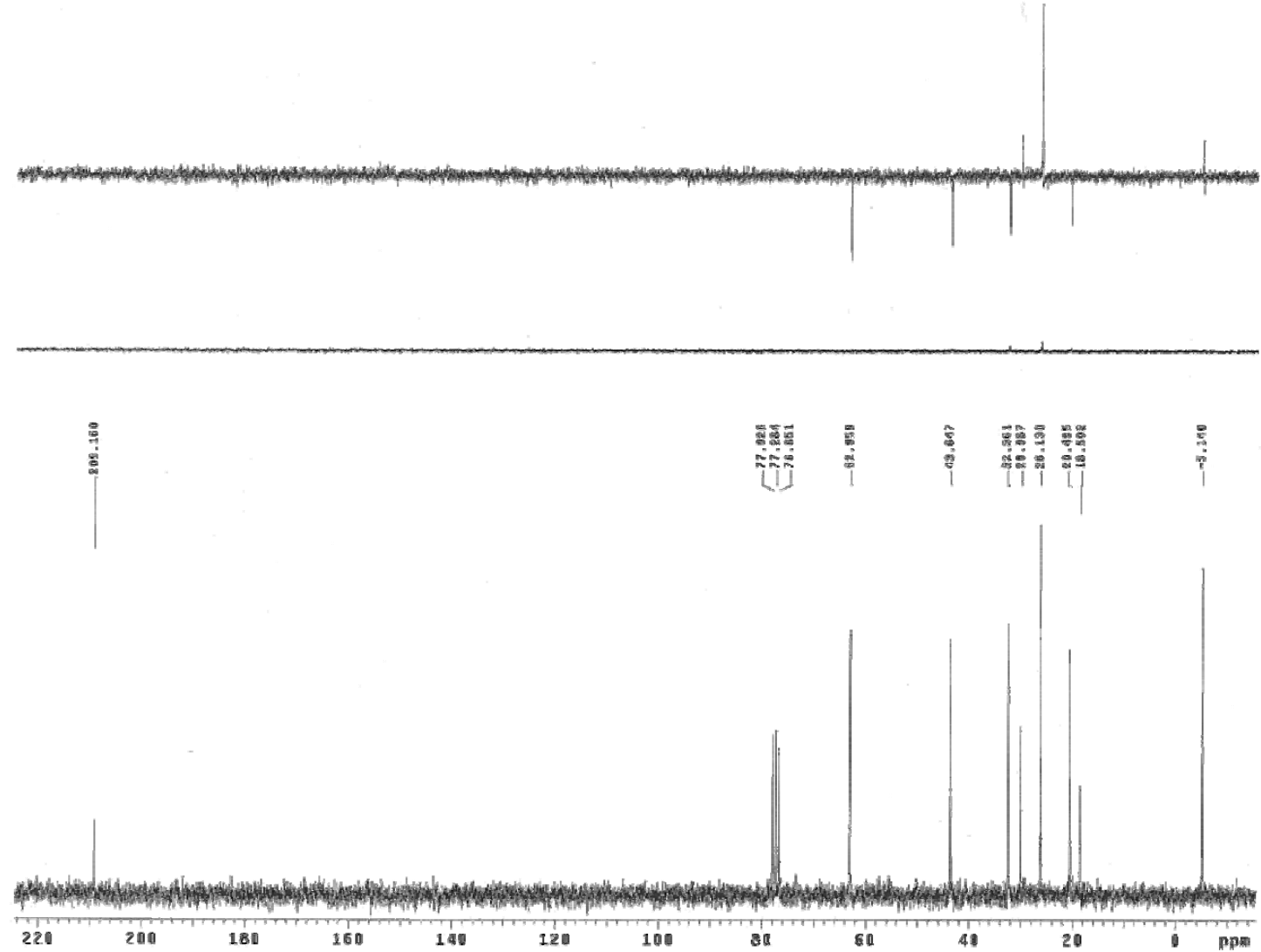

Fig. $82 \mathrm{~d}$

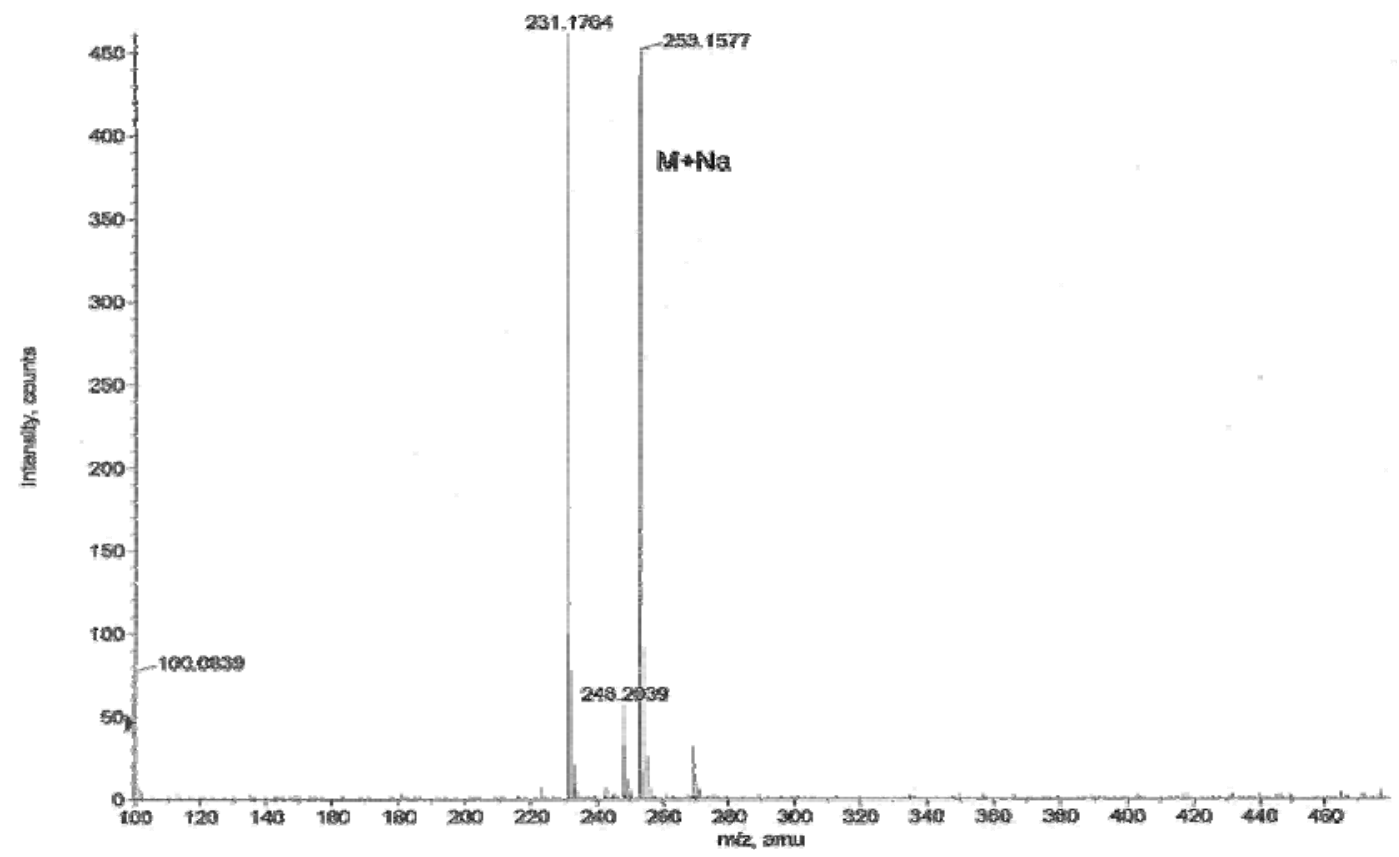


Fig. 83a

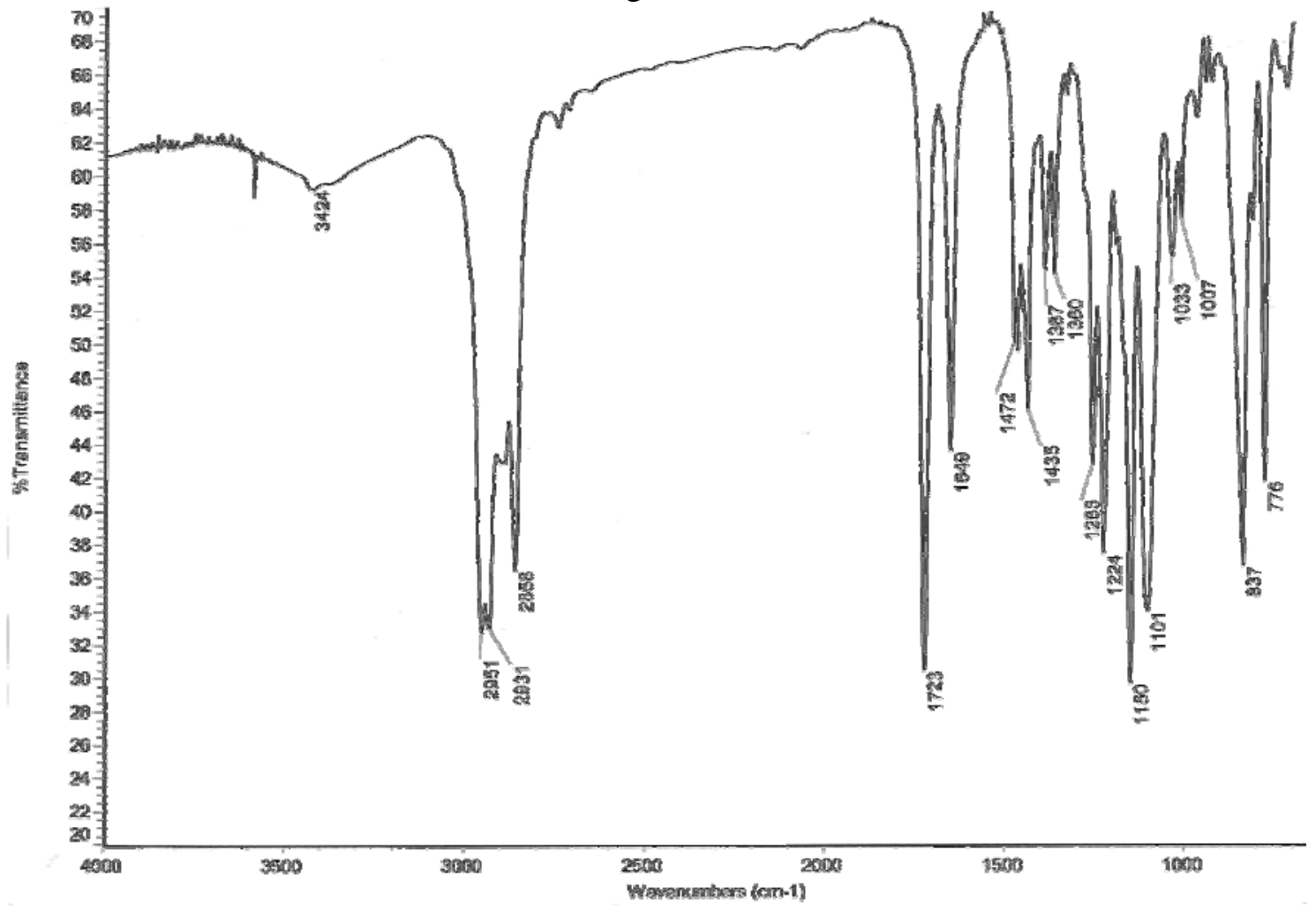

Fig. 83b
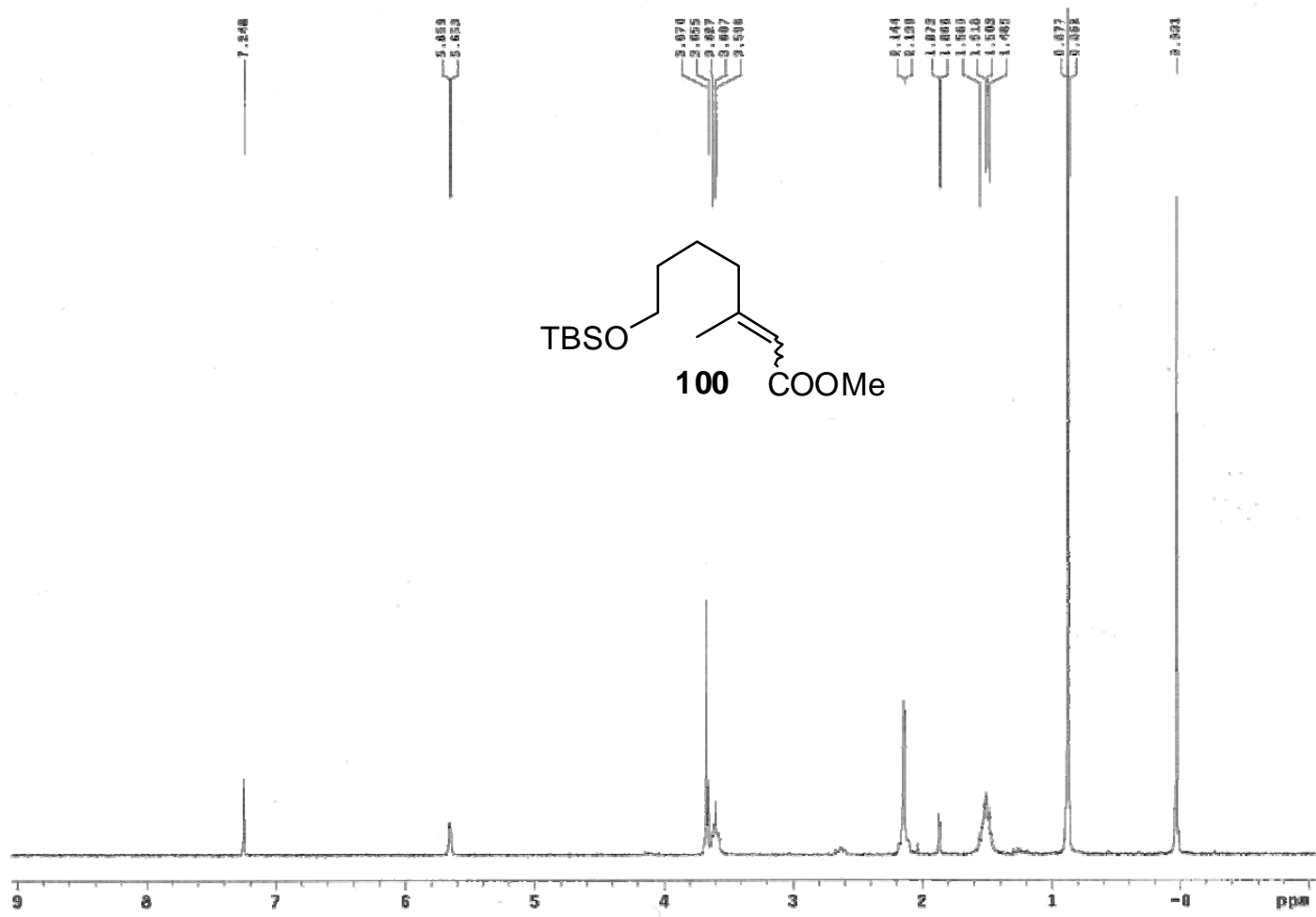
Fig. 83c
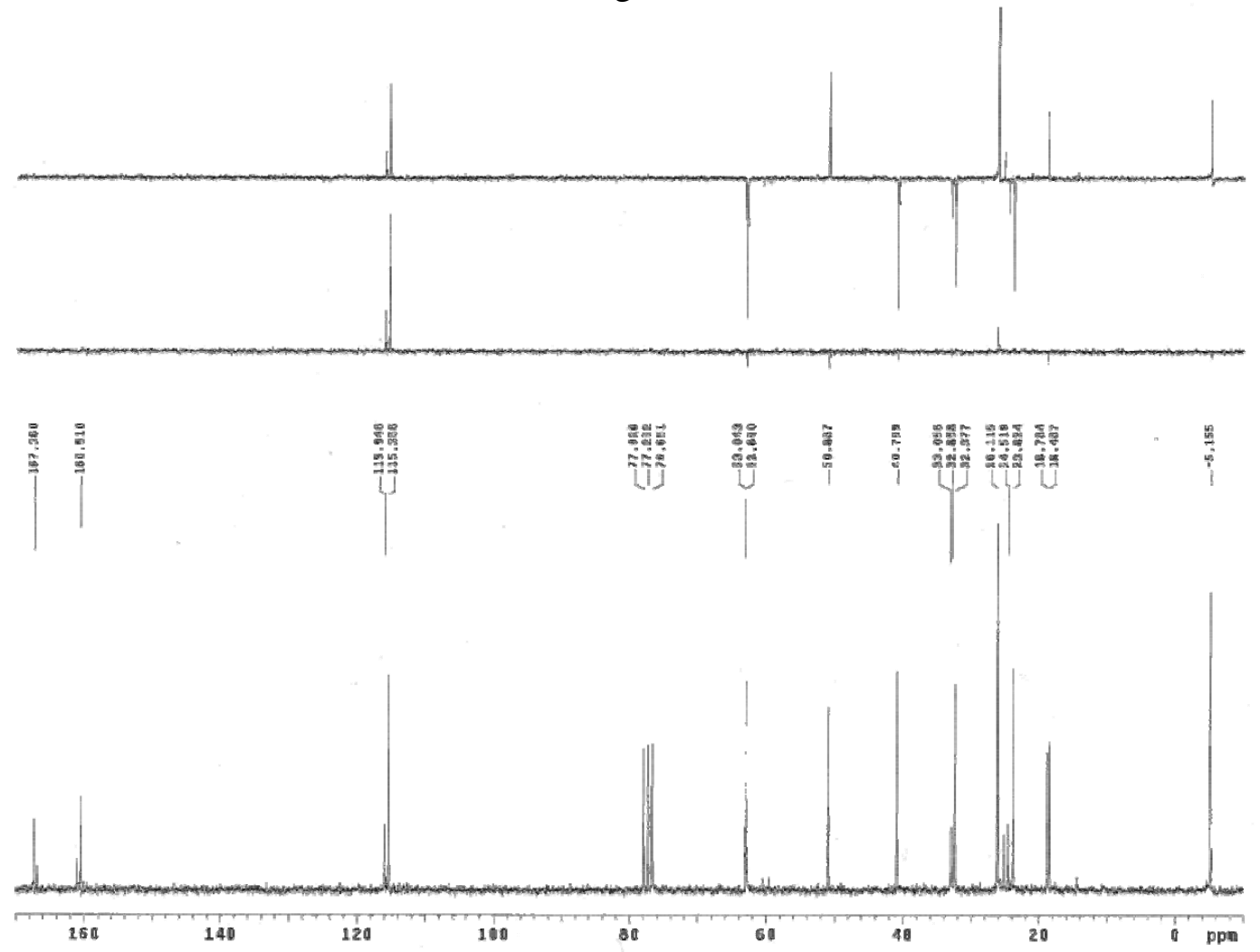

Fig. 83d

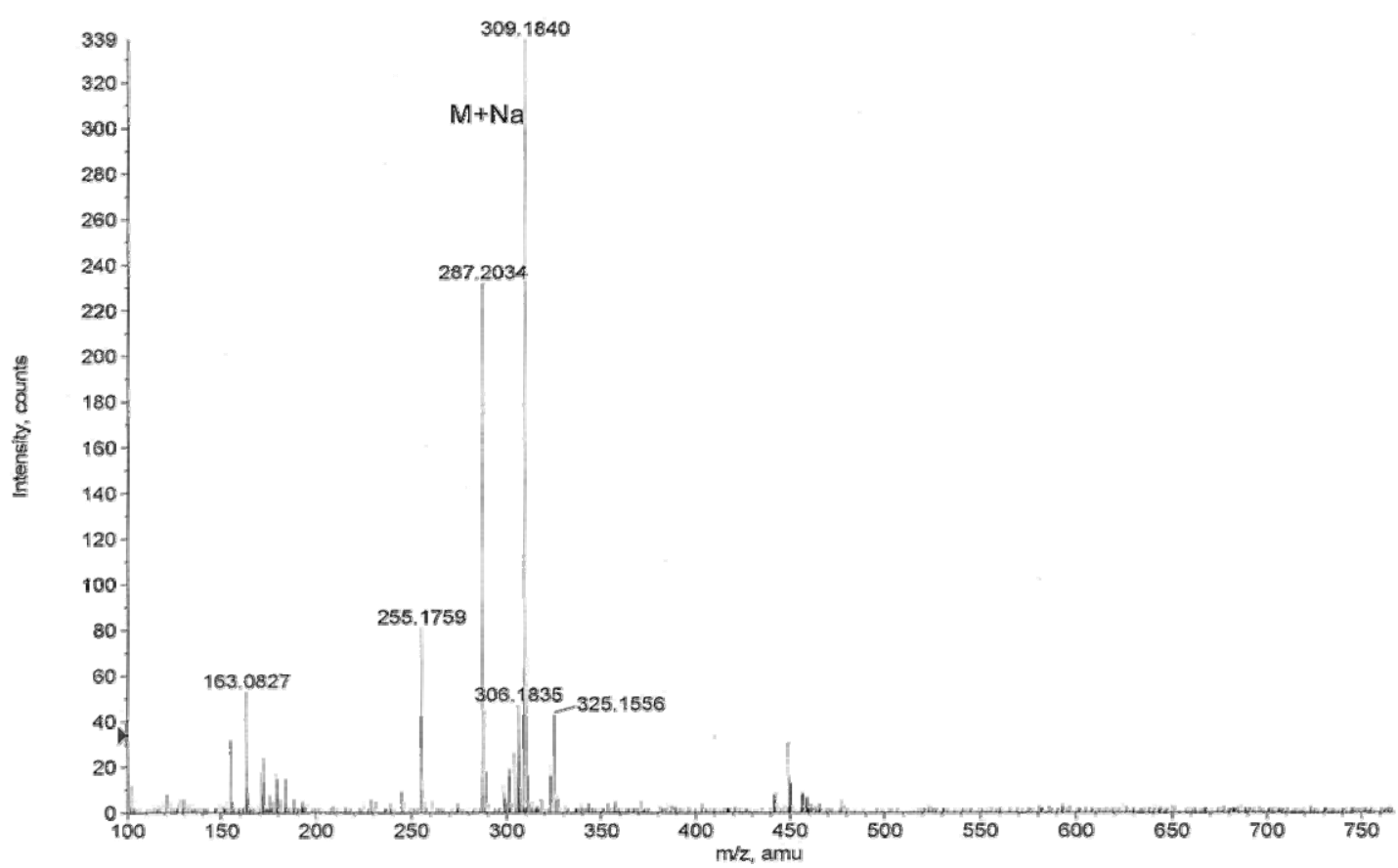


Fig. 84a

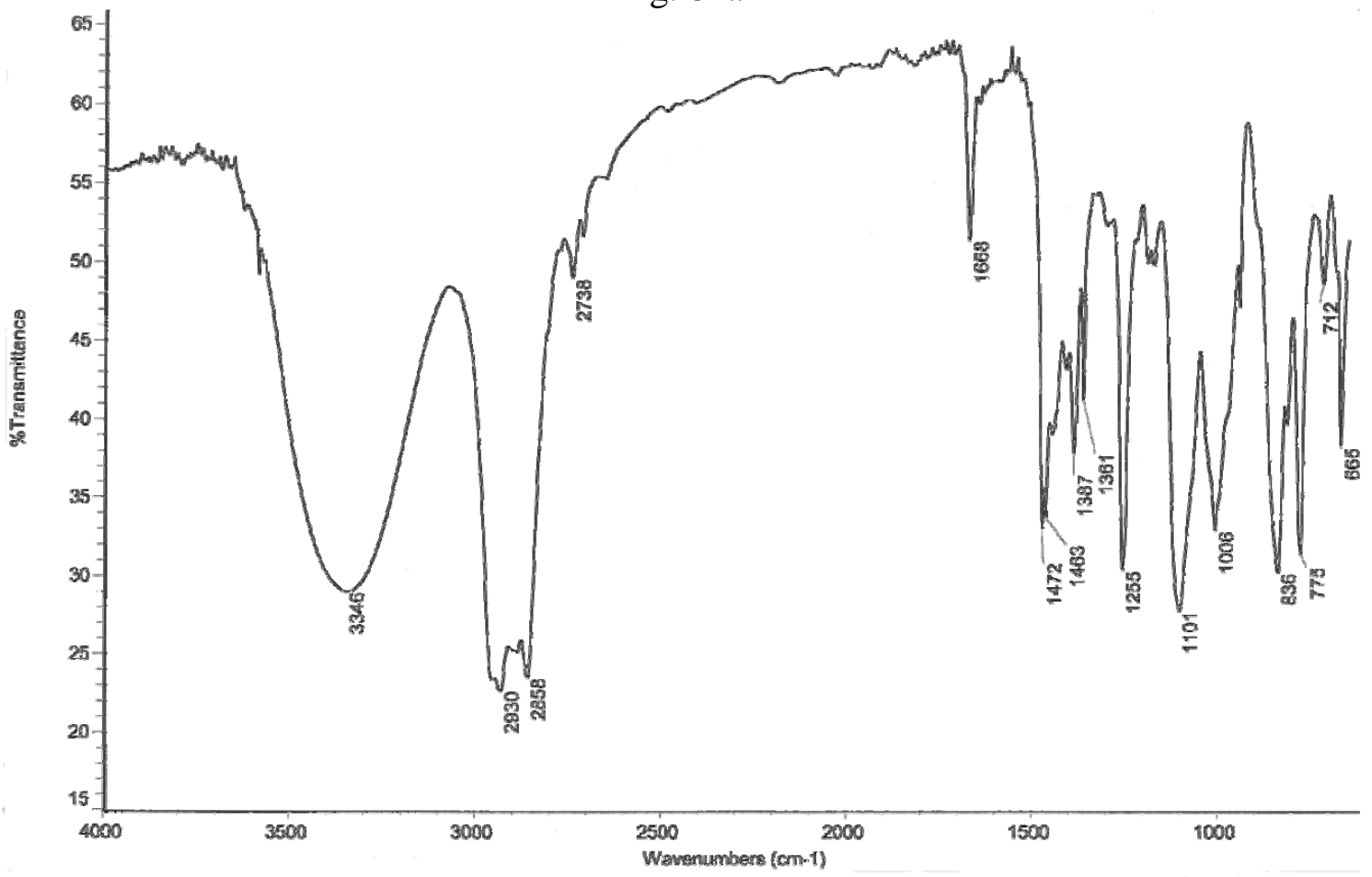

Fig. 84b
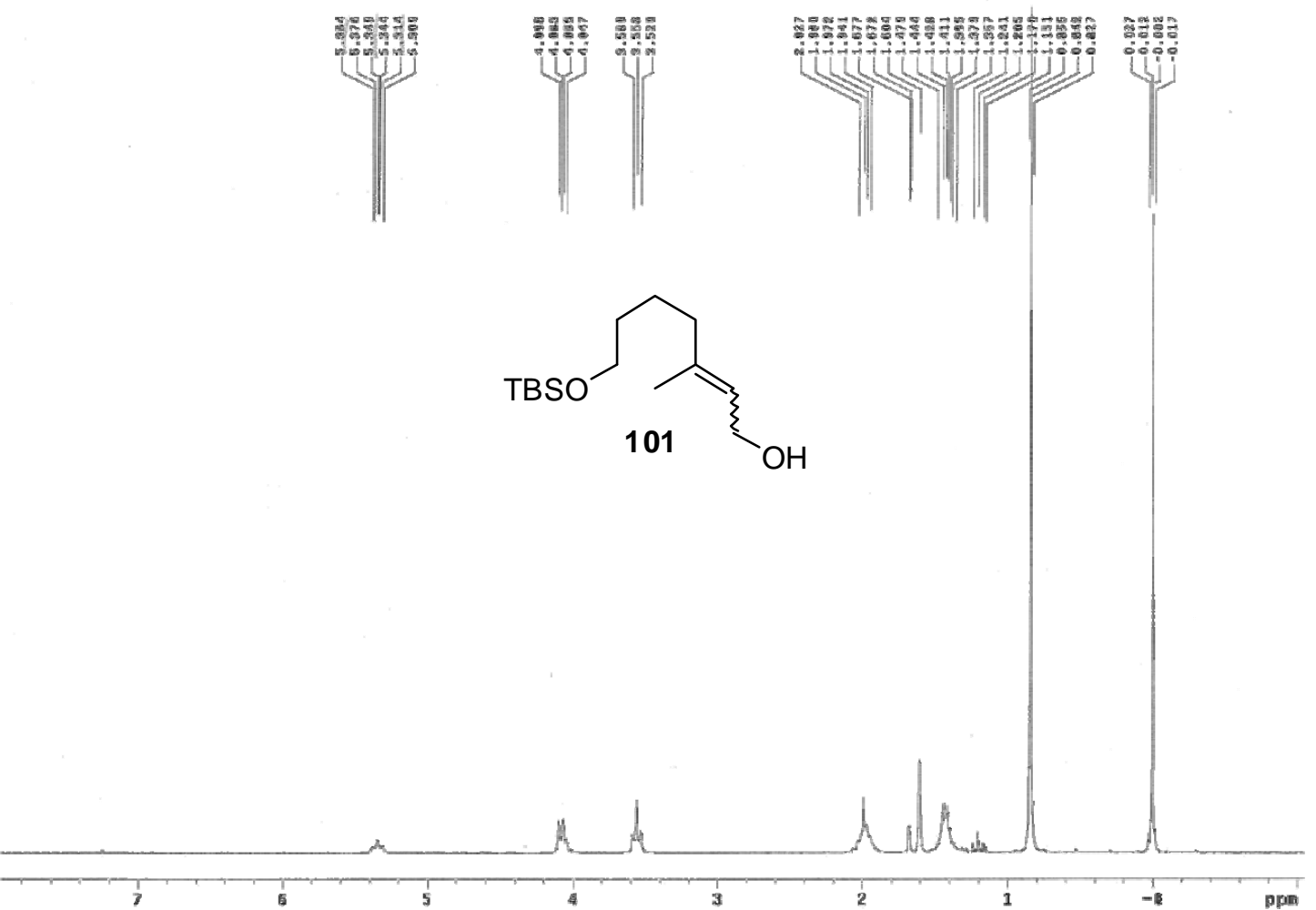

ำํำ

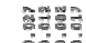


Fig. $84 \mathrm{c}$

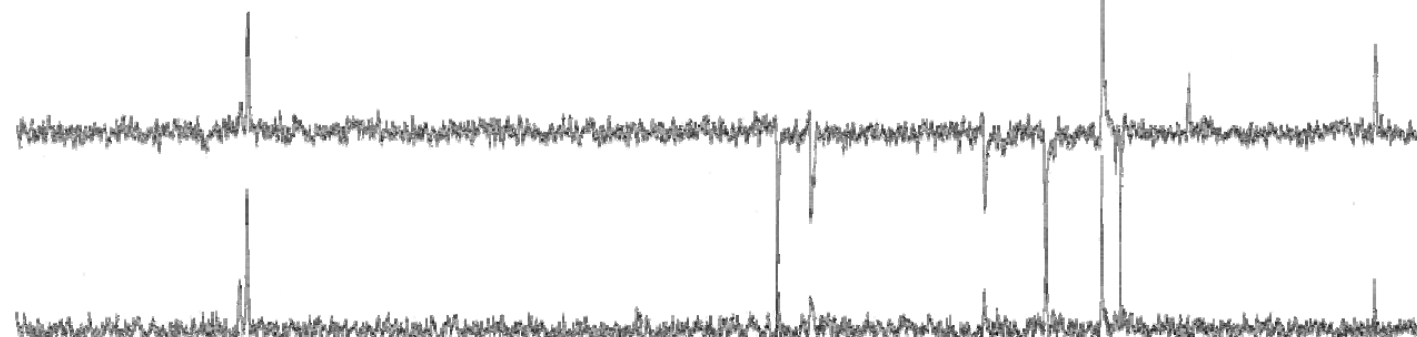
4. M.

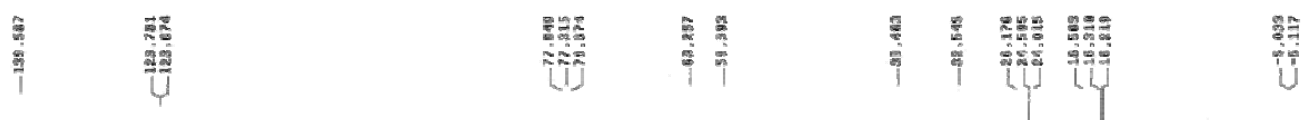

Fig. 84d

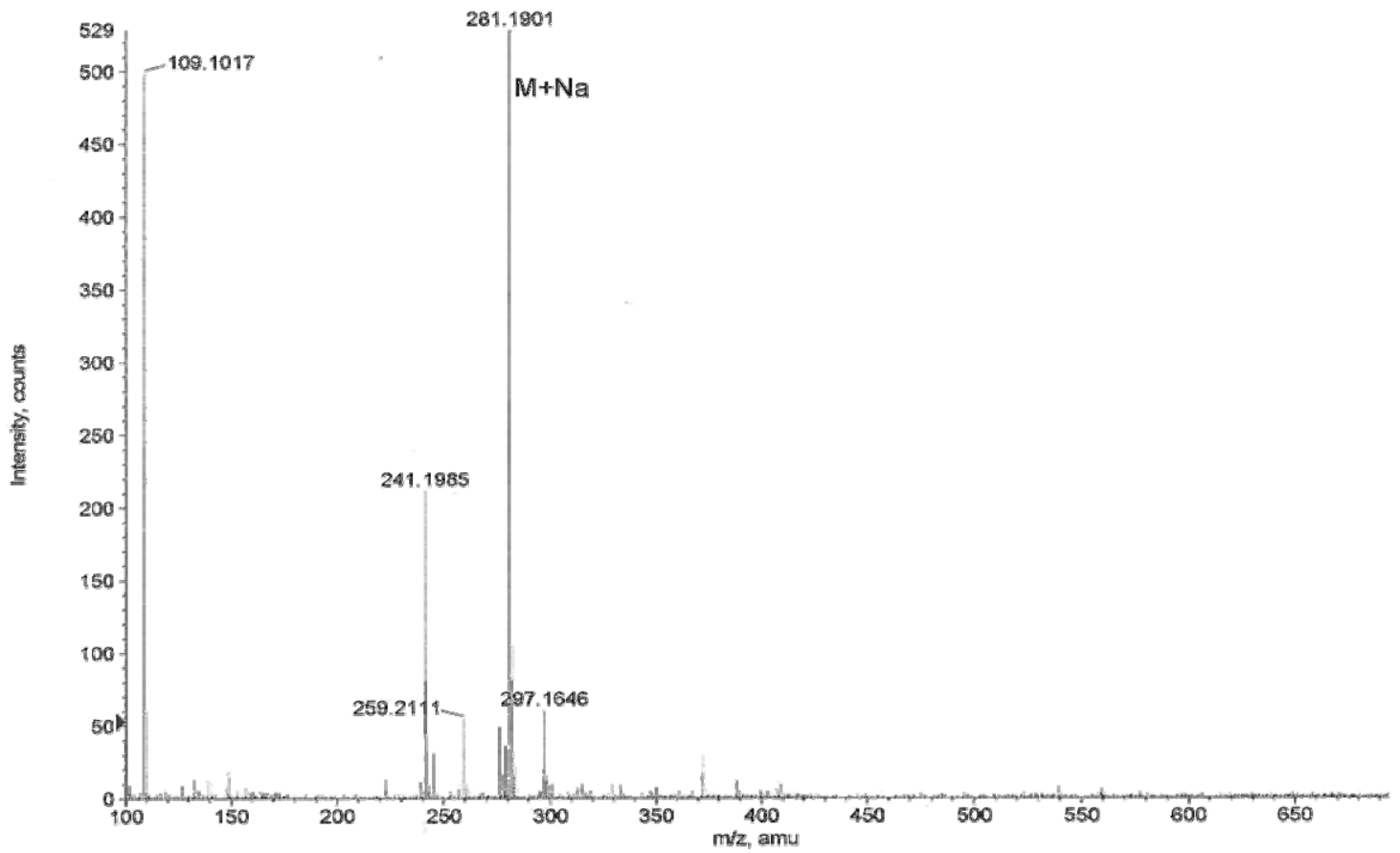


Fig. 85a

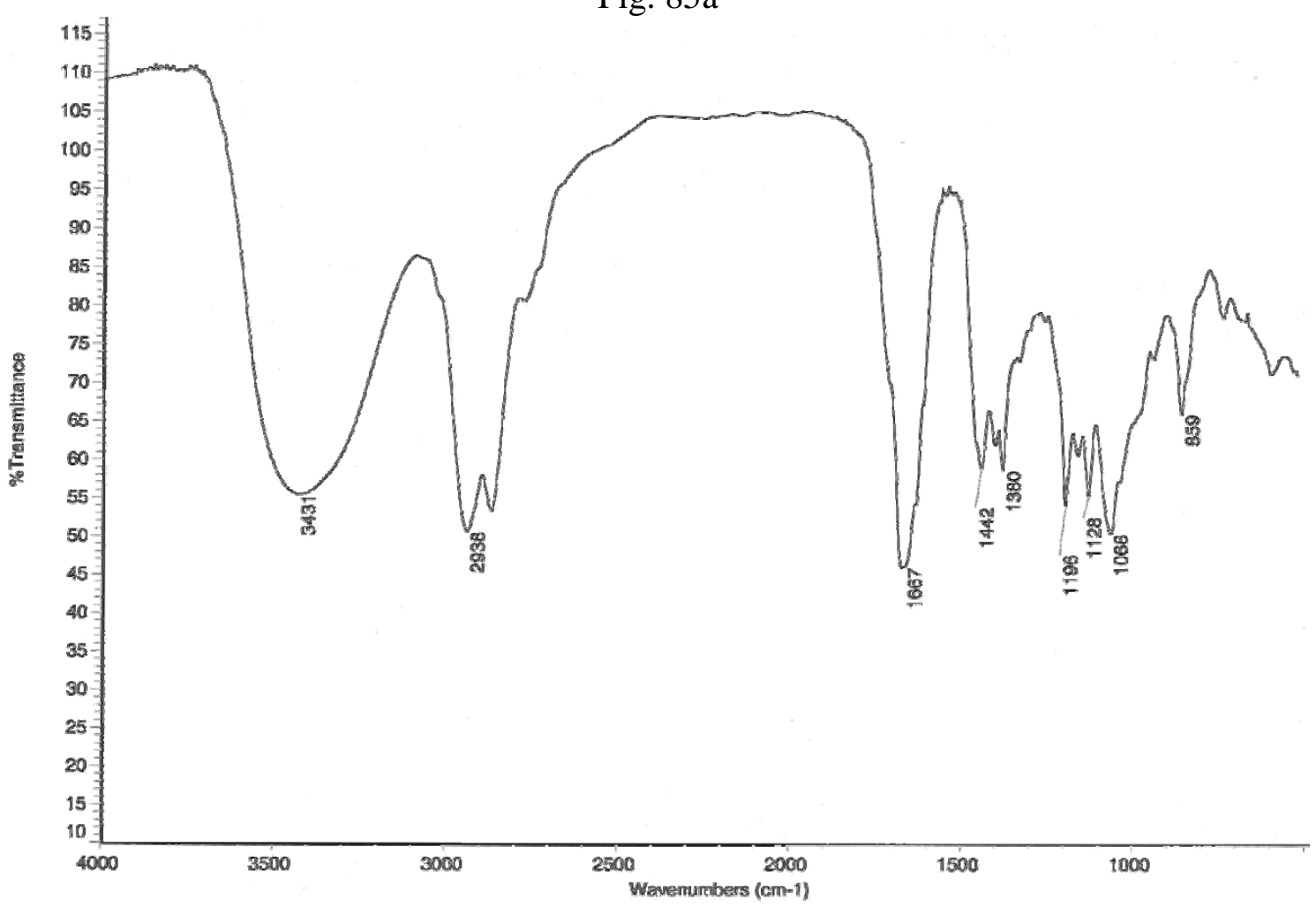

Fig. $85 b$
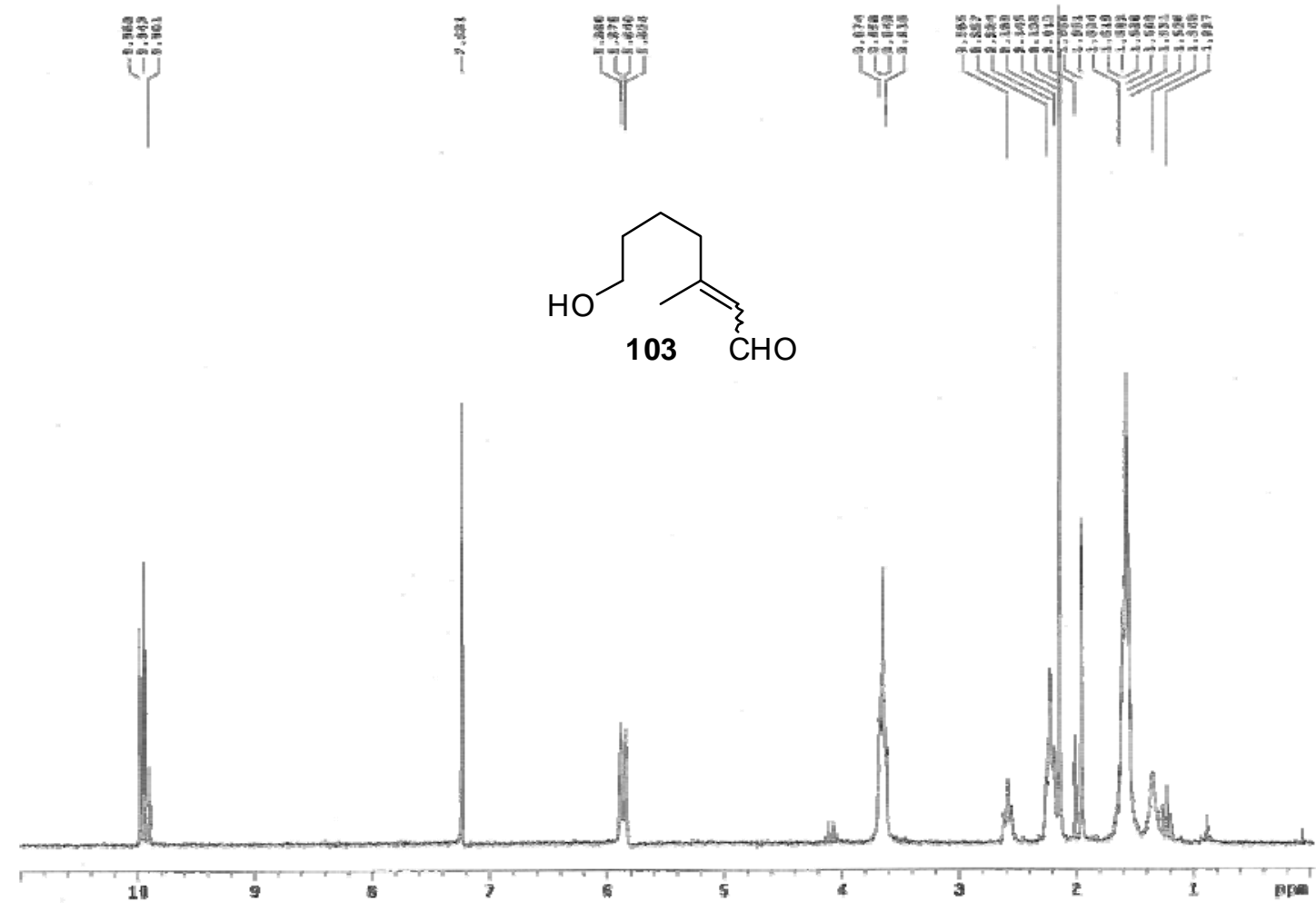
Fig. $85 c$
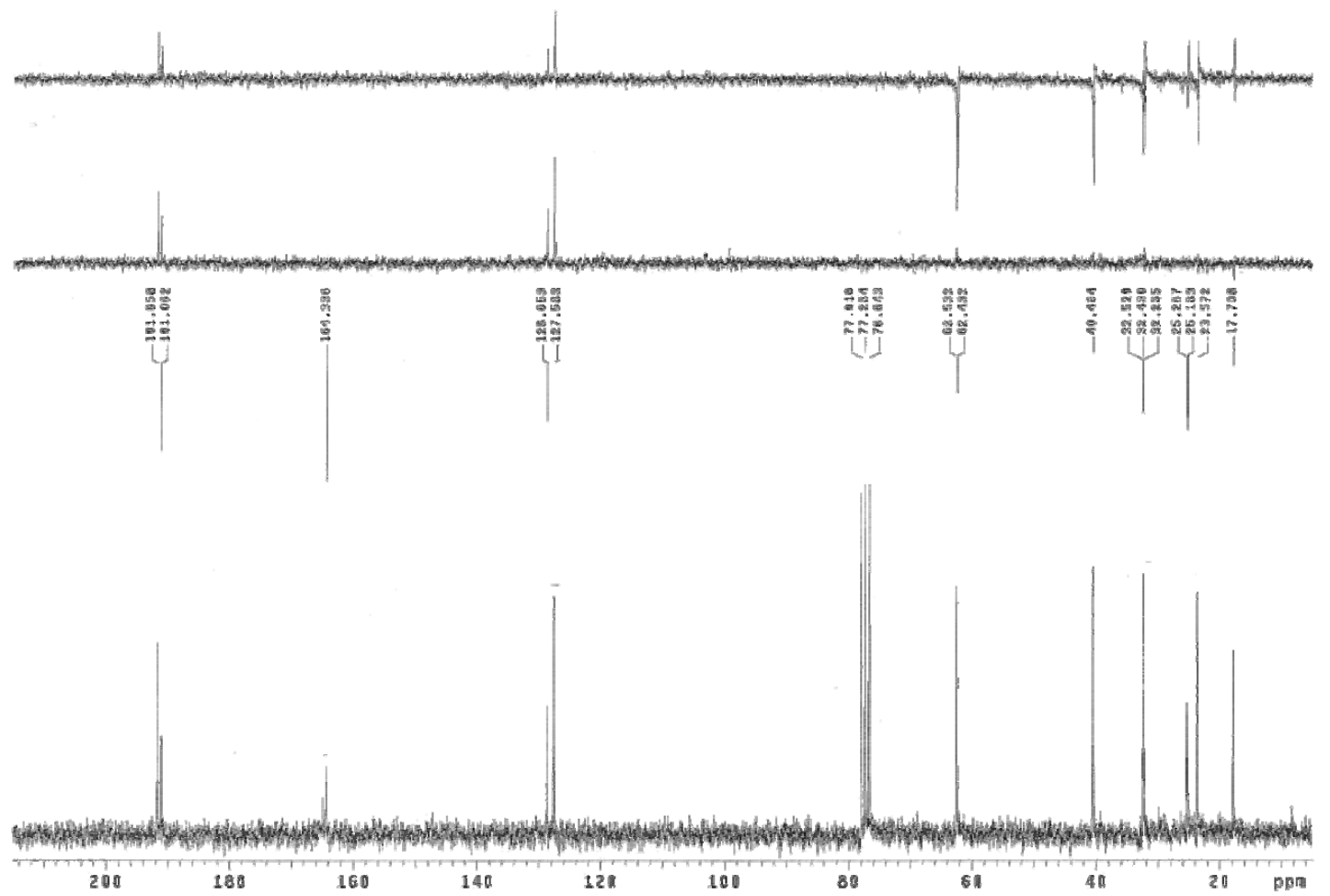

Fig. 85d

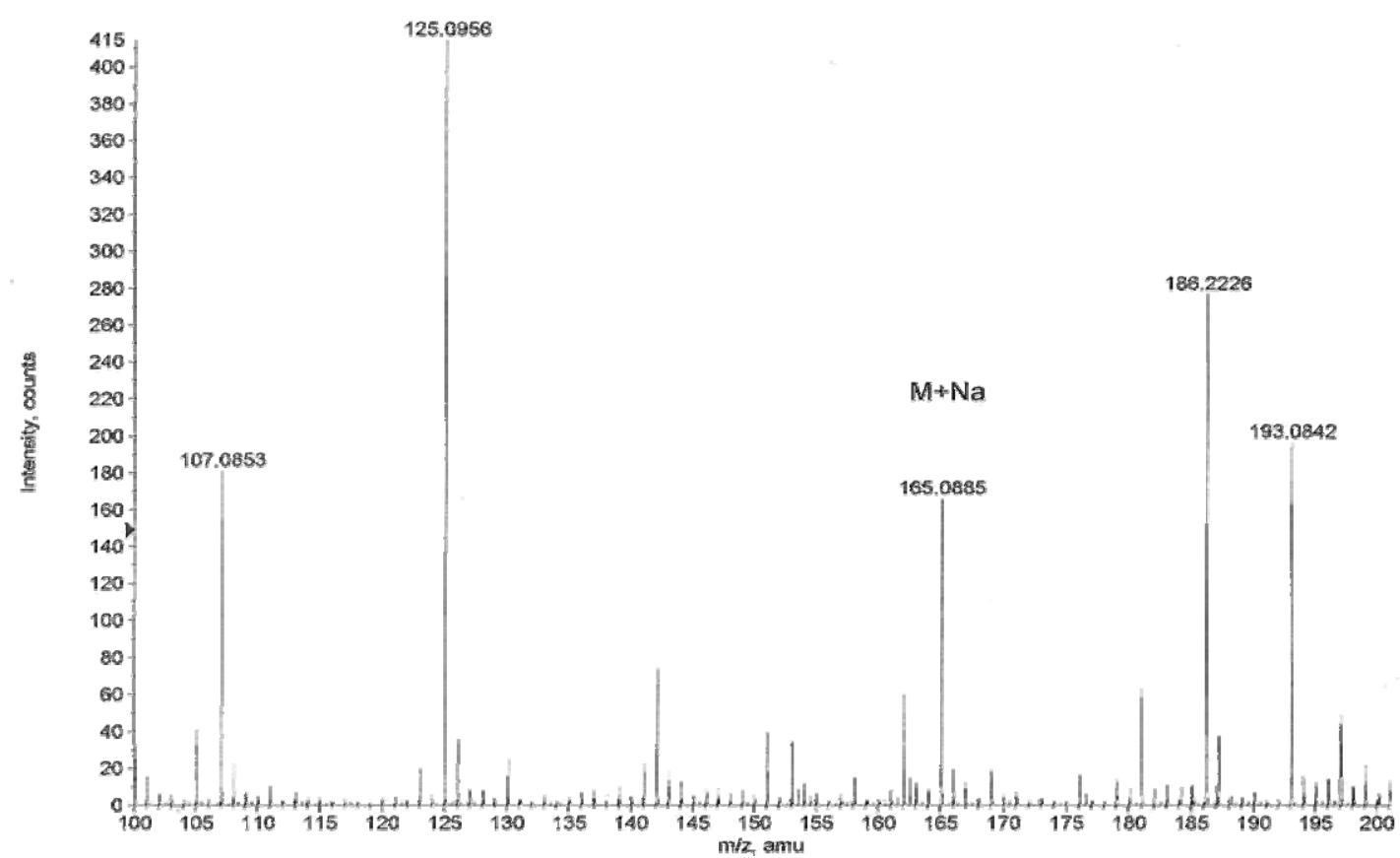


Fig. 86a

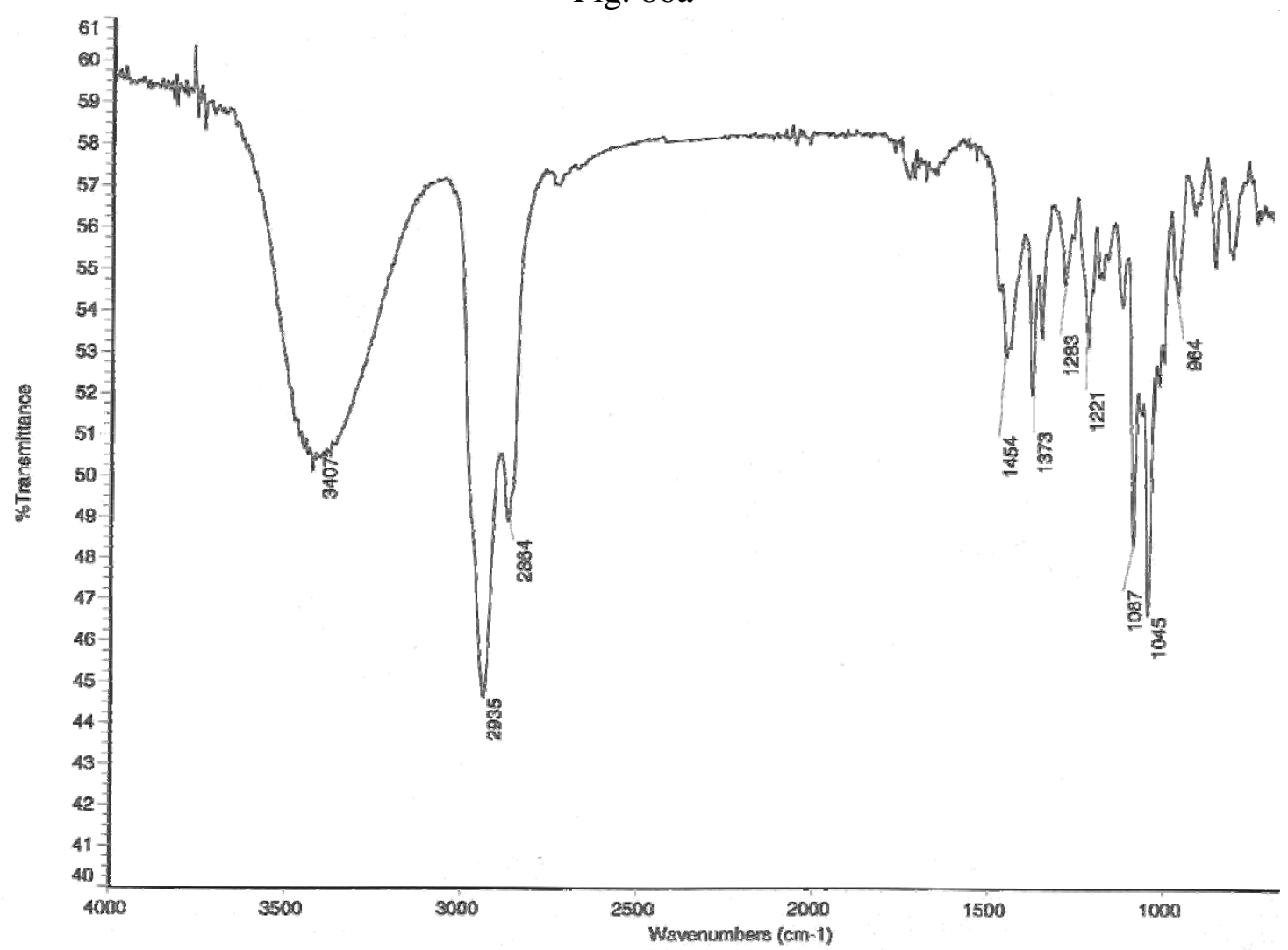

Fig. 86b

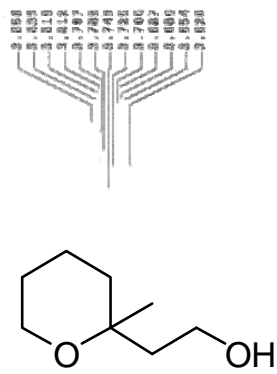

104

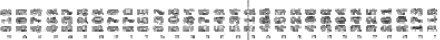
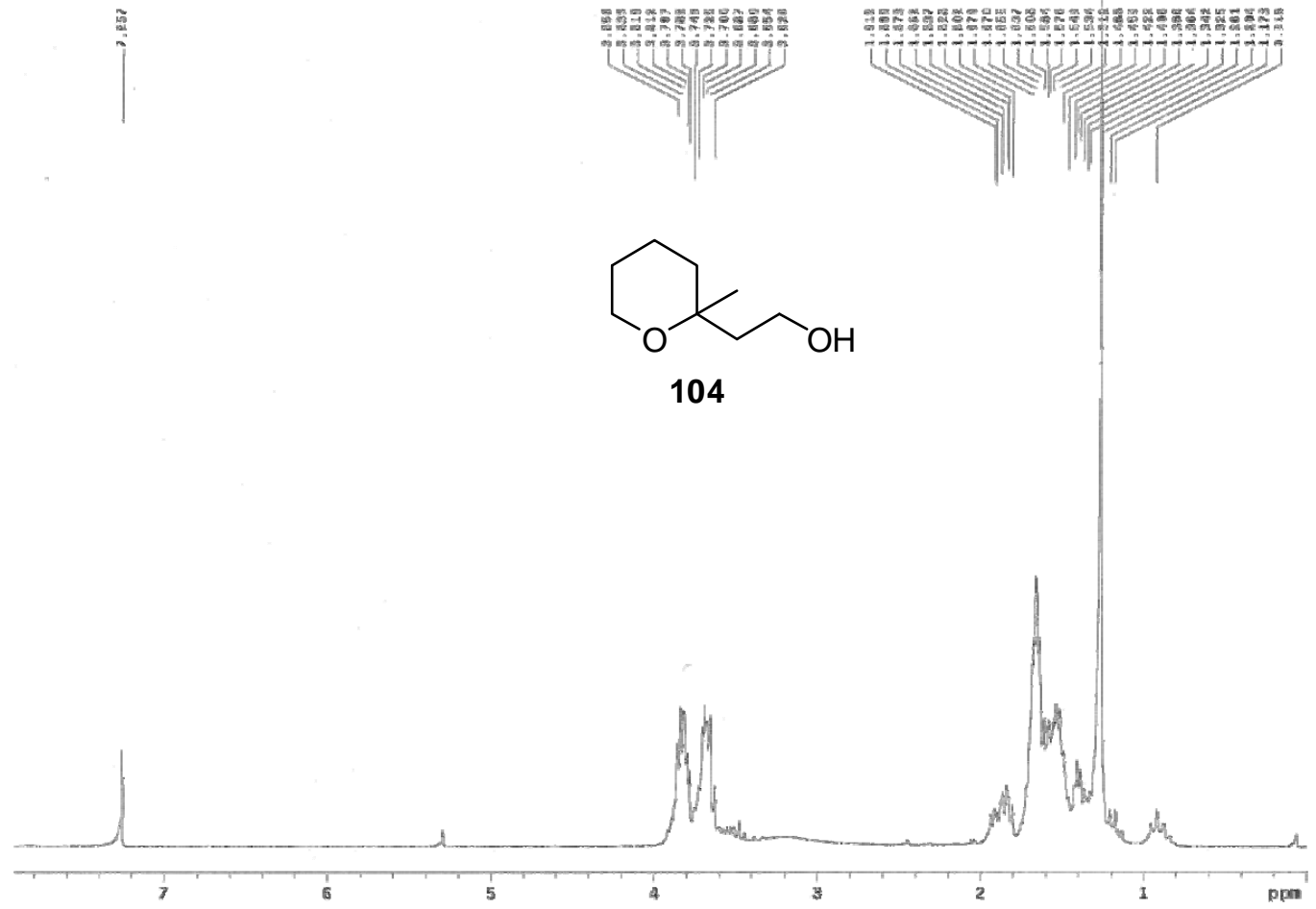
Fig. 86c
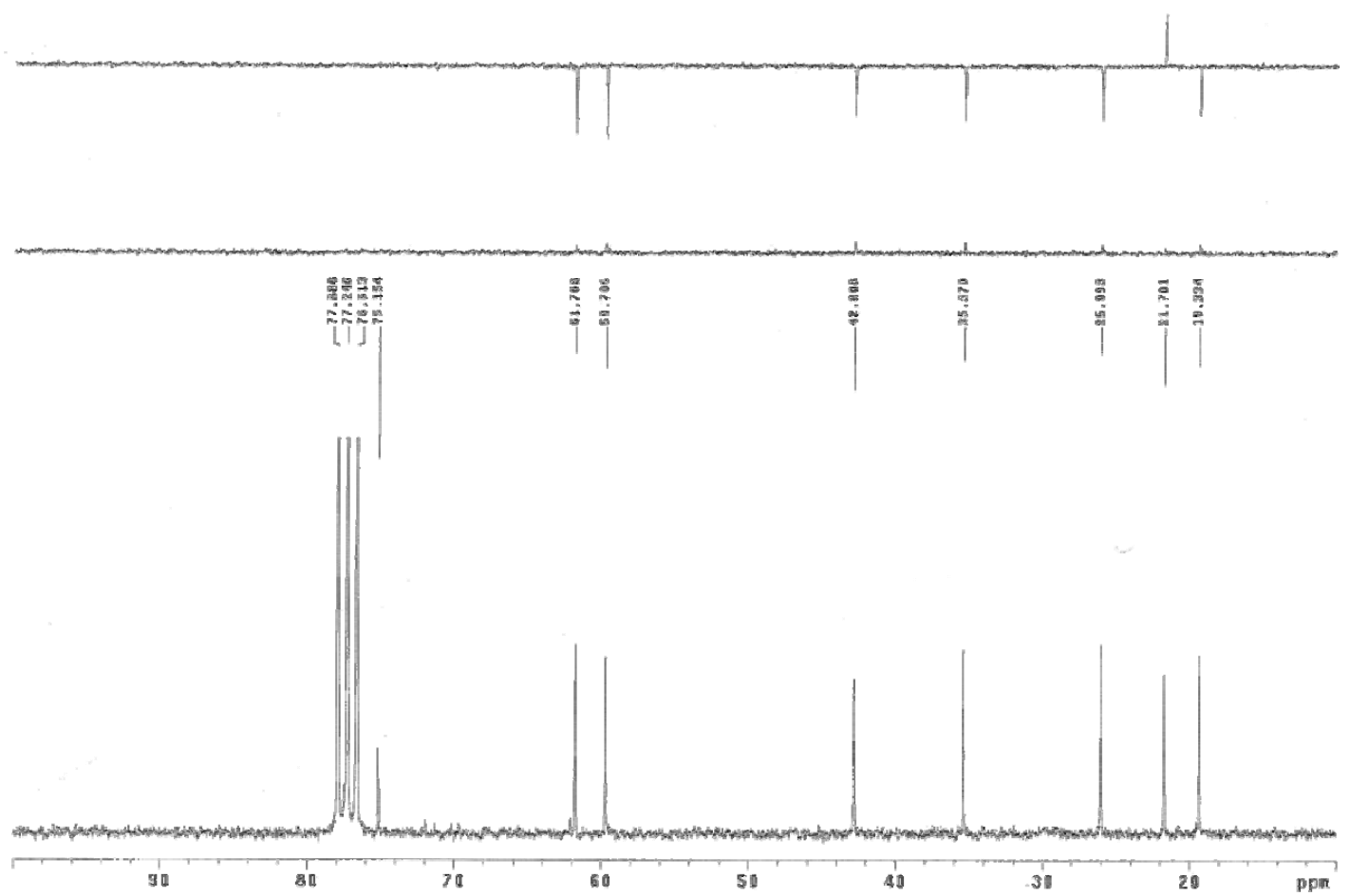

Fig. 86d

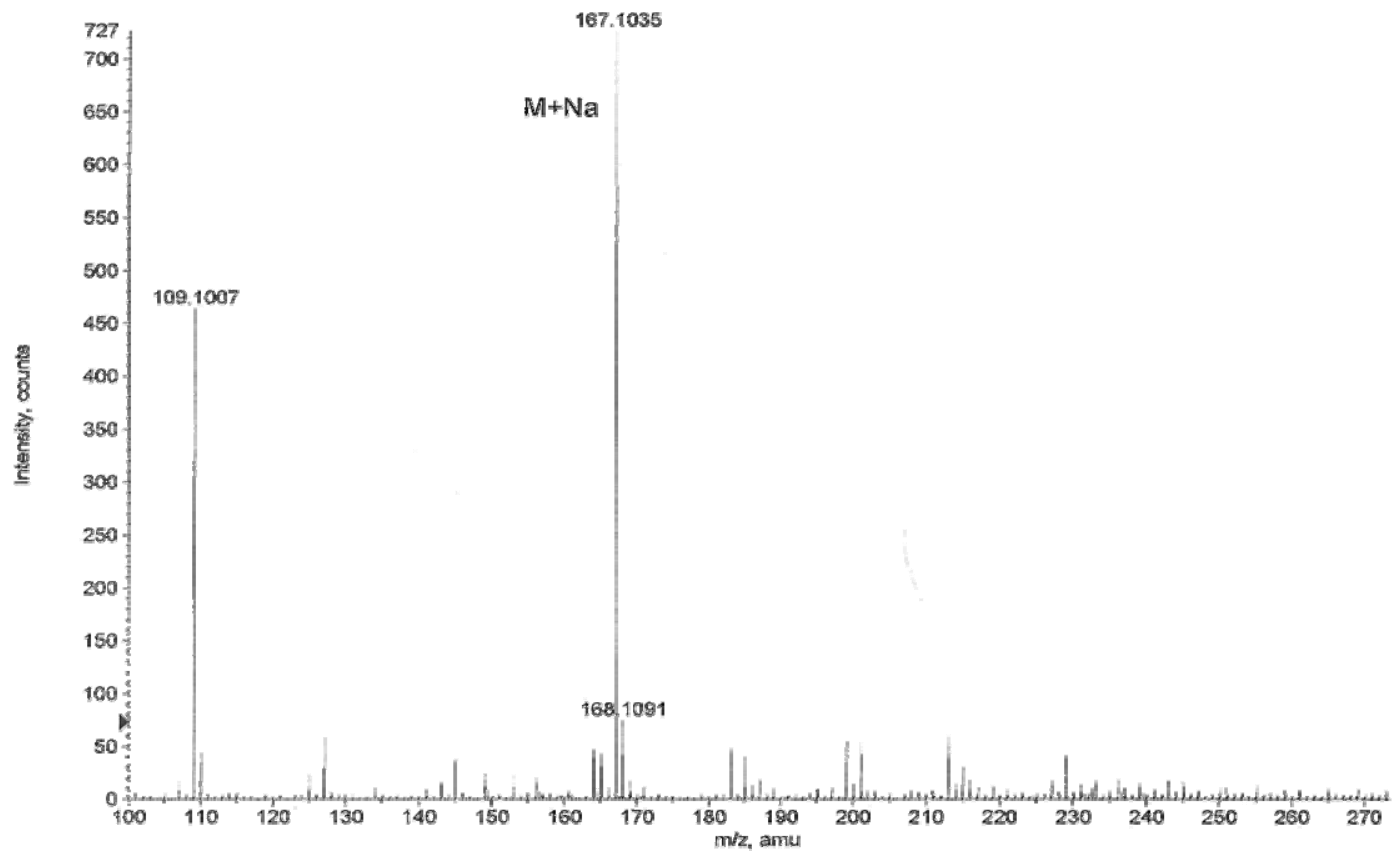


Fig. $87 a$

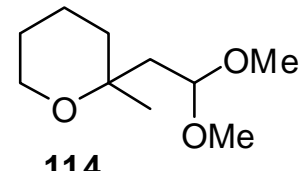

114

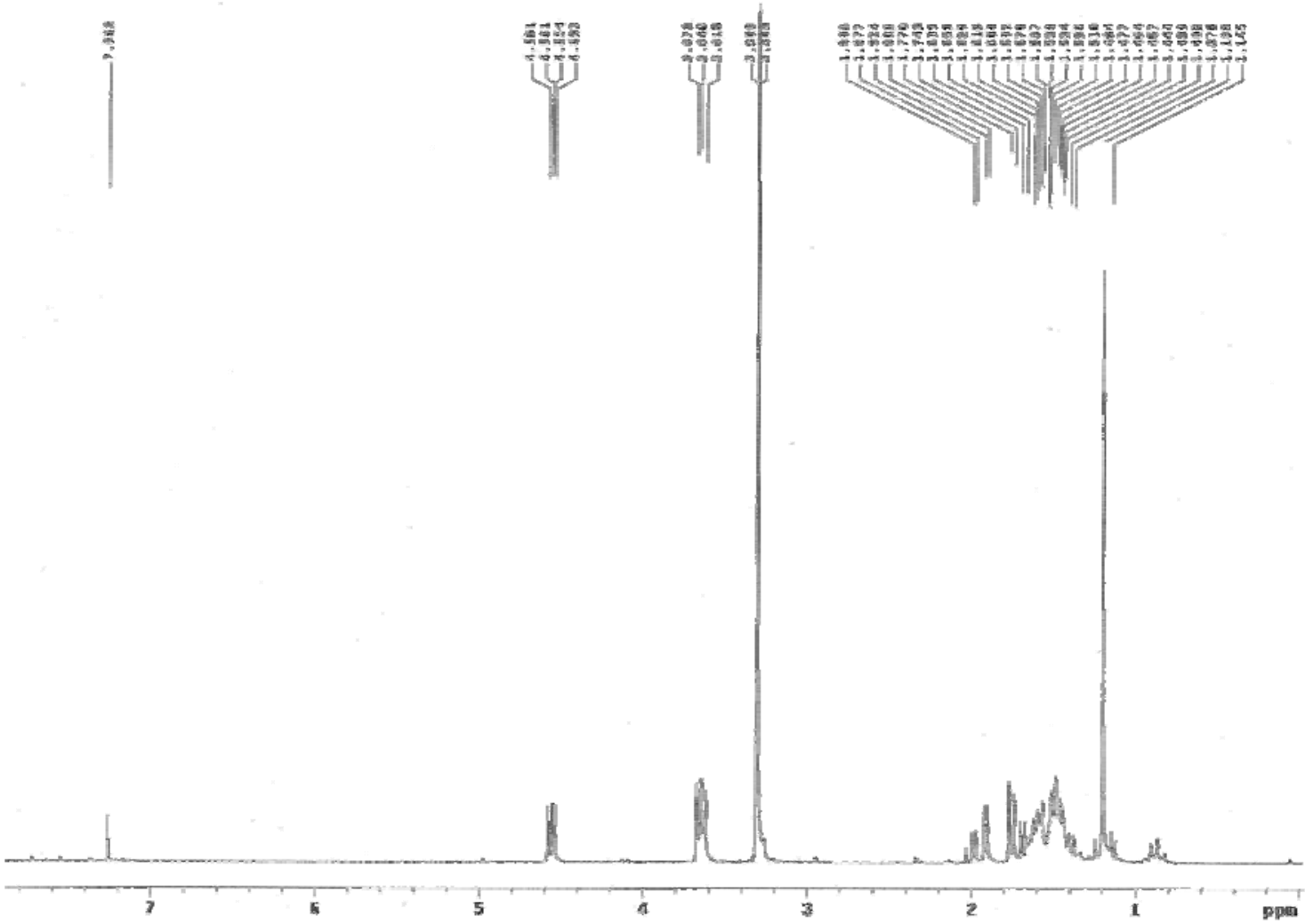


Fig. 88a

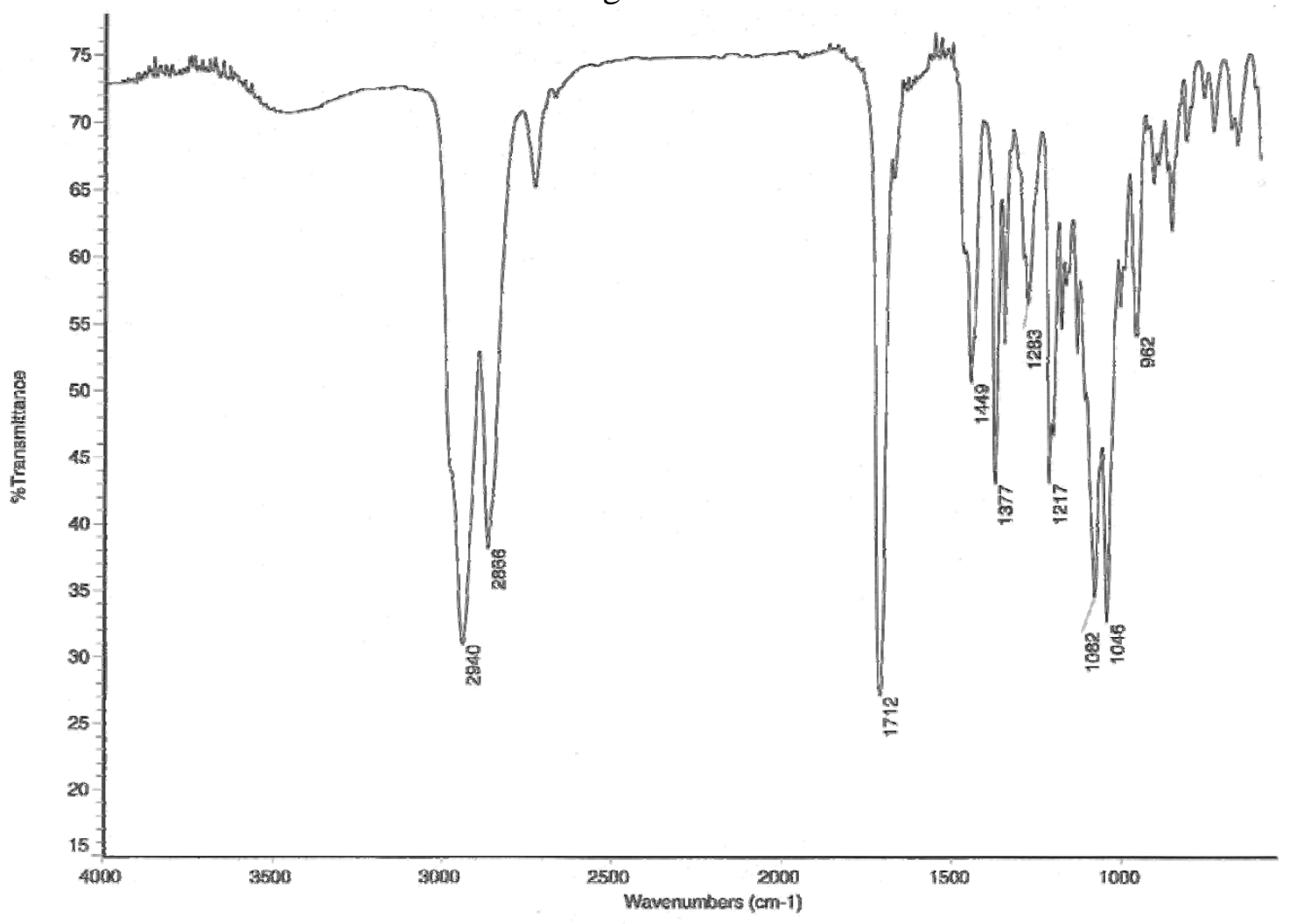

Fig. 88b

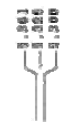

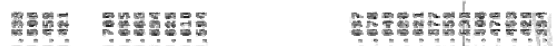
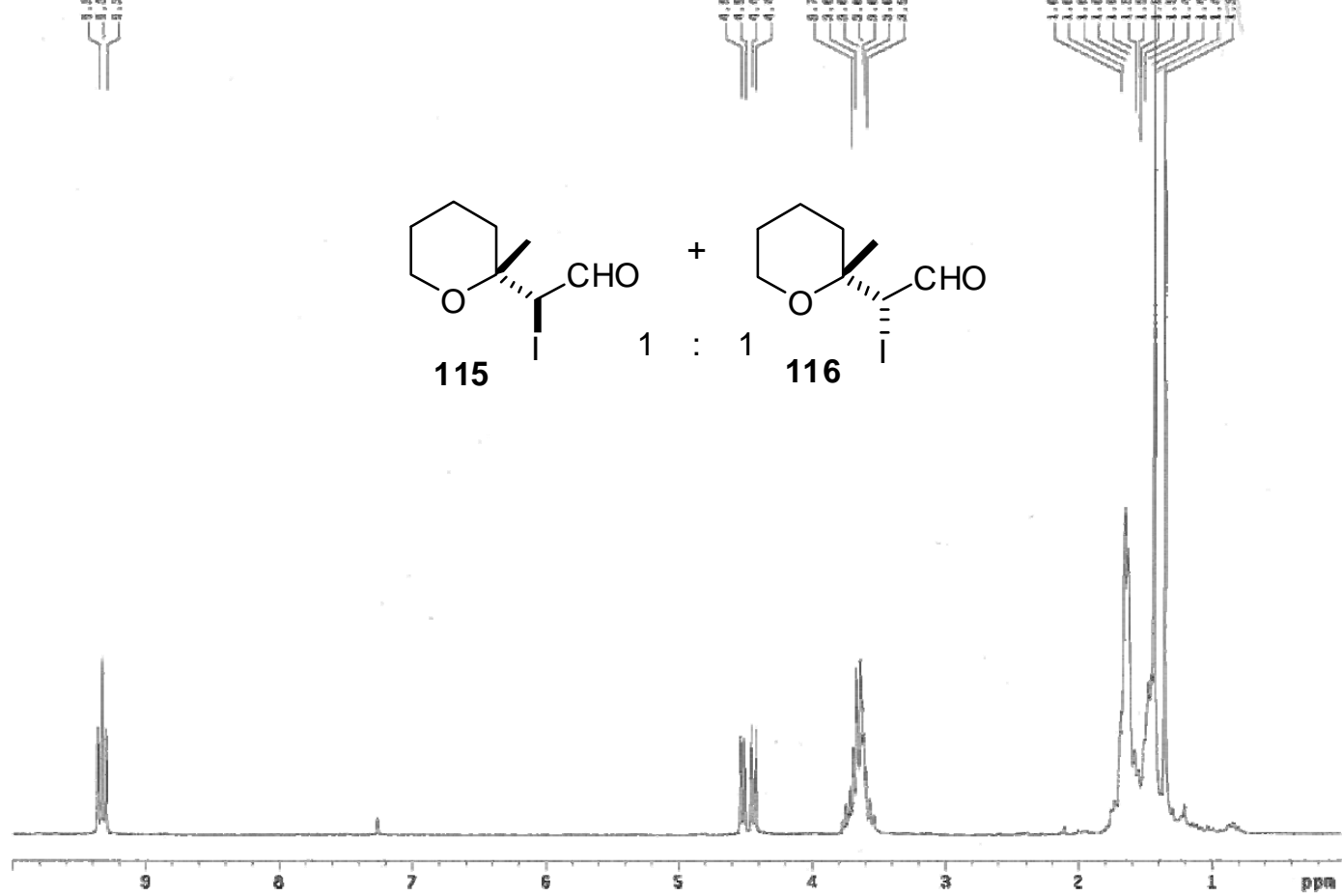
Fig. 88c
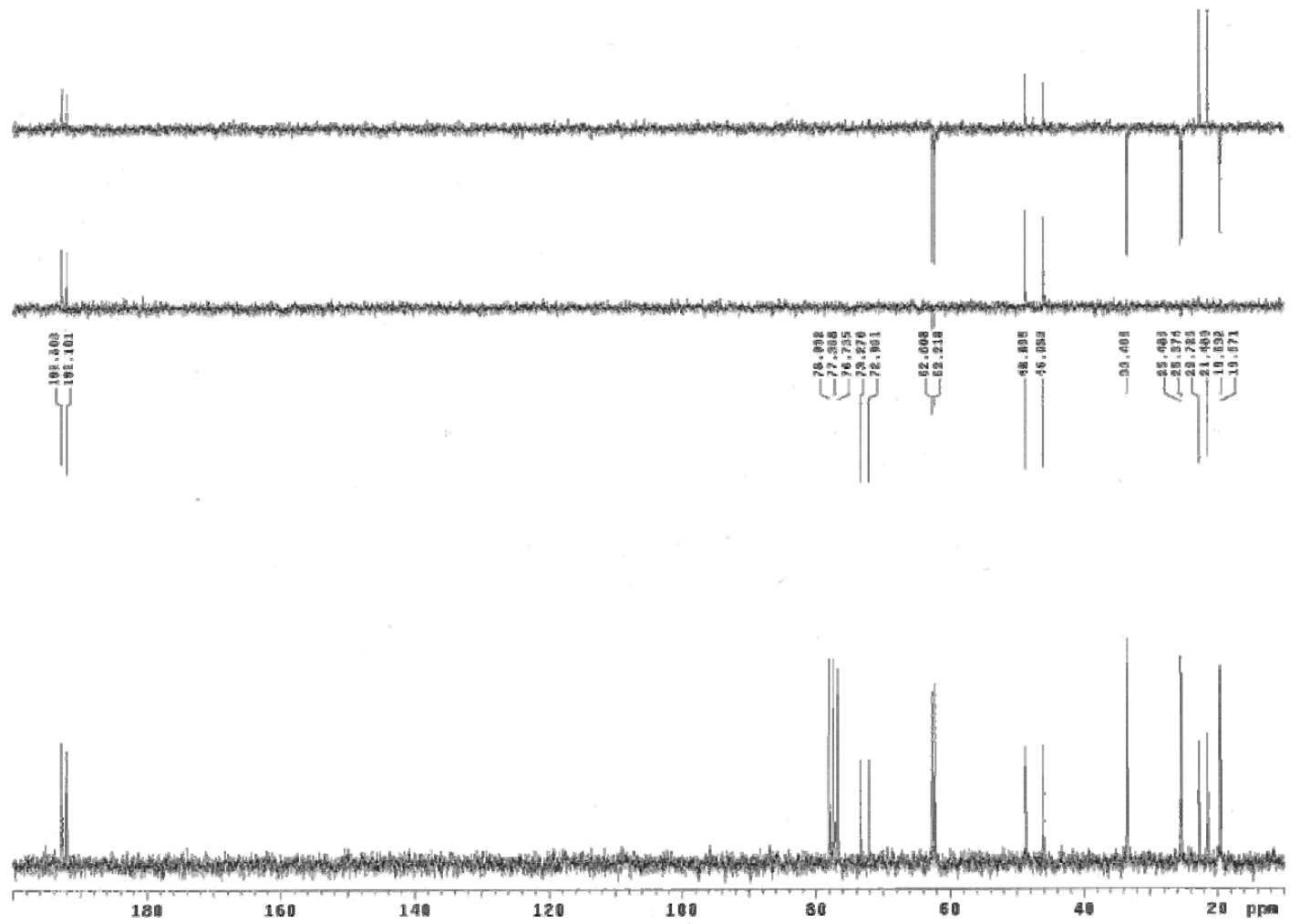

Fig. 88d

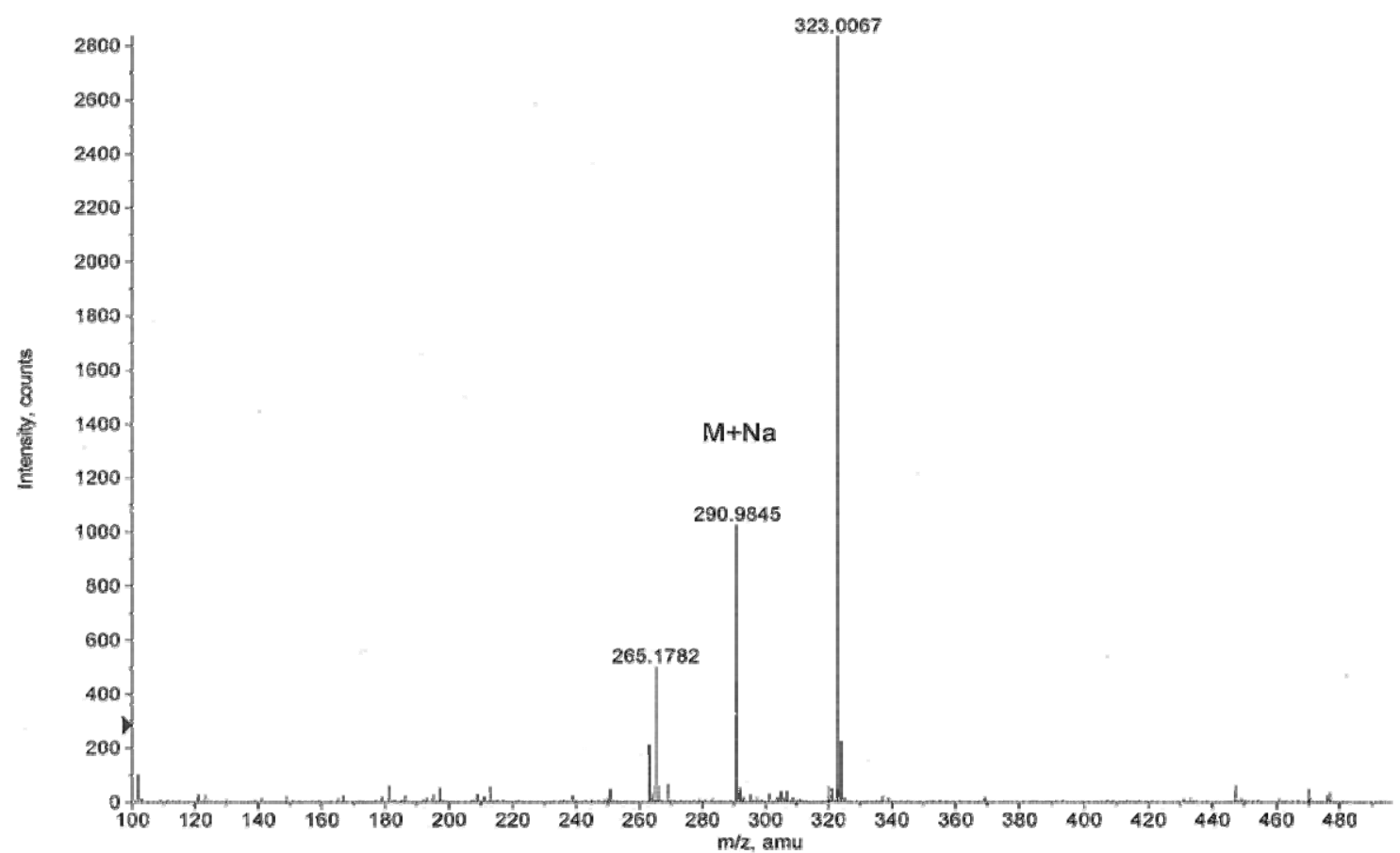


Fig. 89a

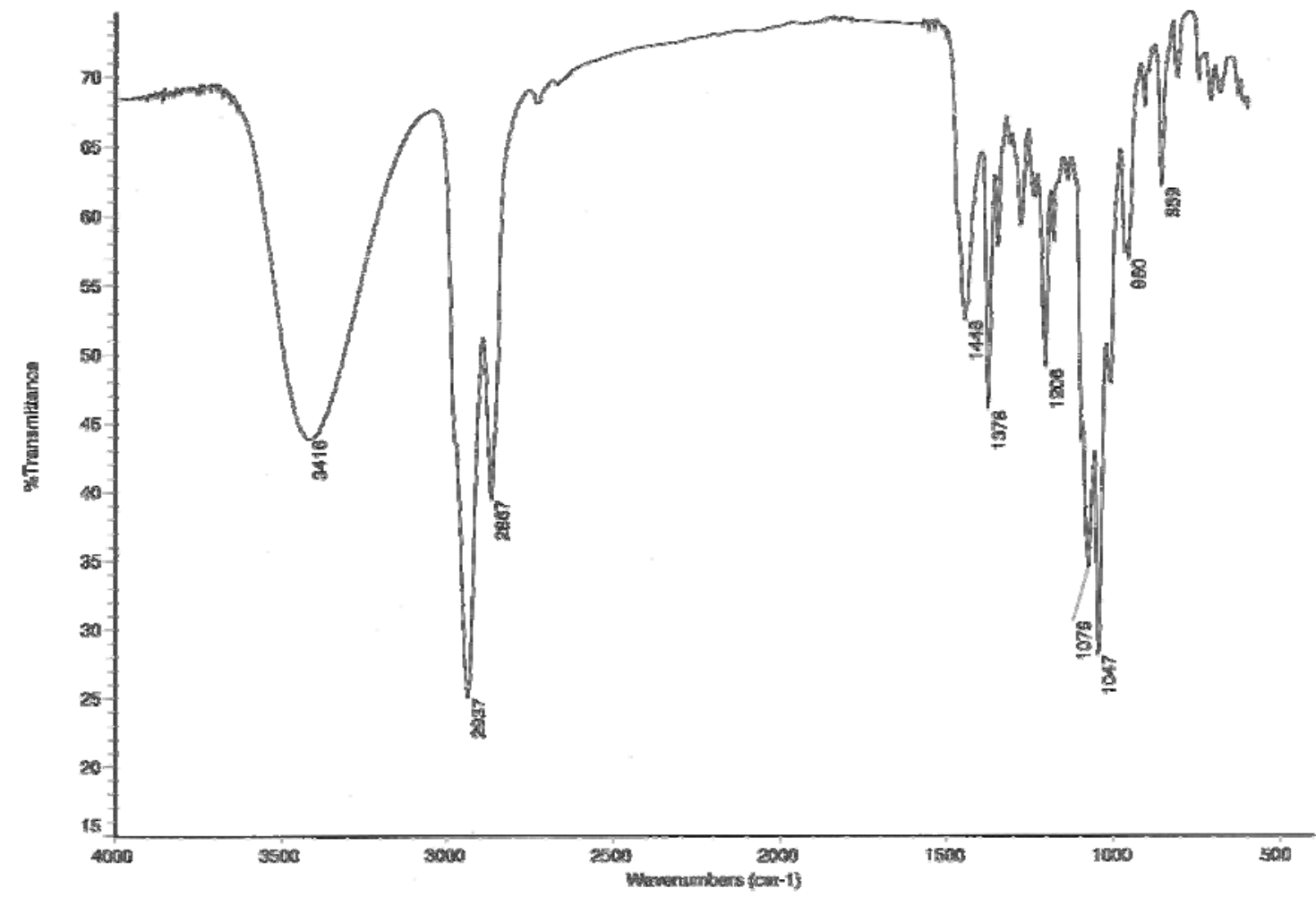

Fig. $89 b$

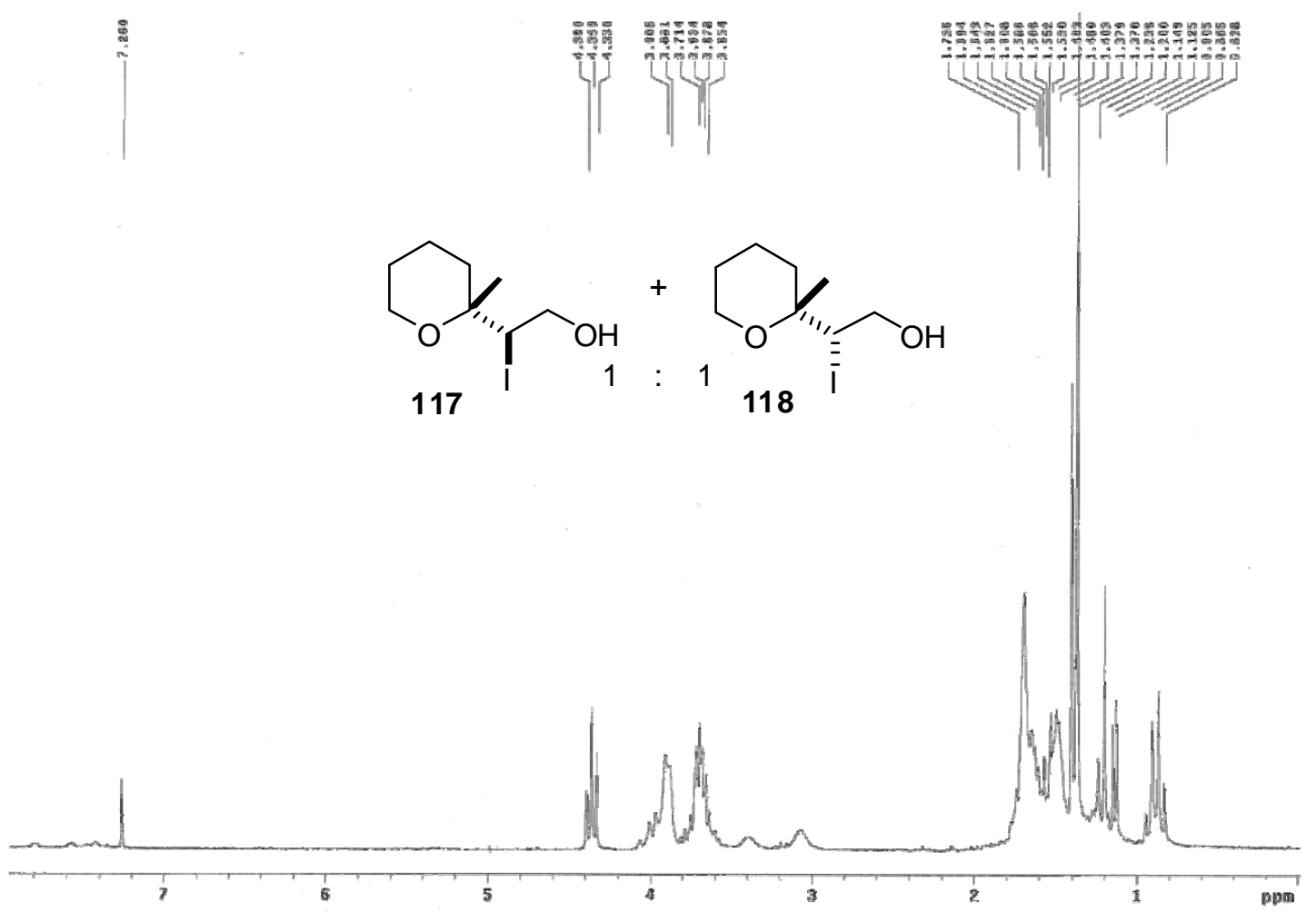


Fig. 89c

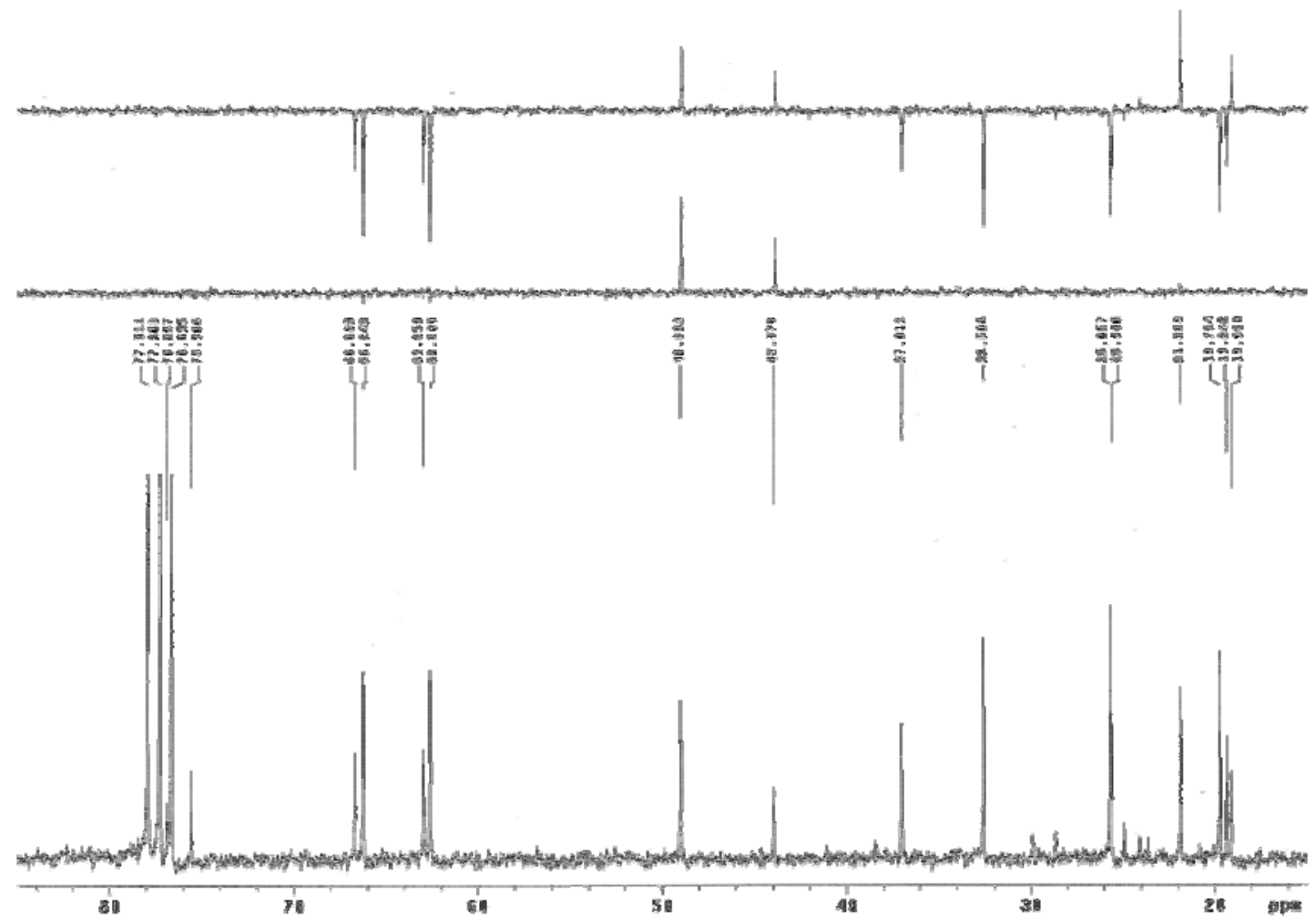


Fig. 90a

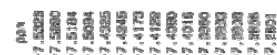

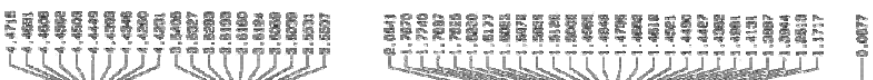

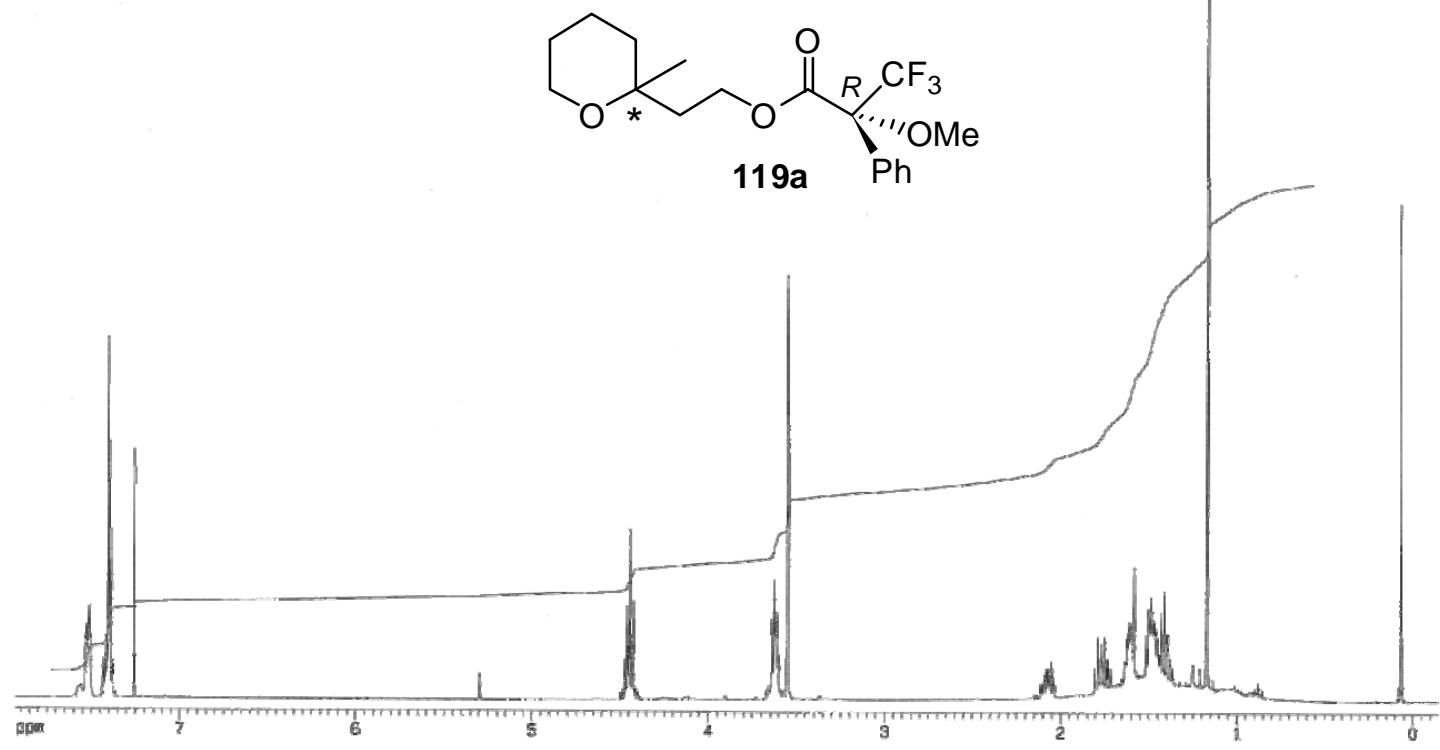

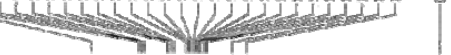

Fig. 90b
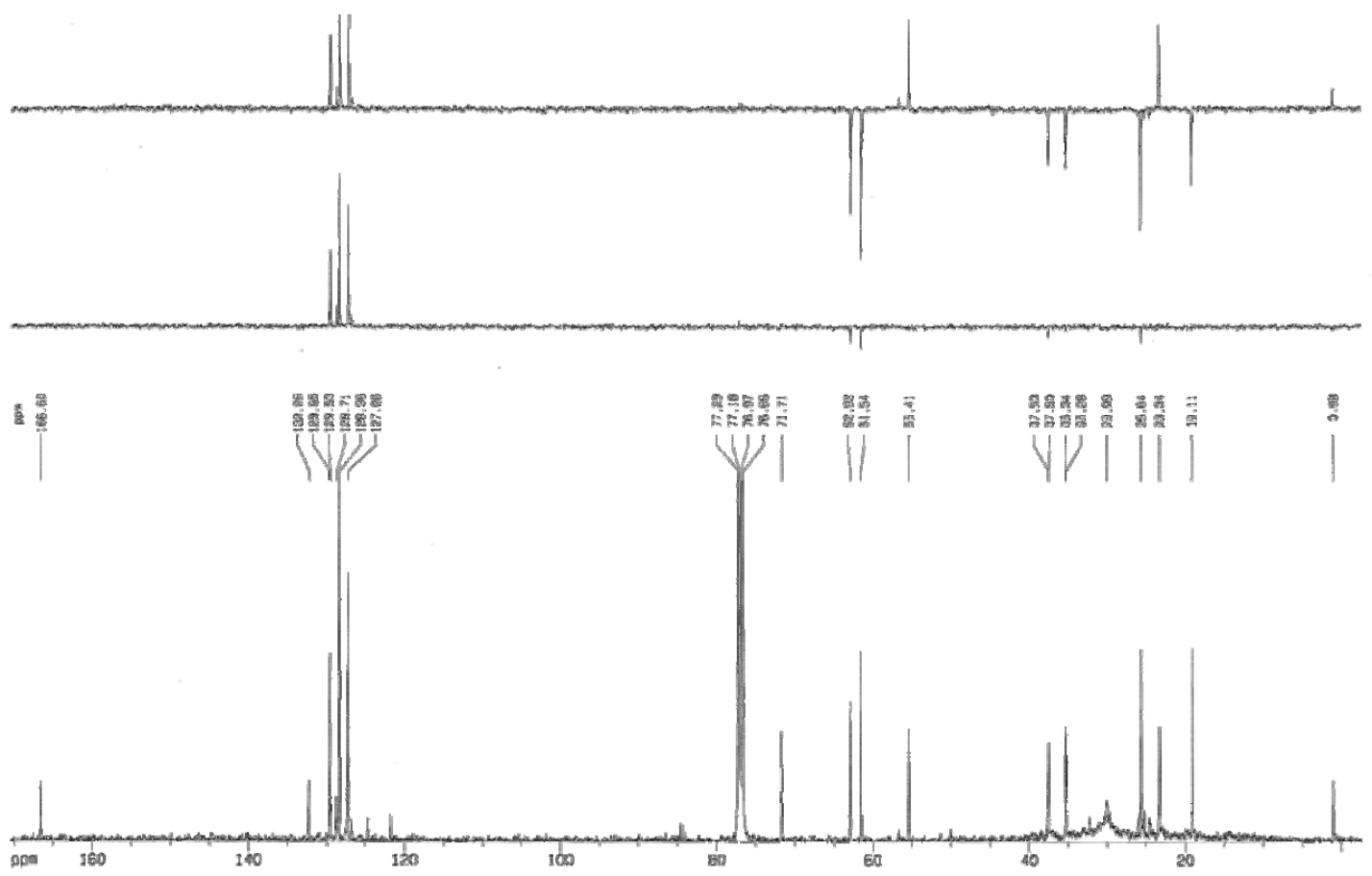
Fig. 91a

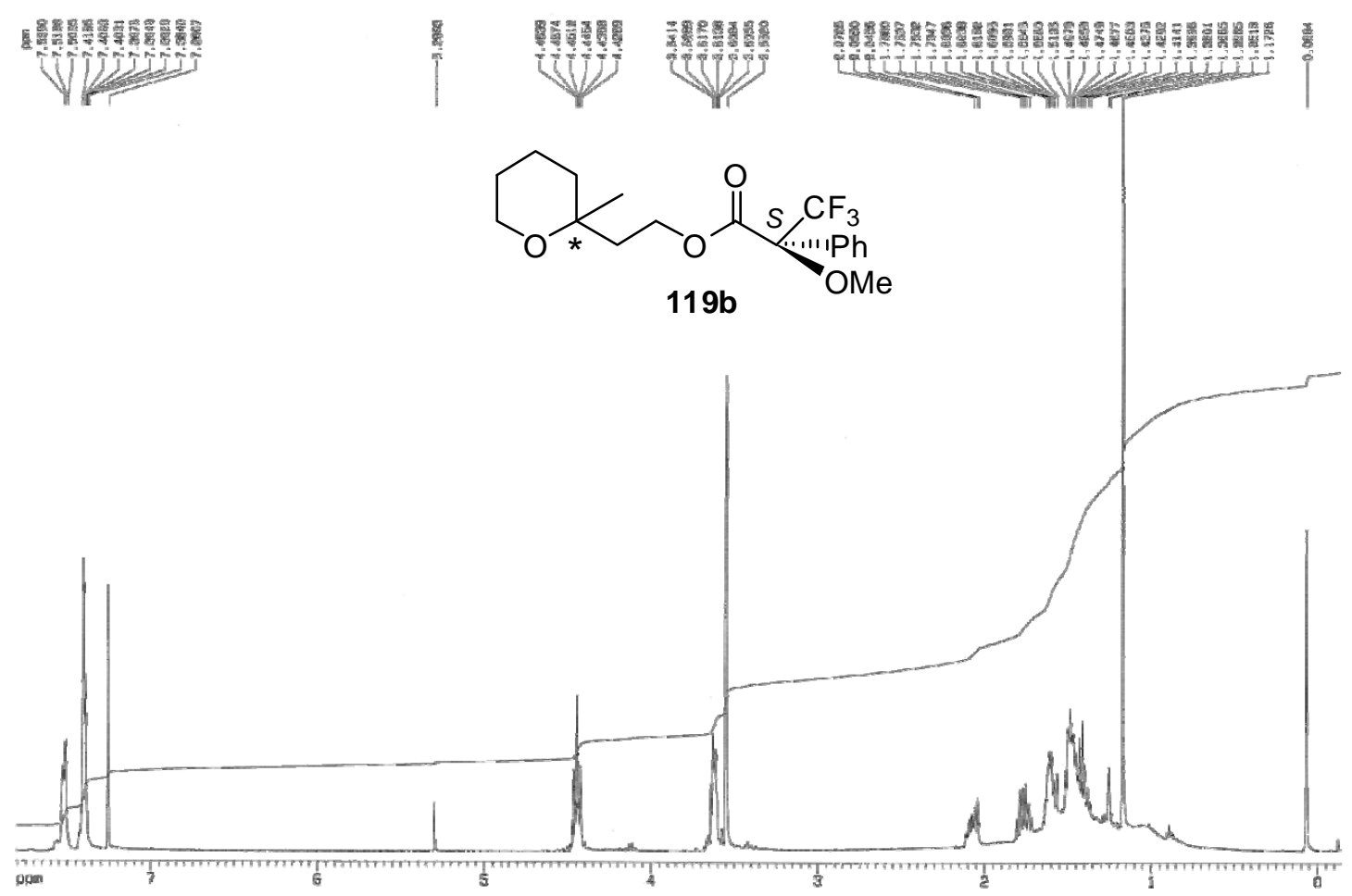

Fig. 91b

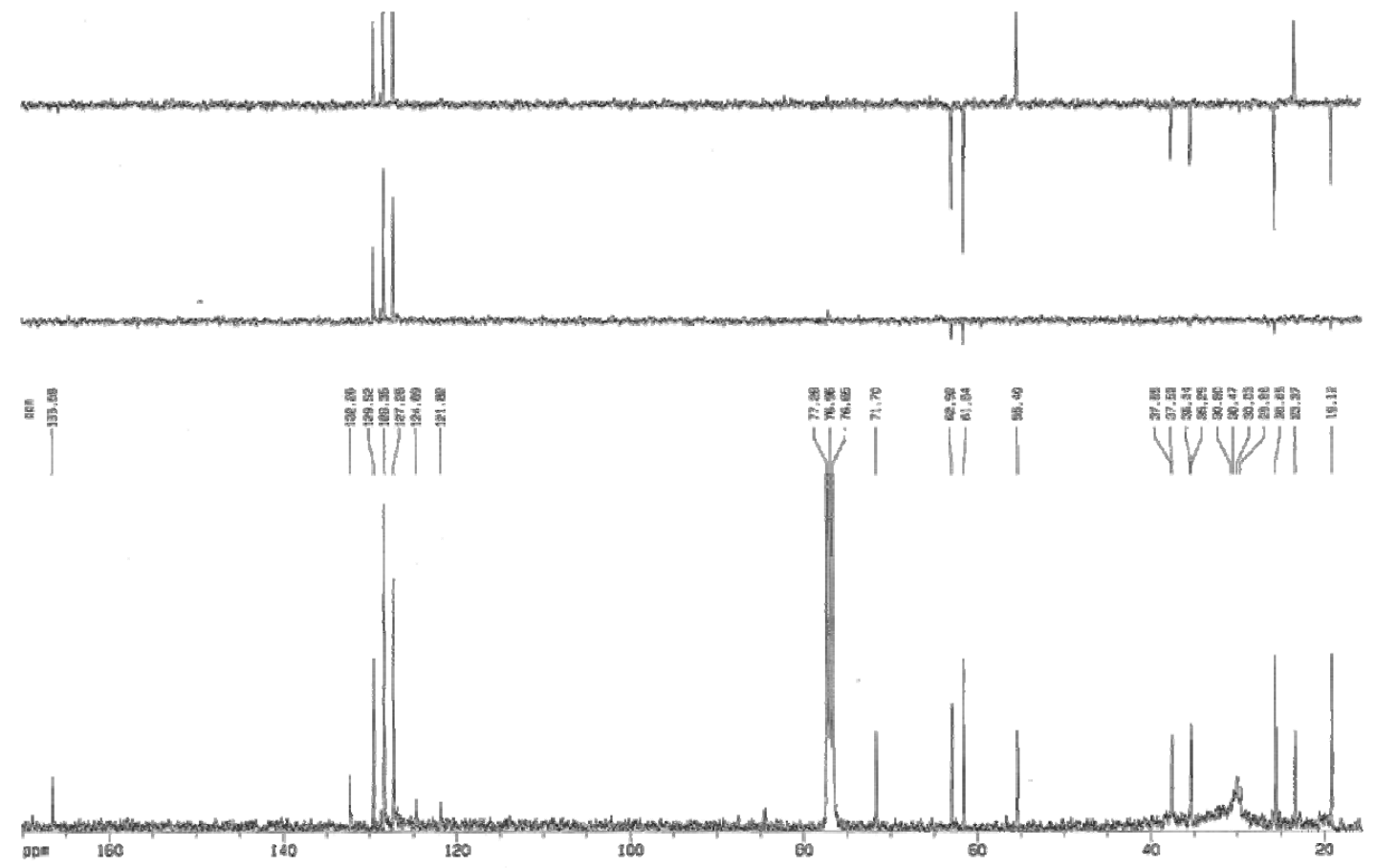


Fig. 92a

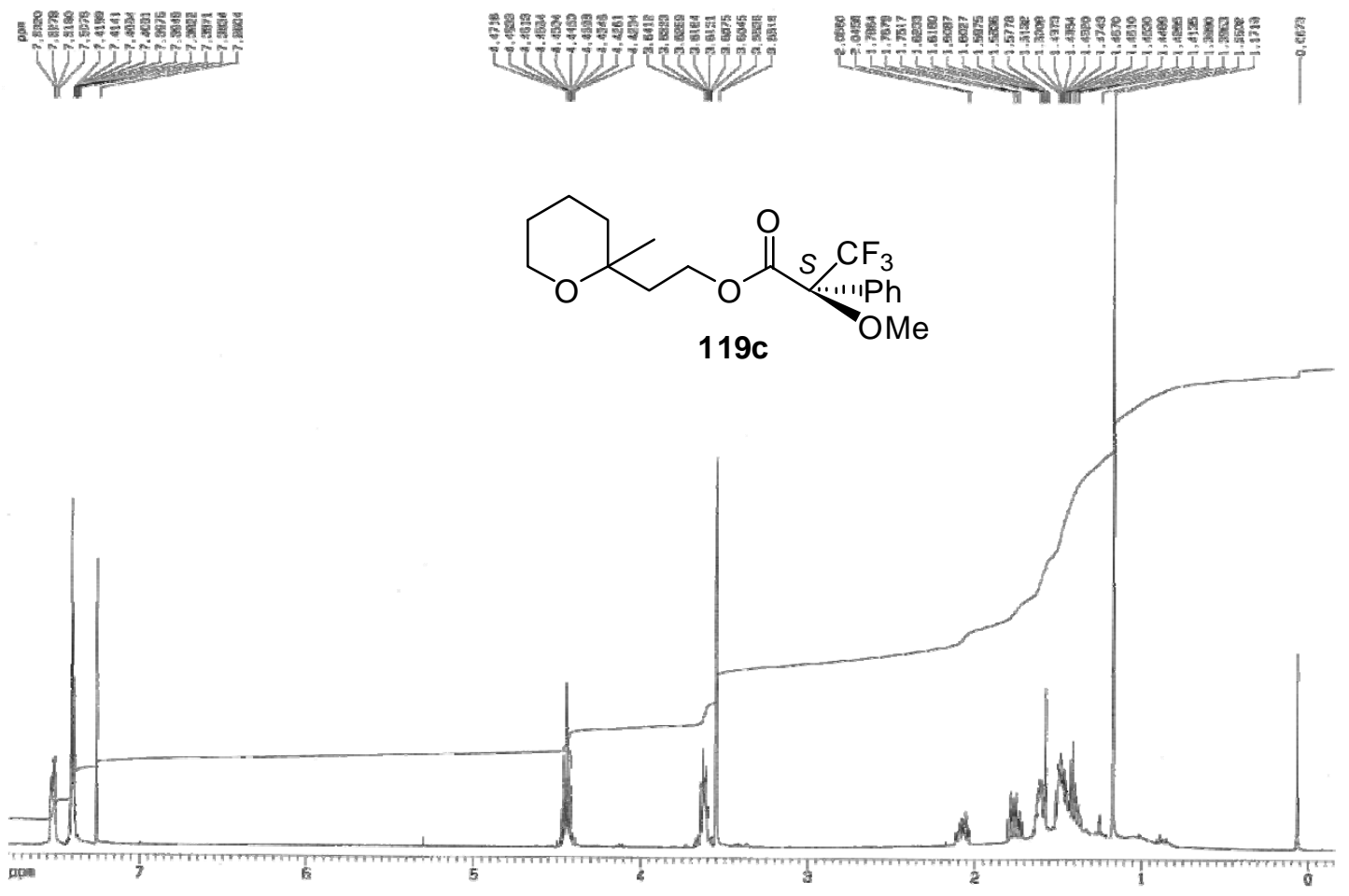

Fig. 92b
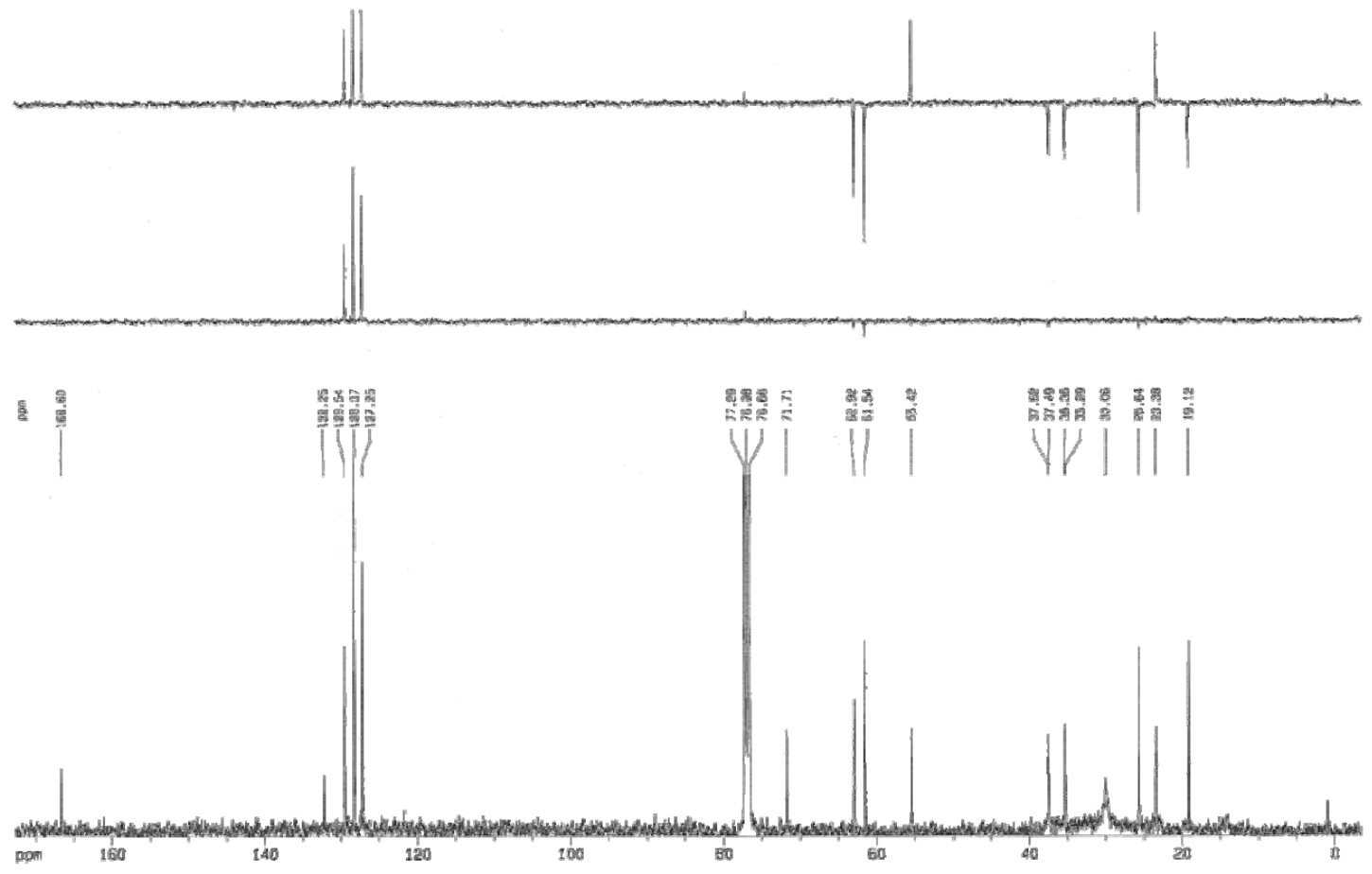
Fig. 93a

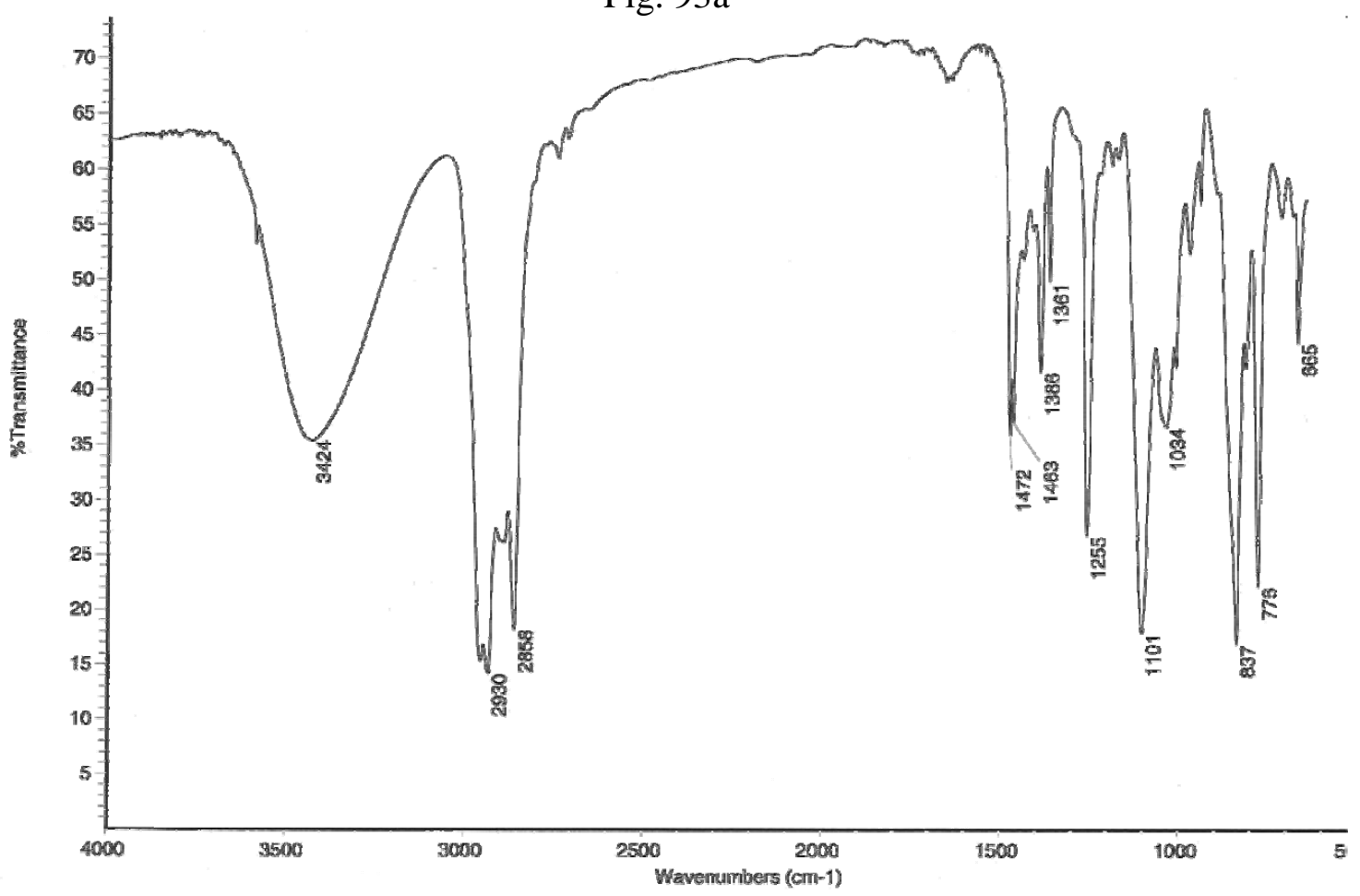

Fig. 93b

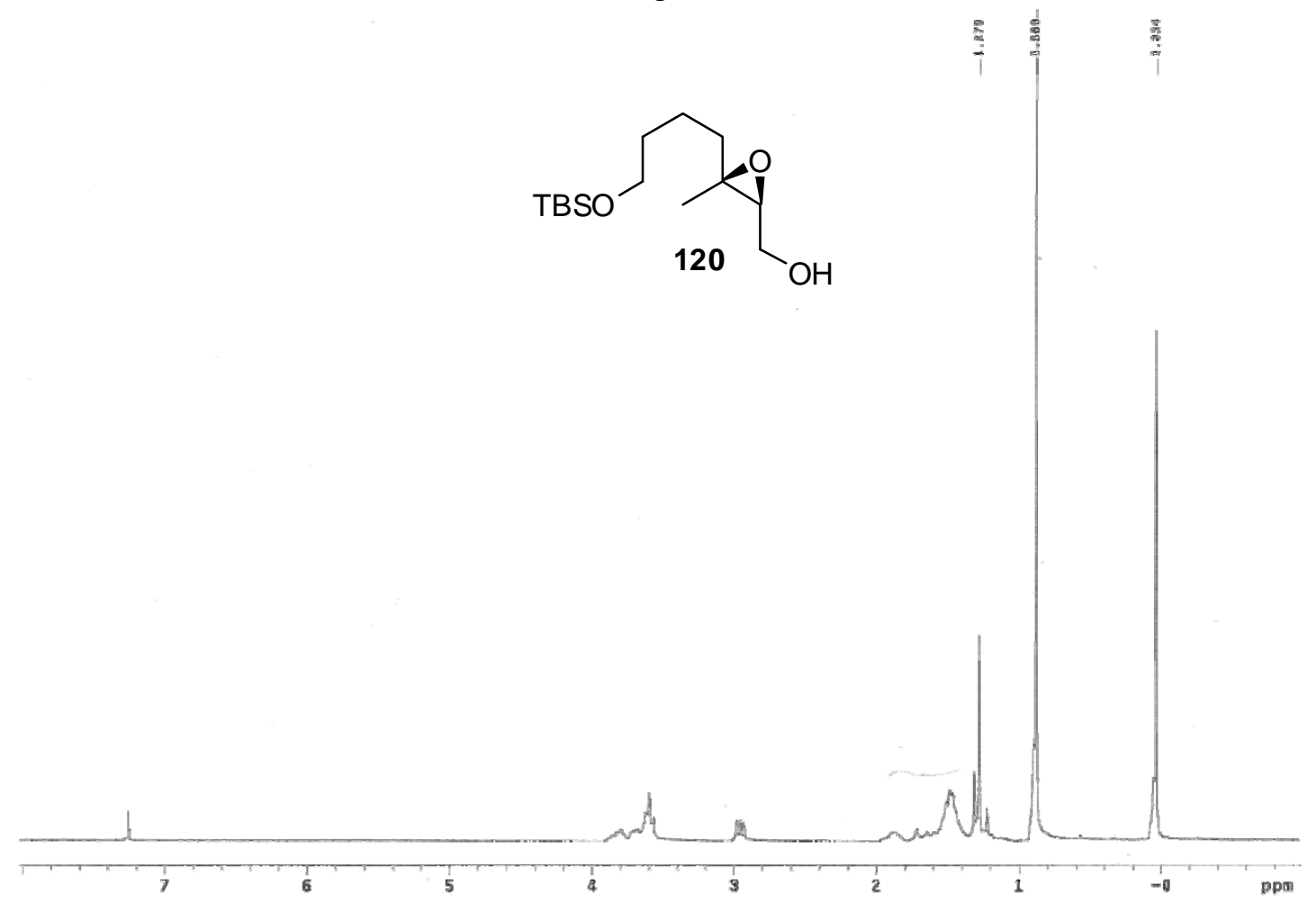


Fig. 93c

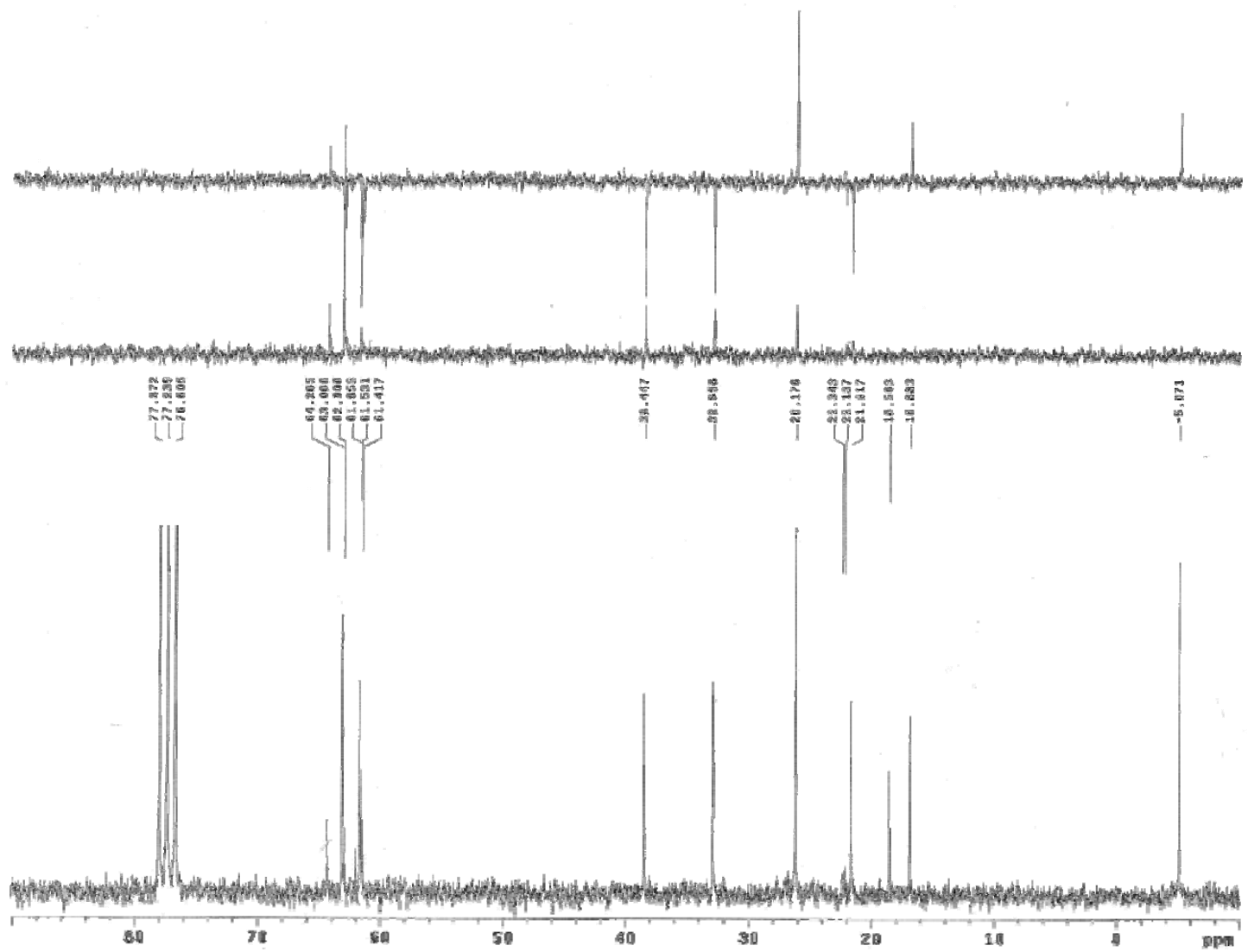

Fig. 93d

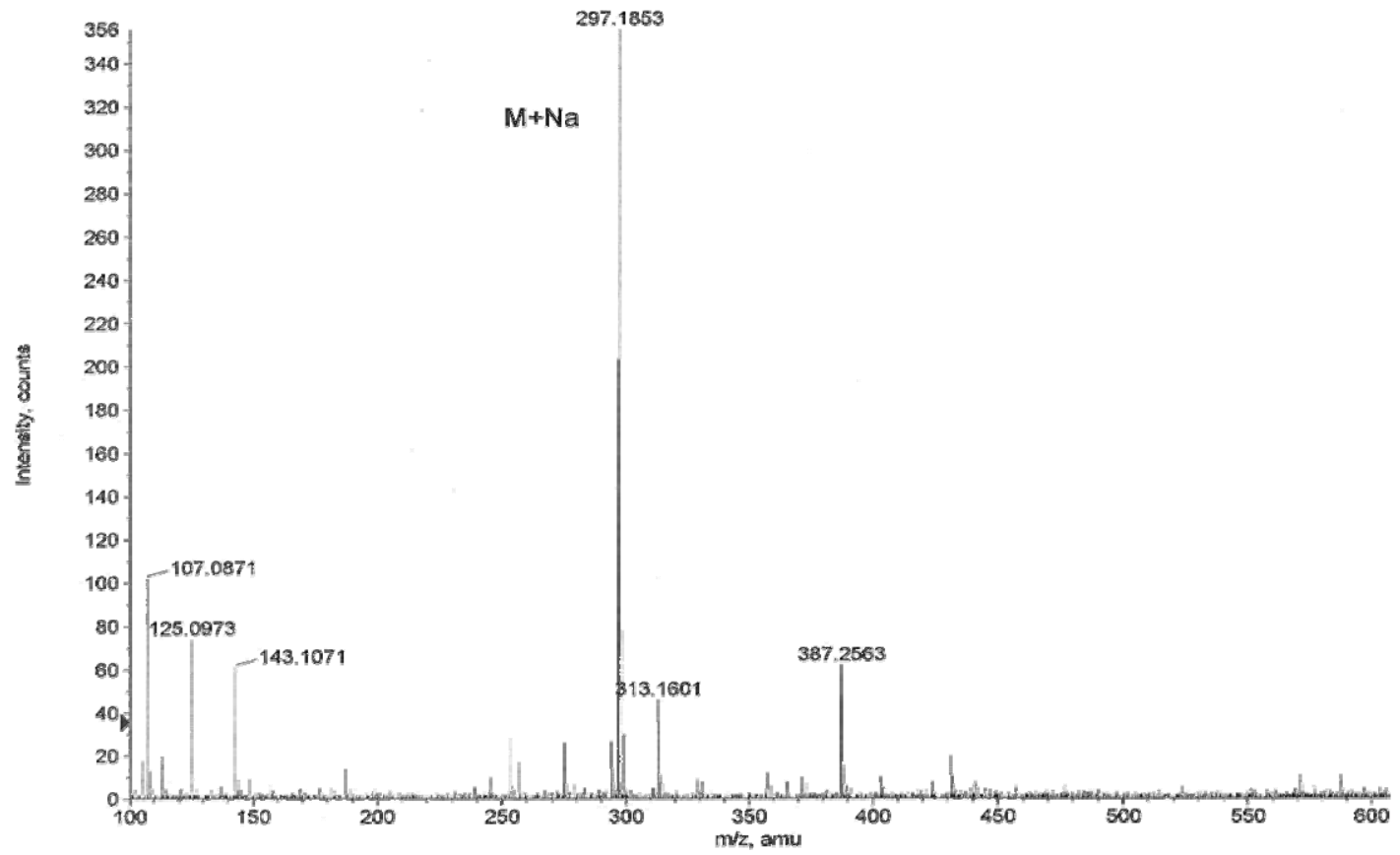


Fig. 94a

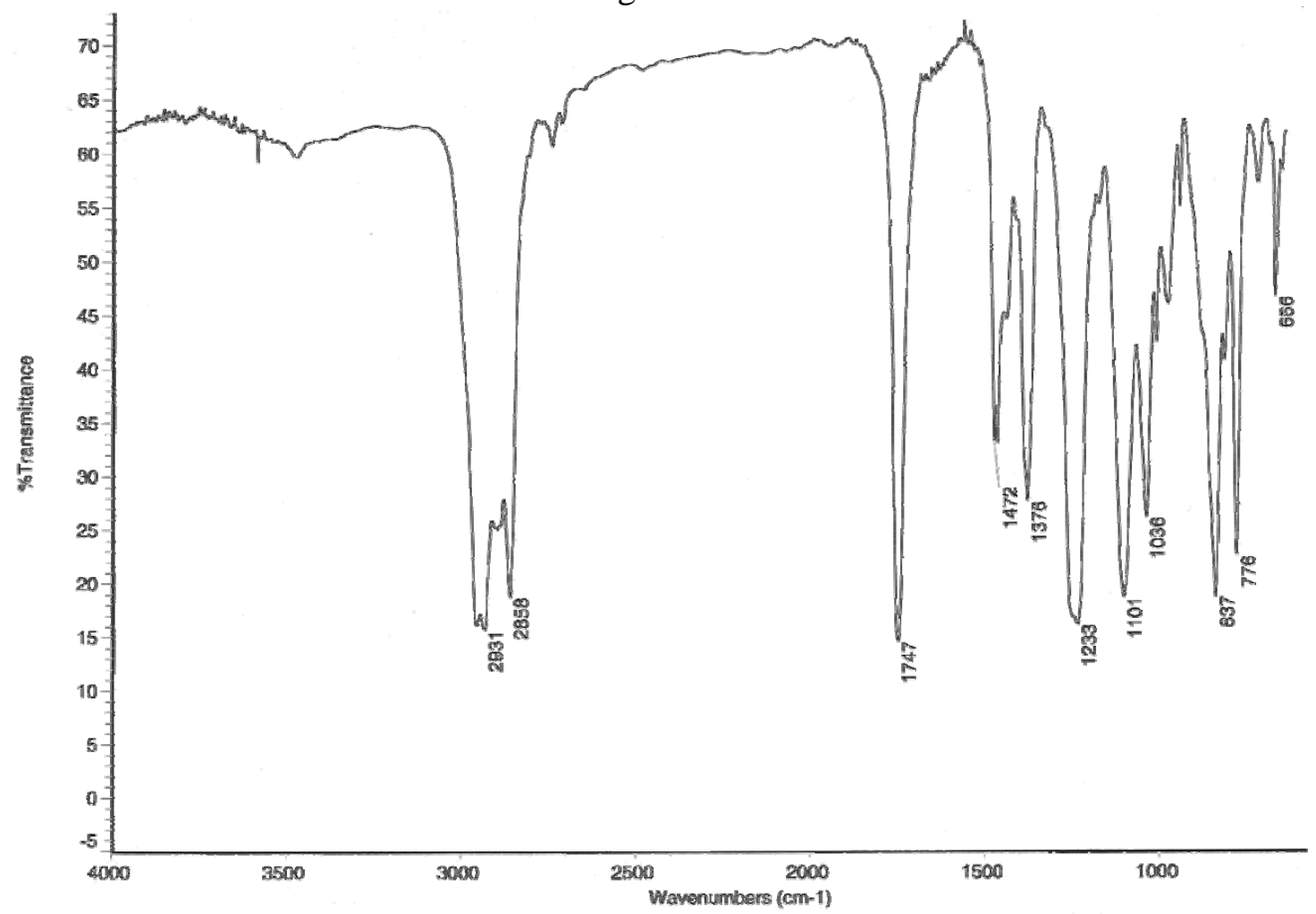

Fig. 94b

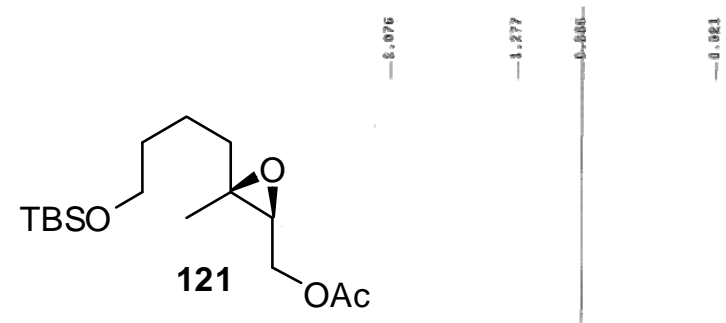


Fig. 94c

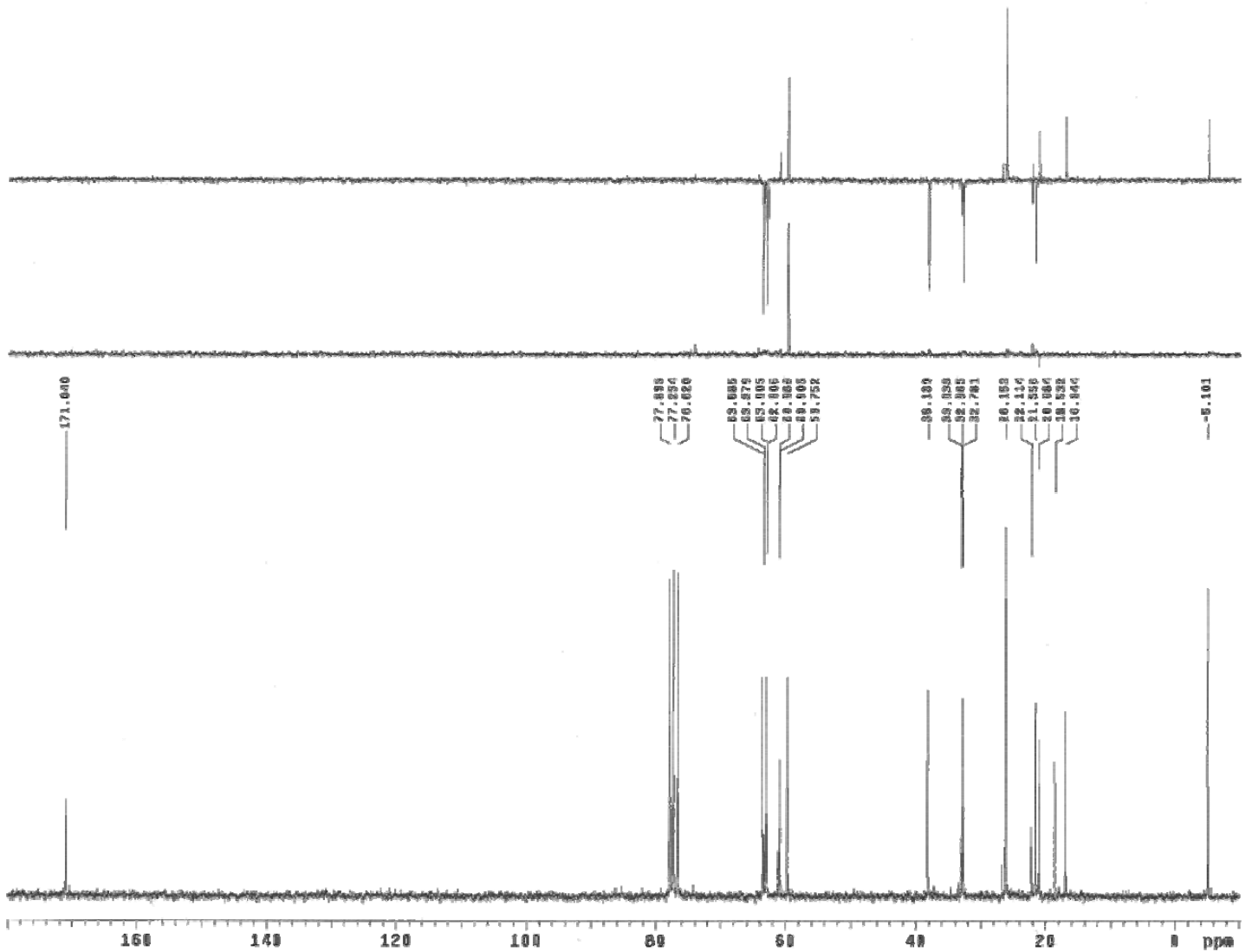

Fig. 94d

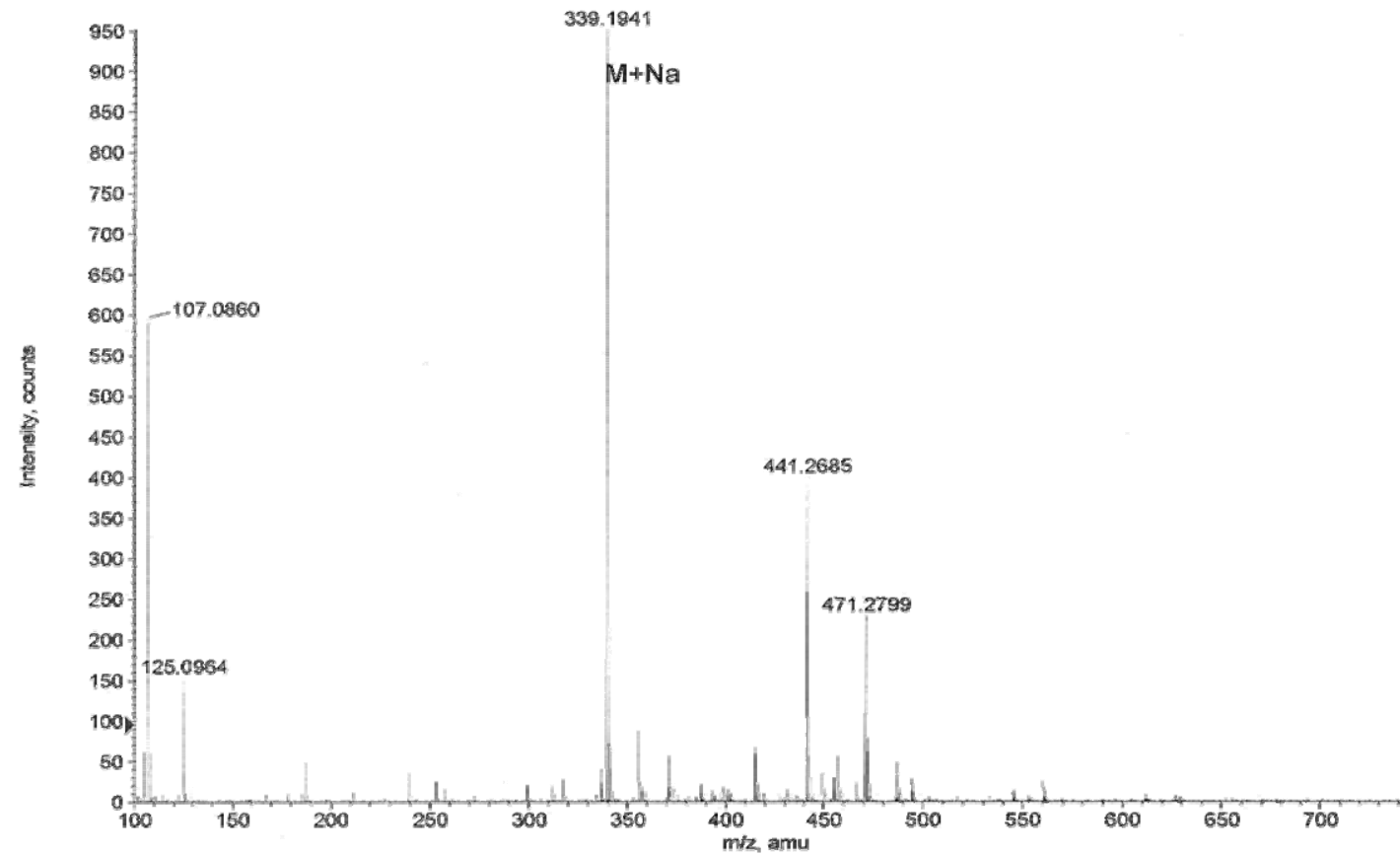


Fig. 95a

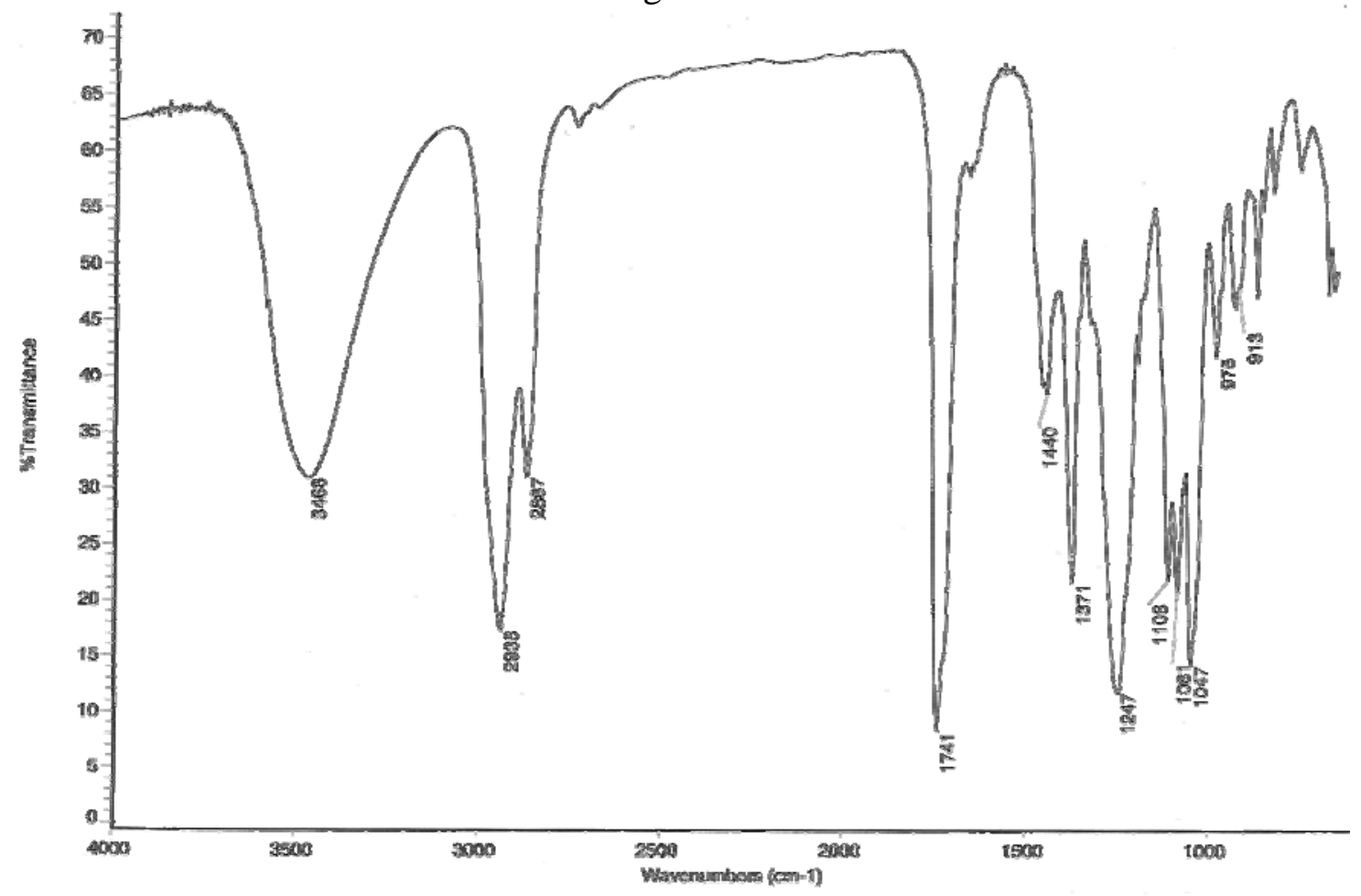

Fig. 95b

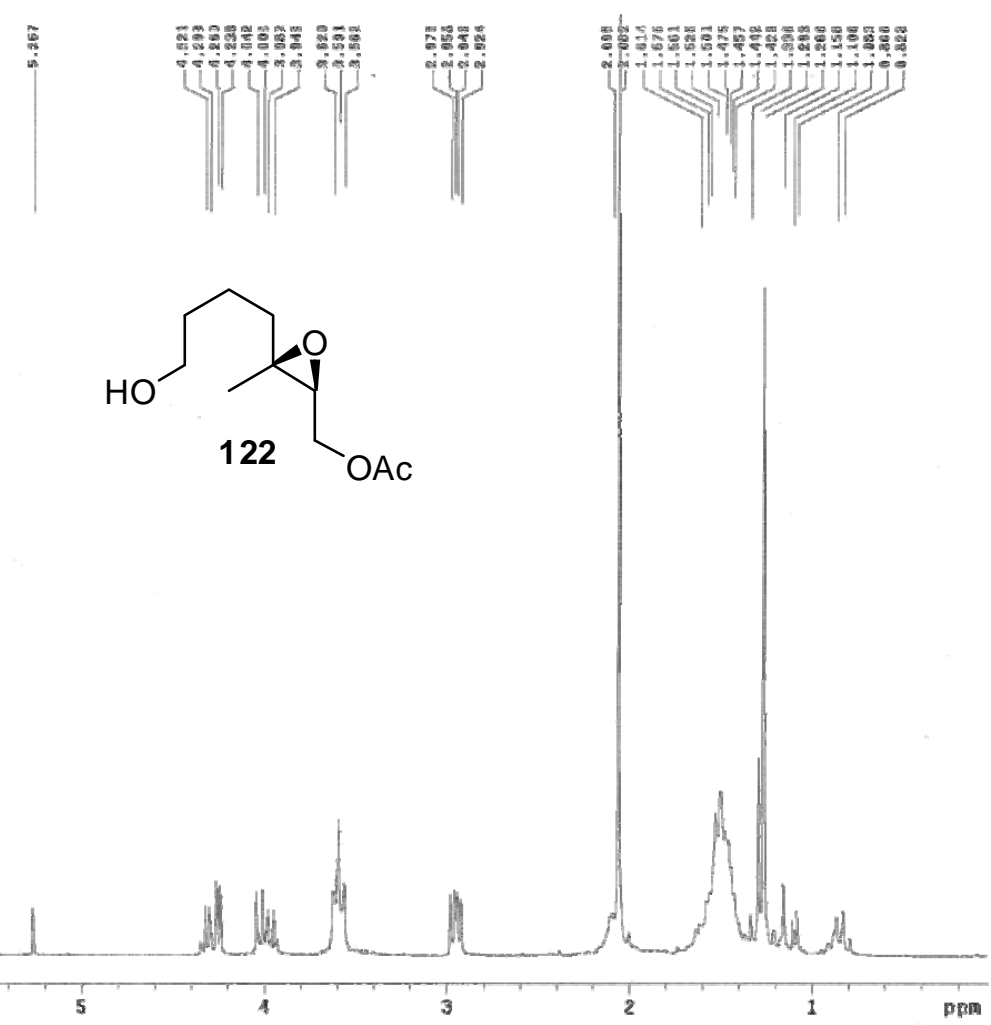


Fig. 95c
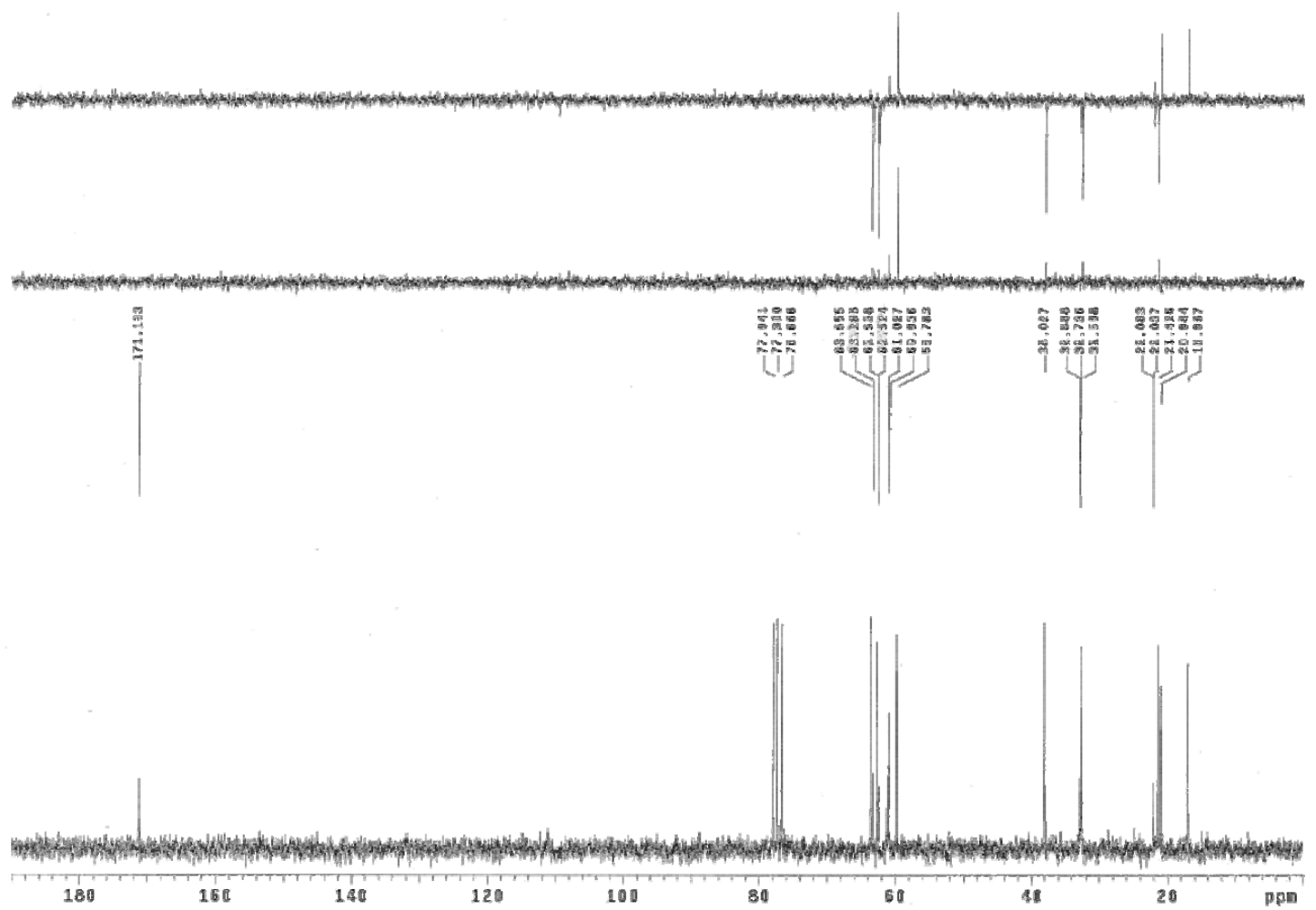

Fig. 95d

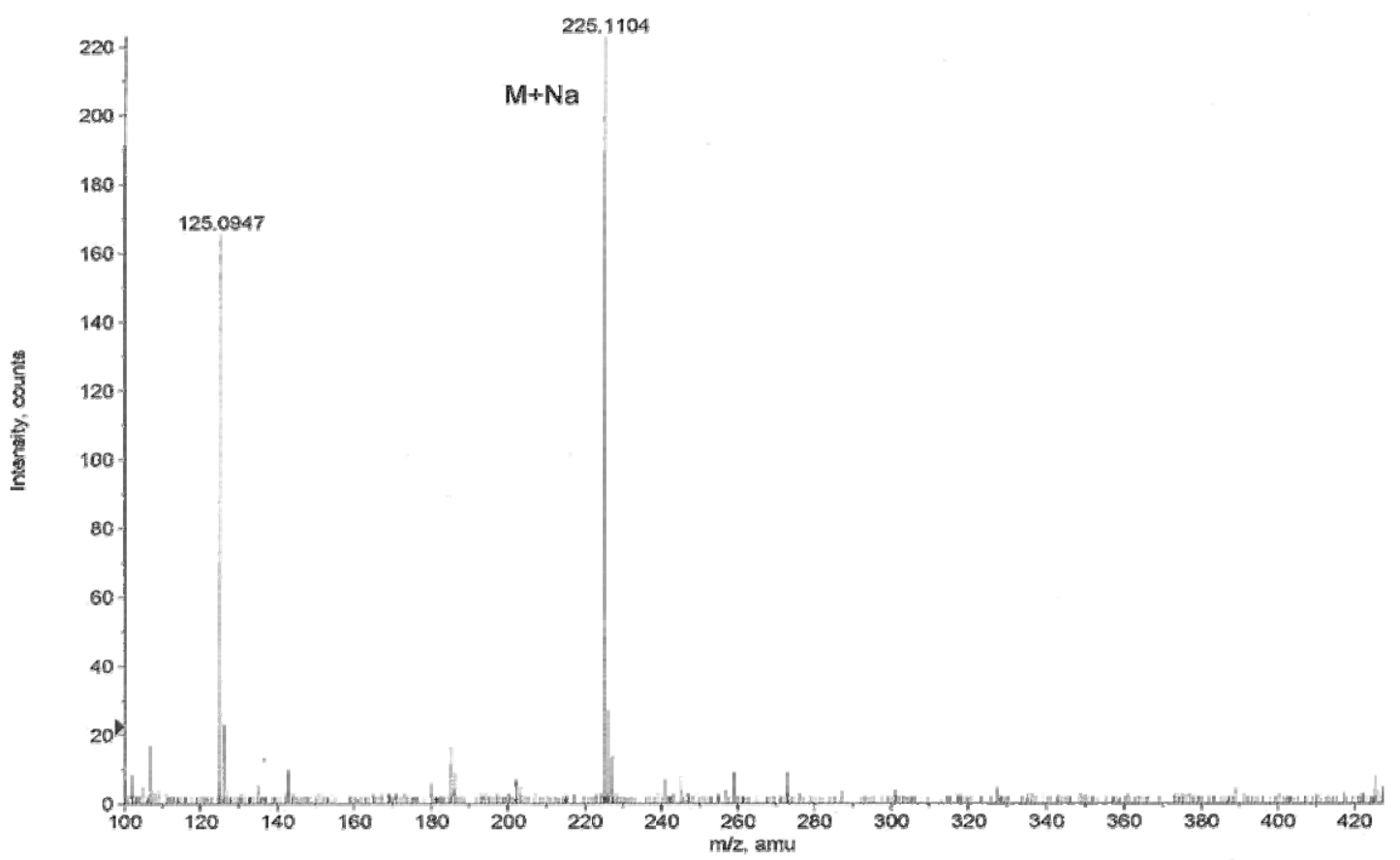


Fig. 96a

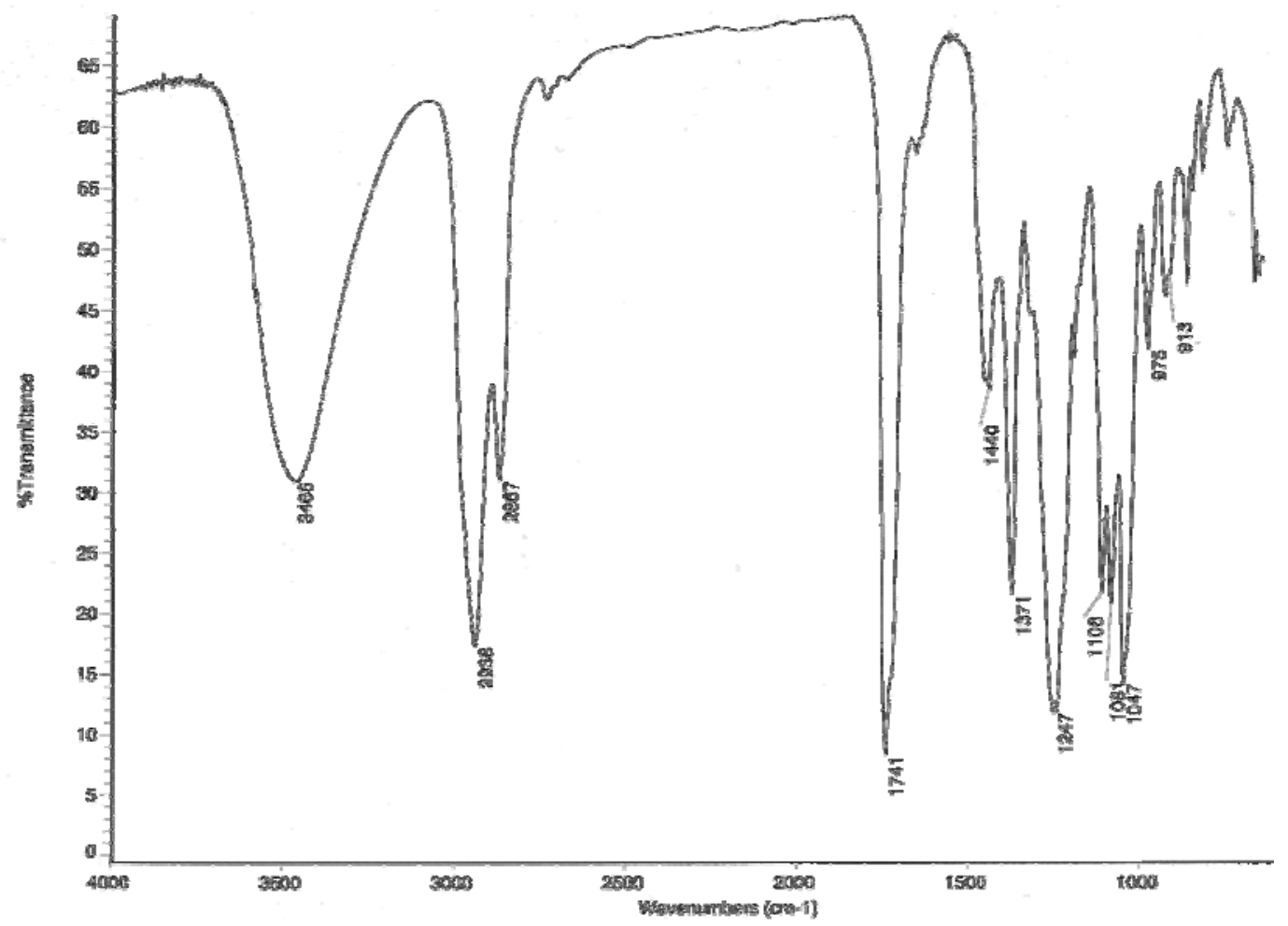

Fig. 96b

T)

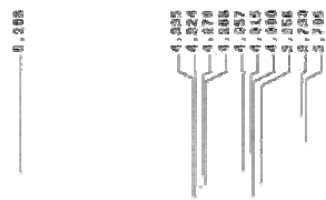

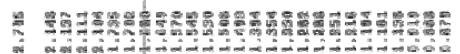
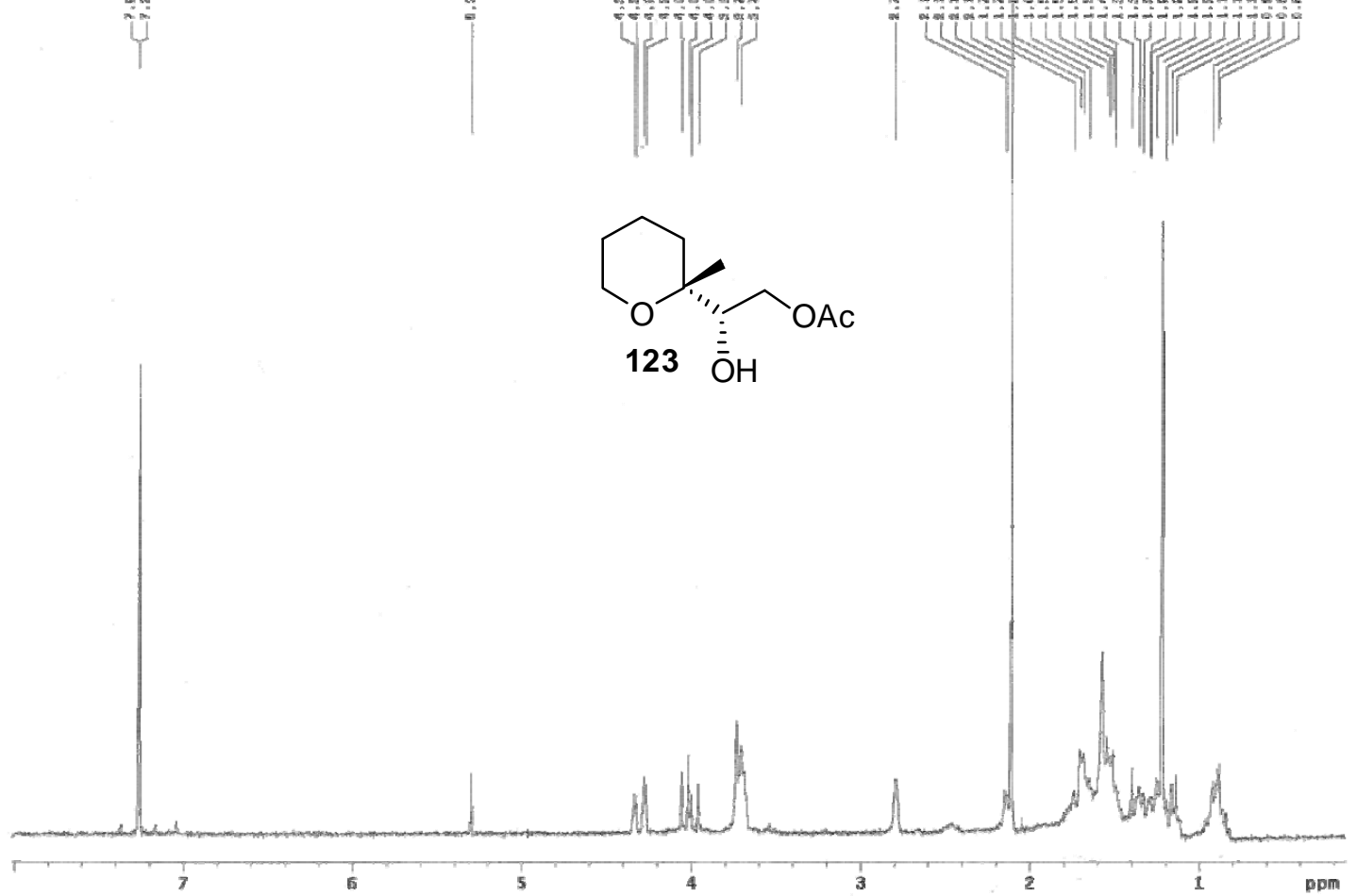
Fig. 96c

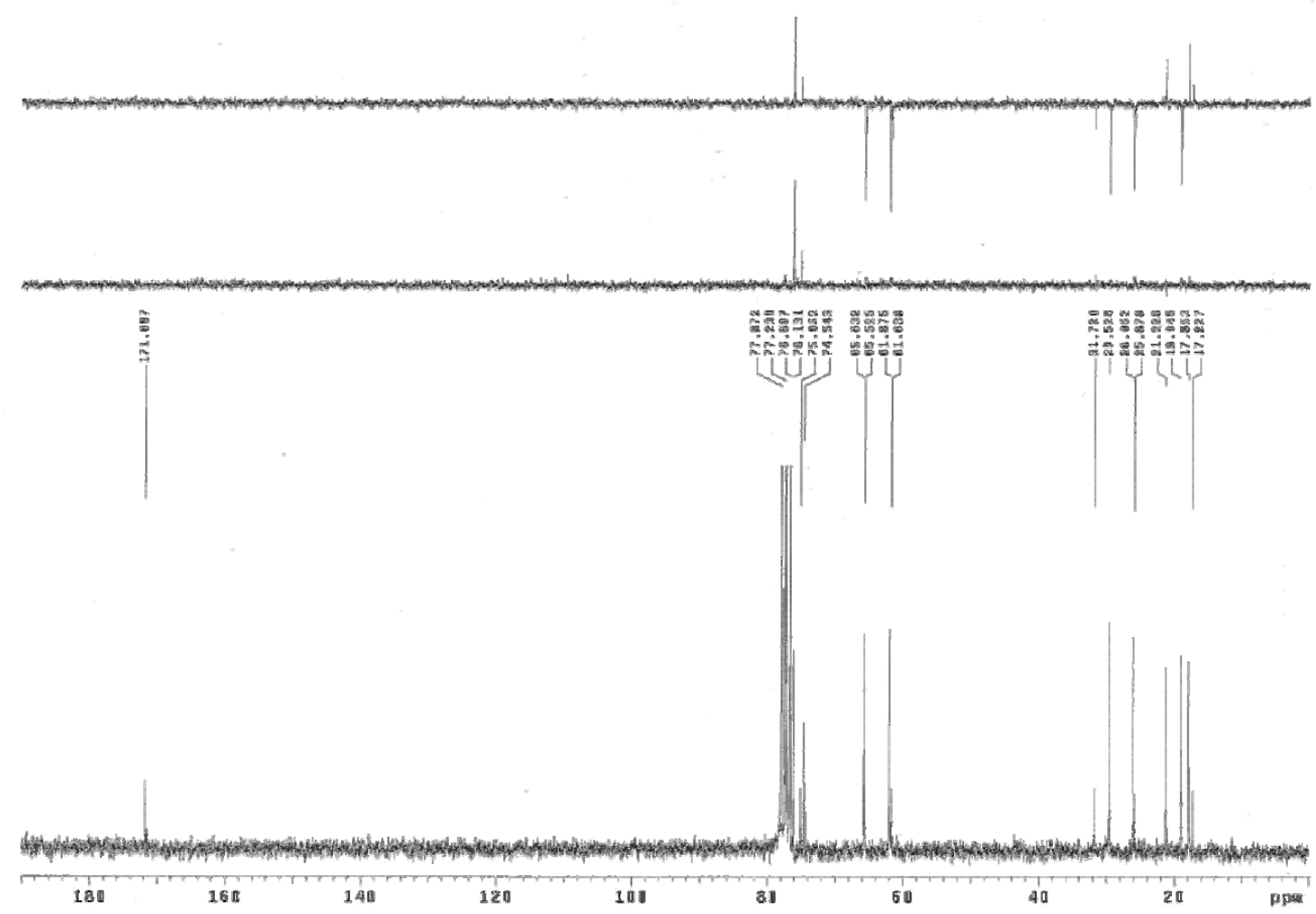

Fig. 96d

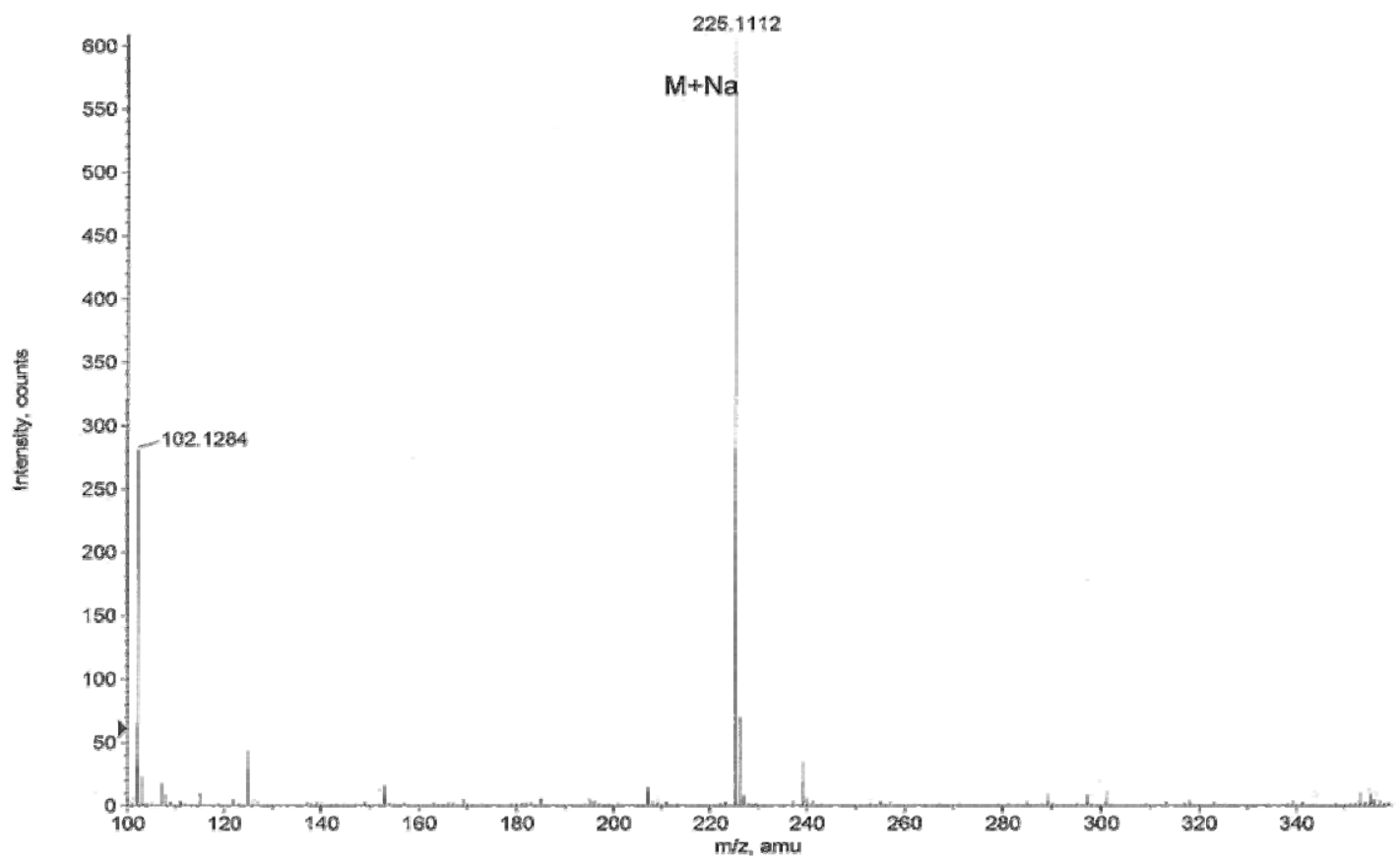


Fig. 97a

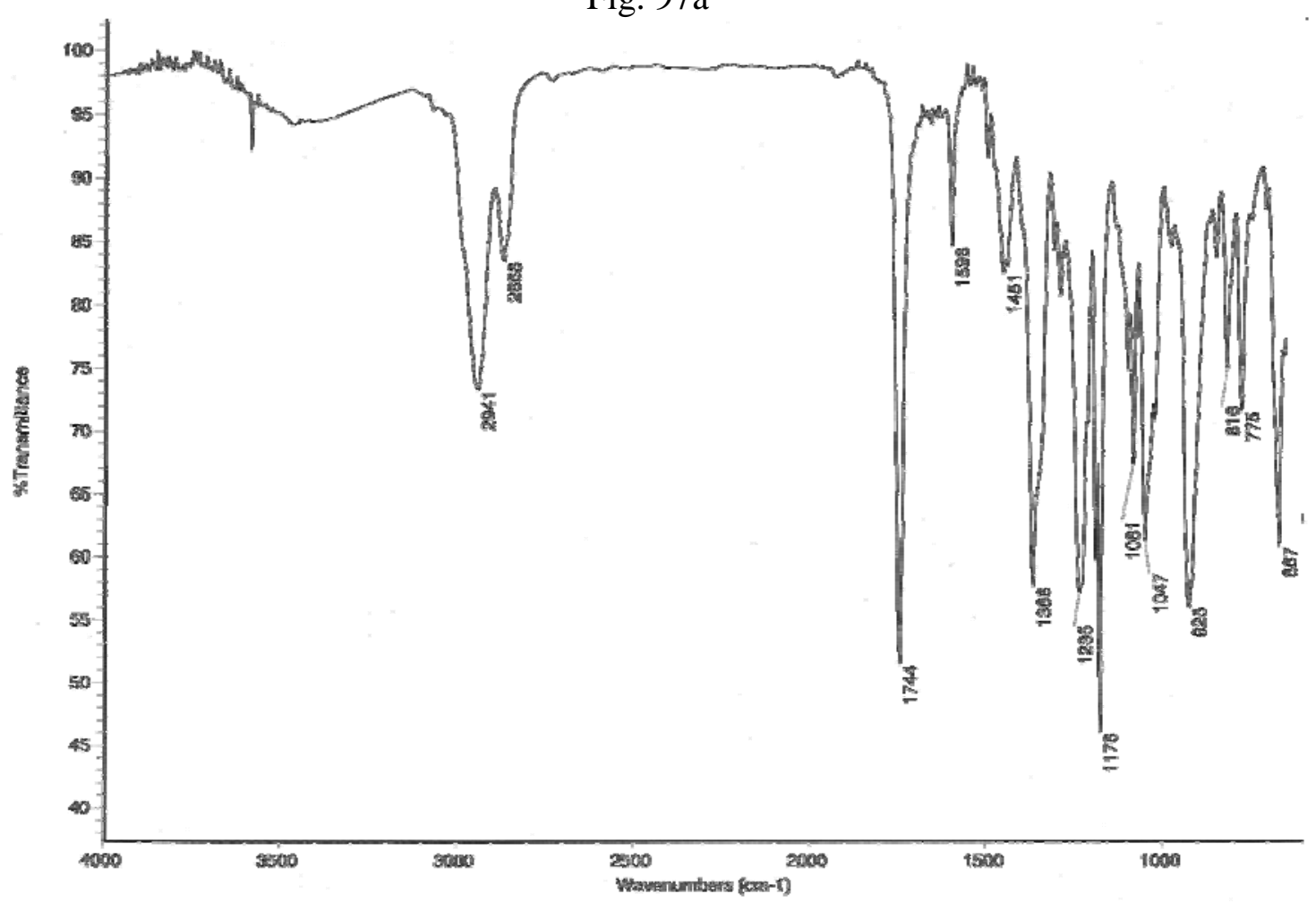

Fig. 97b
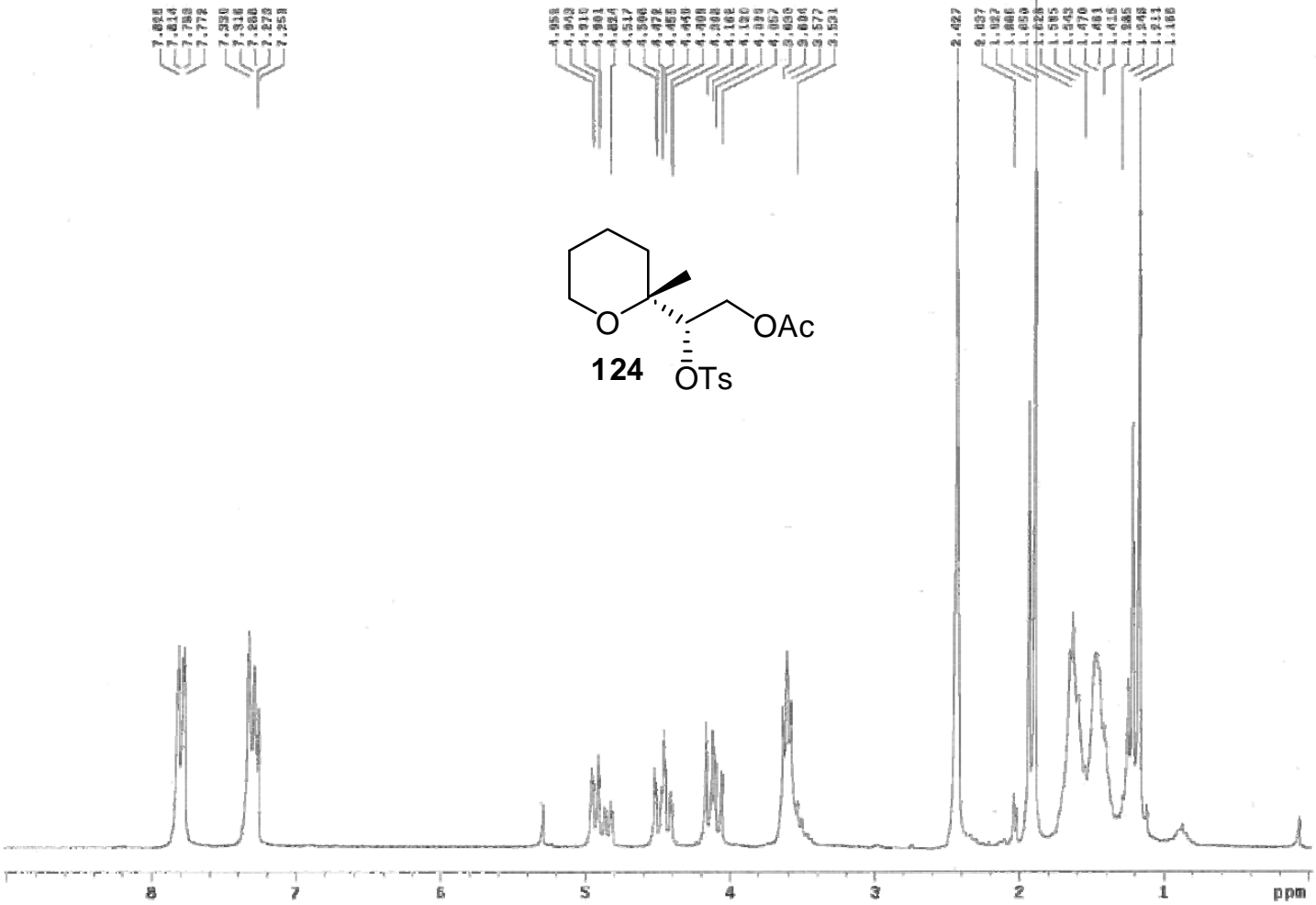
Fig. 97c
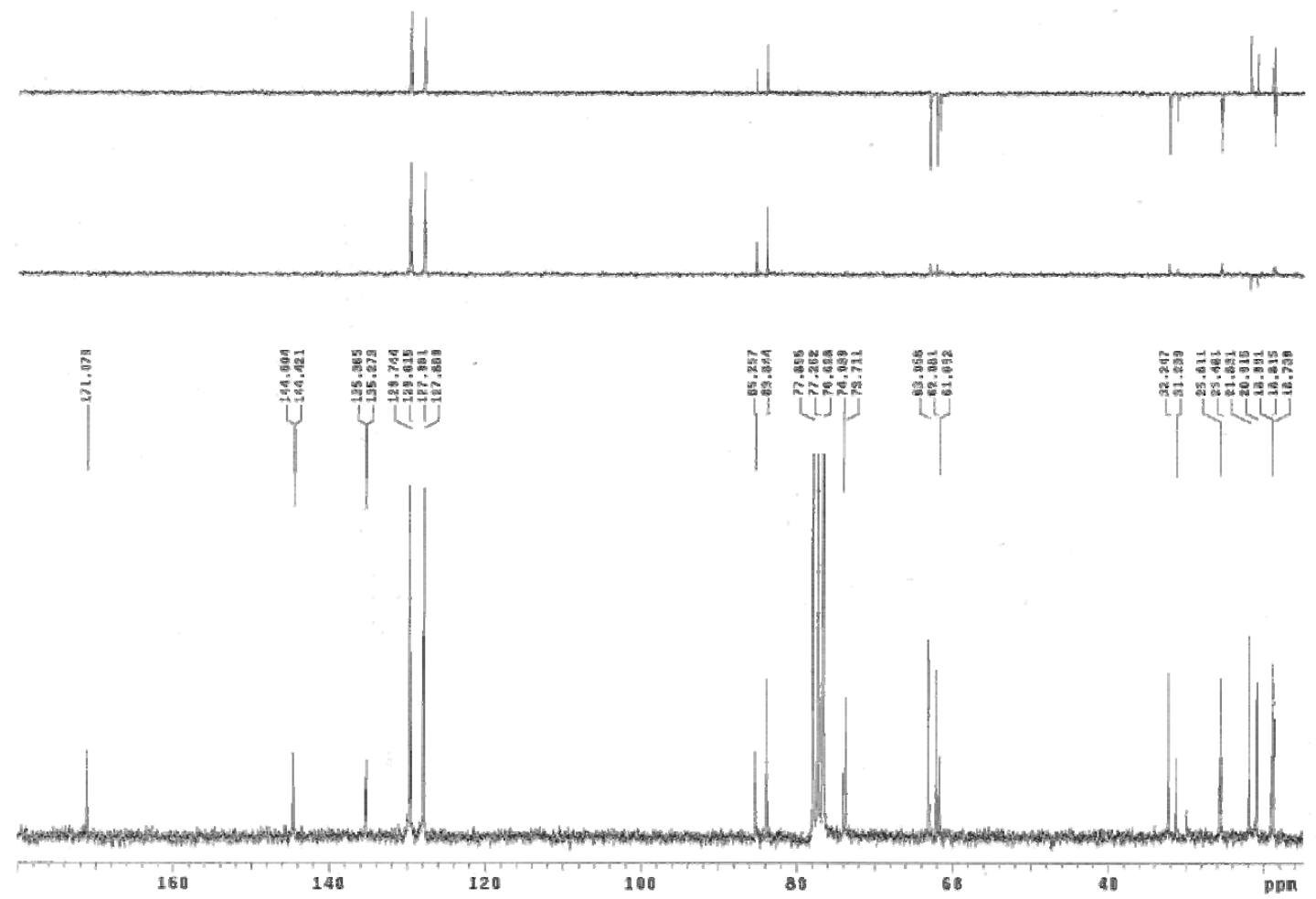

Fig. 97d

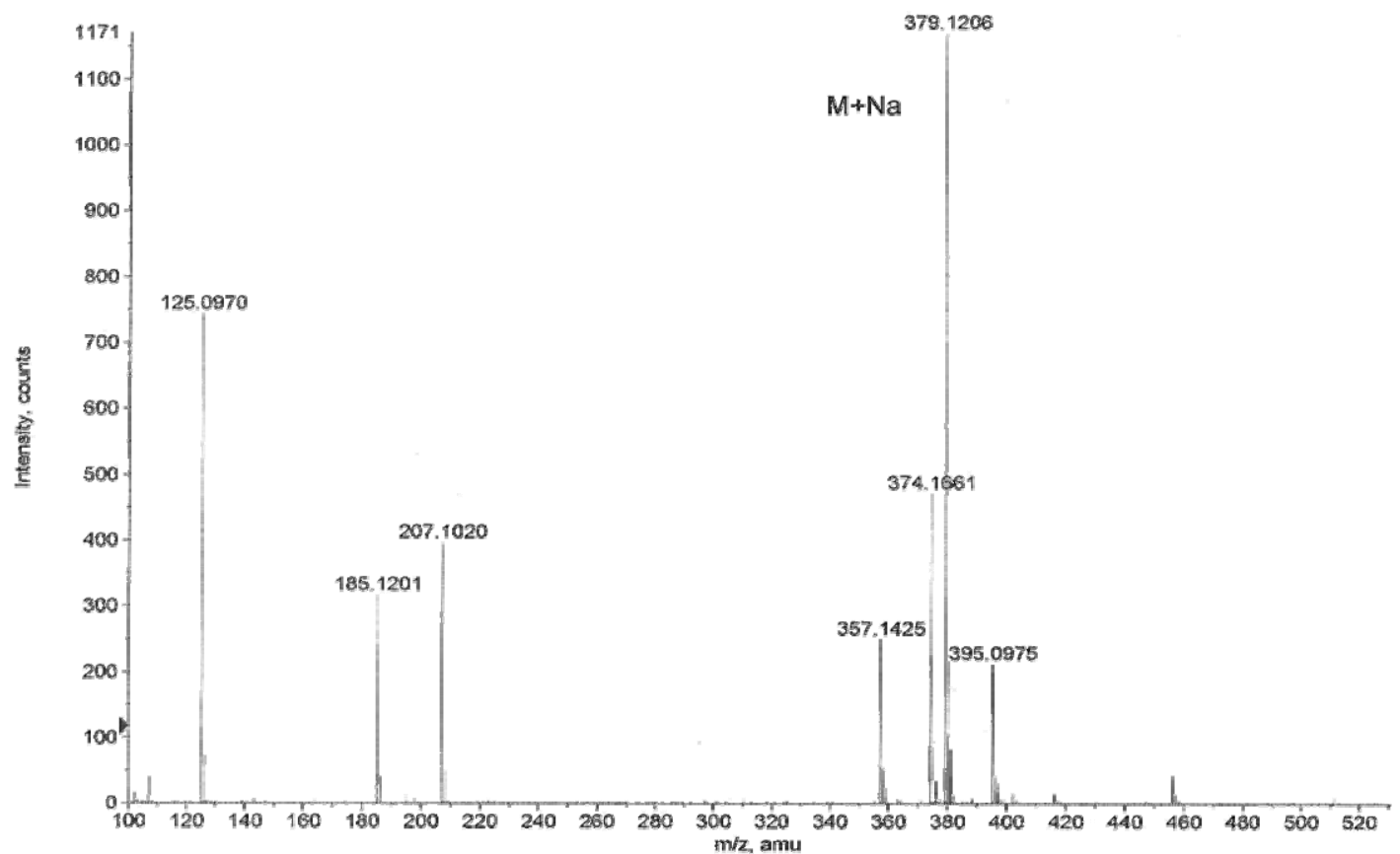


Fig. 98

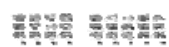

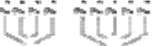
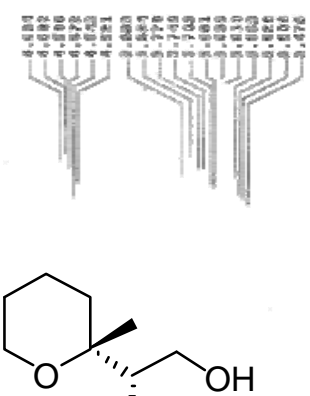

125 ОंTs

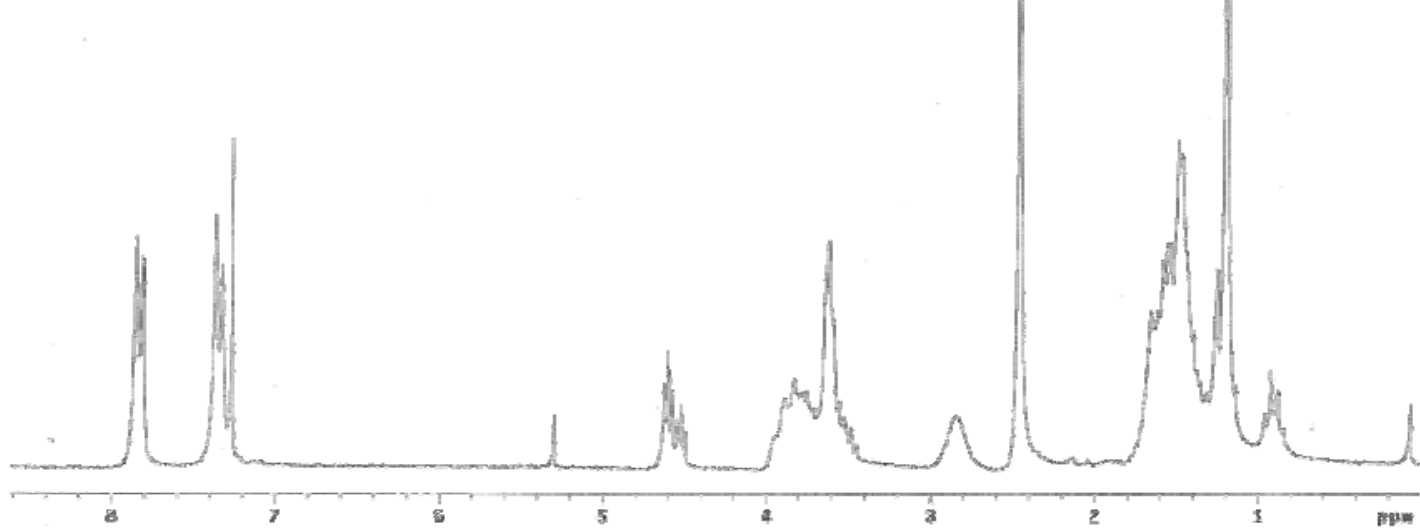


Fig. 99a

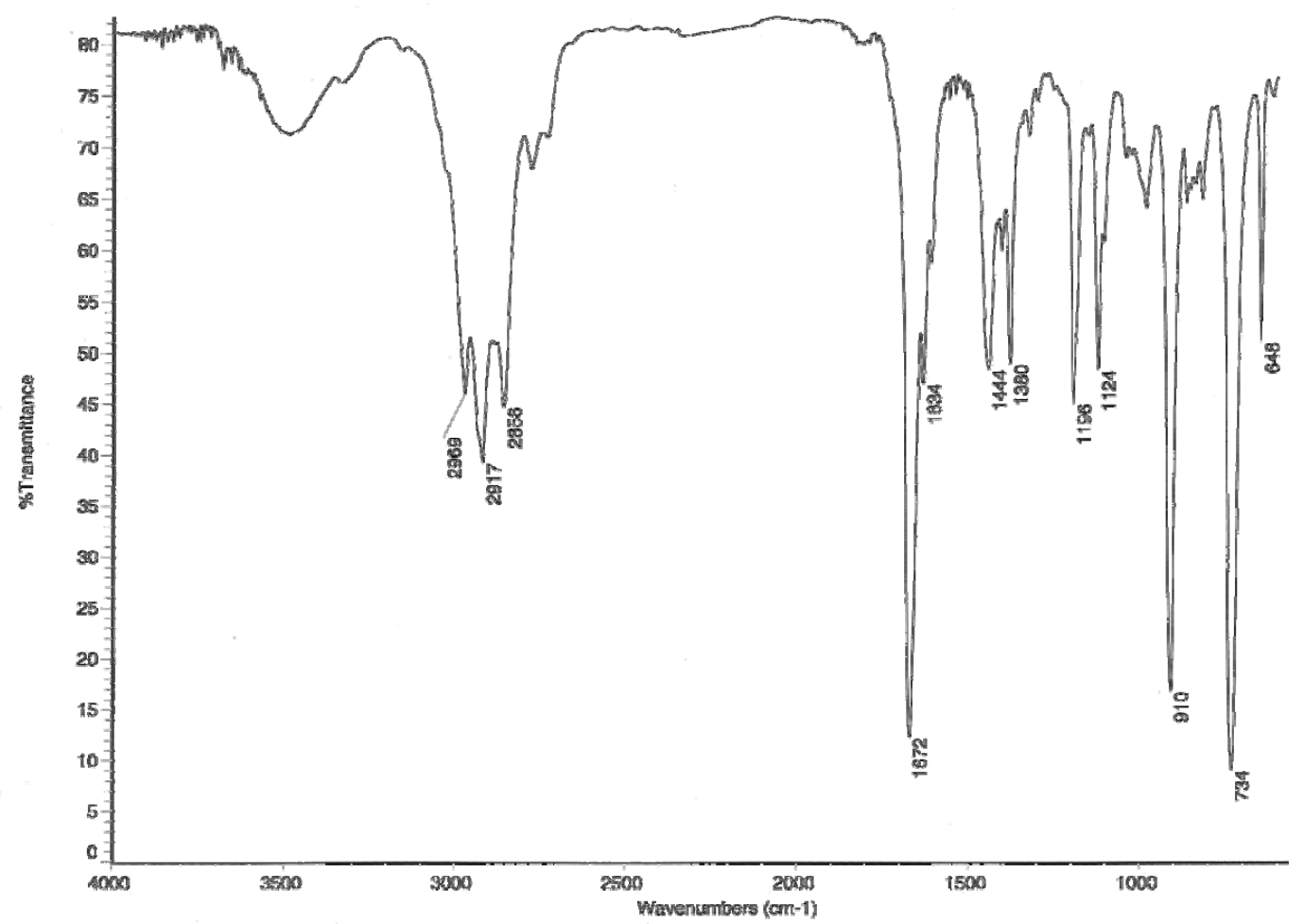

Fig. 99b
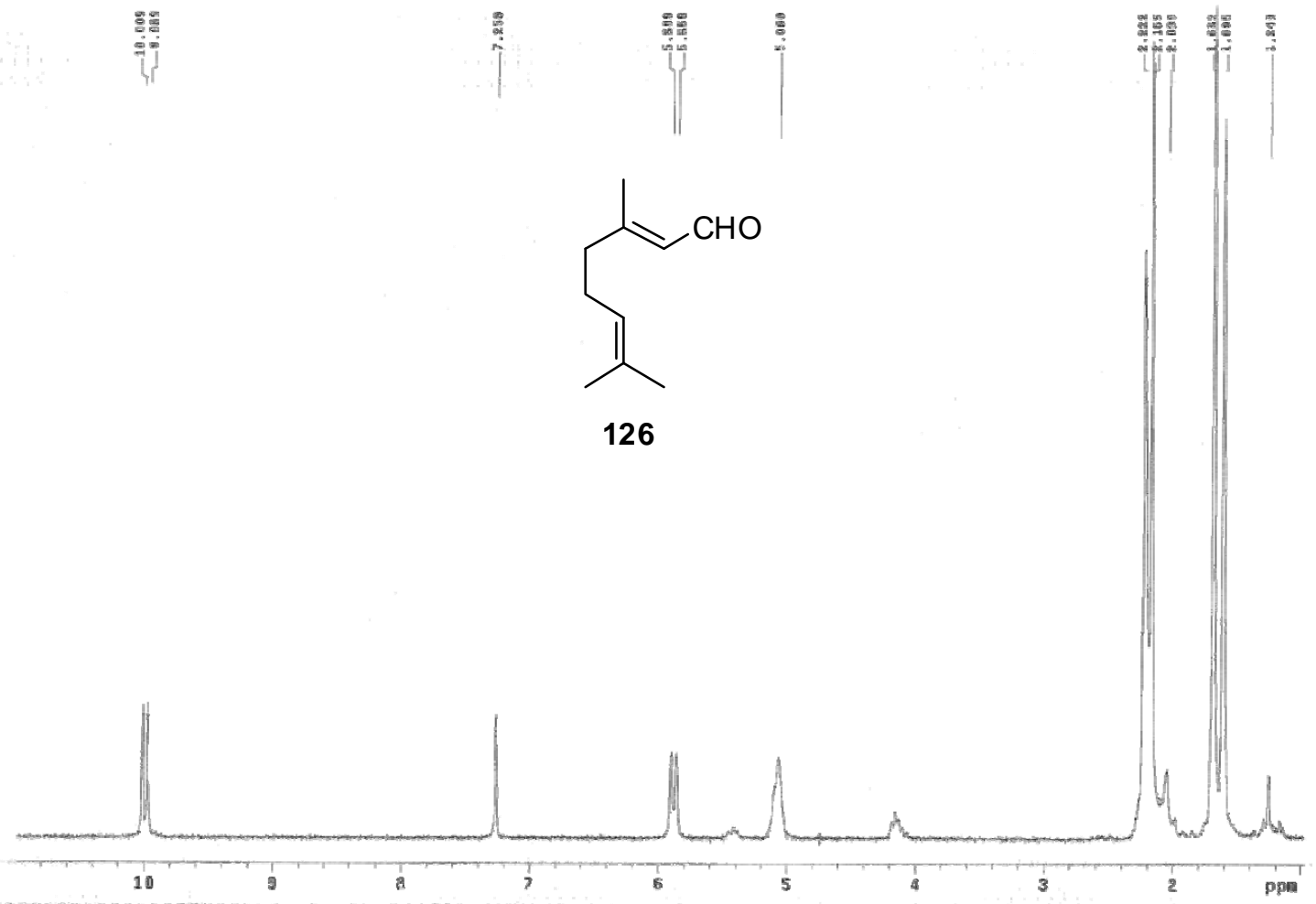
Fig. 99c
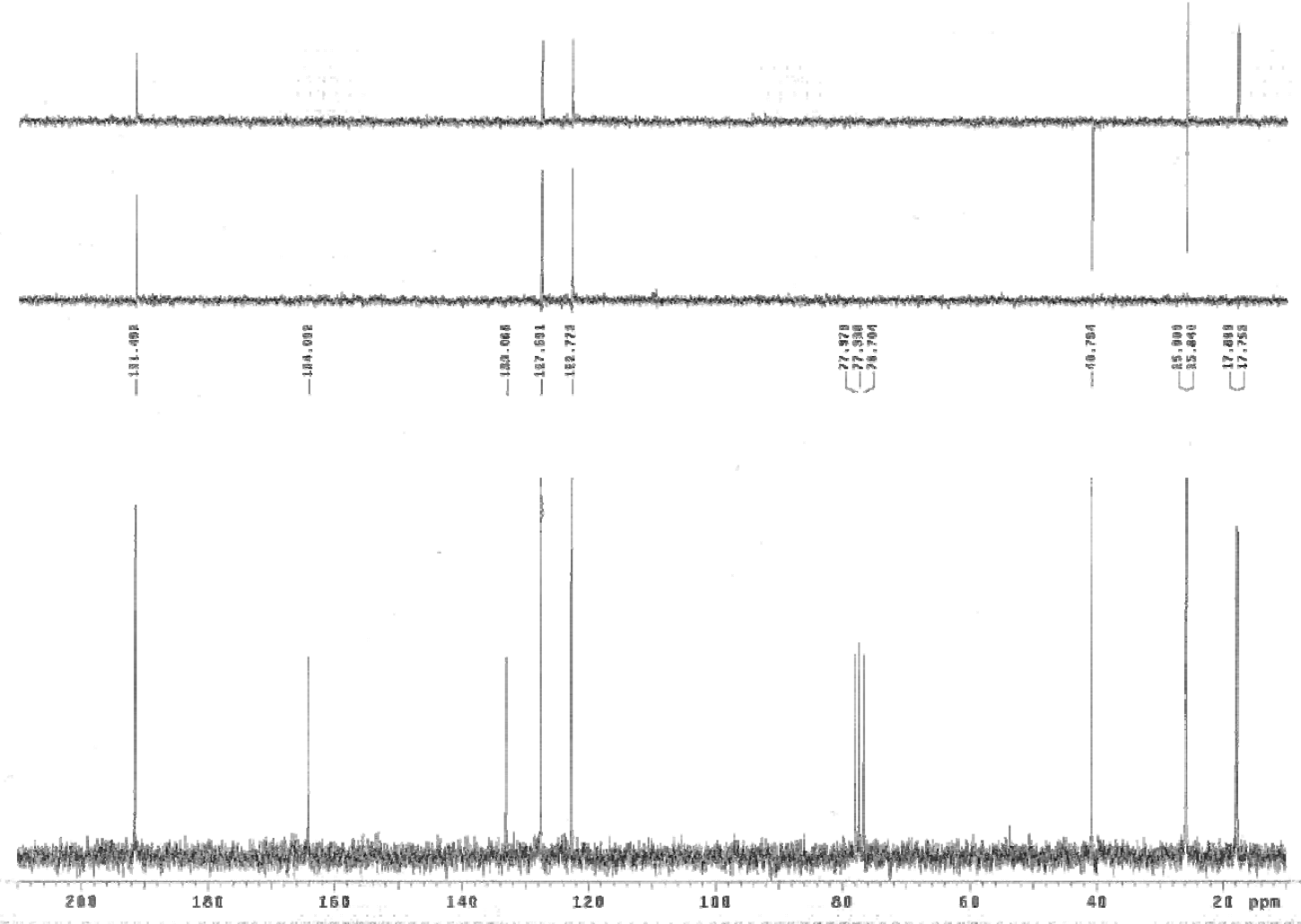


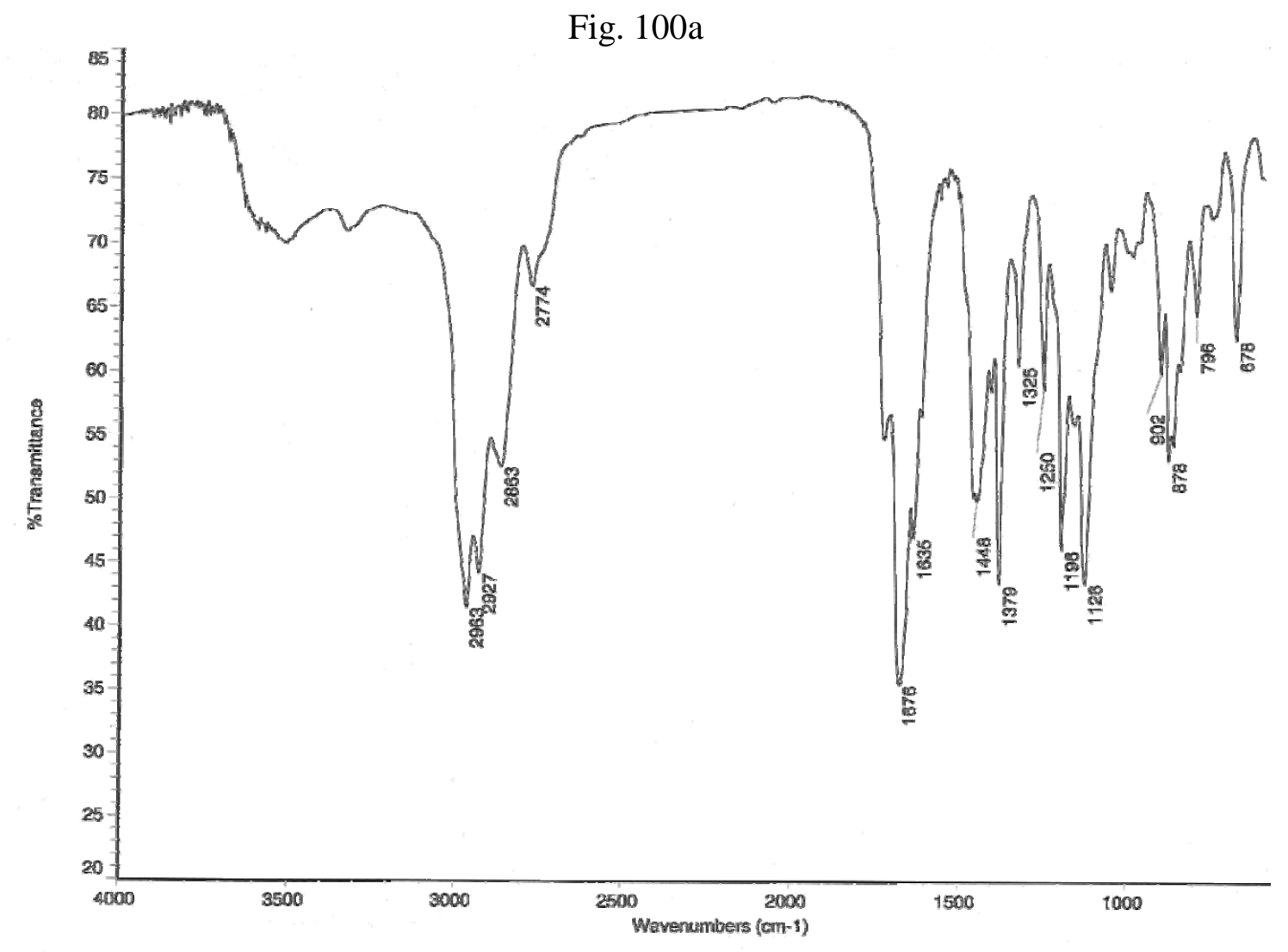

Fig. 100b
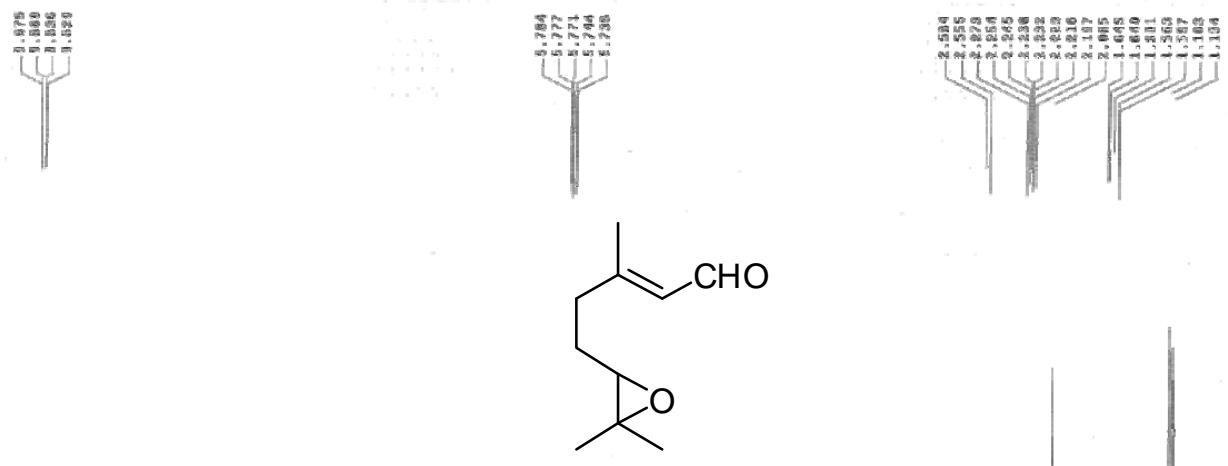

127

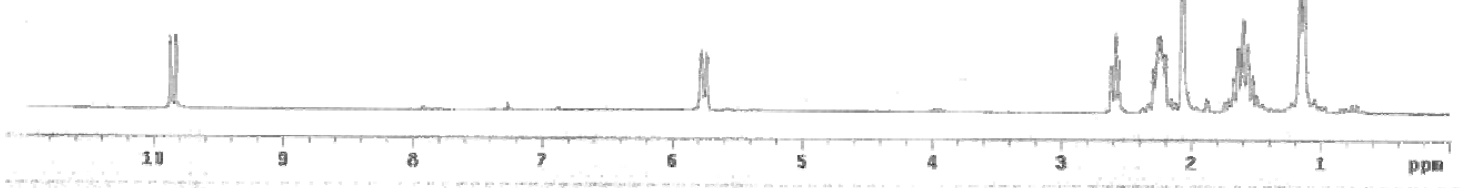


Fig. 100c
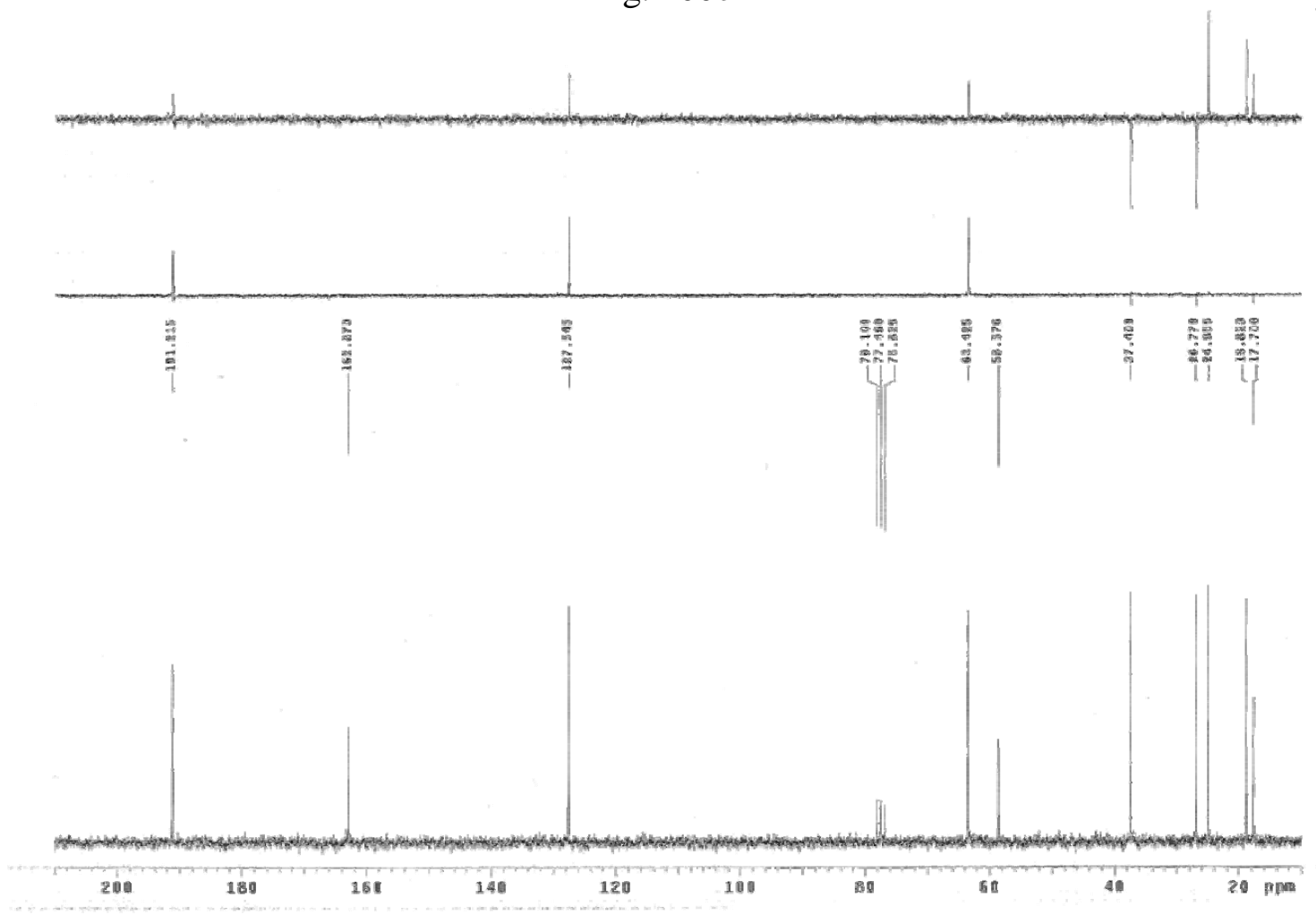

Fig. 100d

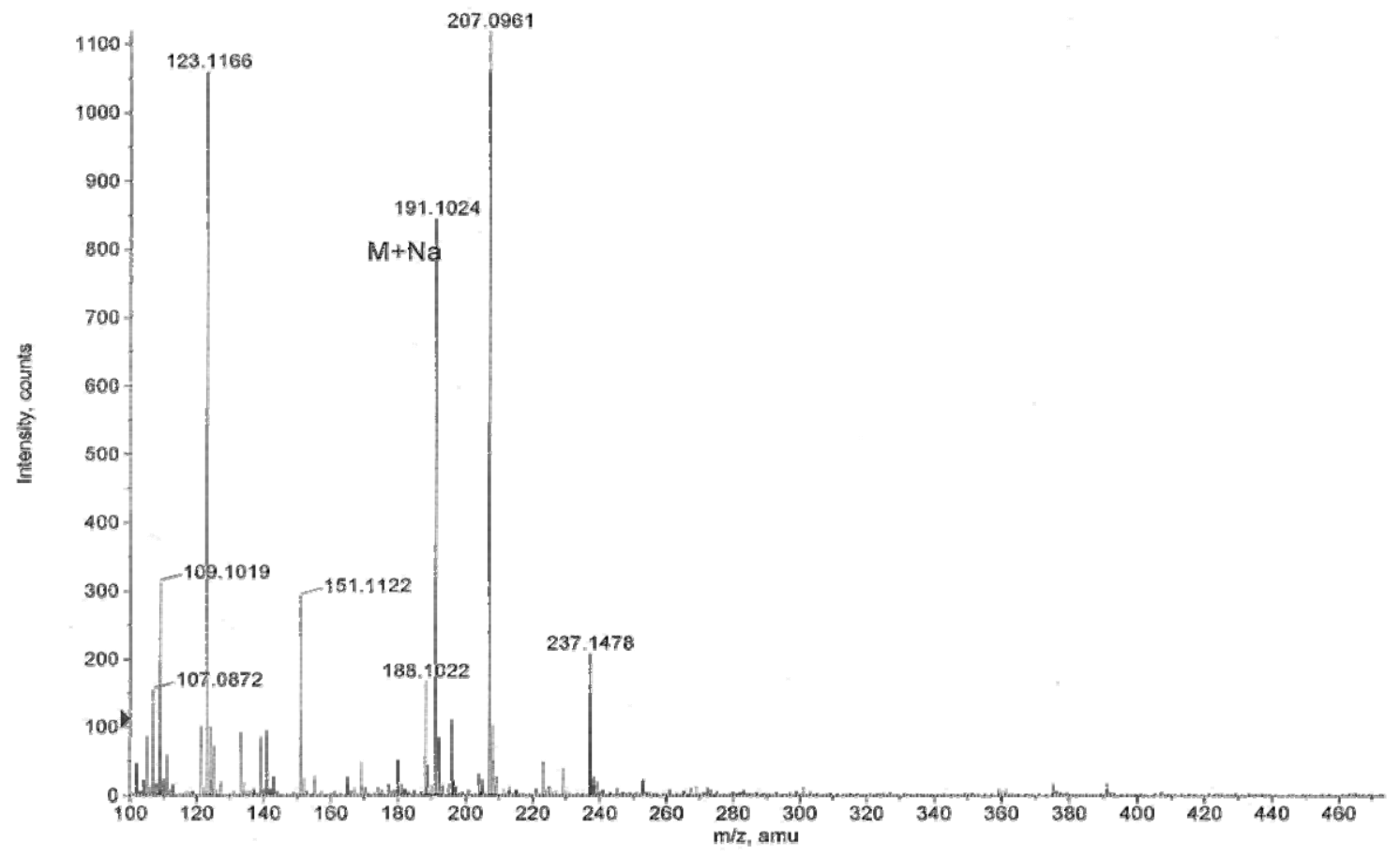


Fig. 101a
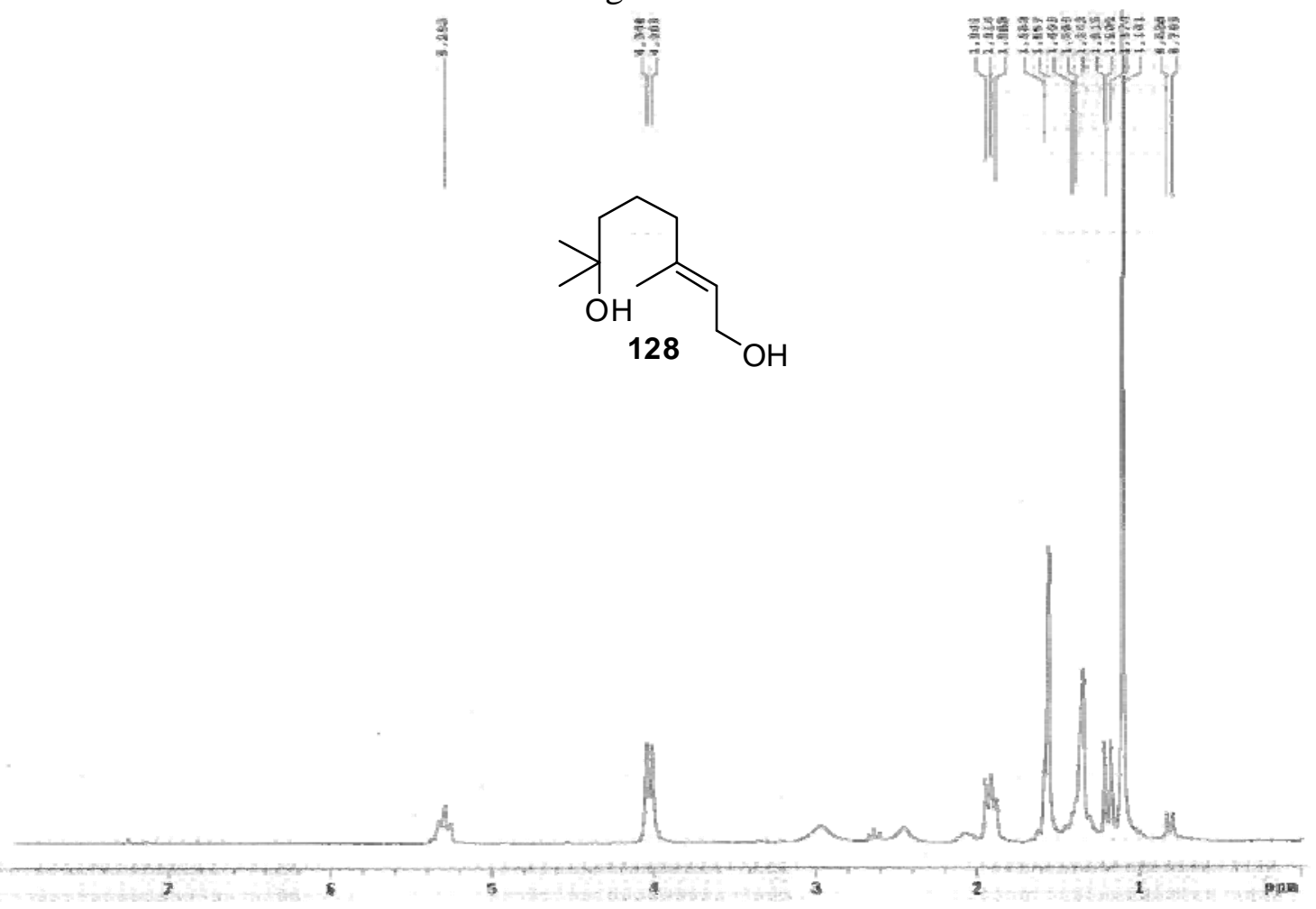

Fig. 101b

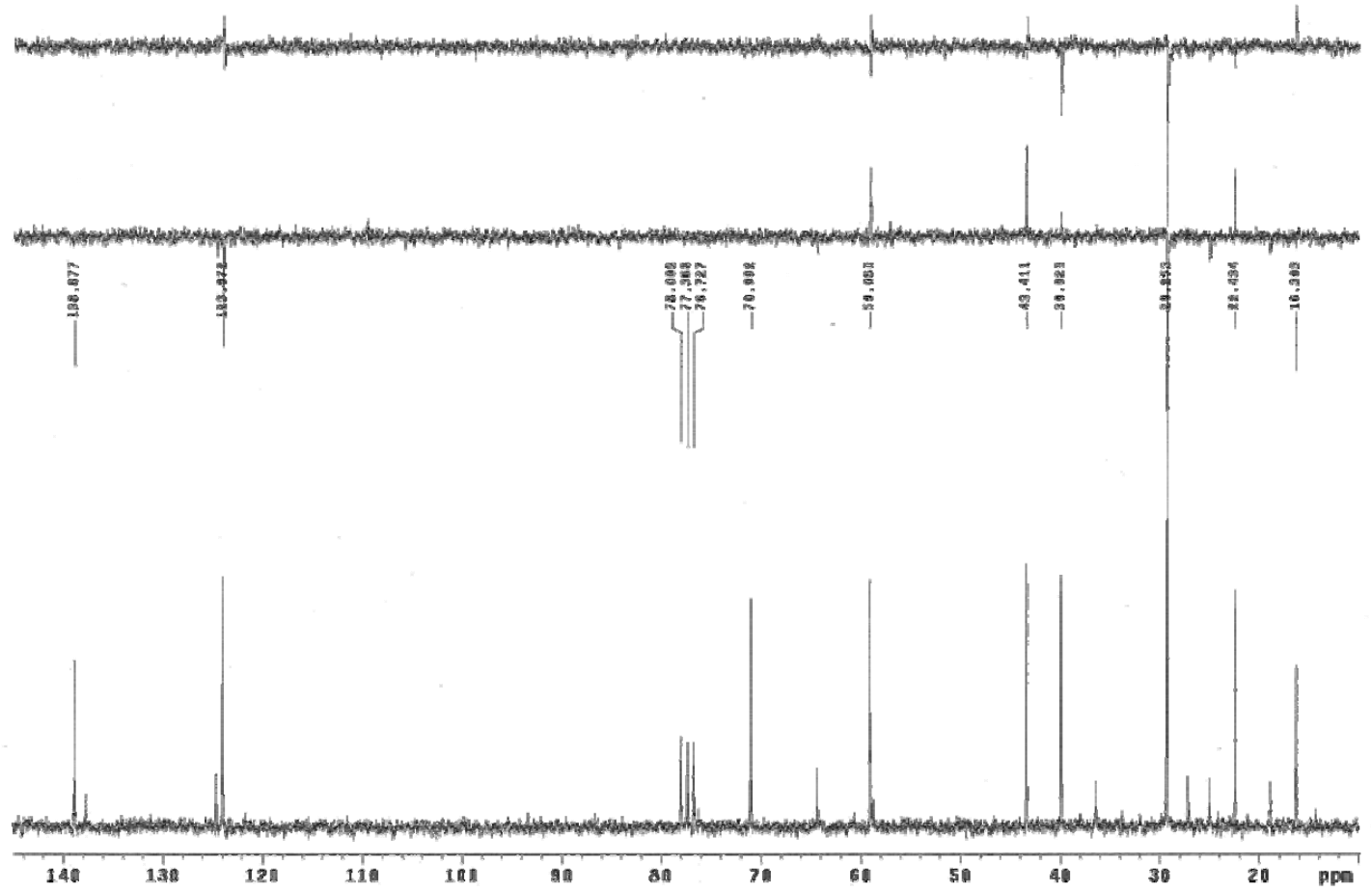


Fig. 102a

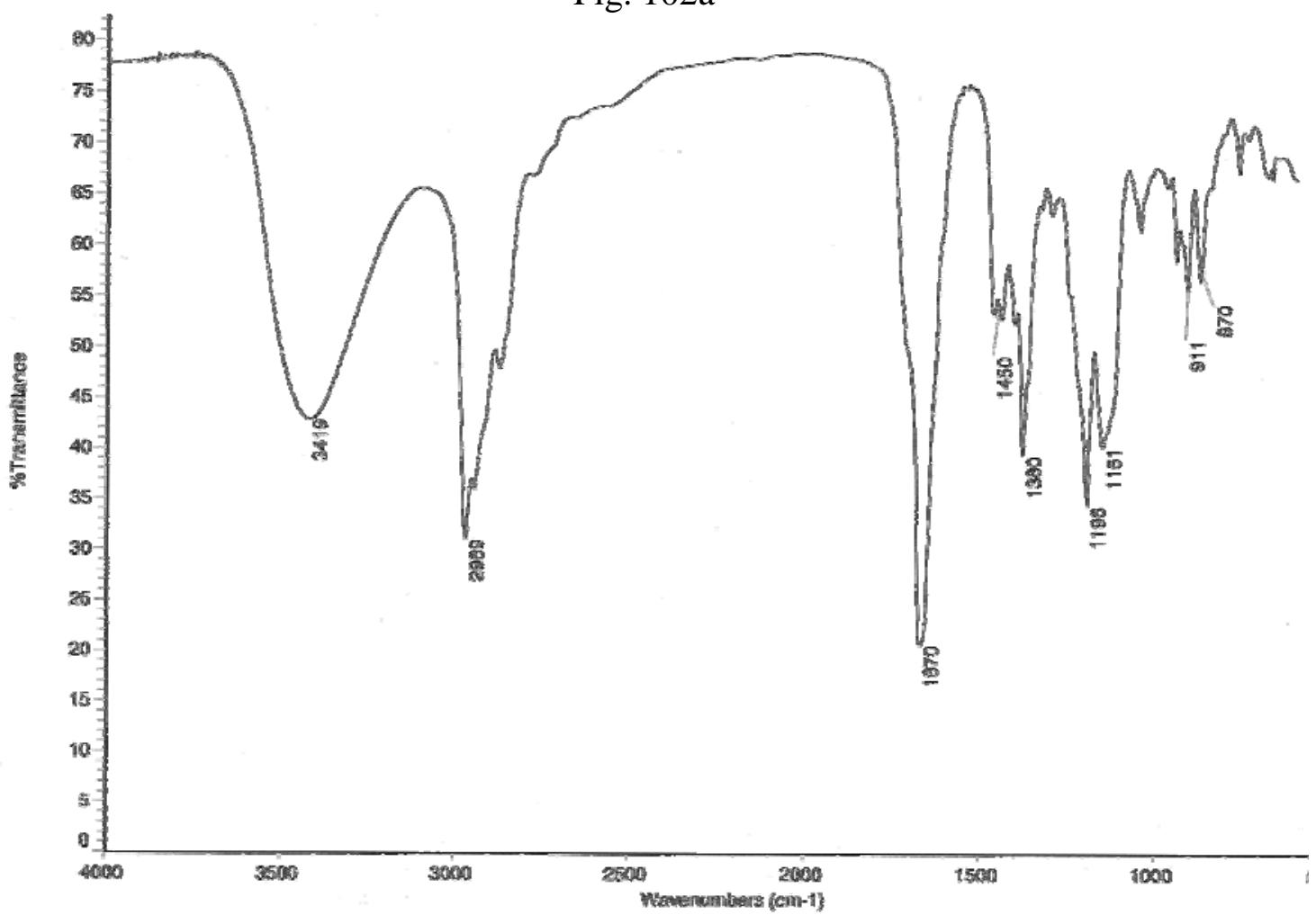

Fig. 102b

(9)

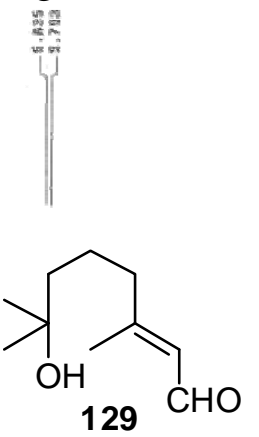

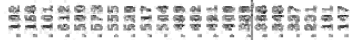
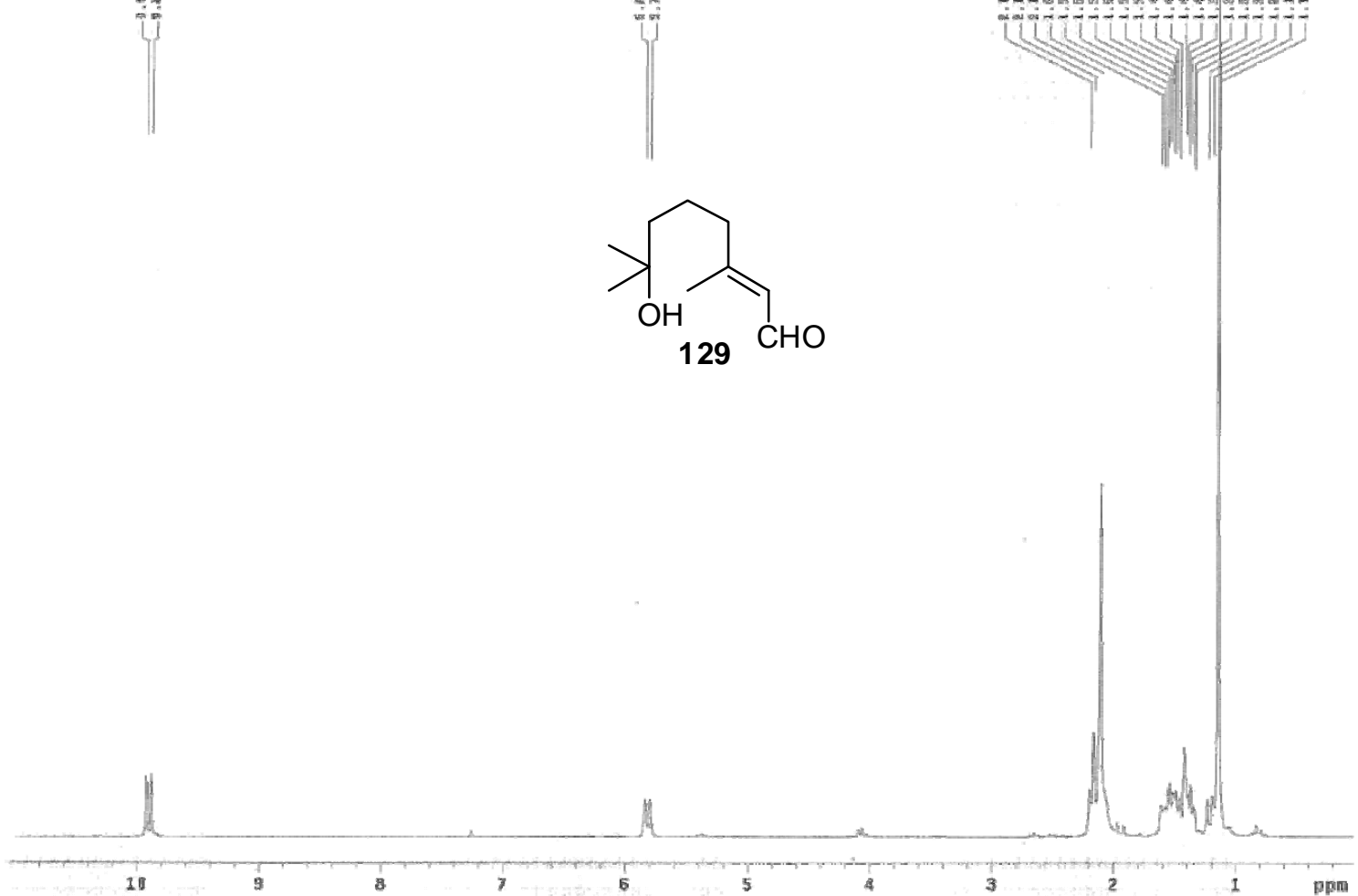
Fig. 102c

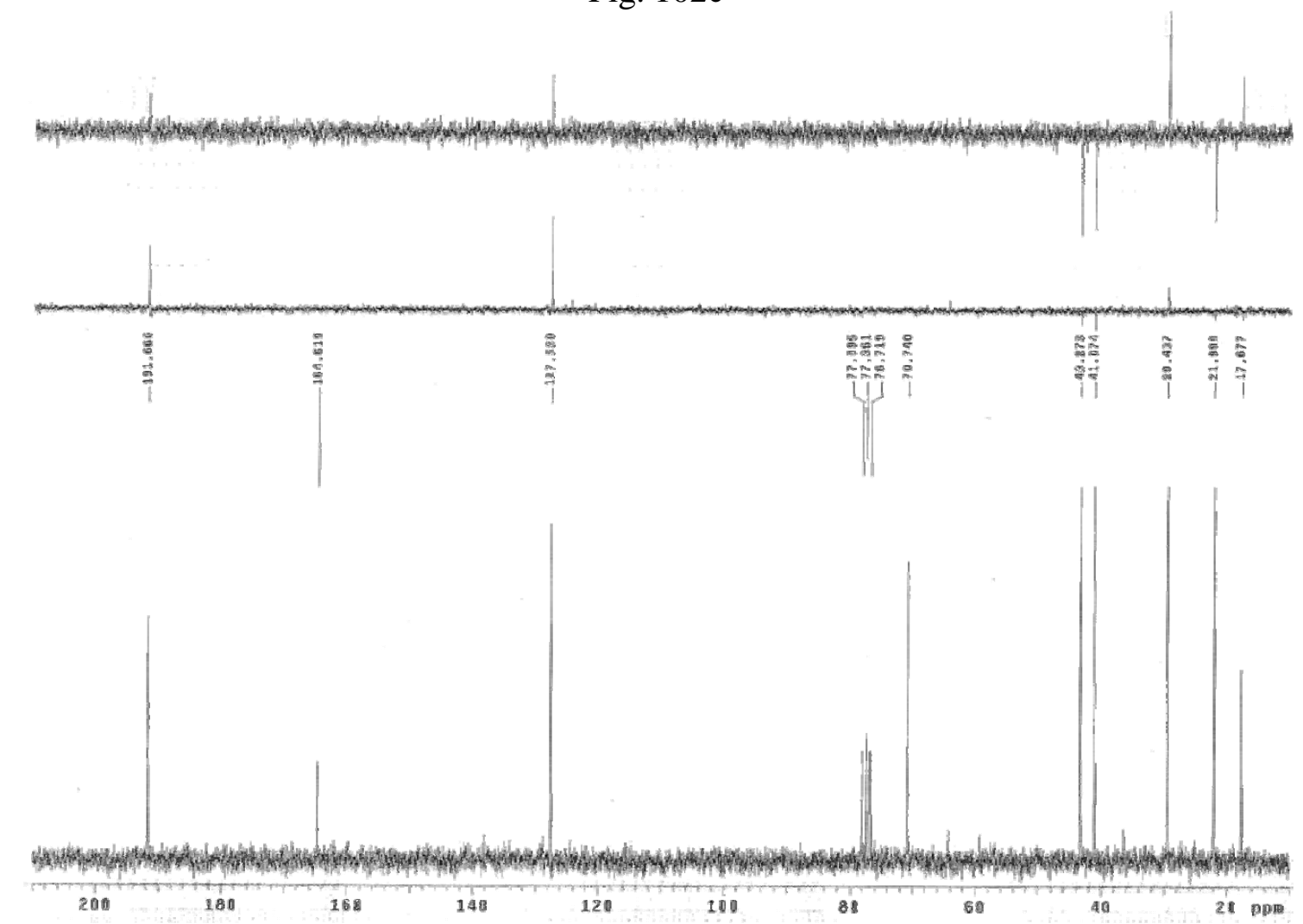

Fig. 102d

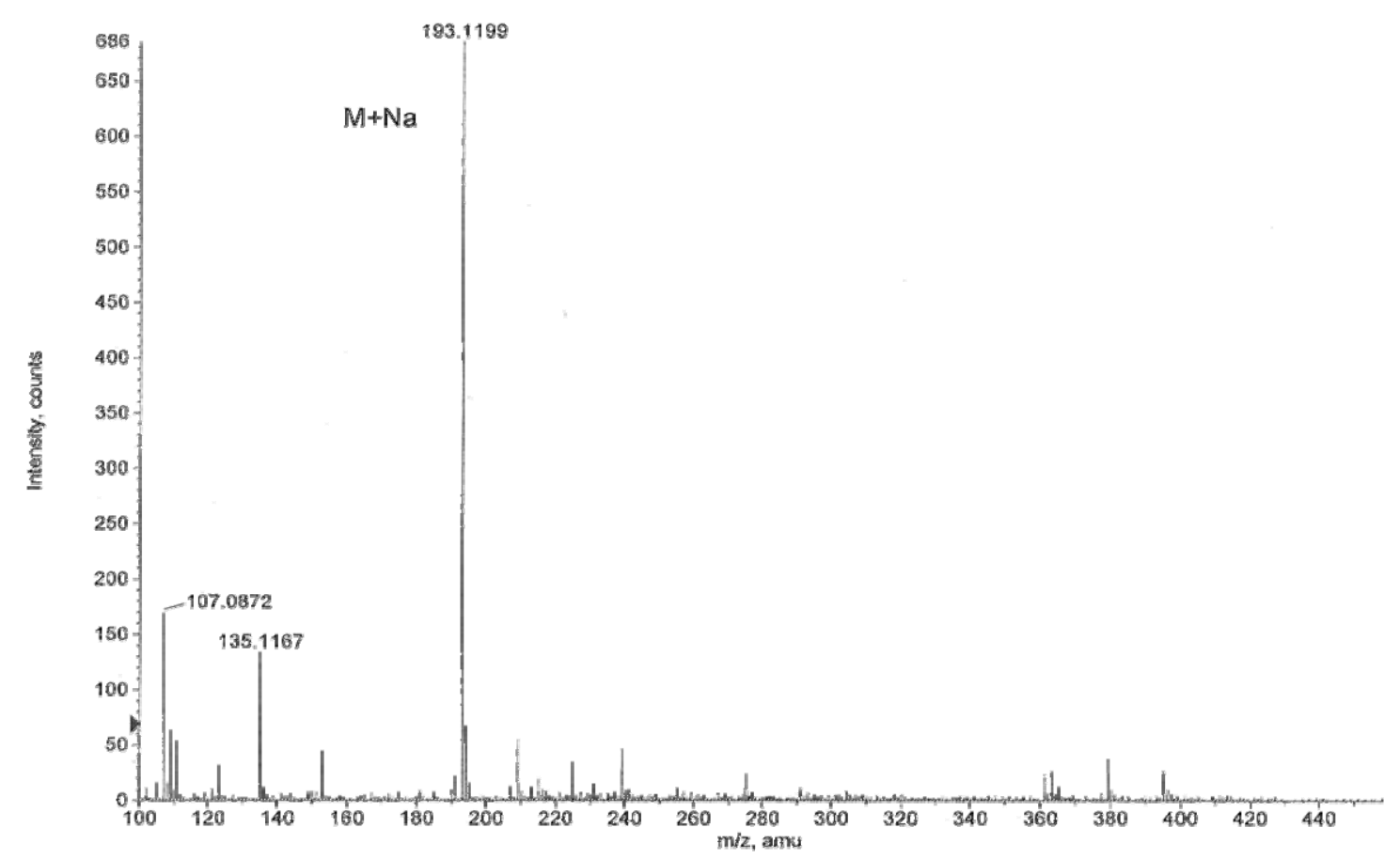


Fig. 103a

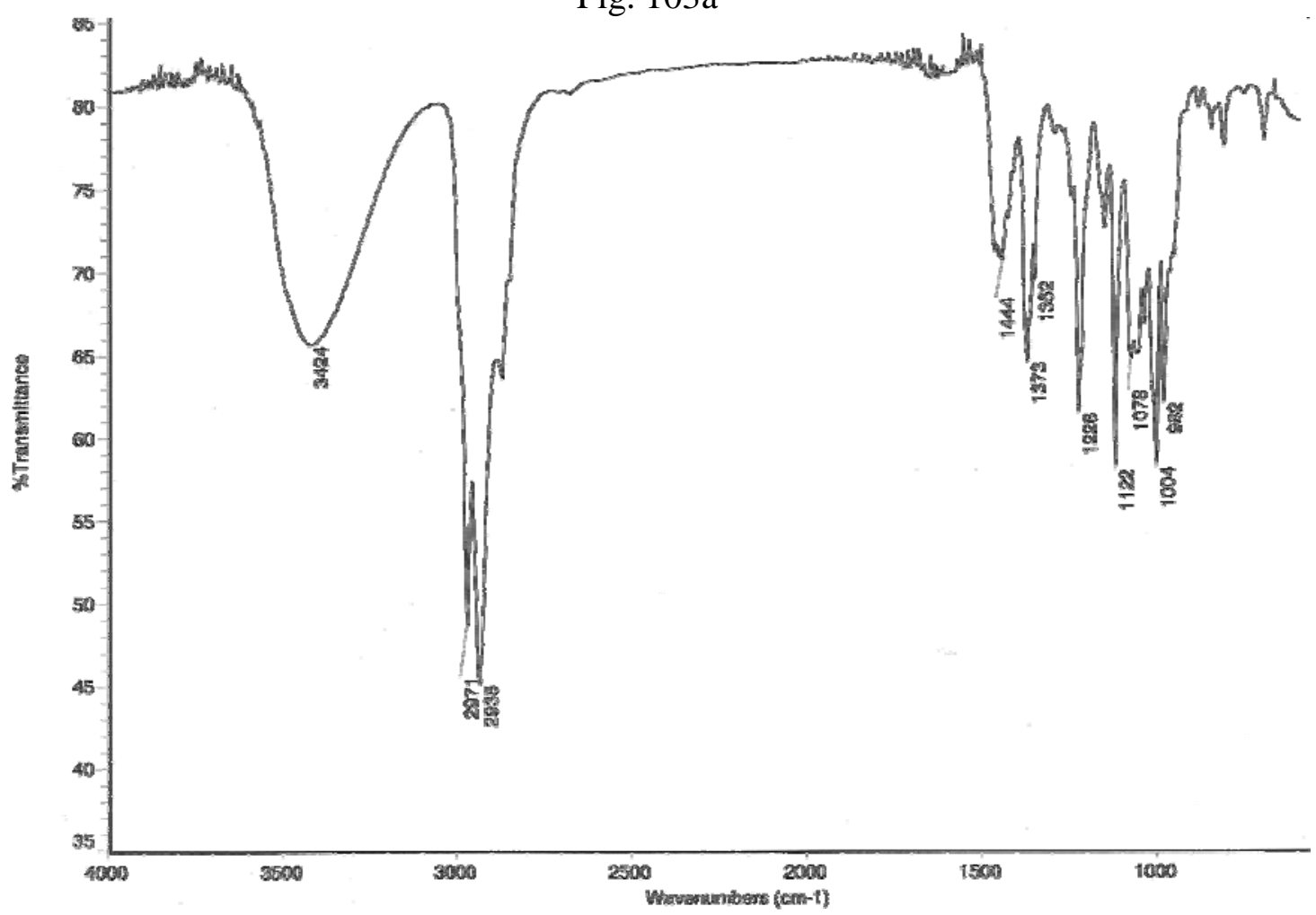

Fig. 103b

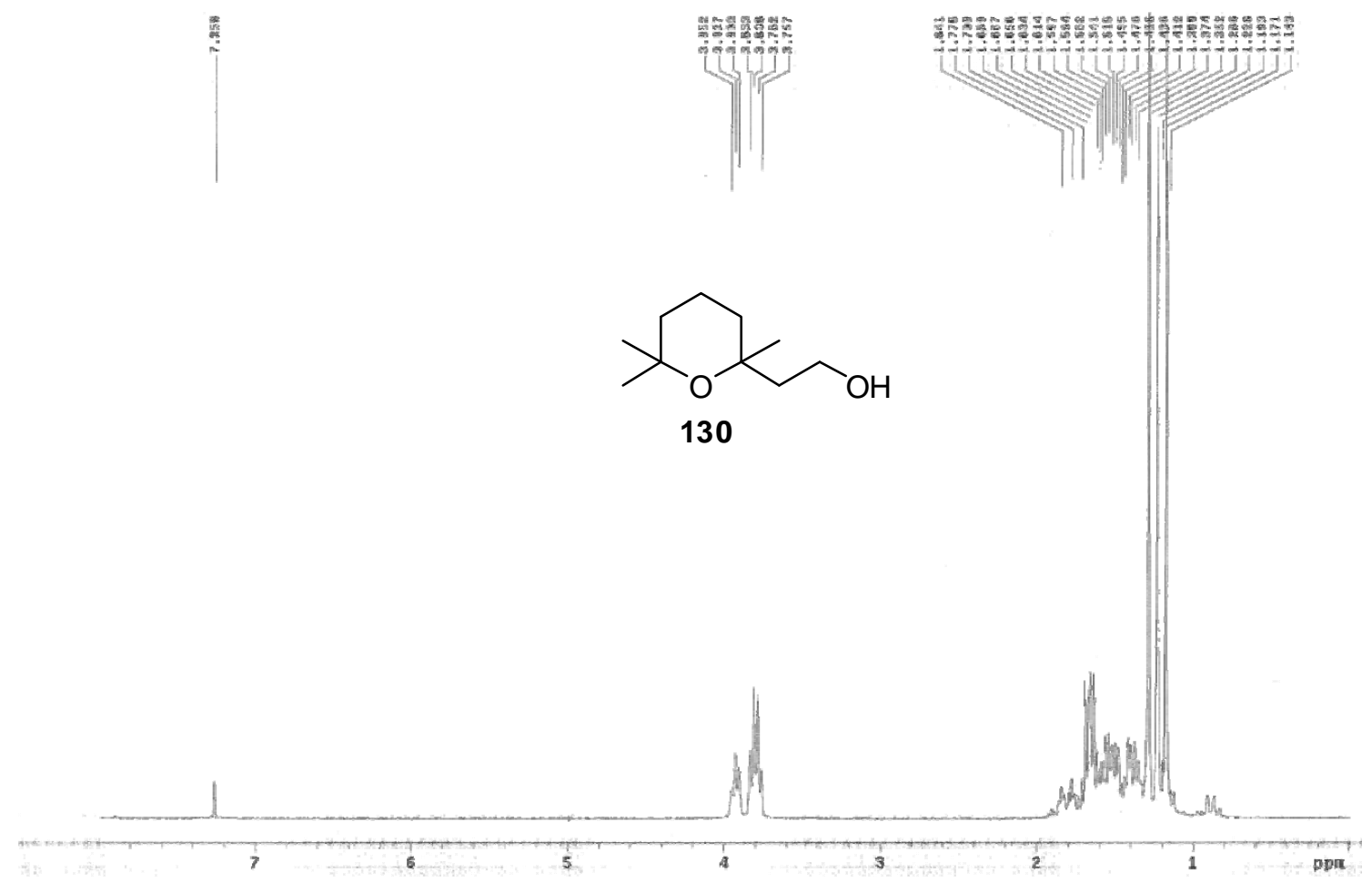

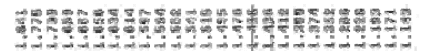


Fig. 103c
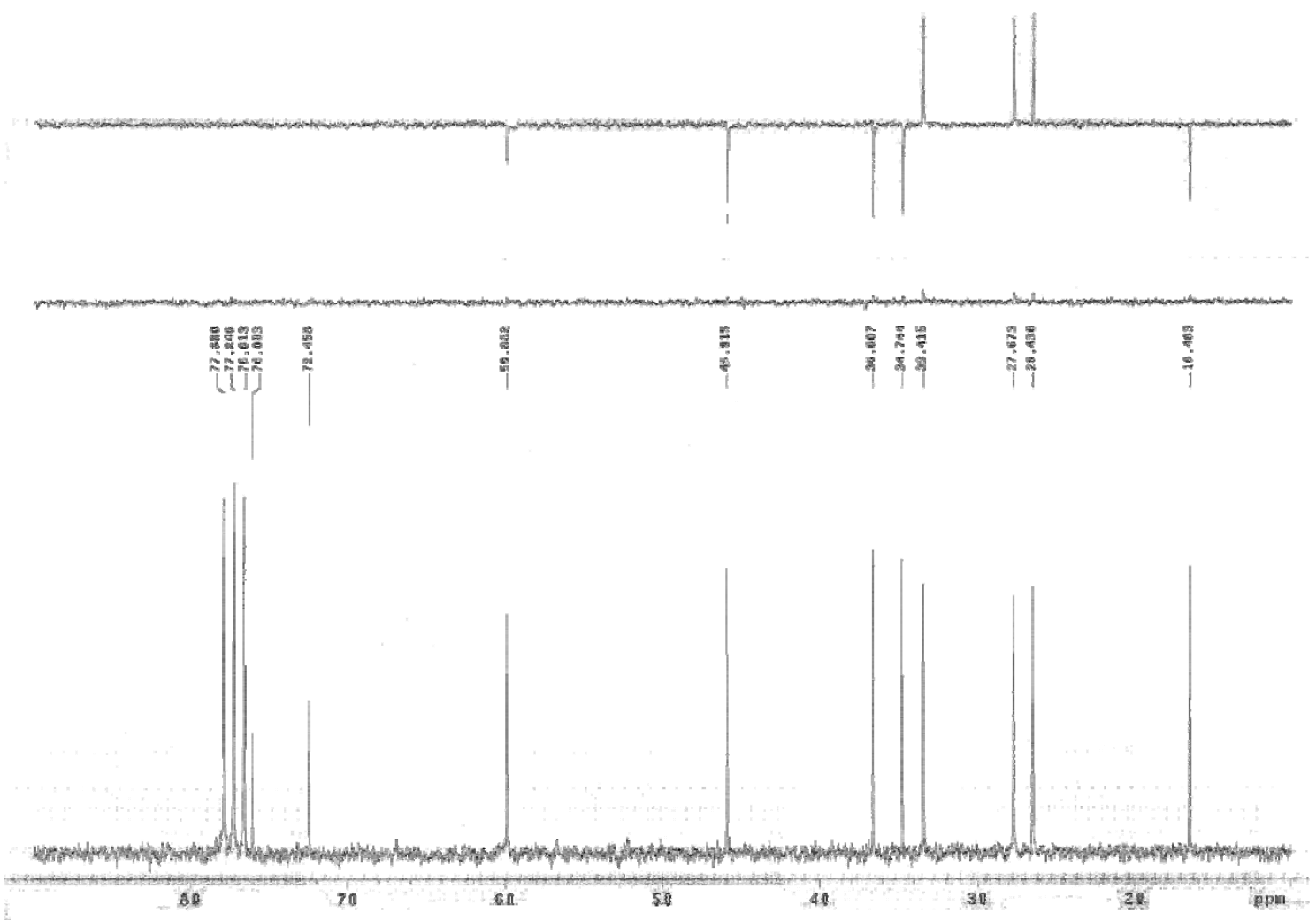

Fig. 103d

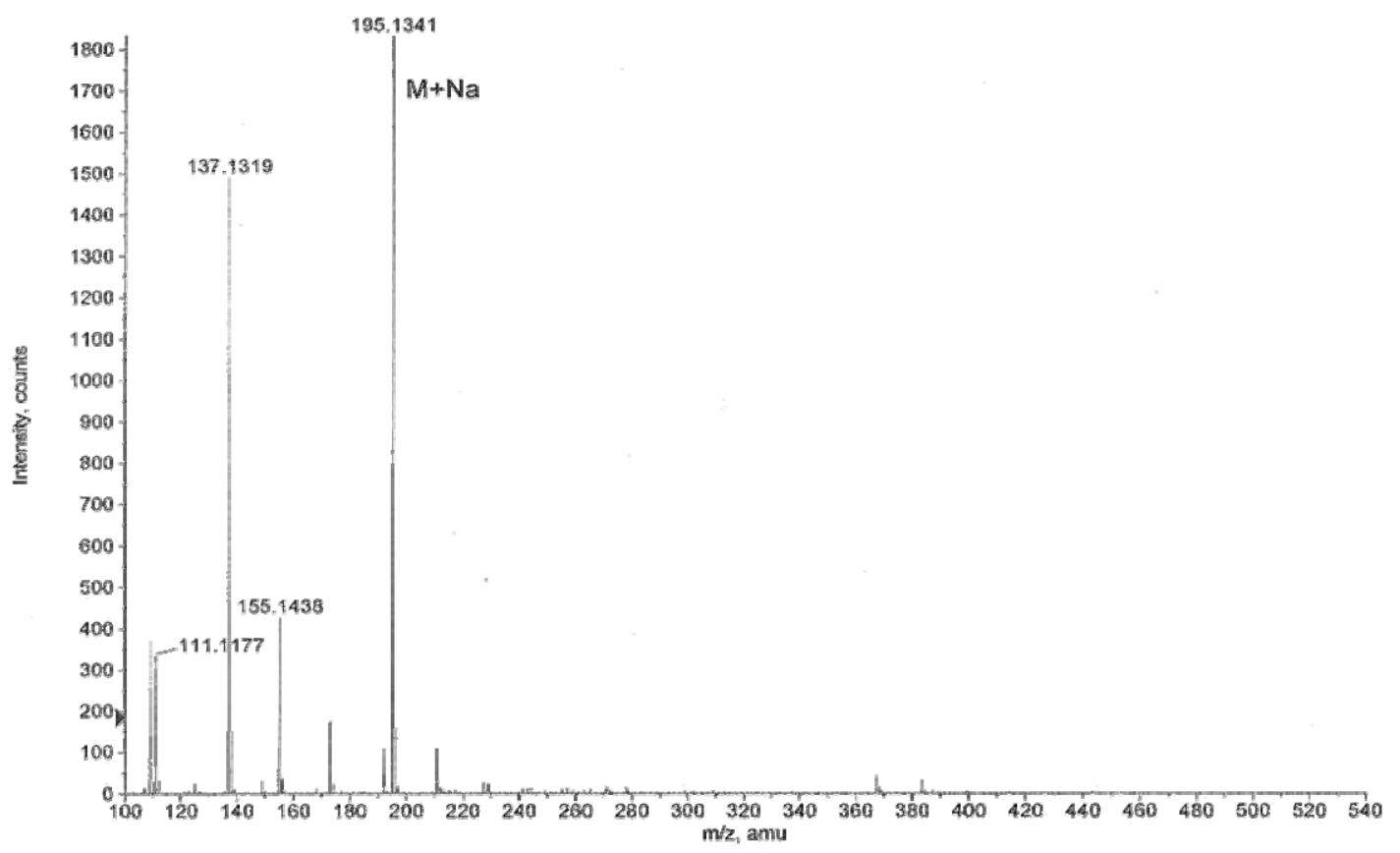


Fig. 104a

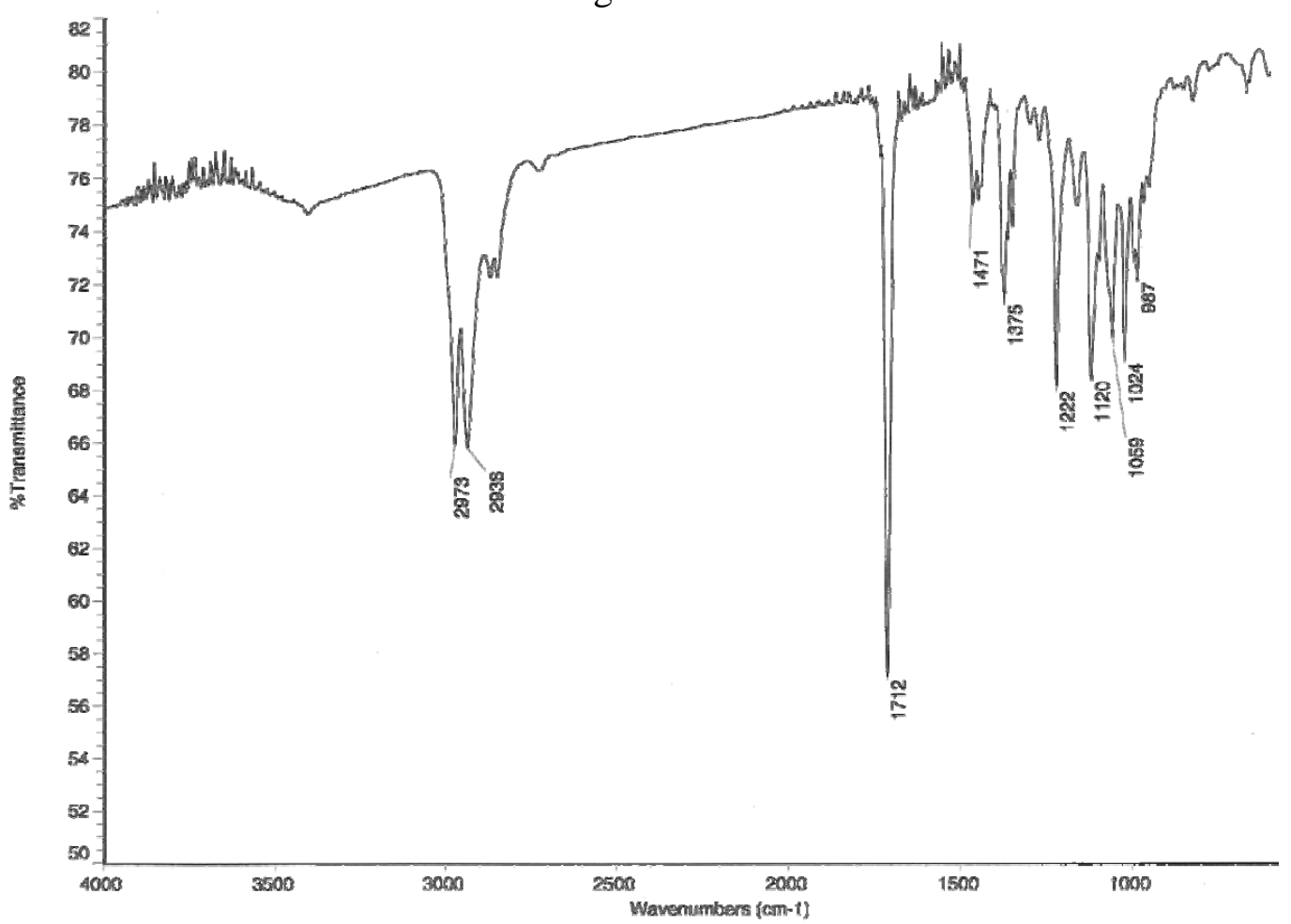

Fig. 104b

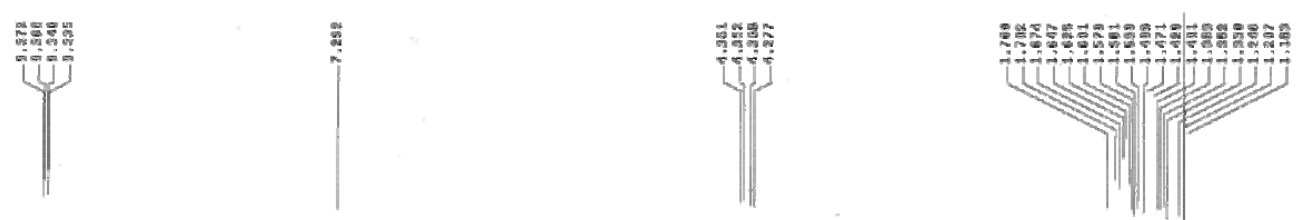<smiles>CC1(C)CCC[C@@](C)([C@H](I)C=O)O1</smiles>

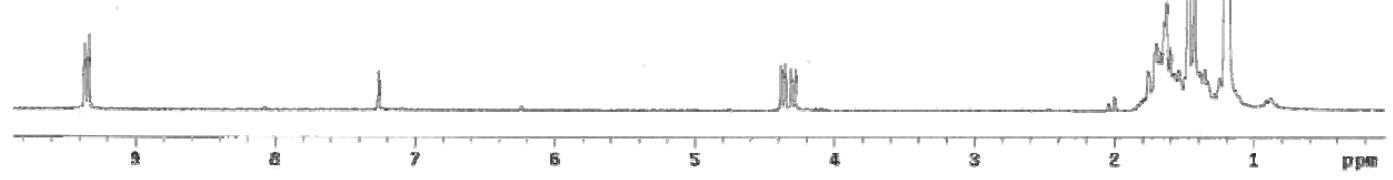


Fig. 104c

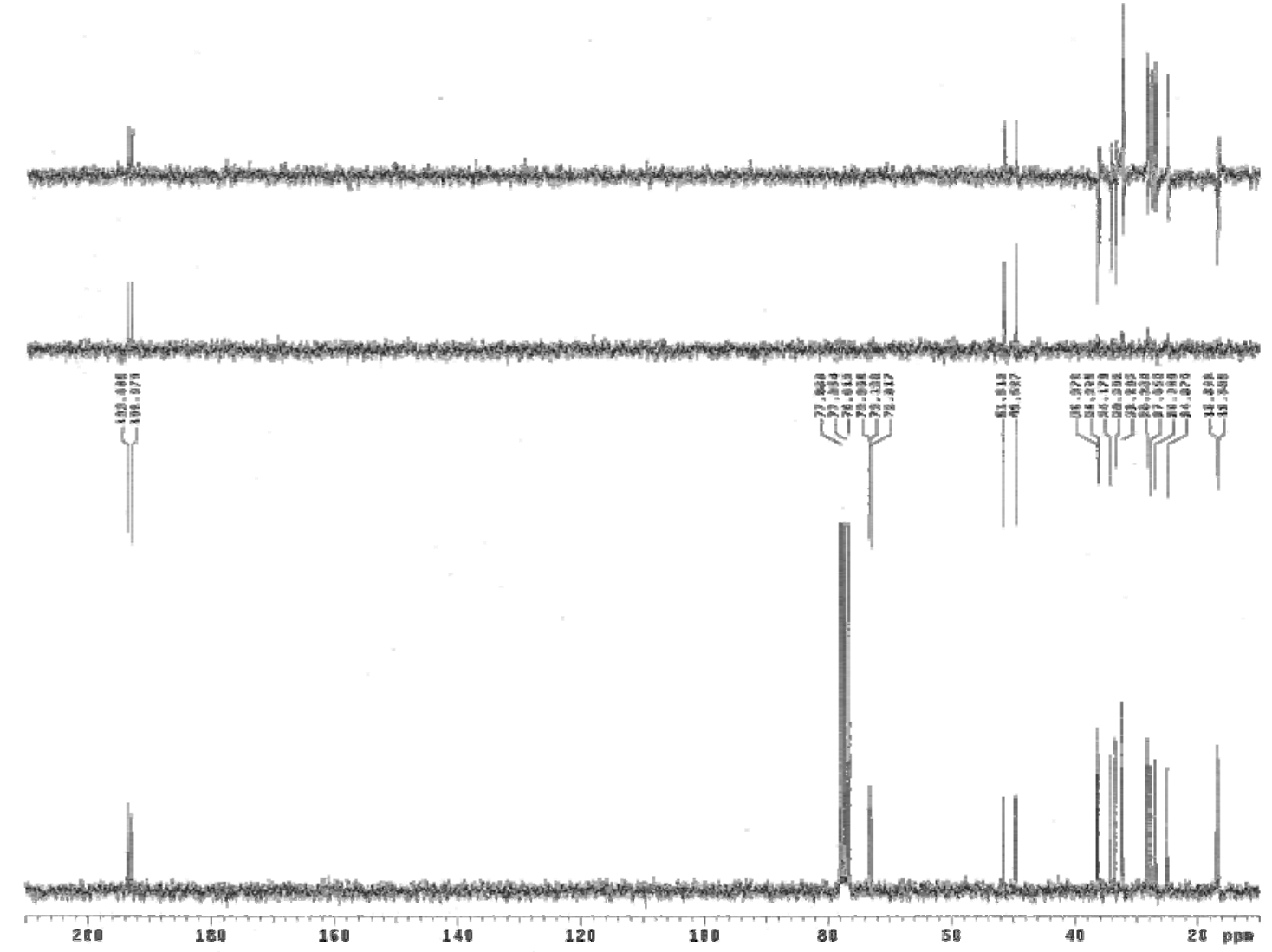

Fig. 104d

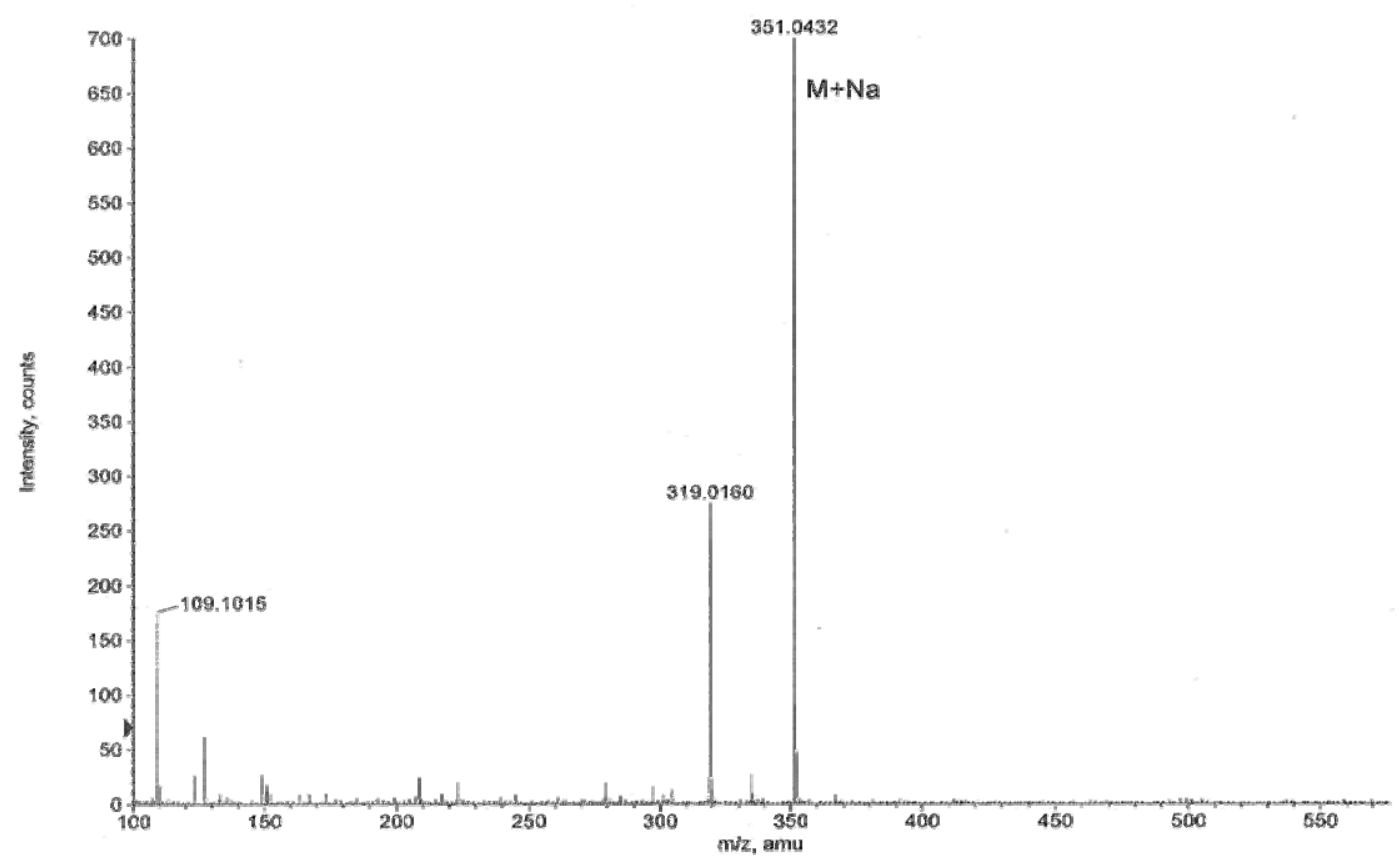




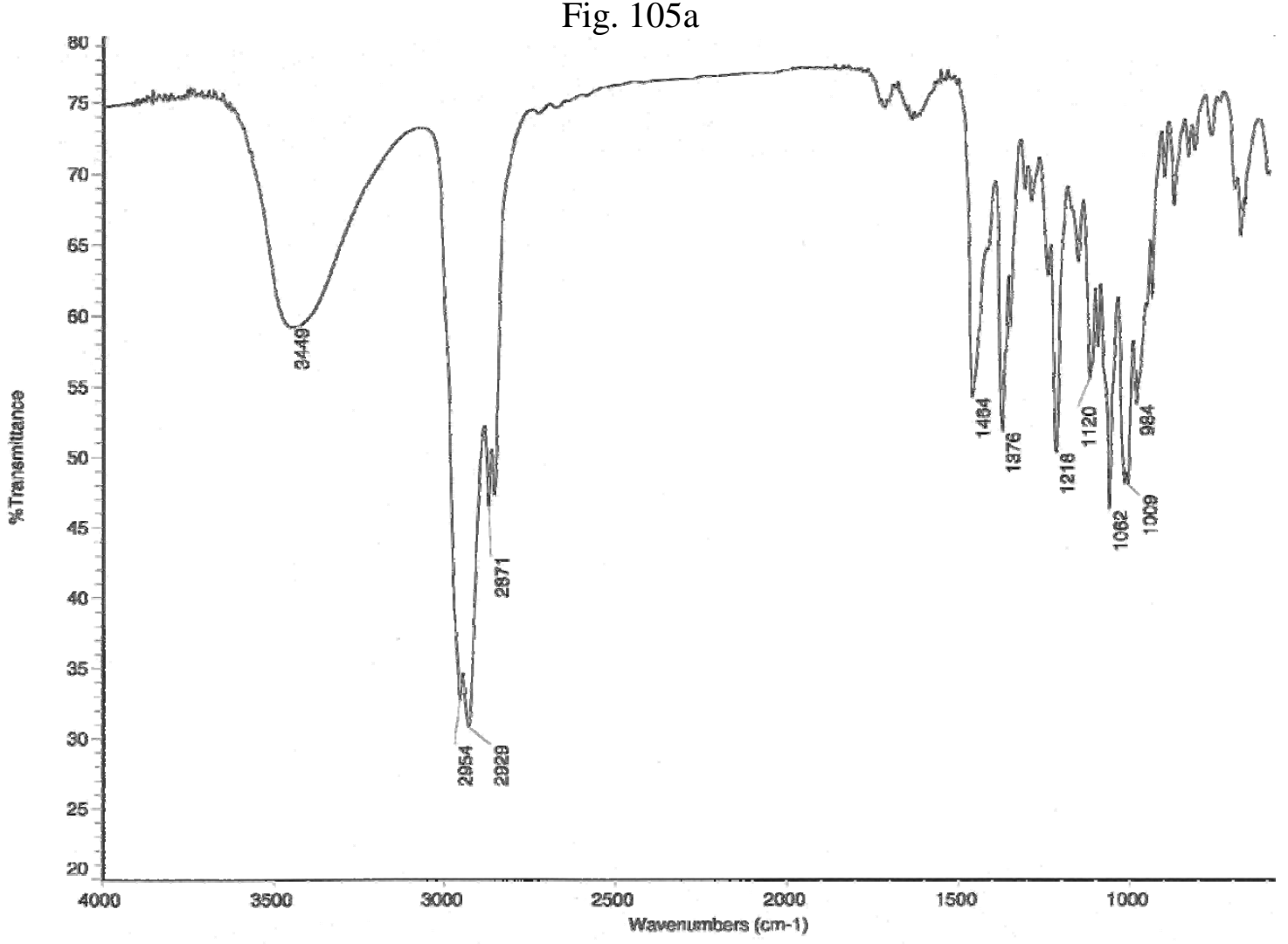

Fig. 105b

i

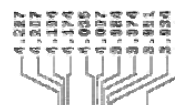

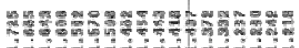

i
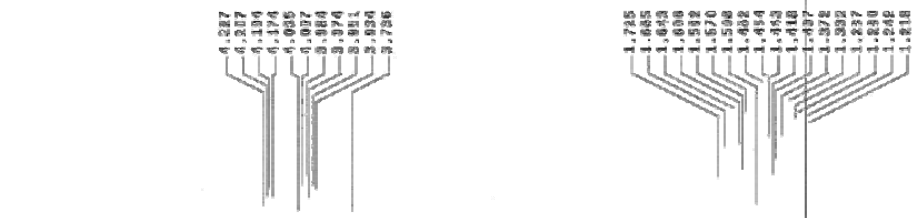<smiles>CC1(C)CCC[C@@](C)([C@H](I)C[OH2+])O1</smiles>

133<smiles>CC1(C)CCC[C@](C)([C@H](I)CO)O1</smiles>

134
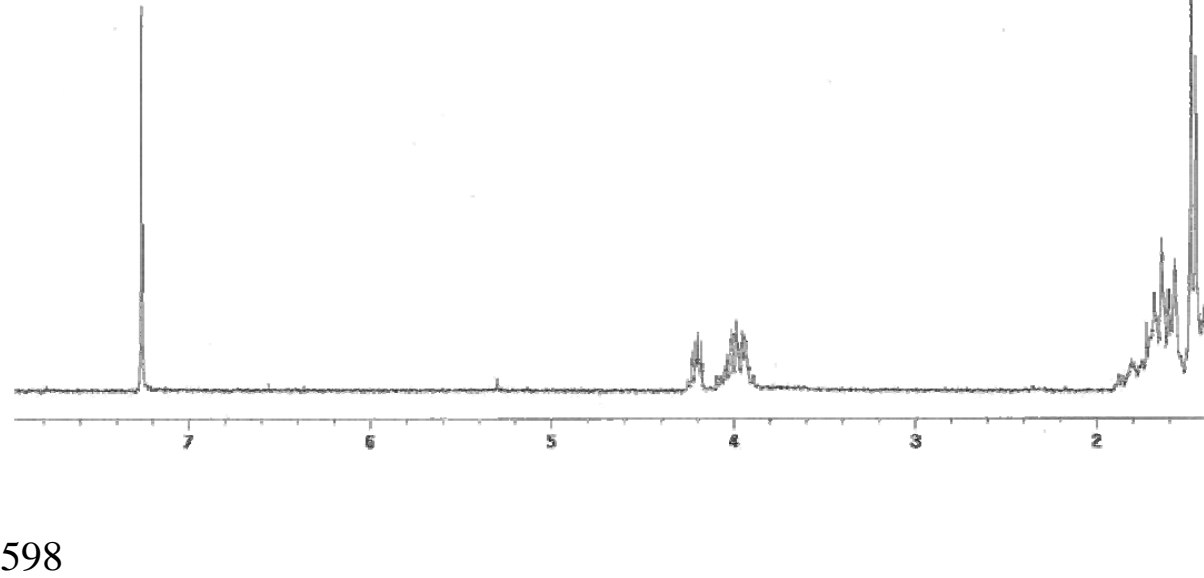
Fig. 105c

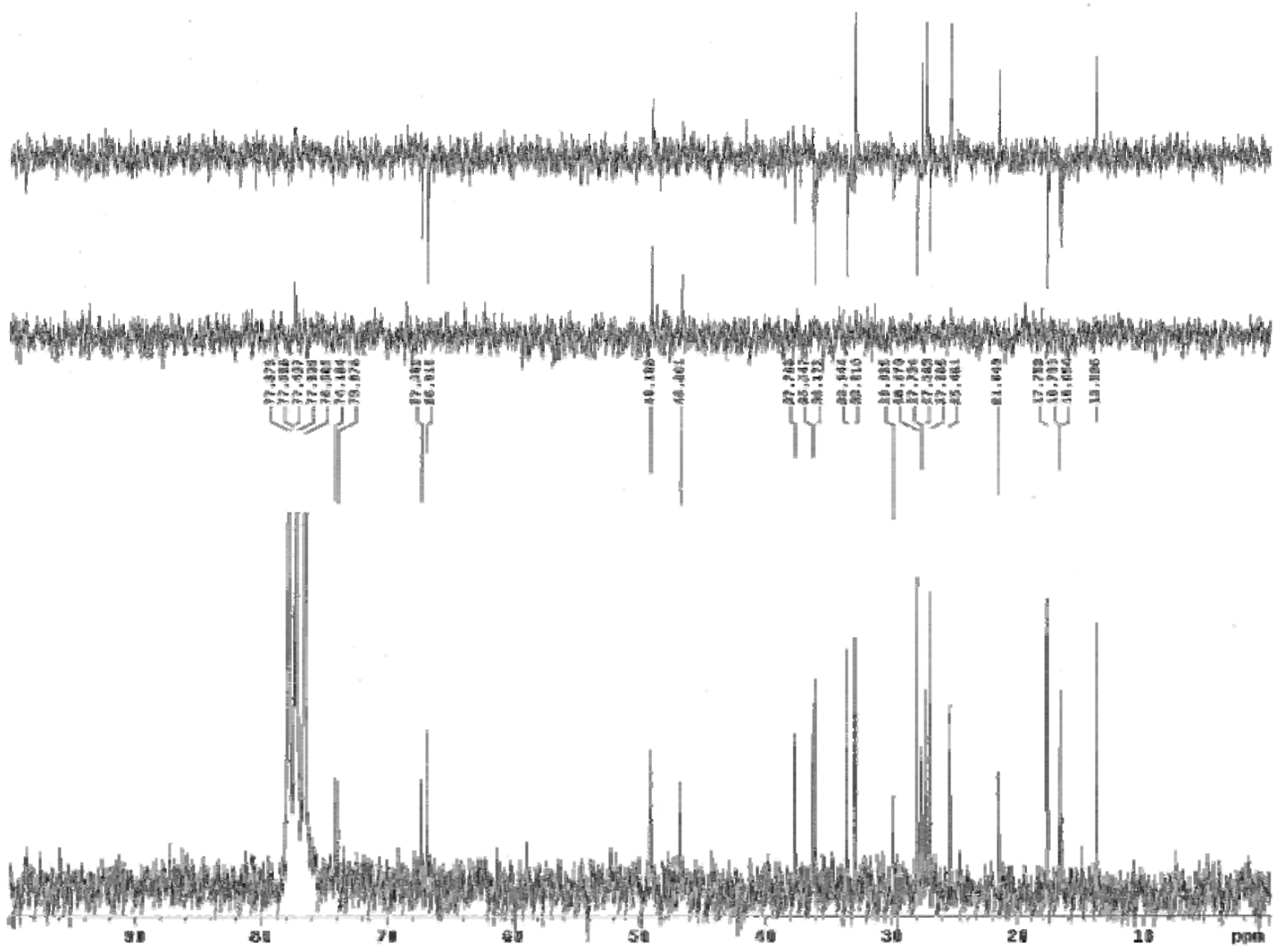

Fig. 105d

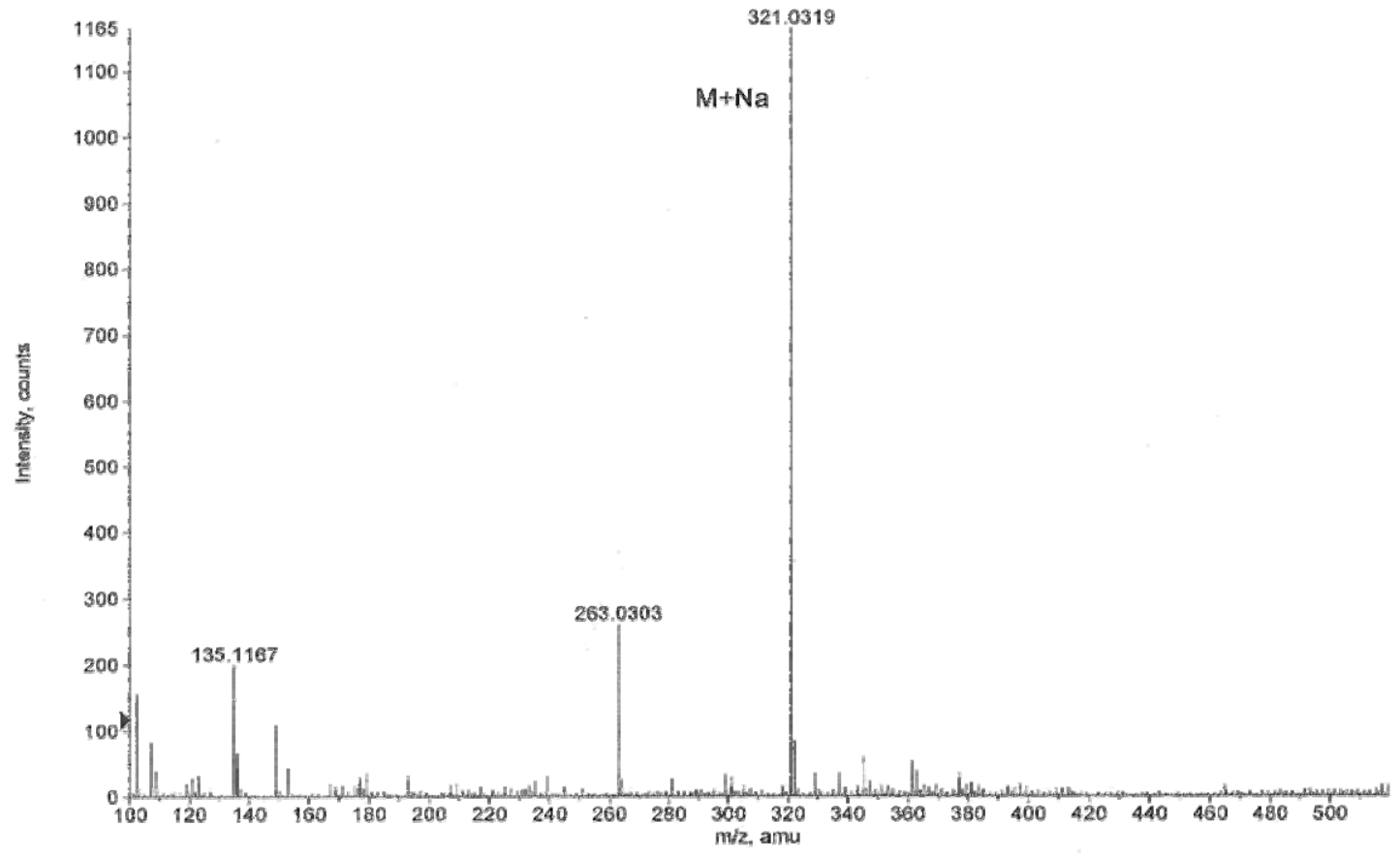


Fig. 106a

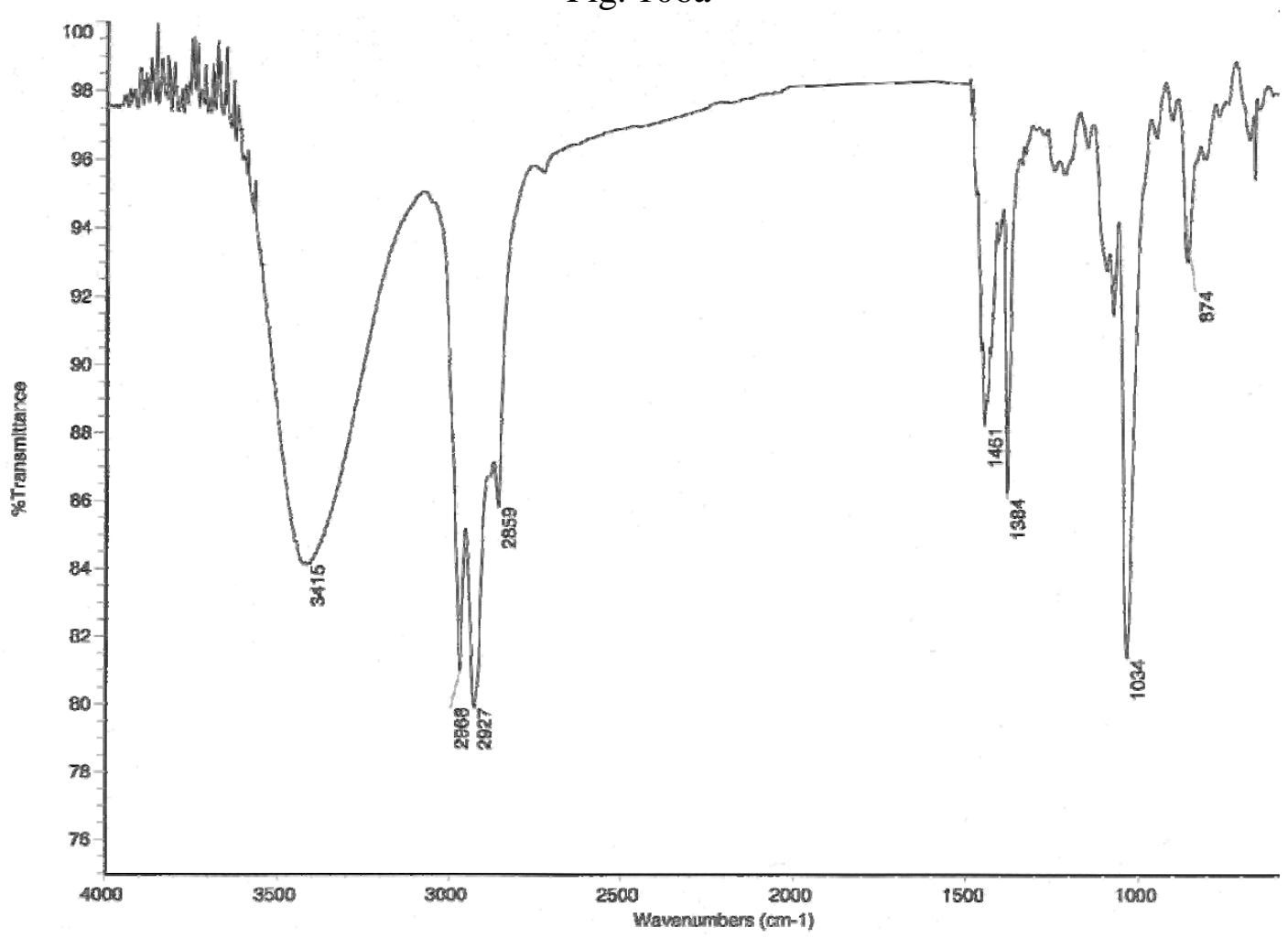

Fig. 106b
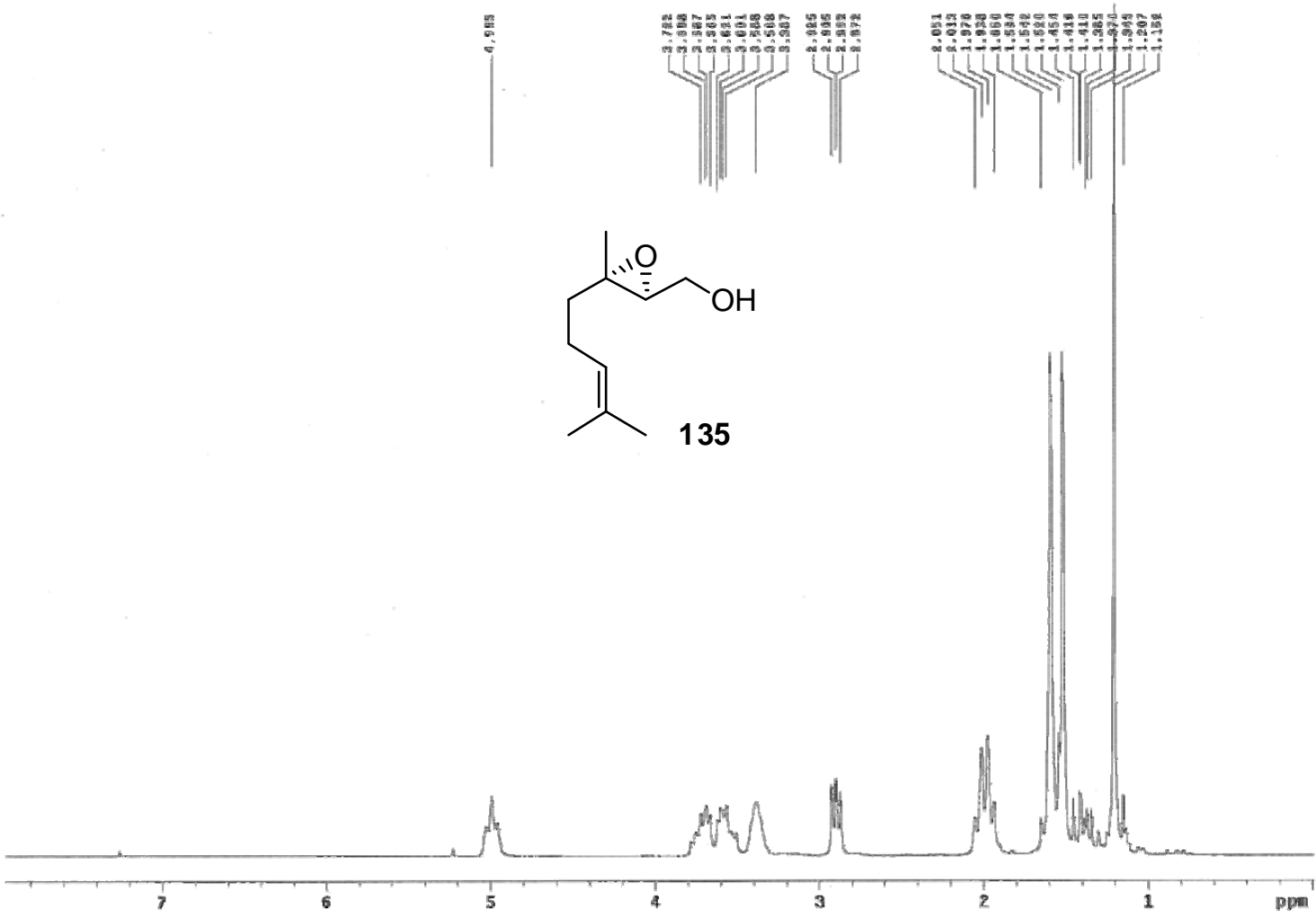
Fig. 106c
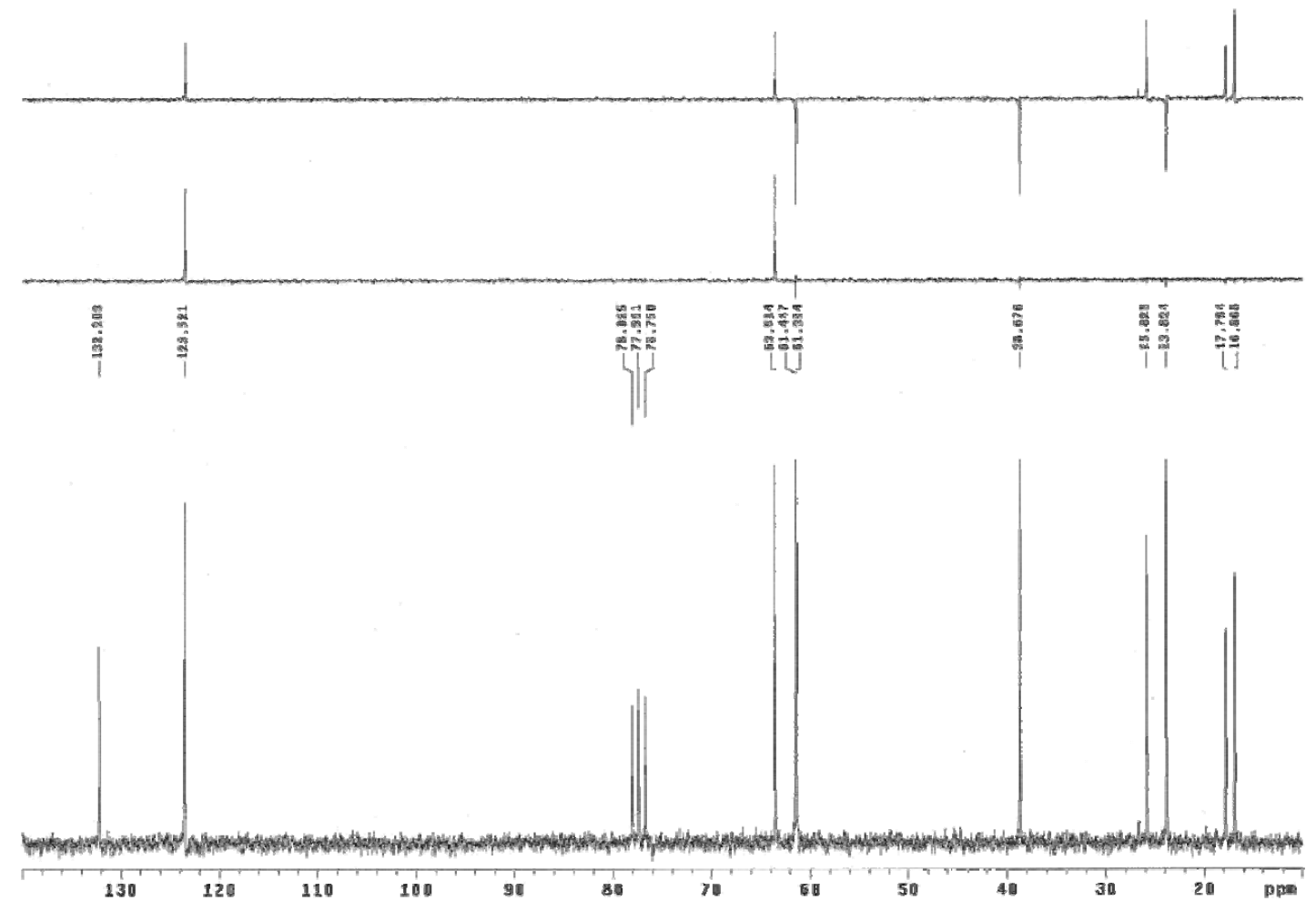

Fig. 106d

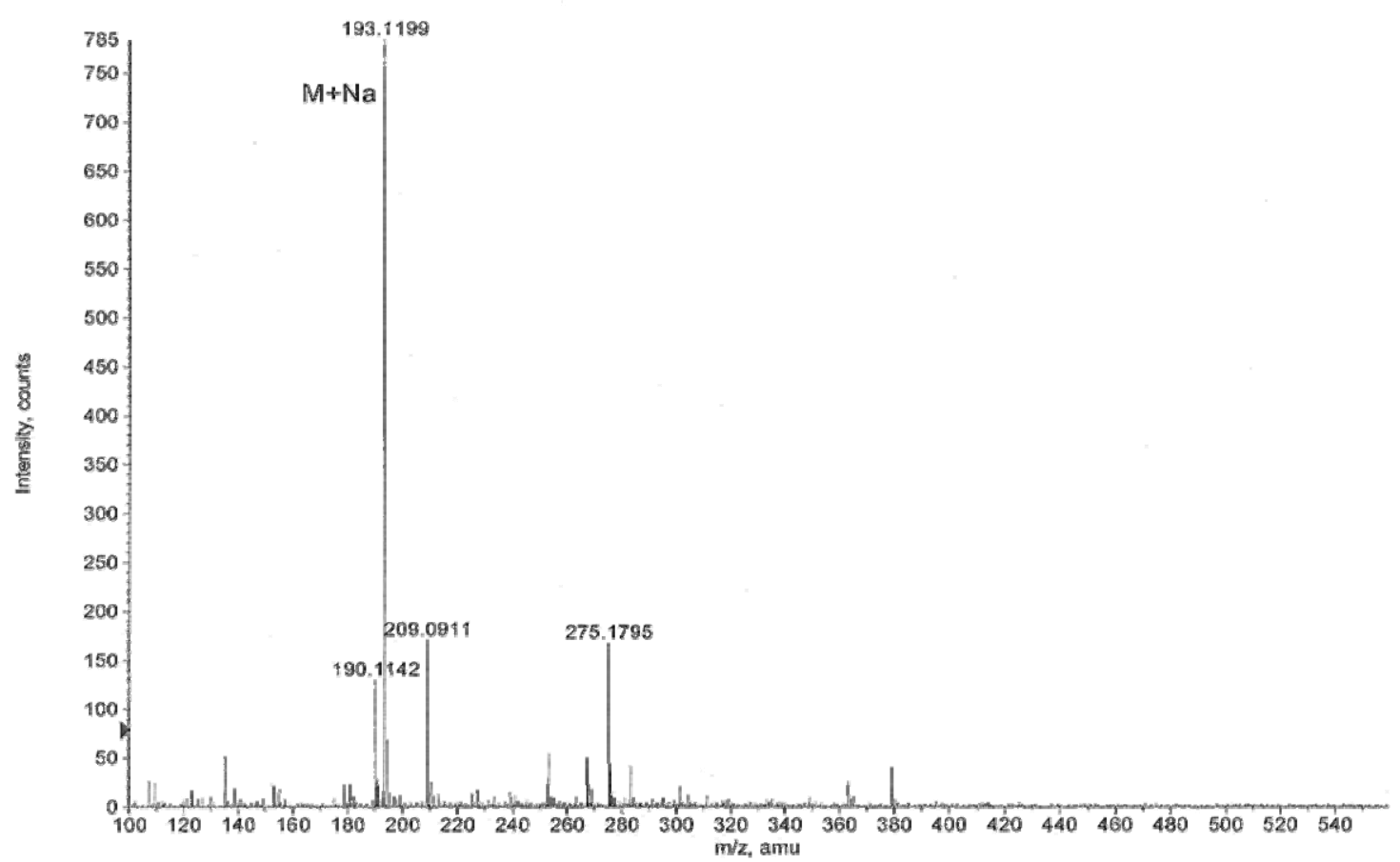


Fig. 107a

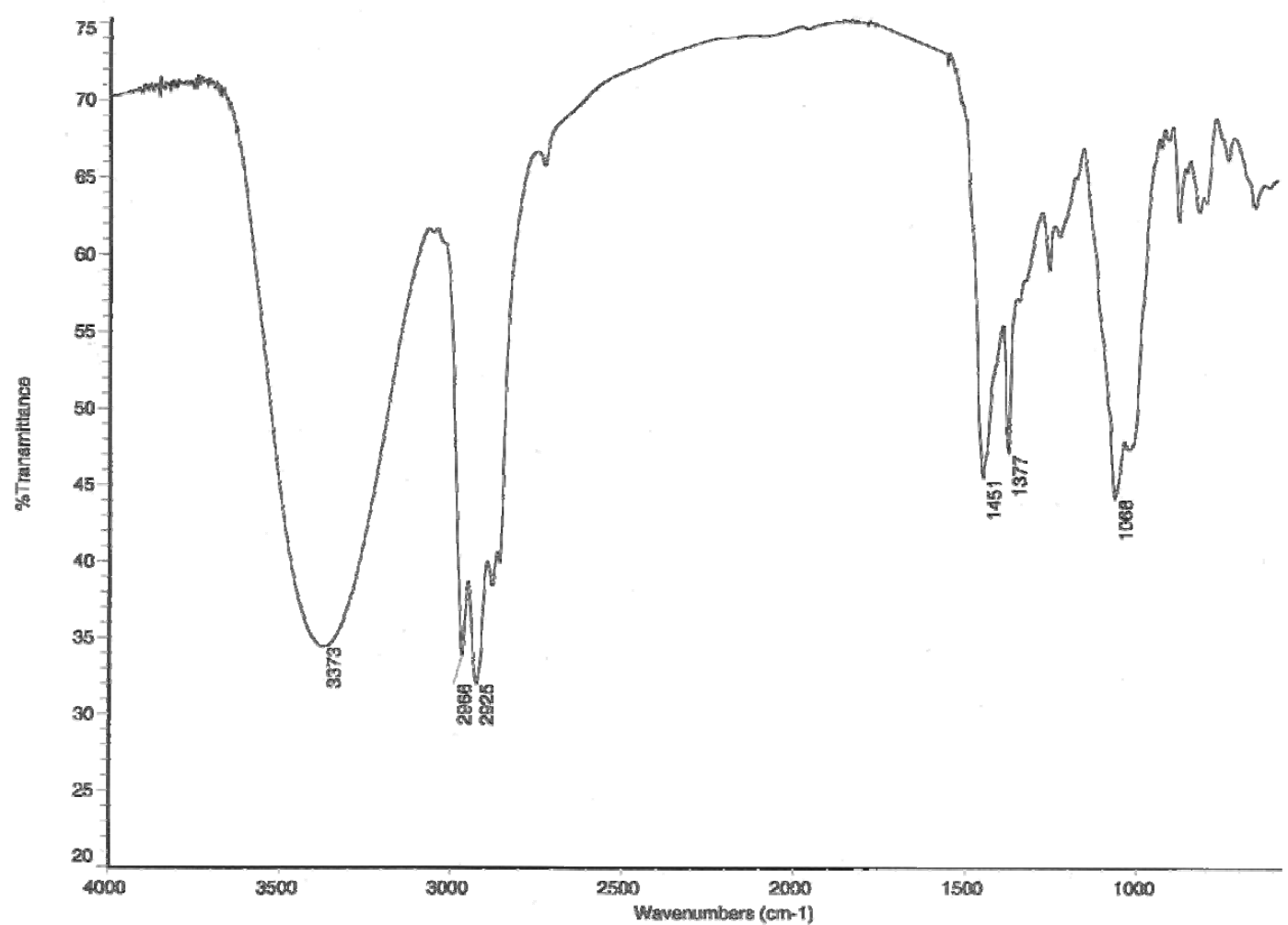

Fig. 107b
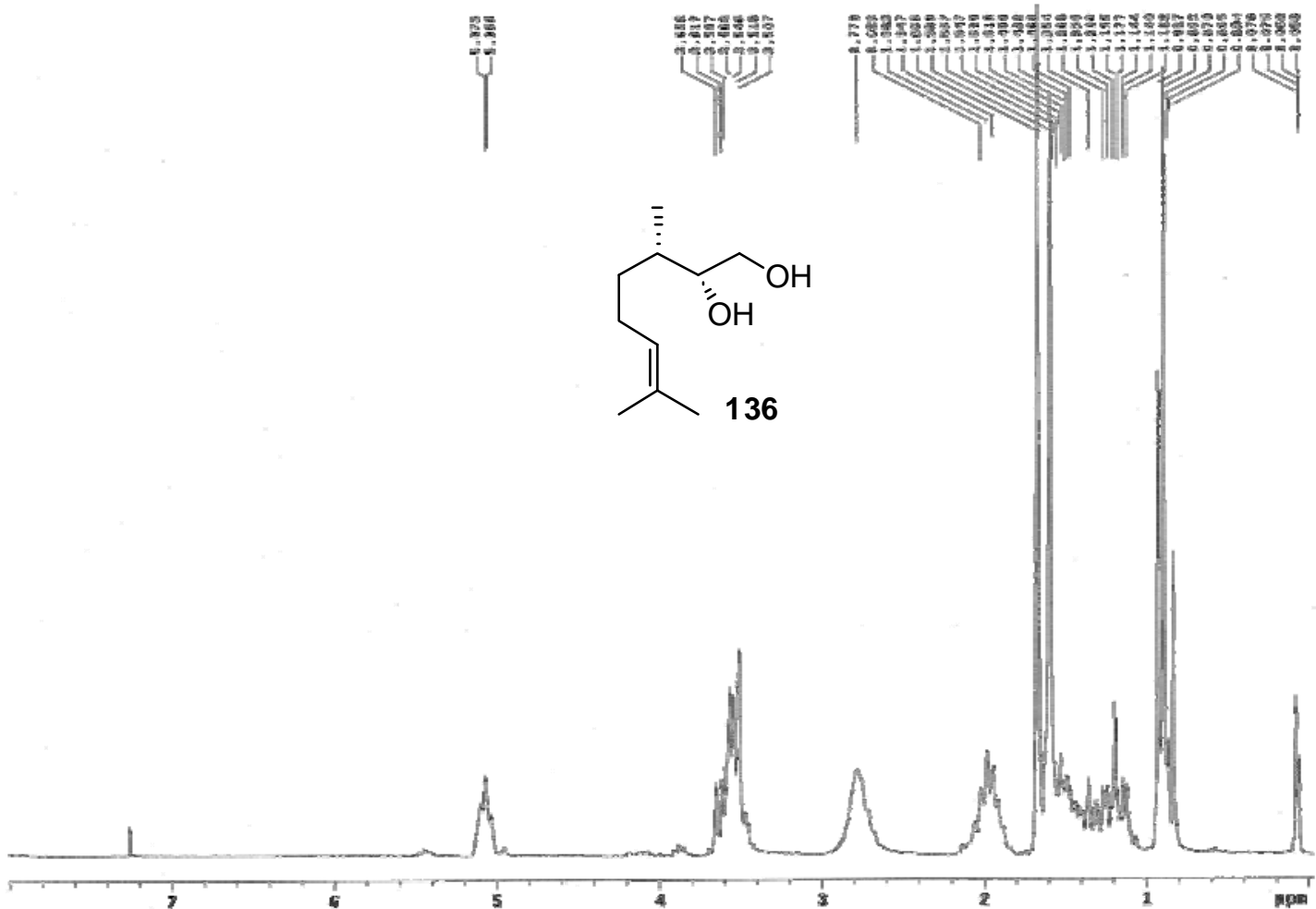
Fig. 107c
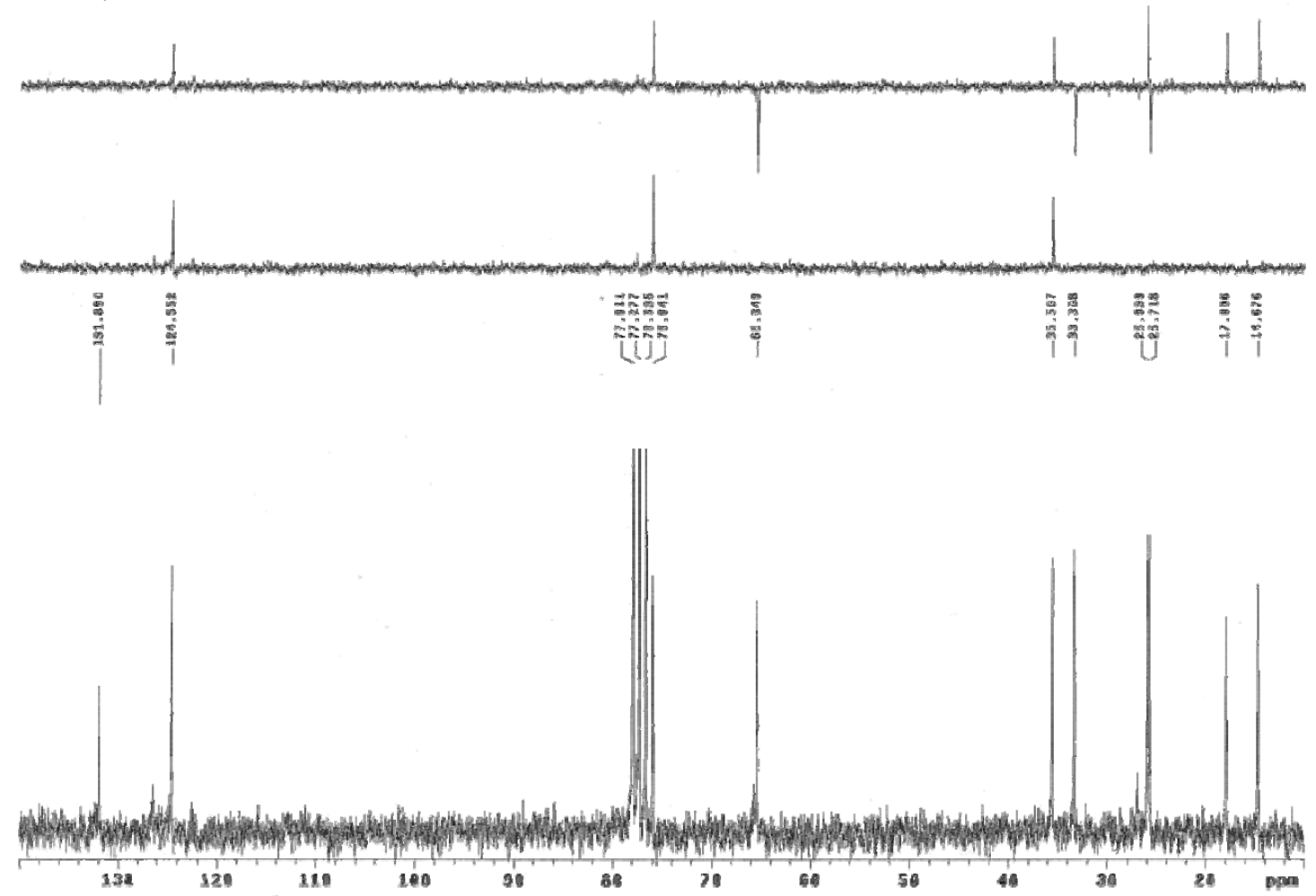

Fig. 107d

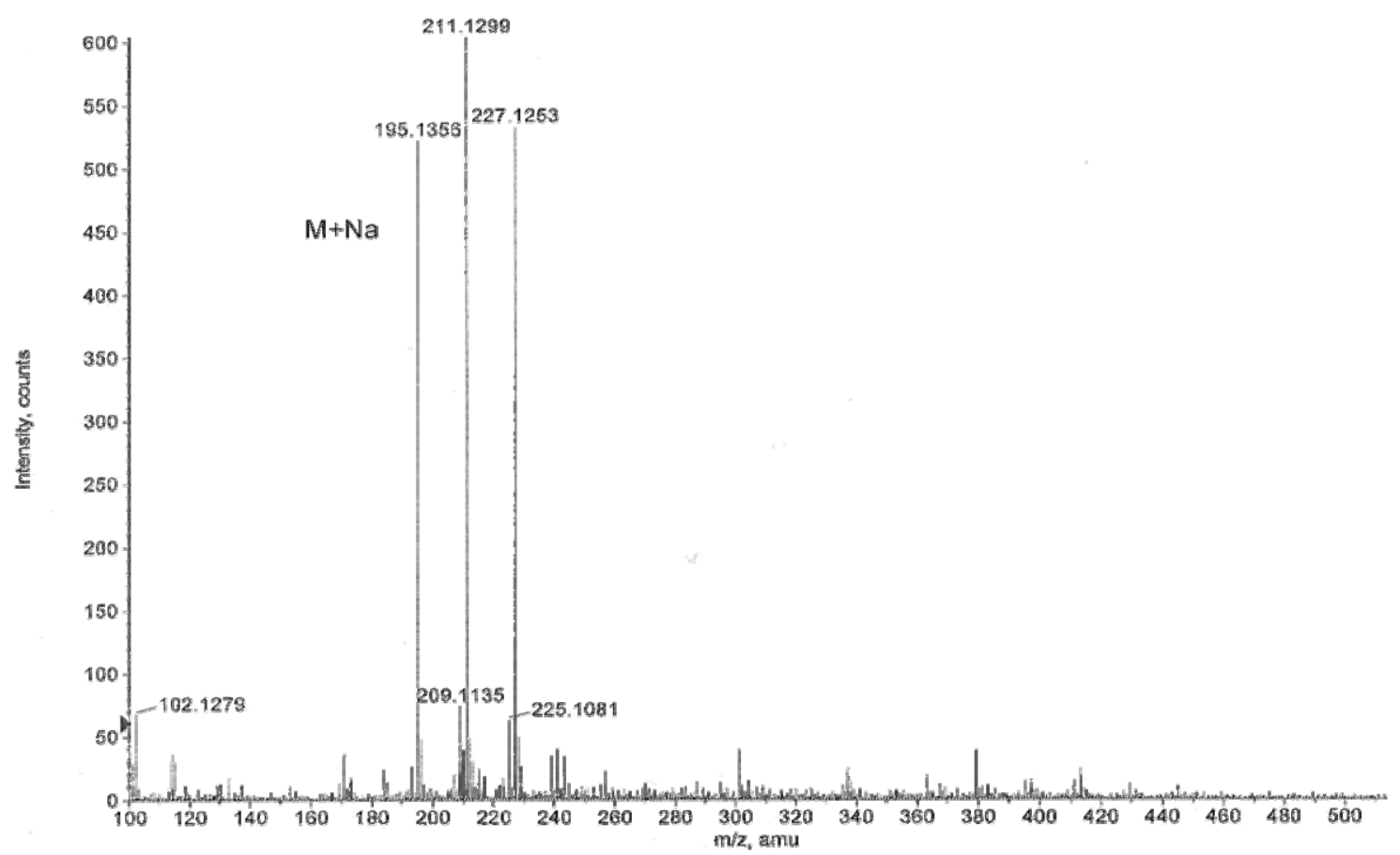


Fig. 108a

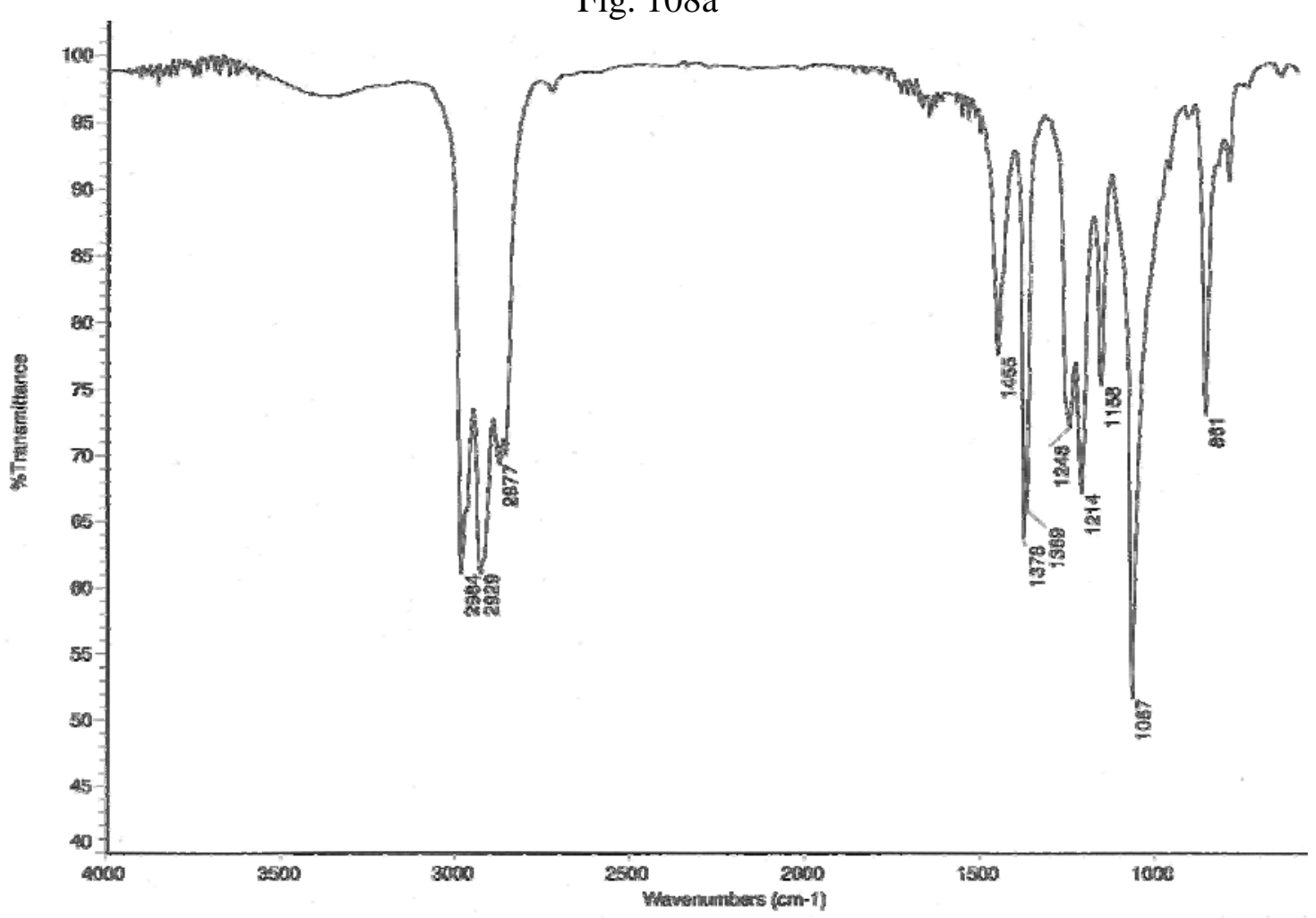

Fig. 108b

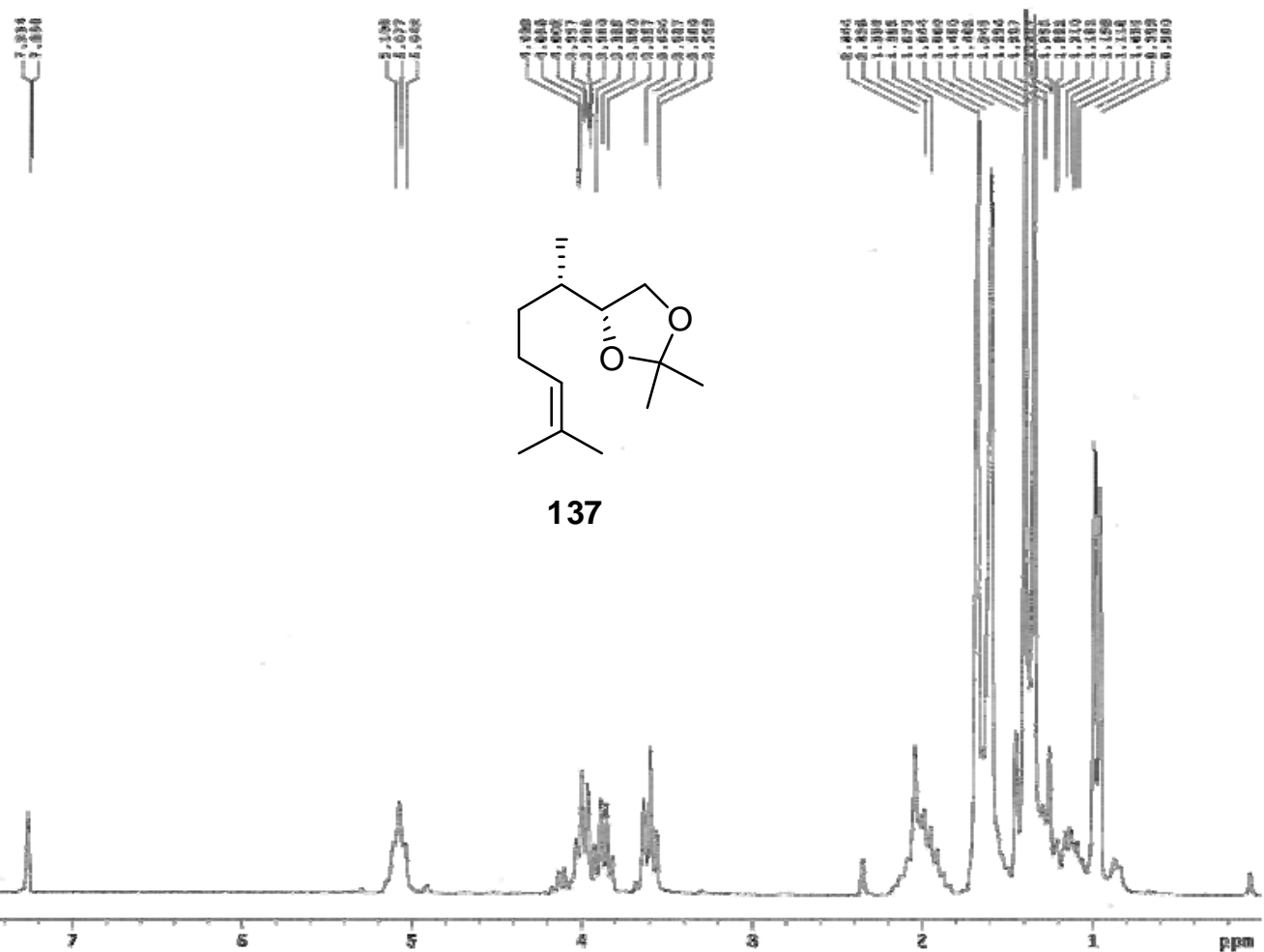


Fig. 108c

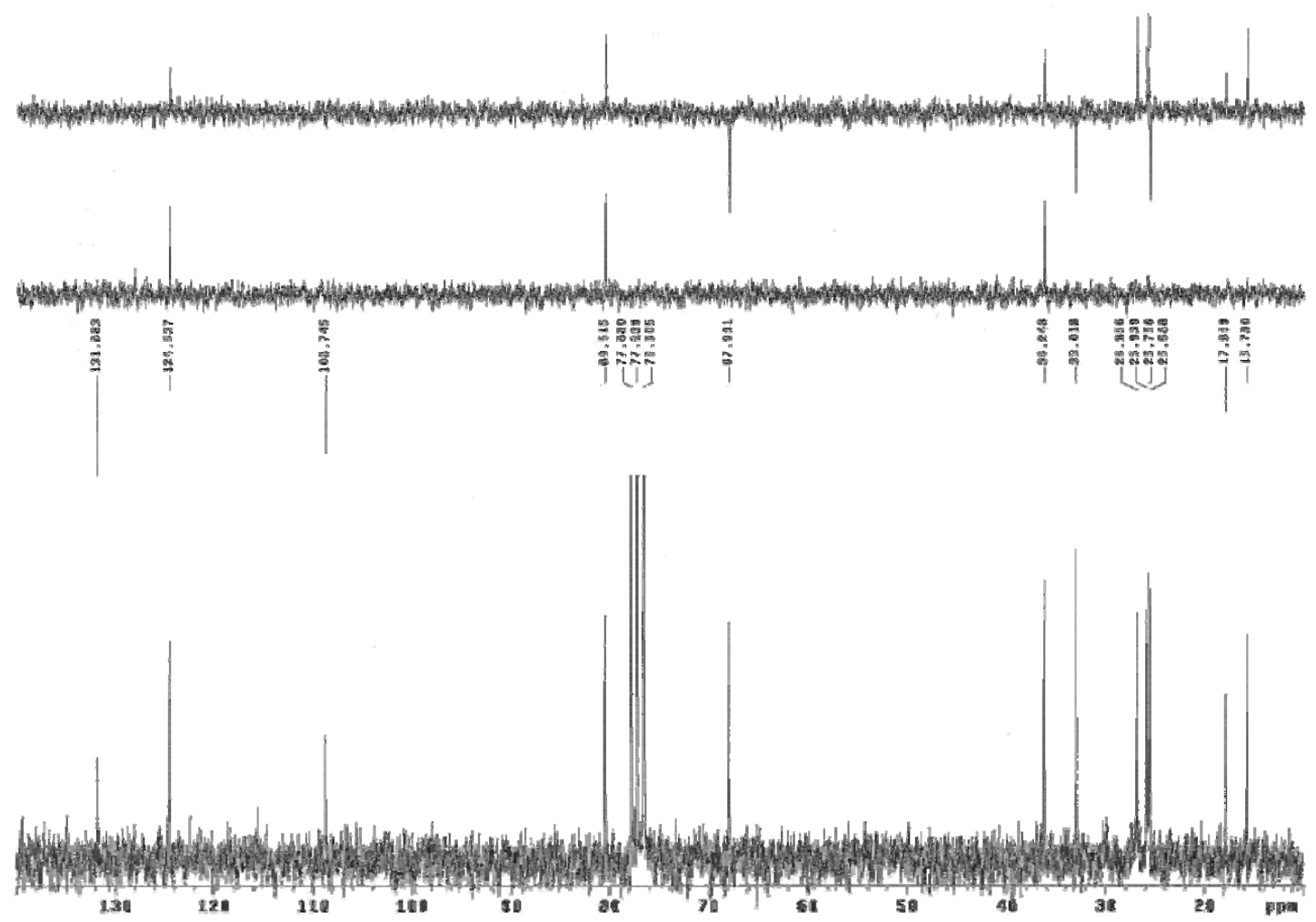


Fig. 109a

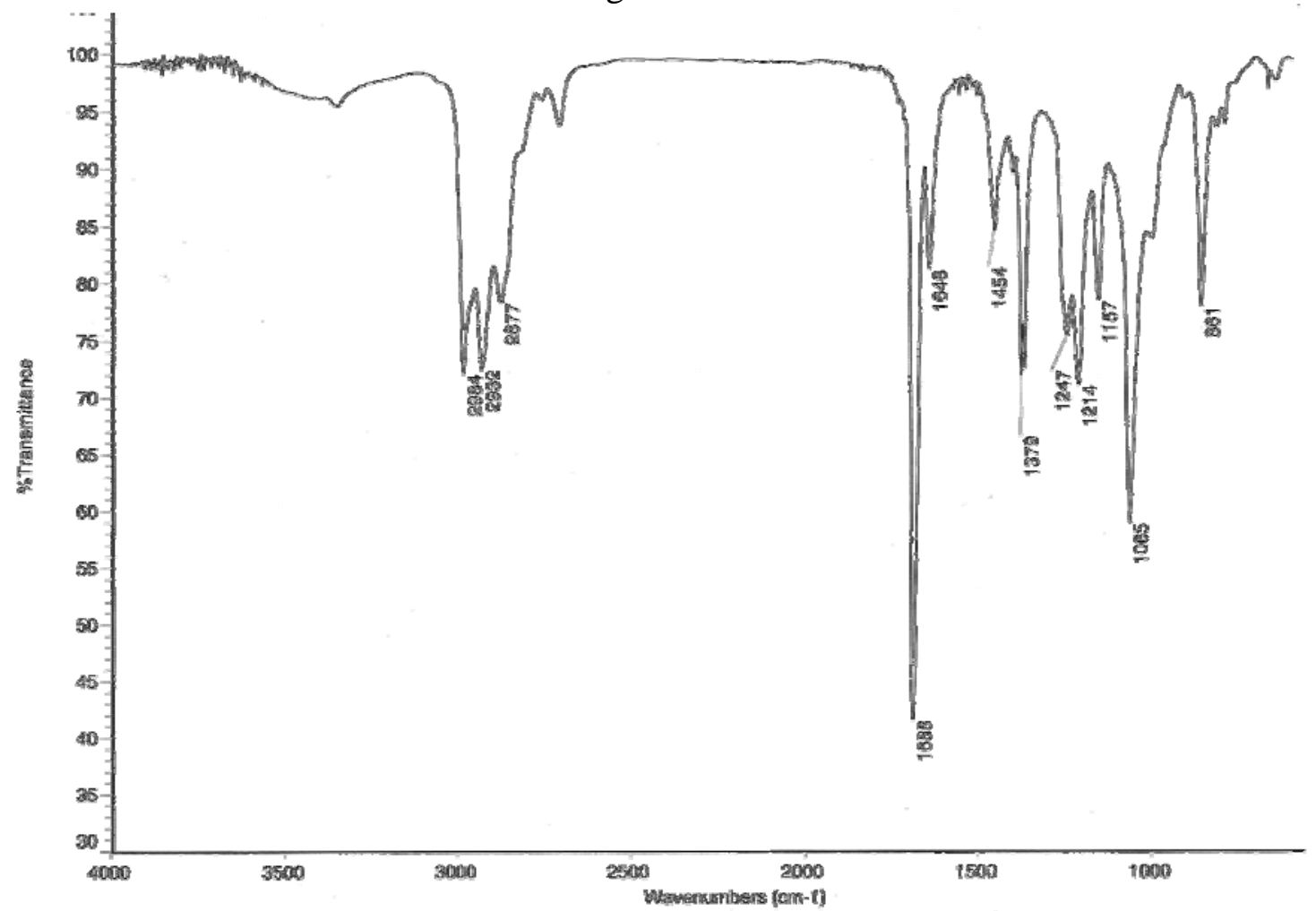

Fig. 109b

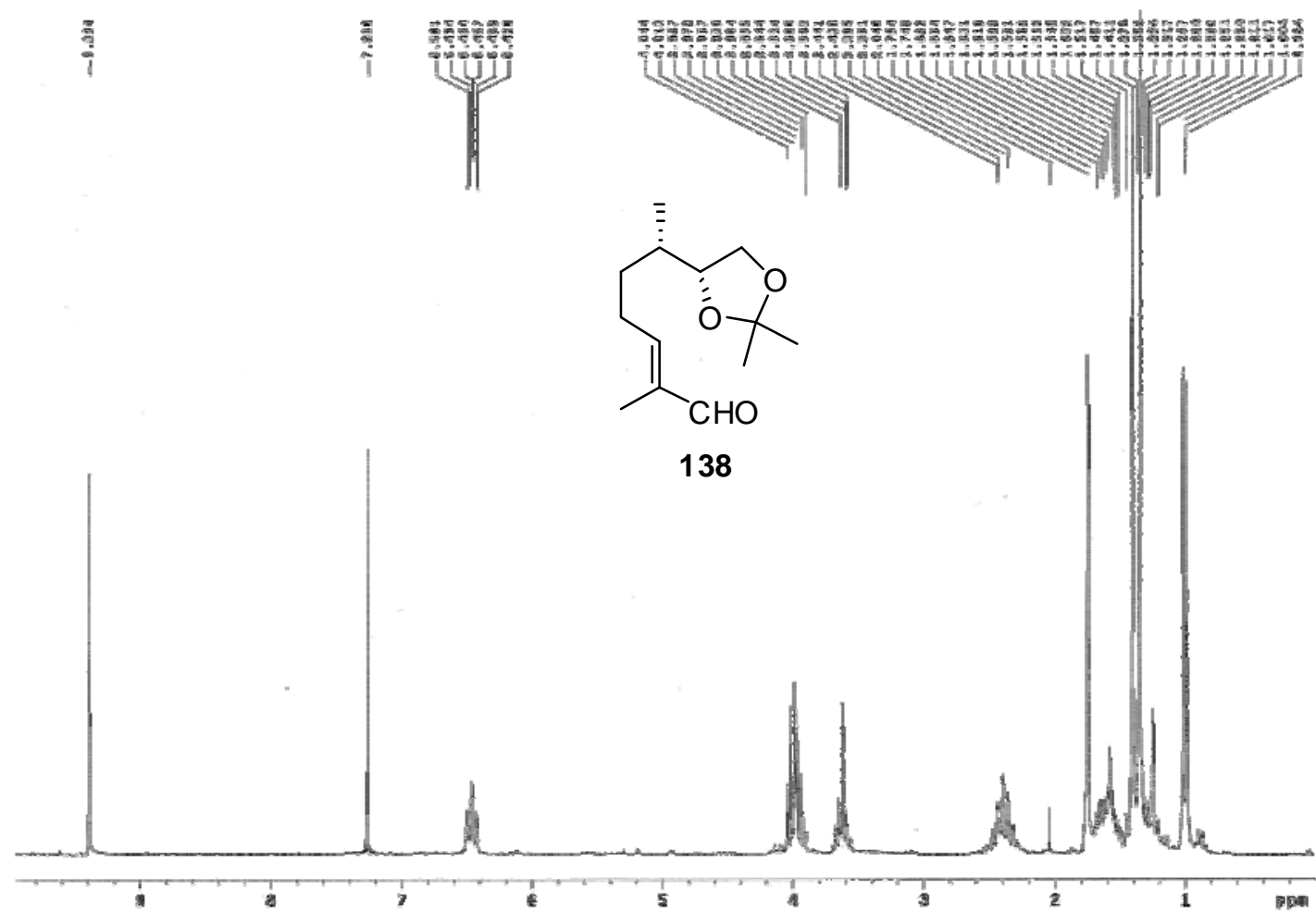


Fig. 109c

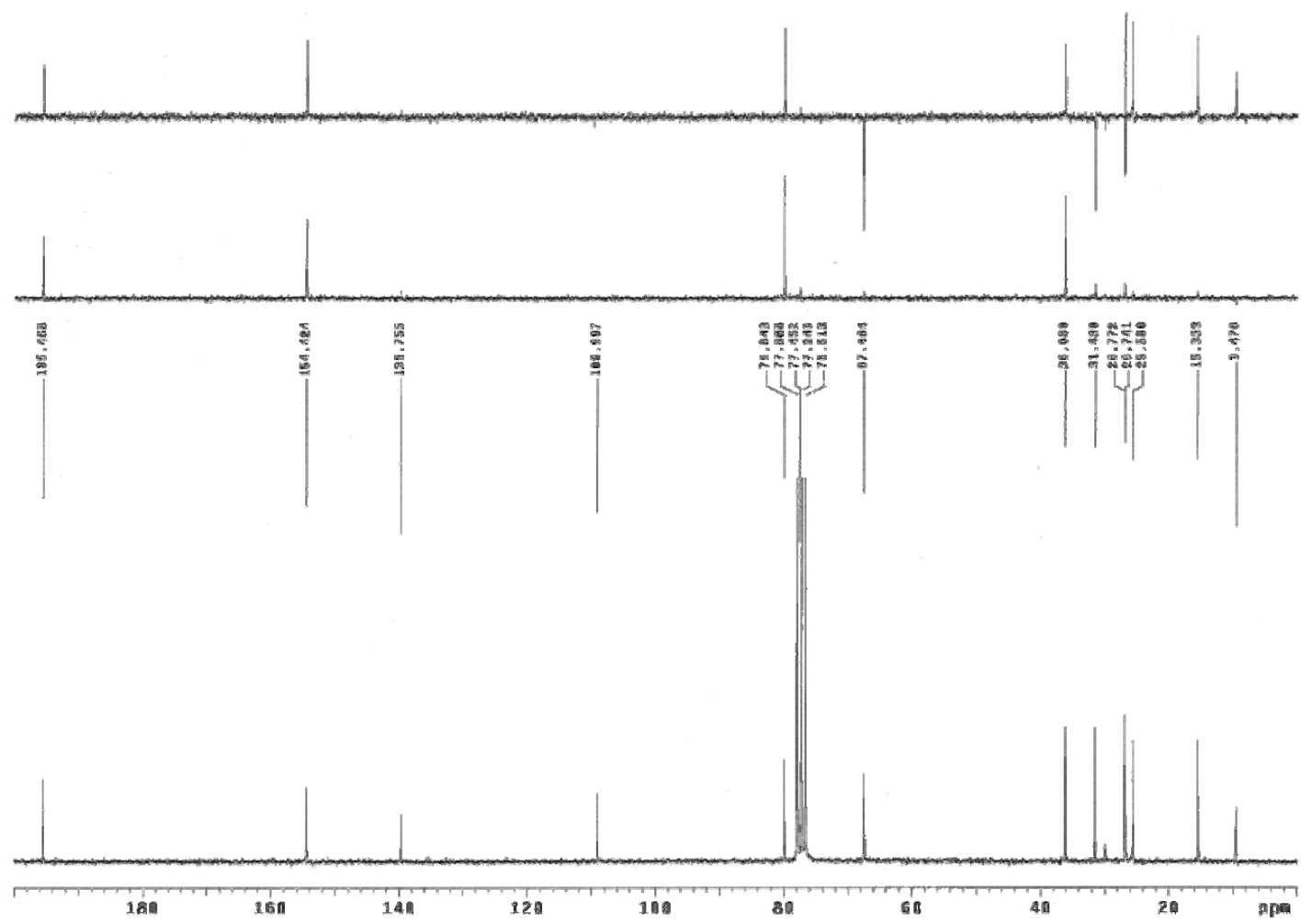

Fig. 109d

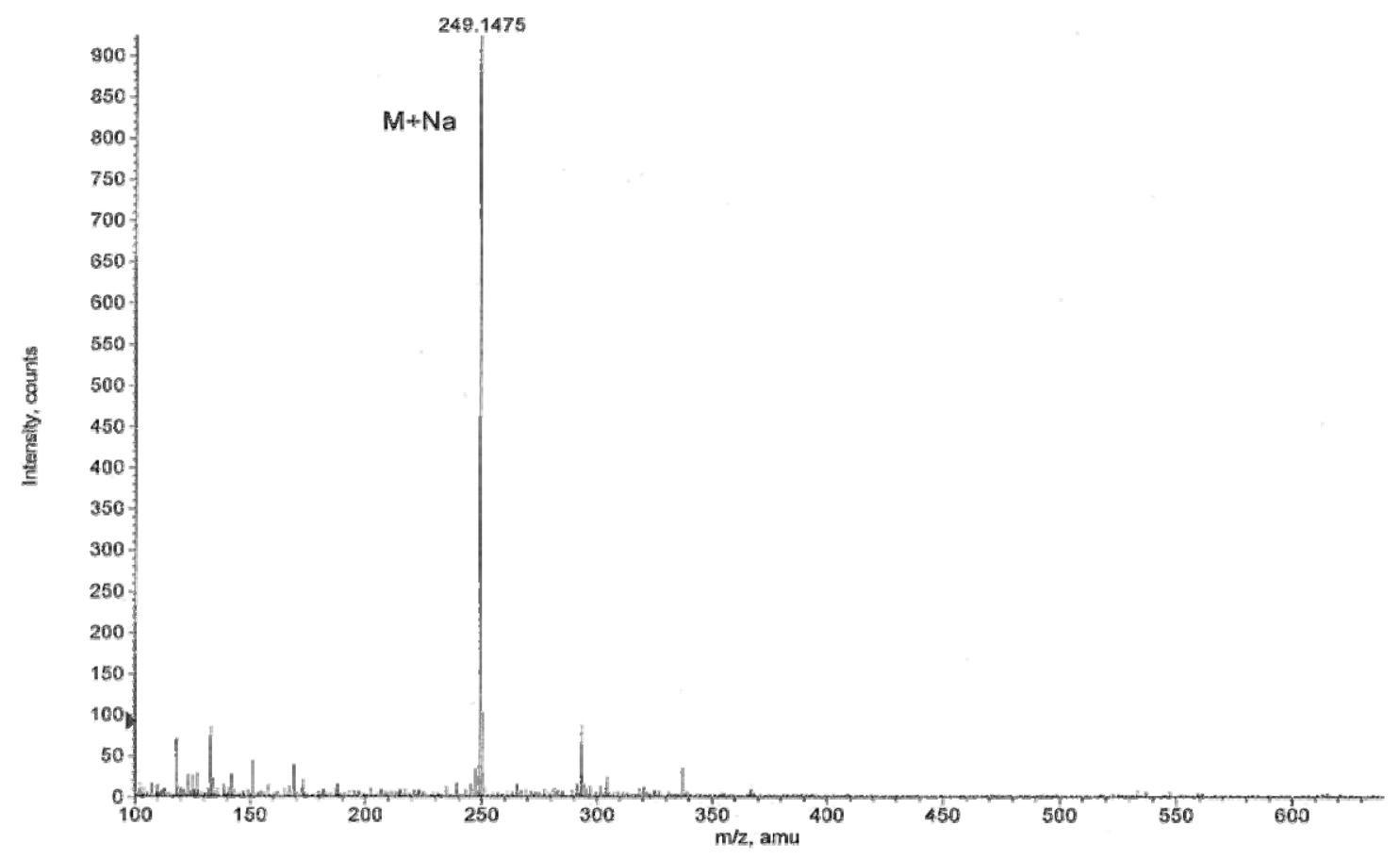


Fig. 110a

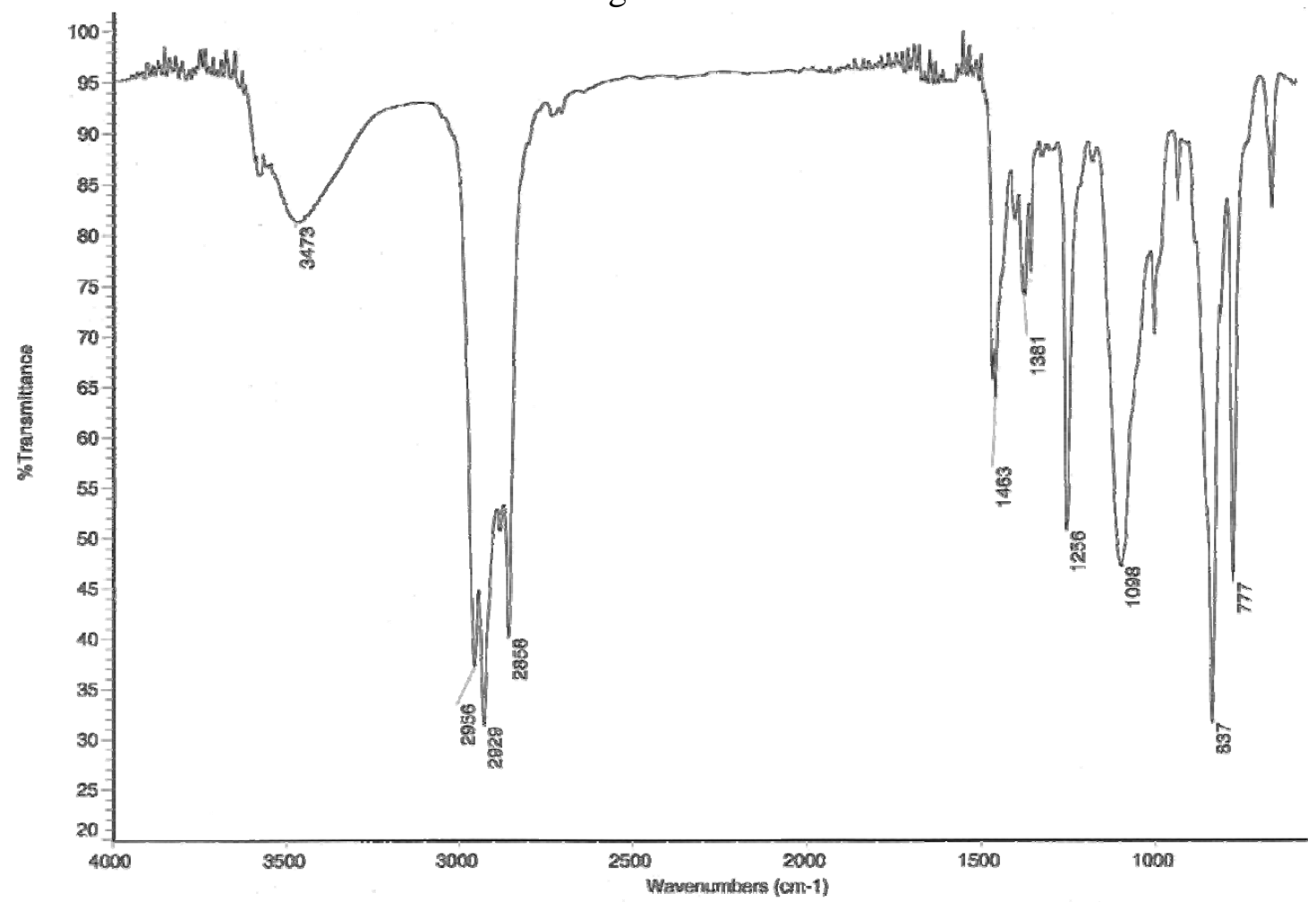

Fig. 110b

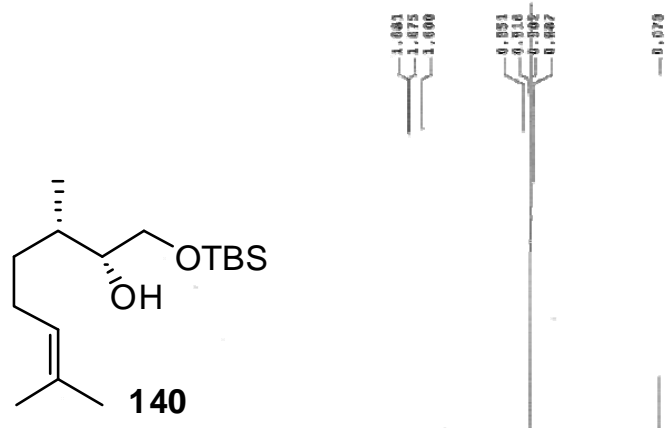


Fig. 110c

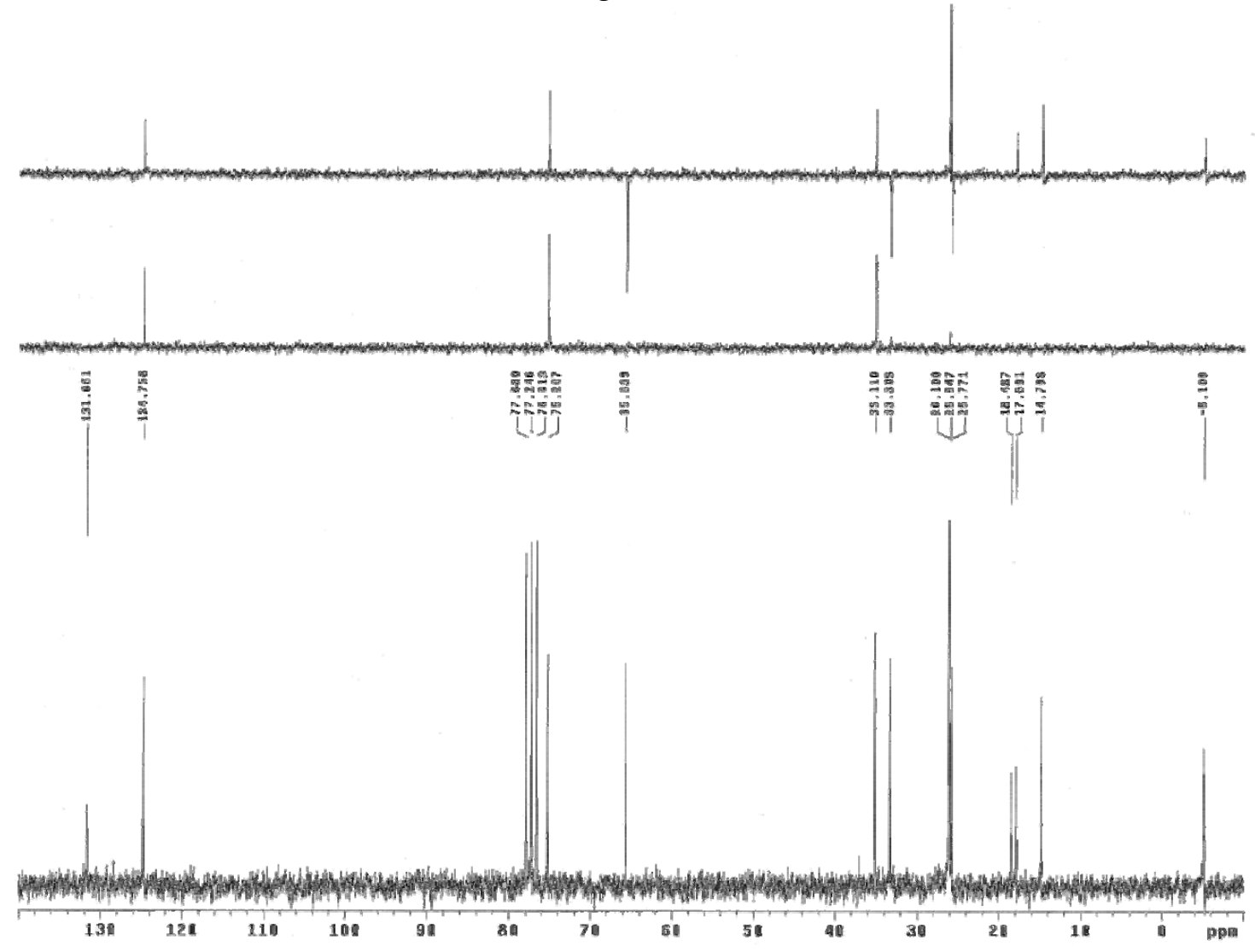

Fig. 110d

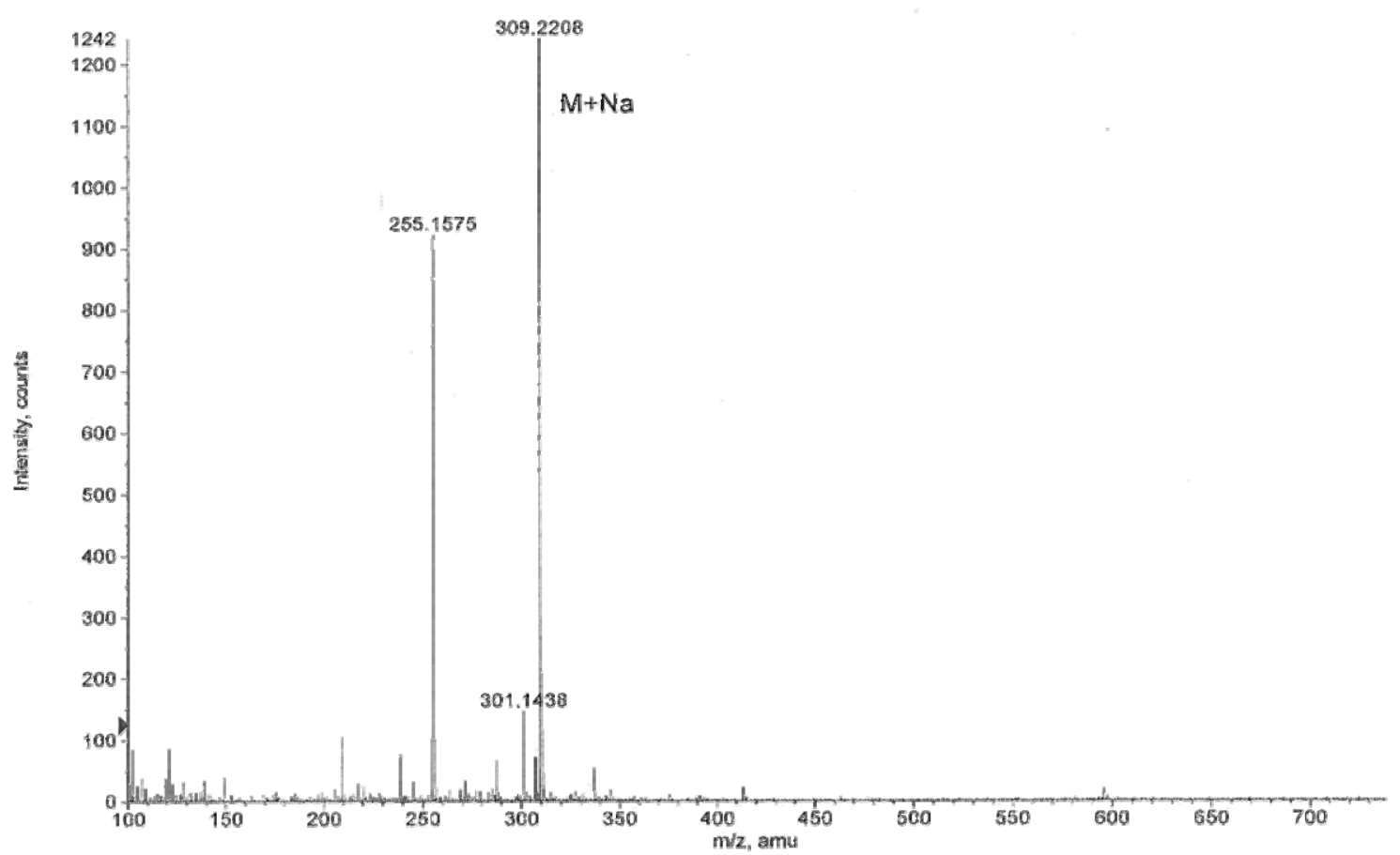


Fig. 111a

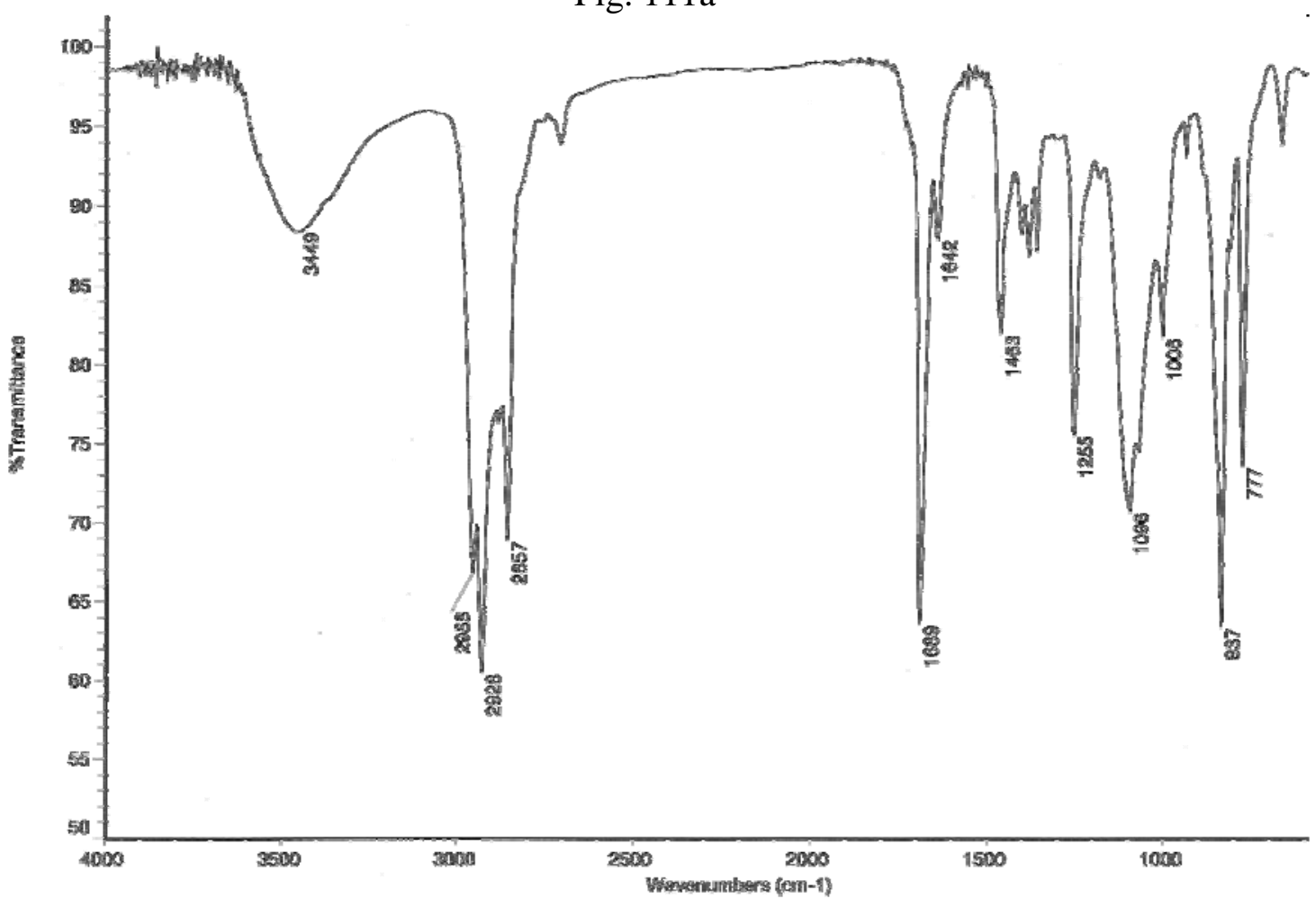

Fig. 111b

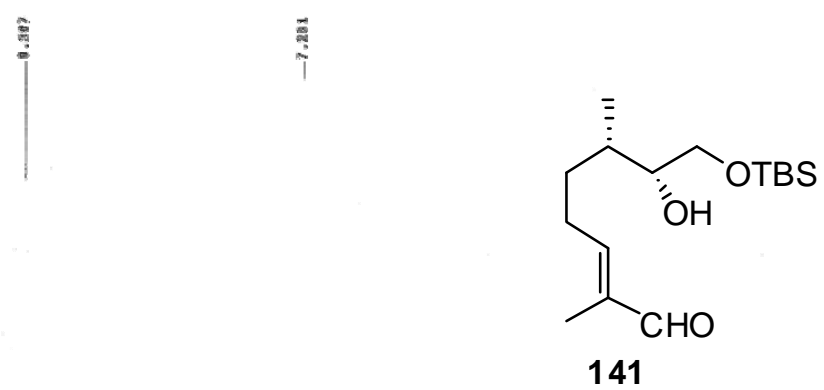

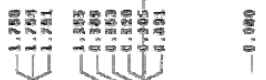

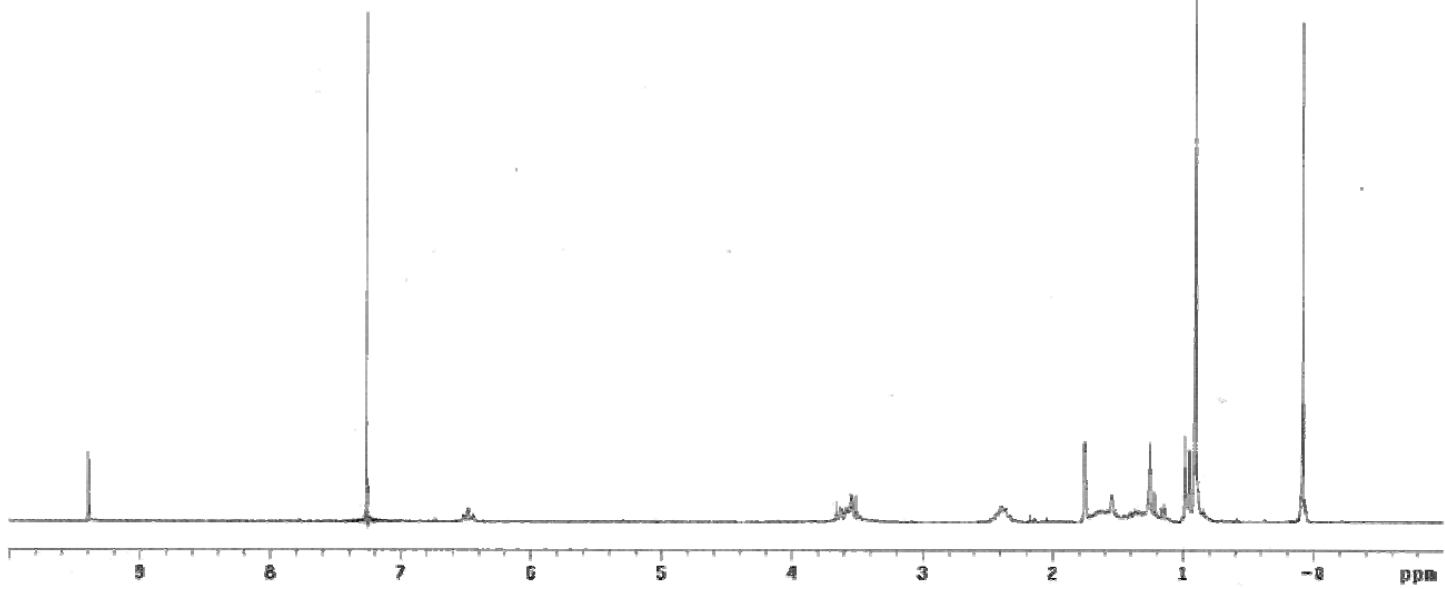


Fig. 111c

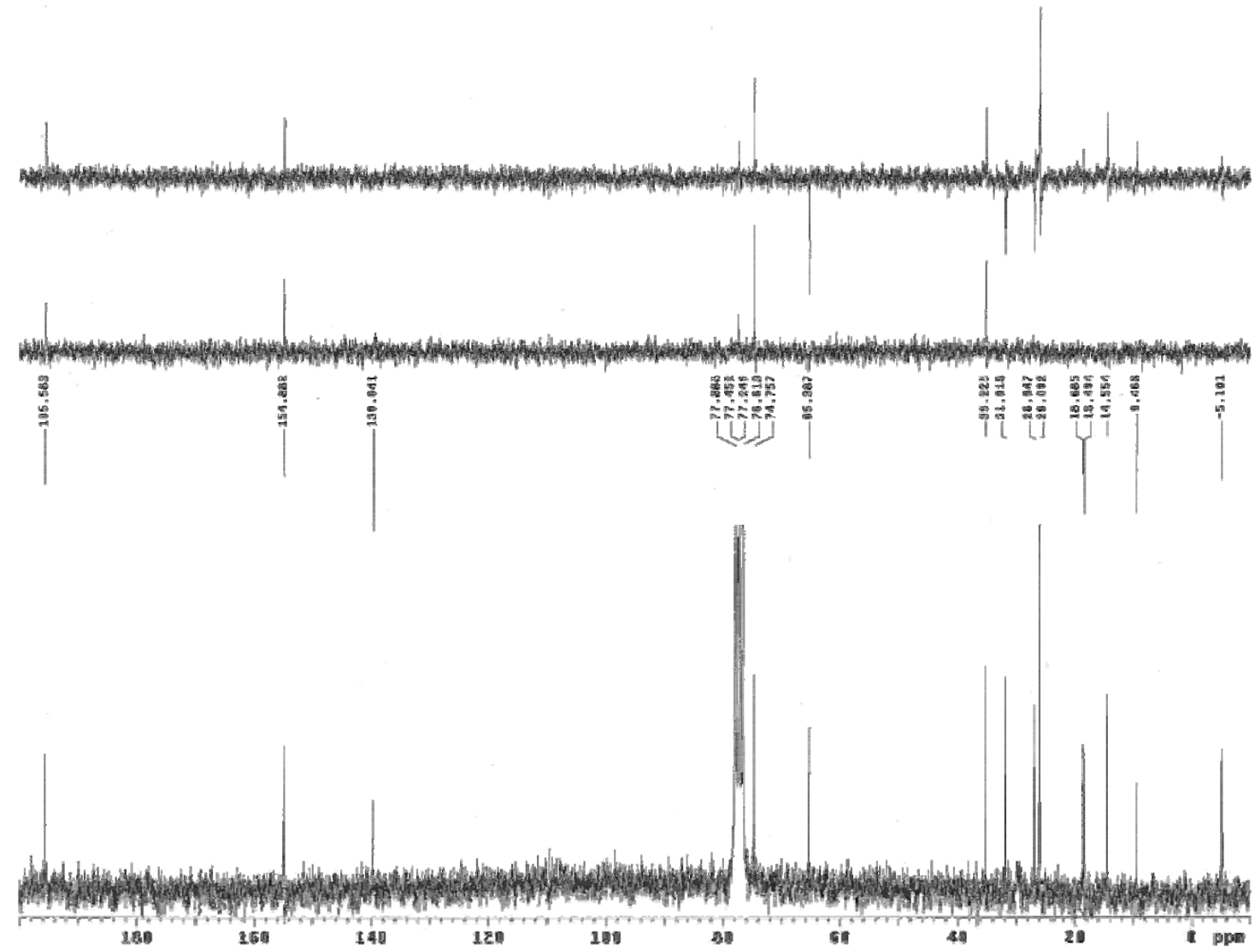

Fig. 111d

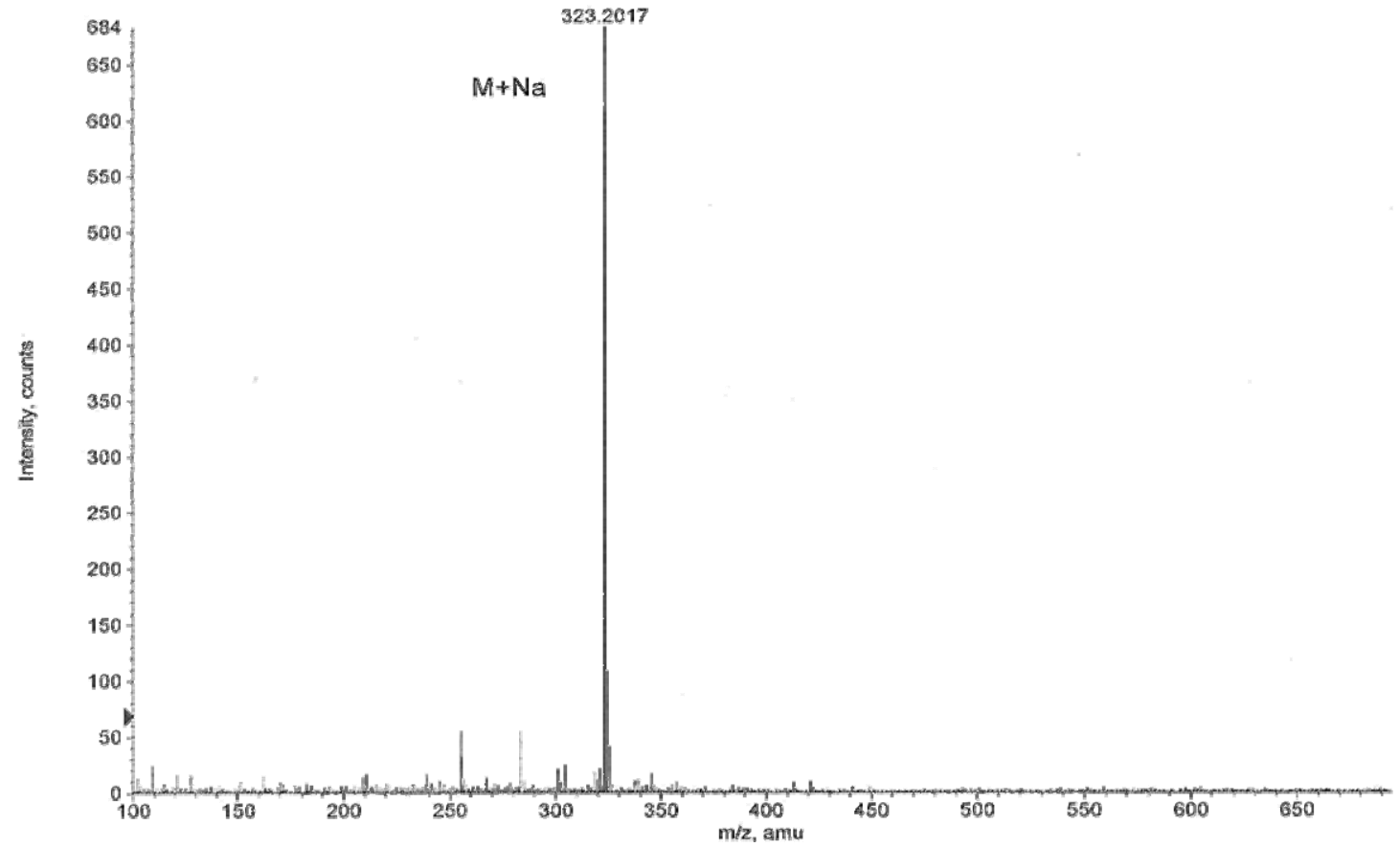






\section{CROMATOGRAMAS CORRESPONDIENTES A LA TABLA 5}

Fig. 112 (entrada 4)

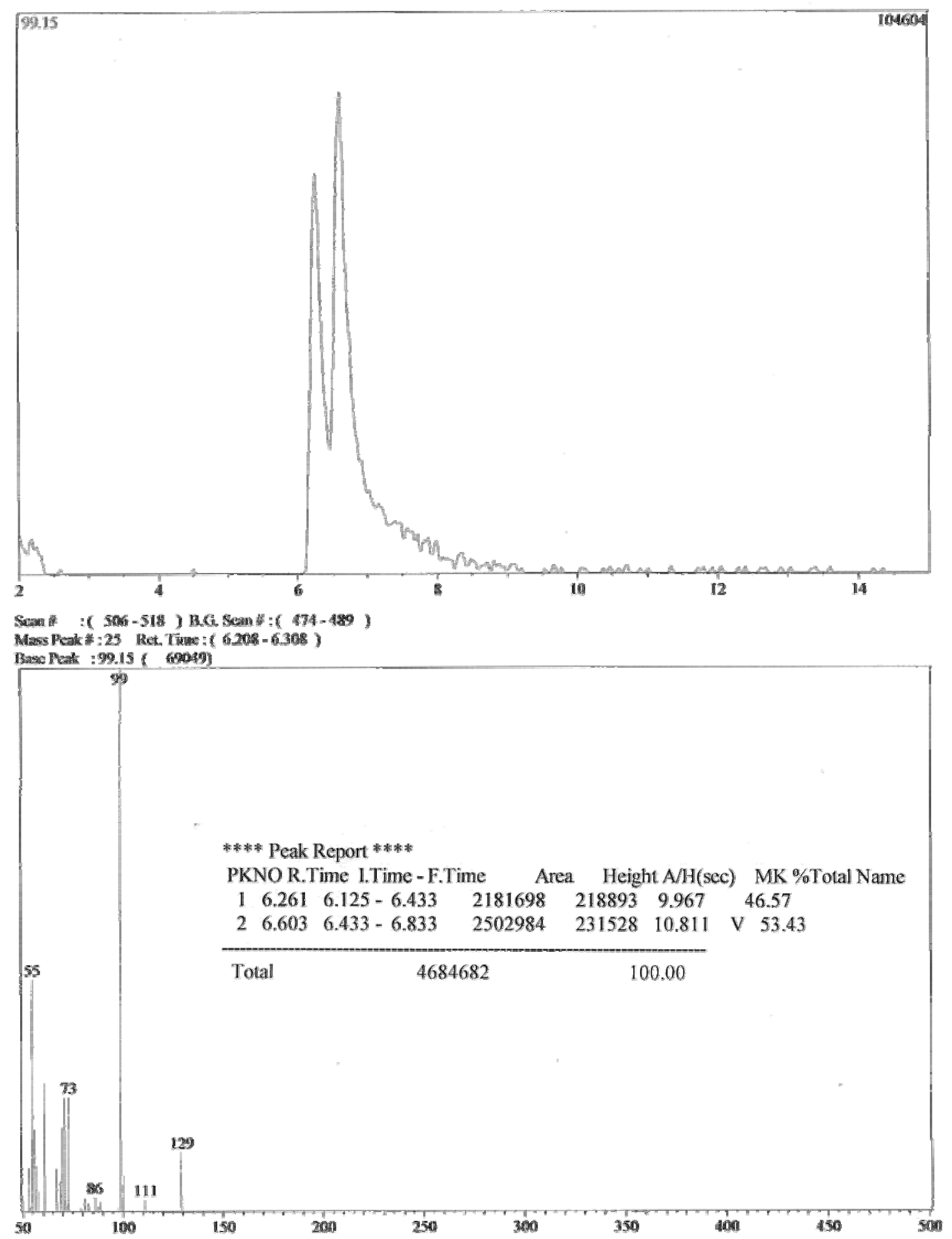


Fig. 113 (entrada 5)

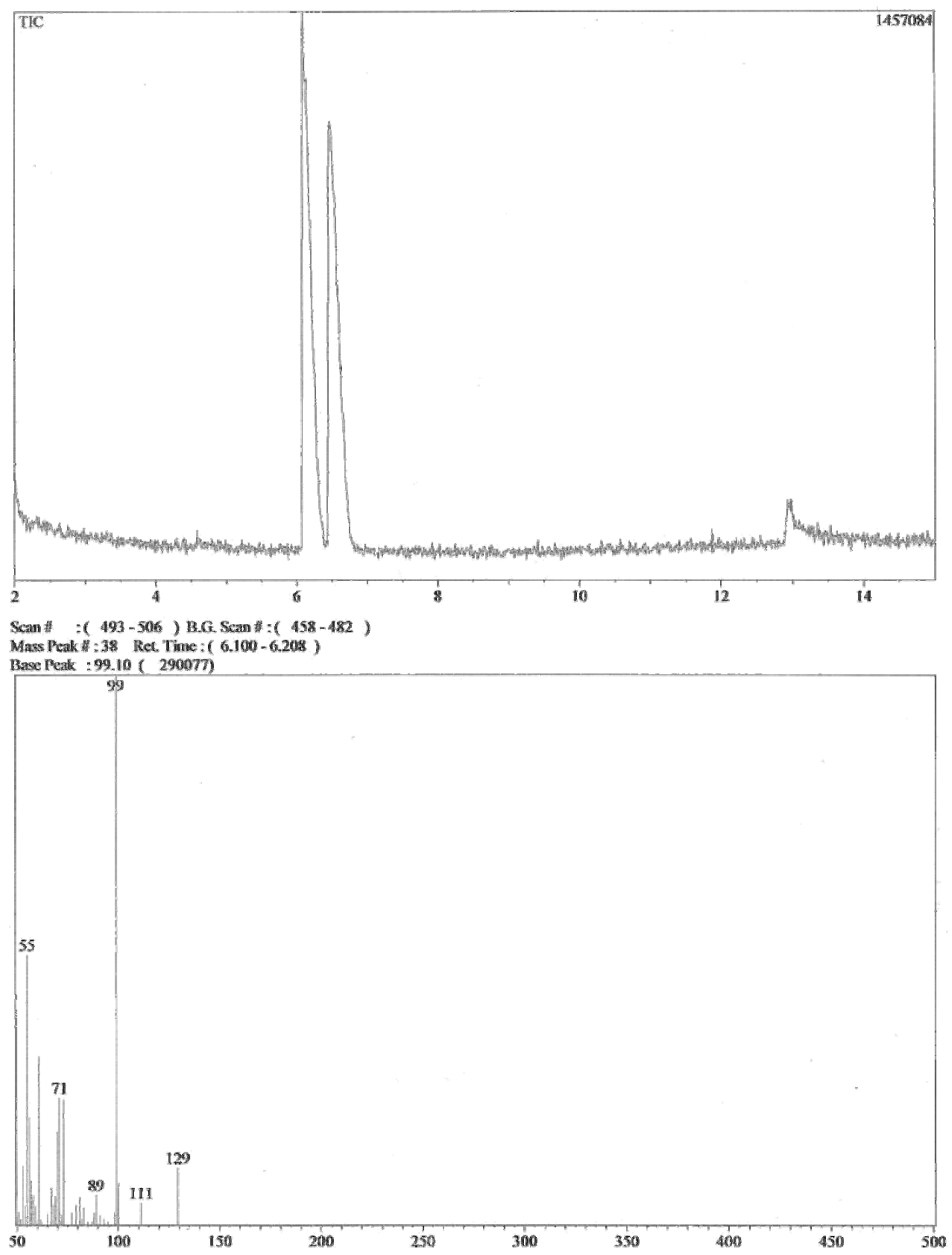


Fig. 114 (entrada 6)

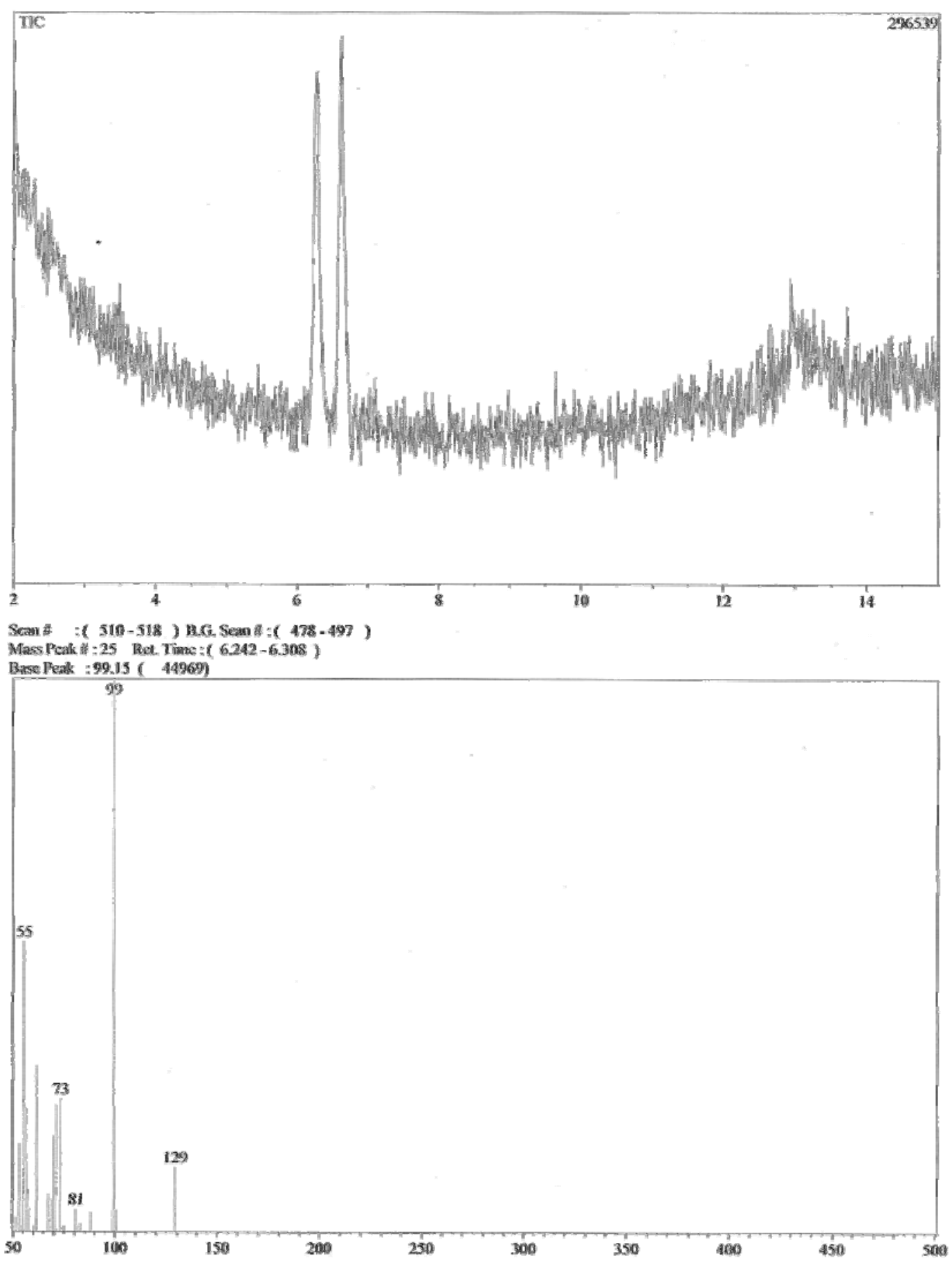


Fig. 115 (entrada 7)

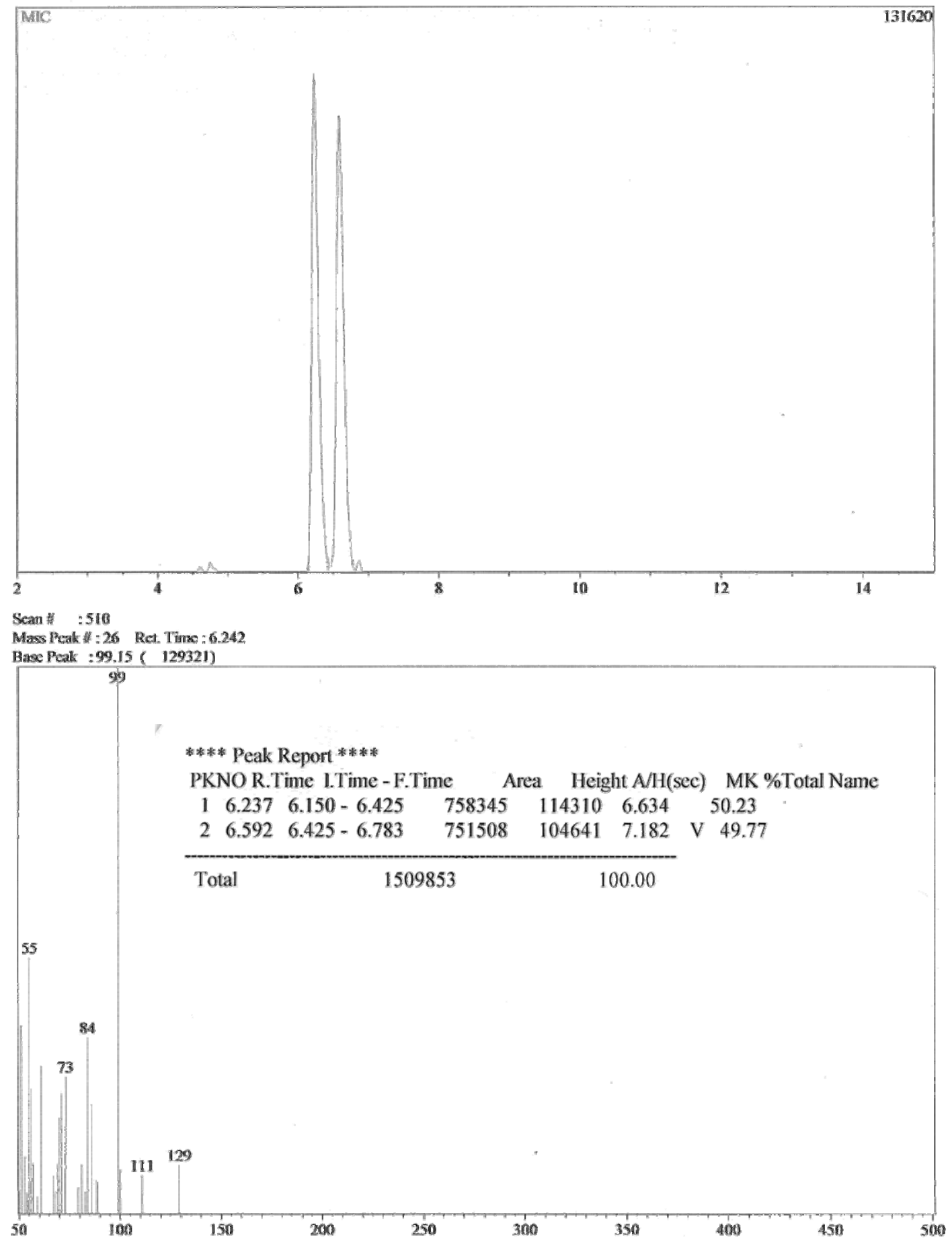


Fig. 116 (entrada 8)

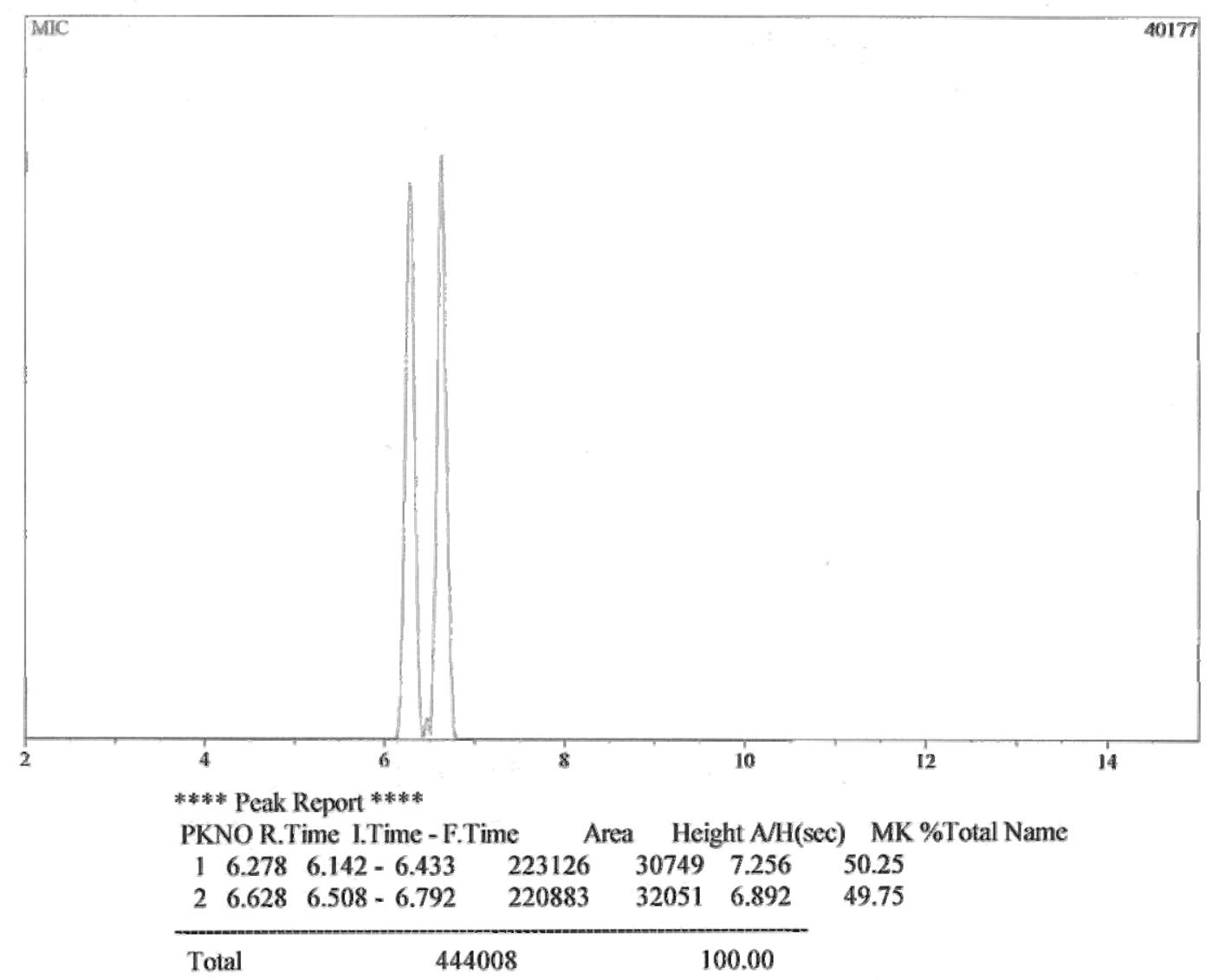


Fig. 117 (entrada 10)

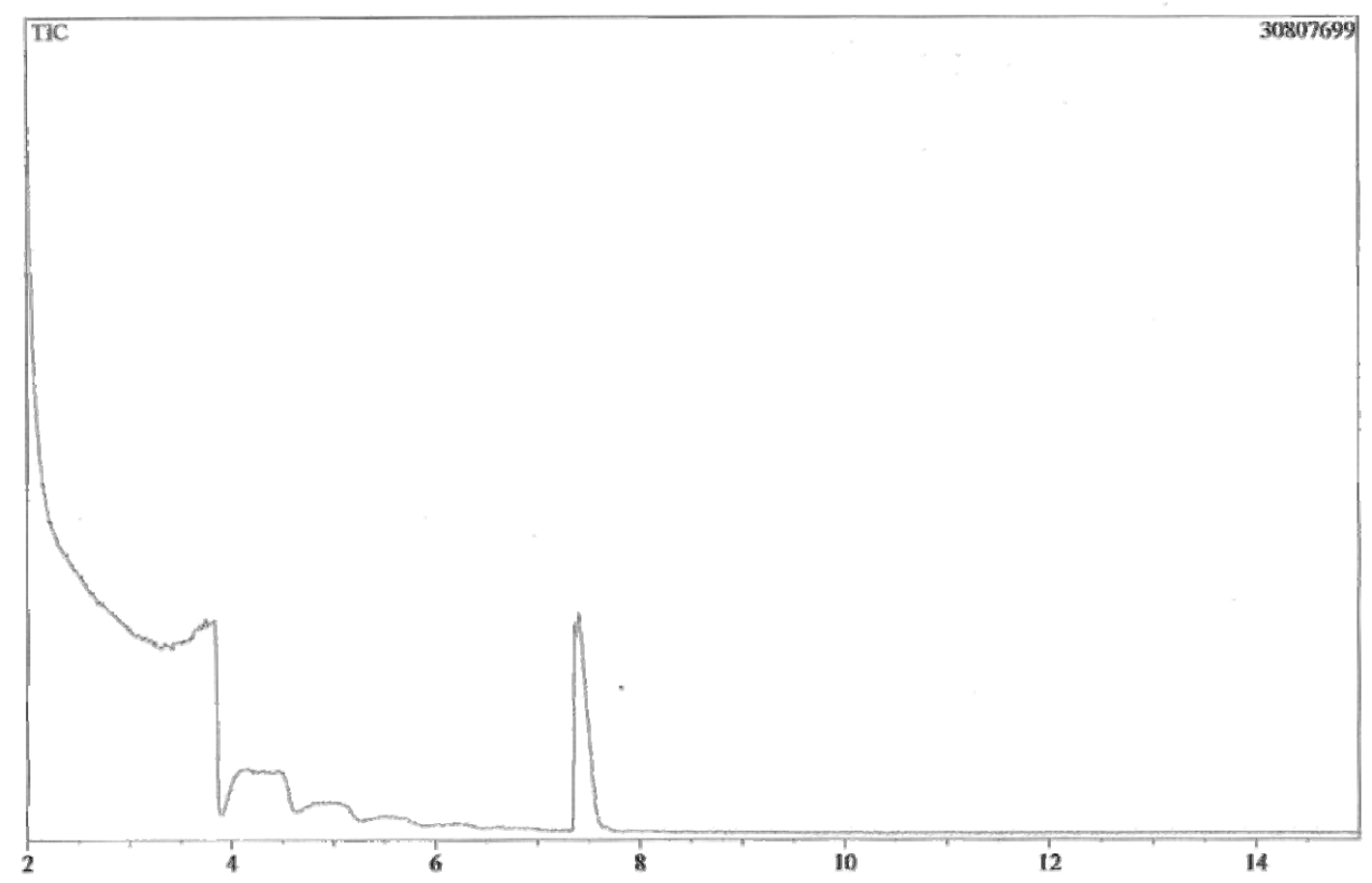

Sern B $^{2}:(644-657)$ B.G. Sean $1:(622-633)$

Mass Peak : : 31 Ret. Time: $(7.358-7.467)$

Base Peak : 75.10 ( 3439490)

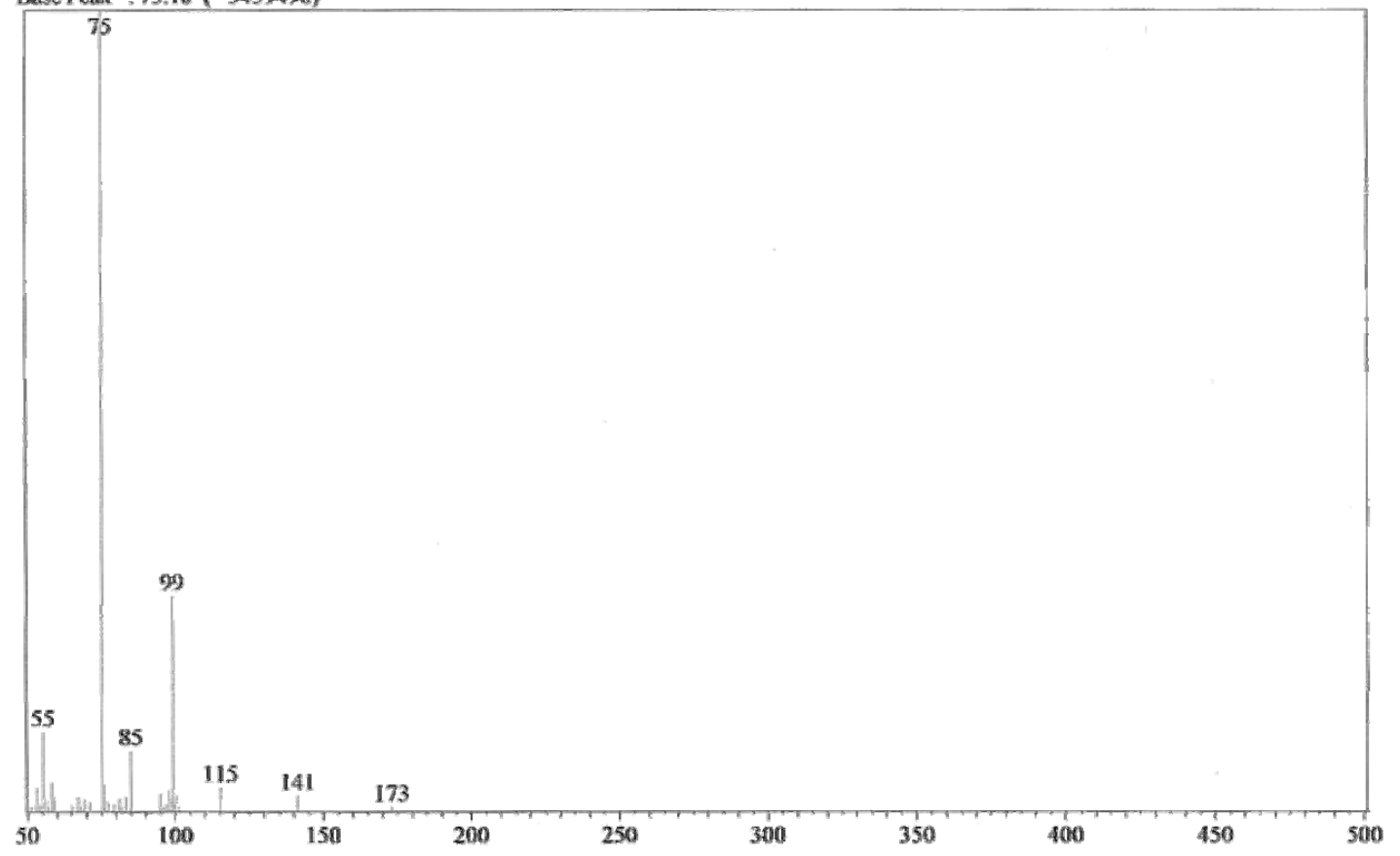


Fig. 118 (entrada 11)

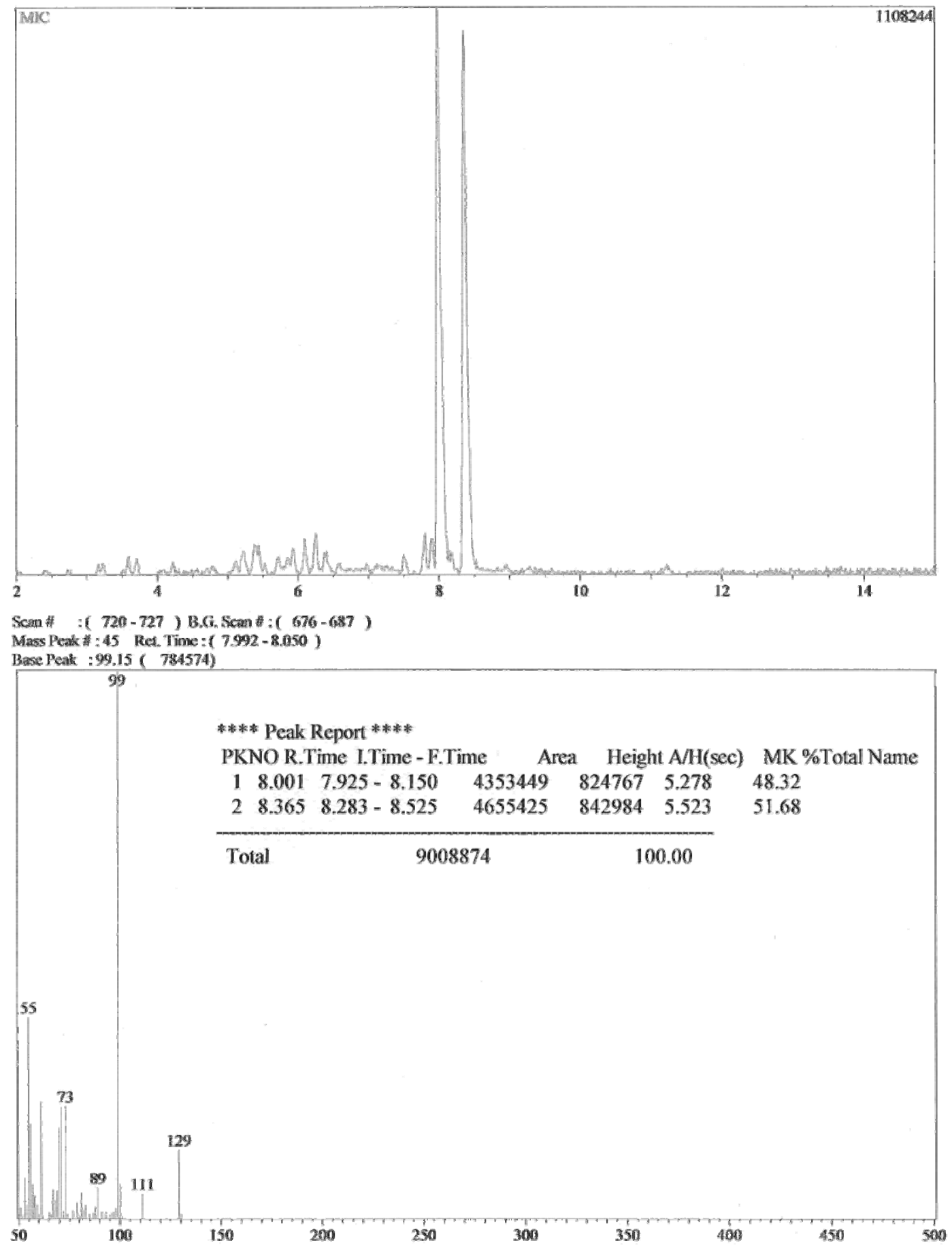


Fig. 119 (entrada 12)

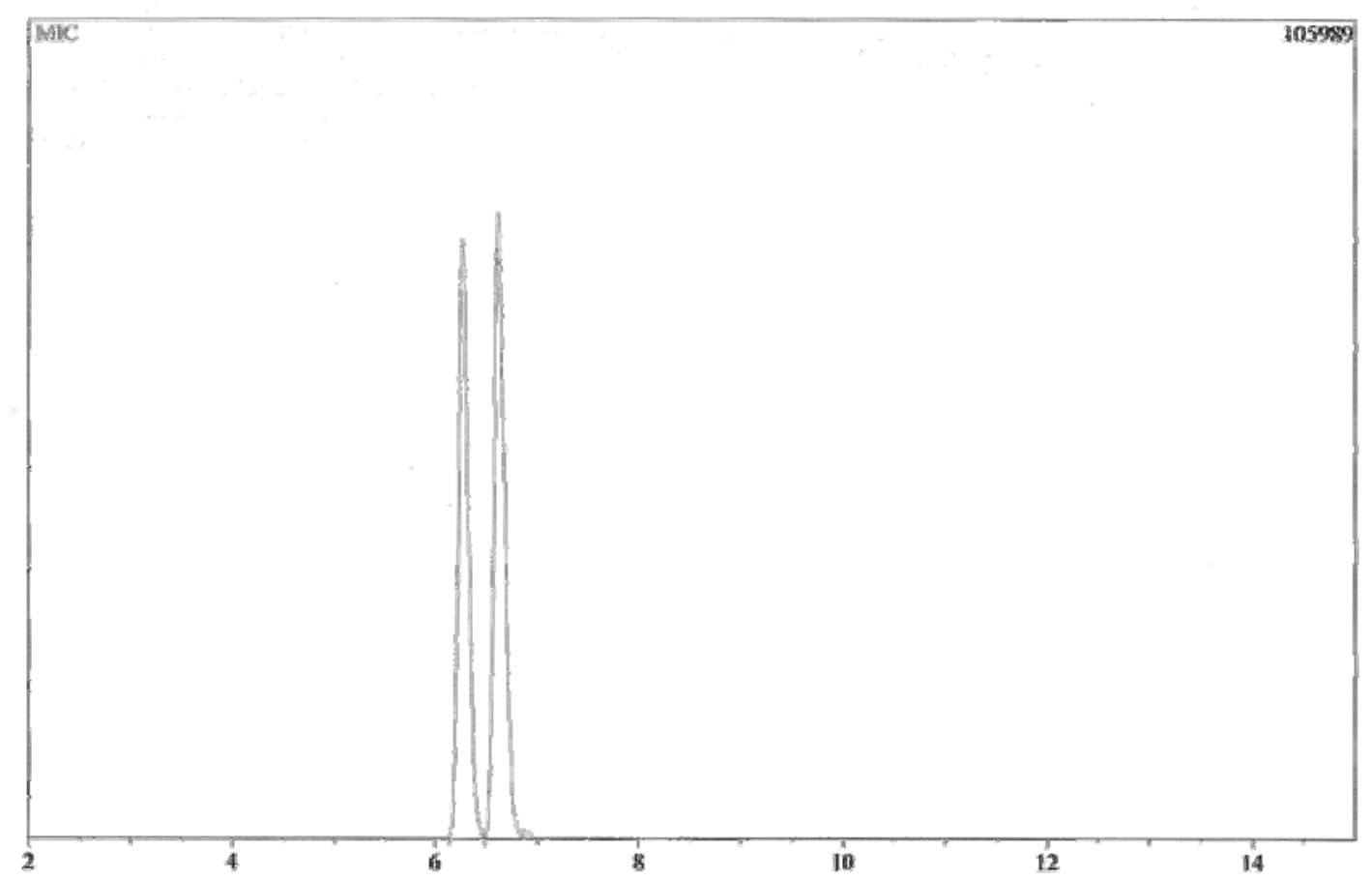

**** Peak Report ****

PKNO R.Time I.Time - F.Time Area Height A/H(sec) MK \%Total Name

$\begin{array}{lllllll}1 & 6.272 & 6.142-6.483 & 536822 & 77459 & 6.930 & 47.51\end{array}$

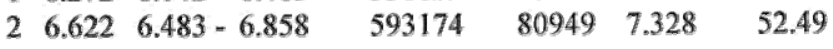

Total

1129995

100.00 
Fig. 120 (entrada 13)

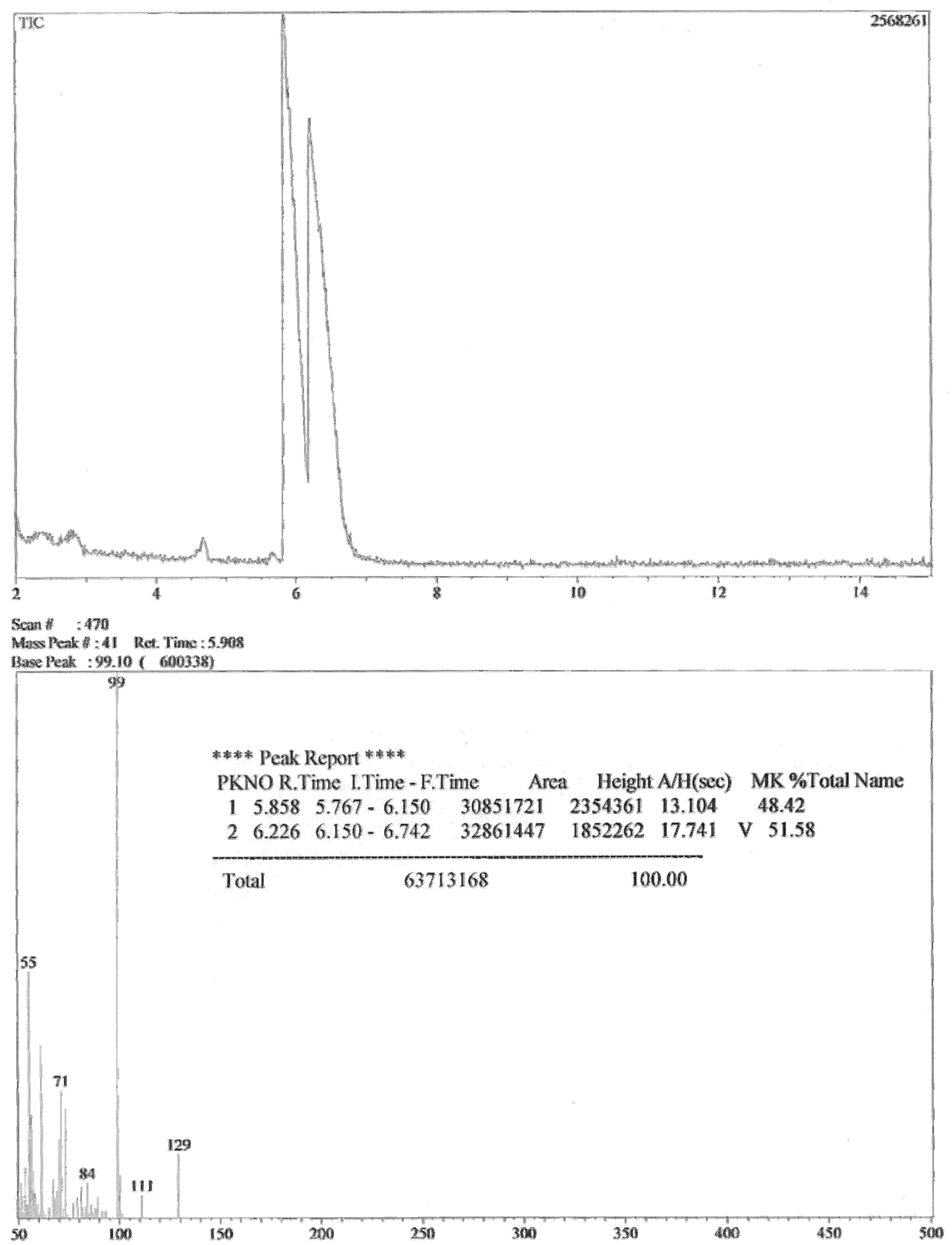


Fig. 121 (entrada 14)

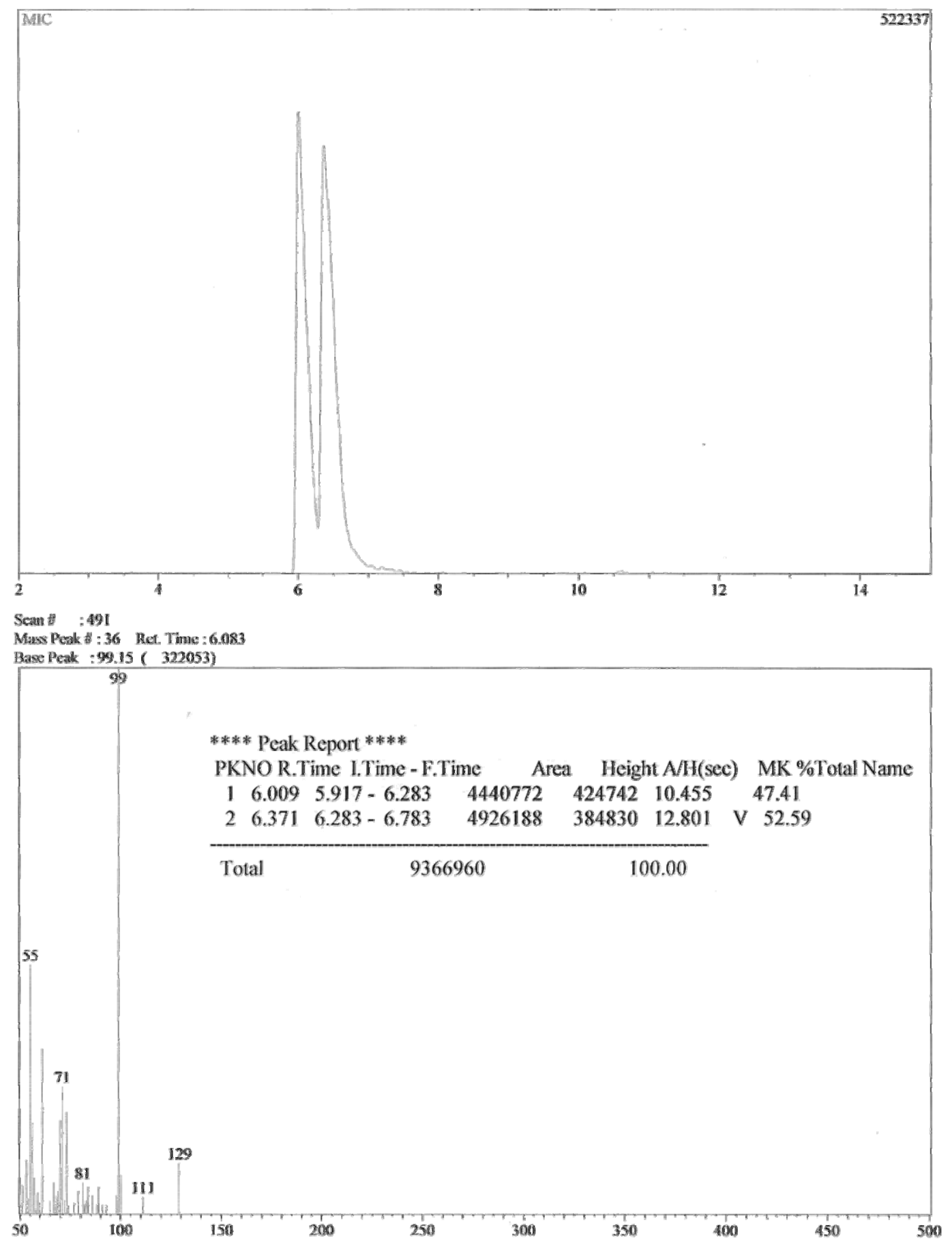


Fig. 122 (entrada 17)

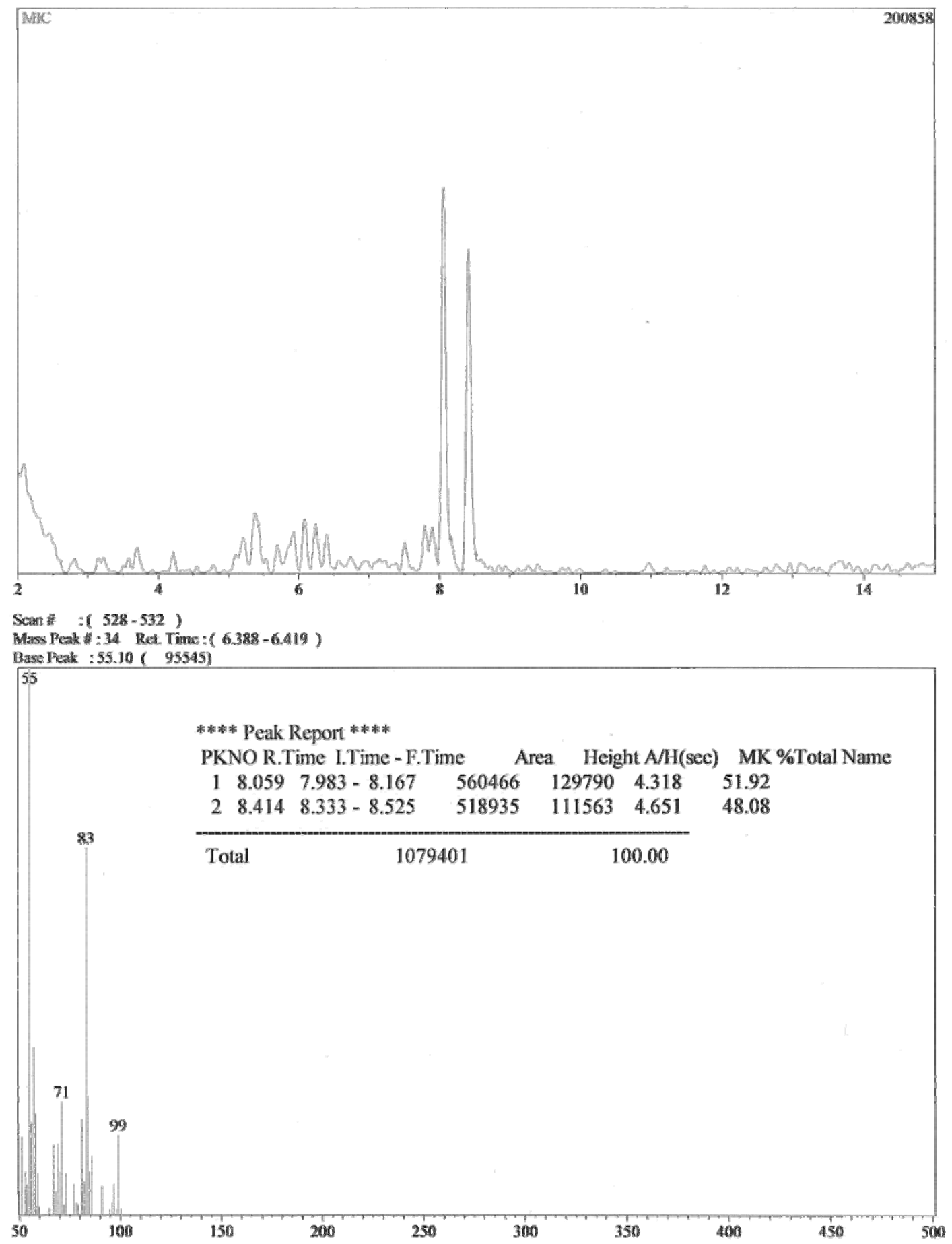


Fig. 123 (entrada 18)

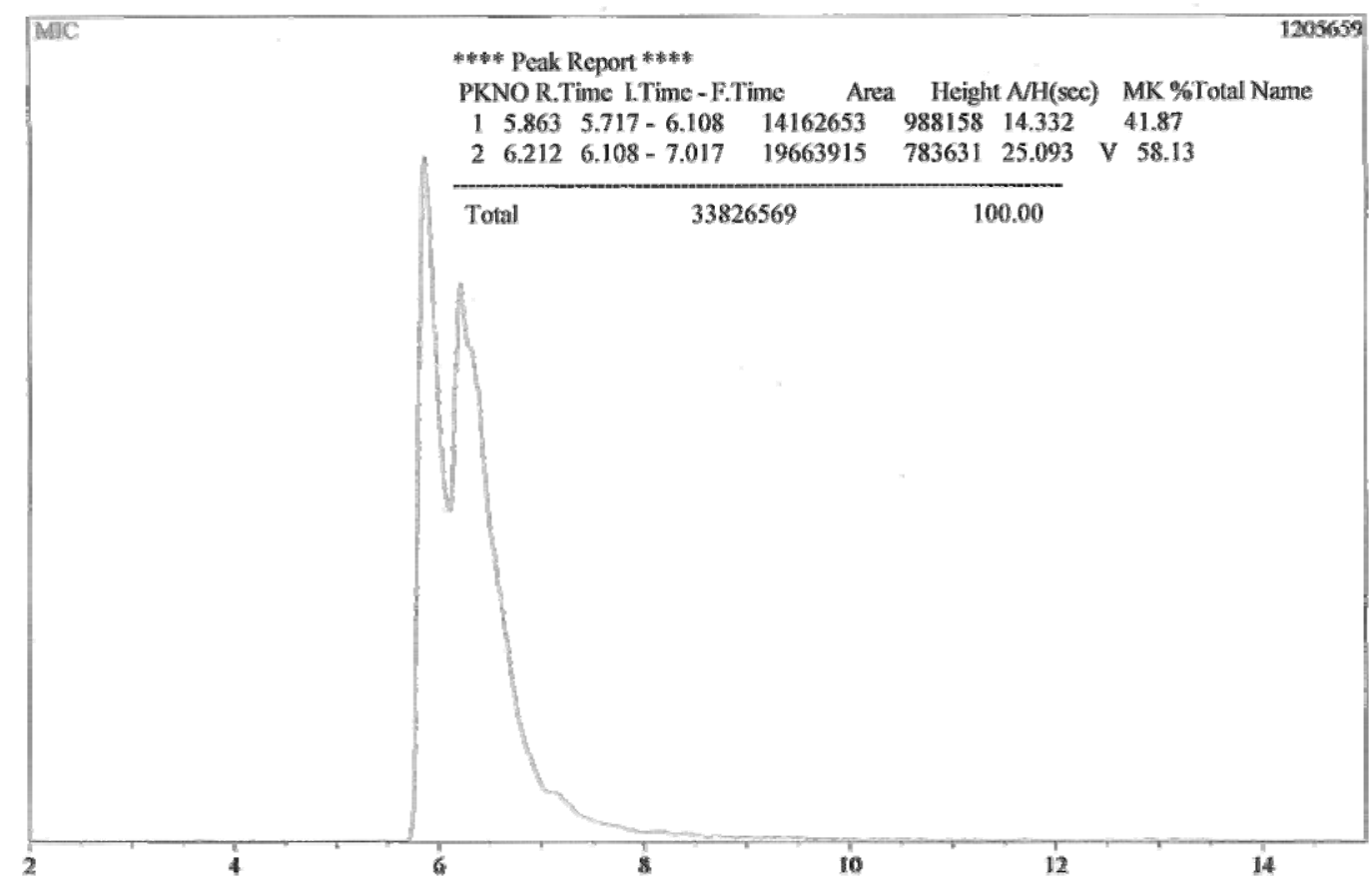

Fig. 124 (entrada 19)

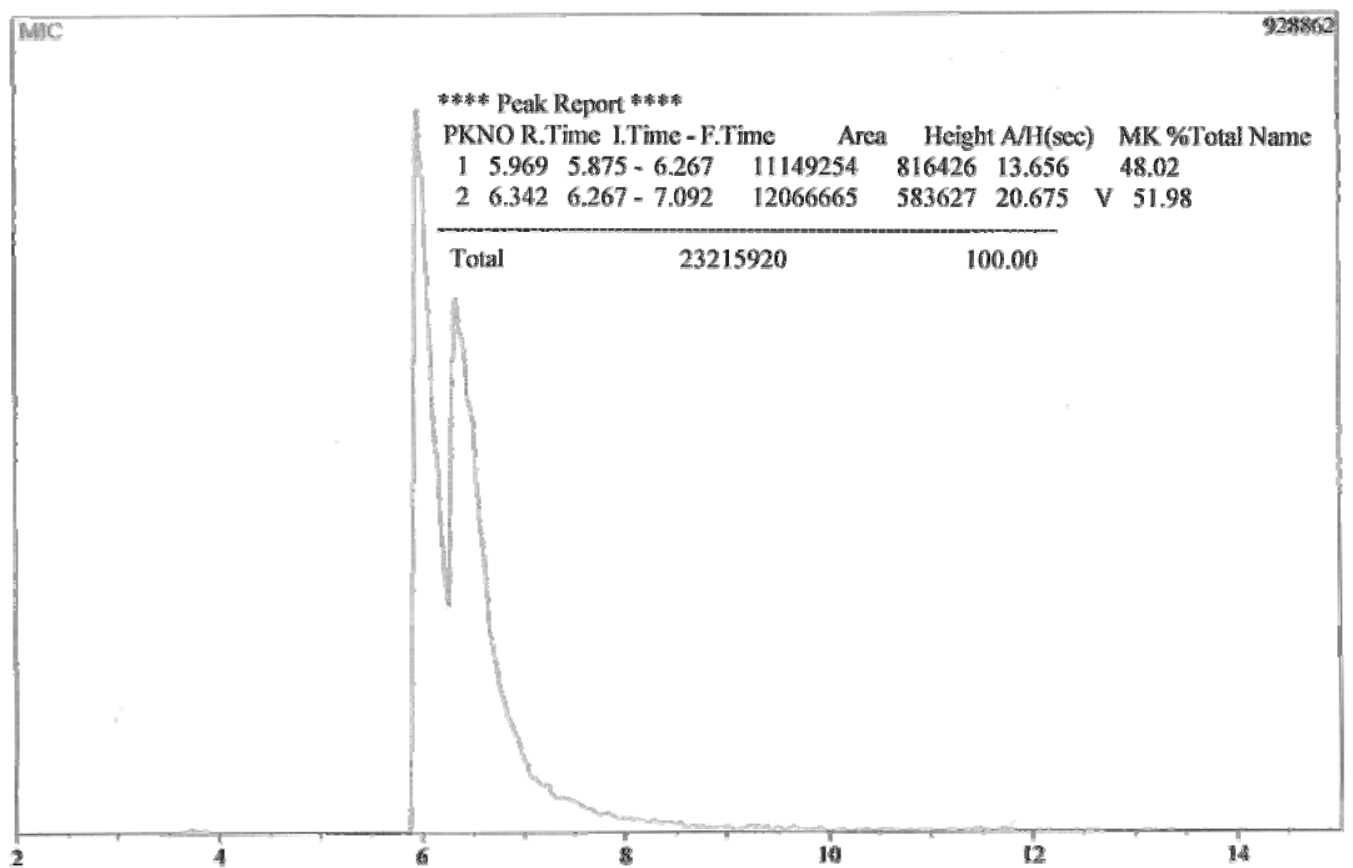




\section{CROMATOGRAMAS CORRESPONDIENTES A LA TABLA 6}

Fig. 125 (entrada 1)

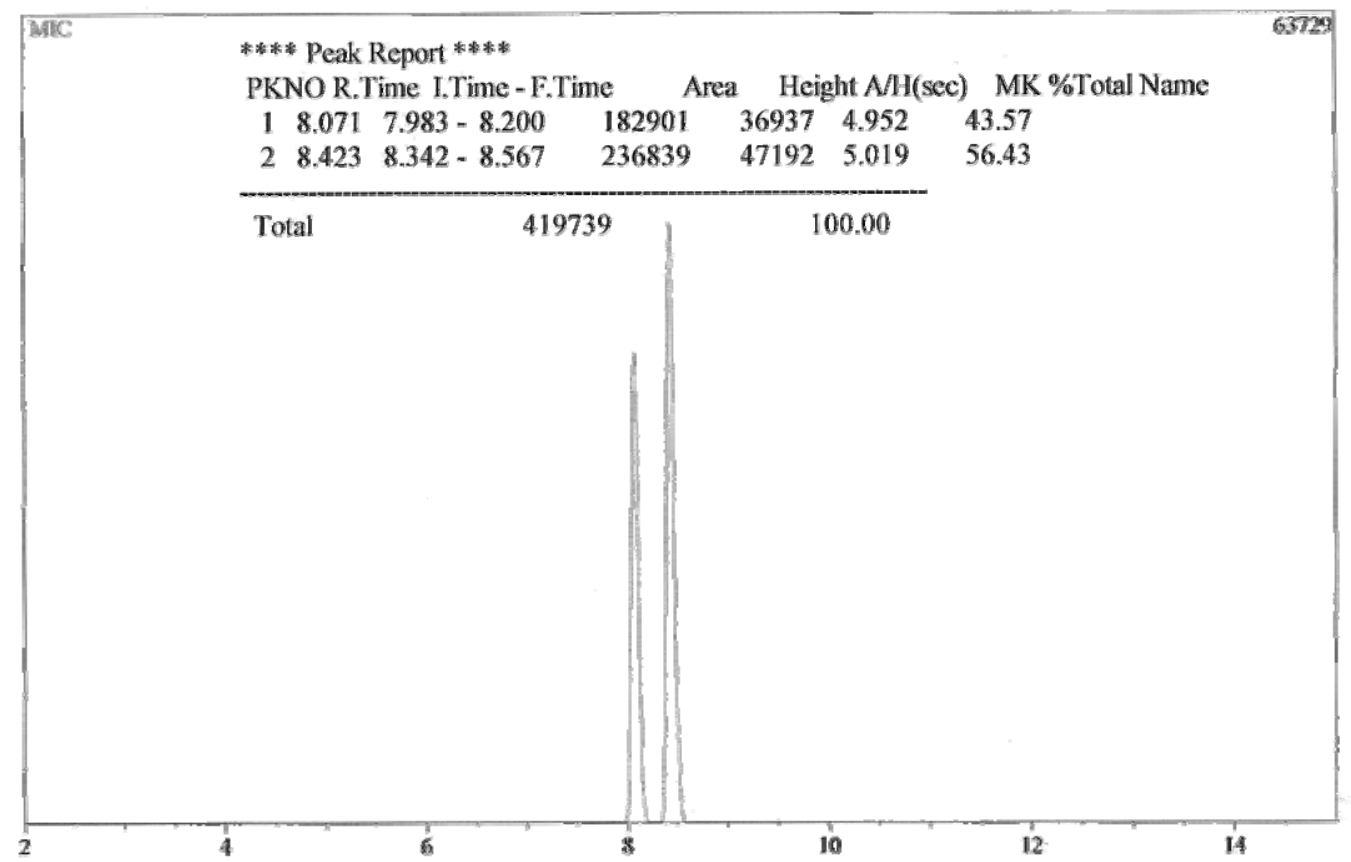

Fig. 126 (entrada 2)

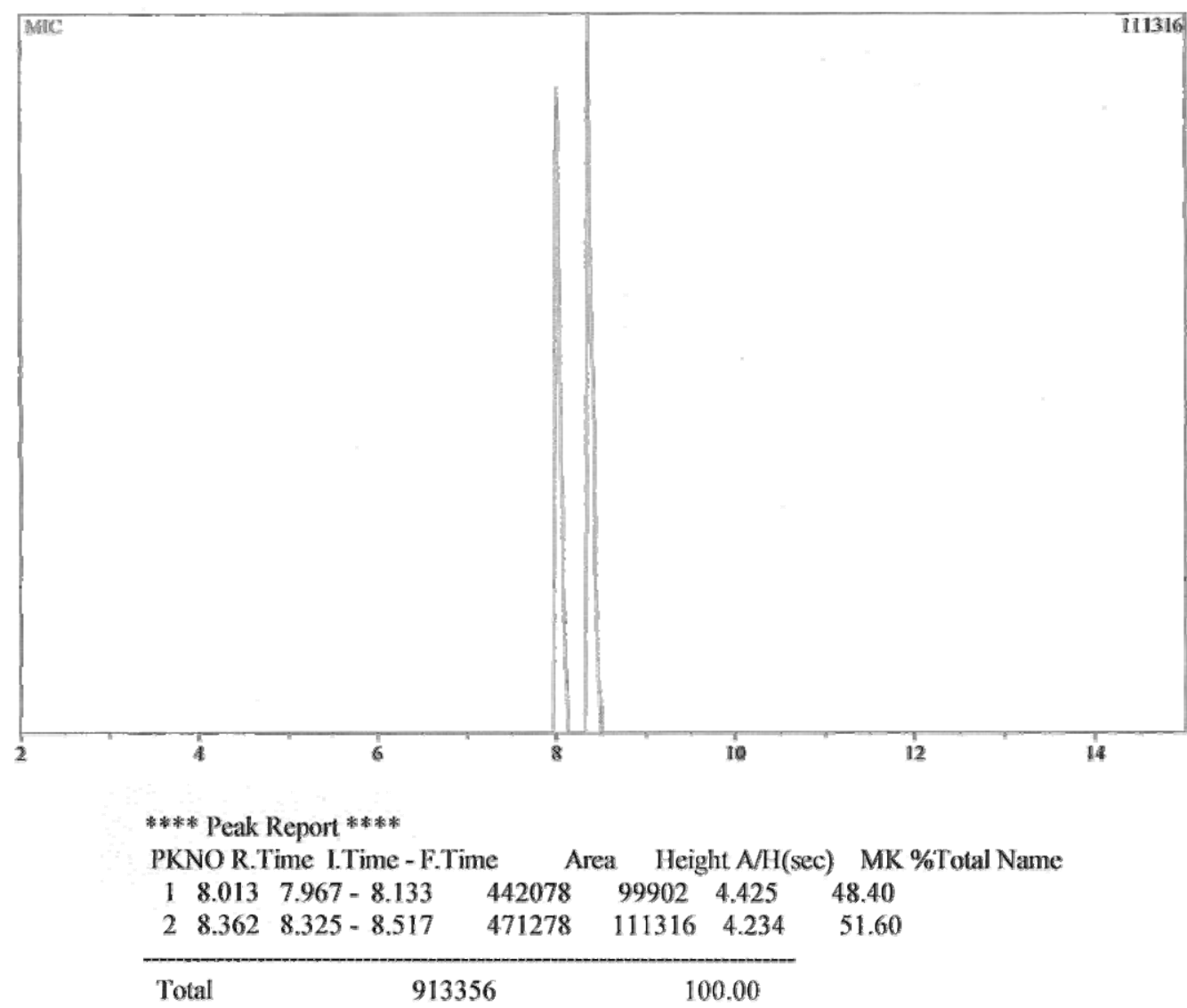


Fig. 127 (entrada 3)

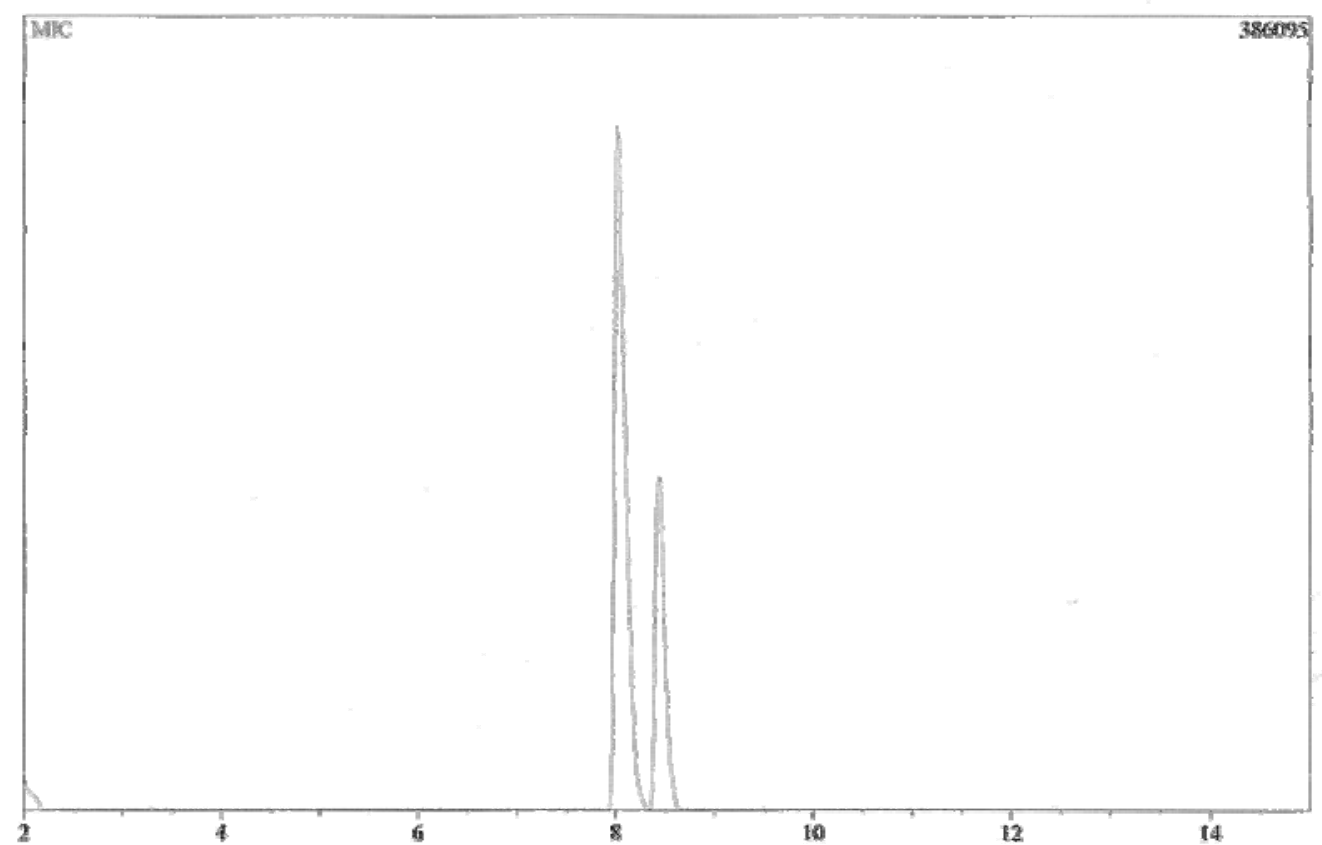

**** Peak Report ****

PKNO R.Time I.Time-F.Time Area Height A/H(sec) MK \%Total Name

$\begin{array}{lllllll}1 & 8.025 & 7.925-8.342 & 2598235 & 332171 & 7.822 & 70.35\end{array}$

$\begin{array}{llllllll}2 & 8.441 & 8.342=8.667 & 1095009 & 162022 & 6.758 & \text { V } & 29.65\end{array}$

$\begin{array}{lll}\text { Total } & 3693243 & 100,00\end{array}$

Fig. 128 (entrada 4)

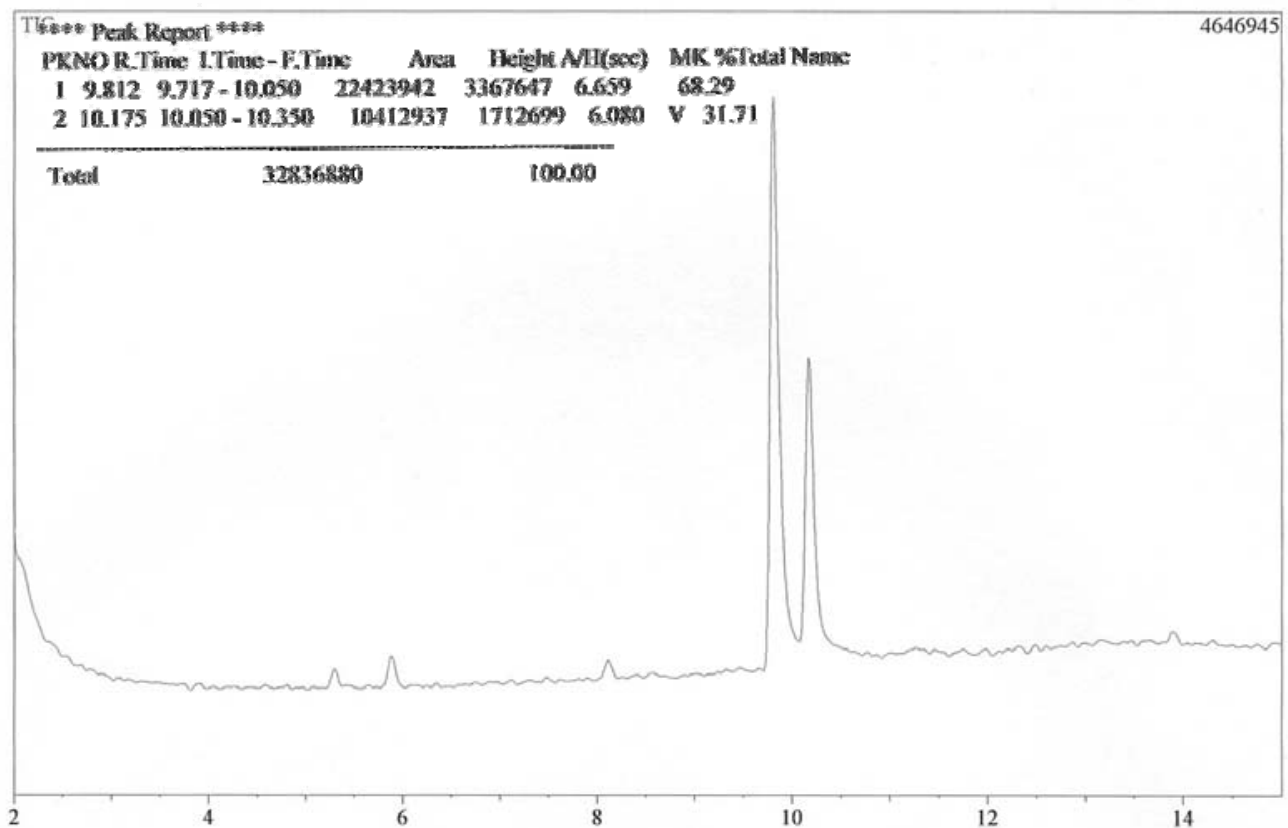


Fig. 129 (entrada 5)

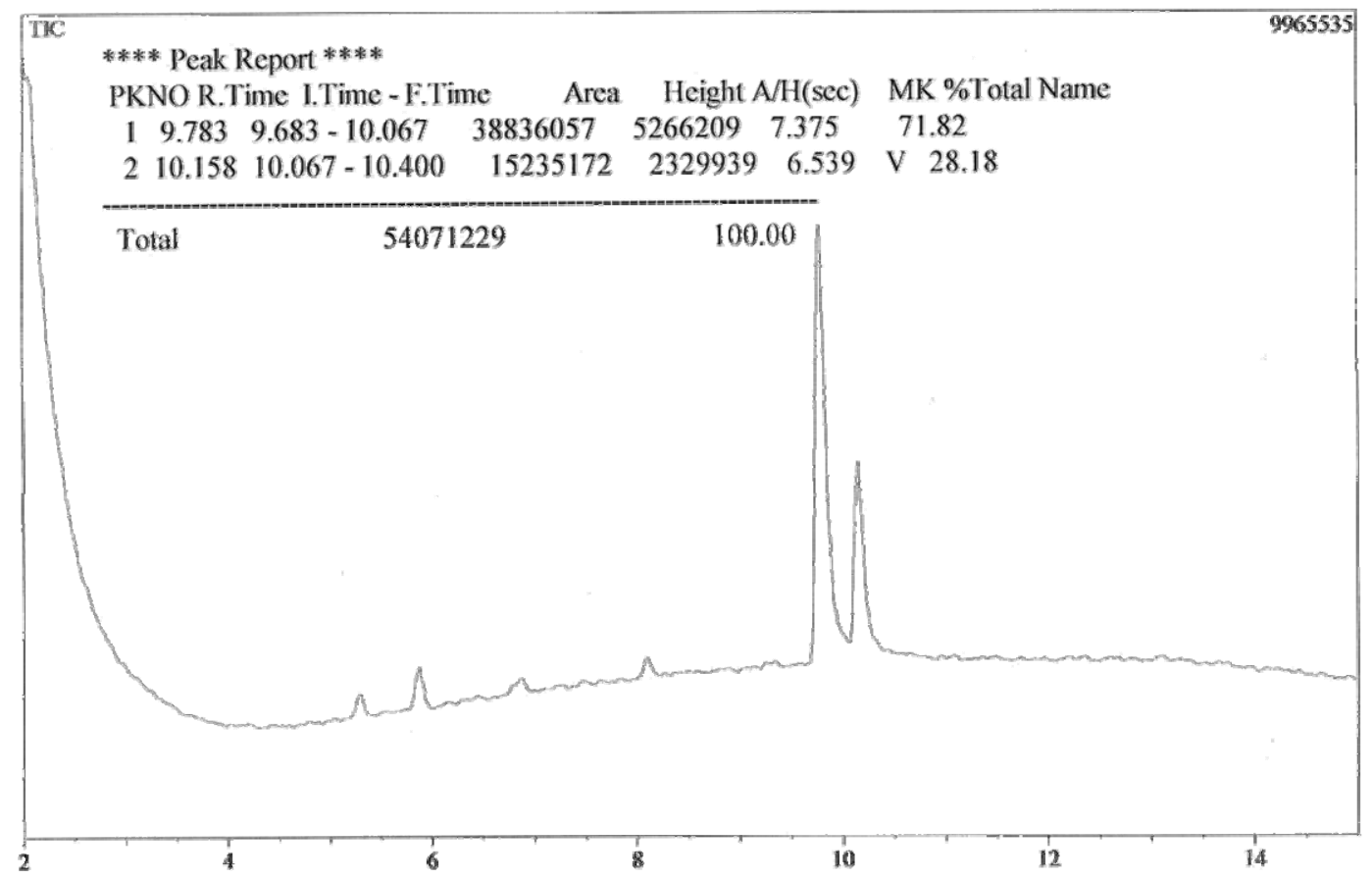

Fig. 130 (entrada 6)

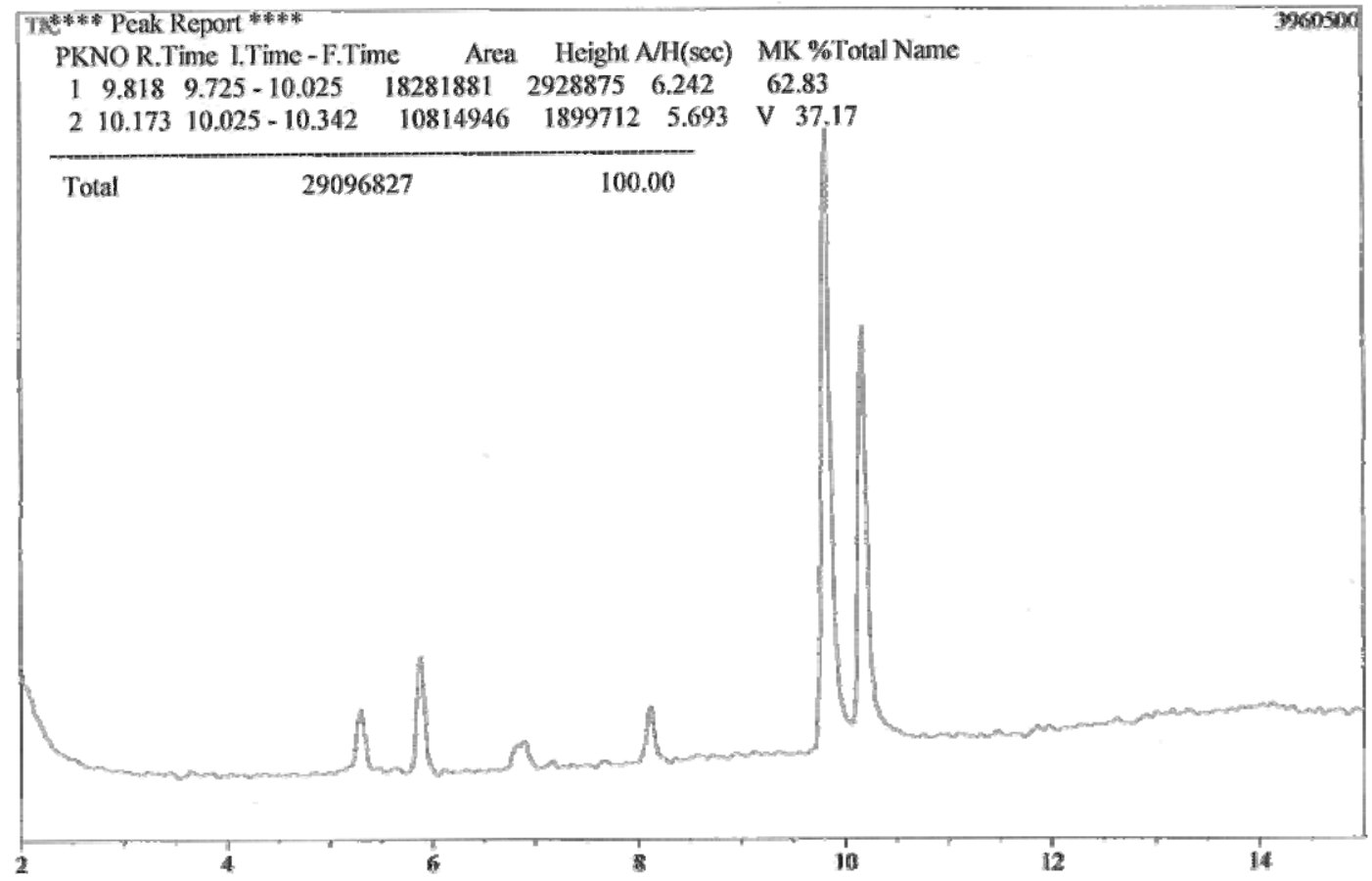


Fig. 131 (entrada 7)

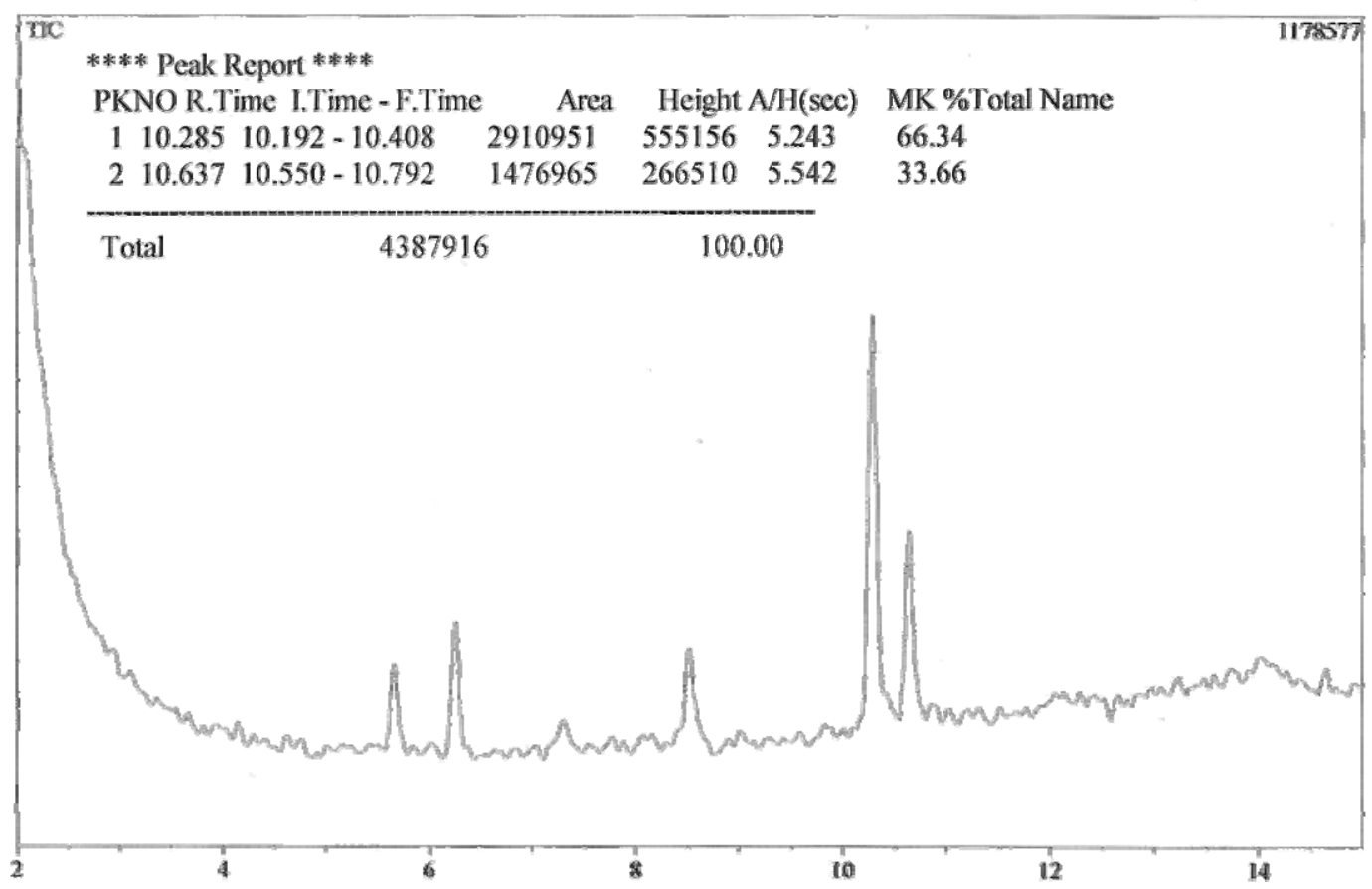

Fig. 132 (entrada 8)

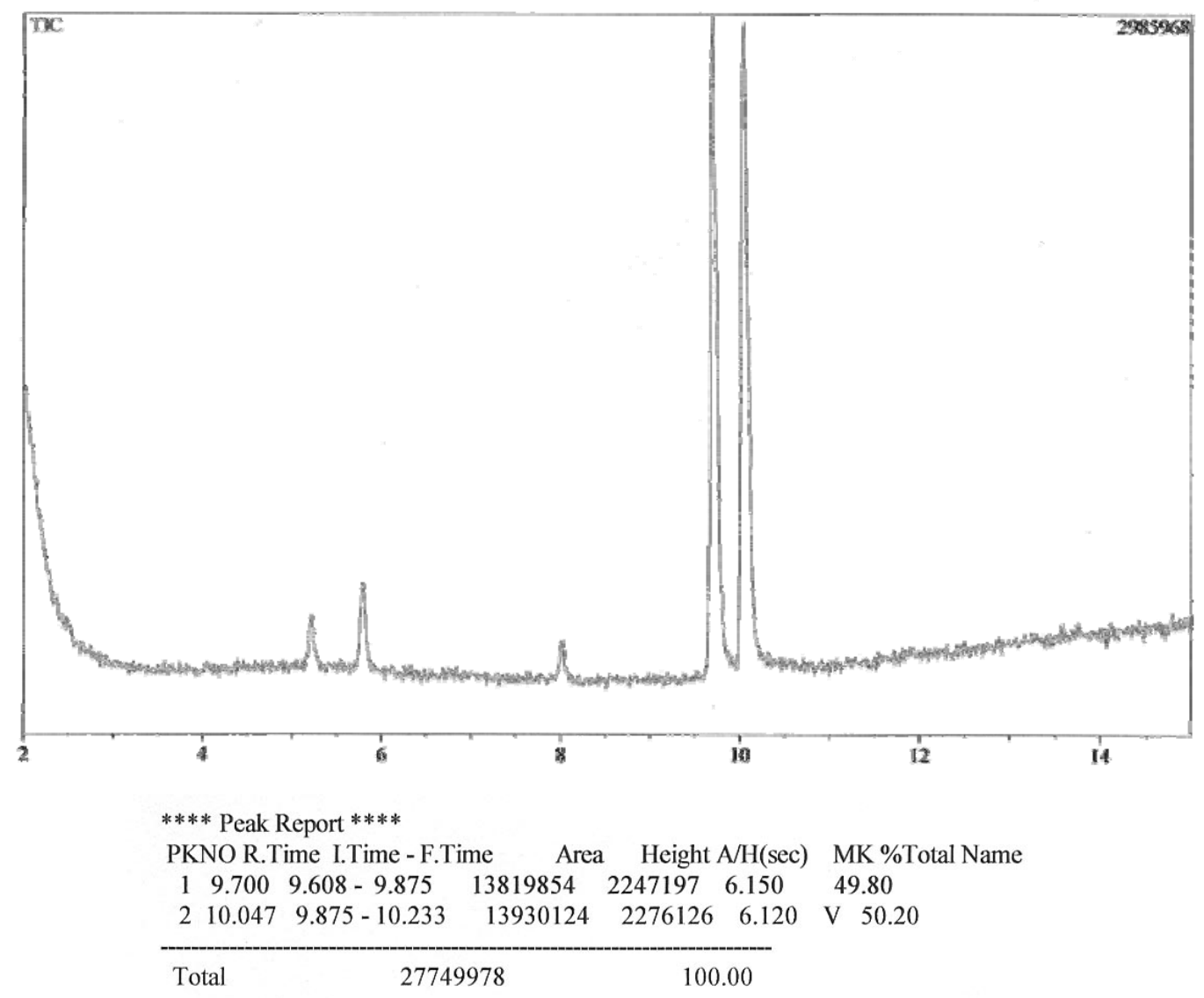


Fig. 133 (entrada 9)

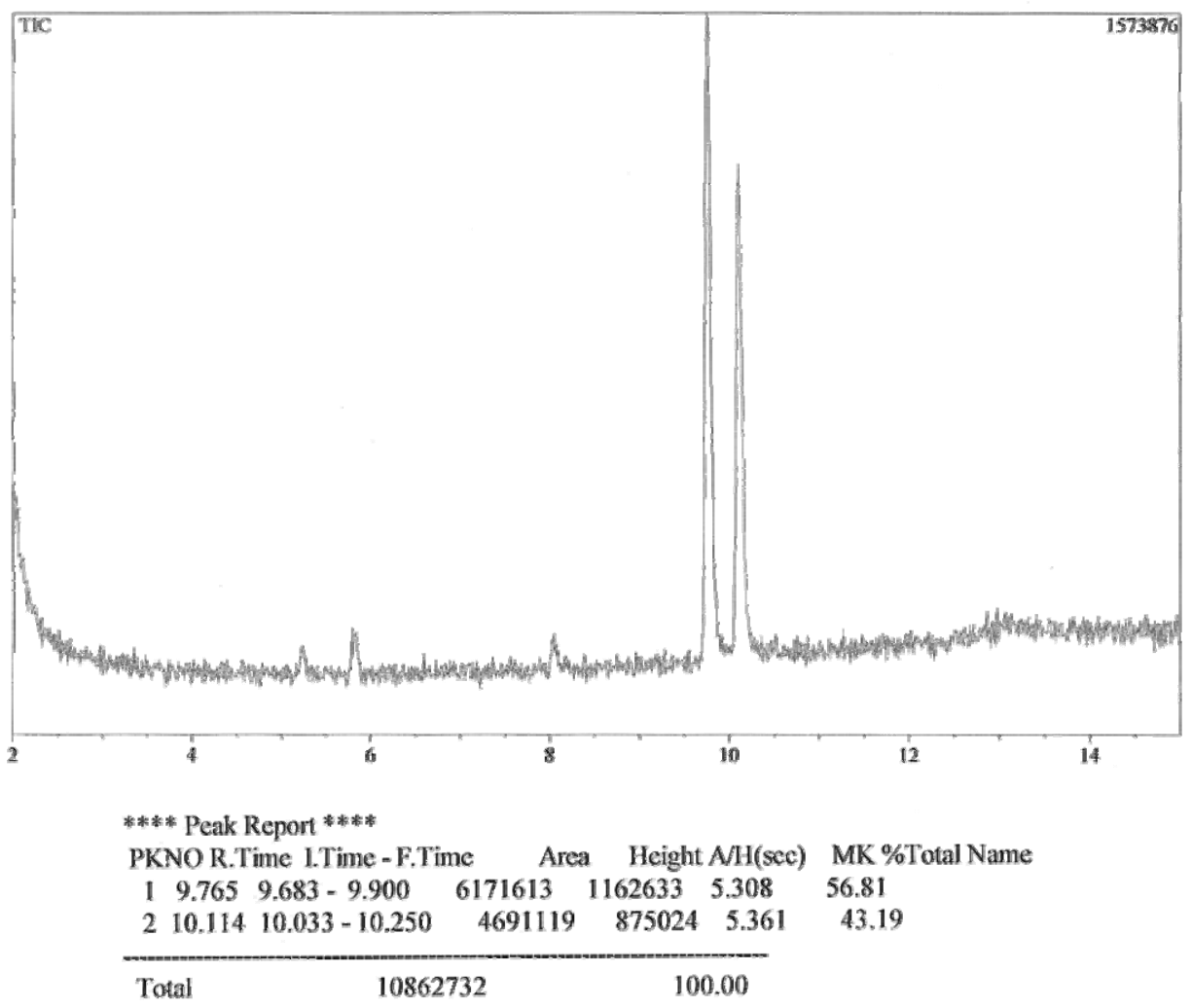

Fig. 134 (entrada 10)

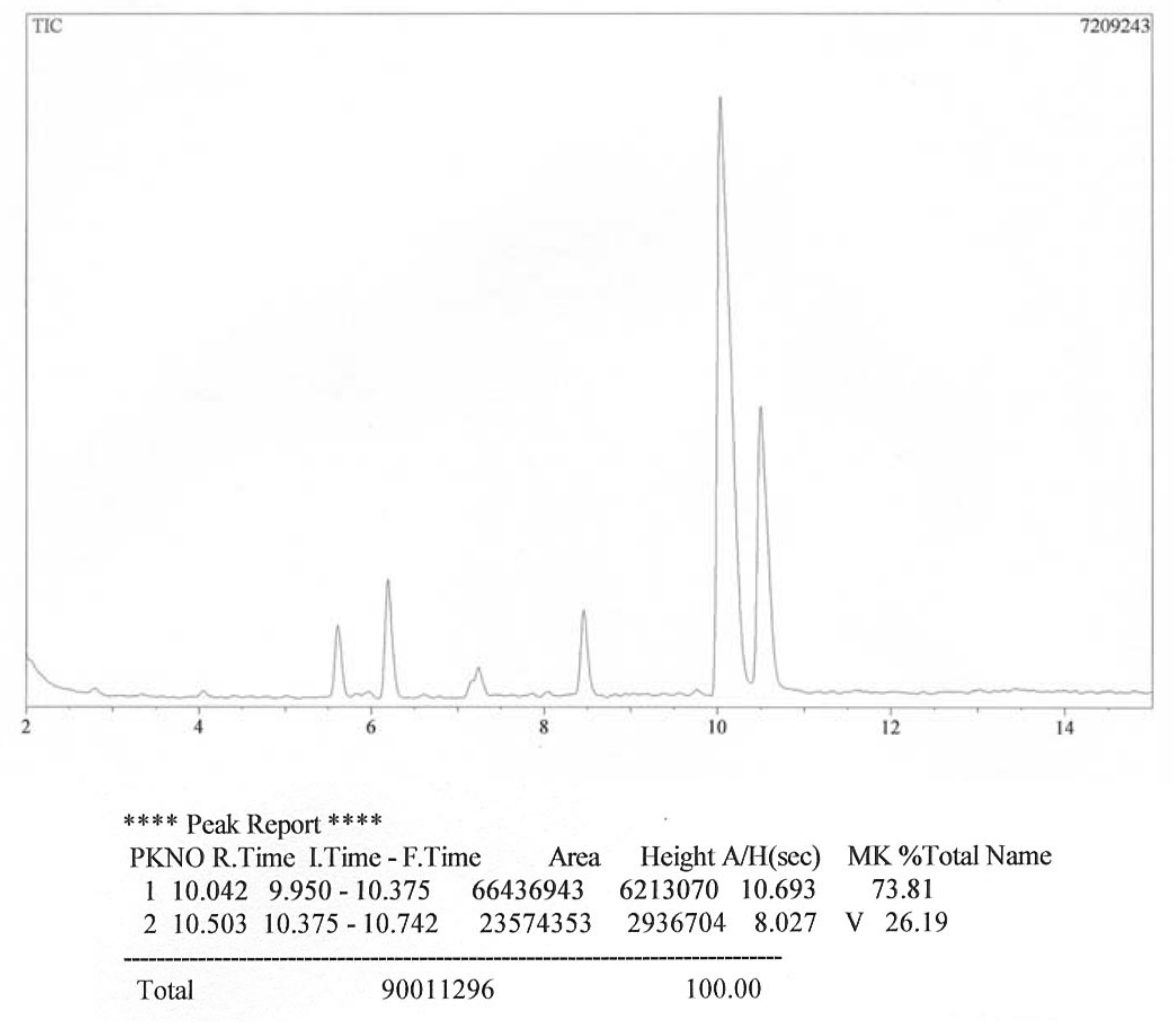


Fig. 135 (entrada 11)

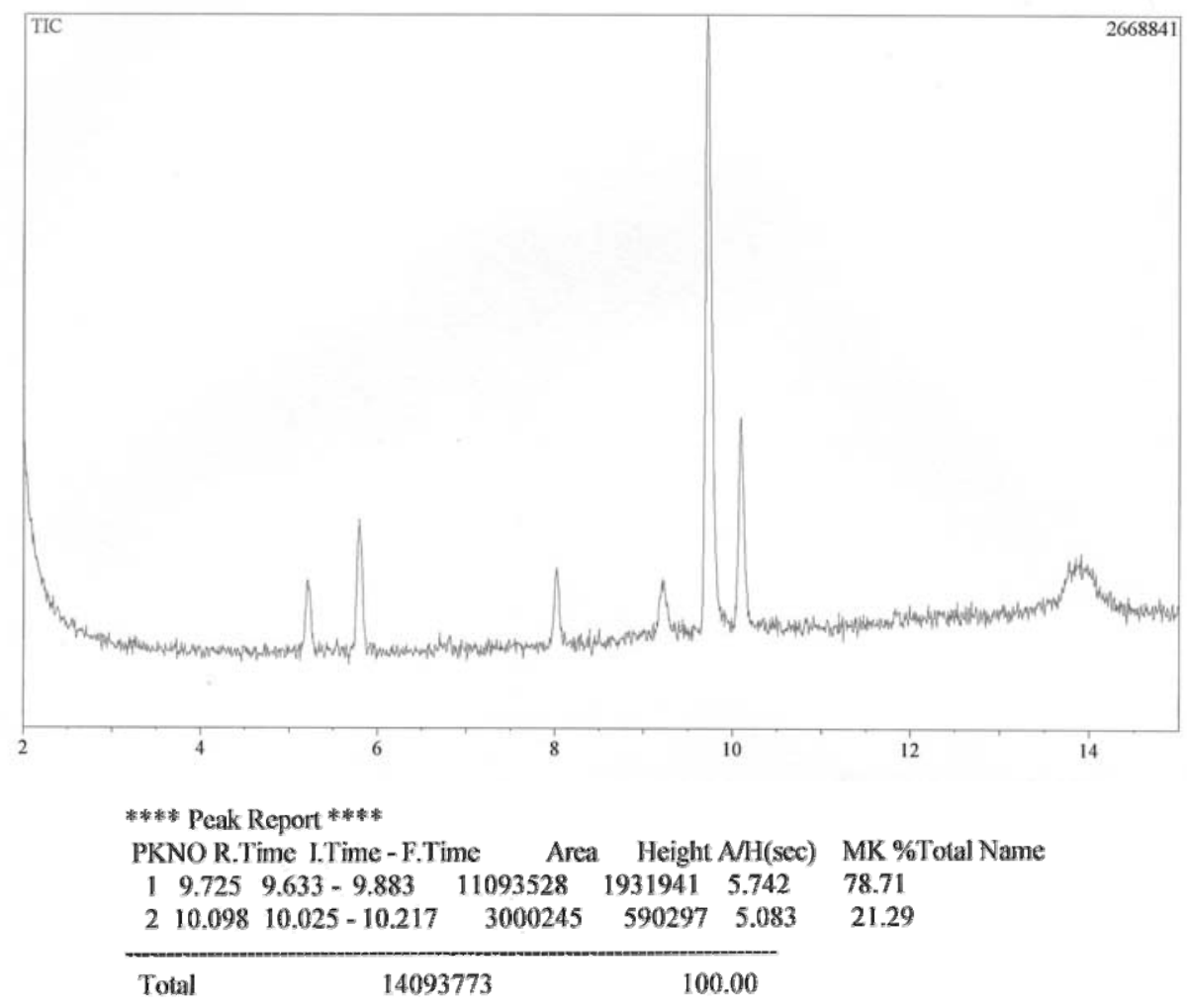

Fig. 136 (entrada 12)

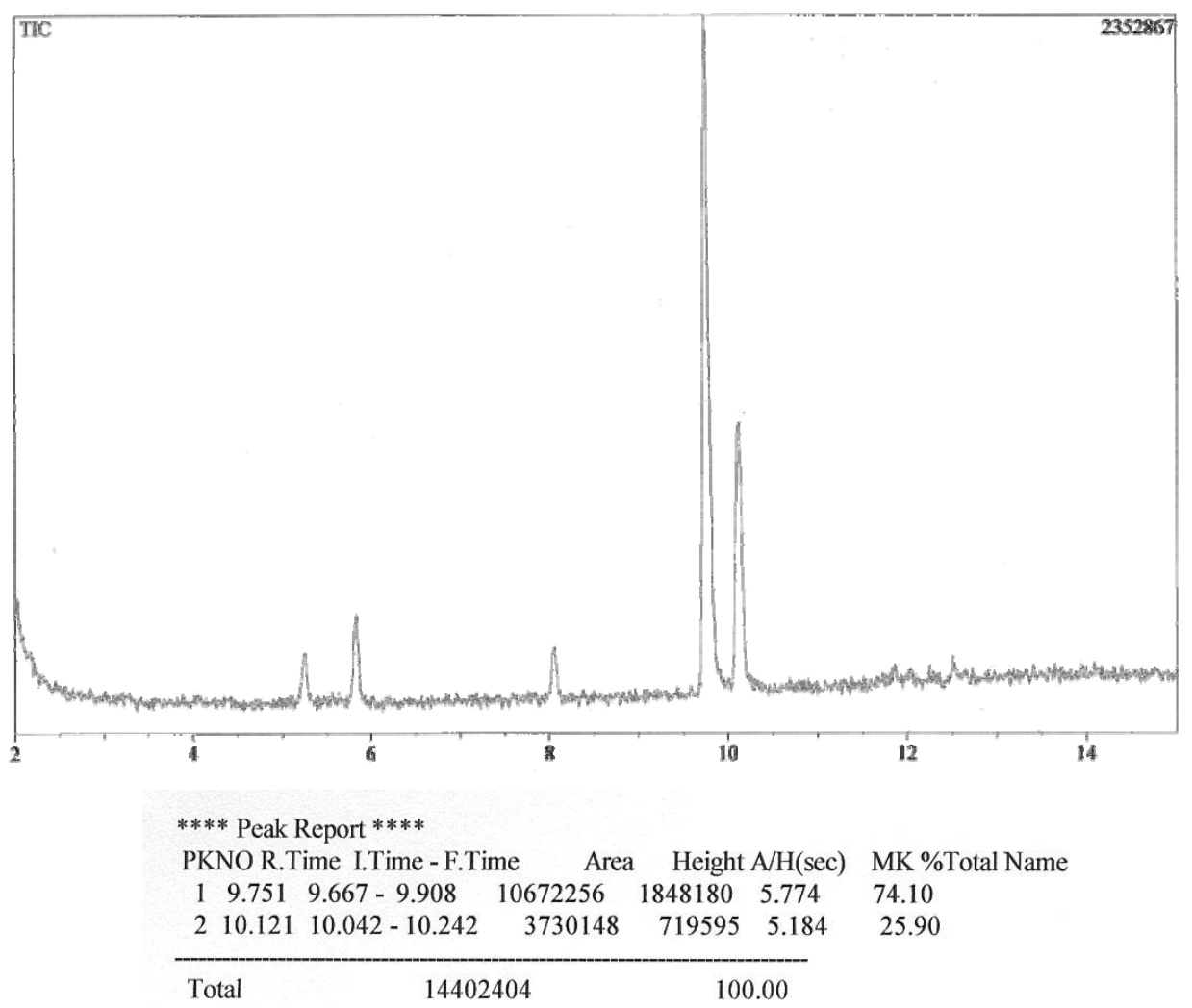


CROMATOGRAMAS CORRESPONDIENTES A LA TABLA 7

Fig. 137 (entrada 1)

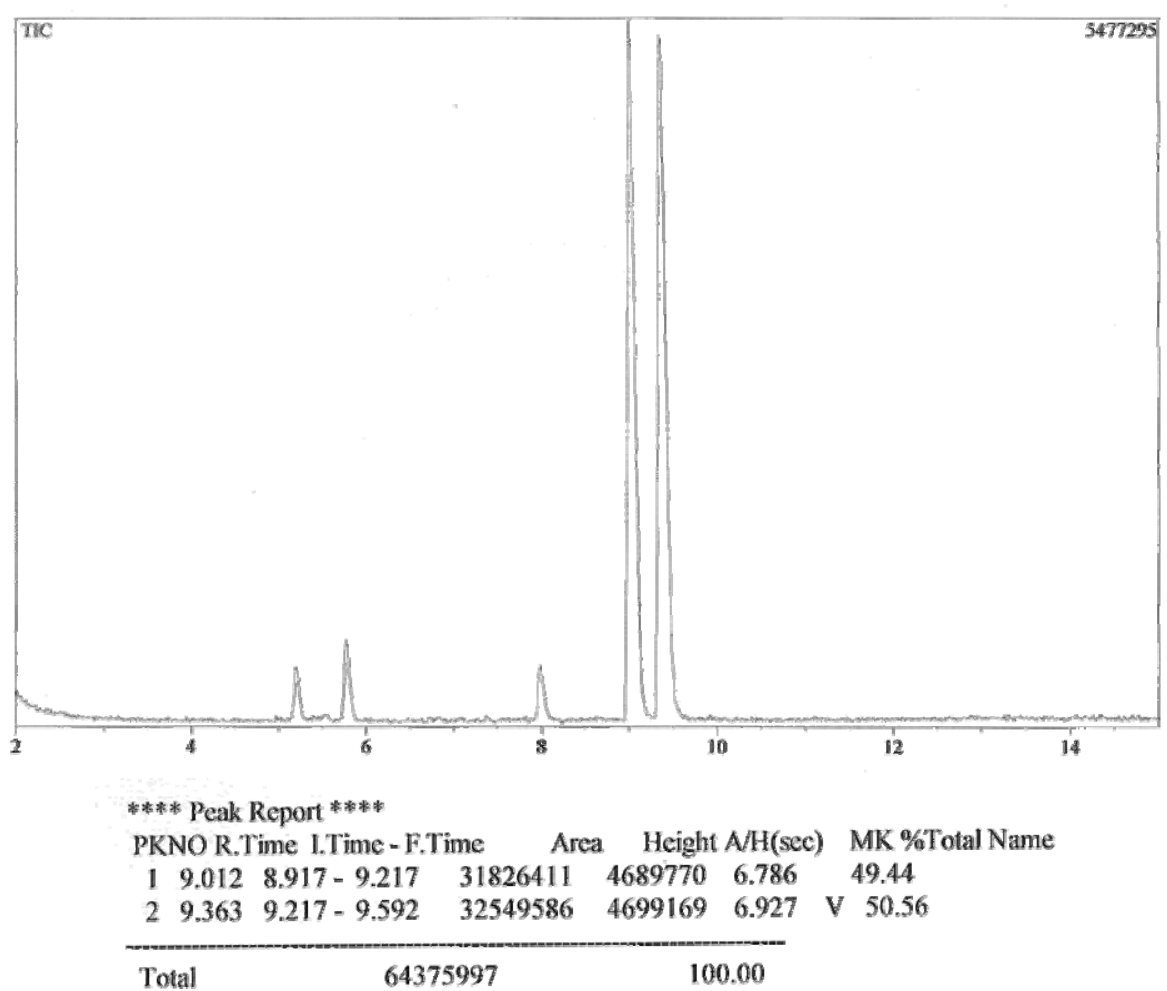

Fig. 138 (entrada 2)

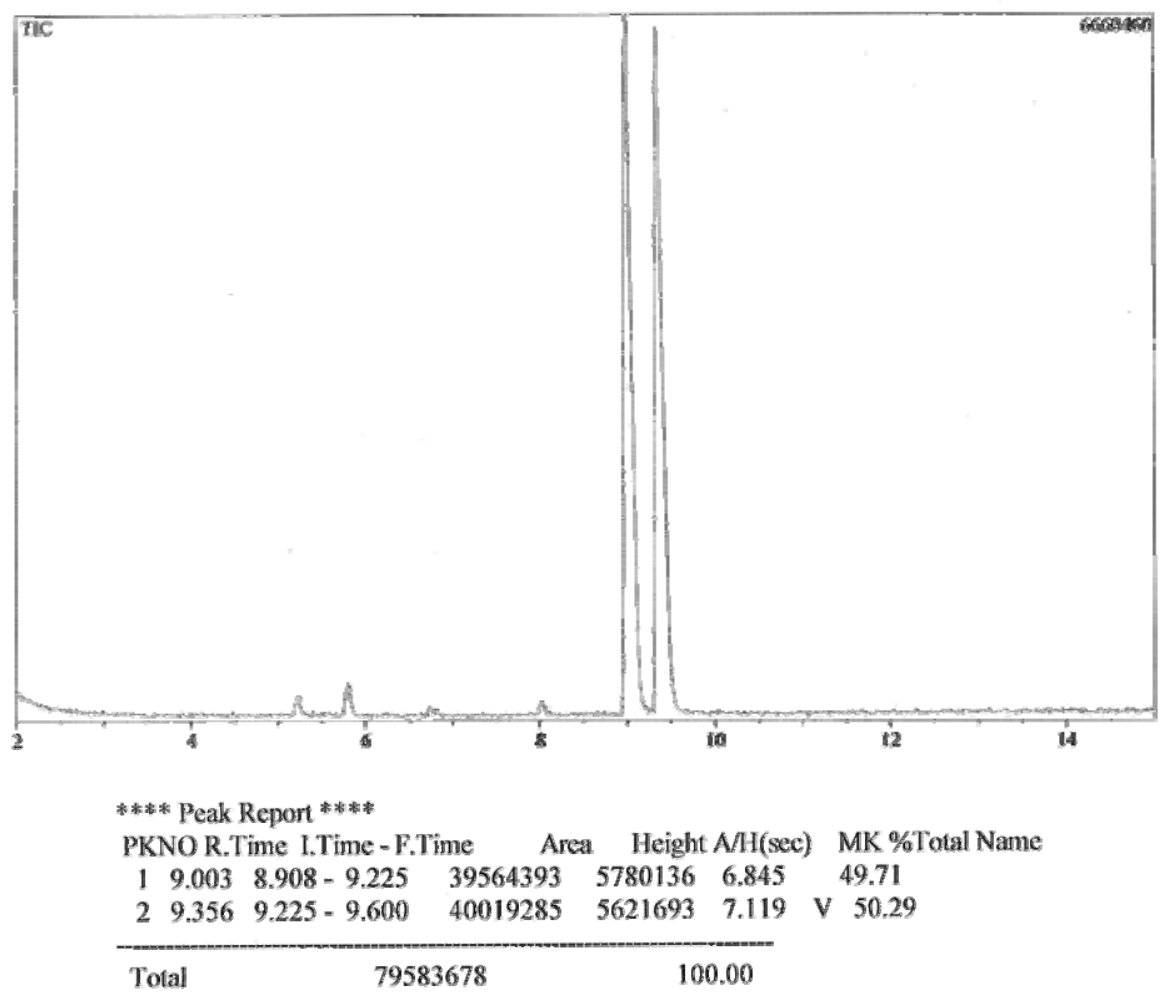


Fig. 139 (entrada 3)

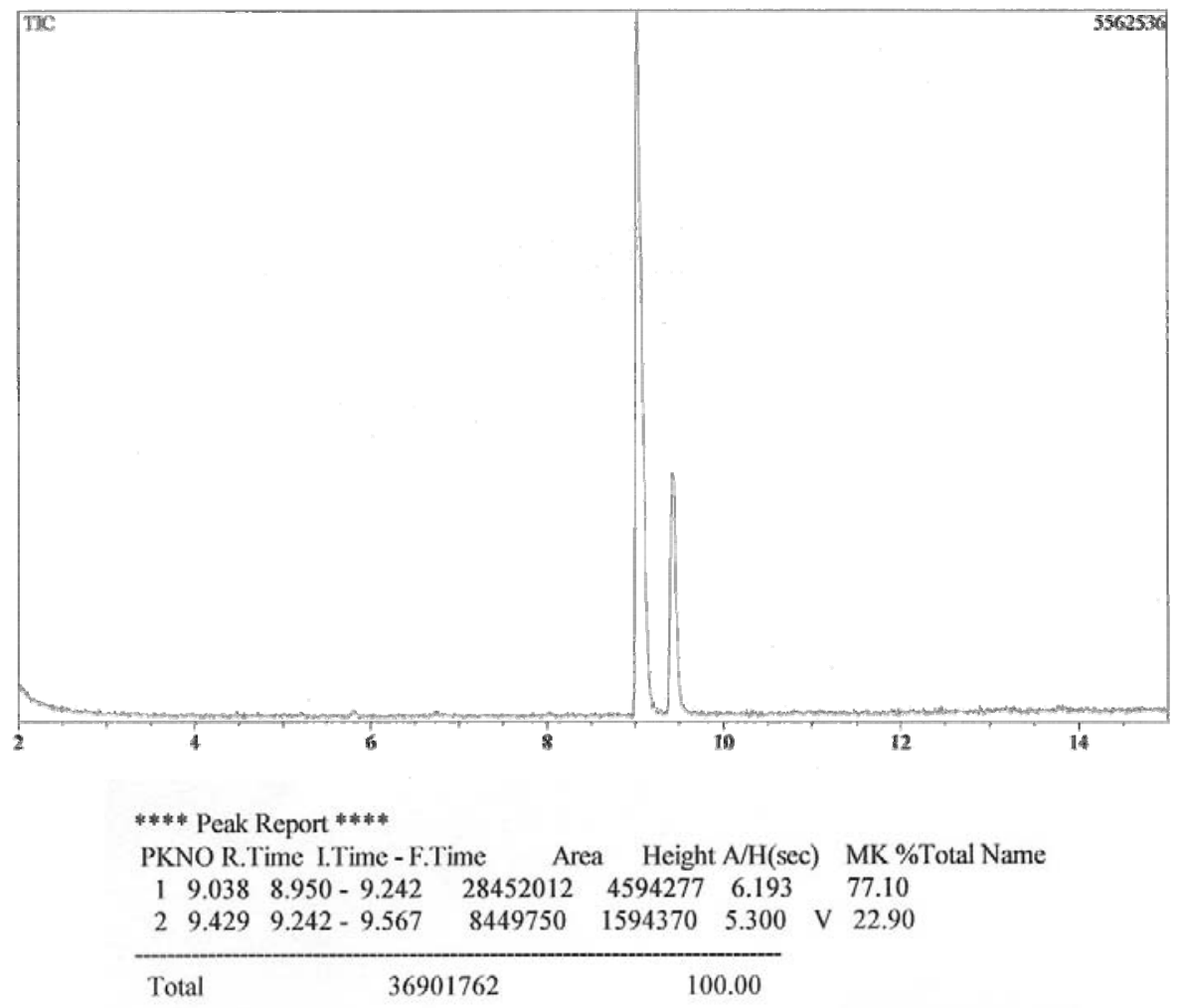

Fig. 140 (entrada 4)

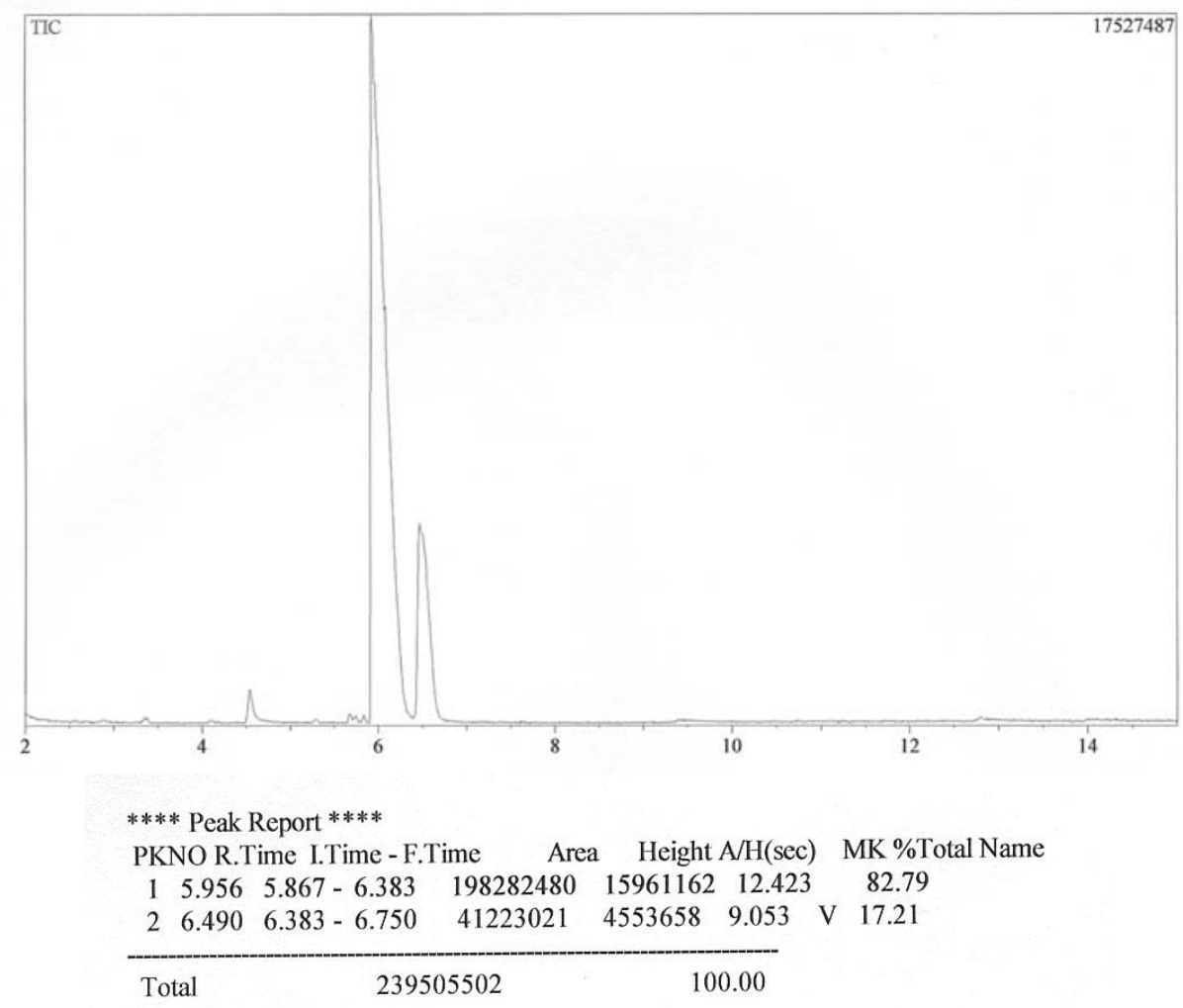


Fig. 141 (entrada 5)

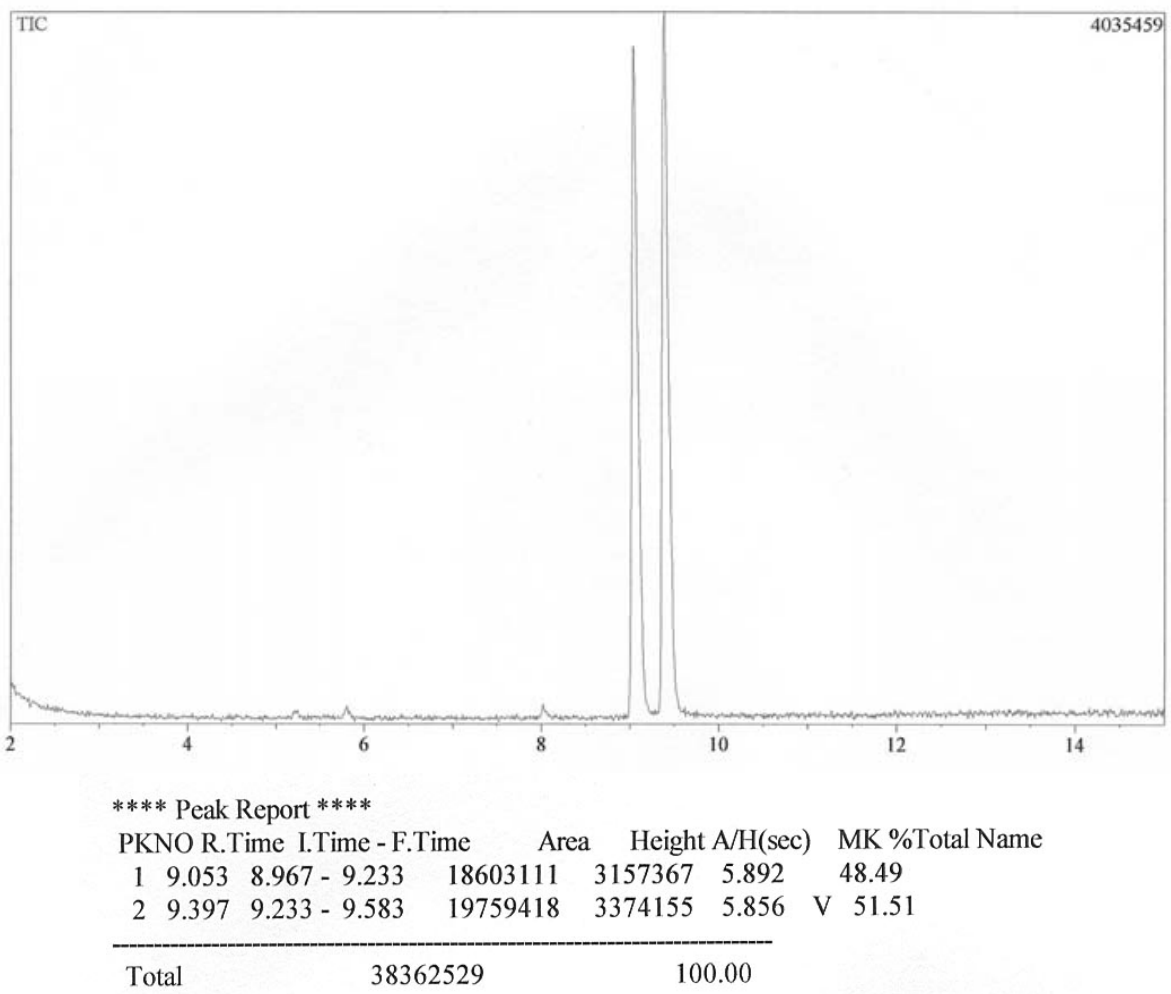

Fig. 142 (entrada 6)

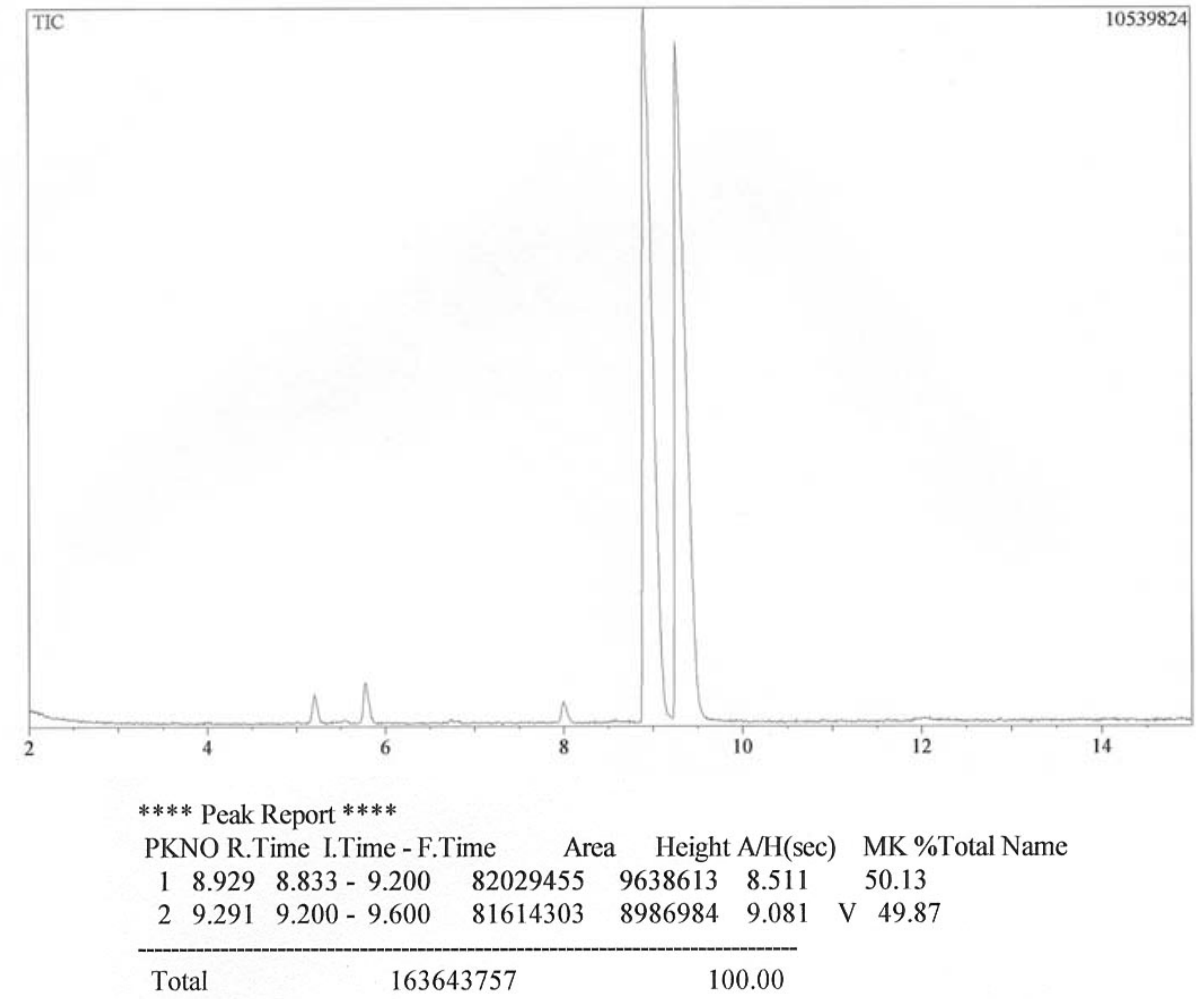


Fig. 143 (entrada 7)

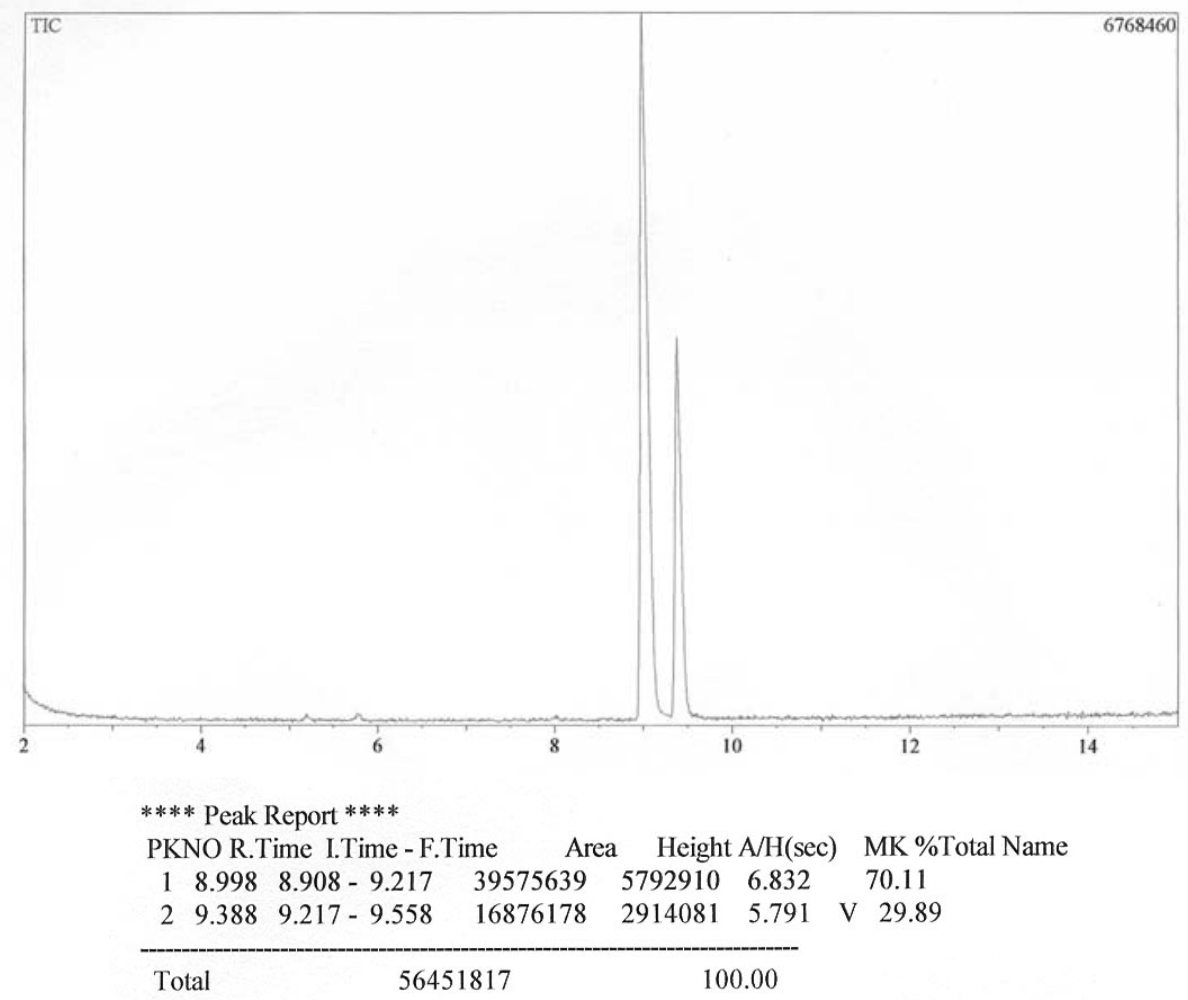

Fig. 144 (entrada 8)

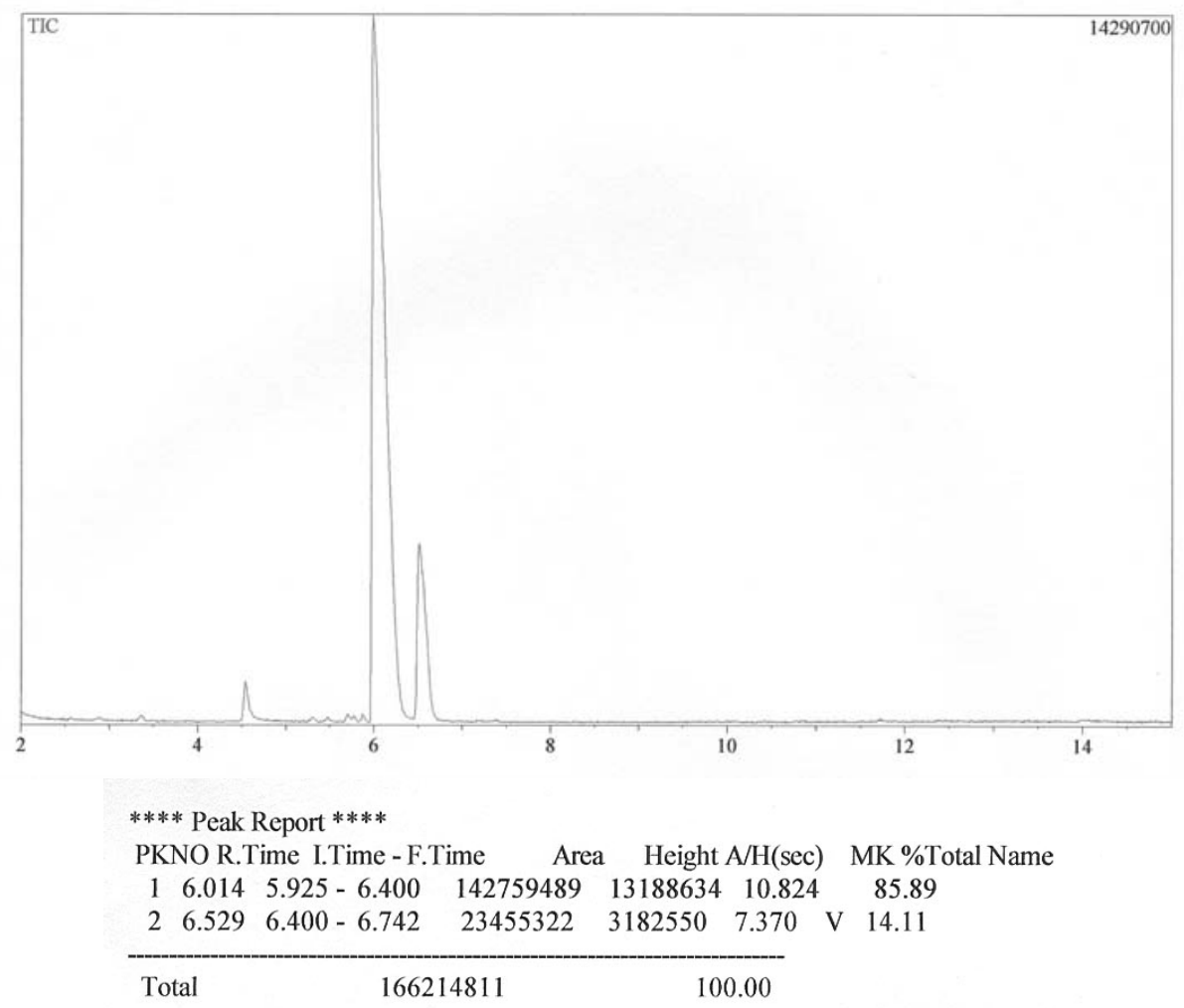


CONCLUSIONES 



\section{CONCLUSIONES}

- Se ha descrito una nueva síntesis de tetrahidropiranos cis-3-oxi-2,2,6,6tetrasustituidos, cuya estructura hemos demostrado. Estos compuestos pueden utilizarse como sintones para la síntesis de importantes productos naturales.<smiles>CC1(C)CC[C@@H](OBr)[C@](C)(C(I)CO)O1</smiles>

34<smiles>CC1(C)CC[C@@H](Br)[C@](C)(C(I)CO)O1</smiles>

35<smiles>CC1(C)CC[C@@H](Br)[C@](C)(C(I)CO)O1</smiles>

36<smiles>CC1(C)CC[C@@H](Br)[C@H](C(I)CO)O1</smiles>

37

El hecho de que puedan obtenerse los diferentes tetrahidropiranos diastereoisómeros con un rendimiento global satisfactorio añade versatilidad a este procedimiento de síntesis.

- Por primera vez se han utilizado reacciones de yodoeterificación para la síntesis de tetrahidropiranos utilizando como sustratos aldehídos $\alpha, \beta$-insaturados.

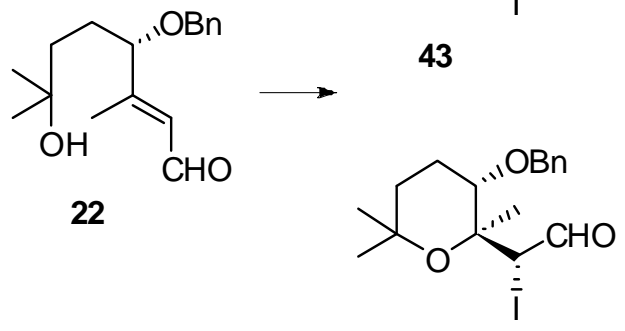

45<smiles>CC1(C)CC[C@@H](Br)[C@](C)(C(I)C=O)O1</smiles>

44<smiles>CC1(C)CC[C@@H](Br)[C@](C)([C@H](I)C=O)O1</smiles>

46

La formación de los compuestos 43-46, cuya estereoquímica hemos determinado, no se puede explicar mediante el mecanismo de reacción habitual a través de un intermedio yodonio, por lo que hemos hecho una nueva propuesta mecanística que pasa a través de la formación de un carbocatión previa a la reacción de ciclación. 
- Aprovechando la metodología desarrollada en nuestro grupo de investigación para la síntesis de nitrilos $\alpha, \beta$-insaturados, hemos llevado a cabo la síntesis de entSachalinol A con un rendimiento global del 35\% a partir del nitrilo $\mathbf{1 8 .}$

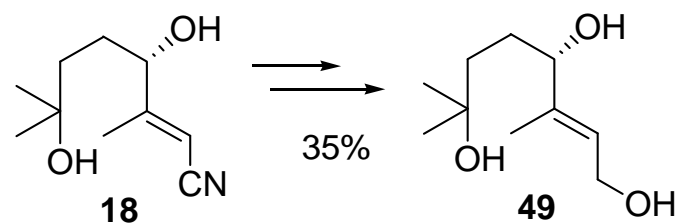

Esta metodología permite sintetizar tanto el ent-Sachalinol A 49 como su enantiómero, el producto natural Sachalinol A, mediante la utilización de L-(+)-DET o D-(-)-DET respectivamente en la epoxidación enantioselectiva de Sharpless, que es el paso de la síntesis en el que se introduce la quiralidad en el sustrato.

- Se han sintetizado los tetrahidrofuranil-dioxolanos 54 y 58 y se ha estudiado su capacidad para complejar cationes alcalinos, dada su analogía con el compuesto bistetrahidrofurano descrito en bibliografía.

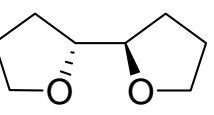

bis-THF

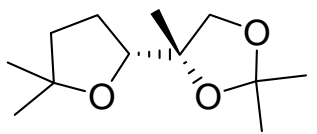

54

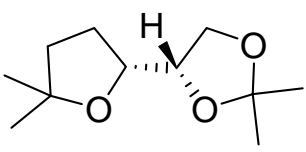

58

Con el fin de encontrar una explicación al hecho de que, experimentalmente, todas las pruebas de complejación llevadas a cabo con los compuestos 54 y 58 fuesen negativas, se llevaron a cabo estudios de modelización molecular. Estos concluyeron que aunque 54 y 58 tendrán menos afinidad por el $\mathrm{Li}^{+}$que el bis-THF descrito en bibliografía, son más asimétricos y por lo tanto pueden ser útiles como catalizadores asimétricos en reacciones con organometálicos de litio. 
- Durante el estudio de los tetrahidropiranos 68 y 69 como catalizadores orgánicos en reacciones de epoxidación asimétrica de olefinas no funcionalizadas, se ha descrito un nuevo reordenamiento oxidativo desde estos 3-(benciloxi)-tetrahidro-2,6,6trimetil-2H-piran-2-carbaldehídos hasta el tetrahidrofuranolactol quiral 70 (ee = $78 \%$ ). Este reordenamiento abre una nueva vía de obtención de sintones quirales.

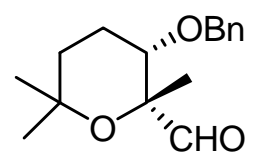

68<smiles>CC1(C)CC[C@@H](Br)[C@](C)(C=O)O1</smiles>

69

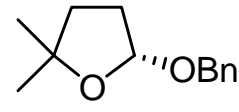

70

- Se han sintetizado los análogos de prolina 84 y 88 para probar su utilidad como catalizadores nucleofílicos en reacciones que transcurren mediante intermedios tipo ión iminio.

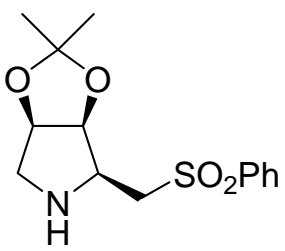

84<smiles>CC1(C)O[C@H]2CN[C@H](CS(=O)(=O)Oc3ccccc3)[C@H]2O1</smiles>

88

El compuesto 88, obtenido en muy pequeña cantidad, no se ha podido probar como catalizador orgánico. Sin embargo, el compuesto 84, obtenido mediante una ruta de 5 pasos optimizada en nuestro grupo de trabajo, se ha probado como catalizador orgánico en reacciones de adición oxo-Michael intramoleculares, lográndose buenos rendimientos $(\eta=80 \%)$ y moderados excesos enantioméricos (ee $=13 \%)$. 
- Se ha abordado por primera vez la síntesis organocatalítica enantioselectiva de tetrahidropiranos mediante reacciones de adición oxo-Michael intramoleculares en aldehídos $\alpha, \beta$-insaturados promovida por catalizadores pirrolidínicos.

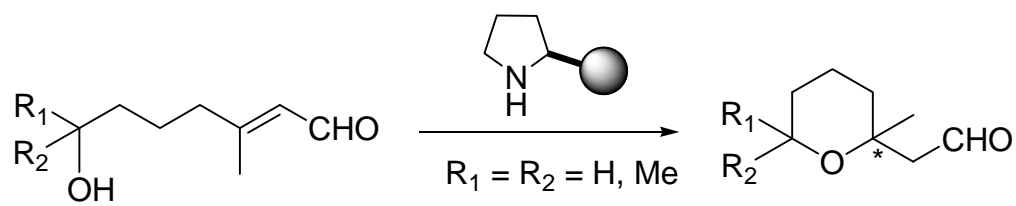

Los mejores resultados se han conseguido con el catalizador comercial (S)-(-)-2-(difenilmetil)pirrolidina $(\eta=54 \%$ en dos pasos; ee $=72 \%)$. Aunque tanto los rendimientos como la enantioselección del proceso han de ser mejorados, estos resultados abren una nueva vía para la obtención organocatalítica de tetrahidropiranos. 
ANEXO:

Relación de moléculas sintetizadas en este trabajo 



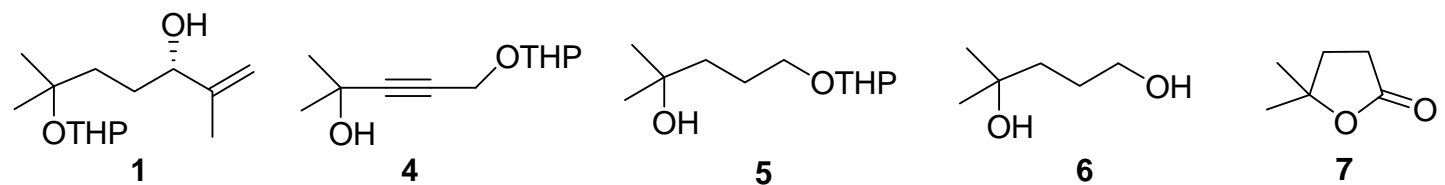<smiles>CC1(C)CCC(O)O1</smiles>

8<smiles>CCOC(=O)C(C)=CCCC(C)(C)O</smiles>

9<smiles>CCOC(=O)/C(C)=C/CCC(C)(C)[OH+]</smiles>

10<smiles>C/C(=C\CCC(C)(C)[OH+]P)CO</smiles>

11<smiles>CC(C)(C)CCC[C@H](O)C(C)([OH+])CO</smiles>

12<smiles>CC(O)(CI)CC[OH+]C(C)(C)CI</smiles>

16<smiles></smiles>

13<smiles>C/C(=C/CCC(C)(C)[OH+])CO</smiles>

14<smiles></smiles>

15<smiles>CC(=CC#N)C(O)CCC(C)(C)[OH+]</smiles>

17<smiles>CC(=CC#N)[C@@H](O)CCC(C)(C)O</smiles>

18<smiles>CC(=CC#N)[C@@H](CCC(C)(C)O)OCc1ccccc1</smiles>

19<smiles>CC(=O)OC(CCC(C)(C)O)C(C)=CC#N</smiles>

20<smiles>C/C(=C/C=O)[C@H](CCC(C)(C)O)O[In]</smiles>

21<smiles>CCCO[C@@H](CCC(C)(C)O)C(C)=CC=O</smiles>

22<smiles>C=C(C)[C@H](O)CCC(C)(C)[OH+]</smiles>

23<smiles>[Z20]P[OH+]C(C)(C)CC[C@@H](O)C(C)=O</smiles><smiles>CC(=O)C(O)CCC(C)(C)O</smiles><smiles>CC(=O)C=C(C)[C@@H](O)CCC(C)(C)O</smiles><smiles>CCCC[C@@H](O)/C(C)=C\C(=O)OC</smiles><smiles>C=C(C)[C@H](CCC(C)(C)O)OCc1ccccc1</smiles><smiles>CCCOC(CCC(C)(C)O)C(C)=O</smiles><smiles>CC(=O)C=C(C)[C@H](CCC(C)(C)O)OCCc1ccccc1</smiles>
30<smiles>COC(=O)/C=C(/C)C(CCC(C)(C)O)O[C@H](C)C(C)(C)O</smiles>

31<smiles>C/C(=C/CO)[C@H](CCC(C)(C)O)O[Ga]</smiles>

32<smiles>CC(=CCO)[C@H](CCC(C)(C)O)OCCc1ccccc1</smiles>

33<smiles>CC1(C)CC[C@@H](Br)[C@](C)(C(I)CO)O1</smiles><smiles>CC1(C)CC[C@@H]([18OH])C(C(I)CO)(C(I)CO)O1</smiles><smiles>CC1(C)CC[C@@H](Br)[C@](C)(C(I)CO)O1</smiles>

36<smiles>CC1(C)CC[C@@H]([Hg]c2ccccc2)[C@](O)(C(I)CO)O1</smiles>

37<smiles>CC1(C)CC[C@@H](Br)[C@](C)(CCO)O1</smiles>

38

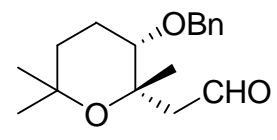

39<smiles>CC1(C)CC[C@@H](Br)[C@](C)(CC(=O)O)O1</smiles>

40

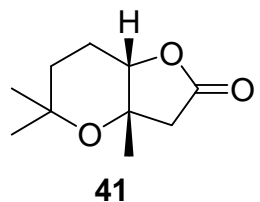

41<smiles>CC1(C)CC[C@@H](OCc2ccccc2)[C@](C)(CCO)O1</smiles>

42<smiles>CC1(C)CC[C@@H](OCc2ccccc2)[C@](C)(C(I)C=O)O1</smiles>

43 i<smiles>CC1(C)CC[C@@H](OCc2ccccc2)[C@](C)(C(I)C=O)O1</smiles> 


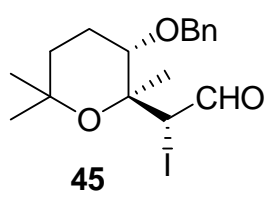<smiles>CC(I)[C@@]1([C@@H](I)C=O)OC(C)(C)CC[C@H]1Br</smiles>
46 51<smiles>C/C(=C\CN)[C@H](CCC(C)(C)O[Se])[O+]=[Se]</smiles>
50<smiles>CC1(C)CC[C@@H](O[Ga]Br)C(CC=O)(CC=O)O1</smiles><smiles>C/C(=C\C=O)[C@H](O)CCC(C)(C)O</smiles><smiles>C/C(=C\CO)[C@H](O)CCC(C)(C)O</smiles>
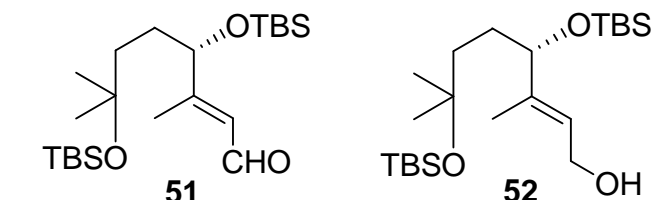<smiles>CO[C@](C(=O)OCC=C(C)[C@@H](CCC(C)(C)O)OC(=O)C(c1ccccc1)(c1ccccc1)C(F)(F)F)(c1ccccc1)C(F)(F)F</smiles><smiles>CC1(C)CCC([C@]2(C)COC(C)(C)O2)O1</smiles>
54<smiles>CCOC(=O)C=CCCC(C)(C)O</smiles><smiles>CC(C)(O)CC/C=C/CO</smiles><smiles>[B][C@@H](CO)[C@@H]1CCC(C)(C)O1</smiles><smiles>CC1(C)CCC([C@H]2COC(C)(C)O2)O1</smiles>
58<smiles>[B-][OH+]C(C)(C)CCC=CC(=O)OCC</smiles>
59<smiles></smiles>
60<smiles>CC1(C)CC[C@@H](Br)[C@](C)(O)CO1</smiles>

65<smiles>C[C@@H](O)CCC(C)(C)[OH+]</smiles>

61<smiles>CC(C)(O)CCC(O[Ga]C(=O)OCc1ccccc1)C1(C)CO1</smiles>

62<smiles>CC(C)(O)CC[C@@H](O[Ga])C(C)(C)C</smiles><smiles>CC1(C)CC[C@@H](OCc2ccccc2)[C@](C)(CO)O1</smiles>

64<smiles>CC1(C)CC[C@@H](OCc2ccccc2)[C@@H](CO)O1</smiles>

66<smiles>CC1(C)CC[C@@H](OBr)[C@](C)(O)CO1</smiles>

67<smiles>CC1(C)CC[C@@H](Br)[C@](C)(C=O)O1</smiles>

68<smiles>CC1(C)CC[C@@H](O[B]c2ccccc2)[C@](C)(C=O)O1</smiles>

69<smiles>CC1(C)CC[C@@H](OCc2ccccc2)O1</smiles>

70<smiles>C=C[C@]1(C)CCC(O)C(C)(C)O1</smiles>

71<smiles>C=CC1(C)CCC(C(C)(C)O)O1</smiles>

72<smiles>C=C[C@]1(C)CCC(O)C(C)(C)O1</smiles>

73<smiles>CC1(C)O[C@@H](CO)[C@H]([C@H](O)CS(=O)(=O)c2ccccc2)O1</smiles>

78<smiles>CC1(C)O[C@](C)(C=O)CCC1OBr</smiles>

74<smiles>CC(=O)CC[C@@H](OBr)C(C)(C)O</smiles>

75<smiles>CC1(C)O[C@H]2CO[C@@H](O)[C@H]2O1</smiles>

76<smiles>CC1(C)O[C@@H](CO)[C@H]([C@H](O)CS(=O)(=O)c2ccccc2)O1</smiles>

77<smiles>CC1(C)OC(/C=C/S(=O)(=O)Oc2ccccc2)C(CO[As])O1</smiles><smiles>CC1(C)O[C@@H]2[C@@H](CS(=O)(=O)c3ccccc3)OC[C@H]2O1</smiles>

81 
<smiles>CC1(C)OC2COC(CS(=O)(=O)c3ccccc3)C2O1</smiles>

82<smiles>CC1(C)OC2CN(Cc3ccccc3)[C@H](CS(=O)(=O)c3ccccc3)C2O1</smiles><smiles>CCOC(=O)C=CCCCO</smiles>

92<smiles>CC1(C)OC2CN(Cc3ccccc3)C(CS(=O)(=O)c3ccccc3)C2O1</smiles><smiles>CC1(C)OC2CN[C@@H](CS(=O)(=O)Oc3ccccc3)C2O1</smiles>
88<smiles>CCOC(=O)/C=C/CCCCO</smiles><smiles>CC1(C)OC2CNC(CS(=O)(=O)Oc3ccccc3)C2O1</smiles><smiles>CC1(C)OC2CN(C(=O)c3ccccc3)C(CS(=O)(=O)c3ccccc3)C2O1</smiles><smiles>CC1(C)OC2CN(C(=O)c3ccccc3)[C@H](CS(=O)(=O)c3ccccc3)C2O1</smiles><smiles>CC(C)(O)CCC=CC=O</smiles><smiles>CC1(C)CCC(CC=O)O1</smiles>
90<smiles>O[C@@H]1CCCCO1</smiles>

91<smiles>OC/C=C/CCCCO</smiles><smiles>O=CC=CCCCCO</smiles><smiles>O=CCC1CCCCO1</smiles>

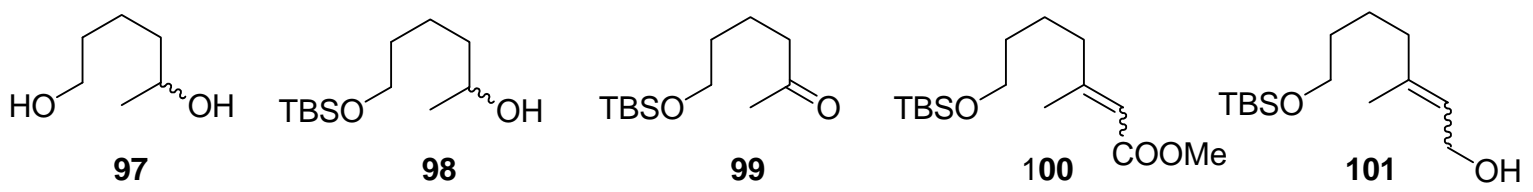<smiles>C/C(=C/CO)CCCCO</smiles><smiles>C/C(=C\C=O)CCCCO</smiles><smiles>CC1(CCO)CCCCO1</smiles>

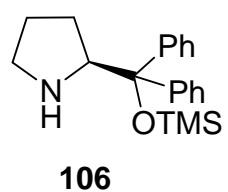<smiles>c1ccc(CC2CCCN2)nc1</smiles><smiles>COC(CC1(C)CCCCO1)OC</smiles><smiles>CC(I)(C=O)C1(C)CCCCO1</smiles><smiles>CCCC(I)C(I)CO</smiles><smiles>CC1(C(I)CO)CCCCO1</smiles><smiles>CC1(CCOC(=O)C(c2ccccc2)(c2ccccc2)C(F)(F)F)CCCCO1</smiles>

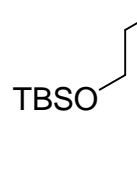<smiles>CCCCC1(C)OC1CO</smiles>

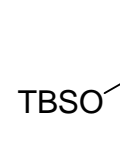<smiles>CCCCC1OC1COC(C)=O</smiles><smiles>CC(=O)OCC1OC1(C)CCCCO</smiles><smiles>CC(=O)OCC[C@]1(C)CCCCO1</smiles><smiles>CC(=O)OCCC1(C)CCCCO1</smiles>
123 Oे 124 ÖTs<smiles>CC1(C([18OH])CO)CCCCO1</smiles><smiles>CC(C)=CCCC(C)=CC=O</smiles><smiles></smiles><smiles></smiles><smiles>CC1(O)CCC/C(=C/C=O)C1(C)O</smiles><smiles>CC1(C)CCCC(C)(CCO)O1</smiles><smiles>CC1(C)CCC[C@@](C)(C(I)C=O)O1</smiles><smiles>CC1(C)CCC[C@](C)([C@H](I)C=O)O1</smiles> 
<smiles>CC1(C)CCCC(C)([C@H](I)CO)O1</smiles>

133<smiles>CC(C=O)=CCC[C@@H](C)C1COC(C)(C)O1</smiles>

138<smiles>CC1(C)CCCC(C)([C@H](I)CO)O1</smiles>

134<smiles>CC(C)=CCCC(C)(O)CCO</smiles>

135<smiles>CC(C)=CCC[C@H](C)CO</smiles><smiles>CC(C)=CCC[C@@H](C)[C@H]1COC(C)(C)O1</smiles><smiles>CC(C)=CCC[C@H](C)CO[SbH2]</smiles>

140<smiles>CC(C=O)=CCC[C@@H](C)C[OH2+]</smiles>

141 

